\title{
Nuclear Fuel Cycle Facility Accident Analysis Handbook
}

Manuscript Completed: March 1998

Date Published: March 1998

Science Applications International Corporation 11251 Roger Bacon Drive

Reston, VA 20190

\section{Prepared for}

Division of Fuel Cycle Safety and Safeguards

Office of Nuclear Material Safety and Safeguards

U.S. Nuclear Regulatory Commission

Washington, DC 20555-0001

NRC Job Code J5074

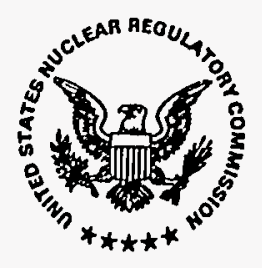




\section{DISCLAIMER}

Portions of this document may be illegible electronic image products. Images are produced from the best available original document. 


\begin{abstract}
The purpose of this Handbook is to provide guidance on how to calculate the characteristics of releases of radioactive materials and/or hazardous chemicals from nonreactor nuclear facilities. In addition, the Handbook provides guidance on how to calculate the consequences of those releases. There are four major chapters: Hazard Evaluation and Scenario Development; Source Term Determination; Transport Within Containment/Confinement; and Atmospheric Dispersion and Consequence Modeling. These chapters are supported by Appendices, including: a summary of chemical and nuclear information that contains descriptions of various fuel cycle facilities; details on how to calculate the characteristics of source terms for releases of hazardous chemicals; a comparison of NRC, EPA, and OSHA programs that address chemical safety; a summary of the performance of HEPA and other filters; and a discussion of uncertainties. Several sample problems are presented: a free-fall spill of powder, an explosion with radioactive release; a fire with radioactive release; filter failure; hydrogen fluoride release from a tankcar, a uranium hexafluoride cylinder rupture; a liquid spill in a vitrification plant; and a criticality incident. Finally, this Handbook includes a computer model, LPF\#1B, that is intended for use in calculating Leak Path Factors. A list of contributors to the Handbook is presented in Chapter 6.
\end{abstract}





\section{TABLE OF CONTENTS}

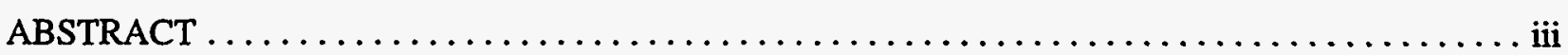

TABLE OF CONTENTS $\ldots \ldots \ldots \ldots \ldots \ldots \ldots \ldots \ldots \ldots \ldots \ldots \ldots \ldots \ldots \ldots \ldots \ldots \ldots \ldots$

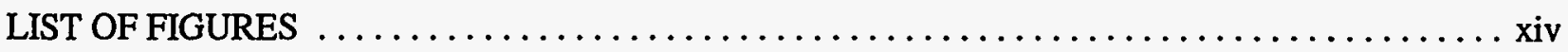

LIST OF TABLES $\ldots \ldots \ldots \ldots \ldots \ldots \ldots \ldots \ldots \ldots \ldots \ldots \ldots \ldots \ldots \ldots \ldots \ldots \ldots \ldots \ldots \ldots$

LIST OF ACRONYMS, ABBREVIATIONS, AND NAMES $\ldots \ldots \ldots \ldots \ldots \ldots \ldots \ldots \ldots$ xvii

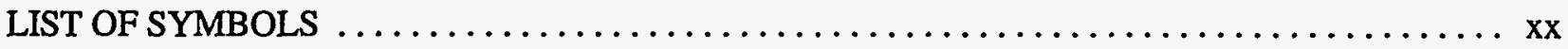

\section{CHAPTER 1: EXECUTIVE SUMMARY}

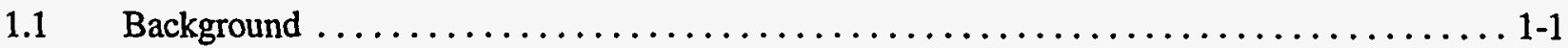

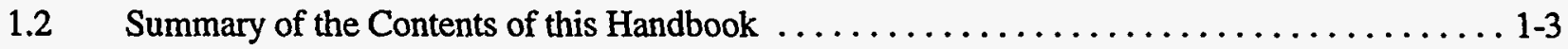

1.2.1 Chapter 2 - Hazard Evaluation and Scenario Development $\ldots \ldots \ldots \ldots \ldots \ldots \ldots \ldots$

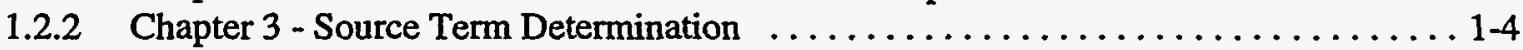

1.2.3 Chapter 4 - Transport Within Containment/Confinement $\ldots \ldots \ldots \ldots \ldots \ldots \ldots \ldots$ 1-5

1.2.4 Chapter 5 - Atmospheric Dispersion and Consequence Modeling ............ 1-6

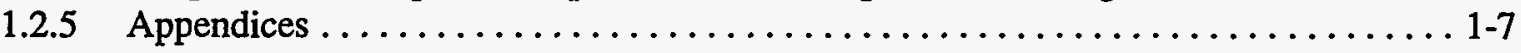

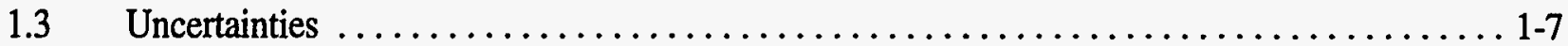

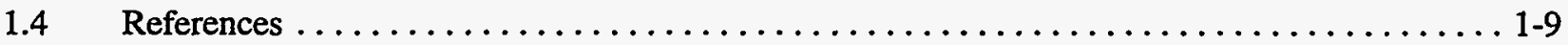

\section{CHAPTER 2: HAZARD EVALUATION AND SCENARIO DEVELOPMENT}

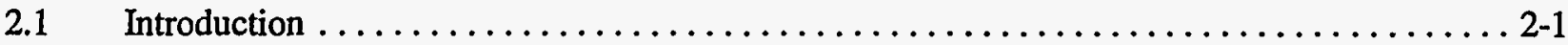

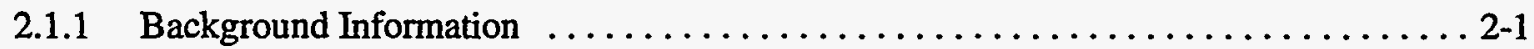

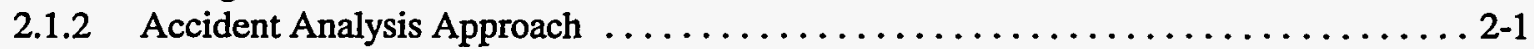

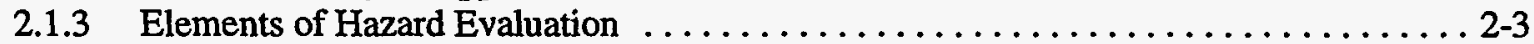

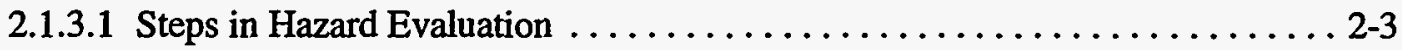

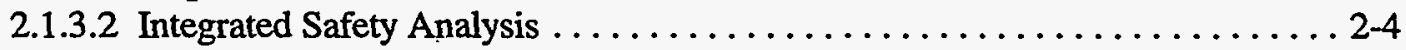

2.1.3.3 Guidance from the Center for Chemical Process Safety ........... 2-4

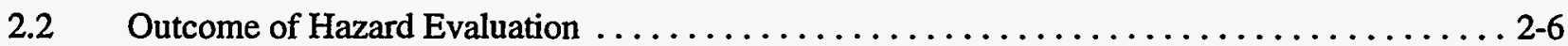

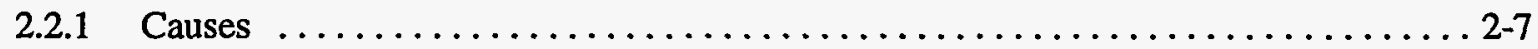

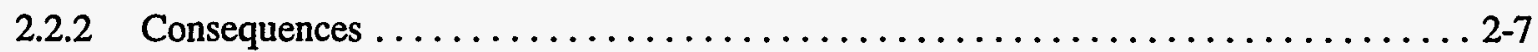

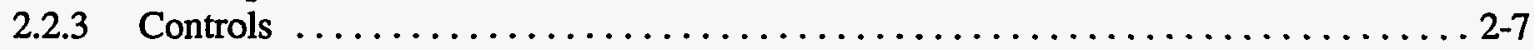

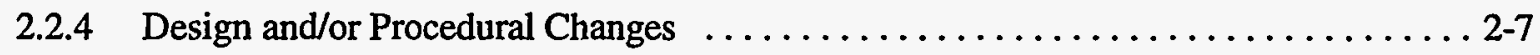

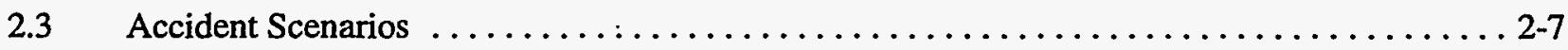




\section{TABLE OF CONTENTS (Continued)}

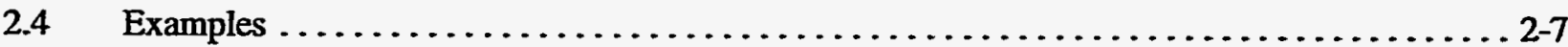

2.4.1 Sample Problem 1. Free-Fall Spill of Powder ................... 2-13

2.4.2 Sample Problem 2. Explosion in a Room with Aerodynamic Entrainment

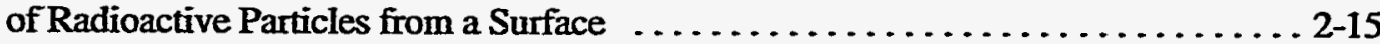

2.4.3 Sample Problem 3. Fire with Suspension of Radioactive Particles from the Burning of Contaminated, Combustible Material . . . . . . . . . . . . . . 2-15

2.4.4 Sample Problem 4. Filter Failure with Release of Radioactive Particulate Previously Trapped by the Filter . ......................... 2-17

2.4.5 Sample Problem 5. Spillage of Hydrogen Fluoride from a Tankcar ... . . . . . . . 2-18

2.4.6 Sample Problem 6. Uranium Hexafluoride Liquid Cylinder Rupture . . . . . . . . . . . 2-19

2.4.7 Sample Problem 7. Release of Radioactive Materials from Falling Slurry in a Vitrification Plant ..................................... 2-19

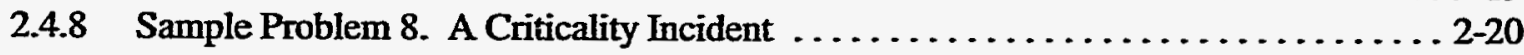

2.5 References

\section{CHAPTER 3: SOURCE TERM DETERMINATION}

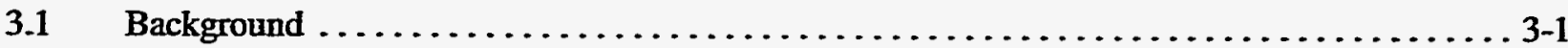

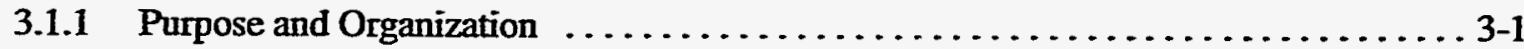

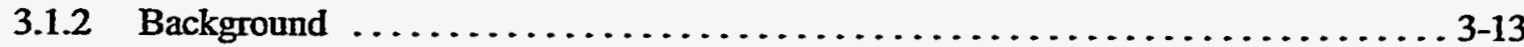

3.1.3 Particle Size and Aerosol Physics Considerations in Consequence Assessments ... . . 3-14

3.2 Determination of the Characteristics of Airborne Releases of Radioactive Materials ... . . . 3-17

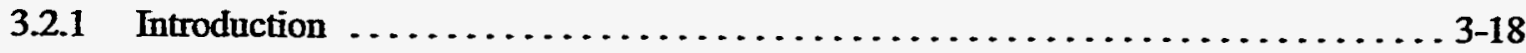

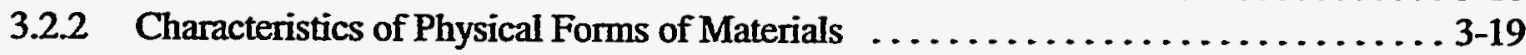

3.2.2.1 Gases ......................................... 3-19

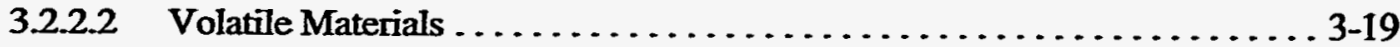

3.2.2.3 Low-Volatility Liquids . . . . . . . . . . . . . . . . . . . . . . . . . 3-19

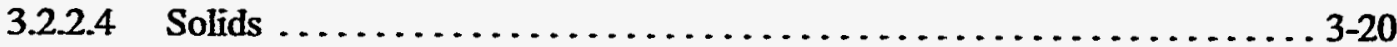

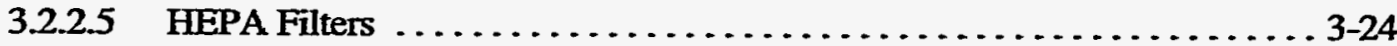

3.2.3 Description of the Effects of Various Stresses Generated to Aerosolize

Physical Forms . . . . . . . . . . . . . . . . . . . . . . . . . . . . . . . . . . 3-24

3.2.3.1 Explosions . . . . . . . . . . . . . . . . . . . . . . . . . . . . . 3-24

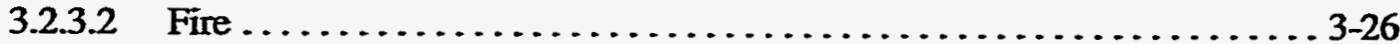

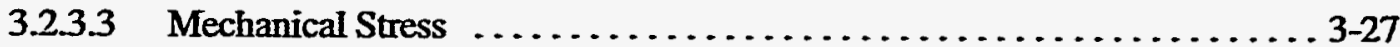

3.2.3.4 Aerodynamic Entrainment/Resuspension $\ldots \ldots \ldots \ldots \ldots \ldots \ldots \ldots \ldots . . .28$

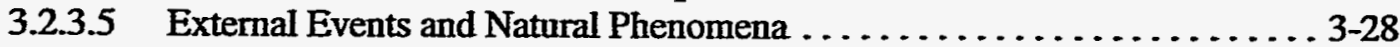

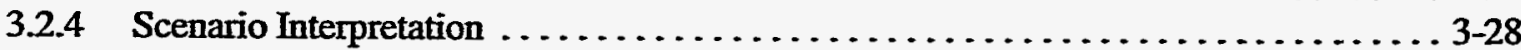

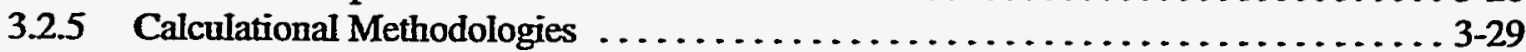

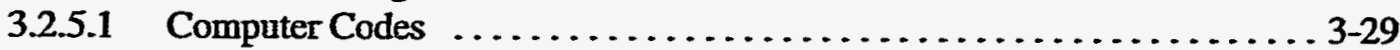

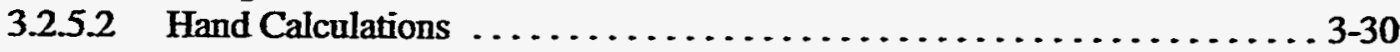

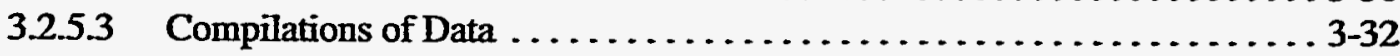




\section{TABLE OF CONTENTS \\ (Continued)}

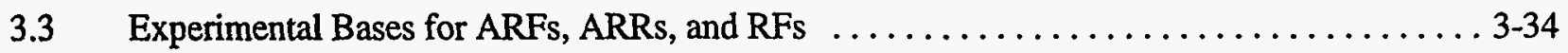

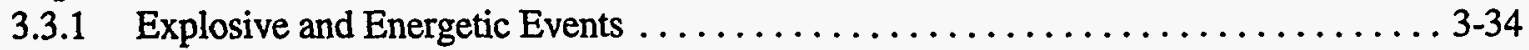

3.3.1.1 Detonations - Reactive Metals (Plutonium) $\ldots \ldots \ldots \ldots \ldots \ldots \ldots \ldots .34$

3.3.1.2 Detonations - Other Metals . .......................... 37

3.3.1.3 Detonations - Metal or Solution ..................... 3-44

3.3.1.4 Detonations - Powder .......................... 3-47

3.3.1.5 Detonations - HEPA Filters ........................ 3-47

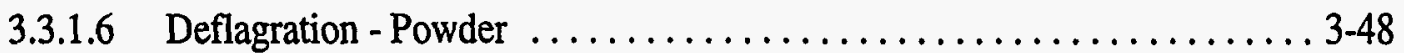

3.3.1.7 Deflagrations - HEPA Filters ...................... 3-49

3.3.1.8 Overpressurization to Rupture $\ldots \ldots \ldots \ldots \ldots \ldots \ldots \ldots \ldots \ldots \ldots . . .49$

3.3.1.9 Overpressurization to Rupture - Liquid, Confined (in vessel/

container): Bounding Values, Rapid Buildup of Pressure ......... 3-56

3.3.1.10 Overpressurization to Rupture - Superheated Liquids, Confined

("Flashing Spray" during Venting): Bounding Values .......... 3-57

3.3.1.11 Overpressurization to Rupture - Powder, Confined (in Vessel

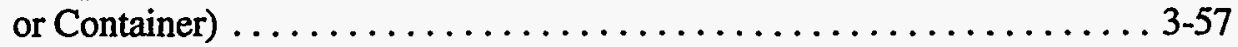

3.3.1.12 Overpressurization to Rupture - Powder, Confined (in Vessel or

Container) - Correlations . . . . . . . . . . . . . . . . . .

3.3.1.13 Overpressurization to Rupture - Vitrified HLW ............... 3-61

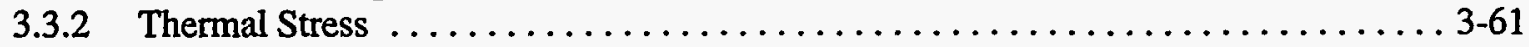

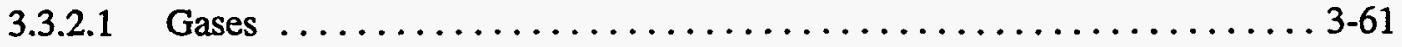

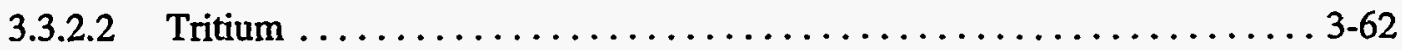

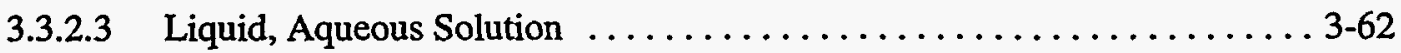

3.3.2.4 Liquid, Organic, Combustible - Volatile Compounds Dissolved in

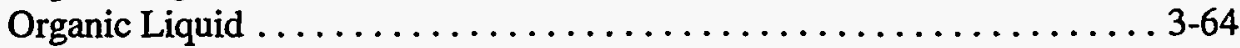

3.3.2.5 Liquid, Organic, Combustible - Non-Volatile Compounds .......... 3-64

3.3.2.6 Liquid, Organic, Combustible - Burning of Combustible Liquid ....... 3-65

3.3.2.7 Solid, Reactive Metal - Plutonium ..................... 3-66

3.3.2.8 Solid, Reactive Metal - Uranium .................... 3-69

3.3.2.9 Solid, Non-Combustible - Aggregate, Concrete .............. 3-71

3.3.2.10 Solid, Non-Combustible - Powders . ................... 3-71

3.3.2.11 Solid, Non-Combustible - Contaminated HEPA Filters . . . . . . . . . . 3-72

3.3.2.12 Solid, Contaminated Combustible - Packaged Waste ............. 3-73

3.3.2.13 Solid, Contaminated Combustible - Unpacked, with Contamination

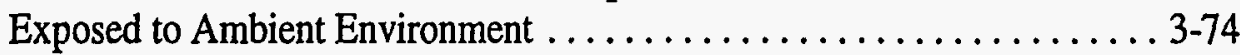

3.3.2.14 Solid, Contaminated Combustible - Light Cellulosic Materials . . . . . . . 3-76

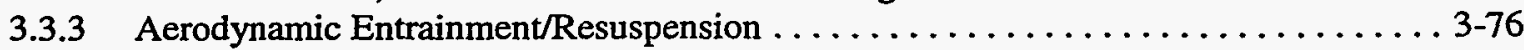

3.3.3.1 Homogeneous Deposit, Liquid - Indoors . . . . . . . . . . . . . . 3-76

3.3.3.2 Homogeneous Deposit, Liquid - Outdoors ............. . . . . 3-77

3.3.3.3 Heterogeneous Deposit, Liquid - Outdoors Absorbed on Soil . . . . . . . . . 3-77

3.3.3.4 Heterogeneous Deposit, Powder - Indoors ................. 3-78

3.3.3.5 Heterogeneous Deposit, Powder - Outdoors ................. . . 3-79

3.3.3.6 Powder Dispersed into Flowing Gas .................. 3-79 


\section{TABLE OF CONTENTS (Continued)}

3.3.4 Mechanical Stress ................................ 3-80

3.3.4.1 Perforation of Vessel/Container/Pipe Wall ............... 3-80

3.3.4.2 Free-Fall Spill - Aqueous Liquids, Bounding Values . . . . . . . . . . 3-81

3.3.4.3 Free-Fall Spill - Aqueous Liquids, Calculated Values ........... . 3-82

3.3.4.4 Free-Fall Spill - Powders, Bounding Values . . . . . . . . . . . 3-83

3.3.4.5 Free-Fall Spill - Powders, Calculated Values . . . . . . . . . . . . 3-84

3.3.4.6 Crush-Impact - HEPA Filters . . . . . . . . . . . . . . . . . . . . . . . 3-86

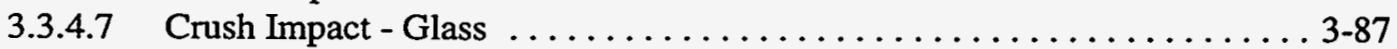

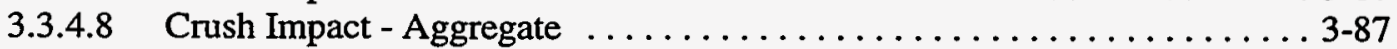

3.3.4.9 Crush Impact - Correlations . . . . . . . . . . . . . . . . . . 3-88

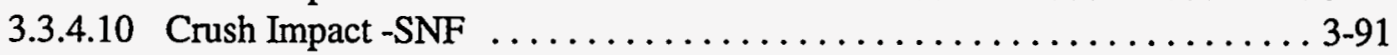

3.3.4.11 Crush Impact - Encapsulated Ceramic Oxide Pellets . . . . . . . . . . 3-91

3.3.4.12 Shock-Vibration . . . . . . . . . . . . . . . . . .

3.4 Source Term Estimations for Inadvertent Nuclear Criticality Excursions . . . . . . . . . 3-93

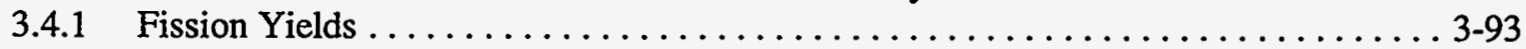

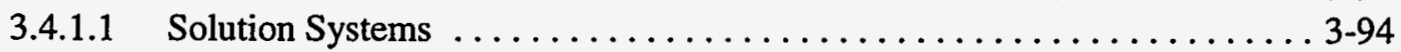

3.4.1.2 Fully Moderated and Reflected Solids . . . . . . . . . . . . . . . . . . . 3-94

3.4.1.3 Powder Systems . . . . . . . . . . . . . . . . . . . . . . . . . . 3-94

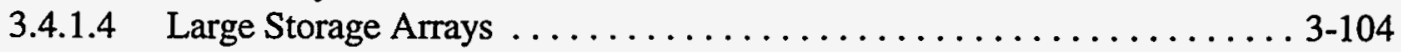

3.4.2 Nuclear Criticality Accident Source Term Estimates . . . . . . . . . . . . . 3-104

3.4.3 Estimation of ARF and RF for Nuclear Criticality Accidents $\ldots \ldots \ldots \ldots \ldots \ldots$ 3-108

3.4.3.1 Rules-of-Thumb for Total Fissions during INC . . . . . . . . . . . . . 3-109

3.4.3.2 Scenario Assumptions and ARFs and RFs ............... 3-110

3.5 Chemicals ........................................ 3114

3.5.1 Identification of a Representative Range of Source Terms ............ . 3-114

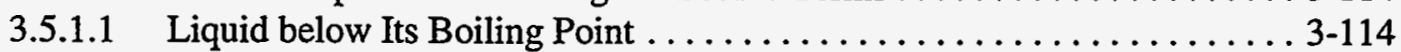

3.5.1.2 Refrigerated Liquid in a Vessel . . . . . . . . . . . . . . . . 3-114

3.5.1.3 Gas Liquefied under Pressure .................... 3-115

3.5.1.4 Releases from the Vapor Space of a Pressurized Vessel

or a Pressurized Pipeline ......................... 3-115

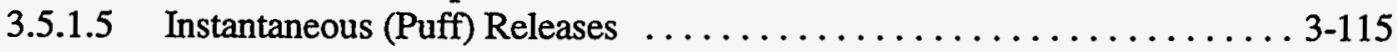

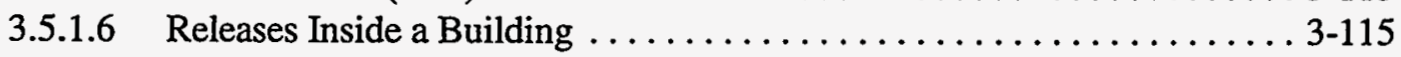

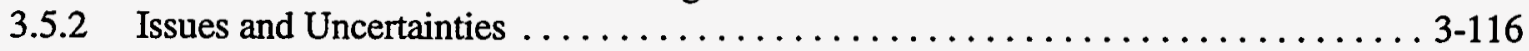

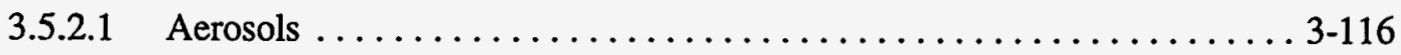

3.5.2.2 Uncertainties ................................ 3-119

3.5.3 Examples - Specific Scenarios ............................. 3-120

3.5.3.1 Puff Release of Ammonia ........................ 3-120

3.5.3.2 Puff Release of Hydrofluoric Acid . . . . . . . . . . . . . . 3-123

3.5.3.3 Puff Release of Propane . . . . . . . . . . . . . . . . . . . . 3-124

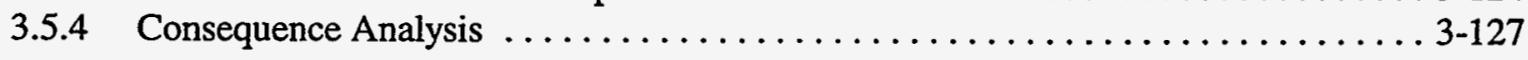

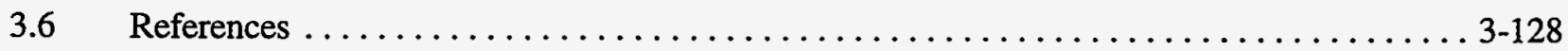

NUREG/CR-6410 viii 


\section{TABLE OF CONTENTS \\ (Continued)}

\section{CHAPTER 4: TRANSPORT WITHIN CONTAINMENT/CONFINEMENT}

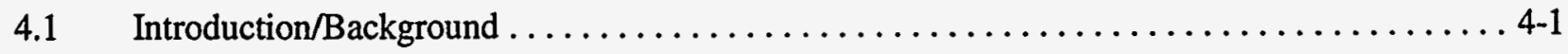

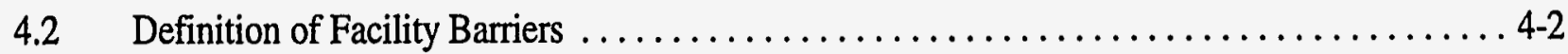

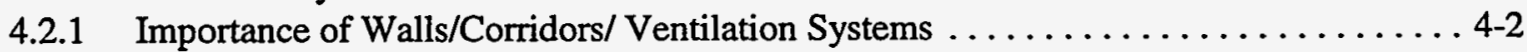

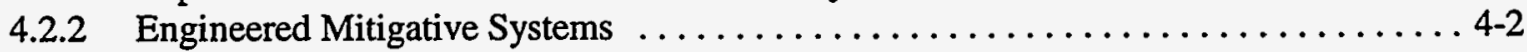

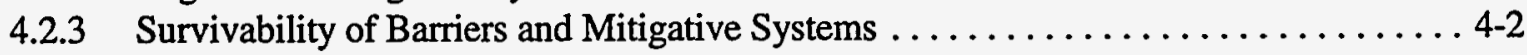

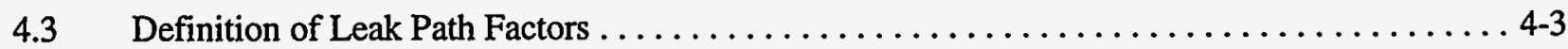

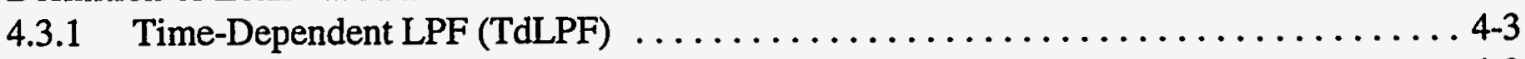

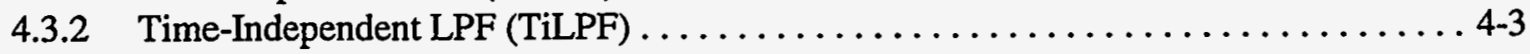

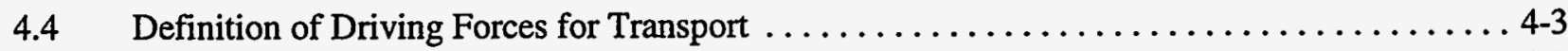

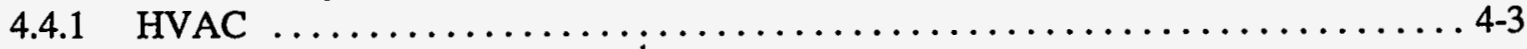

4.4.2 Fires and Other Uncontrolled Chemical Reactions $\ldots \ldots \ldots \ldots \ldots \ldots \ldots \ldots .4$

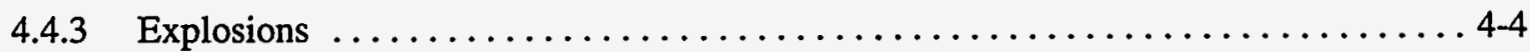

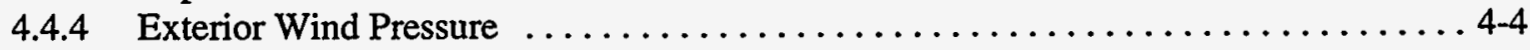

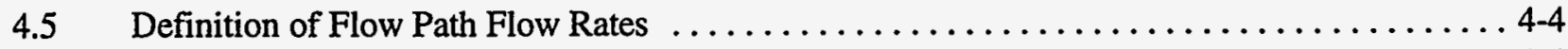

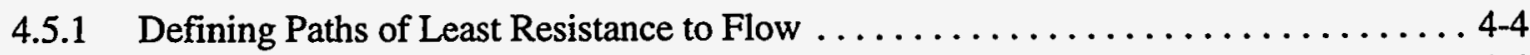

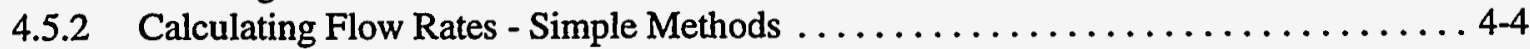

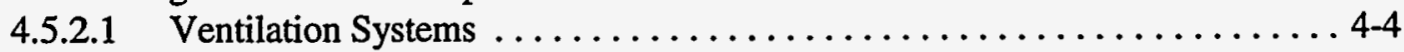

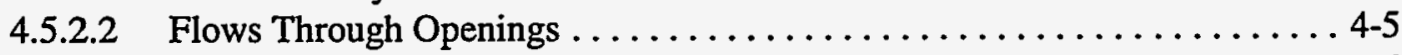

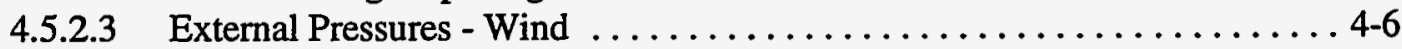

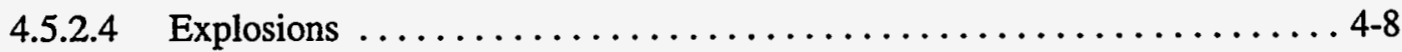

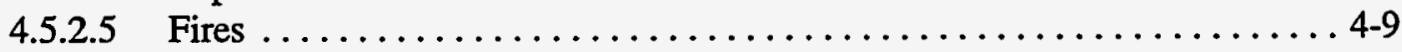

4.5.3 Calculating Flow Rates - Computer Codes .................. $4-12$

4.5.3.1 HVAC System Simulation Capabilities ................... 4 4-13

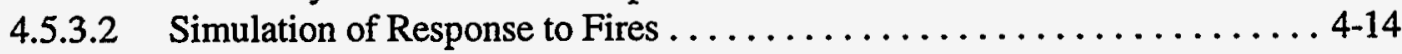

4.5.3.3 Simulation of Response to Explosions .................. 4-14

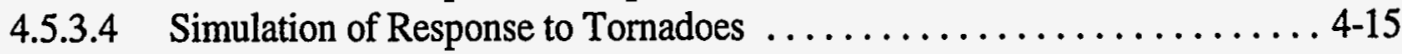

4.5.3.5 Estimation of Transient Release Rates ................ 4-15

4.6 Attenuation of Airborne Materials Along Flow Path $\ldots \ldots \ldots \ldots \ldots \ldots \ldots \ldots \ldots \ldots$

4.6 .1 Aerosols ................................... 4.15

4.6.1.1 Particle Deposition Processes ..................... 4-16

4.6.1.2 Filtration/Mitigative Methods $\ldots \ldots \ldots \ldots \ldots \ldots \ldots \ldots \ldots \ldots \ldots .17$

4.6.1.3 Develop Guidelines for Estimating the Importance

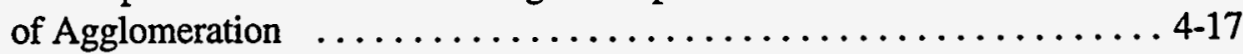

4.6.2 Chemicals ........................................ 4-19

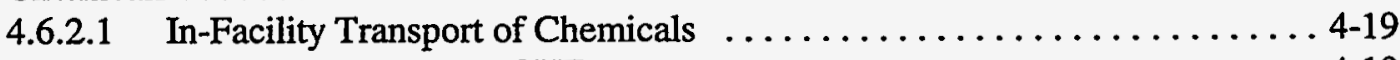

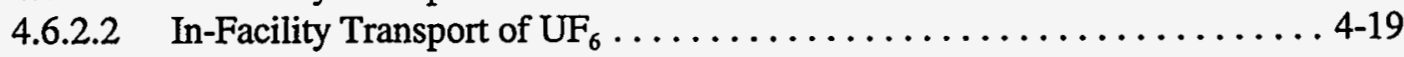




\section{TABLE OF CONTENTS \\ (Continued)}

$4.7 \quad$ Calculating the Leak Path Factor $\ldots \ldots \ldots \ldots \ldots \ldots \ldots \ldots \ldots \ldots \ldots \ldots \ldots \ldots \ldots \ldots \ldots \ldots \ldots \ldots, 21$

4.7.1 Simple Methods - TdLPF $\ldots \ldots \ldots \ldots \ldots \ldots \ldots \ldots \ldots \ldots \ldots \ldots \ldots \ldots, 4-21$

4.7.2 Simple Methods - TiLPF $\ldots \ldots \ldots \ldots \ldots \ldots \ldots \ldots \ldots \ldots \ldots \ldots \ldots \ldots, 4-21$

4.7.2.1 Technical Bases of the LPF\#1 Codes . . . . . . . . . . . . . . . . 4-22

4.7.2.2 Use of $\mathrm{LPF} \# 1 \mathrm{~B}$ Code $\ldots \ldots \ldots \ldots \ldots \ldots \ldots \ldots \ldots \ldots \ldots \ldots \ldots, 4-25$

4.8 Calculating Facility Concentrations $\ldots \ldots \ldots \ldots \ldots \ldots \ldots \ldots \ldots \ldots \ldots \ldots \ldots \ldots \ldots \ldots \ldots \ldots \ldots, 27$

4.8.1 Simple Concentration Estimates - Puff Release ..................... 4-27

4.8.2 Simple Concentration Estimates - Constant Continuous Release ............. 4-27

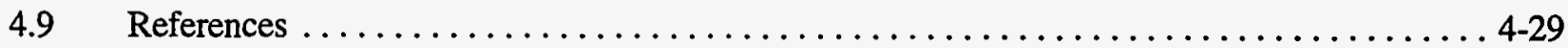

\section{CHAPTER 5: ATMOSPHERIC DISPERSION AND CONSEQUENCE MODELING}

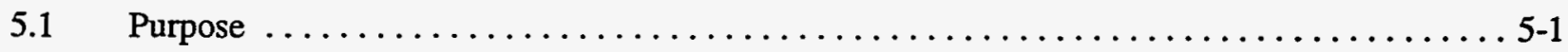

5.2 Types of Atmospheric Dispersion Models - Background $\ldots \ldots \ldots \ldots \ldots \ldots \ldots \ldots \ldots .2$

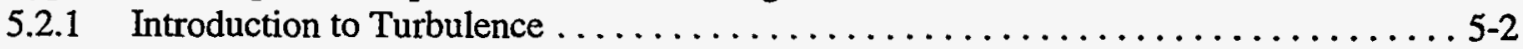

5.2 .2 Neutrally Buoyant Plumes (Gaussian Model) $\ldots \ldots \ldots \ldots \ldots \ldots \ldots \ldots \ldots \ldots .5, \ldots \ldots \ldots$

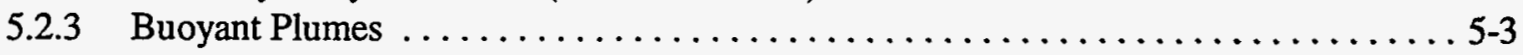

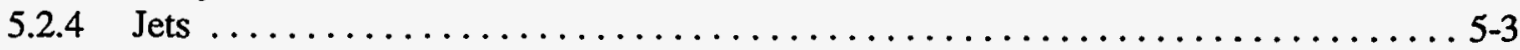

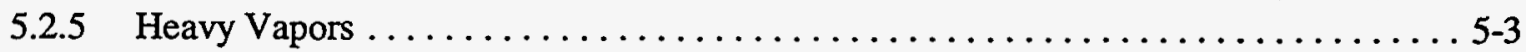

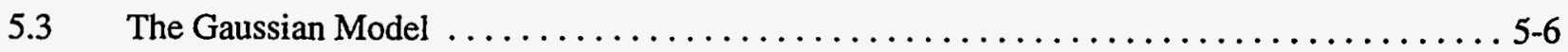

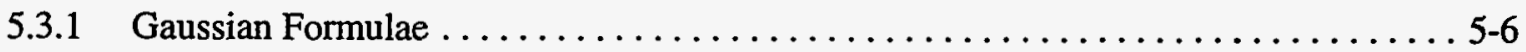

5.3.1.1 Homogeneity of Turbulence ....................... 5-7

5.3.1.2 Stationary Turbulence Conditions and Steady-State

Pollutant Concentration ............................. 5-7

5.3.1.3 The Effect of Diffusion Times . . . . . . . . . . . . . . . . 5-9

5.3.1.4 Significance of the Spatially Constant Basic Flow ............. 5-9

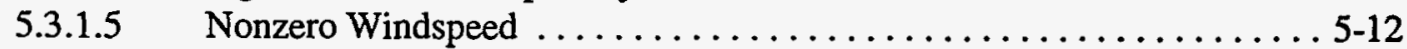

5.3.1.6 Condition for Continuity and Total Reflection at the Ground ....... 5-12

5.3.1.7 Practical Consequences .......................... 5-12

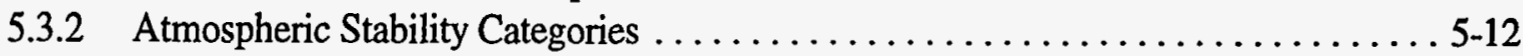

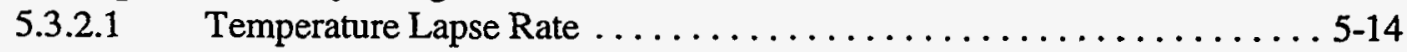

5.3.2.2 Horizontal Fluctuation of Wind Direction $\ldots \ldots \ldots \ldots \ldots \ldots \ldots .14$

5.3.2.3 Split Sigma .............................. 5-17

5.3.2.4 Stability Categories Defined by Reference to Both Temperature

Difference and Windspeed ......................... 5-17

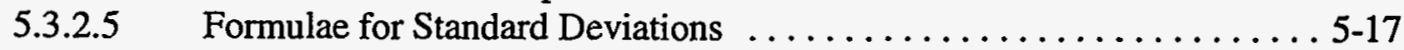

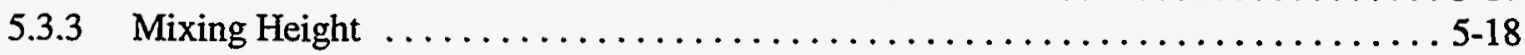

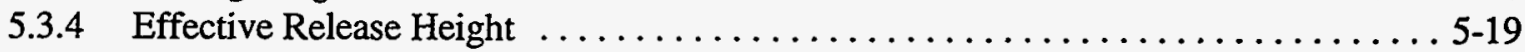

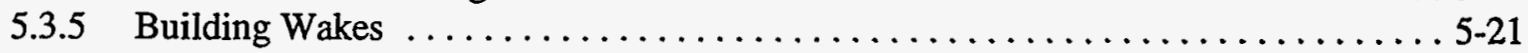

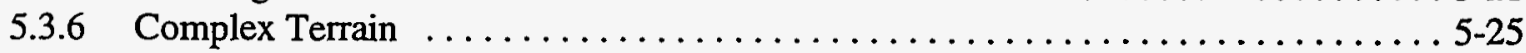




\section{TABLE OF CONTENTS (Continued)}

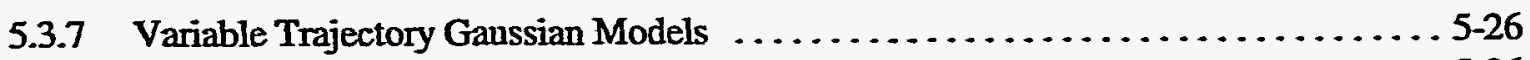

5.3.7.1 Segmented Plume Model $\ldots \ldots \ldots \ldots \ldots \ldots \ldots \ldots \ldots \ldots \ldots \ldots . . \ldots \ldots$

5.3.7.2 Puff Transport Model ......................... 5-28

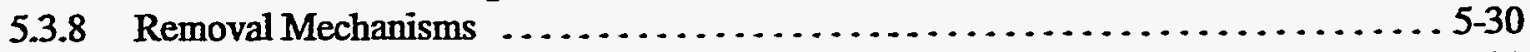

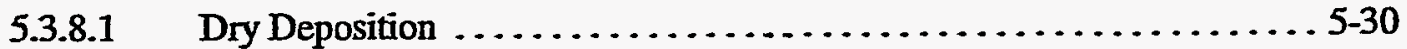

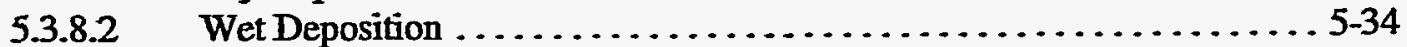

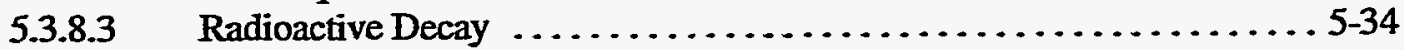

5.3.8.4 Resuspension .............................. 5-35

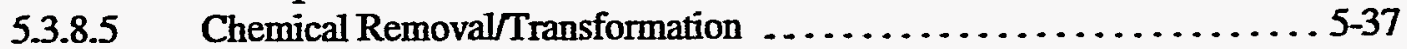

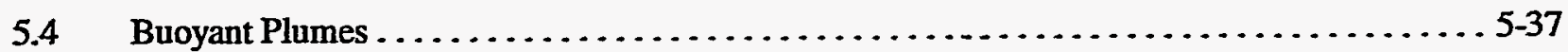

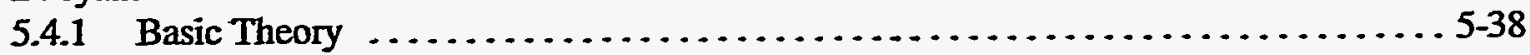

5.4.2 Ground-Level Concentrations Under a Rising Plume $\ldots \ldots \ldots \ldots \ldots \ldots \ldots \ldots . . \ldots \ldots$

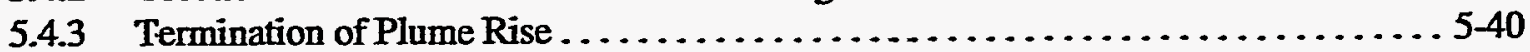

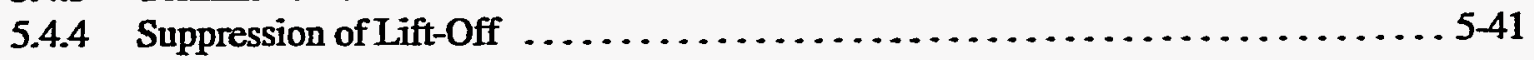

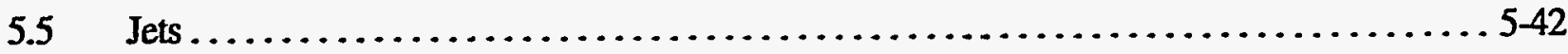

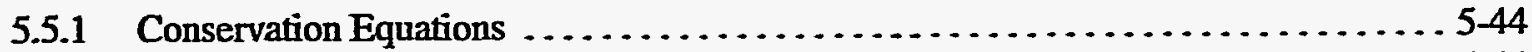

5.5.1.1 Entrainment of Air ....................... 544

5.5.1.2 Conservation of Horizontal Momentum Flux .............. 5 44

5.5.1.3 Conservation of Vertical Momentum Flux ................. 5-44

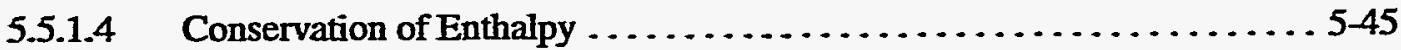

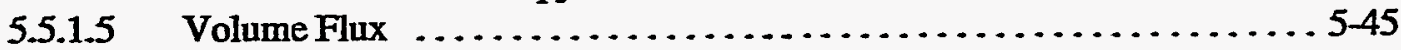

$5.5 .1 .6 \quad$ Cloud Velocity .................................. 545

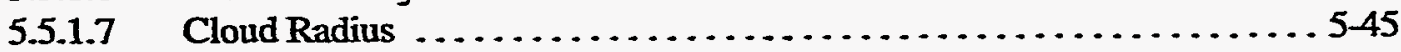

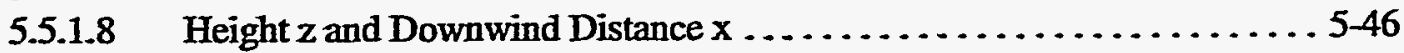

5.5.1.9 Change in Temperature of Air with Height $\ldots \ldots \ldots \ldots \ldots \ldots \ldots \ldots .46$

5.5.1.10 Zone of Flow Establishment ........................ $5-46$

5.5.1.11 Transition to Neutral Buoyancy ....................... 5-46

5.5.1.12 Concentrations Within the Plume $\ldots \ldots \ldots \ldots \ldots \ldots \ldots \ldots \ldots \ldots . . \ldots 7$

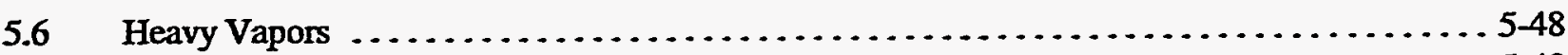

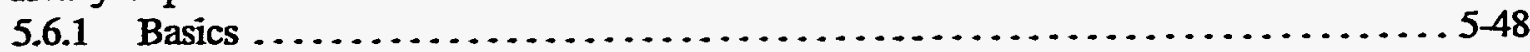

5.6.1.1 Miscellaneous Equations for the Plume $\ldots \ldots \ldots \ldots \ldots \ldots \ldots \ldots \ldots .48$

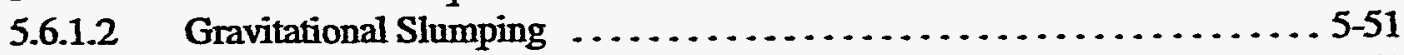

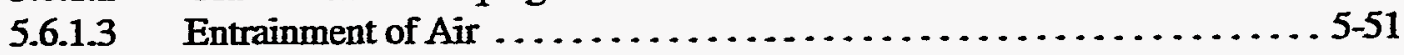

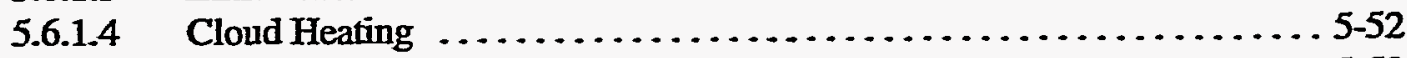

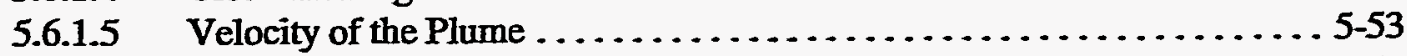

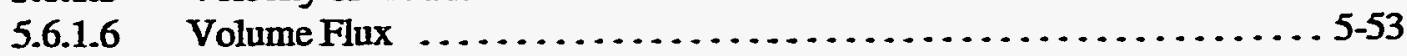

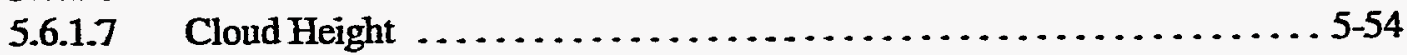

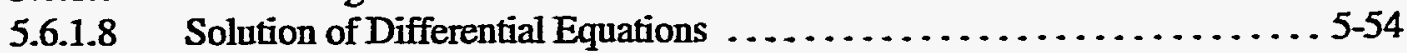

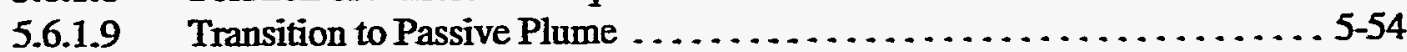

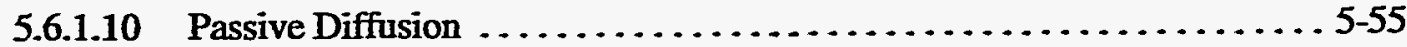




\section{TABLE OF CONTENTS (Continued)}

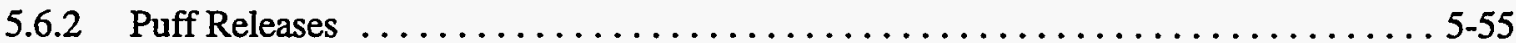

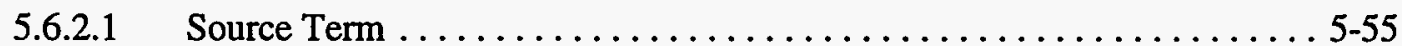

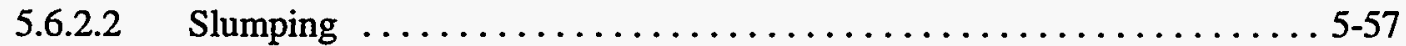

5.6.2.3 Entrainment of Air . . . . . . . . . . . . . . . . . . . . . . . . 5-57

5.6.2.4 Conservation of Momentum ........................... 5-58

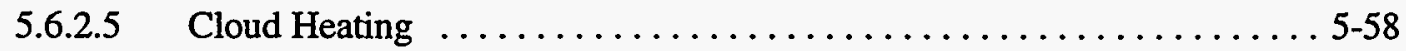

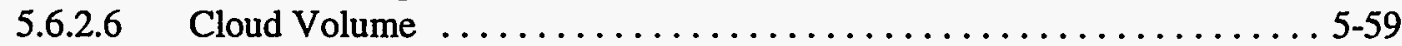

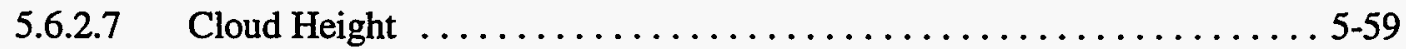

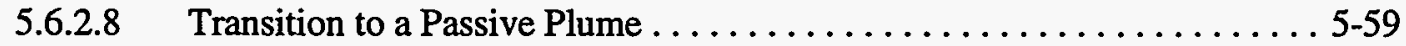

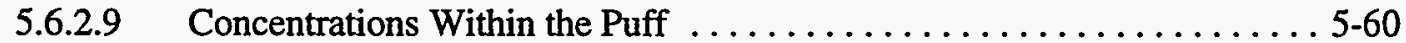

5.6.2.10 Cloud Velocity . . . . . . . . . . . . . . . . . . . . . . . .

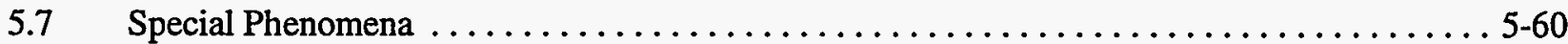

5.7.1 Aerosol Formation - Transport and Evaporation of Liquid Droplets ............ 5-60

5.7.2 Hydrogen Fluoride/Moist Air Thermodynamics .................... 5-61

5.7.2.1 The Oligomerization of Hydrogen Fluoride .............. 5-61

5.7.2.2 Final State of Hydrogen Fluoride/Moist Air Mixtures . . . . . . . . 5-61

5.7.3 Uranium Hexafluoride/Moist Air Thermodynamics .................. 5-61

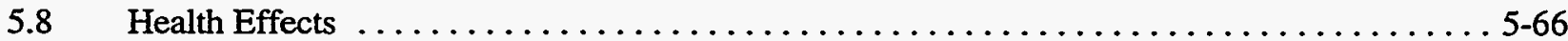

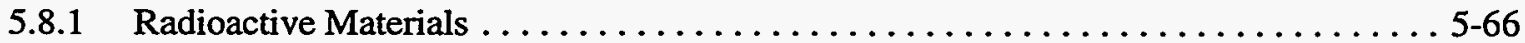

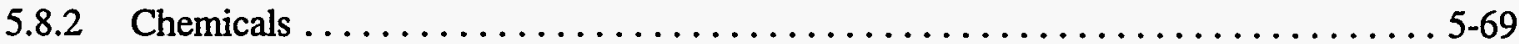

5.8.2.1 Toxic Endpoints . . . . . . . . . . . . . . . . . . . . . . . . 5-69

5.8.2.2 Probits ................................... 5-71

5.8.3 $\mathrm{UF}_{6}-$ Chemical Toxicity and Radiotoxicity $\ldots \ldots \ldots \ldots \ldots \ldots \ldots \ldots \ldots \ldots \ldots \ldots+71$

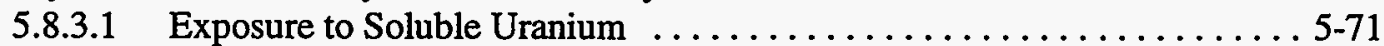

5.8.3.2 Exposure to Hydrogen Fluoride $\ldots \ldots \ldots \ldots \ldots \ldots \ldots \ldots \ldots \ldots \ldots \ldots \ldots \ldots$

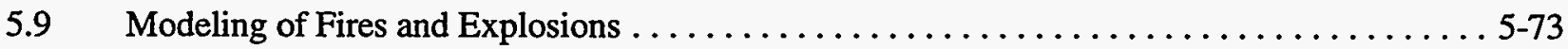

5.9.1 Vapor Cloud Explosions $\ldots \ldots \ldots \ldots \ldots \ldots \ldots \ldots \ldots \ldots \ldots \ldots \ldots \ldots \ldots \ldots \ldots, 73$

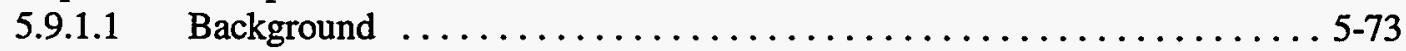

5.9.1.2 Vapor Cloud Explosion Blast Modeling $\ldots \ldots \ldots \ldots \ldots \ldots \ldots \ldots .74$

5.9.1.3 Effects of Vapor Cloud Explosions on Humans and Structures . . . . . . . 5-75

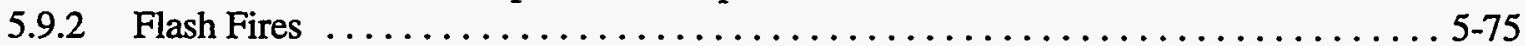

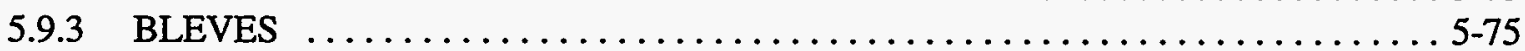

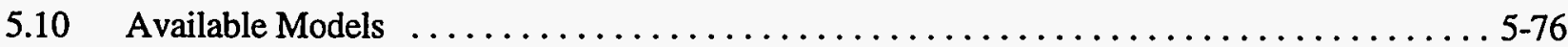

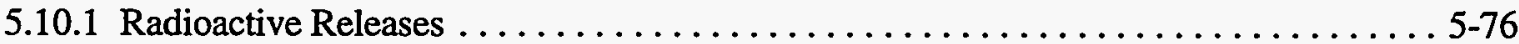

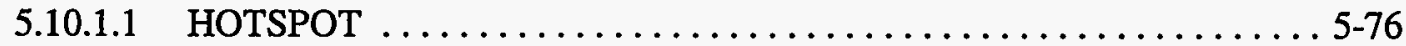

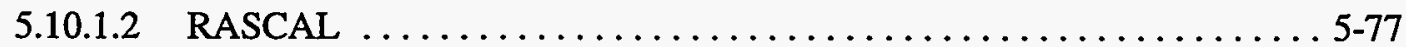

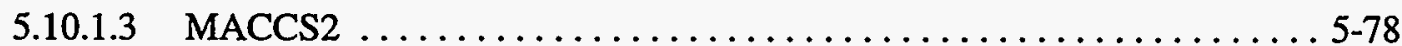

5.10.1.4 Comment ....................................... 5-79

5.10 .2 Hazardous Chemical Releases ................................. 5-79

5.10 .3 Hydrogen Fluoride and Uranium Hexafluoride $\ldots \ldots \ldots \ldots \ldots \ldots \ldots \ldots .5-80$ 


\section{TABLE OF CONTENTS \\ (Continued)}

5.11 Model Uncertainties $\ldots \ldots \ldots \ldots \ldots \ldots \ldots \ldots \ldots \ldots \ldots \ldots \ldots \ldots \ldots \ldots \ldots \ldots \ldots . \ldots \ldots 1$

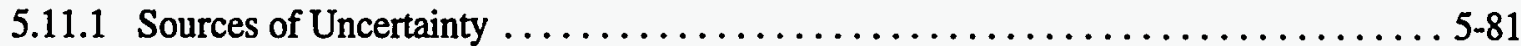

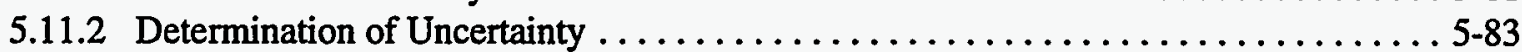

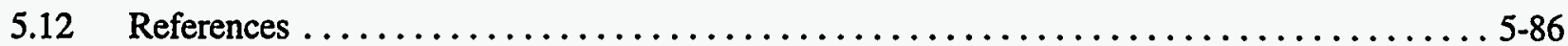

CHAPTER 6: LIST OF CONTRIBUTORS

APPENDIX A: SUMMARY OF CHEMICAL AND NUCLEAR SAFETY INFORMATION

APPENDIX B: SUMMARY OF METHODS FOR PREDICTING THE CHARACTERISTICS OF ACCIDENTAL RELEASES OF CHEMICALS

APPENDIX C: COMPARISON OF NRC, OSHA, AND EPA PROGRAMS THAT ADDRESS CHEMICAL SAFETY

APPENDIX D SAMPLE PROBLEMS

APPENDIX E: RESULTS OF BENCH-MARKING THE LPF \#1B CODE WITH THE MELCOR CODE

APPENDIX F: FILTRATION

APPENDIX G: UNCERTAINTY 


\section{LIST OF FIGURES}

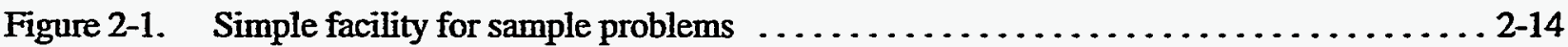

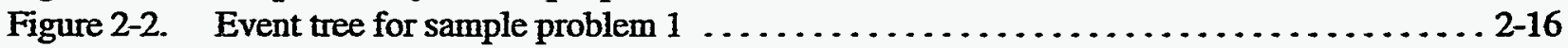

Figure 3-1. Effects of surface area on plutonium ignition temperatures (Stakebake 1992) . . . . . . 3-21

Figure 3-2. Dependence of uranium ignition temperatures on specific area

(Baker, Schnizlein, and Bingle 1966) ........................ 3-22

Figure 3-3. Relationship between RF and ammd for log-normal particle distribution

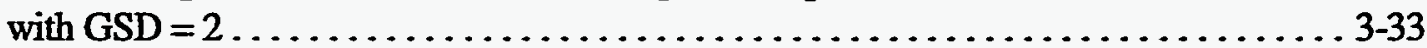

Figure 3-4. All active-particle size distribution for Double Tracks and Clean Slate I

(Shreve, et al. 1965) ..................................... 3-36

Figure 3-5. Near-ground airborne particle-size distribution for Double Tracks test of

Operation Roller Coaster . . . . . . . . . . . . . . . . . . . . . . . . . . 3-38

Figure 3-6. Near-ground airborne particle-size distribution for Clean Slate I in

Operation Roller Coaster . . . .............................. 3-39

Figure 3-7. Near-ground airborne particle-size distribution for Clean Slate II and III in

Operation Roller Coaster . . . . . . . . . . . . . . . . . . . . . . . . . . . . 3 340

Figure 3-8. Fraction airborne vs. mole fraction of pressurizing gas for

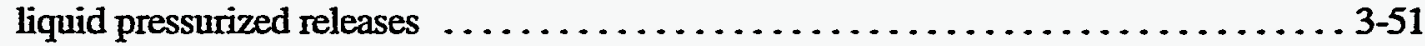

Figure 3-9. Correction curve for estimating effect of evaporation on RF $\ldots \ldots \ldots \ldots \ldots \ldots \ldots \ldots$

Figure 3-10. ARFs as a function of potential powder velocity $\ldots \ldots \ldots \ldots \ldots \ldots \ldots \ldots \ldots \ldots .6 \ldots$

Figure 3-11. Size distribution of bubble-induced droplets (Borkowski, et al. 1968) . . . . . . . . 3-63

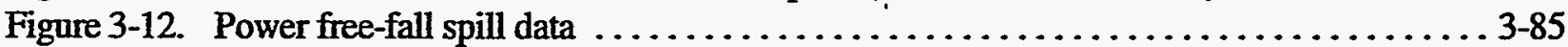

Figure 3-13. Crush impact (KWU data) . . . . . . . . . . . . . . . . . . . . . . . . . . 3-89

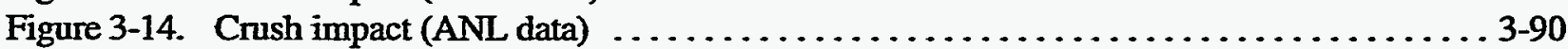

Figure 3-15. Fraction of liquid chlorine falling to the ground as a function of superheat $\ldots \ldots \ldots 3-118$

Figure 4-1. Relationship between RF and ammd for log-normal particle distribution

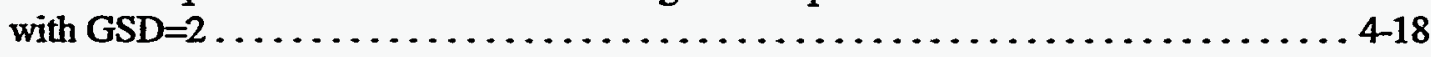

Figure 5-1. Simulation of a buoyant plume in a water tank .................... $5-4$

Figure 5-2. Slumping plume or puff - generation of turbulence at edge $\ldots \ldots \ldots \ldots \ldots \ldots \ldots \ldots$

Figure 5-3. Coordinate system showing Gaussian distributions in the horizontal and

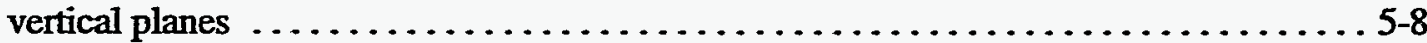

Figure 5-4. The effect of averaging time on plume width (Slade, 1968) . . . . . . . . . . . . 5-10

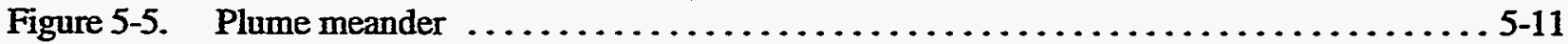

Figure 5-6. Curves of $\sigma_{y}$ and $\sigma_{z}$ for turbulence types based on those reported by Pasquill as

modified by Gifford (Hanna, et al. 1982) ........................ 5

Figure 5-7. Diagram of buoyant plume penetrating an elevated inversion $\ldots \ldots \ldots \ldots \ldots \ldots \ldots \ldots 5-20$

Figure 5-8. Neutral below, stable above (fumigation) $\ldots \ldots \ldots \ldots \ldots \ldots \ldots \ldots \ldots \ldots \ldots .20$

Figure 5-9. Schematic diagram of stack and important physical parameters:

$w_{o}$, effluent velocity; $u$, windspeed; $d$, internal stack diameter, $h_{s}$ stack height;

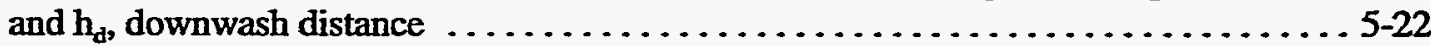

Figure 5-10. Model of flow near a sharp-edged building in a deep boundary layer . . . . . . . . . 5-23

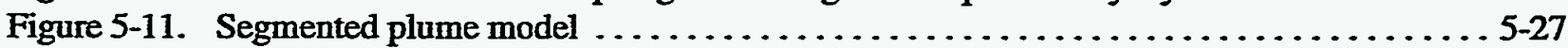

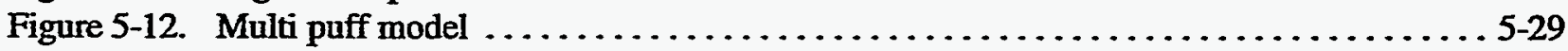




\section{LIST OF FIGURES (Continued)}

Figure 5-13. Atmospheric processes acting upon radiological/toxicological releases

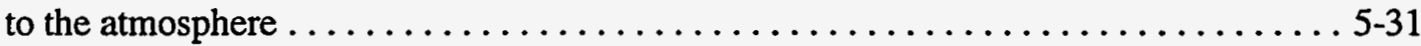

Figure 5-14. Gravitational settling speeds for particles with densities of $5 \mathrm{~g} / \mathrm{cm}^{3}$ near the

earth's surface (Hanna 1982) . . . . . . . . . . . . . . . . . . . . . 5-32

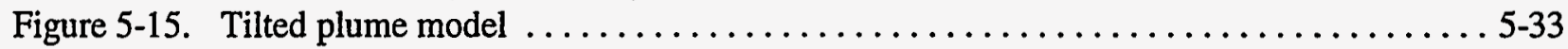

Figure 5-16. Schematic outline of evolution of plume $\ldots \ldots \ldots \ldots \ldots \ldots \ldots \ldots \ldots \ldots \ldots \ldots \ldots \ldots$

Figure 5-17. The configuration of the steady-state continuous plume (denser-than-air vapors) . . . . 5-49

Figure 5-18. The development of the dense gas cloud by slumping and advection $\ldots \ldots \ldots \ldots \ldots 50$

Figure 5-19. The growth of plume width and height across the transition from dense to

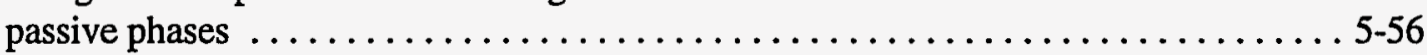

Figure 5-20. Equilibrium temperatures for mixing moist air and $\mathrm{UF}_{6} \ldots \ldots \ldots \ldots \ldots \ldots \ldots \ldots$ 5-64

Figure 5-21. Equilibrium density for mixing moist air and $U_{6} \ldots \ldots \ldots \ldots \ldots \ldots \ldots \ldots \ldots$

\section{LIST OF TABLES}

Table 2-1. Potential Events Impacting Nuclear Facilities $\ldots \ldots \ldots \ldots \ldots \ldots \ldots \ldots \ldots \ldots \ldots$

Table 2-2. Methods of Release of Radioactive Materials Anticipated for Nuclear

Process Facilities . . . . . . . . . . .

Table 3-1. Bounding ARFs and Applicable Experimentally Measured RFs . . . . . . . . . . 3-2

Table 3-2. Test Configuration Descriptions - Operation Roller Coaster . . . . . . . . . . . 3-35

Table 3-3. Particle Size Distributions for Operation Roller Coaster Tests

(Luna 1994) .............................................. 3-41

Table 3-4. Release Fractions from the Single-Point Detonation of Thin Metal Shells

as a Function of Charge (HE) to Mass Ratios (c:m) $\ldots \ldots \ldots \ldots \ldots \ldots \ldots \ldots \ldots \ldots .43$

Table 3-5. Airborne Release Fractions as a Function of Efficiency of Energy Deposited . . . . . 3-43

Table 3-6. ARF and RF as a Function of Mass Ratio (USDOE 1994) . . . . . . . . . . . 3-45

Table 3-7. Size Distribution Parameters for Pressurized Powder Release Aerosols ........ . . 3-59

Table 3-8. Summary of Known Accidental Criticality Excursions (1945 to 1974)

(a) Solution Systems, (b) Metal Systems, and (c) Moderated Foil and Powder Systems

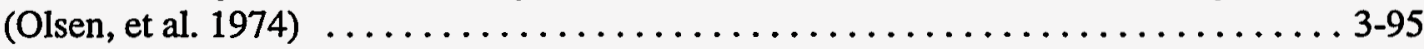

Table 3-9. Accidents in Processing Plants (Paxton 1980) . . . . . . . . . . . . . . . . . 3-99

Table 3-10. Destructive Power Excursion Summary (Nyer, Bright, and McWhorter 1965) . . . . . 3-100

Table 3-11. Inhomogenous Water-Moderated Systems (Stratton 1967) . . . . . . . . . . . 3-101

Table 3-12. Miscellaneous Systems (Stratton 1967) . . . . . . . . . . . . . . . . . . 3-102

Table 3-13. Nuclear Criticality Accidents at Russian Industrial Facilities (Frolov, et al. 1995) . . . 3-103

Table 3-14. Radioactivity Generated in a Uranium Solution Criticality Accident . . . . . . . . 3-105

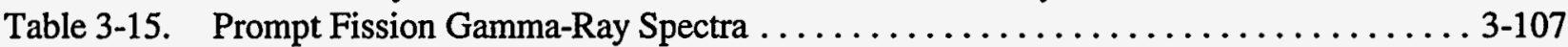

Table 3-16. Prompt Neutron Energy Spectrum . . . . . . . . . . . . . . . . . . . . 3-107

Table 3-17. Criticality Accident Fission Yields (McLaughlin 1991) . . . . . . . . . . . . 3-111 


\section{LIST OF TABLES \\ (Continued)}

Table 3-18. Release Fraction for Various Chemical Classes from Heated Spent Fuel

(Restrepo 1991) ...................................... 3-113

Table 3-19. Chemical Source Term Examples $\ldots \ldots \ldots \ldots \ldots \ldots \ldots \ldots \ldots \ldots \ldots \ldots \ldots \ldots \ldots \ldots \ldots$

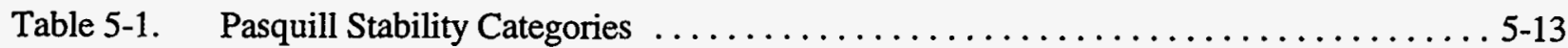

Table 5-2. Classification of Atmospheric Stability by Temperature Lapse Rate . . . . . . . . . 5-16

Table 5-3. Classification of Atmospheric Stability by Standard Deviation of

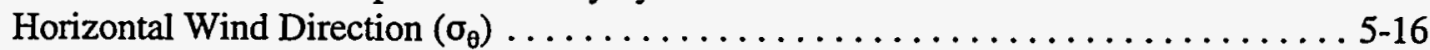

Table 5-4. Stability Categories Defined by Reference to Both Temperature

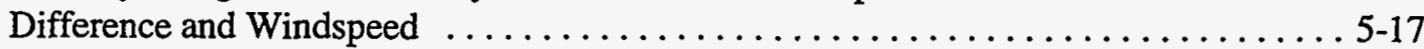

Table 5-5. Formulae Recommended by Briggs (1973) for $\sigma_{y}(x)$ and $\sigma_{z}(x)$

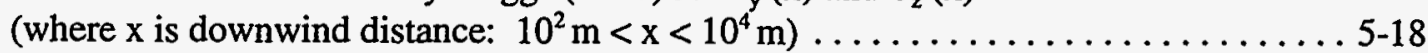

Table 5-6. Predicted and Experimental Association Factors (F)

(Vanderzee and Rosenberg 1970) .......................... 5-62

Table 5-7. Predicted and Experimental Association Factors ( $F$ )

(Strohmeir and Briegleb 1953) ......................... 5-62

Table 5-8. Comparison Between Schotte's Results and Theory Mixing HF Vapor and Air

with 80 Percent RH . .............................. 5-63

Table 5-9. Acute and Delayed Non-cancer Effects of Low LET Radiation and Approximate

Single Doses for 50 percent Incidence in People (Shleien 1992) . . . . . . . . . . 5-68

Table 5-10. Emergency Response Planning Guidelines . . . . . . . . . . . . . . . . . . . 5-70

Table 5-11. Values of ERPGs for Substances Commonly Found at Fuel Cycle Licensees' Sites ... 5-70

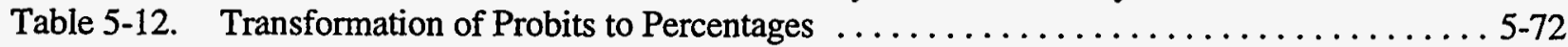

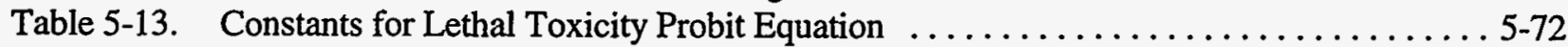

Table 5-14. Confidence Ranges for Parameters Used in Atmospheric Models (NRC 1983c) . . . . 5-83 


\section{LIST OF ACRONYMS, ABBREVIATIONS, AND NAMES}

\begin{tabular}{|c|c|}
\hline $\mathrm{ACC}$ & Air Cleaning Conference \\
\hline ACGIH & American Conference of Government Industrial Hygienists \\
\hline ADU & Ammonium Diuranate \\
\hline AEC & Atomic Energy Commission \\
\hline AED & Aerodynamic Equivalent Diameter \\
\hline $\mathrm{Ag}$ & Silver \\
\hline AIChE & American Institute of Chemical Engineers \\
\hline AIHA & American Industrial Hygiene Association \\
\hline $\mathrm{Al}$ & Aluminum \\
\hline AMAD & Activity Median Aerodynamic Diameter \\
\hline ammd & Aerodynamic Mass Mean Diameter \\
\hline AMS & American Meteorological Society \\
\hline ANSI & American National Standards Institute \\
\hline ARF & Airborne Release Fraction \\
\hline ARR & Airborne Release Rate \\
\hline ASTM & American Society of Testing and Materials \\
\hline AVLIS & Atomic Vapor Laser Isotope Separation \\
\hline BLEVE & Boiling Liquid Expanding Vapor Explosion \\
\hline $\mathrm{CaCO}_{3}$ & Calcium Carbonate \\
\hline $\mathrm{CaF}_{2}$ & Calcium Fluoride \\
\hline CCPS & Center for Chemical Process Safety \\
\hline CEDE & Committed Effective Dose Equivalent \\
\hline CFR & Code of Federal Regulations \\
\hline $\mathrm{Cl}_{2}$ & Chlorine \\
\hline cmd & Count Median Diameter \\
\hline $\mathrm{CO}_{2}$ & Carbon Dioxide \\
\hline $\mathrm{DBA}$ & Design Basis Accident \\
\hline DBGF & Deep Bed Glass Fiber (filter) \\
\hline DDT & Deflagration to Detonation Transition \\
\hline DGM & Geometric Mass Median Diameter \\
\hline DIERS & Design Institute for Emergency Relief Systems \\
\hline DOE & Department of Energy \\
\hline DOP & Dioctyl Phthalate \\
\hline DOT & Department of Transportation \\
\hline DR & Damage Ratio, dimensionless \\
\hline DUO & Depleted Uranium Oxide \\
\hline EPA & Environmental Protection Agency \\
\hline ERPG & Emergency Response Planning Guideline \\
\hline EST & Environmental Source Term \\
\hline${ }^{\circ} \mathrm{F}$ & Degrees Fahrenheit \\
\hline $\mathrm{F}_{2}$ & Fluorine \\
\hline $\mathrm{Fe}$ & Iron \\
\hline FR & Federal Register \\
\hline $\mathrm{Gd}_{2} \mathrm{O}_{3}$ & Gadolinia \\
\hline GDP & Gaseous Diffusion Plant \\
\hline
\end{tabular}




\section{LIST OF ACRONYMS, ABBREVIATIONS, AND NAMES \\ (Continued)}

\begin{tabular}{|c|c|}
\hline GSD & Geometric Standard Deviation \\
\hline $\mathrm{H}_{2}$ & Hydrogen \\
\hline $\mathrm{H}_{2} \mathrm{O}$ & Water \\
\hline $\mathrm{H}_{2} \mathrm{O}_{2}$ & Hydrogen Peroxide \\
\hline $\mathrm{H}_{2} \mathrm{SO}_{4}$ & Sulfuric Acid \\
\hline $\mathrm{HCl}$ & Hydrochloric Acid \\
\hline $\mathrm{HCl}$ & Hydrogen Chloride \\
\hline $\mathrm{HE}$ & High Explosives \\
\hline HEPA & High Efficiency Particulate Air (filter) \\
\hline HEU & High Enriched Uranium \\
\hline $\mathrm{HF}$ & Hydrofluoric Acid \\
\hline $\mathrm{Hg}$ & Mercury \\
\hline $\mathrm{HNO}_{3}$ & Nitric Acid \\
\hline HVAC & Heating, Ventilation, and Air Conditioning \\
\hline $\mathrm{K}_{2} \mathrm{U}_{2} \mathrm{O}_{7}$ & Potassium Diuranate \\
\hline $\mathrm{KOH}$ & Potassium Hydroxide \\
\hline ICRP & International Commission on Radiological Protection \\
\hline $\mathrm{LC}_{\mathrm{x}}$ & Concentration that is fatal to $\mathrm{x} \%$ of those exposed \\
\hline $\mathrm{LC}_{10}$ & Concentration that is fatal to $10 \%$ of those exposed \\
\hline $\mathrm{LC}_{50}$ & Concentration that is fatal to $50 \%$ of those exposed \\
\hline $\mathrm{LC}_{90}$ & Concentration that is fatal to $90 \%$ of those exposed \\
\hline LEU & Low Enriched Uranium \\
\hline LNT & Linear Non-Threshold (theory) \\
\hline LOC & Level of Concern \\
\hline LOCA & Loss of Coolant Accident \\
\hline LPF & Leak Path Factor \\
\hline MACCS & Melcor Accident Consequence Code System \\
\hline MAR & Material at Risk \\
\hline mmd & Mass Mean Diameter \\
\hline $\mathrm{MnO}_{2}$ & Manganese Dioxide \\
\hline MOX & Mixed Oxide Fuel \\
\hline $\mathrm{N}_{2}$ & Nitrogen \\
\hline $\mathrm{NaOH}$ & Sodium Hydroxide \\
\hline NFPA & National Fire Protection Association \\
\hline $\mathrm{NH}_{3}$ & Ammonia \\
\hline $\mathrm{NH}_{4} \mathrm{OH}$ & Ammonium Hydroxide \\
\hline $\mathrm{Ni}$ & Nickel \\
\hline NIOSH & National Institute for Occupational Safety and Health \\
\hline NRC & Nuclear Regulatory Commission \\
\hline NVA & No Value Currently Available \\
\hline ORNL & Oak Ridge National Laboratory \\
\hline OSHA & Occupational Safety and Health Administration \\
\hline PC & Polychlorophene \\
\hline PHA & Process Hazards Analysis \\
\hline PMMA & Polymethylmethacrylate \\
\hline
\end{tabular}




\section{LIST OF ACRONYMS, ABBREVIATIONS, AND NAMES (Continued)}

\begin{tabular}{|c|c|}
\hline PNNL & Pacific Northwest National Laboratory \\
\hline PRA & Probabilistic Risk Assessment \\
\hline PSM & Process Safety Management \\
\hline Pu & Plutonium \\
\hline $\mathrm{PuO}_{2}$ & Plutonium Dioxide \\
\hline PVC & Poly Vinyl Chloride \\
\hline QRA & Quantitative Risk Assessment \\
\hline RARF & Respirable Airborne Release Fraction \\
\hline RF & Respirable Fraction, dimensionless \\
\hline RH & Relative Humidity \\
\hline RMP & Risk Management Program \\
\hline S:M & Surface to Mass Ratio \\
\hline SAIC & Science Applications International Corporation \\
\hline SARA & Superfund Amendments and Reauthorization Act of 1986 \\
\hline SIC & Standard Industrial Code \\
\hline TBP & Tri Butyl Phosphate \\
\hline TdLPF & Time Dependent Leak Path Factór \\
\hline TEDE & Total Effective Dose Equivalent \\
\hline TiLPF & Time Independent Leak Path Factor \\
\hline $\mathrm{TiO}_{2}$ & Titanium Dioxide \\
\hline TNT & Tri-Nitro-Toluene \\
\hline TRU & Transuranic Wastes \\
\hline TSL & Technical Support Level \\
\hline $\mathrm{U}_{3} \mathrm{O}_{8}$ & Triuranium Octoxide \\
\hline $\mathrm{UF}_{4}$ & Uranium Tetrafluonide \\
\hline $\mathbf{U F}_{6}$ & Uranium Hexafluoride \\
\hline UNH & Uranyl Nitrate Hexahydrate \\
\hline $\mathrm{UO}_{2}$ & Uranium Dioxide \\
\hline $\mathrm{UO}_{2}\left(\mathrm{NO}_{3}\right)_{2}$ & Uranyl Nitrate \\
\hline $\mathrm{UO}_{3}$ & Uranium Trioxide \\
\hline $\mathrm{UO}_{4}$ & Uranium Tetroxide \\
\hline $\mathrm{UO}_{2} \mathrm{~F}_{2}$ & Uranyl Fluoride \\
\hline WC & Water Column \\
\hline WG & Water Gauge \\
\hline WIPP & Waste Isolation Pilot Plant \\
\hline
\end{tabular}




\section{LIST OF SYMBOLS}

a

$a_{p}$

A

$\mathrm{Arch}_{\mathrm{a}}$

ARF

$\mathrm{A}_{\mathrm{d}}$

$\mathrm{A}_{\mathrm{f}}$

$\mathrm{A}_{\mathrm{h}}$

$\alpha$

$\alpha_{1}$

$\alpha_{2}$

$$
\alpha_{3}
$$$$
\alpha_{j 1}, \alpha_{j 2}, \alpha_{j 3}
$$

$\alpha_{\mathrm{e}}$

$\alpha_{\mathrm{m}}$

$\alpha_{s}$

$b_{p}$

$\beta$

$\beta_{\mathrm{e}}$

$\beta_{\mathrm{f}}$

\section{c}

$\mathrm{cm}$

$\mathrm{C}$

$\mathrm{cfm}$

$\mathrm{Ci}$

$\mathrm{C}(\mathrm{r})$

$\mathrm{C}(\mathrm{r})$

$C\left(t_{e}\right)$

$\mathrm{C}(\mathrm{x}, \mathrm{y}, \mathrm{z})$

$\mathrm{C}_{\mathrm{d}}$

$\mathrm{C}_{\mathrm{o}}$

$\mathrm{C}_{\mathrm{p}}$

$\mathrm{C}_{\mathrm{pa}}$

$\mathrm{C}_{\mathrm{pg}}$

$\mathrm{C}_{\mathrm{pl}}$

$\mathrm{C}_{\mathrm{s}}$

$\mathrm{C}_{\mathrm{u}}$

$\mathrm{C}_{\mathrm{v}}$

$\mathrm{C}_{\mathrm{D}}(\mathrm{x}, \mathrm{y})$

$C_{D}(x, y)$

${ }^{\circ} \mathrm{C}$

d area of hole or orifice, $\mathrm{m}^{2}$

parameter in probit equation

area of liquid surface or area of orifice, or cross-sectional area of building, $\mathrm{m}^{2}$

Archimedes number, dimensionless

airborne release fraction, dimensionless

cross-sectional area of duct, $\mathrm{m}^{2}$

area of filter, $\mathrm{m}^{2}$

area of hole, $\mathrm{m}^{2}$

thermal diffusivity, $\mathrm{m}^{2} / \mathrm{s}$

empirical coefficient in the edge entrainment equation, dimensionless

empirical coefficient in the top entrainment equation, dimensionless

coefficient in the equation for the heating of the cloud by the ground, dimensionless

entrainment coefficients for entrainment of air into a jet

TNT equivalence based on energy, dimensionless

TNT equivalence based on mass, dimensionless

thermal diffusivity, $\mathrm{m}^{2} / \mathrm{s}$

parameter in probit, dimensionless

ratio of diameters, dimensionless

entrainment constant, dimensionless - or aerodynamic wake correction factor, dimensionless

coefficient of volumetric expansion at the interface between the cloud and the surrounding atmosphere, $\mathrm{m}^{3} / \mathrm{K}$

flow constant, dimensionless

centimeter

specific heat, $\mathrm{J} / \mathrm{kg} / \mathrm{K}$

cubic feet per minute, $\mathrm{ft}^{3} /$ minute

curies

airborne ground level concentration at a distance $r$ from the center of a puff, or airborne concentration of a jet at a distance $\mathrm{r}$ from the centerline, $\mathrm{kg} / \mathrm{m}^{3}$

plume radial concentration before transition to neutral buoyancy at distance $r$ from the centerline, $\mathrm{kg} / \mathrm{m}^{3}$

average airborne concentration for exposure time $\mathrm{t}_{\mathrm{e}}, \mathrm{kg} / \mathrm{m}^{3}$

airborne concentration at point $(\mathrm{x}, \mathrm{y}, \mathrm{z}), \mathrm{kg} / \mathrm{m}^{3}$

drag coefficient, dimensionless

exiting containment concentration from building, $\mathrm{kg} / \mathrm{m}^{3}$

specific heat at constant pressure, $\mathrm{J} / \mathrm{kg} / \mathrm{K}$

specific heat of air at constant pressure, $\mathrm{J} / \mathrm{kg} / \mathrm{K}$

specific heat of gas at constant pressure, $\mathrm{J} / \mathrm{kg} / \mathrm{K}$

specific heat of liquid at constant pressure, $\mathrm{J} / \mathrm{kg} / \mathrm{K}$

potential temperature gradient in atmospheric stability category $\mathrm{S}, \mathrm{K} / 100 \mathrm{~m}$

plume concentration averaged over cross-section, $\mathrm{kg} / \mathrm{m}^{-3}$

specific heat at constant volume, $\mathrm{J} / \mathrm{kg} / \mathrm{K}$

quantity of material deposited per unit area at point $(\mathrm{x}, \mathrm{y}), \mathrm{kg} / \mathrm{m}^{2}$

concentration of radionuclide at position $(\mathrm{x}, \mathrm{y})$ on the ground, $\mathrm{kg} / \mathrm{m}^{2}$

degrees Centigrade

diameter of source, $\mathrm{m}$ 


\title{
LIST OF SYMBOLS (Continued)
}

\author{
$\mathrm{d}_{\mathrm{p}} \quad$ diameter of particle, $\mu \mathrm{m}$ \\ D internal stack diameter, $\mathrm{m}$, or characteristic diameter, $\mathrm{m}$ \\ DGM geometric mass median diameter, $\mu \mathrm{m}$ \\ DN dimensionless number \\ DR damage ratio, dimensionless \\ $\mathrm{D}_{\mathrm{a}} \quad$ aerodynamic diameter, $\mu \mathrm{m}$ \\ $D_{f} \quad$ diameter of a fire, $m$ \\ $\mathrm{D}_{\mathrm{g}} \quad$ geometric diameter, $\mu \mathrm{m}$ \\ $D_{m} \quad$ molecular diffusivity, $\mathrm{m}^{2} / \mathrm{s}$ \\ $\mathrm{D}_{\text {AED }} \quad$ aerodynamic equivalent diameter, $\mu \mathrm{m}$ \\ $\Delta \mathrm{H}_{\mathrm{c}} \quad$ lower heat of combustion, $\mathrm{J} / \mathrm{kg}$ \\ $\mathrm{E}_{\mathrm{d}} \quad$ energy density, $\mathrm{J} / \mathrm{m}_{3}$ \\ $\mathrm{f}$ friction factor, dimensionless \\ F fraction, dimensionless, or buoyancy parameter, $\mathrm{m}^{4} / \mathrm{s}^{3}$ \\ F* radioactivity buoyancy parameter, $\mathrm{m}^{4} / \mathrm{s}^{4}$ \\ $\mathrm{F}(\mathrm{x}) \quad$ fraction of released material remaining airborne at a distance $\mathrm{x}$ downwind \\ $F_{d} \quad$ drag force, $\mathrm{kg} / \mathrm{m} / \mathrm{s}^{2}$ \\ $\mathrm{F}_{\mathrm{mh}} \quad$ horizontal momentum flux, $\mathrm{kg} / \mathrm{m} / \mathrm{s}^{2}$ \\ $\mathrm{F}_{\mathrm{mo}} \quad$ initial total momentum flux, $\mathrm{kg} / \mathrm{m} / \mathrm{s}^{2}$ \\ $F_{m v} \quad$ vertical momentum flux, $\mathrm{kg} / \mathrm{m} / \mathrm{s}^{2}$ \\ Fr Froude number, dimensionless \\ $\mathrm{F}_{\mathrm{u}} \quad$ upward heat flux from ground, $\mathrm{J} / \mathrm{m}^{2} / \mathrm{s}^{1}$ \\ $\gamma \quad \mathrm{C}_{\mathrm{p}} / \mathrm{C}_{\mathrm{v}}$, dimensionless \\ $\mathrm{g} \quad$ acceleration due to gravity, $\mathrm{m} / \mathrm{s}^{2}$ \\ g* $\quad \mathrm{gh}_{\mathrm{p}} \Delta \rho / \rho_{\mathrm{a}}, \mathrm{m}^{2} / \mathrm{s}^{2}$ \\ $h \quad$ static head or depth, $m$, or height of plume axis, $m$ \\ $h_{d} \quad$ plume downwash distance, $m$ \\ $h_{0} \quad$ initial height of release (initial height of plume centerline), $m$ \\ $h_{p} \quad$ initial plume depth (ground level release), $m$ \\ $h_{\mathrm{pr}} \quad$ height of plume rise, $\mathrm{m}$ \\ $h_{p t} \quad$ value of $h_{p}$ at transition point, $m$ \\ $h_{s} \quad$ physical stack height, $m$ \\ $h_{t} \quad$ height of plume top at transition to neutral buoyancy, $m$ \\ $\mathrm{h}_{\mathrm{T}} \quad$ height of terrain feature, $\mathrm{m}$ \\ $\mathrm{H} \quad$ enthalpy, $\mathrm{J} / \mathrm{kg}$ \\ $\mathrm{H}_{c} \quad$ effective height of release, $\mathrm{m}$ \\ $\mathrm{H}_{\mathrm{B}} \quad$ height of building, $\mathrm{m}$ \\ $\mathrm{H}_{\mathrm{F}} \quad$ heat of combustion of fuel in vapor cloud explosion, $\mathrm{J} / \mathrm{kg}$ \\ $\mathrm{H}_{\mathrm{G}} \quad$ height of centerline of gravitationally settling plume, $\mathrm{m}$ \\ $\mathrm{H}_{\mathrm{L}} \quad$ latent heat of vaporization, $\mathrm{J} / \mathrm{kg}$ \\ $\mathrm{H}_{\mathrm{TNT}} \quad$ TNT blast energy, $\mathrm{J} / \mathrm{kg}$ \\ in inch \\ $\epsilon$ turbulence energy dissipation rate outside a plume, $\mathrm{m}^{2} / \mathrm{s}^{3}$ \\ $\epsilon_{\mathrm{i}} \quad$ turbulence energy dissipation rate inside a plume, $\mathrm{m}^{2} / \mathrm{s}^{3}$ \\ $\mathrm{J} / \mathrm{kg} \quad$ joules per kilogram
}




\section{LIST OF SYMBOLS \\ (Continued)}

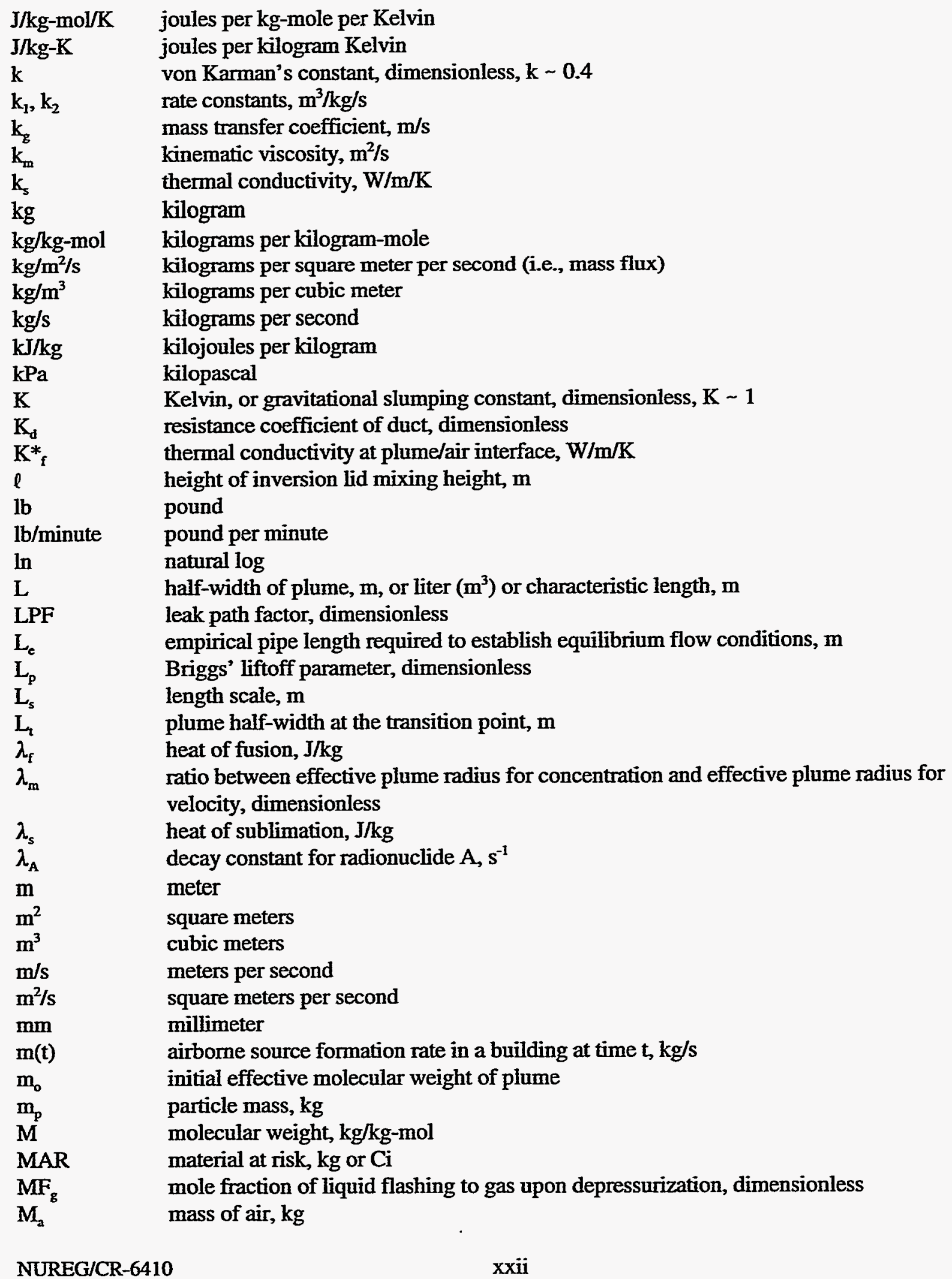




\section{LIST OF SYMBOLS \\ (Continued)}

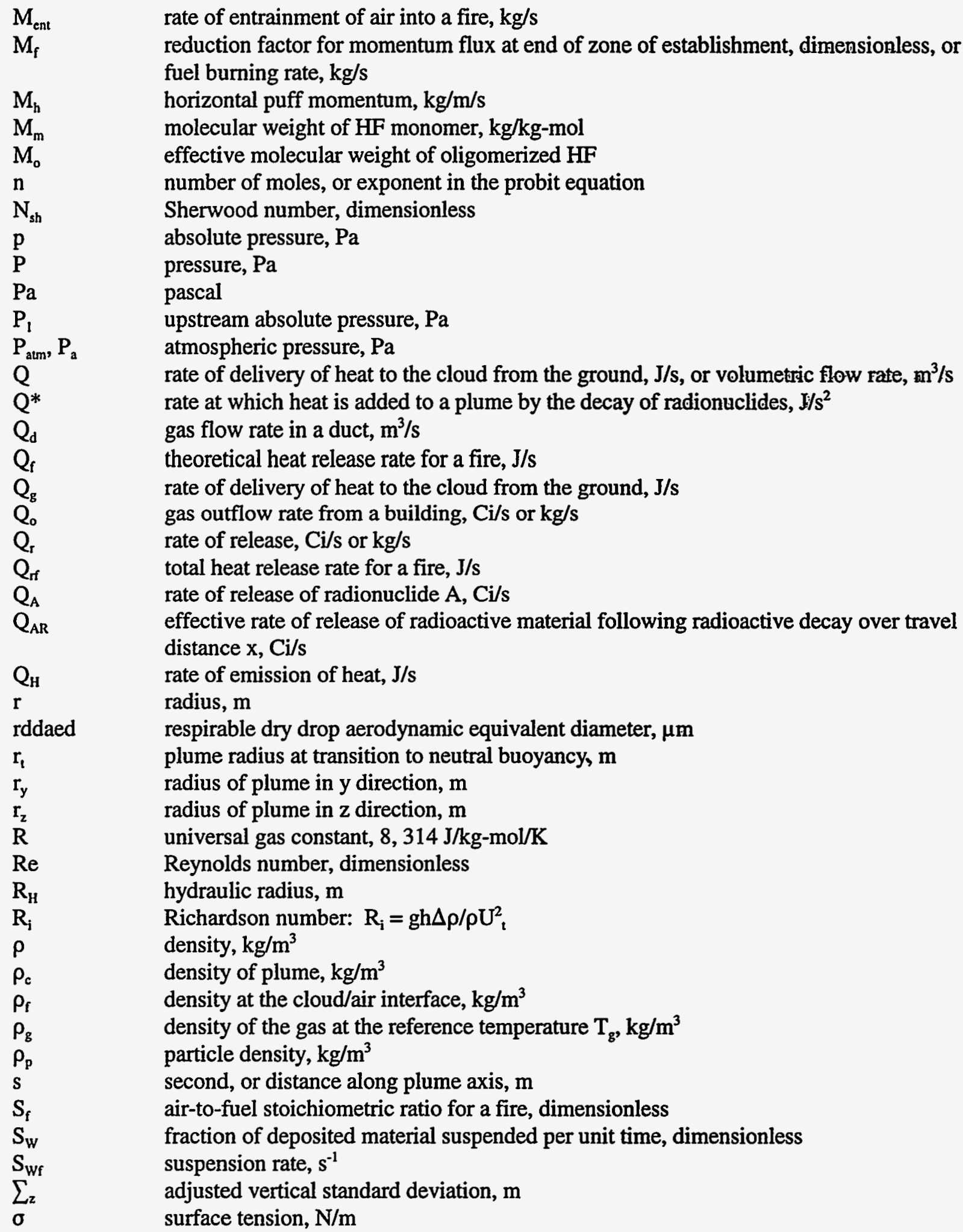




\section{LIST OF SYMBOLS \\ (Continued)}

$\sigma_{g}$

$\sigma_{\mathrm{r}}$

$\sigma_{\mathrm{x}}$

$\sigma_{y}$

$\sigma_{\mathrm{z}}$

$\sigma_{\theta}$

$\Delta \mathrm{T}$

$\mathrm{t}$

$\mathrm{t}_{\mathrm{e}}$

$\mathrm{T}$

$T_{\mathrm{a}}$

$\mathrm{T}_{\mathrm{c}}$

$\mathrm{T}_{\mathrm{g}}$

$\mathrm{T}_{\mathrm{gr}}$

$\mathrm{T}_{\mathrm{i}}$

$T_{0}$

TdLPF

TiLPF

$\tau_{c}$

$\Theta$

$\Theta_{0}$

$\Theta_{\mathrm{T}}$

$\Theta_{\mathrm{Ta}}$

u

$\mathrm{u}$.

$u_{c}$

$\mathrm{u}_{\mathrm{w}}$

$\mu$

$\mu \mathrm{m}$

$\mu_{\mathrm{f}}$

U

$\mathrm{U}_{\mathrm{a}}$

$\mathrm{U}_{\mathrm{s}}$

$\mathrm{U}_{\mathrm{t}}$

$\mathrm{UF}_{6}$

$\mathrm{V}$

$v_{d}$

$v_{e}$

$v_{f}$

$v_{t}$

V

$\mathrm{V}_{\mathrm{a}}$

w

geometric mean standard deviation, $\mu \mathrm{m}$

effective standard deviation of plume before transition to neutral buoyancy, $\mathrm{m}$

longitudinal standard deviation in the Gaussian model, $\mathrm{m}$

crosswind standard deviation, $m$

vertical standard division, $\mathrm{m}$

standard deviation of horizontal wind direction fluctuations, dimensionless

temperature difference between two points, $\mathrm{K}$

time, $s$

exposure time, $\mathrm{s}$ or $\mathrm{hr}$

temperature, $\mathrm{K}$

air temperature, $\mathrm{K}$

critical temperature, $\mathrm{K}$, or cloud temperature, $\mathrm{K}$

reference temperature for gas, $\mathrm{K}$

ground temperature, $\mathrm{K}$

upstream absolute temperature, $\mathrm{K}$

initial temperature of plume, $K$

time-dependent leak path factor, dimensionless

time-independent leak path factor

time constant for chemical decay rate, $s$

angle from horizontal, radius

initial angle of release, radians

potential temperature, $\mathrm{K}$

potential temperature of the atmosphere, $K$

windspeed, $\mathrm{m} / \mathrm{s}$

friction velocity, $\mathrm{m} / \mathrm{s}$

speed of plume, $\mathrm{m} / \mathrm{s}$

windspeed at top of cloud, $\mathrm{m} / \mathrm{s}$

dynamic viscosity, Pas

micrometers

coefficient of dynamic viscosity at the plume/air interface, $\mathrm{kg} / \mathrm{s}^{-1} / \mathrm{m}^{-1}$

plume velocity averaged across jet, $\mathrm{m} / \mathrm{s}$

windspeed at plume centerline, $\mathrm{m} / \mathrm{s}$

$\left|U_{\mathrm{a}} \cos \Theta-U\right|, \mathrm{m} / \mathrm{s}-$ modulus of the difference between the velocity of the plume and the component of the windspeed along the axis of the plume

velocity scale, $\mathrm{m} / \mathrm{s}$

uranium hexafluoride

discharge velocity of gas, $\mathrm{m} / \mathrm{s}$

dry deposition velocity, $\mathrm{m} / \mathrm{s}$

entrainment velocity, $\mathrm{m} / \mathrm{s}$

volume fraction occupied by the dried portion of a droplet that is initially liquid, dimensionless

gravitational settling velocity, $\mathrm{m} / \mathrm{s}$

volume, $\mathrm{m}^{3}$

particle escape velocity from an enclosure, $\mathrm{m} / \mathrm{s}$

upward velocity of plume, $\mathrm{m} / \mathrm{s}$ 


\section{LIST OF SYMBOLS \\ (Continued)}

\begin{tabular}{|c|c|}
\hline$w_{d}$ & downdraft velocity, $\mathrm{m} / \mathrm{s}$ \\
\hline $\mathrm{w}^{*}$ & scaling velocity for a convective mixing layer, $\mathrm{m} / \mathrm{s}$ \\
\hline We & Weber number, dimensionless \\
\hline $\mathrm{W} / \mathrm{m} / \mathrm{K}$ & watt per meter per degree Kelvin \\
\hline$w_{0}$ & plume exit velocity, $\mathrm{m} / \mathrm{s}$ \\
\hline $\mathrm{W}_{\mathrm{p}}$ & width of plume \\
\hline & weight of fuel involved in a vapor cloud explosion, $\mathrm{kg}$ \\
\hline$W_{\text {TNT }}$ & equivalent weight of TNT or yield, $\mathrm{kg}$ \\
\hline $\mathrm{x}$ & vapor fraction, dimensionless, or distance downwind, $\mathrm{m}$ \\
\hline$x_{d}$ & distance from virtual source, $\mathrm{m}$ \\
\hline$x_{t}$ & point at which transition to neutral buoyancy occurs, $m$ \\
\hline$x_{d}^{y}$ & distance from virtual source for crosswind standard deviation, $m$ \\
\hline$x_{d}^{2}$ & distance from virtual source for vertical standard deviation, $m$ \\
\hline y & crosswind distance, $\mathrm{m}$ \\
\hline $\mathbf{z}$ & distance above the ground, $\mathrm{m}$ \\
\hline
\end{tabular}




\section{CHAPTER 1 EXECUTIVE SUMMARY}

\subsection{Background}

10 CFR Part 70 requires that emergency plans for nuclear fuel facilities include information on methods and equipment for consequence analysis of accidental releases of special nuclear materials and any associated radionuclides and hazardous chemicals. Nuclear Regulatory Commission (NRC) staff and fuel cycle licensees need standardized methods for assessing which of the licensees' operations pose significant hazards to workers (i.e., the licensee's staff), the general public, or the environment. The hazards that need to be considered include radioactive materials and/or hazardous chemicals such as: uranium hexafluoride $\left(\mathrm{UF}_{6}\right)$; hydrogen fluoride $(\mathrm{HF})$; fluorine $\left(\mathrm{F}_{2}\right)$; chlorine $\left(\mathrm{Cl}_{2}\right)$; nitric acid $\left(\mathrm{HNO}_{3}\right)$; or other acids, ammonia $\left(\mathrm{NH}_{3}\right)$, and other caustic alkaline chemicals, organic chemicals, and solvents that may be directly or indirectly used or generated as byproducts in the licensed operations.

[Note that NRC's interest in hazardous chemicals is limited to those that can be released from the processing of licensed nuclear material or have the potential for adversely affecting radiological safety. The Occupational Safety and Health Administration (OSHA), the Environmental Protection Agency (EPA), and/or any cognizant state or local agencies are responsible for regulating other aspects of chemical safety at the facility.]

When it was first published in 1988, the Accident Analysis Handbook, NUREG-1320, was a comprehensive effort to collect and codify the information that was then available for accident analyses. The document was directed toward those events that were the principal concern of NRC at that time. The old Handbook is heavily oriented toward spent nuclear fuel reprocessing and the manufacturing of plutonium fuel. It does not address the consequences of accidents and the risks associated with other types of fuel cycle operations such as uranium enrichment and the downblending of high-enriched to lowenriched uranium. It does not address the consequences of releases of chemicals that are associated with fuel cycle processes, nor does it address accidental releases of chemicals such as $\mathrm{NH}_{3}$ or $\mathrm{Cl}_{2}$ that might, if accidentally released, have an impact on the operators processing licensed materials or lead to an escape of radioactive materials. Nevertheless, the old Handbook remains a source of extremely valuable information and guidance. It was judged that it provides an excellent starting point from which to provide the information NRC now needs to develop technical guidance on accident analysis for safety evaluations required by 10 CFR Part 70.

Since 1988, a great deal of new information has become available. For example, the Department of Energy (DOE) Handbook entitled Airborne Release Fractions/Rates and Respirable Fractions for NonReactor Nuclear Facilities (USDOE 1994) summarizes a number of experimental studies on the fractions of radioactive materials that could be released in a wide variety of accidental circumstances. Organizations such as the Center for Chemical Process Safety (CCPS) of the American Institute of Chemical Engineers (AIChE) have produced guidance in the form of guidebooks and conference proceedings that are applicable to chemical process safety at fuel cycle facilities. Also relevant are OSHA's Process Safety Management Standard, 29 CFR 1910.119 and the EPA's Risk Management Program (RMP), 40 CFR Part 68.

The purpose of this Handbook, therefore, is to provide guidance to NRC staff and to fuel cycle licensees on how to calculate the characteristics of releases of radioactive materials and/or hazardous chemicals from 
nonreactor nuclear facilities. In addition, the Handbook provides guidance on how to calculate the consequences of those releases.

It is envisaged that the material presented herein will be applicable to three types of analyses: Integrated Safety Analysis (ISA), Emergency Response Planning and Post Accident Analysis. Nair, et al. (1997) have reviewed some models that are specifically directed towards the modeling of $\mathrm{UF}_{6}$. They make statements about the purpose of these models which, however, are equally applicable to models that have more general capabilities.

1. Integrated Safety Analysis: ISA is a systematic effort to identify process upsets or conditions at a facility that could lead to undesirable consequences. Draft NUREG-1513 (USNRC 1995) indicates that "The ISA is expected to form the basis of a safety program that requires adequate controls and systems to be in place to ensure the safe operation of the facility." In addition, "The results of an ISA consist of the identification of potential accidents, and the controls (i.e., the structure, system, equipment, components, and personnel) relied upon to prevent the accident from occurring or to reduce their consequences." In the context of the ISA, the models described herein provide the means of identifying release scenarios, predicting the characteristics of the source term, predicting the airborne concentrations resulting from a release, assessing the impact on human health, and assessing the adequacy of mitigative measures.

2. Emergency Response Planning: A model that is capable of predicting the concentrations of radioactive materials and hazardous chemicals in the vicinity of a facility will be useful in planning for suitable actions in response to an emergency. For example, models such as those described in this Handbook could be useful in recommending whether employees or members of the public should evacuate or shelter in place. In developing plans for responding to emergency situations prior to their actual occurrence, licensees will benefit from evaluating the consequences of various release scenarios using atmospheric dispersion models. The results of these model runs would then be available for use in planning how to respond to an emergency.

3. Post-Accident Analysis: Following an actual accident, NRC and its licensees have an obligation to investigate the causes, propagation, mitigation, and consequences of the accident. It is important to develop this information so as to prevent similar accidents from occurring in the future or to mitigate their consequences. The public also has a right to know what those consequences were. To ensure that adequate information is provided to the public and to responsible public officials, any available measurements of the consequences may be supplemented by estimates made by using analytical models. This will help health and safety officials to develop treatment procedures for any acute and chronic health effects in workers and members of the public that may result as a consequence of the accident.

The reader should note that the models described in this Handbook are not intended for use during an actual emergency. That is, they should not be used while an emergency is underway to determine whether, for example, a certain area should be evacuated. If it is desired to use the models for such purposes, the user should preprocess a range of site-specific scenarios that cover the spectrum of possibilities at the facility in question. For each preprocessed scenario, the required emergency response activities should be predetermined. In general, (i) there will not be enough time to prepare the input for the models and run them in the course of an emergency and (ii) good data from the field about the characteristics of the source term are notoriously difficult to obtain. 


\subsection{Summary of the Contents of this Handbook}

This Handbook contains four major chapters:

- Chapter 2 - "Hazard Evaluation and Scenario Development"

- Chapter 3 - "Source Term Determination"

- Chapter 4 - "Transport within Containment/Confinement"

- Chapter 5 - "Atmospheric Dispersion and Consequence Modeling"

In addition, there are a number of supporting Appendices and Sample Problems (Appendix D). The sample problems are an extremely important part of this Handbook.

The sample problems are:

1. Free Fall Spill of Powder

2. Explosion with Radioactive Release

3. Fire with Radioactive Release

4. Filter Failure

5. Hydrogen Fluoride Release from a Tankcar

6. Uranium Hexafluoride Liquid $\left(>70^{\circ} \mathrm{C}\right)$ Cylinder Rupture

7. Liquid Spill in a Vitrification Plant, and

8. Criticality Incident

\subsubsection{Chapter 2 - Hazard Evaluation and Scenario Development}

The purpose of Chapter 2 is to describe hazard evaluation, a technique that leads to the identification and qualitative understanding of scenarios that merit further quantitative analysis. Chapter 2 identifies five basic steps in hazard evaluation that are designed to answer the following questions:

1. What hazardous materials are present at the site, in what quantities and under what conditions? (A hazard is a physical or chemical characteristic of a material, system, process or facility that has the potential for causing harm.) This step in hazard evaluation is often called hazard identification.

2. What are the ways in which such materials might accidentally escape, leading to fires, explosions, toxic or radioactive vapor clouds, and to potentially damaging effects on workers, the public, the environment, or other facilities on the same site?

3. What are the design or procedural controls that are intended to prevent or mitigate such accidental releases, and are they adequate?

4. Are there any recommendations for design or procedural changes?

5. Is further analysis required? For example, is there a case to be made for a complete Quantitative Risk Assessment (QRA)? Are there accident scenarios that require further development and quantitative analysis?

The totality of Steps $1-5$ is often called Process Hazards Analysis (PHA).

The emphasis placed upon each of the above-listed elements of hazard evaluation depends upon the overall purpose of the study that is being conducted. In hazard evaluations that are presently conducted at 
operating chemical plants as required by OSHA's Process Safety Management (PSM) Standard or EPA's RMP, the emphasis is on the first four steps (i.e., the principal concem is to determine whether existing controls are adequate). For fuel cycle facilities, the NRC's emphasis encompasses all five elements within the following context:

1. The primary hazardous materials of interest are those that are radioactive,

2. NRC's interest in non-radioactive hazardous chemicals is limited to those that can be released from the processing of licensed nuclear material or have the potential for adversely affecting radiological safety,

3. Both the current version of and the proposed revision to 10 CFR Part 70 require that emergency plans for nuclear fuel cycle facilities include information on methods and equipment for consequence analysis of accidental releases of special nuclear materials and any associated radionuclides and hazardous chemicals, which is why the identification of scenarios for further quantitative analysis is especially important (see Section 2.1.3), and

4. One of the proposed options for revising 10 CFR Part 70) also includes a requirement for licensees/applicants to conduct an ISA, which implies that hazard evaluations should be conducted in a way that is consistent with the ISA.

The ISA is defined and discussed in Draft NUREG 1513 (USNRC 1995), the Integrated Safety Analysis Guidance Document. It is a systematic examination of a facility's processes, equipment, structures, and personnel activities to ensure that all relevant hazards that could result in unacceptable consequences have been adequately evaluated and appropriate protective measures have been identified. NUREG 1513 defines ISA as "an analysis to identify hazards and their potential for initiating event sequences, the potential event sequences and their consequences, and the site, structures, equipment, components and activities of personnel that are relied upon for safety. As used here, integrated means joint consideration of safety measures and controls that might otherwise conflict, including integration of fire protection, radiation safety, criticality safety, chemical safety and physical security measures."

The reader should regard NUREG 1513 as a basic reference document in the context of the use of such techniques at fuel cycle facilities. Everything in Chapter 2 is intended to be consistent with it.

The other major source of information on hazard evaluation techniques is guidance that has been published by the Center for Chemical Process Safety (CCPS), specifically in Guidelines for Hazard Evaluation Procedures - Second Edition with Worked Examples (CCPS 1992). This Guidebook discusses the various techniques of hazard evaluation, including (i) safety review; (ii) checklist analysis; (iii) relative ranking; (iv) preliminary hazards analysis; (v) what-if? analysis; (vi) what-if? checklist analysis; (vii) hazard and operability (HAZOP) review; (viii) failure modes and effects analysis (FMEA); (ix) fault tree analysis; (x) event tree analysis; (xi) cause-consequence analysis, and (xii) human reliability analysis (HRA). The CCPS Guidebook describes the strengths and weaknesses of these methods, how to determine when they should be used, the resources required to use them and gives examples of their use. The CCPS Guidebook is the second major reference source for Chapter 2.

\subsubsection{Chapter 3-Source Term Determination}

The purpose of Chapter 3 is to show how to estimate the characteristics of the source term, such as the total mass released, the rate of release, the temperature, the density, the velocity, the orientation, etc. The 
chapter is divided into two major sections, the first devoted to radioactive materials and the second to hazardous chemicals.

For radioactive materials, the principal quantities that determine the characteristics of the source term are the Airborne Release Fraction (ARF) and the Respirable Fraction (RF). The ARF is the fraction of the material that is potentially available for release that is actually made airborne. For continuous releases, an analogous quantity known as the Airborne Release Rate (ARR) is used instead of the ARF. The RF is the fraction of the ARF or ARR that is actually respirable and is defined as all vapors or any particulate material that has a diameter of less than $10 \mu \mathrm{m}\left(3.9 \times 10^{-5} \mathrm{in}\right)$. The ARF, ARR and RF are used in the well-known five-factor formula, see Equation (3.1). Chapter 3 provides values of ARF/ARR and RF for a great variety of different source terms, produced by the interaction between the radioactive or hazardous material and a number of different "stresses" (i.e., internal or external forces that might initiate the accident sequence). Here, a stress is a force or phenomenon that acts upon a radioactive material and causes some or all of it to become airborne. These stresses include, for example, falling through the air onto a surface, suspension by a stream of air, boiling, fires, explosions, and external events such as earthquakes. A comprehensive list of stresses, with interactions with various materials, is given in Table 3-1, together with appropriate ARFs/ARRs and RFs.

Table 3-1 is where the reader may find source term characteristics that can be input into appropriate atmospheric dispersion models. A great deal of the material in Chapter 3 is devoted to providing the justification for the values quoted in Table 3-1. Many of these values are derived from a review of experimental results. A good number of them come from the DOE Handbook (USDOE 1994). Others come from a review of experimental work that was not reported in the DOE Handbook. In a limited number of cases, empirical formulae are presented, for example, in Section 3.3.4.5, there is an empirical treatment of the ARF as a function of fall distance for the case in which a slug of radioactive material falls from a height.

Chapter 3 also contains a discussion of criticality incidents. In this case, the guidance relies heavily upon updated information from NRC's now withdrawn Regulatory Guides 3.33, 3.34, and 3.35 (USNRC 1977; 1979a; 1979b). The tables presented in the withdrawn Regulatory Guides have been updated with more recently available information. This includes using the computer model ORIGEN2 to generate fission product inventories and using the updated dose conversion factors published by the International Commission on Radiological Protection (ICRP) in ICRP-26 and -30 (ICRP 1977; 1979; 1980).

The second portion of Chapter 3 is devoted to a description of how to estimate the characteristics of source terms for releases of hazardous chemicals. This portion of Chapter 3 is supplemented by Appendices A, B, and $C$. Between them, Chapter 3 and Appendix B describe a range of source terms that are representative of the types of accidental releases that might occur at a fuel cycle facility, including (but not limited to) slowly evaporating pools, flashing liquid jets, vapor jets, and puff releases. The sample problems presented in Appendix D include specific examples of $\mathrm{UF}_{6}$ and $\mathrm{HF}$ release scenarios.

\subsubsection{Chapter 4 - Transport within Containment/Confinement}

Many of the accidents discussed in this Handbook take place indoors. There is therefore a need to be able to predict how materials are transported through rooms and ducts and eventually released to the atmosphere. Chapter 4 describes the phenomena that control transport through buildings. These phenomena include the ventilation and other flows of air, filters that remove particulates (e.g., high 
efficiency particulate air (HEPA) filters) and various effects such as gravitational settling, impaction on surfaces, thermophoresis, etc.

The theories that are described in Chapter 4 have been simplified and incorporated into a computer model, LPF\#1B, that is included in this report. The model is applicable to most of the scenarios that are likely to be of interest at fuel cycle facilities. It is easy to use. The principal reason why it has been included is to give the reader the opportunity to easily vary the input parameters to the model. This is preferable to producing a vast number of tables and nomographs that would be needed to cover all possible scenarios.

In Appendix E, there is a comparison between the results from LPF\#1B with those from a well established and more sophisticated model, MELCOR (Summers, et al. 1991). This comparison shows that the LPF\#1B model performs well.

Overall, Chapter 4 continues the accident analysis process whereby the source term provided in Chapter 3 is carried through and out of the facility. The primary output is the fraction of the source term that escapes the facility in respirable form, the Leak Path Factor (LPF). Secondary outputs are the airborne concentrations and fractions of the initial source term deposited in the facility. To obtain these outputs, Chapter 4 provides guidance to the user: (i) identify the facility barriers that define the flowpath of the airborne material in the facility; (ii) quantify the driving forces moving material along the flow path; (iii) quantify the flow rates along the path; (iv) quantify the mitigating effects of any engineered controls (e.g. filters); (v) quantify the roles of deposition processes along the flow path; and (vi) estimate facility concentrations during the movement of the airborne source term.

\subsubsection{Chapter 5 - Atmospheric Dispersion and Consequence Modeling}

Chapter 5 describes how to determine the consequences of accidental releases of radioactive materials or hazardous chemicals using atmospheric dispersion and consequence models.

For radioactive releases, most models use the classical Gaussian model as the basis for predictions. Loosely speaking, the Gaussian model treats the trajectory of a small particle or packet of gas as a random walk, reflecting the random nature of turbulence in the atmosphere. The Gaussian model can be readily modified to take account of such phenomena as turbulent building wakes, plume rise, inversion lids, dry deposition, wet deposition, etc. There are a large number of available models. Chapter 5 reviews some of them, including HOTSPOT, RASCAL, and MACCS. Many of these models are easy to use and it is recommended that readers obtain one and learn how to use it. This will be much easier than having the enormous pile of nomographs and tables that would be necessary to cover all possible release scenarios.

For releases of hazardous chemicals, the required models are generally more sophisticated than those for radioactive materials. In general, it is necessary to model denser-than-air releases. In addition, there may be complex thermodynamics involved, such as that between $\mathrm{HF}$ and moist air or $\mathrm{UF}_{6}$ and moist air. Therefore, the models for releases of hazardous chemicals are generally not the same as those for releases of radioactive materials. This is an important point for the reader to bear in mind.

Chapter 5 discusses the phenomena that control the atmospheric dispersion of hazardous chemical releases and describes the types of models that are needed for dense, continuous releases, dense puffs, and jets. In addition, there is discussion of the phenomena that control a marginally buoyant plume's ability to lift off the ground. 


\subsubsection{Appendices}

Appendix A contains a summary of chemical and nuclear safety information. This includes sections on toxicological data (various exposure guidelines and specific information on $\mathrm{UF}_{6}, \mathrm{HF}$ and $\mathrm{F}_{2}$ ). There is a section on the physical and chemical properties of various materials that are found at fuel cycle facilities, together with a summary of special handling instructions. This is followed by brief descriptions of fuel cycle facilities, such as: $\mathrm{UF}_{6}$ conversion plants, light water fuel fabrication plants (including mixed oxide (MOX) fuels); uranium enrichment plants (including atomic vapor laser isotopic separation (AVLIS)); enriched uranium downblending, and vitrification facilities.

Appendix B contains a summary of accidental releases of chemicals. This is intended to supplement the last part of Chapter 3. The appendix describes a range of possible release scenarios, including spillages of high-boiling-point liquids at ambient temperatures, spillages of refrigerated liquids, the escape of gases liquefied under pressure, releases from the vapor space of a vessel or pipework, and spillage onto water.

Appendix $\mathrm{C}$ contains a comparison of NRC, EPA, and OSHA programs that address chemical safety. NRC's requirements and guidance are to be found in 10 CFR Parts 20,30, 40, and 70. OSHA's requirements are to be found in the PSM standard, 29 CFR 1910.119 and EPA's requirements are to be found in the RMP, 40 CFR Part 68.

Appendix D contains the sample problems, which are also summarized in more detail in Section 2.4. Appendix $\mathrm{E}$ discusses the results of bench-marking the LPF\#1B code against the MELCOR Code. LPF\#1B is a computer model that is provided with this document for calculating Leak Path Factors, see Chapter 4. It is a tool that is simple to use and is provided in lieu of a vast number of tables and nomographs. Instructions on how to use LPF\#1B are given in Section 4.7.2.2. Appendix $F$ contains information on filtration, particularly the performance of HEPA filters. Finally, Appendix G contains a discussion of uncertainties.

\subsection{Uncertainties}

It is important to be able to understand the range of uncertainties that are associated with the predictions of the analytical and computer models that are described in this Handbook. Unfortunately, that is easier said than done. For example, many of the ARFs and RFs that are listed in Chapter 3/Table 3.1 are based on extremely limited experimental data and the best that can be done is to determine bounding values. In addition, even if the uncertainties in input parameters were well-known, it is still a time-consuming task to propagate those uncertainties through to the final results and to obtain useful quantities such as the mean, median, 5th, and 95th percentiles.

Nair, et al. (1997) performed a careful review of models that are available for determining the consequences of $\mathrm{UF}_{6}$ releases. They identified two models as being the most complete available, HGSYSTEM (Hanna et al. 1994) and a draft model developed for NRC (Chhibber and Kaiser 1993). Nair, et al. stated that "capabilities for conducting uncertainty analysis should be incorporated as an essential feature within each model. This would allow the model user to express his or her state of knowledge regarding an input parameter in terms of a range of likely values, with the associated probabilities of the occurrences of the values within the range. The model can then propagate the uncertainties about the input parameters through every segment of the model to the final predicted concentration in air at a desired location. This will allow the true but unknown concentration to be bounded within a 95 percent subjective confidence interval of the predicted concentration. Results of the 
uncertainty analysis conducted in a Monte Carlo framework could also be used to meet the requirements of a sensitivity analysis.

The HGSYSTEM and NRC models are already fairly complex, and it is recognized that embedding these models in the framework of uncertainty analysis is not a trivial exercise. Nevertheless, further consideration must be given to this aspect with a view to developing appropriate models or to developing appropriate alternatives for performing uncertainty analysis."

Thus, Nair, et al. (1997) recognize that further model development is required for the treatment of uncertainties in just two of the models that are referenced in this Handbook. However, additional model development is outside the scope of the present effort. Therefore, this Handbook generally restricts the discussion of uncertainties to sensitivity studies and/or the establishment of upper bounds. See Appendix $\mathrm{G}$ for further discussion. 


\subsection{References}

Center for Chemical Process Safety (CCPS), Guidelines for Hazard Evaluation Procedures - Second Edition with Worked Examples, American Institute of Chemical Engineers, New York, New York, 1992.

Chhibber, S. and G.D. Kaiser, "SAIC's Computer Models for Modeling the Atmospheric Dispersion of Hazardous Vapors - Draft Model Description and User's Guide," Prepared for the U.S. Nuclear Regulatory Commission, Washington, D.C., 1993.

Hanna, S.R., J.C. Chang, J.X. Zhang, K. McFarlane, L. Post, R.T, Roberts, and H.T.M. Witlox, "HGSYSTEM 3.0 Technical Reference Manual," TNER.94.059, L. Post (ed.), Shell Research Limited, Thornton Research Centre, Thornton, United Kingdom, 1994.

International Commission on Radiological Protection (ICRP). Recommendations of the International Commission on Radiological Protection, ICRP Publication 26, Pergamon Press, 1977.

International Commission on Radiological Protection (ICRP), Limits for Intake of Radionuclides by Workers, ICRP Publication 30, Part 1 and Supplement to Part 1, Pergamon Press, 1979.

International Commission on Radiological Protection (ICRP), Limits for Intake of Radionuclides by Workers, ICRP Publication 30, Part 2, Pergamon Press, 1980.

Nair, S.K., D.B. Chambers, S.H. Park, Z.R. Radonjic, P.T. Coults, C.J. Lewis, J.S. Hammonds, and F.O. Hoffman, "Review of Models Used for Determining Consequences of UF 6 Release," NUREG/CR-6481, Volume 2, U.S. Nuclear Regulatory Commission, Washington, D.C., 1997.

Summers, R.M., et al., "MELCOR 1.8.0: A Computer Code for Nuclear Reactor Severe Accident Source Term and Risk Assessment Analyses," NUREG/CR-5531, U.S. Nuclear Regulatory Commission, Washington, D.C., 1991.

U.S. Department of Energy (USDOE), “Airborne Fractions/Rates and Respirable Fractions for Nonreactor Nuclear Facilities," DOE-HDBK-3010-94, Washington, D.C., 1994.

U.S. Nuclear Regulatory Commission (USNRC), "Assumptions Used for Evaluating the Potential Radiological Consequences of Accidental Nuclear Criticality in a Fuel Reprocessing Plant," Regulatory Guide 3.33, Office of Standards Development, Washington, D.C., 1977.

U.S. Nuclear Regulatory Commission (USNRC), "Assumptions Used for Evaluating the Potential Radiological Consequences of Accidental Nuclear Criticality Uranium Fuel Fabrication Plant," Regulatory Guide 3.34, Office of Standards Development, Washington, D.C., 1979a.

U.S. Nuclear Regulatory Commission (USNRC), "Assumptions Used for Evaluating the Potential Radiological Consequences of Accidental Nuclear Criticality in Plutonium Processing and Fuel Fabrication Plant," Regulatory Guide 3.35, Office of Standards Development, Washington, D.C., $1979 \mathrm{~b}$.

U.S. Nuclear Regulatory Commission (USNRC), "Integrated Safety Analysis Guidance Document," (Draft), NUREG 1513, Washington, D.C., 1995. 


\section{CHAPTER 2 HAZARD EVALUATION AND SCENARIO DEVELOPMENT}

\subsection{Introduction}

The purpose of this chapter is to describe hazard evaluation, leading to the identification and qualitative understanding of scenarios that merit further quantitative analysis.

\subsubsection{Background Information}

The analysis of accidents involving the release of radioactive material has been conducted for the Nuclear Regulatory Commission (NRC), or the former Atomic Energy Commission (AEC), on licensed facilities for over 40 years. The approaches used by NRC staff have been described in Regulatory Guides and NUREG documents, including the "Nuclear Fuel Cycle Accident Analysis Handbook" (NUREG-1320) (hereafter, the Handbook). These analyses have been conducted to support the NRC regulatory mission to protect the health and safety of workers and the public.

In addition, in the United States, general recognition of the importance of chemical hazard evaluation was driven by the Bhopal accident, which led to a number of regulatory initiatives that require the use of hazard evaluation procedures. These include:

- The New Jersey Toxic Catastrophe Prevention Act (1986)

- The State of California's Risk Management and Prevention Program (RMPP -1986)

- The State of Delaware's Extremely Hazardous Substances Risk Management Act (1988)

- The State of Nevada's Highly Hazardous Substance Act (1991)

- The Occupational Health and Safety Administration's (OSHA's) Process Safety Management (PSM) Standard, 29 CFR 1910.119 (1992), and

- The Environmental Protection Agency's (EPA's) Risk Management Program (RMP) for Chemical Accidental Release Prevention, 40 CFR Part 68 (1996).

During the 1980s and 1990s, the chemical industry developed several programs and guidance documents, including:

- A Guidebook on Hazard Evaluation issued by the Center for Chemical Process Safety of the American Institute of Chemical Engineers (CCPS 1992)

- A Recommended Practice, developed by the American Petroleum Institute (API 1990), and

- The Responsible Care Program, developed by the Chemical Manufacturers Association (CMA 1992).

\subsubsection{Accident Analysis Approach}

It is pertinent to address the question of how hazard evaluation fits into the overall scheme of accident analysis. The primary purpose of NRC accident analysis for fuel cycle facilities is to provide reasonable assurance that operations cannot potentially cause harm to workers or adversely affect public health and 
safety. Secondary objectives include identification of controls that mitigate or prevent potential accidents and identification of appropriate emergency response procedures. Thus, accident analysis is an effective method for qualitative and quantitative evaluation of facility safety. To define an accident scenario, it is necessary to consider a combination of: (a) site conditions; (b) potentially affected individuals; (c) facility design, material inventories, equipment configurations, and operating procedures; (d) failure modes; and (e) intra-facility and environmental exposure pathways that produce potential adverse impacts greater than those associated with normal operations. The approach involves selection and analysis of a set of scenarios that span facility operations, ranging from those with expected small impacts to those with potentially catastrophic consequences.

The primary steps in accident scenario development and analysis are:

- Analysis of site conditions and development of a site conceptual model

- Identification of workers and members of the public potentially affected by accidents

- Identification of facility configuration, operating procedures and administrative controls for expected operations

- Identification and analysis of facility conditions, including internal and external initiating events, leading to release of material or energy with potential for adverse impacts

- Characterization of the released materials (mass, release rate, temperature, etc. - the characteristics of the source term)

- Identification and analysis of intra-facility transport pathways

- Identification and analysis of environmental transport pathways, and

- Quantification of impacts on the identified receptors.

Analysis of site conditions and development of a site conceptual model involve review of site meteorological, geologic, and hydrologic conditions that may influence facility operations or play a role in transporting material or energy released from the facility. This includes characterization of earthquakes, straightline winds, tornadoes, and floods, in accordance with 10 CFR Parts 30, 40, 70, 76, and 100, and in accordance with Regulatory Guides 1.76 and 1.59. Such information may already be available in Environmental Reports (ERs) or License Applications.

Identification of potentially affected workers and members of the public involves review of facility descriptions and of demographic information. Most often, workers and fenceline receptors present for specific periods of time and off-site maximally exposed individuals present for the duration of the event provide a reasonable basis for the evaluation of accident impacts.

Methods for reviewing the facility configuration and operations and identifying failures or deviations from design intent that have the potential to release material or energy fall under the general category of hazard evaluation and are further discussed below. Analysis of the characteristics of the source term is discussed in Chapter 3 of this Handbook. Intra-facility transport is discussed in Chapter 4. Environmental transport is discussed in Chapter 5.

A wide spectrum of accident analysis methods and objectives may be associated with each of the above scenario development steps. The level of detail of the analysis should be commensurate with the objective of the analysis and the quality of the data supporting the analysis. Chapters 3,4 , and 5 discuss 
the applicability of supporting data and selection of models appropriate for differing site and facility conditions.

\subsubsection{Elements of Hazard Evaluation}

This section addresses: (i) the steps in hazard evaluation; (ii) NRC's Integrated Safety Analysis (ISA); and (iii) guidance from the CCPS.

\subsubsection{Steps in Hazard Evaluation}

A complete hazard evaluation involves answering the following questions in the order given.

1. What hazardous materials are present at the site and under what conditions? What hazards do they present (a hazard is a physical or chemical characteristic of a material, system, process, or facility that has the potential for causing harm). This step in hazard evaluation is often referred to as hazard identification.

2. What are the ways in which such materials might accidentally escape, leading to fires, explosions, toxic vapor clouds, and to potentially damaging effects on workers, the public, the environment, or other facilities on the same site?

3. What are the design and procedural controls that are intended to prevent or mitigate such accidental releases and are they adequate?

4. Are there any recommendations for design or procedural changes?

5. Is further analysis required? For example, is there a case to be made for a complete Quantitative Risk Assessment (QRA)? Are there accident scenarios that require further development and quantitative analysis?

The emphasis placed on each of the above-listed elements of hazard evaluation depends on the overall purpose of the study that is being conducted. In hazard evaluations that are presently conducted at existing chemical plants as required by OSHA's PSM Standard 29 CFR 1910.119 or EPA's RMP, the emphasis is on the first four steps; i.e., the principal concern is to determine whether existing controls are adequate. For fuel cycle facilities, NRC's emphasis encompasses all five of the elements within the following context:

- The primary hazardous materials of interest are those that are radioactive

- NRC's interest in non-radioactive hazardous chemicals is limited to those that can be released from the processing of licensed nuclear material or have the potential for adversely affecting radiological safety, i.e., their release could lead to releases of radioactive material

- Both the current version of and the proposed revision to 10 CFR Part 70 require that emergency plans for nuclear fuel cycle facilities include information on methods and equipment for consequence analysis of accidental releases of special nuclear materials and any associated radionuclides and hazardous chemicals, which is why the identification of scenarios for further quantitative consequence analysis is especially important (see Section 2.1.3)

- One of the proposed options for revising 10 CFR 70 (favored by industry) also includes a requirement that licensees/applicants conduct an Integrated Safety Analysis (ISA), which implies that hazard evaluations should be conducted in a way that is consistent with ISA. 


\subsubsection{Integrated Safety Analysis}

The ISA is defined and discussed in Draft NUREG 1513 (USNRC 1995), the "Integrated Safety Analysis Guidance Document". It is a systematic examination of a facility's processes, equipment, structures, and personnel activities to ensure that all relevant hazards that could result in unacceptable consequences have been adequately evaluated and that appropriate protective measures have been identified. NUREG 1513 defines ISA as "an analysis to identify hazards and their potential for initiating event sequences, the potential event sequences and their consequences, and the site, structures, equipment, components, and activities of personnel, that are relied upon for safety. As used here, integrated means joint consideration of safety measures and controls that might otherwise conflict, including integration of fire protection, radiation safety, criticality safety, chemical safety, and physical security measures."

NUREG 1513 contains the following information:

- The historical context and regulatory basis within which ISA was developed

- The definition of ISA and its role in a facility's safety program

- ISA methods (these are the same as in the CCPS Guidebook, see below)

- Choosing an ISA method

- Choosing a team for the ISA

- Conducting the ISA, including:

- establishing the scope of the evaluation

- process safety information

- hazard identification

- performing the analysis (preparation, meetings and integration)

- results of the analysis, and

- documenting the results of the ISA and

- Worked examples:

1. What-if? analysis of the pelletizing, rod-loading, and fuel bundle assembly steps in a uranium fuel fabrication operation

2. Hazard and Operability study (HAZOP) of the vaporization step of uranium hexafluoride $\left(\mathrm{UF}_{6}\right)$ dry conversion, and,

3. Qualitative Fault Tree analysis of a major $\mathrm{UF}_{6}$ release during vaporization.

The reader should regard NUREG 1513 as a basic reference document in the context of the use of such techniques at fuel cycle facilities. Everything that follows is intended to be consistent with it.

\subsubsection{Guidance from the Center for Chemical Process Safety}

During the past two decades or so, the chemical, petrochemical, and petroleum industries have developed and used a number of hazard evaluation procedures. These have been extensively described in a Guidebook issued by the CCPS of the American Institute of Chemical Engineers (CCPS 1992). As noted above, the first step in the process of hazard evaluation is hazard identification, which is defined as the process of identification of specific undesirable consequences, followed by the identification of materials, together with system, process, and plant characteristics that could, in theory, produce those consequences. A typical list of undesirable consequences would include:

- human impacts 
- consumer injuries

- community injuries

- on-site personnel injuries

- unit personnel injuries

- loss of employment

- psychological effects

- environmental impacts

- off-site contamination (air, water, soil)

- on-site contamination (air; water, soil)

- property damage

- inventory loss

- production outage

- poor product quality/yield

- lost market share

- legal liability

- negative image

The adverse impacts can be further refined (e.g., injury can be broken down into toxic exposure, thermal exposure, mechanical shock, radiation exposure, electrical shock). The list should be customized for the particular problem being addressed.

Next comes the analysis of material properties and process conditions. As the CCPS Guidebook notes, there is a body of knowledge on which any proposed or existing process is based. An important part of this knowledge is data on all of the chemicals or other hazardous materials used in the process. This information is the foundation of all hazard identification efforts. The CCPS Guidebook gives a table (Table 3-2) of more than 30 organizations that maintain data bases on chemicals. Thus, it is not difficult to collect basic information on chemicals (the same is true for radioactive materials in data bases maintained by organizations like the U.S. Department of Energy (DOE) or NRC). The next step is to look at the conditions of operation of the facility. Some materials can be eliminated at this stage (e.g., if they are used at temperatures well below their flashpoints). The CCPS provides some checklists that can be used to ask questions about individual chemicals.

In addition, CCPS explains how to develop an interaction matrix, which is a simple tool for identifying interactions among specific parameters (including materials, energy sources, environmental conditions, etc.) A specific example of hazard identification and interaction matrix development for a hypothetical Vinyl Chloride Monomer facility is given in Chapter 11 of the CCPS Guidebook. NUREG 1513 also gives an example of an interaction matrix, in this case for an ammonium diuranate (ADU) process.

The typical outcome of hazards identification is:

- A list of flammable materials

- A list of toxic materials and by-products

- A list of hazardous reactions

- A list of chemicals and quantities that would be reportable if released to the environment;

- A list of hazards (e.g., toxicity, flammability) associated with a system, and,

- A list of contaminants and process conditions that can lead to a runaway reaction. 
Once the hazard identification has been completed, the hazard evaluation can be performed. CCPS lists 12 methods:

1. Safety review

2. Checklist Analysis

3. Relative Ranking

4. Preliminary Hazards Analysis

5. What-if? Analysis

6. What-if?/Checklist Analysis

7. HAZOP Review

8. Failure Modes and Effects Analysis (FMEA)

9. Fault Tree Analysis

10. Event Tree Analysis

11. Cause-Consequence Analysis

12. Human Reliability Analysis (HRA)

The CCPS Guidebook gives detailed descriptions of each of these methods, including their strengths and weaknesses and the resources required. It contains guidance on which method to choose for a given project. It also contains detailed worked examples, centered upon a hypothetical Vinyl Chloride Monomer (VCM) manufacturing facility:

- A What-If? Analysis during the research and development phase

- Use of the Preliminary Hazards Analysis method during the conceptual design phase

- Use of the HAZOP method during the pilot plant operation phase

- Use of the Fault Tree and Event Tree methods during the detailed engineering phase

- Use of the Checklist and Safety Review methods during the construction/startup phase

- An illustration of the HAZOP method during the routine operations phase

- Use of the Relative Ranking and HAZOP methods for the addition of a batch process during the plant expansion phase

- Use of the FMEA and HRA methods as part of an incident investigation, and

- Use of the What-If?/Checklist Method during the decommissioning phase.

\subsection{Outcome of Hazard Evaluation}

The usual outcomes of hazard evaluation include:

- Causes of deviations from design intent

- Consequences

- Evaluation of existing controls

- Recommendations for design and/or procedural changes (if any). 


\subsubsection{Causes}

The identification of causes encompasses the issue of initiators. Table 2-1 summarizes a number of potential initiating events that can impact fuel cycle facilities. Table 2-2 summarizes some of the ways in which radioactive materials might be released from these facilities.

\subsubsection{Consequences}

Most of the methods of hazard evaluation outlined above discuss consequences qualitatively. Thus, they can only serve as a starting point for the quantitative analysis of scenarios. Generally, the methods will enable the analyst to identify a sequence of events that leads to a release of a hazardous material.

\subsubsection{Controls}

One of the key parts of most hazard evaluation procedures is to discuss the adequacy of controls that are supposed to prevent or mitigate the occurrence of accidental releases of hazardous materials. Examples include, but are not limited to, the adequacy of protection against vehicular impact; the reliability of emergency shutdown loops; the effectiveness of mechanical integrity programs; or the effectiveness of mitigation measures such as deluge systems. Assumptions about whether these systems work lead to a variety of different accident sequences. Sometimes event trees are useful in helping to ensure completeness and logic in covering these sequences.

\subsubsection{Design and/or Procedural Changes}

Although this issue is not a major concern of this Accident Analysis Handbook, one of the most important outcomes of a hazard evaluation is a set of recommendations for design and/or procedural changes that will enhance both safety and efficiency. Examples could be installing physical barriers to prevent vehicular intrusion, increasing the frequency of inspection of key equipment, revising procedures, training, and a host of other possibilities.

\subsection{Accident Scenarios}

Once the hazard evaluation has been carried out, the scenarios can be defined. Many hazard evaluation procedures (e.g., HAZOP) will identify initiating events (e.g., pipe leak due to corrosion, hose rupture, etc.). This alone may not be enough to completely define the accident scenario, especially if the initiating event is inside a structure. It is then necessary to consider whether the various barriers are intact (e.g., whether walls have holes in them), whether filters are intact, whether the ventilation system still works, etc. If there are mitigation systems, such as automatically activated firewater spray systems, it will also be necessary to consider whether these work. An event tree is often a convenient way of ensuring completeness of the scenarios. An example is given below in Section 2.4.1.

\subsection{Examples}

Several examples have been chosen and are presented in Appendix D in order to illustrate the methods that are described herein. The scenarios chosen are: 


\section{Internal}

A. Explosive Initiators

- Detonations (shock \& blast)

- Deflagrations (blast)

- Others: physical analogs to detonation (molten material + water) and deflagration (overpressurization and venting)

B. Fire Initiators

- Gases (e.g., $\mathrm{H}_{2}$ )

- Liquid fuel

- Solid fuel

- Pyrophoric Materials

C. Mechanical Initiators

- Puncture

- Crush-Impact

- Shock-Vibration

D. Aerodynamic Entrainment

- Falling powder

- Contamination from heterogeneous surfaces (loose powder, attached particles)

- Contamination from homogeneous surfaces (soil, powder)

- Evaporation from pools

E. Chemical Initiators

- Exothermic reactions

- Inadvertent mixing

- Pressure surges

\section{External}

A. Caused by Human Activity

- Adjacent facilities: fire, explosion, chemical intrusion

- Vegetation Fire

- Vehicular: trains, aircraft, trucks, cars

B. Severe Natural Phenomena

- Earthquake

- Tornados/High Straight Winds

- Floods

- Ice/Severe Winter Storms 
Table 2-2. Methods of Release of Radioactive Materials Anticipated for Nuclear Process Facilities

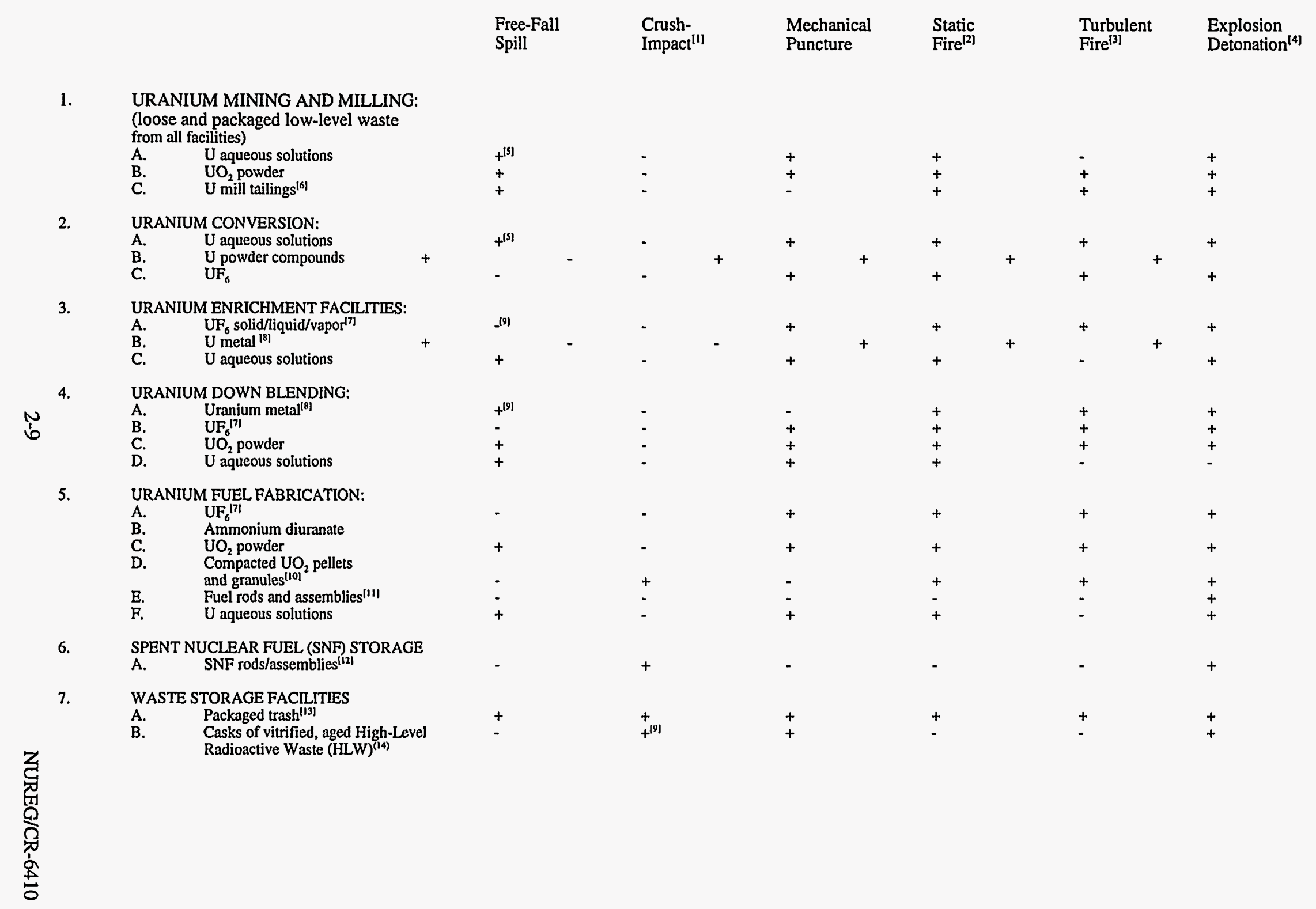


Table 2-2. Methods of Release of Radioactive Materials Anticipated for Nuclear Process Facilities (Continued)

2.

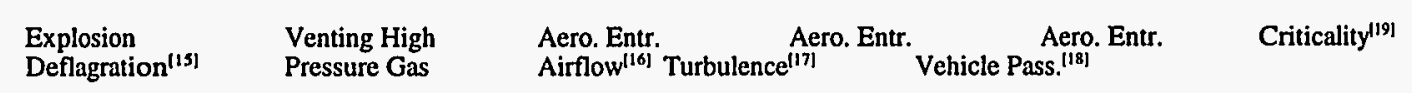

URANIUM MINING AND MILLING:

(loose and packaged low-level waste

from all facilities)

A. U aqueous solutions

B. $\quad \mathrm{UO}_{2}$ powder

2. URANIUM CONVERSION:

$\begin{array}{ll}\text { A. } & \text { U aqueous solutions } \\ \text { B. } & \text { U powder compounds } \\ \text { C. } & \mathrm{UF}_{0}\end{array}$

3. URANIUM ENRICHMENT FACLITIES:

A. $\quad \mathrm{UF}_{6}$ solid/liquid/vaporiti

B. $\quad U$ metal ${ }^{[8]}$

4. URANIUM DOWN BLENDING:

$\begin{array}{ll}\text { A. } & \text { Uranium metal }{ }^{[8]} \\ \text { B. } & \text { UF }_{6}^{(7)} \\ \text { C. } & \text { UO }_{2} \text { powder } \\ \text { D. } & \text { U aqueous solutions }\end{array}$

5. URANIUM FUEL FABRICATION:
A. $\quad \mathrm{UF}_{6}[\mathrm{Z}$
B. Ammonium diuranate
C. $\mathrm{UO}_{2}$ powder
D. Compacted $\mathrm{UO}_{2}$ pellets
E. Fuel rods and assemblies ${ }^{(11)}$

E. Fuel rods and assem

6. SPENT NUCLEAR FUEL (SNF) STORAGE SNF rods/assemblies ${ }^{(12)}$

7. WASTE STORAGE FACILITIES
A
Packaged trash ${ }^{(13)}$
B. Casks of vitrified, aged High-Level Radioactive Waste (HLW) ${ }^{(14)}$ 
0เเ9-ชว/DG8กN

$=\quad \square$

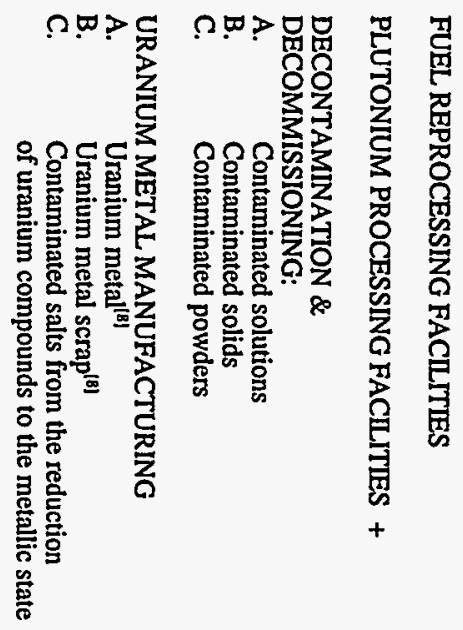

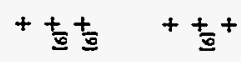

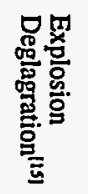

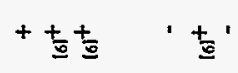

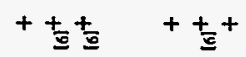

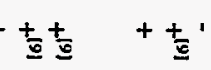

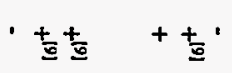

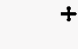

$+$

$\mathfrak{I} I-\mathcal{Z}$

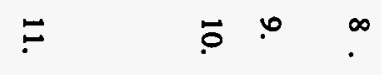

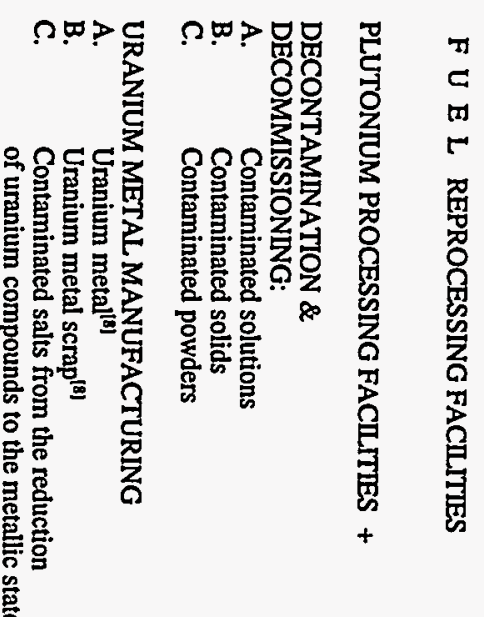

+
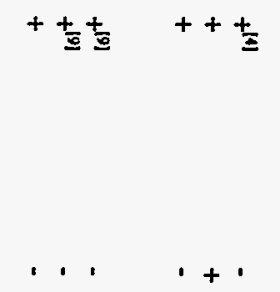

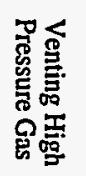
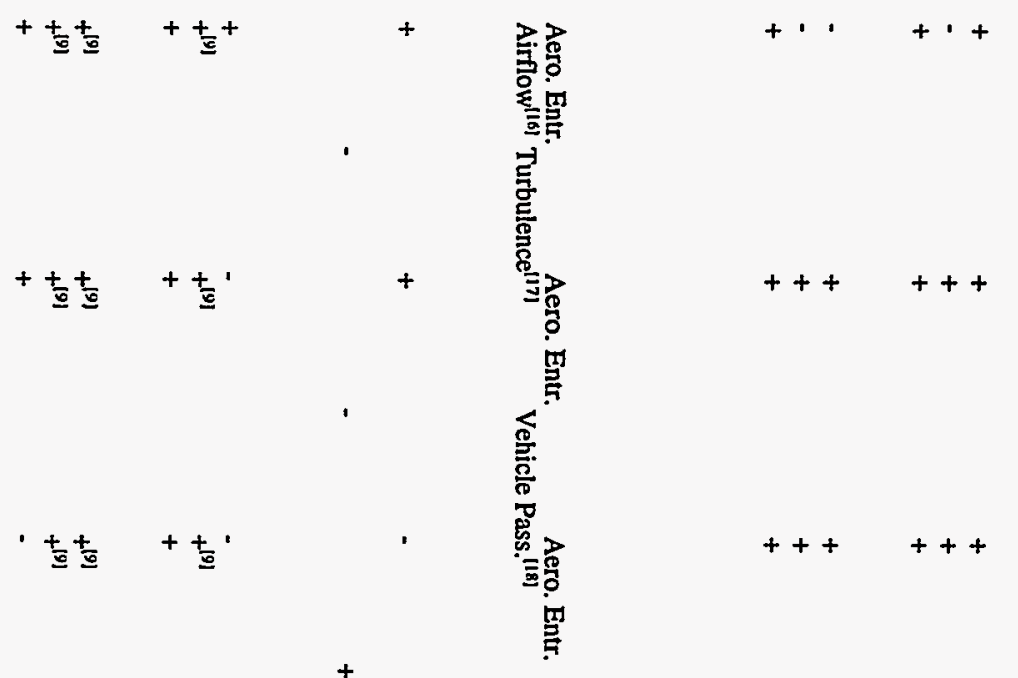

$+$

$+\quad$ 꼴

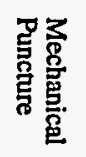

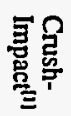

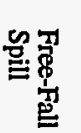

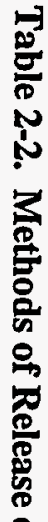

足

雪

㿣.

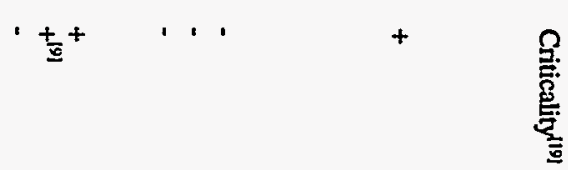

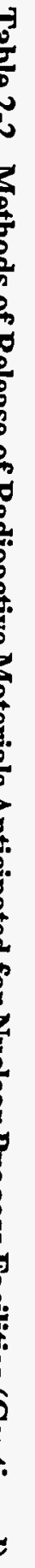




\section{Table 2-2 Footnotes:}

$+\quad$ Stress/event may result in the airborne release of significant amounts ( $>1 E-5$ of inventory) of radionuclides from this physical form.

- Stress/event does not appear to have potential to result in the airborne release of radionuclides from this physical form.

[1] Crush-Impact: Covers both the slow application of force by a solid mass and the shock-vibration due to impact of falling, solid debris upon a solid surface.

[2] Static Fire: Small fires due to the combustion of the material itself or a small amount of low-volatility fuel around, co-located with, contiguous to, or near the material.

[3] Turbulent Fire: Combustion of a large quantity of relatively high-volatility fuel co-located with, contiguous to or near the material.

[4] Explosion, Detonation: Generates some of the energy evolved as a shock wave (no mass movement). Covers both chemical or physical energy sources.

[5] Includes suspension resulting from the impact of falling debris.

[6] Uranium Mill Tailings: The sand-like residue from the uranium milling operations. The principal airborne radiological concern is radon gas emissions. Stream contamination with radium is possible.

[7] Uranium Hexafluoride: All forms (solid, liquid, and vapors) are normally contained in a cask or process equipment under normal process and storage conditions.

[8] Uranium Metal: Both unalloyed and alloyed (less than 1 percent by weight of alloying metal) with a surface to mass ratio of less than $10 \mathrm{~cm}^{2} / \mathrm{g}$.

[9] Applies only to loose particles on the surface.

[10] Compacted $\mathrm{UO}_{2}$ Pellets and Granules: Unirradiated material.

[11] Fuel Rods and Assemblies: Unirradiated, clad stacks of compacted sintered, $\mathrm{UO}_{2}$ pellets clad in either Zircaloy or Stainless Steel.

[12] Spent Nuclear Fuel (SNF) Rods and Assemblies: Irradiated and aged ( $>1-y r$.$) fuel rods and assemblies.$

[13] Packaged Trash: Contaminated combustible and non-combustible trash held in plastic-lined cardboard.

[14] Vitrified, Aged High Level Waste: Aged HLW held in the matrix of borosilicate-glass.

[15] Explosion: Deflagration: Generates its energy as a pressure impulse. Covers both chemical and physical energy sources.

[16] Aerodynamic Entrainment, Airflow: Suspension of particulate material from the action of gases flowing essentially parallel to the surface of concern.

[17] Aerodynamic Entrainment, Turbulence: Suspension of particulate material from surfaces as a result of the flow and turbulence of air or gas as a large, solid object approaches the surface.

[18] Aerodynamic Entrainment, Vehicle Passage: Suspension of a powder from a hard surface due to the passage of a motor vehicle (car, pickup truck) over or adjacent to the surface.

[19] Criticality: The results of an inadvertent chain reaction due to the presence of fissile materials in an unfavorable configuration. Uranium solutions, powders and solids must have adequate enrichment to result in a chain reaction. 
1. Free fall spill of radioactive powder

2. Explosion in a room with aerodynamic entrainment of radioactive particles from a surface

3. Fire with suspension of radioactive particles from the burning of contaminated, combustible material

4. Filter failure with release of radioactive particulate previously trapped by the filter

5. Spillage of HF from a tankcar

6. $\mathrm{UF}_{6}$ Liquid Cylinder Rupture

7. Release of radioactive materials from falling slurry in a vitrification plant, and

8. A criticality incident.

This list was initially chosen in brainstorming sessions by a team that is very knowledgeable about fuel cycle facilities and has accumulated many years of experience in accident analysis of such facilities. The basic question asked by the team was, which already known scenarios will best serve the purpose of exercising most of the models that will be described in this Accident Analysis Handbook? There is, of course, no unique answer to that question. Thus, the method of hazard evaluation that was actually used was heavily dependent on the judgement of experts. In spirit, it is perhaps closest to those methods of hazard evaluation that rely most heavily on the expertise of the team, such as the Checklist or the Whatif? method. However, each of the scenarios identified above could, in principle, have been identified by starting from scratch and using one of the formal hazard evaluation methods discussed in the foregoing.

\subsubsection{Sample Problem 1. Free-Fall Spill of Powder}

Powders are a collection of small solid particles, usually of many different sizes and shapes, held together by weak cohesive forces. Powders of radioactive material are handled and processed in a variety of non-reactor, non-medical nuclear facilities. Powder particles, both individual and smaller aggregates, can be separated and become airborne through events ranging from spills to explosions. One of the simplest and least energetic stresses that can be imposed upon powders is the free-fall spill. This initiating event results in the powder falling as a coherent body that acts as a single entity, referred to as a "slug," through the air or gas. As the slug of powder falls, its forward face is impacted by the air and is continuously made more dispersed; particles at the sides of the slug are subject to shear stress that can entrain the material; and the region of lesser pressure induced on the rear face by the flow around the slug can also cause particle entrainment. For short fall distances, the dominant cause of dispersion appears to be impact upon a hard, unyielding surface. As the fall distances increase, other mechanisms, such as stress caused by airflow around the slug that result in greater dispersion of the mass, tend to increase in importance. The underlying assumption in this sample problem is that the powder is released as a slug and not a highly dispersed mass.

In order to complete the definition of the accident scenario, it is necessary to consider how the airborne powders make their way into the external atmosphere. For this purpose, a sample facility has been defined and is illustrated in Figure 2-1. It consists of a ventilation inlet into a room having a smaller room attached (e.g., a glove box), exhaust ducting to a manifold, and, finally, a stack. There is a HEPA filter in the duct. This configuration is chosen to facilitate illustration of the use of models for predicting the movement of radioactive materials through buildings. Details of the use of such models are given in 


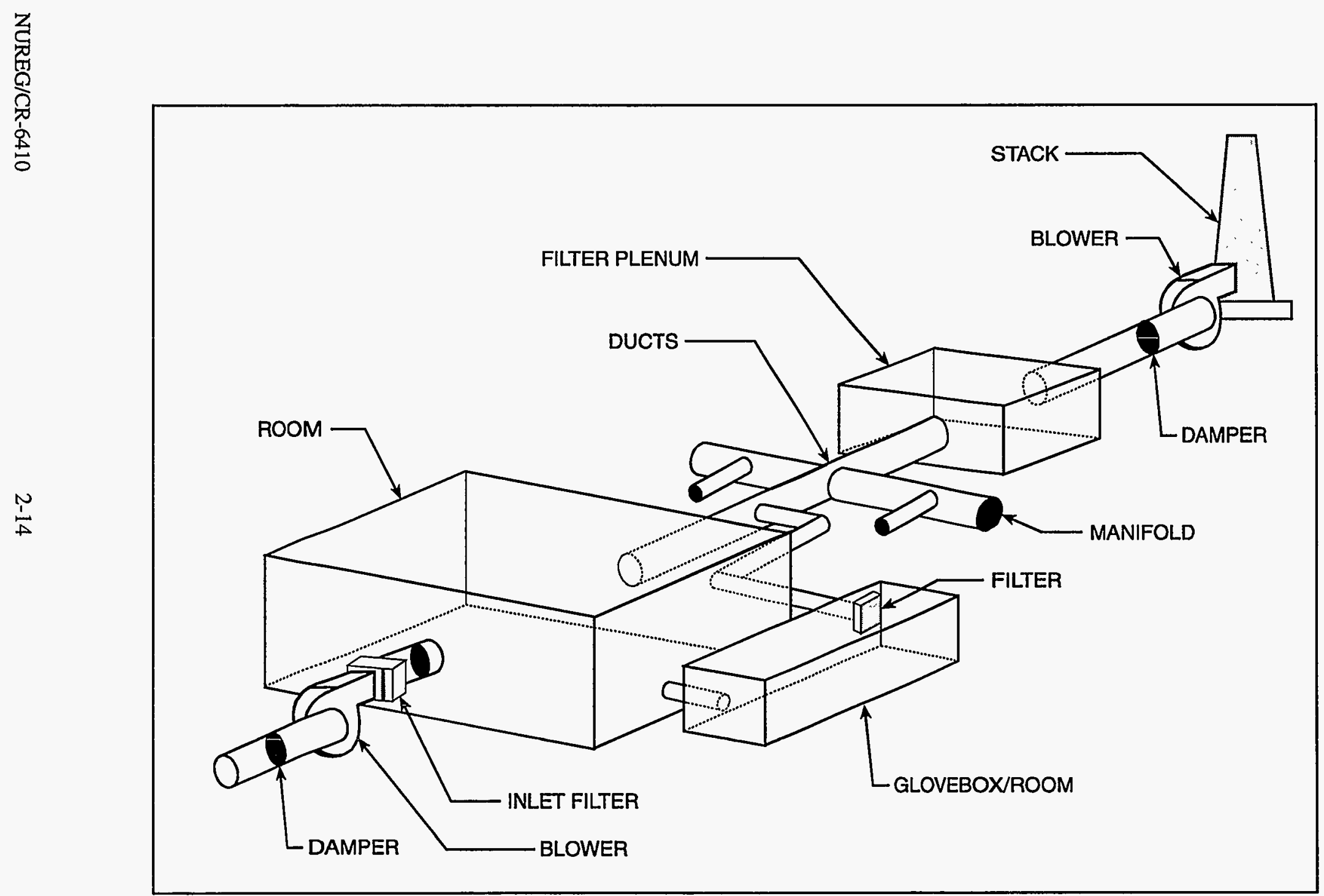

Figure 2-1. Simple facility for sample problems 
Chapter 4. The dimensions of the room and flow rates, etc., are defined for each sample problem. Figure 2-2 displays a simple event tree that represents various different ways in which the powder, once spilled, might make its way to the atmosphere. Thus, for example, if the initiating event that causes the powder spill also damages the facility itself (e.g., an earthquake), then there may be direct leakage to the external atmosphere, as represented by Scenario 1-9 on Figure 2-2. At the other extreme, all systems and buildings function as expected (Scenario 1-1). For the purposes of this analysis, a scenario is considered in which there is no HEPA filter, but, otherwise, the building and its systems function normally (Scenario \#1-3). A second example is considered where there is a HEPA filter, which can reduce the amount of material released to the atmosphere by a factor of up to 2,000 .

A further variation on these scenarios is also considered: the powder is spilled either into the large room or directly into the ductwork.

\subsubsection{Sample Problem 2. Explosion in a Room with Aerodynamic Entrainment of Radioactive Particles from a Surface}

Flammable or combustible gases are used in some facilities to provide a reducing atmosphere for processing (e.g., during sintering of compacted uranium dioxide $\left(\mathrm{UO}_{2}\right)$ pellets) or for space heating. The purpose of Sample Problem 2 is to consider the effect of release of a limited amount of a flammable gas, such as hydrogen, and its subsequent deflagration.

The scenario postulated to illustrate the airborne release and transport of the suspended material from an explosion is the deflagration of a limited volume of flammable gas in a large room. This deflagration is assumed to result in minor overpressures within the volume that would not result in loss of the structure or exhaust flow. It is postulated that $0.3 \mathrm{~m}^{3}\left(\sim 10 \mathrm{ft}^{3}\right)$ of hydrogen gas escapes into the operating room, which is $30.5 \mathrm{~m}(100 \mathrm{ft})$ wide by $91.4 \mathrm{~m}(300 \mathrm{ft})$ long by $6.1 \mathrm{~m}$ ( $20 \mathrm{ft})$ high, with a total volume of $~$ $17,000 \mathrm{~m}^{3}\left(\sim 600,000 \mathrm{ft}^{3}\right)$. The gas is assumed to rise and mix with air. Some undefined ignition source, for example, an electrical connection such as lighting, is assumed to cause ignition in the upper portion of the volume. Ambient air accelerated to high velocity by the rapid burning is assumed to entrain powder from a homogenous substrate (metal bench or equipment). The material then escapes through ducts and a stack, as shown in Figure 2-1.

\subsubsection{Sample Problem 3. Fire with Suspension of Radioactive Particles from the Burning of Contaminated, Combustible Material}

Limited quantities of solid combustible materials are found in non-reactor, non-medical nuclear facilities. The locations of the combustible materials within the operating areas of a facility are generally scattered and not amenable to propagation that would result in a general facility fire. Furthermore, only a limited portion of the combustible materials within the operating area are contaminated with radioactive materials.

The combustion of a solid, combustible material is a heterogeneous process--heat applied to the solid material generates a combustible vapor (pyrolyzate) that rises and mixes with air drawn from around the edges of the flame; the vapor-air mixture attains a dilution that is flammable, is ignited, and burns. Heat generated by the flames radiates back to the surface of the solid material and continues the pyrolyzation process to generate more vapors. The height of the flames above the surface is a function of the vapor 


\begin{tabular}{|c|c|c|c|c|c|}
\hline $\begin{array}{c}\text { Inltiating } \\
\text { Event \#1- } \\
\text { Powder Falls }\end{array}$ & Room Intact? & $\begin{array}{l}\text { Ventilation } \\
\text { System } \\
\text { Working? }\end{array}$ & $\begin{array}{l}\text { HEPA Filter } \\
\text { Present? }\end{array}$ & $\begin{array}{c}\text { Stack } \\
\text { Integrity } \\
\text { Maintained? }\end{array}$ & Scenarios \\
\hline IE\#1 & $\mathrm{RC}$ & VSW & HEPA & SIM & \\
\hline \multirow{7}{*}{ IE\#1 } & & \multirow{3}{*}{ IES } & yec & YES & \multirow{7}{*}{$\begin{array}{l}\text { Scenario \#1-1 } \\
\text { Scenario \#1-2 } \\
\text { Scenario \#1-3 } \\
\text { Scenario \#1-4 } \\
\text { Scenario \#1-5 } \\
\text { Scenario \#1-6 } \\
\text { Scenario \#1-7 } \\
\text { Scenario \#1-8 } \\
\text { Scenario \#1-9 }\end{array}$} \\
\hline & & & & NO & \\
\hline & & & & YES & \\
\hline & YES & \multirow{4}{*}{ No } & & & \\
\hline & \multirow[b]{3}{*}{ NO } & & & YES & \\
\hline & & & $\pm N$ & No & \\
\hline & & & & & \\
\hline
\end{tabular}

Figure 2-2. Event tree for sample problem 1 
generation and mixing required to achieve a burnable mixture. Heat radiated by the flames may also ignite other materials at some distance, depending on the material characteristics, the flame size, and distance.

Materials contaminating the combustible solids may be suspended by destruction of the solid substrate upon which the contamination lies. The physical forms of the contaminant under these conditions (e.g., vapor, solid particles) and the magnitude of the velocity of the vapor generated at the locale combine to carry the particles to the convective flow regime beyond the flames.

It is postulated that contaminated combustible materials are accumulated within the operating area at several locations within a facility handling and processing enriched uranium. The contaminated wastes are from various processes where uranium solutions and oxide powders could be lost as minor leaks. The contaminant could be air-dried residue from uranium nitrate solutions or uranium oxide powders. The waste is assumed to be accumulated at five locations within an operating room $30.5-\mathrm{m}(100-\mathrm{ft})$ wide by $91.4-\mathrm{m}(300-\mathrm{ft})$ long by $6.1-\mathrm{m}(20-\mathrm{ft})$ high that has a total volume of $\sim 17000 \mathrm{~m}^{3}\left(\sim 600000 \mathrm{ft}^{3}\right)$. It is postulated that these fires propagate slowly by igniting other non-contaminated combustibles (e.g., rags, paper, plastic) in the area, resulting in the sequential ignition and burning of the contaminated combustibles held in metal cans.

The combustible loading is assumed to be:

- Combustibles contaminated with air-dried residues (2 locations) $10 \mathrm{~kg}$ ( $22 \mathrm{lb}$ ) of combustibles with $10 \mathrm{~g}(0.02 \mathrm{lb})$ of uranylnitrate hexahydrate $(\mathrm{UNH})$ at each location

- Combustibles contaminated with powder (3 locations) $20 \mathrm{~kg}$ (44 lb) of combustibles with $20 \mathrm{~g}$ $(0.04 \mathrm{lb})$ of $\mathrm{UO}_{2}$ at each location.

\subsubsection{Sample Problem 4. Filter Failure with Release of Radioactive Particulate Previously Trapped by the Filter}

HEPA filters are used in many nuclear facilities as the final barrier between particulate materials airborne in the facility and the ambient environment around the facility. A HEPA filter is essentially a shallow frame of metal or pressed fiber that contains a filtration medium. The medium most commonly found in U.S. facilities is a fine, glass fiber mat, but other materials, such as cellulose, mineral, and metal fibers are also used. Particles in air passing through the medium are collected by three mechanisms--impaction, interception, and diffusion. Impaction collects larger particles $\left(>1 \mu \mathrm{m}\left(3.9 \times 10^{-5}\right.\right.$ in) Aerodynamic Equivalent Diameter [AED]) using (1) the inertial force generated by the mass of the particle and the velocity of air and (2) the inability of the particle to follow the streamlines as it encounters the fine fiber. Smaller particles have less inertia and can partially follow the flow changes. If the particle (micrometer to submicrometer AED) approaches the fiber within the largest dimension of the particle, the particle can be collected on the surface of the fiber. Submicrometer AED particles penetrate into the fiber mat and, due to the tortuous path via the cells created by the matted fiber, diffuse to the surface of the fibers.

For a given combination of fiber diameter and air flow rate or velocity at the face of the filter, there is a size range for the most penetrating particles. For $0.61-\mathrm{m}$ by $0.61-\mathrm{m}(2-\mathrm{ft}$ by $2-\mathrm{ft})$ HEPA filter typical of those used in the U.S., with a volumetric flow of $0.49 \mathrm{~m}^{3} / \mathrm{s}(1000 \mathrm{cfm})$ at a differential pressure of $2.5 \mathrm{~cm}$ ( 1 in) WG (Water Gauge), the most penetrating particles are in the range of $0.1-$ to $0.2-\mu \mathrm{m}\left(4.0 \times 10^{-6}-\right.$ to $8.0 \times 10^{-6}$-in) AED. Particles with larger diameters are more strongly affected by inertial mechanisms 
(e.g., impaction or interception) and particles smaller than the most penetrating size are more strongly affected by the diffusion mechanisms (e.g., turbulent and Brownian).

Filters are designed and tested at the factory to maintain a collection efficiency of 99.97 percent or greater for $0.3 \mu \mathrm{m}\left(1.2 \times 10^{-6} \mathrm{in}\right) \mathrm{AED}$ test particles (typically dioctyl phthalate, DOP, or dioctyl sebecate, DOS). Depending upon the size and characteristics of the materials deposited, HEPA filters can accumulate several kilograms of particulate materials before exhibiting a differential pressure greater than $15 \mathrm{~cm}$ (6 in) WG (a typical value where the cost of generating the differential pressure begins to exceed the cost of replacement) required to maintain the $0.49 \mathrm{~m}^{3} / \mathrm{s}\left(17.3 \mathrm{ft}^{3} / \mathrm{s}\right)$ flow.

Much of the loss of efficiency can be attributed to minute leaks in the sealant joining the filter mat to the frame or pathways through the gasket sealing the filter to the frame. Such paths must be minute in order to maintain the required in-place collection efficiency ( 99.97 percent), but the size range of the particles passing through these leaks is not significantly altered in the micrometer-submicrometer range of the particle's largest dimension.

Various conditions, such as high temperatures, pressures, and poor quality or deterioration of binders used, can cause the HEPA filters to fail. HEPA filters must withstand flame impingement and momentary high temperatures. Filters with mineral sealant have retained collected materials for a temperature as high as $623 \mathrm{~K}\left(660^{\circ} \mathrm{F}\right)$ (Hackney 1983). There are no experimental data for the retention of accumulated materials by glass fiber upon melting, but, based on the behavior of glass, it is postulated that the fibers soften and become "sticky" in the melting process and would retain all accumulated material in the melted glass, similar to vitrified high-level-waste (HLW). New glass fiber filter mats withstand up to $200 \mathrm{~cm}$ ( $80 \mathrm{in}$ ) WG before failure, but, upon loss of binder (binderless glass fiber contains up to 5 percent organic binder), failure can occur at $25 \mathrm{~cm}$ (10 in) WG or less. Experimental data indicate that pleated glass fiber mats used in HEPA filters are perforated at a few locations along a few of the back pleats when challenged by shock waves (Gregory et. al. 1983).

It is postulated that a filter at the end of its productive cycle is subjected to high temperatures that result in filter failure, and that the filter accumulation consists of a maximum of $2 \mathrm{~kg}$ of $\mathrm{UO}_{2}$ particles.

\subsubsection{Sample Problem 5. Spillage of Hydrogen Fluoride from a Tankcar}

Sample Problem 5 is intended to illustrate how to model scenarios that result in the spillage of hazardous chemicals. HF is normally supplied to the facility by tankcar. The unloading process utilizes nitrogen to pressure HF out of the tankcar into an Acid Storage Vessel. The transfer lines connecting the tankcar and the storage vessel are "HF-service" flexible hoses.

Potential accident scenarios arising from the HF tankcar unloading process include:

a. HF vapor release due to a break in the nitrogen padding gas hose.

b. HF liquid release due to a break in the HF liquid transfer hose.

These are assumed to take place outside in the open air, but still within the site boundary. These scenarios illustrate how to model liquid and vapor releases of a hazardous material. They would arise naturally from a hazards evaluation, such as a HAZOP of a truck unloading process. 


\subsubsection{Sample Problem 6. Uranium Hexafluoride Liquid Cylinder Rupture}

This scenario is possible under the following conditions:

Alternative \#1:

An overfilled 12.6 metric ton (14-ton) $\mathrm{UF}_{6}$ cylinder in a fuel enrichment facility is heated. The operator does not realize that the cylinder is overfilled. Thermal expansion of $\mathrm{UF}_{6}$ causes cylinder rupture. In this scenario, all of the $\mathrm{UF}_{6}$ is released instantaneously.

Alternative \#2:

A 14-ton cylinder containing liquid $\mathrm{UF}_{6}$ is accidentally dropped during transportation/moving operations. The fall results in a small hole developing in the cylinder wall. Depending upon the location of the rupture, the contents of the cylinder may be released either (a) as a continuous liquid jet if the hole is below the liquid level, or (b) as a continuous vapor jet if the hole is above the liquid level. For this alternative, continuous jet releases of either liquid or vapor through a 5-cm (2-inch) diameter hole are assumed. This is a typical diameter resulting from a cylinder drop.

These scenarios are possible in fuel conversion, enrichment, downblending, and fabrication facilities. An adequate hazard evaluation procedure would be a checklist based on previous experience or a WhatIf? team session or a formal hazards evaluation exercise, such as HAZOP.

These scenarios are assumed to take place outside in the open air, but still within the site boundary.

\subsubsection{Sample Problem 7. Release of Radioactive Materials from Falling Slurry in a Vitrification Plant}

Liquid spill releases can pose human health and environmental problems if the liquid released is toxic, radioactive, or otherwise hazardous. Liquid releases result from spills that occur during transfer, leaks in pipes or containers, and ruptures from external forces, such as catastrophic impacts and internal overpressurization from uncontrolled reactions.

A liquid spill of hazardous or radioactive material creates airborne as well as liquid transport pathways as a result of evaporation and aerosolization from the liquid surface. The transport of aerosolized particles in air is considered in other sample problems (free-fall spill, explosion, fire, and filter failure). This sample problem focuses on the initial aerosol as liquid and its transport pathways.

To demonstrate the calculation of release fractions, leak path factors, and doses from a liquid spill, the liquid spill scenario has been based upon safety analyses from a facility that combines nuclear waste with glass in a vitrification process. At the vitrification plant, a sludge slurry composed principally of insoluble inorganic salts is fed through underground piping to the process cells housed in the vitrification building. The salts are mixed with glass frit in the slurry mix evaporator and fed to the glass melter via the melter feed tank. In the melter, the frit/waste salt mixture is heated to over $1270 \mathrm{~K}\left(1830^{\circ} \mathrm{F}\right)$ to form a molten glass. The glass is poured into canisters which are cooled, sealed, and stored.

In this generic vitrification facility, the potential for liquid spills is found in the following situations: 
- Overflow in process cells

- Overflow in pump pit and auxiliary pit

- Leaks in process cells (excluding salt processing cell)

- Leaks in salt processing cell

- Leaks in pump pits

- Transfer line leaks

- Canister rupture

- Release of contaminated steam condensate, and

- Release of contaminated cooling tower water.

For illustrative purposes, a process cell overflow of 1 liter $(0.26 \mathrm{gal})$ of salt slurry has been chosen. The slurry has a fall path of two meters $(6.6 \mathrm{ft})$ onto the floor of a building like that shown in Figure 2-1.

\subsubsection{Sample Problem 8. A Criticality Incident}

A criticality incident is an unplanned event resulting in the uncontrolled release of energy from an assemblage of fissile and fissionable radionuclides. Under appropriate accident conditions, fissile and fissionable radionuclides may undergo a self-sustaining nuclear reaction (chain reaction) called an inadvertent nuclear criticality or nuclear excursion.

The nature of the potential nuclear criticality depends on the physical form of the fissionable materials. In nuclear fuel cycle facilities, fissile materials are present as solutions, powders, and solids.

Historically, the most likely material form in a nuclear criticality is a solution of fissile materials, typically an aqueous acid solution. Since they exist as moderated systems, liquid solutions of fissile material have smaller critical masses than do solid ones. There are a few exceptions to this rule, including $\mathrm{Np}^{237}, \mathrm{Pu}^{240}$ and $\mathrm{Am}^{241}$, which have minimum critical masses when unmoderated. These isotopes currently play a minor role in the fuel cycle industry, but may become more important during DOE facilities' transition to NRC regulation. Further, they are quite mobile, and can be formed into nongeometrically favorable shapes with inadvertent reflection, creating the possibility of criticality in unexpected locations.

Inadvertent criticalities involving solids are generally less likely because solids are typically immobile, their movement is easily recognized and controlled, and the mass required for criticality of an unmoderated system is large compared to that for a moderated system. A nuclear criticality involving unmoderated powders is theoretically possible but also very unlikely. Powders have void spaces, making the occurrence of geometries that favor fission unlikely.

However, it should be noted that, in typical fuel cycle facilities, very large quantities of fissile powders are deliberately exposed to moderating materials to accomplish desired operational steps (e.g., the injection of steam into a reactor or kiln in the dry conversion process or the addition of "conditioners" to $5000-\mathrm{kg}(11000-\mathrm{lb})$ blenders), thus increasing the likelihood of criticality excursions in these processes should design controls fail. The inventory of fission products generated during a criticality event is a function of the type of fissile material present (e.g., uranium, plutonium, or thorium isotopes). The quantity of fission products generated is a function of the total number of fissions that occurs during the criticality event. The total number of fissions depends on the amount of fissile material, the 
configuration of the material, and how long the conditions necessary to maintain a critical configuration exist.

The energy produced by a criticality event is dissipated into the environment that surrounds the fissile material. In the case of solutions of fissile materials in water, this energy is dissipated by heating the solutions, resulting in the evaporation of water, which is a moderator. Eventually, the loss of moderation due to the evaporation of the water results in the termination of the criticality event. For solid systems, displacement of the solid or powder can alter the configuration and result in the termination of the criticality.

The facility assumed for the sample problem is a uranium fuel fabrication plant. In this type of facility, an inadvertent criticality might be initiated in the following situations:

- Inadvertent transfer or leakage of a solution of fissile material from a geometrically favorable vessel into an area or vessel with an unfavorable geometrical configuration

- Introduction of excess fissile material into a vessel or solution

- Failure to maintain sufficient neutron absorbing materials in a vessel

- Precipitation of fissile solids from a solution and their retention in a vessel

- Introduction of neutron moderators or reflectors (e.g., by the addition of water to a highly under moderated system)

- Deformation of or failure to maintain favorable storage arrays, or,

- Other actions that can lead to increases in the reactivity of the fissile systems (USNRC 1979).

For the purposes of this sample problem, it is assumed that human error has caused the introduction of a uranium nitrate hexahydrate (UNH) solution into a vessel of unfavorable geometry, causing an inadvertent nuclear criticality. The criticality occurs in a vented vessel of unfavorable geometry containing a solution of $400 \mathrm{~g} / \mathrm{l}$ of uranium enriched in U-235. The criticality produces an initial burst of $10^{18}$ fissions in 0.5 seconds, followed by 47 bursts of $1.9 \times 10^{17}$ fissions, for a total of $10^{19}$ fissions in 8 hours. The criticality is assumed to be terminated by the evaporation of 100 liters of solution.

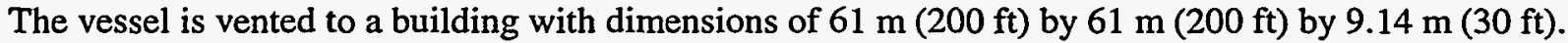
There are approximately 5 air changes per hour through the ventilation system. The effluent exits through a stack that is $60-\mathrm{m}(195-\mathrm{ft})$ high and $2-\mathrm{m}(6.5-\mathrm{ft})$ in diameter. The resulting air flow is $47.2 \mathrm{~m}^{3} / \mathrm{s}$ $(\sim 97000 \mathrm{cfm})$, with an exit velocity of approximately $15 \mathrm{~m} / \mathrm{s}(\sim 2900 \mathrm{ft} / \mathrm{min})$. 


\subsection{References}

American Petroleum Institute (API), "Management of Process Hazards," Recommended Practice 750, Washington D.C., 1990.

Center for Chemical Process Safety (CCPS), "Guidelines for Chemical Process Quantitative Risk Analysis," American Institute of Chemical Engineers, New York, New York, 1989.

Center for Chemical Process Safety (CCPS), "Guidelines for Hazard Evaluation Procedures - Second Edition with Worked Examples," American Institute of Chemical Engineers, New York, New York, 1992.

Chemical Manufacturers Association (CMA), "Responsible Care Resources," Arlington, Virginia, 1992.

Hackney, S., "Fire Testing of HEPA Filters Installed in Filter Housings," Proceedings of the 17th DOE Air Cleaning Conference, CONF-820833, Harvard Air Cleaning Laboratory, Boston, Massachusetts, 1983.

U.S. Nuclear Regulatory Commission (USNRC), "Integrated Safety Analysis Guidance Document" (Draft), NUREG 1513, Washington, D.C., 1995. 


\section{CHAPTER 3 SOURCE TERM DETERMINATION}

\subsection{Background}

\subsubsection{Purpose and Organization}

The purpose of this chapter is to provide information on the methods and values used to estimate the characteristics of airborne release of radioactive materials and hazardous chemicals (e.g., mass/activity, physical characteristics important to inhalation hazard and transport, rate of release, duration, etc.) necessary to provide a source term for use in transport models for assessment of the potential downwind impact of potential accidents.

For releases of radionuclides, the fundamental quantities defining the source terms are the Airborne Release Fraction (ARF), or Airborne Release Rate (ARR), and the Respirable Fraction (RF). These quantities are defined in detail in Section 3.2.5.2. This chapter contains information about ARFs, ARRs, and RFs for a great variety of possible accidental releases of radioactive material. They are summarized in Table 3-1. Each entry in Table 3-1 is then tied to a descriptive Subsection within Section 3.3, ("Experimental Bases for ARFs, ARRs, and RFs"). The Subsections summarize the available experimental evidence and theories, and refer to more detailed references such as the Department of Energy's Handbook on "Airborne Release Fractions/Rates and Respirable Fractions for Nonreactor Nuclear Facilities" (USDOE 1994). The reader who already has defined the scenario that is being modeled should consult Table 3-1 and, if necessary, read the appropriate Subsection within Section 3.3.

This chapter begins with a background section that explores some of the issues and sources of uncertainty in deriving values for ARFs. This is followed by a discussion of particle size and aerosol physics. For many potential scenarios in fuel cycle facilities, radioactive material will be released as small particles. It is, therefore, important to understand the characteristics of these particles, such as their size distribution, as they are released and carried along in the atmosphere as an aerosol. The particle size determines whether the particle will fall out early on, or be carried a considerable distance. Particle size also determines whether the particles are respirable.

Section 3.2 describes how to determine the characteristics of airborne releases of radioactive materials. In general, the ARF/ARR/RFs depend on a number of factors, including the characteristics of the affected material, the type and level of stress imposed, how and when the stress is imposed, and the local environmental conditions. Therefore, the characteristics of the various forms of materials found in fuel cycle facilities are discussed (Section 3.2.2). They include a) gases; b) volatile materials; c) liquids of low volatility (including solutions, slurries and non-Newtonian fluids); d) combustible organic liquids in which radioactive materials are dissolved; e) solids, including reactive metals and non-reactive metals; f) brittle solids, including glass, vitrified high-level waste, fuel pellets, spent nuclear fuel (SNF) and aggregate/concrete; g) powders; h) combustible, contaminated solids; and i) high efficiency particulate air (HEPA) filters.

Section 3.2.3 contains a discussion of initiating events and the resultant stresses that cause aerosolization of various physical forms. A summary of initiating events has already been given in Table 2-1 (Chapter 2). They include explosions, overpressurization, combustion, puncture/perforation, free-fall spills, crushimpact, shock vibration, abrasion, and aerodynamic entrainment and resuspension. 


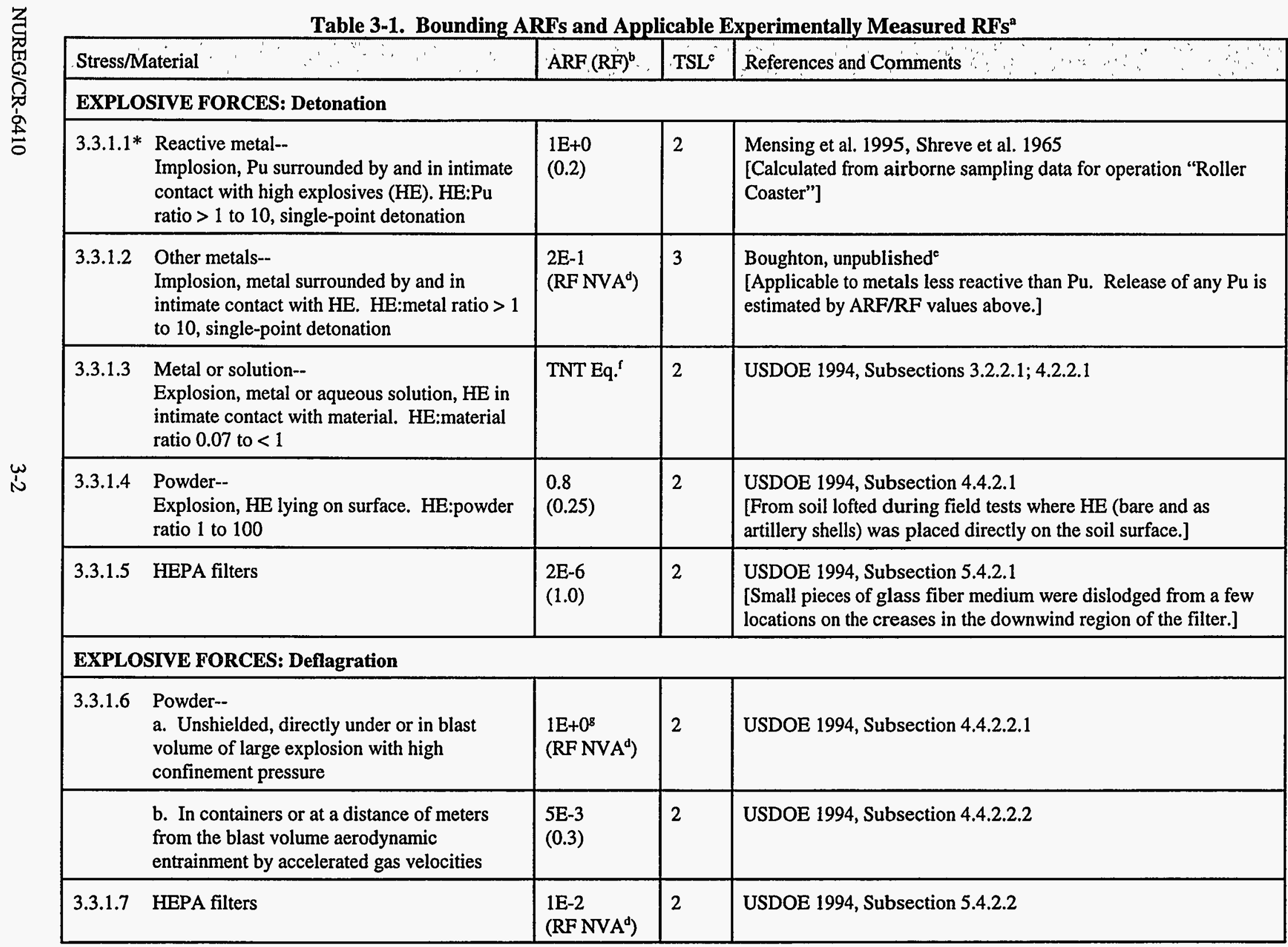


Table 3-1. Bounding ARFs and Applicable Experimentally Measured RFsa (Continued)

\begin{tabular}{|c|c|c|c|c|}
\hline Stress/M: & aterial & $\operatorname{ARF}(R F)^{b}$ & TSL $^{\mathrm{c}}$ & References and Comments \\
\hline \multicolumn{5}{|c|}{ EXPLOSIVE FORCES: Overpressurization to Rupture } \\
\hline \multirow[t]{2}{*}{ 3.3.1.8 } & $\begin{array}{l}\text { Liquid, confined in vessel or container-- } \\
\text { a. Slow buildup of pressure } \\
\text { the surface level of liquid, failure }<0.35 \\
\mathrm{MPa}_{\mathrm{g}}(50.9 \mathrm{psig})\end{array}$ & $\begin{array}{l}5 \mathrm{E}-5 \\
(0.8)\end{array}$ & 2 & USDOE 1994, Subsection 3.2.2.3.2.A \\
\hline & $\begin{array}{l}\text { b. Slow buildup of pressure, vented above } \\
\text { the surface level of liquid, failure pressure } \\
>0.35 \text { up to } 3.5 \mathrm{MPa}_{\mathrm{g}}(>50.9 \text { up to } 510 \mathrm{psig})\end{array}$ & $\begin{array}{l}2 \mathrm{E}-3 \\
(0.3)\end{array}$ & 2 & USDOE 1994, Subsection 3.2.2.3.2.A \\
\hline \multirow[t]{2}{*}{ 3.3.1.9 } & $\begin{array}{l}\text { Liquid, confined in vessel or container } \\
\text { a. Rapid buildup of pressure, vented above } \\
\text { the surface level of liquid }\end{array}$ & NVA $^{d}$ & $\mathrm{i}$ & USDOE 1994, Subsection 3.2.2.3.2.B \\
\hline & $\begin{array}{l}\text { b. Rapid buildup of pressure, vented below } \\
\text { the surface level of liquidi }\end{array}$ & $\begin{array}{l}\text { ARFxRF= } \\
1 \mathrm{E}-4\end{array}$ & 2 & USDOE 1994, Subsection 3.2.2.3.1 \\
\hline \multirow[t]{2}{*}{3.3 .1 .10} & $\begin{array}{l}\text { Superheated liquids-- } \\
\text { a. Superheated liquids ("flashing spray"), } \\
<50 \mathrm{~K}\left(122^{\circ} \mathrm{F}\right) \text { superheat }\end{array}$ & $\begin{array}{l}1 \mathrm{E}-2 \\
(0.6)\end{array}$ & 2 & USDOE 1994, Subsection 3.2.2.3.3.A \\
\hline & $\begin{array}{l}\text { b. Superheated liquids ("flashing spray"), } \\
50 \mathrm{~K}-100 \mathrm{~K}\left(122-212^{\circ} \mathrm{F}\right) \text { superheat }\end{array}$ & $\begin{array}{l}1 \mathrm{E}-1 \\
(0.7)\end{array}$ & 2 & $\begin{array}{l}\text { Mishima, et al. 1968; Borkowski, et al. 1986; Kataoka and Ishii } \\
\text { 1983; USDOE 1994, Subsection 3.2.2.3.3.4 }\end{array}$ \\
\hline 3.3.1.11 & $\begin{array}{l}\text { Powder-- } \\
\text { Confined in vessel or container, release } \\
\text { pressure }<0.17 \mathrm{MPa}_{8}(<25 \mathrm{psig})\end{array}$ & $\begin{array}{l}2 \mathrm{E}-3 \\
(0.4)\end{array}$ & 2 & USDOE 1994, Subsection 4.4.3.3.2 \\
\hline 3.3 .1 .12 & $\begin{array}{l}\text { Powder-- } \\
\text { Confined in vessel or container, release } \\
\text { pressure }>0.17<3.5 \mathrm{MPa}_{\mathrm{g}}(25-500 \mathrm{psig})\end{array}$ & $\begin{array}{l}1 \mathrm{E}-1 \\
(0.5)\end{array}$ & 2 & USDOE 1994, Subsection 4.4.2.3.1 \\
\hline 3.3 .1 .13 & $\begin{array}{l}\text { Vitrified high-level-waste canisters, high } \\
\text { pressure sufficient to dislodge the plug }\end{array}$ & $\begin{array}{l}3 \mathrm{E}-5 \\
(0.7)\end{array}$ & 3 & $\begin{array}{l}\text { USDOE 1994, Subsection 4.3.1.1 } \\
\text { [Based on a measured value of 3.5E-4 of inventory as particles in } \\
\text { the upper plenum of canister and ARF/RF of } 1 \mathrm{E}-1 / 0.7 \text { ] }\end{array}$ \\
\hline
\end{tabular}


Table 3-1. Bounding ARFs and Applicable Experimentally Measured RFs ${ }^{2}$ (Continued)

\begin{tabular}{|c|c|c|c|c|}
\hline \multicolumn{2}{|c|}{ Stress/Material $\quad, \quad \therefore \quad \therefore \quad \therefore \quad \therefore$} & $A R F(R F)^{b}$ & TSLC & References and Comments \\
\hline \multicolumn{5}{|c|}{ THERMAL STRESS } \\
\hline \multicolumn{2}{|c|}{$\begin{array}{l}\text { 3.3.2.1, Volatile compounds } \\
\text { 3.3.2.2 }\end{array}$} & $\begin{array}{l}1 \mathrm{E}+0 \\
(1.0)\end{array}$ & 1 & $\begin{array}{l}\text { Brereton, et al. } 1995 \\
\text { [APAC Spills Report] }\end{array}$ \\
\hline \multirow[t]{2}{*}{ 3.3.2.3 } & $\begin{array}{l}\text { Liquid, aqueous solutions-- } \\
\text { a. Simmering, no visible bubbles }\end{array}$ & $\begin{array}{l}3 \mathrm{E}-5 \\
\left(\mathrm{RF} \mathrm{NVA}^{\mathrm{d}}\right)\end{array}$ & 2 & USDOE 1994, Subsection 3.2.1.1 \\
\hline & b. Boiling & $\begin{array}{l}2 \mathrm{E}-3 \\
\left(\text { RF NVA }^{d}\right)\end{array}$ & 1 & $\begin{array}{l}\text { Mishima, et al. 1968; Borkowski, et al. 1986; Kataoka and Ishii } \\
\text { 1983; USDOE 1994, Subsection 3.2.1.3 }\end{array}$ \\
\hline 3.3.2.4 & $\begin{array}{l}\text { Liquid, organic combustible-- } \\
\text { Volatile compounds dissolved in organic } \\
\text { liquid }\end{array}$ & $\begin{array}{l}1 E+0 \\
\left(R F N V A^{d}\right)\end{array}$ & 2 & USDOE 1994, Subsections $3.3 .1 ; 3.3 .7$ \\
\hline \multirow[t]{3}{*}{ 3.3.2.5 } & $\begin{array}{l}\text { Liquid, organic combustible-- } \\
\text { a. Non-volatile compounds, burns to self- } \\
\text { extinguishment, no significant surface } \\
\text { turbulence }\end{array}$ & $\begin{array}{l}1 \mathrm{E}-2 \\
(\mathrm{RFNVA})\end{array}$ & 2 & USDOE 1994, Subsections 3.3.1; 3.3.7 \\
\hline & $\begin{array}{l}\text { b. Non-volatile compounds, vigorous } \\
\text { burning with surface turbulence, burns to } \\
\text { self-extinguishment }\end{array}$ & $\begin{array}{l}3 \mathrm{E}-2 \\
\left(\mathrm{RF} N \mathrm{NA}^{\mathrm{d}}\right)\end{array}$ & 2 & USDOE 1994 , Subsections $3.3 .3 ; 3.3 .4 ; 3.3 .5 ; 3.3 .7$ \\
\hline & $\begin{array}{l}\text { c. Non-volatile compounds, vigorous } \\
\text { burning with surface turbulence, to complete } \\
\text { dryness }\end{array}$ & $\begin{array}{l}1 \mathrm{E}-1 \\
\left(\mathrm{RF} N \mathrm{NA}^{\mathrm{d}}\right)\end{array}$ & 2 & USDOE 1994, Subsections $3.3 .3 ; 3.3 .7$ \\
\hline \multirow[t]{2}{*}{ 3.3.2.6 } & $\begin{array}{l}\text { Liquid, organic combustible-- } \\
\text { a. Burning of combustible liquid over air- } \\
\text { dried residue from solution on porous, non- } \\
\text { heat-conducting surface }\end{array}$ & $\begin{array}{l}5 \mathrm{E}-3 \\
(0.4)\end{array}$ & 2 & USDOE 1994, Subsections 3.3.6; 3.3.7 \\
\hline & $\begin{array}{l}\text { b. Burning of combustible liquid over air- } \\
\text { dried residue from solution on heat- } \\
\text { conducting surface }\end{array}$ & $\begin{array}{l}2 \mathrm{E}-1 \\
(0.3)\end{array}$ & 2 & USDOE 1994, Subsections 3.3.6; 3.3.7 \\
\hline
\end{tabular}


Table 3-1. Bounding ARFs and Applicable Experimentally Measured RFs" (Continued)

\begin{tabular}{|c|c|c|c|c|}
\hline \multicolumn{2}{|c|}{ Stress/Material } & \multirow{2}{*}{$\begin{array}{l}\text { ARF }(R F)^{b} \\
3 E-5 \\
(0.04)\end{array}$} & \multirow{2}{*}{$\frac{\mathrm{TSE}^{\mathrm{c}}}{2}$} & \multirow{2}{*}{$\frac{\text { References and Comments }}{\text { USDOE } 1994, \text { Subsection 4.2.1.1.2 }}$} \\
\hline 3.3.2.7 & $\begin{array}{l}\text { Solid reactive metal-- } \\
\text { a. Plutonium, }<\text { ignition temperature }{ }^{1} \text { of } \\
\text { oxide formed }\end{array}$ & & & \\
\hline & b. Plutonium, > ignition temperature ${ }^{1}$ & $\begin{array}{l}5 \mathrm{E}-4 \\
(0.5)\end{array}$ & 1 & $\begin{array}{l}\text { Mishima 1965, 1966; Luna 1994; Carter and Stewart 1970; } \\
\text { Eidson, et al. 1988; Eidson and Kanapilly 1983; USDOE 1994, } \\
\text { Subsection 4.2.1.1.3 }\end{array}$ \\
\hline & $\begin{array}{l}\text { c. Plutonium, free-fall spill of molten metal } \\
\text { into air, small fall distance }\end{array}$ & $\begin{array}{l}\text { 1E-2 } \\
(\text { RF NVA })\end{array}$ & 2 & Stewart 1963; USDOE 1994, Subsection 4.2.1.1.4 \\
\hline & $\begin{array}{l}\text { d. Plutonium, small drops of molten metal } \\
\text { violently dispersed that travel greater than } 1 \\
\mathrm{~m} \text { in air }\end{array}$ & $\begin{array}{l}1 E+0 \\
(0.5)\end{array}$ & 1 & $\begin{array}{l}\text { Raabe, et al. 1978; Chatfield 1969; USDOE 1994, Subsection } \\
\text { 4.2.1.1.5 }\end{array}$ \\
\hline 3.3.2.8 & $\begin{array}{l}\text { Solid reactive metal-- } \\
\text { a. Uranium, less than ignition temperature }{ }^{\mathrm{m}} \text {, } \\
>500^{\circ} \mathrm{C}\left(902^{\circ} \mathrm{F}\right)\end{array}$ & $\begin{array}{l}\mathrm{ARFxRF}= \\
1 \mathrm{E}-3\end{array}$ & 2 & USDOE 1994, Subsection 4.2.1.2.1 \\
\hline & $\begin{array}{l}\text { b. Uranium, free-fall spill of molten metal } \\
\text { greater than } 1 \mathrm{~m}(3.28 \mathrm{ft})\end{array}$ & $\begin{array}{l}1 \mathrm{E}-2 \\
\left(\mathrm{RFNVA}^{\mathrm{d}}\right)\end{array}$ & 2 & USDOE 1994, Subsection 4.2.1.2.2 \\
\hline & $\begin{array}{l}\text { c. Uranium, explosive dispersal of thin } \\
\text { sheets of metal }\end{array}$ & $\begin{array}{l}1 \mathrm{E}+0 \\
\left(\mathrm{RF} N \mathrm{NA}^{\mathrm{d}}\right)\end{array}$ & 2 & USDOE 1994, Subsection 4.2.1.2.3 \\
\hline 3.3.2.9 & $\begin{array}{l}\text { Concrete-- } \\
\text { a. Tritium }\left({ }^{3} \mathrm{H}\right) \text { as water, }>20^{\circ} \mathrm{C} \text { to } 200^{\circ} \mathrm{C} \\
\left(>68^{\circ} \mathrm{F} \text { to } 392^{\circ} \mathrm{F}\right)\end{array}$ & $\begin{array}{l}5 \mathrm{E}-1 \\
(1.0)\end{array}$ & 2 & USDOE 1994, Subsection 4.3.1.2 \\
\hline & $\begin{array}{l}\text { b. }{ }^{3} \mathrm{H} \text { as water, }>200^{\circ} \mathrm{C} \text { to } 600^{\circ} \mathrm{C}(>392 \\
\left.{ }^{\circ} \mathrm{F} \text { to } 1100^{\circ} \mathrm{F}\right)\end{array}$ & $\begin{array}{l}1 \mathrm{E}+0 \\
(1.0)\end{array}$ & 2 & $\begin{array}{l}\text { USDOE 1994, Subsection } 4.3 .1 .2 \\
\text { [May also suspend radionuclides present if cement is } \\
\text { decomposed and particles of } \mathrm{CaO} \text { can be suspended.] }\end{array}$ \\
\hline 3.3.2.10 & $\begin{array}{l}\text { Solid, powder-- } \\
\text { a. Nonreactiven, up to } 1000^{\circ} \mathrm{C}\left(1830^{\circ} \mathrm{F}\right) \text {, } \\
\text { upflow around powder to } 100 \mathrm{~cm} / \mathrm{s}(3.28 \\
\mathrm{ft} / \mathrm{sec})\end{array}$ & $\begin{array}{l}6 \mathrm{E}-3 \\
(0.01)\end{array}$ & 2 & USDOE 1994, Subsection 4.4.1.1 \\
\hline
\end{tabular}


Table 3-1. Bounding ARFs and Applicable Experimentally Measured RFs ${ }^{2}$ (Continued)

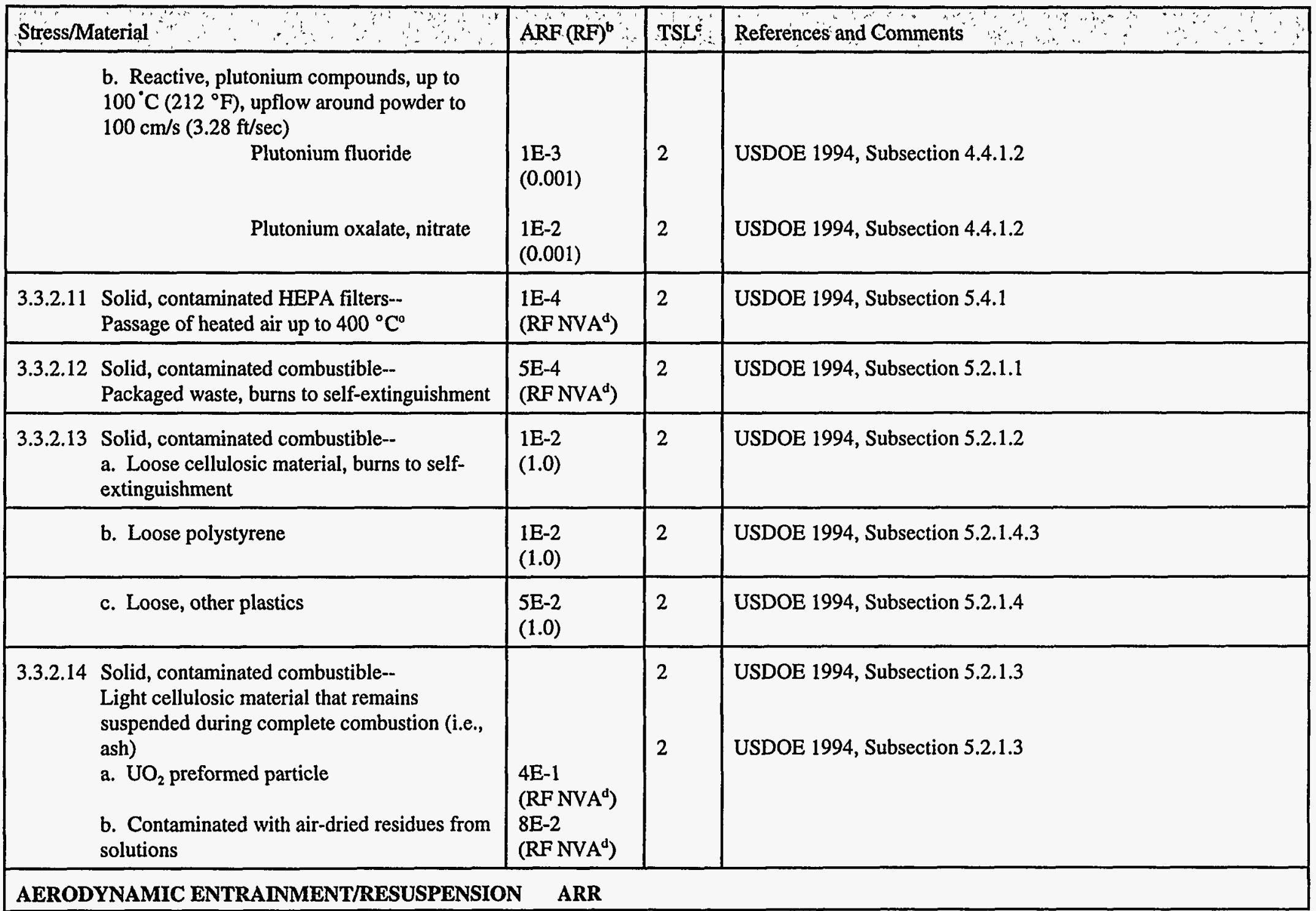


Table 3-1. Bounding ARFs and Applicable Experimentally Measured RFs ${ }^{\mathbf{a}}$ (Continued)

\begin{tabular}{|c|c|c|c|c|}
\hline \multicolumn{2}{|c|}{ Stress/Material } & \multirow{2}{*}{$\begin{array}{l}\text { ARF }(R F)^{b} \\
4 E-7 / h r(R F \\
\left.N^{b} A^{d}\right)\end{array}$} & \multirow{2}{*}{\begin{tabular}{|l}
$\mathrm{TSL}$ \\
3
\end{tabular}} & \multirow{2}{*}{$\frac{\text { References and Comments }}{\text { USDOE 1994, Subsection 3.2.4.5 }}$} \\
\hline 3.3.3.1 & $\begin{array}{l}\text { Homogenous deposit, liquid, indoors-- } \\
\text { a. Liquid, indoors, shallow pool on } \\
\text { heterogeneous surface (e.g., stainless steel, } \\
\text { glass, concrete), normal building ventilation } \\
\text { flow/low airspeed }(<2 \mathrm{~m} / \mathrm{s}, \sim 5 \mathrm{mph})\end{array}$ & & & \\
\hline & $\begin{array}{l}\text { b. Liquid, indoors, as above, covered with } \\
\text { substantial layer of debris or indoor static } \\
\text { conditions }\end{array}$ & $\begin{array}{l}4 \mathrm{E}-8 / \mathrm{hr} \\
\left(\mathrm{RFNVA}^{\mathrm{d}}\right)\end{array}$ & 3 & USDOE 1994, Subsection 3.2.4.5 \\
\hline 3.3.3.2 & $\begin{array}{l}\text { Homogenous deposit, liquid, outdoors-- } \\
\text { Liquid, outdoors, large pool, airspeed across } \\
\text { surface up to } 13.6 \mathrm{~m} / \mathrm{s}(\sim 30 \mathrm{mph})\end{array}$ & $\begin{array}{l}4 \mathrm{E}-6 / \mathrm{hr} \\
\left(\mathrm{RF} \mathrm{NVA}^{\mathrm{d}}\right)\end{array}$ & 3 & USDOE 1994, Subsection 3.2.4.5 \\
\hline 3.3.3.3 & $\begin{array}{l}\text { Heterogeneous deposit-. } \\
\text { Liquid, outdoors, absorbed on soil, no large } \\
\text { standing pools of free liquid, up to } 22.7 \mathrm{~m} / \mathrm{s} \\
(\sim 50 \mathrm{mph})\end{array}$ & $\begin{array}{l}\text { 9E-5/hr } \\
\left(\mathrm{RF} \mathrm{NVA}^{\mathrm{d}}\right)\end{array}$ & 2 & USDOE 1994, Subsection 3.2.4.4 \\
\hline 3.3.3.4a & $\begin{array}{l}\text { Heterogenous deposit, powder, indoors-- } \\
\text { Powder, pile on heterogeneous surface (e.g., } \\
\text { concrete, stainless steel, glass), normal } \\
\text { building ventilation flow/slow airspeed } \\
(<2 \mathrm{~m} / \mathrm{s}, \sim 5 \mathrm{mph})\end{array}$ & $\begin{array}{l}4 \mathrm{E}-5 / \mathrm{hr} \\
\left(\mathrm{RF} \mathrm{NVA}^{\mathrm{d}}\right)\end{array}$ & 3 & USDOE 1994, Subsection 4.4.4.1 \\
\hline 3.3.3.4b & $\begin{array}{l}\text { Heterogenous deposit, powder, outdoors-- } \\
\text { Powder, indoors, as above covered with } \\
\text { substantial layer of debris or indoor static } \\
\text { conditions }\end{array}$ & $\begin{array}{l}4 \mathrm{E}-6 / \mathrm{hr} \\
\left(\mathrm{RF} \mathrm{NVA}^{\mathrm{d}}\right)\end{array}$ & 3 & USDOE 1994, Subsection 4.4.4.1 \\
\hline 3.3.3.5 & $\begin{array}{l}\text { Powder, outdoors, from the passage of } \\
\text { vehicular traffic across or near loose powder } \\
\text { on road, up to } 22.7 \mathrm{~m} / \mathrm{s}(\sim 50 \mathrm{mph})\end{array}$ & $\begin{array}{l}1 \mathrm{E}-2 / \text { pass } \\
\left(\mathrm{RF} \mathrm{NVA}^{\mathrm{d}}\right)\end{array}$ & 2 & USDOE 1994, Subsection 4.4.4.2 \\
\hline 3.3.3.6 & $\begin{array}{l}\text { Powder, dispersed into flowing air, airspeed } \\
\text { up to } 9.1 \mathrm{~m} / \mathrm{s}(\sim 20 \mathrm{mph})\end{array}$ & $\begin{array}{l}\text { See footnote } \\
\text { p. }\end{array}$ & 2 & USDOE 1994, Subsection 4.4.3.2 \\
\hline
\end{tabular}


Table 3-1. Bounding ARFs and Applicable Experimentally Measured RFs ${ }^{\mathrm{a}}$ (Continued)

\begin{tabular}{|c|c|c|c|c|}
\hline \multicolumn{2}{|c|}{ Stress/Material } & ARF $(R F)^{b}$ & TSLC & References and Comments \\
\hline \multicolumn{5}{|c|}{ MECHANICAL STRESS } \\
\hline \multirow[t]{3}{*}{ 3.3.4.2 } & $\begin{array}{l}\text { Free-fall spill, aqueous liquids-- } \\
\text { a. Liquid, aqueous solution, spill distance } \\
<3 \mathrm{~m}(3.28 \mathrm{ft})\end{array}$ & $\begin{array}{l}2 \mathrm{E}-4 \\
(0.4)\end{array}$ & 2 & USDOE 1994, Subsection 3.2.3.1 \\
\hline & $\begin{array}{l}\text { b. Liquid, slurry, }<40 \text { percent solids, spill } \\
\text { distance }<3 \mathrm{~m}(\sim 10 \mathrm{ft})\end{array}$ & $\begin{array}{l}5 \mathrm{E}-5 \\
(0.8) \\
\end{array}$ & 2 & USDOE 1994, Subsection 3.2.3.2 \\
\hline & $\begin{array}{l}\text { c. Liquid, viscous solution, spill distance } \\
<3 \mathrm{~m}(\sim 10 \mathrm{ft})\end{array}$ & $\begin{array}{l}7 \mathrm{E}-6 \\
(0.8)\end{array}$ & 2 & USDOE 1994, Subsection 3.2.3.3 \\
\hline 3.3.4.3 & $\begin{array}{l}\text { Free-fall spill, aqueous liquids-- } \\
\text { Liquid, spill distance }>3 \mathrm{~m}(\sim 10 \mathrm{ft})\end{array}$ & $\begin{array}{l}\text { See cited } \\
\text { reference. }\end{array}$ & 2 & USDOE 1994, Subsection 3.2.3.1 \\
\hline 3.3.4.4 & Powder, spill distance $<3 \mathrm{~m}(\sim 10 \mathrm{ft})$ & $\begin{array}{l}2 \mathrm{E}-3 \\
(0.3)\end{array}$ & 1 & $\begin{array}{l}\text { Sutter, et al. 1981a, b; Ballinger, et al. 1986; Plinke, et al. 1991; } \\
\text { USDOE 1994, Subsection 4.4.3.1.2 }\end{array}$ \\
\hline 3.3.4.5 & Powder, spill distance $>3 \mathrm{~m}(\sim 10 \mathrm{ft})$ & $\begin{array}{l}\text { See cited } \\
\text { reference. }\end{array}$ & 2 & USDOE 1994 , Subsection 4.4.3.1.3 \\
\hline 3.3.4.6a & $\begin{array}{l}\text { HEPA filter, object strikes encased }{ }^{4} \text { filter or } \\
\text { encased filter impacts unyielding surface } \\
\text { after fall }\end{array}$ & $\begin{array}{l}5 E-4 \\
(\text { RF NVA })\end{array}$ & 3 & USDOE 1994, Subsection 5.4.4.1 \\
\hline $3.3 .4 .6 \mathrm{~b}$ & $\begin{array}{l}\text { HEPA filter, object strikes unencased filter or } \\
\text { unencased filter impacts unyielding surface } \\
\text { after fall }\end{array}$ & $\begin{array}{l}1 \mathrm{E}-2 \\
\left(\mathrm{RFNVA}^{\mathrm{d}}\right)\end{array}$ & 3 & USDOE 1994, Subsection 5.4.4.2 \\
\hline 3.3.4.7 & Crush/impact, glass & $\begin{array}{l}\text { See cited } \\
\text { reference \& } \\
\text { footnote s. }\end{array}$ & 2 & USDOE 1994, Subsection 4.3 .3 \\
\hline 3.3.4.8 & Crush/impact, aggregate & $\begin{array}{l}\text { See cited } \\
\text { reference \& } \\
\text { footnote t. }\end{array}$ & 2 & Owczarski and Mishima 1996 \\
\hline
\end{tabular}


Table 3-1. Bounding ARFs and Applicable Experimentally Measured RFs" (Continued)

\begin{tabular}{|c|c|c|c|}
\hline Stress/Material & ARF $(\mathrm{RF})^{\mathrm{b}}$ & TSL $^{c}$ & References and Comments \\
\hline 3.3.4.10 a. Spent nuclear fuel, noble gases & $7 \mathrm{E}-2^{\mathrm{u}}$ & 2 & $\begin{array}{l}\text { Ruhmann, et al. 1985c } \\
\text { [For the degree of fragmentation in experimental program] }\end{array}$ \\
\hline b. Spent nuclear fuel, iodine $\left(\mathrm{I}_{2}\right)$ & $2 \mathrm{E}-3$ & 2 & Ruhmann, et al. $1985 \mathrm{c}$ \\
\hline $\begin{array}{l}\text { c. Spent nuclear fuel, }{ }^{3} \mathrm{H} \text { (as HTO, Tritiated } \\
\text { water) }\end{array}$ & $1 \mathrm{E}-2$ & 2 & Ruhmann, et al. $1985 \mathrm{c}$ \\
\hline d. Spent nuclear fuel, fines & $\begin{array}{l}2 \mathrm{E}-4 \\
(\mathrm{ARF} \times \mathrm{RF}= \\
8 \mathrm{E}-7)\end{array}$ & 2 & 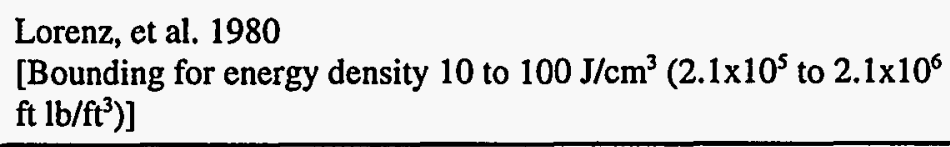 \\
\hline $\begin{array}{l}\text { 3.3.4.11 Encapsulated ceramic oxide pellets, particles } \\
\text { generated but not released, impact velocities } \\
\text { of steel to } 85 \mathrm{~m} / \mathrm{s}(188 \mathrm{mph}) \text {, concrete to } 45 \\
\mathrm{~m} / \mathrm{s}(99 \mathrm{mph}) \text {, and soil to } 250 \mathrm{~m} / \mathrm{s} \text { (550 mph) }\end{array}$ & $\begin{array}{l}5 \mathrm{E}-3 \\
(0.6)\end{array}$ & 2 & Mishima 1995 \\
\hline $\begin{array}{ll}\text { 3.3.4.12a } & \text { Shock/vibration-- } \\
& \text { Loose surface contamination }\end{array}$ & $\begin{array}{l}1 \mathrm{E}-3 \\
(0.3)\end{array}$ & 2 & USDOE 1994, Subsection 4.4.3.3.1 \\
\hline 3.3.4.12b Powder, shock-impact from falling debris & $\begin{array}{l}1 \mathrm{E}-2 \\
(0.1)\end{array}$ & 2 & USDOE 1994, Subsection 4.4.3.3.2 \\
\hline
\end{tabular}


Table 3-1. Bounding ARFs and Applicable Experimentally Measured RFs ${ }^{\mathrm{a}}$ (Continued)

\begin{tabular}{|c|c|c|c|}
\hline Stress/Material & $A R F(R F)^{6}$ & TSLC & Rẹerences and Comments \\
\hline \multicolumn{4}{|c|}{ RULE OF THUMB ESTIMATES OF TOTAL FISSIONS FROM INADVERTENT NUCLEAR CRITICALITIES } \\
\hline $\begin{array}{l}\text { Solutions Systems, greater than } 379 \text { liters (100 gal) } \\
\text { Solutions Systems, less than } 379 \text { liters (100 gal) } \\
\text { Solid Metal Systems } \\
\text { Powder Systems } \\
\text { Large Storage Arrays }\end{array}$ & $\begin{array}{l}1 \mathrm{E}+19 \\
\text { fissions } \\
1 \mathrm{E}+18 \\
\text { fissions } \\
1 \mathrm{E}+18 \\
\text { fissions } \\
1 \mathrm{E}+17 \\
\text { fissions } \\
1 \mathrm{E}+20 \\
\text { fissions }\end{array}$ & 1 & See Section 3.4. \\
\hline
\end{tabular}

$\stackrel{\omega}{\circ}$ 
Table 3-1. Bounding ARFs and Applicable Experimentally Measured RFs (Continued)

\section{Footnotes for Table 3-1}

* Refers to sections in this report.

a. For abbreviations and symbols in this Table, refer to the List of Symbols and the List of Acronyms, Abbreviations and Names at the front of this report.

b. Particles in the respirable size range of initial inventory made airborne, provided that this value does not exceed the fraction of particles in this size range in the source material.

c. TSL: Technical Support Level. 1 - supported by experimental data from more than one independent source of the stated range with experimental support for particle generation mechanism. 2 - experimental support over that stated range. 3 - single experimental datum or inferred from other studies.

d. NVA - No value currently available.

e. Boughton, B.A., and M.E. Kipp, "Private Communication," 1996.

f. A very conservative estimate of mass airborne in respirable size range $\left(10 \mu \mathrm{m}\right.$ aerodynamic equivalent diameter (AED) $\left(3.9 \times 10^{-4}\right.$ in)) is equal to the TNT Equivalent calculated for the explosion.

g. RF for these events cannot exceed the fraction of particles in source material.

h. Absorption and equilibration of gases in liquids is a function of the chemical composition of the solution, the surface area and depth of the liquid, and the volume of gas. Equilibrium may take minutes to hours, depending on conditions.

i. ARF and RF have no values available. Therefore, there is no TSL (Technical Support Level).

j. Generation of RF liquid droplets can be greater than the values shown here that bound round, knife-edge orifices of $0.3-\mathrm{cm}(0.125$-in) diameter and greater with upstream pressures up to $1.38 \mathrm{Mpa}_{\mathrm{g}}(200 \mathrm{psig})$. The "worst-case" for RF droplets of solutions is a crack $50 \mu \mathrm{m}(0.002 \mathrm{in})$ wide. The longer the length, the more liquid that can be vented for a given upstream pressure. This type of crack is not a common or typical occurrence for faults in pipes or vessels and, at higher pressure, would probably propagate into a wider, longer crack.

k. Only applies to bubbly flow (distinct bubbles $<30$ percent liquid in form of bubbles). Does not apply to churn turbulent or chaotic boiling regimes. 


\section{Footnotes for Table 3-1 (Continued)}

1. Ignition temperature for plutonium metal is a function of surface to mass ratio (S:M). At S:M of $100 \mathrm{~cm}^{2} / \mathrm{g}\left(\sim 7000 \mathrm{in}^{2} / \mathrm{lb}\right)$, the measured ignition temperature for plutonium metal is about $160^{\circ} \mathrm{C}$. The ignition temperature rises rapidly when S:M is lower than $10 \mathrm{~cm}^{2} / \mathrm{g}(\sim 700 \mathrm{in} / \mathrm{lb})$ and ranges from 480 to $520^{\circ} \mathrm{C}\left(896\right.$ to $\left.968^{\circ} \mathrm{F}\right)$ for bulk pieces.

m. Like plutonium, the ignition temperature for uranium metal is a function of the surface to mass ratio (S:M). At S:M of $100 \mathrm{~cm}^{2} / \mathrm{g}(\sim 7000 \mathrm{in} / \mathrm{b})$, the uranium ignition temperature is in the range of 200 to $300^{\circ} \mathrm{C}\left(392\right.$ to $\left.572{ }^{\circ} \mathrm{F}\right)$. Like plutonium, it rises rapidly in the region lower than $S: M 10$ $\mathrm{cm}^{2} / \mathrm{g}\left(\sim 700 \mathrm{in}^{2} / \mathrm{lb}\right)$ and reaches temperatures in excess of $700^{\circ} \mathrm{C}\left(\sim 1300^{\circ} \mathrm{F}\right)$. There is some doubt that bulk pieces of uranium can attain ignition conditions except for very special circumstances.

n. Does not react chemically to change form under accident conditions postulated.

o. Assumes HEPA filter medium, glass fiber, softens and melts if subjected to higher temperatures and will retain particles accumulated on the fiber surfaces.

p. $A R F=0.0134[U]+0.00543$, where $U$ is local windspeed in $\mathrm{m} / \mathrm{s}$.

q. Encased denotes a container that does not fail because of impact of falling objects or on impact with unyielding surfaces after fall of the container.

r. Loose surface contamination that can be removed by swiping or low airspeeds, such as blowing across the deposit.

s. Formula for crush-impact forces on brittle solids is shown on p. 4-52 of USDOE (1994). For vitrified HLW, the empirical correlation $2 \mathrm{E}-1\left[\mathrm{~J} / \mathrm{cm}^{3}\right]\left(0.0012\left[\mathrm{Btu} / \mathrm{in}^{2}\right]\right)$ shown is applicable. The user should be cautious in application of this formula, since the value calculated is an energy density applied to the material. If the Crush-Impact force is applied to all the material, the energy density is simply the force/volume. If the Crush-Impact force is only applied to a part of the object (e.g., the object with mass and density only impacts a portion of the surface of the brittle material), the formula only applies to the volume that undergoes crush.

t. For aggregate materials such as cement, sandstone, etc., the correlation factor for use in the formula on p 4-52 of USDOE (1994) is 3E-11.

u. For spent nuclear fuel, the empirical correlation is found in the NRC Safeguards Report (Kent, et al. 1995). 
Section 3.2.4 contains a summary of methods for calculating source terms. A number of computer models are described, including HOTSPOT, EXPAC, FIRIN/FIRAC, and KBERT. This is followed by a discussion of the well known five-factor formula, which is often used as the basis for the hand calculation of source terms. This then goes into Section 3.3, which, as has already been stated, contains many Subsections that provide the technical basis for the ARFs, ARRs, and RFs in Table 3-1.

Section 3.4 contains a summary of information and sources of information on criticality.

Section 3.5 contains a summary of source terms for releases of hazardous chemicals. This section is quite short because much of the Handbook's material on chemical reactions has been incorporated into Appendix B.

References are presented in Section 3.6.

\subsubsection{Background}

The nuclear industry has evaluated the potential downwind impacts of the release of radionuclides almost since its inception in the 1950s. Safety analyses have been performed on postulated severe accident scenarios. The scenarios generally addressed the potential release of radionuclides for what was considered an "upper bound" for the facility. Since many of the facilities in the then-Atomic Energy Commission (then-AEC) complex were sited in remote locations and the facilities were considered to be resistant to most operational accident stresses, the approach was not rigorous, and the results were more a "maximum tolerable" release.

With the advent of commercial enterprises that did not have the luxury of such an approach (many were sited much nearer the general population), use of the same techniques often indicated unacceptable consequences simply because of the gross overestimation of the various factors (including ARFs) that contribute to the airborne release of radionuclides from facilities.

Even with government facilities, many techniques and approaches have been applied to the estimate of the potential downwind impacts. The many approaches often resulted in divergent estimates of the downwind impacts from a very similar or the same postulated event. There was a clear need for standard approaches and techniques.

The potential downwind impacts are evaluated using the amount and characteristics of the airborne release of the material-of-concern (both radionuclides and hazardous materials) with various physicochemical properties, in response to specific postulated accident stresses. The complexity of the actual situations precludes analytical determination of the ARFs. The experimental data are from experimentally measured airborne releases of the specific material (such as plutonium and uranium) or from physically similar materials (e.g., liquids, powders, contaminated combustibles) under the types and level of stress induced by the event. The factors estimate the amount and characteristics of the material-of-concern made airborne by a specific type of stress (e.g., thermal, aerodynamic, mechanical) and level of stress imposed over a given time-frame (e.g., seconds for explosive generated pressures, minutes to hours for a fire, potentially over very long periods of time for aerodynamic stress) and their applicability is limited to the range covered in the experimental study. Experimental data are limited for some of the initiator-response sequences, and values are also inferred from other experimental studies that appear to impose the same type and level of stress on similar materials. As the need arises, additional data and information may be generated to improve/revise the ARFs. But actual accidents are unique events involving physical and 
chemical conditions that cannot be accurately defined in advance, and it would be misleading to leave the impression that estimates of the potential impacts based upon analyses can accurately predict impacts for any actual accident. Therefore, ARFs must be viewed as tools to provide a reasonable estimate of airborne release, but, because of the lack of accuracy in defining the response and behavior of other components of the calculations, highly accurate ARFs do not provide highly accurate estimates of airborne release for an actual accident. The estimates do provide a basis for testing the need for and performance of safety systems and emergency response measures and for findings on protection of public health and safety.

\subsubsection{Particle Size and Aerosol Physics Considerations in Consequence Assessments}

Hazardous materials (toxic chemicals and radioactive materials) exist in all physical forms. For radioactive materials, airborne solids generally constitute the more significant acute hazard. For material in solid forms to constitute a challenge for uptake, the materials must be transported to the receptor. Immediately following the event, solid materials must be in the form of particles (an aerosol, a quasi-stable concentration of particles in a gaseous medium) that can be transported by the ambient flow field to the receptor and be inhaled. For the most serious inhalation challenge, material such as the transuranic elements must be deposited in the deep lung. Pre-formed particles such as powder are already in particulate form and only require separation and suspension to be susceptible to transport by the ambient flow field. Other solids must be fragmented and suspended. Fragmentation normally requires that more energy be inserted into the material than for separation and suspension. There is a range of sizes of particles that can be transported under typical ambient atmospheric conditions to a receptor some distance from the source $(>0.5$ to $1 \mathrm{~km}$ ), be inhaled, and carried to the deep lung. For the purposes of these analyses, this range is designated as the $R F$ and is assumed to consist of particles $10 \mu \mathrm{m}$ aerodynamic equivalent diameter (AED, $\mathrm{D}_{\mathrm{AED}} \leq 10 \mu \mathrm{m}(0.00039$ in) ) and less.

The RF of airborne material is controlled by the initial subdivision, the type and level of the suspension mechanism, and the flow. A default value of 1.0 can be assumed for those situations where there are no data on the response of the material to the initiating event. In the case of a powder suspended by a mechanism that does not result in further fragmentation of the physical form (almost all the categories of suspension mechanisms considered here fall into this category), the default RF is the RF of the source powder. Measured RF values for the material form under consideration can also be applied, if known, under these circumstances.

The values for ARF and RF cited in the sample problems in Appendix $D$ are taken from experimental studies that use specific materials and types and levels of stress. Each specific material has characteristics that are influenced by the type and level of stress imposed, resulting in the separation and suspension of the material. Both the characteristics of the material and type/level of stress affect the airborne release. The ambient airflow around the suspended material affects transport.

Thus, specific values of ARF and RF must be chosen with great care. In many cases, where the material is inert to the chemical environment, the ARF can be representative of the ARF for all similar physical materials. Such is the case for suspension of chemically-inert compounds in powder form by aerodynamic forces at normal temperatures and for the fragmentation of brittle materials by crush-impact forces. In other cases, such as the generation of volatile materials from chemical reactions (e.g., iodine generation), the ARF is sensitive to the chemical and physical environment and is not directly applicable to other volatile materials. Even droplets of aqueous solution can be modified by the environment they are suspended in by the effects of evaporation or the condensation of the solvent during airborne transport. 
The release mechanisms are also different for differing combinations of materials and stress. Pre-formed particles (powders) under aerodynamic stress behave differently, depending upon whether the material is a pile that projects into the flow field, forms a smooth layer within the boundary layer on a heterogenous substrate, a sparse layer, or a homogeneous layer.

The value selected for the ARF must be based on the combination of material characteristics and type and level of stress. The type and level of stress are typically determined by the postulated scenario and the postulated/calculated behavior of the other materials involved (e.g., fire, explosion, earthquake, high winds, process malfunction). On a "worst-case" basis with little analysis of the behavior of materials, equipment, or structures, "bounding" calculations are appropriate. In these cases, the physical limits of the materials are used, such as the total heat of combustion expressed as a trinitrotoluene (TNT) equivalent for explosions. Bear in mind that the TNT equivalents so estimated for gaseous mixtures or for non-explosive solids may be gross exaggerations of the conditions. Nonetheless, if the calculated values for the level of stress are within the bounds of the experimental data, the ARFs and RFs can be applied to physically similar materials.

For more detailed calculations of the potential airborne release, analysis of the limiting parameters and systems (e.g., barriers, oxygen availability for fires, rupture pressure for pressurevolume/overpressurization events) and the responses of materials, barriers, and equipment to the type and level of stress imposed must also be considered. Where experimental data for the material-of-concern and the stress combination are available, the data may be interpolated to provide a closer estimate of airborne release. If the material-of-concern is chemically/physically similar to the materials used in the experimental study, such interpolated results may also be applicable. If the material-of-concern is dissimilar, the level of stress exceeds the range used in the experimental study, or the material-of-concern or type of stress has not been studied, the user should be aware that such extensive engineering studies are of little benefit without experimental data to provide more realistic estimates. In some cases, where experimental studies have used materials with similar characteristics but have deviations that would produce conservative estimates in the specific case addressed (e.g., a finer size distribution of a dry, cohesionless, powder is used in the experimental study), an interpolation could be applicable.

It follows that extrapolation of the results from experimental studies must be approached with great caution. If the release mechanism is known and does not change over the range of interest, extrapolation of the experimental data may be useful (e.g., fragmentation of brittle solids by crush-impact forces), but all parameters that affect the results must be considered. In the example cited, fragmentation of brittle solids by crush-impact forces, both the physical characteristics of the impacted material and the configuration, are important. In the experimental studies, all the brittle materials were subjected to crush-impact forces by ensuring that the plate applying the force covered the entire surface of one side of the specimen. The fragmentation and size distribution of the fragments are a function of the energy density applied per unit volume/mass. For the configuration where the impacting object covers less than the entire surface, the question of the volume impacted must be determined (the volume in which the shock/pressure wave propagates and is reflected through the material to result in fragmentation).

An additional consideration for particles is the size distribution. This affects both the suspension and transport of the suspended materials. Under most circumstances, the particle size unit associated with a measurement is a function of the technique/instrument and the particle characteristic used to evaluate the size. There are different units for different characteristics. For example, one unit often encountered is the Geometric Diameter $\left(\mathrm{D}_{\mathrm{g}}\right)$ of a particle. The Geometric Diameter is the linear diameter (in $\left.\mu \mathrm{m}\right)$ of the particle. But, if the technique employed to measure the size is optical-or electron-microscopy, the 
characteristic measured is projected diameter (the circle equivalent in area to the cross-section of the particle viewed). The technique cannot measure the dimension normal to the viewing area (the depth of the particle), nor the cross-sections at other levels of the particle.

Another form of Geometric Diameter is determined by sieving--the Least Linear Diameter, the smallest cross-sectional area of the particle, that will pass through the sieve mesh.

Optical spectroscopy also gives a form of projected diameter. Light reflected from the surface of the particle is compared with the amount of light reflected by known-sized spheres. The light reflected is dependent on its emissivity (i.e., color) and the characteristics of the surface (e.g., the number of facets or additional surfaces).

Mobility analyzers subject particles to a corona discharge, causing them to accept a single charge, and determine the size by the time to deposit the particle under a known magnetic field.

Techniques that employ aerodynamic characteristics of particles (e.g., various forms of a cascade impactor, liquid sedimentation at normal or accelerated speed) determine aerodynamic characteristics, and their unit is aerodynamic diameter $\left(D_{\mathrm{a}}\right)$. If the density of the particle is considered and the size normalized to a sphere with a density of $1 \mathrm{~g} / \mathrm{cm}^{3}$, the unit is Aerodynamic Equivalent Diameter $\left(D_{A E D}\right)$.

The unit of size used in this chapter is $D_{A E D}$ in micrometers $(\mu \mathrm{m})$. This is appropriate because both the airborne transport and inhalation are functions of the aerodynamic characteristics of the particle.

The size distribution of the airborne particles is a function of the formation process and the time airborne. When initially formed, particles are typically lognormally distributed, and their distribution can be defined by the aerodynamic mass median diameter (ammd) (the diameter of particle that separates the total mass of particles into two halves) and the geometric standard deviation ( $\sigma_{\mathrm{g}}$ or GSD).

The lognormal distribution function is given by:

$$
\frac{\mathrm{dm}}{\mathrm{dD}_{\mathrm{p}}}=\frac{1}{\mathrm{D}_{\mathrm{p}} \sqrt{2 \pi} \ln \left(\sigma_{\mathrm{g}}\right)} \exp \left[-\frac{\left(\ln \left(\mathrm{D}_{\mathrm{p}}\right)-\ln (\mathrm{DGM})\right)^{2}}{2\left(\ln \left(\sigma_{\mathrm{g}}\right)\right)^{2}}\right]
$$

where:

$$
\begin{aligned}
& \mathrm{m}=\text { mass fraction for a given particle diameter } \\
& \mathrm{D}_{\mathrm{p}}=\text { the particle diameter } \\
& \mathrm{DGM}=\text { the geometric mean diameter } \\
& \sigma_{\mathrm{g}}=\text { the geometric standard deviation }
\end{aligned}
$$

For radioactive materials, the Activity Median Aerodynamic Diameter (AMAD), the size above which half the activity is associated with particles of greater and lesser diameters, is a useful measure. Typically, the GSD is calculated by dividing the diameter (in micrometers) of the particle at the 84.13th percentile point on a $\log$ probability plot of the size distribution, by the diameter at the 50th percentile, or the diameter of the particle at the 50th percentile by the diameter at the 15.87 th percentile. These two estimates should be the same. The greater the difference, the greater is the deviation from the lognormal probability distribution. The GSD is a dimensionless number. 
The simple conversion of $D_{g}$ to $D_{A E D}$ is:

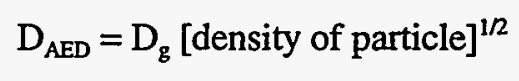

This conversion assumes that the original particle is a coherent solid in spherical form.

If preformed particles (powders) are suspended, the initial size distribution is altered by two factors-deagglomeration (separation of particle clusters into smaller clusters or the individual particles) of the powder and the amount of each size suspended under the specific conditions of airflow and surface characteristics. Particles at rest tend to stick together (agglomerate). The size of the clusters and the "stickiness" depend on such factors as their shape (number of points of contact between particles); size distribution (particles with a wide range of sizes can nestle together with time and fill much of the void space between particles); the physical environment (agglomeration with other particles such as soil that are part of the substrate, or particles may hide in the surface roughness, or moisture can condense between particles, increasing interparticle attraction); and the chemical characteristics of the compound (some compounds can soften or dissolve in the presence of condensed moisture and be bonded by the dried material on loss of moisture). Because of the small spaces between particles, it is often difficult to generate much force between the particles to separate them.

Once airborne, the particles are subject to the environment. Heavier particles (generally greater than $1 \mu \mathrm{m}$ $\left(3.9 \times 10^{-5}\right.$ in) AED) can settle because of the action of gravitational forces. Heavier particles also have momentum that results in inertial effects during changes in direction. Smaller particles (submicrometer particle) are affected by diffusion and electrostatic forces. Particles of all sizes tend to agglomerate; the larger the number of particles per unit volume, the greater the agglomeration rate. Thus, immediately on suspension, various forces begin to alter the size distribution. It is rare to find an airborne population of particles with a single size distribution without special circumstances. Typically, the size distributions observed for airborne materials are multi-modal (the airborne particles have several size distributions, depending on the forces that have acted upon the initial distribution released). Measured distributions that are multi-modal are discussed in Section 3.3.1.1.

For distributions that are composites of more than one particle size distribution, use of ammd and GSD may not provide the information necessary to ascertain the mass or radioactivity associated with the RF. Calculation of a single GSD is typically the average value of the distributions present and does not accurately describe the shape of the distribution curve. Thus, it may not correctly predict the mass associated with any specific range of particle sizes.

More complete coverage of aerosol physics can be found in many textbooks on the subject. Other useful references include Fuchs (1964), Hinds (1982), Hidy (1984), and NEA (1979).

\subsection{Determination of the Characteristics of Airborne Releases of Radioactive Materials}

The objective of this section is to provide techniques that can be used to estimate the amount and size distributions of the materials made airborne from the types and levels of stress caused by internal and external accident initiators. The information is directed towards evaluation of source terms that are postulated for safety analysis, emergency preparedness documentation, or post-accident analysis. The initial Subsections introduce the concepts and processes that must be considered, whereas the latter Subsections provide the technical approach for development and use of the source term estimates. 


\subsubsection{Introduction}

The selection of the appropriate ARF/RF for a stress-material combination is dependent upon the determination of the type and level of stress imposed, the characteristics of the material impacted, how and when the stress is imposed, and the local environmental conditions. Once the material-at-risk and type and level of stress have been identified in the Process Hazards Analysis (see Chapter 2), additional analysis may still be necessary to determine the behavior of other materials, equipment, and structures to determine the impact on the material-of-concern. Thus, for example, if there is an earthquake, there may be a need for calculations to determine the response of a building. Guidance on detailed structural analyses is beyond the scope of this handbook. Then, the appropriate ARF/RF can be selected. However, in the case of "bounding" values based on experimental data over a limited range of the stress, interpretation is necessary to arrive at a reasonable value. The impact of the stress must be understood.

As an example, a gaseous jet may be directed onto the surface of a powder lying on a solid, relatively smooth, substrate. Both the velocity of the gases and direction of impact are important. If the direction of flow of the gas is parallel to the surface on which the powder lies, the gas will act as a wind blowing over the surface of the powder. If the powder is dry and of a broad-size distribution of particles, the initial puff will result in a initial high airborne concentration of particles, which will decrease to some lesser value, depending on the conditions. The powder behaves like sand with various size components undergoing three processes: (1) surface creep (particles with geometrical diameters $\left[D_{g}\right]$ exceeding $120 \mu \mathrm{m}$ ( 0.0047 in), rolling across the surface and initiating movement of smaller particles); (2) saltation (particles in the range of 70 to $120 \mu \mathrm{m}(0.0028$ to $0.0047 \mathrm{in}), \mathrm{D}_{\mathrm{g}}$ will roll and bounce into the air as they encounter obstacles, falling to the ground if they cannot be carried by the local flow); and, (3) suspension (particles that can be carried by the local flow will remain airborne and be transported to the atmospheric flow).

If the gas flow is directed downward onto the surface, the gases will penetrate into the powder and be reflected by the unyielding substrate, resulting in greater suspension by the upward reflected flow and turbulence.

If the powder is not dry or has been moist, the individual particles may be subjected to additional interparticle forces, such as the surface tension of the water that may join the particles, the adhesion of the soluble salts that have been deposited between the individual particles, etc. Furthermore, larger particles may have folds and crevices that will hold fine particles which may be released upon impact of the larger particle with the ground.

If the powder is deposited as a pile, there are flow considerations. The leading edge may be eroded or undercut, eventually allowing large sections of the powder to be carried by the flow. In some cases, these large, airborne "clumps" are deagglomerated by the flow conditions. Furthermore, the flow around the pile will induce a region of lower pressure on the lee side of the pile that may result in suspension from this region.

Thus, it is important to understand the suspension phenomenon to properly interpret the experimental data and apply the experimental data that are the bases for the ARFs/RFs presented. In some cases, the experimental data cover a limited range of the stress parameter that bounds the level of stress of a specific event. In such cases, it may be appropriate to interpolate the ARF/RF values to derive a more appropriate value for the specific scenario. 
When the material at risk (MAR) is divided into many items that are separate and spaced, the components may experience a range of stress levels that may be reasonably represented by a median value of the experimental data.

Where the experimental data span an appropriate range of the stress parameter and the number of data points appears to be adequate, the rate of change of the ARF (and in some cases the RF) can be presented in graphic form as shown elsewhere in this chapter.

\subsubsection{Characteristics of Physical Forms of Materials}

The following are brief descriptions of the relevant characteristics that may influence airborne suspension of the material:

\subsubsection{Gases}

Materials in the gaseous state are loosely bound and fill up the entire volume of the container or containment. From a release perspective, loss of containment/confinement eventually results in complete loss of the material. The rate of loss is a function of the size of the vent and the upstream pressure.

\subsubsection{Volatile Materials}

Nearly all materials are volatile (become vapor) under specific conditions (chemical environment, temperature). With respect to airborne release assessment, a material is volatile if it can generate vapors under the postulated accident conditions (e.g., vaporization of water by heat; the vaporization of volatile, hazardous chemicals by ambient temperatures on release from confinement; the conversion of iodine compounds by acid and oxidizing environment and temperature into molecular iodine vapor or gaseous compounds).

\subsubsection{Low-Volatility Liquids}

Liquids are materials that spread across the surface upon which they lie. Low-volatility liquids must be fragmented into drops that can be suspended and transported to be an airborne concern. The force/stress level necessary to fragment the liquid varies with the liquid characteristics, although these subtle variations are not a major factor in the generic approach for most of the experimental database available. There is more than one category of liquids that is encountered in nuclear facilities. The major categories are aqueous and organic liquids. Each category may have subclasses such as aqueous solutions, aqueous slurries, or aqueous sludges. The characteristics influencing the airborne release of each subclass vary with concentration of solute (e.g., density, viscosity, surface tension). For nuclear facilities, most liquids of concern contain the non-volatile material-of-concern as a solute or solid component of the slurry or sludge. For organic liquids, the same subclasses are possible. The subclass of greatest concern--organic, combustible, liquids--has no aqueous counterpart. Low-volatility liquids include:

Aqueous Liquids. Tritiated water is encountered in nuclear facilities and is generally associated with the storage and dissolution of spent nuclear fuel and liquids from these activities.

Solutions: Aqueous solutions consist of solute dissolved in water or acid. The solutions encountered in nuclear facilities range from very dilute ones, in which the solute is essentially a contaminant, to concentrated, acidic, and basic solutions of radionuclides and stable isotopes. 
Slurries: Aqueous slurries consist of solid particles suspended in water or an aqueous solution. Slurries often require agitation to remain suspended, and their particle concentration gradient may vary with height from the bottom of the container and with time. The solid particles may contain radionuclides (e.g., contaminated materials that carry along some particles containing radionuclides) or the radionuclides are solutes in the solution (e.g., highly concentrated high-level waste (HLW) mixed with glass formers just before vitrification).

Non-Newtonian Fluids: Non-Newtonian liquids are those that are very viscous and deviate from the behavior of typical aqueous liquids. Some sludges (e.g., mixture of amorphous/hygroscopic compounds and particles mixed with very little water) are non-Newtonian. This subclass of aqueous liquids is much denser than aqueous solutions and slurries.

Organic, Combustible Liquids. Combustible organic liquids as solutions, as the liquid component of slurries or sludges, or as combustible materials are concerns in nuclear facilities. For an organic combustible liquid that is the solvent for a radionuclide, combustion of the solvent or evaporation of the solvent can release volatile compounds and, if sufficiently dried, release solute by ejection of the solid residue as a result of the venting of trapped vapors under the surface of the solid. Depending upon the rate of solvent evaporation, in typical situations, the airborne release of the solute can be caused by the generation of liquid droplets containing the solute. As fuel for fire over aqueous solutions bearing radionuclides as solute, if the organic material is transparent and shallow, heating of the aqueous, immiscible substrate can result in boiling or eructation of the aqueous solution.

\subsubsection{Solids}

There are several categories of solid that are of concern in nuclear facilities. As structural materials that act as barriers between the radionuclides and the spaces occupied by individuals, their behavior under severe stresses (e.g., explosions, fires, earthquakes, or tornados) is important. Radionuclides can also be found in solid forms such as reactive metals; non-reactive metals (with activation products); cement; compact ceramic oxides (nuclear fuel); aggregates (concrete/grout); brittle solids (glass, vitrified HLW); powders; and contaminated materials. Each has properties that make them susceptible to some stresses but not to others. Some have subclasses with different properties that influence airborne release.

Reactive Metals (plutonium, uranium): Reactive metals are found in nuclear facilities under special circumstances. Although both plutonium and uranium are chemically reactive under many conditions such as in the presence of heat and oxygen, their behavior is significantly different. Under these conditions, both oxidize at rates that are a function of temperature, going through a "kinetic-controlled regime" (oxidation rate is a function of temperature) and "diffusion-controlled regime" (oxidation is limited by the diffusion of oxygen to the metal oxide interface), also known as ignition. The ignition temperature is also a function of the surface-to-mass ratio and is shown for plutonium and uranium in Figures 3-1 and 3-2, respectively. Plutonium dioxide is the thermodynamically stable oxide, and the matrix spacing of the oxide and metal are so different that the oxide does not adhere to the metal. Uranium metal forms several suboxide forms before attaining the stable oxide, $\mathrm{UO}_{3}$. A thin 1-to-50- $\mu \mathrm{m}\left(3.9 \times 10^{-5}\right.$-to-1.95 $\times 10^{-3}$-in) layer of $\mathrm{UO}_{2}$ forms at the interface between the metal and atmosphere during oxidation, and the oxide has a 


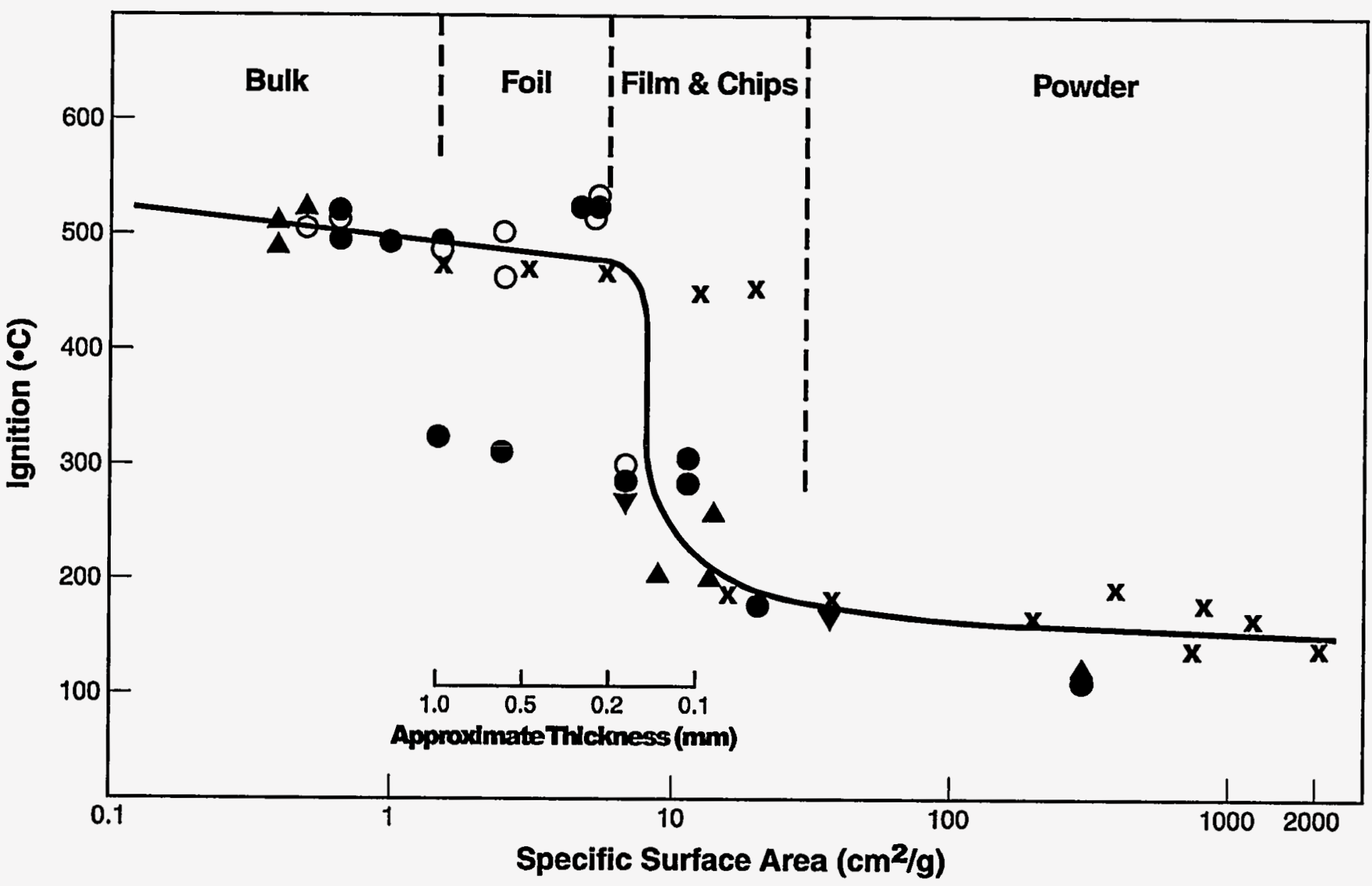

Figure 3-1. Effects of surface area on plutonium ignition temperatures (Stakebake 1992) 


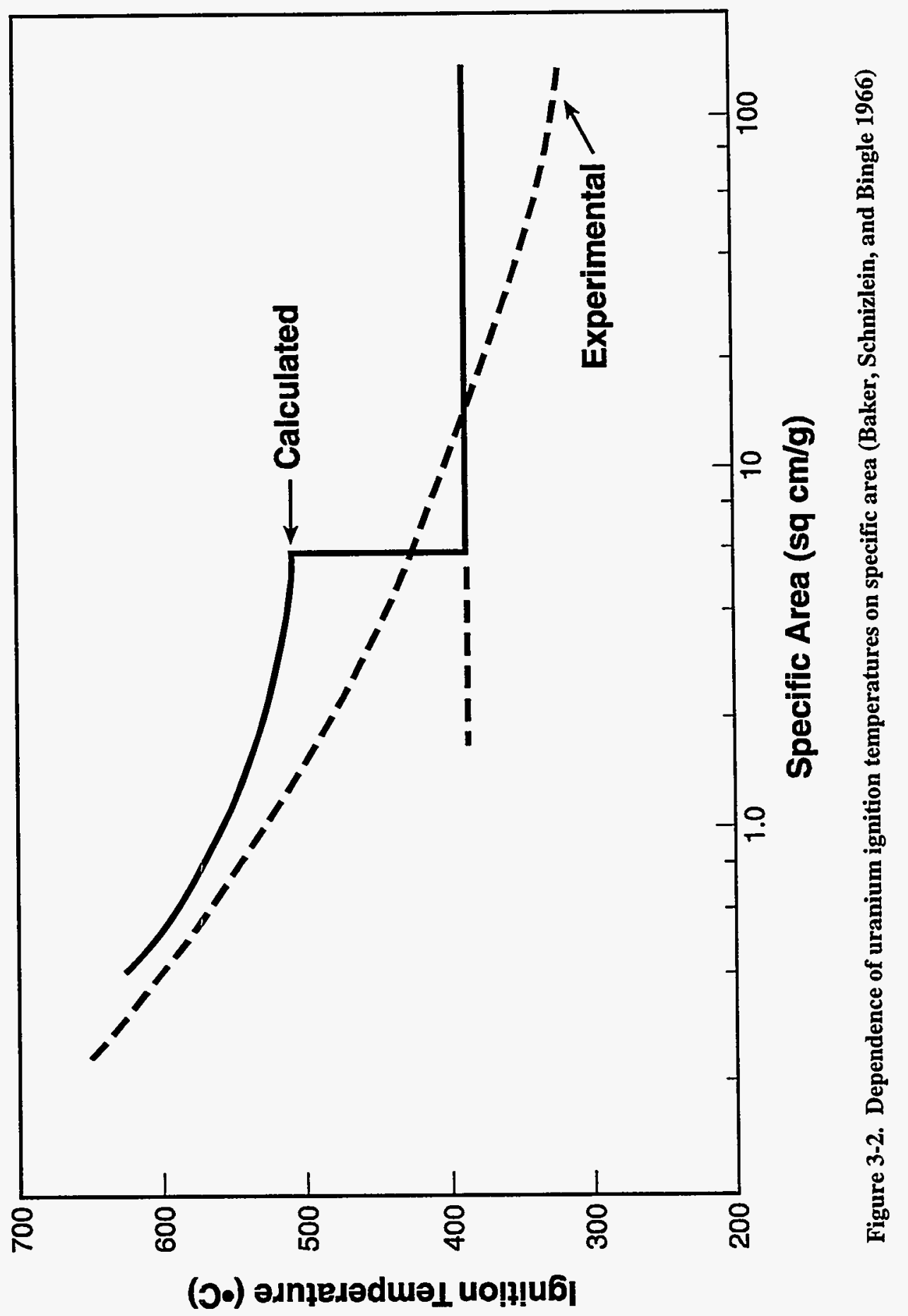


crystalline matrix spacing similar to the gamma form of the metal that allows it to adhere. Additional oxidation results in the outer layer being converted to other suboxide forms (e.g., $\mathrm{U}_{3} \mathrm{O}_{8}$ ) that do not adhere and fall away from the metal-UO $\mathrm{UO}_{2}$ mass. Thus, compacted $\mathrm{UO}_{2}$ masses can be oxidized to powder $\mathrm{UO}_{3}$ under prolonged heating (in excess of $1 \mathrm{hr}$ at $700 \mathrm{~K}\left(800^{\circ} \mathrm{F}\right)$ in the presence of air or oxygen. Oxidation is enhanced by the presence of moisture at ambient to slightly elevated temperatures. Oxides formed slowly at room temperature tend to be finer in size and more chemically active than oxides formed at elevated temperatures.

Metals exhibit elastic-plastic behavior and deform under crush-impact forces and pressure. Eventually, the force exceeds the strength of the material and results in fragmentation. For very high pressures (e.g., the detonation of high-order explosives in contact with the metal), the explosion forms "threads" of metal that break away.

Mechanical stresses may puncture/perforate metal if the force is adequate to exceed the plastic limits for the specific metal configuration (e.g., material strength and thickness).

Non-Reactive Metals: The behavior of non-reactive metals is the same as described for reactive metals above, except the effects generally require more stressful conditions to achieve the same effect.

Brittle Solids (glass, vitrified HLW, fuel pellets, SNF, aggregate/concrete): Brittle materials do not undergo elastic-plastic deformation under crush impact forces, but fracture. Typically, brittle materials have relatively high tensile strength. Most are not combustible. Brittle materials can be eroded by abrasion or age and generate particles that are some multiple of the basic crystallite size. When broken, brittle material tends to cleave along grain boundaries.

Powders: Powders are a collection of particles (typically not spherical but ranging from cubic to flat thin fragments) that may be in a narrow- or broad-size range. At rest, the particles tend to stick together (agglomerate) under the influence of interparticle forces of adhesion (London-Van der Waals forces). The presence of moisture at the point where the particles meet tends to increase the interparticle attraction because of the action of the surface tension of the liquid that condenses at these locations. If the particles are composed of soluble materials, wetting may fuse the material into a solid mass. If the range of particle size is broad, the particles may pack more efficiently with smaller particles, filling the void between larger particles. Many powders will flow because of the action of force of gravity and form a material-specific angle of repose when drained through an opening in the substrate holding the powder. Powders with a very fine particle size (up to $\mu \mathrm{m} \mathrm{D}_{\mathrm{g}}$ ) may have an angle of repose near $90^{\circ}$ and not flow readily.

Combustible Contaminated Solids: Many combustible materials are used in the nuclear industry for a variety of purposes. Rags and paper wipes are used to wipe/mop up contaminated liquid and powder spills in operating areas and inside contaminated equipment (e.g., gloveboxes, cells). Plastic is used as a temporary barrier, packaging material, viewing windows, etc., for confining contamination. Wood is used as a structural and packaging material that comes in contact with or contains contaminated materials. The contaminant can consist of particles on the surface or in the structure of the material. Light-weight combustible materials are typically flexible enough that many of the common accident stresses (mechanical, aerodynamic, explosive) result principally in displacement of the entire item. Larger pieces of material, such as large, thick, pieces of rigid plastic or wood may behave as a brittle material or some other material type. The principal concern is with heat that results in combustion of the material. Combustion results in the destruction of the substrate and liberates the particles of powder or the air-dried 
solids from liquids and generates an upflow by generation of pyrolyzates to carry the liberated particles into the local flow.

Non-Combustible Contaminated Solids: Non-combustible substrates typically consist of brittle materials (e.g., glass, aggregate) or metals. Contamination on non-combustible material tends to be on the surface of the material, although the contaminant may migrate into the surface roughness of the substrate or into cracks and crevices of the substrate with time. The contaminant is typically solid (particles or air-dried solid from solutions or slurries). For some stresses (e.g., aerodynamic entrainment, shock-vibration), the contaminant acts independently of the substrate. Sufficiently energetic mechanisms can fragment the substrate (e.g., explosions, crush-impact). In this case, the contaminant is assumed to remain associated with the surface.

\subsubsection{HEPA Filters}

U.S. standard nuclear grade filters are made of a pleated, $0.38-\mathrm{mm}(0.015-\mathrm{in})$ thick, non-woven mat consisting of 1-to-4- $\mu \mathrm{m}\left(3.9 \times 10^{-5}\right.$-to- $1.6 \times 10^{-4}$-in) diameter glass fiber separated by spacers and sealed to fiber board or metal frame. HEPA filters come in a variety of sizes. A more complete description is provide in Appendix F. The unit is fragile, and the medium is readily punctured by falling objects or perforated by sharp, hand-held objects. Single or multiple units are typically sealed into a more substantial metal housing in the exhaust flow from cells, gloveboxes, or facilities. Three mechanisms are responsible for the removal of particles from gas streams passing through HEPA filters--impaction, interception, and diffusion. Impaction is the process whereby particles in a flowing gas stream have sufficient inertia to cross the streamlines formed during changes of gas direction and impact the barrier to flow (glass fibers). Particles with less inertia deviate from the gas stream lines around the obstruction and, if the particle passes within $\sim D_{p}$ (particle diameter) of the obstruction, attaches to the obstruction. Diffusion of submicron particles occurs in the filter medium (non-woven glass fiber). The flow passes through a series of cells formed by the fiber mat and deposits by turbulent diffusion. The most penetrating particles generally have diameters $\sim 0.15 \mu \mathrm{m}\left(5.9 \times 10^{-6} \mathrm{in}\right) \mathrm{D}_{\mathrm{g}}$ (particle size collected with minimum efficiency) at normal operating conditions. All other particles are collected more efficiently. Standard HEPA filter efficiency is measured in-situ, using aerosol mists comprising a range of particle sizes and must have an insitu efficiency of greater than 99.95 percent. Experiments show that HEPA filters have greater than 99.9 percent collection efficiency for particles of all sizes (Gonzales, Elder, and Ettinger 1976).

HEPA filters can be "blinded" by the condensation of moisture/vapors on the filter mat. Flow through the filter can then be restricted or halted. Most exhaust systems specify that the maximum pressure differential across a filter in an operating system be less than 2200-Pa (9-in) WG to present loss of the filter medium. HEPA filters can withstand relatively high temperatures for short durations, but the exact temperature is a function of previous environmental conditions (see Appendix F).

\subsubsection{Description of the Effects of Various Stresses Generated to Aerosolize Physical Forms}

The physical forces imposed by various initiating events play a role in determining the amount of material that becomes airborne during an accident. This Subsection discusses the types of forces developed by a group of initiating events and describes the response of differing types of MAR to these forces.

\subsubsection{Explosions}

Explosion is a general term and is defined: 
In general, an explosion is said to have occurred in the atmosphere if energy is released over a sufficiently small time in a sufficiently small volume so as to generate a pressure wave of finite amplitude traveling away from the source. This energy may have originally been stored in the system in a variety of forms; these include nuclear, chemical, electrical or pressure energy, for example. However, the release of energy is not considered to be explosive unless it is rapid enough and concentrated enough to produce a pressure wave that one can hear. Even though many explosions damage their surroundings, it is not necessary that external damage be produced by an explosion. All that is necessary is that the explosion is capable of being heard. (Baker, et al. 1983)

Explosions from a chemical energy source may be categorized by the rate of energy release. Detonations are those chemical reactions (combustion/oxidation) with a flame speed that exceeds the local speed of sound (typically branch-chain reactions in the solid or condensed phase). The products (generated in microseconds to milliseconds) cannot be dissipated by the normal mass and heat transport mechanisms and generate a shock (no mass involved) and a pressure wave. Deflagrations are chemical reactions (typically in the gas phase) that have flame speeds less than the local speed of sound, but burn rapidly. The products, generated in milliseconds to seconds, produce a pressure impulse with a positive followed by a negative phase. Under special circumstances of ignition and/or configuration, a reaction may undergo a Deflagration to Detonation Transition (DDT).

There are physical analogs to detonation (the so called "steam-explosion") and deflagrations (pressurevolume type events) that lead to the catastrophic rupture of a vessel.

A. Explosions-Detonations - The release of energy takes place in microseconds; the flame speed is at or exceeds sonic velocities, and the event results in both a shock wave and a pressure impulse. The overpressure can be 20 to 30 times the initial pressure. Shock waves do not have mass and may be reflected and amplified by solid surfaces. Shock waves can fracture brittle materials such as glass and aggregate, and pressure impulses can exert dynamic pressure on surfaces and structures. At very small distances from the blast center, the pressure impulse is sufficient to deform/fragment metals and fracture brittle materials. Even at greater distances, the pressure impulse is adequate to displace items such as containers, equipment, etc., and result in toppling, perforation, and loss of confinement. The accelerated gas passing over or impinging on powders or liquids can lead to drop formation from a liquid or deagglomeration of a powder at rest and suspension of the particles generated.

B. Explosion-Deflagrations - The release of energy takes place in milliseconds to seconds; the flame speed is subsonic. The products may be a pressure impulse or static pressure and possibly heat. The products can do substantial damage to equipment, barriers, and structures, depending upon the energy involved and the distance from the center of the explosion. Fragmentation of containers or barriers and the release of the contained materials can generate secondary effects (e.g., missiles, fires, if flammable/ combustible materials are released). Both the primary and secondary effect can result in the airborne release of particles of the material-of-concern. Under proper conditions (e.g., jet flame initiation, very high turbulence during ignition), deflagrations may transition into detonations if the flame speed achieves the local speed of sound.

C. Explosion - "Steam Explosion" - These are very rare events requiring conditions seldom found in nuclear facilities and are only discussed to provide comprehensive coverage of the phenomenon. For most molten materials in contact with a coolant, rapid heat transfer is precluded because of the low thermal conductivity of the vapor film formed. For some molten materials with specific viscosity and cooling 
characteristics dropped into a coolant such as water, the coolant is trapped under the molten materials, and the partially hardened crust forms an unyielding surface. The vapor pressure may fragment molten material into very fine droplets $\left(<100 \mu \mathrm{m}(0.0039 \mathrm{in}) \mathrm{D}_{g}\right)$ that are violently ejected into the coolant with an almost instantaneous heat transfer that can result in both a shock wave and pressure impulse. The consequences are very much like those from a detonation, but, generally, the energy release is much less than normally associated with detonations of condensed phase explosives (conventional high-order explosives).

The question sometimes arises as to whether steam explosions can occur in waste melters/furnaces. All indications are that molten glass-like materials do not fall into the category for which steam explosions are likely.

D. Explosion-Overpressurization - Venting of pressurized volumes is the physical analog of a deflagration without heat (although heat may be the cause of the pressurization), a pressure-volume event. Powders and liquids in the pressurized volume before and during venting can be swept along by the flow induced by the venting. If the pressurization takes a sufficiently long time, powder particles in the volume can be separated by the expansion of the gas between particles during venting. Liquid droplets can be generated by the rapid release of absorbed gases in the liquid, resulting in a boiling-like phenomenon. Both the solid particles and liquid droplets can be swept along with the flow induced by the rapid release of the gases. If this initial pressurization is rapid and the interparticle void volume is not pressurized, the airborne release is generally less than that for full pressurization.

Although not an explosive event, the behavior of punctured SNF exhibits the same general type of behavior. The clad fuel is pressurized with gas during manufacturing. Additional pressure is generated by the release of fission gases (i.e., noble gas isotopes) and vapors released from the sintered, compacted fuel during irradiation. Puncture of the cladding of SNF results in the venting of fission gases, vapor, and fuel fines generated during irradiation by attrition. The amount of material and the pressure vented differ for cold failure at ambient temperature and hot failure because of elevated temperatures (typically near 1100 to $1200 \mathrm{~K}\left(1520\right.$ to $\left.\left.1700^{\circ} \mathrm{F}\right)\right)$.

E. Energetic Event-Uncontrolled Chemical Reactions - Examples of uncontrolled chemical reactions include rapid decomposition of organic ion exchange resin in nitric-acid solutions of heavy metal. They are also a potential source of airborne release of both particles (e.g., decomposition products from the organic resin) (Miles 1968; Anon October 1976) and liquid droplets (e.g., solution present during the reaction). Damage from the rapid reaction of ion exchange resins appears to be very local in nature, resulting in local rupture of metal columns and shattering of glass columns. Other uncontrolled chemical reactions are also possible, such as the rapid burning of organic material mixed with oxidizers (nitritenitrate salts), a condition found in some dried HLW tanks. The amount and continuity of the organic loading required to produce a run-away reaction has not been established. Non-volatile materials in the mixture may also undergo chemical reaction at the high temperatures associated with this type of event and form fine particles that may be suspended in the gas flow generated by the reaction.

\subsubsection{Fire}

The phenomena of importance to the airborne release process are heat and gas flow (both the upward flow of vapors and the convective flow of the air) and the presence of carbon particles (i.e., soot) and unburned pyrolyzates that can deposit on cooler surfaces, thus carrying particles with the vapor flux (see Restrepo, et 
al. 1996; DiNenno, et al. 1995; Drysdale 1985). The products of combustion and/or thermal decomposition may themselves present a serious airborne hazard.

The heat from combustion may alter the chemical form of non-volatile materials or may result in agglomeration with other non-combustible materials. Chemical changes in the crystalline matrix may result in separation of the particles from the bulk material and in their entrainment in local flows. Heat can also result in the expansion and vaporization of liquids held in vessels, and, if the vessel/containers do not have adequate venting, a pressure-volume, overpressurization event with sudden venting of the contents is possible.

The dissipation of the heat generated is also a factor in the potential consequences. The heat dissipated by convection generates air currents that can disperse the aerosol particles and/or vapors that are produced by the fire. Heat dissipated by radiation can ignite/heat materials and containers nearby, resulting in secondary combustion (if the contents are flammable/combustible liquids) or overpressurization of containers. The heat dissipated by conduction can carry heat over large distances and result in impacts far removed from the source.

A. Homogeneous - Homogenous combustion occurs in those fires that involve both the fuel and oxidant (typically air) in the gaseous phase.

B. Heterogeneous - Heterogeneous combustion involves the generation of the fuel in the vapor state (evaporation of a combustible liquid or pyrolysis of a combustible solid), dilution of the vapors in the presence of an adequate supply of oxygen to generate a flammable mixture, and ignition of the flammable mixture.

\subsubsection{Mechanical Stress}

A. Puncture-Perforation - of a container or confinement can release materials in a number of ways. For the release of a volatile material, evaporation is the dominant mechanism (see Brereton et al. 1995). Some solids (e.g., phenol) may vaporize/sublime on release from perforated containers. Materials that are flammable gases or have combustible vapors can be vented and, in the presence of an ignition source, result in secondary fires. Solutions with non-volatile solvents and powder may vent if the volume is pressurized and can vent either above the level of the material in the vessel (fragmentation of the liquid by bubble formation and rupture at the surface, or separation of particles at rest by the expansion of the gas in the inter-particle void space) or below it (spray formation of liquids either at temperatures above or below the boiling point of the solvent, or by venting of pressurized volume containing powders). Free-fall spill/release of a solid may be followed by a period of evaporation or even sublimation for volatile solids.

B. Free-Fall Spill (Result of Perforation) - The release and free-fall of liquids and powders can result in suspension from shear stress at the air-material interface. A falling slug can thus shed particles/droplets during the fall. Air resistance can result in the disruption of the face of the falling slug of powder, and particles can be shed into the area of lower pressure resulting from the restoration of the streamlines on the back face of the slug. Impact can induce breakup of solids, powder slugs, and liquids. Volatile materials may evaporate on release (see Brereton, et al. 1995).

C. Crush-Impact - This phenomenon imposes force on the surface of the material impacted and can fragment both solids (e.g., brittle fracture, displacement of powders) and liquids (e.g., splashing and droplet formation by displacement and shear). If the force is applied to less than the total surface of the 
material, fragmentation of the material is limited to the volume that experiences shock wave transmission and reflectance in solids, or the surface area affected for liquids.

D. Shock-Vibration - If the surface is not fragmented, particles lying on the surface (e.g., surface contamination, corrosion products) can be jarred from the surface and suspended by vibratory/shock effects.

E. Abrasion - This phenomenon consists of forces applied to the surface layer that induce fragmentation of the surface by mechanical action. Particles generated may be suspended by the mechanical action more efficiently than by aerodynamic forces.

\subsubsection{Aerodynamic Entrainment/Resuspension}

Air passing over a surface or directed onto a surface can induce flow and turbulence that can suspend particles on or from the surface impacted. The presence of obstructions around or over the surface can affect the air flow and, therefore, the suspension of materials from the surface. Sources for gases at accelerated velocities are the passage of or impact by the pressure impulse generated by explosions or by wind.

\subsubsection{External Events and Natural Phenomena}

These phenomena result in the types of stresses discussed above.

\subsubsection{Scenario Interpretation}

The initial steps in accident analysis include identification of the sequence of conditions and events comprising the accident and its consequences, identification of potentially harmful MAR, and characterization of the initiating event. This Subsection presents an introduction to these concepts.

The description of the sequence of events/behavior of materials that result in the airborne release of material-of-concern (the scenario) must contain essential information to provide the basis for the choice of ARFs/RFs and Leak Path Factors (LPFs).

The material at risk (MAR) includes mass/activity at a location that may be impacted by the type of event (i.e., fire, explosion, puncture, etc.); the essential physical characteristics of the MAR (e.g., bulk solid, what type of liquid, particle size distribution of powder) that influence the airborne suspension; location(s); and the physical configuration and environmental conditions (e.g., exposed to ambient atmosphere, characteristics of container, elevated temperatures, etc.).

When discussing initiating events, it is not adequate to simply designate an explosion, for example. The type of explosive event must be defined (e.g., detonation, deflagration, overpressurization/P-V event), together with the sequence of events/behavior that impact airborne suspension. There must be enough detail to provide a basis for the selection of ARFs/RFs/LPFs.

As the level of sophistication of the analysis increases, the input data requirements, engineering analysis, and level of rigor increases. Before attempting to increase the level of sophistication in analysis, the level of sophistication of the data for ARF/RF values should be considered. If the ARF/RF values are "bounding" values based on a few experimental data points covering a limited range of the stress 
parameter, only a level of analysis sufficient to establish that the event is within the bounds of the experimental stress parameter is useful.

If the various levels of the stress parameter were used and resulted in significantly different ARF/RF values from those in the experimental database, it may be desirable to demonstrate that the value of the stress parameter for the specific event is less than some assumed value of the stress parameter used in the consequence analysis. For example, free-fall spill experiments were performed using two fall distances--1 and $3 \mathrm{~m} \mathrm{(3.28} \mathrm{and} 10 \mathrm{ft})$. If analysis demonstrates the material falls less than $1 \mathrm{~m}(3.28 \mathrm{ft})$, the ARF/RF for the lower fall distances may be applied.

Finally, if the experimental bases provides a wide range of the stress parameter with a corresponding range of ARF/RF values, an analysis level adequate to establish a more exact estimate of the stress parameter may be undertaken.

\subsubsection{Calculational Methodologies}

Estimation of source terms for release to the environment includes consideration of MAR, degree of damage to the facility and material, characterization of airborne material, and intra-facility transport. This Subsection identifies several computer models that may be used in source term and impact analysis of specialized situations and introduces a more general approach for systematic stepwise estimation of environmental source terms.

\subsubsection{Computer Codes}

A. HOTSPOT (Homann 1994) - This health physics code package was developed to provide a fastexecuting, field-portable calculational tool for evaluating accidents involving radioactive materials. HOTSPOT consists of four computational modules: radioactive source-terms generated by explosions; radioactive source-terms generated by fires; resuspension of radioactive materials; and a Gaussian dispersion model to estimate the transport of radioactive material as a continuous plume or "puff" release. The calculational and resuspension modules for the source term are based on very conservative assumptions with respect to the configuration and behavior of the material involved and should be examined for compatibility with postulated conditions. The code has not been validated.

B. EXPAC (Gregory and Nichols 1991) - The EXPlosion Analysis Code (EXPAC) can be used to predict explosion-induced gas-dynamic transients and material transport within structures. Source term data must be provided. Although portions of this code are based on experimental data, the code has been neither validated or benchmarked. To the best of the authors' knowledge, there are no plans to perform either function in the immediate future.

C. FIRIN/FIRAC (Nichols, et al. 1986; Chan, et al. 1989) - "FIRAC is designed to estimate the radioactive and nonradioactive source terms and predict fire-induced flow and thermal and material transport through a facility" (Spore, et al. 1996). The code is a lumped-parameter transport model. "FIRAC/FIRIN was selected as the 'best' overall computer code for DOE safety analysis application based on its ability to calculate not only fire characteristics but also the potential source term (radioactive and fire byproducts) generated by scenarios" (Restrepo, et al. 1996). That is, FIRIN/FIRAC is the "best" of a limited set of computer codes that estimate radiological source terms, since no other fire computer model also addresses source terms. Two fire modules can be used with FIRAC: FIRIN, which calculates fuel mass loss rate, energy generation rate, and radioactive release rates in a single compartment, and CFAST 
(developed by the National Institute of Standards and Technology), which models fire growth and smoke transport in multi-component facilities. Many errors and limitations have been noted in the FIRIN model. FIRAC has been benchmarked.

D. KBERT (Browitt, et al. 1995) - This model focuses on calculation of dose and consequences to infacility workers resulting from the accidental release of radioactivity. The input is via dialog boxes for rooms, HVAC plenums, structures, flowpaths, etc. It can provide input source terms for input to atmospheric dispersion models. It does not solve for the flow field (Spore, et al. 1996). The code has been neither validated nor benchmarked. To the best of the authors' knowledge, there are no plans to perform either function in the immediate future.

\subsubsection{Hand Calculations}

The typical accident analysis is performed using hand calculations for screening purposes or to evaluate an event that has little potential for significant downwind radiological consequences. The method described below satisfies most requirements for this type of analysis. Its level of rigor can range from the use of very conservative assumptions for each of the factors to considerable analysis to determine the Damage Ratio (described below) and the stress level imposed on the MAR to select appropriate values for the ARF/RF. Each value used for each factor must be properly and completely documented to allow review by competent peers for each analysis.

A. Methodology - Five-Factor Formula - ARFs can be used to estimate the amount of hazardous (chemical and radioactive) material released to the air under various conditions, a quantity called the "source term." The designation "source term" is used here in its generic sense, the amount and characteristics of a radionuclide(s) made airborne under the postulated conditions. The appellation "source terms" may be applied to many values in the course of an analysis--the airborne materials released from some initiating event (e.g., fire, explosion, etc.); the airborne materials released from an enclosure or carried from an operating area/room; the total amount of radioactive materials attributable to a particular phenomenon (e.g., "fire source term", "explosion source term") when more than one phenomenon will contribute to the airborne materials released from a facility; and the amount, characteristics, and conditions of release of radioactive materials released from a building (i.e., "building source term").

The common use for source terms is to assess downwind radiological impacts. For nonreactor nuclear facilities, historical radionuclide release estimation efforts have produced a consensus that the source term can be defined as a product of five material-specific factors:

$$
\text { Source Term }=\text { MARxDRxARFxRFxLPF }
$$

where MAR is the material-at-risk (in desired units), DR is the damage ratio, ARF is the airborne release fraction (or Airborne Release Rate for continuous release), RF is the respirable fraction, and LPF is the Leak Path Factor. The initial source term and the initial respirable source term are products of the first three factors and the first four factors, respectively. The initial respirable source term is the combination of the $A R F$ and $R F$ into a respirable ARF. A depleted source term after a subsequent stage of deposition or filtration is the product of the initial source term(s) and the relevant LPF. The following paragraphs provide more detailed descriptions of the individual elements of the five-factor formula.

1. MAR: The MAR is the amount of hazardous material available to be acted on by a given physical stress. Depending on the magnitude and scope of the stress, the MAR may range from the total inventory 
of a facility to a subset of the inventory in one operation. For example; an overall natural phenomenon such as an earthquake may involve all material, whereas a process-specific explosion may not. Even in the case of the earthquake, however, different materials may experience different stresses, depending on anticipated building response. As with all of the five-factor formula parameters, the basic progression of the event must be understood to define MAR.

2. DR: The DR is the fraction of MAR actually impacted by a given physical stress from a specific event. It is typically based on consideration of the physical and chemical form of the MAR, engineering analysis of the response of structures to a given stress, and calculations/judgments of the practical limits of the phenomenon (i.e., energy available from stress). Definition of the DR depends on how the MAR has been defined.

As an example, two approaches may be used to determine DR for a case in which $600 \mathrm{~g}(1.32 \mathrm{lb})$ from a total of $1000 \mathrm{~g}(2.2 \mathrm{lb})$ of material $X$ are in the form that would not be affected by an explosion. Of the remaining $400 \mathrm{~g}(0.88 \mathrm{lb}), 200 \mathrm{~g}(0.44 \mathrm{lb})$ have a high respirable fraction, and $200 \mathrm{~g}(0.44 \mathrm{lb})$ have a low respirable fraction. In approach 1 , all $1000 \mathrm{~g}(2.2 \mathrm{lb})$ are included in the MAR, specific DR values are 0 for the unaffected material, 0.2 for the high RF material, and 0.2 for the low RF material. In approach 2, only $400 \mathrm{~g}(0.88 \mathrm{lb})$ of the affected material are included in the MAR, specific DR values are 0.5 for the high RF material and 0.5 for the low respirable fraction material. It is important that one convention for defining DR be applied consistently throughout a given release calculation.

3. $\mathrm{ARF}$ : The ARF is the fraction of impacted material (MAR $\times \mathrm{DR}$ ) that can be suspended to become available for airborne transport following a specific set of induced physical stresses. For discrete events, the ARF is a fraction of the material that becomes airborne during application of the stress. For mechanisms that continuously act to suspend the hazardous materials (e.g., aerodynamic entrainment/resuspension), the airborne release is defined as a release rate. The ARR is expressed as the fraction of the total available material being suspended per unit time. The ARF is the ARR integrated over the total duration of the event. The ARF is a joint function of the original physical and chemical state of the material and the type of physical stress. For example, gases will be released on loss of container confinement, whereas liquids and solids must be subdivided/deagglomerated and suspended. Likewise, a fire will impact or influence material cohesion and inertia in different ways than does a seismic vibration. Thus, the ARF is the airborne material that can be transported, and the LPF (discussed below) is the fraction of the ARF or [ARF][RF] that is transported.

4. $\underline{R F}$ : The RF is the fraction of the material-of-concern initially suspended in the air and present as particles that can be inhaled into the human respiratory system. It is commonly assumed to include particles with AEDs that are $10 \mu \mathrm{m}\left(3.9 \times 10^{-4}\right.$ in) or less. The AED is the diameter of a sphere with a density of $1 \mathrm{~g} / \mathrm{cm}^{3}\left(62 \mathrm{lb} / \mathrm{ft}^{3}\right)$ that exhibits the same terminal velocity as the particle in question.

A wide range of release events must be covered. Broadly speaking, however, this range can be divided into two categories--releases in which the material is fractionated by the event (such as liquid sprays, boiling of solutions, and burning materials) and releases in which pre-fractionated material is merely liberated (such as pouring of powders, boiling of suspensions, and burning powdercontaminated substrates).

For materials fractionated by the release, application of the results to realistic situations is complicated by the fact that the experiments, in general, have used surrogate materials that may have different properties from those of the material of interest in the realistic situation. Because of this, both the ARF and RF 
associated with a release category, as extracted from experiments, may have some uncertainty associated with them. Additional uncertainty in the magnitude of both ARF and RF is associated with measurement techniques (e.g., at the end of a long transport path that may have significantly attenuated the release). However, it is likely that particles in the respirable size range are the least affected by transport losses, so that the Respirable Airborne Release Fraction ([ARF][RF]=RARF) calculated from the measured ARF and RF may be assumed to be reasonably accurate for the material used. For this reason, in some cases, this handbook tabulates the combination ([ARF][RF]) as reported in the experimental studies. Translation of the so determined RARF to other materials than those used in surrogate experiments must be done with caution.

For the category of pre-fractionated inert powders, the RF is likely to be a strong function of the size distribution of the material before release. Many release mechanisms favor the larger particles, so that the $\mathrm{RF}$ of the pre-release material may well bound the RF associated with the released material, provided that no chemical reaction affecting the material occurs. If the surrogate material closely matches the material of interest, it is reasonable to use the RARF of the experiment. If it does not, then it is conservative to use the $\mathrm{RF}$ of the material of interest before release (if known) as the bounding RARF. If the bulk RF is not known or it cannot be reasonably estimated, then it should conservatively be taken as one, and the ARF used to determine the RARF, where the latter is the value measured using the surrogate material.

Figure 3-3 shows the relationship between ammd and the RF, based on the assumption that the particles constitute a lognormal distribution with a GSD of 2 . As shown, distributions with an ammd of $25 \mu \mathrm{m}$ $\left(9.8 \times 10^{-4} \mathrm{in}\right)$ have less than 10 percent of the mass of particles associated with particles having $a D_{A E D}$ of $10 \mu \mathrm{m}\left(3.9 \times 10^{-4} \mathrm{in}\right)(\mathrm{RF}<0.1)$, and distributions with an ammd of $4.2 \mu \mathrm{m}\left(1.6 \times 10^{-4} \mathrm{in}\right)$ or less have greater than 90 percent of the mass in the respirable range $(R F>0.9)$.

5. LPF: The LPF is the fraction of airborne "material-of-concern" that leaves the confinement/ containment barrier after consideration of depletion mechanisms such as precipitation, settling because of the action of gravity or because of agglomeration or filtration (filter or rubble). There can be many LPFs for some accident conditions (e.g., the fraction transported from a package, such as a shipping container, to a cell or glovebox; the fraction leaked from the enclosure or cell to the operating area around the enclosure or room; or the fraction leaked from the room to the building-atmosphere interface). Where multiple leakpaths must be accounted for, their cumulative effect may be expressed as one value that is the product of all leakpath multiples, or a series of LPFs with justification for each value chosen. The LPF is calculated or based on: (1) established relationships between the size of the particulate material, airborne transport mechanisms, and loss by deposition mechanisms; or (2) specific or estimated (for rubble) filtration efficiencies. Confinement transport and filter effectiveness can both be heavily dependent on the accident phenomenology, particularly in terms of physical and structural integrity. Severe accident conditions can involve complete failure of confinement, in which case a conservative LPF of unity is assigned. A complete discussion of LPF is found in the next chapter.

\subsubsection{Compilations of Data}

Previously, five documents have reported ARFs for accident induced stresses. Walker (1978) compiled the reported release values for both reactor and fuel cycle facility events. Walker reported values for: fission product release from molten and oxidized SNF; activity removal by liquid systems; resuspension factors; releases of solid during heating and by impact; releases from solid and liquid during fires and explosions; reduction factors by passage through filters (particulate, halogen and gas), plateout, and passage through small leaks; criticality parameters; and miscellaneous releases. 


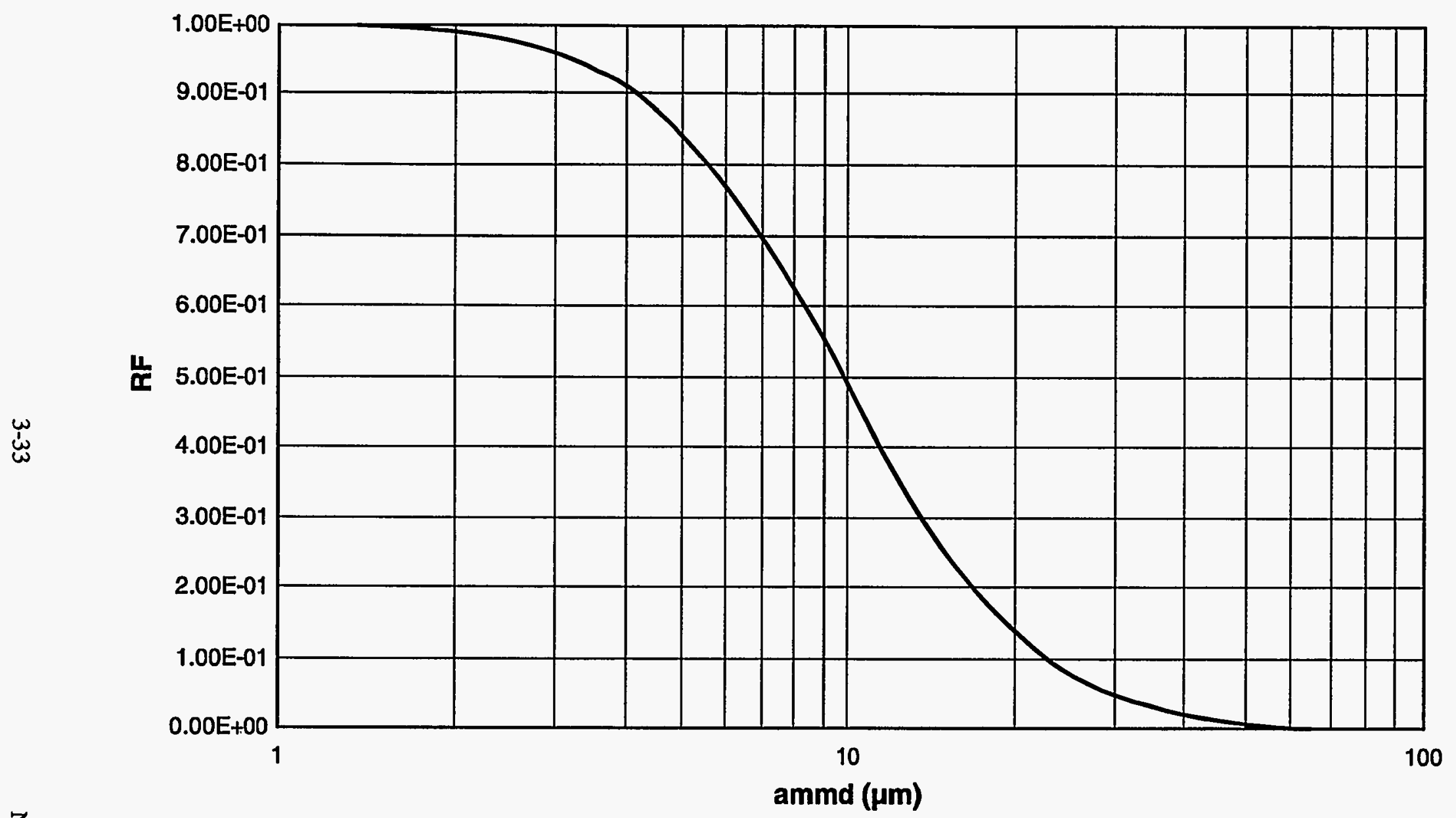

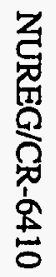

Figure 3-3. Relationship between RF and ammd for log-normal particle distribution with GSD $=2$ 
The Rocky Flats facility published values for ARFs for the actinide materials found at that facility (RFRAG 1985). Values for releases as a result of fire, impact on HEPA filters, spills of and pressurized releases of powders, and inadvertent nuclear criticalities are given.

Elder, et al. (1986) cited generic release values for the entire facility inventory as a consequence of events from TID 14844 and Walker (1978) in their siting and design guide. Screening values for the hazard categorization of facilities are listed in Attachment 1 of DOE-STD-1027-92 (USDOE 1992).

A comprehensive tabulation of reported ARFs by physical type of materials and stress was recently published in DOE-HDBK-3010-94 (USDOE 1994). Much of the material contained here is extracted from this source with additional data from further searches of the literature.

\subsection{Experimental Bases for ARFs, ARRs, and RFs}

Table 3-1 is a summary of the experimental data on ARFs, ARRs, and RFs currently available in the open literature. The table is categorized by the responses of various physical forms to categories of initiating events or behavior. Each entry in Table 3-1 is correlated with an explanatory Subsection in Section 3.3.

\subsubsection{Explosive and Energetic Events}

\subsubsection{Detonations - Reactive Metals (Plutonium)}

Implosion, Pu surrounded by and in intimate contact with High Explosives (HE). HE:Pu ratio $>1$ to 10, single-point detonation. Back calculated from airborne sampling data for operation "Roller Coaster" (Shreve, et al. 1965).

\section{ARF 1.0}

\section{RF 0.2}

Experimental Bases. The first attempts to measure plutonium dispersal from non-nuclear explosions were performed in 1955 and 1956 in Project 57 (Shreve, et al. 1965). These studies were continued in Operation Plumbob in 1957. Because of experimental difficulties and unusual meteorological conditions, the results did not lend themselves to formulation of a generally applicable model for airborne release.

The objectives of Operation Roller Coaster were: (a) to obtain data to permit description of the behavior of airborne plutonium and plutonium deposition on the ground from accidental explosions of the HE in weapons; (b) to provide a complete characterization of the source aerosol; (c) to evaluate the effects of ground cover on the dispersal of plutonium; and (d) to formulate a model of airborne behavior of plutonium using particle settling and turbulent diffusion theory.

The releases from four configurations were studied (see Table 3-2). Single plutonium-bearing units resembling a weapon configuration were fired to simulate an accidental detonation. In three of the four tests, varying numbers of uranium-bearing weapon simulants were also detonated. The test pad was the apex of a 90 degree sector with various sampling arrays. Airborne plutonium particles were collected near ground level (total and respirable plutonium), and, in three of four tests, particles were also collected at various heights by samplers attached to a tethered balloon (total plutonium and particle characteristics). Ground-deposition samples were also collected. 
Table 3-2. Test Configuration Descriptions - Operation Roller Coaster

\begin{tabular}{|c|c|l|l|}
\hline Event & $\begin{array}{c}\text { \# of Units } \\
\text { Detonated }\end{array}$ & \multicolumn{1}{|c|}{ Test Configuration } & \multicolumn{1}{c|}{ Comments } \\
\hline DT & 1 & $\begin{array}{l}\text { 20-cmx20-cm } \\
\text { (8-inx8-in) steel plate }\end{array}$ & $\begin{array}{l}\text { Release with minimum entrainment, cloud and near-surface } \\
\text { air sampling, deposition sampling }\end{array}$ \\
\hline CS I & 9 & $\begin{array}{l}\text { 6-mx6-m (20-ftx20-ft) } \\
\text { concrete pad }\end{array}$ & $\begin{array}{l}\text { Release with entrainment from concrete surface and greater } \\
\text { HE, cloud and near-surface sampling, deposition sampling }\end{array}$ \\
\hline CS II & 19 & Storage structure & $\begin{array}{l}\text { 0.6-m (2-ft) earth cover, cloud and near-storage air sampling, } \\
\text { deposition sampling }\end{array}$ \\
\hline CSIII & 19 & Storage structure & $\begin{array}{l}\text { 2.5-m (8-ft) earth cover, near-surface air sampling, } \\
\text { deposition sampling }\end{array}$ \\
\hline
\end{tabular}

The total plutonium recovery was obtained by integrating the measured depositions and airborne concentrations. Concentration isopleths were calculated for Double Tracks (DT) and Clean Slate (CS names of experimental series) plumes passing through the tethered balloon air sampling array. Approximately 60 percent of the DT and all the CS I visible clouds appeared to pass through the array. The estimated masses of $\mathrm{Pu}$ passing through the array for the two events are: DT $433+/-17 \mathrm{~g}(0.95+/-$ $0.037 \mathrm{lb})$ and CS I $990+/-100 \mathrm{~g}(2.18+/-0.22 \mathrm{lb})$. It is estimated that total recovery was at least 70 percent for each event, but there is considerable uncertainty in this value, given its derivation. The Particle Size Distribution for all active particles is shown in Figure 3-4, which is taken from the report. Inasmuch as CS I involved uranium-bearing weapon simulants and no correlation was found for uranium release, Double Track data are probably more reliable, although there does not appear to be any significant difference between the two distributions shown.

A group of knowledgeable individuals were identified during the Tri-Lab Safety Study to evaluate available information and data on the release of plutonium in accident environments pertinent to the assembly/disassembly operations at the Pantex. Their estimates are presented in a report, "Characterization of Plutonium Aerosols for Various Accident Scenarios by an Expert Panel" (Mensing, et al. 1995). Fifteen hypothetical accident scenarios were evaluated. The mechanisms for environmental exposure considered were:

- A "breach" that would penetrate the metal clad around the reactive metal;

- The presence or absence of a fire;

- Reaction of the HE ranging from burning to gas pressurization to full detonation;

- Whether the HE is Conventional or Insensitive?

- Whether metallic plutonium alone or plutonium metal plus hydride is exposed?

There are many factors that determine the course of the event, including the strength of the confinement around the HE, where the HE is ignited, etc. Each panel member estimated both the ARF and the RF. Estimates of the ARF for a single-point detonation release ranged from 0.75 to 1.0 , with RFs of 0.2 to a value determined by the assumed Particle Size Distribution. The consensus values, ARF $1 E+0 \&$ RF 0.2 , are the commonly accepted "bounding" values. 


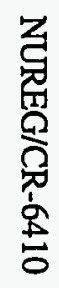

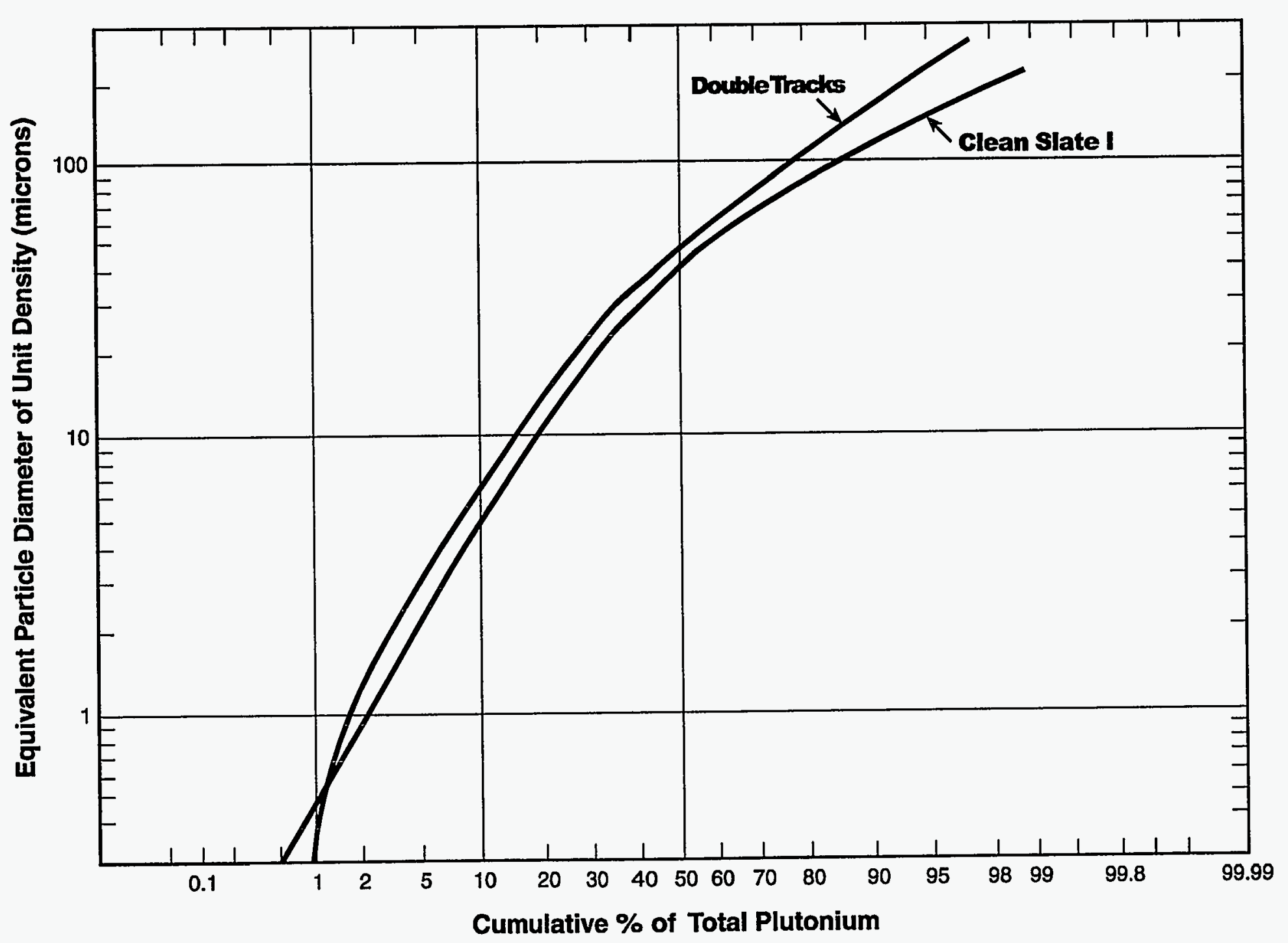

Figure 3-4. All active-particle size distribution for Double Tracks and Clean Slate I (Shreve, et al. 1965) 
In Appendix B.6 of Mensing, et al. (1995) and in a separate report (Stephens 1995), one of the panel members provided estimates of a "Lower Bound" (ARF 7.5E-1, RF 0.15), "Expected" (ARF 1E+0, RF 0.2), and an "Upper Bound" (ARF 1E+0, RF 0.3) values.

The best fit for the size distribution was given as a particle range of 0.1 to $200 \mu \mathrm{m}$ ( $3.9 \times 10^{-6}$ to $0.008 \mathrm{in}$ ) AED, AMAD of $43 \mu \mathrm{m}$ AED (0.0017 in), with a GSD of 3.5 (Griffith, et al. 1996). The RF for the Particle Size Distribution is 0.13 to 0.14. Appendix B of Griffith, et al. (1996) presented the size distribution for Double Tracks, Clean Slate I, II \& III (see Figures 3-5, 3-6, and 3-7). The three distributions are listed in Table 3-3 and give estimates of RF from 0.12 to 0.265 , based on graphical interpolation. The activity size distribution for each test appears to be a composite of at least three distributions (most of the three distributions presented for each test appear to be bi- or multi-modal [i.e., composed of two or more distributions]).

On each of Figures 3-5, 3-6, and 3-7, the data are displayed by a line made up of long dashes. A solid line that lies almost on top of the data is the best-fit trimodal distribution. Three shorter lines on each figure represent the individual components of the trimodal distribution, together with information on median diameter, standard deviation, and percentage contribution to the overall distribution.

Double Tracks involved a single plutonium weapon simulant on a steel plate (a configuration that would result in the entrainment and interaction with the least amount of extraneous material [e.g., soil]) and gives an RF of about 0.12 near ground level several hundreds of meters from the point of generation. Clean Slate I involved nine weapon-configured uranium masses that could contribute to the airborne alpha activity-bearing particles and a concrete pad that is more susceptible to damage than steel. Clean Slates II and III were in Storage Configuration with earth over-burden that is the most likely of the configurations used to generate extraneous airborne particles (uranium is a variable component of all soil), plus each involved the most (19) weapon-configured uranium masses that could contribute alpha activity-bearing particles.

Plastic deformation or melting could result in heated particles that are ejected into the air. Carter and Stewart (1970) and Raabe, et al. (1985) reported an RF of 0.5 with a ARF of $1 E+0$ for the falling of ignited plutonium metal drops through a distance of $1 \mathrm{~m}(3.28 \mathrm{ft})$. Drops of other molten metals in this size range would exhibit similar behavior. Even larger particles or fragments that are not ignited would undergo some additional oxidation during flight and generate smaller oxide particles. The size distributions during all the Roller Coaster tests are the resultant distributions near ground level (either generated near ground level or transported there by gravitational and/or turbulent effects). Thus, none is truly the distribution initially generated; those distributions are highly dependent on the phase of the process during which the aerosol is sampled, the particle depletion and growth mechanisms to which the aerosol was subjected, and the conditions under which the sample to determine the distribution were taken.

The best estimate for plutonium RF at near-ground level at a distance of several hundreds of meters from the source is that for the Double Tracks Test in Operation Roller Coaster, $R F=0.12$. The RF value is not significantly different from the RF value of 0.13 to 0.14 estimated by assuming the particle values in Griffith, et al. (1996). The RF cited here is nearly a factor of 2 greater and is conservative.

\subsubsection{Detonations - Other Metals}

Implosion, metal surrounded by and in intimate contact with $H E ; H E$ :metal ratio $>1$ to 10 , single-point detonation. 


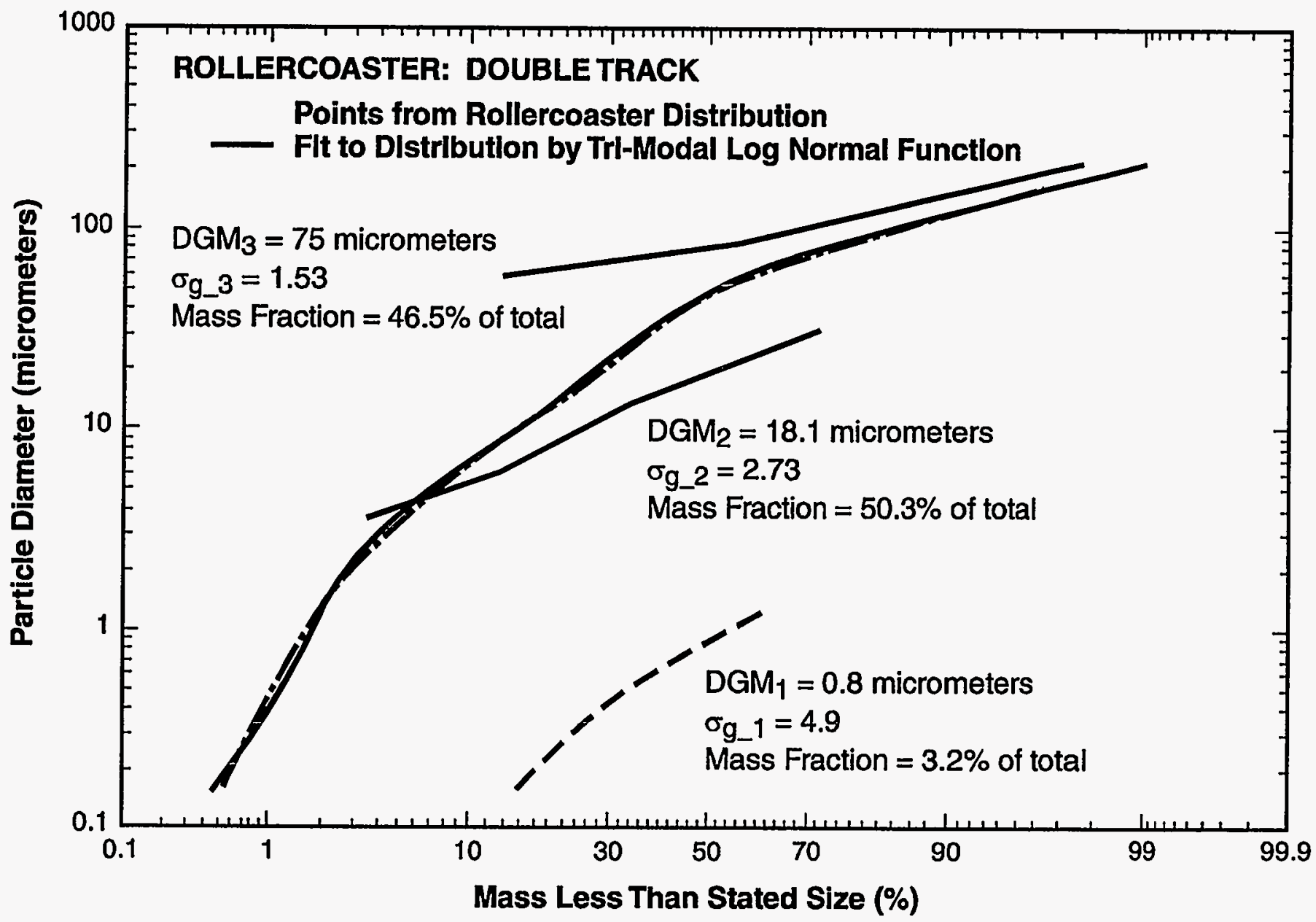

Figure 3-5. Near-ground airborne particle-size distribution for Double Tracks test of Operation Roller Coaster 


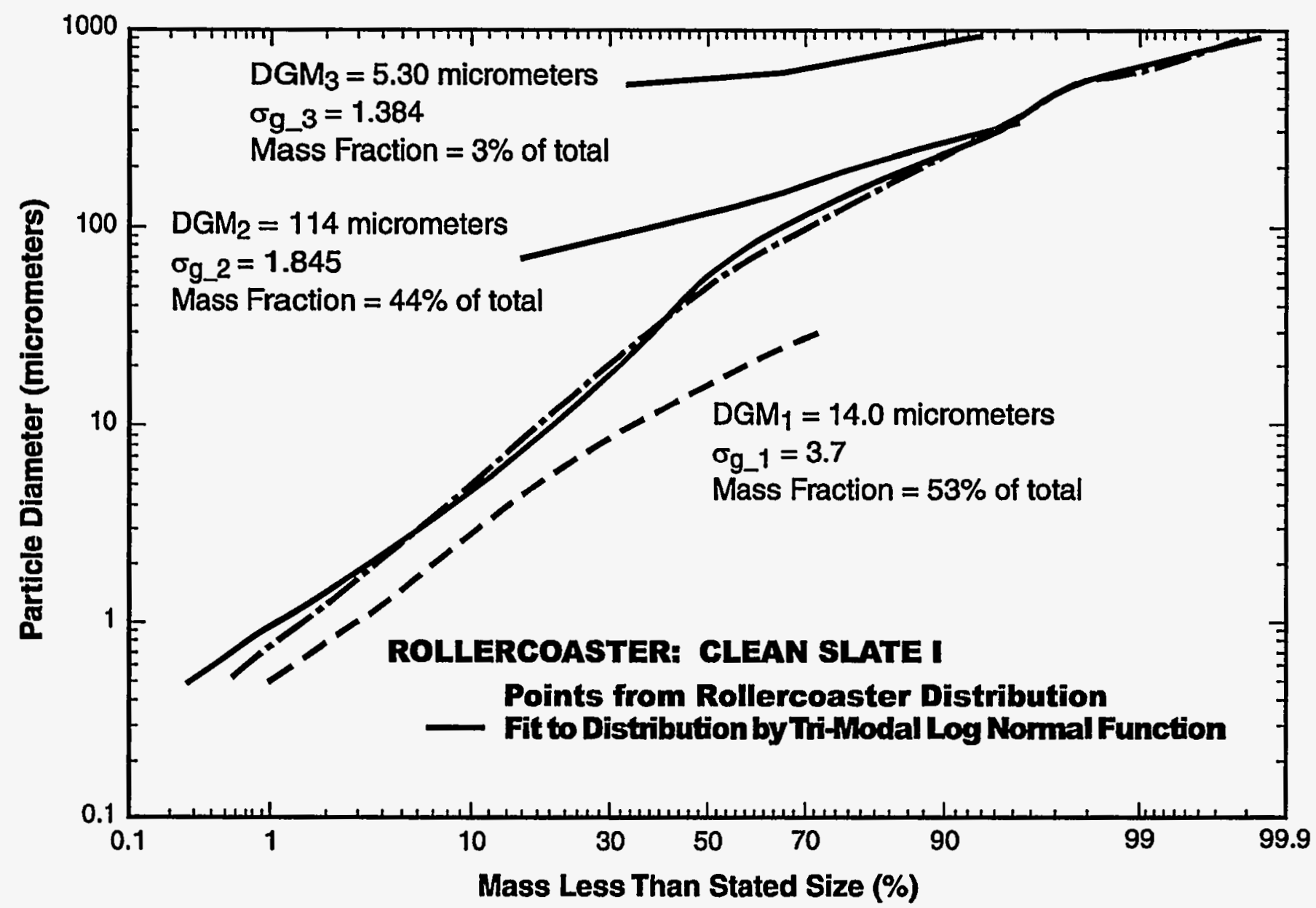

Figure 3-6. Near-ground airborne particle-size distribution for Clean Slate I in Operation Roller Coaster 


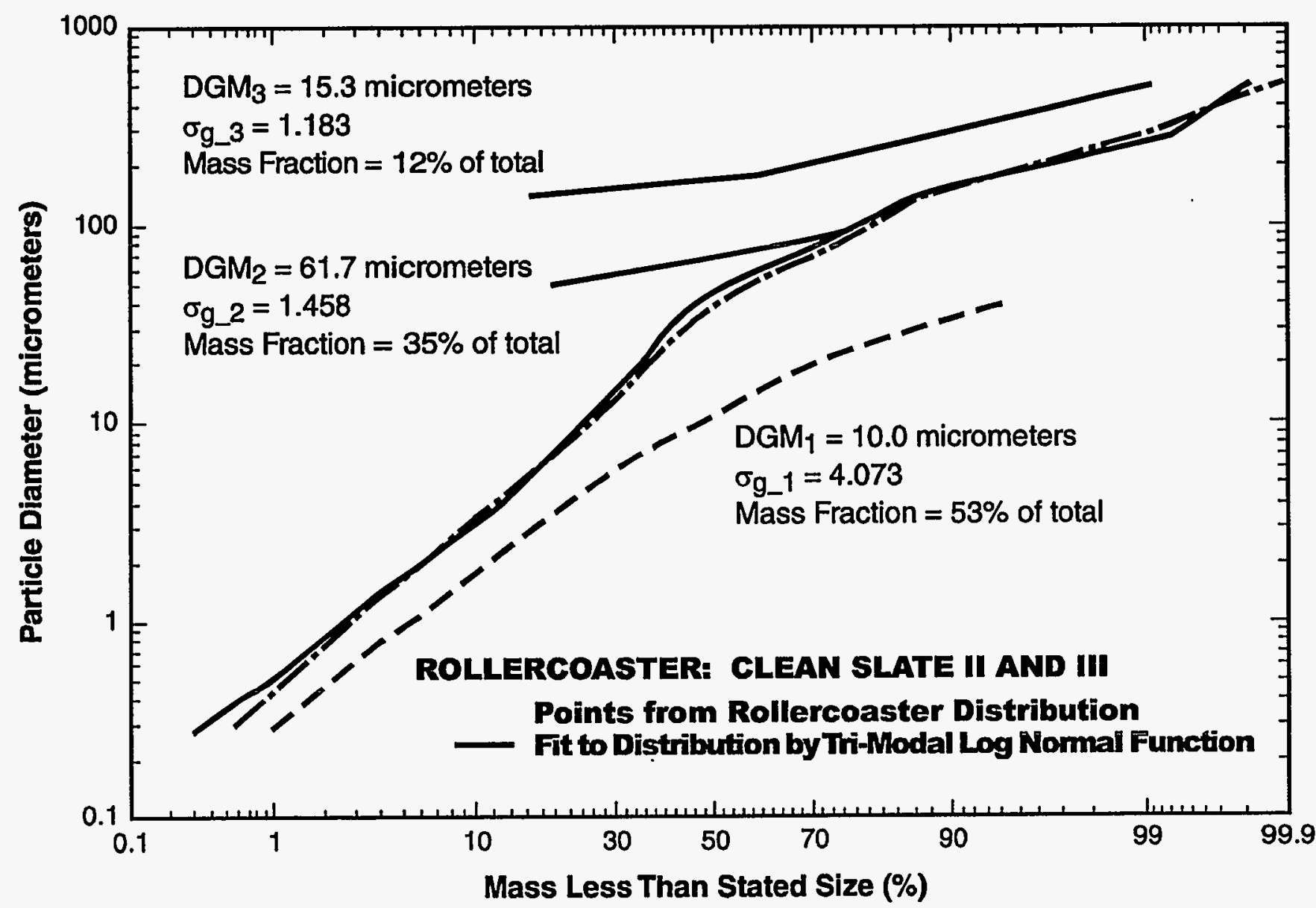

Figure 3-7. Near-ground airborne particle-size distribution for Clean Slate II \& III in Operation Roller Coaster 
Table 3-3. Particle Size Distributions for Operation Roller Coaster Tests (Luna 1994)

\begin{tabular}{|c|c|c|}
\hline \multicolumn{3}{|c|}{ Roller Coaster Double Tracks } \\
\hline $\begin{array}{l}\text { Fraction of } \\
\text { Total } \\
\text { Airborne Mass }\end{array}$ & $\begin{array}{c}\text { Geometric } \\
\text { Mass } \\
\text { Median } \\
\text { Diameter }\end{array}$ & $\begin{array}{c}\text { Geometric } \\
\text { Standard } \\
\text { Deviation } \\
\end{array}$ \\
\hline 3.2 percent & 0.8 micrometers & 4.9 \\
\hline 50.3 percent & $\begin{array}{c}18.1 \\
\text { micrometers }\end{array}$ & 2.73 \\
\hline 46.5 percent & $\begin{array}{c}75.0 \\
\text { micrometers }\end{array}$ & 1.53 \\
\hline
\end{tabular}

\begin{tabular}{|l|c|c|}
\hline \multicolumn{3}{|c|}{ Roller Coaster Clean Slate I } \\
\hline $\begin{array}{l}\text { Fraction of } \\
\text { Total } \\
\text { Airborne Mass }\end{array}$ & $\begin{array}{c}\text { Geometric } \\
\text { Mass } \\
\text { Median } \\
\text { Diameter }\end{array}$ & $\begin{array}{c}\text { Geometric } \\
\text { Standard } \\
\text { Deviation }\end{array}$ \\
\hline 53.0 percent & $\begin{array}{c}14.0 \\
\text { micrometers }\end{array}$ & 3.7 \\
\hline 44.0 percent & 114 micrometers & 1.845 \\
\hline 3.0 percent & 530 micrometers & 1.364 \\
\hline
\end{tabular}

\begin{tabular}{|c|c|c|}
\hline \multicolumn{3}{|c|}{ Roller Coaster Clean Slate II and III } \\
\hline $\begin{array}{l}\text { Fraction of } \\
\text { Total } \\
\text { Airborne Mass }\end{array}$ & $\begin{array}{c}\text { Geometric } \\
\text { Mass } \\
\text { Median } \\
\text { Diameter }\end{array}$ & $\begin{array}{c}\text { Geometric } \\
\text { Standard } \\
\text { Deviation }\end{array}$ \\
\hline 53.0 percent & $\begin{array}{c}10.0 \\
\text { micrometers }\end{array}$ & 4.073 \\
\hline 35.0 percent & $\begin{array}{c}61.7 \\
\text { micrometers }\end{array}$ & 1.458 \\
\hline 12.0 percent & 153 micrometers & 1.183 \\
\hline
\end{tabular}




\section{U: ARF 4E-1, RF NA $(>0.2)$ \\ Other Metals: ARF 2E-1, RF NA}

\section{Technical Basis}

A series of 167 single-point detonation experiments involving hollow hemispheres of various metals have been performed in a 30.5-m (100-ft) air-supported building at the Sandia National Laboratory. ${ }^{1}$ The experiments used hollow metal hemispheres (explosives were placed on the outer surface of the metal), solid spheres (metal sphere with standoff distance to explosives), and powder dispersed on explosives. The hemisphere and the attached explosive charges were normally suspended approximately $0.61 \mathrm{~m}(2 \mathrm{ft})$ above the floor. Charge (HE) to mass ratios ranged from 3 to 12 using $\sim 225 \mathrm{~kg}$ (495 lb) of HE. Large fragments were captured in a 20.9-cm (8.25-in) diameter poly vinyl chloride (PVC) pipe filled with gelatin. This pipe was under the device. Airborne particles were collected by four total particulate air samplers suspended at various heights from each of four wires leading from a center pole to the bottom edge of the four corners in the four major directions. Eight-stage cascade impactors to determine the particle-size distribution of the airborne materials were attached to the top of the wire in two directions, resulting in 14 total particulate air samplers per test. Primary air samplers operated for 15 to 20 minutes after detonation. The airborne fraction was evaluated by assuming that the airborne material stratified into three layers of known volume, and the average airborne concentration of the test material in each layer was determined. Not all samplers in the tests were available for analysis because of the loss of individual samplers or entire wires because of the effect of fragments generated by the device.

The ARF, estimated by the authors to be for particles up to the size range of $200 \mu \mathrm{m}(0.008 \mathrm{in}) \mathrm{AED}$, ranged from 0.04 to 0.4 fraction ( 4 to 40 percent). The data for silver are shown on Table $3-4$, with varying charge to mass ratios (c:m), configurations, and device elevations above the floor. The ARF appears to be affected by direction of the detonation, whether the material is a hollow shell or solid sphere, and the elevation of the device above the ground. The effect of energy deposited in the inert material for these experiments is shown in Table 3-5, with a substantial decrease in ARF with an energy efficiency $\left(\Delta \mathrm{U} / \Delta \mathrm{U}_{\mathrm{lp}}\right)$ of less than some value between 17 percent and 33 percent. The velocities of large, solid fragments ejected from the explosion are estimated to range from 0.5 to $2.5 \mathrm{~km} / \mathrm{s}$ (1120 to $5600 \mathrm{mph}$ ), and they may fragment further from interaction with the environment.

Explosion-generated debris was observed to rapidly flow to the top of the structure, flow several meters down the sides of the structure, and was wrapped back into a toroidal pattern. Visible concentrations of airborne debris were seen near the edges of the structure in a layer 2 to 3 meters $(\sim 6.6$ to $10 \mathrm{ft}$ ) from the top of the structure.

The results of ten experiments involving depleted uranium alloy using the same configuration were reported in Einfield, Craft, and Morrison (1994). A single experiment performed outdoors did not produce usable results. The test parameters and method of measurement were as described above. Charge to mass ratios ranged from 3.5 to 4.8. The ARFs measured were $\mathrm{U} 4 \mathrm{E}-1, \mathrm{Fe} 1 \mathrm{E}-1$, and $\mathrm{Al} 8 \mathrm{E}-2$, with 10 percent to 20 percent of the airborne material in the size range less than $0.5 \mu \mathrm{m}\left(1.95 \times 10^{-5} \mathrm{in}\right) \mathrm{AED}$. More than one particle size distribution was present.

\footnotetext{
${ }^{1}$ Boughton, B.A. and M.E. Kipp. 1996. "Personal Communication," Sandia National Laboratories, Albuquerque, NM.
} 
Table 3-4. Release Fractions from the Single-Point Detonation of Thin Metal Shells as a Function of Charge (HE) to Mass Ratios (c:m)

\begin{tabular}{|l|c|c|}
\hline Device Configuration & c:m & Release Fraction \\
\hline Ag shell (5) & 3 & 0.15 \\
Ag shell, det. on top & 3 & 0.05 \\
Ag shell, elevated $2 \mathrm{~m}$ & 3 & 0.23 \\
Ag shell & 6 & 0.20 \\
\hline Ni shell & 3.5 & 0.12 \\
Ag sphere & 3 & 0.04 \\
Ag sphere (2) & 12 & 0.07 \\
2-3 $\mu \mathrm{m} \mathrm{MnO}_{2}$ powder & 1.1 & 0.03 \\
\hline
\end{tabular}

Table 3-5. Airborne Release Fractions as a Function of Efficiency of Energy Deposited ${ }^{2}$ Aerosolized Fraction Decreases as Energy Deposited in Pit (Tracer) Material is Reduced

\begin{tabular}{|c|c|}
\hline$\Delta \mathrm{U} / \Delta \mathrm{U}_{1 \mathrm{pt}}$ & Release Fraction \\
\hline 1.0 & $\begin{array}{c}0.15 \text { (std error }= \\
0.17 \text { ) }\end{array}$ \\
\hline 0.33 & 0.17 \\
\hline 0.17 & 0.052 \\
\hline 0.10 & 0.012 \\
\hline
\end{tabular}

Note: No particle size distribution data are available

The fate of the fragments has been studied. Grady and Turcano (1994) reported on experiments where spherical copper projectiles, $3.18 \mathrm{~mm}(0.125 \mathrm{in})$ in diameter, were launched into thick beds of low-density urethane foam (a surrogate for the environment produced by high density-high temperature detonation of conventional explosives) at velocities in the range of 2.2 to $4.3 \mathrm{~km} / \mathrm{s}$ (4900 to $9600 \mathrm{mph}$ ). At velocities less than $2.2 \mathrm{~km} / \mathrm{s}(4900 \mathrm{mph})$, no-deforming penetration with little erosion was observed. At velocities in the range of 2.9 to $3.6 \mathrm{~km} / \mathrm{s}$ ( 6400 to $8100 \mathrm{mph}$ ), pervasive plastic deformation of the projectiles occurred, resulting in dish-shaped masses with decreased penetration. At velocities greater than $4.0 \mathrm{~km} / \mathrm{s}$ (8960 mph), the copper spheres shattered, but none of the fragments exceeded a penetration distance of $200 \mathrm{~mm}$ (7.9 in). The experiments were performed in air at ambient temperature and did not reflect the chemical environment anticipated for the atmosphere generated by a detonation of conventional $\mathrm{HE}$.

\footnotetext{
2 Boughton, B.A. and M.E. Kipp, "Personal Communication," Sandia National Laboratories, Albuquerque, NM, 1996.
} 
Furthermore, the work performed in deformation of the metal and the friction experienced by the metal passing through a gas at these high velocities would increase the temperature of the metal. Both these phenomena may explain the enhanced RF found for reactive metals such as plutonium and uranium.

Secondary fragmentation was further studied by Kipp, Grady, and Swegle (1993) using 6.35-mm (0.25-in) well-characterized steel spheres at high velocities ( 3 to $5 \mathrm{~km} / \mathrm{s}$ (6700 to $11200 \mathrm{mph}$ )), colliding with 0.6 - to 11-mm-thick (0.024-in-to-0.43-in-thick) plates of polymethylmethacrylate. Fragments generated were collected and weighed and the size distribution determined. The results were used to determine the accuracy of the current hydrodynamics code ( $\mathrm{CTH}$ code) and provide input for a high-resolution impact fragmentation code.

Kipp (1994) ${ }^{3}$ performed a numerical study of the fragmentation characteristics of thin spherical shells of silver and molybdenum from implosion (the $\mathrm{HE}$ surrounds and is intimate contact with the outer surface of the shell) resulting from a single-point initiation of the explosives. Expansion of the metal resulted in sufficient tensile stress to fragment most of the metal. In some cases, there was sufficient residual heating to lead to liquid and vapor formation. For silver, the fraction of solid was approximately 75 percent for both 25 and $50 \mu \mathrm{m}\left(9.75 \times 10^{-4}\right.$ and $1.95 \times 10^{-3}$ in $) \mathrm{D}_{\mathrm{g}}$ particles, but the vapor fraction increased by an order of magnitude with decreasing diameter. The size distribution of the fragments generated by the explosion was calculated.

\subsubsection{Detonations - Metal or Solution}

Explosion, metal or aqueous solution, HE in intimate contact with material; HE:material ratio 0.07 to $<1$.

ARF and RF based on Mass Ratio (Mass Inert:TNT Equivalent) (see Table 3-6)

\section{Technical Basis}

Steindler and Seefeldt (1980) provided a correlation to experimental data on the fragmentation of metals and aqueous solutions from explosions (detonation where the pressure impulse is directed through the mass of material outward). Both the ARF and RF were correlated to the Mass Ratio (ratio of inert mass to the TNT equivalence of the detonation in comparable mass units) from 1 to 15 . Based on the experimental results, the median diameter was determined, and, using an assumption of a normal distribution of particles, an algorithm was developed that generates the appropriate particle-size distribution. The airborne mass up to approximately $180 \mu \mathrm{m}(0.007 \mathrm{in}) \mathrm{D}_{\mathrm{g}}$ was considered. The $\mathrm{ARF}$ and the RF can be estimated by the choice of the appropriate $\mathrm{D}_{g}$ times the square root of the density of the compound formed. Thus, in Table 3-6, if the density of the material is greater than $10.9 \mathrm{~g} / \mathrm{cm}^{3}\left(680 \mathrm{lb} / \mathrm{ft}^{3}\right)$ (plutonium and uranium dioxides), the $R F$ is the material in the $1-$ and $3-\mu \mathrm{m}\left(3.9 \times 10^{-5}-\right.$ and $1.2 \times 10^{-4}$-in) fractions. If the material is $\mathrm{U}_{3} \mathrm{O}_{8}$ (density $8.30 \mathrm{~g} / \mathrm{cm}^{3}\left(518 \mathrm{lb} / \mathrm{ft}^{3}\right)$ ), all materials up to $\mathrm{D}_{\mathrm{g}}$ of $3.5 \mu \mathrm{m}\left(1.4 \times 10^{-4}\right.$ in) should be included. For practical purposes, the same value used for plutonium and uranium dioxides may be used as an approximation. The values shown in Table 3-6 assume a GSD of 2.

\footnotetext{
3 Kipp, M.E., "Numerical Studies of Implosion Fragmentation," Draft, Sandia National Laboratories, 1994.
} 
Table 3-6. ARF and RF as a Function of Mass Ratio (USDOE 1994)

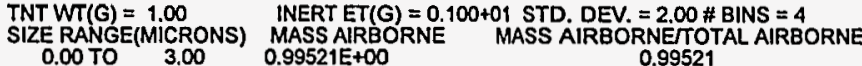
$0.00 \mathrm{TO} 3.00$ $0.99521 E+00$
$0.47636 E-02$

$\begin{array}{rrr}10.00 \text { TO } & 30.00 & 0.28908 \mathrm{E}-04 \\ 30.00 \mathrm{TO} & 100.00 & 0.89407 \mathrm{E}-06\end{array}$

TOTAL MÁSS AIRBORNE $=0.10000$ E $+01 \quad$ FRAC. INERT AIRBORNE $=0.10000 \mathrm{E}+0$

TNTWT(G) $=1.00 \quad$ INERT WT(G) $=0.200 E+01$ STD. DEV $=2.00$ \#INS $=4$ SIZE RANGE(MICRONS) 0.00 TO 3.00 MASS AIRB
$0.22000-02$
$0.18100-020$

$0.22060 \mathrm{E}-02$
$0.18190 \mathrm{E}+00$
$0.10190 \mathrm{C}$ $0.10190 \mathrm{E}+00$

TOTAL MASS AIRBORNE $=0.20000 \mathrm{E}+01$ FRAC. INERT AIRBORNE $=0.10000 \mathrm{E}+01$

TNT WT(G) $=1.00 \quad$ INERT WT(G) $=0.200 E+01$ STD. DEV. $=2.00 \#$ BINS $=4$ $\begin{array}{ccc}\text { SIZE RANGE(MICRONS) MASS AIRBORNE MASS AIRBORNE } / T O T A L & 0.39053 E-03 \\ 0.00 \mathrm{TO} & 3.00 & 0.00013\end{array}$ 3.00 TO $10.0000002032 \mathrm{E}-01$

30.00 TO 100.00 $0.17269 \mathrm{E}+01$

TOTAL MASS AIRBORNE $=0.30000 E+01$ FRAC. INERT AIRBORNE $=0.10000 E+01$

INTWRT WT(G) $=0.300 E+01 \mathrm{STD}$. DEV $=2.00$ \# BINS $=4$
SIZE RANGE(MICRONS)
MASS AIRBOORNE MASS AIRBORINETOTAL AIRBORNE $\begin{array}{llr}0.00 \text { TO } 3.00 & 0.20170 E-03 & \\ 3.00 \text { TO } 10.00 & 0.33887 \mathrm{E}-01 & 0.00005 \\ 1.00 & 30.00 & 0.00847\end{array}$ $\begin{array}{rrr}10.00 \text { TO } 30.00 & 0.81475 E+00 & 0.20369 \\ 30.00 \text { TO } 100.00 & 0.24593 \mathrm{E}+01 & 0.61349\end{array}$

TOTAL AMSS AIRBORNE $=0.400000 \mathrm{E}+01$ FRAC. INERT AIRBORNE $=0.10000 \mathrm{E}+01$

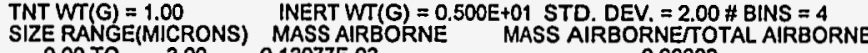
$\begin{array}{llll}0.00 \text { TO } & 3.00 & 0.13977 \mathrm{E}-03 & 0.00003 \\ 3.00 & 1000 & 0.22039 \mathrm{E}-01 & 0.00041\end{array}$

$\begin{array}{rrrr}10.000 \text { TO } & 30.00 & 0.74044 E+00 & 0.0441 \\ 30.00 \text { TO } & 100.00 & 0.30443 E+01 & 0.60886\end{array}$

TOTAL MASS AIRBORNE $=0.50000 \mathrm{E}+01$ FRAC. INERT AIRBORNE $=010000 \mathrm{E}+01$

INTWT $(G)=1.00$
SIZE RANGES(MICRONS)
MASS AIRBORNE $=0.600 E+01$ STD. DEV. $=2.00$ \# BINS $=4$
MASS AIRBORNETOTAL AIRBORN

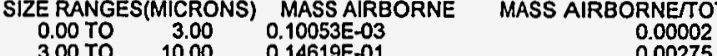

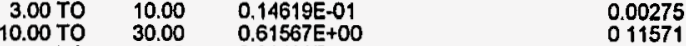

30.00 TO $100.00 \quad 0.31498 E+0$

TOTAL MASS AIRBORNE $=0.53207 E+01$ FRAC INERT AIRBORNE $=0.88679 E+00$
INTWRT WT(G) $=0.700 E+01$ STD. DEV $=2.00$ \# BINS $=4$
TNT $=1.00$ $0.0070 \quad 3.0000 .78466 \mathrm{E}-04 \quad 0.00001$

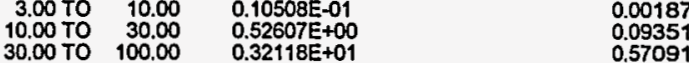

TOTAL MÁSS AIRBORNE $=0.56258 E+01$ FRAC. INERT AIRBORNE $=0.80369 E+00$

TNT WT $(G)=1.00 \quad$ INERT WT(G) $=0.800 E+01$ STD. DEV $=2.00$ \# BINS $=4$ SIZE RANGE(MICRONS) MASS AIRBORNE MASS AIRBORNETTOTAL AIRBORNE

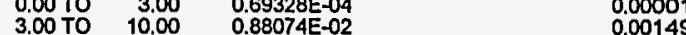
10.00 TO $30.00 \quad 0.48513 \mathrm{E}+00 \quad 000$ TOTAL MÄSS AIRBORNE $=0.59042 E+01 \quad$ FRAC. INERT AIRBORNE= $0.73802 E+\infty$ $=0.00{ }^{2}+01$ STD DEV $=200$ \# BINS $=4$ SIZE RANGE(MICRONS) MASS AIRBORNE MASS AIRBORNETTOTAL AIRBORNE $\begin{array}{rrrr}0.00 \text { TO } & 3.00 & 0.62430 E-04 & 0.00001 \\ 3.00 \text { TO } & 10.00 & 0.75342 E-02 & 0.00122\end{array}$ 30.00 TO $100.00 \quad 0.33337 E+01 \quad 0.54109$

TOTAL MASS AIRBORNE $=0.61612 E+01$ FRAC INERT AIRBORNE $=0.68457 E+00$ TNTWT(G) $=1.00$
INERT WT(G) $=0.100 E+02$ STD. DEV $=2.00$ \# $8 I N S=4$
SIZE RANGE(MICRONS) MASS AIRBORNE MASS AIRBORNETOTAL AIRBORNE $\begin{array}{llll}0.00 \text { TO } & 3.00 & 0.56843 \mathrm{E}-04 & 0.00 \\ 3.00 & 10.00 & 0.65522 \mathrm{E}-02 & 0.00001\end{array}$

$\begin{array}{rrrr}3.00 \text { TO } & 10.00 & 0.65522 E-02 & 0.00102 \\ 10.00 \text { TO } & 30.00 & 0.41954 E+00 & 0.06555 \\ 30.00 \text { To } & 1000 & 0.33713 \mathrm{E}+01 & 0.52673\end{array}$

TAL MASS AIRBORNE $=0.64005 E+01$ FRAC INERT AIRBORNE $=0.64005 E+00$ TNTWT(G) $=1.00$
SIZE RANGE(MICRONS) MASS AIRBORNE

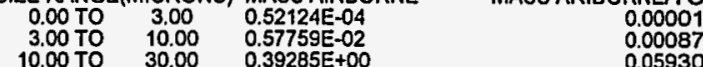
$\begin{array}{rrrr}10.00 \text { TO } & 30.00 & 0.39285+\infty & 0.05 \\ 30.00 \text { TO } & 100.00 & 0.33980 E+01 & 0.51291\end{array}$ TOTAL MASS AIRBORNE $=0.66260 E+01$ FRAC INERT AIRBORNE $=0.60227 \mathrm{E}+00$ TNT WT(G) $=1.00$
SIZE RANGE(MICRONS) MASS $W T(G)=0.120 E+02$ STO. DEV. $=2.00$ \# BINS $=4$
MASBORN
MASS AIRBORNETTOTAL AIRBORNE $0.00 \mathrm{TO} 3.00 \quad 0.48493 \mathrm{E}-04 \quad 0.0000$ $\begin{array}{ll}0.51496 \mathrm{E}-02 & 0.0007 \\ 0.36927 \mathrm{E}+00 & 0.05401\end{array}$ 30.00 TO $100.00 \quad 0.34163 E+01 \quad 049969$

TOTAL MASS AIRBORNE $=0.68368 E+01$ FRAC INERT AIRBORNE $=0.56973 E+00$ 


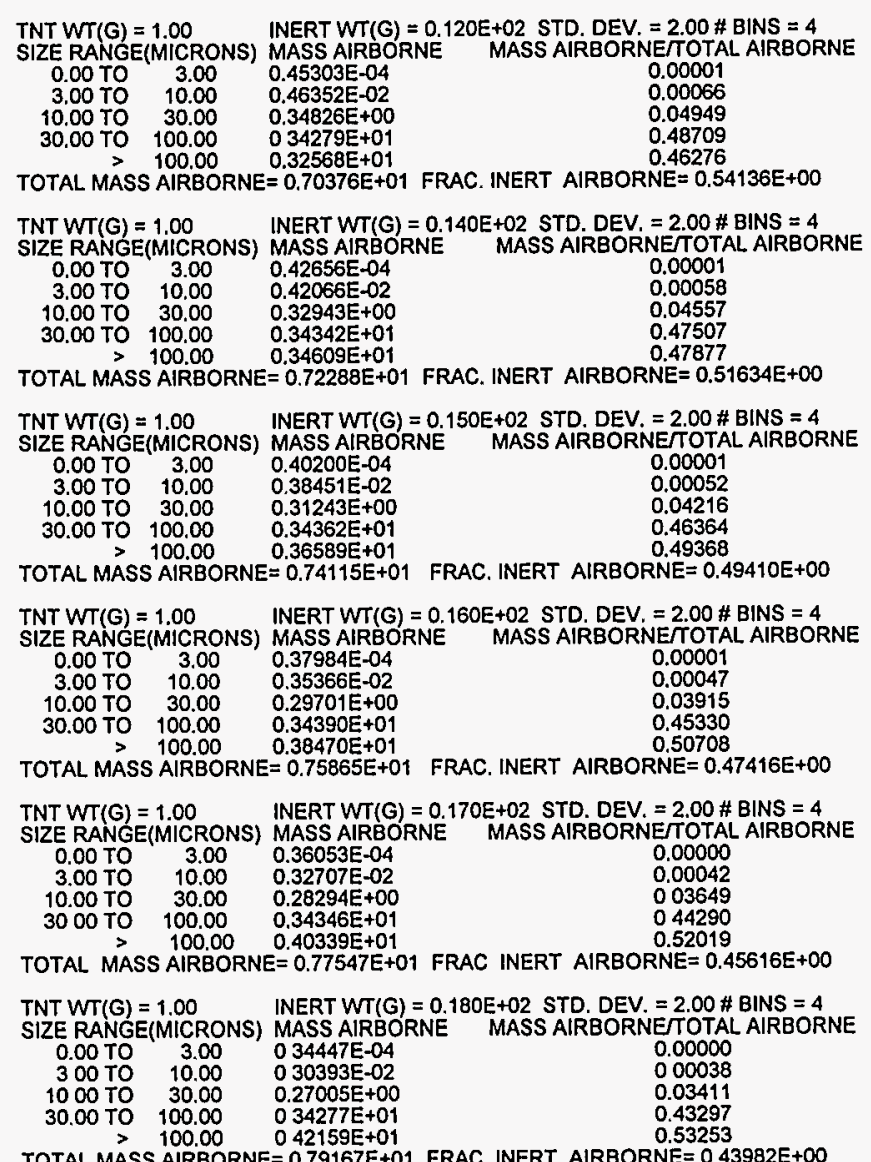

TNT WT(G) $=1.00 \quad$ INERT WT(G) $=0 \quad 190 E+02$ STD. DEV $=2.00$ \# BINS $=4$

\begin{tabular}{cccc} 
SIZE RANGE(MICRONS) & MASS AIRBORNE & MASS AIRBORNESTOTAL \\
0.00 TO & 3.00 & $0.332022-04$ & 0.00000 \\
$3.00 \mathrm{TO}$ & 10.00 & $0.28361-02$ & 0.00035 \\
10.00 TO & 30.00 & $0.25820 \mathrm{E}+00$ & 0.03198 \\
30.00 TO & 100.00 & $0.34187 \mathrm{~T}+01$ & 0.42347 \\
\hline & 100.00 & $0.43933 \mathrm{E}+01$ & 0.54419
\end{tabular}

TOTAL MASS AIRBORNE= $\begin{gathered}100.00731 \mathrm{E}+01 \text { FRAC. INERT AIRBORNE= } 0.42490 \mathrm{0}+\infty \\ 0.00\end{gathered}$

TNTWT(G) $=1.00 \quad$ INERT WT(G) $=0.200 E+02$ STD, DEV. $=2.00$ \# BINS $=4$

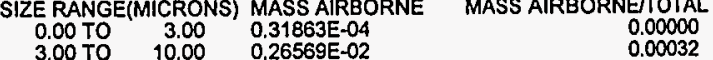

$\begin{array}{rrrr}3.00 \text { TO } & 10.00 & 0.26569 \mathrm{E}-02 & 02 \\ 10.00 \mathrm{TO} & 30.00 & 0.24726 \mathrm{E}+00 & 0.00032 \\ 30.00 \mathrm{TO} & 100.00 & 0.34080 \mathrm{O}+01 & 0.03006\end{array}$

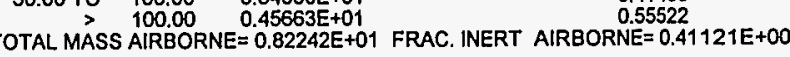
$\begin{array}{ll}\text { TNT WT(G) }=1.00 & \text { INERT WT(G) }=0.210 E+02 \\ \text { STD. DEV. }=2.00 \# \text { BINS }=4 \\ \text { SIZE RANGE(MICRONS) MASS AIRBORNE MASS AIRBORNETOTAL AIRBORNE }\end{array}$

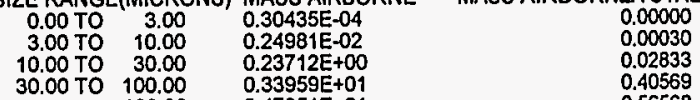

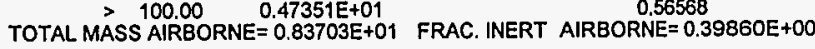
TNT $W T(G)=1.00 \quad$ INERT $W T(G)=0.220 E+02$ STD. DEV. $=2.00$ \# BINS $=4$

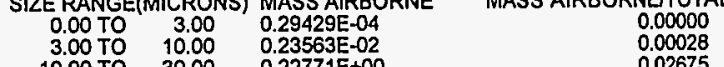

$\begin{array}{rrrr}10.00 \text { TO } & 30.00 & 0.22771 E+00 & 0.02675 \\ 30.00 \text { TO } & 100.00 & 0.33826 E+01 & 0.39736\end{array}$

TOTAL MASS AIRBORNE $=0.85127 \mathrm{E}+01$ FRAC INERT AIRBORNE $=038694 \mathrm{O}=00$ $\begin{array}{ll}\text { TNT WT(G) }=1.00 & \text { INERT WT(G) }=0.230 E+02 \text { STD. DEV. }=2.00 \text { \# BINS }=4 \\ \text { SIZE RANGE(MICRONS) MASS AIRBORNE MASS AIRBORNETOTAL AIRBORNE }\end{array}$ 0.00 TO $3.00 \quad 0.28359 \mathrm{E}-04 \quad 0.00000$ 3..00 $10.00 \quad 0.22289 \mathrm{E}-02$ 30.00 TO $\quad 100.00 \quad 0.33684 E+01$

TOTAL MASS AIRBORNE $=0.86507 E+01$ FRAC INERT AIRBORNE= $037612 E+00$ TNT WT $(G)=100 \quad$ INERT WT(G) $=0.240 E+02$ STD. DEV. $=2.00 \#$ BINS $=4$ SIZE RANGE(MICRONS) MASS AIRBORNE MASS AIRBORNETOTAL AIRBORNE 0.00 TO $3.00 \quad 0.27228 E-04$ $\begin{array}{rrrr}3.00 \text { TO } & 30.00 & 0.21073 \mathrm{E}+00 & 0.0239 \\ 10.00 & 0.33534 \mathrm{TE}+01 & 0.38172\end{array}$ TOTAL MASS AIRBORNE $=0.87849 E+01$ FRAC INERT AIRBORNE $=036604 E+00$ 


\title{
3.3.1.4 Detonations - Powder
}

Explosion, High Explosives lying on surface of powder, HE:powder ratio 1 to 100. From soil lofted during field tests where HE (bare and as artillery shells) were placed on surface of soil for HE:soil ratios 10:10.

\section{ARF 0.8 \\ RF 0.25}

\section{Technical Basis}

Gerrard (1963) reported the detection of a velocity component toward the surface from a detonation that appeared to pass through the powder on the surface and be reflected by the surface (powder could then be suspended by the reflected wave). The Army Corp of Engineers has surveyed and performed experiments to determine battlefield obscuration by dust generated by the explosions of bare charges and munitions on the soil surface.

Strange and Rooke (1988) surveyed the results of some 550 tests involving both cased and uncased (bare) charges on or near the ground surface with TNT equivalent ranging up to $10^{6} \mathrm{~kg}\left(2.2 \times 10^{6} \mathrm{lb}\right)$. Estimates of the cratering (soil dislodged) averaged $150 \mathrm{~kg}$ soil/ $\mathrm{kg}$ TNT (150 lb soil//b TNT) equivalent.

Long, Mason, and Durst (1984) conducted a series of tests using spherical charges of C-4 explosives on the soil surface with TNT Equivalents ranging from $3.4 \mathrm{~kg}(7.5 \mathrm{lb})$ to $11.3 \mathrm{~kg}(24.9 \mathrm{lb})$. The cratering was $65 \mathrm{~kg}(143 \mathrm{lb})$ to $235 \mathrm{~kg}(517 \mathrm{lb})$ soil $/ \mathrm{kg}$ TNT Equivalent, consistent with average cratering value of 150 $\mathrm{kg}$ soil/kg TNT Equivalent as reported by Strange and Rooke (1988) above. Two types of soil were found-sandy clay and sandy clay-sandy soil (indices of the fractions of clay, sand, and loam found). Moisture content ranged from 6.7 percent to 26.7 percent. Assuming a bulk density of $3.0 \mathrm{~g} / \mathrm{cm}^{3}\left(187 \mathrm{lb} / \mathrm{ft}^{3}\right)$, the RF for the soil ranged from 0.24 to 0.26 . The fraction of soil $<100 \mu \mathrm{m}(0.0039 \mathrm{in}) \mathrm{D}_{\mathrm{AED}}$ ranged from 0.42 to 0.50 . The principal parameters influencing dust generation were reported as: in-situ soil particle-size distribution; moisture content of the soil; chemical composition of the soil; the presence/absence of vegetation; and meteorological conditions.

The ARFs determined by the $<100 \mu \mathrm{m}$ ( $0.0039 \mathrm{in})$ fraction collected in high volume sampler at various heights ranged from 0.184 to $0.84 \mathrm{~kg}$ soil $/ \mathrm{kg}$ TNT ( 0.184 to $0.84 \mathrm{lb}$ soil/lb TNT) equivalent. The $<100 \mu \mathrm{m}$ ( 0.0039 in) $D_{A E D}$ fraction in the soil was reported to be from 0.42 to 0.5 and, based upon the mass of soil dislodged (cratering) and carried downwind (ARF), the soil does not appear to have been significantly deagglomerated (separated) by the explosion. From the data, it appears that some parameter or set of parameters affects the ARF, but the specific parameter was not identified. A bounding ARF value of 0.8 [TNT Equivalent] is recommended, and a bounding RF of 0.25 (the RF value for the soil).

\subsubsection{Detonations - HEPA Filters}

Small pieces of glass fiber medium are dislodged from a few locations on the creases of the downstream side of the filter.

\author{
ARF 2E-6 \\ RF 1.0
}




\section{$\underline{\text { Technical Basis }}$}

Gregory, et al. (1983) determined the structural strength, particle loss, and particle collection efficiency during simulated tornado and explosion transients. The explosion transients were simulated by transmission of a shock wave of 54-msec duration from a bank of high-pressure gas cylinders through a $0.91 \mathrm{~m}$ (36 in) diameter shock tube. Pressure was monitored by a transducer just in front of the HEPA filter being tested, and failure was determined photographically from a downstream camera. The filters (total collection area of the glass fiber medium was $1.8 \times 10^{5} \mathrm{~cm}^{2}\left(194 \mathrm{ft}^{2}\right)$ ) were loaded with polystyrene latex particles to a pressure differential 150 percent of the design value $38.7-\mathrm{cm}$ (1.5-in) WG which was estimated to represent $1 \mathrm{~kg}(2.2 \mathrm{lb})$ of particles. The mean $\mathrm{D}_{\mathrm{g}}$ of the particles was $0.46 \mu \mathrm{m}\left(1.8 \times 10^{-5} \mathrm{in}\right)$, but no GSD was given. The structural strength of filters from four manufacturers ranged from an overpressure of $7.2 \mathrm{kPa}(1.04 \mathrm{psi})$ to $17.4 \mathrm{kPa}(2.53 \mathrm{psi})$. Previous experimenters has reported a structural failure at an overpressure of $20.8 \mathrm{kPa}$ (3 psi), and Gregory, et al. (1983) recommended a lower level for failure at an overpressure of $14.8 \mathrm{kPa}(2 \mathrm{psi})$. Peak pressure was not sufficient to define structural strength and, for failures from pulses greater than $20 \mathrm{msec}$, impulse per unit area can be used. For failures at shorter pulse durations, other factors had to be considered.

The measured release from the three filters tested from two manufacturers were $0.41,1 \times 10^{-6}$, and $2 \times 10^{-6}$. The highest ARF was considered an outlier because of pre-creasing of the filter medium. The failure of the other two filters appeared to result from a few small tears to a small section of the filter mat on the rear folds.

The postulated ARF, 2E-6, equates to loss of all contaminant collected in an area of $0.4 \mathrm{~cm}^{2}\left(0.062 \mathrm{in}^{2}\right)$ (a tear $4 \mathrm{~cm}$ (1.6 in) long $\times 0.1 \mathrm{~cm}$ (0.039 in) wide). Dislodging all of the collected contaminants would be a difficult task because some fraction of the contaminant is embedded in the medium matrix.

Particle collection efficiencies for shock-entrained particles were only determined for two high-capacity HEPA filters that are constructed differently than the standard HEPA filters and are not applicable.

\subsubsection{Deflagration - Powder}

a. Unshielded, directly under or in blast volume, large explosion

\section{ARF 1.0 RF NA}

\section{b. In Containers or at Distance (meters) from blast volume (aerodynamic entrainment by accelerated gas velocities)}

\section{ARF 5E-3 \\ RF (0.3)}

\section{Technical Basis}

For powders directly under the blast volume of a large deflagration, the direction of the blast flow will be normal or at an acute angle to the powder resting on a hard, unyielding surface. Royster and Fish (1967) demonstrated that, at acute angles of attack by airflows at moderate velocities under the proper conditions, the suspension of particles (ARF) down to $\mathrm{D}_{\mathrm{g}}$ of $5 \mu \mathrm{m}\left(2.0 \times 10^{-4}\right.$ in) can be essentially complete. The $\mathrm{RF}$ 
under these conditions would be the same as the source material because the forces involved are not sufficient to fragment small particles of most common compounds and deagglomeration may be incomplete.

For powders in containers at some distance from the blast, where the flow would be essentially parallel to the surface, the container is expected to topple or be hurled some small distance under the worst assumptions. Under these conditions, the powder would spill or fall out of the container to the floor. Using the correlation reported in Halverson and Mishima (1986), and estimating the force of the blast wave traveling through the $30 \mathrm{~g}(0.066 \mathrm{lb})$ of powder (a very conservative assumption), the ARF calculated was 5E-3. Other experimental studies (Mishima and Schwendiman 1970) indicate that for this type of phenomenon, an RF of 0.3 is appropriate.

\subsubsection{Deflagrations - HEPA Filters}

HEPA Filters: Response of HEPA filters to blast effects.

\section{ARF 1E-2 RF NA}

\section{Technical Basis}

Gregory et al. (1983) have performed pressure tests on loaded, 1000 cfm HEPA filters. "Loaded" means having accumulated a sufficient amount of particulate material to have an effect on the differential pressure across the filter. Static failure pressure ranged from 9.1 to $20.0 \mathrm{kPa}(1.33$ to $2.9 \mathrm{psig})$, with a mean failure pressure of $16.3 \mathrm{kPa}(2.37 \mathrm{psig})$. The particle collection efficiency for $0.46 \mu \mathrm{m}\left(1.8 \times 10^{-5} \mathrm{in}\right) \mathrm{D}_{\mathrm{g}}$ polystyrene latex spheres degraded from 99.97 percent to 98.9 percent. The ARFs of the collected polystyrene spheres ranged from $7.1 \times 10^{-3}$ to $1.46 \times 10^{-2}$, giving a mean ARF of $9.35 \times 10^{-3}$. The bounding ARF of $1 \mathrm{E}-2$ is recommended with an RF of 1.0 , in the absence of any data on the RF from the release.

\subsubsection{Overpressurization to Rupture}

\section{A. Liquid, Confined (in vessel/container): Bounding Values}

\section{Slow Build up of Pressure:}

a. Vented above the surface level of liquid, failure pressure $<0.35 M P a_{g}(50.9 \mathrm{psig})$

\section{ARF 5E-5 \\ RF (0.8)}

b. Vented above the surface level of liquid, failure pressure $>0.35$ up to $3.5 M P a_{g}(50.9$ up to $510 \mathrm{psig}$ )

ARF 2E-3
RF (0.3)

c. Vented below the surface level of liquid

No value available 
B. Vented above the surface level of liquid, failure pressure $>3.5 \mathrm{M} \mathrm{Pa}_{g}(510 \mathrm{psig})$ :

Estimated values are based upon mole fraction of gases/vapors vented from liquid during release (see
Figure 3-8, "Fraction Airborne vs. Mole Fraction of Pressuring Gas for Liquid Pressurized Release").

$\underline{\text { Technical Basis }}$

Liquids confined within a vessel may be pressurized by a variety of mechanisms (e.g., heating, pressurizing the free-volume above the gas). In the case of most solvents, including water, the vapor pressure of the solvent is much greater than that of the non-volatile solute (boiling temperatures are hundreds of degrees $\mathrm{K}$ higher), and the solvent and solute are separated by fractional distillation. On loss of confinement from vents above the surface of the liquid, the gases and vapors are released to the ambient atmosphere, but only a small fraction of the solution/solutes is released.

Pressures less than $3.5 M P a_{g}(510$ psig)

Experiments have been conducted to measure the ARF and RF during the venting of aqueous solutions-nitric acid heavy metal solution (uranyl nitrate hexahydrate $(\mathrm{UNH})$ ) and dilute aqueous solutions (uranine, sodium fluorocein) at initial pressures ranging from $0.35 \mathrm{MPa}_{\mathrm{g}}\left(50.9 \mathrm{psig}\right.$ ) to $3.5 \mathrm{MPa}_{\mathrm{g}}(510 \mathrm{psig}$ ) (Sutter 1983; Ballinger, M.Y., S.L. Sutter, and W.H. Hodgson 1987). The experimental protocol allowed essentially an equilibrium volume of the pressurizing gas (air) to dissolve in the solutions. The ARF values ranged from $3 \mathrm{E}-6\left(350 \mathrm{~cm}^{3}\left(0.012 \mathrm{ft}^{3}\right)\right)$ of $\mathrm{UNH}$ at an initial pressure of $\left.0.35 \mathrm{MPa}_{\mathrm{g}}(50.9 \mathrm{psig})\right)$ to $2 \mathrm{E}-3\left(100 \mathrm{~cm}^{3}\left(0.0035 \mathrm{ft}^{3}\right)\right)$ of uranine at an initial pressure of $\left.3.5 \mathrm{MPa}_{\mathrm{g}}(510 \mathrm{psig})\right)$. The ARFs varied with type of solution, volume of solution, and initial pressure. The recommended bounding ARF of 2E-3 for the venting of aqueous solutions with an initial pressure up to $3.5 \mathrm{MPa}_{\mathrm{g}}(510 \mathrm{psig})$ is identical to the bounding value for aqueous solutions during boiling (see Section 3.3.2.3).

$\mathrm{RF}$ values ranged from $0.34\left(350 \mathrm{~cm}^{3}\left(0.012 \mathrm{ft}^{3}\right)\right)$ of $\mathrm{UNH}$ at an initial pressure of $\left.3.5 \mathrm{MPa}_{\mathrm{g}}(510 \mathrm{psig})\right)$ to $0.98\left(350 \mathrm{~cm}^{3}\left(0.012 \mathrm{ft}^{3}\right)\right.$ uranine at an initial pressure of $\left.1.7 \mathrm{MPa}_{\mathrm{g}}(248 \mathrm{psig})\right)$. The RF associated with the bounding $A R F, 0.3$, is recommended.

The bounding value for initial pressures up to $0.35 \mathrm{MPa}_{\mathrm{g}}(50.9 \mathrm{psig})$ is lower.

Pressurized Liquids, Pressure Greater than $3.5 M P a_{g}(510$ psig)

For initial pressures greater than $3.5 \mathrm{MPa}_{\mathrm{g}}(510 \mathrm{psig})$, for interpolation between the bounding values, and for "flashing sprays" from the venting of aqueous liquids with greater than $50 \mathrm{~K}$ superheat $(323 \mathrm{~K}$ $\left(122^{\circ} \mathrm{F}\right)$ ), the ARF can be estimated using the Mole Fraction of dissolved gases or vapor vented from the liquid upon release. As discussed below, the particle size of the droplets generated may change as a function of the temperature of the liquid, the hygroscopic character and the concentration of the solute, and the temperature and relative humidity of the atmosphere into which the droplets are released. A superheated liquid or a liquid pressurized with a dissolved gas will produce droplets if the retaining pressure is suddenly lowered. These are exemplified by flashing sprays or a suddenly opened carbonated beverage that has been recently shaken. A significant part of the droplets is produced when bubbles break up. The following shows how the RF and the ARF are estimated. 


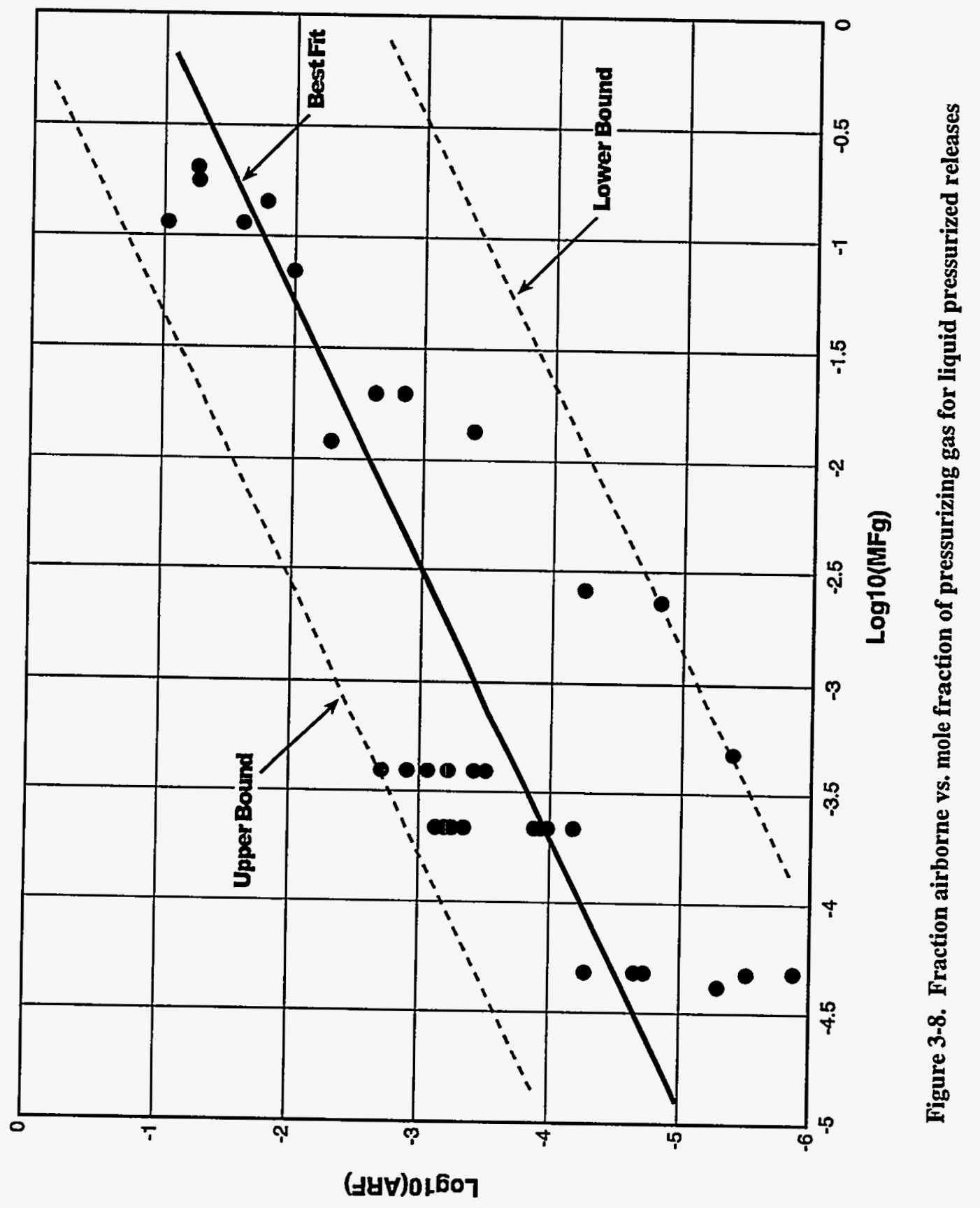


A number of experiments have produced ARF data (Sutter 1983 and Ballinger, et al. 1987) that are useful here, although the particle size data from these experiments have limited quantitative value. The difficulty with describing droplet aerosols is that the individual droplets can evaporate rapidly. (In dry air, at $291 \mathrm{~K}$ $\left(64^{\circ} \mathrm{F}\right)$, a $20 \mu \mathrm{m}\left(7.8 \times 10^{-4}\right.$ in $)$ diameter drop of pure water will evaporate in $0.06 \mathrm{~s}$, whereas at 80 percent relative humidity, it takes $2.5 \mathrm{~s}$. See Davies and Rideal (1963)). Aqueous solutions of non-volatile solutes will always evaporate more slowly than pure water. Thus, the data taken did not measure the initial droplet-size distributions, but rather that of drops that might have lost some or most of the volatile matter. These data were adjusted to reflect evaporation. The data were taken from releases of flashing sprays, airpressurized uranine and UNH solutions, and carbon-dioxide $\left(\mathrm{CO}_{2}\right)$ pressurized uranine solutions. The temperatures of the surrounding air was around $293-295 \mathrm{~K}\left(68-72^{\circ} \mathrm{F}\right)$. Humidities were not measured, although ambient humidities at Hanford are usually fairly low. Temperature and humidity are two very important controlling parameters in evaporation.

The average calculated $R F$ of the initial uranine aerosols was 0.43 , based on information provided in the above references (ammd $=13.5$ and $\sigma_{\mathrm{g}}=4.4$ ). This RF can be the basis for estimating other RFs after evaporation. This document chooses to represent the initial evaporating droplets as $10 \mu \mathrm{m}\left(3.9 \times 10^{-4} \mathrm{in}\right)$ ammd with a $\sigma_{g}=2$. This choice is slightly conservative for the ammd and slightly non-conservative for the $\sigma_{\mathrm{g}}$. It is conservative to assume that the droplet is completely dried, because some solutes will not dry completely in humid air (e.g., UNH is deliquescent in humid air). The UNH data will be used to represent non-evaporating droplets (discussed below).

Droplets that are not likely to evaporate completely include deliquescent/hygroscopic solutes (e.g., UNH) in humid air, any aqueous droplets in 100 percent relative humidity air, and any liquids having high concentrations of colloidal suspended matter. The latter might form a diffusion barrier skin as they start to dry. Some of the former in a fuel cycle facility would be wastes having a very high $\mathrm{pH}$, implying high sodium hydroxide $(\mathrm{NaOH})$ concentrations. $\mathrm{NaOH}$ is deliquescent in humid air. Concentrated $\mathrm{NaOH}$ solution droplets might even grow.

Two approaches are outlined here for determining the RF of droplets produced in pressurized releases. The approaches involve the two extremes: total evaporation and no evaporation. A user of the techniques can decide which is appropriate or can use both to see the range of possible estimates.

Estimating Effects of Evaporation: Assume that, if the droplets can evaporate to dryness, the resulting particle remains a sphere. If the dried droplet has a volume fraction of $\mathrm{v}_{\mathrm{f}}$ of the original volume of the droplet, then each dried droplet has as new diameter that is $v_{f}^{1 / 3}$ times smaller. Thus, evaporation shifts the $\mathrm{RF}$ to a higher value. Figure 3-9 provides a means for correcting the RF for evaporation. This figure assumes that the initial aerosol has an $R F=0.5$, with a $\sigma_{g}=2$. To obtain the dried droplet $R F$, calculate the appropriate respirable dry drop aerodynamic equivalent diameter (rddaed).

$$
\text { rddaed } \left.=\left[10 \text { (initial drop density in } \mathrm{g} / \mathrm{cm}^{3}\right)^{1 / 2} / \mathrm{v}_{\mathrm{f}}^{1 / 3}\right] /\left(\text { dry droplet density in } \mathrm{g} / \mathrm{cm}^{3}\right)^{1 / 2} \text { in } \mu \mathrm{m}
$$

From Figure 3-9, read the RF at the appropriate rddaed. This RF is to be used in LPF estimates in Chapter 4.

Example: A 5 percent by weight aqueous solution of an assumed solute $(\mathrm{AB})$ is involved in a pressurized release. What are its rddaed and $\mathrm{RF}$ ?

Pick as a basis $1 \mathrm{~kg}(2.2 \mathrm{lb})$ of 5 percent solution. 


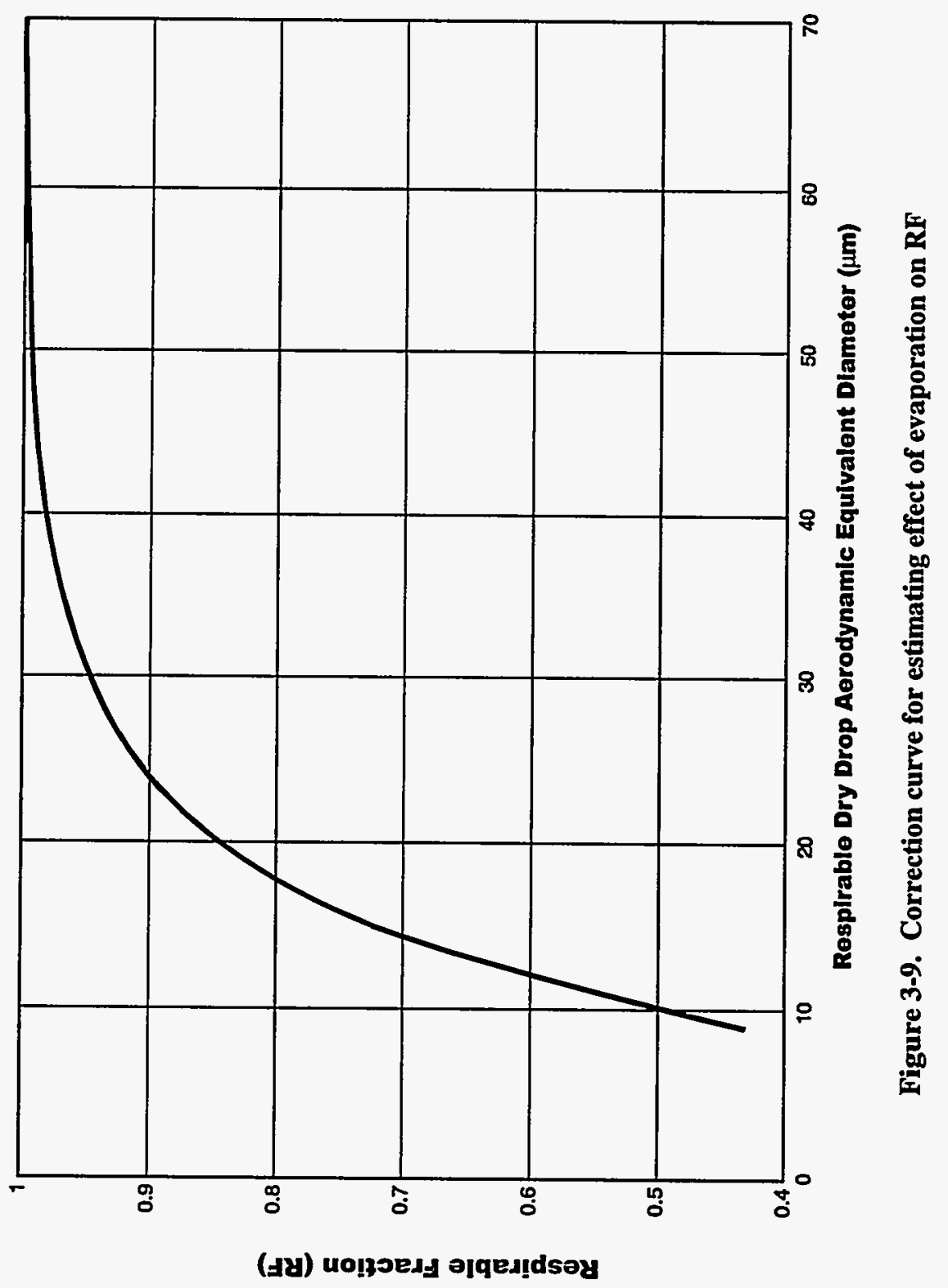


The assumed density of the 5 percent solution at the release time is $1050 \mathrm{~kg} / \mathrm{m}^{3}\left(66 \mathrm{lb} / \mathrm{ft}^{3}\right)$.

The assumed density of dried $A B$ is $5700 \mathrm{~kg} / \mathrm{m}^{3}\left(356 \mathrm{lb} / \mathrm{ft}^{3}\right)$.

The volume of the solution is $1 / 1050=9.524 \mathrm{E}-4 \mathrm{~m}^{3}\left(0.034 \mathrm{ft}^{3}\right)$.

The volume of the $0.05 \mathrm{~kg}$ dry $\mathrm{AB}$ is $0.05 / 5700=8.772 \mathrm{E}-6 \mathrm{~m}^{3}\left(3.1 \times 10^{-4} \mathrm{ft}^{3}\right)$.

$v_{f}=8.772 E-6 / 9.524 E-4=9.214 \mathrm{E}-3$

$v_{f}^{1 / 3}=0.21$

so that

$$
\text { rddaed }=10(1.05)^{1 / 2} / 0.21 / 5.7^{1 / 2}=20.4 \mu \mathrm{m}\left(8.0 \times 10^{-4} \mathrm{in}\right)
$$

From Figure $3-9$, the RF $=0.85$.

\section{Agglomeration}

It is possible that evaporation particles may agglomerate. The interested reader should consult Davies (1996) or Reist (1993).

Non-Evaporating Drops. The approach here is to use the data from UNH pressurized releases. Since the UNH droplets probably evaporated somewhat, using those data as non-evaporating will provide a degree of conservatism. The average ammd and $\sigma_{\mathrm{g}}$ are 13.6 and 4.2, respectively. For lognormal distribution, these values give an $R F=0.42$. This value should be used as a best estimate.

Calculating the ARF. The ARF can be obtained as a best fit of the pressurized release data. This best fit curve is

$$
\mathrm{ARF}=0.115 \mathrm{MF}_{\mathrm{g}}^{0.827}
$$

where $\mathrm{MF}_{\mathrm{g}}$ is the mole fraction of pressurizing gas or vapor. This is the number of moles of gas or vapor produced upon depressurization, divided by the total moles of solvent plus dissolved gas before the depressurization. The ARF equation is the best fit and is shown in Figure 3-8. Upper and lower bound equations are

$$
\begin{gathered}
\mathrm{ARF}_{\mathrm{ub}}=1.28 \mathrm{MF}_{\mathrm{g}}^{0.827} \\
\mathrm{ARF}_{\mathrm{Ib}}=2.23 \mathrm{E}-03 \mathrm{MF}_{\mathrm{g}}^{0.827}
\end{gathered}
$$

These two equations (also shown on Figure 3-8) are useful for determining the potential range of ARFs as well as bounding values.

Flashing Sprays. For superheated liquids, calculating $\mathrm{MF}_{\mathrm{g}}$ precisely can be difficult if appropriate thermodynamic data are not available. The temperature and pressure before and after release are used to 
determine thermodynamic properties of the solution and thus calculate fraction flashed. An energy balance on the system provides the following equation:

$$
\mathrm{H}_{\mathrm{Ll}} \mathrm{M}_{\mathrm{L} 1}=\mathrm{H}_{\mathrm{L} 2} \mathrm{M}_{\mathrm{L} 2}+\mathrm{H}_{\mathrm{V} 2} \mathrm{M}_{\mathrm{V} 2}
$$

where:

$$
\begin{aligned}
& H_{L 1}=\text { enthalpy of the liquid before release at } T_{1} \text { and } p_{1} \\
& M_{L 1}=\text { mass of the liquid before release } \\
& H_{L 2}=\text { enthalpy of the liquid after release at } T_{2} \text { and } p_{2} \\
& M_{L 2}=\text { mass of the liquid after release } \\
& H_{V 1}=\text { enthalpy of the vapor after release } \\
& M_{V 2}=\text { mass of the vapor after release. }
\end{aligned}
$$

If the depressurization occurs into pressure $p_{2}$, then the temperature $T_{2}$ is the boiling point of the residual solution after depressurization.

Since $M_{L 1}=M_{L 2}+M_{V 2}$, the equation can be rearranged to

$$
\mathrm{MF}_{\mathrm{g}}=\frac{\mathrm{M}_{\mathrm{V} 2}}{\mathrm{M}_{\mathrm{L} 1}}=\frac{\mathrm{H}_{\mathrm{L} 1}-\mathrm{H}_{\mathrm{L} 2}}{\mathrm{H}_{\mathrm{V} 2}-\mathrm{H}_{\mathrm{L} 2}}
$$

Using the values for pure water might be the only practical approach for most aqueous solutions. This approach requires a set of steam tables or a Mollier (enthalpy) chart for water.

Example. What is $\mathrm{MF}_{\mathrm{g}}$ for the 5 percent $\mathrm{AB}$ aqueous solution above if the liquid is heated in a fire to 443 $\mathrm{K}\left(338^{\circ} \mathrm{F}\right)$ assuming that, once heated by the fire, the release proceeds adiabatically?

Assume the solution is pure water. For saturated conditions at sea level, the three needed values are

$$
\begin{aligned}
& \mathrm{H}_{\mathrm{L} 1}=719210 \mathrm{~J} / \mathrm{kg} \text { at } 443 \mathrm{~K}\left(\mathrm{p}_{1}=7.917 \mathrm{E}+05 \mathrm{~Pa}\right) \\
& \mathrm{H}_{\mathrm{L} 2}=419040 \mathrm{~J} / \mathrm{kg} \text { at } 373 \mathrm{~K}\left(\mathrm{p}_{2}=1.013 \mathrm{E}+05 \mathrm{~Pa}\right) \\
& \mathrm{H}_{\mathrm{V} 2}=2676100 \mathrm{~J} / \mathrm{kg} \text { at } 373 \mathrm{~K} \\
& \text { Therefore, } \quad \mathrm{MF}_{\mathrm{g}}=(719210-419040) /(2676100-419040)=0.133
\end{aligned}
$$

Gases dissolved in liquids. Here, calculating $\mathrm{MF}_{\mathrm{g}}$ for use in equations 3.6, 3.7, or 3.8 can be difficult because the methods for estimating gas solubilities in complex solutions are not available. The theories behind gas solubilities are also inadequate. For these reasons, actual data must be used wherever possible. There are gas solubility data in various handbooks and other texts. One fairly simple approach is to recognize that at a given temperature, the solubility of a gas in a liquid is directly proportional to its partial pressure. This relationship is called Henry's Law.

$$
\mathrm{MF}_{\mathrm{i}}=\mathrm{p}_{\mathrm{i}} / \mathrm{H}_{\mathrm{i}}
$$


Here, $M F_{i}$ is the mole fraction of gas $i$ in solution, $p_{i}$ is the partial pressure of gas $i$ above the solution, and $\mathrm{H}_{\mathrm{i}}$ is the Henry's Law "constant." This constant is a strong function of temperature and weak function of pressure. For some gases that react with the solvent, Henry's Law constant is also a function of the dissolved gas concentration (e.g., carbon dioxide and ammonia). $\mathrm{H}_{\mathrm{i}}$ is also a function of dissolved solute concentration (e.g., air is generally less soluble in salt solutions than it is in pure water). For gases dissolved in liquids with gas solubilities less than pure water (typically the situation for salt solutions), using pure water to estimate the solubilities produces a conservative (higher MF) for aqueous solutions.

Example. Calculate the dissolved nitrogen concentration as mole fraction in the solution $\mathrm{AB}$ if the solution is stored at $298 \mathrm{~K}\left(76^{\circ} \mathrm{F}\right)$ and under $2.026 \mathrm{E}+05 \mathrm{~Pa}(2 \mathrm{~atm})$ nitrogen pressure. Calculate the upper bound $\mathrm{ARF}$ if this solution is depressurized into air at sea level.

The solubility factor for nitrogen in water at $298 \mathrm{~K}$ is $0.01434 \mathrm{~m}^{3}$ nitrogen $/ \mathrm{m}^{3}$ water with a nitrogen partial pressure of $1.013 \mathrm{E}+5 \mathrm{~Pa}$ (Dean 1992). The volume of nitrogen is given as the volume of gas measured at $273 \mathrm{~K}\left(31^{\circ} \mathrm{F}\right)$ (standard conditions) to make the volume comparable for all temperatures.

The nitrogen concentration at $2 \mathrm{~atm}$ pressure $=2(0.01434)=0.02868 \mathrm{~m}^{3}$ gas at $\mathrm{stp} / \mathrm{m}^{3}$ water

$\mathrm{kg}$ moles of nitrogen $=\mathrm{pV} / \mathrm{RT}$ from the ideal gas law $=(101325)(0.02868) /(8314.7)(273)=0.00128$

$\mathrm{kg}$ moles water in $1 \mathrm{~m}^{3}=1 \mathrm{~m}^{3}\left(1000 \mathrm{~kg} / \mathrm{m}^{3}\right) \mathrm{kg}$ mole $/ 18 \mathrm{~kg}=55.56$

$$
\mathrm{MF}(\text { nitrogen })=0.00128 / 55.56=2.30 \mathrm{E}-05
$$

Not all the dissolved nitrogen is available for making aerosols. Since 79 percent of dry air at sea level is nitrogen, only part of the dissolved nitrogen is available. The fraction of the dissolved gas that is subject to depressurization is $(2.02 \mathrm{E}+5 / 1.01 \mathrm{E}+5)-0.79=1.21$. The available gas amount is $(2.30 \mathrm{E}$ -

05) $1.21(1.01 \mathrm{E}+5) / 2.02 \mathrm{E}+5=1.39 \mathrm{E}-05$. This number is the $\mathrm{MF}_{\mathrm{g}}$ to use in $\mathrm{ARF}$ calculations. Thus,

$$
\mathrm{ARF}_{\mathrm{ub}}=1.28 \mathrm{MF}_{\mathrm{g}}^{0.827}=1.23 \mathrm{E}-04
$$

\subsubsection{Overpressurization to Rupture - Liquid, Confined (in vessel/container): Bounding Values, Rapid Buildup of Pressure}

a. Vented above the surface level of liquid

\section{No value available}

b. Vented below surface level of liquid, spray formation during venting

\section{RARF 1E-4 (ARF X RF).}

\section{Technical Basis}

Experimental data on the ARF from the venting of aqueous liquids from the loss of confinement above the surface of the liquid are not available. It is anticipated that the release will be less than for slow buildup of pressure, where the pressurizing gas can equilibrate with the liquid and form a greater number of bubbles because of the release of a greater volume of the gas. 
For the release of the pressurized liquid from vents in the confinement under the surface of the liquid, the size distribution of the droplet formed by a liquid spray from a commercial spray nozzle bounds the $10 \mu \mathrm{m}$ AED size for nozzle with openings from 1.6 to $8.25 \mathrm{~mm}(0.06$ to $0.32 \mathrm{in})$ with upstream pressures from 0.345 to $1.37 \mathrm{MPa}_{\mathrm{g}}$ (50.2 psig to $199 \mathrm{psig}$ ) (USDOE 1994, Subsection 3.2.2.3.1, pp 3-20 to 3-22). Larger fractions of these size droplets may be formed by venting the pressurized liquid via very small-width "slittype" breaks in piping or vessels. Furthermore, droplets formed may increase, decrease, or remain the same size, depending on the temperature of liquid released, the hygroscopic nature and the concentration of the solute, and the temperature and relative humidity of the environment into which they are released (see above).

\subsubsection{Overpressurization to Rupture - Superheated Liquids, Confined ("Flashing Spray" during Venting): Bounding Values}

a. Solvent temperature greater than boiling temperature but less than $50^{\circ} \mathrm{C}\left(122{ }^{\circ} \mathrm{F}\right)$ superheat.

\section{ARF 1E-2 \\ RF 0.6}

b. Solvent greater than $50^{\circ} \mathrm{C}\left(122^{\circ} \mathrm{F}\right)$ but less than $100^{\circ} \mathrm{C}\left(212^{\circ} \mathrm{F}\right)$ superheat.

\section{ARF 1E-1 \\ RF 0.7}

\section{Technical Basis}

This section applies when liquids heated above the boiling temperature of the liquid/solvent/diluent "flash" (fragmentation caused by the bulk vaporization of the liquid) on release. The only available experimentally measured ARFs and RFs for dilute solutions of uranine heated to temperature above the boiling point of the solvent (water) ranged from ARF 9E-3 to 9E-2, with RF 0.6 to 0.8 . The superheat (degrees temperature exceeding the boiling point of the solvent) ranged from 34 to $140 \mathrm{~K}$ (61 to $252{ }^{\circ} \mathrm{F}$ ). The data are bounded by values of ARF $1 \mathrm{E}-1$ and RF 0.7 (the RF value associated with the bounding $\mathrm{ARF})$ for superheat values up to $102 \mathrm{~K}\left(184^{\circ} \mathrm{F}\right)$. For superheat up to $50 \mathrm{~K}\left(90^{\circ} \mathrm{F}\right)$, a single $\mathrm{ARF}$ and $\mathrm{RF}$ value, $1 \mathrm{E}-2$ and 0.6 respectively, are available and are recommended as a bound.

Other authors addressing aspects of "flashing sprays" (primarily particle size of droplets formed) are Brown and York (1962), Gido and Koestel (1978), and Brockman (1985).

Note: The treatment of pressurized liquids in this and the previous Subsections applies to aqueous liquids. It does not apply to materials like chlorine or ammonia that may be liquefied under pressure.

\subsubsection{Overpressurization to Rupture - Powder, Confined (in Vessel or Container)}

a. Release Pressure $<0.17 M P a_{g}(<25$ psig)

\section{ARF 2E-3 \\ RF 0.4}

b. Release Pressure $>0.17$ but $<3.5 M P a_{g}(>25$ but $<500$ psig) 


\section{ARF 1E-1 \\ RF 0.5}

\section{Technical Basis}

The upper bound values cited above are based on experimental measurements of the ARF and RF from the venting of fine, dry powders with little cohesion with two theoretical densities at release pressures from $0.06 \mathrm{MPa}_{\mathrm{g}}\left(9 \mathrm{psig}\right.$ ) to $3.4 \mathrm{MPa}_{\mathrm{g}}$ (500 psig) (Sutter 1983; Ballinger, et al. 1987). The two powders consisted of a ball-milled uranium dioxide $\left(\mathrm{UO}_{2}\right)$ with a theoretical density of $10.96 \mathrm{~g} / \mathrm{cm}^{3}\left(684 \mathrm{lb} / \mathrm{ft}^{3}\right)$ and an AMAD between 3 and $6 \mu \mathrm{m}\left(1.17 \times 10^{-4}\right.$ to $\left.2.34 \times 10^{-4} \mathrm{in}\right) \mathrm{AED}$, and titanium dioxide $\left(\mathrm{TiO}_{2}\right)$ with a theoretical density of $4.17 \mathrm{~g} / \mathrm{cm}^{3}\left(260 \mathrm{lb} / \mathrm{ft}^{3}\right)$ and an AMAD in approximately the same range as for $\mathrm{UO}_{2}$. The powders were held in a 15.2-cm (6-in) diameter cylinder sealed with a double rupture disk. The cylinder was slowly pressurized with air until the desired pressure was attained. The space between the two rupture disks was pressurized to a value approximately one-half the rated pressure for the disks. With release of the pressure between the two disks, the disks were subjected to a pressure greater than their rated value and ruptured catastrophically.

The measured ARFs and RFs ranged from $5 \mathrm{E}-5$ and $0.6\left(\mathrm{UO}_{2}\right.$ at $0.06 \mathrm{MPa}_{\mathrm{g}}(8.7 \mathrm{psig})$ ) to $1 \mathrm{E}-1$ and 0.5 $\left(\mathrm{TiO}_{2}\right.$ at $\left.3.4 \mathrm{Mpa}_{\mathrm{g}}(500 \mathrm{psig})\right)$. The maximum measured values for these powders at an initial pressure less than $0.17 \mathrm{MPa}_{\mathrm{g}}(25 \mathrm{psig})$ were ARF $2 \mathrm{E}-3$ and $\mathrm{RF} 0.4\left(\mathrm{UO}_{2}\right.$ at $0.17 \mathrm{MPa}_{\mathrm{g}}(25 \mathrm{psig})$ ), i.e., the values recommended above.

For all pressures up to $3.4 \mathrm{MPa}_{\mathrm{g}}$ (500 psig), the maximum measured values are ARF $1 \mathrm{E}-1$ and $\mathrm{RF} 0.5$ $\left(\mathrm{TiO}_{2}\right.$ at $\left.3.4 \mathrm{MPa}_{\mathrm{g}}(500 \mathrm{psig})\right)$. The measured values for three other tests with both $\mathrm{UO}_{2}$ and $\mathrm{TiO}_{2}$ for this pressure are also approximately at this level. The tests were conducted in a $\sim 3-\mathrm{m}-(\sim 10-\mathrm{ft}-)$ diameter stainless steel vessel $\sim 3 \mathrm{~m}$ - ( $\sim 10$-ft-) high. There was some evidence that a portion of the powder may have indeed impacted and clung to the ceiling of the vessel. Powder was observed on the ceiling following a single test at $6.9 \mathrm{MPa}_{\mathrm{g}}(\sim 1000 \mathrm{psig})$ using $\mathrm{TiO}_{2}$. The ARF and RF measured for this tests were $4.5 \mathrm{E}-2$ and 0.6.

Powders with a size distribution of very fine particles tend to be difficult to separate. A distribution approximating the original distribution could only be obtained by sonic agitation of a specimen of the powder in water with a surfactant. The slow pressurization of the powder is necessary to allow all the free volume between the particles to become fully pressurized, so that the depressurization of the gas at these locations may then deagglomerate the powder.

\subsubsection{Overpressurization to Rupture - Powder, Confined (in Vessel or Container) - Correlations}

If the gas phase pressure surrounding a powder is suddenly reduced, the pressurizing gas will disperse the powder to some degree as it expands to fill a larger volume. Pressurized powder release data from Sutter (1983) and Ballinger (1987) were correlated in the original NUREG-1320. These data consisted of ARFs and aerosol size distributions of different quantities of deuterium oxide (DUO) and $\mathrm{TiO}_{2}(0.10$ and $0.35 \mathrm{~kg}$ $(0.22$ and $0.77 \mathrm{lb})$ ) and air pressures of $1.63 \mathrm{E}+05 \mathrm{~Pa}$ absolute $(9 \mathrm{psig})$ to $3.55 \mathrm{E}+06 \mathrm{~Pa}$ absolute (500 psig) released to $1.01 \mathrm{E}+05 \mathrm{~Pa}$ absolute $(0 \mathrm{psig})$. The ARFs, when correlated against a potential powder velocity, $V_{p}$, gave the best correlation $\left(r^{2}=63\right.$ percent). This velocity is the kinetic energy equivalent of the pressurizing gas, that is,

$$
(1 / 2) m V_{p}^{2}=p v_{t} \text { or } V_{p}=\left(2 p v_{t} / m\right)^{1 / 2}
$$


where $m$ is the total mass of the container contents, gas plus powder, $p$ is the pressure above the outside pressure, and $v_{t}$ is the container volume occupied by the gas, including the powder void space.

The best-fit equation is

$$
\mathrm{ARF}=1.0 \mathrm{E}-04 \mathrm{~V}_{\mathbf{p}}^{1.4}
$$

If the slope of the plot of $\log (A R F)$ versus $\log \left(V_{p}\right)$, which is 1.4 , is used to draw two lines through the most outlying data points, two bounding correlations are produced (see Figure 3-10). The upper bound is

$$
\mathrm{ARF}_{\mathrm{ub}}=2.74 \mathrm{E}-04 \mathrm{~V}_{\mathrm{p}}^{1.4}
$$

and the lower bound is

$$
\mathrm{ARF}_{\mathrm{lb}}=1.98 \mathrm{E}-05 \mathrm{~V}_{\mathrm{p}}^{1.4}
$$

This lower-bound equation is useful for estimating the potential range of hypothetical spills.

From the original data, some additional information is useful for defining a source term. Table 3-7 gives that information. The RF is the parameter (along with the ARF) to be used in this handbook for defining the source term. There are several choices of RF (e.g., average, maximum, and average \pm two standard deviations for 95 percent confidence interval).

Table 3-7. Size Distribution Parameters for Pressurized Powder Release Aerosols

\begin{tabular}{|l|c|c|c|}
\hline & $\begin{array}{c}\text { ammd } \\
\text { micrometers }\end{array}$ & RF & $\begin{array}{c}\sigma_{\mathbf{g}} \\
\text { micrometers }\end{array}$ \\
\hline Average & 11.2 & 0.485 & 6 \\
\hline $\begin{array}{l}\text { Standard } \\
\text { deviation }\end{array}$ & 5.2 & 0.124 & 2 \\
\hline Range & $2.4-25.0$ & $0.25-0.72$ & $2-14$ \\
\hline
\end{tabular}

The upper bound and average source terms are calculated in the example below.

Example. A $0.002 \mathrm{~m}^{3}$ (two-liter) sealed can of powdered $\mathrm{PuO}_{2}(2 \mathrm{~kg}(4.4 \mathrm{lb})$ ) overheats and overpressurizes the can to a bursting pressure $1.35 \mathrm{E}+5 \mathrm{~Pa}(5 \mathrm{psig})$. What are the upper bound and average source terms?

The space occupied by the oxide is $2 \mathrm{~kg} /\left(\right.$ particle density, $\left.11460 \mathrm{~kg} / \mathrm{m}^{3}\right)=1.745 \mathrm{E}-04 \mathrm{~m}^{3}\left(6.2 \mathrm{E}-04 \mathrm{ft}^{3}\right)$.

The space occupied by the gas is $0.002-1.745 \mathrm{E}-04=1.825 \mathrm{E}-03 \mathrm{~m}^{3}\left(0.064 \mathrm{ft}^{3}\right)$.

The mass of the gas (assumed to be air initially at $1.01 \mathrm{E}+05 \mathrm{~Pa}\left(1\right.$ atmosphere) and $298 \mathrm{~K}\left(77^{\circ} \mathrm{F}\right)$ is

$$
\mathrm{M}_{\mathrm{w}} \mathrm{pV} /(\mathrm{RT})=29(1.01 \mathrm{E}+05)(1.825 \mathrm{E}-03) /(8314.3)(298)=2.158 \mathrm{E}-03 \mathrm{~kg}(4.7 \mathrm{E}-03 \mathrm{lb})
$$




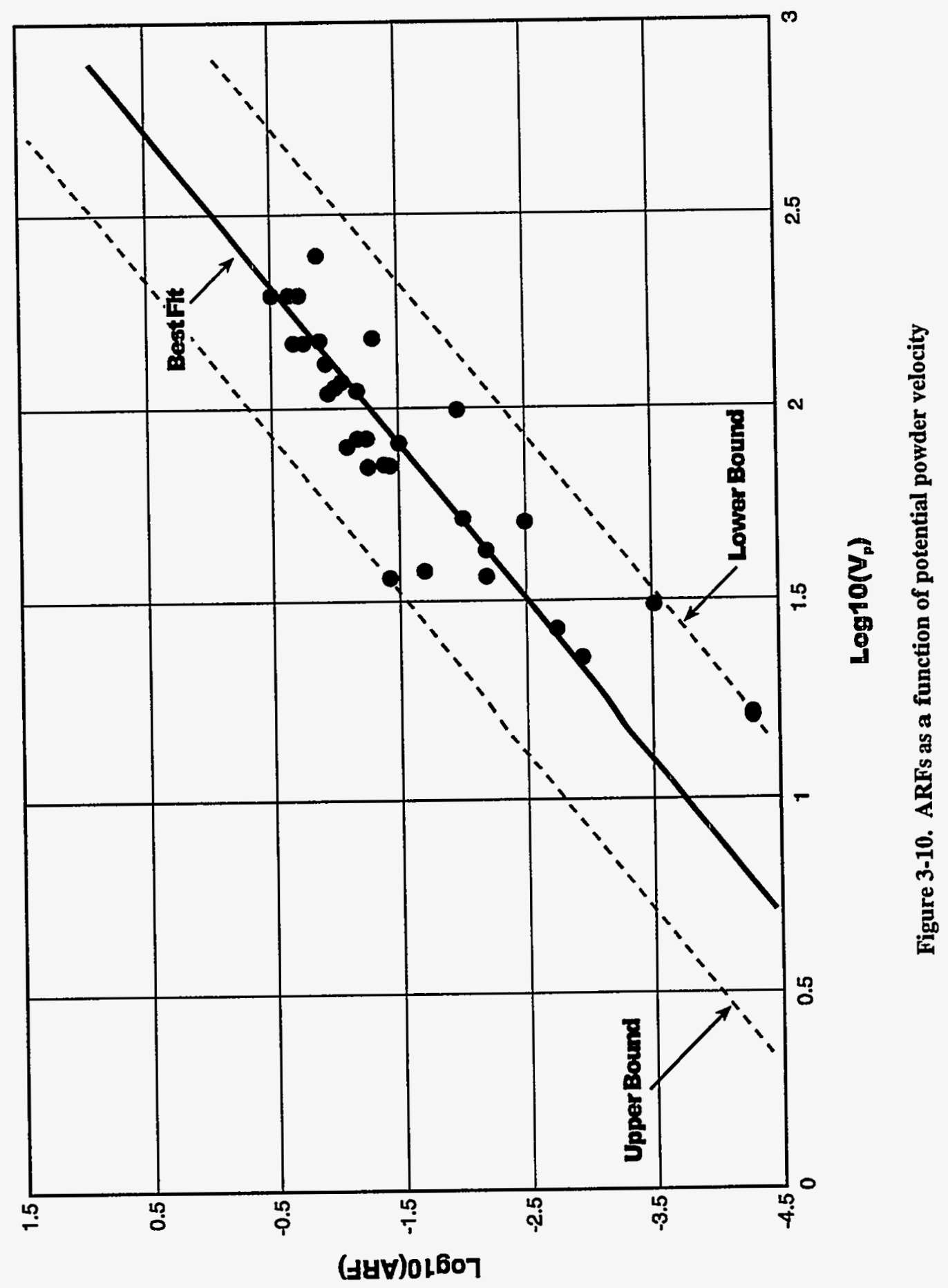


The total mass in the container is $\mathrm{m}=2 .+.002158=2.0 \mathrm{~kg}(4.4 \mathrm{lb})$.

From equation $3.9 \quad \mathrm{~V}_{\mathrm{p}}=[2(3.45 \mathrm{E}+04)(1.825 \mathrm{E}-03) / 2.002]^{1 / 2}=7.93 \mathrm{~m} / \mathrm{s}(17.7 \mathrm{mph})$.

The average or mean source term is

$$
\mathrm{ARF}=1.0 \mathrm{E}-04(7.93)^{1.4}=1.82 \mathrm{E}-03
$$

with an $\mathrm{RF}=0.485$.

The upper-bound source term is

$$
\mathrm{ARF}_{\mathrm{ub}}=2.74 \mathrm{E}-04(7.93)^{1.4}=4.97 \mathrm{E}-03
$$

with an $\mathrm{RF}=0.72$ based on the data range. An even more conservative approach would be to use the maximum $R F=1$.

\subsubsection{Overpressurization to Rupture - Vitrified HLW}

Vitrified HLW, high pressure sufficient to dislodge plug

ARF 3.5E-5

RF 0.7

\section{Technical Basis}

After 9.1-m (30-ft) drop tests, a canister of simulated vitrified HLW was cut open and the particles generated in various regions of the canister were collected. The ARF/RF above are based on a measured value of 3.5E-4 of inventory found, as particles in the upper plenum of the canister. It was estimated that 10 percent would escape as a result of depressurization (pressurized powder release, driving pressure $<3.5$ $\mathrm{Mpa}_{\mathrm{g}}(510 \mathrm{psig})$ ). Note that the pressurization referred to here is assumed to be from heat-induced gas expansion. The fact that the canister had previously been dropped means that the ARF for this case has been conservatively estimated. The glass fragments in the upper plenum are postulated to result from fragmentation of the vitrified HLW that is drawn up the side walls of the metal canister by capillary action and then fragmented by the shock impact from the test and/or thermal strains induced in the glass-like material during cooling (WHC 1993).

\subsubsection{Thermal Stress}

\subsubsection{Gases}

\section{ARF 1E+0, RF not applicable to materials in gaseous state}

\section{Technical Basis}

Volatile materials in the gaseous state or converted into the gaseous state by environmental conditions during an event and free of confinement will be completely released. 


\title{
3.3.2.2 Tritium
}

Any tritium $\left({ }^{3} \mathrm{H}\right)$ in gaseous form will be totally released (true if the release duration is considered very long) if freed from confinement.

\author{
ARF 1E.0 \\ $R F$ not applicable to materials in the gaseous state
}

Technical Basis

Completely released because gaseous.

\subsubsection{Liquid, Aqueous Solution}

a. Simmering, no visible bubbles

\author{
ARF 3E-5 \\ RF (no data available)
}

b. Boiling (does not cover churn turbulent or chaotic boiling regimes), discernible bubble break-up at surface with less than 30 percent of the liquid associated with bubbles

ARF 2E-3

RF NA

\section{Technical Basis}

Heating of liquids results in the release of gases absorbed in the liquid and, at the boiling point, the generation of vapor within the body of the liquid results in the formation of bubbles that rise to the surface, collapse, and form liquid droplets. This is the principal mechanism for the airborne release of non-volatile solutes or particles dissolved or carried in the liquid.

Kataoki and Ishii (1983) classified the boiling phenomenon into three classes--boiling (where less than 30 percent of the liquid can be involved as bubbles and discrete bubbles are observed); churn turbulent (where continuous rollover of the liquid occurs); and chaotic (where the liquid is rapidly displaced by bulk vaporization of the liquid and eructation occurs). Only the airborne release and droplet size for boiling can be defined. The authors further defined three regimes for droplet-size distribution--near the liquid surface where the size distribution is dominated by the process of droplet formation; a middle region where the size distribution is influenced by both the size generated by the process and the size that can be carried by the total flow velocity (the vapor flow velocity and the environmental flow velocity); and the farthest region where the size distribution is dominated by the environmental flow velocity. The droplet size generated by the two formation processes (droplets formed by the bubble film collapse and the droplet formation by the jet formed by the liquid flowing into the cavity created by the bubble collapse) is shown in Figure 3-11 from Borkowski, et al. (1986). From the data, only droplets from bubble film collapse are formed from bubbles with diameters that are less than $0.5 \mathrm{~mm}(0.02 \mathrm{in})$ and jet formation is added when bubble diameters boiling from acidic plutonium nitrate solutions are greater than $0.5 \mathrm{~mm}(0.02$ in) but less than $1.4 \mathrm{~mm}$ (0.055 in). 


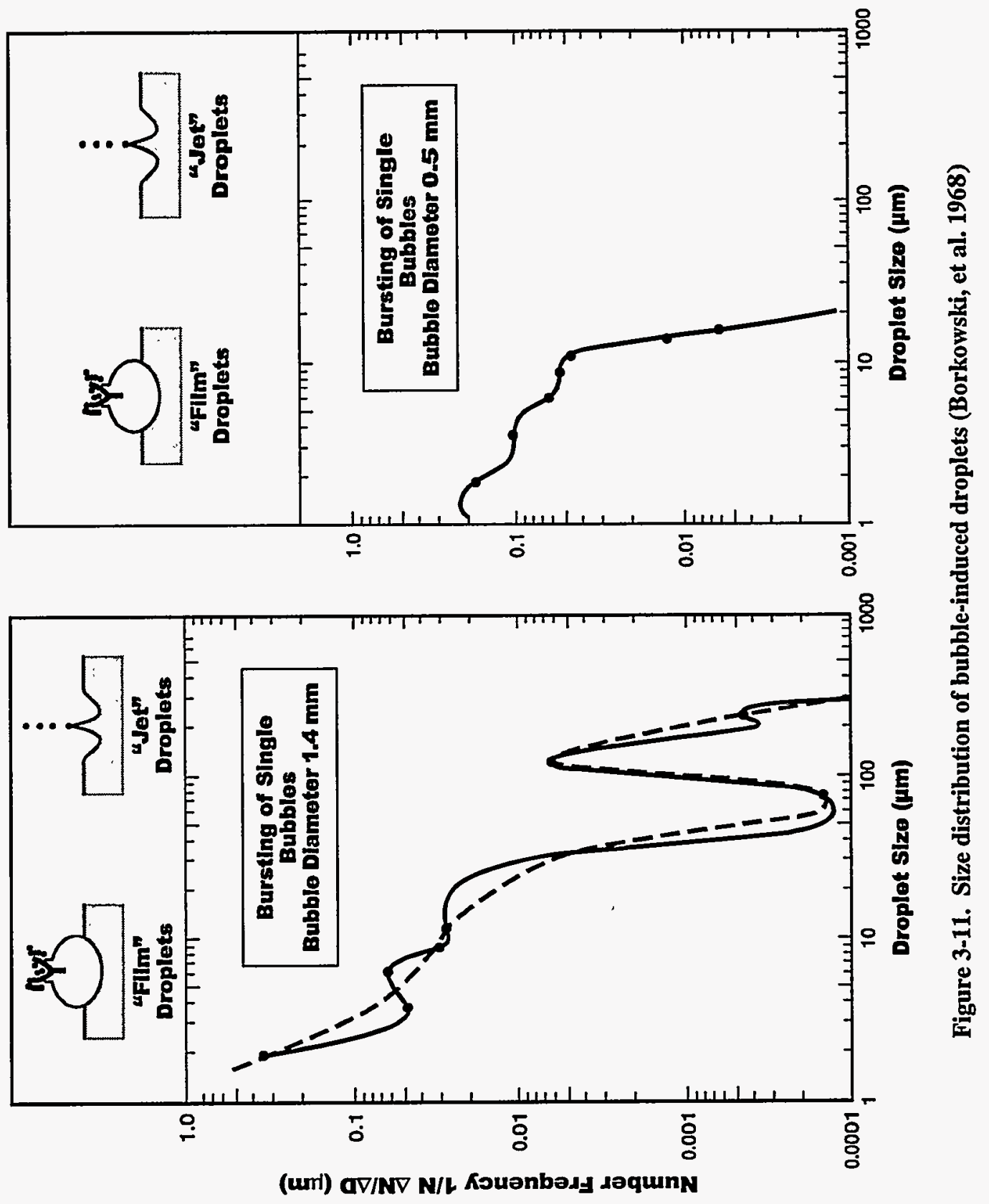


Experimental measurements of ARF and RF have been made for heating in shallow pools without bubble formation, and for deeper pools during the evaporation of 90 percent of the volume (Mishima, et al. 1968). For shallow pools of solution in the temperature range 323 to $372 \mathrm{~K}\left(122\right.$ to $212^{\circ} \mathrm{F}$ ), the ARF ranged from $1 \mathrm{E}-8$ to $3 \mathrm{E}-5$. An air sweep over the liquid with a velocity of 0.5 and $1.0 \mathrm{~m} / \mathrm{s}(1.12$ and $2.24 \mathrm{mph})$ was used. No RFs were measured.

For deeper pools using $100 \mathrm{~cm}^{3}\left(0.0035 \mathrm{ft}^{3}\right)$ of solution in a $200 \mathrm{~cm}^{3}\left(0.007 \mathrm{ft}^{3}\right)$ beaker and an air sweep with an upflow of $1 \mathrm{~cm} / \mathrm{s}(0.022 \mathrm{mph})$, ARFs ranged from $4.5 \mathrm{E}-7$ to $1.1 \mathrm{E}-3$, with the two highest values approximated by collection of all $\mathrm{Pu}$ in the entire collection system upstream of the collection filter. Boiling rates ranged from $0.5 \mathrm{~cm}^{3} / \mathrm{min}\left(1.8 \times 10^{-5} \mathrm{ft}^{3} / \mathrm{min}\right)$ at a temperature of $346 \mathrm{~K}\left(163{ }^{\circ} \mathrm{F}\right)$ to 2.1 $\mathrm{cm}^{3} / \mathrm{min}\left(7.4 \times 10^{-5} \mathrm{ft}^{3} / \mathrm{min}\right)$ at a temperature of $373 \mathrm{~K}\left(212^{\circ} \mathrm{F}\right)$. No RFs were measured.

\title{
3.3.2.4 Liquid, Organic, Combustible - Volatile Compounds Dissolved in Organic Liquid
}

\section{ARF 1E+0 \\ RF not applicable to materials in gaseous state}

\section{Technical Basis}

The bounding value for ARFs for the volatile solute iodine during the burning of combustible solvent (20 percent tributylphosphate in kerosene) is based on the measured releases during combustion of the solution (Mishima and Schwendiman 1973a). A small volume $\left(25 \mathrm{~cm}^{3}\left(8.8 \times 10^{-4} \mathrm{ft}^{3}\right)\right.$ ) in a $50 \mathrm{~cm}^{3}\left(1.8 \times 10^{-3} \mathrm{ft}^{3}\right)$ borosilicate glass beaker was ignited and external heat applied to maintain flaming combustion. Airflow over the burning materials was at a volumetric flow of $0.472 \mathrm{lpm}(0.017 \mathrm{cfm})$ and $0.944 \mathrm{lpm}(0.033 \mathrm{cfm})$. The measured values for ARF were 6.57E-1 and 6.54E-1 for combustion to self-extinguishment at the two volumetric flows and 8.17E-1, 8.43E-1, 8.28E-1 and 8.33E-1 for combustion to complete dryness. All $\mathrm{ARF}$ values are near $1 \mathrm{E}+0$, and this value is recommended as the upper bound.

\subsubsection{Liquid, Organic, Combustible - Non-Volatile Compounds}

a. Non-volatile compounds - solution burns to self-extinguishment, no significant surface turbulence

\section{ARF 1E-2 \\ RF NA}

b. Non-volatile compounds - solution burns vigorously with surface turbulence to self-extinguishment

\section{ARF 3E-2 RF NA}

c. Non-volatile compounds, vigorous burning with surface turbulence, to complete dryness

\author{
ARF 1E-1 \\ RF NA
}




\section{Technical Basis}

ARFs for non-volatile materials (cesium, cerium, and zirconium) were measured in the small-volume, small-surface area, quiet burning experiments reported in Mishima and Schwendiman (1973a). For the two volumetric flows [0.472 lpm $(0.017 \mathrm{cfm})$ and $0.944 \mathrm{lpm}(0.033 \mathrm{cfm})]$ around and over the surface under two burning conditions (self-extinguishment and complete dryness), the ARFs ranged from 2E-4 (uranium to self-extinguishment) to $1 \mathrm{E}-2$ (cesium for complete dryness). The 1E-2 for selfextinguishment, no significant surface turbulence, cited above, is from these results. Halverson, et al. (1987) reported the ARFs for uranium during the burning of 30 percent TriButylPhosphate in kerosene under several circumstances. The surface area for burning was approximately the same as cited in Mishima and Schwendiman (1973a), but the flow around and over the specimen holder was lower. Metal beakers were used during all but one of the tests and external heat supplied in some case; both circumstances allowed accelerated solvent vaporization caused by high heating rates with greater surface turbulence. The measured ARFs for uranium ranged from 2E-3 (burning of organic liquid over a nitric acid layer, enctation of nitric acid layer terminated test) to 7E-2 (tests using glass beaker that allowed burning and evaporation of nitric acid layer to generate a dry residue). The ARF value cited in item 3 above is based on this result.

Malet, et al. (1983) performed a larger scale test of 30 percent TBP-kerosene PUREX-type solvent. ARFs for the uranium are difficult to extract from the data that are reported as a decontamination factor (initial mass/mass collected on filters sampling vessel volume) and a transfer coefficient (initial mass/mass exiting the vessel).

Jordan and Lindner (1983) reported the ARFs from the burning of PUREX-type solvent loaded with uranium. No aqueous layer was involved. Decomposition of nitric acid or nitrates absorbed into the solvent resulted in decomposition products that appear to have added to the surface turbulence. ARFs for uranium ranged from $2 \mathrm{E}-3$ to $2 \mathrm{E}-2$. The ARF value cited in item 2 above is based on the high value here.

\subsubsection{Liquid, Organic, Combustible - Burning of Combustible Liquid}

a. Over air-dried residue from solution on porous, non-heat-conducting surface

\section{ARF 5E-3}

RF 0.4

\section{b. Over air-dried residue from solution on heat-conducting surface}

\section{ARF 2E-1 \\ RF 0.3}

\section{Technical Basis}

Experiments were performed to measure the ARFs for uranium during burning of gasoline over the deposit on various surfaces in a wind tunnel with air velocities between $0.91 \mathrm{~m} / \mathrm{s}(2 \mathrm{mph})$ and $9.1 \mathrm{~m} / \mathrm{s}(20 \mathrm{mph})$ Mishima and Schwendiman (1973b). Acidic UNH solutions and the air-dried residues from UNH solutions were placed on sandy soil, sandy soil with vegetation, asphalt, and stainless steel as substrates. Gasoline was poured over the surface and ignited. For porous, non-heat-conducting surfaces (sandy soil and sandy soil with vegetation), the ARFs ranged from $2 \mathrm{E}-5$ to $1 \mathrm{E}-3$ at $0.91 \mathrm{~m} / \mathrm{s}(2.0 \mathrm{mph})$ and $1 \mathrm{E}-3$ and 
$5 E-3$ at $9.1 \mathrm{~m} / \mathrm{s}(20 \mathrm{mph})$. The ARF values for suspension from asphalt were subsumed by the ARFs for soil, above. The largest ARF value with its associated RF is cited above.

There is a significant increase in the ARFs for the two air velocities for experiments performed on a stainless steel surface (ARFs of $1 E-2$ at $0.91 \mathrm{~m} / \mathrm{s}$ and $1 \mathrm{E}-1$ at $9.1 \mathrm{~m} / \mathrm{s}$ ) that is attributed to the added heat from conduction by the surface, resulting in accelerated heating of the liquid and liquid droplet formation.

\subsubsection{Solid, Reactive Metal - Plutonium}

a. At less than ignition temperature

\section{ARF 3E-5 of oxide formed RF 0.04}

b. At or above ignition temperature

ARF 5E-4

RF 0.5

c. Spill of molten metal into air, fall distance $>2.5 \mathrm{~cm}$ (1 in)

RARF 1E-2

RF (no data available)

d. Small drops (equal to or less than $100 \mu \mathrm{m}\left(3.9 \times 10^{-3}\right.$ in) $\left.D_{g}\right)$ of molten $P u$ that travel $>1 \mathrm{~m}(3.28 \mathrm{ft})$ in air

\section{ARF 1E+0 \\ RF 0.5}

\section{Technical Basis}

Plutonium is a chemically active material that oxidizes readily under the proper conditions and forms particles of plutonium dioxide, a thermodynamically stable compound. The reaction is exothermic. The oxidation of plutonium metal has been divided into two regimes--a "kinetic controlled regime" and a "diffusion controlled regime." Under most circumstances, at temperatures less than those required to initiate a self-sustaining reaction (ignition), the reaction rate is controlled by external heat supplied from rapid heat transfer by convection. The ignition temperature as a function of surface to mass ratio is illustrated in Figure 3-1.

When a self-sustaining reaction is achieved, the heat generated by the reaction is more than adequate to sustain reaction, and the temperature increases to a level that is supported by the diffusion of oxygen to the metal interface $\left(1271 \mathrm{~K}\right.$ to $1373 \mathrm{~K}\left(1830^{\circ} \mathrm{F}\right.$ to $\left.\left.2010^{\circ} \mathrm{F}\right)\right)$. The melting temperature of the epsilon phase of plutonium metal is $749 \mathrm{~K}\left(890^{\circ} \mathrm{F}\right)$ to $913 \mathrm{~K}\left(1140^{\circ} \mathrm{F}\right)$, and the metal is molten during this process. The oxide forms a crust with some strength, and a dark glowing mass is observed. Periodically, because of induced stresses, the crust is ruptured, and molten metal can be observed to flow down the sides of large pieces. 
Many experimental studies have been performed to determine the ARF and RF resulting from the oxidation of plutonium metal under various conditions and temperatures. Most of the experiments have been performed on small specimens $(20 \mathrm{~g}(0.044 \mathrm{lb})$ or less) and may not be representative of the ARF/RF for larger specimens.

Room Temperature Oxidation. Both Stewart (1963) and Chatfield (1968) have studied the suspension of plutonium dioxide, from room temperature corrosion for unalloyed and delta-stabilized metal in dry (0.1 percent relative humidity) and 100 percent relative humidity air. Removal rates were expressed as microcuries $\left(3.7 \times 10^{6} \mathrm{~Bq}\right)$ per $\mathrm{cm}^{2}$ surface exposed/hour. Under the assumption that the plutonium is weapons-grade metal, the removal rates for unalloyed plutonium metal are in the range of $2 \times 10^{-6} \mu \mathrm{g} / \mathrm{cm}^{2} \mathrm{hr}$ $\left(4 \times 10^{-12} \mathrm{lb} / \mathrm{ft}^{2} \mathrm{hr}\right)$ and $7 \times 10^{-3} \mu \mathrm{g} / \mathrm{cm}^{2} \mathrm{hr}\left(1.4 \times 10^{-8} \mathrm{lb} / \mathrm{ft}^{2} \mathrm{hr}\right)$ for dry air and 100 percent $\mathrm{RH}$ air, respectively. For delta-phase stabilized metal, the range for the same RH air is $7 \times 10^{-8} \mu \mathrm{g} / \mathrm{cm}^{2} \mathrm{hr}$ $\left(1.4 \times 10^{-13} \mathrm{lb} / \mathrm{ft}^{2} \mathrm{hr}\right)$ to $6 \times 10^{-4} \mu \mathrm{g} / \mathrm{cm}^{2} \mathrm{hr}\left(1.2 \times 10^{-9} \mathrm{lb} / \mathrm{ft}^{2} \mathrm{hr}\right)$, respectively. The topic is covered in greater detail in Subsection 4.2.1.1.1, pp 4-12 to 4-15 in the DOE Handbook (USDOE 1994). The RF for the suspended materials is 0.7 for all conditions.

Stewart (1963) oxidized small specimens of both alpha-phase and delta-phase stabilized plutonium metal at temperatures less than those necessary for sèlf-sustaining reactions. For temperatures under $396 \mathrm{~K}$ $\left(253^{\circ} \mathrm{F}\right)$, ARFs ranged from $6 \times 10^{-7}$ to $3 \times 10^{-5}$, with the exception of a single specimen that was 3.3 percent oxidized. Based upon the estimates of airborne release of particles $<10 \mu \mathrm{m}\left(3.9 \times 10^{-4} \mathrm{in}\right) \mathrm{D}_{\mathrm{AED}}$, an RF of 0.04 is derived. This is the value cited in item (a) above (see pp 4-17 to 4-21 in [USDOE 1994] for further details).

Self-Sustained Oxidation. A number of measurements of ARFs and RFs for both phases of plutonium metal under a variety of conditions has been reported (Stewart 1963; Mishima 1965; 1966; Carter and Stewart 1970; Eidson and Kanapilly 1983; Eidson, Yeh, and Kanapilly 1988; and Luna 1994). Haschke (1992) estimated the oxidation rate and size distribution from existing data. The material is covered in detail in Section 4.2.1.1.3, pp 4-21 to 31, in (USDOE 1994).

For oxidation in air and nitrogen with various oxygen concentrations using both cylindrical solids and turnings, Stewart (1963) reported ARFs ranging from $1.5 \times 10^{-5}$ ( mass mean diameter (MMD) $8 \mu \mathrm{m}$ $\left(3.12 \times 10^{-4}\right.$ in) $\left.\mathrm{D}_{\mathrm{AED}}\right)$ to $2.4 \times 10^{-3}$ (MMD $11 \mu \mathrm{m}\left(4.3 \times 10^{-4}\right.$ in) $\left.\mathrm{D}_{\mathrm{AED}}\right)$.

Mishima (1965) oxidized small right cylinders of plutonium metal in flowing air at nominal velocities from 3.3 to $50 \mathrm{~cm} / \mathrm{s}(0.0074$ to $0.11 \mathrm{mph})$ in a quartz tube held in a furnace. Final temperatures ranged from $833 \mathrm{~K}\left(1040^{\circ} \mathrm{F}\right)$ to $1173 \mathrm{~K}\left(1650^{\circ} \mathrm{F}\right)$. Measured ARFs ranged from $2.8 \times 10^{-8}$ to $5.3 \times 10^{-7}$. No RFs were reported.

Mishima (1966) reported the ARF and size distribution for the only experiments using large pieces of unalloyed and delta-phase stabilized plutonium metal during oxidation from self-sustained reaction. Three unalloyed and one delta-phase stabilized metal pieces weighing from $455.5 \mathrm{~g}(1 \mathrm{lb})$ to $1770 \mathrm{~g} \mathrm{(3.9} \mathrm{lb)} \mathrm{were}$ ignited and allowed to oxidize completely in flowing air. The ARFs ranged from $3.9 \times 10^{-6}$ to $4.9 \times 10^{-4}$. The size distribution of the airborne material from one of the tests was sized using Transmission Electron Microscopy and the MMD was determined to be $14 \mu \mathrm{m}\left(5.5 \times 10^{-4}\right.$ in $) \mathrm{D}_{\mathrm{AED}}\left(4.2 \mu \mathrm{m}\left(1.6 \times 10^{-4} \mathrm{in}\right) \mathrm{D}_{\mathrm{g}}\right)$.

Carter and Stewart (1970) reviewed their previous data, reported and unreported, and estimated an ARF of $1 \times 10^{-4}$ at the 95 percent confidence level. 
Eidson and Kanapilly (1983) and Eidson, Yeh, and Kanapilly (1988) reported on the ARFs from the reaction of delta-phase stabilized plutonium metal and various atmospheres ranging from argon and air mixtures to a mixture simulating the gaseous products from the burning of propellants. Specimen masses were small (most were under 1 gram), although the last tests used specimens with masses to 10 grams. Temperatures ranged from $373 \mathrm{~K}\left(212^{\circ} \mathrm{F}\right)$ to $1273 \mathrm{~K}\left(1830^{\circ} \mathrm{F}\right)$. ARFs ranged from $5.2 \times 10^{-6}$ to $4.6 \times 10^{-3}$. Because of the initial assumptions for the release estimates, the authors believed that some of the initial values may be overstated.

Luna (1994) reanalyzed the data from the Vixen A trials, where the airborne release and transport of plutonium metal held in a basket suspended above burning gasoline in a chimney were measured. For the two tests reported, the ARFs back-calculated from downwind sampling, and assumptions with respect to the airborne transport were ARF $1 \times 10^{-2}$ with an $R F$ of 0.01 , and ARF $3 \times 10^{-4}$ with an $\mathrm{RF}$ of 0.08 . The fractions of respirable particles formed as a function of the total inventory were $1 \times 10^{-4}$ and $3.2 \times 10^{-4}$ and approximate the maximum value during the burning of large pieces, $2.5 \times 10^{-4}$, reported by Mishima (1966).

Haschke (1992) estimated the oxidation rate and size distribution of plutonium metal during self-sustained oxidation. His conclusions were, "If the largest diameter of releasable materials is assumed to be $10 \mu \mathrm{m}$ $\mathrm{D}_{\mathrm{g}}$, the maximum releasable mass fraction for plutonium and $\mathrm{O}_{2}$ is 0.0007 ." A $10 \mu \mathrm{m}\left(3.9 \times 10^{-4} \mathrm{in}\right) \mathrm{D}_{\mathrm{g}}$ particle of $\mathrm{PuO}_{2}$ (density $11.46 \mathrm{~g} / \mathrm{cm}^{3}\left(715 \mathrm{lb} / \mathrm{ft}^{3}\right)$ ) is equivalent to a $34 \mu \mathrm{m}(0.0013 \mathrm{in}) \mathrm{D}_{\mathrm{AED}}$. Under the assumption of a Geometric Standard Deviation for a lognormal distribution, the RF would be 1 to 2 orders of magnitude less than the reported values.

Barr et al. (1970) determined the characteristics of $\mathrm{PuO}_{2}$ produced by various precursors. For Burned $\mathrm{Pu}$ Metal, the material obtained for analysis had been dry ball-milled for 72 hours and is not representative of oxide generated by the oxidation of plutonium metal under accident conditions.

The values reported by Mishima (1966) for the ARF and RF during the self-sustained oxidation of plutonium metal in flowing air, ARF 5E-4.RF 0.5, are cited in item (b) above

Flowing Molten Plutonium. (See Subsection 4.2.1.1.4, pp 4-25 and 4-26 of [USDOE 1994].) Carter and Stewart (1970) reported the violent reaction of small pieces of plutonium metal heated in pure oxygen with an ARF of $1 \times 10^{-2}$ and an MMD of $0.3 \mu \mathrm{m}\left(1.2 \times 10^{-5}\right.$ in $) \mathrm{D}_{\mathrm{AED}}$. ARFs were measured in tests using the freefall of molten droplets through a $0.75-\mathrm{m}(2.46-\mathrm{ft})$ tube with an upflow of air. The velocity was adequate to support a $30-\mu \mathrm{m}\left(0.0012\right.$-in) $\mathrm{D}_{\mathrm{AED}}$. The $\mathrm{RF}$ fraction of the airborne material with respect to the total inventory of plutonium (RARF) was measured. A value of $1 E-2$ for this fraction at the 95 percent confidence level was quoted by the authors and is cited here.

Explosive Oxidation by Falling Molten Metal Drops (less than $100 \mu \mathrm{m} \mathrm{D}_{\mathrm{g}}$ Falling through Air). Chatfield (1969) reported the ARFs and RFs for the explosive release of plutonium metal wrapped in sodium metal foil. The mixture was heated to $573 \mathrm{~K}\left(572^{\circ} \mathrm{F}\right)$ in argon and then the flow was switched to air. The ARFs for the small specimens (less than 1 gram) ranged from $3.6 \times 10^{-7}$ (RF 0.8 ) to $6.3 \times 10^{-3}$ (RF 0.28). The RFs, not measured for all tests, ranged from 0.11 (ARF $2.7 \times 10^{-5}$ ) to 0.88 (ARF $4.2 \times 10^{-7}$ ).

Carter and Stewart (1970) reported two types of tests. One configuration allowed plutonium metal heated beyond the ignition temperature to free-fall through a $0.75-\mathrm{m}(2.46-\mathrm{ft})$ tube with an upflow of air initial temperature of $933 \mathrm{~K}\left(1220^{\circ} \mathrm{F}\right)$, but heating due to the heat of reaction may have raised the temperature to in excess of $2273 \mathrm{~K}\left(3630^{\circ} \mathrm{F}\right)$. The second dispersed the plutonium metal using the exploding wire 
technique. The authors reported an ARF of 5E-1, with an RF of 1.0, at the 95 percent confidence level, for these tests.

Raabe, et al. (1978) created molten droplets by laser-heating $50 \mu \mathrm{m}(0.002$ in) thick foils of plutonium metal using a laser and allowing the molten metal to free-fall through a 3-m- $(\sim 10 \mathrm{ft}-)$-tall-tube with an upflow of air. The authors reported that essentially all the metal was airborne, with approximately 40 percent in the RF.

Based on the two sets of experiments that yield RARF of $\sim 0.5$ (Carter and Stewart [1970], ARF 1E+0/RF 0.5 and Raabe, et al. [1978] ARF 1.0/RF 0.4), the bounding value cited in item (d) above is an ARF of $1 \mathrm{E}+0$ with an RF of 0.5 .

\title{
3.3.2.8 Solid, Reactive Metal - Uranium
}

Uranium (see Subsection 4.2.1.2, "Uranium," in (USDOE 1994).

a. At less than ignition temperature but greater than $773 \mathrm{~K}\left(932{ }^{\circ} \mathrm{F}\right)$ for bulk metal with diameters $2.5 \mathrm{~cm}$ (1 in) or greater

RARF 1E-3 of oxide formed

b. Spill of molten metal $>1$ meter (3.28 ft) through air

ARF 1E-2

RF (no data available)

c. Explosive dispersal of thin sheets of metal

\author{
ARF 1E+0 \\ RF (no data available)
}

\section{Technical Basis}

The behavior of uranium as production fuel has been studied since the 1940s. Size distributions of the oxides generated have been reported but are not cited here.

The fragmentation of uranium metal alloy $(99.25$ percent depleted uranium +0.75 percent titanium, "stabaloy") has been recently studied during tests of armor-penetrating projectiles. The size distribution of the fragments collected after oxidation is usually cited, although Elder and Tinkle (1980) made some measurements of the ARF and RF as a function of time during their experiments. An additional complexity is that uranium may form several oxides moving toward the stable $\mathrm{UO}_{3}$. Generally, the oxidation behavior of uranium metal is to form a thin (1-to-50- $\mu \mathrm{m}$-thick (3.9 $\times 10^{-5}$-to $2.0 \times 10^{-3}$-in-thick)) layer of $\mathrm{UO}_{2}$ that adheres to the metal surface (the matrix spacing of $\mathrm{UO}_{2}$ is close to that of the gammaphase of the metal). As additional heating and oxygen availability dictate, the surface converts to $\mathrm{U}_{3} \mathrm{O}_{8}$ that is not adherent and falls away from the metal. With sufficient heating and oxygen availability, the $\mathrm{U}_{3} \mathrm{O}_{8}$ can be oxidized to $\mathrm{UO}_{3}$. There is some uncertainty associated with the suboxides formed in this process, and various compounds have been suggested as the intermediaries. Much of this type of 
background material may be found in Mishima, et al. (1985). Unlike plutonium, large pieces of uranium metal are difficult to ignite (see Figure 3-2). Its oxidation is a step function under some conditions.

Elder and Tinkle (1980) heated 2.5-cm (1-in) diameter x 33-cm (13-in) long bars of stabaloy at various temperatures in flowing air and air $+\mathrm{CO}_{2}$ mixtures. The ARF times the RF ranged from $1 \mathrm{E}-1$ ( $773 \mathrm{~K}$ $\left(932^{\circ} \mathrm{F}\right)$ in $3.2 \mathrm{~m} / \mathrm{s}\left(7.16 \mathrm{mph}\right.$ ) air $+\mathrm{CO}_{2}$ mixture) to $5 \mathrm{E}-3$ (periodic burning of [10] aliquots of burning propellant in $3.2 \mathrm{~m} / \mathrm{s}(7.16 \mathrm{mph}$ ) air). Carter and Stewart (1970), using uranium metal oxidized in air or free-falling molten metal drops, report [ARF] $R F$ ] of $4 \mathrm{E}-4$ for oxidizing metal at the 95 percent confidence level and 6E-3 from free-falling molten metal drops.

A large number of munitions burning tests have been performed to qualify kinetic-energy rounds with stabaloy penetrators (Gilchrist, et al. 1978; Hooker, et al. 1985; Haggard, et al. 1986; Parkhurst, et al. 1990). A pre-determined number of cases of munitions are surrounded by wood and doused with 208.1 liters (55 gallons) of diesel fuel. The stack is ignited and the mass explosive and thermal hazards are measured. For the depleted uranium materials, airborne and oxide powder generated by the oxidation of the uranium is also determined. In all cases, the oxides recovered are predominantly $\mathrm{U}_{3} \mathrm{O}_{8}$. The lung solubility class is predominantly " $Y$ " (year, dissolution halftime in simulated interstitial lung fluid greater than 100 days) with an RF less than $1 \times 10^{-3}$.

Samples of airborne particles generated by other tests involving these penetrators (test firing against targets) was reviewed by Jette, et al. (1989). In firing tests performed using the same size stabaloy bars used in Elder and Tinkle (1980), Glissmeyer and Mishima (1979) collected airborne samples of particles by size fraction. For the particles in the RF, approximately 50 percent were " $D$ " class (day, dissolution halftime in simulated interstitial lung fluid of 1 day). It would appear that the heating over a long duration (from 8 to 24 hours) in the fire results in some sintering or changes in the surfaces of the particle, rendering them less susceptible to dissolution.

The values cited above are derived from these data. The airborne release of RF particles was determined to be bounded by the maximum ARF measured in Elder and Tinkle (1980) and the RARF measured from oxide powder after the burn test that was consistently below $1 \times 10^{-3}$.

The value for release during the free-fall of molten metal drops is a very conservative bound of the data reported in Carter and Stewart (1970).

The ARF value for explosive dispersion is based on a very conservative interpretation of the results reported by Benson and Rader (1988), in which foils of uranium metal were explosively hurled down range using a Hydrodynamic Thruster (a very high voltage is discharged through the foil placed in front of a negatively-charged plate that violently ejects the particles generated by the exploding wire action). The bounding ARF and RF are both assumed to be $1 E+0$ because of the limited amount of data available.

Barr, et al. (1970) determined the physical properties of some uranium dioxide powder prepared for use in mixed oxide fuel fabrication. The powders were specially processed to obtain a reasonably fine material that enhances uniformity in the fuel. The powders were two calcined ammonium diuranate precipitates. The size distributions measured for both the $\mathrm{UO}_{2}$ powders and the $\mathrm{PuO}_{2}$ powders are agglomerates of particles and are a function of the amount of dispersant used (above some minimum value) and the type and duration of the dispersion forces (e.g., hand-shaking, centrifugal, sonic). For the $\mathrm{UO}_{2}$ powders used in the study, the particles measured in the size range less than 10 micrometers $\mathrm{Da}$ (Stokes diameter) were strongly depending on the factors mentioned (Figure 2, Barr, et al. 1970). 


\subsubsection{Solid, Non-Combustible - Aggregate, Concrete}

a. $H^{3}$ as water vapor, temperature of concrete greater than $373 \mathrm{~K}$ to $473 \mathrm{~K}\left(212^{\circ} \mathrm{F}\right.$ to $\left.392{ }^{\circ} \mathrm{F}\right)$

\section{ARF 5E- 1 (loss of adsorbed water) RF (not applicable to vapors)}

b. $H^{3}$ as water vapor, temperature of concrete greater than $473 \mathrm{~K}$ to $873 \mathrm{~K}\left(392^{\circ} \mathrm{F}\right.$ to $\left.1100{ }^{\circ} \mathrm{F}\right)$. May also suspend non-volatile-radionuclides present if cement is decomposed and particles of $\mathrm{CaO}$ can be suspended.

\section{ARF 1E + 0 (loss of adsorbed and chemically bound water) RF (not applicable to vapors)}

Technical Basis

These estimates are based on the known water loss characteristics of cement.

\subsubsection{Solid, Non-Combustible - Powders}

a. Non-Reactive, up to $1000^{\circ} \mathrm{C}\left(1830^{\circ} \mathrm{F}\right)$, upflow around powder to $100 \mathrm{~cm} / \mathrm{s}(2.24 \mathrm{mph})$

\section{ARF 6E-3 \\ RF 0.01}

b. Reactive, plutonium compounds, up to $100^{\circ} \mathrm{C}\left(212^{\circ} \mathrm{F}\right)$, upflow around to $100 \mathrm{~cm} / \mathrm{s}(2.24 \mathrm{mph})$ :

- Pufluoride

\section{ARF 1E-3 \\ RF 0.001}

- Pu oxalate, nitrate

\section{ARF 1E-2 \\ RF 0.001}

\section{Technical Basis}

The ARFs during the heating of plutonium compounds in flowing air were measured by Mishima, Schwendiman, and Radasch (1968a; 1968b). For heating to temperatures up to $1273 \mathrm{~K}\left(1832^{\circ} \mathrm{F}\right)$ and air velocities to $100 \mathrm{~cm} / \mathrm{s}(2.24 \mathrm{mph})$, the maximum measured values are cited above. The $\mathrm{ARFs}$ for $\mathrm{PuO}_{2}$ ranged from $6.1 \times 10^{-6}$ to $5.6 \times 10^{-3}$. The ARFs for partially oxidized plutonium oxalate powder ranged from $<8 \times 10^{-5}$ to $8.8 \times 10^{-3}$ at the highest temperature and flow velocity. The range of ARFs for plutonium oxalate powder was $<8 \times 10^{-5}$ to $9.5 \times 10^{-3}$ at $973 \mathrm{~K}\left(1290^{\circ} \mathrm{F}\right)$ and $100 \mathrm{~cm} / \mathrm{s}(2.24 \mathrm{mph})$ flow velocity. The range of ARFs for plutonium fluoride powder was significantly less than for the oxalate or air-dried nitrate powder within a range from $<8 \times 10^{-5}$ to $7 \times 10^{-4}$ at the highest temperature and flow velocity. Air-dried 
nitrate powder from the acidic, plutonium nitrate solution was similar to that found for the oxalate powder with a range from $2 \times 10^{-5}$ to $1.5 \times 10^{3}$. Optical microscopy indicated that the $R F$ for the highest ARF values above was $<10^{-5}$. For additional details on the apparatus used and other values measured, see the references cited below or Subsection 4.4.1 "Powders - Thermal Stress," pp 4-55 to 4-6,1 in (USDOE 1994).

Barr, et al. (1970) determined some physical properties of $\mathrm{PuO}_{2}$ from various precursor compounds to determine their value for mixed oxide fuel fabrication. The $\mathrm{PuO}_{2}$ powders were from carefully controlled calcination of oxalate precipitate and dried nitrate solution. The as-received materials appeared to be made up of two to three distributions, and, depending upon calcination temperature, the RF ranged from 0.1 (calcined at $1273 \mathrm{~K}\left(1832^{\circ} \mathrm{F}\right)$ ) to 0.25 (calcined at $673 \mathrm{~K}\left(752^{\circ} \mathrm{F}\right)$ ). The size distribution varied with the amount of dispersant used and the duration of the dispersion. The RF varied from 0.1 for a $15 \mathrm{~min}$ dispersion time to 0.4 for a $2 \mathrm{hr}$ period for $\mathrm{PuO}_{2}$ calcined at $1273 \mathrm{~K}\left(1832^{\circ} \mathrm{F}\right)$. For $\mathrm{PuO}_{2}$ calcined at 973 $\mathrm{K}\left(1290^{\circ} \mathrm{F}\right)$, the $\mathrm{RF}$ varied from 0.2 (5 min dispersion) to 0.7 (105 min dispersion). Thus, both the presence or absence of dispersion and the type and level of dispersing forces (hand-shaking, vibratory action, sonic agitation, etc., in a liquid) affect the apparent size distribution. Dispersion would not be expected under accident conditions, nor the dispersion forces (agitation in a liquid) used here.

Similar behavior and size distribution characteristics were found for the oxide from dried-nitrate solution. The $\mathrm{RF}$ varied from 0.3 to 0.4 for calcination at $723 \mathrm{~K}$ to $1273 \mathrm{~K}\left(842\right.$ to $\left.1832^{\circ} \mathrm{F}\right)$. The $\mathrm{RF}$ decreased as the calcination temperature increased.

Ricketts (1995) reported the change in particle size distribution of $\mathrm{PuO}_{2}$ from heating oxides generated from hydride-catalyzed oxidation of pure metal, from the calcination of oxalate precipitated from acid nitrate and from chloride solutions. The oxide from metal was stored in a dry glovebox for 2 months before characterization. The oxide from the nitrate solution and chloride solutions had been stored in a vault for approximately 3 and $1.5 \mathrm{yrs}$, respectively. The RF for the as-received materials ranged from 0.029 (Hydride-Catalyzed metal) to $3.5 \times 10^{-5}$ for the oxide from the chloride solutions. All three oxides increased in size as a result of the heating, with the RF decreasing to 0.002 for the metal oxide and $1.3 \times 10^{-5}$ for the chloride solution oxide. As shown in Barr, et al. (1970), the size distribution measured is a function of the presence or absence of a dispersant and the type and level of force used for dispersion. It would also appear that the materials used underwent some alteration of surface characteristics that enhanced agglomeration at higher temperatures (possibly a softening of the surface of particles that results in an increasing degree of "stickiness"). It would be anticipated that oxides formed from plutonium compounds in powder form would be subject to higher temperatures during a fire and provide support for the RF cited above.

\title{
3.3.2.11 Solid, Non-Combustible - Contaminated HEPA Filters
}

Contaminated HEPA Filters, passage of heated air up to $673 \mathrm{~K}\left(720^{\circ} \mathrm{F}\right)$ before melting of glass fiber filter medium

\author{
ARF 1E-4 \\ RF (no data available)
}




\title{
Technical Basis
}

The particle collection medium used in HEPA filters is a glass fiber mat. The fibers are approximately 4 $\mu \mathrm{m}$ in diameter and, subjected to temperatures near the melting point of glass, soften and become molten. Particles of non-volatile materials adhering to the surface not suspended before the softening of the glass will be captured in the molten glass. HEPA filters resist momentary exposure to temperatures as high as $1098 \mathrm{~K}\left(1520^{\circ} \mathrm{F}\right)$ before failure and have withstood temperatures as high as $773 \mathrm{~K}\left(932^{\circ} \mathrm{F}\right)$ for greater than 45 min without loss of particle-collection capability (Hackney 1983).

New and used HEPA filters were tested using $1.8 \mu \mathrm{m}\left(7.1 \times 10^{-5}\right.$ in) $D_{g}$ solid particles at a range of temperatures less than required for failure (Ammerich, et al. 1989). No releases were observed at temperatures less than $423 \mathrm{~K}\left(302^{\circ} \mathrm{F}\right)$. At greater temperatures, the release showed an initial high level $\left(1 \times 10^{-6} / \mathrm{min}\right.$ for a $1000-\mathrm{cfm}\left(0.47-\mathrm{m}^{3} / \mathrm{s}\right)$ HEPA filter at $\left.448 \mathrm{~K}\left(337^{\circ} \mathrm{F}\right)\right)$ but decayed to a much lower value $\left(2 \times 10^{-8} / \mathrm{min}\right.$ in $\left.1 \mathrm{hr}\right)$. The initial decay of release rate was exponential and approached the low level asymptotically. With some degree of conservatism, it is postulated that the ARF for a HEPA filter may be $1 \times 10^{-5}$. A value for the ARF an order of magnitude greater is assumed for conservatism, because of the limited data base. There was no measurement of particle-size distribution of the airborne materials and an $\mathrm{RF}$ of 1.0 is conservatively assumed.

\subsubsection{Solid, Contaminated Combustible - Packaged Waste}

Burns to self-extinguishment, only convective flow generated by burning materials

\author{
ARF 5E-4 \\ RF (no data available)
}

\section{Technical Basis}

The values cited here are the maximum measured ARF from experiments reported in Mishima and Schwendiman (1973c). Cardboard waste cartons (45.7-cm (1.5-ft) x 45.7-cm (1.5-ft) x 61-cm (2.0-ft) tall) lined with a plastic bag filled with a mixture of loose, contaminated, cellulose-plastic-rubber waste were ignited and burned to self-extinguishment in a 3-m- (9.8-ft-) diameter x 3-m- $(9.8-\mathrm{ft}-)$ high stainless steel vessel. The waste was contaminated with ball-milled $\mathrm{UO}_{2}$ powder (AMAD 3 to $6 \mu \mathrm{m}\left(1.2 \times 10^{-4}\right.$ to $2.3 \times 10^{-4}$ in) $\mathrm{D}_{\mathrm{g}}$ ), an acidic UNH solution, and/or the residue from air-drying of the acidic UNH solution. ARFs were measured by collection of materials on filters on high-volume samplers at the exhaust port of the vessel. The values measured ranged from $3 \times 10^{-5}$ to $5 \times 10^{-4}$. No measurement of the size distribution of the airborne particles were made and no RF is given. The conservative assumption is that all the particles are in this size range.

Quintiere and Kaiser (1995) reviewed the experimentally measured ARFs'.

Currently Transuranic (TRU) wastes and other waste forms are packaged in more substantial, noncombustible containers, whose behavior under fire conditions may vary significantly from cardboard cartons. Metal 208.2-liter (55-gallon) drums are commonly used for TRU wastes. The container is sealed

\footnotetext{
4 Quintiere, J.G., and G.D. Kaiser, "A Review of Airbome Release Fractions for Contaminated Waste in Large Scale Liquid Pool Fires, Final Report" (undocumented), Science Applications International Corporation, Reston, Virginia, 1995.
} 
with a formed, sheet metal lid held in placed by a metal retaining ring. Typically, the waste is held in a thick, rigid polyethylene liner with a lid. Various studies and tests have been performed using various physical configurations and waste loading characteristics.

In 1991, DOE issued a "Position Paper on the Flammability Concern Associated with TRU Waste Destined for WIPP (Waste Isolation Pilot Plant)" and stated that "...given the applicable regulations and restrictions, it is unlikely that a TRU waste drum which qualifies for transportation and disposal will contribute to any incident related to overpressurization or flammability of the waste."

Hasegawa et al. (1993) tested 208.2-liter (55-gallon) metal drums filled with $10 \mathrm{~kg}$ (22 lb) of combustible materials and spiked with isopropanol to assure combustion of the materials. Four drums were placed in a $2-\mathrm{m}(6.6-\mathrm{ft})$ isopropanol fuel pool that was ignited. In some tests, one or more of the drums violently ejected their lids and spread their combustible material contents in the immediate area. The drums did not have filtered vents, although, even if there were filters, it is uncertain how effective the small, compacted carbon filters would be in venting the rapid pressure rise (because of generation of pyrolyzates and moisture from the heating of the combustible materials or from the plugging/blinding of the filter by these materials).

Greenhalgh, et al. (1994) reported the behavior of drums typically used at their location (metal 208.2-1 (55gallon) drum with polyethylene liner and vent) during a fire. Four loaded drums (range 130 to $174 \mathrm{~kg}$ (286 to $383 \mathrm{lb}$ )) of a typical mixture of paper, wood, plastic, rags, HEPA filters, etc.) were stacked two-high in a rack and placed in a wood-metal building scheduled for destruction. Additional combustible materials were placed inside the structure to assure adequate fuel. None of the drums violently ejected its lid but vented the gas via small vents around the periphery of the lid.

Haecker, et al. (1995) exposed the typical waste drum to a series of fires (heated by a $0.48 \mathrm{~m}(1.6 \mathrm{ft}$ ) propane burner, by a $1.2 \mathrm{~m}(3.94 \mathrm{ft})$ propane burner, a trash fire, and a $2.1-\mathrm{m}(6.89-\mathrm{ft})$ pool fire). At higher heating rates, such as in a liquid pool fire (an engulfing fire), many to all of the drums violently ejected their lids and hurled some to all of the contained waste into the adjacent area. The burning of a single waste drum does not propagate to adjacent drums.

Thus, under fire conditions that result in pressure-rise rates, the drums overpressurize and violently eject their contents. The rate at which this occurs was not determined, but, given the variation of strength and the tightness of the retaining ring, there may be considerable variation in the behavior of individual drums. Loose combustibles may fall into the fire and burn or may be carried away from the fire and ignite by radiant heat or not, depending on the mass and inertia imparted by the venting of the overpressure. Packaged material (plastic wrap) may have sufficient mass and inertia to escape the fire and would fall rapidly to the ground because of its mass.

\subsubsection{Solid, Contaminated Combustible - Unpacked, with Contamination Exposed to Ambient Environment}

a. Loose cellulosic material (contaminant exposed to ambient environment), external heat flux supplied, burn to self-extinguishment, airflow up to $100 \mathrm{~cm} / \mathrm{s}(2.24 \mathrm{mph})$ across or upflow around burning materials

\section{ARF 1E-2}

RF 1.0 
b. Loose polystyrene (contaminant exposed to ambient environment), external heat applied to ignition and during tests, upflow around burning material less than $20 \mathrm{~cm} / \mathrm{s}(0.45 \mathrm{mph})$

\section{ARF 1E-2}

RF 1.0

c. Loose materials consisting of other plastics (polymethylmethacrylate, etc.), burns to selfextinguishment, external heat supplied to ignition and during test, upflow around burning material less than $20 \mathrm{~cm} / \mathrm{s}(0.45 \mathrm{mph})$

ARF 5E-2

RF 1.0

\section{Technical Basis}

The ARF has been measured during the burning of contaminated, loose (the contaminated surface is exposed to the ambient environment), cellulosic materials. Substrate materials include tissue paper (Kleenex), cardboard, rags, and wood (Mishima and Schwendiman 1970; Halverson, et al. 1987). Contaminants range from acid plutonium nitrate solutions, ball-milled $\mathrm{UO}_{2}$ power, acidic UNH solutions, to the air-dried residues from the acidic nitrate solutions. Air flow in some experiments had a nominal velocity over the burning materials of $\sim 6 \mathrm{~cm} / \mathrm{s}(0.13 \mathrm{mph})$ and, in other experiments, had a velocity from tens of $\mathrm{cm} / \mathrm{s}$ to $1 \mathrm{~m} / \mathrm{s}\left(0.2\right.$ to $2 \mathrm{mph}$ ). The ARFs ranged from $7 \times 10^{-5}$ (for cheese cloth contaminated with acidic plutonium nitrate solution with $\sim 6 \mathrm{~cm} / \mathrm{s}(0.13 \mathrm{mph})$ drawn across and over the burning material) to $1 \times 10^{-2}$ (corrugated cardboard contaminated with acidic plutonium nitrate solution with air at $\sim 6 \mathrm{~cm} / \mathrm{s}(0.13$ $\mathrm{mph}$ ) drawn across and over the burning material). RFs for the airborne materials were only determined in two experiments, for paper towels contaminated with ball-milled depleted $\mathrm{UO}_{2}$ with air flow in the tens of $\mathrm{cm} / \mathrm{s}$ drawn around and over the burning materials, and were 0.97 and 0.47 . The values cited in item (c) above are based on these data. Additional information can be found in the referenced documents or Subsection 5.2.1.2 of (USDOE 1994).

The ARF and RF cited for release during the burning of contaminated, loose, polystyrene are based on very limited data, namely three tests reported in Halverson, et al. (1987). All tests were performed using UNH solutions to simulate ion-exchange resin processing conditions. The ARFs varied from $2 \times 10^{-3}$ to $8 \times 10^{-3}$, with a single RF value of 0.9 associated with the largest ARF measured. The maximum measured ARF was increased to $1 \mathrm{E}-2$, cited above, to compensate for the limited data. This value is significantly lower than the value discussed below for other plastics and elastomers. Additional information can be found in the reference cited.

The ARF and RF were measured for releases during the burning of other plastics (polymethylmethacrylate, (PMMA)) and polychloroprene/rubber (PC) (Mishima and Schwendiman 1970; Halverson, et al. 1987). The ARFs for PMMA ranged from $2 \times 10^{-3}$ (released during the burning of acidic UNH-contaminated, loose PMMA with air flow drawn around and over the burning material at a nominal velocity in the tens of $\mathrm{cm} / \mathrm{s}$ ) to $4.5 \times 10^{-2}$ (released during burning of a pile of ball-milled depleted $\mathrm{UO}_{2}$ powder resting on the surface of PMMA with air flow also drawn around and over the burning material). RFs were not measured for all experiments and the four values range from 0.63 to 0.95 . An RF value of 0.86 was associated with an ARF of $3.6 \times 10^{-2}$, near the maximum measured value. The ARFs for $\mathrm{PC} /$ rubber ranged from $2 \times 10^{-4}$ (acidic plutonium nitrate solution on rubber) to $3.5 \times 10^{-2}$ (ball-milled depleted $\mathrm{UO}_{2}$ powder). Only a single $\mathrm{RF}$ 
value, 0.16 , was measured. The maximum measured ARF was rounded upwards to 5E-2, and the maximum measured RF rounded upwards to 1.0. Additional information can be found in the referenced documents or Subsection 5.2.1 of (USDOE 1994).

\title{
3.3.2.14 Solid, Contaminated Combustible - Light Cellulosic Materials
}

That is, light cellulosic material that remains suspended in convective flow or fireballs during complete combustion. Ash and mineral components fall into the upflow.

a. Contaminant $\mathrm{UO}_{2}$ pre-formed particle

ARF 4E-1

RF (no data available)

b. Contaminant air-dried residues from solutions

\author{
ARF 8E-2 \\ RF (no data available)
}

Technical Basis

The values cited above are from measurements made during one set of experiments (Mishima and Schwendiman 1970). Ball-milled depleted $\mathrm{UO}_{2}$ powder and $\mathrm{UNH}$ solution were used as contaminants on various combustible materials (tissue paper, cheesecloth, corrugated cardboard) and ignited on a fine mesh stainless steel in a 7.6-cm (3-in) diameter quartz tube. Air at a minimum velocity of $1 \mathrm{~m} / \mathrm{s}(2.24 \mathrm{mph})$ was drawn up through the tube, and the downstream end was sealed by a glass fiber filter to collect all materials. The AMAD of the ball-milled $\mathrm{UO}_{2}$ was 3 to $6 \mu \mathrm{m}\left(1.2 \times 10^{-4}\right.$ to $2.3 \times 10^{-4}$ in $) \mathrm{D}_{\mathrm{AED}}$, and the velocity was capable of carrying particles up to $130 \mu \mathrm{m}(0.005 \mathrm{in}) \mathrm{D}_{\mathrm{AED}}$ through the tube. The measured ARFs ranged from $1.6 \times 10^{-2}$ to $3.8 \times 10^{-1}$ for the $\mathrm{UO}_{2}$ and $3.4 \times 10^{-6}$ to $8 \times 10^{-2}$ for the UNH. No RFs were determined for the airborne material. The maximum measured ARF is cited for two contaminants after rounding to a single digit. Additional information can be obtained from the referenced document or Subsection 5.2.1.3 in (USDOE 1994).

\subsubsection{Aerodynamic Entrainment/Resuspension}

\subsubsection{Homogeneous Deposit, Liquid - Indoors}

a. Shallow pool on heterogeneous surface (e.g., stainless steel, glass, concrete), normal building ventilation flow/low airspeed $(<2 \mathrm{~m} / \mathrm{s}, \sim 5 \mathrm{mph})$

\section{ARR 4E-7/hr \\ RF (no data available)}

b. Shallow pools, as above, but covered with substantial layer of debris

\author{
ARR 4E-8/hr \\ RF (no data available)
}




\title{
$\underline{\text { Technical Basis }}$
}

There is limited experimental data for the aerodynamic entrainment (resuspension) of liquids from shallow pools by air passing over the material parallel to the surface. For a non-volatile solute, the suspension of the liquid droplets carrying the solute is required. Three experiments reporting the aerodynamic entrainment of plutonium from a shallow pool of acid plutonium nitrate solution have been performed (Mishima, et al. 1960). Air at a velocity of 10 to $100 \mathrm{~cm} / \mathrm{s}(0.224$ to $2.24 \mathrm{mph})$ was passed over a pool of acidic plutonium nitrate solution $\sim 2.5 \mathrm{~cm}$ ( 1 in) in diameter and 2-to-4 mm- (0.079-to 0.16-in-) deep. Airborne materials were collected by a filter over 2 to 24 hours. The Airborne Release Rates (ARRs) ranged from $<2.0 \times 10^{-15} / \mathrm{s}$ to $3 \times 10^{-14} / \mathrm{s}$ with $\mathrm{ARFs}$ for the entire sampling period ranging from $<2 \times 10^{-10}$ to $2.5 \times 10^{-9}$. Based upon data gathered from experiments of suspension of contaminants from Hanford soils during three of four seasons, Sehmel and Lloyd (1976) determined the ARF for particle contaminants to be in the range $10^{-8}$ to $10^{-10}$. The measured values for shallow pools are within this range and appear conservative. Additional information is found in the referenced documents and Subsection 3.2.4.2 in (USDOE 1994).

The lesser ARR cited for shallow pools of liquid covered by debris is based on reasoned judgment because of the lesser velocity impacting the surface when material is covered by debris and the more difficult egress to the ambient atmosphere.

\subsubsection{Homogeneous Deposit, Liquid - Outdoors}

Large pool, airflow across (parallel to surface) up to $13.6 \mathrm{~m} / \mathrm{s}(\sim 30 \mathrm{mph})$

ARR 4E-6/hr
RF (no data available)

\section{Technical Basis}

Roblyer and Owczarski (1992) published the SPRAYMAS model based upon the suspension from sea water as a function of wind velocity and fetch (upstream distance to develop a constant flow pattern). Under the assumption of a $10-\mathrm{m}(32.8-\mathrm{ft})$ fetch, a windspeed of $15 \mathrm{~m} / \mathrm{s}(33.6 \mathrm{mph})$, and an effective depth of $1 \mathrm{~mm}$ to $1 \mathrm{~cm}(0.04$ to $0.4 \mathrm{in})$, the Airborne Release rate was calculated to range from 4E-6/hr to $4 \mathrm{E}-8 / \mathrm{hr}$. The higher value is cited above. Further information can be found in the referenced document.

\subsubsection{Heterogeneous Deposit, Liquid - Outdoors Absorbed on Soil}

Outdoors, absorbed on soil, no large standing pools of free liquid, up to $22.7 \mathrm{~m} / \mathrm{s}$ (50 mph)

\author{
ARR 9E-5/hr \\ RF (no data available)
}

\section{Technical Basis}

Before determination of airborne release during the burning of gasoline over acidic UNH solution on soil in a wind tunnel, some measurements were made of the aerodynamic entrainment of the uranium at ambient temperatures at windspeeds of 1 to $9.5 \mathrm{~m} / \mathrm{s}(2.24$ to $21.25 \mathrm{mph}$ ) (Mishima and Schwendiman $1973 \mathrm{~b})$. Only three ARRs were measured, and, at the two windspeeds, the ARRs ranged from $4 \times 10^{-6} / \mathrm{hr}$ to 
$9 \times 10^{-5} / \mathrm{hr}$. The highest measured value is cited above. No measurements were made of the RF in the airborne material.

\title{
3.3.3.4 Heterogeneous Deposit, Powder - Indoors
}

a. Piles of powder on heterogeneous surface (e.g., concrete, stainless steel, glass), normal building ventilation flow, slow air velocity $(<2 \mathrm{~m} / \mathrm{s}, \sim 5 \mathrm{mph})$

\section{ARR 4E-5/hr \\ RF (no data available)}

b. Indoors, as above, covered with substantial layer of debris

\author{
ARR 4E-6/hr \\ RF (no data available)
}

\section{Technical Basis}

Aerodynamic entrainment of powders (resuspension) has been extensively studied (Alonso, et al. 1981; Anspaugh, et al. 1975 and 1976; Braaten, et al. 1986; Brockman 1985; Corn and Stein 1965; Fish, et al. 1966; Fromentin 1989; Garland 1982; Sehmel and Lloyd 1976; Sehmel 1980; Stewart 1967; Wright and Pattison 1984) and divides into roughly two categories--suspension from homogeneous and heterogeneous surfaces.

Homogeneous surfaces are those that behave like the particle contaminant--for example, particle contaminants on soil. Homogeneous surfaces may be relatively thick, but the contaminant may only be involved with the uppermost layer of the surface. Heterogeneous surfaces are typically fixed, do not behave like the particle contaminant, and the powders are typically sparse deposits, scattered and less than two particle diameters in depth. Both types of surfaces may have surface imperfections/roughness that allow smaller particles to be shielded from gas passing over the surface. Both types of deposits behave in much the same manner, although each type of surface may have dissimilar effects on the flow passing over the surface. The behavior of particles under aerodynamic stress is based partially on the $\mathrm{D}_{\mathrm{g}}$. Particles greater than 120 to $150 \mu \mathrm{m}(0.005$ to $0.006 \mathrm{in}) \mathrm{D}_{\mathrm{g}}$ exhibit "surface creep" (the rolling of particles along the surface) when movement is initiated. Particles in the range 70 to $120 \mu \mathrm{m}(0.0027$ to $0.005 \mathrm{in}) \mathrm{D}_{\mathrm{g}}$ saltate, (i.e., roll/bounce along the ground), until they encounter an obstruction, then vault into the air for heights up to $0.5 \mathrm{~m}$ (1.64 ft). Particles in this size range appear to be the first to be moved by aerodynamic stress. Particles of less than $70 \mu \mathrm{m}\left(0.0027\right.$ in) $\mathrm{D}_{\mathrm{g}}$ can be suspended in the air by the impact from or shed from saltating particles and can be carried some distance, depending on the local windspeed. Particles of $10 \mu \mathrm{m}$ $\left(3.9 \times 10^{-4} \mathrm{in}\right) \mathrm{D}_{\mathrm{AED}}$ can be transported appreciable distances (greater than $1 \mathrm{~km}(0.62 \mathrm{mi})$ ) and are an inhalation hazard.

Many of the studies listed above were conducted under controlled experimental conditions to investigate aspects of postulated theories and may not always be applicable to actual field conditions. Defining the initial and experimental conditions for field studies is often difficult.

The values cited above are taken by field measurements (Sehmel and Lloyd 1976) of the entrainment of a powder distributed on sparsely vegetated soil at various windspeeds. The measured value indicated that the ARR for the material was in the range of $1 \times 10^{-8} / \mathrm{s}$ to $1 \times 10^{-10} / \mathrm{s}$. The larger value multiplied by 3600 
seconds/hour and rounded upwards to a single digit yielded an ARR of 4E-5, cited above. No measurement of the $\mathrm{RF}$ associated with the airborne material was given.

The value cited for the ARR of a pile of powder covered by debris is based upon reasoned judgment to incorporate the assumed effects of shielding of the deposit from air flow and the reduction in air velocity from the presence of the debris.

\title{
3.3.3.5 Heterogeneous Deposit, Powder - Outdoors
}

Outdoors, because of the passage of vehicular traffic across or by loose powder on road, up to $22.7 \mathrm{~m} / \mathrm{s}$ (50 mph)

\author{
ARR 1E-2/pass \\ RF (no data available)
}

\section{Technical Basis}

The cited values are based on experimental measurements of the ARR for the suspension of powder from an asphalt road during the passage of a passenger automobile and a light truck (pickup), both through the material and passing by the deposited powder on an adjacent lane (Sehmel 1973). The contaminant was zinc sulfide with a mass median diameter of $<5 \mu \mathrm{m}\left(2 \times 10^{-4} \mathrm{in}\right) \mathrm{D}_{\mathrm{g}}$. The densities of the two forms of zinc sulfide, wurtsite and sphalerite, are 3.98 and $4.102 \mathrm{~g} / \mathrm{cm}^{3}$ (249 and $\left.256 \mathrm{lb} / \mathrm{ft}^{3}\right)$. Using an average density, the AMAD would be $<10 \mu \mathrm{m}\left(3.9 \times 10^{-4}\right.$ in $) \mathrm{D}_{\mathrm{AED}}$.

The maximum measured ARR was for a passenger automobile driven through the powder deposit at a speed of $80-\mathrm{km} / \mathrm{hr}(50 \mathrm{mph})$. The ARR ranged from $5 \times 10^{-5} /$ passage (passenger automobile passing by the deposited powder in an adjacent lane at a speed of $8 \mathrm{~km} / \mathrm{hr}(5 \mathrm{mph})$ to the maximum measured value cited. Light trucks driven through the deposited powder gave ARRs ranging from $2.5 \times 10^{-3} /$ pass to $7 \times 10^{-3} /$ pass over the same range of speeds.

\subsubsection{Powder Dispersed into Flowing Gas}

Dispersal into flowing air, airspeed up to $9.1 \mathrm{~m} / \mathrm{s}(20 \mathrm{mph})$

$$
\begin{gathered}
\text { ARF }=0.0134(\mathrm{U})+0.00543 \text { (where } U=\text { local windspeed in } \mathrm{m} / \mathrm{s} \text { ) } \\
\text { RF (as a function of windspeed) }
\end{gathered}
$$

\section{Technical Basis}

The value cited above is based on experiments in which dried, contaminated soil was deagglomerated and dropped into flowing air in a wind tunnel (Sutter 1980). The windspeed ranged from 1.45 to $9.1 \mathrm{~m} / \mathrm{s}$ ( 3.24 to $20.4 \mathrm{mph}$ ). The data were linear within the windspeed range used and were limited by the capacity of the wind tunnel. The RF values ranged from 0.44 at $1.45 \mathrm{~m} / \mathrm{s}(3.24 \mathrm{mph})$ to 0.90 at $9.1 \mathrm{~m} / \mathrm{s}(20.4 \mathrm{mph})$ for the size distribution of the soil used. The RF was not linear with windspeed, and a value of less than 0.9 would be applicable within the windspeed range cited. An RF of 0.4 was measured at a windspeed of 1.45 $\mathrm{m} / \mathrm{s}$ (3.24 mph) and 0.9 measured at a windspeed of $9.1 \mathrm{~m} / \mathrm{s}(20.4 \mathrm{mph})$. For RFs from aerodynamic entrainment at windspeed between the two windspeeds, the values cited in the referenced document can be 
applied at the appropriate windspeed or, if the windspeed is between measured values, the RF for the next highest windspeed may be used.

\title{
3.3.4 Mechanical Stress
}

\subsubsection{Perforation of Vessel/Container/Pipe Wall}

a. Liquids (see Explosive and Energetic Events, c. Overpressurization to Rupture, 1. Liquids, 2. Superheated Liquid, and 3. Powders, Sections 3.3.1.9-3.3.1.12)

b. Solids, Powder (see B. Free-Fall Spill, Section 3.3.4.2)

c. Spent Nuclear Fuel - Release of "gap activity" on loss of containment, bounding values:

\author{
Noble gases: RARF 5E-2 \\ Iodine: RARF 2.5E-3 \\ Cesium: RARF 2.E-3
}

Fuel fine: ARF 2E-4, RARF 8E-7

\section{Technical Basis}

There are various considerations affecting the $\mathrm{ARF}$ for liquids vented under pressure. In some cases, the RF may increase because of the shape of the vent. "Slot" vents may act as a series of very fine orifices/capillaries and generate large RFs and high volumetric flows. If the openings are in the tens of micrometer range, and the upstream pressure is small, the result may only be dripping of the liquid rather than the formation of a spray. These small particles may be further reduced in size by evaporation of the liquid, depending on the liquid and gas temperature, the relative humidity of the gas, and the effects of solute concentration, if solutes are involved. The phenomenon is of special importance with "flashing sprays" formed by venting of superheated liquids.

Soffer (1993) defined the "gap activity" by reviewing the currently experimental data and evaluations. The immediate release was defined as the "gap activity." The experiments that are the basis for many values of release from SNF are for releases of materials caused by failure of the clad at very high temperatures and do not differentiate between the radionuclides released by loss of clad and by additional migration caused by the effects of high temperature.

Experimental studies of releases during pulverization of spent fuel fragments (Ruhmann, et al. 1985) and venting during high-temperature failure of clad irradiated fuel (Lorenz, et al. 1980) estimated the release of iodine and cesium on the basis that 95 percent of the iodine released existed as cesium iodide, and that the release in the gaseous state should be $0.05[0.5]=2.5 \mathrm{E}-3$ rather than the total iodine (and cesium, the other element in the compound). This value is cited above. Also, the ARF for fuel fines, based on limited experimental data, was cited at $2.4 \times 10^{-4}$ (Lorenz 1988). Evaluation of the size distribution based on the assumption of a lognormal distribution with a geometric standard deviation of 2 yielded an RARF of $8 \times 10^{-7}$. 


\subsubsection{Free-Fall Spill - Aqueous Liquids, Bounding Values}

a. Aqueous solutions (experiments performed using acidic UNH and sodium fluorocein), spill distance up to $3 m(\sim 10 \mathrm{ft})$

\section{ARF 2E-4 \\ RF 0.4}

b. Aqueous slurries, $<40$ percent solids, spill distance $<3 m(\sim 10 \mathrm{ft})$

\section{ARF 5E-5 \\ RF 0.8}

c. Aqueous viscous solutions, spill distance $<3 m(\sim 10 \mathrm{ft})$

\section{ARF 7E-6 \\ RF 0.8}

\section{Technical Basis}

The bounding values cited above are taken from experiments where "slugs" (a relatively coherent mass of material acting as a unit) were dropped from a height of $3 \mathrm{~m}(\sim 10 \mathrm{ft}$ ) onto a stainless steel surface (Sutter, et al. 1981; Ballinger, et al. 1986). Aqueous solutions at two concentrations, aqueous slurries and viscous aqueous (non-Newtonian) solutions, were used. ARFs and RFs were measured by collecting samples of the airborne particulate material present in the 3-m (10-ft) diameter $\times 3-\mathrm{m}(10-\mathrm{ft})$ tall stainless containment vessel. The ARF values varied with fall distance and volume of solution dropped, demonstrating dependence of the ARF on impact forces that cause the fragmentation of the liquid. Breakup of the leading face of the slug, shear stress along the sides of the slug falling through air, and suspension from the rear face caused by the area of lower pressure formed by the aerodynamics of the flow may also contribute. For aqueous solutions for a fall distance of $3 \mathrm{~m}(\sim 10 \mathrm{ft})$ and volumes between 125 and $1000 \mathrm{~cm}^{3}(0.004$ and $0.034 \mathrm{ft}^{3}$ ), the ARFs ranged from $4 \times 10^{-6}$ to $2 \times 10^{-4}$, with $\mathrm{RF}$ values from 0.45 to 0.82 . The $\mathrm{RF}$ associated with the maximum measured $\mathrm{ARF}\left(2 \times 10^{-4}\right)$ was 0.4 , and these values are listed as the upper bound for these conditions. Additional information is available in the referenced document or Subsection 3.2.3.1 in (USDOE 1994).

Aqueous slurries are affected by the same phenomenon. Slurries composed of titanium dioxide, glass frit, and uranine, with specific gravities ranging from 1.12 and 1.41 , were tested as described above for aqueous solutions (Sutter, et al. 1981; Ballinger, et al. 1986). The maximum solid loading was 40 percent. The ARFs measured ranged from $9 \times 10^{-7}$ to $5 \times 10^{-5}$ with RFs values from 0.64 to 0.81 . The maximum ARFs measured with the associated RF, $5 E-5$ and 0.8 , are cited above. Further information can be found in the referenced documents or Subsection 3.2.3.2, in (USDOE 1994).

The ARFs and RFs for viscous solutions composed of sucrose, uranine, and water were determined in the manner described above for aqueous solutions. The measured viscosities ranged from 1.3 to 46.0 centipoise for the solutions used in the experiments. The measured ARFs and RFs ranged from $2 \times 10^{-6}$ to $2 \times 10^{-5}$ and 0.59 to 0.9 , respectively, and decreased with increasing viscosity. The maximum measured value for ARF with the associated RF for solution with viscosity $>0.0079$ Pa-s (7.9 centipoise), ARF 7E-6 
and RF 0.8 , are cited above. Additional information can be obtained from the reference documents or Subsection 3.2.3.3, in (USDOE 1994).

\subsubsection{Free-Fall Spill - Aqueous Liquids, Calculated Values}

Calculated values for distance up to and greater than $3 m(\sim 10 \mathrm{ft})$

$$
\mathrm{ARF}=8.12 \times 10^{-10} \operatorname{Arch}_{\mathrm{a}}^{0.55}
$$

Technical Basis

An empirical correlation of the ARF and droplet-size distribution generated by the free-fall spill of aqueous solutions, slurries, and viscous aqueous solution was prepared by Ballinger, et al. (1986). The Archimedes number for spill in air is:

$$
\operatorname{Arch}_{\mathrm{a}}=[\text { air density }]^{2} \times[\text { Height of spill }]^{3} \times{\text { [gravitational acceleration }] /[\text { liquid viscosity }]^{2}}^{2}
$$

where:

air density, $\mathrm{g} / \mathrm{cm}^{3}$

height of spill, $\mathrm{cm}$

gravitational acceleration, $9.81 \mathrm{~m} / \mathrm{s}^{2}$

solution viscosity, poise

The size distributions for the various liquids are:

\begin{tabular}{|l|l|l|l|}
\hline & AMAD $^{\mathbf{2}}$ & GSD $^{\mathbf{b}}$ & RF \\
\hline All data & 21.5 & 7.3 & 0.4 \\
\hline $\mathrm{UNH}^{\mathrm{c}}$ & 27.2 & 6.0 & 0.3 \\
\hline Dilute soln & 27.1 & 3.0 & 0.2 \\
\hline Viscous soln & 12.5 & 12.3 & 0.5 \\
\hline Slurries & 15.8 & 10.1 & 0.4 \\
\hline
\end{tabular}

- Activity Median Aerodynamic Diameter - half the activity is associated with droplets greater than and smaller than the stated size, $\mu \mathrm{m}$.

- Geometric Standard Deviation.

c Acidic Uranium Nitrate Hexahydrate solution.

For liquid spills with fall distance exceeding $3 \mathrm{~m}(\sim 10 \mathrm{ft})$, data for the aqueous solutions, slurries, and viscous solutions indicate that the empirical correlation for ARF and the drop size distribution presented are adequate, provided the ARF $x$ RF exceeds the bounding values presented in the previous Subsection 3.3.4.2, "Free-Fall Spill, Aqueous Liquids, Bounding Values."

The maximum distance for which this correlation is applicable has not been defined. As the liquid slug falls through the air, the leading face is progressively impacted by the compression of air in front of it. As the coherence of the leading edge deteriorates, the air penetrates deeper and deeper into the slug, and the 
entire slug may lose coherence. The empirical correlation is based on slugs falling $3 \mathrm{~m}(\sim 10 \mathrm{ft})$, and it would appear that 4.5 to $5 \mathrm{~m}(14.8$ to $16.4 \mathrm{ft})$ may be a fall distance up to which deterioration of the slug, while falling, is not a significant problem. Beyond this region, many factors, such as the surface tension, viscosity, etc., may influence the coherence of the slug.

\subsubsection{Free-Fall Spill - Powders, Bounding Values}

For a dry, fine, powder with little cohesion:

\section{ARF 2E-3 \\ RF 0.3}

\section{Technical Basis}

The ARFs and RFs were determined by the collection of the airborne material resulting from the free-fall spill of a slug of finely divided ball-milled uranium dioxide (AMAD 3-4 $\mu \mathrm{m}\left(1.2 \times 10^{-4}\right.$ to $1.6 \times 10^{-4}$ in) $\mathrm{D}_{\text {AED }}$ ) and titanium dioxide traced with sodium fluorocein (AMAD $1-2 \mu \mathrm{m}\left(3.9 \times 10^{-5}\right.$ to $7.8 \times 10^{-5}$ in) $\left.\mathrm{D}_{\mathrm{AED}}\right)$ for distances up to $3 \mathrm{~m}(\sim 10 \mathrm{ft}$ ) (Sutter, et al. 1981). The bounding value cited above is based on the maximum measured value. The $A R F$ and $R F s$ value in these experiments are a function of the mass and fall distance. For a 3-m $(\sim 10 \mathrm{ft})$ fall distance, the $\mathrm{ARF}$ and $\mathrm{RF}$ values for $\mathrm{TiO}_{2}$ ranged from $8 \times 10^{-5} / 0.5$ (25-g (0.055-lb) sample) to $1.5 \times 10^{-3} / 0.25(1000 \mathrm{~g}(2.2 \mathrm{lb}))$, and for $\mathrm{UO}_{2} 4 \times 10^{-5} / 0.91(100 \mathrm{~g}(0.22 \mathrm{lb}))$ and $1.2 \times 10^{-3} / 0.49(1000 \mathrm{~g}(2.2 \mathrm{lb}))$. For a $1 \mathrm{~m}(3.28 \mathrm{ft})$ fall distance, the ARF and $\mathrm{RF}$ values for each powder ranged from: $\mathrm{TiO}_{2}-1 \times 10^{-4} / 0.62(25 \mathrm{~g}(0.055 \mathrm{lb}))$ to $5 \times 10^{-4} / 0.53(1000 \mathrm{~g}(2.2 \mathrm{lb})) ; \mathrm{UO}_{2}-2 \times 10^{-5} / 0.93(100 \mathrm{~g}$ $(0.22 \mathrm{lb}))$ to $8 \times 10^{-5} / 0.50(1000 \mathrm{~g}(2.2 \mathrm{lb}))$. The bounding ARF is rounded upward from $1.5 \times 10^{-3}$ to $2 \mathrm{E}-3$.

Other experimenters have studied the airborne release from free-fall spills of powders from the aspect of industrial hygiene (Plinke, et al. 1991). Although the experimental apparatus and configuration are different to maximize efficiency for characterization of aspect of the phenomenon of interest, the estimates of ARFs are consistent with the differences in fall distance and materials used.

Both sets of experiments are based upon the spill of a powder in the form of a slug (a mass of powder that behaves in a coherent manner). They do not cover powders that are initially widely dispersed. The falling slug of powder is more affected by the impact of the aerodynamics of the situation than are liquids, because of its initial dispersed conditions. The leading face is more readily attacked by the compression of gases in front of it, and the gas may more readily invade the coherence of the material, depending on the characteristics of the powder (e.g., moist or dry, size distribution of the particles, and packing). The dry, non-adherent particles more readily shear from the side by gas flowing over the side and also on the rear face area where there is lower pressure. There does not appear to be a comprehensive theory for the suspension of particles for the above-mentioned phenomena.

Additional information on the topic can be found in the references documents or Subsection 4.4 .3 of (USDOE 1994). 


\subsubsection{Free-Fall Spill-Powders, Calculated Values}

Technical Basis

A more precise value for the ARF could be derived using the empirical correlation to the experimental values shown in Figure 3-12 within the range of experimental parameters of fall distance and powder characteristics. The basis for the correlation shown is reported in Ballinger, et al. (1988) and is a function of a number (DN):

where:

$$
\mathrm{DN}=\left[\mathrm{M}^{0.125}\right]\left[\mathrm{H}^{2.37}\right] /\left[\mathrm{BD}_{\mathrm{p}}{ }^{1.02}\right]
$$

$\mathrm{M}=$ mass of powder spilled, $\mathrm{kg}$

$\mathrm{H}=$ fall distance, $\mathrm{m}$

$\mathrm{BD}_{\mathrm{p}}=$ powder bulk density, $\mathrm{kg} / \mathrm{m}^{3}$

As shown, the $\mathrm{DN}$ is a strong function of the fall distance and is a limited function of the total energy of impact and the degree of powder dispersion (how much void space exists between individual particles). To illustrate, the bulk density of $\mathrm{UO}_{2}$ powder is typically about $3000 \mathrm{~kg} / \mathrm{m}^{3}\left(187 \mathrm{lb} / \mathrm{ft}^{3}\right)$, whereas the fundamental particle density of $\mathrm{UO}_{2}$ is $10960 \mathrm{~kg} / \mathrm{m}^{3}\left(683 \mathrm{lb} / \mathrm{ft}^{3}\right)$.

Through modeling and data regression analysis of the data, two lines are shown in Figure 3-12, ARF vs. DN and an "Upper Bound" ARF vs. DN. For the median ARF value, the ARF is:

$$
\mathrm{ARF}_{\mathrm{BF}}=0.1064[\mathrm{DN}]
$$

For the "Upper Bound" value, ARF is:

$$
\mathrm{ARF}_{\mathrm{UB}}=0.3573[\mathrm{DN}]
$$

These equations are intended for use at $298 \mathrm{~K}\left(77^{\circ} \mathrm{F}\right)$ and $101.1 \mathrm{kPa}(14.67 \mathrm{psia})$. Significant deviations from this temperature and pressure (exceeding $10 \mathrm{~K}\left(50^{\circ} \mathrm{F}\right)$ and $10 \mathrm{kPa}(1.47 \mathrm{psi})$ would require correction.

For the event postulated, a $2-\mathrm{m}(6.6-\mathrm{ft})$ fall of $5 \mathrm{~kg}(11 \mathrm{~kg})$ of $\mathrm{UO}_{2}$, the $\mathrm{DN}$ is:

$$
\mathrm{DN}=\left[5^{0.125}\right]\left[2^{2.37}\right] /\left[3000^{1.02}\right]=0.0018
$$

and the "Best-Fit" $\mathrm{ARF}$ is:

$$
\mathrm{ARF}_{\mathrm{BF}}=0.1064[0.0018]=2 \mathrm{E}-4
$$

The "Upper-Bound" ARF is:

$$
\mathrm{ARF}_{U B}=0.3573[0.0018]=6 \mathrm{E}-4
$$




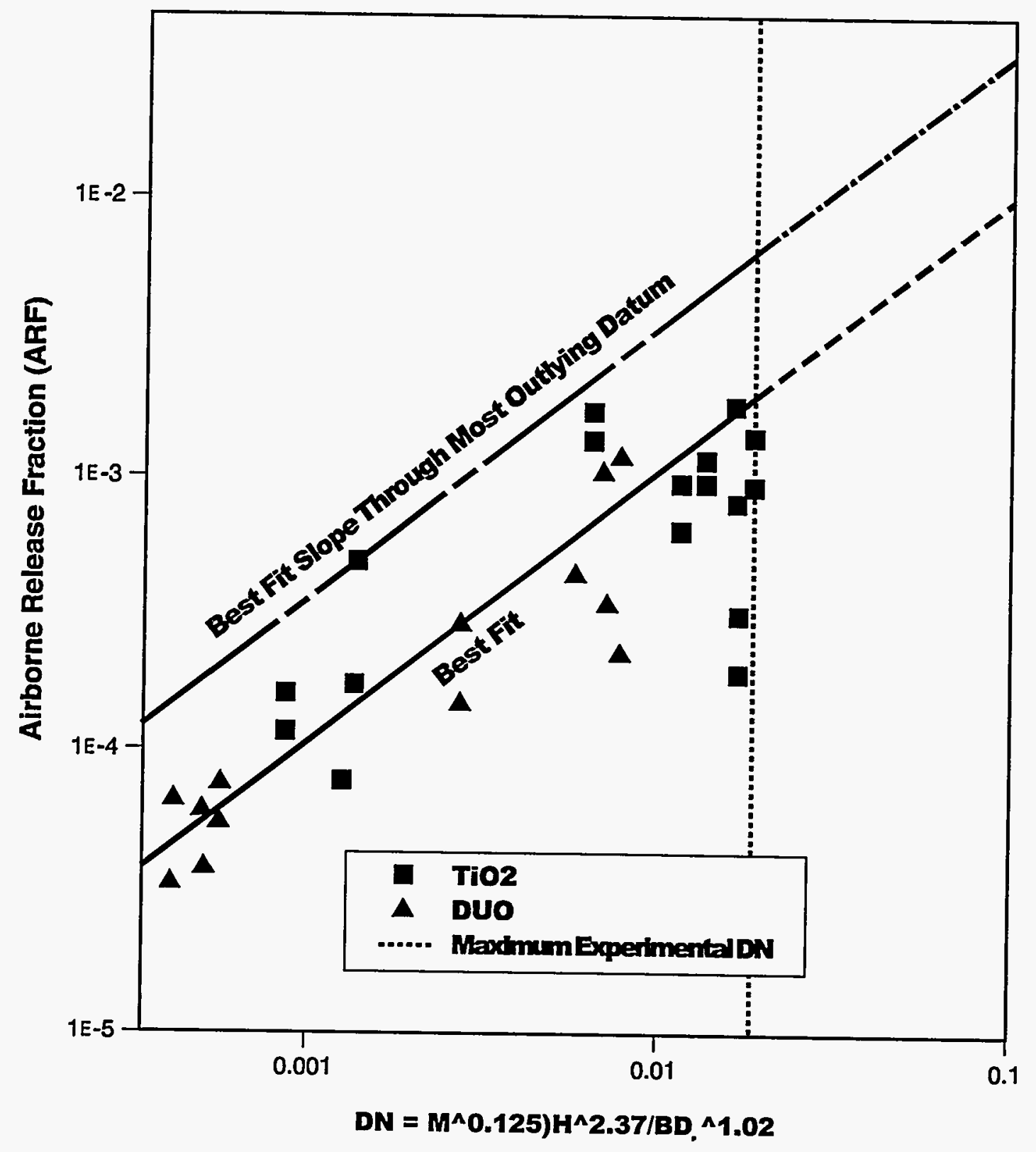

Figure 3-12. Powder free-fall spill data 
For the purpose of these analyses, the "bounding" value for the experimental data set, $2 E-3$, is selected. The ARF selected is a factor of 3.3 greater than $A R F_{U B}$ and a factor of 10 greater than the $A R F_{B F}$, with a resultant dose that is larger by the same amounts. This factor of 10 represents the range of uncertainty arising from the characterization of the source term.

For the "bounding" values measured experimentally, the measured value, $R F=0.3$, can be applied.

As noted above, there are several options available for estimates of the ARF, using the alternate methods above. If the "best-fit" ARF is selected, the median RF for ARFs in this release range may be applied. Inspection of the experimental data for DUO indicates the "Best-Fit" ARF calculated above, 2E-4, corresponds to the third-highest of 13 DUO ARF values measured and is, therefore, a "median" value for this experimental set. The RF measured at this level is 0.25 , and rounding the value results in an RF of 0.3 , which is the same $R F$ value for the "bounding" measured value for a $3-\mathrm{m}(-10 \mathrm{ft})$ fall distance.

A more conservative approach would be to assume that all the particles in the respirable size range of the source powder are made airborne. If the particle-size distribution of the powder spilled is available, the RF can be limited to the mass of the particles in the $10 \mu \mathrm{m}$ AED and less range (the mass of the powder in the [ARF] $[R F]$ cannot exceed the mass of respirable particles present in the source powder because the forces generated in free-fall spills are generally not sufficient to fragment the particles further). As an example, if the RF in the source powder is 0.001 and the estimated ARF is $5 E-3(0.005)$, the RF assumed for the event would be 0.2 (i.e., $0.001 / 0.005$ ).

In the absence of any data, the most conservative approach is to assume that all the particles made airborne are in the respirable size range $(R F=1.0)$. However, since the maximum experimentally measured ARF was selected for the purposes of these analyses, the RF associated with that value, 0.3 , is selected.

\title{
3.3.4.6 Crush-Impact - HEPA Filters
}

a. HEPA filter rupture by object striking encased filter, or encased filter impacts unyielding surface after fall

\section{ARF 5E-4 \\ RF (no data available)}

b. HEPA filter rupture by object strikes unencased filter or unencased filter impacts unyielding surface after fall

\author{
ARF 1E-2 \\ RF (no data available)
}

\section{Technical Basis}

Tests were performed at the Rocky Flats Environmental Test Site to determine if spent HEPA filters at the site could meet the Waste Isolation Pilot Plant (WIPP) Waste Acceptance Criteria (WAC)(Arnold 1986). Spent $0.61-\mathrm{mx} 0.61-\mathrm{m}$ (2-ftx2-ft) HEPA filters removed from the exhaust treatment system were wrapped in plastic and hurled 10 times from a height of approximately $1 \mathrm{~m}(3.28 \mathrm{ft})$ to the concrete floor. The fraction of particles $\leq 25 \mu \mathrm{m}\left(9.8 \times 10^{-4}\right.$ in $) \mathrm{D}_{\mathrm{g}}$ was measured. The density of material in the particles was such that this could consist of glass fragments from the medium, $\mathrm{PuO}_{2}$ or inert dust carried by the airflow, 
or fragments from other components of the filter, such as gasketing, adhesive, etc. The fraction was estimated to be $5 \times 10^{-5}$ of the overall weight of the filter and the fraction less than $10 \mu \mathrm{m} \mathrm{D}_{\mathrm{g}}\left(3.9 \times 10^{-4} \mathrm{in}\right)$ was $1 \times 10^{-5}$. Because of great uncertainty about whether the test protocol represents all possible impact dislodgement mechanisms for encased HEPA filters and the representativeness of the filters used, the bounding value is set an order of magnitude higher than the maximum measured value as cited above. Bear in mind that this value is actually the fraction of fragments generated, not just those airborne, and is a very conservative value.

The fraction of particles $10 \mu \mathrm{m}\left(3.9 \times 10^{-4} \mathrm{in}\right) \mathrm{D}_{\mathrm{g}}$ or less formed by repetitive jarring or crushing of spent HEPA filter ranged from $1 \times 10^{-5}$ to $7 \times 10^{-3}$ of the mass of the filter medium. In many instances, the mass of particles exceeded the mass of $\mathrm{Pu}$ measured for the filters, and using the weight of the glass fiber medium is applicable. A conservative value of $1 \mathrm{E}-2$ was selected to bound this phenomenon. As mentioned in the paragraph above, this value is very conservative, since it actually represents all of the fragments formed and not just the fragments suspended.

Further information can be found in Subsection 5.4.4 of (USDOE 1994) and in Appendix F of this Handbook.

\subsubsection{Crush Impact - Glass}

(Bounding values based upon fragments formed, not suspended)

\section{Respirable Airborne Release Fraction: $2 \mathrm{E}-11\left[\mathrm{~J} / \mathrm{cm}^{3}\right]$}

\section{Technical Basis}

Experimental data were obtained for fragments produced by the crush-impact of small specimens of borosilicate glass or borosilicate glass-like simulated vitrified HLW by application of force to the entire upper surface of specimen (area of impacting component exceeded the area of specimen impacted). The correlation is based on energy density imparted to the material, and the factor is applied to the affected volume of the material impacted. Guidance as to the affected volume, where the surface of the mass impacted exceeds the surface of the impacting component, is not available. Bounding [ARF][RF] $=2 \mathrm{E}-11$ [fall distance of impacting component, $\mathrm{cm}$ ][density of impacting component, $\left.\mathrm{g} / \mathrm{cm}^{3}\right]$ [gravitational acceleration, $980 \mathrm{~cm} / \mathrm{s}^{2}\left(32 \mathrm{ft} / \mathrm{s}^{2}\right)$ ] (see Subsection 4.2 .3 of [USDOE 1994]).

\subsubsection{Crush Impact - Aggregate}

\section{$[\mathrm{ARF}][\mathrm{RF}]=3 \mathrm{E}-11\left[\mathrm{~J} / \mathrm{cm}^{3}\right]$}

Experimental data were obtained for fragments of small right cylinders of brittle materials (e.g., borosilicate glass, aggregate [sandstone, cement] and compacted ceramic oxide [uranium dioxide pellets]) by application of force to the entire upper surface of the specimen by a component with an area greater than that of the impacted surface. The empirical correlation of the particles in the respirable size range generated is based on an applied energy density to the affected volume and is not applicable to conditions where the surface area of the impacting component is smaller than the surface impacted, for which guidance with respect to the affected volume is not currently available. The $[A R F][R F]=3 E-11$ [fall distance of impacting component, $\mathrm{cm}]\left[\right.$ density of impacting component, $\left.\mathrm{g} / \mathrm{cm}^{3}\right]$ [gravitational acceleration, $\left.980 \mathrm{~cm} / \mathrm{s}^{2}\right]$. 


\subsubsection{Crush Impact - Correlations}

When a hard, cohesive brittle solid material is impacted and crushed by some force (usually by another solid) the first solid absorbs some or all of the impacting kinetic energy and can form fine particles. Some fraction of these particles might be respirable. However, the impact might not make all the RF airborne. Two sets of data help define the RF for the impact. The first data were taken on the crush impact of spent nuclear fuel at Kraft Werke Union (KWU) (Ruhmann 1985) and the second on various brittle solids at Argonne National Laboratories (ANL) (Jardine, et al. 1982). Each data set produced its own correlation of $R F$ versus energy density of the impact $\left(\mathrm{J} / \mathrm{m}^{3}\right.$ ) (see Figures 3-13 and 3-14, respectively).

KWU Data Correlation. After reviewing Appendix IV of Sanders (1992), it was decided that the data cited from Ruhmann (1985) are the best available for estimating airborne source terms from crushing spent fuel. The reasons for making this judgment are: (1) the data are from crushed irradiated clad pellets; (2) the pellets are from a normal pressurized waste reactor (PWR) irradiated to normal burn-up levels; and (3) the impact energy densities span two orders of magnitude.

The KWU particle measurement technique could not determine RFs. If it is assumed that the particles are lognormally distributed, the lack of fines measurements by Ruhmann is of no importance. If one makes this assumption, because the data have an average geometric standard deviation, $\sigma_{g}$, of 19 , there is a large respirable fines tail to the distributions. This large tail, when airborne, will not settle rapidly during transport within a cask and could potentially lead to a fairly large environmental source term.

Ruhmann provided one plot of cumulative mass versus particle diameter on log probability paper for 33 GWD/MTU fuel impacted at specific energy densities $\left(E_{d}\right)$ of $1.1 E+8,2.2 E+8,5.5 E+8,1.1 E+9,2.2 E+9$, $5.5 \mathrm{E}+9$, and $1.1 \mathrm{E}+10 \mathrm{~J} / \mathrm{m}^{3}$. The 50 percent diameters were measured from Ruhmann's plot and converted to ammds. The following empirical relationship was obtained by curve fitting:

$$
\text { ammd }=5842-557.8 \log _{10}\left(E_{d}\right)
$$

Here, ammd is in $\mu \mathrm{m}$ and $\mathrm{E}_{\mathrm{d}}$ is in $\mathrm{J} / \mathrm{m}^{3}$. The log normal distribution was integrated to obtain the cumulative fraction $F_{c}$ from 0 to $d_{c}$, a specified diameter. With $d_{c}$ representing the upper limit of the respirable range (0-10 $\mu \mathrm{m}$ aerodynamic diameter), the integral becomes:

$$
R F=0.5\left\{1+\operatorname{erf}\left[\ln \left(\mathrm{d}_{\mathrm{c}} / \mathrm{ammd}\right) /\left(2^{0.5} \ln \sigma_{\mathrm{g}}\right)\right]\right\}
$$

The above equations were used together (with $\sigma_{g}=19$ ) to get a semi-log plot of RF versus impact specific energy density $\left(E_{d}\right)$ (see Figure 3-14).

ANL Data Correlation. Some data of this type have been taken on the crushing of $\mathrm{UO}_{2}$ fuel pellets, quartzite, coal, glass, and other hard solids (Jardine 1982) but with a low range of energy density input to the material ( $1 \mathrm{E}+06$ to $1 \mathrm{E}+07 \mathrm{~J} / \mathrm{m}^{3}$ or 27 to $\left.270 \mathrm{Btu} / \mathrm{ft}^{3}\right)$. A straight line log-log fit of the Jardine data gives the correlation $R F=3.27 \mathrm{E}-11\left(\mathrm{E}_{\mathrm{d}}, \mathrm{J} / \mathrm{m}^{3}\right)^{1.131}$. This correlation should be used when energy densities are less than $1 \mathrm{E}+07 \mathrm{~J} / \mathrm{m}^{3}\left(6 \mathrm{Btu} / \mathrm{ft}^{3}\right)$.

Selecting RF and ARF. The two approaches above offer two ranges of energy density for finding RFs. The data from KWU cover $1 \mathrm{E}+8$ to $1 \mathrm{E}+10 \mathrm{~J} / \mathrm{m}^{3}\left(2680\right.$ to $\left.268000 \mathrm{Btu} / \mathrm{ft}^{3}\right)$ and the data from ANL cover $1 \mathrm{E}+6$ to $1 \mathrm{E}+7 \mathrm{~J} / \mathrm{m}^{3}$ (27 to $\left.270 \mathrm{Btu} / \mathrm{ft}^{3}\right)$. The KWU correlation should be used for $1 \mathrm{E}+8$ and higher and the 


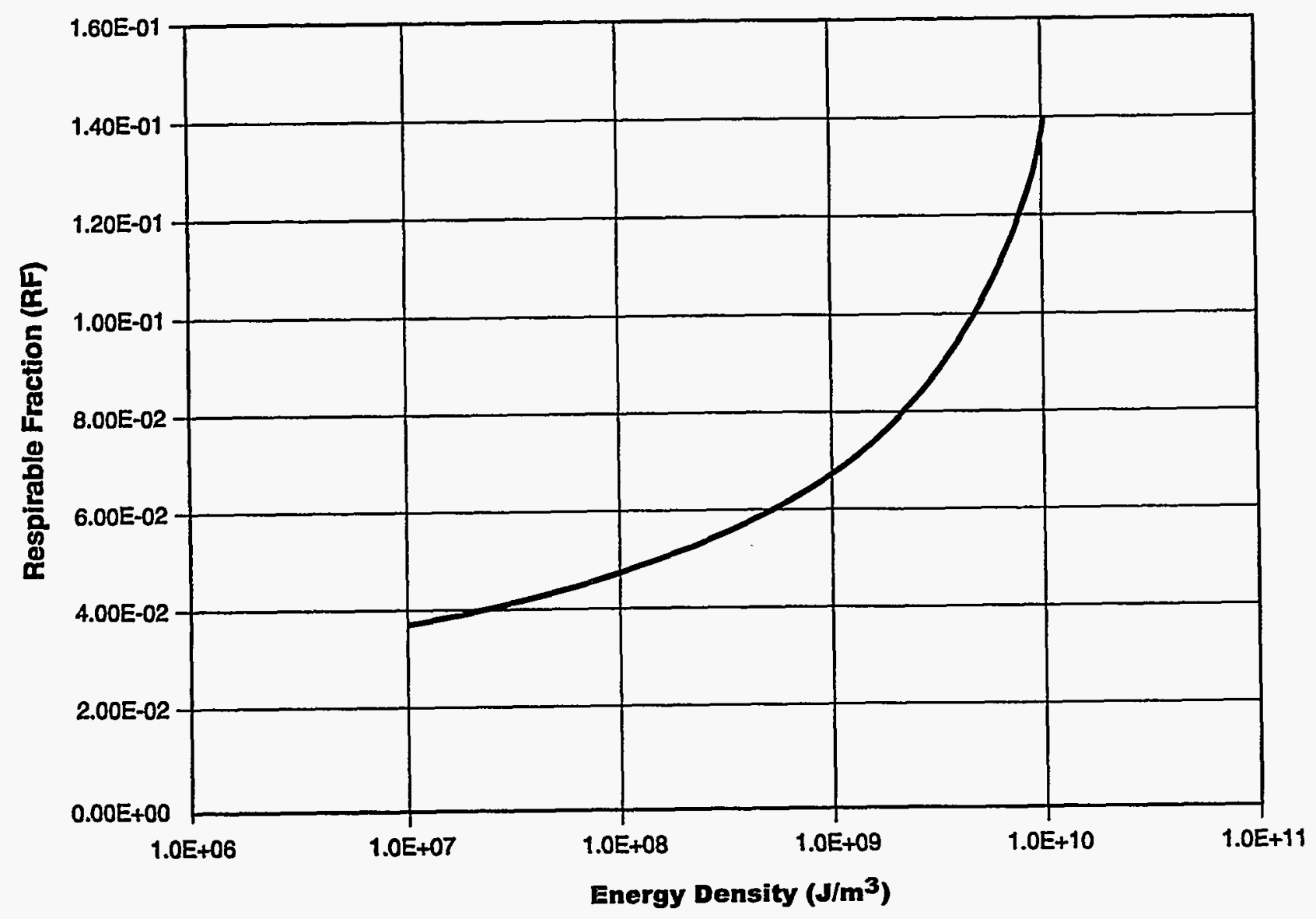

Figure 3-13. Crush impact (KWU data) 


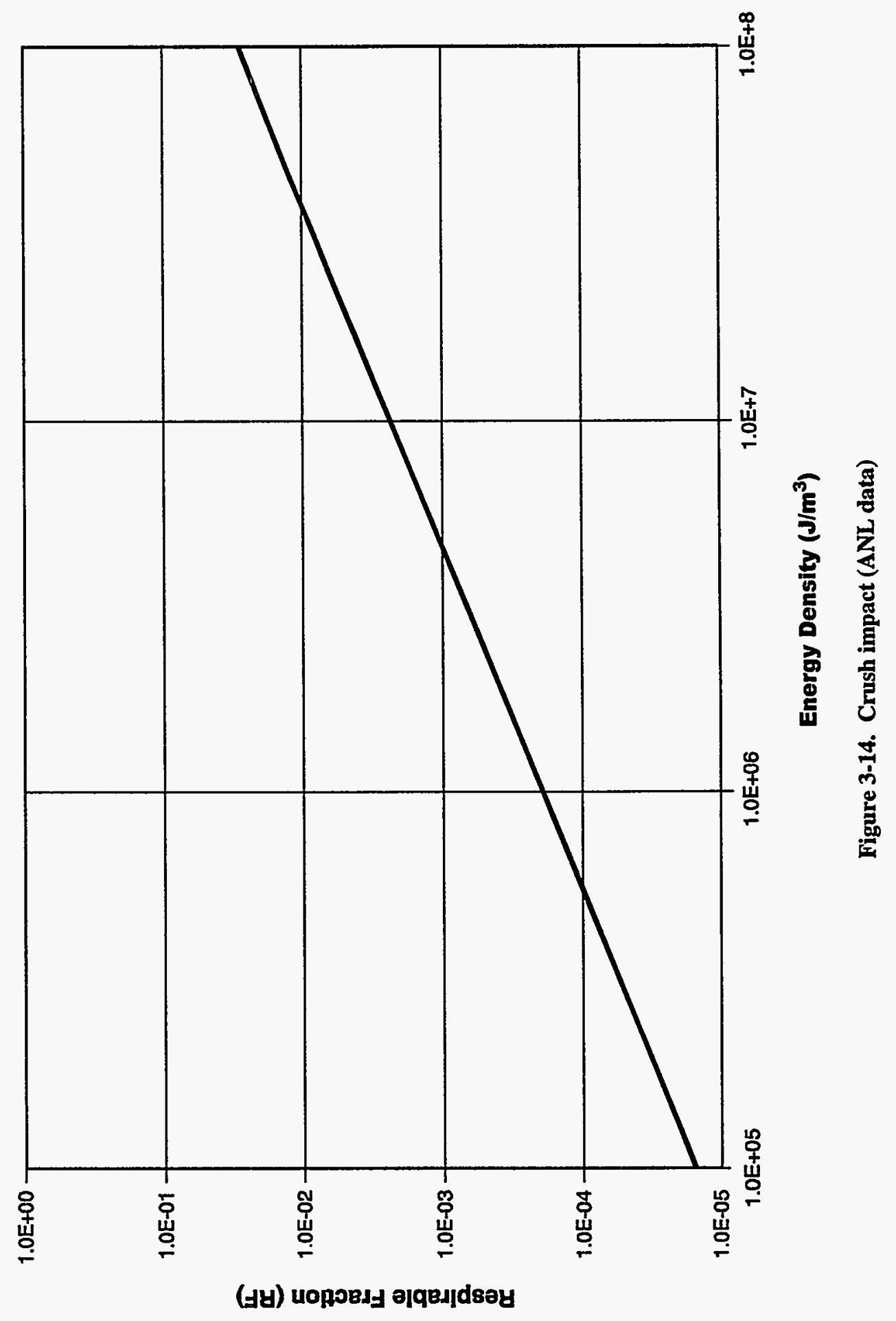

NUREG/CR-6410 
ANL correlation for $1 E+7$ and lower. For the $1 E+7$ to $1 E+8$ range, in between, either could be used. The two correlations intersect at approximately $\mathrm{RF}=0.05$ and $\mathrm{E}_{\mathrm{d}}=1.3 \mathrm{E}+8$. The ANL correlation is less conservative below this point in the $1 \mathrm{E}+7$ to $1 \mathrm{E}+8$ region. The user must decide on the appropriate correlation in this range.

Selecting the ARF is difficult because the experiments did not necessarily measure ARFs. The simplest, most conservative approach is to assume $A R F=1$. This assumption might not be satisfactory if other methods are available to relate accident stresses to ARFs.

\subsubsection{Crush Impact - SNF}

(See Figure 3-13, "Crush impact (KWU data)".)

\section{Technical Basis}

Based on experimental data for the particles generated by crush-impact forces on small pieces of unclad SNF pellets by an impacting component with a greater area than the volume impacted (Ruhmann, et al. 1985), the values for RF versus the Energy Density $\left(\mathrm{J} / \mathrm{cm}^{3}\right)$ are shown in Figure 3-13, "Crush Impact (KWU Data)." The energy densities used in the experimental study ranged from 10 to $100 \mathrm{~J} / \mathrm{cm}^{3}$ (268 to $2680 \mathrm{Btu} / \mathrm{ft}^{3}$ ). For the degree of fragmentation in experimental study, the fission product release was also measured, as follows:
a. Noble Gases
7E-2
b. Iodine $\left(\mathrm{I}_{2}\right)$
2E-3
c. $\mathbf{H}^{3}$ (as HTO)
1E-2
d. Fuel
2E-3

\subsubsection{Crush Impact - Encapsulated Ceramic Oxide Pellets}

Particles generated but not released. Impact velocities for various surface used: steel to $85 \mathrm{~m} / \mathrm{s}(\sim 188$ $\mathrm{mph}$ ); concrete to $44.7 \mathrm{~m} / \mathrm{s}(\sim 99 \mathrm{mph})$; and soil to $250 \mathrm{~m} / \mathrm{s}(\sim 550 \mathrm{mph})$

\section{ARF 5E-3 \\ RF 0.6}

\section{Technical Basis}

As part of the development of the General Purpose Heat Source (GPHS), iridium- and titanium-clad compacted $\mathrm{PuO}_{2}$ and $\mathrm{UO}_{2}\left(\mathrm{a} \mathrm{PuO}{ }_{2}\right.$ simulant) pellets were impacted against various surfaces (steel, concrete, and sand) and the size distribution of the particles generated measured (see list of references). Use of this data of particles generated as an upper bound for the particles that may be suspended is very conservative; however, these are the only applicable data for this phenomenon. The range of ARF (in this case, all particles generated) and RF (in this case, particles with $10 \mu \mathrm{m}\left(3.9 \times 10^{-5}\right.$ in) $\mathrm{D}_{\mathrm{AED}}$ and less generated) for $\mathrm{PuO}_{2}$ impacting at velocities from 45 to $90.5 \mathrm{~m} / \mathrm{s}(\sim 100$ to $200 \mathrm{mph})$ onto steel and concrete was ARF $2.1 \times 10^{-3}$ to $9.6 \times 10^{-3}$ and $\mathrm{RF}$ from 0.13 to 0.39 . For clad $\mathrm{UO}_{2}$ pellets impacting at velocities from 45 to $250 \mathrm{~m} / \mathrm{s}$ ( 100 to $560 \mathrm{mph}$ ) on steel, sand, and concrete, the ARFs ranged from $9 \times 10^{-4}$ to $1.52 \times 10^{-2}$, with RFs ranging from 0.23 to 0.61 , for tests in which all the material was collected. In three cases, some $\mathrm{UO}_{2}$ was lost. The median ARF and RF were selected because of the extreme conditions used for the 
experiments compared with that anticipated in fuel cycle accidents and the relative consistency of the data for fragment generation without respect to velocity or surface.

Additional information may be obtained from the following references: Cull 1989a, b; George and Pavone 1986; Cull and Pavone 1986; George 1986, 1987a, b; George and Schonfeld 1984a, b; George and Pavone 1986; Pavone et al. 1985; Pavone 1986; Schonfeld and George 1984a, b.

\subsubsection{Shock-Vibration}

a. Loose Surface Contamination. Based upon experimental studies where loose powder and powder in unlidded sheet metal can were "bounced" by the impact of rocks weighing up to $2.27 \mathrm{~kg}(5 \mathrm{lb})$ on the plywood deck supporting the powder. Air passed parallel over surface during impact.

\section{Bounding ARF 1E-3}

RF 0.3

b. Powder Suspended by Falling Debris. Based upon the experimental measurement in (a) above, but adjusted because of the limited weight of the debris employed.

\section{Bounding ARF 1E-2 \\ RF 0.1}

Technical Basis

Langer (1987) performed experiments to determine the ARF and RF from the impact of falling debris. Three rocks $(1.29 \mathrm{~kg}(2.8 \mathrm{lb}), 1.17 \mathrm{~kg}(2.6 \mathrm{lb})$, and $1.82 \mathrm{~kg}(4 \mathrm{lb}))$ were dropped $3.7 \mathrm{~m}(12 \mathrm{ft})$ onto powders of different materials and size distributions, in and out of containers resting on a piece of plywood. Air at a velocity of $0.36 \mathrm{~m} / \mathrm{s}(0.81 \mathrm{mph})$ was drawn through a wind tunnel during the tests, and all the airborne materials were sampled. Single tests were performed with sand of various-size distributions (see the referenced document or Subsection 4.4.3.3.2 of USDOE 1994) and $\mathrm{Al}_{2} \mathrm{O}_{3}$ and nickel. Two of the tests were performed with the sand in containers that were tilted and arranged to topple by the impact of the falling rocks. The ARFs and RFs ranged from ARF $1.8 \times 10^{-4}$, with an RF of 0.57 , for nickel powder with $<0.2$ percent of the particles $<25 \mu \mathrm{m}\left(9.8 \times 10^{-4}\right.$ in) $\mathrm{D}_{\mathrm{g}}$ to ARF $1.2 \times 10^{-3}$, with an $\mathrm{RF}$ of 0.27 for $\mathrm{Al}_{2} \mathrm{O}_{3}$, with all $<300 \mu \mathrm{m}(0.012 \mathrm{in}) \mathrm{D}_{\mathrm{g}}$ and 24 percent $<25 \mu \mathrm{m}\left(9.8 \times 10^{-4} \mathrm{in}\right) \mathrm{D}_{\mathrm{g}}$. The maximum ARF is for a test involving a ceramic oxide powder resting on plywood that is impacted by both the impact/turbulence from the falling debris, but also by the shock-vibration of the rock impacting the pliable plywood. The ARF value with the associated RF is assumed to bound most impact-induced shockvibration that may dislodge loose surface contamination that has some, little though it may be, attractive force binding the particles to the surface that is greater than the forces holding a dry, ceramic oxide powder.

The same experimental data can be applied to the suspension of powder impacted by falling debris. Both the fall distance $(3.7 \mathrm{~m}$ or $12 \mathrm{ft}$ ) and debris weight (less than $2.27 \mathrm{~kg}$ or $5 \mathrm{lb}$ ) may not bound what might happen during a seismic event, when the turbulence and velocity would increase. Therefore, the ARF and $\mathrm{RF}$ for this suspension mechanism are adjusted to $1 \mathrm{E}-2$ and 0.1 , respectively, to accommodate the increased stresses. 


\subsection{Source Term Estimations for Inadvertent Nuclear Criticality Excursions}

A nuclear criticality accident is defined as the release of energy as a result of inadvertently producing a self-sustaining or divergent neutron chain reaction. In fuel cycle facilities, a criticality accident may occur following: (1) transfer or leakage of fissile material from a geometrically favorable container to a container with unfavorable geometry; (2) introduction of excess fissile material into a container or area; (3) overconcentration of a solution; (4) failure to maintain adequate quantities of neutron absorbing materials; (5) precipitation of fissile solids; (6) introduction of neutron moderators into a system or area, and (7) alteration of system or area geometry.

A nuclear criticality differs from other fuel cycle facility accidents in that radioactive material is generated in the event and short-lived fission products not normally encountered are present. Nuclear criticality events may be terminated by control systems or by thermal expansion, loss of fissile material or moderator mass, change in density, or mixing caused by the rapid release of energy.

Criticality accident hazards include direct exposure to prompt neutron and gamma radiation produced in the criticality event, release of gaseous radioactive material, and expulsion or entrainment of radioactive aerosols. Direct exposures in the immediate vicinity of the event can be substantial, but off-site impacts are generally below detectable levels.

For nuclear criticality safety (NCS) evaluations, systems are categorized as solutions; moderated/reflected solids; bare, dry solids; and large storage arrays. The total amount of energy released in the event is generally small, and physical damage to ventilation and gas clean-up systems is not expected to occur. Mixing within the confining building and normal function of off-gas systems delays and mitigates the consequences of the event. The time during which a criticality occurs and the severity of the event depend in a complicated manner on the quantities, physical and chemical form, and concentrations of the fissile material and on the size, configuration, moderation, reflection, and neutron absorption characteristics of the system.

NRC requirements for NCS at fuel cycle facilities include adherence to the double-contingency principle in process design and operation, thus reducing the probability of an accident to a small value. Because of application of the double contingency principle, criticality accident scenarios involve multiple equipment or control system failures and are of such complexity that generally applicable analytical tools are not available. Thus, the nature and magnitude of possible accidents are assessed individually and conservative analyses are used to evaluate the adequacy of NCS protection systems. The balance of this section discusses the magnitude of possible criticality events at fuel cycle facilities and presents a representative method of source term estimation using a solution criticality at a uranium fuel fabrication facility as an example case. Other aspects of accident analysis for nuclear criticality events are discussed in a sample problem presented in Section 9 of Appendix D.

\subsubsection{Fission Yields}

The amounts of energy and radionuclides produced in nuclear criticality accidents are proportional to the total number of fissions occurring in the event. Thus, estimation of the total number of fissions provides a necessary basis for estimation of accident source terms. Estimates of the total number of fissions have been based on review of criticality accidents (Stratton 1989 and Frolov, et al 1995), reactor excursion experiments (Nyer, et al 1965), and other experiments. Reviews of these data and empirical models developed primarily for solution systems (Olson, et al. 1974) provide perspective on estimates of total 
number of fissions and energy generation rates. Descriptive information and data reported in the literature for a variety of systems are summarized in Tables 3-8, 3-9, 3-10, 3-11, 3-12, and 3-13. These data and estimates are discussed below for the four major types of reactive systems. Mathematical models capable of estimation of criticality accident progression and termination require coupled representation of hydrodynamic and neutronic phenomena. Although such models have been developed for power reactor system, models capable of estimating energy generation and total number of fissions have not been developed for the diverse systems encountered at fuel cycle facilities.

\subsubsection{Solution Systems}

Solutions are of principal concern for NCS evaluations at fuel cycle facilities because liquids are mobile and can be formed into geometrically unfavorable shapes with inadvertent moderation. Data for accidents that occurred in the U.S. are presented in Tables 3-8 and 3-9. Data for accidents that occurred in the former Soviet Union are presented in Table 3-13. Of the 13 accidents listed in Tables 3-8 and 3-9 that involve solutions, 8 occurred in process facilities whereas 5 occurred in nuclear criticality experimental facilities. Inadvertent transfers to non-favorable geometry vessels and failure to follow or properly interpret procedures were the most common causes of the accidents. The total number of fissions for the accidents ranged from $1 \times 10^{15}$ to $4 \times 10^{19}$ and an initial burst was generally followed by a plateau period characterized by a lesser and declining fission rate. Because of the duration of the plateau period, the major portion of energy release occurred during this time. The highest fission yield $\left(4 \times 10^{19}\right)$ occurred when a relatively large volume containing approximately 70 times the critical mass (i.e., $34.8 \mathrm{~kg}$ of U-235) was transferred to a vessel of unfavorable geometry positioned above concrete, which reflects neutrons. Of the 12 accidents listed in Table 3-13, 11 involve aqueous or organic solutions. The accidents generally had an initial burst followed by repeated smaller bursts extending over periods of time of the order of hours. Of these events, the largest had a yield of $7.9 \times 10^{17}$ fissions and involved approximately $2.8 \mathrm{~kg}(6 \mathrm{lb})$ of highly enriched uranium.

\subsubsection{Fully Moderated and Reflected Solids}

Estimates of peak fission rate and total number of fissions for an accidental nuclear criticality in a moderated, reflected solid system may be derived from data from accidents and from experiments with light- and heavy-water-moderated reactors. Criticality accident data are reported in Tables 3-8(b) and 3-11 for uranium and plutonium elements of various shapes with water or graphite moderation. The reactor excursion data reported in Table 3-10 is for uranium-aluminum and $\mathrm{UO}_{2}$ stainless steel clad fuels. The total number of fissions for the relevant accidental criticalities reported in Table 3-8(a) ranges from $1 \times 10^{15}$ to $1 \times 10^{17}$ while the total number of fissions for reactor excursions is bounded by $5 \times 10^{18}$ for the power levels reported in Table 3-10. Criticality events in moderated, reflected solid systems were characterized by an initial burst with little or no plateau period.

\subsubsection{Powder Systems}

Limited experimental data exist for powder systems of the type found in fuel cycle facilities. Data from accidents presented in Tables 3-8(c), 3-11, and 3-12, for systems that may serve as surrogates for powder system, are bounded by a total number of fissions that is less than $2 \times 10^{17}$. 
Table 3-8. Summary of Known Accidental Criticality Excursions (1945 to 1974)

(a) Solution Systems, (b) Metal Systems, and (c) Moderated Foil and Powder Systems

(Olsen, et al. 1974)

\begin{tabular}{|c|c|c|c|c|c|c|c|c|c|c|}
\hline No. & Date & Location & $\begin{array}{c}\text { Title } \\
\text { for Ref. }\end{array}$ & Fissionable Material & $\begin{array}{c}\text { Arrangement } \\
\vdots\end{array}$ & $\begin{array}{l}\text { Initial Prompt } \\
\text { Critical Burst, } \\
\text { Fissions. }\end{array}$ & Duration & $\begin{array}{c}\text { Total } \\
\text { Fissions }\end{array}$ & $\begin{array}{r}\text { Cause } \\
\therefore \quad \therefore\end{array}$ & $\begin{array}{l}\text { Physical } \\
\text { Damage }\end{array}$ \\
\hline \multicolumn{11}{|c|}{ (a) Solution Systems } \\
\hline SE 1 & $12 / 49$ & LASL, NM & $\begin{array}{l}\text { Water } \\
\text { Boiler }\end{array}$ & $\begin{array}{c}\mathrm{U}(93) \mathrm{O}_{2}\left(\mathrm{NO}_{3}\right)_{2} \\
(\sim 1 \mathrm{~kg} \mathrm{U} 235 ; 13.6 .1)\end{array}$ & $\begin{array}{l}\text { Sphere, } \\
\text { graphite- } \\
\text { reflected }\end{array}$ & $\begin{array}{c}\sim 3 \times 10^{15} \\
\text { (barely over } \\
\text { prompt } \\
\text { critical) }\end{array}$ & $\begin{array}{c}\text { Not } \\
\text { known }\end{array}$ & $3-4 \times 10^{16}$ & $\begin{array}{l}\text { Control rods } \\
\text { withdrawn } \\
\text { too fast }\end{array}$ & None \\
\hline SE 2 & $11 / 16 / 51$ & $\begin{array}{c}\text { Hanford works - } \\
\text { Richland, WA }\end{array}$ & P-11 & $\begin{array}{c}\mathrm{PuO}_{2}\left(\mathrm{NO}_{3}\right)_{2} \\
(1.15 \mathrm{~kg} \mathrm{Pu} ; 63.81)\end{array}$ & $\begin{array}{l}\text { Sphere, } 93 \text { percent } \\
\text { full-reflected }\end{array}$ & $8 \times 10^{16}$ & $\begin{array}{c}\text { Single } \\
\text { burst }\end{array}$ & $8 \times 10^{16}$ & $\begin{array}{l}\text { Too high } \\
\text { fuel addition }\end{array}$ & None \\
\hline SE 3 & $5 / 26 / 54$ & ORNL, TN & Spider & $\mathrm{UO}_{2} \mathrm{~F}_{2}(18.3 \mathrm{~kg} \mathrm{U} 235 ;$ & $\begin{array}{l}\text { Cylindrical } \\
\text { annulus, } \\
\text { unreflected }\end{array}$ & $5 \times 10^{16}$ & $\begin{array}{c}\text { Not } \\
\text { known }\end{array}$ & $1 \times 10^{17}$ & $\begin{array}{l}\text { Shift of } \\
\text { poison }\end{array}$ & None \\
\hline SE 4 & $2 / 1 / 56$ & ORNL, TN & $\begin{array}{l}\text { Scram } \\
\text { blade }\end{array}$ & $\begin{array}{c}\mathrm{UO}_{2} \mathrm{~F}_{2}(27.7 \mathrm{~kg} \mathrm{U} 235 ; \\
58.9 \mathrm{l})\end{array}$ & $\begin{array}{l}\text { Cylinder, } \\
\text { unreflected }\end{array}$ & $1.6 \times 10^{17}$ & $\begin{array}{c}\text { Single } \\
\text { burst }\end{array}$ & $1.6 \times 10^{17}$ & $\begin{array}{l}\text { Geometry } \\
\text { change }\end{array}$ & $\begin{array}{l}\text { Warping of } \\
\text { bottom of } \\
\text { cylinder }\end{array}$ \\
\hline SE 5 & $1 / 30 / 68$ & ORNL, TN & U-233 & $\begin{array}{c}\mathrm{UO}_{2}\left(\mathrm{NO}_{3}\right)_{2} \\
\sim 1 \mathrm{~kg} \mathrm{U233;} 5.8 \mathrm{l})\end{array}$ & $\begin{array}{l}\text { Sphere, water- } \\
\text { reflected }\end{array}$ & $1.0 \times 10^{16}$ & $\begin{array}{c}\text { Single } \\
\text { burst }\end{array}$ & $1.1 \times 10^{16}$ & Air in line & None \\
\hline P 1 & $6 / 16 / 58$ & $\begin{array}{l}\text { ORNL, TN - } \\
\text { Y-12 Processing } \\
\text { Plant }\end{array}$ & $\mathrm{Y}-12$ & $\begin{array}{c}\mathrm{UO}_{2}\left(\mathrm{NO}_{3}\right)_{2} \\
(2.5 \mathrm{~kg} \mathrm{U235} ; 56 \mathrm{l})\end{array}$ & $\begin{array}{c}\text { Cylinder, } \\
\text { concrete- } \\
\text { reflected below }\end{array}$ & $\sim 1.1 \times 10^{16}$ & $13 \mathrm{~min}$. & $1.3 \times 10^{18}$ & $\begin{array}{l}\text { Valve leaked } \\
\text { or left open }\end{array}$ & $\begin{array}{c}\text { None } \\
\text { (loss: } \$ 1000)\end{array}$ \\
\hline P 2 & $12 / 30 / 58$ & $\begin{array}{l}\text { LASL, NM - Pu } \\
\text { Processing Plant }\end{array}$ & Agitator & $\begin{array}{c}\mathrm{PuO}_{2}\left(\mathrm{NO}_{3}\right)_{2} \\
(3.27 \mathrm{~kg} \mathrm{Pu} ; 168 \mathrm{l})\end{array}$ & $\begin{array}{c}\text { Cylinder, } \\
\text { water- } \\
\text { reflected below }\end{array}$ & $1.5 \times 10^{17}$ & $\begin{array}{l}\text { Single } \\
\text { burst }\end{array}$ & $1.5 \times 10^{17}$ & $\begin{array}{l}\text { Procedure not } \\
\text { followed }\end{array}$ & None \\
\hline P 3 & $10 / 16 / 59$ & $\begin{array}{l}\text { Idaho Reactor } \\
\text { Testing Area, } \\
\text { Chemical } \\
\text { Processing Plant }\end{array}$ & $\begin{array}{c}\text { 1F-1 } \\
\text { (siphon) }\end{array}$ & $\begin{array}{c}\mathrm{UO}_{2}\left(\mathrm{NO}_{3}\right)_{2} \\
(34.5 \mathrm{~kg} \mathrm{U} 235 ; \sim 800 \mathrm{l})\end{array}$ & $\begin{array}{l}\text { Cylinder, } \\
\text { concrete- } \\
\text { reflected below }\end{array}$ & $-10^{17}$ & $\underset{\text { known }}{\text { Not }}$ & $\sim 4 \times 10^{19}$ & $\begin{array}{l}\text { Sparge gauge } \\
\text { plugged }\end{array}$ & $\begin{array}{c}\text { None } \\
\text { (loss: } \$ 62,000)\end{array}$ \\
\hline
\end{tabular}




\begin{tabular}{|c|c|c|c|c|c|c|c|c|c|c|}
\hline \multicolumn{11}{|c|}{$\begin{array}{l}\text { Table 3-8. Summary of Known Accidental Criticality Excursions (1945 to 1974) } \\
\text { (a) Solution Systems, (b) Metal Systems, and (c) Moderated Foil and Powder Systems } \\
\text { (Olsen, et al. 1974) (Continued) }\end{array}$} \\
\hline P 4 & $1 / 25 / 61$ & $\begin{array}{l}\text { Idaho Reactor } \\
\text { Testing Area, } \\
\text { Chemical } \\
\text { Processing Plant }\end{array}$ & $\begin{array}{c}1 \mathrm{~F}-11 \\
\text { (air lift) }\end{array}$ & $\begin{array}{c}\mathrm{UO}_{2}\left(\mathrm{NO}_{3}\right)_{2} \\
(8 \mathrm{~kg} \mathrm{U} 235 ; 40 \mathrm{l})\end{array}$ & Cylinder & No estimate & $\begin{array}{c}\text { Not } \\
\text { known }\end{array}$ & $6 \times 10^{17}$ & $\begin{array}{l}\text { Instruction } \\
\text { misinterprete } \\
\text { d }\end{array}$ & $\begin{array}{c}\text { None } \\
\text { (loss: } \$ 6000)\end{array}$ \\
\hline P5 & $4 / 7 / 62$ & $\begin{array}{l}\text { Hanford works - } \\
\text { Richland, WA }\end{array}$ & Recuplex & Pu complex (1.5 kg Pu) & $\begin{array}{l}\text { Cylinder, } \\
\text { unreflected }\end{array}$ & $\sim 10^{16}$ & 37 hrs & $8 \times 10^{17}$ & $\begin{array}{l}\text { Valve leaked } \\
\text { or opened }\end{array}$ & $\begin{array}{c}\text { None } \\
\text { (loss: } \$ 1000 \text { ) }\end{array}$ \\
\hline P6 & $7 / 24 / 64$ & $\begin{array}{l}\text { Wood River } \\
\text { Junction, RI - } \\
\text { scrap recovery } \\
\text { facility }\end{array}$ & $\begin{array}{l}\text { Wood } \\
\text { River }\end{array}$ & $\begin{array}{c}\mathrm{UO}_{2}\left(\mathrm{NO}_{3}\right)_{2} \\
(2.64 \mathrm{~kg} \mathrm{U} 235)\end{array}$ & $\begin{array}{l}\text { Cylinder, } \\
\text { unreflected }\end{array}$ & $1.1 \times 10^{17}$ & $\begin{array}{c}\text { Not } \\
\text { known }\end{array}$ & $1.3 \times 10^{17}$ & $\begin{array}{l}\text { Procedure } \\
\text { not followed }\end{array}$ & None \\
\hline \multicolumn{11}{|c|}{ (b) Metal Systems } \\
\hline ME 1 & $6 / 4 / 45$ & LASL, NM & $\begin{array}{l}\text { Metal } \\
\text { Cubes }\end{array}$ & $\begin{array}{c}83 \% \text { U235 enriched U } \\
\text { metal 1 } 1 / 2 \text { in. cubes } \\
(35.4 \mathrm{~kg})\end{array}$ & $\begin{array}{l}\text { Array of cubes; } \\
\text { water-reflected }\end{array}$ & $-3 \times 10^{15}$ & $\begin{array}{c}\text { Not } \\
\text { known } \\
\text { (perhaps } \\
3 \text { bursts) }\end{array}$ & $\sim 3 \times 10^{16}$ & $\begin{array}{l}\text { Water leaked } \\
\text { into array }\end{array}$ & None \\
\hline$\overline{M E} 2$ & $8 / 21 / 45$ & LASL, NM & Dragon & $\begin{array}{l}\text { Delta phase Pu metal } \\
(6.2 \mathrm{~kg})\end{array}$ & $\begin{array}{c}\text { Sphere reflected } \\
\text { by Be }\end{array}$ & $\begin{array}{c}-1.8 \times 10^{15} \\
(10 \text { cents over })\end{array}$ & $<1 \mathrm{sec}$ & $\sim 1 \times 10^{16}$ & $\begin{array}{l}\text { Dropped } \\
\text { reflector } \\
\text { block }\end{array}$ & None \\
\hline ME 3 & $5 / 21 / 46$ & LASL, NM & $\begin{array}{l}\text { Screw- } \\
\text { driver }\end{array}$ & Delta phase Pu metal & $\begin{array}{l}\text { Sphere reflected } \\
\text { by WC }\end{array}$ & $\sim 1.8 \times 10^{14}$ & $\underset{\text { known }}{\text { Not }}$ & $\sim 3 \times 10^{15}$ & $\begin{array}{l}\text { Screwdriver } \\
\text { holding } \\
\text { reflector away } \\
\text { from } \mathrm{Pu} \\
\text { slipped }\end{array}$ & None \\
\hline ME 4 & $2 / 1 / 51$ & LASL, NM & $\begin{array}{l}\text { Aquarium } \\
\text { machine }\end{array}$ & $\begin{array}{c}\text { Two cylinders U(93) } \\
\text { metal (24.4 kg and } 38.5 \\
\mathrm{~kg})\end{array}$ & $\begin{array}{l}\text { Side by side in } \\
\text { water tank }\end{array}$ & $\sim 6 \times 10^{15}$ & $\begin{array}{l}\text { Not } \\
\text { known } \\
\text { (perhaps } \\
\text { several } \\
\text { bursts) }\end{array}$ & $1 \times 10^{17}$ & $\begin{array}{l}\text { Went critical } \\
\text { during } \\
\text { practice } \\
\text { scram }\end{array}$ & $\begin{array}{l}\text { Slight } \\
\text { oxidation }\end{array}$ \\
\hline
\end{tabular}


Table 3-8. Summary of Known Accidental Criticality Excursions (1945 to 1974)

(a) Solution Systems, (b) Metal Systems, and (c) Moderated Foil and Powder Systems (Olsen, et al. 1974) (Continued)

\begin{tabular}{|c|c|c|c|c|c|c|c|c|c|c|}
\hline $\begin{array}{l}\text { No. } \\
\because\end{array}$ & Date & $\begin{array}{l}\text { Location } \\
\therefore\end{array}$ & $\begin{array}{c}\text { Title } \\
\text { for Ref. }\end{array}$ & Fissionable Material & Arrangement & $\begin{array}{l}\text { Initial Prompt } \\
\text { Critical Burst, } \\
\text { Fissions }\end{array}$ & $\begin{array}{r}\text { Duration } \\
\because \\
\because\end{array}$ & Total & \begin{tabular}{c} 
Cause \\
$\vdots \vdots$ \\
\hdashline$\vdots$
\end{tabular} & $\begin{array}{l}\because \text { Physical } \\
\text { Damage }\end{array}$ \\
\hline ME 5 & $4 / 18 / 52$ & LASL, NM & Jamima & $\mathrm{U}(93)$ metal $(92.4 \mathrm{~kg})$ & $\begin{array}{l}\text { Cylinder, } \\
\text { unreflected }\end{array}$ & $\begin{array}{c}\sim 1 \times 10^{15} \\
(21 \text { cents over) }\end{array}$ & $<1 \mathrm{sec}$ & $1.5 \times 10^{16}$ & $\begin{array}{l}\text { Computation } \\
\text { error }\end{array}$ & None \\
\hline ME 6 & $2 / 3 / 54$ & LASL, NM & Godiva I & $\mathrm{U}(93)$ metal $(53 \mathrm{~kg})$ & $\begin{array}{l}\text { Sphere, } \\
\text { unreflected }\end{array}$ & $5.6 \times 10^{16}$ & $\begin{array}{c}\text { Single } \\
\text { burst }\end{array}$ & $5.6 \times 10^{16}$ & $\begin{array}{l}\text { Assembled } \\
\text { too rapidly }\end{array}$ & $\begin{array}{l}\text { Slight } \\
\text { warping of } \\
\text { pieces } \\
\text { (loss: } \$ 600 \text { ) }\end{array}$ \\
\hline ME 7 & $2 / 12 / 57$ & LASL, NM & Godiva II & $\mathrm{U}(93)$ metal $(54 \mathrm{~kg})$ & $\begin{array}{l}\text { Sphere, } \\
\text { unreflected }\end{array}$ & $\begin{array}{c}1.2 \times 10^{17} \\
(21 \text { cents over) }\end{array}$ & $\begin{array}{l}\text { Single } \\
\text { burst }\end{array}$ & $1.2 \times 10^{17}$ & $\begin{array}{l}\text { Graphite fell } \\
\text { against } \\
\text { assembly }\end{array}$ & $\begin{array}{c}\text { Warping } \\
\text { oxidation; } \\
\text { near melting } \\
\text { close to center } \\
\text { (loss: } \$ 2100 \text { ) }\end{array}$ \\
\hline ME 8 & $6 / 17 / 60$ & LASL, NM & $\begin{array}{l}\text { 9-inch } \\
\text { cylinder }\end{array}$ & $\mathrm{U}(93)$ metal (48 kg) & $\begin{array}{l}\text { Cylinder, } \\
\text { graphite- } \\
\text { reflected }\end{array}$ & $\sim 1 \times 10^{15}$ & $\begin{array}{c}\text { Not } \\
\text { known }\end{array}$ & $6 \times 10^{16}$ & $\begin{array}{l}\text { Error in } \\
\text { addition } \\
\text { estimate }\end{array}$ & Trivial \\
\hline ME 9 & $11 / 10 / 61$ & ORNL, TN & $\underset{\text { Paraffin }}{\text { U- }}$ & $\mathrm{U}(93)$ metal $(\sim 75 \mathrm{~kg})$ & $\begin{array}{l}\text { Cylinder, } \\
\text { parraffin- } \\
\text { reflected }\end{array}$ & $\sim 1 \times 10^{15}$ & $\underset{\text { known }}{\text { Not }}$ & $\sim 1 \times 10^{16}$ & $\begin{array}{l}\text { Error in } \\
\text { addition } \\
\text { estimate }\end{array}$ & None \\
\hline ME 10 & $3 / 26 / 63$ & LARL, CA & LRL & $\mathrm{U}(93)$ metal $(47 \mathrm{~kg})$ & $\begin{array}{l}\text { Cylinder, } \\
\text { Be-reflected }\end{array}$ & $1 \times 10^{17}$ & $\begin{array}{c}\text { Not } \\
\text { known }\end{array}$ & $3.8 \times 10^{17}$ & $\begin{array}{l}\text { Ram caught } \\
\text { reflector; } \\
\text { lifted; fell }\end{array}$ & $\begin{array}{l}\text { Metal melted } \\
\text { and some } \\
\text { burned; } \\
\text { contamination } \\
\text { (loss: } \$ 95,000 \text { ) }\end{array}$ \\
\hline ME 11 & $5 / 28 / 65$ & WSMR, NM & $\begin{array}{l}\text { U-Mo } \\
\text { Alloy }\end{array}$ & $\mathrm{U}(93)-1.0 \% \mathrm{Mo}(96 \mathrm{~kg})$ & $\begin{array}{l}\text { Cylinder, } \\
\text { unreflected }\end{array}$ & $1.5 \times 10^{17}$ & $\begin{array}{c}\text { Not } \\
\text { known }\end{array}$ & $1.5 \times 10^{17}$ & $\begin{array}{l}\text { Incorrect } \\
\text { operation }\end{array}$ & $\begin{array}{l}\text { Assembly bolts } \\
\text { broken, minor } \\
\text { damage to } \\
\text { coating }\end{array}$ \\
\hline
\end{tabular}




Table 3-8. Summary of Known Accidental Criticality Excursions (1945 to 1974)
(a) Solution Systems, (b) Metal Systems, and (c) Moderated Foil and Powder Systems
(Olsen, et al. 1974) (Continued)

$\underset{b}{\omega}$ 
Table 3.9. Accidents in Processing Plants (Paxton 1980)

\begin{tabular}{|c|c|c|c|c|c|}
\hline Date & Plant & Total & $\begin{array}{l}\text { First } \\
\text { Pulse }\end{array}$ & Doses (Rads) & Notes \\
\hline $6 / 16 / 58$ & $Y-12$ & $1.3 \times 10^{18}$ & $\sim 7 \times 10^{16}$ & $\begin{array}{c}365,339 \\
327 \\
270,236,69 \\
69,23\end{array}$ & $\begin{array}{l}{ }^{235} U \text { solution } \\
\text { washed into drum }\end{array}$ \\
\hline $12 / 30 / 58$ & LASL & $1.5 \times 10^{17}$ & $1.5 \times 10^{17}$ & $\begin{array}{c}\sim 4400 \\
\text { (fatal), } \\
135,35\end{array}$ & $\begin{array}{l}\text { Pu concentrated } \\
\text { in solvent layer }\end{array}$ \\
\hline $10 / 16 / 59$ & Idaho CPP & $4 \times 10^{19}$ & $\sim 10^{17}$ & $\begin{array}{l}50 \mathrm{R}, 32 \mathrm{R}, \\
\text { mostly beta }\end{array}$ & $\begin{array}{l}{ }^{235} \mathrm{U} \text { solution } \\
\text { siphoned into tank }\end{array}$ \\
\hline $1 / 2 / 61$ & Idaho CPP & $6 \times 10^{17}$ & $6 \times 10^{17}$ & None & $\begin{array}{l}{ }^{235} \mathrm{U} \text { solution } \\
\text { forced into } \\
\text { cylinder by air }\end{array}$ \\
\hline $4 / 7 / 62$ & $\begin{array}{c}\text { RECUPLE } \\
X\end{array}$ & $8.2 \times 10^{17}$ & $\sim 10^{16}$ & $87,33,16$ & $\begin{array}{l}\text { Pu solution in } \\
\text { sump sucked } \\
\text { into tank }\end{array}$ \\
\hline $7 / 24 / 64$ & $\begin{array}{l}\text { Wood River } \\
\text { Junction }\end{array}$ & $1.3 \times 10^{17}$ & $\sim 10^{17}$ & $\begin{array}{c}10,000 \text { (fatal), } \\
\text { two } 60-100\end{array}$ & $\begin{array}{l}{ }^{235} \mathrm{U} \text { solution } \\
\text { poured into tank }\end{array}$ \\
\hline $8 / 24 / 70$ & Windscale & $10^{15}$ & $\sim 10^{15}$ & Negligible & $\begin{array}{l}\text { Pu concentrated } \\
\text { in trapped solvent }\end{array}$ \\
\hline $10 / 17 / 78$ & Idaho CPP & $3 \times 10^{18}$ & Unknown & None & $\begin{array}{l}{ }^{235} \mathrm{U} \text { buildup in } \\
\text { diluted scrub } \\
\text { solution }\end{array}$ \\
\hline
\end{tabular}




Table 3-10. Destructive Power Excursion Summary
(Nyer, Bright, and McWhorter 1965)


Table 3-11. Inhomogenous Water-Moderated Systems (Stratton 1967)

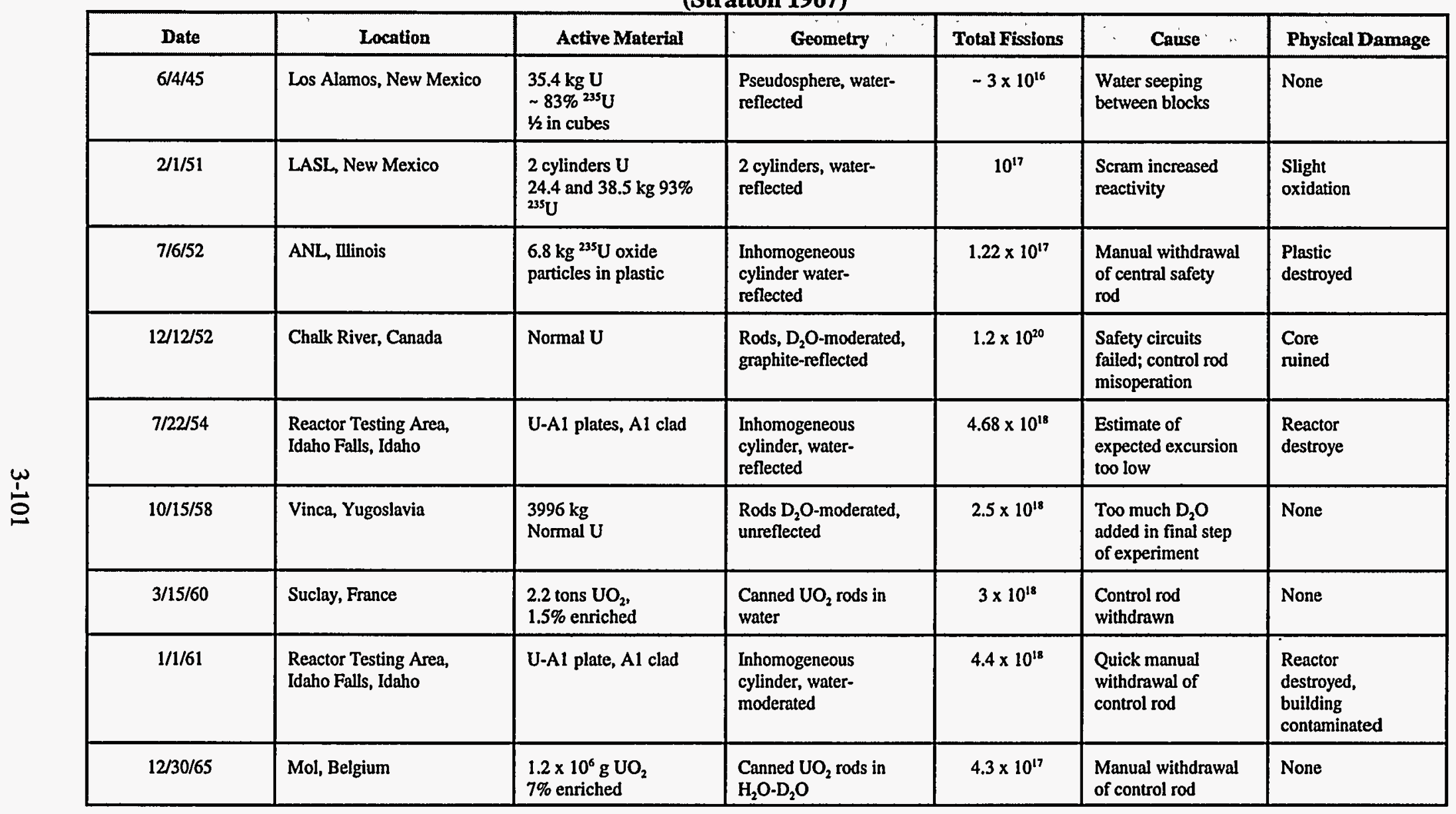


Table 3-12. Miscellaneous Systems

(Stratton 1967)

\begin{tabular}{|c|c|c|c|c|c|c|}
\hline "Date" & $\because "$ Location & Active Material & $\therefore$ Geometry & Total Fissions & Cause & Physical Damage \\
\hline $2 / 11 / 45$ & Los Alamos, New Mexico & $\mathrm{UH}_{3}$ pressed in styrex & Cylinder & $-6 \times 10^{15}$ & $\begin{array}{l}\text { Reflector added } \\
\text { and/or source too } \\
\text { large }\end{array}$ & $\begin{array}{l}\mathrm{UH}_{3} \text {-styrex cubes } \\
\text { swollen and } \\
\text { blistered }\end{array}$ \\
\hline 1953 & USSR & $\mathrm{Pu}\left(\mathrm{NO}_{3}\right)_{4}$ & Block tank & $2.5 \times 10^{17}$ & $\begin{array}{l}\text { Transfer to unsafe } \\
\text { geometry }\end{array}$ & None \\
\hline - & Idaho Reactor Testing Area & $1 / 2$ in ${ }^{235} U$ rods & $\begin{array}{l}\text { Cylinder, rods } \\
\text { NaK cooled }\end{array}$ & $4.7 \times 10^{17}$ & Incorrect scram used & Core molten \\
\hline $7 / 3 / 56$ & LASL, New Mexico & $\begin{array}{l}58 \mathrm{~kg} \mathrm{U} \\
93 \%{ }^{235} \mathrm{U}, 2-\text { and } \\
5 \text {-mil foils }\end{array}$ & Cylinder & $3.2 \times 10^{16}$ & $\begin{array}{l}\text { Change of } k \text { from } \\
\text { previous assembly } \\
\text { too large }\end{array}$ & None \\
\hline $11 / 18 / 56$ & $\begin{array}{l}\text { Reactor Testing Area, } \\
\text { Idaho Falls, Idaho }\end{array}$ & $\begin{array}{l}{ }^{235} \mathrm{U} \text { Ni-Cr elements, } \\
\text { ZrH-moderated }\end{array}$ & $\begin{array}{l}\text { Cylinder, prototype } \\
\text { aircraft engine }\end{array}$ & $2.5 \times 10^{19}$ & $\begin{array}{l}\text { Incorrect wiring in } \\
\text { ion chamber circuit }\end{array}$ & $\begin{array}{l}\text { Every fuel } \\
\text { cartridge melted }\end{array}$ \\
\hline $12 / 11 / 62$ & LASL, New Mexico & ${ }^{235} \mathrm{U}$ foils in graphite & $\begin{array}{l}\text { Cylinder, graphic } \\
\text { and Be-reflected }\end{array}$ & $3 \times 10^{16}$ & $\begin{array}{l}\text { Inadequate } \\
\text { communication } \\
\text { between work crews }\end{array}$ & None \\
\hline
\end{tabular}


Table 3.13. Nuclear Criticality Accidents at Russian Industrial Facilities (Frolov, et al. 1995)

\begin{tabular}{|c|c|c|c|}
\hline Date & Plant & Total Fissions & Notes \\
\hline $3 / 15 / 53$ & Mayak Enterprise & $2.5 \times 10^{17}$ & $\begin{array}{l}\text { Transfer of Pu solution into unsafe } \\
\text { geometry vessel. }\end{array}$ \\
\hline $4 / 21 / 57$ & Mayak Enterprise & $2 \times 10^{17}$ & $\begin{array}{l}\text { Unmonitored accumulation of uranium } \\
\text { oxolate precipitate. }\end{array}$ \\
\hline $1 / 2 / 58$ & Mayak Enterprise & $2.3 \times 10^{17}$ & $\begin{array}{l}\text { Workers tip vessel, creating unsafe } \\
\text { solution geometry. }\end{array}$ \\
\hline $12 / 5 / 60$ & Mayak Enterprise & $1 \times 10^{17}$ & $\begin{array}{l}\text { Faulty plutonium mass analysis, } \\
\text { accumulation of solution and precipitate } \\
\text { in unsafe geometry vessel. }\end{array}$ \\
\hline $8 / 14 / 61$ & $\begin{array}{l}\text { Siberian Chemical } \\
\text { Combine }\end{array}$ & $1 \times 10^{16}$ & $\begin{array}{l}\text { Unmonitored accumulation of uranium } \\
\text { hexafluoride in oil vessel. }\end{array}$ \\
\hline $9 / 7 / 62$ & Mayak Enterprise & $2 \times 10^{17}$ & $\begin{array}{l}\text { Unmonitored addition of Pu scrap to } \\
\text { dissolver vessel. }\end{array}$ \\
\hline $1 / 30 / 63$ & $\begin{array}{l}\text { Siberian Chemical } \\
\text { Combine }\end{array}$ & $7.9 \times 10^{17}$ & $\begin{array}{l}\text { Error in measuring uranium solution } \\
\text { concentration, transfer to unsafe } \\
\text { geometry vessel. }\end{array}$ \\
\hline $12 / 13 / 65$ & $\begin{array}{l}\text { Siberian Chemical } \\
\text { Combine }\end{array}$ & $2 \times 10^{17}$ & $\begin{array}{l}\text { Unmonitored accumulation of uranium } \\
\text { solution in unsafe geometry vessel. }\end{array}$ \\
\hline $11 / 13 / 65$ & $\begin{array}{l}\text { Electrostal Fuel } \\
\text { Fabrication Plant }\end{array}$ & $1 \times 10^{15}$ & $\begin{array}{l}\text { Unmonitored accumulation of } \mathrm{UO}_{2} \\
\text { slurry in holding vessel. }\end{array}$ \\
\hline $12 / 16 / 65$ & Mayak Enterprise & $7 \times 10^{17}$ & $\begin{array}{l}\text { Faulty accounting, loading of uranium } \\
\text { solid into a dissolver with unsafe } \\
\text { geometry. }\end{array}$ \\
\hline $12 / 10 / 68$ & Mayak Enterprise & $6 \times 10^{16}$ & $\begin{array}{l}\text { Unmonitored concentration in } \\
\text { extractant, transfer to unsafe geometry } \\
\text { vessel. }\end{array}$ \\
\hline $12 / 13 / 78$ & $\begin{array}{l}\text { Siberian Chemical } \\
\text { Combine }\end{array}$ & $3 \times 10^{15}$ & $\begin{array}{l}\text { Unmonitored transfer of Pu metal into } \\
\text { storage container. }\end{array}$ \\
\hline
\end{tabular}




\subsubsection{Large Storage Arrays}

Limited experimental data exists for large storage array systems of the type found in fuel cycle facilities. Use of the reactor excursion data assumes development of a flooded condition and a bounding estimate of total number of fissions of $5 \times 10^{18}$. As in the case of moderated, reflected metal systems, the event is expected to be characterized by a single burst with little or no plateau period.

\subsubsection{Nuclear Criticality Accident Source Term Estimates}

Estimation of the potential impacts of a nuclear criticality accident involves estimation of the total amounts of radioactive material and energy generated in the event and consideration of the fraction of this material and energy that escapes from the facility. This section presents a method for estimation of criticality accident source terms using a uranium solution criticality as an example. The method is representative of the technical approach that may be applied to evaluation of generic criticality events. Methods for estimation of airborne release fractions and respirable fractions for release modes characterizing criticality accidents are also discussed.

Estimation of criticality accident source terms begins with development of a conceptualization of the physical system that retains the important characteristics of the system, but which allows application of mathematical models and analytical tools to predict the behavior of the system. The analysis aims to bound potential impacts rather than predict system behavior in great detail. To this end, the historically observed behavior of solution criticalities as involving an initial burst followed by an extended plateau is adopted as describing the event. The plateau period is represented as comprising a series of pulses each with total number of fissions less than the initial burst. Following reported accident events, the initial burst is taken to be $1 \times 10^{18}$ fissions, with 47 subsequent bursts each involving $1.92 \times 10^{17}$ fissions, for a total of $1 \times 10^{19}$ fissions. Each burst lasts 5 seconds and is separated from the preceding burst by 10 minutes, yielding a total accident duration of 8 hours. The example consists of a tank containing a solution of $\mathrm{UO}_{2}\left(\mathrm{NO}_{3}\right)_{2}$ enriched to 4 per cent in the U-235 isotope. The concentration of uranium is taken to be 400 $\mathrm{g} / \ell\left(\sim 25 \mathrm{lb} / \mathrm{ft}^{3}\right)$ and the total volume is $400 \ell\left(\sim 0.011 \mathrm{ft}^{3}\right)$. The actual geometry of the system is approximated by a sphere and the physical state is represented as a homogeneous liquid mixture.

For the example, the analysis may be separated into estimation of fission product generation rates and estimation of gamma ray and neutron currents escaping the system. The fission product generation rates are estimated using the ORIGEN2 computer code (ORNL 1989). ORIGEN2 is a point-depletion and radioactive decay computer code that can be used to simulate nuclear reactor processes. The fission product yields for important isotopes predicted using the code are presented in Table 3-14.

Because ORIGEN2 does not provide output data on prompt gamma and neutron generation rates, a supporting model is needed. The gamma ray generation rate and energy distribution are adopted from power reactor operating data. The prompt photon production rate is reported as 7.03 photons per fission, with the energy spectra presented in Table $3-15$. For the example case, a total of $7 \times 10^{19}$ prompt photons would be produced over the 8-hour period. The total production could be conservatively adopted as the release rate or the source could be represented as uniformly distributed through the spherical, aqueous system (with a radius of $45.7 \mathrm{~cm}(18 \mathrm{in})$ ) and a shielding code used to estimate the rate and energy distribution of photons escaping the system.

A similar approach could be used to evaluate escape of prompt neutrons. For U-235, approximately 2.4 prompt neutrons are produced for each fission, yielding a total of $2.4 \times 10^{19}$ prompt neutrons for the entire 
Table 3-14. Radioactivity Generated in a Uranium Solution Criticality Accident

\begin{tabular}{|c|c|c|c|c|c|c|}
\hline \multirow[t]{2}{*}{ Nuclide } & \multirow[t]{2}{*}{ Half-life } & \multicolumn{3}{|c|}{ Radioactivity, Bq (Ci) } & \multicolumn{2}{|c|}{ Average Decay Energy (MeV) } \\
\hline & & $0.0 .5 \mathrm{hr}$ & $0.5-8 \mathrm{hr}$ & Total & $\gamma$ & $\beta$ \\
\hline $\mathrm{Kr}-83 \mathrm{~m}$ & $1.8 \mathrm{hr}$ & $\begin{array}{c}7.4 \mathrm{E} 11^{\mathrm{a}} \\
(20)\end{array}$ & $\begin{array}{c}4.6 \mathrm{E} 12 \\
(130)\end{array}$ & $\begin{array}{c}5.4 \mathrm{E} 12 \\
(150)\end{array}$ & 2.7E-3 & $2.9 \mathrm{E}-2$ \\
\hline $\mathrm{Kr}-85 \mathrm{~m}$ & $4.5 \mathrm{hr}$ & $\begin{array}{c}4.5 \mathrm{E} 11 \\
(12)\end{array}$ & $\begin{array}{c}2.8 \mathrm{E} 12 \\
(77)\end{array}$ & $\begin{array}{c}3.3 \mathrm{E} 12 \\
(89)\end{array}$ & $1.6 \mathrm{E}-1$ & $26 \mathrm{E}-1$ \\
\hline $\mathrm{Kr}-85$ & $10.7 \mathrm{hr}$ & $\begin{array}{c}6.7 \mathrm{E} 4 \\
(1.8 \mathrm{E}-6)\end{array}$ & $\begin{array}{c}4.1 \mathrm{E} 5 \\
(1.1 \mathrm{E}-5)\end{array}$ & $\begin{array}{c}4.8 \mathrm{E} 5 \\
(1.3 \mathrm{E}-5)\end{array}$ & 2.2E-3 & $2.5 \mathrm{E}-1$ \\
\hline $\mathrm{Kr}-87$ & $76.3 \mathrm{~min}$ & $\begin{array}{c}5.5 \mathrm{E} 12 \\
(150)\end{array}$ & $\begin{array}{c}3.4 \mathrm{E} 13 \\
(920)\end{array}$ & $\begin{array}{l}4.0 \mathrm{E} 13 \\
(1070)\end{array}$ & $7.9 E-1$ & $1.3 \mathrm{E} 0$ \\
\hline $\mathrm{Kr}-88$ & $2.8 \mathrm{hr}$ & $\begin{array}{c}3.4 \mathrm{E} 12 \\
(91)\end{array}$ & $\begin{array}{c}2.1 \mathrm{E} 13 \\
(570)\end{array}$ & $\begin{array}{c}2.4 \mathrm{E} 13 \\
(660)\end{array}$ & $1.9 \mathrm{E} 0$ & 3.6E-1 \\
\hline $\mathrm{Kr}-89$ & $3.2 \mathrm{~min}$ & $\begin{array}{c}2.3 \mathrm{E} 14 \\
(6300)\end{array}$ & $\begin{array}{c}1.5 \mathrm{E} 15 \\
(40000)\end{array}$ & $\begin{array}{c}1.7 \mathrm{E} 15 \\
(46000)\end{array}$ & $1.6 \mathrm{E} 0$ & $1.3 \mathrm{E} 0$ \\
\hline
\end{tabular}

\begin{tabular}{|c|c|c|c|c|c|c|}
\hline \multirow[t]{2}{*}{ Nuclide } & \multirow[t]{2}{*}{ Half-life } & \multicolumn{3}{|c|}{ Radioactivity, Bq (Ci) } & \multicolumn{2}{|c|}{ Average Decay Energy (MeV) } \\
\hline & & $0-0.5 \mathrm{hr}$ & $0.5 .8 \mathrm{hr}$ & Total & $\gamma$ & $\beta$ \\
\hline Sr-91 & $9.5 \mathrm{hr}$ & $\begin{array}{c}1.6 \mathrm{E} 12 \\
(44)\end{array}$ & $\begin{array}{c}1.0 \mathrm{E} 13 \\
(280)\end{array}$ & $\begin{array}{c}1.2 \mathrm{E} 13 \\
(320)\end{array}$ & $6.9 \mathrm{E}-1$ & $6.6 \mathrm{E}-1$ \\
\hline Sr-92 & $2.7 \mathrm{hr}$ & $\begin{array}{c}5.9 \mathrm{E} 12 \\
(160)\end{array}$ & $\begin{array}{c}3.7 \mathrm{E} 13 \\
(990)\end{array}$ & $\begin{array}{c}4.2 \mathrm{E} 13 \\
(1200)\end{array}$ & $1.3 \mathrm{E} 0$ & $2.0 \mathrm{E}-1$ \\
\hline Ru-106 & 368 day & $\begin{array}{c}1.2 \mathrm{E} 8 \\
(3.3 \mathrm{E}-3)\end{array}$ & $\begin{array}{c}7.4 \mathrm{E} 8 \\
(2.0 \mathrm{E}-2)\end{array}$ & $\begin{array}{c}7.4 \mathrm{E} 8 \\
(2.0 \mathrm{E}-2)\end{array}$ & - & $1.0 \mathrm{E}-2$ \\
\hline Cs-137 & $30.0 \mathrm{yr}$ & $\begin{array}{c}6.3 \mathrm{E} 7 \\
(1.7 \mathrm{E}-3)\end{array}$ & $\begin{array}{c}3.7 \mathrm{E} 8 \\
(1.0 \mathrm{E}-2)\end{array}$ & $\begin{array}{c}3.7 \mathrm{E} 8 \\
(1.0 \mathrm{E}-2)\end{array}$ & - & $1.9 \mathrm{E}-1$ \\
\hline Ba-139 & $82.7 \mathrm{~min}$ & $\begin{array}{c}1.3 \mathrm{E} 13 \\
(340)\end{array}$ & $\begin{array}{l}7.8 \mathrm{E} 13 \\
(2100)\end{array}$ & $\begin{array}{l}9.1 \mathrm{E} 13 \\
(2400)\end{array}$ & 4.3E-2 & $9.0 \mathrm{E}-1$ \\
\hline $\mathrm{Ba}-140$ & 12.7 day & $\begin{array}{c}5.5 \mathrm{E} 10 \\
(1.5)\end{array}$ & $\begin{array}{c}3.5 \mathrm{E} 11 \\
(9.5)\end{array}$ & $\begin{array}{c}4.1 \mathrm{E} 11 \\
(11)\end{array}$ & $1.8 \mathrm{E}-1$ & $3.1 \mathrm{E}-1$ \\
\hline Ce-143 & $33.0 \mathrm{hr}$ & $\begin{array}{c}5.2 \mathrm{E} 11 \\
(14)\end{array}$ & $\begin{array}{c}3.2 \mathrm{E} 12 \\
(87)\end{array}$ & $\begin{array}{c}3.7 \mathrm{E} 12 \\
(100)\end{array}$ & 2.8E-1 & 4.3E-1 \\
\hline
\end{tabular}


Table 3-14. Radioactivity Generated in a Uranium Solution Criticality Accident (Continued)

\begin{tabular}{llccccc}
\hline Nuclide & Half-life & \multicolumn{3}{c}{ Radioactivity, Bq (Ci) } & \multicolumn{2}{c}{ Average Decay Energy (MeV) } \\
& & $\mathbf{0 - 0 . 5} \mathbf{~ h r}$ & $\mathbf{0 . 5 - 8} \mathbf{~ h r}$ & Total & $\gamma$ & $\beta$ \\
\hline $\mathrm{Xe}-133$ & 5.2 day & $1.4 \mathrm{E} 7$ & $8.5 \mathrm{E} 7$ & $1.0 \mathrm{E} 8$ & $4.6 \mathrm{E}-2$ & $1.4 \mathrm{E}-1$ \\
& & $(3.7 \mathrm{E}-4)$ & $(2.3 \mathrm{E}-3)$ & $(2.7 \mathrm{E}-3)$ & & \\
$\mathrm{Xe}-133 \mathrm{~m}$ & \multirow{2}{*}{2.2 day } & $9.6 \mathrm{E} 7$ & $6.3 \mathrm{E} 8$ & $7.0 \mathrm{E} 8$ & $4.1 \mathrm{E}-2$ & $1.9 \mathrm{E}-1$ \\
& & $(2.6 \mathrm{E}-3)$ & $(1.7 \mathrm{E}-2)$ & $(1.9 \mathrm{E}-2)$ & & \\
$\mathrm{Xe}-135$ & \multirow{2}{*}{$9.1 \mathrm{hr}$} & $2.7 \mathrm{E} 10$ & $1.7 \mathrm{E} 11$ & $1.9 \mathrm{E} 11$ & $2.5 \mathrm{E}-1$ & $3.2 \mathrm{E}-1$ \\
& & $(7.3 \mathrm{E}-1)$ & $(4.5)$ & $(5.2)$ & & \\
$\mathrm{Xe}-135 \mathrm{~m}$ & \multirow{2}{*}{$15.3 \mathrm{~min}$} & $1.7 \mathrm{E} 12$ & $1.0 \mathrm{E} 13$ & $1.2 \mathrm{E} 13$ & $4.3 \mathrm{E}-1$ & $9.8 \mathrm{E}-2$ \\
& & $(45)$ & $(280)$ & $(330)$ & & \\
$\mathrm{Xe}-137$ & \multirow{3}{*}{$3.8 \mathrm{~min}$} & $1.2 \mathrm{E} 14$ & $7.6 \mathrm{E} 14$ & $8.8 \mathrm{E} 14$ & $1.6 \mathrm{E}-1$ & $1.8 \mathrm{E} 0$ \\
& & $(3300)$ & $(21000)$ & $(24000)$ & & \\
$\mathrm{Xe}-138$ & \multirow{2}{*}{$14.2 \mathrm{~min}$} & $5.2 \mathrm{E} 13$ & $3.2 \mathrm{E} 14$ & $3.7 \mathrm{E} 14$ & $1.1 \mathrm{E} 0$ & $6.7 \mathrm{E}-1$ \\
& & $(1400)$ & $(8700)$ & $(10000)$ & & \\
\hline
\end{tabular}

\begin{tabular}{lcccccc}
\hline Nuclide & Half-life & \multicolumn{3}{c}{ Radioactivity, Bq (Ci) } & \multicolumn{2}{c}{ Average Decay Energy (MeV) } \\
& & $\mathbf{0 - 0 . 5 ~ h r}$ & $\mathbf{0 . 5 - 8} \mathbf{~ h r}$ & Total & $\boldsymbol{\gamma}$ & $\beta$ \\
\hline $\mathrm{I}-131$ & 8.0 day & $3.7 \mathrm{E} 10$ & $2.3 \mathrm{E} 11$ & $2.7 \mathrm{E} 11$ & $3.8 \mathrm{E}-1$ & $1.9 \mathrm{E}-1$ \\
& & $(1.0)$ & $(6.3)$ & $(7.3)$ & & \\
$\mathrm{I}-132$ & $2.3 \mathrm{hr}$ & $5.2 \mathrm{E} 12$ & $3.2 \mathrm{E} 13$ & $3.8 \mathrm{E} 13$ & $2.2 \mathrm{E} 0$ & $4.9 \mathrm{E}-1$ \\
& & $(140)$ & $(880)$ & $(1,000)$ & & \\
$\mathrm{I}-133$ & $20.8 \mathrm{hr}$ & $8.6 \mathrm{E} 11$ & $5.4 \mathrm{E} 12$ & $6.2 \mathrm{E} 12$ & $6.0 \mathrm{E}-1$ & $4.1 \mathrm{E}-1$ \\
& & $(23)$ & $(150)$ & $(170)$ & & \\
$\mathrm{I}-134$ & $52.6 \mathrm{~min}$ & $2.1 \mathrm{E} 13$ & $1.3 \mathrm{E} 14$ & $1.5 \mathrm{E} 14$ & $2.6 \mathrm{E} 0$ & $6.2 \mathrm{E}-1$ \\
& & $(570)$ & $(3,600)$ & $(4,200)$ & & $3.6 \mathrm{E}-1$ \\
$\mathrm{I}-135$ & $6.6 \mathrm{hr}$ & $2.6 \mathrm{E} 12$ & $1.6 \mathrm{E} 13$ & $1.9 \mathrm{E} 13$ & $1.6 \mathrm{E} 0$ & \\
& & $(69)$ & $(430)$ & $(500)$ & & \\
\hline
\end{tabular}

a exponential notation, $7.4 \mathrm{E} 11=7.4 \times 10^{11}$ 
Table 3-15. Prompt Fission Gamma-Ray

\begin{tabular}{cc}
\multicolumn{2}{c}{ Spectra* } \\
\hline $\begin{array}{c}\mathrm{E} \\
\text { (MEV) }\end{array}$ & $\begin{array}{c}\mathrm{N}(\mathrm{E}) \\
\gamma^{\prime} \text { 's/fission }\end{array}$ \\
\hline 0.5 & 3.1 \\
1.0 & 1.9 \\
1.5 & 0.84 \\
2.0 & 0.55 \\
2.5 & 0.29 \\
3.0 & 0.15 \\
3.5 & 0.062 \\
4.0 & 0.065 \\
4.5 & 0.024 \\
5.0 & 0.019 \\
5.5 & 0.017 \\
6.0 & 0.007 \\
6.5 & 0.004 \\
\hline
\end{tabular}

Table 3-16. Prompt Neutron Energy Spectrum

\begin{tabular}{cc}
$\begin{array}{c}\text { Energy } \\
(\mathrm{MeV})\end{array}$ & $\begin{array}{c}\text { Fraction of } \\
\text { Neutrons }\end{array}$ \\
\hline $0.0-0.2$ & 0.038 \\
$0.2-0.4$ & 0.061 \\
$0.4-0.6$ & 0.069 \\
$0.6-0.8$ & 0.071 \\
$0.8-1.0$ & 0.071 \\
$1.0-1.2$ & 0.068 \\
$1.2-1.4$ & 0.064 \\
$1.4-1.6$ & 0.059 \\
$1.6-1.8$ & 0.055 \\
$1.8-2.0$ & 0.050 \\
$2.0-2.2$ & 0.046 \\
$2.2-2.4$ & 0.041 \\
$2.4-2.6$ & 0.037 \\
$2.6-2.8$ & 0.032 \\
$2.8-3.0$ & 0.030 \\
$3.0-3.2$ & 0.026 \\
$3.2-3.4$ & 0.023 \\
$3.4-3.6$ & 0.020 \\
$3.6-3.8$ & 0.018 \\
$3.8-4.0$ & 0.016 \\
$4.0-5.0$ & 0.054 \\
$5.0-6.0$ & 0.027 \\
$6.0-8.0$ & 0.019 \\
$8.0-10.0$ & 0.004 \\
$>10.0$ & 0.001 \\
\hline &
\end{tabular}

criticality event. The energy distribution reported (LaMarsh 1983) for these neutron is summarized in Table 3-16. As in the case of the prompt gamma rays, the prompt neutron source could conservatively be used as the released source or the source could be uniformly distributed through the spherical system, with the rate and energy distribution of neutrons escaping the system estimated using a shielding code.

In the case of neutrons, a third analytical approach could be applied. A single-group thermal diffusion model could be used to model the neutron fiux, with the escape fraction estimated as the integral over the surface of the system of the product of neutron diffusivity and gradient of neutron flux. This approach yields a total escape of $2.7 \times 10^{17}$ neutrons during the 8 hours of the criticality event. Application of these concepts is further illustrated in the sample problem discussed in Section 9 of Appendix D. 


\subsubsection{Estimation of ARF and RF for Nuclear Criticality Accidents}

Estimation of the airborne source term resulting from an inadvertent nuclear criticality (INC) is based upon the same 5-factor formula used for other events. The evaluation of the various components may have expanded definitions. Some considerations in the evaluation of the five components are:

MAR. The MAR is the radionuclide inventory that can be at risk during the postulated event. Unlike the MAR for most events, where the MAR is a fixed value (typically the entire radionuclide inventory within some fixed physical boundary), the MAR for an INC depends on the fissile/fissionable materials involved and the total fission yield. As discussed previously, the inventory can be estimated by use of a computer code such as ORIGEN2, which evaluates the fission product (FP) inventory generated by a specific fissile material (i.e., ${ }^{233} \mathrm{U},{ }^{235} \mathrm{U},{ }^{239} \mathrm{Pu}$ ) during an nuclear excursion. In some instances (e.g., acid solutions of SNF and other materials that contain a mixture of fissile and fissionable materials), the other fissile and fissionable materials can fission (depending on duration of excursion and neutronics of the situation) and generate their own spectrum of FPs. Typically, the duration of the excursion is short, and contributions from this source are ignored, but it should be borne in mind that even code values are approximations, with some level of uncertainty depending on the conditions.

DR. The DR reflects the fraction of the MAR that is actually impacted by the specific event postulated. As an example, a fire may range from a small fire with a limited amount of fuel or oxygen availability affecting only a fraction of the MAR, to a large fire that affects all of the contents within the physical boundaries that prevent its propagation. For INCs, the DR is typically assumed to be 1.0 .

ARF. Because of the various physical forms of the radionuclides (gases, vapor, non-volatile) and the matrix (solutions, metal, powders, irradiated compacted ceramic oxides [SNF] and cermets), there is more than a single ARF for the airborne release resulting from an INC. The ARFs for various physical forms of the radionuclides and matrix are discussed in greater detail below.

$\underline{R F}$. The $R F$ is defined as the fraction of the $A R F$ that is in the particle size range $D_{A E D} 10$ micrometers and less. Since noncondensible gases and vapors (materials airborne in the gaseous state) are not particles, the RF applies only to materials that are made airborne as particles (non-volatile compounds in solid or liquid form).

LPF. There are many LPFs possible during the transport of materials made airborne during an event from the point of origination to release from the facility-atmosphere interface. The LPFs may be expressed as a single value that represents the summation of all LPFs, or that represents the single LPF phenomenon considered. In most event analyses, the LPF represents phenomena that occur after the radionuclides are made airborne in some confinement. In the case of INCs, there is one category of matrix (large storage arrays), with one class of materials, clad, (i.e., SNF, "pits"), where an LPF may exist at the point of origination.

For SNF, the clad is designed for operation at high temperatures and pressure found in nuclear reactors, and those that have not failed in this environment have a reasonable expectation of resisting the temperature and additional internal pressure generated by an INC. No airborne release is anticipated from intact, clad, SNF in an INC. The SNFs that have already failed are assumed to have released their "gap" inventory of FPs generated by irradiation in the reactor, and the same fraction of the INC-generated inventory would be released. 
"Pits" (weapons-grade plutonium hollow metal spheres encased into a welded and tested stainless clad with and without a small-diameter tube leading into the internal cavity) also offer some degree of resistance to airborne release of the event-generated FPs. If the calculated metal temperature induced by the energy from the INC exceeds the melting point of the weld material $\left(\sim 423 \mathrm{~K} 302{ }^{\circ} \mathrm{F}\right)$, the encased Pu would be exposed to air. At these temperatures, air oxidation of $\mathrm{Pu}$ is slow. If the temperatures exceed the ignition temperature (the temperature at which a self-sustained oxidation reaction is initiated, the metal temperature would increase to 1273 to $1373 \mathrm{~K}\left(1832\right.$ to $\left.2012^{\circ} \mathrm{F}\right)$, failing the stainless steel clad); all of the metal would be assumed to be oxidized; and the ARF and RF for Pu metal under thermal stress (ARF 5E-4 and RF 0.5 ) would also apply.

\subsubsection{Rules-of-Thumb for Total Fissions during INC}

Because of the complexity of the phenomenon and the many factors that should be considered to obtain an estimate of the total fissions generated by a specific event, "rules-of-thumb" provide users with a quick, bounding assumption for total fissions and other phenomena that may affect the total release of radionuclides.

\section{a. Liquid Systems}

1. Large systems involving greater than $380 \ell(100$ gal). The reaction terminates by evaporation of 100 liters ( 26 gal) of liquid: $1 \times 10^{19}$ total fissions $\left(1 \times 10^{18}\right.$ initial burst $[0.5$ seconds], followed by 47 bursts of $1.9 \times 10^{17}$ fissions at $10 \mathrm{~min}$ intervals). The fission product generated is dependent on the initial fissile materials involved and should be estimated by a code such as ORIGEN2 or equivalent. The aerosol generated by the boil-off of water suspends $5 \times 10^{-4}$ of the salt content of the liquid evaporated (100 liters (26 gal) required to terminate the reaction).

2. Small systems involving less than $380 \ell(100 \mathrm{gal})$. The reaction terminates by eructation of a portion of the liquid (release from a free-fall spill of liquid and suspension of a fraction of the liquid): $1 \times 10^{18}$ total fissions in a 0.5 -s burst. Reaction is terminated by eructation of liquid, and a free-fall spill release value should be applied under this assumption. The fission products generated are dependent on the initial fissile materials involved and should be estimated by a code, such as ORIGEN2 or equivalent.

For any liquid system, the assumptions for fission product release are:

- All the noble gases generated are released

- Most of the volatile iodine isotopes are retained in the liquid and 25 percent is released.

b. Solid Metal Systems - $1 \times 10^{18}$ total fissions. Fission product generated depending on initial fissile materials involved and should be estimated by a code such as ORIGEN2 or equivalent. For release assumption, see text.

c. Powder Systems $-1 \times 10^{17}$ total fissions. Fission product generated depending on initial fissile materials involved and should be estimated by a code such as ORIGEN2 or equivalent. For release assumptions, see text.

d. Large Storage Arrays - $1 \times 10^{20}$ total fissions. Fission product generated depending on initial fissile materials involved and should be estimated by a code such as ORIGEN2 or equivalent. 


\section{Technical Basis}

The value for the solid metal system and powder systems is based upon a value that bounds most of the reported data for inadvertent nuclear criticalities that have occurred and are listed in Tables 3-8 -

"Summary of Known Accidental Criticality Excursions (a. Solution Systems, b. Metal Systems, and c. Moderated Foil and Powder Systems (1945 to 1974)"; 3-9 - "Accidents in Processing Plants"; 3-10 "Destructive Power Excursion Summary"; 3-11 - "Inhomogeneous Water-Moderated Systems"; 3-12 "Miscellaneous Systems"; and 3-13 - "Nuclear Criticality Accidents at Russian Industrial Facilities." All but one of the inadvertent nuclear criticalities that have occurred in processing facilities have involved solutions. Solids are more readily controlled because of their fixed physical configuration. Likewise, powders tend to flow and much more than the minimum critical mass stated in the standards (ANSI 1983) and other relevant documents (Clayton 1979; Thomas 1978) is required for criticality in the conditions and geometries encountered in processing plants. McLaughlin (1991) presented a table of "Criticality Accident Fission Yields" that was proposed for estimation of safe exclusion areas within work places (Table 3-17 "Criticality Accident Fission Yields"). The values are larger in many cases than those cited here.

The total fission value for large storage arrays is based upon the data presented of the events that have occurred, consideration of the yield from reactor excursions, and Woodcock's estimates shown in McLaughlin's table. No estimates are made for the fission product release.

\subsubsection{Scenario Assumptions and ARFs and RFs}

\section{Solution Systems}

1. Scenario Assumptions. As discussed in Subsection 3.4.2.1, "Nuclear Criticality Accident Source Term Estimation Methods," the assumed total fission yield from the event in a spherical system $45.7 \mathrm{~cm}$ (18 in) in radius is an initial burst of $1 \times 10^{18}$ fissions, followed by 475 -sec bursts of $1.92 \times 10^{17}$ fissions each 10 minutes, for a total of $1 \times 10^{19}$ total fissions. The volume of a sphere with a radius of $45.7 \mathrm{~cm}$ is approximately 400 liters ( $100 \mathrm{gal})$. The "rule-of-thumb" for the total fission yield is based on the estimated total fission from the INCs that have occurred in solutions and provides a reasonable upper bound value for events other than those that occur in very large volumes that greatly exceed the critical mass.

2. ARFs and RFs. The estimated inventories from an INC involving ${ }^{235} U$ in solution is shown in Table 314, "Radioactivity Generated in a Uranium Solution Criticality Accident." The physical forms of radionuclides generated (shown in Table 3-14) are those typically involved (although the inventories differ) and include noncondensible gas (noble gases), volatiles (iodine in heated, acid solution), and nonvolatiles (all remaining radionuclides that are dissolved in the acid solution). Thus, ARFs are required for the noble gases and iodine and ARFs and RFs are required for the non-volatile materials generated and present in the solution (the fissile material and other non-volatiles present in dissolved SNF).

- Noble gases - All noble gases present are assumed to be released during the generation and subsequent boiling of the liquid. The ARF assigned is $1 E+0$ (unity). 
Table 3-17. Criticality Accident Fission Yields (McLaughlin 1991)

\begin{tabular}{|l|c|c|}
\hline \multicolumn{1}{|c|}{ System } & $\begin{array}{c}\text { Initial Burst Yield } \\
\text { (Fissions) }\end{array}$ & $\begin{array}{c}\text { Total Yield } \\
\text { (Fissions) }\end{array}$ \\
\hline $\begin{array}{l}\text { Solutions under } 100 \mathrm{gal} \\
\left(0.38 \mathrm{~m}^{3}\right)\end{array}$ & $1 \times 10^{17}$ & $3 \times 10^{18}$ \\
\hline $\begin{array}{l}\text { Solutions over } 100 \mathrm{gal} \\
\left(0.38 \mathrm{~m}^{3}\right)\end{array}$ & $1 \times 10^{18}$ & $3 \times 10^{19}$ \\
\hline Liquid/powder & $3 \times 10^{20}$ & $3 \times 10^{20}$ \\
\hline Liquid/metal pieces & $3 \times 10^{18}$ & $1 \times 10^{19}$ \\
\hline Solid uranium & $3 \times 10^{19}$ & $3 \times 10^{19}$ \\
\hline Solid plutonium & $1 \times 10^{18}$ & $1 \times 10^{18}$ \\
\hline $\begin{array}{l}\text { Large storage arrays below } \\
\text { prompt critical }\end{array}$ & None & $1 \times 10^{19}$ \\
\hline $\begin{array}{l}\text { Large storage arrays above } \\
\text { prompt critical }\end{array}$ & $3 \times 10^{22}$ & $3 \times 10^{22}$ \\
\hline
\end{tabular}

- Iodine - All iodine isotopes are assumed to be quantitatively released during the boiling of the acid solution. This includes all iodine isotopes that may already be in solution (e.g., ${ }^{129} \mathrm{I}$ and ${ }^{131} \mathrm{I}$ in dissolved $\mathrm{SNF}$ ). The ARF assigned is $1 \mathrm{E}+0$ (unity). Iodine is a highly reactive chemical material that will react with materials (structural, airborne inert particles, engineered exhaust treatment components such as filters and absorbers) encountered along pathway to release. The typical assumption is that an upper bound of 0.25 of the iodine released from the liquid escapes the facility and is released into the atmosphere.

- Non-Volatile - The suspension mechanism for non-volatiles in solution is the formation and suspension of liquid droplets from film-break up. Films are formed by the generation of bubbles of gas or vapor as they rise to the surface thinning the upper film of the bubble until the bubbles burst.

The experimentally measured upper bound value for the ARF is $2 E-3$, with no measured RF. Since the boiling is assumed to reduce the volume of solution to a level that is no longer a critical configuration, not all the liquid is evaporated in the process. For small volumes, there is a reasonable expectation that the initial burst of $1 \times 10^{18}$ fissions should result in a sufficient loss of volume to terminate the criticality excursion. Thus, it is assumed that less than 25 percent of the volume is evaporated and that the applicable ARF is $[2 \mathrm{E}-3][0.25]$ or $5 \mathrm{E}-4$ with an $\mathrm{RF}$ of 1.0 .

The ARF and RF values are applicable to all non-volatile compounds in the liquid, including the fissile material and non-volatiles present in the reacting solution and all the INC-generated FPs. As shown in Table 3-14, for an INC involving ${ }^{235} \mathrm{U}$, the highest inventory of non-volatile FP generated by the excursion is $1200 \mathrm{Ci}$ of ${ }^{92} \mathrm{Sr}$. 


\section{Metal Systems}

Scenario Assumptions. An INC involving a metal would result in FPs formed throughout the metal matrix. Unless energy levels are sufficient to soften the metal, only the FPs on the metal surface are likely to be released. Restrepo (1992) reviewed the literature on FP release from failed fuel elements heated to a temperature that resulted in fuel slumping. He divided the elements into categories that appear to behave similarly under these conditions. The ARFs derived are shown in Table 3-18, "Release Fractions for Various Chemical Classes from Heated Spent Fuel". The values represent the release estimated for unclad SNF heated to temperatures exceeding those anticipated for INCs and are easily upper-bound values for these materials from INCs.

\section{Powder Systems}

1. Scenario Assumptions. As with a metal matrix, an INC involving fissile materials in powder form would result in the formation of FPs within the matrix of the material involved. The tendency is to favor formation near the surface region where the neutron flux is greater. With the larger surface area per mass of powder than for a metal, the values applicable to metal are not relevant.

2. ARFs and RFs. The surface to mass ratio for a powder is dependent on both its particle size distribution and shape. Both are unknown and the upper-bound values are conservatively assumed to be:

Noble gases - ARF 1E+0, RF NA

Iodine - ARF 1E+0, RF NA

Non-volatile - [based on the suspension during the heating of an chemically, non-reactive compound from (DOE 1994, p. 4-57)] ARF 6E-3, RF 0.01.

\section{Large Storage Arrays}

1. Scenario Assumptions. This category of material represents a very large inventory of fissile materials storage in a geometrically favorable configuration. It is impacted by an event that defeats the system to produce a geometrically unfavorable configuration.

There are two relevant classes of materials:

1. Metal Clad Material - SNF, "pits"

2. Unclad - metal, powders, etc.

The anticipated behavior of the two classes of Large Storage Array materials was discussed in Subsection 3.4.3, LPF. The amount released to the ambient atmosphere is the product of the ARF \& RF, if applicable, and the LPF.

2. ARFs and RFs for INCs Involving Large Storage Arrays. For the unclad materials, the ARFs and RFs for the material forms are applicable.

For clad materials, the integrity of the clad during and following the excursion determines the release. The amount of material released through the clad may be considered LPF $_{\mathrm{i}}$ (Leak Path Factor, initial - the fraction of material released within the clad that penetrates the clad). 
There is more than one form of SNF. The common forms are a compacted, sintered, ceramic oxide pellet clad in zircaloy or stainless steel (commercial nuclear fuel); uranium metal clad in aluminum or zircaloy; enriched uranium metal-aluminum alloy; cermets, etc. There has been experimental measurements of FP release during fuel failure from heating, and metal alloy and cermet targets. The derivation of ARFs from ceramic oxide fuel heated to slumping has been covered in Subsection 3.4.3.1.b ("Metals"), and these are applicable for this class of clad material.

Table 3-18. Release Fraction for Various Chemical Classes from Heated Spent Fuel (Restrepo 1991)

\begin{tabular}{|c|c|c|c|c|}
\hline $\begin{array}{l}\text { Group } \\
\text { No. }\end{array}$ & Group Name & Rep. Ele. & Elements in Group. & ARF \\
\hline 1 & Noble Gases & $\mathrm{Xe}$ & $\mathrm{Xe}, \mathrm{Kr}, \mathrm{He}, \mathrm{Ne}, \mathrm{Ar}, \mathrm{Rn}, \mathrm{H}$ & $5 \mathrm{E}-1$ \\
\hline 2 & Alkali Metals & Cs & Cs, Rb, Li, K, Fr, Na & $2 \mathrm{E}-1$ \\
\hline 3 & Alkali Earths & $\mathrm{Ba}$ & $\mathrm{Ba}, \mathrm{Sr}, \mathrm{Mg}, \mathrm{Ca}, \mathrm{Ra}, \mathrm{Be}$ & $3 E-2$ \\
\hline 4 & Halogens & I & $\mathrm{I}, \mathrm{F}, \mathrm{Cl}, \mathrm{Br}, \mathrm{At}$ & $5 \mathrm{E}-2$ \\
\hline 5 & Chalogens & $\mathrm{Te}$ & $\mathrm{Te}, \mathrm{S}, \mathrm{Se}, \mathrm{O}, \mathrm{Po}, \mathrm{N}$ & $7 \mathrm{E}-2$ \\
\hline 6 & Platinoids & $\mathbf{R u}$ & $\mathrm{Ru}, \mathrm{Rh}, \mathrm{Pd}, \mathrm{Os}, \mathrm{Ir}, \mathrm{Pt}, \mathrm{Au}, \mathrm{Ni}$ & $2 \mathrm{E}-3$ \\
\hline 7 & $\begin{array}{l}\text { Transition } \\
\text { Metals } \\
\end{array}$ & Mo & $\mathrm{Mo}, \mathrm{V}, \mathrm{Cr}, \mathrm{Fe}, \mathrm{Co}, \mathrm{Mn}, \mathrm{Nb}, \mathrm{Tc}$ & $3 E-2$ \\
\hline 8 & Tetravalent & $\mathrm{Ce}$ & $\begin{array}{l}\mathrm{Ce}, \mathrm{Ti}, \mathrm{Zr}, \mathrm{Hf}, \mathrm{Th}, \mathrm{Pa}, \mathrm{U}, \mathrm{Np} \text {, } \\
\mathrm{Pu}\end{array}$ & $4 E-4$ \\
\hline 9 & Trivalent & $\mathrm{La}$ & $\begin{array}{l}\mathrm{La}, \mathrm{Al}, \mathrm{Sc}, \mathrm{Y}, \mathrm{Ac}, \mathrm{Pr}, \mathrm{Nd}, \mathrm{Pm} \\
\mathrm{Sm}, \mathrm{Eu}, \mathrm{Gd}, \mathrm{Tb}, \mathrm{Dy}, \mathrm{Ho}, \mathrm{Er} \\
\mathrm{Tm}, \\
\mathrm{Yb}, \mathrm{Lu}, \mathrm{Am}, \mathrm{Bk}, \mathrm{Cf}\end{array}$ & $6 E-4$ \\
\hline 10 & Main Group I & $\mathrm{Cd}$ & $\mathrm{Cd}, \mathrm{Hg}, \mathrm{Zn}, \mathrm{As}, \mathrm{Sb}, \mathrm{Pd}, \mathrm{Tl}, \mathrm{Bi}$ & $4 \mathrm{E}-3$ \\
\hline 11 & Main Group II & Sn & $\mathrm{Sn}, \mathrm{Ca}, \mathrm{In}, \mathrm{Ag}$ & $4 \mathrm{E}-3$ \\
\hline 12 & Boron & B & $\mathrm{B}, \mathrm{Si}, \mathrm{P}, \mathrm{C}$ & $6 \mathrm{E}-4$ \\
\hline
\end{tabular}

The experimental data for release from metals and cermets were analyzed in DOE (December 1994). The ARFs are divided into "instantaneous" (recovered during a 2-min collection period) and "total" (recovered during a 60-min collection period). Only values for three elemental forms were given:

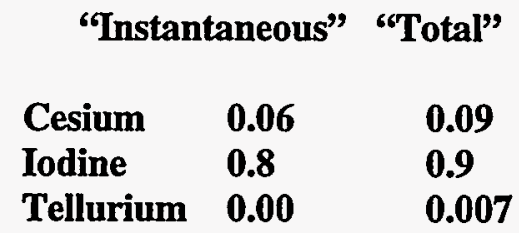


Although the other non-volatile radionuclides are not specifically listed, the values for tellurium, which can be volatile under some conditions, can be applied as upper bounds.

\subsection{Chemicals}

The purpose of this section is to describe how to calculate the characteristics of accidental releases of hazardous chemicals such as uranium hexafluoride, hydrogen fluoride, ammonia, chlorine, and other chemicals commonly found at nuclear fuel cycle facilities. The characteristics of the chemical source term include rate of release, temperature, momentum, orientation, height, and aerosol content. These quantities are required for atmospheric dispersion modeling, which is discussed in Chapter 5 of this Handbook.

\subsubsection{Identification of a Representative Range of Source Terms}

No single atmospheric dispersion model or source term will suffice for the range of scenarios possible at the fuel cycle facilities. At the same time, it may not be necessary to develop or use highly sophisticated models that take into account every possible detail about the source term. Certain aspects of the source term need not be fully quantified, if they can be shown to have little or no impact on the final risk estimate. Hence, the selection of the appropriate source term is as much an art as a science. This section provides guidance on the selection of the appropriate source term for the types of accident scenarios involving chemicals possible at the fuel cycle facilities by providing a broad overview of the range of source terms. For modeling details of each type of source term described herein, the reader is directed to Appendix B of this Handbook.

\subsubsection{Liquid below Its Boiling Point}

If spilled accidentally, liquids with boiling points that are well above ambient temperature will form a pool on the ground and evaporate slowly at a rate determined by the ambient temperature, the windspeed and the area of the spill. No aerosolization is expected in such a spillage. Hydrofluoric acid (normal boiling point $293 \mathrm{~K}\left(68^{\circ} \mathrm{F}\right)$ is an example of a liquid that can be spilled below its boiling point if the spill occurs from a storage tank at an ambient temperature that is less than $293 \mathrm{~K}\left(68^{\circ} \mathrm{F}\right)$.

If the spill initially occurs from a severed line, then Bernoulli's equation can be used to estimate the flow rate onto the ground (see equation B.1 in Appendix B). Bernoulli's equation takes into account the influence of static liquid pressure head, and the influence of vapor pressure above the liquid level.

After a spill, the methods developed for estimating the evaporation rate of slowly evaporating liquids from pools can be used. These methods assume that heat transfer from the underlying surface of the pool is rapid, and is not the limiting factor for evaporation. The rate of evaporation is limited by the rate of mass transfer across a stagnant film of air at the surface of the pool. The method for predicting the evaporation rate is described in Section B.2.1, equations B.2, B.3, and B.4 of Appendix B. An example of a calculation of an evaporating pool of $\mathrm{HF}$ at a temperature of $280 \mathrm{~K}\left(44^{\circ} \mathrm{F}\right)$ is given in Sample Problem No. 5.

\subsubsection{Refrigerated Liquid in a Vessel}

The method used to estimate the release rate of a liquid below its boiling point (Bernoulli's equation), can also be used to estimate the release rate of a refrigerated liquid. Examples of refrigerated liquids include freon and ammonia. In the present context, refrigerated liquids have boiling points that are well below 
ambient temperature (e.g., ammonia with a boiling point of $\left.239 \mathrm{~K}\left(-29^{\circ} \mathrm{F}\right)\right)$. The rate of evaporation of a pool of refrigerated liquid is limited by heat conducted from the surface underlying the pool. The method for calculating the rate of evaporation of a refrigerated liquid is described in Section B.2.3. Note that the authors are not currently aware of any refrigerated liquids being kept at NRC-licensed sites. However, the discussion of this type of scenario is included for completeness.

\subsubsection{Gas Liquefied under Pressure}

Gases liquefied under pressure flash on release to the atmosphere. Examples of gases that are frequently stored as liquids under pressure include ammonia, hydrogen fluoride, and propane. The flash phenomenon results in aerosolization of the condensed liquid into fine, suspended droplets or particles that do not fall to the ground. The flash phenomenon also leads to a significant cooling of the released material--thus rendering the vapor heavier than if it were at ambient temperature. This phenomenon, along with the presence of dense droplets or particles in an aerosol, can lead to the formation of dense vapor clouds-an important distinction from the risk standpoint, since dense vapors tend to hug the ground. More discussion on aerosols is given in Section 3.5.3.1.

The release can be continuous, such as from a sheared pipe or a broken valve, or instantaneous, such as from the catastrophic rupture of a tank. Discussion of the characteristics of the source terms from flashing liquid jets is given in Section B.3, with specific references to HF in Section B.3.2 and $\mathrm{UF}_{6}$ in Section B.3.5. Sample Problem No. 6 also addresses flashing liquid jets of $\mathrm{UF}_{6}$.

\subsubsection{Releases from the Vapor Space of a Pressurized Vessel or a Pressurized Pipeline}

If a small hole or a release pathway develops from the vapor space of a pressurized vessel, a vapor release can occur. Examples of materials that can be released in this way include hydrogen fluoride, ammonia and $\mathrm{UF}_{6}$. The flow can be choked or critical (i.e., the discharge occurs at the speed of sound), or sub-critical (i.e., with a velocity that is lower than the speed of sound). Since the pressurized gas expands adiabatically (i.e., with little or no heat exchange from the surroundings), it cools as it exits the vessel. If the cooling is significant, then partial condensation of the released vapor is possible. It is therefore necessary to establish if the flow is choked and if there is condensation. The methods used to calculate source term characteristics for these types of scenarios are described in Section B.3.2 and Section B.4. An example of a vapor release scenario for $\mathrm{UF}_{6}$ is given in Sample Problem No. 6.

\subsubsection{Instantaneous (Puff) Releases}

A puff release corresponds to the catastrophic failure of a vessel whereby the contents are released instantaneously. In the case of a gas liquefied under pressure (such as ammonia, propane, hydrogen

fluoride, or uranium hexafluoride), a fraction of the liquid may flash to vapor and the remainder is fragmented, remaining airborne as fine liquid droplets (or solid particles in the case of $\mathrm{UF}_{6}$ ). Puff releases are possible if there are catastrophic ruptures of large tanks such as railcars, tanks, trucks, or storage tanks. See Section B.5. Sample problem No. 6 contains an example of a puff release of $\mathrm{UF}_{6}$.

\subsubsection{Releases Inside a Building}

Indoor releases of chemicals pose complex challenges to risk assessors. A large number of phenomena governs the release and transport of chemicals inside buildings, necessitating a case-by-case approach. These phenomena are discussed in Chapter 4. 
In addition to the initiators that can lead to releases outdoors, indoor processes are vulnerable to some special accident sequences. Earthquakes can cause building damage and structures to collapse upon process equipment and thereby cause a release. Buildings also present complex release flow paths by means of ventilation ducts, rooms, and filters. The flow pressures may be natural, or forced depending on the type of building and the scenario being modeled. A forced flow situation exists in a building in which the release pathway is a forced-flow ventilation duct. A natural flow situation may exist in an earthquakedamaged building in which the forced-flow ventilating systems have been damaged to a point where they are no longer functional.

Once released, the chemicals are subject to dilution in rooms, removal by surface deposition, removal by gravitational settling, and removal by liquid sprays (Owczarski, et al. 1991).

If there are aerosols present in the indoor release, then they can deposit by a number of mechanisms. These are Brownian diffusion, gravity settling, electrophoresis, thermophoresis, diffusiophoresis, turbulent deposition, inertial impaction, and interception (Owczarski, et al. 1991). Under certain conditions, gravity settling may be the dominant settling mechanism. Some fuel cycle buildings maintain an indoor temperature that is always higher than the ambient conditions. This leads to the possibility of an indoor release being initially buoyant when it escapes into the atmosphere.

If the indoor release is able to escape from the building, then there is the possibility of the release being caught in the building wake. It is not possible to state whether this is beneficial or detrimental from a risk perspective. This is because building wakes exhibit complex behavior. There are competing mechanisms in a building wake that affect risk. It has generally been known that building wakes dilute the release and thereby reduce the airborne concentration. This is a beneficial phenomenon. However, initially buoyant releases that would ordinarily rise clear off the ground, in the absence of a building wake, may be 'caught' in one, and result in higher ground-level concentrations. Experiments conducted in the United Kingdom (UK) have established criteria that attempt to resolve the issue of plume lift-off in a building wake (Hall, et al. 1995).

\subsubsection{Issues and Uncertainties}

\subsubsection{Aerosols}

As noted above, aerosols can be formed in many of the scenarios that are of interest. In the present context, aerosols are suspensions of liquid droplets in a vapor that is generally a mixture of air and the released vapor (e.g., air, ammonia vapor, and liquid ammonia droplets). The one exception is $\mathrm{UF}_{6}$, in which the fine particles will be solid. There are several mechanisms whereby aerosols can be formed:

Flashing: if a material that is normally gaseous under ambient conditions is liquefied under pressure and is then released to the atmosphere, the phenomenon of flashing takes place. Some percentage of the liquid flashes to vapor. This is accomplished by bulk boiling and bubble growth throughout the liquid and is so vigorous that the fraction that is not vaporized is shattered into very fine liquid droplets (Woodward 1995). This phenomenon has been observed repeatedly in a variety of experiments, including large-scale releases of ammonia (the "Desert Tortoise" experiments, Goldwire, et al. 1983) and of hydrogen fluoride (the "Goldfish" series of experiments, Blewitt, et al. 1987).

Aerodynamic Mechanisms: if a liquid jet emerges from an orifice at high velocity, aerodynamic mechanisms can cause breakup (De Vaull, et al. 1995). Whether breakup occurs depends on the relative 
strength of inertial/shear forces and capillary forces on the drop. Breakup is expected to occur if the Weber number, We, exceeds a critical value of around 10-15:

where:

$$
\mathrm{We}=0.5 \rho_{\mathrm{a}} \mathrm{u}_{0}^{2} \mathrm{~d} / \sigma
$$

$$
\begin{aligned}
& \rho_{\mathrm{a}}=\text { density of air, } \mathrm{kg} / \mathrm{m}^{3} \\
& \mathrm{u}_{\mathrm{o}}=\text { centerline jet velocity, } \mathrm{m} / \mathrm{s} \\
& \mathrm{d}_{\mathrm{p}}=\text { droplet diameter, } \mathrm{m} \\
& \sigma=\text { surface tension, } \mathrm{N} / \mathrm{m}
\end{aligned}
$$

Condensation: when a vapor at high pressure is released, it expands and cools. Condensation may then occur. This issue is discussed in some detail in Sections B.3.1 and B.4 of Appendix B. The droplets formed in this case are expected to be very small and will evaporate as the plume is diluted.

For fuel cycle facilities, the scenarios in which significant aerosolization is expected to be most likely are flashing liquid releases of ammonia, uranium hexafluoride, and hydrogen fluoride. The issue of most concern is whether the liquid droplets remain airborne until they have evaporated, or whether they fall to the ground. There has been considerable experimental and theoreticalyork on this issue. Figure 3-15 shows the results of some experiments that were carried out on liquid chlorine and reported by Johnson (1991). Figure 3-15 shows the percentage of chlorine that falls to the ground as a function of superheat, which is the difference in temperature between the chlorine initially in the vessel and its boiling point. Figure 3-15 also shows the results of the Dow Model (Dow 1993), which predicts that the fraction of liquid droplets that remains airborne is 5 times the vapor flash fraction (the fraction of chlorine that immediately vaporizes as it is released to the atmosphere). The Dow model appears to be conservative (i.e., it predicts too much chlorine falls back to the ground, [i.e., too much rainout]).

Figure 3-15 also shows the results of a model (Ianello, et al. 1989), known as the "RELEASE" model, that was used by Johnson (1991) to try to reproduce the experimental results. As can be seen, agreement is poor ${ }^{5}$, possibly because the model neglects the evaporation from the airborne droplets as they fall towards the ground, and/or from the pool. Other models that take this evaporation into account lead to better agreement with experiments (Woodward 1995).

The authors do not know of a publicly available model that accurately simulates flashing, aerosol formation, and subsequent rainout. Those models that have been developed seem rather complex. However, it is possible to make simplifications that will address most circumstances of interest in the present work. For example, Figure 3-15 shows that, down to superheats that are as low as $10 \mathrm{~K}$, no more than about 20 percent of the chlorine remains airborne. Therefore, the error introduced by assuming that all of the chlorine remains airborne is quite small and is on the conservative side.

For cases of interest at fuel cycle facilities, ammonia stored under pressure at ambient temperatures is typically $50 \mathrm{~K}\left(90^{\circ} \mathrm{F}\right)$ above its atmospheric boiling point of $239 \mathrm{~K}\left(-29^{\circ} \mathrm{F}\right)$. Therefore, any aerosols that may be formed by flashing can confidently be assumed to remain airborne. For $\mathrm{UF}_{6}$, the scenarios of interest are those in which liquid filled cylinders are breached. For example, in Sample Problem No. 6,

\footnotetext{
${ }^{5}$ Recently, CCPS has funded changed to the RELEASE mode that greatly improve its agreement with the data (Johnson, D.W., Private Communication, 1991). However, at the time of writing, the modified version RELEASE has not yet been issued by the CCPS.
} 


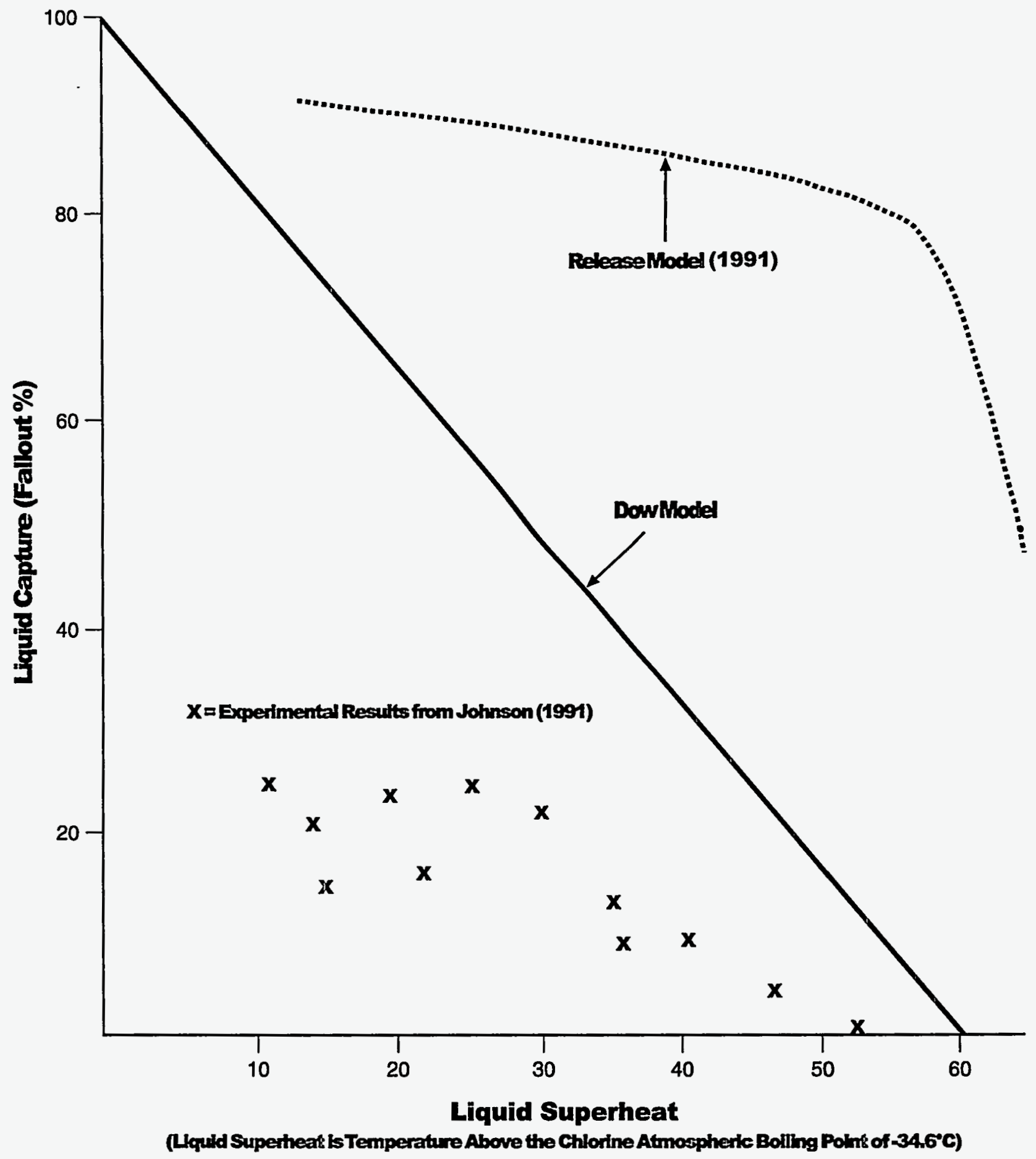

Figure 3-15. Fraction of liquid chlorine falling to the ground as a function of superheat 
scenarios are addressed in which it is assumed that the initial temperature of the $\mathrm{UF}_{6}$ is either $343 \mathrm{~K}$ or 366 $\mathrm{K}\left(158^{\circ} \mathrm{F}\right.$ or $\left.200^{\circ} \mathrm{F}\right)$.

Both of these temperatures are more than $10 \mathrm{~K}\left(18^{\circ} \mathrm{F}\right)$ above the atmospheric sublimation point. HF is more problematical. Its boiling point is $293 \mathrm{~K}\left(68^{\circ} \mathrm{F}\right)$, which lies within the range of ambient temperatures at many sites. Therefore, its temperature could be either above or below its boiling point. However, on a very hot day, the HF in a storage vessel could be at temperatures that are $10 \mathrm{~K}\left(18^{\circ} \mathrm{F}\right)$ or more in excess of its boiling point, especially if the tank is in direct sunlight, and complete aerosolization might be expected, at least as a conservative worst case.

A further source of uncertainty occurs if there are obstacles or if the flashing jet is directed at the ground. Experiments with ammonia (Resplandy 1969) and HF (Muralidhar, et al. 1995) show that, when a twophase jet impinges on an obstacle, much of the liquid in the jet is captured. The amount that is captured depends heavily on the exact configuration of the obstacles, so there is no simple rule-of-thumb that can be applied and the analyst is generally forced to make the conservative assumption that all the aerosol remains airborne.

\subsubsection{Uncertainties}

Estimates of risks from accidents are often accompanied by uncertainty because of the complexity of the postulated accident scenarios and the physical models used to describe them. For a given accident scenario and its model, there is another source of uncertainty that arises from imperfect knowledge of some of the model parameters. Thus, uncertainty stems from an inadequate description of: (1) the conceptual model of the phenomenon; (2) the mathematical model used to describe the risk-bearing event; and (3) parameters used in the mathematical model (Apostolakis 1990).

Simple examples of uncertainty in the conceptualization of a phenomenon include basic assumptions such as where the point of release is located. For example, in the case of a gas liquefied under pressure, there is a large variation in the source term, depending on whether the point of release is located in the liquid or vapor space. In general, the latter will lead to a much lower release rate than the former, with a lower density also. As another example, if the liquid is released directly from an orifice in the wall of a vessel, it will emerge as a liquid and flash outside the vessel. If it is discharged through a pipe, it may well partially flash in the pipe, leading to a two-phase release at a rate intermediate between that of a pure liquid and a pure vapor.

If the initial conditions are carefully specified (that is, if the conceptualizations agree), then the formulae for release rates in Appendix B (e.g., Bernoulli's formula for liquids or the formulae for choked or subcritical vapor flow - i.e., the mathematical models used to describe the risk-bearing event) have been proven to be quite accurate - certainly in the sense that their contribution to the overall uncertainties in accident analysis is relatively small.

Parameter uncertainties are generally quite small. For example, Bernoulli's formula, equation (B.1 of Appendix B), depends on: (1) the pressure in the vessel or reservoir; (2) the area of the orifice; (3) the density of the liquid; and (4) the static head. These quantities are generally known quite well. In an accident situation, the area of the orifice might not be well-known and the release rate is directly proportional to the area. However, the models described in this Handbook are not intended for use during an emergency (precisely because it may be difficult to quickly obtain reliable values of input parameters). 
They are intended for calculations such as those that may be used in a Safety Analysis Report, or for calculations used to plan for emergency response.

As noted above, for some of the releases considered, aerosols are important, and the amount of aerosol that remains airborne can be difficult to estimate.

\subsubsection{Examples - Specific Scenarios}

Examples for the estimation of chemical source terms for atmospheric dispersion modeling have been described in Appendix B and in the Sample Problem Report. To provide guidance for estimating chemical source terms in this chapter, additional examples of release scenarios are described here. Table 3-19 shows examples that have already been developed in other sections of the Handbook:

The following release scenarios are described in this chapter to supplement those described elsewhere:

1. Puff release of ammonia

2. Puff release of hydrofluoric acid

3. Puff release of propane

\subsubsection{Puff Release of Ammonia}

This scenario is possible if a tankcar containing liquid ammonia ruptures catastrophically. following an accidental collision. There could also be other causes of such a failure. These include dropping cylinders containing ammonia from a height, leading to a rupture. A hazards analysis identification exercise such as HAZOP or "What-If" could give rise to this scenario. This scenario is possible at $\mathrm{UF}_{6}$ conversion plants and at fuel fabrication facilities. The following assumptions were used in determining source term characteristics:

- Mass of ammonia in cylinder $=1000 \mathrm{~kg}$-liquid $(2200 \mathrm{lb})$

- The density of liquid ammonia is $607.7 \mathrm{~kg} / \mathrm{m}^{3}\left(37.9 \mathrm{lb} / \mathrm{ft}^{3}\right)$

- Cylinder is stored at ambient temperature $\left(294 \mathrm{~K}\right.$ or $\left.70^{\circ} \mathrm{F}\right)$

- Contents of cylinder are assumed to be at vapor pressure of ammonia $\left(8.8 \times 10^{5} \mathrm{~Pa}(128 \mathrm{psia})\right)$ at $294 \mathrm{~K}\left(70^{\circ} \mathrm{F}\right)$. This pressure is over eight times the normal atmospheric pressure.

- Following the rupture and flash, the temperature of ammonia is equal to the atmospheric boiling point $\left.239 \mathrm{~K}\left(-29^{\circ} \mathrm{F}\right)\right)$.

- Ten times by mass of air mixes in with the puff following the flash. This is because of the vigor of the flash phenomenon.

As the ruptured cylinder rapidly depressurizes, liquid ammonia is fragmented and rendered airborne (see Section 3.5.3.1). In past accidents involving large releases of liquid ammonia, it was observed that no ammonia was left on the ground and that the entire inventory of liquid ammonia was fragmented into fine droplets (Kaiser 1979). In addition, the large scale Desert Tortoise $\mathrm{NH}_{3}$ experiments (Goldwire, et al. 1983) show little or no ammonia remaining on the ground.

The vapor fraction of ammonia following the flash is given by (Christensen and Kaiser 1993):

$$
\mathrm{x}_{\mathrm{r}}=\mathrm{C}_{\mathrm{pl}}\left(\mathrm{T}_{1}-\mathrm{T}_{\mathrm{r}}\right) / \mathrm{H}_{\mathrm{L}}
$$


Table 3-19. Chemical Source Term Examples

\begin{tabular}{|l|l|}
\hline \multicolumn{1}{|c|}{ Example } & \multicolumn{1}{|c|}{ Evaporating Pools } \\
\hline Spillage of liquid hydrofluoric acid & $\begin{array}{l}\text { Appendix B, Section B.2.1, and Sample Problem } \\
\text { No. } 5\end{array}$ \\
\hline Spillage of refrigerated ammonia into a diked area & Appendix B, Section B.2.3 \\
\hline \multicolumn{2}{|c|}{ Liquid Jets } \\
\hline Hydrofluoric acid jet & Appendix B, Section B.3.2 \\
\hline Ammonia jet & Appendix B, Section B.3.3 \\
\hline $\begin{array}{l}\text { Uranium hexafluoride jet release from a } \\
\text { pressurized cylinder }\end{array}$ & $\begin{array}{l}\text { Appendix B, Section B.3.5, and Sample Problem } \\
\text { No. 6 }\end{array}$ \\
\hline \multicolumn{1}{|c|}{ Vapor Jet } \\
\hline Ammonia vapor release & Appendix B, Section B.4.2 \\
\hline Uranium hexafluoride vapor release & $\begin{array}{l}\text { Appendix B, Section B.4.3, and Sample Problem } \\
\text { No. 6 }\end{array}$ \\
\hline Chlorine vapor release & Appendix B, Section B.4.1 \\
\hline & Puffs \\
\hline Small cylinder of ammonia & Appendix B, Section B.5.2 \\
\hline Large cylinder of uranium hexafluoride & $\begin{array}{l}\text { Appendix B, Section B.5.3, and Sample Problem } \\
\text { No. 6 }\end{array}$ \\
\hline
\end{tabular}

where:

$\mathrm{x}_{\mathrm{T}}=$ the flash fraction

$\mathrm{T}_{1}=$ the initial temperature in the cylinder, $294 \mathrm{~K}$

$\mathrm{T}_{\mathrm{r}}=$ the discharge temperature equal to the boiling point, $239 \mathrm{~K}$

$\mathrm{H}_{\mathrm{L}}=$ the latent heat of vaporization at the atmospheric boiling point, $1.183 \times 10^{6} \mathrm{~J} / \mathrm{kg}$

$\mathrm{C}_{\mathrm{pl}}=$ the heat capacity of the liquid averaged over the temperature range $T_{1}$ to $T_{r} \mathrm{~J} / \mathrm{kg} / \mathrm{K}$ (4722 $\mathrm{J} / \mathrm{kg} / \mathrm{K}$ )

Thus,

$$
x_{f}=4722 \times(294-239) / 1.183 \times 10^{6}=0.216
$$

This implies that $21.6(1725 \mathrm{lb})$ percent by mass $(216 \mathrm{~kg}(475 \mathrm{lb}))$ of ammonia flashes to vapor and the remaining 78.4 percent by mass $(784 \mathrm{~kg}$ ) of ammonia remains liquid. At this point, a rule -of-thumb comes into play, based on analysis of previous ammonia incidents and experiments, namely that the initial 
flashing process causes the immediate mixing of about 10 times as much air by mass as there initially is ammonia (Kaiser 1979). (Note: The ultimate results of dispersion calculations are not particularly sensitive to whether this initial mass mixing ratio is in the range of 3-30.) When 10 times by mass of air $(10000 \mathrm{~kg}(22000 \mathrm{lb}))$ mixes in the cloud, it warms the cloud and evaporates some or all the liquid droplets. The heat required to boil $784 \mathrm{~kg}$ of ammonia is equal to:

$$
784 \times 1.18 \times 10^{6}=9.25 \times 10^{8} \mathrm{~J}\left(6.8 \times 10^{8} \mathrm{ft} \mathrm{lb}\right)
$$

The heat released by $10000 \mathrm{~kg}$ of air at ambient temperature $(294 \mathrm{~K})$ to cool to $239 \mathrm{~K}$ is:

$$
10000 \times 713.8 \times(294-239)=3.93 \times 10^{8} \mathrm{~J}\left(2.9 \times 10^{8} \mathrm{ft} \mathrm{lb}\right)
$$

The heat required to evaporate all liquid droplets is more than the heat available from cooling the ambient air to the boiling point of ammonia. Thus, not all the liquid droplets will evaporate. At equilibrium conditions the mixture temperature is equal to the boiling point of ammonia, (i.e., $\sim 239 \mathrm{~K}\left(-29^{\circ} \mathrm{F}\right)$ ). The mass of liquid ammonia that evaporates is equal to:

$$
\frac{3.93 \times 10^{8}}{1.18 \times 10^{6}}=330 \mathrm{~kg}
$$

Thus, (784-330) $=454 \mathrm{~kg}$ of ammonia remain liquid, and $546 \mathrm{~kg}$ of ammonia evaporates to form vapor. The density of the cloud, $\rho$, is given by:

$$
\begin{aligned}
\rho & =\frac{\text { (ammonia mass }+ \text { air mass) }}{(\text { air volume+ammonia vapor volume+ammonia liquid volume) }} \\
& =\frac{(1000+10000)}{\left(\frac{10000}{29}+\frac{546}{17}\right) \times\left(\frac{8314 \times 240}{101325}\right)+\left(\frac{454}{607.7}\right)} \\
& =1.48 \mathrm{~kg} / \mathrm{m}^{3}\left(0.095 \mathrm{lb} / \mathrm{ft}^{3}\right)
\end{aligned}
$$

The ambient air density at $294 \mathrm{~K}$ is $1.202 \mathrm{~kg} / \mathrm{m}^{3}$. The cloud of ammonia is initially heavier than air. The total volume of the cloud is given by:

$$
\text { Total volume }=11000 / 1.48 \sim 7400 \mathrm{~m}^{3}\left(\sim 250000 \mathrm{ft}^{3}\right) .
$$

The ammonia mass has no initial momentum because it was at rest immediately before rupture and mixing with air. The ambient air does have a velocity and imparts a momentum to the well-mixed cloud. Assuming that the mass mix ratio is 10 air masses to 1 ammonia mass, and the initial velocity of the air is $\mathrm{v}$, the velocity of the resultant mixture is $\mathrm{v}=\mathrm{v} / 1.1$ (from the law of conservation of momentum). 
In summary,

$\begin{array}{ll}\text { Mass of airborne ammonia } & 1000 \mathrm{~kg}(2200 \mathrm{lb}) \\ \text { Immediately mixed mass of air } & 10000 \mathrm{~kg}(22000 \mathrm{lb}) \\ \text { Volume } & 7400 \mathrm{~m}^{3}\left(250000 \mathrm{ft}^{3}\right) \\ \text { Mass of airborne droplets } & 454 \mathrm{~kg}(1000 \mathrm{lb})(\mathrm{after} \text { mixing with } 10000 \mathrm{~kg}(22000 \mathrm{lb}) \text { of air }) \\ \text { Density } & \left.1.40 \mathrm{~kg} / \mathrm{m}^{3} 0.095 \mathrm{lb} / \mathrm{ft}^{3}\right) \\ \text { Temperature } & 239 \mathrm{~K}\left(-29^{\circ} \mathrm{F}\right) \\ \text { Velocity } & \mathrm{v} / 1.1 \mathrm{~m} / \mathrm{s}\end{array}$

The above data can be used as input to a puff model of atmospheric dispersion. The biggest uncertainty is what fraction of the initially airborne liquid droplets falls to the ground. As noted above, the flash fraction is -20 percent, so that, if all liquid droplets were to fall to the ground or impinge on surfaces, only $200 \mathrm{~kg}$ $(440 \mathrm{lb})$ would remain airborne -an uncertainty of a factor of 5 . However, as noted above, experimental observation favors the assumption that most, if not all, the liquid droplets remain airborne.

\subsubsection{Puff Release of Hydrofluoric Acid}

This scenario is possible if a catastrophic rupture occurs in a storage tank or a tankcar of HF. Such a scenario is possible in $\mathrm{UF}_{6}$ conversion facilities and ore-processing facilities. A hazards analysis exercise such as a checklist based on previous experience, a What-If? team session or a formal hazards identification exercise such as a HAZOP may identify this hazard. Considerable work has been done in the area of estimation of source term characteristics for HF (Kaiser \& Chhibber 1994; Muralidhar, et al. 1995; Appendix B).

The following assumptions were made to analyze this scenario:

- A storage tank containing $1000 \mathrm{~kg}(2200 \mathrm{lb}) \mathrm{HF}$ ruptures catastrophically.

- The storage temperature is $305 \mathrm{~K}\left(90^{\circ} \mathrm{F}\right), 12 \mathrm{~K}\left(22^{\circ} \mathrm{F}\right)$ above the normal boiling point of $293 \mathrm{~K}$ $\left(68^{\circ} \mathrm{F}\right)$. At this temperature, the vapor pressure of $\mathrm{HF}$ is $1.539 \times 10^{5} \mathrm{~Pa}(\sim 1.5$ atmospheres $)$. HF is stored as a liquid under its own vapor pressure. There are $900 \mathrm{~kg}(1980 \mathrm{lb})$ of HF liquid and $100 \mathrm{~kg}(220 \mathrm{lb})$ of HF vapor in the tank.

- The flash following the rupture fragments the liquid into a mist of fine suspended HF droplets. All the HF droplets remain airborne.

- The flash phenomenon results in mixing with ten times by mass of air at $305 \mathrm{~K}\left(90^{\circ} \mathrm{F}\right)$ and 50 percent relative humidity.

- HF thermodynamics as described in (Kaiser and Chhibber 1994) were used. A computer program was used to estimate the equilibrium conditions of the mixture of $1000 \mathrm{~kg}(2200 \mathrm{lb})$ of $\mathrm{HF}$ and $10000 \mathrm{~kg}(22000 \mathrm{lb})$ air. This computer program is able to account for:

- $\quad$ oligomerization of $\mathrm{HF}$;

- $\quad$ non-ideal solution formation of HF and water; and

- heat effects associated with the above phenomena.

The computer program calculated the final equilibrium conditions to be a temperature of $280 \mathrm{~K}$ ( $45^{\circ} \mathrm{F}$ ) and a density of $5.276 \mathrm{~kg} / \mathrm{m}^{3}\left(0.34 \mathrm{lb} / \mathrm{ft}^{3}\right)$. The reduction in temperature occurs because there is a cooling effect produced by the rapid expansion and boiling of liquid HF. The deoligomerization phenomenon also 
cools the cloud. The reduction in the temperature, the presence of HF oligomers, and HF-water condensates, contribute to the density of the cloud.

The total volume of the puff can be estimated by dividing the total mass by the total density:

$$
\text { Total volume }=(11,000 / 5.276)=2085 \mathrm{~m}^{3}\left(71600 \mathrm{ft}^{3}\right)
$$

As before, assuming that the initial velocity of the air is $\mathrm{v}$, the velocity of the resultant mixture is $v^{\prime}=v / 1.1$.

In summary,

$\begin{array}{ll}\text { Mass of airborne hydrofluoric acid } & 1000 \mathrm{~kg}(2200 \mathrm{lb}) \\ \text { Immediately mixed mass of air } & 10000 \mathrm{~kg}(22000 \mathrm{lb}) \\ \text { Volume } & 2085 \mathrm{~m}^{3}\left(71600 \mathrm{ft}^{3}\right) \\ \text { Density } & 5.276 \mathrm{~kg} / \mathrm{m}^{3}\left(0.34 \mathrm{lb} / \mathrm{ft}^{3}\right) \\ \text { Temperature } & 280 \mathrm{~K}\left(45^{\circ} \mathrm{F}\right) \\ \text { Velocity } & \mathrm{v} / 1.1 \mathrm{~m} / \mathrm{s}\end{array}$

The above data can be used as input to a puff model of atmospheric dispersion. The biggest uncertainty is what fraction of the initially airborne liquid droplets fall to the ground. As noted above, experimental observation favors the assumption that most, if not all, of the liquid droplets remain airborne.

\subsubsection{Puff Release of Propane}

Liquid propane is often stored in storage tanks of up to $18900 \ell$ (5000 gallons) at various fuel cycle facilities. A catastrophic rupture of a propane storage tank is possible at fuel manufacturing facilities. For instance, an overfilled propane tank may burst if heated inadvertently by proximity to a fire. A hazards analysis exercise such as a checklist based on previous experience, a What-If? team session, or a formal hazards identification exercise such as a HAZOP may identify this hazard.

The following assumptions were made to analyze this scenario:

- A $18900 \ell$ (5000 gallon) tank of propane bursts catastrophically.

- The density of liquid propane is $482.2 \mathrm{~kg} / \mathrm{m}^{3}\left(30.9 \mathrm{lb} / \mathrm{ft}^{3}\right)$. Thus, the total mass in the tank is equal to 5000 gallons $\times 3.78$ gallons $/$ liter $\times 10^{-3} \mathrm{~m}^{3} /$ iter $\times 482.2 \mathrm{~kg} / \mathrm{m}^{3}=9114 \mathrm{~kg}(20000 \mathrm{lb})$.

- The storage temperature is $305 \mathrm{~K}\left(90^{\circ} \mathrm{F}\right)$. At this temperature, the vapor pressure of propane is $1.131 \times 10^{6} \mathrm{~Pa}(\sim 10$ atmospheres). Propane is stored as a liquid under its own vapor pressure.

- The flash following the rupture fragments the liquid into a mist of fine suspended propane droplets. All the propane droplets remain airborne.

- The flash phenomena results in mixing with ten times by mass of air at $305 \mathrm{~K}\left(90^{\circ} \mathrm{F}\right)$.

- Immediately following the rupture and flash, but before mixing with air, the temperature of propane is equal to the atmospheric boiling point $\left(231.1 \mathrm{~K}\left(-41^{\circ} \mathrm{F}\right)\right)$.

- Ten times by mass of air mixes in with the puff following the flash. This is because of the vigor of the flash phenomenon. 
The vapor fraction of propane following the flash is given by equation 3.22, with the following assumptions about the initial conditions and the physical constants:

- $\quad \mathrm{T}_{1}$, the initial temperature in the cylinder, $305 \mathrm{~K}\left(90^{\circ} \mathrm{F}\right)$

- $\quad T_{r}$, the discharge temperature equal to the boiling point, $231.1 \mathrm{~K}\left(-41^{\circ} \mathrm{F}\right)$

- $\quad \mathrm{H}_{\mathrm{L}}$, the latent heat of vaporization at the atmospheric boiling point, $323,000 \mathrm{~J} / \mathrm{kg}(13.9$ $\mathrm{Btu} / \mathrm{lb})$

- $\quad C_{p l}$, the heat capacity of the liquid averaged over the temperature range $T_{1}$ to $T_{r}$, is 2764 $\mathrm{J} / \mathrm{kg} / \mathrm{K}\left(0.66 \mathrm{Btu} / \mathrm{lb} /{ }^{\circ} \mathrm{F}\right)$

Thus, the flash fraction $x_{r}$ is given by:

$$
x_{r}=\frac{2764 \times(305-231.1)}{323000}=0.632
$$

This implies that 36.8 percent by mass $(3354 \mathrm{~kg}(7380 \mathrm{lb})$ ) of propane flashes to vapor and 63.2 percent by mass $(5760 \mathrm{~kg}(12700 \mathrm{lb}))$ of propane remains liquid. When ten times by mass of air $(91140 \mathrm{~kg}$ $(\sim 200000 \mathrm{lb}))$ mixes in the cloud, it warms the cloud and evaporates the liquid droplets. The heat required to boil $5760 \mathrm{~kg}$ of propane is equal to:

$$
5760 \times 323000=1.860 \times 10^{9} \mathrm{~J}\left(1.37 \times 10^{9} \mathrm{ft} \mathrm{lb}\right)
$$

The heat released by $91140 \mathrm{~kg}$ of air at ambient temperature $(305 \mathrm{~K})$ to cool to $231.1 \mathrm{~K}$ is:

$91140 \times 713.8 \times(305-231.1)=4.808 \times 10^{9} \mathrm{~J}\left(3.55 \times 10^{9} \mathrm{ft} \mathrm{lb}\right)$

The heat required for evaporating all liquid droplets is less than the heat available from cooling the ambient air to the boiling point of propane. Thus, all the liquid droplets will evaporate and the equilibrium temperature will be somewhere between the boiling point of propane and ambient temperature. At equilibrium conditions, the mixture temperature is given by a simple heat balance:

$$
m_{a} C_{p}^{a}\left(T_{a}-T\right)=m_{g}^{1} h_{L}+m_{g} C_{p}^{g}\left(T-T_{b}\right) \Rightarrow T=\frac{\left(m_{a} C_{p}^{a} T_{a}-m_{g}^{l} h_{L}+m_{g} C_{p}^{g} T_{b}\right)}{\left(m_{a} C_{p}^{a}+m_{g} C_{p}^{g}\right)}
$$

where:

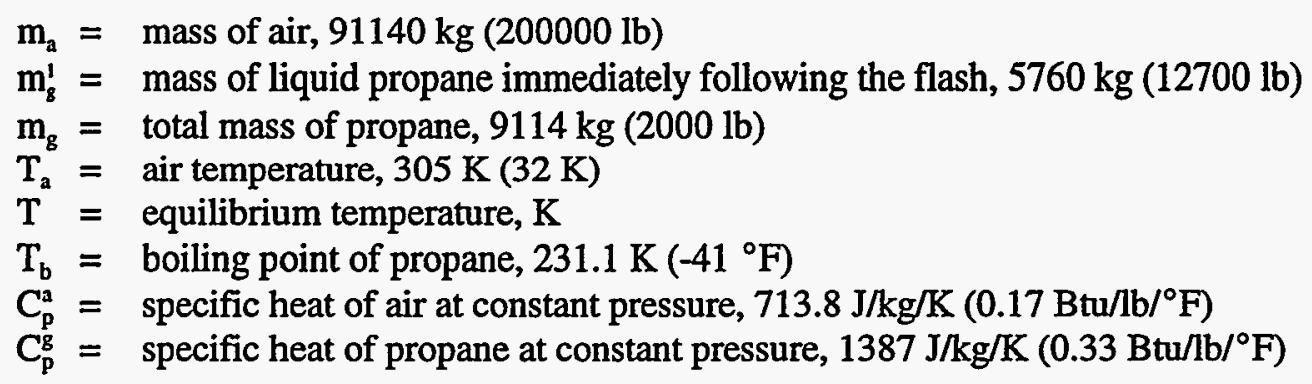


The equilibrium temperature is:

$$
\begin{aligned}
\mathrm{T} & =\frac{(91140 \times 713.8 \times 305-5760 \times 323000+9114 \times 1387 \times 231.1)}{(91140 \times 713.8+9114 \times 1387)} \\
& =269 \mathrm{~K}\left(25^{\circ} \mathrm{F}\right)
\end{aligned}
$$

This temperature is just below freezing and significantly cooler than ambient conditions. Furthermore, since the molecular weight of propane (44.1) is greater than that of air (28.9), the puff of propane-air mixture will be initially denser than air.

The density of the cloud, $\rho$, is given by:

$$
\begin{aligned}
\rho & =\frac{\text { (propane mass }+ \text { air mass) }}{\text { (air volume }+ \text { propane vapor volume) }} \\
& =\frac{(9114+91140)}{\left(\frac{91140}{29}+\frac{9114}{41.1}\right) \times\left(\frac{8314 \times 269}{101325}\right)}=1.35 \mathrm{~kg} / \mathrm{m}^{3}\left(0.087 \mathrm{lb} / \mathrm{ft}^{3}\right)
\end{aligned}
$$

(neglecting any freezing of water vapor in the cloud).

The ambient air density at $305 \mathrm{~K}$ is $1.159 \mathrm{~kg} / \mathrm{m}^{3}$. Thus, the cloud of propane is initially heavier than air. The total volume of the cloud is given by:

$$
\frac{91140+9114}{1.35}=74538 \mathrm{~m}^{3}\left(2.6 \times 10^{6} \mathrm{ft}^{3}\right)
$$

The propane mass has no initial momentum because it was at rest immediately before rupture and mixing with air. The ambient air does have a velocity and imparts a momentum to the well-mixed cloud. As before, if the initial velocity of the air is $v$, the velocity of the resultant mixture is $v^{\prime}=v / 1.1$ (from the law of conservation of momentum).

In summary,

Mass of airborne propane Immediately mixed mass of air Volume

Mass of airborne droplets

Density
$9114 \mathrm{~kg}(20000) \mathrm{lb})$

$91140 \mathrm{~kg}(200000) \mathrm{lb})$

$74000 \mathrm{~m}^{3}\left(2.6 \times 10^{6} \mathrm{ft}^{3}\right)$

$5760 \mathrm{~kg}(12700 \mathrm{lb})$ (after mixing with $91140 \mathrm{~kg}\left(2.0 \times 10^{5} \mathrm{lb}\right)$ of air)

$1.345 \mathrm{~kg} / \mathrm{m}^{3}\left(0.087 \mathrm{lb} / \mathrm{ft}^{3}\right)$ 
Temperature

Velocity
$269 \mathrm{~K}\left(25^{\circ} \mathrm{F}\right)$

$\mathrm{v} / 1.1 \mathrm{~m} / \mathrm{s}$

\subsubsection{Consequence Analysis}

In Chapter 5, atmospheric dispersion and consequence models are discussed. In addition, the consequences of propane explosions are described. 


\subsection{References}

Alonso, A., R. Bolado, and M. Hontanon, "Aerosol Resuspension in the Reactor Cooling System of LWRs under Severe Accident Conditions," EUR 13789 EN, Directorate for Science and Development, Joint Research Centre - Ispra Site, 1981.

American Nuclear Society (ANSI), "American National Standard for Nuclear Criticality Safety in Operations with Fissionable Materials Outside Reactor," ANSI/ANS-8.1-1983, La Grange, Ilinois, 1983.

Ammerich, A., A. Briand, J.C. Laborde, P.H. Mulcay, and J. Savorin, "Contamination Releases from HEPA Filters Under High Temperature Conditions," Proceedings of the 20th DOE/NRC Air Cleaning Conference (M./W. First, Ed), NUREG/CP-0098 (CONF-880822), Harvard Air Cleaning Laboratory, Boston, Massachusetts, 1989.

Anon, "Report of Investigation of the Chemical Explosion of an Ion Exchange Resin Column and Resulting Americium Contamination of Personnel in the 2422-Z Building, August 30, 1976," U.S. Energy Research and Development Administration - Richland Operations Office, Richland, Washington, October 1976.

Ansphaugh, L.R., J.H. Shinn, P.L. Phelps, and N.C. Kennedy, "Resuspension and Redistribution of Pu in Soils" Health Physics, 29; pp. 571-582, 1975.

Ansphaugh, L.R., P.L. Phelps, N.C. Kennedy, J.H. Shinn, and J.M. Reichman, "Experimental Studies on the Resuspension of Plutonium From Aged Sources at the Nevada Test Site," Atmosphere-Surface Exchange of Particulate and Gaseous Pollutants - 1974 (R.J. Englemann and G.A. Sehmel, Ed), CONF740921, pp. 727-743, National Technical Information Services, Springfield, Virginia, 1976.

Apostolakis, G.E., "The Concept of Probability in Safety Assessments of Technological Systems," Science, Vol. 250, pp. 1459-64, 1990.

Argonne National Laboratory (ANL), Reactor Physics Constants, ANL-5800, ANL, Argonne, Illinois, July 1963.

Arnold, P.M. "Characterization of Spent HEPA Filters from Rocky Flats Plant," AO 6629, Rockwell International, Golden, Colorado, September 1986.

Baker, W.E., P.A. Cox, P.S. Westine, J.J. Kulesz, and R.A. Strehlow, Explosion Hazard and Evaluation, Elsevier Scientific Publishing Company, New York, New York, 1983.

Baker, L., Jr., J.G. Schnizlein, and J.D. Bingle, "The Ignition of Uranium," Journal of Nuclear Materials, 20; pp. 22-38, 1966.

Ballinger, M.Y., J.W. Buck, P.C. Owczarski, and J.E. Ayer, "Methods for Describing Airborne Release Fractions of Free-Fall Spills of Powders and Liquids," NUREG/CR-4997 (PNL-6300), Pacific Northwest Laboratory, Richland, Washington, 1986. 
Ballinger, M.Y., S.L. Sutter, and W.H. Hodgson, "New Data for Aerosols Generated by Releases of Pressurized Powders and Solutions," NUREG/CR-4779 (PNL 6065), Pacific Northwest Laboratory, Richland, Washington, 1987.

Barr, M.J., M.W. Urie, J.L. Daniel, and S.J. Mayhan, "Characterization of some $\mathrm{UO}_{2}$ and $\mathrm{PuO}_{2}$ Powders," BNWL-1441, Pacific Northwest Laboratory, Richland, Washington, 1970.

Benson, D.A., and Rader, D.J., "Aerosol Production by High-Velocity Molten-Metal Droplets," SAND880678, Sandia National Laboratory, Albuquerque, New Mexico, 1980.

Blewitt, D.N., J.F. Yohn, R.P. Koopman, and T.C. Brown, "Conduct of Anhydrous Hydrofluoric Acid Spill Experiments," in Proceedings of the International Conference on Vapor Cloud Modeling, Center for Chemical Process Safety of the American Institute of Chemical Engineers, New York, 1987.

Borkowski, R., H. Bunz, and W. Schoeck, "Resuspension of Fission Products during Severe Accidents in Light-Water Reactors," KfK 3987 (EUR 10391 EN), Kernsforchungszenrum Karlsruhe, Germany, 1986.

Braaten, D.A., R.H. Shaw, and P.T. Paw U., "Particle Detachment in Turbulent Boundary Layer," Proceedings of the Second International Aerosol Conference - West Berlin, 1986.

Brereton, S., D. Hesse, D. Kalinich, V. Mubyi, and J. Shinn, "Final Report of the Accident Phenomenology and Consequence Methodology Evaluation - Spills Working Group," UCRL-ID-125479, Lawrence Livermore National Laboratory, Livermore, California, 1997.

Brockman, J.E., "Range of Possible Resuspension of Fission Products During Containment Depressurization," Appendix D of "Uncertainty in Radionuclide Release Under Specific LWR Accident Conditions, Volume II - TMLbeta Analysis," SAND84-0410, Sandia National Laboratory, Albuquerque, New Mexico, 1985.

Browitt, D.S., et al., "User's Guide for the KBERT Code," SAND95-1324, Sandia National Laboratory, Albuquerque, New Mexico, 1995.

Brown, R. and J.L. York, "Sprays Formed by Flashing Liquid," A.I.Ch.E. Journal, 8, No. 2; pp. 149-153, 1962.

Carter, R.F. and K. Stewart, "On the Oxide Fume Formed by the Combustion of Plutonium and Uranium," Inhaled Particles III (Proceedings of an International Symposium, British Occupational Hygiene Society, London, Sept. 14-23, 1970, Unwin Brothers Limited - The Gresham Press, Old Woking, Surrey, England, 1970.

Chan, M.K., M.Y. Ballinger, and P.C. Owczarski, "User's Manual for FIRIN," NUREG/CR-3037 (PNL4532), Pacific Northwest Laboratory, Richland, Washington, 1989.

Chatfield, E.J., "Some Studies on the Aerosol Produced by the Combustion or Vaporization of PlutoniumAlkali Mixtures," Journal of Nuclear Materials, 32; pp. 228-246, 1969.

Chatfield, E.J., "The Generation of Particulate Aerosol From Plutonium Surfaces," Atmospheric Environment, 2; pp. 97-101, 1968. 
Christensen, D., and Kaiser, G.D., "Contingency Analysis Modeling for Superfund Sites and Other Sources, “ prepared for U.S. Environmental Protection Agency, February, 1993.

Clayton, E.D., “Anomalies of Nuclear Criticality,” PNL-SA-4868, Rev. 5, Pacific Northwest Laboratory, Richland, Washington, 1979.

Corn, M. and F. Stein, "Re-Entrainment of Particles from a Plane Surface," American Industrial Hygiene Association J., 26, No. 1; pp. 325-336, 1965.

Cull, T.A., T.G. George, and D. Pavone, "General-Purpose Heat Source Development: Safety Verification Test Program, Explosion Overpressure Test Series," LA-10697-MD, Los Alamos National Laboratory, Los Alamos, New Mexico, 1986a.

Cull, T.A. and D. Pavone, "General-Purpose Heat Source Development Program: Safety Verification Test Program, Flyer-Plate Test-Series," LA-10742, Los Alamos National Laboratory, Los Alamos, New Mexico, 1986.

Cull, T.A., "General-Purpose Heat Source Development: Extended Series Test Program, Large Fragment Tests," LA-115907, Los Alamos National Laboratory, Los Alamos, New Mexico, 1989a.

Cull, T.A., "General-Purpose Heat Source Development: Extended Series Test Program, SRB Fragment Fuselage Tests," LA-11574, Los Alamos National Laboratory, Los Alamos, New Mexico, 1989b.

Davies, C.N., Aerosol Sciences, Academic Press, New York, New York, 1996.

Davies, J.T. and E.K. Rideal, Interfacial Phenomena, 2nd Edition, Academic Press, New York, New York, 1963.

Dean, J.A., Lange's Handbook of Chemistry, Fourteenth Edition, McGraw-Hill, Inc., New York, New York, 1992.

Dennis, R., Handbook on Aerosols, TID-26608, U.S. Energy Research and Development Agency - Office of Public Affairs, Washington, D.C., 1976.

DeVaull, G. E., J.A. King, R.J. Lantzy, and D.J. Fontaine,"An Atmospheric Dispersion Primer: Accidental Releases of Gases, Vapors, Liquids, and Aerosols to the Environment", in the Proceedings of the International Conference and Workshop on Modeling and Mitigating the Consequences of Accidental Releases of Hazardous Materials, New Orleans, Louisiana, September, 1995.

DiNenno, P.J., C.L. Beyler, R.L.P. Custer, W.D. Walton, J.M. Watts, Jr., D. Drysdale, and J.R. Hall, Jr., SFPE Handbook of Fire Protection Engineering, Society of Fire Protection Engineers, Boston, Massachusetts, 1995.

Dow Chemical Exposure Index, 1993.

Drysdale, D., An Introduction to Fire Dynamics, John Wiley and Sons, New York, New York, 1985. 
Eidson, A.F. and G.M. Kanapily, "Plutonium Aerosolization Studies: Phase I Final Report," Lovelace Laboratory, Albuquerque, New Mexico, 1983.

Eidson, A.F., H.C. Yeh, and G.M. Kanapily, "Plutonium Aerosol Generation in Reducing and Oxidizing Atmospheres," Journal of Nuclear Materials, 152; pp. 41-55, 1988.

Einfield W., C.M. Craft, and D.J. Morrison, "Estimates of Uranium Aerosol Release from Detonation of an Explosive Device - Lawrence Livermore National Laboratory Hydrotest 6904, Vol 1. Sampling and Analysis Results, SAND94-1658/1, Sandia National Laboratories, Albuquerque, New Mexico, 1994.

Elder, J.C. and M.C. Tinkle, "Oxidation of Depleted Uranium Penetrators and Aerosol Dispersal at High Temperatures," LA-8610-MS, Los Alamos National Laboratory, Los Alamos, New Mexico, 1980.

Elder, J.C., J.M. Graf, J.M. Dewart, T.E. Buhl, W.J. Wenzel, L.J. Walker, and A.K. Stoker, “A Guide to Radiological Accident Considerations for Siting and Design of DOE Nonreactor Nuclear Facilities," LA10294-MS, Los Alamos National Laboratory, Los Alamos, New Mexico, 1986.

Fish, B.R, R.L. Walker, G.W. Royster, and J.I. Thompson, "Redistribution of Settled Particles," Proceedings of the Surface Contamination Symposium (B.R. Fish, Ed.), pp 75-81, Pergamon Press, New York, New York, 1967.

Frolov, V.V., B.S. Ryazanov, and V.I. Sviridov, "A Review of Criticality Accidents Which Occurred in the Russian Industry," in Proceedings of the Fifth International Conference on Nuclear Criticality Safety, Los Alamos National Laboratory, Los Alamos, NM, September 1995.

Fromentin, A., "Particle Resuspension from a Multi-Layer Deposit by Turbulent Flow," PSI-Bericht NR. 38, Paul Sherer Institut, Wuerlingen, Switzerland, 1989.

Fuchs, N.A. (Translation edited by C.N. Davies), The Mechanics of Aerosols, The MacMillan Company, New York, New York, 1964.

Garland, J.A., "Some Recent Studies of the Resuspension of Deposited Material from Soil and Grasses," Proceedings of the Fourth International Conference on Precipitation Scavenging, Deposition, and Resuspension, St. Monica, California, 1982.

George, T.G., "General-Purpose Heat Source Development Test: Safety Verification Test Program, Titanium Bullet/Fragment Test Series," LA-10724, Los Alamos National Laboratory, Los Alamos, New Mexico, 1986.

George, T.G. and D. Pavone, "General-Purpose Heat Source Safety Verification Test Series: SVT-11 through SVT-13," LA-10710-MS, Los Alamos National Laboratory, Los Alamos, New Mexico, 1986.

George, T.G., "Space Nuclear Safety Program, October - December 1987," LA-11756-PR, Los Alamos National Laboratory, Los Alamos, New Mexico, 1987a.

George, T.G., "General-Purpose Heat Source Safety Verification Test Program: Edge-on Flyer Plate Tests," LA-10872-MS, Los Alamos National Laboratory, Los Alamos, New Mexico, 1987b. 
George, T.G. and F.W. Schonfeld, "General-Purpose Heat Source Development: Safety Test Program, Post-impact Evaluation, Design Test Iteration Test 4," LA-10217-SR, Los Alamos National Laboratory, Los Alamos, New Mexico, 1984a.

George, T.G. and F.W. Schonfeld, "General-Purpose Heat Source Development: Safety Test Program, Post-impact Evaluation, Design Iteration Test 5," LA-10232-SR, Los Alamos National Laboratory, Los Alamos, New Mexico, 1984b.

George, T.G. and D. Pavone, "General-Purpose Heat Source Safety Verification Tests Series: SVT-7 through SVT-10," LA-10408, Los Alamos National Laboratory, Los Alamos, New Mexico, 1985.

Gerrard, J.H., "An Experimental Investigation of the Initial Stages of the Dispersion of Dust by Shock Waves," British J. of Applied Physics, 14; pp. 186-192, 1963.

Gido, R.G. and A. Koestel, "LOCA-Generated Drop Size Distribution - A Thermal Fragmentation Model," Transactions of ANS, 30 pp 371-372, 1978.

Gilchrist, R.I, G.B. Parker, and J. Mishima, "Radiological and Toxicological Assessment of an External Heat (Burn) Test of the 105-mm Cartridge, APFSDS, XM-774," PNL-2881, Pacific Northwest Laboratory, Richland, Washington, 1978.

Glissmeyer, J.A. and J. Mishima, "Characterization of Airborne Uranium from Test Firing of XM774 Ammunition,” PNL-2944, Pacific Northwest Laboratory, Richland, Washington, 1979.

Goldwire, Jr., H.C., T.G. McRae, G.W. Johnson, D.L. Hipple, R.P. Koopman, J.W. McLure, L.K. Morris, and R.T. Cederwall, "Desert Tortoise Series Data Report - 1983 Pressurized Ammonia Spills," UCID20562, Lawrence Livermore National Laboratories, Livermore, California, 1985.

Grady D.E. and T.G. Turcano, "Entry Shock and Penetration Fragmentation in Underdense Media," SAND93-2620, Sandia National Laboratories, Albuquerque, New Mexico, 1994.

Greenhalgh, W.O., J.A. Demiter, and W.W. Olson, "Exposure of Drummed Solid Waste to Fires," WHCSD-WM-DTR-032, Rev 0, Westinghouse Hanford Co., Richland, Washington, 1974.

Gregory, W.S., R.A. Martin, P.R. Smith and D.E. Fenton, "Response of HEPA Filter to Simulated Accident Conditions," Proceedings of the 17th DOE Nuclear Air Cleaning Conference (M.W. First, Ed), CONF-820833, Harvard Air Cleaning Laboratory, Boston, Massachusetts, 1983.

Gregory, W.S. and B.D. Nichols, "EXPAC User's Manual: A Computer Code to Simulate Explosive Accidents in Nuclear Facilities," Los Alamos National Laboratory, Los Alamos, New Mexico, 1991.

Griffith, R.O., D. Carlson, N. Grandjean, R. Luna, K. Murata, J. Sprung, E. Tadios and M. Young, "Preliminary Assessment of the Radiological Consequences of an Accident Involving High Explosives and Plutonium in a PANTEX Assembly Cell," SAND97-3112, Sandia National Laboratory, Albuquerque, New Mexico, 1997. 
Hackney, S., "Fire Testing of HEPA Filters Installed in Filter Housings," Proceedings of the 17th DOE Nuclear Air Cleaning Conference (M.W. First, Ed), CONF-820833, Harvard Air Cleaning Laboratory, Boston, Massachusetts, 1983.

Haecker, C.F., B.T. Rhoads, J.J Beitel, D.T Gottuck, C.L. Beyler, and E.R. Rosenbaum, "Analytical and Experimental Evaluation of Solid Waste Drum Fire Experiments," (Volumes 1, 2, 3 and 4), Hughes Associates, Inc., Columbia, Maryland, 1995.

Haggard, D.L., W.M. Herrington, C.D. Hooker, J. Mishima, M.A. Parkhurst, R.I Scherpelz, L.A. Sigalla, and D.E. Hadlock, "Hazard Classification Test of the 120-mm, APFSDS-T, M829 Cartridge: Metal Shipping Container," PNL-5928, Pacific Northwest Laboratory, Richland, Washington, 1986.

Hall, D.J, V. Kukadia, S. Walker, and G.W. Marsland, "Plume Dispersion From Chemical Warehouse Fires," Building Research Establishment Client Report CR 56/95, Building Research Establishment, Watford, UK, September, 1995.

Halverson, M.A. and J. Mishima, "Initial Concepts on Energetics and Mass Releases during Explosive Events," NUREG/CR-4593, Pacific Northwest Laboratory, Richland, Washington, 1986.

Halverson, M.A., M.Y. Ballinger, and G.W. Dennis, "Combustion Aerosols Formed During the Burning of Radioactively Contaminated Materials - Experimental Results," NUREG/CR-4736 (PNL-5999), Pacific Northwest Laboratory, Richland, Washington, 1987.

Haschke, J.M., "Evaluation of Source-Term Data for Plutonium Oxidation," LA-12315-MS, Los Alamos National Laboratory, Los Alamos, New Mexico, 1992.

Hasegawa, H.K., K.J Staggs, and S.M. Doughty, "Fire Testing of 55 Gallon Metal Drums for Dry Storage," URCL-CR-116037, Lawrence Livermore National Laboratory, Livermore, California, 1993.

Hidy, G.M., Aerosols - An Industrial and Environmental Science, Academic Press, New York, New York, 1984.

Hinds, W.C., Aerosol Technology, Wiley-Interscience Publications, New York, New York, 1982.

Homann, S.G., "HOTSPOT - Health Physics Codes for the PC," UCRL-MA-106315, Lawrence Livermore National Laboratory, Livermore, California, 1994.

Hooker, C.D., D.E. Hadlock, J. Mishima, and G.L. Gilchrist, "Hazard Classification Test of the Cartridge, 120-mm, APFSDS-T, XM829," PNL-4459, Pacific Northwest Laboratory, Richland, Washington, 1994.

Ianello, V., P.H. Rothe, G.B. Wallis, R. Diener, and S. Schreiber, "Aerosol Research Program: Improved Source Term Definition for Modeling the Ambient Impact of Accidental Release of Hazardous Liquids," in the Proceedings of the 6th International Symposium on Loss Prevention and Safety Promotion in the Process Industries, June 1989, Oslo, Norway, 1989.

Jardine, L.J., W.J. Mecham, G.T. Reedy, and M.J. Steindler, "Final Report of Experimental LaboratoryScale Brittle Fracture Studies of Glass and Ceramics," ANL-8239, Argonne National Laboratory, Argonne, Illinois, 60439, 1982. 
Jette, S.J., J.A. Glissmeyer, J. Mishima, D.J. Sherwood, and R.E. Williford, "Potential Aerosolization (Airborne Suspension) of Depleted Uranium during Test Firing," PNL-7137, Pacific Northwest Laboratory, Richland, Washington, 1989.

Johnson, D.W., "Prediction of Aerosol Formation from the Release of Pressurized, Superheated Liquids to the Atmosphere," in the Proceedings of the International Conference and Workshop on Modeling and Mitigating the Consequences of Accidental Releases of Hazardous Materials, New Orleans, April, 1991: Center for Chemical Process Safety of the American Institute of Chemical Engineers, New York, 1991.

Jordan, S., and Lindner, W., "Aerosol Released from Solvent Fire Accident in Reprocessing Plants," Proceedings of the CSNI Specialists Meeting in Nuclear Aerosols in Reactor Safety, (W.O. Schikarski and W. Schoeck, Ed.), KfK 3800 (CSNI Report No. 95), Kernforschungszentrum Karlsruhe, Germany, 1985.

Kaiser, G.D., and Chhibber, S., "SAIC's Computer Programs for Modeling the Atmospheric Dispersion of Hazardous Vapors - Model Description and User's Guide," prepared for USNRC, 1993.

Kataoki, I. and M. Ishii, "Mechanism Modeling for Correlation for Pool Entrainment Phenomenon," NUREG/CR-3304 (ANL-83-37), Argonne National Laboratory, Argonne, nlinois, 1983.

Kipp M.E., D.E. Grady, and J.W. Swegele, "Experimental and Numerical Studies of High-Velocity Impact Fragmentation," SAND93-0773, Sandia National Laboratories, Albuquerque, New Mexico, 1993.

LaMarsh, J.R. Introduction to Nuclear Engineering, Addison-Wesley Publishing Company, Reading, Massachusetts, 1983.

Langer, G., "Simulated Seismic Event Release Fraction Data, Progress Report April 1986 - April 1998," RFP-4161, Rockwell International, Rocky Flats Plant, Golden, Colorado, 1987.

Long, K.S., J.B. Mason, and B.P. Durst, "Results of Fort Carson, Colorado, Terrain Dust Obscuration Test Using Explosives: Soil, Cratering, and Dust Control Properties," Miscellaneous Paper EL-84-6, U.S. Army Corps of Engineers - Waterway Experiment Station, Vicksburg, Michigan, 1984.

Lorenz, R.A., J.L. Collins, A.P. Malinuaskas, O.L. Kirkland, and R.L. Town, "Fission Product Release from Highly Irradiated LWR Fuel," NUREG/CR-0722, Oak Ridge National Laboratory, Oak Ridge, Tennessee, 1980.

Lorenz, R.A., "Fission Product Release from Highly Irradiated LWR Fuel," NUREG/CR-6722, Oak Ridge National Laboratory, Oak Ridge, Tennessee, 1988.

Luna, R.E., "A New Analysis of the VIXEN A Trials," SAND93-2528, Sandia National Laboratory, Albuquerque, New Mexico, 1994.

Malet, J.C., C. Duverger de Cuy, R. Gasteiger, and J. Janburg, "Solvent Pool Fires Testing," Proceedings of the CSNI Specialists Meeting on Interaction of Fire and explosion with Ventilation Systems in Nuclear Facilities, LA-9911-C (CSNI Report No. 83), Los Alamos National Laboratory, Los Alamos, New Mexico, 1983. 
McLaughlin, T.P., "Process Criticality Accident Likelihood, Consequences, and Emergency Planning," LA-UR-91-2325, Los Alamos National Laboratory, Los Alamos, New Mexico, 1991.

Mensing, R.W., T.R. Bement, and R.E. Luna (Compilers), "Characterization of Plutonium Aerosols for Various Accident Scenarios by an Expert Panel," LA-CP-95-55, Los Alamos National Laboratory, Los Alamos, New Mexico, 1995.

Miles, F.W., "Ion-exchange Resin System Failures in Processing Actinides," Nuclear Safety, 9:No. 5, pp 394-406, 1968.

Mishima, J., "Plutonium Release Studies II: Release from Ignited, Bulk Metallic Pieces," BNWL-357, Pacific Northwest Laboratory, Richland, Washington, 1965.

Mishima, J., "Plutonium Release Studies I: Release from Ignited Metal," BNWL-205, Pacific Northwest Laboratory, Richland, Washington, 1966.

Mishima, J., L.C. Schwendiman, and C.A. Radasch, "Plutonium Release Studies III. Release from Heated Plutonium Bearing Powders," BNWL-786, Pacific Northwest Laboratory, Richland, Washington, 1968a.

Mishima, J., L.C. Schwendiman, and C.A. Radasch, "Plutonium Release Studies IV: Fractional Release from Heating Plutonium Nitrate Solution in Flowing Air," BNWL-931, Pacific Northwest Laboratory, Richland, Washington, 1968b.

Mishima, J. and L.C. Schwendiman, "The Amount and Characteristics of Plutonium Made Airborne under Thermal Stress," BNWL-SA-3379, Pacific Northwest Laboratory, Richland, Washington, 1970.

Mishima, J and L.C. Schwendiman, "Interim Report: The Fractional Airborne Release of Dissolved Radioactive Materials during the Burning of 30 Percent Normal Tributyl Phosphate in a Kerosine-Type Diluent," BNWL-B-274, Pacific Northwest Laboratory, Richland, Washington, 1973a.

Mishima, J. and L.C. Schwendiman, "Fractional Airborne Release of Uranium (Representing Plutonium) in Transportation Accidents," BNWL-1732, Pacific Northwest Laboratory, Richland, Washington, $1973 \mathrm{~b}$.

Mishima, J. and L.C. Schwendiman, "Fractional Airborne Release of Uranium (Representing Plutonium) during Burning of Contaminated, Combustible Wastes," BNWL-1730, Pacific Northwest Laboratory, Richland, Washington, 1973c.

Mishima, J. and L.C. Schwendiman, "Some Experimental Measurements of Airborne Uranium (Representing Plutonium) in Transportation Accidents," BNWL-1732, Pacific Northwest Laboratory, Richland, Washington, 1973d.

Mishima, J., M.A. Parkhurst, R.I. Scherpelz, and D.E. Hadlock, "Potential Behavior of Depleted Uranium Penetrators under Shipping and Bulk Storage Accident Conditions," PNL-5415, Pacific Northwest Laboratory, Richland, Washington, 1985.

Mishima, J., "LANL TA-55 'Particles Generated by Impact of Bare Fuel Pellets," Letter Report to Robert Jackson, SAIC, Golden, Richland, Washington, 1995. 
Muralidhar, R., G.R. Jersey, F.J. Krambeck, and S. Sundaresan, "A Two-Phase Model for Subcooled and Superheated Liquid Jets" published in the International Conference and Workshop on Modeling and Mitigating the Consequences of Accidental Releases of Hazardous Materials, New Orleans, Louisiana, Center for Chemical Process Safety of the American Institute of Chemical Engineers, September, 1995.

Nichols, B.D. and W.S. Gregory, "FIRAC User's Manual: A Computer Code to Simulate Fire Accidents in Nuclear Facilities," NUREG/CR-4561, Los Alamos National Laboratory, Los Alamos, New Mexico, 1986.

Nuclear Energy Agency (NEA), "Nuclear Aerosols in Reactor Safety," Organization for Economic CoOperation and Development, Paris, France, 1979.

Nyer, N.E., G.O. Bright, and R.J. McWhorter, "Reactor Excursion Behavior," Proceedings of the Third International Conference on the Peaceful Uses of Atomic Energy, Vol. 13, Nuclear Safety, United Nations, New York, New York, 1979.

Oak Ridge National Laboratory (ORNL). "ORIGEN2 Isotope Generation and Depletion Code," CCC371, ORNL, Oak Ridge, Tennessee, April 1989.

Olsen, A.R., G.O. Bright, V.O. Uotinen, C.L Brown et al., "Empirical Method for Estimating the Total Number of Fissions from Accidental Criticality in Uranium and Plutonium Systems," BNWL-1840, Pacific Northwest Laboratory, Richland, Washington, 1974.

Owczarski, P. C., K. W. Burk, J. V. Ramsdell, and D. D. Yasuda, "FPFP_2: A Code for Following Airborne Fission Products in Generic Nuclear Power Plant Flow Paths," NUREG/CR-5658, 1991.

Parkhurst, M.A. J. Mishima, D.E. Hadlock, and S.J. Jette, "Hazard Classification and Airborne Dispersion Characteristics of the 25-mm, APFSDS-T XM919 Cartridge," PNL-7232, Pacific Northwest Laboratory, Richland, Washington, 1990.

Pavone, D., T.G. George, and C.E. Franz, "General-Purpose Heat Source Safety Verification Test Series: SVT-1 through SVT-6," LA-10333, Los Alamos National Laboratory, Los Alamos, New Mexico, 1985.

Pavone, D., "GPHS Safety Test, Particle Size Data Package," LACP-86-62, Los Alamos National Laboratory, Los Alamos, New Mexico, 1986.

Paxton, H.C., "Historical Perspective on Criticality Safety in the United States," Proceedings of ANS Topical Meeting Nuclear Criticality Safety, SAND80-1675, Sandia National Laboratory, Albuquerque, New Mexico, 1980.

Plinke, M.E.A., D. Leith, D.B. Holstein, and M.G. Boundy, "Experimental Examinations of Factors That Affect Dust Generation," American Industrial Hygiene Association J., 52:No. 12, pp. 521-528, 1991.

Raabe, O.G., S.V. Teague, N.L. Richardson, and L.S. Nelson, "Aerodynamic and Dissolution Behavior of Fume Aerosol Produced During the Combustion of Laser-Ignited Plutonium Droplets in Air," Health Physics, 35: pp. 663-674, 1978.

Reist, P.C., Aerosol Science and Technology, McGraw-Hill, Inc., New York, New York, 1993. 
Resplandy, A., "Etude Experimentale des Proprietes de l'Ammoniac," Chim. Ind. Gen. Chim. 102, 691 et seq., 1969.

Restrepo, L.F., "The Annular Core Research Reactor (ACRR) Limiting Event for Workers and Public Consequences," SAND91-0572, Sandia National Laboratory, Albuquerque, New Mexico, 1992.

Restrepo, L.F., D.J. Hesse, D. Kalinich, V.F. Nicolette, W.S. Gregory, and R.S. O'Neill, "Draft Report of the Accident Phenomenology and Consequence (APAC) Methodology Evaluation - Fire Working Group," Sandia National Laboratory, Albuquerque, New Mexico, 1996.

RFRAG, Rocky Flats Risk Assessment Guide, North American Space Operations, Rocky Flats Plant, Golden, Colorado, 1985.

Ricketts, "Mass Fraction of Respirable and Dispersible Particles as a Function of Processing History and Thermal Treatment," letter to Jerry Stakebake dated October 19, 1995, Los Alamos National Laboratory, Los Alamos, New Mexico, 1995.

Roblyer, S.P. and P.C. Owczarski, "Determining Windspeed Spray Release from Effluent Disposal Ponds Using AIRSOURCE Model," paper presented at HAZMACON '92, March 30-April 2, 1992, Long Beach, California, 1992.

Royster, G.W. and B.R. Fish, "Techniques for Assessing 'Removable' Surface Contamination," Surface Contamination (B.R. Fish, Ed), pp. 201-207, Pergamon Press, New York, New York, 1967.

Ruhmann, H., A. Bleier, G. Kaspar, G. Hofmann, H. Loescher, and M. Peehs, Mark, "Untersuchsprogramm Zum Verhalten abgegrannter Brennelemente bei starken mechanischen einwirkungen (Research Program into the Behaviour of Burnt-Up Fuel Assemblies Under Strong Mechanical Impacts)," BMFT KWA 5215/7, Kraft Werke Union, Germany, 1985a.

Ruhmann, H., et al., "Research Program about Behavior of Spent Fuel Rods due to Strong Mechanical Loads," Kraft Werk Union Report BMFT KWA 5215/7, 1985 b.

Ruhmann, H., A. Bleier, G. Kaspar, G. Hofman, H. Loescher, and M. Peehs, "Forschungsprogamm Entsorgung, Untersuchungsprogramm zum Verhalten abgebrannter Brennelsmente bei starken mechanisn Einvirkungen" (in German), KWU Report BMFI KWA 5215/7, Kraft Werke Union AG, Germany, 1985c.

Sanders, T., et al., "A Method for Determining the Spent-Fuel Contribution to Transport Cask Containment Requirement," SAND 90-2406, Sandia National Laboratory, Albuquerque, New Mexico, 1992.

Schonfeld, F.W. and T.G. George, "General-Purpose Heat Source Development: Safety Test Program, Post-Impact Evaluation, Design Iteration Test 2," LA-10034-SR, Los Alamos National Laboratory, Los Alamos, New Mexico, 1984a.

Schonfeld, F.W. and T.G. George, "General-Purpose Heat Source Development: Safety Test Program, Post-Impact Evaluation, Design Iteration Test 3," LA-10034-SR, Los Alamos National Laboratory, Los Alamos, New Mexico, 1984b. 
Sehmel, G.A., "Particle Resuspension from an Asphalt Road caused By Car and Truck Traffic," Atmospheric Environment, 7:pp. 291-301, 1973.

Sehmel, G.A. and F.D. Lloyd, "Particle Resuspension Rates," Atmosphere-Surface Exchange of Particulate and Gaseous Pollutants (R.D. Englemann and G.A. Sehmel, Ed), ERDA Symp. Series \#38, Technical Information Center, Energy Research and Development Administration (now U.S. Department of Energy), Washington, D.C., 1976.

Sehmel, G.A., "Particle Resuspension Rates: A Review," Environment International, 4:pp 107-127, 1980.

Shreve, J.D., Jr., D.M.C. Thomas, R.H. Wilson, J.P. Friend, J.K. Perry, H.E. Menker and H.W. Church, "Operation Roller Coaster - A Joint Field Operation of the Department of Defense, the Atomic Energy Commission, and the United Kingdom Atomic Energy Authority (AWRE)," DASA-1644, Department of Defense, Washington, D.C., 1965.

Soffer, L., "Revision of Reactor Accident Source Terms and Implications for Nuclear Air Cleaning Requirement," Proceedings of the 22nd DOE/NRC Nuclear Air Cleaning Conference (M.W. First, Ed), NUREG-CP-0130 (CONF-9020823), Harvard Air Cleaning Laboratory, Boston, Massachusetts, 1993.

Spore, J.W., B.E. Boyak, W.R. Bohl, R. Gasser, K. Hamm, and J. Saunders, "In-Facility Transport Review," LA-UR-96-2952, Los Alamos National Laboratory, Los Alamos, New Mexico, 1996.

Stakebake, J.L., “Plutonium Pyrophoricity,” RFP-4517, EG\&G, Rocky Flats, Inc., Golden, Colorado, 1992.

Stephens, D.R., "Source Term for Plutonium Aerosolization from Nuclear Weapon Accident," UCRL-ID119303, Lawrence Livermore National Laboratory, Livermore, California, 1995.

Stewart, K., "The Particulate Material Formed by the Oxidation of Plutonium," Progress in Nuclear Energy Series IV, Vol. 5, pp 535-579, 1963.

Stewart, K., "The Resuspension of Particulate from Surface," Proceedings of the Surface Contamination Symposium (B.R. Fish, Ed.), pp 64-74, Pergamon Press, New York, New York, 1967.

Strange, J.N. and A.D Rooke, Jr., "Battlefield Dust from Exploding Munitions: Contribution by Cratering from Artillery and Mortar Projectiles," Technical Report EL-88-16, Science and Technology Company, Hampton, Virginia, 1988.

Stratton, W.F., "A Review of Criticality Accidents," LA-3611, Los Alamos National Laboratory, Los Alamos, New Mexico, 1967.

Steindler, M.J. and W.H. Seefeldt, "A Method for Estimating the Challenge to Air Cleaning Systems," Proceedings of the 16th DOE Air Cleaning Conference (M.W. First, Ed), CONF-801038, Harvard Air Cleaning Laboratory, Boston, Massachusetts, 1980.

Sutter, S.L., "Potential Airborne Release from Soil-Working Operations in a Contaminated Area," PNL3498, Pacific Northwest Laboratory, Richland, Washington, 1980. 
Sutter, S.L., J.W. Johnston, and J. Mishima, "Aerosol Generated by Free Fall Spills of Powder and Solutions in Static Air," NUREG/CR-2139 (PNL-3786), Pacific Northwest Laboratory, Richland, Washington, 1981a.

Sutter, S.L, J.W. Johnston, and J. Mishima, "Aerosols Generated by Free-Fall Spill of Powder and Liquid," NUREG/CR-2139 (PNL-3786), Pacific Northwest Laboratory, Richland, Washington, $1981 b$.

Sutter, S.L., "Aerosols Generated by Releases of Pressurized Powders and Solutions in Static Air," NUREG/CR-3093 (PNL-4566), Pacific Northwest Laboratory, Richland, Washington, 1983.

Thomas, J.T., Ed., "Nuclear Safety Guide, TID-7016, Rev. 2," NUREG/CR-0095, Oak Ridge National Laboratory, Oak Ridge, Tennessee, 1978.

U.S. Department of Energy (USDOE), "DOE STANDARD - Hazard Categorization and Accident Analysis Techniques for Compliance with DOE Order 5480.23, Nuclear Safety Analysis Reports," DOESTD-1027-92, U.S. Department of Energy, Washington, D.C., 20585, 1992.

U.S. Department of Energy (USDOE), "DOE HANDBOOK - Airborne Release Fractions/Rates and Respirable Fractions for Nonreactor Nuclear Facilities," DOE-HDBK-3010-94, Washington, D.C., 1994.

Walker, E., "A Summary of Parameters Affecting the Release and Transport of Radioactive Material from Unplanned Incidents," Bechtel, Inc., San Francisco, California, 1978.

Westinghouse Hanford Company (WHC), "Preliminary Safety Analysis Report for Hanford Waste Vitrification Plant," (DRAFT), WHC-SD-HWV-PSAR-001, Richland, Washington, 1993.

Woodward, J. L., "Aerosol Drop Size Correlation and Corrected Rainout Data Using Models of Drop Evaporation, Pool Absorption and Pool Evaporation," in the Proceedings of the International Conference and Workshop on Modeling and Mitigating the Consequences of Accidental Releases of Hazardous Materials, New Orleans, Louisiana, September, 1995.

Wright, A.L. and W.L. Pattison, "Results from Simulated Upper-Plenum Aerosol Transport and Aerosol Resuspension," Proceedings of CNSI Specialist Meeting on Nuclear Aerosols in Reactor Safety, Karlsruhe, Germany, 1984. 


\section{CHAPTER 4 TRANSPORT WITHIN CONTAINMENT/CONFINEMENT}

\subsection{Introduction/Background}

This chapter describes in-facility transport and deposition of gases, heavy gases, vapors, and particles, together with controlling parameters, basic aerosol physics, and airborne chemical reactions. The chapter emphasizes airborne particles, because such aerosols seem to predominate in accidents that might occur in fuel cycle facilities. The quantitative value that expresses the fraction of initially airborne material that successfully escapes the facility is called the Leak Path factor (LPF). For particles, the LPF primarily depends on three parameters: the flow rate of the aerosol through the facility, the particle sizes, and the areas available for deposition of contaminants.

The objective of this chapter is to provide the tools necessary for defining the fraction of accidentgenerated airborne material that escapes the facility and, if desired, the concentrations of airborne material throughout the facility as well as the amount of initially airborne material that has deposited within the facility.

This chapter continues the accident analysis process whereby the source term provided in Chapter 3 is carried through and out of the facility. The primary final output is the fraction (for particles, the respirable fraction (RF)) of the source term that escapes the facility, the LPF. Secondary outputs are the concentrations and amounts deposited in the facility of the initial source term. To obtain these outputs, Chapter 4 provides guidance to help the user: (1) identify the facility barriers that define the flow path of the airborne material in the facility; (2) quantify the driving forces moving material along the flow path; (3) quantify the flow rates along the path; (4) quantify the effects of any mitigating engineered safeguards (e.g., filters); (5) quantify the roles of deposition processes along the flow path; and (6) estimate facility concentrations during the movement of the airborne source term.

The analytical process discussed in this chapter employs already developed models or codes and existing data rather than developing new models or codes or obtaining new experimental data. A principal aim of this chapter is to organize available methods and data in a user-friendly manner. Codes and models are used to generate calculated "data" that are useful as tables and graphs for accident analyses. One simple code (LPF \#1) for calculating LPFs, accompanies this chapter.

Chapter 4 calculations will introduce some uncertainties in the source terms and will reflect uncertainties in the amount of material at risk (MAR) and damage ratios (DRs), and in the values of airborne release fraction (ARF) and RF obtained in Chapter 3. Since the LPF depends strongly on particle sizes (RF), the range of possible RFs for a given source term will define much of the quantifiable uncertainty in the LPF. Other uncertainties could be found in calculating post-accident flow rates through the facility, the availability of surfaces for deposition, and the degrees of mixing of contaminated gases in the facility.

The biggest uncertainty is probably introduced by assuming that the experimentally determined RFs and ARFs for very specific powders apply universally. It is impossible to quantify the pertinent differences in powders for each application of this handbook. For aerosols, although not for chemical vapors, these uncertainties coupled to the statistical uncertainties of the data probably overwhelm all other uncertainties in the calculations of this handbook. 


\subsection{Definition of Facility Barriers}

Section 4.2 focuses on defining the flow path for the airborne source term from the source to the facility boundary. The flow path definition is important because mitigative processes that remove some of the airborne material can occur along the flow path. These mitigative processes impact the LPF and cause it to be less than 1.0. Under normal operations, the process off-gas or the heating, ventilating, and air conditioning (HVAC) filters can reduce LPFs to a very small fraction of 1.0.

\subsubsection{Importance of Walls/Corridors/ Ventilation Systems}

The building structure is the primary containment for Design Basis Accidents (DBAs). It is of paramount importance that the flow path of airborne material be carefully specified for the transport calculations. Each wall, floor, and ceiling along the flow path is a possible deposition surface for particles and vapors. In many DBAs, the building exhaust system is the end part of the flow path and it plays a major role in the calculations.

The best way to begin the process of estimating the effects of the structure is as follows:

- If the MARxDRxRF is already small, temporarily skip this chapter, assign an LPF $=1$, and see if the dose is acceptably small. See Chapter 3 for definitions of the MAR, DR, and RF.

- If filters are intact and the ventilation systems are functioning, apply the LPF of the filter and repeat the dose calculation, and see if the dose is acceptably small. (Be sure the accident event does not cause flow through an unfiltered path.) If not, proceed with the rest of the steps.

- If the power fails and the ventilation systems become passive, then the flow path might involve other driving forces to move aerosols and gases. Accident-generated gases and heat (fires and explosions) and external wind pressures might become the principal movers of the airborne material. Here also the flows through leaky door cracks, penetration failures, and accidentgenerated structure failures (earthquakes) become important. Thus one must, at this point, identify the driving forces and the flow paths of the airborne materials.

\subsubsection{Engineered Mitigative Systems}

The facility structure and the operating ventilation systems are the principal engineered mitigative systems. Within the ventilation systems are fans and filters (see Appendix F for more on filters). In some facilities, the ventilation systems include sprays and special adsorbers/absorbers. Sprays are more frequently found in nuclear reactor systems. Adsorbers/absorbers are used when molecular iodine and organic iodides could be present. Refer to design criteria and vendor literature for characteristics of these mitigative systems.

\subsubsection{Survivability of Barriers and Mitigative Systems}

Accidents such as fires, explosions, and earthquakes can damage the facility and engineered safety systems. If accident scenarios require walls to fall, burn, or crack, or filters or spray systems to fail, estimate the impact of these configurations on flow path definition. 


\subsection{Definition of Leak Path Factors}

The LPF is the fraction of airborne material that exits the facility while remaining airborne. The LPF is normally a function of time as the accident proceeds, but in many cases only an overall LPF is needed (time independent). Detailed mathematical expressions for LPFs are given below. For particles these expressions are for the RF only.

\subsubsection{Time-Dependent LPF (TdLPF)}

Calculating the TdLPF can be involved. Calculation of TdLPF might be needed for time dependent dispersion/dose calculations (Chapter 5). The TdLPF is also related to interior facility concentrations.

The most useful TdLPF is a ratio of two integrals. The numerator is just the cumulative quantity of material leaked to the environment from the beginning of the accident to some time $t^{\prime}$. The denominator is the total quantity made airborne up to $t^{\prime}$. If $Q_{0}$ is the building contaminated gas outflow rate $\left(\mathrm{m}^{3} / \mathrm{s}\right), C_{0}$ the exiting contaminant concentration $\left(\mathrm{kg} / \mathrm{m}^{3}\right)$, and $\mathrm{m}(\mathrm{t})$ is the airborne source formation rate $(\mathrm{kg} / \mathrm{s})$, then

$$
\operatorname{TdLPF}=\int_{0}^{\mathrm{t}^{\prime}} \mathrm{C}_{0} \mathrm{Q}_{0} \mathrm{dt} / \int_{0}^{\mathrm{t}^{\prime}} \mathrm{m}(\mathrm{t}) \mathrm{dt}
$$

If the values for $Q_{0}$ and $m(t)$ are very simple functions, then $C_{o}$ might also be a simple function of time, and the TdLPF could be easy to calculate. Otherwise, computer codes are necessary.

\subsubsection{Time-Independent LPF (TiLPF)}

The TiLPF is the overall LPF given infinite time. The TiLPF is easier to estimate than TdLPF, particularly if flow rates are constant and the airborne source term is either an initial puff or a constant value for some time interval. Tables, graphs, and simple equations/codes can then be used for estimates if the flow path is simple.

The TiLPF is simply the TdLPF with $\mathrm{t}^{\prime} \rightarrow \infty$. The implications of this definition are that, after some long period of time, the interior concentration of the airborne contaminant is zero or that there is no driving force and $Q_{0}=0$. Since no building is perfectly tight, wind pressures will cause some $Q_{0}$.

\subsection{Definition of Driving Forces for Transport}

Forces that can move airborne materials through and out of a facility include ventilation systems, fires and other chemical reactions, explosions, and external wind pressures. Less likely but still possible is a building collapse. Building collapse is not discussed further.

\subsubsection{HVAC}

For many DBAs the ventilation systems are the primary movers of airborne material. Here design specifications are adequate for defining the accident flow rates and flow paths. 


\subsubsection{Fires and Other Uncontrolled Chemical Reactions}

The release of thermal energy and gases might cause gas flow into unusual places within the facility. For example, a pressurizing fire can force source term material upstream in the ventilation systems or out glovebox ports.

\subsubsection{Explosions}

Pressure rise in deflagrations and shock wave effects from detonations influence gas movement. The explosion itself might cause instantaneous gas/aerosol movement, and net increases in gas volume can cause time-dependent depressurization.

\subsubsection{Exterior Wind Pressure}

Wind pressures at facility penetrations of final barrier, such as ventilation system failure, can be of prime importance.

\subsection{Definition of Flow Path Flow Rates}

The definition of flow rates includes calculation of flow resistances for the possible air pathways between airborne sources and open building penetrations, and assessment of the influence of driving forces and flow regimes (e.g., single-phase versus multi-phase, or turbulent versus laminar flows).

\subsubsection{Defining Paths of Least Resistance to Flow}

Setting up essential flow paths can be one of the most important steps. Flow paths should be as simple as possible without introducing significant uncertainty in the Five Factor Formula ${ }^{1}$ results. Flow resistances can be in parallel or in series, but relationships to driving forces are often nonlinear.

\subsubsection{Calculating Flow Rates - Simple Methods}

Simplified methods for calculating flow rates include the use of design flows, steady gas flow calculations such as those taken from the Crane Manual 410M (Crane 1977), orifice and duct flow equations, and computer-code-generated flow curves.

\subsubsection{Ventilation Systems}

Normal ventilation system flow rates are specified by design. For accidents such as drops or spills which do not affect accident compartment temperature or pressure, the normal design ventilation system flows can be used in the accident analysis. If occurrence of the accident changes the ventilation system driving forces more than a few percent, use of the more complex analysis techniques discussed below may be required. If loss of power occurs and fans stop functioning, but dampers remain open, simplified methods

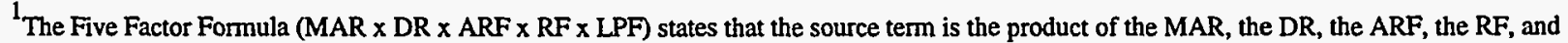
the LPF. Refer to Chapter 3 for definition of these terms.
} 
may remain applicable. In this case, the filters will normally become the dominating flow resistance in the ventilation system.

\section{Calculating Filter Flow Rates}

Filters are usually rated by the manufacturer. For instance, clean HEPA filters might have the rating of so many $\mathrm{m}^{3} / \mathrm{s} / \mathrm{m}^{2} / \mathrm{Pa}\left(\mathrm{cfm} / \mathrm{ft}^{2} / \mathrm{in}\right.$. w.c.). One inch of water at $60^{\circ} \mathrm{F}$ or $289 \mathrm{~K}$ equals $248.84 \mathrm{~Pa}$.). For instance,

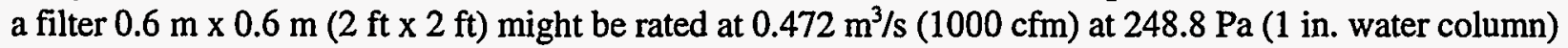
pressure drop. Most filters are operated in laminar flow with respect to the fiber diameters. Flows through packed beds are proportional to the pressure drop in laminar flow (Bird 1960). Thus, the clean HEPA filter above will have a flow rate

$$
\mathrm{Q}\left(\mathrm{m}^{3} / \mathrm{s}\right)=\mathrm{a} A_{f} \Delta \mathrm{p}
$$

where:

$$
\begin{aligned}
& \left.A_{f}=\text { the area of the filters (e.g., } 0.35 \mathrm{~m}^{2}\right) \\
& a=5.27 \mathrm{E}-03\left(\mathrm{~m}^{3} / \mathrm{s}\right) / \mathrm{m}^{2} / \mathrm{Pa}
\end{aligned}
$$

With this equation, one can calculate HEPA flow rates during post-accident conditions, unless the filter clogs with trapped particles. For loading effects in fires, see Fenton (1983).

\subsubsection{Flows Through Openings}

The calculation of flow through openings is demonstrated for orifices and ducts. Calculational methods available for similar geometric configurations to orifices and ducts are applied. Holes in thin walls can be assumed to be orifices and pipes can be assumed to be ducts.

For orifices, if $A_{h}$ is the area of the hole $\left(\mathrm{m}^{2}\right)$ and $\Delta p$ is the pressure drop (pascals) across the hole, then from Crane Co. (1977), the flow rate $\left(\mathrm{m}^{3} / \mathrm{s}\right)$ is

$$
Q_{d}=0.8484 A_{h}(\Delta p / \rho)^{1 / 2}
$$

where the gas density $\left(\mathrm{kg} / \mathrm{m}^{3}\right)$ is

$$
\rho=\mathrm{p}_{1} \mathrm{M} / \mathrm{RT}_{1}
$$

$M$ is the gas molecular weight, and $p_{1}$ and $T_{1}$ are the upstream absolute pressure (pascals) and temperature $(K)$, respectively. For the applications discussed in this chapter, $\Delta p$ can only be a small percentage of $p_{1}$ (i.e., $\Delta \mathrm{p}<0.01 \mathrm{P}$ ). The Crane Manual (Crane Co. 1977) addresses the case where $\Delta \mathrm{p} / \mathrm{p}_{1}$ is high.

For ducts, the suitable equation for low-pressure drops is:

$$
\mathrm{Q}_{\mathrm{d}}=1.414 \mathrm{~A}_{\mathrm{d}}(\Delta \mathrm{p} / \mathrm{\rho} / \mathrm{K})^{3 / 2}
$$

where:

$$
A_{d}=\text { the cross-sectional area }\left(\mathrm{m}^{2}\right) \text { of the duct }
$$


$\mathrm{K}_{d}=$ the resistance coefficient of the duct

For a simple duct,

$$
\mathrm{K}_{\mathrm{d}}=\mathrm{fL} / \mathrm{D}+1+0.5
$$

where:

$$
\begin{aligned}
& \mathrm{f}=\text { the function factor } \\
& \mathrm{L}=\text { the duct length } \\
& \mathrm{K}_{\mathrm{d}}=\text { the resistance coefficient of the duct }
\end{aligned}
$$

Details on the calculation of $K_{d}$ can be found in Crane Co. (1977). For noncircular ducts, $D=4 R_{H}$, where $R_{H}=$ hydraulic radius = cross-sectional flow area $A_{d}$ /cross-sectional flow perimeter (for gases). The value of 1 is a duct discharge coefficient, and the value of 0.5 is an entrance coefficient. These coefficients are to be used only if the duct ends "see" larger cross sections.

The friction factor $\mathrm{f}$ can require iteration to find its true value. Since $\mathrm{f}$ depends on the Reynolds number $R e=D Q_{d} / A_{d} / v$, where $v$ is the kinematic gas viscosity, it is necessary to first estimate $f$, calculate $Q_{d}$, recalculate $f$ from the $f$ versus $R e$ chart from Crane Co. (1977), and repeat this until $f$ does not change.

\subsubsection{External Pressures - Wind}

\section{Wind-induced building flows}

Steady wind pressures on a leaky building will cause steady infiltration/exfiltration flows through the building. These pressures will also act on the building's ventilation systems causing flows. Since wind pressures might be the only diving forces for airborne material movement within and from the building, methods to estimate the flows must be found. Although the actual problem might be difficult to solve exactly, some simplifications can make the problem tractable.

Wind pressures on the sides of a building take the following form (Blevins 1992):

$$
\mathrm{p}=\mathrm{p}_{\mathrm{o}}+c \rho v^{2} / 2
$$

where:

$$
\begin{aligned}
& c=\text { measured coefficient } \\
& \rho=\text { the wind density } \\
& v=\text { its velocity } \\
& p_{0}=\text { the atmospheric pressure (101325 Pa equivalent to } 1 \text { atmosphere or } 760 \mathrm{~mm} \mathrm{Hg} \text { pressure) }
\end{aligned}
$$

If $\rho$ is in $\mathrm{kg} / \mathrm{m}^{3}$ and $\mathrm{v}$ in $\mathrm{m} / \mathrm{s}$, then all pressure units are in $\mathrm{Pa}$. The coefficient $\mathrm{c}$ depends on the shape and side of the building. For a low square building with wind perpendicular to one side, $c=0.9$ on that side and -0.3 on the back side. The side coefficients are -0.4 , and the roof coefficient is 0.55 . These coefficients are taken from Blevins (1992), where many more shapes are found, along with coefficients, for winds at various angles to the sides. 
A generalized simple case is to take the square low building with the wind blowing perpendicular to the north side. The simplifying assumption is that the resistance to air flow inside the building is small compared to those of the exterior walls and roof. Thus, the interior pressure can be represented by a single pressure $\mathrm{p}_{i}$. If each wall and the roof has leakpath that can be approximated by a single rough cylindrical pipe of cross-sectional area $\mathrm{A}$, diameter $\mathrm{d}$, length $\mathrm{l}$, and friction factor $\mathrm{f}$, then the governing equations are:

$$
\begin{array}{ll}
\mathrm{Q}_{\mathrm{n}}=1.414 \mathrm{~A}_{\mathrm{n}}\left(\Delta \mathrm{p}_{\mathrm{n}} / \mathrm{K}_{\mathrm{n}}\right)^{1 / 2} & \text { for the north wall } \\
\Delta \mathrm{p}_{\mathrm{n}}=\mathrm{p}_{\mathrm{o}}+0.9 \rho v^{2} / 2-\mathrm{p}_{\mathrm{i}} & \\
\mathrm{K}_{\mathrm{n}}=1.5+\mathrm{f}_{\mathrm{n}} \mathrm{l}_{\mathrm{n}} / \mathrm{d}_{\mathrm{n}} & \\
\mathrm{Q}_{\mathrm{s}}=1.414 \mathrm{~A}_{\mathrm{s}}\left(\Delta \mathrm{p}_{\mathrm{s}} / \mathrm{K}_{\mathrm{s}}\right)^{1 / 2} \quad \text { for the south wall } \\
\Delta \mathrm{p}_{\mathrm{s}}=\mathrm{p}_{\mathrm{s}}-0.3 \rho v^{2} / 2-\mathrm{p}_{\mathrm{i}} & \\
\mathrm{K}_{\mathrm{s}}=1.5+\mathrm{f}_{\mathrm{s}} 1_{\mathrm{s}} / \mathrm{d}_{\mathrm{s}} &
\end{array}
$$

and likewise for the east $\left(Q_{c}\right)$ and west $\left(Q_{w}\right)$ walls and the roof $\left(Q_{r}\right)$. Since wind pressure drops are small relative to the atmospheric pressure, a mass balance can be approximated by:

$$
Q_{n}=Q_{s}+Q_{c}+Q_{w}+Q_{r}
$$

This last equation is a nonlinear equation with the single unknown $\mathrm{p}_{\mathrm{i}}$. To solve for $\mathrm{p}_{\mathrm{i}}$, one needs a simple graphical technique, such as plotting both the right and left sides of the equation versus $\mathrm{p}_{\mathrm{i}}$. The intersection of the two curves is at the correct $p_{i .}$. Now each $Q$ can be calculated.

There are two pitfalls in the above approach. The first is that the friction factors might not apply (i.e., laminar versus turbulent flow), or that the leakage area for one wall might be large compared with the other walls, necessitating a sign change in equation 4.14 in front of one of the Qs. The only apparent way through these pitfalls is a trial and error approach. If the $p_{i}$ found does not make sense, replace the suspected + sign in equation 4.14 with a - sign and repeat the solution technique. Then check each $\mathrm{Q} / \mathrm{A}$, which is the leakpath velocity for its Reynolds number $\operatorname{Re}=\rho \mathrm{d}^{\prime}(\mathrm{Q} / \mathrm{A})^{\prime} /(\mu=$ gas viscosity). If $\operatorname{Re}<2000$, the leakpath low is laminar and $f=64 / \mathrm{Re}$. Thus, a new level of difficulty is encountered. Re becomes another independent unknown and must be solved for any $\mathrm{p}_{\mathrm{i}}$. A quick check of the Re values will reveal whether the flow is laminar or turbulent. (The $\mathrm{d}^{\prime}$ and $(\mathrm{Q} / \mathrm{A})^{\prime}$ are calculated for the average single leak path in a wall and $d^{\prime}=4 R_{h}$, the hydraulic radius of the leakpath. See Crane (1977)).

\section{A Simple Example}

A square low style facility has an annual average wind velocity from the north, of $4 \mathrm{~m} / \mathrm{s}(9 \mathrm{mph})$. The facility has four leaky doors that normally allow inleakage of $0.0944 \mathrm{~m}^{3} / \mathrm{s}$ at $124.4 \mathrm{~Pa}(200 \mathrm{cfm}$ at $0.5 \mathrm{in}$. w.c.). What is the annual average flow through the building? Three of the leaky doors are on the south side and one is on the north side. Assume that the ventilation system is off and that closed dampers block any flow through the filters. Assume that the door cracks can be represented by an orifice of $\mathrm{A} \mathrm{m}^{2}$. Find A. The calculation is as follows:

At $298^{\circ} \mathrm{K}$ and $1.01 \mathrm{E}+05 \mathrm{~Pa}\left(25^{\circ} \mathrm{C}, 1 \mathrm{~atm}\right)$, the density of air is $1.18 \mathrm{~kg} / \mathrm{m}^{3}\left(0.072 \mathrm{lb} / \mathrm{ft}^{3}\right)$. Then

$$
0.0944=0.8484 \mathrm{~A}(124.4 / 1.18)^{0.5} \text { or } \mathrm{A}=1.084 \mathrm{E}-02 \mathrm{~m}^{2}\left(0.117 \mathrm{ft}^{2}\right)
$$

from equation (4.3). Divide the leakage area equally over all four doors. Thus 


$$
\mathrm{A}_{\mathrm{d}}=1.0894 \mathrm{E}-04 / 4=2.709 \mathrm{E}-03 \mathrm{~m}^{2}
$$

With the inside pressure at $p_{i}$

$$
\begin{gathered}
\text { Q(in) }=\mathrm{Q} \text { (out) } \\
\text { or } \quad 0.8484 \mathrm{~A}_{d}\left[\left(101325 .+(0.9) 1.18(4)^{2} / 2-\mathrm{p}_{\mathrm{i}}\right]^{0.5}=0.8484\left(3 \mathrm{~A}_{\mathrm{d}}\right)\left[\left(\mathrm{p}_{\mathrm{i}}-101325 .+(0.3) 1.18(4)^{2} / 2\right]^{0.5}\right.\right.
\end{gathered}
$$

Square both sides and solve for $\mathrm{p}_{\mathrm{i}}$. Here $\mathrm{p}_{\mathrm{i}}=101323.3 \mathrm{~Pa}$ or $1.7 \mathrm{~Pa}$ lower than atmospheric pressure.

Thus, $\quad Q$ (in) $=0.8484(2.709 \mathrm{E}-03)[101325.0+8.496-101323.3]^{0.5}=7.34 \mathrm{E}-03 \mathrm{~m}^{3} / \mathrm{s}$ and

$$
\mathrm{Q}(\text { out })=0.8484(3) 2.709 \mathrm{E}-03[101323.3+2.832-101325 .]^{0.5}=7.34 \mathrm{E}-03
$$

The above example illustrates several points: (1) the orifice is a simple flow resistance with no complicating friction factors for very slow flow rates, see Crane (1977) for departures from this situation; (2) wind pressures are usually much lower than atmospheric pressures; the six significant figures used here for atmospheric pressure were necessary to illustrate this point; (3) if there are only two leaky sides of a building with only the one driving force per side (i.e., $\Delta \mathrm{p}^{0.5}$ ), the problem reduces to a linear equation by squaring both sides of the mass balance; (4) since the interior resistance was neglected, the actual flow rate through the building would be less. Thus, the Qs represent an upper bound on the flow.

\subsubsection{Explosions}

Depressurization flows after an explosion can be very complex in all but the simplest flow system. The simplest system is addressed here. The general equations for flow out of a room that has been pressurized by an explosion, with filtered and unfiltered flow paths, are given.

Assume that the initial post-explosion atmosphere of the room of the room is at p' and T' (the reader will have to find an independent method to calculate these). The original conditions were at $p_{i}$ and $T_{i}$. The explosion gases vent to pressure $p_{i}$. The number of moles of gas in the room at $t=0$ are $n=p^{\prime} V / R T$ '. Here, $\mathrm{R}$ is the ideal gas constant, and $\mathrm{V}$ is the room volume. If both a filter and an orifice represent the filtered and unfiltered flow paths, then from equations (4.2) and (4.3), the molar rate of flow out of the room is

$$
\mathrm{dn} / \mathrm{dt}=-0.8484 \mathrm{~A}_{\mathrm{o}}\left[\left(\mathrm{p}-\mathrm{p}_{\mathrm{i}}\right) / \mathrm{\rho}\right]^{1 / 2} \mathrm{p} / \mathrm{RT}-\mathrm{aA} \mathrm{A}_{\mathrm{f}}\left(\mathrm{p}-\mathrm{p}_{\mathrm{i}}\right) \mathrm{p} / \mathrm{RT}
$$

where $\mathrm{P}$ and $\mathrm{T}$ are, at any time, $\mathrm{t}$. With $\Delta \mathrm{p}=\mathrm{p}-\mathrm{p}_{\mathrm{i}}$, the ideal gas law, the assumption that all ps not in $\Delta \mathrm{p}$ can be represented approximately by $p$ (the average of $\mathrm{p}^{\text {' and }} \mathrm{p}_{\mathrm{i}}$ ), the assumption that $\rho$ is a constant (at $p$ and $T^{\prime}$ ), then the above equation can be written

$$
\mathrm{d} \Delta \mathrm{p} / \mathrm{dt}=-\alpha \Delta \mathrm{p}^{3 / 2}-\mathrm{h} \Delta \mathrm{p}
$$

This equation can be integrated for isothermal flow (at T') to get

$$
\Delta \mathrm{p}=\left\{\left[\left(\alpha+\mathrm{h} \Delta \mathrm{p}_{\mathrm{o}}^{1 / 2}\right) \mathrm{e}^{-\mathrm{h} / 2}-\alpha\right] / \mathrm{h}\right\}^{2}
$$

where $\Delta \mathrm{p}_{\mathrm{o}}$ is the initial value. Outflow stops at $\mathrm{t}=(2 / \mathrm{h}) \ln \left[\left(\alpha+\Delta \mathrm{p}_{\mathrm{o}}^{1 / 2}\right) / \alpha\right]$ when $\Delta \mathrm{p}=0$. 
If $\alpha=0$ (no unfiltered leak), then

$$
\Delta p=\Delta p_{o} e^{-h t}
$$

and flow does not stop until infinite time. If $\mathrm{h}=0$ (no filter), then

$$
\Delta \mathrm{p}=\left[\left(2 \Delta \mathrm{p}_{0}^{1 / 2}=\alpha \mathrm{t}\right) / 2\right]^{2}
$$

Flow stops at $\mathrm{t}=2 \Delta \mathrm{p}_{\mathrm{o}}^{1 / 2} / \alpha$. Now one can use the appropriate $\Delta \mathrm{p}$ into a flow equation and obtain the $\mathrm{Q}(\mathrm{t})$ flow equation.

For the above, the constants $\alpha$ and $h$ are

$$
\begin{gathered}
\alpha=0.8484 \mathrm{~A}_{\alpha} p / V / \rho^{3 / 2}, \rho=p \mathrm{M} / \mathrm{R} / \mathrm{T}^{\prime} \\
h=a \mathrm{~A}_{\mathrm{f}} p / \mathrm{V}
\end{gathered}
$$

where $M$ is the molecular weight of the gas in the room. It is difficult to use these equations for calculating TiLPF, since these equations represent rapidly changing or transient conditions. The volume of gas expelled at $p$ and $\mathrm{T}^{\prime}$ is approximately $\left(\mathrm{p}^{\prime}-\mathrm{p}_{\mathrm{i}}\right) \mathrm{V} / p$. If this volume of gas cannot fill a major portion of the inlet/outlet ducts to the room, then the explosion itself will not likely transport aerosols to the building boundaries. With these equations, one can obtain a fair estimate of where the initial aerosols will go and how much went that way. If a normal ventilation system is operating, then this will continue to transport aerosols. If wind pressures are the only forces operating, then those forces will carry the aerosol to building exit points.

The TiLPF calculation could use the above equations directly. FPFP_2 (Owczarski 1991; Stege 1996) is one code that accommodates this information in its transport calculations.

\subsubsection{Fires}

This part demonstrates the relationship between fire size and ventilation system characteristics. Fires can involve a large range of combustible types and quantities. Accidental fires could range from the simple small fire to major facility fires, where even the integrity of the facility is challenged. Analysis of fires is a complex undertaking, involving simultaneous transfer of mass, momentum, and energy in a rapidly changing environment. However, the small fire can be examined with simpler methods. (See also Appendix D, third sample problem.) The SFPE Handbook of Fire Protection Engineering provides detailed guidance on the complexity and analytical techniques related to analysis of fire events.

The simple method described here is concerned with establishing a bounding fire size below which the normal ventilation system can successfully exhaust the combustible products. This is important because the pathway, followed by airborne material, depends on whether the combustion room overpressurizes. If it does overpressurize, then the pathways of contaminated air might include the inlet duct and leaky doors. With such a complication, the use of computer codes might be necessary to obtain reasonable answers.

To obtain some sort of guideline, an example is described below. Assume that the fire compartment has a kerosene pool fire. How big does this fire have to be to exceed the normal vent outflow with combustion gases? This calculation will be bounding because heat losses from the smoke plume will be neglected. 
For kerosene, the lower heat of combustion and burning rate are reported as $43.2 \mathrm{E}+06 \mathrm{~J} / \mathrm{kg}$ and 0.039 $\mathrm{kg} / \mathrm{m}^{2} / \mathrm{s}$ (Babraukas 1988), respectively.

If the fire area is $A_{p} m^{2}$, then the burning power of the fire is

$$
4.3 E+07(0.039) \mathrm{A}_{\mathrm{p}}=1.68 \mathrm{E}+06 \mathrm{~A}_{\mathrm{p}} \text { watts }
$$

while $0.039 \mathrm{~A}_{\mathrm{p}} \mathrm{kg} / \mathrm{s}$ of kerosene is being consumed. Now the gas flow through the fire is to be calculated.

The combustion is 91 percent efficient, and 57 percent of the heat stays with the gas (the rest is radiated away). Therefore, for each $0.039 \mathrm{~A}_{\mathrm{p}} \mathrm{kg} / \mathrm{s}$ consumed, only $0.91\left(0.039 \mathrm{~A}_{\mathrm{p}}\right)=0.036 \mathrm{~A}_{\mathrm{p}}$ is actually burned, producing

$$
0.91(0.57) 1.68+06 \mathrm{~A}_{p}=8.70+05 \mathrm{~A}_{\mathrm{p}} \text { watts into the gas phase. }
$$

Assume that the kerosene can be represented by dodecane, $\mathrm{C}_{12} \mathrm{H}_{26}$, so the combustion products from one mole of dodecane are $12 \mathrm{CO}_{2}$ and $13 \mathrm{H}_{2} \mathrm{O}$, requiring 18.5 moles of $\mathrm{O}_{2}$. The molecular weight of dodecane is 170 , so there are

$$
0.036 \mathrm{~A}_{\mathrm{p}} / 170=2.12 \mathrm{E}-04 \mathrm{~A}_{\mathrm{p}} \mathrm{kg}-\mathrm{moles} / \mathrm{s}
$$

of kerosene being burned, requiring $18.5\left(2.12 \mathrm{E}-04 \mathrm{~A}_{\mathrm{p}}\right)=3.92 \mathrm{E}-03 \mathrm{~A}_{\mathrm{p}} \mathrm{kg}-$ moles $\mathrm{O}_{2} / \mathrm{s}$.

Since air contains about 21 percent oxygen, the minimum rate of air flow required is

$$
3.92 \mathrm{E}-03 \mathrm{~A}_{\mathrm{p}} / .21=1.87 \mathrm{E}-02 \mathrm{~A}_{\mathrm{p}} \mathrm{kg} / \mathrm{moles} \text { air/s }
$$

This corresponds to a stoichiometric mass of air to mass of fuel ratio(s) of 14.94. This estimate may be corroborated by application of the guideline that for most fuels the heat released per unit mass of air consumed is $3000 \mathrm{~J} / \mathrm{g}_{\mathrm{air}}\left(1290 \mathrm{Btu} / \mathrm{lb}_{\mathrm{air}}\right.$ ) (Walton and Thomas 1988). For the above cited efficiency, the heat release rate is $1.6 \mathrm{E}+06 \mathrm{Ap} \mathrm{J} / \mathrm{s}$. Using the guideline air consumption rate and a value of $29.0 \mathrm{~kg}$ per $\mathrm{kg}$-mole for the molecular weight of air produces an air consumption rate estimate of $1.84 \mathrm{E}-02 \mathrm{~A} \mathrm{p} \mathrm{kg}-$ moles air/s. This guideline-based estimate is in close agreement with the estimate-based stoichiometry.

The rate of entrainment of air into the fire plume is estimated using correlations developed for turbulent jet flames and pool fires (Delichatsios 1988). The relation presented for distances from 1 to 4 pool diameters above the pool surface is:

$$
M_{e n t}=\left(S_{f}+D M_{f} \frac{0.093}{F r}\left(\frac{Z}{D_{f}}\right)^{3 / 2}\right.
$$


where

$$
\mathrm{Fr}=\frac{\mathrm{Q}_{\mathrm{f}}}{\rho_{\mathrm{a}}\left(\frac{\Delta \mathrm{H}_{\mathrm{c}}}{\mathrm{S}_{\mathrm{f}}+1}\right) \mathrm{D}_{\mathrm{f}}^{2} \sqrt{\frac{\Delta \mathrm{H}_{\mathrm{c}}}{\left(\mathrm{S}_{\mathrm{f}}+1\right) \mathrm{C}_{\mathrm{pg}} \mathrm{T}_{\mathrm{a}}} \mathrm{gD}_{\mathrm{f}}\left(\chi_{\mathrm{a}}-\chi_{\mathrm{r}}\right)}}
$$

and

$$
\begin{aligned}
& \mathrm{M}_{\mathrm{ent}}=\text { air entrainment rate, } \mathrm{kg} / \mathrm{s} \\
& \mathrm{M}_{\mathrm{f}}=\text { fuel burning rate of fire, } \mathrm{kg} / \mathrm{s} \\
& \mathrm{S}_{\mathrm{f}}=\text { air-to-fuel stoichoimetric ratio, } \mathrm{kg}_{\mathrm{air}} / \mathrm{kg}_{\mathrm{fuel}} \\
& \mathrm{F}_{\mathrm{r}}=\text { Froud number for the fire, dim } \\
& \mathrm{Z}=\text { vertical distance from the pool surface, } \mathrm{m} \\
& \mathrm{D}_{\mathrm{f}}=\text { diameter of pool fire, } \mathrm{m} \\
& \mathrm{Q}_{\mathrm{f}}=\text { theoretical heat release rate of fire, } \mathrm{v} / \mathrm{s} \\
& \Delta \mathrm{H}_{\mathrm{c}}=\text { lower heat of combustion of the fuel, } \mathrm{J} / \mathrm{kg} \\
& \rho_{\mathrm{a}}=\text { ambient air density, } \mathrm{kg} / \mathrm{m}^{3} \\
& \mathrm{~T}_{\mathrm{a}}=\text { ambient temperature, } \mathrm{K} \\
& \mathrm{C}_{\mathrm{pg}}=\text { heat capacity of combustion gases, } \mathrm{J} / \mathrm{kg} / \mathrm{K} \\
& \mathrm{g}=\text { acceleration due to gravity, } \mathrm{m} / \mathrm{s}^{2} \\
& \chi_{\mathrm{a}}=\text { combustion efficiency, dim } \\
& \chi_{\mathrm{r}}=\text { fraction of the theoretical heat release rate lost by radiation, dim }
\end{aligned}
$$

In this calculation, the entrainment rate at the point at which the combustion reactions are complete, the mean flame height, is estimated. The estimate is developed using the correlation (Heskestad 1988):

$$
L_{f}=-1.02 D_{f}+0.235 \frac{Q_{r f}}{1000}
$$

where

$$
\begin{aligned}
& \mathrm{L}_{\mathrm{f}}=\text { mean flame height, } \mathrm{m} \\
& \mathrm{D}_{\mathrm{f}}=\text { diameter of fire source, } \mathrm{m} \\
& \mathrm{Q}_{\mathrm{rf}}=\text { total heat release rate of fire, } \mathrm{J} / \mathrm{s}
\end{aligned}
$$

Using a fire diameter of $1.13 \mathrm{~m}\left(\mathrm{~A}_{\mathrm{p}}=1 \mathrm{~m}^{2}\right)$ and a heat release rate of $1530 \mathrm{~kJ} / \mathrm{s}[(0.91)(0.039)(4.3 \mathrm{E}+07)]$ equation 4.24 yields an estimated flame height of $3.27 \mathrm{~m}(10.7 \mathrm{ft})$. Using this flame height, ambient air density and temperature of $1.2 \mathrm{~kg} / \mathrm{m}^{3}\left(93.2 \mathrm{lb} / \mathrm{ft}^{3}\right)$ and $298 \mathrm{~K}\left(76^{\circ} \mathrm{F}\right)$, combustion gas specific heat of $1000 \mathrm{~J} / \mathrm{kg} / \mathrm{K}\left(0.24 \mathrm{Btu} / \mathrm{lb} /{ }^{\circ} \mathrm{F}\right)$ (Hougen 1958), and the above-cited combustion heats and efficiencies; a Froud number of 0.053 and an air entrainment rate of $4.95 \mathrm{~kg} / \mathrm{s}(10.9 \mathrm{lb} / \mathrm{s})$ are estimated using equations (4.23) and (4.24). This result is in agreement with the reported experimental result (Delichatsios 1988) that at the flame tip, the flow rate on the plume is approximately 10 times the flow rate corresponding to the stoichiometric requirement for combustion. The total rate is in the plume at this elevation is the sum of fuel plus entrained air or $5.0 \mathrm{~kg} / \mathrm{s}(11 \mathrm{lb} / \mathrm{s})$. 
An estimate of the temperature in the plume may be developed by equating the convective heat release to the sensible heat of the hot gas. For a fire with area of $1 \mathrm{~m}^{2}$,

$$
(0.91)(0.57)(0.039)(4.3 \mathrm{e} 7)=(5.0)(1000)(\mathrm{Tp}-298)
$$

yielding a plume temperature estimate of $472 \mathrm{~K}\left(390^{\circ} \mathrm{F}\right)$. Because the plume is almost entirely air, the average molecular weight is approximate $29.0 \mathrm{~kg} / \mathrm{kg}$-mole and the volumetric flow rate of the plume is $(472 / 273)(5.0 / 29.0)(22.4)=6.68 \mathrm{~m}^{3} / \mathrm{s}\left(236 \mathrm{ft}^{3} / \mathrm{s}\right)$, where $1 \mathrm{~kg}$-mole occupies $22.4 \mathrm{~m}^{3}\left(791 \mathrm{ft}^{3}\right)$ at $273 \mathrm{~K}(32$ $\left.{ }^{\circ} \mathrm{F}\right)$ and $1.01 \mathrm{E}+05 \mathrm{~Pa}(14.7 \mathrm{psia})$.

The role of the ventilation system may be evaluated by considering conditions in the fire compartment, the adjoining upstream and downstream compartments and entrance and exit pressure gains or losses.

Pressure in the upstream compartment will be higher than that in the fire compartment due to exit and duct losses. Thus the pressure in the fire compartment can increase to the pressure level of the upstream compartment before flow reversal can occur. Because duct flows are normally turbulent, the exit losses will not depend strongly on temperature and pressure forces driving flow and pressure losses limiting exist flow at the onset of the fire will be similar to of normal operating conditions. Thus, if the fire plume flow rate is less than the normal exhaust ventilation flow rate, the fire compartment pressure would not increase enough to cause flow reversal.

Application of these considerations will vary within each facility and from one facility to another. However, compartments at fuel cycle facilities are generally large with height, length, and width of 5, 20, and $15 \mathrm{~m}$ respectively, representative of typical dimensions. Because ventilation rates vary from 2 to 10 or more room changes per hour, normal ventilation could be as high as $4.2 \mathrm{~m}^{3} / \mathrm{s}$ for the representative compartment. Because the plume flow rate estimated for a relatively small fire (pool area $=1 \mathrm{~m}^{2}$ ) exceeds this typical ventilation rate, the analysis indicates that case-by-case evaluation of fire compartments for over-pressurization and flow reversal is indicated.

The above approach is fairly simplistic, but has value as an aid in decision-making. It is useful to see if the sample fire problem method of Appendix $D$ is applicable to the user's facility. In that problem, it was assumed that the normal ventilation system flows dominated the net fire output. In reality, all fires will temporarily raise the room pressure, however small. In worse scenarios, if the outlet filter can become laden with smoke particles and water, room pressures will rise to the point of flow reversal. When that occurs, fresh air will be denied to the fire, and it will eventually die down. The concluding point here is that if postulated fires are large and generate a lot of smoke, sophisticated analytical techniques such as those discussed in the following paragraphs are required for detailed analysis of a fire event.

\subsubsection{Calculating Flow Rates - Computer Codes}

The methods for estimation of system flow rates presented in Section 4.5.2 are applicable to relatively simple, steady-state series and parallel flow networks, with limited interconnectivity and recirculation. The limitation to steady-state conditions requires that occurrence of the accident does not perturb the preexisting flows. This constraint may be met in spills of powder or non-volatile liquids, but release of large quantities of gases in tank rupture or volatilization events or occurrence of tornadoes, fires, and explosions would not be well-represented by the simplified analysis method. Simulation of complex flow systems or of transient conditions requires solution of large numbers of simultaneous algebraic or differential equations subject to constraints imposed by external pressures and the characteristics of system components. In these case, computerized solutions using distributed or lumped parameter modeling 
approaches are the most effective analytical tools. Distributed parameter models represent the threedimensional distribution of system geometry and flow resistances to predict temperature, pressure, and flow rates at all points in the system as a function of time. While such models are useful in specific elements of accident analysis, they are not broad enough for application to the variety of accident conditions considered in this handbook. Lumped parameter models aggregate mass, momentum, and energy capacitances and transfer resistances into discrete volumes, thereby reducing the complexity of the governing equations and allowing for simulation of complex systems at a manageable level of detail. The FIRAC/EXPAC/TORAC series of computer codes and the MELCOR computer code, all developed at Los Alamos National Laboratory, are examples of lumped parameter models useful for representation of accident conditions in fuel cycle facility ventilation systems. The following paragraphs provide an overview of the use of the codes; more detailed instructions and supporting descriptions are provided in the user manuals for the FIRAC (Nichols and Gregory 1986), EXPAC (Gregory et al. 1983), TORAC (Andrae et al. 1985), and MELCOR (Summers et al. 1991) computer codes. It should be recognized that codes of this type, while of broad applicability, are not useful in all cases and require commitment of time in developing familiarity with the use and limitations of the codes. Also, the codes discussed here are not the only codes available for this type of analysis but are representative of the analytical approach appropriate for accident analysis.

\subsubsection{HVAC System Simulation Capabilities}

The FIRAC/EXPAC/TORAC codes represent a ventilation system as a network of branches and nodes, where the branches are ducts, filters, dampers, and blowers, and the nodes are branch or room capacitances (volumes). Specially-defined nodes connect the system to the environment, providing boundary conditions for steady-state simulations. The code is designed to model movement of ventilation air with secondary particulate and gas species contaminants, but does not model liquids or phase transitions. Air flow rates may vary with time, but are constant along the length of any single branch, and are determined by the resistance characteristics of the branch and the pressure and elevations of rooms connected to each end of the branch. Flow behavior in a branch is characterized by a single momentum balance for ducts, filters, and dampers, and by a single head/flow characteristic for blowers. Mass and energy balances are formulated for each room and simultaneous solution of the branch momentum, and room mass and energy balances determine the air flow rates, temperatures, and pressures throughout the system for both steady state and transient conditions. The transient response of the system is driven by user-defined time functions, which specify conditions for a selected room. Time functions are provided for injection of mass (air), energy, particulates, and gaseous species, and for specification of time dependence of room temperature and pressure. Concentrations of particulates and gaseous species are assumed low enough to be neglected in estimation of branch air-flow rates. Concentrations and intra-room transfer rates of particulates and gaseous species are determined, using the previously calculated branch flow rates and mass balances formulated around each room.

The MELCOR computer code was developed to simulate accident conditions in light-water nuclear reactors. The model framework is, however, general and flexible enough to allow representation of fuel cycle facility ventilation systems. The description provided here does not describe the extensive reactorrelated features of the model, but summarizes those features relevant to simulation of fuel cycle facility accidents. MELCOR can represent a ventilation system as a branch/node network capable of transporting air, liquid water, and entrained contaminants. Flow paths connect volumes and are characterized by physical dimensions and frictional loss coefficients and material flow rates. Flow paths may represent ducts, filters, blowers, and pumps. Control volumes are characterized by physical dimensions and material and energy inventories and are well-mixed in the air and liquid spaces. Momentum balances are 
formulated for flow paths, and mass and energy balances are formulated for control volumes. Simultaneous solution of the resulting set of equations using a two-fluid approach, predicts control volume temperature, pressure, and air and liquid masses and flow path air and liquid flow rates. Internally modeled combustion of hydrogen and user-defined sources of material and heat in rooms are used to drive transient conditions. User-defined sources of radioactive material may be used to simulate release events.

The initial step in ventilation system simulation for either FIRAC or MELCOR is development of a line diagram of the system and tabulation of the dimensions for rooms and flow paths and of resistance characteristics for flow paths. Initial conditions, including specification of external environment temperatures and pressures, are selected to establish system steady state conditions. The type of transient forcing function appropriate to the accident under consideration is then selected and the transient simulation completed. Quantities of material released to the environment are subsequently used in separate health impact analysis.

\subsubsection{Simulation of Response to Fires}

The effects of fire on facility ventilation system flow rates can be simulated in FIRAC by two methods. In the first, the combustible material smoke, radioactive particulate, and energy generation rate can be estimated by the analyst, and mass, energy, and particulate injection time functions used to perturb conditions in a fire compartment (room). In this method, temperature and pressure conditions will be uniform throughout the room, and transient system response will be simulated. In the second method, a fire compartment module, termed FIRIN, can be used to provide a more detailed representation of the progression of the fire. The FIRIN model (Chan et al. 1982) is a two-layer fire compartment model, which allows specification of type and order of combustion for nine types of combustible material. The model estimates smoke and radioactive material generation rates for user-specified conditions and is interfaced with the FIRAC ventilation system model for estimation of transport rates through the facility and release to the environment. Additional perspective on the development and effects of a compartment fire is provided by the CFAST computer code (Portier et al. 1992). CFAST includes a multi-layer fire compartment model and node-network simulation of the ventilation system, but does not consider radioactive material.

Simulation of ventilation system response to fire with MELCOR is limited to combustion of hydrogen and carbon monoxide in control volumes specified to contain ignitors. The combustion calculation is initiated when gas concentrations meet a combustibility criterion and burn duration and propagation are evaluated. User-specified injection of radioactive material can be used to simulate release events.

\subsubsection{Simulation of Response to Explosions}

Ventilation system response to explosion is simulated in FIRAC or EXPAC, based on the assumptions that the explosion can be represented as a rapid rise in temperature and pressure, and that the explosion does not destroy system components. In this case, mass, temperature, and pressure time functions defined for a given room simulate the effects of explosion in that room. Time-dependent response of branch flow rates and room temperatures and pressures are the primary output of the simulation. Particulate time injection functions can be used to simulate response of radioactive material during the explosion. The MELCOR code is not designed to simulate detonations. 


\subsubsection{Simulation of Response to Tornadoes}

Ventilation system response to tornadoes can be simulated using either the FIRAC or TORAC codes. The method requires specification of a pressure time function with appropriate pressure rate drop, total drop, and response for a node connected to the environment. The code then calculates the flow rates and internal pressures generated in response to the specified boundary conditions. A particulate injection time function can be used to simulate a radioactive material release caused by the pressure transient.

\subsubsection{Estimation of Transient Release Rates}

Ventilation system simulation codes can be used to estimate the time dependent release rate to the environment for particulate material made airborne at a location inside of the building. The following paragraphs describe the capabilities of the FIRAC and MELCOR computer codes for transient release calculations.

The capability of FIRAC for estimation of time dependent ventilation system air flows has been described in Section 4.5.3. Time-dependent particulate generation rates in rooms are calculated using the FIRINgenerated particulate concentration or the user-supplied particulate injection time function. The diameter and density of injected particulate are specified by the user for time functions and estimated internally for FIRIN sources. Time dependent particulate branch transfer rates and room particulate concentrations are calculated using the previously calculated system air flow rates, the above-mentioned particulate generation rates, and particulate material balances formulated around each room. Particulate transfer rate through a duct is calculated as the particulate concentration for the source room multiplied by the branch flow rate. Thus, particulate material transport calculations are decoupled from the gas dynamic calculations. The calculations consider gravitational settling, but neglect agglomeration and diffusional and temperature gradient related deposition. Using the above procedure, particulate branch transfer rates for branches connected to the environment, provide the facility release estimate. Because the particulate modeling is completed on a mass basis, simplifying assumptions must be applied to estimate release rates for individual radionuclides.

The MELCOR computer code uses a similar decoupling of the gas dynamics and particulate transfer calculations, but groups radionuclides into 15 classes based on physical and chemical properties. The aerosol dynamics calculations consider agglomeration contributions from turbulent and Brownian diffusion and deposition due to gravity settling, Brownian diffusion, thermophoresis, and diffusionphoresis. The initial concentration of particulate in a room can be specified by the user. Solution of particulate mass balances, using previously derived air flow rates and the above described agglomeration and deposition processes, provides control volume concentrations, flow path transfer rates, and facility release rates for the 15 classes of radionuclides.

\subsection{Attenuation of Airborne Materials Along Flow Path}

\subsubsection{Aerosols}

This section addresses the importance of particle sizes, together with aerosol physics, including the role of agglomeration, condensation, evaporation, and gas dynamics. 


\subsubsection{Particle Deposition Processes}

All aerosols tend to be unstable. This instability is caused by the many forces acting on the particles. These include gravity, electric fields, inertia, molecular collisions, temperature and gas molecular weight fields, and van der Waals forces. These forces can move particles within the gas. Any surface in contact with the aerosol can serve as deposition surfaces for moving particles. When particles hit a surface they can adhere due to van der Waals attractive forces. The most important mechanisms for bringing particles to contact surfaces are:

Gravity settling. Here an upward facing surface is required. Gravity acts on all particles, but is most important on particles larger than one micrometer. This mechanism is the only one active in the LPF \#1 code. Including just gravity settling is usually conservative for common particle size distributions in the nuclear fuel cycle.

Brownian diffusion. Particles can move in the direction of a concentration gradient due to random collisions with the aerosol gas molecules. Only particles with diameters less than 0.1 micrometer show any significant diffusion. Freshly formed smoke particles are in this category, but since initial smoke is fairly dense, these tiny particles agglomerate into larger particles and no longer exhibit diffusion.

Turbulent diffusion. This process hurls particles out of turbulent eddies and is important for larger particles traveling in a high velocity gas. Only in the initial instant of an explosion depressurization would this mechanism be important, but on only a small fraction of the initial aerosol, so it has been ignored for the scenarios discussed in this Handbook.

Thermophoresis. Particles are forced to move down a temperature gradient. This type of deposition occurs in fires when hot smoke contacts cold walls. Sine these walls rapidly warm, the driving force diminishes in time. The FIRIN/FIRAC code (Nichols and Gregory 1986) models this phenomena. A detailed unsteady state heat transfer analysis of the walls is employed in this code. A rough estimate of the importance of this mechanism in room fires showed that 10 percent or less of the initial smoke can deposit this way.

Diffusiophoresis. This mechanism operates if there is a molecular weight gradient in the aerosol carrier gas. The particles are forced up a such a gradient. Fires with combustion produced water vapor condensing on cool walls is an example of how this mechanism can operate. Like thermophoresis, this gradient wanes as the fire progresses. Vapor condensation causing particles to move with the vapor is called Stefan Flow and it can operate against diffusiophoresis. Again the FIRIN/FIRAC code has a model for Stefan Flow and uses detailed heat-transfer models. In fires, these phenomena are about as important as thermophoresis.

Electrical forces. Particles themselves can have electrical charges. These charges can cause agglomeration (coulombic attraction of opposite charges) and deposition on neutral surfaces by inducing opposite charges on the surface. Large scale electrical (and magnetic) fields can cause charged particle movement. Electrostatic precipitation and electrophoresis are commercial processes using this effect. Dust layers build up on television-set screens because of this effect. In accident situations, defining electrical fields quantitatively is nearly an impossible task, which makes their exclusion easy to justify.

Inertial forces. Inertial forces play an important role in deposition in addition to turbulent deposition mentioned above. When a fast-moving aerosol stream rapidly changes direction, the larger particles can 
easily move out of the stream and impact the surface causing the direction change. This impaction principal is the basis for cascade impactor particle samplers. Most flow situations in fuel cycle accidents will not exhibit significant impaction to justify estimating this effect. However, in flows through fine cracks or through door leaks etc. this mechanism could be important. Quantifying credit for this deposition is very difficult in these flow paths unless path geometries are well understood, which is highly unlikely.

Interception. This mechanism is important in filtration where the filter fibers directly intercept particles in the gas stream. The efficiency of this mechanism appears to increase as the ratio particle diameter/fiber diameter increases. This mechanism is inherent in filter bed efficiencies.

For accidents with the initial airborne aerodynamic mass median diameter (ammd) less than or equal to 1 micrometer, it is possible that the phoretic mechanisms above could cause more deposition than gravity settling, which can be nil. However, even without carrying the analysis to the next level of complexity (e.g. FIRIN/FIRAC), it appears that these phoretic mechanisms might offer no more than 10 to 20 percent deposition. This level of deposition is noise within the uncertainties of the assumptions and scenario definitions. Further analyses would then not provide enough LPF decrease to be certain of the significance of the reduction.

\subsubsection{Filtration/Mitigative Methods}

Appendix F presents detailed information on filtration. Normal efficiencies are given, along with causes and effects of filter failure. Sample problem \#4 described in Appendix D evaluates impacts of filter failure.

\subsubsection{Develop Guidelines for Estimating the Importance of Agglomeration}

Agglomeration is a process whereby collisions between particles result in the formation of larger particles. These larger particles settle faster than the smaller initial particles. Therefore, for typical airborne particles which might be released from accidents at fuel cycle facilities, neglecting agglomeration, if it occurs, can lead to a conservative result in an LPF analysis. However, including agglomeration in an analysis raises the complexity of analysis significantly. If the initial mass which is airborne is large or if the accident produces a large quantity of smoke (fire) or uranium hexafluoride $\left(\mathrm{UF}_{6}\right)$ spill produces a dense uranyl fluoride $\left(\mathrm{UO}_{2} \mathrm{~F}_{2}\right)$ cloud, then one might suspect that agglomeration might be present. A simple test will let one know if significant agglomeration is occurring.

This test is based on the calculation of the number density $\mathrm{N}$, number $/ \mathrm{m}^{3}$, of particles in the initial aerosol. Starting with the RF of the initial aerosol, the mass median diameter (mmd) of the aerosol must first be estimated. To do this, use the curve in Figure 4-1.

This plot of RF versus ammd gives the ammd for the specified RF. Then the mmd is ammd/(particle mass density in $\mathrm{g} / \mathrm{cc})^{1 / 2}$. The next step is the calculation of the count mean diameter (cmd). For log-normally distributed particles,

$$
\text { cmd }=\text { ammd } \exp \left(-2.5 \ln ^{2} \sigma_{g}\right)=0.3 \text { ammd if } \sigma_{g}=2 \text { (Dennis 1976) }
$$

where $\sigma_{\mathrm{g}}$ is the geometric standard deviation of the particle size distribution. 


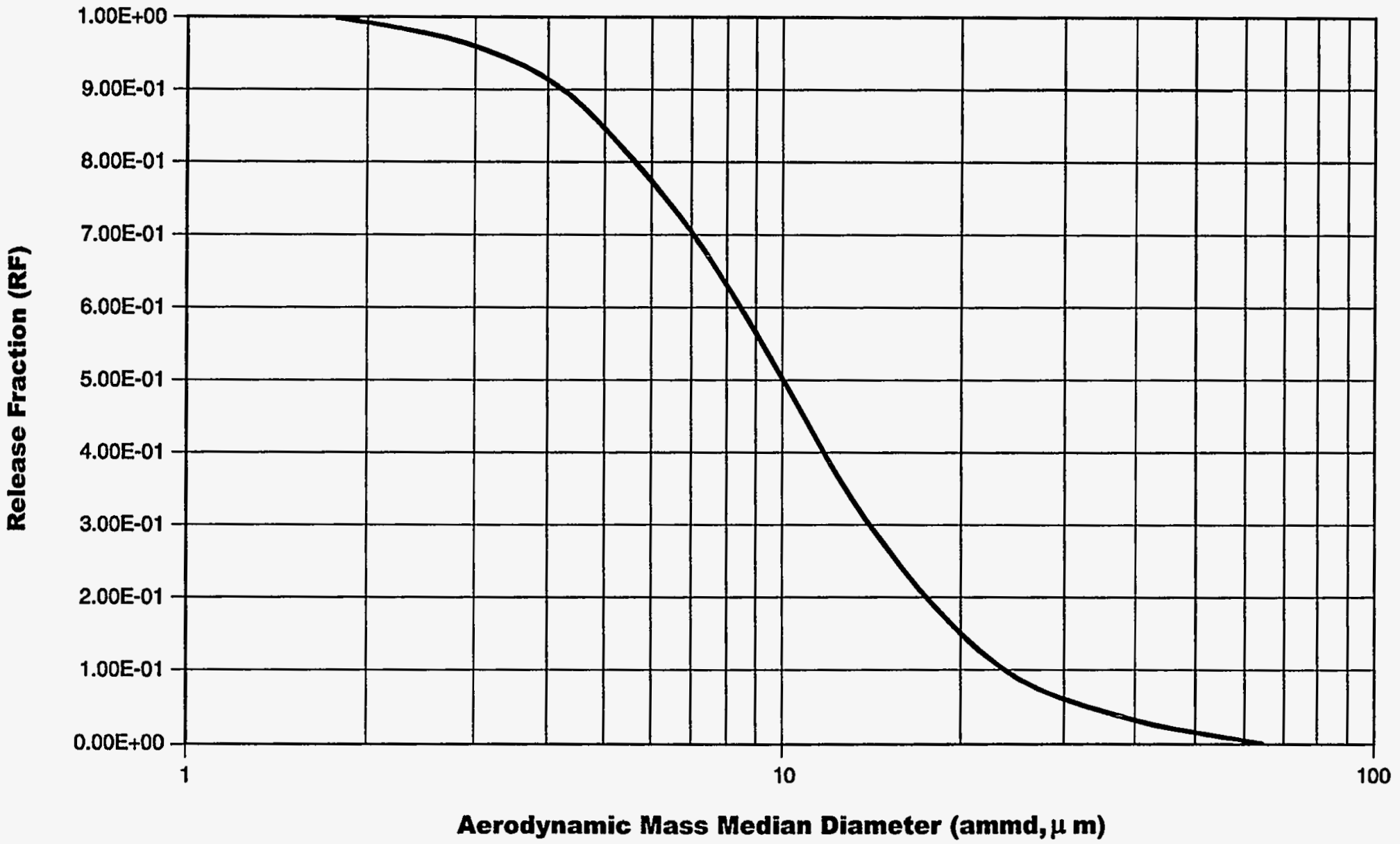

Figure 4-1. Relationship between RF and ammd for log-normal particle distribution with GSD=2 
The step to calculate $\mathrm{N}$ is

$$
\mathrm{N}=[\text { (initial mass airborne/ vol of source enclosure)/particle density }] /\left(\pi \mathrm{cmd}^{3} / 6\right) \text {. }
$$

If this $\mathrm{N}$ is less than $10^{10}$ particles $/ \mathrm{m}^{3}$ (if $\mathrm{cmd}<1$ micrometer) to $10^{11}$ (if $\mathrm{cmd}>1$ micrometer), no significant agglomeration should occur during transport through the facility. These are very rough guidelines. See Hesketh (1977) for more details.

An example is shown here of the calculation of the mass of initial airborne $\mathrm{UO}_{2}$ that produces $10^{10}$ particles $/ \mathrm{m}^{3}$ in a $1000 \mathrm{~m}^{3}$ room. The aerosol has an $\mathrm{RF}=0.5$.

From Figure 4-1, the corresponding ammd $=10$ micrometers. Assuming that $\sigma_{g}=2$, then $\mathrm{cmd}=0.3(10)=$ 3 micrometers or $3 E-06 \mathrm{~m}$. For this case, $N=10^{11}$. Since the particle density is $10.96 \mathrm{~g} / \mathrm{cc}$,

$$
\text { initial mass airborne }=\left(1 \mathrm{E}+11 \mathrm{~m}^{-3}\right)(\pi 16)(3 \mathrm{E}-06 \mathrm{~m})^{3}\left(1000 \mathrm{~m}^{3}\right)\left(10960 \mathrm{~kg} / \mathrm{m}^{3}\right)=15.5 \mathrm{~kg}
$$

The MELCOR code (see Section 4.5.3) handles agglomeration in a sophisticated manner and may be useful in analysis of particulate transport, where agglomeration is important, as it would be in this case.

\subsubsection{Chemicals}

\subsubsection{In-Facility Transport of Chemicals}

Nuclear fuel cycle facilities contain chemicals such as: ammonia $\left(\mathrm{NH}_{3}\right)$; nitric acid $\left(\mathrm{HNO}_{3}\right)$; hydrogen fluoride $(\mathrm{HF})$; $\mathrm{UF}_{6}$; fluorine $\left(\mathrm{F}_{2}\right)$; hydrogen chloride $(\mathrm{HCl})$, and hydrogen peroxide $\left(\mathrm{H}_{2} \mathrm{O}_{2}\right)$ (see Appendix A). The transport of $\mathrm{UF}_{6}$, which reacts readily with moisture in air, is also discussed.

$\mathrm{NH}_{3}, \mathrm{HF}, \mathrm{F}_{2}$, and $\mathrm{HCl}$ are gaseous at ambient conditions and are likely to pose a hazard for in-facility transport. These chemicals can produce a variety of source terms, such as vapor jets, slowly evaporating liquid pools, flashing liquid jets, and flashing puff releases. In-facility transport will be greatly affected by the mode of release and the presence of liquid droplets (if any). Liquid droplets enhance deposition and may be generated during flashing releases of $\mathrm{NH}_{3}, \mathrm{HF}, \mathrm{F}_{2}$, and $\mathrm{HCl}$.

Reactive chemicals, such as $\mathrm{F}_{2}, \mathrm{HCl}, \mathrm{HF}$, and $\mathrm{UF}_{6}$ are likely to be depleted inside a facility, and, consequently, the LPF will be less than unity. The extent to which depletion occurs through reactions with objects inside a facility depends upon the reactivity of the chemical and the presence of materials with which the chemical can react.

$\mathrm{HNO}_{3}$ and $\mathrm{H}_{2} \mathrm{O}_{2}$ have low vapor pressures and are not expected to generate important source terms for in-facility transport when present at ambient temperatures. At elevated temperatures, the vapor pressure and hazard level of these materials increase as for example, solutions of boiling $\mathrm{HNO}_{3}$ may release hazardous levels of nitrogen oxide fumes. Also, these materials are strong oxiding agents and may react violently with organic materials.

\subsubsection{In-Facility Transport of $\mathrm{UF}_{6}$}

$\mathrm{UF}_{6}$ releases are possible in conversion plants, gaseous diffusion plants, and fuel manufacturing facilities. When $\mathrm{UF}_{6}$ comes in contact with airborne moisture, it reacts exothermically to form a solid precipitate, 
$\mathrm{UO}_{2} \mathrm{~F}_{2}$ and $\mathrm{HF}$. This unique behavior affects the transport of $\mathrm{UF}_{6}$ and its reaction products inside a facility. $\mathrm{UO}_{2} \mathrm{~F}_{2}$ particles can deposit inside a facility. $\mathrm{HF}$ is a strong oxidizing agent and a very corrosive material. Unreacted vapor $\mathrm{UF}_{6}$ may desublime to form a solid.

A better understanding of in-facility transport of $U_{6}$ can be obtained by postulating an accident scenario in a gaseous diffusion plant (GDP). A GDP contains many compressors that pump gaseous $\mathrm{UF}_{6}$ through large cylindrical steel vessels, known as converters. A compressor, a converter, and interconnecting piping compose one stage. Groups of eight stages are typically called a cell. Groups of ten connected cells compose a unit. There are typically six to eight units in the main process building of a GDP, or a total of 480 to 640 stages.

A stage compresses a stream of $\mathrm{UF}_{6}$ vapor and passes it through a converter. The converter separates the incoming $\mathrm{UF}_{6}$ into two approximately equal streams: one low pressure, slightly enriched in U-235, and the other high pressure, slightly depleted in U-235. Each cell has block valves on the enriched and depleted process lines at each end of the cell. If a block valve on the high pressure line is closed without closing the corresponding low-pressure line block valve, $\mathrm{UF}_{6}$ gas will accumulate upstream of the closed valve, significantly raising the pressure in that location. If corrective action is not taken within a few minutes, the pressure in the high-pressure line will rise enough to rupture expansion joints in the process piping, releasing $\mathrm{UF}_{6}$ gas into the cell housing. The release rate of $U_{6}$ gas could be as high as $60 \mathrm{~kg} / \mathrm{s}$ for ten to thirty minutes (i.e., a total of $36000 \mathrm{~kg}$ to $108000 \mathrm{~kg}$ ) (79000 lb to $238000 \mathrm{lb})$.

The reaction of $\mathrm{UF}_{6}$ with water vapor may or may not go to completion, depending upon the indoor humidity. Deposition of aerosols (unreacted solid $\mathrm{UF}_{6}, \mathrm{UO}_{2} \mathrm{~F}_{2}$ precipitate or $\mathrm{HF}$-water solution) is possible. Aerosol deposition models are built into available in-facility transport models such as MELCOR (Summers et al. 1991) and CSCDSM (Williams 1986). However, these models do not take into account the detailed thermodynamic behavior of $\mathrm{UF}_{6}$ and its reaction products. Thus, simplifying assumptions are often made. These may include assuming that the reaction of $\mathrm{UF}_{6}$ goes to completion and/or neglecting the formation of a non-ideal aqueous solution of HF. These assumptions may lead to conservative analysis. For example, if aqueous HF solution formation is ignored, then the amount of HF deposited may be underestimated and lead to larger indoor and outdoor concentrations. Similarly, neglecting the high reactivity of $\mathrm{HF}$ with metal, glass, and even concrete may lead to an overestimation of the concentrations of $\mathrm{HF}$ in the air.

For a GDP in particular, the ventilation patterns vary widely from summer to winter conditions, leading to significantly different airflow patterns. Often, during the summer, the ventilation system works as a once-through system in which air is drawn into the operating floor and then forced to the cell floor by large blowers. In the winter, to prevent process gas from freezing due to low temperatures, the air is recirculated. These differences can cause large variations in the air flow paths and in-facility transport. During the winter, in particular, control room operators may be exposed during accidental releases because of the recirculating airflow patterns.

Aerosols can grow by agglomeration and by condensation. Guidance on the uranium particle size distribution is available from measurements in NUREG-1189, Vol. 1 (USNRC 1986). According to the measurements, most of the uranium particles generated in a release event were in the size range between 0.4 micrometer $\left(1.6 \times 10^{-5} \mathrm{in}\right)$ and 2.5 micrometer $\left(9.8 \times 10^{-5} \mathrm{in}\right)$ diameter, with a peak between 1.27 micrometer $\left(5.0 \times 10^{-5} \mathrm{in}\right)$ and 1.59 micrometer $\left(6.3 \times 10^{-5} \mathrm{in}\right)$. An experiment was also performed to study $\mathrm{UO}_{2} \mathrm{~F}_{2}$ particle formation following a UF ${ }_{6}$ release in a small bell jar and in a Plexiglas cube (Pickrell 1982). The conclusion drawn from the series of tests is that particles produced in high relative humidity start out 
as spheroids in the 0.3 to $0.6 \mu \mathrm{m}\left(1.2 \times 10^{-5}\right.$ to $2.4 \times 10^{-5}$ in) range and age to be between 1 to $2 \mu \mathrm{m}\left(3.9 \times 10^{-5}\right.$ to $7.8 \times 10^{-5} \mathrm{in}$ ). Another experiment was conducted by Lux (1982), where $\mathrm{UF}_{6}$ samples were released within a chamber. An average particle size appeared to be in the range of $1.1 \sim 1.4 \mu \mathrm{m}\left(4.3 \times 10^{-5} \sim 5.5 \times 10^{-}\right.$ ${ }^{5}$ in). This appears to corroborate the data in NUREG-1189. The density of a $\mathrm{UO}_{2} \mathrm{~F}_{2}$ particle is 6,375 $\mathrm{kg} / \mathrm{m}^{3}\left(397 \mathrm{lb} / \mathrm{ft}^{3}\right)$ (Williams 1986). The density of the cloud produced in a $\mathrm{UF}_{6}$ release can vary greatly depending on equipment configuration, $\mathrm{UF}_{6}$ physical state, and degree of mixing with ambient air.

For the postulated accident in summer conditions, it may be reasonable to assume that all of the $\mathrm{UF}_{6}$ is eventually reacted with moisture in the building and no $\mathrm{UF}_{6}$ gets released into the environment. About half of the $\mathrm{UO}_{2} \mathrm{~F}_{2}$ and most of the HF formed may reach the external environment. This is because about half of the $\mathrm{UO}_{2} \mathrm{~F}_{2}$ may settle on the floor as particles. The reactivity of $\mathrm{HF}$ and deposition modeling of aqueous HF droplets may reduce the amount reaching the external environment. Thus, the assumption that most of the HF formed may reach the environment is perhaps conservative. Detailed analysis using computer models can reveal how much HF gets released outside the building.

For the same accident in winter conditions, the deposition of $\mathrm{UO}_{2} \mathrm{~F}_{2}$ inside the building may be even more significant because of recirculation. It is possible that all of the $\mathrm{UO}_{2} \mathrm{~F}_{2}$ may deposit inside the building.

\subsection{Calculating the Leak Path Factor}

The LPF is defined in general terms in Section 4.3. The flow component of the LPF is found in Section 4.5. The final step in calculating the LPF is adding the deposition components. This section provides a tool that combines the flow component with deposition of particles. This tool is the code LPF\#1B (derived from LPF\#1, see Pinkson (1993)), which calculates a TiLPF for steady flows through a series of rooms and ducts.

\subsubsection{Simple Methods - TdLPF}

For estimating the TdLPF, no really simple methods exist. This LPF is a function of time and is rarely simple. Codes modeling release events do not usually provide LPFs directly but, rather, provide the source term in mass or radioactivity units. To obtain an LPF, one would have to use certain code outputs and perform some hand calculations. However, time dependent source terms are frequently desired for dose and dispersion calculations. It is possible to break a TiLPF into time increments. On the basis of knowledge of flow magnitudes, one might assign 90 percent of a release to the first hour and 10 percent to the next 10 hours. If the TiLPF is 0.6 , then the first hour LPF is 0.54 , and the next period LPF is 0.06 . This type of LPF breakdown is truly time dependent and simple.

\subsubsection{Simple Methods - TiLPF}

This section introduces methods for estimating LPFs in steady flows. Tables and graphs supplied for this purpose are found in the first two sample problems (Appendix D). Their use is discussed there. To avoid difficult interpolations with these tables and graphs, the LPF\#1B code is supplied. The technical bases and user's instructions are provided for this code. 


\subsubsection{Technical Bases of the LPF\#1 Codes}

This section describes the development of the equations used for determining steady flow LPFs in wellmixed enclosures and well-mixed plug flow ducts with gravity settling as the only particle depletion mechanism. These are the methods used in the LPF\#1B code. First, gravity settling of particles will be defined; equations describing the LPF in enclosures, in ducts, and in series combinations of enclosures and ducts will be developed. Finally, the use of the log-normal particle distribution is described.

Gravity settling of particles on upward-facing surfaces is the only depletion mechanism used here. This conservative choice ignores other forces that can remove suspended particles from the carrier gas. The other forces can be significant, but they are more difficult to compute, e.g., thermophoretic forces due to temperature gradients, diffusionphoretic forces due to molecular weight gradients in the gas or condensation forces, inertial forces, and electrostatic forces. Brownian diffusion can also lead to deposition, but this mechanism is only significant for particles with diameters smaller than $0.1 \mu \mathrm{m}$, which represents only a tiny fraction of typical fuel cycle aerosol particles. Since the target of gravitational forces is easy to determine (projected horizontal area of upward-facing surfaces), gravitational settling can be predicted with relative confidence.

All aerosol particles in a gravitational field are near their terminal settling velocity relative to the bulk gas motion. This terminal velocity $V_{p}$ is calculated from a force balance

$$
m_{p} d V_{p} / d t=0=m_{p} g-F_{d}
$$

where:

$$
\begin{aligned}
& \mathrm{m}_{\mathrm{p}}=\text { the particle mass } \\
& \mathrm{V}_{\mathrm{p}}=\text { its velocity } \\
& \mathrm{g}=\text { the acceleration due to gravity } \\
& \mathrm{F}_{\mathrm{d}}=\text { the drag force }
\end{aligned}
$$

$F_{d}$ is commonly expressed as

$$
F_{d}=f A_{p}\left(1 / 2 \rho V_{p}^{2}\right)
$$

where:

$$
\begin{array}{ll}
\mathrm{f} & =\text { a friction factor } \\
\mathrm{A}_{\mathrm{p}} & =\text { the projected area of the particle in the flow direction } \\
\left(1 / 2 \rho \mathrm{V}_{\mathrm{p}}^{2}\right) & =\text { the kinetic energy density of the gas at density } \rho \text { flowing past the particle }
\end{array}
$$

From now on, all particles will be referred to as spheres of diameter d. Any particle, regardless of shape, can be given an equivalent sphere diameter based on its settling properties and density $\rho_{p}$. Thus, for spheres $m_{p}=\rho_{p} \pi d^{3} / 6$ and $A_{p}=\pi d^{2} / 4$. The friction factor $f$ is a function of the Reynolds number, $\rho d V_{p} / \mu$, where $\mu$ is the gas viscosity. Empirical values of $f$ versus the Reynolds number are coded in a subroutine of the LPF\#1 code.

Now that the deposition velocity is defined, the technical definition of the leakpath factor can be completed. The LPF will be defined for an event as the ratio of total respirable particle mass escaped to 
the environment via air pathways to the total respirable mass made airborne in the event. If the airborne source term is $\mathrm{m}(\mathrm{t})$, in $\mathrm{kg} / \mathrm{s}$, the air volumetric flow rate out of the facility $\mathrm{Q}(\mathrm{t})$, in $\mathrm{m}^{3} / \mathrm{s}$, and aerosol particle concentration entering the environment $\mathrm{C}$, in $\mathrm{kg} / \mathrm{m}^{3}$, then the

$$
\operatorname{TiLPF}=\int_{0}^{\infty} \mathrm{Q}(\mathrm{t}) \mathrm{C}(\mathrm{t}) \mathrm{dt} / \int_{0}^{\infty} \mathrm{m}(\mathrm{t}) \mathrm{dt}
$$

For purposes of obtaining simple computations, the source term $\mathrm{m}(\mathrm{t})$ is treated as an instantaneous puff release $M_{o}$, where the flow rate $Q$ is constant. Thus,

$$
\mathrm{LPF}=\int \mathrm{QC}(\mathrm{t}) \mathrm{dt} / \mathrm{M}_{\mathrm{o}}
$$

It is emphasized that the LPF defined according to equation (4.29) is independent of time, so that for any dispersion calculation, the time element does not appear in the LPF. The LPF says that if any mass M is made airborne, the mass reaching the environment is $\mathrm{M} \times \mathrm{LPF}$. The dispersion/dose computation can assume any time frame desired.

Calculation of the concentration integral in equation 4.28 considers two general spaces: the enclosure and the duct. Each is treated uniquely. The enclosure is assumed to be well-mixed throughout, whereas the duct is assumed to be only well-mixed perpendicular to the flow path.

LPFs in Enclosures. The well-mixed enclosure has the following differential equation for the timedependent concentration, $\mathrm{C}$ :

$$
\mathrm{VdC} / \mathrm{dt}=-\mathrm{QC}-\mathrm{V}_{\mathrm{p}} \mathrm{A}_{\mathrm{f}} \mathrm{C}
$$

where:

$$
\begin{aligned}
& V=\text { enclosure volume, } \mathrm{m}^{3} \\
& V_{p}=\text { deposition velocity, } \mathrm{m} / \mathrm{s} \\
& A_{f}=\text { floor area plus upward-facing area, } \mathrm{m}^{2}
\end{aligned}
$$

and other variables are as defined above.

For a single initial release of mass $M_{o}$ at $t=0$, the equation integrates to

$$
C(t)=\left(M_{o} / V\right) \exp \left[-\left(Q+V_{p} A_{f}\right) t / V\right]
$$

The time integral in equation 4.31 is

$$
M_{\mathrm{o}} /\left(\mathrm{Q}+\mathrm{V}_{\mathrm{p}} A_{\mathrm{f}}\right)
$$

thus

$$
L P F=1 /\left(1+V_{p} A_{p} / Q\right)
$$


The ratio $Q / A_{f}$ is referred to as the particle "escape" velocity, $V_{a}$, i.e., a particle escapes the enclosure at that velocity or deposits at $V_{p}$. So then

$$
\operatorname{TiLPF}=1 /\left(1+\mathrm{V}_{\mathrm{p}} / \mathrm{V}_{\mathrm{a}}\right)=\mathrm{V}_{\mathrm{a}} /\left(\mathrm{V}_{\mathrm{a}}+\mathrm{V}_{\mathrm{p}}\right)
$$

The LPF defined above is for one enclosure. Since an LPF is defined only for a constant $V_{p}$, only one particle diameter $i$ satisfies this, so an individual $L_{P F}$ for each particle size is definable with a corresponding $\mathrm{VP}_{\mathrm{pi}}$.

$$
\mathrm{LPF}_{\mathrm{i}}=1 /\left(1+\mathrm{V}_{\mathrm{pi}} / \mathrm{V}_{\mathrm{a}}\right)
$$

LPFs in Ducts. For a duct of rectangular cross section, the differential equation for concentration within the duct is

$$
\mathrm{Q} d \mathrm{~d} / \mathrm{dz}=-\mathrm{V}_{\mathrm{p}} \mathrm{WC}
$$

where $\mathrm{z}$ is the $\mathrm{Q}$ flow direction and $\mathrm{W}$ is the duct width. This equation integrates over the duct length to give

$$
C=C_{0} \exp \left(-V_{p} A_{p} / Q\right)
$$

where $\mathrm{C}_{\mathrm{o}}$ is the concentration at the duct entrance and $\mathrm{C}$ at the exit. The LPF for the duct for particle size $\mathrm{i}$ follows as

$$
\mathrm{C} / \mathrm{C}_{\mathrm{o}}=\mathrm{LPF}_{\mathrm{i}}=\exp \left(-\mathrm{V}_{\mathrm{pi}} \mathrm{A}_{\mathrm{p}} / \mathrm{Q}\right)
$$

LPFs in Series Combinations. Since each $\mathrm{LPF}_{\mathrm{i}}$ is a transmittance factor for particle size $\mathrm{i}$, then the fraction of $i$ successfully challenging the flow path in a series of $j$ enclosures and ducts is the product

$$
\mathrm{LPF}_{\mathrm{i}}=\Pi^{\mathrm{j}} \mathrm{LPF}_{\mathrm{ij}}
$$

where the $\mathrm{LPF}_{\mathrm{ij}}$ now stands for the $\mathrm{LPF}_{\mathrm{i}}$ in enclosure or duct $\mathrm{j}$.

The Log-Normal Distribution and Overall LPFs. The overall LPF is designated as just the LPF and calculated according to a prescribed method based on an assumed log-normal particle diameter distribution. For the LPF, the RF that escapes the building boundary must be known. Many aerosol particle distributions are log-normal or fairly close to it. With a log-normal distribution, the specifying RF and $\sigma_{\mathrm{g}}$ defines the size distribution of the aerosol. $\sigma_{\mathrm{g}}$ is the geometric standard deviation of the distribution, where $\sigma_{g}=2$ is very common in nature. The expression for the log-normal distribution is found in numerous aerosol books (e.g., Dennis 1976). It is a symmetrical bell-shaped curve with $\ln (\mathrm{d})$ as the abscissa, where $d$ is the particle diameter.

In the LPF\#1B code, the log-normal distribution defined by the respirable fraction and geometric standard deviation specified by the analyst is used to assign particle mass fractions $\mathrm{f}_{\mathrm{io}}$ to a series of discrete diameters i such that

$$
\Sigma \mathrm{f}_{\mathrm{io}}=1
$$


To calculate an overall LPF, the mass leaving the facility can be defined as M:

$$
\mathrm{M}=\mathrm{M}_{\mathrm{o}} \Sigma_{\mathrm{i}}\left(\mathrm{f}_{\mathrm{io}} \mathrm{LPF}_{\mathrm{i}}\right)
$$

where the product is taken over indices for particle diameters less than $10 \mu, M_{o}$ and $M$ are the initial and final respirable mass respectively, and $M / M_{0}=$ overall $L P F=L P F$. The exiting distribution is not $\log$ normal but rather has the individual

$$
\mathrm{f}_{\mathrm{i}}=\mathrm{f}_{\mathrm{io}} * \mathrm{LPF}_{\mathrm{i}}
$$

To calculate the overall LPF for a series of rooms and ducts, the computer code LPF\#1 is used. This approach is necessary since each downstream component of the series does not see a log-normal distribution, and the tables and figures of Sample Problem 1 (Appendix D) apply only to the first upstream component in a series. Additional tables and graphs found in Sample Problem 2 have one room and one duct in a series. With code LPF\#1B discussed in Section 4.7.2.2, one can put many rooms and ducts in a series.

LPF\#1 will compute one set of LPF versus RF for any series combination of enclosures and ducts. The input file LPF\#1.DAT is constructed of a title line, a line designating the number of enclosures and ducts, and lines of the values of flow rate/upward-facing area for each enclosure and then each duct. LPF\#1 was used to generate all the LPF tables and graphs of the Sample Problems, but using these requires difficult interpolation. Using LPF\#1B eliminates any interpolation.

LPF\#1/LPF\#1B Validation. The LPF\#1/B codes were benchmarked against the MELCOR code. Twenty different cases were run with each code with good agreement. Details of this benchmarking process and results are found in Appendix E.

\subsubsection{Use of LPF\#1B Code}

To run the LPF\#1 codes requires a PC with a math coprocessor and a 3.5" diskette reader. Since the input file is an ASCII form, some ASCII editor is needed to create the file.

LPF\#1B differs slightly from LPF\#1. Both codes do the same calculation of LPF. The B code eliminates any need for interpolating between output RF values. The input requirements for $B$ include the values of the RF and $\sigma_{g}$ of the aerosol in question. If the latter is not known, use 2.

LPF\#1B computes the overall LPF for a series of rooms and ducts. The user needs to establish the steady flow rates (Qs) out of each component through this series. Then the user must calculate the values of the $\mathrm{Q} / \mathrm{A}$ for each room and duct in meters/second. A is the horizontal upward facing surface area of each room or duct. The A's should include an estimate of the area of surface areas of equipment that could serve as a settling surface.

The following input quantities are required in LPF\#1B.DAT:

Line 1

an 80 character title, or leave blank

Line 2 
no. of rooms (NR with 12 maximum), and ducts (ND with 12 maximum), separated by a comma

Next NR lines

Q/A for each room outflow rate/upward facing area in the velocity units $\mathrm{m} / \mathrm{s}$

Next ND lines

$\mathrm{Q} / \mathrm{A}$ for each duct outflow rate/upward facing area in the velocity units $\mathrm{m} / \mathrm{s}$

Last line

$\mathrm{RFi}=$ respirable fraction of initial aerosol.

$\sigma_{g}$, the aerosol geometric standard deviation. Use 2 if none is available.

Example: The LPF for a room/duct series flow system is required. The room has a $100 \mathrm{~m}^{2}\left(1075 \mathrm{ft}^{2}\right)$ floor area and the duct a $45 \mathrm{~m}^{2}\left(485 \mathrm{ft}^{2}\right)$ horizontally upward-facing surface area. The flow rate through the system is $10 \mathrm{~m}^{3} / \mathrm{s}\left(353 \mathrm{ft}^{3} / \mathrm{s}\right)$. The room $\mathrm{Q} / \mathrm{A}$ is $10 / 100=0.1 \mathrm{~m} / \mathrm{s}(0.33 \mathrm{ft} / \mathrm{s})$, and the duct $\mathrm{Q} / \mathrm{A}$ is $100 / 45=$ $0.22 \mathrm{~m} / \mathrm{s}(0.72 \mathrm{ft} / \mathrm{s})$. The aerosol in question has a respirable fraction of $0.4 . \sigma_{\mathrm{g}}$ is unknown. The input file LPF\#1B.DAT should look like this:

LPF Calculation w/ one room and one duct in series. (Title optional or left blank)

1,1

0.1

0.2222

$0.4,2$.

The title must start on line 1 .

The enclosed diskette has a copy of LPF\#1B.EXE and LPF\#1B.DAT (see below). Store the input file in the same directory as LPF\#1B.EXE. To run the code, type LPF\#1B and hit <Enter>. An output file should be available in a few seconds. You can examine the output ASCI file with an editor or convert it to a text file. The following has been converted:

\section{PROGRAM LPF\#1B OUTPUT}

LPF Calculation w/ one room and one duct in series.

Enclosure 1 Escape velocity $=1.000000 \mathrm{E}-01 \mathrm{~m} / \mathrm{s}$

Duct 1 Escape velocity $=2.222000 \mathrm{E}-01 \mathrm{~m} / \mathrm{s}$

Initial aerosol parameters:

respirable fraction $=4.000000000000000 \mathrm{E}-001$

geom std deviation $=2.000000000000000$

OVERALL RESPIRABLE LEAKPATH FACTOR = 9.796E-01 


\subsection{Calculating Facility Concentrations}

One of the major concerns in accident analyses is making onsite dose estimates. These estimates require making estimates of the in-facility concentrations and personnel placement on a local basis to obtain accurate predictions. Since both are very difficult to assess, reliance on models or codes seems to be one acceptable way to approximate facility concentrations as a function location and time in the post-accident period. One suite of codes specifically designed for this is called HABIT 1.0 (Stege 1996). A very simple approach is described below, which applies when ventilation flows are constant in the post-accident period.

\subsubsection{Simple Concentration Estimates - Puff Release}

This simple approach will include two compartments in series connected by a duct. Compartment 1 is the accident source location, and compartment 2 is filled with a puff of contaminant of mass (or $\mathrm{Ci}$ ) $\mathrm{M}_{\mathrm{o}}$. The compartments are assumed to be well mixed, so the initial compartment concentration in compartment 1 is $M_{0} / V_{1}$, where $V_{1}$ is the volume of compartment 1 . The flow out of 1 is the constant $Q_{1}$. A portion of $Q_{1}$ is $\mathrm{Q}_{2 \mathrm{i}}$, which enters 2. The exhaust rate from 2 is $\mathrm{Q}_{20}$. For the puff release in 1, the time history of $\mathrm{M}_{\mathrm{o}}$ in the two compartments is

$$
\begin{gathered}
M_{1}=M_{0} \exp \left(-Q_{1} t / V_{1}\right) \\
M_{2}=M_{0}\left(Q_{2 i} / V_{1}\right)\left[\exp \left(-Q_{20} t / V_{2}\right)-\exp \left(-Q_{1} t / V_{1}\right)\right] /\left(Q_{1} / V_{1}+Q_{20} / V_{2}\right)
\end{gathered}
$$

The concentrations in each compartment are $\mathrm{M}_{1} / \mathrm{V}_{1}$ and $\mathrm{M}_{2} / \mathrm{V}_{2}$. The maximum concentration in 1 is at $t=$ 0 and, in 2 , is at

$$
\mathrm{t}\left(\max \mathrm{M}_{2} / \mathrm{V}_{2}\right)=\ln \left[\left(\mathrm{Q}_{20} \mathrm{~V}_{1}\right) /\left(\mathrm{Q}_{1} / \mathrm{V}_{2}\right] /\left(\mathrm{Q}_{20} / \mathrm{V}_{2}-\mathrm{Q}_{1} / \mathrm{V}_{1}\right)\right.
$$

Place the value of the time at maximum concentration into equation (4.44) to obtain the maximum concentration.

The equations become much more complex if polydisperse aerosol deposition is to be included and the approach is no longer "simple".

\subsubsection{Simple Concentration Estimates - Constant Continuous Release}

Another type of release that is amenable to fairly simple computation is the continuous release. One might expect to find this behavior in a prolonged fire of contaminated combustibles or a continuous drip from a leaky pipe. The continuous release in 1 is represented by $\underline{\mathrm{M}}$ in $\mathrm{kg} / \mathrm{s}$. With all other quantities as above, the time dependent concentration in 1 is

$$
\mathrm{M}_{1} / \mathrm{V}_{1}=\left(\underline{\mathrm{M}} / \mathrm{Q}_{1}\right)\left[1-\exp \left(-\mathrm{Q}_{1} \mathrm{t} / \mathrm{V}_{1}\right)\right]
$$


which reaches the $\mathrm{M} / \mathrm{Q}_{1}$ maximum as $\mathrm{t} \rightarrow \infty$. Compartment 2 receives part of the 1 output at the inflow rate $\mathrm{Q}_{2 \mathrm{i}}$ and its concentration

$$
\begin{aligned}
& M_{2} / V_{2}=\left(\underline{M} V_{2} / Q_{1}\right)\left[1+\exp \left(-Q_{20} t / V_{2}\right]-\underline{M}\left(Q_{2 i} / Q_{1}\right)\left[\exp \left(-Q_{20} t / V_{2}\right)-\exp \left(-Q_{1} t / V_{1}\right)\right] /\right. \\
& \left(Q_{1} / V_{1}-Q_{20} / V_{2}\right)
\end{aligned}
$$

which also reaches a maximum of $\left(\mathrm{M} / \mathrm{Q}_{1}\right)\left(\mathrm{Q}_{2 \mathrm{i}} / \mathrm{Q}_{20}\right)$ as $\mathrm{t} \rightarrow \infty$. (Note: $\mathrm{Q}_{2 \mathrm{i}} \leq \mathrm{Q}_{20}$. $)$ 


\subsection{References}

Andrae, R.W., et al., "TORAC User's Manual - Computer Code for Analyzing Tornado-Induced Flow and Material Transport in Nuclear Facilities," NUREG/CR-4260, LA-10435-M, Los Alamos National Laboratory, Los Alamos, New Mexico, 1985.

Arnedt, T.R., "Evaluation of Self-Contained HEPA Filter", Proceedings of the 23rd NRC/DOE Nuclear Air Cleaning Conference (M.W. First, Ed), NUREG/CP-0141 (CONF-940738), Harvard Air Cleaning Laboratory, Boston, Massachusetts, 02115, February 1995.

Babraukas, V., "Burning Rates," in the SFPE Handbook of Fire Protection Engineering, National Fire Protection Association, Quincy, MA, 1988.

Bergman, W. and S.R. Sawyer, "Development of a High-Efficiency, High-Performance Air Filter Medium," Proceeding of the 20th DOE Nuclear Air Cleaning Conference (M.W. First, Ed), Harvard Air Cleaning Laboratory, Boston, Massachusetts, 02115, 1989.

Bergman, W., G. Larsen, W.P. Wilson, R. Lopez, G. Vilha, J. Conners, J. Carr, K. Williams, A. Bierman, K. Wilson, P. Moore, C. Gellner, D. Rapchun, K. Simons, J. Rurley, L. Frye, and D. Moore, "Development and Evaluation of Cleanable High Efficiency Steel Filter," Proceedings of the 23rd NRC/DOE Nuclear Air Cleaning Conference (M.W. First, Ed), NUREG/CP-0141 (CONF-940738), Harvard Air Cleaning Laboratory, Boston, Massachusetts, 02115, February 1995b.

Bergman, W., M.W. First, W.L. Anderson, H. Gilbert, and J.W. Jacox, "Criteria for Calculation the Efficiency of Deep-Pleated HEPA Filters with Aluminum Separators During and After Design Basis Accidents", Proceedings of the 23rd DOE/NRC Nuclear Air Cleaning Conference (M.W. First, Ed), NUREG/CP-0141 (CONF-940738), Harvard Air Cleaning Laboratory, Boston, Massachusetts, 02115, February 1995a.

Blevins, R.D., Applied Fluid Dynamics Handbook, Krieger Publishing Co., Malabar, Florida, 1992.

Burchsted, C.A. and A.B Fuller, "Design, Construction, and Testing of High-Efficiency Air Filtration Systems for Nuclear Application," ORNL-NSIC-65, Oak Ridge National Laboratory, Oak Ridge, Tennessee, 37830, January 1970.

Burchsted, C.A., J.E. Kahn, and A.B. Fuller, Nuclear Air Cleaning Handbook, ERDA 76-21, U.S. Energy Research and Development Administration (currently the U.S. Department of Energy), Oak Ridge National Laboratory, Oak Ridge, Tennessee, 37830, 1976.

Chan, M.K. et al., "User's Manual for FIRIN1: A Computer Code to Characterize Accidental Fire and Radioactive Source Terms in Nuclear Facilities", NUREG/CR-3037, Battelle Pacific Northwest Laboratory, Richland, Washington, 1982.

Crane Co., "Flow of Fluids Through Valves, Fittings, and Pipes," Metric Edition - SI Units. Technical Paper No. 410M, Crane Co., 4100 S. Kedzie Avenue, Chicago, Illinois, 60632, 1977.

Delichatsios, M.A., "Air Entrainment into Buoyant Jet Flames and Pool Fires," in the SFPE Handbook of Fire Protection Engineering, National Fire Protection Associatoin, Quincy, MA, 1988. 
Dennis, Richard, editor, Handbook on Aerosols, TID-26608, U.S. Energy Research and Development Administration, Washington, D.C., 1976.

Dyment, J. and C. Hamblin, "The Development of a HEPA Filter with Improved Dust Holding Characteristics", Proceedings of the 23rd DOE/NRC Nuclear Air Cleaning Conference (M.W. First, Ed), Harvard Air Cleaning Laboratory, February 1995.

Elder, J.C., J.M. Graf, J.M. Dewart, T.E. Buhl, W.J. Wenzel, L.J. Walker, and A,K, Stoker, "A Guide to Radiological Accident Considerations for Siting and Design of DOE Nonreactor Nuclear Facilities," LA10294-MS, Los Alamos National Laboratory, Los Alamos, New Mexico, 87545, January 1986.

Fenton, D.L. et al., "Filter Loading by Combustion Products," LA-9911-C, Vol. II pp 405-417, CSNI Report No. 83, Proceedings of the CSNI Specialist Meeting on Interactions of Fire and Explosion with Ventilation Systems in Nuclear Facilities, Los Alamos National Laboratory, Los Alamos, New Mexico, 1983.

First, M.W., "A Brief History of the Air Cleaning Conferences", Proceedings of the 23rd DOENRR Nuclear Air Cleaning Conference (M.W. First, Ed), NUREG/CP-0141 (CONF-940738), Harvard Air Cleaning Laboratory, Boston, Massachusetts, 02115, February 1995.

Gregory, W.S. et al., "EVENT User's Manual: A Computer Code for Analyzing Explosion-Induced GasDynamic Transients in Flow Networks", LA-9624-M, Los Alamos National Laboratory, Los Alamos, New Mexico, 1983.

Grewal, G., Z. Milatovic, F.L Landon, and W.R Harty, "Application of High Efficiency Metal Fiber Filters in Ventilation Systems of Non-Reactor Nuclear Facilities,"Proceeding of the 22nd NRC/DOE Nuclear Air Cleaning Conference (M.W. First, Ed), CONF-920823, Harvard Air Cleaning Laboratory, Boston, Massachusetts, 1993.

Hekestad, G., "Fire Plumes," in the SFPE Handbook of Fire Protection Engineering, National Fire Protection Association, Quincy, MA, 1988.

Hesketh, H.E., Fine Particles in Gaseous Media, Ann Arbor Science Publishers Inc, Ann Arbor, Michigan, 1977.

Kmetyk, L. N., "MELCOR 1.8.1 Assessment: LACE Aerosol Experiments LA4," SAND91-1532, Sandia National Laboratories, 1991.

Kovach, J.L., "Review of Containment Vent Filter Technology", Proceedings of the 23rd DOE/NRC Nuclear Air Cleaning Conference (M.W. First, Ed), NUREG/CP-0141 (CONF-940738), Harvard Air Cleaning Laboratory, Boston, Massachusetts, 02115, February 1995.

Lux, C. J., "UF6 Release Studies Under Controlled Conditions," GAT/GDP-2014, GoodYear Atomic Corporation, June 3, 1982.

Moore, E.B. (ed), R. Aaberg, G.H. Bryan, L.L. Berger, C.A. Counts, D.A. Dingee, H.T. Fullam, C.M. Heeb, J.D. Ludwick, E.D. McClanahan, J. Mishima, L.G. Morgan, A.M. Screiber, and R.I. Smith, 
"Control Technology for Radioactive Emissions to the Atmosphere at U.S. Department of Energy Facilities," PNL-4621, Pacific Northwest Laboratory, Richland, Washington, 99352, October 1984.

Muller, C. and J.R. Davis, "GASFLOW Comparisons with Bureau of Mines Experiments," LA-UR-942020, ANS 1994 Winter Annual Meeting, November 13-17, 1994.

National Fire Protection Association (NFPA), "SFPE Handbook of Fire Protection Engineering," Society of Fire Protection Engineers, Boston, Massachusetts, 1988.

Nichols, B.D. and W.S. Gregory, "FIRAC User's Manual: A Computer Code to Simulate Fire Accidents in Nuclear Facilities," NUREG/CR-4561, LA-10678-M, Los Alamos, New Mexico, 1986.

Owczarski, P.C., et al., "FPFP 2: Code for Following Airborne Fission Products in Generic Nuclear Plant Flow Paths." NUREG/CR-5658, U.S. Nuclear Regulatory Commission, Washington, D.C., 1991.

Pickrell, P.W., "Characterization of the Solid, Airborne Materials Created by the Interaction of UF6 with Atmospheric Moisture in a Contained Volume," K/PS-144, Nuclear Division, Union Carbide Corporation, April 30, 1982.

Pinkston, David, ed., "U.S. Department of Energy Defense Programs Safety Survey Report. Volume I: Main Report," DOE/DP/70056-H1, U.S. Department of Energy, Washington, D.C., 1993.

Portier, R.W., et al., "A User's Guide for CFAST Version 1.6," NISTIR 4985, National Institute of Standards and Technology, Gaithersburg, Maryland, 1992.

Summers, R. M., et al., "MELCOR 1.8.0: A Computer Code for Nuclear Reactor Severe Accident Source Term and Risk Assessment Analyses," NUREG/CR-5531, U.S. Nuclear Regulatory Commission, 1991.

Travis, J.R., K.L. Lam and T.L. Wilson, "GASFLOW: A Three-Dimensional Finite-Volume FluidDynamics Code for Calculating the Transport, Mixing and Combustion of Flammable Gases in Geometrically Complex Domains," LA-UR-94-2270, Los Alamos National Laboratory, Los Alamos, New Mexico, July 1994.

U.S. Nuclear Regulatory Commission (USNRC), "Assessment of the Public Health Impact from the Accidental Release of $\mathrm{UF}_{6}$ at the Sequoyah Fuels Corporation Facility at Gore, Oklahoma", NUREG-1189, Vol. 1, 1986.

Walton, W.D. and P.H. Thomas, "Estimating Temperatures in Compartment Fires," in the SFPE Handbook of Fire Protection Engineering, National Fire Protection Association, Quincy, MA, 1988.

Watson, J.P.H., "A Novel Permanently Magnetized High Gradient Filter using Assisted Capture for Fine Particles", Proceedings of the 23rd DOE/NRC Nuclear Air Cleaning Conference (M.W. First, Ed), NUREG/CP-0141 (CONF-940738), Harvard Air Cleaning Laboratory, Boston, Massachusetts, 02115, February 1995.

Williams, W. R., "Computer Programs for Developing Source Terms for a UF6 Dispersion Model to Simulate Postulated UF6 Release from Buildings", K/D-5695, Oak Ridge Gaseous Diffusion Plant, Oak Ridge, Tennessee, 1986. 


\section{CHAPTER 5 ATMOSPHERIC DISPERSION AND CONSEQUENCE MODELING}

\subsection{Purpose}

The purpose of this chapter is to explain atmospheric dispersion and consequence modeling. Different types of models, including the Gaussian model, the model for buoyant plumes, the jet model, and the heavy vapor model, are discussed.

This chapter is organized in the following way. Section 5.2 provides background on the types of atmospheric dispersion models and on the important phenomena that control atmospheric dispersion. There are four types of models that are discussed below. There is the "classical" Gaussian dispersion model, which applies to the case of a passive plume or puff release. A passive plume is one that does not disturb the ambient atmospheric turbulence. Then there are buoyant plumes, denser-than-air ("heavy") plumes, and high momentum jets. The overriding physical phenomenon that controls the atmospheric dispersion and dilution in all cases is atmospheric turbulence; Section 5.2 contains an introduction to the subject of turbulence. Other phenomena that influence atmospheric dispersion include a) inversion lids, b) dry deposition, c) wet deposition, d) building wake effects, e) suppression of lift-off of buoyant plumes in high windspeeds and/or in building wakes, f) complex terrain, $g$ ) weather changes and wind shifts, $h$ ) the formation of aerosols, and $i)$ the complex thermodynamics of mixtures of moist air and reactive chemicals such as hydrogen fluoride $(\mathrm{HF})$ and uranium hexafluoride $\left(\mathrm{UF}_{6}\right)$.

For the reader who is just beginning to learn the rudiments of atmospheric dispersion modeling, this may seem to be a formidable list of phenomena. The authors recommend first obtaining one of the publicly available Gaussian computer models, such as RASCAL (Athey et al. 1993) or HOTSPOT (Homman 1994), which are further discussed in Section 5.10. These models are easy to use and cover a number of the phenomena, such as the basic Gaussian model, elevated versus ground level releases, varying weather conditions, inversion lids, dry deposition, and building wakes. Sensitivity studies can be performed very quickly, and the user will soon gain an understanding of the relative importance of the various phenomena. With respect to complex terrain, most of the fuel cycle licensee facility accident analyses will probably not need to address this. However, if the reader wishes to investigate models of complex terrain, a good starting point is the review by Hosker (1981a) or in Section 13-10 of Atmospheric Science and Power Production (Randerson 1984). Section 5.3 contains some brief introductory material on these issues.

The next step should be to obtain one of the commercially available heavy vapor dispersion models. For example, SLAB (Ermak 1990) is relatively easy to use and enables the user to cover a wide range of phenomena relating to heavy vapors and jets. More complex models such as DEGADIS (Havens and Spicer 1985, 1988), HGSYSTEM (Hanna et al. 1994a, b), and the model prepared for NRC (Chhibber and Kaiser 1993) may take a week or two of a person's time, but, in the heavy vapor field, there is really no substitute for such a period of study and learning to use the models. Once the time has been invested, it becomes possible to run a wide variety of cases very quickly.

Section 5.3 discusses the basic Gaussian model, including how to determine stability categories and estimate the standard deviations. Modifications to the Gaussian model to take account of mixing height (inversion lids), building wakes, dry and wet deposition, radioactive decay, and resuspension are also presented. 
Section 5.4 consists of an introduction to the subject of buoyant plumes, including the potential suppression of lift-off in high windspeeds or in building wakes. Jet models and heavy vapor models are discussed in Sections 5.5. and 5.6, respectively. Special phenomena (aerosol formation, hydrogen fluoride/moist air thermodynamics, and uranium hexafluoride/moist air thermodynamics) are described in Section 5.7.

Section 5.8 consists of a brief review of how to proceed from the predictions of airborne concentration to the calculation of health effects.

Section 5.9 describes how to predict the effects of vapor cloud explosions, fires, and BLEVES (Boiling Liquid, Expanding Vapor Explosions). Finally, Section 5.10 discusses some of the available computer models.

\subsection{Types of Atmospheric Dispersion Models - Background}

This section begins with a brief introduction to the phenomenon that controls atmospheric dispersion, namely turbulence in the atmosphere and/or within the plume. The different kinds of dispersion models necessary in order for the analyst to have a range of tools that will be appropriate for all of the different kinds of source terms identified in Chapter 3 are discussed. In addition, the important phenomena that influence the calculation of airborne concentrations as a function of weather condition and distance downwind, such as dry depósition, wet deposition, and building wakes, are introduced. An excellent introductory reference to atmospheric dispersion (with the exception of heavy vapor models) is given in Atmospheric Science and Power Production (Randerson 1984).

\subsubsection{Introduction to Turbulence}

The study of atmospheric dispersion is primarily the study of the effect of turbulence, which consists of irregular, chaotic motions that cause a fluid such as the atmosphere to become mixed. In general, a turbulent fluid flow can be defined as one that has the ability to disperse embedded particles and gases at a rapid rate (Randerson 1984). Experimental evidence shows that the rate of turbulent dispersion is orders of magnitude greater than that due to molecular diffusion (so that a heavy vapor being mixed with air by turbulence will not separate into a heavy and a lighter layer under the influence of molecular diffusion).

Turbulence is the primary process by which momentum, heat, and moisture are fed into the atmosphere from the surface of the earth and then mixed over time and space. Turbulence tends to manifest itself as eddies of all sizes, the largest eddies being limited by the size of the fluid system, and the smallest being determined by the non-linear terms in the equation of motion. A continuous hierarchy exists from the largest down to the smallest eddies, with molecular diffusion being at the bottom of the scale. There is a continuous transfer of kinetic energy from the largest eddies down to the smallest ones, where the energy is dissipated as heat.

Turbulence tends to occur when there is a velocity gradient. In the atmosphere, when there is wind blowing over a rough surface, mechanical turbulence will be generated. Turbulence also occurs when there is convection. On a hot day, pockets of air that are warmed by heating of the surface rise into the atmosphere and are replaced by downward flows of air. These flows serve to disperse entrained materials and are known as convective turbulence in the atmosphere. 
Source terms themselves can also generate turbulence:

- A high velocity jet, such as might emerge through an orifice in a pipe under pressure, is highly turbulent and entrains the surrounding atmosphere by the action of mechanical turbulence.

- A buoyant plume is highly turbulent. This is illustrated in Figure 5-1, which displays a salt solution falling through water to simulate a buoyant plume (albeit one that is upside down). A beaker containing the salt solution was placed on a wheeled trolley above a tank of water. The denser salt solution was allowed to run through a tube into the water as the trolley was pulled along. The salt solution was made visible by shining a light through it. It was notable that, should a wisp of salt solution attempt to escape from the main body of the plume, it was immediately snatched back, such was the vigor of the turbulence within the plume. Furthermore, when the plume was traversed by a salt sensitive probe, the concentration distribution was very much a "top hat" one; that is, there was a distinct boundary between the plume and its surroundings and a constant concentration across the plume, evidence of rapid internal mixing.

- Plumes or puffs that are denser than air ("heavy" vapors) tend to slump. As they do so, the leading edge becomes highly turbulent, like a wave does (see Figure 5-2).

- Flashing liquid jets are those in which a material such as chlorine (when stored as a liquid under pressure) is released as a liquid, part of which immediately "flashes" to vapor. Some, or usually all, of the remaining liquid is fragmented and remains airborne. The whole flashing and fragmentation process is highly turbulent and air is entrained.

\subsubsection{Neutrally Buoyant Plumes (Gaussian Model)}

Neutrally buoyant plumes or puffs are those that do not possess turbulence of their own and do not influence the intensity of the ambient atmospheric turbulence. Their transport and dispersion are described by the Gaussian model, which is discussed below in Section 5.3. The Gaussian model essentially characterizes the movement of small particles or small pockets of gas as a series of random steps, caused by the action of atmospheric turbulence. Many of the radioactive releases described in this Handbook are neutrally buoyant.

\subsubsection{Buoyant Plumes}

As noted above, buoyant plumes are internally turbulent. As they rise, this internal turbulence entrains air and causes dilution. Plume rise will eventually cease, after which the plume can be regarded as being neutrally buoyant. Plume rise modeling is discussed in Section 5.4.

\subsubsection{Jets}

As noted above, high velocity jets generate mechanical turbulence. There are well established models for calculating the rate of entrainment of air into such plumes (see Section 5.5).

\subsubsection{Heavy Vapors}

Vapors may be heavy for one of several reasons. Some have molecular weights that exceed that of air (e.g., chlorine, propane). Others may be exceedingly cold when released (e.g., methane evaporating from a 


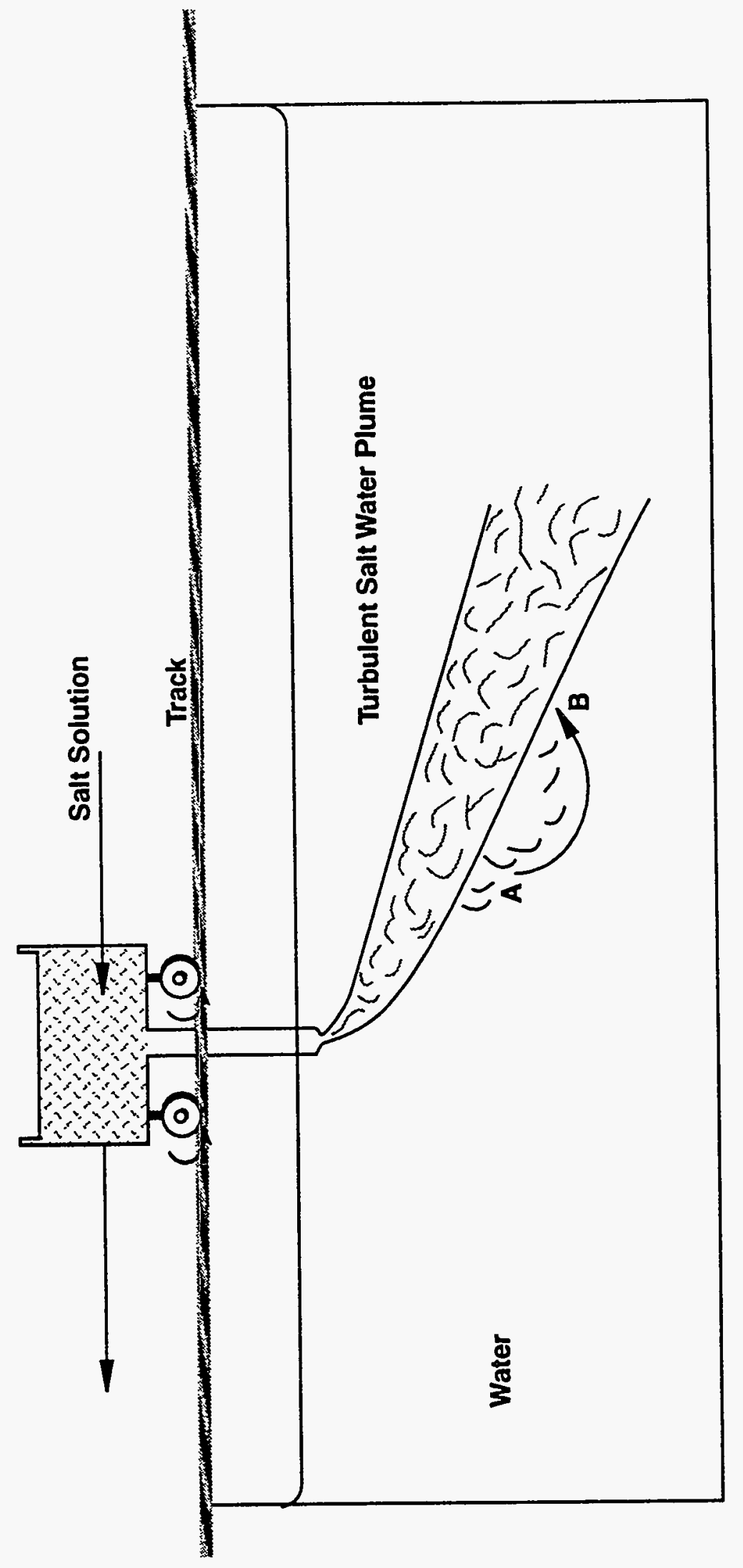

 


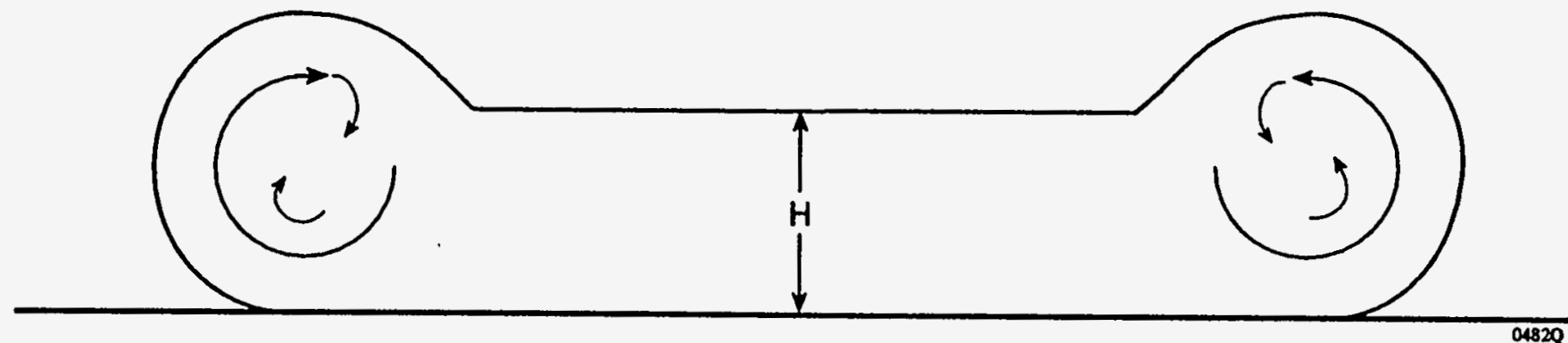

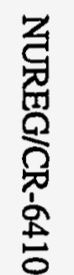

Figure 5-2. Slumping plume or puff-generation of turbulence at edge 
spill of Liquefied Natural Gas). Others may be heavy because the mode of release includes droplet or particulate formation (e.g., flashing liquid ammonia, chlorine, hydrogen fluoride, or uranium hexafluoride). For others, there may be unique thermodynamic effects. Pure HF vapor, for example, exists as a mixture of monomer, dimer, and hexamer, and has an effective molecular weight of about 70 at a temperature of $300 \mathrm{~K}\left(80^{\circ} \mathrm{F}\right)$. In this chapter, many of these reasons for being heavier-than-air are plausible for hazardous chemicals that can be released from fuel cycle facilities. However, they do not apply to radioactive releases, with the exception of uranium hexafluoride. See Section 5.6 for a discussion of heavy vapor modeling.

\subsection{The Gaussian Model}

The origin of the Gaussian model is found in work by Sutton (1932), Pasquill $(1961,1974)$, and Gifford (1961, 1968). It is the simplest and still the most widely used of the dispersion models. Its enduring popularity is primarily because:

- It produces results that agree well with experimental data

- It is fairly easy to perform mathematical operations on the basic equation

- It is consistent with the random nature of turbulence

- It has been referenced in many government guidebooks, thus acquiring a high level of acceptance.

In its basic form, it is suitable for modeling the dispersion of neutrally buoyant plumes. A neutrally buoyant plume is one in which the plume has the same density as air, with negligible relative momentum and negligible internal turbulence. With relatively simple modifications, the model can be made to account for various phenomena such as inversion lids, deposition, and building wakes.

\subsubsection{Gaussian Formulae}

The stability of the atmosphere within the atmospheric boundary layer largely determines the intensity of turbulence and, subsequently, the diffusion process which affects effluents released into this layer. The two most common approaches to describing turbulent diffusion are gradient transport theory and statistical theory.

The gradient transport theory deals with atmospheric transport at a fixed point proportional to the local concentration gradient. Since the focus of this theory is the atmospheric transport at a fixed point in space, it may be said to be Eulerian in nature. This means it considers properties of the fluid motion relative to a spatially fixed coordinate system.

The statistical theory differs from the gradient transport theory in that the history of motion of individual fluid particles is studied, and an attempt is made to characterize the statistical properties necessary to represent diffusion. In this approach, the coordinate system moves through space along with the plume and is Langrangian in nature.

For large diffusion times (e.g., nearly uncorrelated particle motion), the fundamental solutions to the equations based on both the gradient and statistical theories yield the well-known normal Gaussian distribution of the pollutant material in the atmosphere (Slade 1968; Pasquill 1974). The basic equation of the Gaussian plume model is derived from the solution to the statistical theory by taking into account all theoretical requirements, assumptions, and boundary conditions. A step-by-step derivation of this equation 
is beyond the scope of this guidance; for this information, reference is made to the original literature (i.e., Slade 1968; Hanna et al. 1982). The following is the basic equation of the Gaussian plume model:

$$
C(x, y, z)=\frac{Q_{r}}{2 \pi u \sigma_{y} \sigma_{z}} \exp \left(-\frac{y^{2}}{2 \sigma_{y}^{2}}\right)\left\{\exp \left(-\frac{\left(z-H_{e}\right)^{2}}{2 \sigma_{z}^{2}}\right)+\exp \left(-\frac{\left(z+H_{e}\right)^{2}}{2 \sigma_{z}^{2}}\right)\right\}
$$

where:

$$
\begin{array}{ll}
\mathrm{C}(\mathrm{x}, \mathrm{y}, \mathrm{z}) & =\text { concentration of pollutant at point }(\mathrm{x}, \mathrm{y}, \mathrm{z})\left(\mathrm{kg} / \mathrm{m}^{3} \text { or } \mathrm{Ci} / \mathrm{m}^{3}\right) \\
\mathrm{Q}_{\mathrm{r}} & =\text { release rate }(\mathrm{kg} / \mathrm{s} \text { or } \mathrm{Ci} / \mathrm{s}) \\
\mathbf{u} & =\text { mean plume velocity along x-axis }(\mathrm{m} / \mathrm{s}) \\
\sigma_{y_{1}} \sigma_{\mathrm{z}} & =\text { standard deviations of the distribution } \mathrm{C} \text { in the } \mathrm{y} \text { and } \mathrm{z} \text { directions, respectively }(\mathrm{m}) \\
\mathrm{x} & =\text { distance downwind }(\mathrm{m}) \\
\mathrm{H}_{\mathrm{c}} & =\text { effective release height of pollutant }(\mathrm{m}) \\
\mathrm{y} & =\text { horizontal location at right angles to the plume axis, with y equal to zero on the axis }(\mathrm{m}) \\
\mathrm{z} & =\text { height above ground }(\mathrm{m})
\end{array}
$$

The Gaussian model is displayed in Figure 5-3. To adequately understand the practical possibilities and limits in the application of the Gaussian plume model, the most important assumptions need to be discussed. In theory, the model is valid under the following basic conditions:

- Homogeneity of turbulence

- Stationary turbulence conditions and steady-state pollutant concentrations

- Sufficiently long diffusion times

- Spatially constant basic flow

- Nonzero windspeed

- The continuity condition must hold true, and

- Total reflection of the plume at the ground.

\subsubsection{Homogeneity of Turbulence}

Homogeneity of turbulence means that the plume constituents exhibit normal distributions in both the $y$ and $\mathrm{z}$ directions (cross wind and vertical directions, respectively). In the real atmosphere, this state practically never occurs. Horizontal homogeneity occurs when the local topography exhibits only minor variations (i.e., mechanical turbulence is minimal), as in the case of flat plains with very little surface roughness. Vertical homogeneity occurs even less often, because of the continual changes in convective turbulence produced by diurnal heating and cooling that are always present. A typical example of the vertical inhomogeneity of the atmosphere is the increase of the windspeed with height.

\subsubsection{Stationary Turbulence Conditions and Steady-State Pollutant Concentration}

In the derivation of the basic Gaussian plume model, it is assumed that the atmospheric turbulence and release source strength are constant in terms of time. In reality, neither of these parameters is constant over prolonged periods. The turbulence in the atmosphere varies with the diurnal cycle of insolation and 


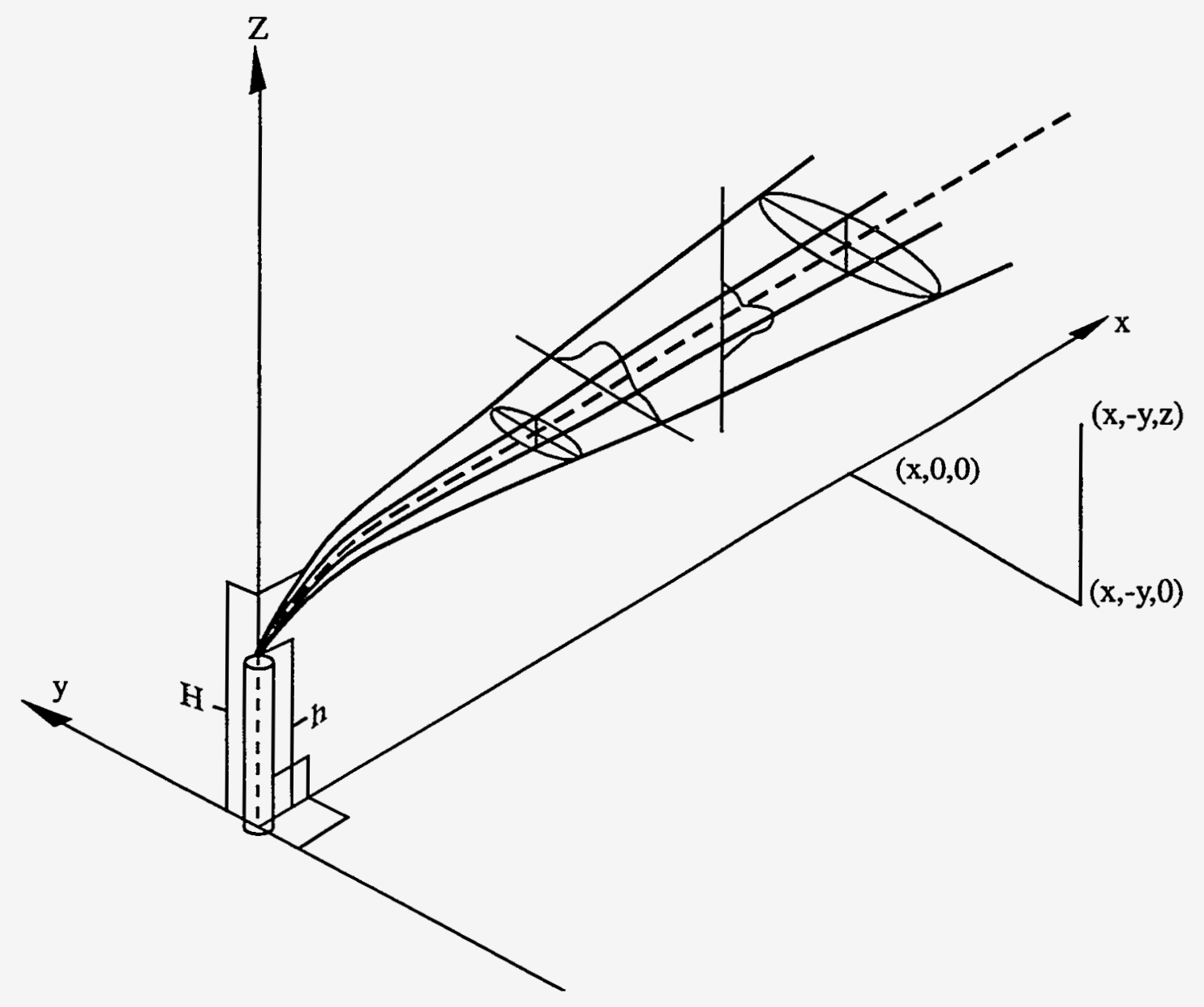

Figure 5-3. Coordinate system showing Gaussian distributions in the horizontal and vertical planes 
changes in the general weather conditions. The release of pollutants into the atmosphere is also likely to vary over time, particularly under conditions postulated during accident analysis. This implies that the pollutant concentrations can be calculated according to the model for relatively short time periods only. If a calculation of pollutant concentration is required for longer periods of time (i.e., days, months, years), theduration of release must be broken into intervals in which the stationary condition is fulfilled. The contributions from each interval are then superimposed to obtain the total contribution.

\subsubsection{The Effect of Diffusion Times}

Pollutant concentrations calculated using the Gaussian plume model represent a mean value over a certain diffusion time (Slade 1968). The equations for the standard deviations of the Gaussian concentration distribution (i.e., $\sigma_{y}, \sigma_{z}$ ) are representative of plume characteristics averaged over a finite time of observation. The longer the time over which the observations are averaged, the larger the standard deviations, the larger the diffusion, and the wider the plume boundaries.

Consequently, concentrations downwind decrease, with increasing averaging times due primarily to an increase in the meander of wind direction. The longer averaging times tend to smooth out the fluctuations in the parameters used to determine atmospheric turbulence. The implications of this condition are shown in Figure 5-4.

Eddy currents within the atmospheric boundary layer influence the rate of diffusion and plume direction. Intuitively, the influence of small eddies decreases as the plume grows, since small oscillations of particles deep within the plume do not contribute to movement of the plume as a whole. Eddies with diameters larger than the plume dimension influence the direction of the plume and cause it to meander (see Figure 5-5). Thus, as the diffusion time increases and the plume reaches greater and greater distances and grows in size, larger and larger, turbulent eddy sizes become effective in diffusing the plume, and smaller eddies become increasingly ineffective.

If the time-averaged diagrams of the plume shown in Figure 5-4 were extended to distances quite far from the source, the boundaries of the time-smoothed plume (e.g., $2 \mathrm{hr}$ averaging time) would meander, because the plume would come under the influence of eddies that are quite large in area. Consequently, the original averaging times would be too short to show a time-averaged picture of these larger fluctuations.

As a result, for increasing distances from the source, the averaging time must be increased in order to obtain a sufficiently smooth pollutant distribution. Otherwise, the concentrations observed do not generally correspond with the concentrations calculated according to equation 5.1. Another effect is that equation 5.1 is not able to predict short-period fluctuations (i.e., single instantaneous values of pollutant concentrations in the air). Due to the very long averaging time for the assessment of routine releases, this is of little importance. However, in the case of accidental releases, this may lead to difficulties, since, for very short averaging times, it becomes impossible to make an adequate prediction of the short-term concentration.

\subsubsection{Significance of the Spatially Constant Basic Flow}

In principle, the spatial constancy of the basic flow is a property that is already covered by the requirements of homogeneity. However, this property can limit the practical application of the Gaussian plume model. 


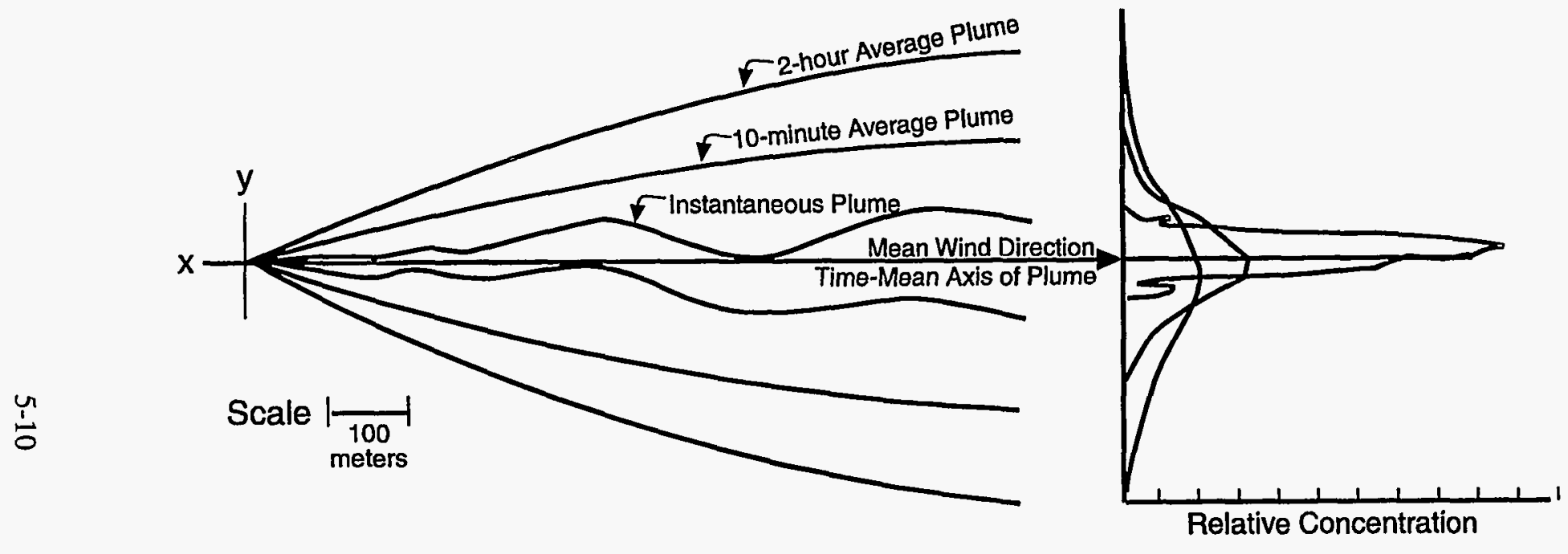

0628Q-7

Figure 5-4. The effect of averaging time on plume width

[The diagram on the left represents the approximate outlines of a smoke plume released instantaneously and of plumes averaged over $10 \mathrm{~min}$. and $2 \mathrm{~h}$.

The diagram on the right shows the corresponding cross-wind distributions] 


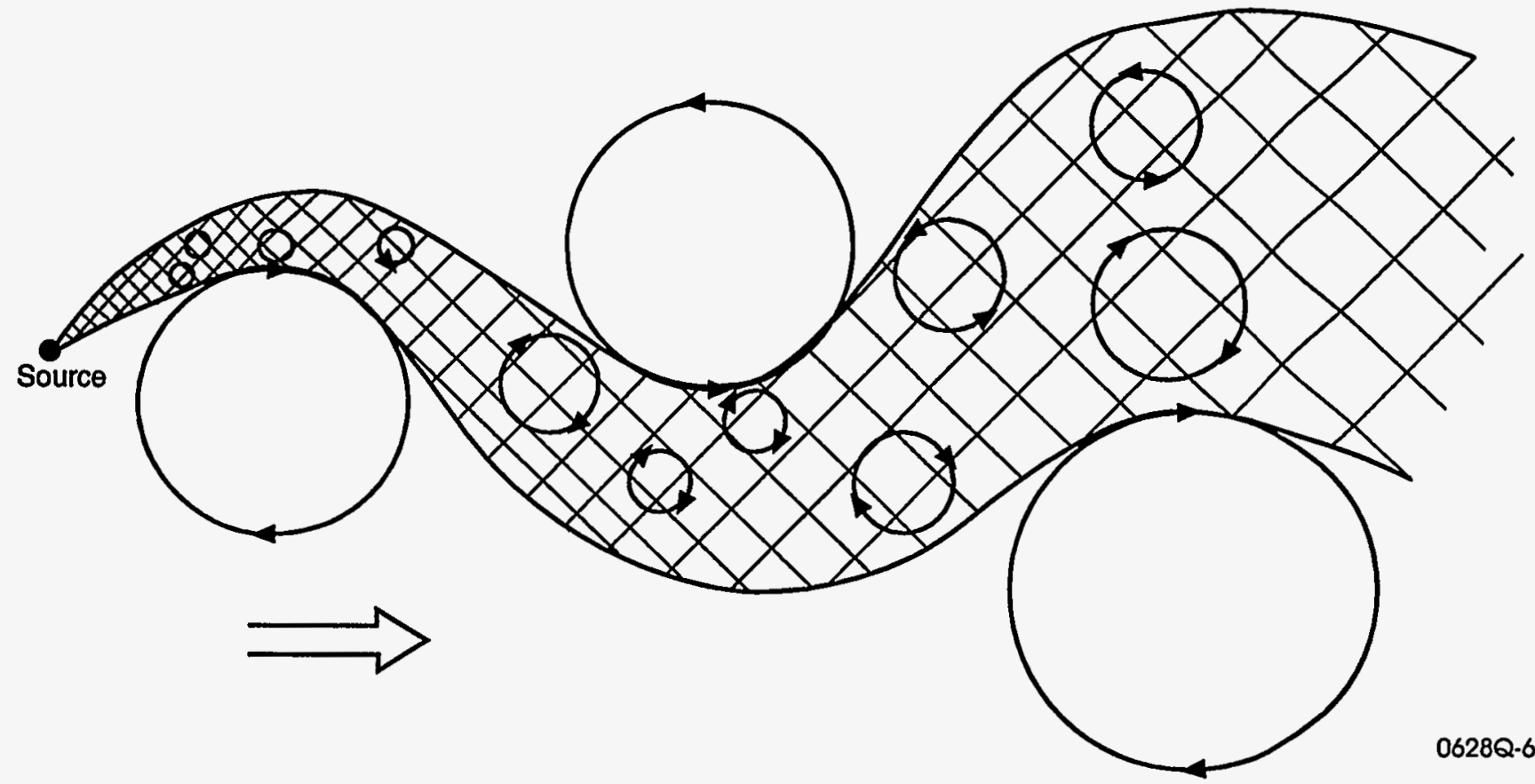

Figure 5-5. Plume meander

[Eddies that are larger than the plume tend to cause the plume to meander; whereas those that are smaller tend to cause mixing.] 
For horizontal changes, this requirement is essentially fulfilled. In the vertical direction, as mentioned previously, there is a pronounced wind profile which changes depending on surface roughness, geographical latitude, and stability of the atmosphere. The velocity of the wind increases in proportion to the height, with the wind direction initially remaining constant with height, but then changing to the geostrophic wind direction at greater heights. The geostrophic wind depends on air density, Coriolis force, and pressure gradient. As a result, a relatively quick change of the wind velocity in proportion to height takes place in the lower boundary layer, which is important to pollutant diffusion near ground level.

Many Gaussian plume models do not account for the vertical wind profile. However, the model does require the windspeed at the effective release height. As a result, if the release height is different from the height at which the windspeed is measured, a correction may need to be applied.

\subsubsection{Nonzero Windspeed}

Another important condition for the application of the Gaussian plume model is that diffusion along the $\mathrm{x}$ axis (e.g., direction of travel) is small compared to transport and can be neglected (Pasquill 1974). This condition is generally true for windspeeds above approximately $0.5 \mathrm{~m} / \mathrm{s}(1.1 \mathrm{mph})$. In the real atmosphere, this condition is usually fulfilled, particularly for heights above $100 \mathrm{~m}(330 \mathrm{ft})$. For lower heights (e.g., ground releases), where there is a higher fraction of calms, the Gaussian plume model does not always strictly apply. For cases of very low windspeeds, it becomes necessary to introduce the diffusion term in the $x$ direction and, thus, base the calculation on the Gaussian puff model (Start et al. 1974; Doury 1980; Vogt et al. 1978) or on more sophisticated models.

\subsubsection{Condition for Continuity and Total Reflection at the Ground}

Continuity of the emitted material is maintained, or, in other words, none is removed from or added to the plume as it moves downwind, and there is complete reflection at the ground. In the real atmosphere, neither condition of continuity is fulfilled. Both sources (i.e., resuspension of material) and removal mechanisms (i.e., deposition, decay, etc.) exist. These discontinuities in the atmosphere are not accounted for in the derivation of the Gaussian plume model. However, it is common practice to account for these effects by introducing factors into the calculations to balance the amount of material transported.

The assumption of total reflection at the ground is not fulfilled either, since, in reality, material is deposited as the plume contacts the ground. This assumption leads to an overestimation of the pollutant concentration in air and, therefore, yields more conservative exposure values.

\subsubsection{Practical Consequences}

Although the theoretical assumptions and boundary conditions for the Gaussian plume model are rarely fulfilled in the atmosphere, through development of the diffusion parameters ( $\sigma$ s) from the results of field studies, the Gaussian model can produce results which are in reasonable agreement with data.

\subsubsection{Atmospheric Stability Categories}

As a result of the requirement for stationary turbulence conditions, it is necessary to categorize the different states of turbulence in the atmosphere (as identified by experimental results) in such a way that a relevant set of diffusion parameters (i.e., $\sigma_{y}, \sigma_{z}$ ) can be determined for all states of turbulence. The American Meteorological Society (AMS 1983) has published recommendations in this area. 
The term "stability" refers to the rate of mixing within the atmospheric boundary layer. Simple methods define this layer as existing in one of three conditions: unstable, neutral, and stable. If the layer is unstable, the vertical motion of a parcel of air is enhanced. If the layer is stable, the vertical motion of a parcel of air is damped. If the layer is neutral, the vertical motion is neither enhanced nor damped. A plume in a stable atmosphere is narrow, both vertically and horizontally; a plume in an unstable atmosphere is broad, both vertically and horizontally; and a plume in a neutral atmosphere is somewhere in between.

Atmospheric turbulence can be determined by direct measurement; however, due to the difficulty and expense, this is usually not practical. Consequently, atmospheric turbulence is usually inferred from available meteorological information. The Gaussian plume model has been expressed in terms of diffusion parameters, $\sigma_{y}, \sigma_{z}$, where diffusion is directly related to the degree of turbulence. The most subjective and controversial aspect of using the model is the selection of appropriate horizontal or vertical coefficients. For an estimate of $\sigma_{y}$ and $\sigma_{z}$ in the absence of direct measurements of turbulence, the stability class must first be determined, preferably by a simple method based on inexpensive and easy measurements.

Most published curves of $\sigma_{y}$ and $\sigma_{z}$, as a function of downwind distance and stability, are based on a few diffusion experiments performed during the 1950s and 1960s. The most widely used scheme for classifying atmospheric turbulence was developed by Pasquill (1961). The criteria for Pasquill's original classification considered the relationship of windspeed, insolation (amount of incoming solar radiation), and cloudiness. Six classifications are distinguished from A (highly unstable) to F (highly stable). Table 5-1 presents the meteorological conditions used to derive the Pasquill stability classes (Hanna et al. 1982; Turner 1967).

Table 5-1. Pasquill Stability Categories

\begin{tabular}{|llllll|}
\hline A & Extremely unstable & C & Slightly unstable & E & Slightly stable \\
B & Moderately unstable & D & Neutral $^{\mathrm{a}}$ & F & Moderately stable \\
\hline
\end{tabular}

\begin{tabular}{|c|c|c|c|c|c|}
\hline \multirow[b]{2}{*}{$\begin{array}{c}\text { Surface } \\
\text { windspeed at } \\
10 \mathrm{~m}(\mathrm{~m} / \mathrm{s})\end{array}$} & \multicolumn{3}{|c|}{ Daytime Insolation } & \multicolumn{2}{|c|}{ Nighttime Conditions } \\
\hline & strong & moderate & slight & $\begin{array}{c}\text { thinly } \\
\text { overcast or }> \\
3 / 8 \text { cloud } \\
\text { cover }^{\mathrm{b}}\end{array}$ & $\begin{array}{c}\leq 3 / 8 \text { cloud } \\
\text { cover }\end{array}$ \\
\hline $\begin{array}{l}<2 \\
2-3 \\
3-5 \\
5-6 \\
>6\end{array}$ & $\begin{array}{c}A \\
A-B \\
B \\
C \\
C\end{array}$ & $\begin{array}{c}A-B \\
B \\
B-C \\
C-D \\
D\end{array}$ & $\begin{array}{l}\text { B } \\
\text { C } \\
\text { C } \\
\text { D } \\
\text { D }\end{array}$ & $\begin{array}{l}\text { E } \\
\text { D } \\
\text { D } \\
\text { D } \\
\end{array}$ & $\begin{array}{l}\text { F } \\
\text { E } \\
\text { D } \\
\text { D }\end{array}$ \\
\hline
\end{tabular}

"Applicable to heavy overcast day or night.

'The degree of cloudiness is defined as that fraction of sky above the local apparent horizon that is covered by clouds. 
The classifications and resulting curves developed by Pasquill were adapted by Gifford into the form shown in Figure 5-6 (Gifford 1968). Because of the origins of the diffusion measurements used for the derivation of the Pasquill-Gifford curves, these functions are strictly applicable for short-term (6-10 min) releases near ground level in uniform terrain out to distances less than $1 \mathrm{~km}(0.6 \mathrm{mi})$. Extrapolation of sigma values out to distances on the order of $100 \mathrm{~km}(62 \mathrm{mi})$ have little basis in observation. They may require modification before application to situations in which terrain effects and special meteorological conditions exist (see sections 5.3.3-5.3.6).

There are several other systems that are widely used to classify atmospheric turbulence. Many of these systems use only one parameter. Three of the more common methods include:

- temperature lapse rate ( $\Delta \mathrm{T}$ or vertical temperature gradient)

- the horizontal fluctuation of the wind direction

- the split sigma approach

\subsubsection{Temperature Lapse Rate}

The temperature lapse rate method uses the vertical temperature gradient between two levels in the atmosphere to characterize both the horizontal and vertical turbulence. The measurements are relatively simple and inexpensive to perform on a fixed tower. Many dispersion experiments have been conducted over a period of years to determine the correlation between temperature lapse rate and measured conditions. Based on these studies, a correspondence between temperature lapse rate and the Pasquill stability classes has evolved. This relationship is presented in Table 5-2, for a temperature gradient measured over $100 \mathrm{~m}$ ( $330 \mathrm{ft})$. Note that NRC has added an "extremely stable" class (" $G$ ") because of the concern about accidental releases of radioactive material from nuclear power plants during low-windspeed, very stable conditions.

Measurements through deeper atmospheric layers do not properly reflect changes nearer the surface. $\Delta T$ is a poor indicator of unstable conditions and should not be considered as the best stability indicator for evaluating diffusion from elevated release points (at heights above about $100 \mathrm{~m}(330 \mathrm{ft})$ ). $\Delta \mathrm{T}$ is probably most useful in estimating turbulence intensity during low-windspeed, stable conditions, because the measurement is unaffected by instrument response to windspeed. $\Delta \mathrm{T}$ is primarily an indicator of vertical diffusion.

\subsubsection{Horizontal Fluctuation of Wind Direction}

Horizontal fluctuations in the wind direction are the direct result of the intensity of turbulence and are functions of surface characteristics and measurement height. The standard deviation of the horizontal wind direction fluctuations $\left(\sigma_{\theta}\right)$ have been related to stability classes. Large $\sigma_{\theta}$ values result in wide plumes (unstable conditions), and small values, narrow plumes (stable conditions). Table 5-3 presents the $\sigma_{\theta}$ classification scheme promulgated by the NRC, based on an analysis performed by Slade (Slade 1968; USNRC 1972).

The applicability of the $\sigma_{\theta}$ method is determined by the responsiveness of the measurement instrumentation and the methodology used to calculate the standard deviation of the fluctuations. Some wind vanes are not sufficiently responsive at low windspeeds to allow a meaningful determination of wind direction fluctuations. NRC has recommended that $\sigma_{\theta}$ be used only for windspeeds greater than $1.5 \mathrm{~m} / \mathrm{s}$ 


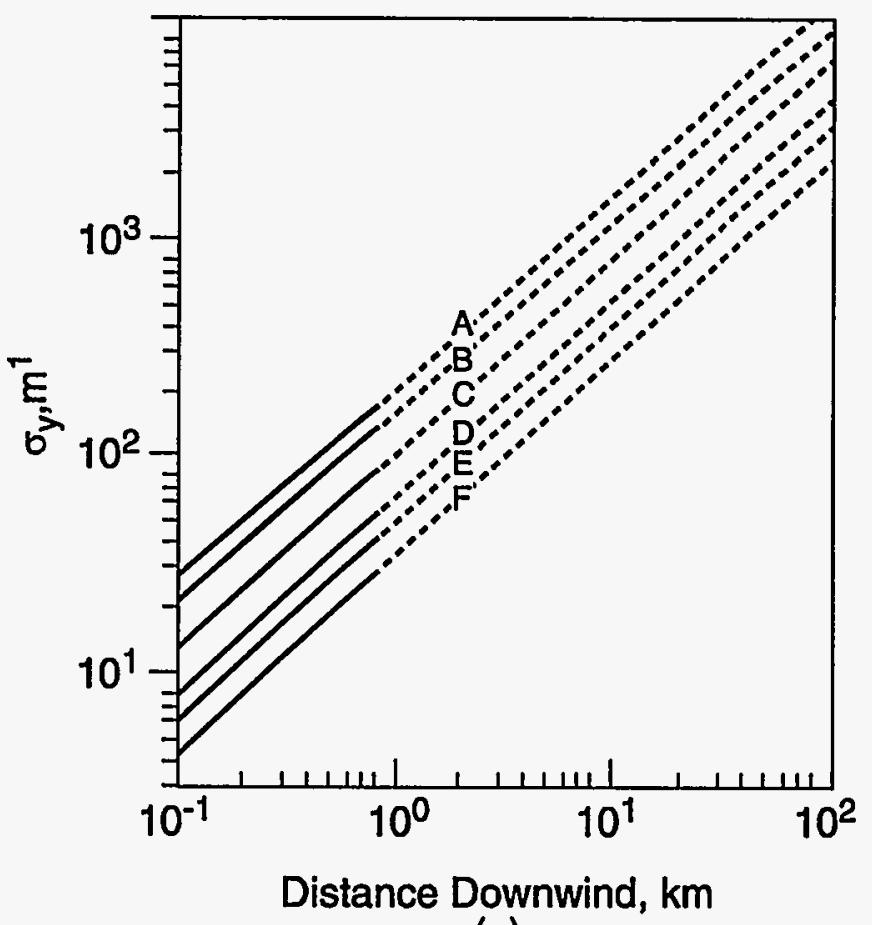

(a)

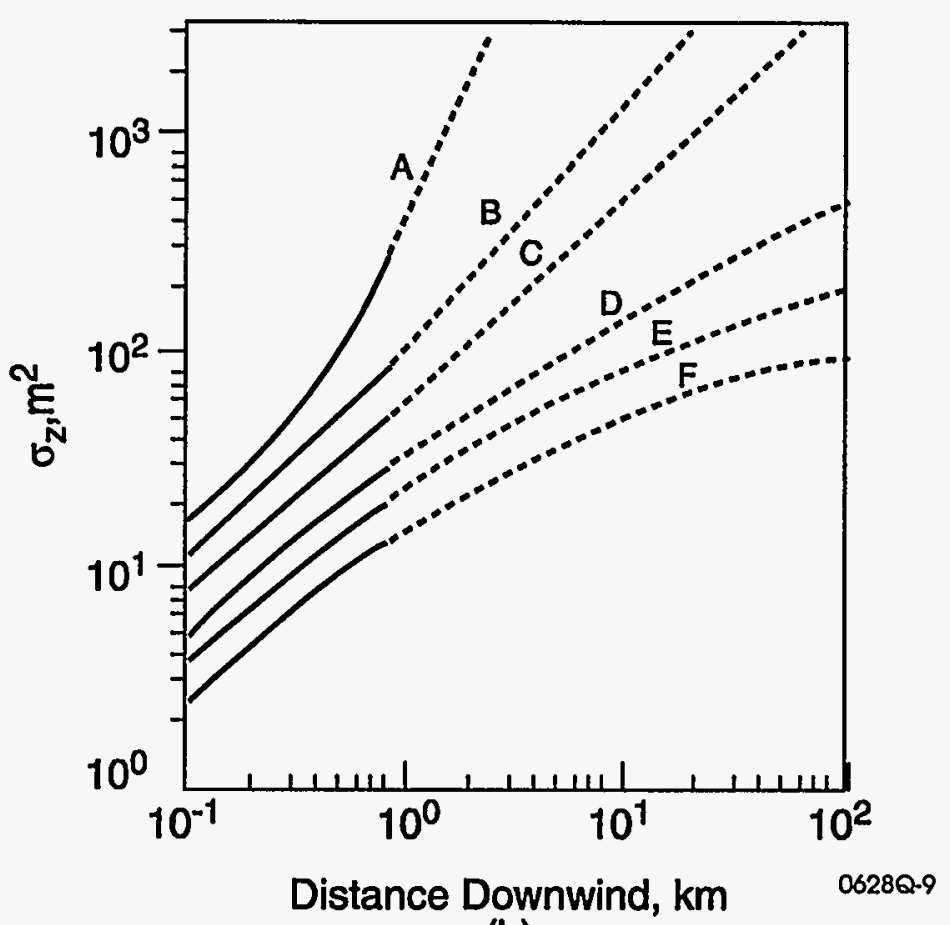

(b)

1. $\sigma_{\mathrm{y}}$ : horizontal standard deviation

1. $\sigma_{z}:$ vertical standard deviation

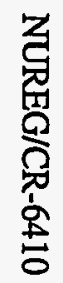

Figure 5-6. Curves of $\sigma_{y}$ and $\sigma_{z}$ for turbulence types based on those reported by Pasquill as modified by Gifford (Hanna, et al. 1982) 
Table 5-2. Classification of Atmospheric Stability by Temperature Lapse Rate

\begin{tabular}{|l|c|c|}
\hline \multicolumn{1}{|c|}{ Stability Classification } & Pasquill Categories & $\begin{array}{c}\text { Temperature Change with } \\
\text { Height }\left({ }^{\circ} \mathrm{C} / 100 \mathrm{~m}\right)\end{array}$ \\
\hline Extremely unstable & A & $\Delta \mathrm{T} / \Delta \mathrm{z} \leq-1.9$ \\
\hline Moderately unstable & $\mathrm{B}$ & $-1.9<\Delta \mathrm{T} / \Delta \mathrm{z} \leq-1.7$ \\
\hline Slightly unstable & $\mathrm{C}$ & $-1.7<\Delta \mathrm{T} / \Delta \mathrm{z} \leq-1.5$ \\
\hline Neutral & $\mathrm{D}$ & $-1.5<\Delta \mathrm{T} / \Delta \mathrm{z} \leq-0.5$ \\
\hline Slightly stable & $\mathrm{E}$ & $-0.5<\Delta \mathrm{T} / \Delta \mathrm{z} \leq 1.5$ \\
\hline Moderately stable & $\mathrm{F}$ & $1.5<\Delta \mathrm{T} / \Delta \mathrm{z} \leq 4.0$ \\
\hline Extremely stable* & $\mathrm{G}$ & $4.0<\Delta \mathrm{T} / \Delta \mathrm{Z}$ \\
\hline
\end{tabular}

*The NRC developed $\sigma_{y}$ and $\sigma_{z}$ curves for " $G$ " stability using the following relationships to the $\sigma_{y}$ and $\sigma_{z}$ curves for " $F$ " stability:

$$
\begin{aligned}
& \sigma_{y}(G)=2 / 3 \sigma_{y}(F) \\
& \sigma_{z}(G)=3 / 5 \sigma_{z}(F)
\end{aligned}
$$

Table 5-3. Classification of Atmospheric Stability ${ }^{2}$ by Standard Deviation of Horizontal Wind Direction $\left(\sigma_{\theta}\right)$

\begin{tabular}{|l|c|c|}
\hline \multicolumn{1}{|c|}{ Stability classification } & Pasquill categories & $\sigma_{\theta}{ }^{b}(\mathbf{d e g})$ \\
\hline Extremely unstable & $\mathrm{A}$ & $\sigma_{\theta} \geq 22.5$ \\
\hline Moderately unstable & $\mathrm{B}$ & $22.5>\sigma_{\theta} \geq 17.5$ \\
\hline Slightly unstable & $\mathrm{C}$ & $17.5>\sigma_{\theta} \geq 12.5$ \\
\hline Neutral & $\mathrm{D}$ & $12.5>\sigma_{\theta} \geq 7.5$ \\
\hline Slightly stable & $\mathrm{E}$ & $7.5>\sigma_{\theta} \geq 3.8$ \\
\hline Moderately stable $^{\prime}$ & $\mathrm{F}$ & $3.8>\sigma_{\theta} \geq 2.1$ \\
\hline Extremely stable $^{\mathrm{c}}$ & $\mathrm{G}$ & $2.1>\sigma_{\theta}$ \\
\hline
\end{tabular}

"Use of $\sigma_{\theta}$ to represent atmospheric stability when windspeeds are less than $1.5 \mathrm{~m} / \mathrm{s}$ should be verified by local experimentation. If $\sigma_{\theta}$ is to be used as an indicator of vertical diffusion (atmospheric stability), adjustments to the sampling interval may be needed to eliminate wind fluctuations in the horizontal which do not occur in the vertical, especially during nighttime conditions.

'Determined for a 15 min to $1 \mathrm{~h}$ period for horizontal diffusion.

The NRC has included a " $G$ " stability class for comparability with the temperature lapse rate scheme.

(3.4 $\mathrm{mph}$ ) and that at least 180 instantaneous values of wind direction be used to achieve a meaningful representation of the standard deviation (USNRC 1972). $\sigma_{\theta}$ is regarded primarily as an indicator of horizontal diffusion. 


\subsubsection{Split Sigma}

To accommodate their respective strengths, the $\sigma_{\theta}$ and $\Delta T$ schemes are sometimes used in conjunction with what is called the "split sigma" approach. In this approach, the horizontal stability class is derived according to $\sigma_{\theta}$ and the vertical, according to $\Delta \mathrm{T}$, and $\sigma_{y}$ and $\sigma_{z}$ values, are determined accordingly. The $\Delta \mathrm{T}$ method is generally used to represent a single stability class for windspeed conditions less than $1.5 \mathrm{~m} / \mathrm{s}$ (3.4 mph).

\subsubsection{Stability Categories Defined by Reference to Both Temperature Difference and Windspeed}

In the PRA Procedures Guide (USNRC 1983d), NRC recommended the use of the scheme summarized in Table 5-4. This is usually a practical and easily implemented way in which to define the stability category.

Table 5-4. Stability Categories Defined by Reference to Both Temperature Difference and Windspeed ${ }^{2}$

\begin{tabular}{|c|c|c|c|c|c|c|}
\hline \multirow{2}{*}{$\begin{array}{c}\text { Windspeed } \\
\text { (m/sec) }\end{array}$} & \multicolumn{6}{|c|}{$\Delta \mathrm{T} / \Delta \mathrm{Z}\left({ }^{\circ} \mathrm{C} / 100 \mathrm{~m}\right)$} \\
\cline { 2 - 7 } & $<-1.9$ & $\mathbf{- 1 . 9}$ to -1.7 & -1.7 to -1.5 & -1.5 to -0.5 & -0.5 to 1.5 & 1.5 to 4 \\
\hline$<2$ & A & B & B & B & E & F \\
\hline 2 to 3 & A & B & C & C & E & F \\
\hline 3 to 5 & B & B & C & D & E & F \\
\hline 5 to 6 & C & C & C & D & D & D \\
\hline$>6$ & C & C & C & D & D & C \\
\hline
\end{tabular}

'Scheme based on the typing scheme recommended by Pasquill and the scheme presented in NRC Regulatory Guide 1.23.

\subsubsection{Formulae for Standard Deviations}

To use the Gaussian model to make practical estimates, the appropriate values for the diffusions parameters $\sigma_{y}$ and $\sigma_{z}$ must be selected for travel distance, surface conditions and meteorological conditions under consideration. If turbulence measurements are available, it is preferable to estimate $\sigma_{y}$ and $\sigma_{z}$, where the derived formulae are functions of travel distance and atmospheric stability class. These formulae are often incorporated into computerized atmospheric transport and dispersion models.

A widely used set of formulas was developed by Briggs (Briggs 1973), who combined the Pasquill curves with curves derived from data observed at Brookhaven National Laboratory and the Tennessee Valley Authority. The equations are associated with dispersion experiments conducted over short grassy surfaces and include observations out to a downwind distance of $10 \mathrm{~km}$ (6.2 mi). Taking into consideration relationships between terrain roughness and $\sigma_{z}$ developed by other researchers, Briggs also developed formulae for rough urban surfaces. Briggs' formulae are considered applicable from a distance of $0.1 \mathrm{~km}$ to $\sim 10 \mathrm{~km}(0.06 \mathrm{mi}$ to $\sim 6.2 \mathrm{mi})$ and can be extended to 20 or $30 \mathrm{~km}(12.4$ or $18.6 \mathrm{mi})$, although the author does not recommend this extension. In practice, for lack of any other validation schemes, these formulas are commonly used out to a distance or $100 \mathrm{~km}$. Briggs' formulas are given in Table 5-5. Other 
Table 5-5. Formulae Recommended by Briggs (1973) for $\sigma_{y}(x)$ and $\sigma_{z}(x)$ (where $\mathrm{x}$ is downwind distance: $10^{2} \mathrm{~m}<\mathrm{x}<10^{4} \mathrm{~m}$ )

\begin{tabular}{|c|c|c|}
\hline $\begin{array}{l}\text { Pasquill } \\
\text { type }\end{array}$ & $\therefore \quad \boldsymbol{\sigma}_{\mathbf{y}} \mathbf{m}$ & $\boldsymbol{\sigma}_{\boldsymbol{z}}, \mathbf{m}$ \\
\hline \multicolumn{3}{|c|}{ Open-Country Conditions } \\
\hline $\mathrm{A}$ & $0.22 \mathrm{x}(1+0.0001 \mathrm{x})^{-3 / 2}$ & $0.20 \mathrm{x}$ \\
\hline $\mathrm{B}$ & $0.16 x(1+0.0001 x)^{-1 / 2}$ & $0.12 x$ \\
\hline $\mathrm{C}$ & $0.11 \times(1+0.0001 x)^{-3 / 2}$ & $0.08 \times(1+0.0002 x)^{-3 / 2}$ \\
\hline $\mathrm{D}$ & $0.08 x(1+0.0001 x)^{-3 / 2}$ & $0.06 x(1+0.0015 x)^{-1 / 2}$ \\
\hline$E$ & $0.06 x(1+0.0001 x)^{-1 / 2}$ & $0.03 x(1+0.0003 x)^{-1 / 2}$ \\
\hline $\mathrm{F}$ & $0.04 x(1+0.0001 x)^{-1 / 2}$ & $0.016 x(1+0.0003 x)^{-2 / 2}$ \\
\hline \multicolumn{3}{|c|}{ Urban Conditions } \\
\hline A-B & $0.32 \mathrm{x}(1+0.0004 \mathrm{x})^{-1 / 2}$ & $0.24 x(1+0.001 x)^{-1 / 2}$ \\
\hline $\mathrm{C}$ & $0.22 x(1+0.0004 x)^{-3 / 2}$ & $0.20 x$ \\
\hline $\mathrm{D}$ & $0.16 x(1+0.0004 x)^{-3 / 2}$ & $0.14 \mathrm{x}(1+0.0003 \mathrm{x})^{-1 / 2}$ \\
\hline E-F & $0.11 x(1+0.0004 x)^{-1 / 2}$ & $0.08 x(1+0.00015 x)^{-3 / 2}$ \\
\hline
\end{tabular}

mathematical approximations to the Pasquill-Gifford curves, has been developed by Martin and Tikvart (1968), Tadmor and Gur (1969), and Hosker (1974). An excellent survey of cloud growth parameters is given by Gifford (1976).

\subsubsection{Mixing Height}

As mentioned previously, vertical diffusion is assumed to apply to material released into the atmospheric boundary layer (or mixing layer). Vertical diffusion of material is effectively limited by the inversion that marks the top of the layer. The depth of this layer is, therefore, of concern in atmospheric diffusion calculations. The height of the atmospheric boundary layer generally ranges from $\sim 200$ to $\sim 2000 \mathrm{~m}$ $(\sim 0.12$ to $\sim 1.2 \mathrm{mi})$. Within this layer, ground surface effects are important. Diurnal variations in air temperature due to heating and cooling of the earth's surface are discernible. Windspeed tends to increase, and wind direction varies with height as a result of reduced friction between the air and the earth's surface.

The depth of the mixing layer is a function of the thermal and roughness characteristics of the surface. During the day, the thermal characteristics are usually the dominant factor in determining the mixing layer thickness. When surface heating is the driving force of turbulence in the mixing layer, it is frequently referred to as the convective boundary layer and usually ranges from $\sim 500$ to $\sim 2000 \mathrm{~m}(\sim 0.31$ to $\sim 1.2 \mathrm{mi}$ ) in depth. At night and in stable conditions, when surface heating is reduced, turbulence is generated by surface roughness, and the thickness of the boundary layer is reduced, generally ranging from $\sim 100$ to $\sim 200 \mathrm{~m}(\sim 0.06$ to $\sim 0.12 \mathrm{mi})$ in depth.

The rate of diffusion across the "boundary" that marks the top of the mixing layer is small compared to the rate of diffusion within the mixing layer. The height of the mixing layer is called the mixing height. After 
an effluent plume diffuses to the mixing height, the concentration distribution in the vertical will become more uniform. Mixing heights change diurnally and seasonally, generally being largest on summer afternoons and least on autumn mornings.

Mixing heights also vary considerably by geographic location. Holzworth (1972) has published extensive summaries of mixing height information for the United States.

Since the vertical diffusion is limited by the mixing layer height, when a plume has traveled a sufficient horizontal distance, the calculated value of the vertical diffusion coefficient $\left(\sigma_{z}\right)$ exceeds the inversion height $(\ell) \sigma_{z}$ is set to the value $\ell$ and, equation 5.1 becomes:

$$
\begin{aligned}
& \sigma_{z}>\ell: \\
& C(x, y, z)=\frac{Q_{r}}{(2 \pi)^{1 / 2} u \sigma_{y} \ell} \exp \left(-\frac{y^{2}}{2 \sigma_{y}^{2}}\right)
\end{aligned}
$$

To avoid the sharp transition between equations 5.1 and 5.2, some computer codes start the transition into the inversion layer equation when $\sigma_{\mathrm{z}}$ reaches a pre-established percentage of $\ell$ and completes the transition when $\sigma_{z}$ equals $\ell$. Between these two values, the code interpolates between the two equations.

If the material is released above the mixing height or with enough vertical energy to penetrate the mixing layer, vertical diffusion can be greatly restricted, resulting in high plume concentrations at relatively large distances from the source. Due to the limited vertical diffusion above the layer, the plume remains above ground level and sets up the potential for a condition called fumigation. Fumigation can occur when the plume diffuses vertically (or the depth of the mixing layer increases) until it reaches the level of the mixing layer boundary (Hanna 1982). At that time, the plume can mix rapidly to the ground (see Figures 5-7 and 5-8). For a discussion of this effect, see Randerson (1984).

\subsubsection{Effective Release Height}

The factors affecting effective release height are the actual release height, plume rise, and aerodynamic effects of structures and terrain. Mathematically, the effective release height is the algebraic sum of these factors and is generally presented in the form:

$$
\mathrm{H}_{c}=\mathrm{h}_{\mathrm{s}}+\mathrm{h}_{\mathrm{pr}}-\mathrm{h}_{\mathrm{T}}-\mathrm{c}
$$

where:

$$
\begin{aligned}
& \mathrm{H}_{\mathrm{c}}=\text { effective release height }(\mathrm{m}) \\
& \mathrm{h}_{\mathrm{s}}=\text { physical stack height }(\mathrm{m}) \\
& \mathrm{h}_{\mathrm{pr}}=\text { plume rise }(\mathrm{m}) \\
& \mathrm{h}_{\mathrm{T}}=\text { height of terrain }(\mathrm{m}) \\
& \mathrm{c}=\text { aerodynamic wake correction factor }
\end{aligned}
$$

There is an extensive literature base related to plume rise, and numerous models are available for its estimation. Briggs (1984) has summarized available plume rise models, and plume rise is discussed in several of the references provided (see Section 5.4 for further discussions). There is also extensive 


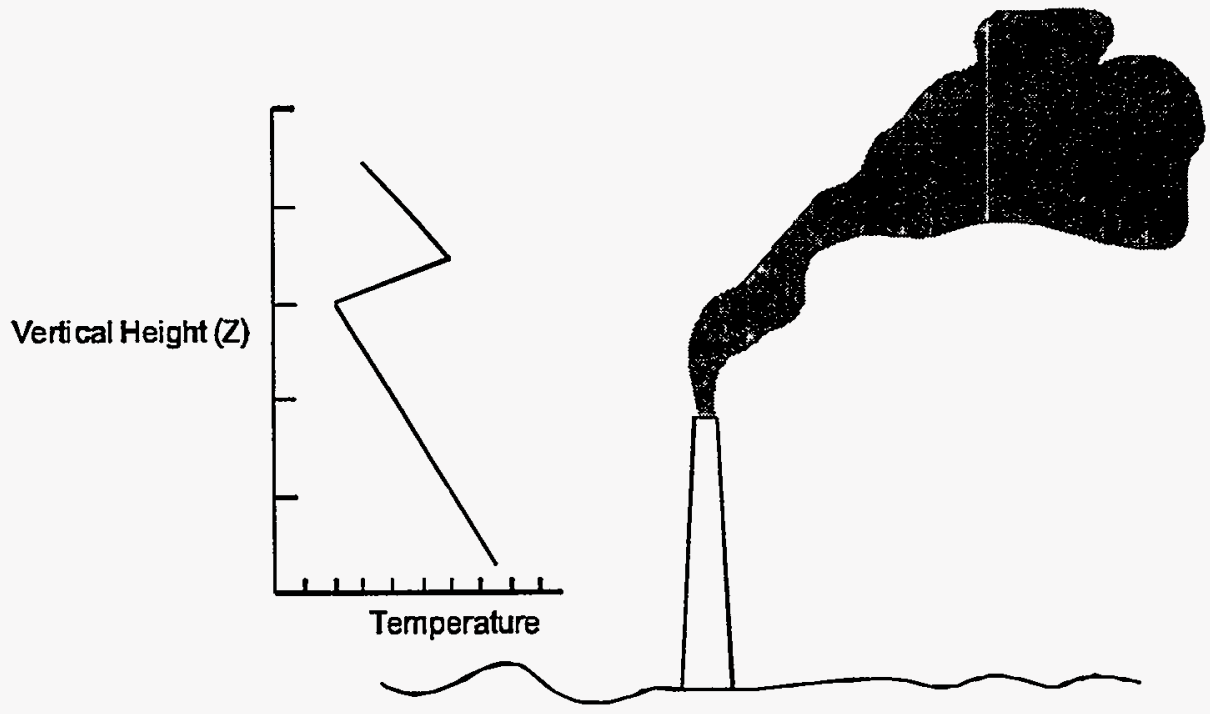

Figure 5-7. Diagram of buoyant plume penetrating an elevated inversion

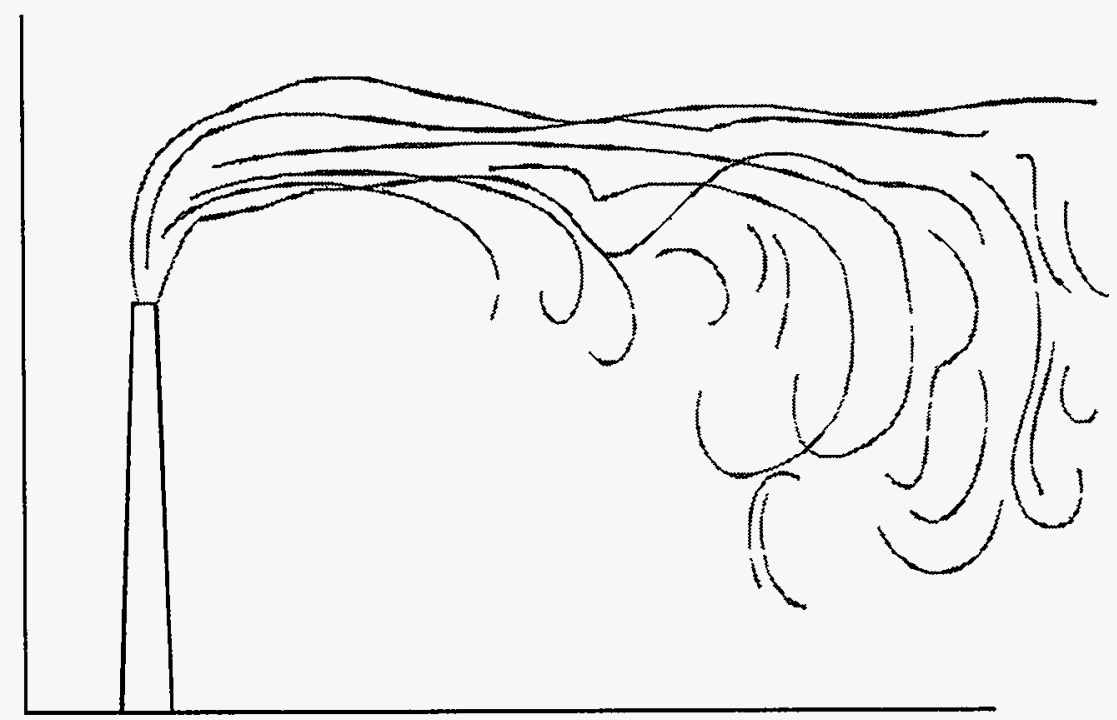

Figure 5-8. Neutral below, stable above (fumigation) 
literature on aerodynamic effects (e.g., Briggs 1973; Hosker 1981a, b; Hanna et al. 1982; Randerson 1984); however, due to the complexity of real structures and terrain, they tend to focus on simple isolated shapes and qualitative descriptions. In determining effective stack height during conditions of low windspeed, physical stack height and plume rise are the dominant factors, while physical stack height and the aerodynamic correction are dominant during high winds.

Plume rise may increase the effective stack height by appreciable factors ( 2 to 10$)$, and, because the maximum ground-level concentration is roughly proportional to the inverse square of the effective stack height, plume rise can reduce ground-level concentrations by as much as a factor of 100 . Plume rise may be due either to momentum, buoyancy, or a combination of both. For most plumes, early rise is probably dominated by momentum. During normal operations, most fuel cycle facilities do not generate enough heat to make buoyancy a significant factor in plume rise; however, this can be a significant factor under accident conditions (e.g., fire). Plume rise due to momentum is a complex function of the exit velocity, atmospheric stability, and windspeed.

Aerodynamic effects are caused by the perturbations of the air flow around structures close to the point of release. For example, low pressure in the wake of a stack may cause the plume to be drawn downward behind the stack. Downwash can be effectively prevented by maintaining the effluent exit velocity $\left(w_{0}\right)$ at a magnitude greater than the windspeed $(\mathrm{u})$. It is generally recognized that downwash will not occur for $w_{0} / u$ greater than 1.5. For $w_{0} / u$ less than 1.5, Briggs (1973a) suggests that the distance $\left(h_{d}\right)$ the plume downwashes below the top of the stack can be estimated by the following formula:

where:

$$
h_{d}=2\left(\frac{w_{0}}{u}-1.5\right) D
$$

$\mathrm{D}=$ the internal stack diameter, as illustrated in Figure 5-9

\subsubsection{Building Wakes}

Building wake effects are generally not considered significant for elevated releases. The distinction between releases considered as ground-level and those considered elevated is somewhat ill-defined. In general, observation has shown that, if the release height is 2.5 times greater then the height of adjacent buildings, few downwash problems occur. Another common approach is to consider a release to be ground-level when the release point is below the height of the associated buildings. Releases that occur in the range between 2.5 times the height of adjacent buildings and the building height escape the building wake under certain conditions, become completely entrained into the building wake under certain conditions, or behave as mixtures of these two types for the remaining conditions.

U.S. Nuclear Regulatory Commission Regulatory Guide 1.111 (USNRC 1977) suggests that, for effluents released at the level of or above adjacent solid structures, but lower than elevated release points (e.g., 2.5 times rule of thumb), the effluent should be considered as an elevated release whenever the vertical exit velocity of the plume $\left(w_{0}\right)$, is at least five times the horizontal windspeed $u$, at the height of release (e.g., $\mathrm{w}_{0} / \mathrm{u} \geq 5.0$ ). If $\mathrm{w}_{0} / \mathrm{u}$ is less than 1.0 or unknown, a ground-level release should be assumed. It is also suggested that, for cases where $\mathrm{w}_{0} / \mathrm{u}$ is between 1.0 and 5.0, a mixed mode should be assumed. Suggested entrainment coefficients are provided for mixed mode release conditions.

As a result of many wind-tunnel experiments and field measurements, rèsearchers have developed a fairly good idea of the flow around a simple building, as illustrated in Figure 5-10. The important features of the 


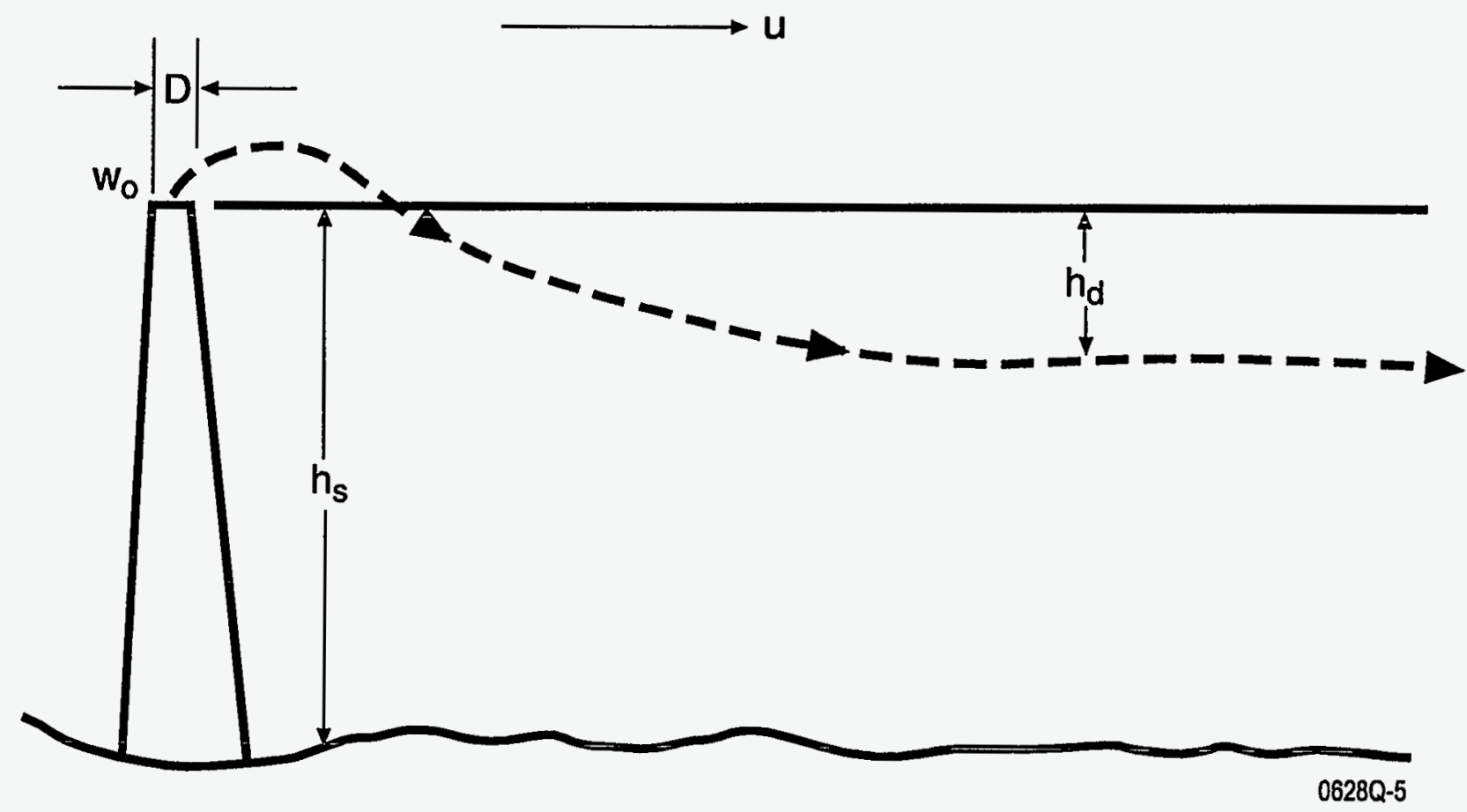

Figure 5-9. Schematic diagram of stack and important physical parameters: $w_{0}$, effluent velocity; $u$, windspeed; d, internal stack diameter; $h_{s}$, stack height; and $h_{d}$, downwash distance 


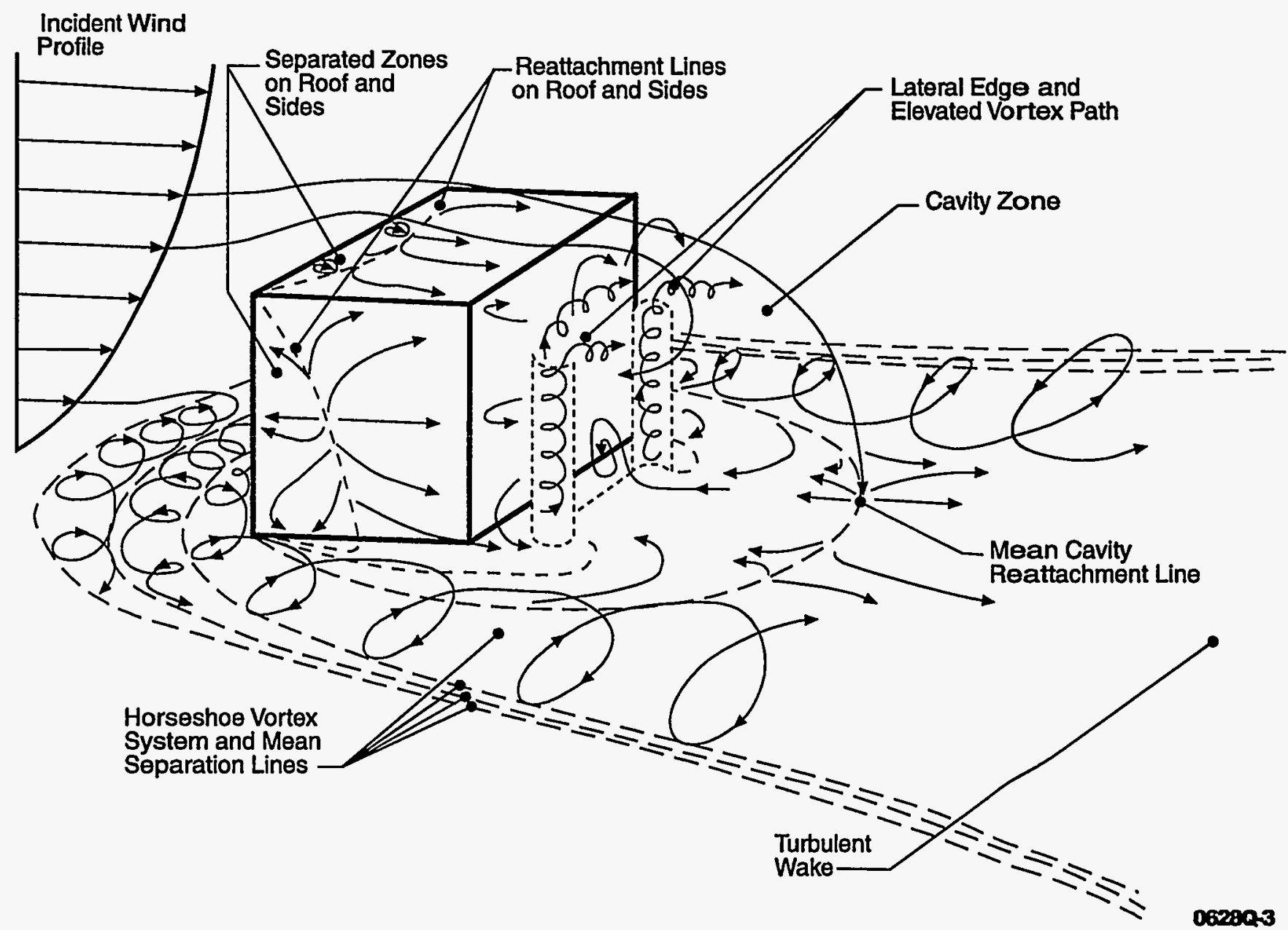

Figure 5-10. Model of flow near a sharp-edged building in a deep boundary layer 
diagram are the separated recirculation zones on the roof and sides, the turbulent wake cavity zone, and the turbulent wake.

Material released at or nearby the building will most likely by entrained into the wake, thus increasing diffusion.

Modifications to $\sigma_{y}$ and $\sigma_{z}$ can be made to take into consideration the effects of nearby buildings. Most techniques assume that the wind is perpendicular to the building face; if it is not, the flow is drastically changed, and the assumptions made to develop the modifications do not hold. A discussion of the effect of wind incidence angle on diffusion near buildings can be found in Randerson (1984). The most common form of the Gaussian model to consider the effect of building wakes for short-term plume centerline calculations is (Hanna et al. 1982).

$$
C(x, y, z)=\frac{Q_{r}}{\left(\pi \sigma_{y} \sigma_{z}+c A\right) u}
$$

where:
$A=$
cross-sectional area of the building normal to the flow
$c=$ "shape factor" to represent the fraction of A over which the plume is dispersed; $c=0.5$ is a conservative value which is commonly used

Using this equation to represent conditions at short distances from the building leads to unrealistically effective diffusion and dilution because the magnitude of the cross-sectional area completely overwhelms small values of $\sigma_{y}$ and $\sigma_{z}$. As a result, the NRC has recommended (USNRC 1977) that the effect of building wake on diffusion be limited to no more than $\sqrt{3}$ of the diffusion expected without the building for short-term centerline calculations. For determination of the building wake effect for long sampling times, the adjustment is made only to $\sigma_{z}$, because diffusion is assumed to be uniform in the horizontal direction over the region of interest. This adjustment takes the form:

$$
\begin{aligned}
& \quad \Sigma_{\mathrm{z}}=\left(\sigma_{\mathrm{z}}^{2}+\frac{\mathrm{H}_{\mathrm{B}}^{2}}{2 \pi}\right)^{1 / 2} \leq \sqrt{3} \sigma_{\mathrm{z}} \\
& \text { and } \\
& \Sigma_{\mathrm{z}}=\sqrt{3} \sigma_{\mathrm{z}} \text { when }\left(\sigma_{\mathrm{z}}^{2}+\frac{\mathrm{H}_{\mathrm{B}}^{2}}{2 \pi}\right)^{1 / 2}>\sqrt{3} \sigma_{\mathrm{z}}
\end{aligned}
$$

where:

$\Sigma_{z}=$ the adjusted vertical diffusion parameter

$\mathrm{H}_{\mathrm{B}}=$ maximum adjacent building height, either upwind or downwind from the release point

NRC guidance to staff and licensees describes several acceptable methods for estimating dispersion in building wakes, for example Regulatory Guide 1.111 (USNRC 1977 (Regulatory Guide 1.145(USNRC 1983b), and the Murphy-Campe procedure (Murphy 1974) referenced in Standard Review Plan 6.4 (USNRC 1987). Work performed in support of power reactor control room habitability assessments has 
examined the accuracy of these models. The results (Ramsdell 1988), show that the models do not predict the variations in atmospheric concentrations that are due to changes in building area and atmospheric conditions very well. They also show that the models significantly over predict concentrations at low wind speeds (Ramsdell 1995a).

A revised model has been developed (Ramsdell 1995a and 1995b) that does not over predict concentrations at low wind speeds. The revised model is a Gaussian model that uses modified diffusion coefficients. The modified diffusion coefficients consist of three components. The first component is a standard diffusion coefficient. The second component is a low speed correction to the standard diffusion coefficient. The correction, which accounts for enhanced dispersion resulting from meander, is larger at low wind speeds and decreases as the wind speed increases. The third component is a building-wake correction. The correction is a function of building area and wind speed. It is small at. low wind speeds and increases as the wind speed increases. Turbulence parameters have been evaluated using experimental data and model performance has been evaluated against alternative models which do not use the Gaussian method as a basis (Ramsdell 1995a).

\subsubsection{Complex Terrain}

Irregular terrain also affects diffusion and the applicability of standard diffusion parameters.

Complications to the general Gaussian analysis methodology can be introduced by everything from rolling hills to steep mountains, as well as spatial variations in surface heating rates due to albedo, moisture, or vegetation. At present, there is no generalized method of calculating diffusion and transport in complex terrain. Each situation is different and some form of site specific characterization is often required to develop an adequate model.

Perhaps the major uncertainty introduced into the analysis plume diffusion and transport is the result of strong space- and time-dependent local circulation caused by complex terrain features. These systems of motion depend on the scale of the terrain features, their height, and steepness, as well as the large-scale atmospheric structure consisting of temperature and windspeed and direction. Specific application requires the development of a relationship between source dimensions and terrain structure.

Some assessment should be made of the importance of the terrain effects prior to investing the resources and effort necessary to formulate and run complicated terrain specific models. For example, for a site having well separated, relatively isolated topographical obstacles, if the dimensions of the obstacles are small compared to the plume dimensions when the plume encounters any individual obstacle, the features are likely to have only a minor influence on plume deflection or growth. Wind fields in a large valley or basin may be distinctly governed by topography, but well documented by a series of observation sites. Unless the dynamics of the winds are important to the application, observed winds or historical data may be sufficient for the analysis. However, careful judgement must be exercised before extrapolating one or two surface meteorological observation data sets to an entire region. Topographic variations are likely to have more effect under light wind and stable conditions than in the daytime with vigorous winds and unstable conditions.

Numerical or physical models can be used to estimate flow over complex terrain. Most of the work prior to 1975 has been reported by Egan (1975). Numerical models in use are mostly "research-grade". In practice, it is difficult to obtain the necessary detail (small grid size) while still retaining a large enough domain size to cover the area of interest. Physical models of flow over complex terrain have been reviewed by Hosker (1981a), who points out that the most obvious effects occur when the flow is stratified. 
Discussions of specific complex terrain situations, such as urban heat island, diurnal mountain/valley flow, coastal environments, vegetative canopies, and others, can be found in the referenced literature. (e.g., Randerson 1984, Hanna 1982)

\subsubsection{Variable Trajectory Gaussian Models}

Variations in the basic Gaussian model equation can be used to account for temporal and spatial variations in the meteorological parameters. The straight-line Gaussian models differ from the variable trajectory models in their treatment of the division between transport and diffusion. Straight-line Gaussian models concentrate on the diffusion of material and treat transport implicitly by assuming infinite temporal and spatial persistence of the wind direction, windspeed, and diffusion conditions existing at the time of the release. The variable trajectory models treat the transport and diffusion separately and explicitly.

Straight-line Gaussian models are most appropriate for use in those aspects of facility licensing where statistical treatment of meteorological conditions is reasonable. They are also of value in making initial consequence estimates during emergency response; however, their utility diminishes as the distance from the facility increases. Beyond a few kilometers downwind, additional compensating measures should be incorporated into the assessment methodology.

Variable trajectory Gaussian models require a wind field in their explicit treatment of transport. In general, the wind fields used tend to be two-dimensional, and can be derived from surface wind data and adjusted to the height of release using standard meteorological relationships that are a function of surface roughness and stability. They normally assume a constant windspeed and direction throughout the vertical extent of the boundary layer. Two of the most common forms of the variable trajectory Gaussian model are the segmented plume model and the puff transport model.

\subsubsection{Segmented Plume Model}

The segmented plume model normally keeps all variables constant with time, except for wind direction, windspeed, and atmospheric stability, which are allowed to vary. Segments of time are selected (usually $15 \mathrm{~min}$ or $1 \mathrm{~h}$ intervals) so that only broader scale fluctuations or deviations are considered. The "plume" is allowed to disperse in a downwind direction until the next time segment is encountered, when meteorological conditions are allowed to vary. The plume then grows under the new meteorological conditions until the next time interval, when the computation process is repeated. As a result, the dispersion plume is allowed to represent the Gaussian distribution under varying conditions. Figure 5-11 provides a representation of a segmented plume.

As with the straight-line model, it is assumed that there is a continuous emission from the source, diffusion in the direction of transport may be neglected, the material released remains suspended for long periods of time, and the plume constituents display a Gaussian distribution in both crosswind and vertical directions. In addition, it is assumed that meteorological conditions change uniformly across the area of plume transport, and that no other dynamic meteorological conditions (e.g., crosswind flows, vertical uplifting, etc.) occur.

The segmented plume model may assist in representing those locations where wind trajectory deviations, caused by terrain effects or diurnal variations of the wind, exist. The segmented plume model does require additional modifications to account for varying stability classifications between time intervals and for the handling of calm wind conditions. 


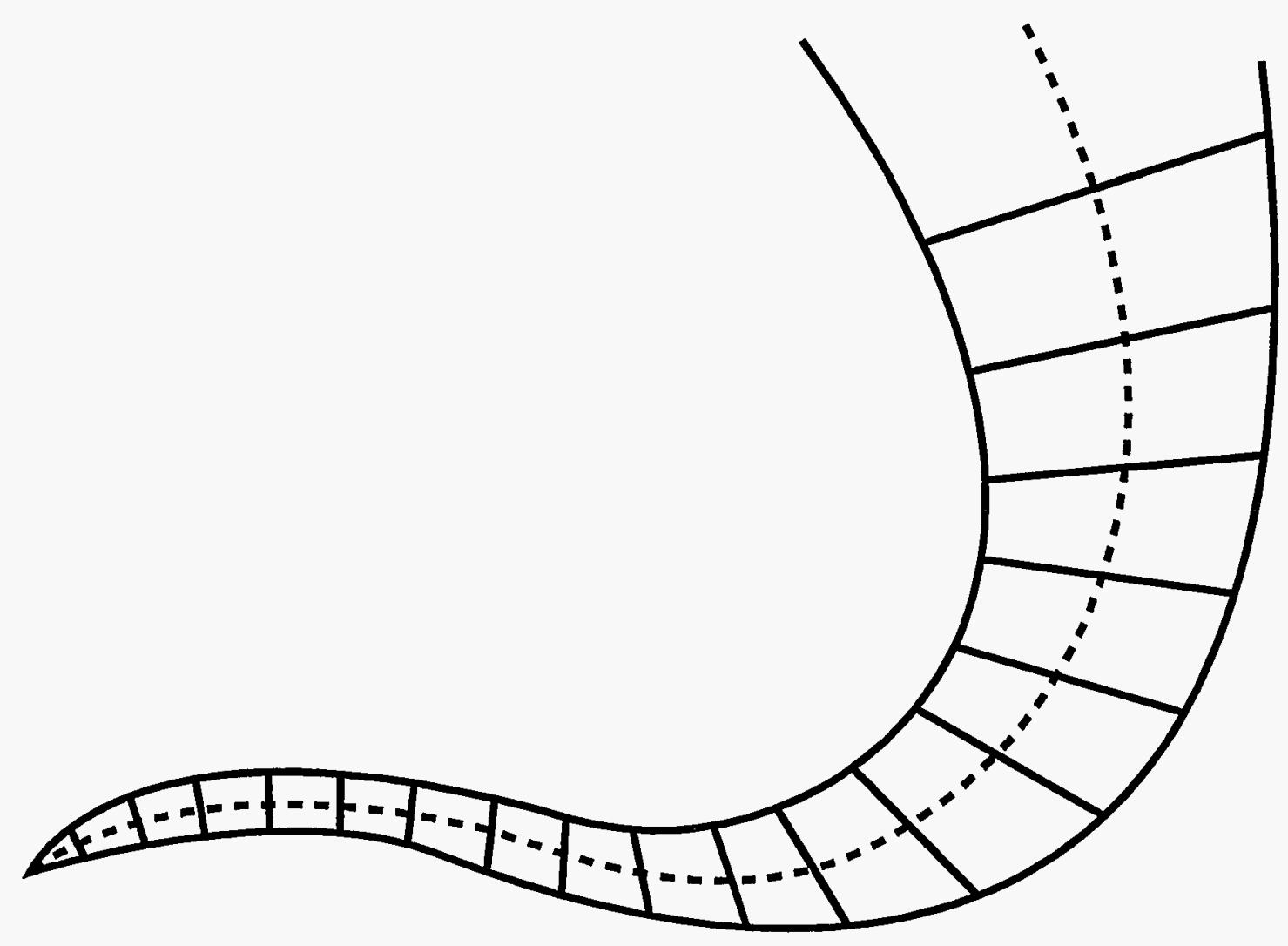

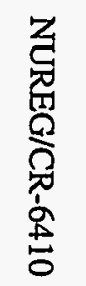

Figure 5-11. Segmented plume model

062ва-2 
Except for handling the results of computations, the basic equations used in the straight-line Gaussian dispersion model are also used for the segmented plume model.

\subsubsection{Puff Transport Model}

The puff transport model uses a series of discrete puffs to approximate a continuous plume. Each puff emitted by the source has its own source strength and release height. At finite intervals (usually $15 \mathrm{~min}$ ), windspeed, wind direction, mixing depth, and stability are updated. During the next interval, all puffs move under the influence of the updated meteorological conditions. The use of discrete puffs permits temporal variations in source characteristics and both spatial and temporal variations in meteorological conditions. For instance, the source can be turned off, and material previously released will remain on the receptor grid until removed by meteorological conditions. As a result, the puff formulation is applicable to both a continuous release over a long period of time and an instantaneous release occurring over a very short period of time. This model is illustrated in Figure 5-12.

The interval between releases of puffs varies with meteorological conditions. Windspeed and stability class at the source are used to select a puff release rate that will maintain sufficient overlapping of successive puffs to ensure an accurate approximation of a continuous plume.

In the simplest models, the puffs are assumed to have a circular cross section (i.e., $\sigma_{\mathrm{x}}=\sigma_{\mathrm{y}}$ ). Diffusion of the material in puffs is assumed to be Gaussian in nature. Ground-level concentration of a contaminant, $j$, at a receptor within a puff, $I$, is given by the equation:

$$
C_{j}(r)=\frac{Q_{r}}{(2 \pi)^{1.5} \sigma_{y}^{2} \sigma_{z}} \exp \left(-\frac{r^{2}}{2 \sigma_{y}^{2}}\right) \exp \left(-\frac{H_{c}^{2}}{2 \sigma_{z}^{2}}\right)
$$

where:

$$
\begin{array}{ll}
\mathrm{C}_{\mathrm{j}}(\mathrm{r}) & =\text { ground level concentration of pollutant } \mathrm{j} \text { at } \mathrm{r}_{\mathrm{i}}\left(\mathrm{kg} / \mathrm{m}^{3}\right) \\
\mathrm{Q}_{\mathrm{r}} & =\text { total quantity of pollutant released during puff interval }(\mathrm{kg}) \\
\mathrm{r} & =\text { radial distance from puff center to receptor }(\mathrm{m}) \\
\sigma_{\mathrm{y}, 2} & =\text { standard deviations of the distribution in the y and } \mathrm{z} \text { directions, respectively }(\mathrm{m}) \\
\mathrm{H}_{\mathrm{e}} & =\text { effective puff release height }(\mathrm{m})
\end{array}
$$

The algorithm identifies receptors within the circular footprint of each puff out to a distance of $3 \sigma_{y}$ from the puff center. Total ground level concentration of pollutant is the sum of concentrations from all puffs affecting that receptor.

Diffusion coefficients are calculated as a function of atmospheric stability and puff travel distance. This relationship is differentiated with respect to travel distance to obtain the rates of change of the diffusion coefficients with respect to travel distance. For each time interval, the diffusion coefficients are calculated for the current stability class for each puff. This method ensures that each puff diffuses as a function of time regardless of its straight-line distance from the source. 


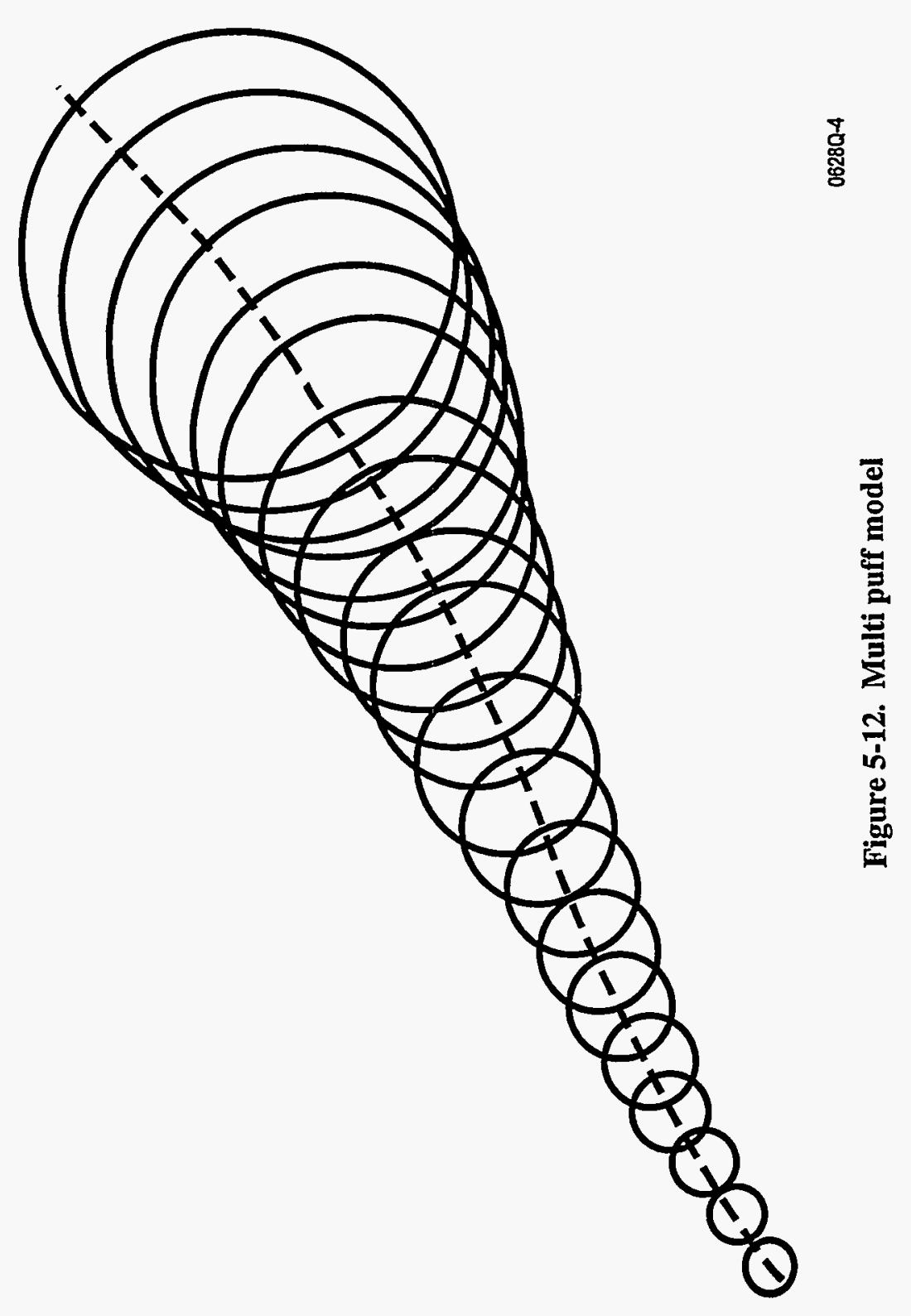

5-29

NUREG/CR-6410 
Equation 5.7 above is used to calculate ground-level concentrations from a puff whose vertical extent has not exceeded the current mixing depth. A Gaussian distribution of material in the vertical is assumed. When a puff's vertical extent exceeds the mixing depth, material in the puff is assumed to have a uniform vertical distribution in the current and each succeeding time interval (see Section 5.3.3).

\subsubsection{Removal Mechanisms}

As material released to the atmosphere moves downwind, many processes are acting upon the plume, which affect the total quantity of material transported. Figure 5-13 illustrates a number of these processes. Figure 5-13 is applicable to a great number of different kinds of facilities.

\subsubsection{Dry Deposition}

Particles with radii greater than about $5 \mu \mathrm{m}\left(2.0 \times 10^{-4}\right.$ in)can have significant gravitational settling velocities $(v)$. Stokes' law for terminal gravitational settling velocities is valid for particles with radii $r$ less than 10 to $30 \mu \mathrm{m}\left(4 \times 10^{-4}\right.$ to $1.2 \times 10^{-3}$ in) (depending on particle density):

$$
v_{t}=\frac{2 r^{2} g \rho_{p}}{9 \mu}
$$

where:

$\mathrm{r} \quad=$ particle radius $(\mathrm{m})$

$\rho_{\mathrm{p}}=$ particle density $\left(\mathrm{kg} / \mathrm{m}^{3}\right)$

$\mu=$ the dynamic viscosity of air $\left(1.8 \mathrm{E}-4 \mathrm{~kg} \mathrm{~s}^{-1} \mathrm{~m}^{-1}\right)$

$\mathrm{g}=$ acceleration due to gravity $\left(9.80 \mathrm{~m} / \mathrm{s}^{2}\right)$

For particles with larger radii, Stokes' law must be modified somewhat, and the graphical solution (Van der Hoven 1968) for spherical particles with densities of $5 \mathrm{~g} / \mathrm{cm}^{3}\left(3.2 \mathrm{lb} / \mathrm{ft}^{3}\right)$ is plotted for sea-level conditions in Figure 5-14. Settling speeds for particles with different densities $\left(\rho_{\mathrm{p}}\right)$ can be approximated by multiplying the speed in the figure by $\left[\rho_{\mathrm{p}} /\left(5 \mathrm{~g} / \mathrm{cm}^{3}\right)\left(3.2 \mathrm{lb} / \mathrm{ft}^{3}\right)\right]$. Particles with settling velocities greater than $100 \mathrm{~cm} / \mathrm{s}(0.33 \mathrm{ft} / \mathrm{s})$ (radius $\mathrm{r}>\sim 100 \mu \mathrm{m}\left(4 \times 10^{-3} \mathrm{in}\right)$ ) are assumed to follow ballistic trajectories, with the velocity vector being the resultant of the gravitational settling velocity and the horizontal windspeed. For settling velocities less than $100 \mathrm{~cm} / \mathrm{s}$ (radius $\mathrm{r}<\sim 100 \mu \mathrm{m}\left(4 \times 10^{-3}\right.$ in)), the particles are assumed to be dispersed by turbulence in the same way as particles having no inertia. A plume model is used, but the effective plume height term $\left(\mathrm{H}_{e}\right)$ is replaced by $\mathrm{H}_{\mathrm{g}}=\mathrm{H}_{\mathrm{e}}-\mathrm{xv}_{\mathrm{t}} / \mathrm{u}$ to account for gravitational settling. This model is called the "tilted plume model" and is illustrated in Figure 5-15. Deposition of particles with $~ 5$ $\mathrm{cm} / \mathrm{s}(0.11 \mathrm{mph}) \leq \mathrm{v}_{\mathrm{t}} \leq \sim 100 \mathrm{~cm} / \mathrm{s}(2.2 \mathrm{mph})$ at the ground at any position $\mathrm{x}, \mathrm{y}$ is given by the expression, $\dot{C}_{D}=v_{t} C(x, y, 0)$, where $\dot{C}_{D}$ is the deposition rate in mass per unit area per unit time. In a Gaussian model, roughly half of the material is deposited within a distance $\mathrm{x}=\mathrm{H}_{\mathrm{e}} \mathrm{u} / \mathrm{v}_{\mathrm{t}}$, where the particle plume centerline strikes the ground. For example, for $\mathrm{H}_{\mathrm{e}}$ equal to $100 \mathrm{~m}$ (330 ft), u equal to $5 \mathrm{~m} / \mathrm{sec}(11 \mathrm{mph})$, and $20 \mu \mathrm{m}$ $\left(7.9 \times 10^{-4}\right.$ in) diameter particles with densities of $5 \mathrm{~g} / \mathrm{cm}^{3}\left(3.2 \mathrm{lb} / \mathrm{ft}^{3}\right)\left(\mathrm{v}_{\mathrm{t}}=6 \mathrm{~cm} / \mathrm{sec}(0.13 \mathrm{mph})\right.$, about half of the material is deposited within a distance of $8.3 \mathrm{~km}$ (5.2 mi) (Hanna et al. 1982).

Very small particles and gases are also deposited on surfaces as a result of turbulent diffusion and Brownian motion. Chemical absorption, impaction, photosynthesis, and other biological, chemical, and physical processes cause material to be retained at the surface. In this case, a dry deposition velocity $\left(v_{d}\right)$ can be defined as an empirical function of the observed deposition rate $\left(\dot{C}_{D}\right)$ and the concentration near the 


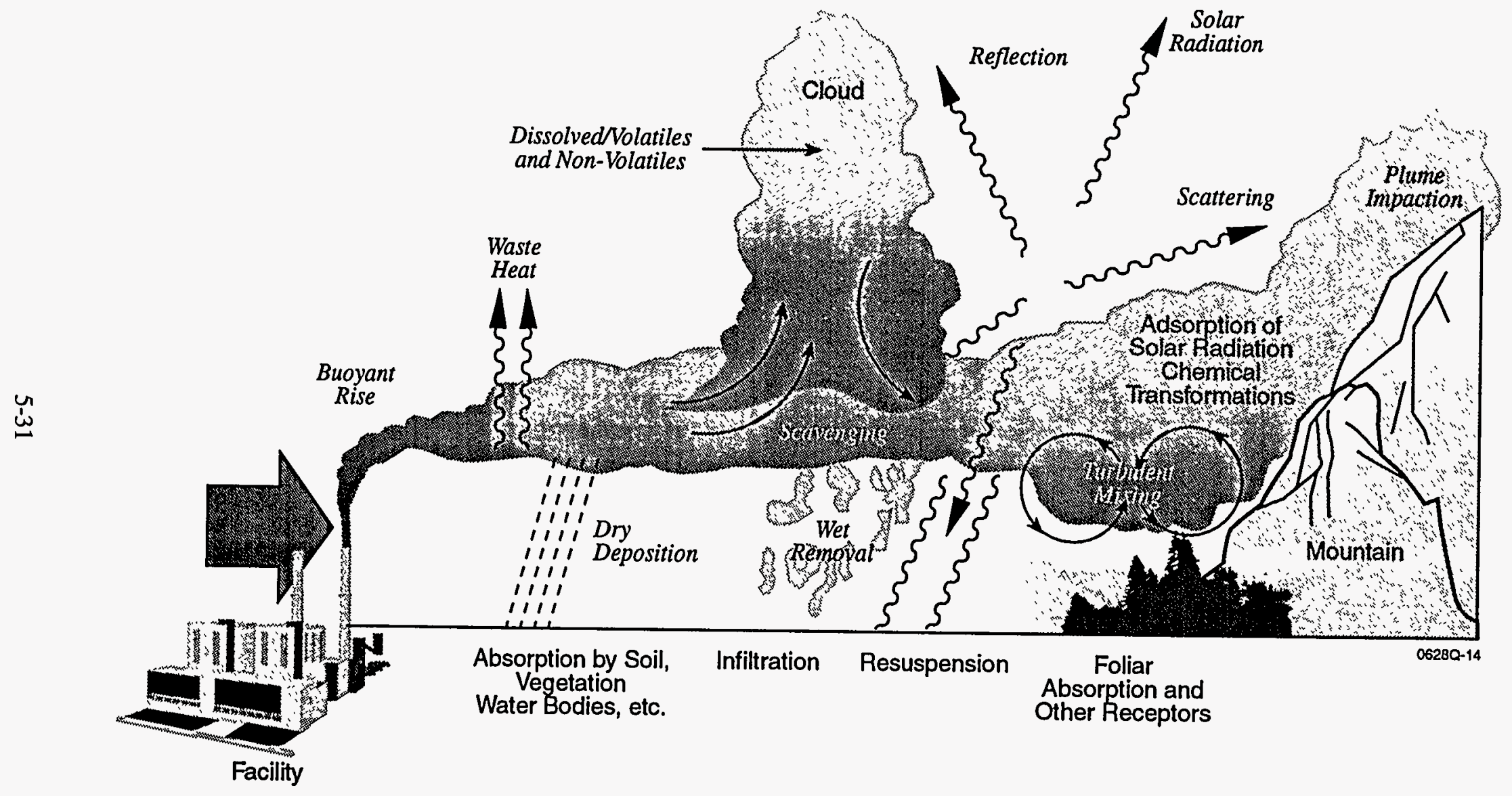

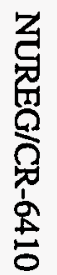

Figure 5-13. Atmospheric processes acting upon radiological/toxicological releases to the atmosphere 


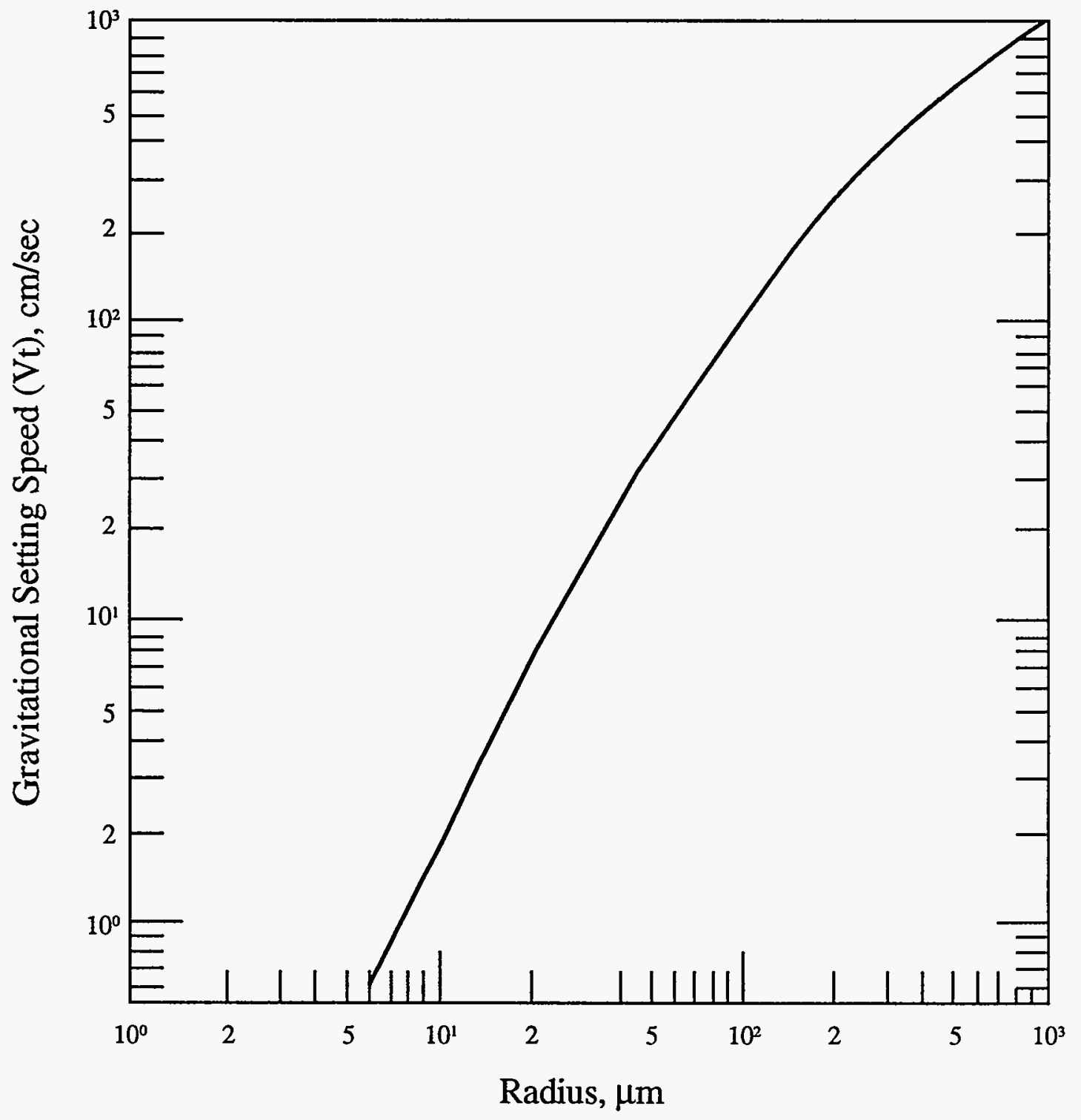

Figure 5-14. Gravitational settling speeds for particles with densities of $5 \mathrm{~g} / \mathrm{cm}^{3}$ near the earth's surface (Hanna 1982) 


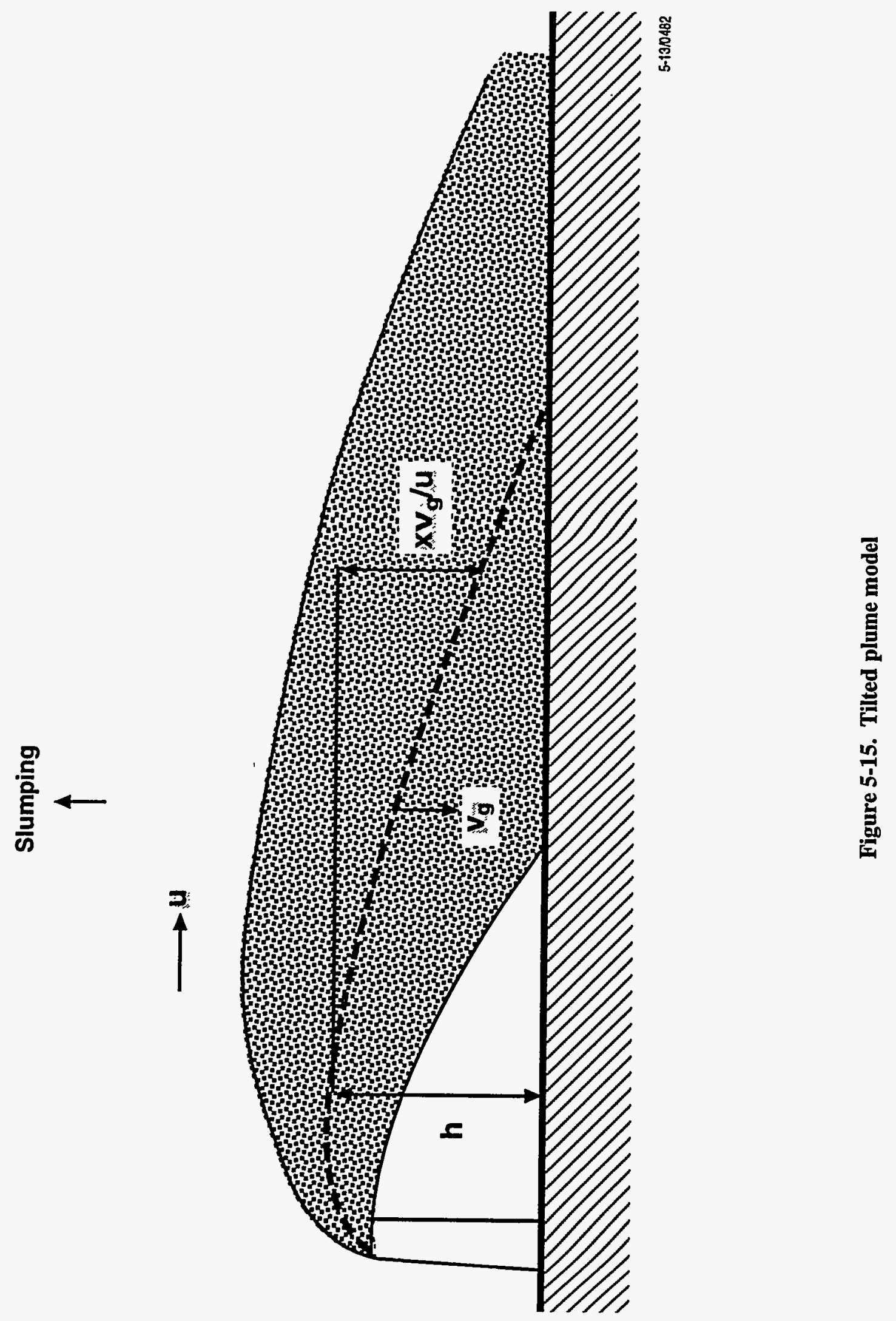


surface $C(x, y, z):\left[v_{d}=\dot{C}_{D} /(C(x, y, z)](C h a m b e r l a i n\right.$ and Chadwick 1953). The height at which $C(x, y, z)$ is typically measured is about $z=1 \mathrm{~m}(3.3 \mathrm{ft})$. Once $v_{d}$ is known for a given set of conditions, the formula $C_{D}$ $=v_{d} C(x, y, 1)$ can be used to predict dry deposition of gases and small particles.

Many methods of incorporating dry deposition into existing effluent dispersion models are available and have been described in the referenced literature (Hanna et al. 1982). Atmospheric Science and Power Production (Randerson 1984), Chapter 12, Deposition and Resuspension, provides a discussion of the variables that affect dry deposition and presents information in tabular and graphical form that can be used to make an estimate of deposition velocity under various conditions. Sehmel (1980) has provided a comprehensive review of particle and gas dry deposition.

\subsubsection{Wet Deposition}

Precipitation scavenging (wet deposition, wet removal, washout) is the removal of pollutants from the atmosphere by various types of precipitation (e.g., rain, hail, snow, etc.). The theoretical treatment of wet deposition is often divided into rainout (within cloud scavenging) and washout (below cloud scavenging). In practical applications, the two processes are generally lumped together since they can be modeled similarly.

Wet deposition (or washout depletion) is frequently modeled as an exponential decay by the introduction of a scavenging rate. Slinn (1978) gives approximate expressions for scavenging rates of both rain and snow. The scavenging rate is representative of only a small volume of the plume. To determine the plume depletion, it is necessary to integrate the product of the scavenging rate and concentration vertically through the plume. Then the resulting flux can be used to define wet deposition velocity. Alternatively, a wet deposition velocity can be defined as the product of a washout ratio and surface precipitation rate, in which the washout ratio contains the results of the vertical integration. Slinn suggests that estimates of scavenging rates and washout ratios be treated as order-of-magnitude estimates. Examples of washout ratios for various materials can be found in NUREG/CR-3332, Radiological Assessment (USNRC, 1983).

Detailed discussion of the methods used for modeling wet deposition are contained in the referenced literature (e.g., Hanna et al. 1982; Randerson 1984; and Slinn 1978).

\subsubsection{Radioactive Decay}

Another process that can both remove and add material to a plume is radioactive decay. As atoms of a specific nuclide within a plume decay, an observer downwind will see an effectively reduced emission rate for that nuclide. If the decay of a nuclide produces a daughter nuclide, then a downwind observer will see an effectively increased emission rate for the daughter nuclide. For example, let $R_{A}$ be the rate (atoms/unit time) at which atoms of radionuclide $A$ are being emitted from a point source. If $\lambda_{A}$ is the decay constant $\left(\sec ^{-1}\right)$ for radionuclide $A$, an observer downwind will see an effectively reduced emission rate due to radioactive decay. The effective emission rate, $\mathrm{Q}_{\mathrm{Ar}_{\mathrm{r}}}(\mathrm{x})$, as a function of downwind distance, $\mathrm{x}$, is given by:

$$
Q_{A r}(x)=Q_{A r}(0) \exp \left(-\lambda_{A} \frac{x}{u}\right)
$$

where:

$\mathrm{u}=$ windspeed at release height 
If a daughter radionuclide, $\mathrm{B}$, is produced by the decay of radionuclide $\mathrm{A}$, then the effective emission rate of radionuclide $B$ will increase with downwind distance as follows:

$$
Q_{B r}(x)=\frac{\lambda_{B} Q_{A r}(0) \exp \left(-\lambda_{B} \frac{x}{u}\right)}{\lambda_{A}-\lambda_{B}} \quad\left(1-\exp \left(-\left(\lambda_{A}-\lambda_{B}\right) \frac{x}{u}\right)\right)
$$

Many versions of the Gaussian model have been modified to account for radioactive decay as a removal mechanism; however, only a few account for daughter ingrowth. The attributes of a large number of dispersion models are presented in Atmospheric Dispersion Modeling Resources (Mazzola 1995), including their ability to incorporate radioactive decay and daughter ingrowth.

\subsubsection{Resuspension}

Resuspension describes material deposited from the atmosphere and then subsequently reentrained or resuspended into the atmosphere. Resuspension occurs both as a result of wind and the mechanical disturbance of the soil. Based on limited data, some estimates of wind-induced and mechanical resuspension rates have been produced (see Randerson 1984). For the purposes of accident analyses, resuspension due to wind is of primary concern.

Wind-driven mechanisms that result in movement of particles deposited onto surfaces include surface creep (particles rolling along the surface), saltation (particles bouncing along the surface that become

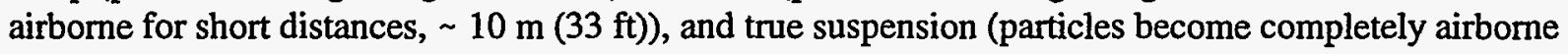
and travel up to thousands of meters). The rate of change of deposited material may be represented as:

$$
\frac{d C_{D}}{d t}=v_{d} C(t)-S_{w} C_{D}
$$

where:

$C_{D}=a$ real concentration (per $\mathrm{m}^{2}$ ) of material on the ground

$\mathrm{v}_{\mathrm{d}}=$ deposition velocity $(\mathrm{m} / \mathrm{s})$

$C(t)=$ airborne concentration at time $t\left(\right.$ per $\left.\mathrm{m}^{3}\right)$

$\mathrm{S}_{\mathrm{w}}=$ suspension rate $\left(\mathrm{s}^{-1}\right)$, or the fraction of deposited material resuspended per unit time

The loss of material from the surface due to migration downward in soil or loss by mechanisms other than resuspension has been omitted for simplicity. The equilibrium solution to this equation is:

$$
\frac{\mathrm{dC}_{\mathrm{D}}}{\mathrm{dt}}=0, \therefore \mathrm{v}_{\mathrm{d}} \mathrm{C}(\mathrm{t})=\mathrm{S}_{\mathrm{w}} \mathrm{C}_{\mathrm{D}}
$$

The ratio of the airborne concentration to the areal concentration of deposited material is:

$$
\frac{C(t)}{C_{D}}=\frac{S_{w}}{v_{d}} \frac{\left(s^{-1}\right)}{\left(m^{-1}\right)}=R F\left(m^{-1}\right)
$$


The quantity $\mathrm{RF}$ as used in this equation is known as the resuspension factor and has units of inverse length. The concentration is measured at some height such as $1 \mathrm{~m}(3.3 \mathrm{ft})$. Neither the air sampling height nor the depth of surface soil sampling is specified; however, breathing height and a $1 \mathrm{~cm}(0.4 \mathrm{in})$ depth sample in the ground could be used.

The resuspension factor may also be estimated using a time-dependent function developed by Anspaugh et al. (1975). For low windspeeds $(\mathrm{u} \leq 3 \mathrm{~m} / \mathrm{s}(6.7 \mathrm{mph})$ ), the Anspaugh resuspension factor is given as:

$$
R F=10^{-4} \exp (-0.15 \sqrt{t})+10^{-9}
$$

for $\mathrm{u}>3 \mathrm{~m} / \mathrm{s}, \mathrm{RF}(\mathrm{u})=\mathrm{RF}(\mathrm{u} / 3)^{2}$

where:

$$
\begin{aligned}
\mathrm{RF}= & \text { resuspension factor }\left(\mathrm{m}^{-1}\right) \\
10^{-4}= & \text { resuspension factor at time } \mathrm{t}=0\left(\mathrm{~m}^{-1}\right) \\
0.15= & \text { effective decay constant controlling the availability of material for resuspension (days } \left.\mathrm{s}^{1 / 2}\right) \\
\mathrm{t}= & \text { time after deposition (days) } \\
10^{-9}= & \text { resuspension factor after } 17 \text { years }\left(\mathrm{m}^{-1}\right) \text {, added based on the assumption that no further } \\
& \text { measurable decrease in the resuspension factor process occurs after about } 17 \text { years, the longest } \\
& \text { period for which there are data available }
\end{aligned}
$$

Variations on this relationship have been developed by other researchers, and some are presented in Radiological Assessment (USNRC 1983c). The resuspension factor can also be determined from atmospheric mass loading as:

$$
R F=\frac{C_{s}}{\rho}
$$

where:

$$
\begin{aligned}
& C_{s}=\text { mass loading of soil in air }\left(\mathrm{g} / \mathrm{m}^{3}\right) \\
& \rho=\text { soil surface density }\left(\mathrm{g} / \mathrm{m}^{2}\right)
\end{aligned}
$$

The magnitude of resuspension factors has ranged in experimental studies from about $1 \mathrm{E}-11$ to $1 \mathrm{E}-2 \mathrm{~m}^{-1}$ (3E-12 to $\left.3 \mathrm{E}-3 \mathrm{ft}^{-1}\right)$ (9E-11 to $3 \mathrm{E}-4 \mathrm{~m}^{-1}\left(2.7 \mathrm{E}-11\right.$ to $9.1 \mathrm{E}-5 \mathrm{ft}$ ) for wind resuspension and $1 \mathrm{E}-10$ to $4 \mathrm{E}-2 \mathrm{~m}^{-}$ ' $\left(3.0 \mathrm{E}-11\right.$ to $\left.1.2 \mathrm{E}-2 \mathrm{ft}^{-1}\right)$ for mechanical stresses) (Randerson 1984). The results of experimental studies depend in part on the sampling techniques used to measure particle concentrations, the height of the measurement above the surface and the soil sample depth. Different measurement conditions and particle sizes can greatly change the resulting resuspension factor. Variables that influence resuspension include particle properties, soil properties, particle-soil interaction, surface properties, topography, and meteorological conditions. Randerson (1984) provides a full list of variables that influence resuspension and a brief description of some of them.

The precise relationship between the variables affecting resuspension and resuspension rate and resuspension factors is not well understood. Measured values for both have shown considerable variation, ranging over several orders of magnitude. Because of the high degree of uncertainty, resuspension is often not considered during emergency response consequence estimates or other accident analyses where 
consequences are estimated from short duration exposures (i.e., a few hours to days). If resuspension is judged to be a concern, then careful consideration should be given to the resuspension rates or factors chosen, to ensure that they are as representative of the situation being modeled as possible.

\subsubsection{Chemical Removal/Transformation}

Once pollutants have been released to the atmosphere, they can undergo chemical reactions as a result of interactions with other elements in the atmosphere or meteorological conditions (e.g., change in temperature, energy from sunlight, humidity, etc.). The products of these reactions can be non-toxic in nature, thus reducing the concentration of hazardous material, or they can be toxic having a different (sometimes more serious) consequence.

Methods used to model the chemical reactions for a specific material are determined by available experimental data and the associated understanding of the reaction process. Some reactions can be adequately characterized by an exponential chemical decay, where the chemical decay rate is assumed with time constant $\tau_{\mathrm{c}}$ :

$$
\frac{C(t)}{C(0)}=e^{-v \tau_{c}}
$$

Reaction rates will depend on meteorological conditions and the presence of other elements necessary for the reaction in the atmosphere; thus $\tau_{c}$ will usually be based on measurements or experimental data.

Chemical removal/transformation can also be modeled by using the kinetic equations. For example, assume that the following two chemical kinetic equations are valid:

where:

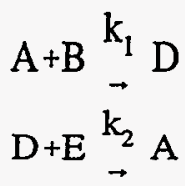

$$
\mathrm{k}_{1} \text { and } \mathrm{k}_{2}=\text { rate constants (concentration }{ }^{-1} \text { time }^{-1} \text { ) }
$$

Then the rate of change of concentration of substance $\mathrm{D}$ due to chemical reactions is given by the equation:

$$
\frac{d C_{D}}{d t}=k_{1} C_{A} C_{B}-k_{2} C_{D} C_{E}
$$

Chemical reactions in the atmosphere can be complex and are usually very specific to the hazardous material of concern. Transport and diffusion models that incorporate chemical removal processes have usually been developed to address specific hazardous materials of concern to a facility (i.e., ammonia, uranium hexafluoride). The application of models incorporating chemical processes may require additional input parameters, such as the temperature of the effluent, relative humidity, solar insolation, etc.

\subsection{Buoyant Plumes}

Buoyant plumes are relevant in the case of fires or explosions. The basic theory is discussed below, and then important issues like how plume rise is terminated are examined. In particular, the question of 
whether a buoyant plume at ground level will lift off is an important one for buoyant plumes in building wakes and for plumes that potentially become buoyant as they are diluted with air (e.g., UF 6 and HF). A comprehensive review of plume rise models has been given by Briggs (1984).

\subsubsection{Basic Theory}

Briggs considers three independent conservation laws. Conservation of mass states that the rate at which the mass of air within any element of space changes is equal to the net flow of mass across the boundaries of the element. Conservation of momentum is simply Newton's second law of motion, namely that the rate of change of momentum of an element of a plume equals the force acting upon it. Finally, in Briggs' treatment, the balance of heat flowing into and out of the plume is expressed as the law of conservation of buoyancy. This states that the cooling of the plume as it rises is adiabatic, so that $\Theta_{\mathrm{T}}$, the potential temperature of the plume, remains constant. These conservation laws are not unique. Russo (1976), for example, uses conservation of enthalpy rather than of buoyancy and introduces an additional conservation law to take account of water in the plume.

A complete description of the action of turbulence within and outside the plume is probably still beyond the capacity of any computer, even in the late 1990s. It is, therefore, necessary to make some simplifying assumption about the action of both plume-dominated turbulence and the atmospheric turbulence. The effect of atmospheric turbulence is dealt with by introducing the concept of plume breakup (see Section 5.4.2). The effect of the plume-dominated turbulence is embodied in the concept of an entrainment velocity, $v_{e}: \rho_{a} v_{c}$ gives the rate at which mass is entrained into the plume across unit area.

Briggs lists a large number of entrainment criteria. One of the simplest consists of the assumption that:

$$
v_{e}=\beta_{e} w
$$

where:

$$
\begin{aligned}
& \beta_{\mathrm{e}}=\text { the entrainment constant } \\
& \mathrm{w}=\text { the upward velocity of the plume }(\mathrm{m} / \mathrm{s})
\end{aligned}
$$

Equation 5.19, coupled with assumptions about conservation of mass, buoyancy, and momentum, can be used to derive a relatively simple differential equation:

$$
\mathrm{d}^{2}\left(\mathrm{z}^{\prime}\right)^{3} / \mathrm{dt} \mathrm{t}^{2}+\beta_{\mathrm{T}}\left(\mathrm{z}^{\prime}\right)^{3}-3\left(\mathrm{~F}^{*} \mathrm{t}+\mathrm{F}\right) / \beta_{\mathrm{e}} \mathrm{u}=0
$$

for a "bent-over" plume--that is, a continuous plume with a horizontal velocity equal to the mean windspeed $u$. Here, $z^{\prime}$ is the height above an arbitrarily chosen virtual origin and $t$ is the time. $F$ is the buoyancy parameter:

$$
F=g Q_{H} /\left(\pi \rho_{a} C_{p a} T_{a}\right)\left(m^{4} / s^{3}\right)
$$

(for gases with molecular weight close to that of air)

where:

$\mathrm{g}=$ the acceleration due to gravity $\left(\mathrm{m} / \mathrm{s}^{2}\right)$ 
$\mathrm{Q}_{\mathrm{H}}=$ the rate of emission of heat from a stack or orifice $(\mathrm{J} / \mathrm{s})$

$\rho_{\mathrm{a}}=$ the density of the air $\left(\mathrm{kg} / \mathrm{m}^{3}\right)$

$C_{\mathrm{pa}}=$ the specific heat of air at constant pressure $(\mathrm{J} / \mathrm{kg} / \mathrm{K})$

$T_{a}=$ the temperature of the air $(K)$

$\mathrm{F}^{*}$ is the radioactivity buoyancy parameter:

$$
F^{*}=g Q^{*} /\left(\pi \rho_{a} C_{p a} T_{a}\right)\left(m^{4} / s^{4}\right)
$$

where:

$Q^{*}=$ the rate at which heat is added to the plume by the decay of radionuclides in the plume $\left(\mathrm{J} / \mathrm{s}^{2}\right)$

For the typical plume emitted from a fuel cycle facility, $\mathrm{F}^{*}$ will be very small. It only tends to be important for accidental releases from nuclear reactors.

$$
\beta_{\mathrm{T}}=\left(\mathrm{g} / \mathrm{T}_{\mathrm{a}}\right)\left(\mathrm{d} \Theta_{\mathrm{Ta}} / \mathrm{dz}\right)
$$

where:

$\Theta_{\mathrm{ta}}=$ the atmospheric potential temperature

$\beta_{\mathrm{T}}$ has dimensions of $\mathrm{s}^{-2}$ and is the square of a quantity known as the Brunt-Väisälä frequency.

Solutions of equation 5.20 are provided by Gifford (1967).

One noteworthy feature of equation 5.20 is that, when $\beta_{r}>0$, which corresponds to stable weather conditions, the solution for $\mathrm{z}^{\prime 3}$ oscillates indefinitely. This is a consequence of the simplified entrainment assumption, equation 5.19: when $w$ is negative, the plume shrinks! This difficulty is overcome if it is assumed that:

$$
v_{e}=\beta_{e}|w|
$$

However, if equation 5.24 is used, equation 5.20 must be solved numerically. There remains the task of choosing a value for $\beta_{e}$. For a bent-over plume, $\beta_{e}$ is $\sim 0.5-0.6$ (Briggs 1984)

\subsubsection{Ground-Level Concentrations Under a Rising Plume}

These concentrations are exceedingly small, as is shown by the discussion of Figure 5-1. For convenience, the radial concentration profile across a rising plume can be taken to be Gaussian, with the radius $r$ defining the 10 percent concentration contour. [The 10 percent concentration contour is the circle defined by the radius at which the concentration is 10 percent of that at the center of the plume] That is:

$$
C(r)=Q_{r} \exp \left(-r^{2} / 2 \sigma_{r}^{2}\right) /\left(2 \pi \sigma_{r} u_{c}\right)
$$

where:

$$
C(r)=\text { the concentration at a distance } r \text { from the centerline of the plume }\left(\mathrm{Ci} / \mathrm{m}^{3} \text { or } \mathrm{kg} / \mathrm{m}^{3}\right)
$$


$\sigma_{\mathrm{r}}=$ the radius of the plume divided by 2.14 (in the Gaussian formulation, this ensures that the 10 percent concentration contour coincides with the radius) (m)

$\mathrm{u}_{\mathrm{c}}=$ the speed of the plume $(\mathrm{m} / \mathrm{s})$

$Q_{r}=$ the rate of emission of radioactive material or gas $(\mathrm{Ci} / \mathrm{s}$ or $\mathrm{kg} / \mathrm{s})$

\subsubsection{Termination of Plume Rise}

In Briggs' treatment, plume rise is terminated according to the prescriptions given below.

(i) The action of atmospheric turbulence: The rise of the plume is terminated when the "vigor" of the turbulence in the plume decays to equal the "vigor" of the turbulence in the atmosphere.

Mathematically, this is achieved by equating the turbulence energy dissipation rates within $\left(\epsilon_{\mathrm{i}}\right)$ and outside $(\epsilon)$ the plume. The quantity $\epsilon$ is given by:

where:

$$
\epsilon=u_{*}^{3} /(\mathrm{kz})+0.1 \mathrm{H}_{\mathrm{q}}
$$

$\mathrm{u}_{*}=$ the friction velocity $(\mathrm{m} / \mathrm{s})$

$\mathrm{k}=0.4$ is Von Karman's constant

$\mathrm{z}=$ the height of the plume center-line above the ground $(\mathrm{m})$

$\epsilon=\mathrm{u}_{*}{ }^{3} /(\mathrm{kz})$ applies in conditions dominated by mechanically generated turbulence

$\mathrm{H}_{\mathrm{q}}$ is given by the equation:

where:

$$
H_{q}=F_{u} g /\left(C_{p a} \rho_{a} T_{a}\right)
$$

$F_{u}=$ the upward heat flux from the ground $\left(\mathrm{J} / \mathrm{m}^{2} / \mathrm{s}\right)$

$\mathrm{T}_{\mathrm{a}}=$ the temperature of the air at height $\mathrm{z}(\mathrm{K})$

$\epsilon=0.1 \mathrm{H}_{\mathrm{q}}$ applies in conditions dominated by convectively generated turbulence

The quantity $\epsilon_{\mathfrak{i}}$ inside the plume is given by (Briggs 1984):

where:

$$
\epsilon_{\mathrm{i}}=\eta \mathrm{w}^{-3} /\left(\mathrm{z}-\mathrm{h}_{\mathrm{o}}\right)
$$

$$
\begin{aligned}
& \eta=\text { constant } \sim 1.5 \\
& h_{\mathrm{o}}=\text { the height of release } \\
& \mathrm{w}=\text { the upward velocity of the plume, } \mathrm{u}_{\mathrm{c}} \sin \theta
\end{aligned}
$$

(ii) Meander: In highly unstable weather conditions, there are strong upward thermals (as from an asphalt surface on a hot day) and compensating down drafts. When the upward velocity of the plume is comparable to the velocity $w_{d}$ of these currents, the plume rise is terminated. A typical downdraught velocity $w_{d}$ is

$$
w_{d}=0.4 w_{*}
$$


where:

w. = a scaling velocity for a convective mixing layer for which suitable expressions are

$$
\begin{aligned}
& w_{*}=\left(H_{q} \ell\right)^{1 / 3} \text { if } z>\ell / 3 \\
& w_{*}=\left(3 \mathrm{H}_{q} z\right)^{1 / 3} \text { if } z \leq \ell / 3
\end{aligned}
$$

$\mathrm{H}$ is given by equation 5.27 and $\ell$ is the height of the convective mixing layer, or "lid" (see below).

(iii) Presence of an Overhead Inversion: An atmosphere in which the stability is neutral or unstable is always "capped" by an overhead inversion, which is effectively a region of great stability into which the plume may penetrate little or not at all. The rise of the plume is terminated when its upper edge touches this "lid". Holzworth (1984) has given estimates of the height of this lid for the U.S.A., and a convenient summary of his work appears in Appendix VI of the Reactor Safety Study (USNRC 1975). Typical values in unstable or neutral conditions are $1 \mathrm{~km}$ or more and a few hundred meters in stable conditions.

(iv) In stable atmospheric conditions, the difference in temperature between the plume and the atmosphere declines as the plume rises. Thus, the density of the atmosphere eventually equals that of the plume; when this happens, the rise of the plume is terminated.

\subsubsection{Suppression of Lift-Off}

A buoyant plume of width $W_{p}$ and height $h_{p}$ may not lift off the ground. This is a windspeed dependent effect and has been explained by Briggs $(1973 \mathrm{~b}, 1984)$ in terms of a lift-off parameter or Richardson number:

$$
L_{p}=g h_{p} \Delta \rho / 2 \rho_{\mathrm{a}} u_{*}^{2}
$$

where $\Delta \rho=\rho_{\mathrm{a}}-\rho$, and the other parameters have been introduced previously. One simple way of looking at the right hand side of equation 5.32 is to regard it as proportional to the ratio of the mean potential energy carried by unit volume of the plume $\left(\mathrm{gh}_{\mathrm{p}} \Delta \rho / 2\right)$ and the turbulent energy carried in unit volume of air $\rho_{\mathrm{a}} \mathrm{u}_{*}{ }^{2} / 2$. If $\mathrm{L}_{\mathrm{p}}$ is large, the potential energy in the plume dominates and it lifts off. If $\mathrm{L}_{\mathrm{p}}$ is small (i.e., the windspeed is high), the atmospheric turbulence is energetic enough to break up the plume so that it disperses as if passive. On the basis of experimental evidence (Meroney 1979), a critical value of 30 has been assigned to $\mathrm{L}_{\mathrm{p}}$.

Note that an alternative expression for $L_{p}$ is:

where:

$$
L_{p}=\pi F /\left(u_{c} u_{*}^{2} W_{p}\right)
$$

$\mathrm{F}=$ the buoyancy flux in $\mathrm{m}^{4} / \mathrm{s}^{3}$

$$
F \propto g Q_{H} /\left(\pi C_{p} \rho_{a} T_{a}\right)+g(1-m / 28.9)\left(T_{a} / T_{o}\right) \dot{V}_{o} / \rho_{a}
$$

Here, $Q_{H}$ is the rate of emission of heat from the source $(J / s), T_{a}$ is the temperature of the air at the source, $\mathrm{T}_{0}$ is the temperature of the source, $\dot{\mathrm{V}}_{\mathrm{o}}$ is the initial volume flux, and $\mathrm{m}$ is the effective molecular weight 
of the emission at the source. The second term on the right hand side of equation 5.34 is important when the molecular weight $M$ of the gas is significantly different from that of air (28.9). If $M-28.9$, the second term becomes unimportant, and $\mathrm{F}$ becomes the same as in equation 5.21.

Recent relevant work on plume lift-off has been carried out at the Building Research Establishment (BRE) in the UK (Hall et al., 1995; 1996). The BRE wind tunnel experiments considered fires in buildings with a single roof opening, two roof openings, multiple roof openings, complete roof collapse (i.e., the building shell only), and a case with no building present. In addition, different building sizes and shapes were considered.

Hall et al.'s results indicate that Briggs' lift-off criterion with $L_{p}=30$ is a good indicator of whether the plume rise will be sufficient to cause major reductions in grand level concentrations when compared with a release that does not rise. Other interesting information is that, all other things being equal, the plume is much more likely to rise clear of the building if there is a single opening rather than many openings or a building shell. Readers who are interested in the many details in Hall et al.'s work may obtain the reports from the Building Research Establishment (see references for address).

\subsection{Jets}

Section 5.4 was devoted to a simplified discussion of plume rise. In practice, vapor jets and stack releases, buoyant or otherwise, can be modeled using the following sets of conservation equations. Typical plume behavior is shown in Figure 5-16. Note that, for jets, as well as for continuous heavy vapor plumes at ground level, and for heavy vapor puffs (see Sections 5.6.1 and 5.6.2, respectively), most, if not all, available models rely on the numerical solution of differential equations. In the following sections, the focus is on relatively simple models that use coupled first-order differential equations. The models and equations presented below should be regarded as typical of the approach generally adopted by modelers.

The available models are discussed in Section 5.10. The reader should note that, if he or she wishes to perform atmospheric dispersion calculations in this field, there is no substitute for choosing and learning to use one or more of the computer programs.

In the following sections, models for the atmospheric dispersion of jets, continuous releases of heavy vapors and heavy vapor puff releases are considered. In general, there are no simple analytical solutions of these models. Instead, the models are expressed as first-order, non-linear differential equations that have to be solved numerically. The models have many features in common, and they are described in the same way, with text and equations that cover the following:

- Expression of conservation laws as differential equations (e.g. conservation of mass, momentum and enthalpy)

- Expression of some subsidiary relationships (e.g., relationship between temperature in the atmosphere and height as a function of distance traveled by a jet or buoyant plume)

- Consideration of transition to neutral buoyancy, and

- How to calculate airborne concentrations within the plume, especially at ground level. 


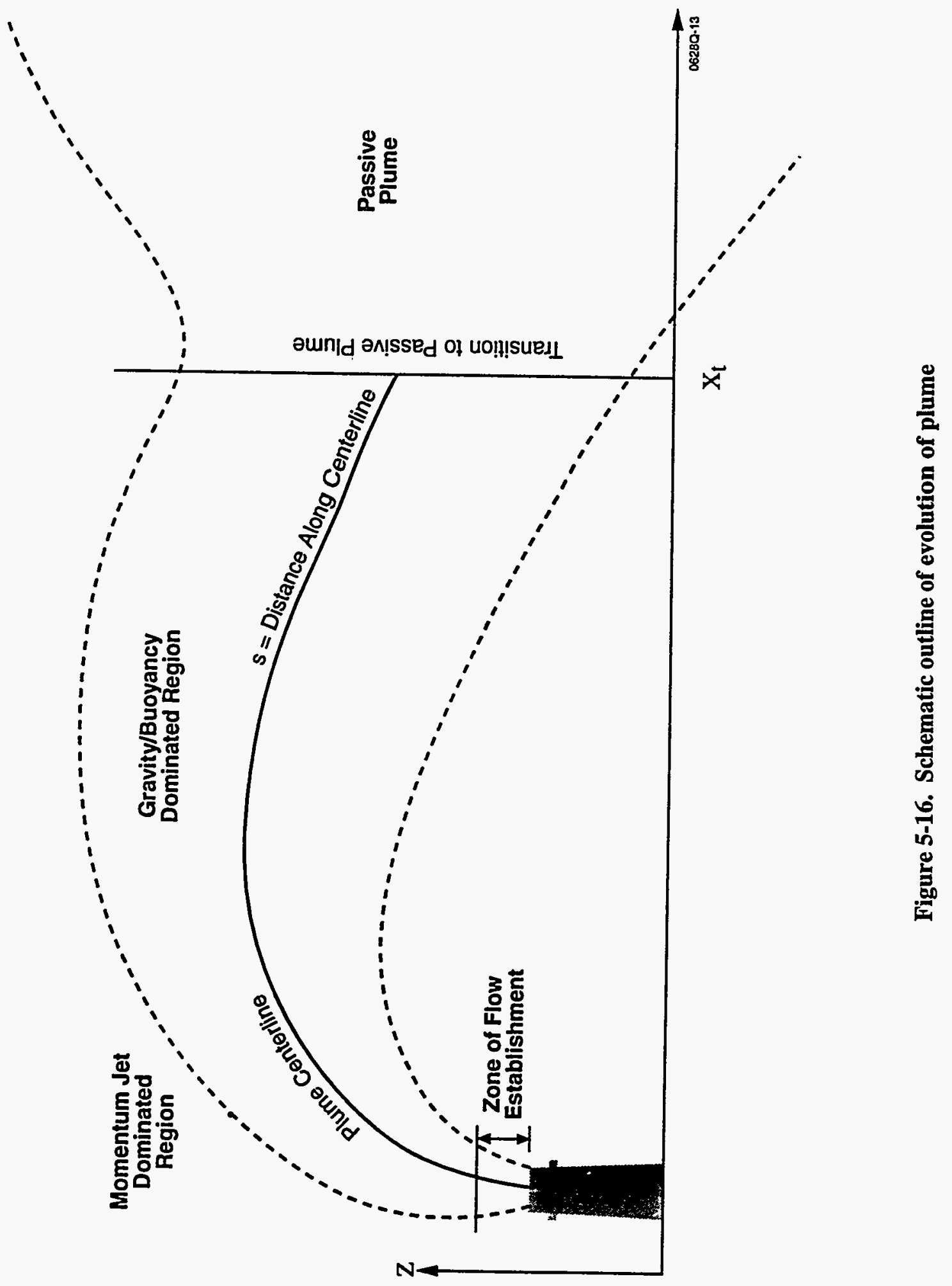




\subsubsection{Conservation Equations}

\subsubsection{Entrainment of Air}

Following Ooms (1974), Ooms et al. (1974), Ooms and Duijm (1984), and Li Xiao-yun et al. (1986), there are three terms in the equation for entrainment of air.

$$
\mathrm{d} \dot{M}_{\mathrm{a}} / \mathrm{ds}=\sqrt{2} \pi \mathrm{r} \rho_{\mathrm{a}}\left[\alpha_{\mathrm{j} 1} \mathrm{U}_{\mathrm{s}}+\alpha_{\mathrm{j} 2} \mathrm{U}_{\mathrm{a}}\left(|\sin \theta| \cos \theta+\alpha_{\mathrm{j} 3}(\epsilon \mathrm{r})^{1 / 3}\right]\right.
$$

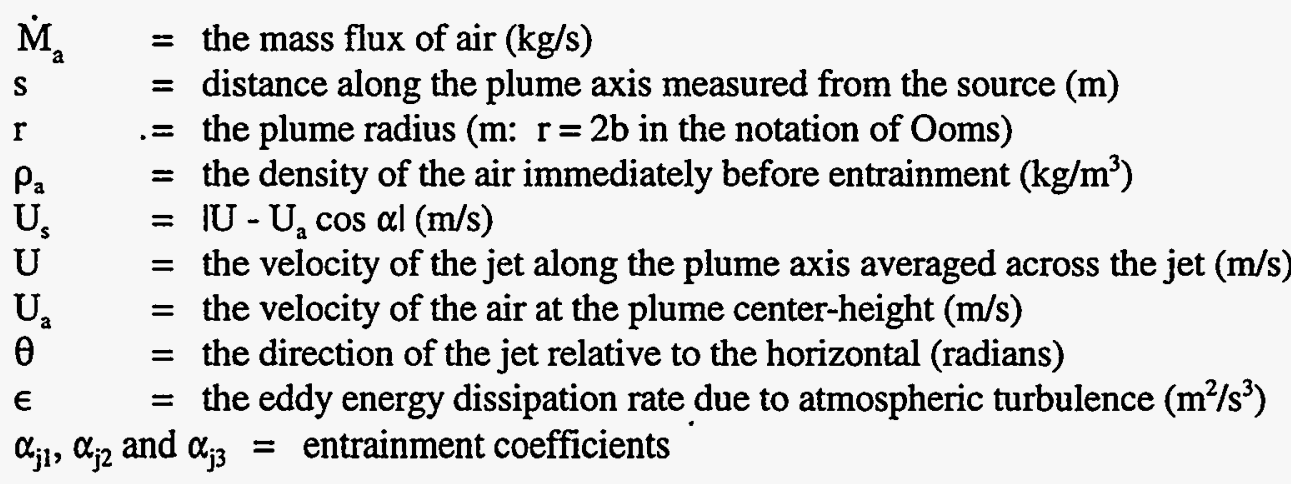

(i) The first term represents the well-known equation for the rate of entrainment into a high-velocity jet, for which $\alpha_{\mathrm{jl}}=0.057$.

(ii) The second term represents the rate of entrainment of air into a plume by the action of its own internal turbulence (Briggs 1984) with $\alpha_{\mathrm{j} 2}=0.5$.

(iii) The third term represents the action of atmospheric turbulence on the dilution of the plume. Following Briggs (1984), the turbulent energy dissipation rate is given by equation 5.26.

\subsubsection{Conservation of Horizontal Momentum Flux}

The conservation of the flux of horizontal momentum $F_{m h}$ is given by the equation:

$$
\mathrm{dF}_{\mathrm{mh}} / \mathrm{ds}=2 \pi \mathrm{r} \rho_{\mathrm{a}} \mathrm{U}_{\mathrm{a}}\left[\alpha_{\mathrm{j} 1} \mathrm{U}_{\mathrm{s}}+\alpha_{\mathrm{j} 2} \mathrm{U}_{\mathrm{a}}|\sin \theta| \cos \theta+\alpha_{\mathrm{j} 3}(\epsilon \mathrm{r})^{1 / 3}\right]+\mathrm{C}_{\mathrm{d}}(\pi / \sqrt{2}) \mathrm{r} \rho_{\mathrm{a}} \mathrm{U}_{\mathrm{a}}^{2}\left|\sin ^{3} \theta\right|
$$

where the first term on the right side represents the increase in momentum due to the entrainment of air. The second term is due to the drag force exerted on the plume by the wind, with $C_{d}=0.3$.

\subsubsection{Conservation of Vertical Momentum Flux}

The conservation of vertical momentum flux $\mathrm{F}_{\mathrm{mv}}$ is given by the equation:

$$
\mathrm{dF}_{\mathrm{m}} / \mathrm{ds}=\pi \mathrm{r}^{2} \mathrm{~g}\left(\rho_{\mathrm{a}}-\rho\right) \pm \mathrm{C}_{\mathrm{d}}(\pi / \sqrt{2}) \mathrm{r} \rho_{\mathrm{a}} \mathrm{U}^{2} \sin ^{2} \theta \cos \theta
$$

The first term on the right side takes account of the acceleration of the plume due to the difference between the density of the plume and that of the atmosphere $\rho_{\mathrm{a}}$. The second term represents the influence of the drag force in the $\mathrm{z}$ direction and always acts in the direction opposite to the vertical velocity of the plume. 


\subsubsection{Conservation of Enthalpy}

Conservation of enthalpy (heat content) is represented by the following equation for the rate of change of cloud temperature $T_{c}$ :

$$
\mathrm{dT}_{\mathrm{c}} / \mathrm{ds}=\left(\mathrm{T}_{\mathrm{a}}-\mathrm{T}_{\mathrm{c}}\right) \mathrm{C}_{\mathrm{pa}}\left(\mathrm{d} \dot{\mathrm{M}}_{\mathrm{a}} / \mathrm{ds}\right) /\left(\dot{\mathrm{M}}_{\mathrm{a}} \mathrm{C}_{\mathrm{pa}}+\dot{\mathrm{M}}_{\mathrm{g}} \mathrm{C}_{\mathrm{pg}}\right)
$$

where:

$\dot{\mathrm{M}}_{\mathrm{g}}=$ the initial mass flux of the gas $(\mathrm{kg} / \mathrm{s})$

$\mathrm{C}_{\mathrm{pg}}=$ the specific heat of the gas at constant pressure $(\mathrm{J} / \mathrm{kg} / \mathrm{K})$

This equation is valid for an ideal gas and represents the addition of heat as air is mixed into the plume.

\subsubsection{Volume Flux}

The volume flux of the plume at a temperature $T$ is given by:

$$
\dot{V}=\left[\left(\dot{M}_{a} / \rho_{a} T_{a}\right)+\left(\dot{M}_{g} / \rho_{g} T_{g}\right)\right] T
$$

where:

$$
\begin{aligned}
& \dot{M}_{a} \text { and } \dot{M}_{g}=\text { the mass fluxes of air and gas }(\mathrm{kg} / \mathrm{s}) \\
& \rho_{\mathrm{a}}=\text { the density of air at the reference temperature } \mathrm{T}_{\mathrm{a}}\left(\mathrm{kg} / \mathrm{m}^{3}\right) \\
& \rho_{\mathrm{g}}=\text { the density of the gas at the reference temperature } \mathrm{T}_{\mathrm{g}}\left(\mathrm{kg} / \mathrm{m}^{3}\right)
\end{aligned}
$$

Some models differentiate equation 5.39 and add it to the equation set that needs to be solved.

\subsubsection{Cloud Velocity}

The velocity of the cloud is given by:

where:

$$
u_{c}=\left(F_{m h}^{2}+F_{m v}^{2}\right)^{1 / 2} /\left(\dot{M}_{a}+\dot{M}_{g}\right)
$$

$$
\begin{aligned}
& F_{m h}=\text { the horizontal momentum flux }\left(\mathrm{kg} \mathrm{m} / \mathrm{s}^{2}\right) \\
& F_{m v}=\text { the vertical momentum flux }\left(\mathrm{kg} \mathrm{m} / \mathrm{s}^{2}\right)
\end{aligned}
$$

\subsubsection{Cloud Radius}

The radius of the cloud is given by:

where:

$$
r=\left(\dot{V} / \pi u_{c}\right)^{1 / 2}
$$

$$
\begin{aligned}
\dot{v} & =\text { the volume flux } \\
u_{c} & =\text { the cloud velocity }\left(u_{c} \equiv U\right)
\end{aligned}
$$




\subsubsection{Height $\mathrm{z}$ and Downwind Distance $\mathrm{x}$}

The rate of change of $\mathrm{x}$ and $\mathrm{z}$ with $\mathrm{s}$ is given by the equations:

and

$$
\mathrm{dz} / \mathrm{ds}=\sin \theta
$$

$$
\mathrm{dx} / \mathrm{ds}=\cos \theta
$$

\subsubsection{Change in Temperature of Air with Height}

The temperature of the air at the plume center line is a function of height and may be obtained by solving the equation:

where:

$$
\mathrm{dT}_{\mathrm{a}} / \mathrm{ds}=\sin \theta\left(\theta_{\mathrm{Ta}} \mathrm{T}_{\mathrm{a}} /\left(\mathrm{T}_{\mathrm{ag}}+\left(\mathrm{d} \theta_{\mathrm{Ta}} / \mathrm{dz}\right) \mathrm{z}\right)-\mathrm{g} / \mathrm{C}_{\mathrm{pa}}\right)
$$

$\theta_{\mathrm{Ta}}=$ the potential temperature. Conservatively (that is, plume rise is minimized), the rate of change of $\theta_{\mathrm{Ta}}$ with height is taken to be zero in atmospheric stability categories $A-D, 1.5 \mathrm{~K} / 100 \mathrm{~m}\left(8.2 \mathrm{E}-3{ }^{\circ} \mathrm{F} / \mathrm{ft}\right)$ in category $\mathrm{E}$ and $4 \mathrm{~K} / 100 \mathrm{~m}\left(0.02^{\circ} \mathrm{F} / \mathrm{ft}\right)$ in category $\mathrm{F}$

Equation 5.44 simply corresponds to a linear potential temperature gradient.

\subsubsection{Zone of Flow Establishment}

In Figure 5-16, the typical plume behavior is shown. Initially, there is a "zone of plume establishment" which is not well represented by the set of equations presented above. This zone has length $s$ where $s$ is approximately $21 / 2$ stack diameters. This makes little difference to the results within the accuracy required by typical risk calculations. In the paper by $\mathrm{Li}$ Xiao-yun et al. (1986), it was determined that the momentum flux decreases by a factor $\mathrm{M}_{\mathrm{f}}$ over the zone of establishment. Experimental measurements show that $\mathrm{M}_{\mathrm{f}} \sim 0.85$ (note that, in earlier work [e.g., Ooms et al. (1974)], $\mathrm{M}_{f}$ was taken to be 0.5).

\subsubsection{Transition to Neutral Buoyancy}

For a denser-than-air jet, one possible simple criterion is that the plume makes a transition to neutral buoyancy (or to the passive phase) when both of conditions (i) and (ii) are satisfied or condition (iii) is satisfied:

(i) $\quad\left(\rho-\rho_{\mathrm{a}}\right) / \rho_{\mathrm{a}}<0.001$

(ii) $\quad \mid \mathrm{U}-\mathrm{U}_{\mathrm{a}} \cos \theta \mathrm{V} \mathrm{U}_{\mathrm{a}}<0.1$

(iii) the rates of change of plume radii in the horizontal and vertical directions due to the action of atmospheric turbulence exceed the rates of change due to initial jet effects

If

and

$$
\mathrm{dr}_{\mathrm{y}} / \mathrm{ds}_{\text {initial phase }}<\mathrm{dr}_{\mathrm{y}} / \mathrm{ds}_{\text {passive }}
$$

$$
\mathrm{dr}_{z} / \mathrm{ds}_{\text {initial phase }}<\mathrm{dr}_{\mathbf{z}} / \mathrm{ds}_{\text {passive }}
$$

then condition (iii) is satisfied. 
For buoyant plumes, the transition criteria are discussed in Section 5.4.2.

\subsubsection{Concentrations Within the Plume}

\section{(i) While Buoyant or Denser-than-Air}

While the plume is still heavier than air or buoyant, it is assumed to have a circular cross-section and radius $\mathrm{r}$, as given by the solution of the differential equations in Section (2.1). As discussed by Ooms et al. (1974), the material in the plume is assumed to be spread out over a radius $\lambda_{\mathrm{m}} \mathrm{r}$, where $\lambda_{\mathrm{m}}{ }^{2} \sim 1.35$. The concentration is assumed to be constant within this radius and zero outside. The concentration within the plume, averaged perpendicular to the wind direction, is given by

$$
C_{u}=\dot{M}_{g} /\left(\pi \lambda_{m}^{2} r^{2} U\right)
$$

The equivalent axial concentration if a Gaussian plume is assumed with its 10 percent edges at $\lambda_{\mathrm{m}} \mathrm{r}$ is

$$
C(r)=\dot{M}_{g} \exp \left(-r^{2} / 2 \sigma_{r}^{2}\right) /\left(2 \pi \sigma_{r} U\right)
$$

where:

$$
\sigma_{\mathrm{r}}=\lambda_{\mathrm{m}} \mathrm{r} / 2.14
$$

which gives $\mathrm{C}(0) \sim 2 \mathrm{C}_{u}$, i.e., the concentration averaged across the plume cross-section is about half the peak concentration.

\section{(ii) Beyond the Transition Point}

Beyond the transition point $\mathrm{x}_{\mathrm{v}}$, atmospheric dispersion continues to dilute the plume so that the conventional Gaussian formula may be used

$$
\mathrm{C}(\mathrm{x}, \mathrm{y}, \mathrm{z})=\dot{\mathrm{M}}_{\mathrm{g}} \exp \left(-\mathrm{y}^{2} / 2 \sigma_{\mathrm{y}}^{*^{2}}\left(\mathrm{x}_{\mathrm{d}}^{\mathrm{y}}\right)\right) S\left(\mathrm{~h}_{\mathrm{t}}, \mathrm{x}_{\mathrm{d}}^{\mathrm{z}}, \mathrm{z}\right) /\left(2 \pi \sigma_{\mathrm{z}}^{*}\left(\mathrm{x}_{\mathrm{d}}^{\mathrm{z}}\right) \sigma_{\mathrm{y}}^{*}\left(\mathrm{x}_{\mathrm{d}}^{\mathrm{y}}\right) \mathrm{U}_{\mathrm{a}}\right)
$$

where:

$$
S\left(h_{t}, x_{d}{ }^{2}, z\right)=\exp \left[-\left(z+h_{1}\right)^{2} / 2 \sigma_{z}^{* 2}\left(x_{d}{ }^{2}\right)\right]+\exp \left[-\left(z-h_{\nu}\right)^{2} / 2 \sigma_{z}^{* 2}\left(x_{d}{ }^{2}\right)\right]
$$

and $x_{d}{ }^{y}$ and $x_{d}{ }^{z}$ are the distances from the virtual source for horizontal and vertical speed respectively. $\sigma_{y}{ }^{*}\left(x_{d}{ }^{y}\right)$ and $\sigma_{z}{ }^{\prime \prime}\left(x_{d}{ }^{2}\right)$ are the standard deviation at a distance, $x_{d}$, from the virtual source. $x_{d}$ is calculated by determining the distance from a hypothetical passive source at which the height and width of the given cloud are equal to the height and width of the hypothetical passive cloud by using the appropriate parametrization of standard deviations.

For instance, if the radius or width of the given cloud is $r$, the virtual distance from the source, $x_{d}{ }^{y}$, is such that

$$
\sigma_{y}^{*}\left(x_{d}^{y}\right)=\lambda_{m} r / 2.14
$$




\subsection{Heavy Vapors}

\subsubsection{Basics}

Figure 5-17 displays a typical continuous heavy vapor plume released at ground level. For simplicity, the dense vapor is considered to emerge through a rectangular area in the vertical plane perpendicular to both the plume direction and the ambient wind direction. The rectangular coordinate system is aligned so that this direction lies along the $\mathrm{x}$-axis, the $\mathrm{y}$-axis is across the wind, and the $\mathrm{z}$-axis is vertical. The gas flux at the source and at every plane perpendicular to the wind direction is constant and equals the rate of release. The plume can be visualized as consisting of a number of rectangular elements or "puffs" emerging from the source at regular time intervals. The model follows the development of these puffs at a series of downwind points as illustrated in Figure 5-18. The plume slumps under the influence of gravity and entrains air through its sides and top. A considerable simplification is made by allowing the plume to slump only across the wind (i.e., the slumping of the front end of the plume is not taken into account).

\subsubsection{Miscellaneous Equations for the Plume}

For a steady plume entraining air, the mass of a small element of the plume of thickness $\mathrm{dx}$ at a distance $\mathrm{x}$ downwind of the source is:

$$
\begin{aligned}
M_{T}(x) d x & =\left(M_{a}(x)+M_{g}(x)\right) d x \\
& =2 L(x) h_{p}(x) \rho_{c}(x) d x
\end{aligned}
$$

where:

$$
\begin{aligned}
& M_{\mathrm{T}}(\mathrm{x})=\text { the total mass per unit length of the plume at a distance } \mathrm{x} \text { downwind }(\mathrm{kg}) \\
& \mathrm{M}_{\mathrm{a}}(\mathrm{x}) \quad=\text { the mass of air per unit length }(\mathrm{kg}) \\
& \mathrm{M}_{\mathrm{g}}(\mathrm{x}) \quad=\text { the mass of gas per unit length }(\mathrm{kg}) \\
& \mathrm{L} \\
& \mathrm{h}_{\mathrm{p}} \quad=\text { the half width of the plume }(\mathrm{m}) \\
& \rho_{\mathrm{c}} \quad=\text { the height } \mathrm{f} \text { the plume }(\mathrm{m})
\end{aligned}
$$

Equation 5.53 can be manipulated so that:

$$
\dot{\mathrm{M}}_{\mathrm{T}}=\dot{\mathrm{M}}_{\mathrm{a}}+\dot{\mathrm{M}}_{\mathrm{g}}=2 \mathrm{~L}(\mathrm{x})_{\mathrm{hp}}(\mathrm{x}) \rho_{\mathrm{c}} \mathrm{u}_{\mathrm{c}}(\mathrm{x})
$$

where $\dot{\mathrm{M}}_{\mathrm{T}}, \dot{\mathrm{M}}_{\mathrm{g}}$ and $\dot{\mathrm{M}}_{\mathrm{a}}$ are interpreted as the rates at which mass passes through a cross-sectional area of the plume that is normal to the wind direction at a distance $\mathrm{x}$ downwind.

Differentiating equation 5.53 and putting the plume velocity $\mathrm{u}_{c}=\mathrm{dx} / \mathrm{dt}$ gives the gaseous mass flux: where the period over a symbol signifies differentiation with respect to time. A similar expression for the gaseous volume flux, $\dot{\mathrm{V}}$, gives:

$$
\dot{\mathrm{V}}=2 \mathrm{~L}(\mathrm{x}) \mathrm{h}_{\mathrm{p}}(\mathrm{x}) \mathrm{u}_{\mathrm{c}}(\mathrm{x})
$$

Combining these expressions with the equation of state for the plume (assumed to be the perfect gas law) yields expressions for plume density and volume flux, at any point downwind of the source, in terms of the 


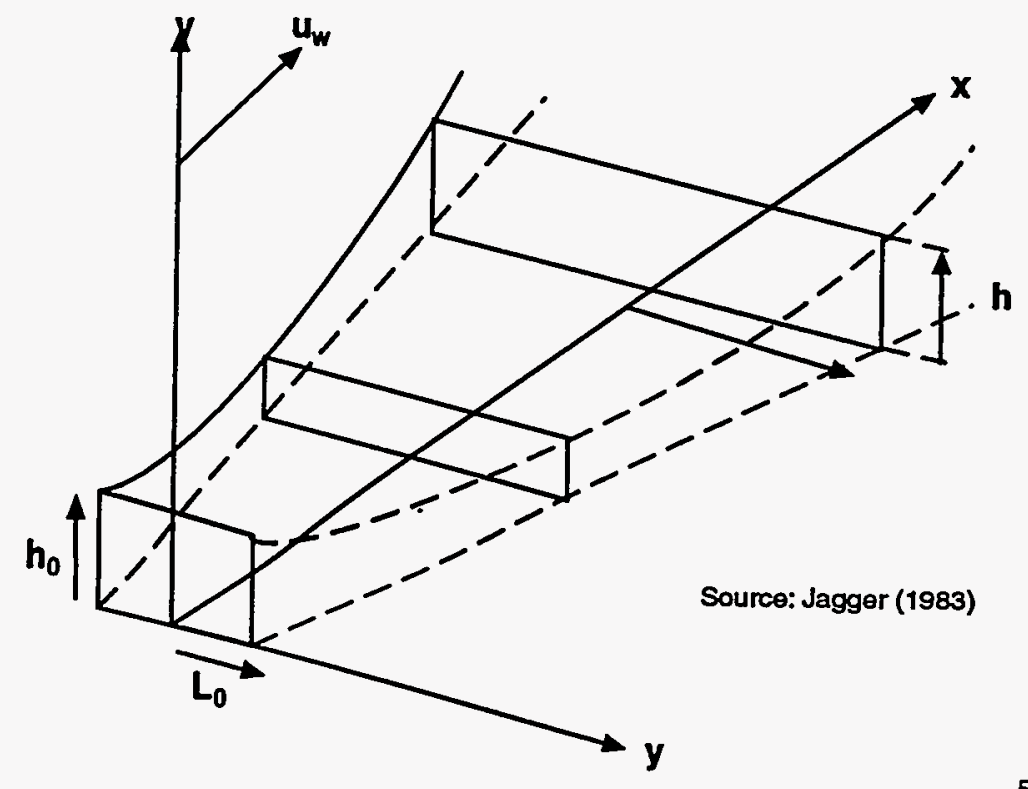

$5-15104820$

Figure 5-17. The configuration of the steady-state continuous plume (denser-than-air vapors) 


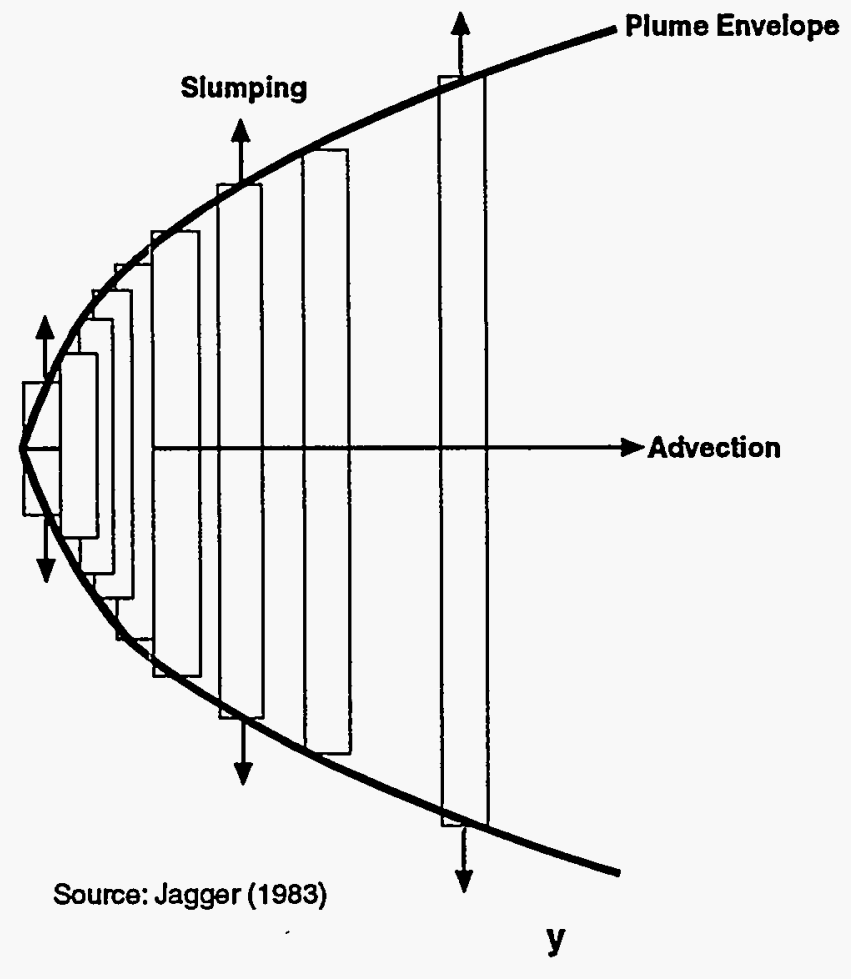

$5-16104820$

Figure 5-18. The development of the dense gas cloud by slumping and advection 
species mass fluxes, temperatures $T_{a}$ (air), $T_{g}$ (gas) and $T_{c}$ (cloud or plume), and densities $\rho_{a}$ (air) and $\rho_{g}$ (gas) at ambient conditions:

$$
\begin{gathered}
\rho_{c}=\left(\dot{M}_{a}+\dot{M}_{g}\right) \dot{V} \\
\dot{V}=\left(T_{c} \dot{M}_{a}\right) /\left(\rho_{a} T_{a}\right)+\left(T_{c} \dot{M}_{g}\right) /\left(\rho_{g} T_{g}\right)
\end{gathered}
$$

The assumption that the concentration is uniform across the plume is good in the near field, but becomes progressively less defensible as the difference in density between the plume and the air decreases.

The assumption that the plume obeys the perfect gas law is one that is made in most of the models listed in Section 5.10. In general, where it is incorrect (e.g. uranium hexafluoride/moist air thermodynamics), special modeling is needed.

Concentrations of the contaminant, assumed to be uniform everywhere during the gravity dominated phase, are given by:

$$
\mathrm{C}(\mathrm{x}, \mathrm{y}, \mathrm{z})=\dot{\mathrm{M}}_{\mathrm{g}} / \dot{\mathrm{V}}
$$

The momentum flux is the momentum carried by the mass of gas crossing a plane perpendicular to the wind direction each second:

$$
F_{m h}=\dot{V} \rho_{c} u_{c}
$$

\subsubsection{Gravitational Slumping}

While the plume is denser than air, it is assumed to slump everywhere in a direction perpendicular to the direction of travel of the plume. No slumping is considered along the wind. An expression for the rate of growth of the width of a dense cloud due to gravitational spreading has been obtained by analogy with the

$$
\mathrm{dL} / \mathrm{dt}=\mathrm{K}\left(\mathrm{g} * \mathrm{~h}_{\mathrm{p}}\right)^{\mathrm{t} / 2}
$$

collapse of a liquid column. The rate of growth of the cloud half-width, $\mathrm{L}$, is: $\mathrm{K}$ is the gravitational slumping constant, typically taken to be about unity.

Using equation 5.55, this can be converted to:

$$
\mathrm{dL} / \mathrm{dx}=\mathrm{K}\left(\mathrm{g} * \dot{\mathrm{V}} / 2 \mathrm{Lu}_{\mathrm{c}}^{3}\right)^{1 / 2}
$$

where:

$$
g^{*}=g\left(\rho_{c}-\rho_{a}\right) / \rho_{a}=g \Delta \rho / \rho_{a}
$$

\subsubsection{Entrainment of Air}

Entrainment is the process by which the cloud is diluted. The model incorporates entrainment of air at the edge and top of the plume. 
During the initial phases of dispersion, when the cloud is slumping rapidly, both field trials (UKHSE 1986b; Picknett 1981) and laboratory experiments (Simpson and Britter 1979) indicate that the edge resembles the front of a gravity current with a raised head, where there is considerable mixing with air (see Figure 5-2). This mixing is a complicated three-dimensional process. Here, a simplified scheme is adopted in which the entrainment is related to the area of the cloud edge and an entrainment velocity which is proportional to the rate of advance of the edge. Comparison with experiments show that the rate of change of the mass flux of air due to edge entrainment is then given by:

$$
\mathrm{d} \dot{\mathrm{M}}_{\mathrm{a}} / \mathrm{dx}=2 \mathrm{~h}_{\mathrm{p}} \rho_{\mathrm{a}} \alpha_{1} \mathrm{dL} / \mathrm{dt}
$$

where:

$$
\alpha_{1}=\text { an empirical constant that has been found to have a value of about } 0.7
$$

The rate of change of the mass flux of air due to entrainment over the top surface is given by:

where:

$$
\mathrm{d} \dot{\mathrm{M}}_{\mathrm{a}} / \mathrm{dx}=2 \mathrm{~L}_{\mathrm{s}} \rho_{\mathrm{a}} \mathrm{v}_{\mathrm{e}}
$$

$$
\begin{aligned}
& L_{s}=a \text { length scale } \\
& v_{c}=\text { an entrainment velocity given by: }
\end{aligned}
$$

and

$$
v_{e}=\alpha_{2} U_{t} R_{i}^{-1}
$$

$$
\mathrm{R}_{\mathrm{i}}=\left(\mathrm{gL}_{\mathrm{s}} \mathrm{U}_{\mathrm{t}}^{2}\right) \Delta \rho / \rho_{\mathrm{a}}
$$

Here, $R_{i}$ is a Richardson number, $L_{s}$ is a length scale, $U_{t}$ is a velocity scale, and $\alpha_{2}$ is an empirical constant which has been found to take on the value 0.14 . Clearly, the choice of $L_{s}$, and $U_{t}$ is critical if equation 5.64 is to be realistic in simulating the rate of entrainment of air over the top of the plume. Therefore, $L_{s}$ and $U_{t}$ have been chosen on the basis of the continuous release experiments that were carried out at Thorney Island (UKHSE 1986). $L_{s}$ equals the height of the plume, $h_{p}$, and

$$
\mathrm{U}_{\mathrm{t}}=0.16 \mathrm{u}_{\mathrm{c}}
$$

where, as noted above, $u_{c}$ is the velocity of the plume.

By combining equations 5.64, 5.65, and 5.66 and substituting the expression for gaseous volume flux, 5.51 , the following expression can be obtained for the simultaneous entrainment of air at the edge and the top:

$$
\mathrm{d} \dot{\mathrm{M}}_{\mathrm{a}} / \mathrm{dx}=2 \mathrm{~L} \rho_{\mathrm{a}} \mathrm{U}_{\mathrm{e}}+\left(\rho_{\mathrm{a}} \dot{\mathrm{V}} \alpha_{\mathrm{l}} / \mathrm{L}\right) \mathrm{dL} / \mathrm{dx}
$$

\subsubsection{Cloud Heating}

Dense gas clouds are often produced at temperatures far below that of the surrounding environment; hence, the heating of the cloud by the ground and by entrained air has an important influence on the density of the plume. In principle, other heating mechanisms, such as solar radiation, could be incorporated into the model, but only the above two are considered here. Heating by the ground is assumed to be driven by 
turbulent natural convection. If the cloud is colder than the ground, the heating rate per unit area is given by:

$$
\dot{\mathrm{Q}}=\alpha_{3}\left(\mathrm{~T}_{\mathrm{gr}}-\mathrm{T}_{\mathrm{c}}\right)^{4 / 3}
$$

where: $\mathrm{T}_{\mathrm{gr}}=$ the temperature of the ground and

where:

$$
\alpha_{3}=0.1457 \mathrm{~K}_{\mathrm{f}}^{*}\left(\left(\rho_{\mathrm{f}}^{2} \mathrm{~g} \beta_{\mathrm{f}} / \mu_{\mathrm{f}}^{2}\right)\left(\mathrm{C}_{\mathrm{p}} \mu / \mathrm{K} *\right)_{\mathrm{f}}\right)^{1 / 3}
$$

$\mathrm{C}_{\mathrm{p}}=$ the specific heat of the mixture at constant pressure $(\mathrm{J} / \mathrm{kg} / \mathrm{K})$

$\mathrm{f}=$ a subscript denoting quantities evaluated at the film temperature $\left(\mathrm{T}_{\mathrm{gr}}+\mathrm{T}_{\mathrm{c}}\right) / 2$

$\beta_{\mathrm{f}}=$ the volumetric coefficient of expansion of the cloud $\left(\mathrm{m}^{3} / \mathrm{K}\right)$

$\mathrm{K}_{\mathrm{f}}=$ the thermal conductivity of the cloud $(\mathrm{W} / \mathrm{m} / \mathrm{K})$

$\mu_{f}=$ the viscosity of the cloud (Pas)

$\rho_{\mathrm{f}}=$ the density of the cloud $\left(\mathrm{kg} / \mathrm{m}^{3}\right)$

Application of a simple heat balance to a cloud element then gives the rate of rise of temperature due to heating by the ground and by entrained air as:

$$
\mathrm{dT}_{\mathrm{c}} / \mathrm{dx}=\left(\left(\mathrm{T}_{\mathrm{a}}-\mathrm{T}_{\mathrm{c}}\right) \mathrm{C}_{\mathrm{pa}} \mathrm{d} \dot{\mathrm{M}}_{\mathrm{a}} / \mathrm{dx}+2 \mathrm{LQ}\right) /\left(\dot{\mathrm{M}}_{\mathrm{a}} \mathrm{C}_{\mathrm{pa}}+\dot{\mathrm{M}}_{\mathrm{g}} \mathrm{C}_{\mathrm{pg}}\right)
$$

(a)

(b)

Here, (a) and (b) represent the rate of change of temperature due to the entrainment of air and heating by the ground, respectively.

\subsubsection{Velocity of the Plume}

The velocity of the plume, $u_{c}$, is calculated by assuming conservation of momentum flux in the $x$-direction, incorporating a model proposed by Wheatley, et al. (1986):

$$
\mathrm{dM}_{\mathrm{f}} / \mathrm{dx}=\rho_{\mathrm{a}}(\mathrm{d} \dot{\mathrm{V}} / \mathrm{dx})\left(0.8 \mathrm{u}_{\mathrm{w}}+\mathrm{u}_{\mathrm{c}}\right) / 2
$$

where:

$$
\mathrm{d} \dot{\mathrm{V}} / \mathrm{dx}=\mathrm{A}(\mathrm{dT} / \mathrm{dx})+\left(\mathrm{T}_{\mathrm{c}} / \rho_{\mathrm{a}} \mathrm{T}_{\mathrm{a}}\right)\left(\mathrm{d} \dot{\mathrm{M}}_{\mathrm{a}} / \mathrm{dx}\right)
$$

$u_{w}=$ the velocity of the wind at the top surface of the plume

and

$$
A=\dot{M}_{\mathrm{a}} /\left(\rho_{\mathrm{a}} \mathrm{T}_{\mathrm{a}}\right)+{ }_{\mathrm{g}}\left(\rho_{\mathrm{g}} \mathrm{T}_{\mathrm{g}}\right)
$$

The first term in equation 5.73 represents the expansion of the cloud as its temperature increases. The second term represents the rate of increase of volume flux due to the entrainment of air.

\subsubsection{Volume Flux}

The volume flux is given by: 


$$
\dot{V}=\left(\dot{M}_{\mathrm{a}} \mathrm{T}_{c} / \rho_{\mathrm{a}} \mathrm{T}_{\mathrm{a}}\right)+\left(\dot{\mathrm{M}}_{\mathrm{g}} \mathrm{T} / \rho_{\mathrm{g}} \mathrm{T}_{\mathrm{g}}\right)
$$

where:

$\dot{\mathrm{M}}_{\mathrm{a}}, \dot{\mathrm{M}}_{\mathrm{g}}=$ the mass fluxes of air and the gaseous fractions of the released material, respectively (kg)

$\mathrm{T}_{\mathrm{c}} \quad=$ the cloud temperature $(\mathrm{K})$

$\rho_{a}=$ the air density at a reference temperature of $T_{a}\left(\mathrm{~kg} / \mathrm{m}^{3}\right)$. Likewise, $\rho_{\mathrm{g}}$ is the reference density of the released material at a temperature $\mathrm{T}_{\mathrm{g}}$

Therefore,

$$
\begin{aligned}
\mathrm{d} \dot{V} / \mathrm{dx}= & \mathrm{dT} / \mathrm{dx}\left[\left(\dot{\mathrm{M}}_{\mathrm{a}} / \rho_{\mathrm{a}} \mathrm{T}_{\mathrm{a}}\right)+\left(\dot{\mathrm{M}}_{\mathrm{g}} / \rho_{\mathrm{g}} \mathrm{T}_{\mathrm{g}}\right)\right]+\mathrm{T}_{\mathrm{c}}\left[\left(\mathrm{d} \dot{\mathrm{M}}_{\mathrm{a}} / \mathrm{dx}\right) / \rho_{\mathrm{a}} \mathrm{T}_{\mathrm{a}}\right) \\
& \left.\left.\left.+\left(\dot{\mathrm{M}}_{\mathrm{g}} / \rho_{\mathrm{g}} \mathrm{T}_{\mathrm{g}}\right)\right]+\mathrm{T}_{\mathrm{c}}\left[\left(\mathrm{d} \dot{M}_{\mathrm{a}} / \mathrm{dx}\right) / \rho_{\mathrm{a}} \mathrm{T}_{\mathrm{a}}\right)+\left(\mathrm{d} \dot{\mathrm{M}}_{\mathrm{g}} / \mathrm{dx}\right) / \rho_{\mathrm{g}} \mathrm{T}_{\mathrm{g}}\right)\right]
\end{aligned}
$$

\subsubsection{Cloud Height}

The height of the plume, $h_{p}$ (the top of the plume, not its center line), is given by:

$$
h_{p}=\left(\dot{V}\left(\dot{M}_{a}+\dot{M}_{g}\right)\right) /\left(2 F_{m h}\right)
$$

This equation can be differentiated with respect to $\mathrm{x}$ in order to provide a first-order differential equation that is a function of quantities already defined above.

\subsubsection{Solution of Differential Equations}

As was the case with the jet/stack model, the above form a set of coupled, non-linear differential equations which must be solved numerically.

\subsubsection{Transition to Passive Plume}

As the cloud's density decreases, its density approaches that of the surrounding air, and, at some distance $x_{t}$ downwind, it may be considered to disperse as would a passive plume. One simple criterion is:

$$
\Delta \rho / \rho_{\mathrm{a}}<10^{-3}
$$

This is recognized to be a very simple way of determining the value of $x_{t}$, and it may lead to some discontinuities in the rate of change of concentration as a function of distance. The analyst can always experiment with different cut-off values for $\Delta \rho / \rho_{\mathrm{a}}$.

Alternatively, the rate of change of cloud width (dL/dx) passive and height $\left(\mathrm{dh}_{\mathrm{p}} / \mathrm{dx}\right)_{\text {passive }}$ due to turbulence in the atmosphere can be compared with $(\mathrm{dL} / \mathrm{dx})_{\text {gravitational }}$ and $\left(\mathrm{dh}_{\mathrm{p}} / \mathrm{dx}\right)_{\text {gravitational, }}$, respectively. The model makes the transition to the passive phase if passive effects begin to dominate, that is, if:

and

$$
(\mathrm{dL} / \mathrm{dx})_{\text {gravitational }}<(\mathrm{dL} / \mathrm{dx})_{\text {passive }}
$$

$$
\left(\mathrm{dh}_{\mathrm{p}} / \mathrm{dx}\right)_{\text {gravitational }}>\left(\mathrm{dh}_{\mathrm{p}} / \mathrm{dx}\right)_{\text {passive }}
$$


where, for a given location $\mathrm{x},(\mathrm{dL} / \mathrm{dx})_{\text {passive }}$ is given by:

$$
(\mathrm{dL} / \mathrm{dx})_{\text {passive }}=2.14 \mathrm{~d} \sigma_{\mathrm{y}}(\mathrm{x}) / \mathrm{dx}
$$

where $x^{\prime}$ is such that the corresponding passive phase half-width is equal to $2.14 \sigma_{y}=10$ percent edge of the cloud. This is a traditional assumption based upon Pasquill's original work. This criteria makes the transition from the slumping to the passive phase smoother. There is a similar equation for $\left(d_{\mathrm{p}} / d x\right)$ passive.

\subsubsection{Passive Diffusion}

At distances downwind of the transition point $x_{t}$, the concentration profile is taken to be Gaussian:

where:

$$
\begin{gathered}
C(x, y, z)=\dot{M}_{g} \exp \left(-y^{2} / 2 \sigma_{y}^{2}(x)\right) S(x, z) F(x) /\left(2 \pi \sigma_{z}(x) \sigma_{y}(x) u_{c}\right) \\
S(x, z)=2 \exp \left(-z^{2} / 2 \sigma_{z}{ }^{2}(x)\right)
\end{gathered}
$$

and the inversion lid is very large relative to $\sigma_{z} . F(x)$ is the fraction of the cloud remaining airborne at a distance $x$ downwind in the event that dry deposition is incorporated.

The width and height of the plume during the passive dispersion phase are specified by the lateral and vertical standard deviations, $\sigma_{y}(x)$ and $\sigma_{z}(x)$, which are functions of atmospheric stability category, roughness length, and downwind distance. At the transition point $x_{t}$, the plume half width is $\mathrm{L}_{t}$ and the plume height is $h_{t}$. Assuming that the edges of the cloud are defined by the 10 percent of peak concentration contour, the equivalent passive dispersion parameters at the transition point are:

and

$$
\sigma_{\mathrm{yt}}=\mathrm{L}_{\mathrm{r}} / 2.14
$$

$$
\sigma_{\mathrm{zt}}=\mathrm{h}_{\mathrm{r}} / 2.14
$$

Upwind of the transition point, the width and height of the plume grow more and less rapidly respectively than would the width and height of a passive plume released under the same conditions. Thus, at the transition point, the plume width is equivalent to that of a passive plume released upwind of the actual source at $x_{v y}<0$, and the plume height is equivalent to that of a passive plume originating at a distance $x_{v z}$ $>0$ downwind of the source. This situation is shown in plan and elevation on Figure 5-19.

For distances further downwind than $x_{1}, \sigma_{y}$ and $\sigma_{z}$ are calculated on the basis of the distance from the virtual source.

\subsubsection{Puff Releases}

\subsubsection{Source Term}

It is convenient to describe a heavy puff source as an initial "source cylinder", specified as follows:

(i) the mass of released gas

(ii) the quantity of air entrained during the formation of the cylinder 

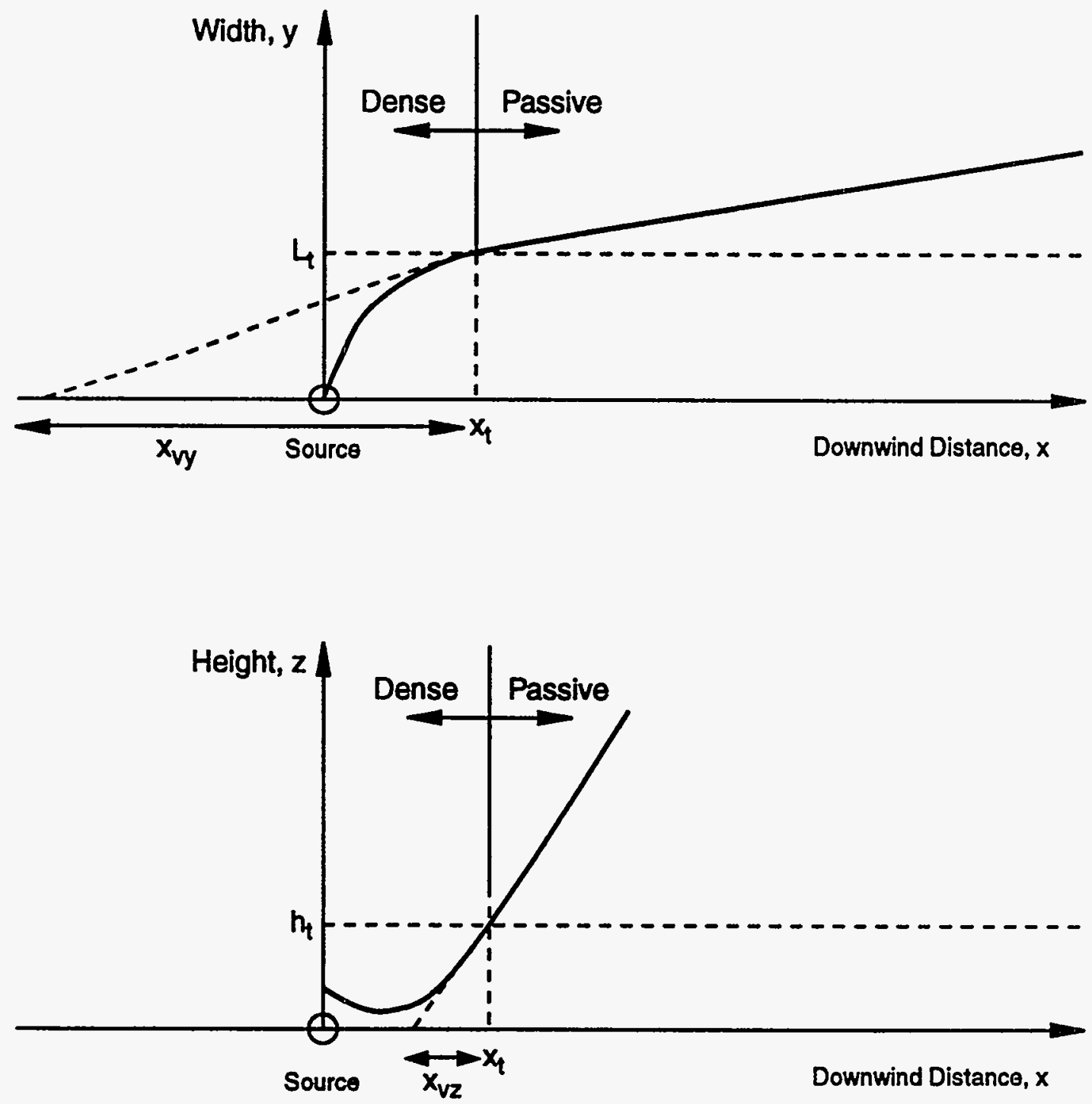

Figure 5-19. The growth of plume width and height across the transition from dense to passive phases 
(iii) the temperature and density of the mixture in the cylinder

(iv) the initial velocity of the cylinder

(v) the initial height and radius of the cylinder

\subsubsection{Slumping}

Once formed, the source cylinder begins to slump as would a column of liquid. The velocity of the edge of the cloud is described by the liquid column analogy:

$$
\mathrm{dr} / \mathrm{dt}=\mathrm{K}\left(\mathrm{gh}_{\mathrm{p}} \Delta \rho / \rho_{\mathrm{a}}\right)^{1 / 2}
$$

where:

$r=$ the radius of the cloud (m)

$\mathrm{t}=$ the time (s)

$\mathrm{K}=$ a constant $(\mathrm{K} \sim 1)$

$\rho_{\mathrm{a}}=$ the density of air $\left(\mathrm{kg} / \mathrm{m}^{3}\right)$

$\rho_{c}=$ the density of the cloud $\left(\mathrm{kg} / \mathrm{m}^{3}\right)$

$\Delta \rho=\rho_{c}-\rho_{a}\left(\mathrm{~kg} / \mathrm{m}^{3}\right)$

$\mathrm{g}=$ is the acceleration due to gravity $\left(9.82 \mathrm{~m} / \mathrm{s}^{2}\right)$

$h_{p}=$ the height of the cloud (m)

Making use of the equation $V=\pi r^{2} h_{p}$, equation 5.86 becomes

$$
\mathrm{d}\left(\mathrm{r}^{2}\right) / \mathrm{dt}=2 \mathrm{~K}\left[\mathrm{~g} \Delta \rho \mathrm{V} /\left(\pi \rho_{\mathrm{a}}\right)\right]^{1 / 2}
$$

where: $V=$ the volume of the cloud $\left(\mathrm{m}^{3}\right)$

\subsubsection{Entrainment of Air}

The rate of entrainment of air is given by:

$$
\mathrm{dM}_{\mathrm{a}} / \mathrm{dt}=\rho_{\mathrm{a}}\left(\pi \mathrm{r}^{2}\right) \mathrm{U}_{\mathrm{e}}+2 \rho \mathrm{p}_{\mathrm{p}} \alpha_{1} \mathrm{dr} / \mathrm{dt}
$$

The second term on the right side represents edge entrainment as the cloud slumps. A value of $\alpha_{1}$ consistent with the Thorney Island experiments is $\alpha_{1}=0.7$ (Wheatley et al. 1986).

The first term on the right hand side represents top entrainment. $U_{c}$ is the entrainment velocity $(\mathrm{m} / \mathrm{s})$ given by:

where:

$$
\mathrm{U}_{\mathrm{e}}=\alpha_{2} \mathrm{U}_{\mathrm{t}}\left(\mathrm{R}_{\mathrm{i}}\right)^{-1}
$$

$\mathrm{U}_{\mathrm{t}}=$ an empirically determined velocity $(\mathrm{m} / \mathrm{s})$

$R_{i}=a$ Richardson number, given by:

$$
\mathrm{R}_{\mathrm{i}}=\left(\mathrm{gL}_{\mathrm{s}} \mathrm{U}_{\mathrm{t}}^{2}\right) \Delta \rho / \rho_{\mathrm{a}}
$$


where:

$\mathrm{L}_{s}=$ a length scale $(\mathrm{m})$, set equal to the height $\mathrm{h}$ of the plume

$\alpha_{2}=$ an empirical constant with a value of 0.14

From an analysis of the Thorney Island experiments, $U_{t}=0.16 u_{c}, u_{c}$ being the velocity of the cloud.

\subsubsection{Conservation of Momentum}

Let $M_{h}$ be the horizontal momentum of the cloud. Using the work of Wheatley and Prince (1986),

$$
\mathrm{dM}_{\mathrm{h}} / \mathrm{dt}=0.5\left(\mathrm{u}_{\mathrm{c}}+0.8 \mathrm{u}_{\mathrm{w}}\right) \mathrm{dM_{ \textrm {a } }} / \mathrm{dt}+\pi \mathrm{r}^{2}\left(\tau_{\mathrm{a}}+\tau_{\mathrm{g}}\right)
$$

The first term on the right side is the rate of change of momentum due to the entrainment of air; $u_{c}$ is the puff speed and $u_{w}$ is the windspeed at the plume height. In the second term on the right side, $\tau_{\mathrm{a}}$ and $\tau_{\mathrm{g}}$ are the turbulent shear stresses at the top of the cloud and the ground, respectively. They are neglected in some approaches.

\subsubsection{Cloud Heating}

The rate of change of cloud temperature $T$ is given by

where:

$$
\mathrm{dT} / \mathrm{dt}=\left(\mathrm{dm}_{\mathrm{a}} / \mathrm{dt}\right) \mathrm{C}_{\mathrm{pa}}+\alpha_{3}\left(\pi \mathrm{R}^{2}\right)\left(\Delta \mathrm{T}_{\mathrm{g}}\right)^{4 / 3} / \mathrm{B}
$$

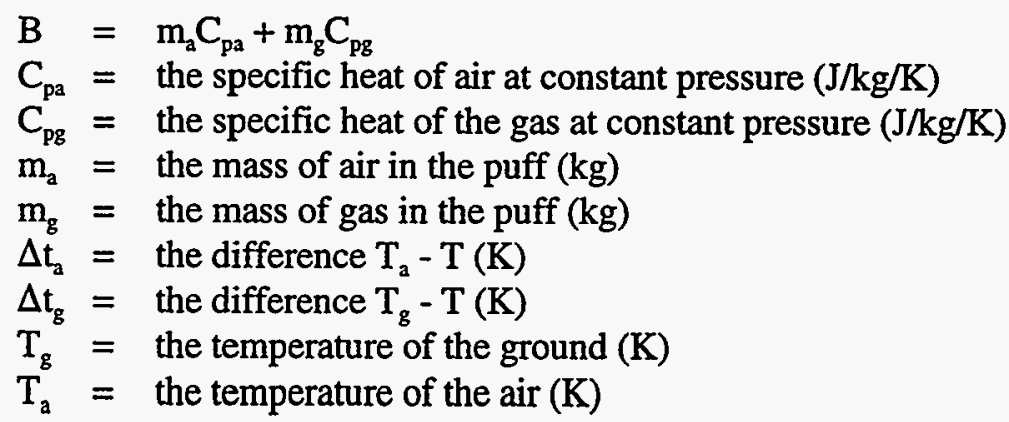

The first term on the right hand side of equation 5.92 gives the rate of heating due to the entrainment of air. The second term gives the rate of heating by the ground due to turbulent natural convection with:

where:

$$
\dot{Q}=\left(0.1457 K_{f}^{*} / L\right) \cdot\left(\left(L^{3} \rho_{f}^{2} g \beta_{f} \mu T_{g} / \mu_{f}^{2}\right)\left(C_{p} \mu / K *\right)_{f}\right)^{0.33}\left(\Delta T_{g}\right)^{4 / 3}
$$

$\mathrm{C}_{\mathrm{p}}=$ the specific heat of the puff at constant pressure $(\mathrm{J} / \mathrm{kg} / \mathrm{K})$

$\mathrm{f}=$ a subscript denoting quantities evaluated at the film temperature $\left(T+T_{g}\right) / 2$

$\mathrm{L}=\mathrm{a}$ typical dimension of the cloud (note that $\mathrm{L}$ cancels out in equation 5.93) (m)

$B=$ the volumetric coefficient of expansion of the cloud

$\mu=$ the viscosity

$\mathrm{K}^{*}=$ the thermal conductivity of the cloud $\left(\mathrm{kg} \mathrm{s}^{-1} \mathrm{~m}^{-1}\right)$ 
Typical values of $\alpha_{3}$ are about unity.

\subsubsection{Cloud Volume}

The volume of a cylindrical puff is given by:

where:

$$
\mathrm{V}=\left(\mathrm{m}_{\mathrm{a}} / \mathrm{M}_{\mathrm{a}}+\mathrm{m}_{\mathrm{g}} / \mathrm{M}_{\mathrm{g}}\right) \mathrm{RT} / \mathrm{P}_{\mathrm{atm}}
$$

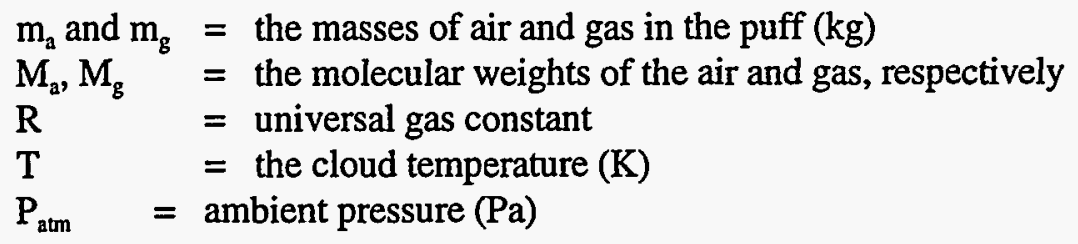

The rate of change of volume is given by differentiating equation 5.94 with respect to $t$.

\subsubsection{Cloud Height}

The height of the puff is given by:

$$
h_{p}=V / \pi R^{2}
$$

\subsubsection{Transition to a Passive Plume}

There are two possible tests to determine whether the plume may be deemed to be passive. The first test sees whether both of the following conditions are satisfied: the gravitational slumping must cause a rate of increase of radius not exceeding that to be expected by the atmospheric turbulence alone (making the conceptual assumption that the radius is at the 10 percent edge of a Gaussian profile). The rate of growth of plume height predicted by the heavy vapor dispersion model must exceed that predicted by the traditional Gaussian dispersion model. If both of these conditions are satisfied, the plume makes the transition to passive diffusion. Meanwhile, the density difference $\Delta \rho / \rho_{\mathrm{a}}$ is also calculated, and, if this quantity is less than $0.001 \mathrm{~kg} \mathrm{~m}^{-3}\left(6.2 \times 10^{-5} \mathrm{lb} / \mathrm{ft}^{3}\right)$, it is assumed that the plume becomes passive. The critical value of $\Delta \rho / \rho_{\mathrm{a}}$ can be varied by the analyst.

At greater distances downwind, $\sigma_{\mathrm{y}}$ and $\sigma_{\mathrm{z}}$ are calculated on the basis of the distance from a virtual source.

The virtual source is defined as the source from which an initially passive plume produces the same height or half-width as the given plume at the transition point. (Note: The distance from the virtual source based upon the comparison of heights differs from that based upon the comparison of half-widths.) In other words, the distance from the virtual source, $x_{d}$, is such that:

and

$$
\sigma_{y}\left(x_{d}\right)=r_{r} / 2.14
$$

$$
\sigma_{\mathrm{z}}\left(\mathrm{x}_{\mathrm{d}}\right)=\mathrm{h}_{\mathrm{pr}} / 2.14
$$

Note that, in the passive phase, the longitudinal spreading rate exceeds the lateral spreading rate because of wind shear. This can be accomplished according to a simple model given by Ermak (1990): 


$$
\sigma_{x}^{2}(x)=\sigma_{y}^{2}(x)+\beta^{2} x^{2}
$$

where $\beta$ is a function of stability category and takes on the values $0.047,0.045,0.064,0.097,0.235$, and 0.375 in categories $A, B, C, D, E$ and $F$, respectively.

\subsubsection{Concentrations Within the Puff}

If a total quantity $\mathrm{M}_{\mathrm{g}}$ of toxic or radioactive material is released, the assumption is made that the material is distributed in a Gaussian fashion across the "puff". At any point $(x, y, z)$ and at time $t$, the airborne concentration is given by

where:

$$
C(x, y, z, t)=M_{g} G(x, y, z, t) /\left(\sqrt{2} \pi^{3 / 2} \sigma_{x} \sigma_{y} \sigma_{z}\right)
$$

$$
G(x, y, z, t)=\exp \left(-y^{2} / 2 \sigma_{y}^{2}-z^{2} / 2 \sigma_{z}^{2}-(x-x(t))^{2} / 2 \sigma_{x}^{2}\right)
$$

$x(t)=$ the position of the "puff" center point at time $t$

$$
x(t)=\int_{0}^{t} u_{c}(t) d t^{*}
$$

\subsubsection{Cloud Velocity}

Prior to reaching the transition point from denser-than-air to passive diffusion $x_{\imath}$, the velocity of the puff is calculated from the solution to equation 5.91, which given $\mathrm{M}_{\mathrm{h}}$, the cloud momentum as a function of downwind distance. The mass of material in the puff is $M_{a}+M_{g}$, where $M_{g}$ is the mass of released gas and $\mathrm{M}_{\mathrm{a}}$ is the mass of air, obtained from the solution of equation 5.88 . It follows that:

$$
u_{c}=M_{h} /\left(M_{a}+M_{s}\right)
$$

Downwind of $x_{t}$, the prescription of Chatwin is used (Wheatley and Prince 1986):

$$
u_{c}=0.82 u_{w}
$$

where: $u_{w}=$ the windspeed at the top of the puff

\subsection{Special Phenomena}

In some cases, it is necessary to modify the basic models to account for specific physical or thermodynamic effects that strongly influence such key parameters as density or temperature.

\subsubsection{Aerosol Formation - Transport and Evaporation of Liquid Droplets}

Section 3.5.2.1 of this Handbook explains the mechanisms of the formation of fine, airborne liquid droplets as a result of flashing liquid releases. (In the case of $\mathrm{UF}_{6}$, fine, solid particles are formed.) Dispersion models must be able to take these droplets into account because they affect the properties of the cloud; for example, its density. Several of the models described in Section 5.10.2 are able to handle droplet transport and evaporation. 


\subsubsection{Hydrogen Fluoride/Moist Air Thermodynamics}

Any model of HF moist air interactions has to take into account the following phenomena:

\subsubsection{The Oligomerization of Hydrogen Fluoride}

One model postulates that HF oligomerizes into the monomer, dimer, and hexamer forms (Clough et al. 1987a,b). There is some controversy about whether this is the best possible model, but it appears to provide a reasonable fit to data in the range of sub-atmospheric partial pressures that are of interest in the context of atmospheric dispersion (see Tables 5-6 and 5-7).

A similar model was incorporated into the draft $\mathrm{UF}_{6} / \mathrm{HF}$ heavy vapor model that was sponsored by NRC (Chhibber and Kaiser 1993). In Tables 5-6 and 5-7, F is the ratio of the effective molecular weight of the mixture of oligomers to the molecular weight of HF monomer (20). The subscript exp refers to experimental results, SRD refers to the model of Clough et al. and NRC refers to the model sponsored by NRC. $T$ is the temperature at which the experiments were conducted and $P$ is the experimental value of the partial pressure of HF. Tables 5-6 and 5-7 are representative of the results that can be obtained by models of oligomerization that require numerical solutions.

\subsubsection{Final State of Hydrogen Fluoride/Moist Air Mixtures}

The problem is to take HF in an initial state that may contain droplets and vapor, mix it with air of specified temperature and relative humidity, and then search for a physically plausible final state using $\Delta H$ $=0$, where $\Delta \mathrm{H}$ is the change in enthalpy. There are numerous contributions to $\Delta \mathrm{H}$, including:

- The change in the internal energy of the air

- The change in the internal energy of the HF, which includes cooling due to the de-oligomerization of HF and cooling due to the evaporation of initial liquid droplets of HF

- The change in the internal energy of water in the air

- The change in internal energy due to the formation of droplets containing HF and water.

The equation $\Delta \mathrm{H}=0$ can only be solved by complex numerical methods. That it can be done successfully, however, is shown by Table 5-8, which shows one particular model's agreement with data. In Table 5-8, the first column shows the total mole percentage of HF in the air/HF mixture that was used in experiments by Schotte (1987). The second column shows the corresponding mixing ratio (mass of air : mass of HF). The next two columns shows the initial temperature of the air and of the HF before mixing took place. Upon mixing, HF/water droplets were formed, leading to a fog. The "Fog Exp" column gives the experimentally measured temperature of the fog and "Fog (NRC)" gives the predictions of the model developed for NRC. $\mathrm{X}_{\mathrm{HF}}$ is the mole percentage of $\mathrm{HF}$ in the liquid droplets, and a comparison with experiment is shown. The last two columns show a similiar comparison of experimental measurements and a theoretical prediction of the percentage of HF that condenses.

\subsubsection{Uranium Hexafluoride/Moist Air Thermodynamics}

$\mathrm{UF}_{6}$ reacts with airborne moisture according to:

$$
\mathrm{UF}_{6}+2 \mathrm{H}_{2} \mathrm{O} \Leftrightarrow 4 \mathrm{HF}+\mathrm{UO}_{2} \mathrm{~F}_{2}+\text { heat }
$$


Table 5-6. Predicted and Experimental Association Factors (F) (Vanderzee and Rosenberg 1970)

\begin{tabular}{|c|c|c|c|c|}
\hline $\begin{array}{c}\mathbf{T} \\
\left({ }^{\circ} \mathbf{C}\right)\end{array}$ & $\begin{array}{c}\mathbf{P} \\
\left(\mathbf{N} / \mathbf{m}^{2}\right)\end{array}$ & $\mathbf{F}_{\text {exp }}$ & $\begin{array}{c}\mathbf{F} \\
(\mathbf{S R D})\end{array}$ & $\begin{array}{c}\mathbf{F}_{\text {calc }} \\
(\mathbf{N R C})\end{array}$ \\
\hline-20 & $2.00 \mathrm{E} \mathrm{04}$ & 4.048 & 4.172 & 4.204 \\
\hline-10 & $3.13 \mathrm{E} \mathrm{04}$ & 3.905 & 3.948 & 3.983 \\
\hline 0 & $4.85 \mathrm{E} \mathrm{04}$ & 3.750 & 3.758 & 3.792 \\
\hline 10 & $7.15 \mathrm{E} \mathrm{04}$ & 3.591 & 3.533 & 3.570 \\
\hline 15 & $8.61 \mathrm{E} \mathrm{05}$ & 3.510 & 3.427 & 3.467 \\
\hline 19.7 & $1.01 \mathrm{E} \mathrm{05}$ & 3.429 & 3.318 & 3.349 \\
\hline
\end{tabular}

Table 5-7. Predicted and Experimental Association Factors (F) (Strohmeir and Briegleb 1953)

\begin{tabular}{|c|c|c|c|c|}
\hline $\begin{array}{c}\mathbf{T} \\
\left({ }^{\circ} \mathbf{C}\right)\end{array}$ & $\begin{array}{c}\mathbf{P} \\
\left(\mathbf{N} / \mathbf{m}^{2}\right)\end{array}$ & $\mathbf{F}_{\text {exp }}$ & $\begin{array}{c}\mathbf{F}_{\text {calc }} \\
(\mathbf{S R D})\end{array}$ & $\begin{array}{c}\mathbf{F}_{\text {calc }} \\
(\mathbf{N R C})\end{array}$ \\
\hline 26 & $6.96 \mathrm{E} \mathrm{04}$ & 1.832 & 2.008 & 2.048 \\
\hline 26 & $5.6 .2 \mathrm{E} \mathrm{04}$ & 1.431 & 1.630 & 1.665 \\
\hline 26 & $3.67 \mathrm{E} \mathrm{04}$ & 1.104 & 1.173 & 1.186 \\
\hline 26 & $2.30 \mathrm{E} \mathrm{04}$ & 1.034 & 1.042 & 1.044 \\
\hline 26 & $1.46 \mathrm{E} \mathrm{04}$ & 1.019 & 1.019 & 1.019 \\
\hline 26 & $0.89 \mathrm{E} \mathrm{04}$ & 1.011 & 1.010 & 1.011 \\
\hline 32 & $8.64 \mathrm{E} \mathrm{04}$ & 1.743 & 1.915 & 1.956 \\
\hline 32 & $6.77 \mathrm{E} \mathrm{04}$ & 1.338 & 1.512 & 1.543 \\
\hline 32 & $4.00 \mathrm{E} \mathrm{04}$ & 1.065 & 1.096 & 1.102 \\
\hline 32 & $1.20 \mathrm{E} \mathrm{04}$ & 1.012 & 1.011 & 1.011 \\
\hline 38 & $9.04 \mathrm{E} \mathrm{04}$ & 1.391 & 1.563 & 1.594 \\
\hline 38 & $1.37 \mathrm{E} \mathrm{04}$ & 1.011 & 1.010 & 1.010 \\
\hline
\end{tabular}

Keys to Tables 5-6 and 5-7

$\mathrm{SRD}=$ model of Clough et al. $(1987 \mathrm{a}, \mathrm{b})$

$\mathrm{NRC}=$ model developed for NRC (1993)

$\mathrm{F}=\mathrm{M}_{\mathrm{o}} / \mathrm{M}_{\mathrm{m}}$

$M_{0} \quad=$ the effective molecular weight of oligomerized HF

$\mathrm{M}_{\mathrm{m}}=$ the molecular weight of the monomer

$\mathrm{P} \quad=$ partial pressure of $\mathrm{HF}$ 
Table 5-8. Comparison Between Schotte's Results and Theory Mixing HF Vapor and Air with 80 Percent RH

\begin{tabular}{|c|c|c|c|c|c|c|c|c|c|}
\hline \multirow{2}{*}{$\begin{array}{c}\text { Total Mol } \\
\text { percent } \\
\text { HF }\end{array}$} & \multirow[b]{2}{*}{$\begin{array}{c}\text { Mixing } \\
\text { Ratio }\end{array}$} & \multicolumn{4}{|c|}{ Temperature (K) } & \multicolumn{2}{|c|}{$\mathbf{X}_{\mathrm{HF}^{*}}$} & \multicolumn{2}{|c|}{$\begin{array}{l}\text { percent HiF } \\
\text { Condensed }\end{array}$} \\
\hline & & Air & HF & $\begin{array}{l}\text { Fog } \\
\text { Exp }\end{array}$ & $\begin{array}{c}\text { Fog } \\
\text { (NRC) }\end{array}$ & expt & (NRC) & $\operatorname{expt}$ & (NRC) \\
\hline 0.373 & 387 & 298.9 & 299.6 & 300.1 & 300.8 & 0.261 & 0.263 & 26.7 & 26.29 \\
\hline .0696 & 207 & 299.1 & 299.7 & 303.8 & 302.8 & 0.306 & 0.302 & 29.5 & 28.33 \\
\hline 1.13 & 127 & 299 & 299.7 & 305.5 & 304.2 & 0.346 & 0.340 & 29.8 & 29.11 \\
\hline 1.52 & 94.7 & 298.9 & 299.8 & 306.8 & 305.1 & 0.370 & 0.351 & 29.8 & 28.04 \\
\hline 1.90 & 75.8 & 298.8 & 299.7 & 307.2 & 305.7 & 0.389 & 0.374 & 29.7 & 28.35 \\
\hline 2.86 & 50.3 & 299 & 298.9 & 308.9 & 306.9 & 0.423 & 0.421 & 29.3 & 29.21 \\
\hline 5.55 & 25.9 & 298.7 & 299.2 & 308.6 & 307 & 0.490 & 0.476 & 28.7 & 27.92 \\
\hline 8.85 & 16.3 & 298.7 & 298.8 & 305.0 & 303.8 & 0.553 & 0.524 & 28.8 & 26.83 \\
\hline 12.07 & 11.9 & 298.5 & 298.1 & 296.2 & 299.2 & 0.620 & 0.597 & 29.5 & 28.69 \\
\hline
\end{tabular}

$* \mathrm{X}_{\mathrm{HF}}$ is the mole percentage of $\mathrm{HF}$ in solution $=\mathrm{M}_{\mathrm{HF}}^{\text {sol }} /\left(\mathrm{M}_{\mathrm{HF}}^{\text {sol }}+\mathrm{M}_{\mathrm{H}_{2} \mathrm{O}}\right)$, where $\mathrm{M}_{\mathrm{HF}}^{\text {sol }}$ is the number of moles in solution, and $\mathrm{M}_{\mathrm{H} 20}{ }^{\text {sol }}$ is the number of moles of water in solution. NRC means the draft model sponsored by NRC (Chhibber and Kaiser 1993). Data from Schotte (1987).

$\mathrm{UO}_{2} \mathrm{~F}_{2}$ is a solid precipitate. The heat released is equal to $117,147 \mathrm{~J} / \mathrm{mole} \mathrm{UF}_{6}$ at $25^{\circ} \mathrm{C}(25,199 \mathrm{Btu} / \mathrm{lb}$ mole $\mathrm{H}_{2} \mathrm{O}$ at $77^{\circ} \mathrm{F}$ ). The heat of the reaction tends to reduce the density of the plume, which can swing from being extremely dense to being less dense than air. The reaction is rapid and is assumed to be instantaneous. Generally, $\mathrm{UF}_{6}$ thermodynamics models assume instantaneous mixing. The solid $\mathrm{UO}_{2} \mathrm{~F}_{2}$ product is assumed to consist of fine particulate and remain airborne. Its presence contributes towards increasing the density of the cloud.

In addition to the $\mathrm{UF}_{6}$ /moist-air interactions, an adequate model must consider the oligomerization of HF and the formation of droplets containing $\mathrm{HF}$ and water. As for $\mathrm{HF}$, a numerical solution of the equation $\Delta \mathrm{H}=0$ is required.

Figures 5-20 and 5-21 show an example of the variation of the mixture temperature and mixture density with mixing ratio, respectively (Chhibber and Kaiser 1993). From Figure 5-20, as the mass fraction of $\mathrm{UF}_{6}$ is reduced from 1 to 0.56 , there is a reduction of mixture temperature due to the sublimation of solid $\mathrm{UF}_{6}$ present initially. As more air is mixed in, the hydrolysis reaction of $\mathrm{UF}_{6}$ goes to completion and releases heat. Thus, the temperature increases as the mass fraction of $\mathrm{UF}_{6}$ is reduced from 0.56 to 0.16 (the stoichiometric ratio) when the reaction is complete. Further reduction of the mass fraction of $\mathrm{UF}_{6}$ lowers the mixture temperature as cooler air is added and the temperature begins to approach the ambient temperature in the limit. 


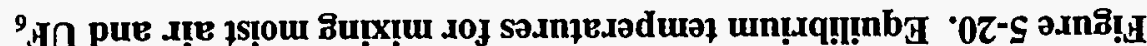

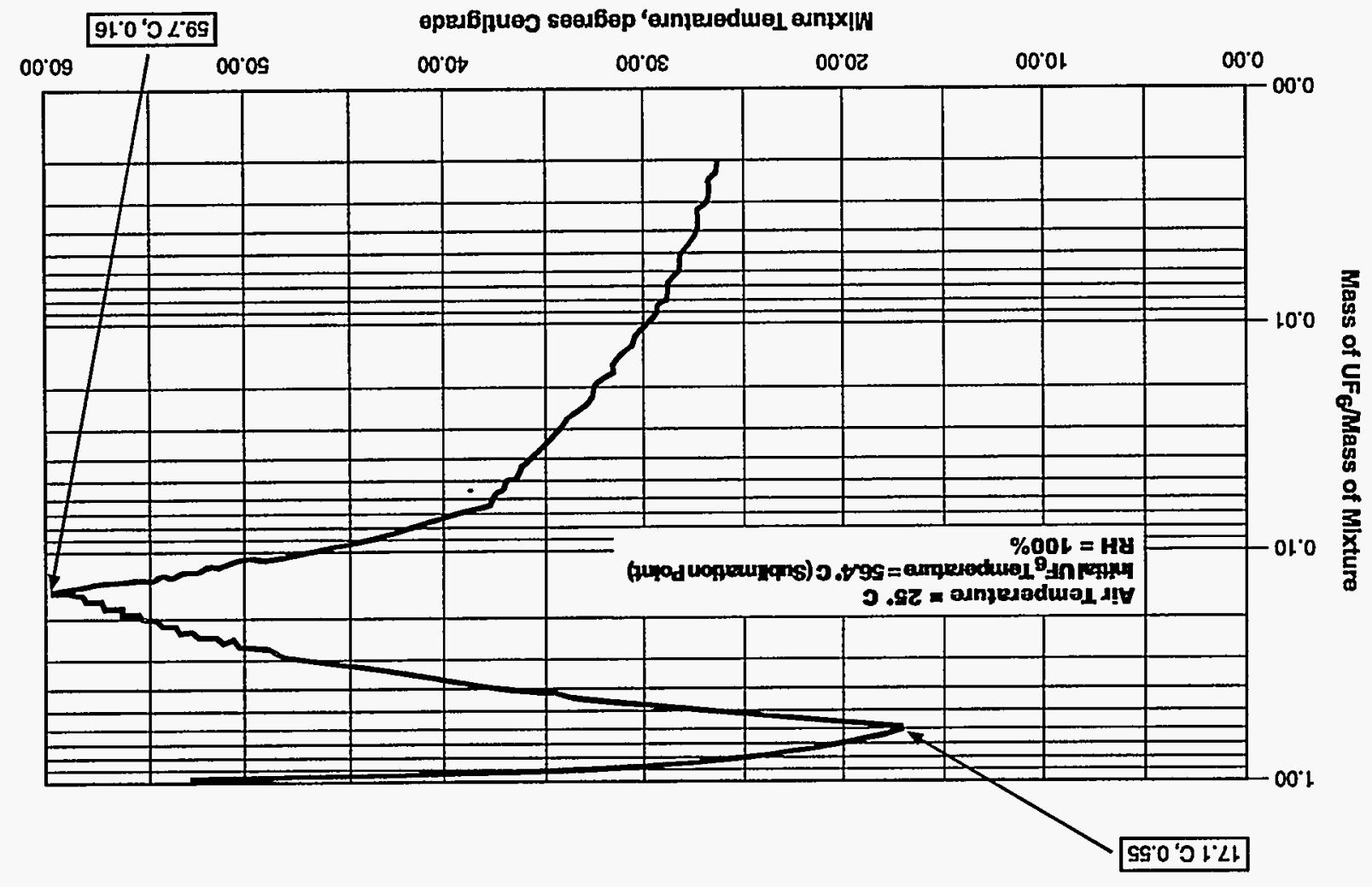




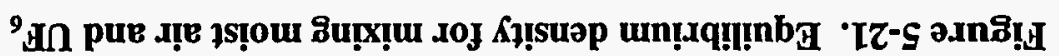

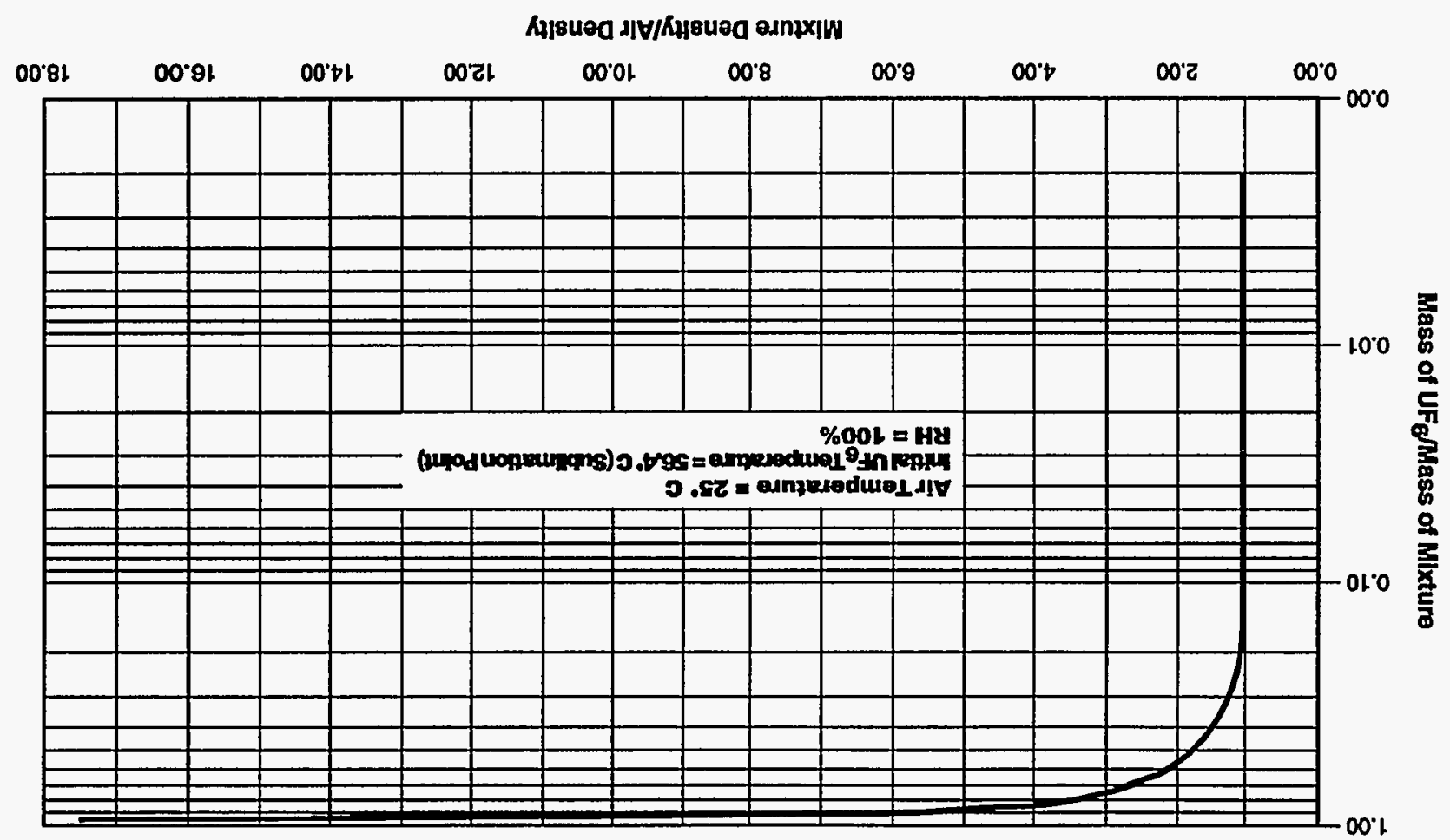


Figure 5-21 shows the variation of mixture density with mix ratio. Initially, when the mix ratio is 1 , the plume is very heavy, but, as more air is mixed in, the density reduces. The plume becomes slightly buoyant when the mix ratio drops beyond 0.06 (i.e., 6 percent $U F_{6}$ by mass). No deposition of $U_{2} F_{2}$ is considered.

The results given in Figures 5-20 and 5-21 are in good agreement with the work of Rodean (1989). It must be borne in mind that Figures 5-20 and 5-21 are input data specific. Varying the initial conditions will generate different curves.

\subsection{Health Effects}

The methods described so far in this chapter enable the reader to calculate airborne concentrations of radioactive materials or chemicals a a function of distance downwind. The purpose of this section is to discuss how the concentration calculations can be related to the occurrence of health effects in exposed individuals.

\subsubsection{Radioactive Materials}

The consequences of exposure to radioactive materials can be broadly classified into two categories, stochastic and non-stochastic effects. Most biological effects fall into the category of non-stochastic effects. Non-stochastic effects are characterized by three qualities: first, a certain amount of dose must be exceeded before the particular effect is observed; second, the magnitude of the effect increases with the size of the dose; and, third, there is a clear causal relationship between exposure and the observed effect. Because of the minimum dose that must be exceeded before an individual shows the effect, non-stochastic effects are also called threshold effects.

Stochastic effects are those effects that occur by chance, and they occur among unexposed people as well as among exposed individuals. Stochastic effects are, therefore, not unequivocally related to exposure. In the context of radiation exposure, the main stochastic effects are cancer and genetic effects. Since no direct casual link can be established between the exposure and the effects, no threshold of occurrence can be obtained; therefore, the best that can be done is to estimate the probability that the effect was caused by the exposure. For this reason, stochastic effects are often called linear, zero-threshold dose-response effects. According to the resulting model, every increment of radiation, no matter how small, carries with it a corresponding increase in risk of stochastic effect.

In the estimation of consequences, the analyst is often concerned with two types of exposure: (a) a single accidental exposure to a high dose of radiation during a short time, commonly called acute exposure, and which may produce biological effects within a short time after exposure and (b) long-term, low level overexposure, commonly called continuous or chronic exposure, where the results of the overexposure may not be apparent for years.

Acute whole body overexposure affects all the organs and systems of the body. However, since not all organs and organ systems are equally sensitive to radiation, the pattern of response depends on the magnitude of the dose. Acute effects can include: mortality, nausea and vomiting, malaise and fatigue, increased temperature, blood changes, skin effects (e.g., epilation, blistering, necrosis, and ulceration), and sterility. 
Delayed effects of radiation exposure may be due to either a single large overexposure or continuing lowlevel overexposure. This type of overexposure can be due to external radiation fields or can result from inhalation or ingestion of a radioisotope which then becomes fixed in the body. Following intake by ingestion or inhalation, a radionuclide may be absorbed from the respiratory and gastrointestinal tracts into the blood. The rate of absorption will depend on how soluble the material is in the body. From the blood stream the radionuclide may then be taken up by other organs and subsequently removed at rates that depend on the organs' metabolic processes and the chemical properties of the material.

For controlling radiation exposure to workers and for accident analysis inhalation is often the primary exposure pathway of concern. The rate at which radioisotopes deposited in the lung and pulmonary tract migrate to other organs has a direct effect on the dose received by the body. Retention classes (also known as solubility classes) have been established to describe the clearance of inhaled radionuclides from the lung. The classes are designated as D (days), W (weeks), and Y (years), and refer to the approximate length of retention in the pulmonary region. The range of half-lives is less than 10 days for class $D$, from 10 to 100 days for class $W$, and greater than 100 days for class $Y$ (see 10 CFR 835, Appendix A, Occupational Radiation Protection).

Internally deposited radioisotopes may continue to irradiate the tissue for a long time. As a note, it should be pointed out that in this context, the adjectives "acute" and "chronic" as ordinarily used, are not directly applicable to inhaled or ingested radioisotopes, since a single or "acute" exposure may lead to continuous or "chronic" irradiation of the tissue. Among the delayed consequences of overexposure are the increased risk of cancer, genetic effects, shortening of life span and cataracts.

Table 5-9 lists the dose thresholds at which it is expected that about 50 percent of the people exposed will exhibit some of the acute and delayed effects listed.

In the case of risks from low-level exposure to ionizing radiation, the stochastic nature of the adverse effects of exposure, together with their very low probability, implies that the magnitude of the risk can be measured only by studying large population groups. The latest findings (at this time, 1997) of such work were published by the (U.S.) National Research Council, Committee on the Biological Effects of Ionizing Radiation, in what is known as the BEIR V Report, Health Effects of Exposure To Low Levels Of Ionizing Radiation: 1990. This report is the latest in a series that addresses the health effects of exposure of human populations to low-dose radiation, focusing on carcinogenesis and genetic injury. A primary result of the study is a recommendation supporting the hypothesis that the frequency of cancer induction and genetic effects increases with low-level radiation as a linear, non-threshold function of dose.

Note that this section of this Handbook addresses health effects resulting from relatively large exposures to hazardous materials from accidental releases to the atmosphere. Current discussions concerning Linear Non-Threshold (LNT) theory are focused at very low levels of exposure and are therefore not directly germaine to the topic of this section. Also, even a 'brief' introduction to this complex and controversial topic would have to be lengthy in order for the reader to gain even a rudimentary understanding of the topic.

It should be noted that some radioactive materials also have toxic properties and sometime the adverse toxic health effects can be more severe than the radiological effects. For fuel cycle facilities uranium and uranium compounds are the primary materials that exhibit these properties. Uranium is a heavy metal and 
Table 5-9. Acute and Delayed Non-cancer Effects of Low LET Radiation and Approximate Single Doses for 50 percent Incidence in People (Shleien 1992)

\begin{tabular}{|l|c|c|}
\hline \multicolumn{1}{|c|}{ Irradiation } & Rad pose for 50 \\
\hline Whole Body (External) & Health Effect & percent \\
\hline & Anorexia & 150 \\
\hline & Nausea & 210 \\
\hline & Fatigue & 220 \\
\hline & Vomiting & 280 \\
\hline & Epilation & 300 \\
\hline & Diarrhea & 350 \\
\hline Thorax (External) & Hemorrhage & 400 \\
\hline & Mortality & 345 \\
\hline Lung (Internal) & Pneumonitis & 1,050 \\
\hline Abdomen (External) & Mortality & $1,700^{c}$ \\
\hline Gastrointestinal Tract (Internal) & Mortality & $>10,000^{c}$ \\
\hline Reproductive Organs (External) & Mortality & $>1,500$ \\
\hline & Sterility - Males (temporary) & $>3,000^{c}$ \\
\hline & Sterility - Females (permanent) & 80 \\
\hline & Mortality & 200 \\
\hline
\end{tabular}

- Doses at which 10 percent incidence would be expected are approximately one-fourth of those listed. Protraction of the radiation exposure increases the dose required for each level of effect. For example, one mathematical model for predicting mortality estimates the 50 percent lethal dose in rad by using the expression:

$$
\mathrm{LD}_{\mathrm{SD}}=345 \mathrm{t}^{0.26}
$$

where $t$ is the time in weeks over which the radiation is delivered and $345 \mathrm{rad}$ is the 50 percent lethal dose for low LET radiation delivered in less than one week. The equivalent 10 percent and 90 percent lethal dose values are 110 rad and $585 \mathrm{rad}$, respectively (Lushbaugh 1981).

- To obtain SI dose, divide by 100 .

c Projected from studies in laboratory animals.

if ingested or inhaled into the body in sufficient quantities can act as a poison. Natural and depleted uranium are primarily toxic hazards, once the enrichment level exceeds approximately 10 percent the hazard from the radioactivity starts to outweigh the toxic hazard. $\mathrm{UF}_{6}$ is also a toxic hazard, both because of the uranium and the other toxic by-products that can be released (see discussion in section 5.8.3). 


\subsubsection{Chemicals}

\subsubsection{Toxic Endpoints}

There are a number of toxic endpoints (the EPA's terminology in the Risk Management Program Rule 40 CFR Part 68) that can be used as measures of the effect of accidental releases on the public. For the purposes of the RMP, EPA uses the Emergency Response Planning Guideline-2 (ERPG-2). The definitions of the three levels of ERPGs are given in Table 5-10. They have been promulgated by the American Industrial Hygiene Association (AIHA 1988). They are valid for an exposure time of one hour, and no information is available on how to extrapolate them to different exposure times. ERPGs for some commonly used substances at fuel cycle licensees' sites are given in Table 5-11.

In practice, the average concentration $C\left(t_{e}\right)$ required to produce any given health effect is, in general, a function of the exposure time, $t_{e}$. One simple basis for extrapolation is that the hazard levels correspond to constant dosage. If the hazard level for one hour is $\mathrm{C}(1)$, that for an exposure time $t_{e}$ is given by

$$
C\left(t_{e}\right)=C(1) / t_{e}
$$

where $t_{c}$ is in hours. Equation 5.105 is an expression of Haber's law (USEPA 1987). The AIHA has been considering the validity of extrapolations such as equation 5.105. An alternative approach which may be adopted is the guidance that, for small exposure times, such as $t_{e}=1 / 12 \mathrm{hr}=5 \mathrm{~min}$, a more cautious extrapolation could be used:

$$
C\left(t_{e}\right)=C(1) /\left(2 t_{e}\right)
$$

which reduces the ceiling predicted by Haber's Law by a factor of two. In practice, in order to join equations 5.105 and 5.106 smoothly, a linear interpolation could be adopted between $t_{c}=1 / 3 \mathrm{hr}(20 \mathrm{~min})$ and $t_{c}=1 / 12 \mathrm{hr}(5 \mathrm{~min})$. In addition, there is no extrapolation below $t_{c}=1 / 12$. Thus:

$$
\begin{aligned}
& C\left(t_{e}\right)=C(1) / t_{e}\left(\text { for } t_{e}>1 / 3 h r\right) \\
& \left.C\left(t_{e}\right)=C(1)\left[2+1 /\left(3 t_{e}\right)\right] \text { for } 1 / 12<t_{e} \leq 1 / 3 h r\right) \\
& C\left(t_{e}\right)=6 C(1) \text { for } t_{e}<1 / 12 h r
\end{aligned}
$$

Note that more recent guidance from AIHA indicates that there is no general extrapolation that is valid for all toxic chemicals. The validity of equations 5.105 through 5.107 must be assessed on a case-by-case basis. For HF, however, there have been experiments on rodents that support the use of Haber's law down to an exposure time of as little as two minutes (Maher and Kaiser 1995).

The EPA provides a discussion of toxic endpoints (which it also names levels of concerns (LOCs) in Appendix D of (USEPA 1987). The reader should note that EPA recommends that worker exposure limits such as Threshold Limit Values (TLVs, published by ACGIH [1986]) should not be used outside the workplace. 
Table 5-10. Emergency Response Planning Guidelines

The Emergency Response Planning Guideline (ERPG) values are intended to provide estimates of concentration ranges where one reasonably might anticipate observing adverse effects as described in the definitions for ERPG-1, ERPG-2, and ERPG-3 as a consequence of exposure to the specific substance.

The ERPG-1 is the maximum airborne concentration below which it is believed that nearly all ${ }^{*}$ individuals could be exposed for up to $1 \mathrm{hr}^{+}$without experiencing other than mild transient adverse health effects or perceiving a clearly defined, objectionable odor.

The ERPG-2 is the maximum airborne concentration below which it is believed that nearly all individuals could be exposed for up to $1 \mathrm{hr}$ without experiencing or developing irreversible or other serious health effects or symptoms which could impair an individual's ability to take protective action.

The ERPG-3 is the maximum airborne concentration below which it is believed that nearly all individuals could be exposed for up to $1 \mathrm{hr}$ without experiencing or developing life-threatening health effects.

It should be remembered that human responses do not occur at precise exposure levels but can extend over a wide range of concentrations. The values derived for ERPGs should not be expected to protect everyone but should be applicable to most individuals in the general population. In all populations, there are hypersensitive

individuals who will show adverse responses at exposure concentrations far below levels where most individuals normally would respond. Furthermore, since these values have been derived as planning and emergency response guidelines, not exposure guidelines, they do not contain the safety factors normally incorporated into exposure guidelines. Instead, they are estimates by the AIHA ERPG committee of the thresholds above which there would be an unacceptable likelihood of observing the defined effects. The estimates are based on the available data that are summarized in the documentation. In some cases where the data are limited, the uncertainty of these estimates is large. Users of the ERPG values are encouraged strongly to review carefully the documentation before applying these values.

- It is recognized that there is a range of times that one might consider for these guidelines; however, it was the committee's decision to focus its efforts on only one time period. This decision was based on the availability of toxicology information and a reasonable estimate for an exposure scenario. Users who may choose to extrapolate these values to other time periods are cautioned to review the documentation fully since such extrapolations tend to hold only over very limited time frames, if at all.

Table 5-11. Values of ERPGs for Substances Commonly Found at Fuel Cycle Licensees' Sites

\begin{tabular}{|l|c|c|c|}
\hline \multicolumn{1}{|c|}{ Substance } & ERPG-3 & ERPG-2 & ERPG-1 \\
\hline Ammonia & $1,000 \mathrm{ppm}$ & $200 \mathrm{ppm}$ & $25 \mathrm{ppm}$ \\
\hline Chlorine & $20 \mathrm{ppm}$ & $3 \mathrm{ppm}$ & $1 \mathrm{ppm}$ \\
\hline Hydrogen Fluoride & $50 \mathrm{ppm}$ & $20 \mathrm{ppm}$ & $5^{*} \mathrm{ppm}$ \\
\hline Sulfur Dioxide & $15 \mathrm{ppm}$ & $3 \mathrm{ppm}$ & $0.3 \mathrm{ppm}$ \\
\hline Uranium Hexafluoride & $30 \mathrm{mg} / \mathrm{m}^{3}$ & $15 \mathrm{mg} / \mathrm{m}^{3}$ & $5 \mathrm{mg} / \mathrm{m}^{3}$ \\
\hline
\end{tabular}

- The AIHA is expected to change the ERPG-2 for HF to $2 \mathrm{ppm}$ (private communication from G. Rusch of Allied Signal 1994). 


\subsubsection{Probits}

The user specifies the three parameters $a_{p}, b_{p}$, and $n$ in the probit equation (CCPS 1989), where the probit $\mathrm{Pr}$ is given by:

$$
\operatorname{Pr}=a_{p}+b_{p} \ln \left(C\left(t_{e}\right)^{n_{t}}\right)
$$

where $t_{c}$ is in minutes. Table 5-12 shows how to relate probits to percentages of people who would suffer fatality if exposed to concentration $C\left(t_{c}\right)$ for time $t_{c} . a_{p}, b_{p}$ and $n$ are empirical coefficients. Values of the constants $a_{p}, b_{p}$, and $n$ for the lethal toxicity probit equation are chemical specific and examples are given in Table 5-13 for $\mathrm{NH}_{3}$ and $\mathrm{HF}$.

\subsection{3 $\mathrm{UF}_{6}-$ Chemical Toxicity and Radiotoxicity}

\subsubsection{Exposure to Soluble Uranium}

Health Effects Model 1 - The level specified in NUREG-1391 (McGuire 1991) to cause permanent renal damage to a 70-kg (154-lb) individual by inhalation is $40 \mathrm{mg}\left(8.8 \times 10^{-5} \mathrm{lb}\right)$ soluble uranium, due to chemical damage. To convert from airborne concentrations to inhaled mass, the breathing rate of the exposed individual may be assumed to be $2.6 \times 10^{-4} \mathrm{~m}^{3} / \mathrm{s}\left(33 \mathrm{ft}^{3} / \mathrm{hr}\right)$, consistent with people in an active state (USNRC 1988). The intake level necessary to cause renal damage is independent of exposure duration.

Health Effects Model 2 - As noted above, the American Industrial Hygiene Association has recently published Emergency Response Planning Guideline (ERPG) values for UF $_{6}$. The ERPG-2 value is the maximum airborne concentration below which it is believed nearly all individuals could be exposed for up to one hour without experiencing or developing irreversible or other serious health effects that could impair an individual's ability to take protective action. The ERPG-2 value for $\mathrm{UF}_{6}$ is $15 \mathrm{mg} / \mathrm{m}^{3}$ $\left(9.4 \times 10^{-7} \mathrm{lb} / \mathrm{ft}^{3}\right)$. This corresponds to $9.5 \mathrm{mg}\left(2.1 \times 10^{-5} \mathrm{lb}\right)$ of soluble uranium intake in one hour. Haber's law can, in principle, be used to extrapolate to different exposure times:

$$
\mathrm{C} \times \mathrm{t}_{\mathrm{e}}=\text { constant }
$$

where:

$\mathrm{C}=$ the concentration in $\mathrm{mg} / \mathrm{m}^{3}$

$\mathrm{t}_{\mathrm{c}}=$ exposure time in minutes

The Haber's law constant for $\mathrm{UF}_{6}$ is $900 \mathrm{mg}$-minutes $/ \mathrm{m}^{3}\left(5.6 \times 10^{-5} \mathrm{lb}\right.$-minutes $\left./ \mathrm{ft}^{3}\right)$.

\subsubsection{Exposure to Hydrogen Fluoride}

Moderate exposure to HF in air can cause smarting of the skin, respiratory irritation, irritation of the conjunctiva, and pronounced taste. Massive exposure to HF can cause progressive destruction of the bronchial mucous membrane and swelling of the lung tissue, which can be fatal. The criterion specified in NUREG-1391 for HF toxicity is:

$$
\mathrm{C}=2.5 \times 10^{-5}\left(30 / \mathrm{t}_{\mathrm{e}}\right)^{0.5}
$$


Table 5-12. Transformation of Probits to Percentages*

\begin{tabular}{|c|c|c|c|c|c|}
\hline percent & $\mathbf{0}$ & $\mathbf{2}$ & $\mathbf{4}$ & $\mathbf{6}$ & $\mathbf{8}$ \\
\hline 0 & $\ldots$ & 2.95 & 3.25 & 3.45 & 3.59 \\
\hline 10 & 3.72 & 3.82 & 3.92 & 4.01 & 4.08 \\
\hline 20 & 4.16 & 4.23 & 4.29 & 4.36 & 4.42 \\
\hline 30 & 4.48 & 4.53 & 4.59 & 4.64 & 4.69 \\
\hline 40 & 4.75 & 4.80 & 4.85 & 4.90 & 4.95 \\
\hline 50 & 5.00 & 5.05 & 5.10 & 5.15 & 5.20 \\
\hline 60 & 5.25 & 5.31 & 5.36 & 5.41 & 5.47 \\
\hline 70 & 5.52 & 5.58 & 5.64 & 5.71 & 5.77 \\
\hline 80 & 5.84 & 5.92 & 5.99 & 6.08 & 6.18 \\
\hline 90 & 6.28 & 6.41 & 6.55 & 6.75 & 7.05 \\
\hline 99 & 7.33 & 7.41 & 7.46 & 7.65 & 7.88 \\
\hline
\end{tabular}

* Source: CCPS (1989). To use this table, calculate the value of the probit from equation 5.108: e.g. for a chlorine concentration of $400 \mathrm{ppm}$ and an exposure time of 60 minutes $\mathrm{Pr}=-8.29+0.92 \mathrm{ln}\left(\left(400^{2}(60)\right)=6.5\right.$. From Table 5-12, the corresponding percentage is $82-84$. This means that appoximately 84 percent of those exposed to 400 ppm for one hour would be expected to suffer fatality.

Table 5-13. Constants for Lethal Toxicity Probit Equation*

\begin{tabular}{|l|c|c|c|}
\hline \multicolumn{1}{|c|}{ Substance } & $\begin{array}{c}\mathbf{a}_{\mathbf{p}} \\
(\mathbf{p p m})\end{array}$ & $\begin{array}{c}\mathbf{b}_{\mathbf{p}} \\
(\mathbf{p p m})\end{array}$ & $\mathbf{n}$ \\
\hline Ammonia & -35.9 & 1.85 & 2 \\
\hline Hydrogen fluoride & -35.87 & 3.354 & 1 \\
\hline Chlorine & -8.29 & 0.92 & 2 \\
\hline
\end{tabular}

*Source: CCPS (1989). These are the only substances at fuel cycle facilities for which CCPS gives data.

where:

$\mathrm{C}=$ the concentration $\left(\mathrm{kg} / \mathrm{m}^{3}\right)$ of $\mathrm{HF}$ that an individual can be exposed to for a duration of $\mathrm{t}_{\mathrm{e}}$ minutes that would not cause "any escape-impairing symptoms or any irreversible health effects". This level corresponds to a toxic load of $25 \mathrm{mg} / \mathrm{m}^{3}\left(1.6 \times 10^{-6} \mathrm{lb} / \mathrm{ft}^{3}\right)$ of $\mathrm{HF}$ for 30 minutes. 
Noting that when 352 mass-units of $\mathrm{UF}_{6}$ react completely with water, 80 mass-units of $\mathrm{HF}$ are produced, the exposure criterion can be rewritten in terms of an equivalent concentration of $\mathrm{UF}_{6}$ that will produce the same effect:

$$
\mathrm{C}=2.5 \times 10^{-5} \times(352 / 80)\left(30 / \mathrm{t}_{\mathrm{e}}\right)^{0.5} \sim 1.1 \times 10^{-4}\left(30 / \mathrm{t}_{\mathrm{e}}\right)^{0.5}
$$

The above equation states that an individual could be exposed to HF produced by the complete reaction of $\mathrm{UF}_{6}$ concentration of $1.125 \times 10^{-4} \mathrm{~kg} / \mathrm{m}^{3}\left(7.0 \times 10^{-6} \mathrm{lb} / \mathrm{ft}^{3}\right)$ for 30 minutes without causing any escapeimpairing symptoms or any irreversible health effects. This alternate form of expressing the exposure criterion in terms of $\mathrm{UF}_{6}$ concentration is meaningful because, at such low concentrations, $\mathrm{UF}_{6}$ will react completely with water to form HF.

\subsection{Modeling of Fires and Explosions}

An excellent source of information on how to calculate the consequences of vapor cloud explosions, flash fires and BLEVES (Boiling Liquid Expanding Vapor Explosions) is to be found in the Center for Chemical Process Safety's Guidelines for Evaluating the Characteristics of Vapor Cloud Explosions, Flash Fires and Bleves (CCPS 1994).

\subsubsection{Vapor Cloud Explosions}

\subsubsection{Background}

Factory Mutual Research Corporation (1990) defines a vapor cloud explosion very simply as an explosion occurring outdoors, producing a damaging overpressure. In general, several features need to be present for a vapor cloud explosion with damaging overpressure to occur.

1. The released material must be flammable and at suitable conditions of temperature and pressure. Such materials include liquefied gases under pressure (e.g., propane, butane); ordinary flammable liquids, particularly at elevated temperatures and/or pressures (e.g., cyclohexane, naptha); and nonliquefied flammable gases (e.g., methane, ethylene, acetylene).

2. A sufficiently large cloud must form prior to ignition. If ignition should occur instantly, a large fire, jet flame, or fireball may occur, but significant blast-pressure damage is unlikely. Ignition delays of one to five minutes are considered the most probable for developing vapor cloud explosions.

3. A sufficient amount of the cloud must lie between the upper and lower flammable limits. The amount that lies between flammable limits is a very sensitive function of source term characteristics and weather conditions (Hanna and Drivas 1987).

4. The blast effects produced by vapor cloud explosions can vary greatly and are determined by the speed of flame propagation. In most cases, the mode of flame propagation is deflagration. It is only in extreme cases that detonation occurs in a vapor cloud.

A deflagration is a mode of combustion in which the propagation rate is dominated by both molecular and turbulent transport processes. In the absence of turbulence (i.e., under laminar or near-laminar conditions), flame speeds for normal hydrocarbons are in the order of 5 to $30 \mathrm{~m} / \mathrm{s}$ (11 to $67 \mathrm{mph}$ ), too low to produce any significant blast overpressure. Such an event would be described as a large flash fire. Therefore, turbulence is always present in a vapor cloud explosion and may arise in any of three ways. 
1. By turbulence associated with the release itself (e.g., a jet release, a catastrophic failure of a pressurized vessel, or a slumping heavy vapor cloud).

2. By turbulence produced in unburned gases expanding ahead of a flame propagating through a congested space.

3. By externally-induced turbulence from objects such as ventilation systems, finned-tube heat exchangers, and fans.

These mechanisms may cause very high flame speeds (but less than the speed of sound) and generate strong blast pressures. The generation of high combustion rates is limited to the congested area, or the area affected by the turbulent release. As soon as the flame enters an area without turbulence, both the combustion rate and the pressure will drop.

In the extreme, the turbulence can cause transition from deflagration to detonation, with propagation speeds two to five times the speed of sound and maximum overpressures of about $1.8 \times 10^{6} \mathrm{MPa}(260 \mathrm{psi})$. Once detonation occurs, turbulence is no longer necessary to maintain its speed of propagation. This means that uncongested and/or quiescent flammable portions of the cloud may also contribute to the blast. However, for a detonation to propagate, the flammable portion of the cloud must be very homogeneously mixed. Such homogeneity rarely occurs, so that vapor cloud detonations are not likely.

The available energy of ignition also influences whether deflagration or detonation occurs. An ignition energy of approximately $10^{-4} \mathrm{~J}\left(9.5 \times 10^{-8} \mathrm{Btu}\right)$ will initiate deflagration in normal hydrocarbon-air mixtures, whereas direct initiation of detonation requires an initiating energy of $\sim 10^{6} \mathrm{~J}(\sim 950 \mathrm{Btu})$, comparable to the energy generated by a high explosive charge. A directly initiated detonation is, therefore, highly unlikely.

\subsubsection{Vapor Cloud Explosion Blast Modeling}

Many models are based on an equivalence to TNT. The available combustion energy in a vapor cloud is converted to an equivalent charge weight of TNT:

$$
\mathrm{W}_{\mathrm{TNT}}=\mathrm{d}_{\mathrm{e}} \mathrm{W}_{\mathrm{F}} \mathrm{H}_{\mathrm{F}} / \mathrm{H}_{\mathrm{TNT}}=\mathrm{d}_{\mathrm{m}} \mathrm{W}_{\mathrm{f}}
$$

where:

$$
\begin{array}{ll}
\mathrm{W}_{\mathrm{f}} & =\text { the weight of fuel involved }(\mathrm{kg}) \\
\mathrm{W}_{\mathrm{TNT}} & =\text { equivalent weight of TNT or yield }(\mathrm{kg}) \\
\mathrm{H}_{\mathrm{F}} & =\text { heat of combustion of the fuel in question }(\mathrm{J} / \mathrm{kg}) \\
\mathrm{H}_{\mathrm{TNT}} & =\text { TNT blast energy }(\mathrm{J} / \mathrm{kg}) \\
\alpha_{\mathrm{e}} & =\text { TNT equivalency based on energy } \\
\alpha_{\mathrm{m}} & =\text { TNT equivalence based on mass }
\end{array}
$$

Typical values of $\alpha_{e}$ and $\alpha_{m}$ are 0.03 and 0.1 , respectively. The predicted distance to which a given overpressure is exceeded is then proportional to $\left(\mathrm{W}_{\mathrm{TNT}}\right)^{1 / 3}$. (USEPA 1996b) gives extensive tabulations of distances to $6890 \mathrm{~Pa}$ (1 psi) overpressures. Chapter 7 of (CCPS 1994) gives an example of a TNT equivalency calculation based on the accidental release of $20000 \mathrm{~kg}$ (44000 lb) of propane at $8 \mathrm{Mpa}(1160$ psia) through an orifice of diameter $0.1 \mathrm{~m}(0.3 \mathrm{ft})$. CCPS (1994) also describes several different approaches to the TNT equivalency model, including those due to the Dow Chemical Company (Brasie 
and Simpson 1968), IIT Research (Eichler and Napadensky 1977), the UK Health and Safety Executive (UKHSE 1979; 1986), Industrial Risk Insurers (IRI 1990), Factory Mutual Research Corporation (1990), Hazard Reduction Engineering (Prugh 1987), and British Gas (Harris and Wickens 1989).

A somewhat more sophisticated method, called the Baker-Strehlow method (Baker et al. 1983), requires the user to determine the maximum flame speed that will be obtained, in which case the peak overpressure can be read from nomographs. The literature provides the basis for the user to objectively determine the maximum flame speed that will be achieved with a particular combination of confinement, obstacles, fuel reactivity, and ignition source.

The multienergy model (Van den Berg 1985; Van den Berg et al. 1987) is based on an exhaustive study of available experimental data, which tends to show that, for quiescent clouds, both the scale and strength of a blast are unrelated to fuel quantity present in a cloud. These parameters are, in fact, determined primarily by the size and nature of partially-confined and obstructed regions within which turbulence can be generated, and deflagration can occur. Therefore, the multienergy model consists of identifying volumes in which deflagration can occur, performing a blast calculation for each volume and then calculating the resultant overpressures at each location of interest. Chapter 7 of (CCPS 1994) gives an example of a multienergy model calculation of the release of $20000 \mathrm{~kg}$ (44000 lb) of propane.

Finally, there do exist multidimensional numerical methods such as BLAST and REAGAS (Van den Berg 1980; 1989; Van den Berg et al. 1991). Appendix F of (CCPS 1994) presents a case study of gas explosions in a process plant using a three-dimensional computer model.

\subsubsection{Effects of Vapor Cloud Explosions on Humans and Structures}

Appendix B of (CCPS 1994) summarizes the effects of explosions on structures; Appendix C summarizes the effects of explosions on humans.

\subsubsection{Flash Fires}

As noted in Section 5.9.1, a flash fire results from the combustion of a flammable vapor cloud in which there is no flame acceleration. The principal dangers resulting from a flash fire are radiation and direct flame contact. Section 5.2 of (CCPS 1994) describes flash-fire radiation models. The potential for direct flame contact is calculated using an atmospheric dispersion model to calculate the area covered by that portion of a vapor cloud that lies between its upper and lower flammable limits. Chapter 8 of (CCPS 1994) contains sample flash fire problems.

\subsubsection{BLEVES}

The term "BLEVE" is used to describe any sudden loss of containment of a liquid, which, at the moment of its failure, is above its normal boiling point (e.g., propane liquefied under pressure). It results in the production of a shock wave and fragments or missiles. If the cause of the BLEVE is a fire, there can also be a fireball which produces major radiant heat flame. Chapter 6 of (CCPS 1994) describes methods for calculating the radiant heat produced by fireballs, the blast effects of BLEVEs and pressure vessel bursts, and the velocities and ranges of fragments. Chapter 9 of (CCPS 1994) contains sample problems for BLEVEs. 


\subsection{Available Models}

There are a large number of computer models that are suitable for both radioactive releases or hazardous chemical releases. This section briefly surveys those that are available and gives advice on choosing ones that are relatively user friendly. However, this section is not intended to mention all of the models that may be available.

\subsubsection{Radioactive Releases}

There is a large number of models specifically designed to represent the transport and dispersion of radioactive materials released to the environment. The choice of a model for a specific application can be influenced by the type of application (e.g., emergency planning/response, hazards assessment, safety analysis), the characteristics of the radioactive material (e.g., gas, particulate, type of radiation emitted), exposure pathway of interest (e.g., direct, inhalation, ingestion), type of releases postulated (e.g., ground, elevated, explosive, fire), and characteristics of the specific site/facility to be analyzed (e.g., meteorology, terrain, population distribution). Other factors which may influence the choice of a model include availability, ease of use, computational requirements (i.e., hardware, software, run time), cost, and the level of documentation, verification, and validation.

Estimating the consequences resulting from the release of radioactive materials has been studied for many years. This, coupled with the wide range of influences listed above, has led to the development of numerous models for estimating consequences from the release of radioactive material to the environment. A comprehensive discussion of available models is beyond the scope of this document. However, the characteristics of several models currently in common use are discussed. More comprehensive listings of available models can be found in Atmospheric Dispersion Modeling Resources (Mazzola and Addis 1995) and Directory of Atmospheric Transport and Diffusion Models, Equipment, and Projects (U.S. Department of Commerce 1993).

\subsubsection{HOTSPOT}

The HOTSPOT programs (Homman 1994) were created to provide health physics personnel with a fast field-portable calculational tool for evaluating accidents involving radioactive material. There are 11 separate programs which make up the HOTSPOT modeling system, ranging from general programs for downwind assessment following the release of radioactive material to more specific programs dealing with the release of plutonium, uranium, or tritium. Other programs estimate the committed effective dose equivalent from inhalation of various radionuclides and estimate the effects of a surface-burst nuclear weapon. The HOTSPOT codes are intended to provide a first-order approximation of the radiation effects associated with the atmospheric release of radionuclides.

Dispersion algorithms are based on the standard straight-line Gaussian plume model and are subject to all the limitations previously discussed for this model. Users needing to model explosive and fire releases can input mixing height and buoyant plume rise. Required meteorological input includes windspeed ( 2 or 10 m height), solar insolation data (e.g., Sun High, Low, Cloudy/Night), or direct input of stability class (i.e., A-F). The programs include removal processes for radioactive decay and dry deposition.

Output is related to a three-axis Cartesian coordinate system. The code can model a single source located at the origin of the reference system with variable release height. Receptors may be located on or off the plume centerline axis at ground level. HOTSPOT contains a library of common radionuclides and 
supports both classic (i.e., rem, Curie, etc.) units and SI (i.e., gray, Becquerel, etc.) units. The source term can be comprised of a single nuclide or a user-specified mixture. The dosimetric methods of ICRP publication 30 have been used throughout the HOTSPOT programs. Individual organ dose (unweighted) are produced, along with committed effective dose equivalent.

The HOTSPOT programs will run on an IBM (or compatible) desktop computer or handheld computer with at least 256 kilobytes of RAM. The output can be provided in tabular or graphical format. The code is designed to be quick and easy to use.

\subsubsection{RASCAL}

RASCAL is an acronym for Radiological Assessment System for Consequence Analysis (Athey et al. 1993). RASCAL was developed by the U.S. Nuclear Regulatory Commission, and it is intended to be used as a screening tool to evaluate potential consequences of releases from nuclear power plants. It includes modules to estimate source terms, to evaluate the transport and diffusion in the atmosphere and deposition on surfaces, and to estimate doses from radionuclides in the environment.

As a screening tool, it can be used for hazards evaluation, emergency response planning, or as a tool in evaluating potential actions in the event of an emergency. It is not intended to be used for detailed assessments during or following an emergency.

The models use Gaussian diffusion with diffusion coefficients estimated using stability class and travel distance. The user has the choice of a puff or straight-line Gaussian plume calculational model without plume rise. Plume reflection is assumed at the ground and top of the mixing layer. Dry deposition and washout are addressed with mass balance maintained by source depletion. Consideration of building wakes can be selected by the user. Wind direction, wind speed, stability class, and mixing height are required inputs. Default values are supplied by the code. The code utilizes a three-layer wind field based on surface or tower measurements. The wind field is time dependent but horizontally uniform.

The source can be elevated or ground-level and is located at the center of a polar and Cartesian grid. The polar grid is used out to $3200 \mathrm{~m}$ (two miles) and the Cartesian beyond $3200 \mathrm{~m}$ (two miles.) Receptors are specified at fixed locations on the plume centerline by the code. The source term can be determined based on plant conditions, monitoring information, pre-defined accident scenarios (e.g., WASH-1400), or specified by the analyst. The code contains a library of nuclides common to power reactor accidents. Effective release height can be entered by the user.

Calculations of doses are based on ICRP publications 26 and 30. The codes support both classical (i.e., rem, Curie, etc.) units and SI (i.e., gray, Becquerel, etc.) units. Available outputs include: total dose Total Effective Dose Equivalent [TEDE] and acute), whole body cloud shine, whole body ground shine, inhalation dose to bone marrow Committed Effective Dose Equivalent [CEDE], 50-year commitment) and acute (30-day commitment), thyroid dose, and surface contamination.

Some of the model limitations include: (a) the source term is constant once established; (b) multiple release points cannot be simulated; (c) limited to meteorological data from a single location; (d) cannot model meteorological conditions such as wind shear, fumigation, etc.; and (e) there is no ingrowth of daughters in the radionuclide decay scheme.

RASCAL is designed to run on an IBM (or compatible) PC using DOS 3.0 or later. 


\subsubsection{MACCS2}

The MELCOR Accident Consequence Code System (MACCS2) was developed to calculate the probabilistic human health and economic consequences of hypothetical accidents at nuclear facilities (Jow, et al. 1986; 1990). The principle phenomena considered in MACCS2 are atmospheric transport and deposition under time-variant meteorology, short- and long-term mitigative actions, dose accumulation by a number of pathways, including food and water ingestion, deterministic and stochastic health effects, and economic costs. MACCS/MACCS2 has been used for emergency planning, research studies, probabilistic risk assessments, NEPA studies, and authorization basis analyses performed for Safety Analysis Reports (SARs).

The code was designed to calculate the probabilistic consequences of nuclear accidents and allows input of site-specific population, density, land use, and meteorological information. Assumptions on evacuation scenarios and other mitigative actions can be input. A year of onsite meteorological data may be input so that consequence uncertainty due to stochastic variation of the weather can be calculated.

The code uses the straight-line Gaussian diffusion model (spatially and temporally invariant) and is not capable of calculating consequences over complex terrain or involving complex meteorological conditions (i.e., wind shear, fumigation, etc.). At a minimum, the code requires windspeed, wind direction, and an indicator of atmospheric stability as meteorological inputs. Ground level and elevated releases can be modeled, and dry and wet depositions are considered.

MACCS2 has the ability to treat most nuclides of interest for power reactors or DOE facility accidents. Radioactive decay and daughter ingrowth are included. The user is able to specify multiple source terms, and the code will keep track of multiple plumes. The code uses a polar grid to store and report results. The code uses current ICRP methodology to calculate two types of doses: acute and lifetime. Acute doses are calculated to estimate health effects that can arise from high doses delivered at high dose rates. Lifetime doses are the 50-year commitments to either specific tissues (e.g., red marrow and lungs), or a weighted sum of tissue doses, referred to as Committed Effective Dose Equivalent (CEDE). Lifetime doses may be used to calculate the stochastic health effect risk resulting from exposure.

Available code results include:

- Atmospheric results at specific downwind locations

- Cases of specified health effects

- Early fatalities

- Population exceeding dose threshold

- Average individual risk of health effects

- Total collective dose from material deposited within region

- Centerline dose versus distance

- Centerline risk versus distance

- Population-weighted safety goal risk

- Maximum observed dose at a specified distance ring (Direction-independent dose)

- Maximum observed dose at a specific location (Direction-dependent dose)

- Breakdown of population dose by pathway

- Economic costs of mitigative actions

- Maximum distance for the various mitigative actions 
- Impacted area/population results

- Maximum individual dose from food-chain model.

MACCS2 allows the user to define values for a wide range of model parameters and allows the user to select among alternative modeling approaches with regard to emergency evacuation and radionuclide transfer through the food chain. This flexibility makes the code useful for diverse purposes and also requires a higher degree of technical expertise on the part of the user to obtain meaningful results.

\subsubsection{Comment}

Overall, several of the available models are very easy to use (e.g., HOTSPOT and RASCAL). It is worth investing the few days worth of effort to learn how to run them, so that the analyst is then able to run any case that may be of interest.

\subsubsection{Hazardous Chemical Releases}

Every four years, the Center for Chemical Process Safety (CCPS) organizes an International Conference on Vapor Cloud Modeling (CCPS 1987; 1991; 1995). The conference proceedings are excellent sources of information on currently available models for the accidental release of hazardous chemicals in an industrial environment.

The Environmental Protection Agency (EPA) also publishes relevant guidance (Touma, et al. 1991; Touma 1995). In 1991, EPA conducted a statistical model evaluation of seven dense gas models using data from three field experiments (USEPA 1991). Two models (DEGADIS [Havens and Spicer 1985; 1988] and SLAB [Ermak 1990]) are in the public domain, and the remaining five are proprietary (AIRTOX [Heinold, et al. 1988; Mills 1988], CHARM [Radian Corporation 1991], FOCUS [Quest Consultants 1990], SAFEMODE [Raj 1990] and TRACE [DuPont 1989]). The field data used were the Desert Tortoise series of pressurized ammonia releases (Goldwire, et al. 1985), the Burro liquefied natural gas spill tests (Koopman, et al. 1982), and the Goldfish anhydrous hydrofluoric acid spill experiments (Blewitt, et al. 1987b). Each model's predictions of maximum concentration and plume half-width were compared to the data. Model performance varied, with no model exhibiting consistently good performance across all of the databases. However, when combined across the three databases, all models performed to within a factor of two.

Hanna, et al. (1991) have published a comparison of several public domain models, including AFTOX (Kunkel 1988), Britter and McQuaid's Workbook (Britter and McQuaid 1988), DEGADIS, INPUFF (Peterson and Lavdas 1986), OB/DG (Nou 1963), SLAB, and a Gaussian Dispersion Model (Hanna, et al. 1982). In addition, Hanna, et al. analyzed three proprietary models-AIRTOX, CHARM, and TRACE. The field experiments that were analyzed included Burro, Coyote (Goldwire, et al. 1983), Desert Tortoise, Goldfish, Porton Down (Picknett 1978), Maplin Sands (Puttock, et al. 1984), Thorney Island (UKHSE 1986b), Prairie Grass (Barad 1958) and Hanford (Nickola, et al. 1970). These experiments involved both dense and neutrally buoyant releases of gases from both instantaneous and continuous sources. Hanna, et al. found that a few of the models exhibit relatively good performance in their predictions of maximum concentrations on monitoring arcs, with relative mean biases of \pm 30 percent or less and values of root mean square error that are about 40 percent to 60 percent of the mean. It was also found that most models performed reasonably well in predictions of plume width. Overall, Hanna, et al. state that the SLAB model demonstrates consistently good behavior across all comparisons with observations. 
The work of EPA (1991) and Hanna, et al. (1991) appears to show that these models can be expected to perform to within a factor of two. However, with all of these models, the initial characterization of the release is critical. Models which contain similar treatment of atmospheric dispersion and utilize the same meteorological inputs predict concentrations that can differ by several orders of magnitude. That is, the source terms are often the major sources of uncertainty in these models. In order to provide guidance in this area, in 1993, the EPA published Contingency Analysis Modeling for Superfund Sites and Other Industrial Sources (USEPA 1993b). This report contains a systematic approach to developing source terms for use with SLAB and DEGADIS across a variety of release situations. The scenarios include liquid spills onto the ground (both refrigerated and ambient temperature), flashing liquid jets, vapor jets, continuous heavy vapor releases, and puff releases.

EPA also published a document entitled Guidance on Application of Refined Dispersion Models for Hazardous/Toxic Air Releases (USEPA 1993). This report shows how to use ADAM (Mullett and Raj 1990), ALOHA (1994), DEGADIS, HGSYSTEM (McFarlane, et al. 1990; Witlox 1991) and SLAB. Specifically, this EPA document:

- Helps determine likely or reasonable storage conditions for specific chemicals for which a release might occur

- Helps determine release classes (e.g., liquid or gaseous phase) of a hazardous chemical release

- Defines the steps to be taken when determining if a release should be considered a dense gas release (and thus requires the use of a model capable of such a simulation)

- Defines the methods to be used to determine the input variables used by commonly-used refined models in the public domain

- Points out the implications and effects of various choices of input information

- Shows, by example, the calculation of the input variables used by the models

- Describes the outputs available from the models

- Discusses how to determine the input that gives the "worst- case" impact conditions.

EPA has also produced a Workbook of Screening Techniques for Assessing Impacts of Toxic Air Pollutants (Revised) (USEPA 1992). This workbook is built around 27 different release scenarios and produces estimates of the maximum short-term ground level concentrations. The computer model TSCREEN (USEPA 1994) implements the scenarios in the workbook.

\subsubsection{Hydrogen Fluoride and Uranium Hexafluoride}

As has already been discussed in the foregoing, the characteristics of the source terms for accidental releases of $\mathrm{UF}_{6}$ and $\mathrm{HF}$ are strongly influenced by the complex thermodynamic properties of $\mathrm{UF}_{6} /$ moist air and $\mathrm{HF} /$ moist air interactions. By no means all of the models described above are able to model these properties.

Sykes and Lewellen (1992) evaluated five models for their effectiveness in modeling $\mathrm{UF}_{6}$ releases: PLM89A, TRIAD, HGSYSTEM, ADAM, and SLAB. Although the first two were developed specifically to handle $\mathrm{UF}_{6}$ releases, it was concluded that none of the candidate models met all of the requirements for a safety analysis model. As a result, HGSYSTEM was modified to include UF $_{6}$-specific physical and chemical mechanisms (Hanna, et al. 1994a, 1995; Goode, et al 1995; Hanna, et al. 1995). 
Nair, et al. (1997) have conducted a comprehensive review of available models for $\mathrm{UF}_{6}$ atmospheric dispersion and identified three models that have capabilities that are suitable for $\mathrm{UF}_{6}$ modeling. These are HGSYSTEM, a draft set of models prepared for the NRC (Chhibber and Kaiser 1993) and RTM-96 (McKenna, et al. 1996). RTM-96 is a screening-level, hand calculation procedure, which was developed to predict conservative estimates of health impacts from the releases of $\mathrm{UF}_{6}$ into the atmosphere. The RTM-96 model addresses $U_{6}$-specific chemistry in a limited manner; it does not include $U_{6}$-specific thermodynamics or plume development, and it uses a passing plume characterization defined by Gaussian plume models to perform the dispersion calculations.

Note that Nair, et al.'s review contained limited comparisons with experimental work (Ducouret 1978; Doumenc, et al. 1978; Hanna, et al. 1994b) and an accidental release of UF $_{6}$ (USNRC 1986).

With respect to HF, a few more models contain explicit HF/moist air thermodynamics. These include HGSYSTEM and the draft NRC model referred to above, CHARM and ADAM. Blewitt, et al. (1987a) have conducted evaluations of SLAB and DEGADIS against HF spill data.

Overall, licensees or other analysts who wish to model releases of HF or $\mathrm{UF}_{6}$ should take the trouble to familiarize themselves with and use one of the available models (this is what was done for the GDPs, for which HGSYSTEM was used). In Appendix D, sample problems \#5 and \#6 address $\mathrm{HF}$ and $\mathrm{UF}_{6}$ releases, respectively.

\subsection{Model Uncertainties}

All atmospheric transport and dispersion models are inherently uncertain. At best, they can only approximate real-world phenomena. Detailed models are usually limited by the lack of data for model parameters, while simpler models, requiring much less information, reduce physically complex systems to a few equations.

\subsubsection{Sources of Uncertainty}

Uncertainties arise from two principal areas: limitations in the models and limitations in the data used in the models. Modeling uncertainty arises from: (a) an incomplete understanding of the phenomena involved in the transport and dispersion of hazardous materials and the resulting consequences to man; and (b) simplifications made in the modeling process to reduce costs, complexity, and requirements for input data. Uncertainties in the data used as input to the models arise from the quality or appropriateness of the data and from statistical variations. Often, data that are appropriate for use in an analysis may not be available, in which case subjective opinion (e.g., default values) is generally used. Other potential sources of uncertainty include variations in weather conditions following a release that can have a large impact on predicted consequences. In addition, there can be uncertainty with respect to the completeness of the analysis (e.g., has everything that could affect the results been considered?).

In estimating concentrations of radioactive material released to the atmosphere, the first source of uncertainty encountered is in estimating the source term. Errors in the source term are propagated throughout all diffusion and deposition estimates. Next comes the uncertainties related to the random nature of the atmosphere. Sources of uncertainty in diffusion and transport include: 
For relative diffusion:

- Diffusion parameter estimates

- Mixing height estimates

- Effective release height

- Wind speed.

For diffusion parameter estimates:

- Representativeness of the turbulence characterization and measurements if Lagrangian similarity and statistical parameter models are used

- Selection of a diffusion (stability) classification scheme, if used

- Representativeness of data used to select a diffusion class

- Accuracy of the measurement.

For concentrations at specific locations relative to the ground:

- Uncertainty in transport

- Uncertainty in relative diffusion

- Uncertainty in deposition and washout.

Table 5-14 summarizes confidence intervals for most of the measured parameters used in transport, diffusion, and deposition estimates using typical instrumentation.

In 1977, the American Meteorological Society Committee on Atmospheric Turbulence and Diffusion (AMS 1978) estimated the upper limit of accuracy for diffusion models to be about a factor of two under conditions where the meteorological parameters controlling diffusion are measured near the point of release and where topographical relief is minimal. Under exceptional circumstances (i.e., rough terrain, wake flows, over water trajectories, extremes of atmospheric stability or instability, and ranges of more than $10 \mathrm{~km}$ ), uncertainties may be as great as an order of magnitude if standard models are used.

Use of site-specific models may decrease the uncertainty. Working Group $C$ at an NRC-Sponsored Workshop (Dabberdt et al. 1982) estimated the uncertainty of site-specific models to be about a factor of three under optimum daytime conditions with relatively strong winds. Greater uncertainty, approaching a factor of 10, was estimated for conditions when the windspeed decreases toward calm. A similar range of uncertainty (factor of 3 to 10) was given for nighttime, ground-level releases. The uncertainty range was extended to a factor of 100 for complex terrain. No level of uncertainty was estimated for nonstationary meteorological conditions such as sea breezes.

These uncertainty estimates are generally for maximum ground-level concentrations and consider only diffusion. They do not consider other atmospheric processes affecting concentrations, such as radioactive decay, dry deposition, and washout by precipitation. It is also important to note that they are estimates of the uncertainty at the plume centerline; they are not estimates of uncertainty at specific points in space. This difference is significant. Estimates of uncertainty at a point in space must include uncertainty in plume position, a source of uncertainty not included in the estimates given. 
Table 5-14. Confidence Ranges for Parameters Used in Atmospheric Models* (NRC 1983c)

\begin{tabular}{|ll|}
\hline Wind Direction & $\begin{array}{l} \pm 50^{\circ} \text { for measured values, } 40^{\circ} \text { root mean square (rms) error in } \\
\text { interpolated or forecast directions }\end{array}$ \\
Wind Speed & $\begin{array}{l} \pm 0.5 \mathrm{~m} / \mathrm{s} \text { for measured values, } \pm 2 \text { to } 3 \mathrm{~m} / \mathrm{s} \text { rms error for } \\
\text { interpolated or forecast speeds }\end{array}$ \\
$\begin{array}{l}\text { Horizontal Diffusion } \\
\text { Parameter }\end{array}$ & $\begin{array}{l}\text { Factor of } 2 \text { or more, depending on topography and technique used } \\
\text { to estimate parameter }\end{array}$ \\
Vertical Diffusion & $\begin{array}{l}\text { Factor of } 2 \text { or more, depending on topography, stability, and } \\
\text { Parameter }\end{array}$ \\
technique used to estimate parameter \\
Dry Deposition Velocity & $\begin{array}{l}\text { No better than an order of magnitude estimate if constant value } \\
\text { assumed }\end{array}$ \\
Washout Ratio & No better than an order of magnitude estimate \\
Precipitation Rate & Factor of 2 for steady-state precipitation, more for convective \\
& precipitation \\
Temperature & $\pm 0.5^{\circ} \mathrm{C}$ if properly exposed \\
Temperature Difference & $\pm 0.10^{\circ} \mathrm{C}$ if properly exposed and matched sensors are used
\end{tabular}

* Confidence ranges provided are associated with hourly averages of measurement data

The uncertainty associated with model estimates is also a function of averaging time. In general, uncertainty decreases with increasing averaging time. Estimates given above are associated with hourly averages of measured values of the parameters. If the averaging interval is reduced to five or ten, minutes an additional factor of two can he added to the uncertainty (Ramsdell and Hinds 1971). Uncertainties associated with instantaneous spot estimates and observations are even larger (USNRC 1983c).

\subsubsection{Determination of Uncertainty}

When using atmospheric transport and dispersion models, a key question to consider is: What is the accuracy of the model prediction? In the past, the use of conservative assumptions has led to estimates that were expected to overestimate the actual exposure received. Even using the conservative assumptions, most doses calculated for releases from nuclear facilities were small fractions of the regulatory standards. However, during the past few years, numerical guides and regulatory limits have been consistently lowered. As a result, conservative estimates are producing results that cannot be considered well within the exposure limits. This has placed increased emphasis on replacing the conservative assumptions with those deemed more realistic.

When models using "realistic" rather than "conservative" assumptions produce estimates that approach an established limit by even an order of magnitude, the question arises: Is there a possibility that the actual 
exposure might exceed the limit? This question provides increased incentive for evaluating uncertainties associated with current models.

It is convenient to think of a model as a function $Y=f\left(X_{1}, \ldots, X_{2}, t\right)$ of the independent variables $X_{1}, \ldots, X_{z}$ and possibly time, $t$. The variables $X_{1}, \ldots, X_{2}$ represent a variety of phenomena within the model, e.g., temperature, windspeed, release height, or other entities, such as branch points, built-in data tables, or submodels within larger models. In general, uncertainty analysis is the determination of the variation or imprecision in $Y$ that results from the collective variation in the model variables $X_{1}, \ldots, X_{z}$. The results of analyzing the uncertainty associated with $Y$ help answer the following questions of interest: (a) What is the range of Y?; (b) What are the mean and median values of Y?; (c) What are the lower and upper 5 percent values of $\mathrm{Y}$ ?; and (d) Are there any disconitinuities associated with the range of $\mathrm{Y}$ ?

An important tool in the analysis of uncertainty is the process of sensitivity analysis. Sensitivity analysis is the determination of the change in the response of a model to changes in model parameters and specifications. The results of the analysis provide important information on the main contributors to the variation or imprecision in the model.

The models to be examined are often large and complex, and frequently display many of the following characteristics:

- There are many input parameters

- Alterations to the model are difficult and time consuming

- It is difficult to reduce the model to a single system of equations

- Discontinuities exist in the behavior of the model

- Correlations exist among the input variables, and the effects of possible synergisms are difficult to identify

- Model outputs are nonlinear, multi variate, time-dependent functions of the input variables

- The relative importance of individual input variables is a function of time.

There are many techniques for uncertainty and sensitivity analysis. In order to produce meaningful results, the technique employed must be capable of addressing the specific characteristics of the model (or system of models) being studied.

Some frequently used approaches to uncertainty and sensitivity analysis for computer-based models include:

- Response surface replacement

- Modified Monte Carlo (e.g., Latin hypercube sampling)

- Differential analysis

- Adjoint techniques

- Green's function techniques

- Fourier amplitude sensitivity test.

A detailed discussion of the use of such techniques for uncertainty and sensitivity analysis is beyond the scope of this handbook. However, as the interest in quantifying uncertainty has grown, so has the body of information available on the applicable techniques. As a result, the most current information can be found 
in statistical texts, government and industry reports, journal articles, and published meeting proceedings. Chapter references contain citations for several documents containing discussions of uncertainty and sensitivity analysis techniques (e.g., Murphy and Or 1984; Iman et al. 1981a, b, and c; Alpert and Helton 1985).

Typically, large systems of models such as the MELCOR Accident Consequence Code System (Jow et al. $1986 ; 1990)$ are too complex to permit a simple examination of uncertainty in its entirety. Therefore, considerable effort is invested in examining the components of the system. For complex systems of models, it is necessary to first determine the impact of uncertainty on individual models in the system and then to study the impact on the entire system. 


\subsection{References}

ALOHA, "User's Manual for the ALOHA Model, ALOHA 5.0, Areal Locations of Hazardous Atmospheres," Hazardous Materials Response Branch, National Oceanic and Atmospheric Administration, Seattle, Washington, and Chemical Emergency Preparedness and Prevention Office, U.S. Environmental Protection Agency, Washington, D.C., 1994.

Alpert, D.J. and J.C. Helton, "Uncertainty and Sensitivity Analysis for Reactor Accident Consequence Models," SAND85-0885C, Sandia National Laboratories, Albuquerque, New Mexico, 1985.

American Conference of Government Industrial Hygienists (ACGIH), "Threshold Limit Values and Biological Exposure Indices for 1986-87," Cincinnati, Ohio, 1986.

American Industrial Hygiene Association (AIHA), "Emergency Response Planning Guidelines," Akron, Ohio, 1988-1996.

American Meteorological Society Workshop (AMS), "Stability Classification Schemes and Sigma Curves--Summary of Recommendations," Bulletin of the American Meteorological Society, 58 pp.1305-1309, 1977.

American Meteorological Society (AMS), "Accuracy of Dispersion Models," Bulletin of the American Meteorological Society, 59 pp 1025-1026, 1978.

Anspaugh, L.R., J. H. Shinn, P.L. Phelps, and N.C. Kennedy, "Resuspension and Redistribution of Plutonium in Soils." Health Physics, 29 pp.571-582, 1975.

Athey, G.F., A.L. Sjoreen, and T.J. McKenna, "RASCAL Version 2.0 User's Guide," NUREG/CR-5247, PNL-8454, Vol. 1, Rev. 1, U.S. Nuclear Regulatory Commission, Washington, D.C., 1993.

Baker, W.E., P.A. Cox, P.S. Westine, J.J. Kulesz, and R.A. Strehlow, "Explosion Hazards and Evaluation," in Fundamental Studies in Engineering, Vol. 5, Elsevier, Amsterdam, 1983.

Barad, M.L., "Project Prairie Grass, A Field Program in Diffusion, Vol. 1," AFCRC-TR-58-235 (I), AD 152572, AFGL, Hanscom AFB, Massachusetts, 1958.

Blewitt, D.N., J.F. Yohn, and D.L. Ermak, "An Evaluation of SLAB and DEGADIS Heavy Gas Dispersion Models Using the HF Spill Test Data," International Conference on Vapor Cloud Modeling, Boston, Massachusetts; American Institute of Chemical Engineers, New York, 1987a.

Blewitt, D.N., J.F. Yohn, R.P. Koopman, and T.C. Brown, "Conduct of Anhydrous Hydrofluoric Acid Spill Experiments," International Conference on Vapor Cloud Modeling, Boston, Massachusetts; American Institute of Chemical Engineers, New York, $1987 \mathrm{~b}$.

Brasie, W.C. and D.W. Simpson, "Guidelines for Estimating Damage Explosion," Proc. 63rd Nat. AIChE Meeting, American Institute of Chemical Engineers, New York, New York, 1968. 
Briggs, G.A., "Diffusion Estimates for Small Emissions," ATDL Contribution File No. 79, Air Resources Atmospheric Turbulence and Diffusion Laboratory, National Oceanic and Atmospheric Administration, Oak Ridge, Tennessee, 1973a.

Briggs, G.A., "Lift Off of Buoyant Gas Initially on the Ground," Environmental Research Laboratories, Air Resources, Atmospheric Turbulence and Diffusion Laboratory, ATDL Contribution File No. 87 (draft), National Oceanic and Atmospheric Administration, Oak Ridge, Tennessee, 1973b.

Briggs, G.A., "Plume Rise and Buoyancy Effects," Chapter 8 of Atmospheric Science and Power Production, DOE/TIC-27601, Ed. D. Randerson, U.S. Department of Energy Technical Information Center, Springfield, Virginia, 1984.

Britter, R.E. and J. McQuaid, "Workbook on the Dispersion of Dense Gases," HSE Contract Research Report No. 17/1988, UK Health and Safety Executive, Sheffield, United Kingdom, 1988.

Center for Chemical Process Safety (CCPS), International Conference on Vapor Cloud Modeling, Boston, $M A$, American Institute of Chemical Engineers, New York, New York, CCPS 1987.

Center for Chemical Process Safety (CCPS), "Guidelines for Chemical Process Quantitative Risk Analysis," American Institute of Chemical Engineers, New York, New York, 1989.

Center for Chemical Process Safety (CCPS), International Conference and Workshop on Modeling and Mitigating the Consequences of Accidental Releases of Hazardous Materials, New Orleans, LA, American Institute of Chemical Engineers, New York, New York, 1991.

Center for Chemical Process Safety (CCPS), "Guidelines for Evaluating the Characteristics of Vapor Clouds Explosion, Flash Fires, and BLEVES," American Institute of Chemical Engineers, New York, New York, 1994.

Center for Chemical Process Safety (CCPS), International Conference and Workshop on Modeling and Mitigating the Consequences of Accidental Releases of Hazardous Materials, New Orleans, LA, American Institute of Chemical Engineers, New York, New York, 1995.

Chamberlain, A.C. and R.C. Chadwick, "Transport of Gases to and from Grass and Grass-like Surfaces," Proceedings of the Royal Society A290, 236 - 265, 1953.

Chamberlain, A.C. and R.C. Chadwick, "Deposition of Airborne Radio-Iodine Vapour," Nucleonics $\underline{8}$, 22-25: Chamberlain, A.C., 1966.

Chhibber, S. And G.D. Kaiser, "SAIC's Computer Programs for Modeling the Atmospheric Dispersion of Hazardous Vapors, Draft Model Description and User's Guide," Prepared for the U.S. Nuclear Regulatory Commission, Washington, D.C., 1993.

Clough, P.N., D.R. Grist, and C.J. Wheatley, "The Mixing of Anhydrous Hydrofluoric Acid with Moist Air," International Conference on Vapor Cloud Modeling, Boston, Massachusetts; American Institute of Chemical Engineers, New York, 1987a. 
Clough, P.N., Grist, D.R. and Wheatley, C.J., Thermodynamics of Mixing and Final State of a Mixture Formed by the Dilution of Anhydrous Hydrogen Fluoride with Moist Air, SRD/HSE/SRD R 396 C.1, $1987 \mathrm{~b}$.

Dabbert, W.F., F.L. Ludwig, S. Ruff, S. SethuRaman, J. Tickler, and A. Patrions, "Workshop on Meteorological Aspects of Emergency Response Plans for Nuclear Power Plants: Proceedings and Recommendations," Final Report, SRI Project 3689, SRI International, Menlo Park, California, 1982.

Doumenc, A., R. Gerard, and J.P. Maigne, "Provision Quantitative des Pollutions Consecutives à un Rejet d'uf dans l'Air," Proceedings of the Specialists Meeting on the Safety Problems Associated with the Handling and Storage of UF 6 , Bochuls, The Netherlands, 27-29 June, 1978.

Doury, A., "Practiques Francaises en Matiere D'Evaluation Quantitative de la Pollution Atmospherique Potentille Liee aux Activities Nucleaires," Commissariat a l'Energie Atomique Rapport DSN No. 397 , 92260 Fontenay aux Roses, France, 1980.

DuCouret, A.J., "An Experience of Accident Release of $\mathrm{UF}_{6}$," Proceedings of the Specialists Meeting on the Safety Problems Associated with the Handling and Storage of UF ${ }_{6}$, Bochuls, The Netherlands, 27-29 June, 1978.

Egan, B.A., "Turbulent Diffusion in Complex Terrain," in Lectures on Air Pollution and Environmental Impact Analyses, pp.112-135, D. Haugen (Ed.), American Meteorological Society, Boston, Massachusetts, 1975.

Eichler, T.V. and H.S. Napadensky, “Accidental Vapor Phase Explosions on Transportation Routes Near Nuclear Power Plants," IIT Research Institute Final Report No. J6405, Chicago, Illinois, 1977.

E.I. du Pont de Nemours, "Description of Modeling Techniques for Hazardous Chemical Releases," DuPont SAFER Emergency Systems, Westlake Village, California, 1989.

Ermak, D.L., "User's Manual for SLAB: An Atmospheric Dispersion Model for Denser-than-Air Releases," Lawrence Livermore National Laboratory Reports UCRL-MA-105607, Livermore, California, 1990.

Factory Mutual Research Corporation, "Guidelines for the Estimation of Property Damage from Outdoor Vapor Cloud Explosion in Chemical Processing Facilities,” Technical Report, March 1990.

Gifford, F A., Jr., Use of Routine Meteorological Observations for Estimating Atmospheric Dispersion, "Nuclear Safety", 2(4) pp 47-57, 1961.

Gifford, F.A., Jr., "The Rise of Strongly Radioactive Plumes," J. Appl. Meteor. 6 pp 664 et seq, 1967.

Gifford, F.A., Jr., "An Outline of Theories of Diffusion in the Lower Layers of the Atmosphere", in Meteorology and Atomic Energy, pp. 66-116, D. H. Slade (Ed.), USAEC Report TID-24190, U.S. Atomic Energy Commission, NTIS, 1968. 
Goldwire, H.C., Jr., H.C. Roedean, R.T. Cederwall, E.J. Kansa, R.P. Koopman, J.W. McClure, T.G. McRae, L.K. Morris, L. Kamppinen, R.D. Kiefer, P.A. Urtlew, and C.D. Lind, "Coyote Series Data Report, LLNL/NWC 1981 LNG Spill Tests: Dispersion, Vapor Burn and Rapid Phase Transition," UCID199953, Lawrence Livermore National Laboratory, Livermore, California, 1983.

Goldwire, H.C., Jr., T.G. McRae, G.W. Johnson, D.L. Hipple, R.P. Koopman, J.W. McLure, L.K. Morris, and R.T. Cederwall, "Desert Tortoise Series Data Report - 1983 Pressurized Ammonia Spills," Lawrence Livermore National Laboratories Report UCID-20562, 1985; Goldwire, Jr., H.C., Chem. Eng. Prog., pp 35-41, April, 1986.

Goode, W.R., Jr., S.G. Bloom, and K.D. Keith, Jr., "Application of HGSYSTEM/UF 6 Model to Simulate Atmospheric Dispersion of $\mathrm{UF}_{6}$ from Uranium Enrichment Plant," in CCPS pp 905-920., 1995.

Hall, D.J., V. Kukadico, S. Walker and G.W. Marshland, "Plume Dispersion from Chemical Warehouse Fires," Building Research Establishment Client Report 56/95, Gaston, Watford WD2 7JR, UK, 1995.

Hall, D.J., V. Kukadico, S. Walker and G.W. Marshland, "Deposition of Large Particles from Warehouse Fire Plumes-A Small-Scaled Wind Tunnel Model Study," Building Research Establishment Client Report CR 42/96, Gaston, Watford WD27JR, UK, 1996.

Hanna, S.R., Briggs, G. A, and Hosker, R. P., Jr., "Handbook on Atmospheric Diffusion", DOE/TIC11223, Technical Information Center, U.S. Department of Energy, 1982.

Hanna, S.R. and P.J. Drivas, Guidelines for Use of Vapor Cloud Dispersion Models, Center for Chemical Process Safety, American Institute of Chemical Engineers, New York, New York, 1987.

Hanna, S.R., D.G. Strimatis, and J.C. Chang, "Uncertainties in Hazardous Gas Model Predictions," in CCPS (1991) pp 345-368, 1991.

Hanna, S.R., J.C. Chang, J.X. Zhang, "Technical Documentation of HGSYSTEM/UF 6 Model," K/SUB/93-XJ947, Lockheed Martin Energy Systems, Oak Ridge, Tennessee, 1994a.

Hanna, S.R., J.C. Chang, J.X. Zhang, K. McFarlane, L. Post, R.T. Roberts, and H.W.M. Witlox, “HGSYSTEM 3.0 Technical Reference Manual," TNER.94-059 (L. Post, ed.), Shell Research Center Limited, Thornton Research Centre, Thornton, United Kingdom, $1994 \mathrm{~b}$.

Hanna, S.R., J. Chang, and Xiaoming Zhang, "Modifications to HGSYSTEM to Account for UF Chemistry and Thermodynamics," in CCPS pp 225-242, 1995.

Harris, R.J. and M. J. Wickens, "Understanding Vapor Cloud Explosions - an Experimental Study," 55th Autumn Meeting of the Institution of Gas Engineers, Kensington, United Kingdom, 1989.

Havens, J.A. and T.O. Spicer, "Development of an Atmospheric Dispersion Model for Heavier-than-Air Gas Mixtures," Final Report to US Coast Guard, CG-D-23-85, Washington, D.C., 1985.

Havens, J.A. and T.O. Spicer, “A Dispersion Model for Elevated Dense Gas Releases,” U.S. Environmental Protection Agency Report EPA 450/4-88-006a (Volume 1) and -006b (Volume II - User's Guide), Washington, D.C., 1988. 
Heinold, D., R. Paine, K. Walker and D. Smith, "Evaluation of the AIRTOX Dispersion Algorithms Using Data from Heavy Gas Field Experiments," Fifth Joint Conference of Applications of Air Pollution Meteorology, American Meteorological Society, Research Triangle Park, North Carolina, 1986.

Holzworth, G.C., "Mixing Heights, Windspeeds-Potential for Urban Air Pollution Throughout the Continental Untied States," AP-101, U.S. Environmental Protection Agency, Office of Air Programs, Research Triangle Park, North Carolina, 1972.

Holzworth, G.C., "Estimates of Mean Maximum Mixing Depths in the Contiguous United States," Monthly Weather Review 92, pp.235 et seq, 1984.

Homman, S.G., "HOTSPOT Health Physics Codes for the PC," UCRL-MA-106315, Hazards Control Department, Lawrence Livermore National Laboratory, University of California, 1994.

Hosker, Jr., R.P., "Estimates of Dry Deposition and Plume Depletion over Forest and Grassland," Physical Behavior of Radioactive Contaminants in the Atmosphere, International Atomic Energy Agency IAEA/STI/PUB/354(1974) 291, 1974.

Hosker, R.P., Jr., "Flow and Diffusion Near Obstacles," in Atmospheric Science and Power Production, Darryl Randerson, (Ed.), DOE Report DOE/TIC-27601, 1981a.

Hosker, R.P., Jr., "Methods for Estimating Wake Flow and Effluent Dispersion Near Simple Block Like Buildings." NOAA Technical Memorandum, ERL ARL-108, 138 p, $1981 \mathrm{~b}$.

Iman, R.L., J.C. Helton, and J.E. Campbell, "A Comparison of Uncertainty and Sensitivity Analysis Techniques for Computer Models," SAND84-1461, NUREG/CR-3904, Sandia National Laboratories, Albuquerque, New Mexico, 1981a.

Iman, R.L. and J.C. Helton, "An Approach to Sensitivity Analysis of Computer Models: Part I Introduction, Input Variable Selection and Preliminary Variable Assessment," Journal of Quality Technology, Vol. 123, No. 3, pp 149-220, 1981 b.

Iman, R.L. and J.C. Helton, "An Approach to Sensitivity Analysis of Computer Models: Part II - Ranking of Input Variables, Response Surface Validation, Distribution Effect and Technique Synopsis," Journal of Quality Technology, Vol. 123, No. 4, pp 221-282, 1981c.

Industrial Risk Insurers (IRI), "Oil and Chemical Properties Loss Prevention Guide," IRI-Information, February 1990.

Jow, H.N. et al., "MELCOR Accident Consequence Code System (MACCS): Model Description, Volume II," SAND86-162, NUREG/CR-4691, Sandia National Laboratories, Code Manual for MACCS2: Volume 1, User's Guide, 1986.

Jow, H.N., J.L. Sprung, J.A. Rollstin, L.T. Ritchie, and D.I. Chanin, "MELCOR Accident Consequence Code System (MACCS), Model Description," NUREG/CR-4691, SAND86-1562, Vol. 2, Sandia National Laboratories, Albuquerque, New Mexico, 1990. 
Koopman, R.P., J. Baker, R.T. Cederwall, H.C. Goldwin, Jr., W.J. Hogan, L.M. Kamppinen, R.D. Keifer, J.W. McClure, T.G. McRae, D.L.O Morgan, L.K.Morris, M.W. Spann, Jr., and C.D. Lind, "Burro Series Data Report, LLNL/NWC 1980 LNG Spill Tests," UCID-19705, Lawrence Livermore National Laboratory, Livermore, California, 1982.

Kunkel, B.A., "User's Guide for the Air Force Chemical Dispersion Model (AFTOX)," AFGL-TR-880009, AF Geophysics Laboratory, Hanscom AFB, Massachusetts, 1988.

Maher, S.T. and G.D. Kaiser, "Torrance Refinery Safety Advisor Project: Evaluation of Modified HF Alkylation Catalyst," EQE International Report 59111.01, Irvine, California, 1995.

Martin, D.O., and J.A. Tikvart, "A General Atmospheric Diffusion Model for Estimating the effects on Air Quality of One or More Source," Presented at 61st Annual Meeting of the Air Pollution Control Association (APCA), ACPA, St. Paul, Minnesota, 1969.

Mazola, C.A. and R.P. Addis, "Atmospheric Dispersion Modeling Resources," Second edition, published by Oak Ridge Associated Universities under contract to the U.S. Department of Energy, 1995.

McFarlane, K., A. Prothero, J. S. Puttock, P. T Roberts, and H. W. M. Witlox, "Development and Validation of Atmospheric Dispersion Models for Ideal Gases and Hydrogen Fluoride," Part I: Technical Review Manual, Shell Research Limited, Thornton Research Centre, P. O. Box 1, Chester, England, 1990.

McGuire, S.A., "Chemical Toxicity of Uranium Hexafluoride Compared to Acute Effects of Radiation," NUREG-1391, U.S. Nuclear Regulatory Commission, Washington, D.C., 1991.

McKenna, T., J. Trefether, K. Gant, J. Jolicoeur, G. Kuzo, and G. Athey, "U.S. Nuclear Regulatory Commission RTM-96 Response Technical Manual," NUREG/BR-0150, Vol. 1, Rev. 4, U.S. Nuclear Regulatory Commission, Washington, D.C., 1994.

Meroney, R.N., "Lift-Off of Buoyant Gas Initially on the Ground," J. Industrial Mathematics, Vol. 5, 1979.

Mills, M., "Techniques for Modeling Jet Releases for Emergency Prevention and Preparedness Applications," Hazardous Materials Spills Conference, Co-Sponsored by the American Institute of Chemical Engineers and the National Response Team, Chicago, Illinois, 1988.

Mullett, G. and P. Raj, “User's Manual for Adam," Air Force No. GL-TR-90-0321(II), AF Geophysics Laboratory, Hanscom AFB, Massachusetts, 1990.

Murphy, B.D. and S.Y. Or, "The Limitations of Atmospheric Dispersion Data and Their Contribution to Uncertainties to Dose Assessment," Health Physics, Vol. 48, No. 3, pp 315-324, March 1984.

Murphy, K.G., and K.M. Campe, "Nuclear Power Plant Control Room Ventilation System Design for Meeting General Design Criteria 19," In Proceedings of the 13th AEC Air Cleaning Conference, San Francisco, California, CONF-740807, U.S. Atmoic Energy Commission, Washington, D.C., 1974.

Nair, S.K., D.B. Chambers, S.H. Park, Z.R. Radonjic, P.T. Coutts, C.J. Lewis, J.S. Hammonds, and F.O. Hoffman, "Review of Models Used for Determining Consequences of UF 6 Release," NUREG/CR-6481, Vol. 2, U.S. Nuclear Regulatory Commission, Washington, D.C., 1997. 
Nickola, P.W., J.V. Ramsdell, Jr., and J.D. Ludwick, "Detailed Time-Histories of Concentrations Resulting from Puff and Short-Period Releases of Inert Radioactive Gas: A Volume of Atmospheric Dispersion Data," BNWL-1272, UC-53, Battelle Pacific Northwest Laboratories, Richland, Washington, 1970.

Nou, J.V., "The Ocean Breeze and Dry Gulch Diffusion Programs," AFCRL, Hanscom AFB, Massachusetts, 1963.

Ooms, G., "A New Method for the Calculation of the Plume Path of Gases Emitted by a Stack," Atmospheric Environment 6 pp 899-909, 1974.

Ooms, G., A.P. Mahieu, and F. Zelis, "The Plume Path of Vent Gases Heavier Than Air," First International Symposium on Loss Prevention and Safety Promotion in the Process Industries, The Hague, 1974.

Ooms, G. and N.J. Duijm, "Dispersion of a Stack Plume Heavier than Air," IUTAM Symposium on the Atmospheric Dispersion of Heavy Gases and Small Particles, Delft, 1983; Springer-Verlag, Berlin/Heidelberg, 1984.

Pasquill, F., "The Estimate of the Dispersion of Windborne Material," Meteorology Magazine 90 pp 3349, 1961.

Pasquill, F., Atmospheric Diffusion, 2nd Edition, John Wiley \& Sons, New York, 1974.

Peterson, W.B. and L.G. Lavdas, "INPUFF 2.0 - A Multiple Source Gaussian Puff Dispersion Algorithm,” EPA/600/8-86/024, U.S. Environmental Protection Agency, Washington, D.C., 1986.

Picknett, R.G., "Field Experiments on the Behavior of Dense Clouds (Part 1. Main Report)," Ptn Il 1154/78/1, Contract Report to the UK Health and Safety Executive, Porton Down, United Kingdom, 1978.

Picknett, R.G., "Dispersion of Dense Gas Puffs Released in The Atmosphere at Ground Level," Atmos. Env. 15 p 509, 1981.

Prugh, R.W., "Evaluation of Unconfined Vapor Cloud Explosion Hazards," J. Loss Prev. Proc. Industries 2(4) pp 187-193, 1987.

Puttock, J.S., D.R. Blackmore, G.W. Colenbrander, P.T. Davies, A. Evans, J.B. Homer, J.J. Redfearn, W.C. Van't Sant, and R.P. Wilson, "Spill Tests of LNG and Refrigerated Liquid Propane on the Sea, Maplin Sands, 1980: Experimental Details of the Dispersion Tests," TNER.84.046, Shell Research Ltd. Thornton Research Centre, United Kingdom, 1984.

Quest Consultants, Inc., “Focus Input and Reference Manuals,” Norman, Oklahoma, 1990.

Radian Corporation, "CHARM, Complex Hazardous Air Release Model, Version 5.0 User's Manual," Radian Corporation, Austin, Texas, 1991.

Ramsdell, J.V., and C.J. Fosmire, "Atmospheric dispersion Estimates in the Vicinity of Buildings," PNL10286, Battelle Pacific Northwest Laboratory, Richland, Washington, 1995a. 
Ramsdell, J.V., C.A. Simonen, and S.B. Smyth, "Atmospheric Relative Concentrations in Building Wakes," NUREG/CR-6331 (PNL-10521), U.S. Nuclear Regulatory Commission, Washington, D.C., $1995 \mathrm{~b}$.

Raj, K., "User's Guide to the SAFEMODE Model," Technology and Management Systems, Burlington, Massachusetts, 1990.

Ramsdell, J.V. and Hinds, "Concentration Fluctuations and Peak-to-Mean Concentration Ratios in Plumes from Ground-Level Continuous Point Source," Atmos. Environ., 5 pp 483-495, 1971.

Randerson, D. (Ed.), “Atmospheric Science and Power Production,” DOE/TIC-27601, U.S. Department of Energy, Office of Energy Research, Washington D.C., 1984.

Rodean, H.C., "Toward More Realistic Models for Release and Dispersion of Heavy Gases," UCRL53902, Lawrence Livermore National Laboratory, Livermore, California, 1989.

Russo, A.J., "Reactor Accident Plume Rise Calculations," Sandia Laboratory Report SAND76-034, Albuquerque, New Mexico, 1976.

Schotte, Fog Formation of HF in Air, Ind. Eng. Chem. Res. vol. 26, pp. 300-306, 1987.

Sehmel, G.A., "Particle and Gas Dry Deposition - A Review," Atmos. Env. 14, 983 - 1011, 1980.

Shleien, B. (Ed.), "The Health Physics and Radiological Health Handbook," Revised Edition, ISBN 0917251-05-9, Scinta, Inc., Silver Spring, Maryland, 1992.

Simpson, J.E. and R.E. Britter, "The Dynamics of the Head of a Gravity Current Advancing over a Horizontal Surface," J. Fluid Mech. 94, 1979.

Slade, D.H. (Ed.), "Meteorology and Atomic Energy," U.S. Atomic Energy Commission, Office of Information Services, Washington, D.C., 1968.

Slinn, W.G.N., "Parameterizations for Resuspension and for Wet and Dry Deposition of Particles and Gases for Use in Radiation Dose Calculations," Nuclear Safety, 19 pp 205-219, 1978.

Start, G.E., and Wendell, L.L., "Regional Effluent Dispersion Calculations Considering Spatial and Temporal Meteorological Variations," NOAA Technical Memo ERL-ARL-44, 1974.

Strohmeier, W. and Briegleb, B., "The State of Associations of Hydrofluoric Acid in the Gaseous State," $I$. New Experimental Measurements Z. Elektrochem., 57, p. 662, 1953.

Sutton, O.G., "A Theory of Eddy Diffusion in the Atmosphere," Proc. R. Soc. (London), Ser. A 135 pp 143, 1932.

Sykes, R.I., and W.S. Lewellen, "Review of Potential Models for UF ${ }_{6}$ Dispersion," Document Prepared for Martin Marietta Energy Systems, Inc., K/6DP/SAR-19, Oak Ridge, Tennessee, 1992. 
Tadmor, J., and T. Gur, "Analytical Expressions for Vertical and Lateral Dispersion Coefficients in Atmospheric Dispersion," Atmos. Environment, 3:688-689, 1969.

Touma, J.S., J.G. Zapert, H. Thistle, R.J. Landergun, and Ropazio, "Performance Evaluation of Air Toxics Dispersion Models for Simulating Heavier-Than-Air Releases," in CCPS, 1991.

Touma. J.S., "Developments in EPA's Air Dispersion Modeling for Toxic Releases, “ in CCPS, 1995.

Turner, D.B., Workbook of Atmospheric Dispersion Estimates, Public Health Service, Publication 999-AP26, Robert A. Taft Sanitary Engineering Center, Cincinnati, Ohio, 1967.

United Kingdom Health and Safety Executive (UKHSE), Second Report Advisory Committee on Major Hazards, Her Majesty's Stationery Office, London, 1979.

United Kingdom Health and Safety Executive (UKHSE), "The Effect of Explosions in the Process Industries," Loss Prevention Bulletin 68 pp 37-47, 1986a.

United Kingdom Health and Safety Executive (UKHSE), Second Symposium on Heavy Gas Dispersion Trials at Thorney Island, Sheffield, United Kingdom, October, 1986.

U.S. Department of Commerce, "Directory of Atmospheric Transport and Diffusion Models, Equipment, and Projects," FCM-13-1993, Office of the Federal Coordinator for Meteorological Services and Supporting Research, Washington, D.C., 1993.

U.S. Environmental Protection Agency, Federal Emergency Management Agency and U.S. Department of Transportation (USEPA), "Technical Guidance for Hazards Analysis," Washington, D.C., 1987.

U.S. Environmental Protection Agency (USEPA), "Evaluation of Dense Gas Simulation Models," EPA450/R-90-018, Research Triangle Park, North Carolina, 1991.

U.S. Environmental Protection Agency (USEPA), Workbook of Screening Techniques for Assessing Impacts of Toxic Air Pollutants (Revised), EPA-454R-92-024, Research Triangle Park, North Carolina, 1992.

U.S. Environmental Protection Agency (USEPA). "Guidance on the Application of Refined Dispersion Models for Hazardous/Toxic Air Releases," EPA-454/R-93-002, Research Triangle Park, North Carolina, 1993a.

U.S. Environmental Protection Agency (USEPA), "Contingency Analysis Modeling for Superfund Sites and Other Industrial Sources," EPA-454/R-93-001, Research Triangle Park, North Carolina, 1993b.

U.S. Environmental Protection Agency (USEPA), "User's Guide to TSCREEN, A Model for Screening Toxic Air Pollution Concentrations (Revised)," EPA-450/R-92-006, Research Triangle Park, North Carolina, 1994.

U.S. Environmental Protection Agency (USEPA), "Offsite Consequence Analysis Guidance," Prepared in Support of the Risk Management Program 40 CFR Part 68, Washington, D.C., 1996. 
U.S. Nuclear Regulatory Commission (USNRC), "On-Site Meteorological Programs," Regulatory Guide 1.23, Washington, D.C., 1972.

U.S. Nuclear Regulatory Commission (USNRC), "Reactor Safety Study," WASH-1400 (NUREG-75-014), Washington, D.C., 1975.

U.S. Nuclear Regulatory Commission (USNRC), "Methods for Estimating Atmospheric Transport and Dispersion of Gaseous Effluents in Routine Releases from Light-Water-Cooled Reactors," Regulatory Guide 1.111, Washington D.C., 1977.

U.S. Nuclear Regulatory Commission (USNRC), "Dose Projection Considerations for Emergency Conditions at Nuclear Power Plants," Regulatory Guide, NUREG/CR-3011 (PNL-4491), Washington, D.C., 1983a

U.S. Nuclear Regulatory Commission (USNRC), "Atmospheric Dispersion Models for Potential Accident Consequence Assessment at Nuclear Power Plants," Regulatory Guide 1.145, Washington, D.C., 1983 b.

U.S. Nuclear Regulatory Commission (USNRC), "Radiological Assessment: A Textbook on Environmental Dose Analysis," Till, J. E. (Ed.), NUREG/CR-3332, Washington, D.C., 1983c.

U. S. Nuclear Regulatory Commission (USNRC), "PRA Procedures Guide," NUREG/CR-2300, Washington, D.C., 1983d.

U. S. Nuclear Regulatory Commission (USNRC), "Assessment of the Public Health Impact From the Accidental Release of $\mathrm{UF}_{6}$ at the Sequoyah Fuels Corporation Facility at Gore, Oklahoma, Main Report," NUREG-1189, Vol. 1, Washington, D.C., 1986.

U.S. Nuclear Regulatory Commission (USNRC), "Control Room Habitability System," Standard Review Plan for the Review of Safety Analysis Reports for Power Plants, NUREG-0800, Washington, D.C., 1987.

Van den Berg, A.C., "BLAST - A 1-D Variable Flame Speed Blast Simulation Code Using a FluxCorrected Transport Algorithm," Prinz Maurits Laboratory TNO Report No. PML 1980-62, Netherlands, 1980.

Van den Berg, A.C., "The Multi-Energy Method - A Framework for Vapor Cloud Explosion Blast Prediction," Journal of Hazardous Material, 12 pp 1-10, 1985.

Van deb Berg, A.C., C.J.M. van Wingerden, J.P. Zeewen, and H.J. Pasman, "Current Research at TNO on Vapor Cloud Explosion Modeling," in CCPS, pp 687-711, 1987.

Van den Berg, A.C., "REAGAS - A Code for Numerical Simulation of 2-D Reactive Gas Dynamics in Gas Explosions," Prinz Maurits Laboratory TNO Report No. PML 1989-IN48, Netherlands, 1989.

Van den Berg, A.C., C.J.M. van Wingerden, and H.J. The, "Vapor Cloud Explosion Blast Modeling," in CCPS, pp 543-562, 1991.

Van der Hoven, I., "Deposition of Particles and Gases," in Meteorology and Atomic Energy - 1968, pp. 202-207, D. Slade (Ed.), USAEC Report TID-24190, U.S. Atomic Energy Commission, NTIS, 1968. 
Vanderzee, C. E. and Rodenberg, W. W., Gas Imperfections and Thermodynamic Excess Properties of Gaseous Hydrogen Fluoride, Journal Chem. Thermodynam., 2, (4), pp.461-478, 1970.

Vogt, K. J., Straka, J., and Geiss, H., "An Extension of the Gaussian Plume Model for the Case of Changing Weather Conditions," paper presented at the 10th International Technical Meeting on Air Pollution Modeling and its Application of the NATO/CCMS Air Pollution Pilot Study, Rome, Italy, 1979.

Wheatley, C.J., P.W.M. Brighton, and A.J. Prince, "Comparison Between Data from the Heavy Gas Dispersion Experiments at Thorney Island and Predictions of Simple Models," United Kingdom Health and Safety Executive, Second Symposium on Heavy Gas Dispersion Trials at Thorney Island, Sheffield, United Kingdom, October 1986.

Wheatley, C.J., "A Theory of Heterogeneous Equilibrium Between Vapour and Liquid Phases of Binary Systems and Formulae for the Partial Pressures of HF and $\mathrm{H}_{2} \mathrm{O}$ Vapour," SRD R 357, 1986.

Witlox, H.W.M., "HGSYSTEM: Dispersion Models for Ideal Gases and Hydrogen Fluoride, Tutorial and Quick Reference Guide," Report TNER.91.007, [EGG 1067-1150; NTIS DE93-000952] Thornton Research Center, Shell Research, Chester, England, 1991.

Xiao-yun, L., H. Leijdens, and G. Ooms, "An Experimental Verification of a Theoretical Model for the Dispersion of a Stack Plume Heavier than Air," Atmospheric Environment 20 pp 1087-1094, 1986. 


\section{CHAPTER 6 \\ LIST OF CONTRIBUTORS}

The organizations and individuals listed below are the principal contributors to this Handbook.

NRC staff managed the effort and provided technical direction while a contractor, Science Applications

International Corporation (SAIC), prepared the technical material presented in the Handbook.

\section{Contributor}

U.S. Nuclear Regulatory Commission

Tin Mo, Ph.D.

Nuclear Chemistry

NRC Project Manager

Santiago Parra, Ph.D.

Nuclear Engineering

David A. Ayres, B.S.

Chemical Engineering
Science Applications International Corporation

Geoffrey D. Kaiser, Ph.D.

Physics

SAIC Project Manager

Sumeet Chhibber, Ph.D.

Mechanical Engineering

Phuoc T. Le, M.S.

Chemical Engineering

Gregory F. Martin, M.S.

Health Physics

Jofu Mishima, B.S.

Chemistry

Peter C. Owczarski, Ph.D.

Chemical Engineering

Joseph D. Price, Ph.D.

Chemical Engineering

Deborah Raja, M.S.

Environmental Engineering 


\section{APPENDIX A}

\section{SUMMARY OF CHEMICAL AND NUCLEAR SAFETY INFORMATION}




\section{APPENDIX A \\ TABLE OF CONTENTS}

\section{APPENDIX A: SUMMARY OF CHEMICAL AND NUCLEAR SAFETY INFORMATION}

TABLE OF CONTENTS $\ldots \ldots \ldots \ldots \ldots \ldots \ldots \ldots \ldots \ldots \ldots \ldots \ldots \ldots \ldots \ldots \ldots \ldots \ldots \ldots \ldots$

LIST OF FIGURES $\ldots \ldots \ldots \ldots \ldots \ldots \ldots \ldots \ldots \ldots \ldots \ldots \ldots \ldots \ldots \ldots \ldots \ldots \ldots \ldots \ldots \ldots \ldots$

LIST OF TABLES $\ldots \ldots \ldots \ldots \ldots \ldots \ldots \ldots \ldots \ldots \ldots \ldots \ldots \ldots \ldots \ldots \ldots \ldots \ldots \ldots \ldots$

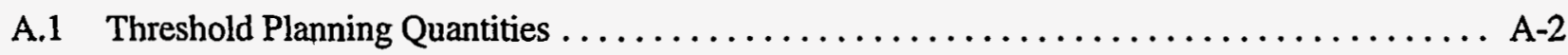

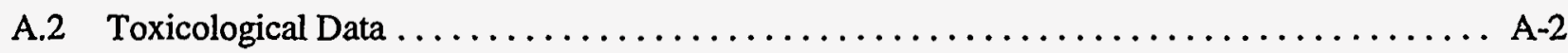

A.2.1 Exposure Guidelines . . . . . . . . . . . . . . . . . . . . .

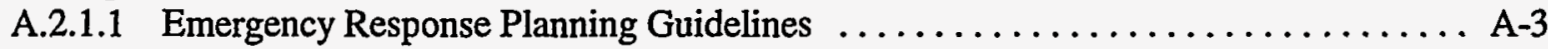

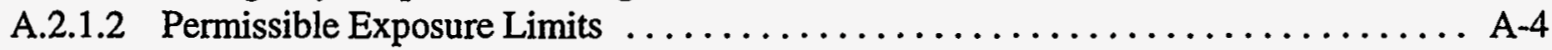

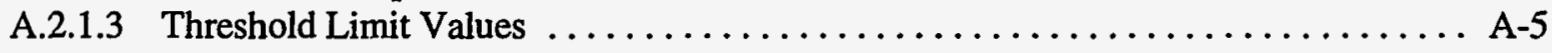

A.2.1.4 Immediately Dangerous to Life and Health Concentrations ............. A-5

A.2.2 Uranium Hexafluoride, Hydrogen Fluoride, and Fluorine Toxicity . . . . . . . . A A 5

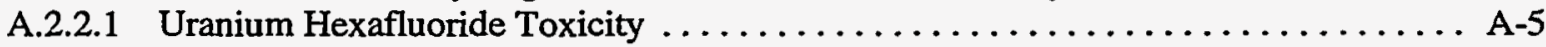

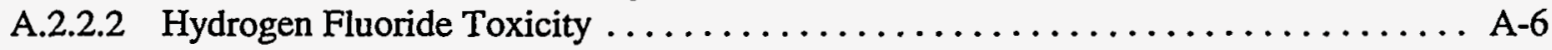

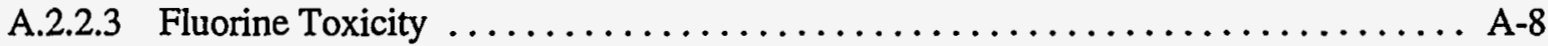

A.3 Physical and Chemical Properties $\ldots \ldots \ldots \ldots \ldots \ldots \ldots \ldots \ldots \ldots \ldots \ldots \ldots \ldots \ldots$

A.4 Special Instructions for Handling Hazardous Chemicals $\ldots \ldots \ldots \ldots \ldots \ldots \ldots \ldots \ldots \ldots$

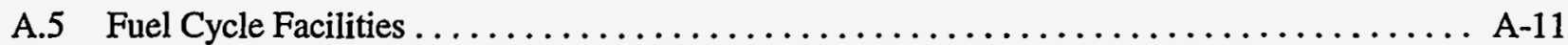

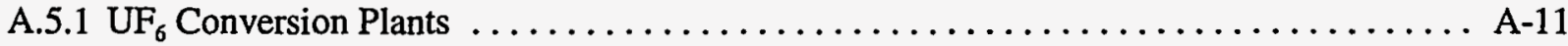

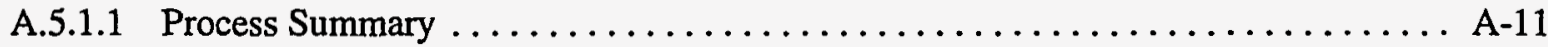

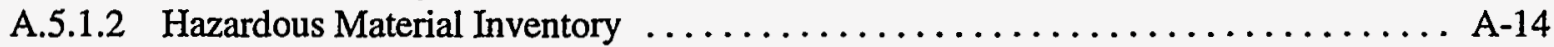

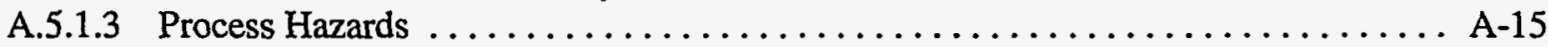

A.5.2 Plants for Fabrication of Fuel for Light-Water-Reactors $\ldots \ldots \ldots \ldots \ldots \ldots \ldots \ldots$ A-16

A.5.2.1 Process Summary ............................... A

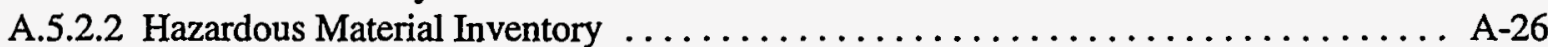

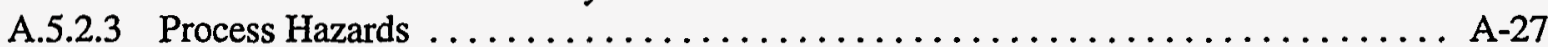

A.5.3 Uranium Enrichment Plants . . . . . . . . . . . . . . . . . . . . A

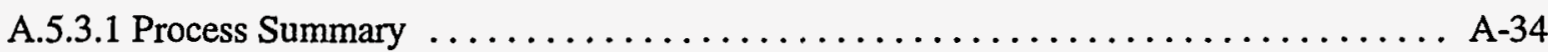

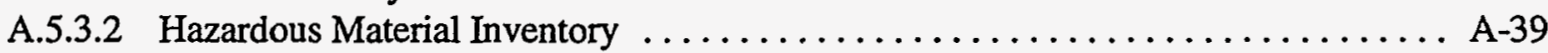

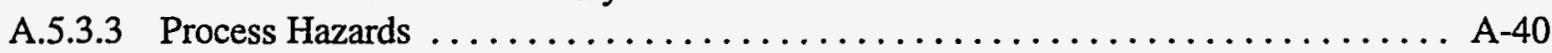

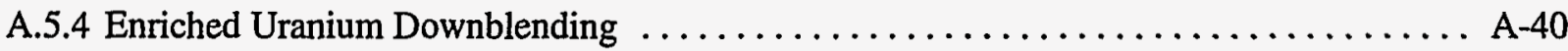

A.5.4.1 Process Summary $\ldots \ldots \ldots \ldots \ldots \ldots \ldots \ldots \ldots \ldots \ldots \ldots \ldots \ldots \ldots \ldots \ldots \ldots \ldots$

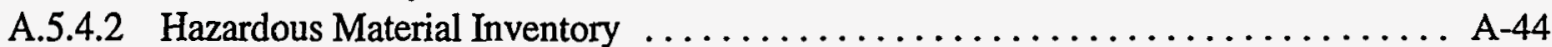

A.5.4.3 Process Hazards . . . . . . . . . . . . . . . . . . . .

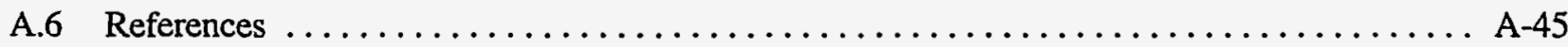




\section{APPENDIX A}

\section{LIST OF FIGURES}

Figure A-1. Basic steps in a typical $\mathrm{UF}_{6}$ dry conversion process $\ldots \ldots \ldots \ldots \ldots \ldots \ldots \ldots \ldots$ A-12

Figure A-2. Basic steps in light-water-reactor $\mathrm{UO}_{2}$ fuel fabrication $\ldots \ldots \ldots \ldots \ldots \ldots \ldots \ldots$ A-18

Figure A-3. Basic steps in light-water-reactor MOX fuel fabrication $\ldots \ldots \ldots \ldots \ldots \ldots \ldots \ldots$ A-19

Figure A-4. Schematic $\mathrm{UO}_{2}$ fuel fabrication plant processing diagram for a wet ammonium

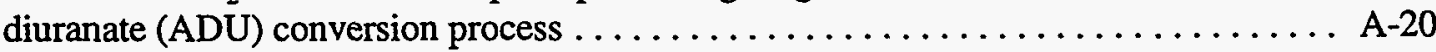

Figure A-5. Schematic $\mathrm{UO}_{2}$ fuel fabrication plant processing diagram for a dry conversion process . A-22

Figure A-6. Schematic $\mathrm{MOX}$ fuel fabrication plant process design for $\mathrm{PuO}_{2}$ powder preparation . . . A-24

Figure A-7. UF 6 phase diagram [Source: USDOE (1991)] . . . . . . . . . . . . . . A-29

Figure A-8. Some conceivable release mechanisms for fuel cycle chemicals $\ldots \ldots \ldots \ldots \ldots \ldots \ldots$ A-32

Figure A-9. Schematic of the gas centrifuge enrichment process $\ldots \ldots \ldots \ldots \ldots \ldots \ldots \ldots \ldots$ A-35

Figure A-10. Schematic of the $\mathrm{UF}_{6}$ downblending process $\ldots \ldots \ldots \ldots \ldots \ldots \ldots \ldots \ldots \ldots \ldots$ A-41

Figure A-11. Schematic of the UNH downblending process $\ldots \ldots \ldots \ldots \ldots \ldots \ldots \ldots \ldots \ldots$

\section{LIST OF TABLES}

Table A-1. Threshold Planning Quantities for Hazardous Chemicals Used at Fuel

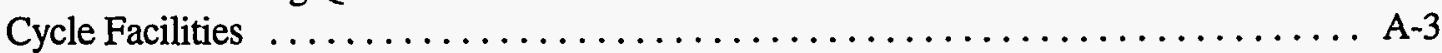

Table A-2. Levels of Concern for Selected Chemicals $\ldots \ldots \ldots \ldots \ldots \ldots \ldots \ldots \ldots \ldots \ldots$ A-4

Table A-3. Health Effects From Soluble Uranium Intake $\ldots \ldots \ldots \ldots \ldots \ldots \ldots \ldots \ldots \ldots \ldots$

Table A-4. Time-Averaged HF Toxicity Values Corresponding to the ERPG-2

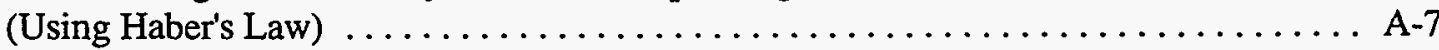

Table A-5. Physical Constants for Selected Chemicals $\ldots \ldots \ldots \ldots \ldots \ldots \ldots \ldots \ldots \ldots \ldots$ A-10

Table A-6. Typical Chemical Inventories at $\mathrm{UF}_{6}$ Conversion Plants $\ldots \ldots \ldots \ldots \ldots \ldots \ldots \ldots$ A-15

Table A-7. Typical $U_{6}$ Inventories in Process Vessels $\ldots \ldots \ldots \ldots \ldots \ldots \ldots \ldots \ldots \ldots \ldots$ A-16

Table A-8. Typical Chemical Inventories at Light-Water-Reactor $\mathrm{UO}_{2}$ Fuel

Fabrication Facilities . . . . . . . . . . . . . . .

Table A-9. Typical Radioactive Material Possession Limits $\ldots \ldots \ldots \ldots \ldots \ldots \ldots \ldots \ldots \ldots$ A-28 


\section{APPENDIX A SUMMARY OF CHEMICAL AND NUCLEAR SAFETY INFORMATION}

The objective of this Appendix is to discuss issues relevant to the safety evaluation and preliminary safety analysis of fuel cycle facilities regulated by the U.S. Nuclear Regulatory Commission (NRC).

This Appendix identifies nuclear and chemical process accident scenarios that have the potential to compromise radiological safety. It also contains nuclear and chemical process information useful for developing accident scenarios and release source terms for atmospheric dispersion modeling.

In this Appendix, typical inventories of various chemicals are tabulated, and the processes at the fuel cycle facilities are described. Relevant data, such as physical constants, toxicological information, levels of concern, and threshold planning quantities for the chemicals of interest are given. A brief discussion of the nuclear and chemical process hazards and radiological hazards is also given.

As described in Section A.1, the hazardous chemicals of interest at NRC-licensed fuel cycle facilities are ammonia $\left(\mathrm{NH}_{3}\right)$, nitric acid $\left(\mathrm{HNO}_{3}\right)$, hydrogen fluoride $(\mathrm{HF})$, hydrogen $\left(\mathrm{H}_{2}\right)$, uranium hexafluoride $\left(\mathrm{UF}_{6}\right)$, fluorine $\left(\mathrm{F}_{2}\right)$, hydrogen chloride $(\mathrm{HCl})$, and hydrogen peroxide $\left(\mathrm{H}_{2} \mathrm{O}_{2}\right)$. The Occupational Safety and Health Administration (OSHA) and the U.S. Environmental Protection Agency (EPA) have established threshold planning quantities (TPQs) for the hazardous chemicals of interest with the exception of $\mathrm{UF}_{6}$ for which a TPQ has not been established by either OSHA or EPA.

Federal, state, and industry organizations have issued exposure guidelines to protect workers and the public from adverse health effects of hazardous chemical exposure. The four most common exposure guidelines are as follows: (1) emergency response planning guidelines (ERPG), (2) permissible exposure limits (PEL), (3) threshold limit values (TLV), and (4) immediately dangerous to life or health (IDLH) concentrations. These guidelines are defined in Section A.2.

The toxic effects of these chemicals are addressed in Section A.2 and include poisoning that can affect the kidneys, cause damage to capillary membranes, result in destruction of lung tissue, effect the nervous system, cause respiratory irritation, and result in acid burns on the skin. The principle hazards of $\mathrm{H}_{2}$ are fire and explosions.

For an accidental release of hazardous material, the inventories and release rates of these materials must be estimated to model their dispersion in the atmosphere and to estimate potential health effects to the exposed individuals. The physical and chemical properties of a hazardous material that are used to calculate the source term for a given type of release are described in Section A.3. The physical and chemical properties include density, molecular weight, vapor pressure, boiling point, critical temperature, critical pressure, latent heat of vaporization, heat capacity, and diffusivity. Appendix B shows how these quantities are used in source term calculations. Special instructions for handling these hazardous chemicals of interest are described in Section A.4.

Section A.5 gives a process summary, an estimated hazardous material inventory, radioactive material possession limits, and a description of process hazards for various fuel cycle facilities: plants for $\mathrm{UF}_{6}$ conversion, light-water reactor fuel fabrication (including MOX), uranium enrichment (including atomic vapor laser isotope separation (AVLIS)), and enriched uranium downblending. 
For these fuel cycle facilities, process hazards include corrosion, damage, or rupture of a process vessel and subsequent release of hazardous material, nuclear criticalities, fires, and explosions.

In 1990, Congress included requirements for accidental release prevention regulations in Section 112(r) of the Clean Air Act. The accident prevention regulations were established to reduce the likelihood and severity of chemical releases that could harm the public and the environment. As mandated by Congress, OSHA issued a regulation [29 Code of Federal Regulations (CFR) 1910.119 entitled "Process Safety Management of Highly Hazardous Materials; Explosives and Blast Materials"] on February 24, 1992, covering Process Safety Management (PSM) to protect workers from workplace effects of chemical accidents. The Clean Air Act also required the EPA to develop a list of at least 100 substances that, in the event of an accidental release, could cause death, injury, or serious adverse effects to human health. The list includes 77 toxic substances and 63 flammable substances. In addition, EPA published its own Risk Management Program (RMP) rule, 40 CFR Part 68, on May 24, 1996.

\section{A.1 Threshold Planning Quantities}

The Emergency Planning and Community Right-to-Know Act of 1986 requires facilities that handle hazardous chemicals to develop and maintain an inventory of those chemicals and report annually the inventory to the local community. As a result of the Superfund Amendments and Reauthorization Act (SARA) Title III, EPA has issued a list of hazardous materials that must be included in the annual inventories required by the Emergency Planning and Community Right-to-Know Act. The list establishes threshold planning quantities for extremely hazardous substances. As currently codified in Appendix A of 40 CFR Part 355, titled "The List of Extremely Hazardous Substances and Their Threshold Planning Quantities," there are approximately 300 threshold planning quantities for non-radioactive hazardous materials. Facilities having inventories of these hazardous materials in excess of the threshold planning quantities are required to have an emergency management program. The potential risk from accidental releases of hazardous materials are reflected in the threshold planning quantities. Hazardous material inventories greater than the threshold planning quantities are assumed to have public health and safety impacts. However, EPA did not simply reissue the SARA Title III list when it developed its RMP regulations. As noted above, the RMP list, published in 59 FR 4478 (USEPA 1994), consists of 77 toxic substances and 63 flammable substances. The hazardous chemicals on the EPA's list that are of the most interest at fuel cycle facilities are shown in Table A-1, together with their threshold planning quantities.

OSHA has a similar list of threshold planning quantities (known as threshold quantities) solely for protecting worker health and safety. Appendix A of 29 CFR 1910.119, titled "List of Highly Hazardous Chemicals, Toxics, and Reactives (Mandatory)," contains a listing of toxic and reactive highly hazardous chemicals which present a potential for a catastrophic event at or above the threshold quantity. Table A-1 also lists the OSHA threshold planning quantities.

\section{A.2 Toxicological Data}

\section{A.2.1 Exposure Guidelines}

Guidelines have been issued by Federal, State, and industry organizations to protect workers and the public from the potential adverse health effects of hazardous chemical exposure. These exposure guidelines are based on available medical, biological, engineering, chemical, and trade data relevant to each hazardous substance. 
Table A-1. Threshold Planning Quantities for Hazardous Chemicals Used at Fuel Cycle Facilities

\begin{tabular}{lcc}
\hline Chemical (symbol) & $\begin{array}{c}\text { OSHA } \\
\text { threshold planning } \\
\text { quantity,* } \\
\text { kg [lb] }\end{array}$ & $\begin{array}{c}\text { EPA } \\
\text { threshold planning } \\
\text { quantity,** } \\
\text { kg [lb] }\end{array}$ \\
\hline Ammonia $\left(\mathrm{NH}_{3}\right)$ & $4500[10000]$ & $4500[10000]$ \\
Nitric acid $\left(\mathrm{HNO}_{3}\right)$ & - & $450[1000]$ \\
Hydrogen fluoride $(\mathrm{HF})$ & $450[1000]$ & $45[100]$ \\
Hydrogen $\left(\mathrm{H}_{2}\right)$ & -- & $4500[10000]$ \\
Uranium hexafluoride $\left(\mathrm{UF}_{6}\right)^{\wedge}$ & $2000[4400]$ & $200[440]$ \\
Fluorine $\left(\mathrm{F}_{2}\right)$ & $450[1000]$ & $230[500]$ \\
Hydrogen chloride $(\mathrm{HCl})$ & $2300[5000]$ & $230[500]$ \\
Hydrogen peroxide $\left(\mathrm{H}_{2} \mathrm{O}_{2}\right)$ & $3400[7500]$ & $450[1000]$ \\
\hline
\end{tabular}

* Source: Appendix A of 29 CFR 1910.119

** Source: 59 FR 4478 (USEPA 1994)

$\wedge \mathrm{UF}_{6}$ is not on the EPA and OSHA lists for threshold planning quantities. Estimated value is based on the mass of HF released following complete hydrolysis of $\mathrm{UF}_{6}: \mathrm{UF}_{6}+2 \mathrm{H}_{2} \mathrm{O} \rightarrow \mathrm{UO}_{2} \mathrm{~F}_{2}+4 \mathrm{HF}$.

The exposure guidelines have specific applications (e.g., workplace exposure limits, respirator selection, emergency response, etc.) Consequently, an understanding of the purpose and use of each exposure guideline is necessary. The four most common exposure guidelines are:

1. Emergency Response Planning Guidelines (ERPGs)

2. Permissible Exposure Limits (PELs)

3. Threshold Limit Values (TLVs)

4. Immediately Dangerous to Life and Health concentrations (IDLHs)

Table A-2 presents the exposure guidelines for hazardous chemicals of interest (excluding $\mathrm{UF}_{6}$ ) at NRCregulated fuel cycle facilities. In Table A-2, ERPG values, which are the most widely accepted, are presented first, followed in order by the other three exposure values listed above.

\section{A.2.1.1 Emergency Response Planning Guidelines}

The American Industrial Hygiene Association (AIHA 1990) has developed concentration ranges, known as ERPGs, for over seventy chemicals. The ERPGs are intended to provide estimates of concentration ranges where one might anticipate observing defined adverse health effects among the public as a consequence of exposure for three exposure levels. The three exposure levels are:

- ERPG-1: The maximum airborne concentration below which it is believed that nearly all individuals could be exposed for up to one hour without experiencing other than mild transient adverse health effects or perceiving a clearly defined, objectionable odor. 
Table A-2. Levels of Concern for Selected Chemicals

\begin{tabular}{|c|c|c|c|c|c|c|}
\hline \multirow[b]{2}{*}{ Chemical (symbol) } & \multicolumn{6}{|c|}{ Concentration (ppm), unless otherwise stated } \\
\hline & *ERPG-3 & *ERPG-2 & *ERPG-1 & $\begin{array}{c}* * \text { Permissible } \\
\text { exposure } \\
\text { limits }\end{array}$ & $\begin{array}{c}\text { "Threshold } \\
\text { limit } \\
\text { value } \\
\end{array}$ & $\begin{array}{l}\text { ^Immediately } \\
\text { dangerous to } \\
\text { life and health } \\
\text { concentration }\end{array}$ \\
\hline Ammonia $\left(\mathrm{NH}_{3}\right)$ & 1000 & 200 & 25 & 50 & 25 & 500 \\
\hline Nitric acid $\left(\mathrm{HNO}_{3}\right)$ & ^^_- & $\wedge \wedge$ & $\wedge \wedge$ & 2 & $\wedge \wedge_{--}$ & 100 \\
\hline Hydrogen fluoride (HF) & 50 & 20 & 5 & 3 & 3 & 30 \\
\hline Hydrogen $\left(\mathrm{H}_{2}\right)$ & $\wedge \wedge_{-}$ & $\wedge \wedge_{--}$ & $\wedge \wedge_{--}$ & $\wedge_{--}$ & $\wedge \wedge_{--}$ & $\wedge \wedge_{--}$ \\
\hline Fluorine $\left(\mathrm{F}_{2}\right)$ & $\wedge \wedge_{-}$ & $\wedge$ ^_- & $\wedge \wedge_{-}$ & 0.1 & 1 & 25 \\
\hline Hydrogen chloride ( $\mathrm{HCl})$ & 100 & 20 & 3 & 5 & 5 & 100 \\
\hline Hydrogen peroxide $\left(\mathrm{H}_{2} \mathrm{O}_{2}\right)$ & $\wedge_{-}$ & $\wedge \wedge_{--}$ & $\wedge_{\ldots}$ & 1 & 1 & 75 \\
\hline $\begin{array}{l}\text { Uranium hexafluoride } \\
\left.\text { (UF })_{6}\right)\end{array}$ & $30 \mathrm{mg} / \mathrm{m}^{3}$ & $15 \mathrm{mg} / \mathrm{m}^{3}$ & $5 \mathrm{mg} / \mathrm{m}^{3}$ & $0.05 \mathrm{mg}-\mathrm{U} / \mathrm{m}^{3}$ & $\begin{array}{c}0.2 \mathrm{mg}- \\
\mathrm{U} / \mathrm{m}^{3}\end{array}$ & $\wedge_{--}$ \\
\hline
\end{tabular}

* ERPG = Emergency Response Planning Guidelines; Source: AIHA (1990)

** Source: 29 CFR 1910.1000

"Source: ACGIH (1992)

$\wedge$ Source: U.S. DHHS (1990)

$\wedge \wedge=$ No value has been established for this substance

- ERPG-2: The maximum airborne concentration below which it is believed that nearly all individuals could be exposed for up to one hour without experiencing or developing irreversible or other serious health effects or symptoms which could impair an individual's ability to take protective action.

- ERPG-3: The maximum airborne concentration below which it is believed that nearly all individuals could be exposed for up to one hour without experiencing or developing lifethreatening health effects.

The ERPG-2 level of concern has found favor among many Federal, State, and local agencies that are responsible for health and safety.

\section{A.2.1.2 Permissible Exposure Limits}

Acting under the authority of the Occupational Safety and Health Act of 1979, the National Institute for Occupational Safety and Health (NIOSH) develops and periodically revises recommended exposure limits for hazardous substances or conditions in the workplace. NIOSH also recommends appropriate preventive measures to reduce or eliminate adverse health and safety effects of these hazards. These

recommendations are forwarded to OSHA for use in promulgating legal standards, known as permissible exposure limits, for hazardous chemicals. 
The permissible exposure limits, which are codified in 29 CFR 1910.1000, are time-weighted average concentrations that must not be exceeded during any 8-hour work shift of a 40-hour work week. Permissible exposure limits are legally-enforceable standards of exposure for workers under routine conditions, but should not be used as emergency response guidelines.

\section{A.2.1.3 Threshold Limit Values}

The American Conference of Governmental Industrial Hygienists has published threshold limit values (ACGIH 1992). The threshold limit values represent the concentration and conditions for which nearly all workers may be repeatedly exposed to hazardous chemicals without adverse effects. The threshold limit values are eight-hour time weighted average concentrations and are not legally-enforceable. They should not be used as emergency response guidelines.

\section{A.2.1.4 Immediately Dangerous to Life and Health Concentrations}

Immediately dangerous to life and health concentrations, issued by NIOSH (U.S. DHHS 1990), represent the maximum concentration from which, in the event of a respirator failure, one could tolerate a hazardous chemical exposure for 30 minutes without experiencing irreversible health effects. These values were determined only for the purpose of respirator selection and are not legally-enforceable.

\section{A.2.2 Uranium Hexafluoride, Hydrogen Fluoride, and Fluorine Toxicity}

When released to the atmosphere, $\mathrm{UF}_{6}$ reacts with moisture to form $\mathrm{HF}$ and uranyl fluoride $\left(\mathrm{UO}_{2} \mathrm{~F}_{2}\right)$ :

$$
\mathrm{UF}_{6(\mathrm{~g})}+2 \mathrm{H}_{2} \mathrm{O}-\mathrm{UO}_{2} \mathrm{~F}_{2}+4 \mathrm{HF}
$$

The $\mathrm{UO}_{2} \mathrm{~F}_{2}$ particulate, which is easily carried by wind, is very soluble. The corrosive properties of $\mathrm{UF}_{6}$ and $\mathrm{HF}$ are such that exposure can result in lung damage and skin burns. The reaction of $1 \mathrm{~kg}(2.2 \mathrm{lb})$ of $\mathrm{UF}_{6}$ combining with $0.1 \mathrm{~kg}(0.22 \mathrm{lb})$ of water, results in the formation of $0.88 \mathrm{~kg}(1.9 \mathrm{lb})$ of $\mathrm{UO}_{2} \mathrm{~F}_{2}$ (containing $0.68 \mathrm{~kg}(1.5 \mathrm{lb})$ of uranium) and $0.23 \mathrm{~kg}(0.5 \mathrm{lb})$ of $\mathrm{HF}$.

According to NUREG-1391 (USNRC 1991), the chemicals formed by the above reaction have three main toxic effects:

1. The uranyl ion, $\mathrm{UO}_{2}{ }^{+}$, acts as a heavy-metal poison that can affect the kidneys.

2. The $\mathrm{HF}$ can cause acid burns on the skin or lungs if concentrated.

3. The fluorides can cause fluoride poisoning if intakes are large.

\section{A.2.2.1 Uranium Hexafluoride Toxicity}

Activities involving $\mathrm{UF}_{6}$ are regulated by the NRC. The AIHA has established ERPGs for $\mathrm{UF}_{6}$ as follows:

- ERPG-1: $5 \mathrm{mg} / \mathrm{m}^{3}$

- ERPG-2: $15 \mathrm{mg} / \mathrm{m}^{3}$

- ERPG-3: $30 \mathrm{mg} / \mathrm{m}^{3}$ 
In moist air, $\mathrm{UF}_{6}$ hydrolyzes into $\mathrm{HF}$ and $\mathrm{UO}_{2} \mathrm{~F}_{2}{ }^{1}$ Based on actual events and laboratory experiments, the health effects of $\mathrm{UF}_{6}$ exposure are generally understood. Data have shown that damage to the kidneys is the most important toxic effect of uranium. High doses of uranium also affect the blood and may damage the capillary membranes. Uranium's effects on the nervous system are similar to those from poisoning by other heavy metals.

Comprehensive evaluations of the chemical toxicity of UF 6 exposures were reported in NUREG-1391 and NUREG/CR-5566 (USNRC 1990). NUREG-1391 compared the early chemical effects from acute exposures to $\mathrm{UF}_{6}$ with the effects from acute radiation doses of 25 rems to the whole body and 300 rems to the thyroid. The reader is encouraged to review NUREG-1391 for further details. The health effects presented in NUREG-1391 from the intake of soluble uranium are reproduced in Table A-3.

Table A-3. Health Effects From Soluble Uranium Intake

\begin{tabular}{lccc}
\hline & $\begin{array}{c}\text { Uranium intake } \\
\text { per kg body } \\
\text { weight } \\
\text { (mg-U/kg) }\end{array}$ & $\begin{array}{c}\text { Uranium } \\
\text { in 70-kg } \\
\text { person } \\
\text { (mg) }\end{array}$ & $\begin{array}{c}\text { Uranium } \\
\text { inhaled by } \\
\text { 70-kg person } \\
\text { (mg) }\end{array}$ \\
\hline Health effect & 1.63 & 114 & 230 \\
50 percent lethality & 0.3 & 21 & 40 \\
$\begin{array}{l}\text { Threshold for permanent } \\
\text { renal damage }\end{array}$ & 0.058 & 4.06 & 8.3 \\
$\begin{array}{l}\text { Threshold for transient renal } \\
\text { injury or effect }\end{array}$ & 0.03 & 2.1 & 4.3 \\
No effect & & & \\
\hline
\end{tabular}

Source: NUREG-1391 (USNRC 1991)

In evaluating the potential health risks from a $\mathrm{UF}_{6}$ release, it is important to consider a worst-case accident, such as the rupture of a $U_{6}$ cylinder. The release of $U_{6}$ from a cylinder is possible because $U_{6} F_{6}$ is volatile above room temperature. As reported in NUREG-1140 (USNRC 1988), the rupture of a heated Model 48 cylinder would cause the largest release of $\mathrm{UF}_{6}$. Based upon cylinder specifications, this event was assumed to release $9500 \mathrm{~kg}(20900 \mathrm{lb})$ of $\mathrm{UF}_{6}$ and $4800 \mathrm{~kg}(10600 \mathrm{lb})$ of natural uranium (in the form of $\mathrm{UO}_{2} \mathrm{~F}_{2}$ ), as a result of hydrolysis.

\section{A.2.2.2 Hydrogen Fluoride Toxicity}

The health and safety consequences of HF releases have recently received great attention because of wellpublicized accidents, such as the event in Texas City, Texas, in 1987 (USEPA 1993 and Ryan 1988), in

For acute exposures to soluble uranium, short-term radiotoxicity would be negligible compared with chemical toxicity, even at 97.5 percent U-235 and 1.14 percent $U-234$ enrichment. Very high exposure conditions are necessary for injury and lethality due to HF gas released when UF, is hydrolyzed. 
which a crane severed a line from an $\mathrm{HF}$ storage vessel. $\mathrm{HF}$ will react with water or steam to produce toxic and corrosive fumes.

Moderate exposures to $\mathrm{HF}$ in air can cause smarting of the skin, respiratory irritation, and pronounced taste. Massive exposures to $\mathrm{HF}$ can cause progressive destruction of lung tissue which can be fatal. Existing exposure guideline concentrations for HF are shown in Table A-2.

The volatility of HF means that the contents of a vessel or process can be released very rapidly, which makes it necessary to calculate concentration limits for exposures less than one hour. Haber's law is one possible way of extrapolating such exposure times:

$$
\mathrm{C} \mathrm{x} \mathrm{t}=\text { constant }
$$

where $\mathrm{C}$ is the ambient airborne concentration in ppm that will produce a given health effect corresponding to exposure time $t_{c}$ in minutes (USEPA, FEMA, and DOT 1987).

For example, using the ERPG-2 value of $20 \mathrm{ppm}$ for $\mathrm{C}$ and 60 minutes for $\mathrm{t}_{\mathrm{c}}$ as a baseline, the Haber's constant is $1200 \mathrm{ppm}$-minute. Applying this constant to exposure times less than one hour results in the time-averaged $\mathrm{HF}$ toxicity values shown in Table A-4.

Table A-4. Time-Averaged HF Toxicity Values Corresponding to the ERPG-2 (Using Haber's Law)

\begin{tabular}{cc}
\hline $\begin{array}{c}\text { Time } \\
\text { (minutes) }\end{array}$ & $\begin{array}{c}\text { Concentration } \\
\text { (ppm) }\end{array}$ \\
\hline 120 & 10 \\
60 & $20^{*}$ \\
30 & 40 \\
20 & 60 \\
10 & 120 \\
5 & 240 \\
\hline
\end{tabular}

*Actual ERPG-2 value published by AIHA.

Haber's law for concentrations appears to be followed by HF toxicity data for rodents (Maher and Kaiser 1995). However, the reader should be aware that the extrapolation of concentrations to small exposure times using Haber's law remains controversial. The EPA's RMP, for example, requires the use of a constant value of the ERPG-2 (e.g., 20 ppm for HF), irrespective of the exposure time.

The probit equation is a different approach that reflects the observation that for some chemicals, the severity of harm increases in a non-linear fashion with concentration. Thus, allowable exposure times decrease more than proportionately with an increase in concentration. At concentrations higher than ERPG-2, there is the increasing possibility of fatality. This chance of fatality can be estimated by using the probit equation, which can be expressed as: 


$$
\left(\mathrm{LC}_{\mathrm{X}}\right)^{\mathrm{n}} \mathrm{t}_{\mathrm{e}}=\text { constant }
$$

where $\mathrm{LC}_{\mathrm{X}}$ is the concentration that is fatal to $\mathrm{X}$ percent of those exposed for time $t_{\mathrm{c}}$. For HF, $\mathrm{n}=1$, and the constant is 9.2 for the $\mathrm{LC}_{50}$ and 8.3 for the $\mathrm{LC}_{10}$ (AIChE 1989).

Probit equations can be used in quantitative risk assessments as input to calculations of individual and societal (population) risk.

\section{A.2.2.3 Fluorine Toxicity}

Fluorine is a skin irritant and is corrosive to all living tissue. It can induce coughing, difficulty in breathing, and abnormal fluid formation in the nose, mouth, and throat. Its effects on the eyes are similar to those of HF. Severe exposures to fluorine can cause extreme burning and destruction of the tissues or death (Sax and Lewis 1989).

Fluorine is a pale yellow to greenish gas with a pungent, irritating odor. It reacts violently with all combustible materials. Although fluorine is a nonflammable gas, it is an extremely strong oxidizer.

Presently, the NIOSH/OSHA recommended chronic or long-term exposure limit for fluorine is $0.1 \mathrm{ppm}$ $\left(0.2 \mathrm{mg} / \mathrm{m}^{3}\right)$. The acute or immediately dangerous to life and health concentration, applicable to respirator failure, is $25 \mathrm{ppm}$.

\section{A.3 Physical and Chemical Properties}

To properly estimate the downwind concentrations of hazardous material released from an accident, it is critical to accurately model the release source term. The physical and chemical properties of a hazardous material enable the modeler to calculate the source term from a particular type of release. In general, the following release types are of greatest interest:

- Evaporating liquid pools

- Jets (liquids and vapors)

- Instantaneous puff releases.

Typical property data include physical constants, such as latent heat of vaporization, flash point, molecular weight, density, boiling point, vapor pressure, critical temperature, and critical pressure. All of these properties are used in chemical process calculations and process safety analyses.

The main physical and chemical properties are explained below:

- Density: the mass per unit volume of a homogeneous material. The density of a gas will determine the extent of gravitational slumping, which is a phenomenon in which gases denser than air collapse in a direction perpendicular to plume travel or in all directions for a puff.

- Vapor pressure: the pressure exerted by a vapor in equilibrium with a liquid or a solid. For liquid spills where the boiling point of the liquid is above ambient, a pool will form and will slowly evaporate dependent upon vapor pressure, substrate type, and atmospheric conditions. As the pool spreads, it will absorb heat and evaporate, producing a vapor cloud. Vapor pressure is important for determining chemical volatility. 
- Normal boiling point: the temperature at which vapor pressure equals atmospheric pressure. The normal boiling point is important in calculating flash fractions caused by rapid depressurization.

- Critical temperature: the highest temperature at which liquid and vapor can coexist.

- Critical pressure: the highest pressure at which liquid and vapor can coexist.

- Latent heat of vaporization: the amount of heat required to convert one unit mass of liquid to vapor at constant pressure. A gas with a high latent heat of vaporization evolves a considerable amount of heat as it liquefies.

- Diffusivity: a measure of the rate at which substances mix, even though originally separate. According to Graham's law, at standard conditions of temperature and pressure, the average velocity of a gas is inversely proportional to the square root of its molecular weight. Diffusivity is important for calculating the liquid evaporation rates from pools.

The physical constant data for hazardous chemicals found at NRC-licensed fuel cycle facilities are tabulated in Table A-5.

\section{A.4 Special Instructions for Handling Hazardous Chemicals}

According to the material safety data sheets from the Chemical Manufacturer's Association (1994), the following special handling instructions should be followed for the hazardous chemicals of interest at NRClicensed fuel cycle facilities:

- $\mathrm{NH}_{3}$ : Store tanks in cool, well-ventilated, fire resistant location, away from oxidizing agents, combustible materials, and sources of heat or ignition.

- $\mathrm{HNO}_{3}$ : Handle and store using equipment suitably designed for acid service. Keep container tightly closed. Store in a cool, dry place away from excessive heat. Reseal containers immediately after use.

- HF: Protect cylinders from physical damage. Store in cool, dry, well ventilated areas of nonflammable construction. Keep away from all flammable or other non-compatible materials. Containers may be hazardous when emptied.

- $\mathrm{H}_{2}$ : Use proper grounding procedure to avoid electrostatic charge accumulation.

- $\mathrm{F}_{2}$ : Protect cylinders from physical damage. Store in cool, dry, well ventilated areas of nonflammable construction. Keep away from all flammable or other non-compatible materials. Provide special training to workers handling fluorine. Use a check valve or trap in the discharge line to prevent hazardous back-flow into container.

- $\mathrm{HCl}$ : Keep away from water. Containers of this material may be hazardous when emptied because of product residues.

- $\mathrm{H}_{2} \mathrm{O}_{2}$ : Provide general and local exhaust ventilation as necessary.

The packaging and transportation of radioactive materials are regulated by several organizations, including the U.S. Department of Energy (DOE), U.S. Department of Transportation (DOT), NRC, U.S. Postal Service, and state and local governments. $\mathrm{UF}_{6}$ cylinders are designed, built, tested, and certified to meet DOT regulations (49 CFR Parts 171 through 178), NRC regulations (10 CFR Parts 50 and 71), and American National Standards Institute (ANSI) Standard N.14 ("Uranium Hexafluoride: Packaging for Transport"). 


\begin{tabular}{|c|c|c|c|c|c|c|c|c|c|c|}
\hline $\begin{array}{l}\text { Chemical } \\
\text { (symbol) }\end{array}$ & $\begin{array}{l}\text { Liquid } \\
\text { density } \\
\left(\mathrm{kg} / \mathrm{m}^{3}\right) \\
\end{array}$ & $\begin{array}{c}\text { Molecular } \\
\text { weight } \\
(\mathrm{kg} / \mathrm{kmol}) \\
\end{array}$ & $\begin{array}{c}\text { Normal } \\
\text { melting } \\
\text { point } \\
(\mathrm{K}) \\
\end{array}$ & $\begin{array}{c}\text { Latent } \\
\text { heat } \\
\text { of fusion } \\
\text { (J/kg) }\end{array}$ & $\begin{array}{c}\text { Normal } \\
\text { boiling } \\
\text { point } \\
(\mathrm{K}) \\
\end{array}$ & $\begin{array}{c}\text { Latent } \\
\text { heat of } \\
\text { vaporization } \\
(\mathrm{J} / \mathrm{kg})\end{array}$ & $\begin{array}{l}\text { Liquid } \\
\text { heat } \\
\text { capacity } \\
\text { (J/kg-K) }\end{array}$ & $\begin{array}{c}\text { Ideal gas } \\
\text { heat capacity } \\
(\mathrm{J} / \mathrm{kg}-\mathrm{K})\end{array}$ & $\begin{array}{c}\text { Vapor } \\
\text { pressure }^{b} \\
(\mathrm{~Pa})\end{array}$ & $\begin{array}{c}\text { Diffusivity } \\
\left(\mathrm{m}^{2} / \mathrm{s}\right)\end{array}$ \\
\hline $\begin{array}{l}\text { Ammonia } \\
\left(\mathrm{NH}_{3}\right)\end{array}$ & $6.816 \times 10^{2}$ & 17.030 & 195.41 & $3.322 \times 10^{5}$ & 239.72 & $1.355 \times 10^{6}$ & $4.632 \times 10^{3}$ & $2.066 \times 10^{3}$ & $5.124 \times 10^{5}$ & $1.780 \times 10^{-5}$ \\
\hline $\begin{array}{l}\text { Nitric acid } \\
\left(\mathrm{HNO}_{3}\right)\end{array}$ & $1.540 \times 10^{3}$ & 63.013 & 231.55 & $1.662 \times 10^{5}$ & 356.15 & $6.594 \times 10^{5}$ & $1.754 \times 10^{3}$ & $8.189 \times 10^{2}$ & $2.599 \times 10^{3}$ & $9.533 \times 10^{-6}$ \\
\hline $\begin{array}{l}\text { Hydrogen } \\
\text { fluoride } \\
\text { (HF) }\end{array}$ & $9.880 \times 10^{2}$ & 20.006 & 189.58 & $2.290 \times 10^{5}$ & 292.67 & $9.33 \times 10^{5}$ & $2.447 \times 10^{3}$ & $1.457 \times 10^{3}$ & $5.835 \times 10^{4}$ & $1.294 \times 10^{-5}$ \\
\hline $\begin{array}{l}\text { Hydrogen } \\
\left(\mathrm{H}_{2}\right)\end{array}$ & $7.09 \times 10^{1}$ & 2.016 & 13.95 & $5.811 \times 10^{4}$ & 20.38 & $4.52 \times 10^{5}$ & ${ }^{c} 1.879 \times 10^{4}$ & ${ }^{c} 1.446 \times 10^{4}$ & $\ldots-^{d}$ & $6.670 \times 10^{-5}$ \\
\hline $\begin{array}{l}\text { Uranium } \\
\text { hexafluoride } \\
\left(\mathrm{UF}_{6}\right)\end{array}$ & $3.67 \times 10^{3}$ & 352.020 & $\ldots{ }^{d}$ & $5.458 \times 10^{4}$ & -..-d & $8.375 \times 10^{4}$ & $5.633 \times 10^{2}$ & $3.694 \times 10^{2}$ & $3.447 \times 10^{3}$ & $7.9 \times 10^{-6}$ \\
\hline $\begin{array}{l}\text { Fluorine } \\
\left(\mathrm{F}_{2}\right)\end{array}$ & $1.510 \times 10^{3}$ & 37.997 & 50.15 & $-\cdots$ & 86.15 & ${ }^{c} 1.807 \times 10^{5}$ & $7.492 \times 10^{2}$ & $1.028 \times 10^{3}$ & $1.01 \times 10^{5}$ & $1.603 \times 10^{-5}$ \\
\hline $\begin{array}{l}\text { Hydrogen } \\
\text { chloride } \\
\text { (HCl) }\end{array}$ & $3.976 \times 10^{1}$ & 36.461 & 158.97 & $5.481 \times 10^{4}$ & 188.15 & $4.871 \times 10^{3}$ & $1.983 \times 10^{3}$ & $7.989 \times 10^{2}$ & $2.968 \times 10^{6}$ & $1.470 \times 10^{-5}$ \\
\hline $\begin{array}{l}\text { Hydrogen } \\
\text { peroxide } \\
\left(\mathrm{H}_{2} \mathrm{O}_{2}\right) \\
\end{array}$ & $1.112 \times 10^{0}$ & 34.020 & 271.15 & $3.101 \times 10^{5}$ & 424.55 & ${ }^{c} 1.264 \times 10^{6}$ & $2.635 \times 10^{3}$ & $1.45 \times 10^{3}$ & ${ }^{8} 6.665 \times 10^{2}$ & ${ }^{\mathrm{h}} 1.880 \times 10^{-5}$ \\
\hline \multicolumn{11}{|c|}{$\begin{array}{l}\text { a. At the normal boiling point } \\
\text { b. At } 278 \mathrm{~K} \\
\text { c. At critical temperature } \\
\text { d. }- \text { - }=\text { Property is inappropriate for this substance } \\
\text { e. At melting point } \\
\text { f. At } 300 \mathrm{~K} \\
\text { g. At } 303 \mathrm{~K} \\
\text { h. At } 333 \mathrm{~K} \\
\text { Source: Daubert and Danner (1985) }\end{array}$} \\
\hline
\end{tabular}


No special handling instructions for $\mathrm{UF}_{6}$ have been recommended by the Chemical Manufacturer's Association. According to the DOE (USDOE 1991), UF $_{6}$ should be handled as follows:

- Minimize movement of large cylinders containing liquid $\mathrm{UF}_{6}$.

- Minimize movement of partially filled, heated cylinders because movement could result in surges of the dense liquid that can upset handling equipment and cause loss of control.

- A cylinder should not be shipped until its contents have completely solidified and the pressure in the cylinder is below atmospheric.

\section{A.5 Fuel Cycle Facilities}

The four types of fuel cycle facilities considered in this appendix are $\mathrm{UF}_{6}$ conversion plants, light-water-reactor fuel fabrication plants, enrichment plants, and plants for downblending highly enriched uranium (HEU). Sections A.5.1 through A.5.4 give a summary of the processes, estimate hazardous material and radiological material inventories, and describe the potential hazards of the processes at the fuel cycle facilities.

\section{A.5.1 UF 6 Conversion Plants}

Conversion plants convert uranium ore shipped from mills into $\mathrm{UF}_{6}$. The $\mathrm{UF}_{6}$ product, which has a uranium-235 concentration of $0.7 \mathrm{wt}$ percent, is produced in liquid form. The $\mathrm{UF}_{6}$ is pumped into Model 48 cylinders and placed into storage for several days until the contents solidify. Eventually, the cylinders of solid $\mathrm{UF}_{6}$ are shipped to enrichment plants, where the uranium-235 concentration is further enriched.

Uranium ore concentrates, received from uranium mills, are sampled, pre-treated, calcined, blended, and crushed to a suitable size for conversion to $\mathrm{UO}_{2}$ powder, which is converted chemically to $\mathrm{UF}_{6}$. Typical production of $\mathrm{UF}_{6}$ by a "dry conversion process" is illustrated in Figure A-1.

The uranium ore concentrates are sampled using an auger mechanism, then repackaged, weighed, and stored until accountability and impurity analyses have been completed. Some ore components contain undesirable contaminants, primarily sodium and potassium, which must be minimized before the concentrates are converted into $\mathrm{UO}_{2}$. Typically, a one-stage sulfuric acid $\left(\mathrm{H}_{2} \mathrm{SO}_{4}\right)$ leach followed by $\mathrm{NH}_{3}$ precipitation is performed as pretreatment. After precipitation, uranium bearing solids are settled, filtered, and calcined. Following calcination, the ore concentrates are blended, agglomerated, dried, crushed, and sized to a uniform particle size.

\section{A.5.1.1 Process Summary}

The primary steps in the conversion of uranium ore to $\mathrm{UF}_{6}$ are:

1. Reduction

2. Hydrofluorination

3. Fluorination

4. Distillation and product packaging

5. Off-gas cleanup

6. Uranium recovery 


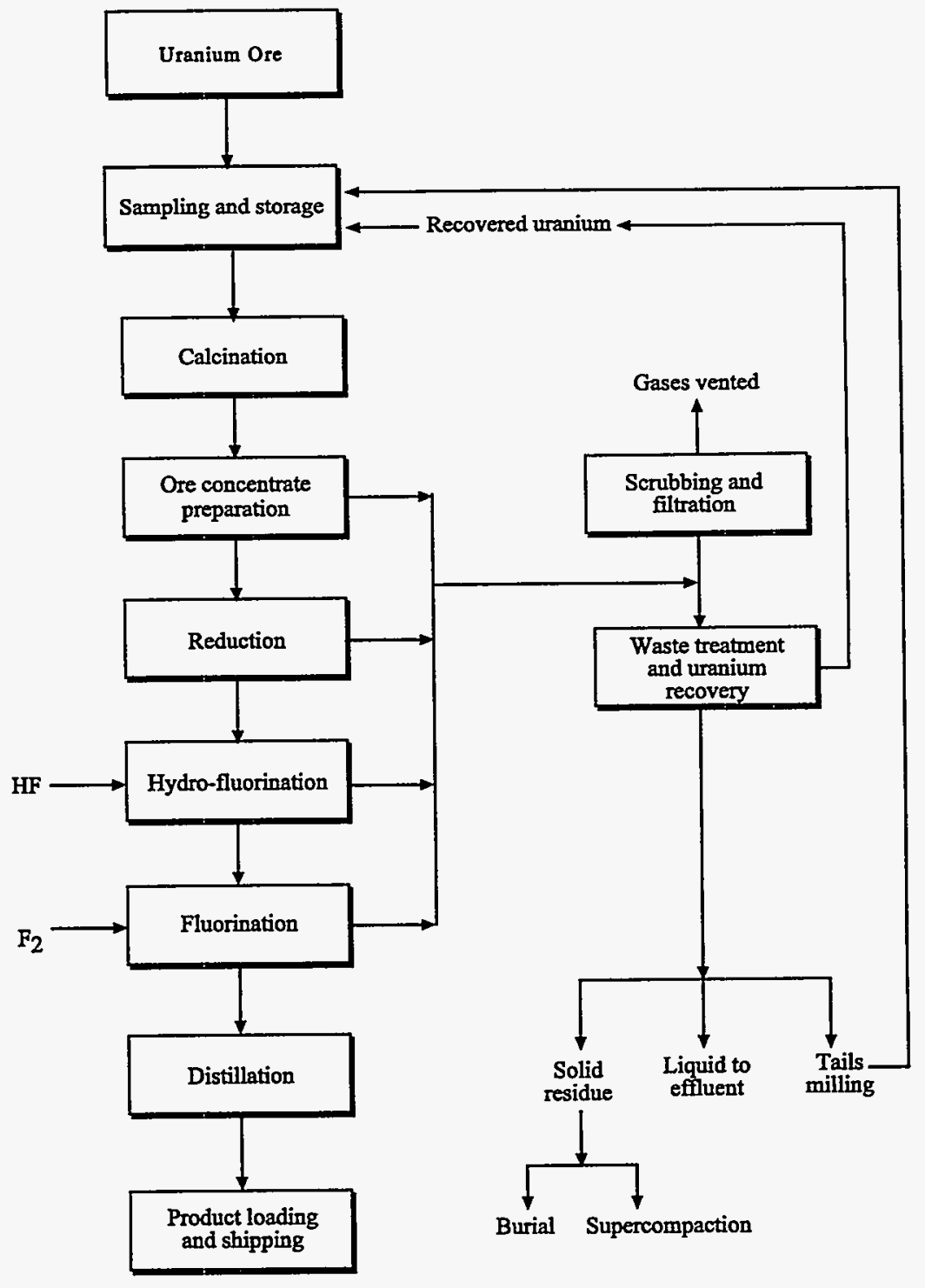

20000

Figure A-1. Basic steps in a typical UF 6 dry conversion process 


\section{Reduction}

Sized uranium concentrates are reduced to $\mathrm{UO}_{2}$ in fluidized-bed reactors utilizing $\mathrm{H}_{2}$ and $\mathrm{N}_{2}$ from dissociated $\mathrm{NH}_{3}$ as a fluidizing gas. Steam is used to vaporize the $\mathrm{NH}_{3}$ fed to the dissociators which use high temperatures and a catalyst to break the $\mathrm{NH}_{3}$ into its elemental components. The reductor off-gas (principally nitrogen, water vapor, hydrogen, and hydrogen sulfide) is passed through filters to remove particulate uranium, and the residual gas is then incinerated to convert the hydrogen sulfide into sulfur dioxide and water. The chemical equation for the reduction process is:

$$
\mathrm{U}_{3} \mathrm{O}_{8}+2 \mathrm{H}_{2} \rightarrow 3 \mathrm{UO}_{2}+2 \mathrm{H}_{2} \mathrm{O}
$$

\section{Hydrofluorination}

The $\mathrm{UO}_{2}$ from the reductor is fed into fluidized-bed hydrofluorinators. A counter-current flow of anhydrous $\mathrm{HF}$ fluidizing gas converts the $\mathrm{UO}_{2}$ into uranium tetrafluoride $\left(\mathrm{UF}_{4}\right)$. $\mathrm{HF}$ is stored on site as a liquid. Through a system of vaporizers and heat exchangers, the HF is changed to a gaseous form and brought to the proper reaction temperature before being introduced into fluidized-bed reactors. The chemical equation for hydrofluorination is:

$$
\mathrm{UO}_{2}+4 \mathrm{HF} \rightarrow \mathrm{UF}_{4}+2 \mathrm{H}_{2} \mathrm{O}
$$

Off-gas is filtered to remove particulate uranium and scrubbed with water and potassium hydroxide (KOH) solution to remove $\mathrm{HF}$ before being vented to the atmosphere. The HF scrubber liquors are neutralized and treated to remove fluoride. This waste fluoride is subsequently converted into a recyclable synthetic calcium fluoride $\left(\mathrm{CaF}_{2}\right)$ product.

\section{Fluorination}

$\mathrm{UF}_{4}$ is fed into one of three available fluidized-bed fluorinators that also contain inert bed material. Elemental fluorine is used as the fluidizing gas to convert solid $\mathrm{UF}_{4}$ to gaseous $\mathrm{UF}_{6}$. Some residual uranium and non-volatile uranium daughter products remain in the bed material, which is recycled and reused until the buildup of contaminants prohibit further use. The bed material is then retired for radioactive decay and recovery of the uranium content. The volatilized gas containing $\mathrm{UF}_{6}$, excess fluorine, and $\mathrm{HF}$ is passed through a series of filters for particulate removal and cold traps for $\mathrm{UF}_{6}$ collection. The chemical equation for fluorination is:

$$
\mathrm{UF}_{4}+\mathrm{F}_{2} \rightarrow \mathrm{UF}_{6}
$$

\section{Distillation and Product Packaging}

$\mathrm{UF}_{6}$ must be liquefied in the cold trap and pumped or drained to a distillation column feed tank before being fed to the distillation column. Crude $\mathrm{UF}_{6}$ is fed into a low boiler distillation column. The UF 6 that has been stripped of low-boiling impurities is then fed into a high boiler distillation column where high boiling impurities are eliminated. The product, which exceeds purity requirements, is condensed and packaged into approved product cylinders. 


\section{Off-Gas Cleanup}

The bulk of the UFF ${ }_{6}$ is condensed in a series of primary cold traps which are operated at approximately $266 \mathrm{~K}\left(19^{\circ} \mathrm{F}\right)$. The secondary and tertiary traps operate at lower temperatures and remove essentially all of the remaining $\mathrm{UF}_{6}$. Crude $\mathrm{UF}_{6}$ is removed from the cold traps intermittently following liquefaction by heating, and then it is transferred to tanks to await purification by fractional distillation.

Uncondensed gas from the cold traps consisting of fluorine, air, and traces of $\mathrm{UF}_{6}$ is routed into scrubbers. There, contact with $\mathrm{KOH}$ solution removes fluorides and traces of uranium prior to release to the atmosphere. The scrubbing solutions are routed for regeneration of $\mathrm{KOH}$ which is subsequently reused in the process scrubbers. The chemical equation for the reaction of $\mathrm{UF}_{6}$ and $\mathrm{KOH}$ is:

$$
2 \mathrm{UF}_{6}+14 \mathrm{KOH} \rightarrow \mathrm{K}_{2} \mathrm{U}_{2} \mathrm{O}_{7}+12 \mathrm{KF}+7 \mathrm{H}_{2} \mathrm{O}
$$

Potassium diuranate $\left(\mathrm{K}_{2} \mathrm{U}_{2} \mathrm{O}_{7}\right)$, precipitated in the off-gas scrubbers, is settled from the $\mathrm{KOH}$ solution, washed to remove soluble fluorides, and recycled to the pre-treatment facility for potassium removal prior to re-entry into the main uranium process flow.

\section{Uranium Recovery}

Fluorinator filter fines, contaminated fluorinator bed material, miscellaneous recovered dust, and scrap materials may be processed through the plant uranium recovery process. These residues, which contain economically recoverable quantities of uranium, are recycled to a licensed uranium mill for recovery of the uranium.

The uranium recovery process treats liquids from plant operations which contain recoverable quantities of uranium. These liquids are primarily sodium carbonate solutions from which the uranium is precipitated using sodium hydroxide. The precipitated sodium diuranate is processed for sodium removal, and the liquids are filtered before final treatment.

Periodically, $\mathrm{UF}_{6}$ product cylinders must be washed and pressure tested to assure that there has been no significant degradation of design integrity. The cylinders are washed with sodium carbonate solution to recover uranium. The leach liquors are filtered, and the uranium bearing liquid is transferred to uranium recovery. The filter residue, which contains daughter products of uranium, principally thorium and protactinium, is stored on site and will be eventually disposed of at a licensed waste disposal facility.

\section{A.5.1.2 Hazardous Material Inventory}

\section{Chemical Inventory}

The primary chemicals associated with the conversion of uranium ore to $\mathrm{UF}_{6}$ include:

- $\mathrm{NH}_{3}$ : used to produce hydrogen for $\mathrm{U}_{3} \mathrm{O}_{8}$ reduction; also used as hydrogen supply in fluidized-bed reduction reactors

- $\mathrm{F}_{2}$ : used to convert $\mathrm{UF}_{4}$ to $\mathrm{UF}_{6}$

- $\mathrm{HF}$ : used to convert $\mathrm{UO}_{2}$ to $\mathrm{UF}_{4}$; also used to generate fluorine gas used in the fluorination system

- $\mathrm{KOH}$ : used to remove $\mathrm{HF}$ off-gas produced during hydrofluorination 
- $\mathrm{UF}_{6}:$ a product of uranium ore conversion process

- $\mathrm{H}_{2} \mathrm{SO}_{4}$ : used for the acid treatment of ores.

Typical inventories of each chemical are provided in Table A- 6 .

Table A-6. Typical Chemical Inventories at $\mathrm{UF}_{6}$ Conversion Plants

\begin{tabular}{lccl}
\hline Chemical (symbol) & $\begin{array}{c}\text { Container size } \\
(\mathbf{k g})\end{array}$ & $\begin{array}{c}\text { Site inventory } \\
(\mathbf{k g})\end{array}$ & \multicolumn{1}{c}{$\begin{array}{c}\text { Storage } \\
\text { conditions }\end{array}$} \\
\hline Ammonia $\left(\mathrm{NH}_{3}\right)$ & 26000 & 60000 & Tank farm \\
Fluorine $\left(\mathrm{F}_{2}\right)$ & $20^{*}$ & $20^{*}$ & Not stored on site \\
Hydrogen fluoride $(\mathrm{HF})$ & 55000 & 190000 & Tank farm \\
Potassium hydroxide $(\mathrm{KOH})$ & 23000 & 47000 & Off-gas scrubbers \\
Uranium hexafluoride $\left(\mathrm{UF}_{6}\right)$ & 12000 & 2000000 & Model 48 cylinders \\
Sulfuric acid $\left(\mathrm{H}_{2} \mathrm{SO}_{4}\right)$ & 120000 & 120000 & Tanks \\
\hline
\end{tabular}

Source: Allied-Signal, Inc. (1990)

'Surge tank capacity

\section{Radiological Inventory}

The typical inventory of licensed source material is about 68 million $\mathrm{kg}$ ( 150 million $\mathrm{lb}$ ) in the form of natural uranium. From this feedstock, approximately 13000 metric tons (14000 tons) of $\mathrm{UF}_{6}$ are produced annually.

Significant quantities of $\mathrm{UF}_{6}$ can be found throughout the conversion process. A radiological inventory of those process vessels containing large amounts of $\mathrm{UF}_{6}$ are listed in Table A-7.

\section{A.5.1.3 Process Hazards}

As noted in Section A.5.1.1, uranium ore conversion plants convert uranium ore to $\mathrm{UF}_{6}$. The ore is fluorinated using HF. The primary chemical hazards at the conversion facilities are associated with the accumulation of $\mathrm{UF}_{6}, \mathrm{NH}_{3}, \mathrm{~F}_{2}, \mathrm{H}_{2}$, and $\mathrm{HF}$ and are listed below:

- Corrosion of storage equipment could cause leaks resulting in atmospheric releases. The hazards associated with the storage of these chemicals are similar to those described for light water reactor fuel fabrication plants in Section A.5.2.3.

- Potential acid burns to workers in the pre-treatment facility, hydrofluorination, fluorination, cold traps and off-gas cleanup, uranium recovery, and distillation and product packaging process areas are possible. 
Table A-7. Typical UF 6 Inventories in Process Vessels

\begin{tabular}{lc}
\hline Process vessel & Inventory (kg) \\
\hline$U_{6}$ vaporizer & 4500 \\
UF $_{6}$ cylinder fill & 12000 \\
Fluorinator & 9 \\
Condenser & 90 \\
Fluorination filter & 23 \\
Still feed tank & 27000 \\
Cold trap & 20000 \\
\hline
\end{tabular}

Source: Allied Signal, Inc. (1990)

- Physical stress and pinch points while handling drums in the sampling and storage area and during ore concentrates preparation are possible. This could cause releases of the drums' contents.

- Adverse impact on workers from process stack emissions in the sampling and storage, ore concentrates preparation, hydrofluorination, and fluorination process areas is possible.

- The ore reduction process consumes $\mathrm{H}_{2}$, which is flammable and could cause fires or explosions.

- The fluorination process consumes fluorine, which is an extremely strong oxidizing agent. Fluorine is corrosive to equipment and causes skin burns upon contact. Contact of $F_{2}$ or $U_{6}$ with oil can initiate an uncontrolled chemical reaction. Fluorine leaks from process equipment may produce a significant safety hazard.

- Heating of cold traps containing excessive amounts of $\mathrm{UF}_{6}$ could produce overpressurization.

- Heating of vessels and cylinders containing excessive amounts of $\mathrm{UF}_{6}$ in the distillation and product packaging areas could cause overpressurization. There is an increased potential for $\mathrm{UF}_{6}$ releases because the $\mathrm{UF}_{6}$ in the distillation and product packaging areas is processed as a liquid and a gas under pressure.

Potential sources of radiological exposure and contamination include $\mathrm{UO}_{2}, \mathrm{UF}_{4}$, and $\mathrm{UF}_{6}$. Although uranium is handled in many different chemical forms, $\mathrm{UF}_{6}$ is the only chemical form that is readily dispersible. Consequently, an airborne release of $\mathrm{UF}_{6}$ is the only credible radiological event which might have offsite impacts. In the liquid and gaseous forms, $U_{6}$ is the most dispersible radioactive material in the conversion facilities. It is present as vapor in the fluorination fluidized bed, exit stream, and as a liquid in the distillation and product loading operations. Large amounts of $\mathrm{UF}_{6}$ are stored as solids in the Model 48 cylinders used to store natural uranium.

\section{A.5.2 Plants for Fabrication of Fuel for Light-Water-Reactors}

Fuel fabrication plants primarily manufacture $\mathrm{UO}_{2}$ fuel assemblies for light-water-reactors. These plants receive $\mathrm{UF}_{6}$ enriched in uranium-235 and convert it to $\mathrm{UO}_{2}$ powder. The $\mathrm{UO}_{2}$ powder is formed into fuel 
pellets and loaded into metal-clad fuel rods. The fuel rods are bundled into element assemblies and then shipped to light-water-reactors. In most cases, the $\mathrm{UF}_{6}$ is enriched to less than $5 \mathrm{wt}$ percent uranium-235. In plants fabricating MOX fuels for light-water-reactors, $\mathrm{PuO}_{2}$, and $\mathrm{UO}_{2}$ are mixed, formed into pellets, loaded into rods, and assembled into elements. The steps in fabricating $\mathrm{UO}_{2}$ and $\mathrm{MOX}$ light-water-reactor fuel are illustrated in Figures A-2 and A-3, respectively. The $\mathrm{UO}_{2}$ and $\mathrm{MOX}$ plants differ in that $\mathrm{PuO}_{2}$ powder requires greater confinement than $\mathrm{UO}_{2}$ powder (Brite 1973). The fuel rods and assemblies can be designed to the same standards and geometry resulting in similar process steps following blending of the $\mathrm{UO}_{2}$ and $\mathrm{PuO}_{2}$ powders (Buckner and Parks 1992). The following sections describe the chemical conversion steps for preparation of $\mathrm{UO}_{2}$ and $\mathrm{PuO}_{2}$ powders and the physical and mechanical operations involved in the pellet formation, rod loading, and bundle assembly steps representative of both $\mathrm{UO}_{2}$ and MOX fuel fabrication.

\section{A.5.2.1 Process Summary}

The primary steps in the manufacture of light-water-reactor fuel assemblies are:

1. Chemical conversion and powder preparation

2. Pellet preparation

3. Rod fabrication

4. Element assembly

5. Scrap recovery.

The $\mathrm{UO}_{2}$ and mixed oxides processes start with the receipt of $\mathrm{UF}_{6}$ feed-stock, which is shipped in solid form in Model 30 cylinders used to store enriched uranium. The cylinders, which are made of American Society of Testing and Materials (ASTM)-A-516 stainless steel, contain a maximum of $2277 \mathrm{~kg}(5020 \mathrm{lb})$ of $\mathrm{UF}_{6}$. The $\mathrm{UF}_{6}$ cylinders are removed from their protected overpacks, inspected, weighed, and then placed in temporary storage until needed for production. The MOX process also involves receipt of feedstock $\mathrm{Pu}$ in metallic, oxide or solution forms.

\section{Chemical Conversion and Preparation of $\mathrm{UO}_{2}$ Powder}

$\mathrm{UF}_{6}$ is chemically converted to $\mathrm{UO}_{2}$ by one of two processes:

1. Wet conversion

2. Dry conversion

\section{Wet Conversion}

In the wet conversion process, gaseous $\mathrm{UF}_{6}$ is contacted with water to form $\mathrm{UO}_{2} \mathrm{~F}_{2}$, which is then reacted with ammonium hydroxide $\left(\mathrm{NH}_{4} \mathrm{OH}\right)$ to produce ammonium diuranate (ADU) crystals. These ADU crystals are centrifuged and dried to remove liquids and then calcined to convert the $\mathrm{ADU}$ solids to $\mathrm{UO}_{2}$ powder. The ADU conversion process, which is illustrated in Figure A-4, is governed by the following reactions:

$$
\begin{gathered}
\mathrm{UF}_{6(\mathrm{~g})}+2 \mathrm{H}_{2} \mathrm{O} \rightarrow \mathrm{UO}_{2} \mathrm{~F}_{2}+4 \mathrm{HF} \\
2 \mathrm{UO}_{2} \mathrm{~F}_{2}+6 \mathrm{NH}_{4} \mathrm{OH} \rightarrow\left(\mathrm{NH}_{4}\right)_{2} \mathrm{U}_{2} \mathrm{O}_{7}+4 \mathrm{NH}_{4} \mathrm{~F}+3 \mathrm{H}_{2} \mathrm{O}
\end{gathered}
$$




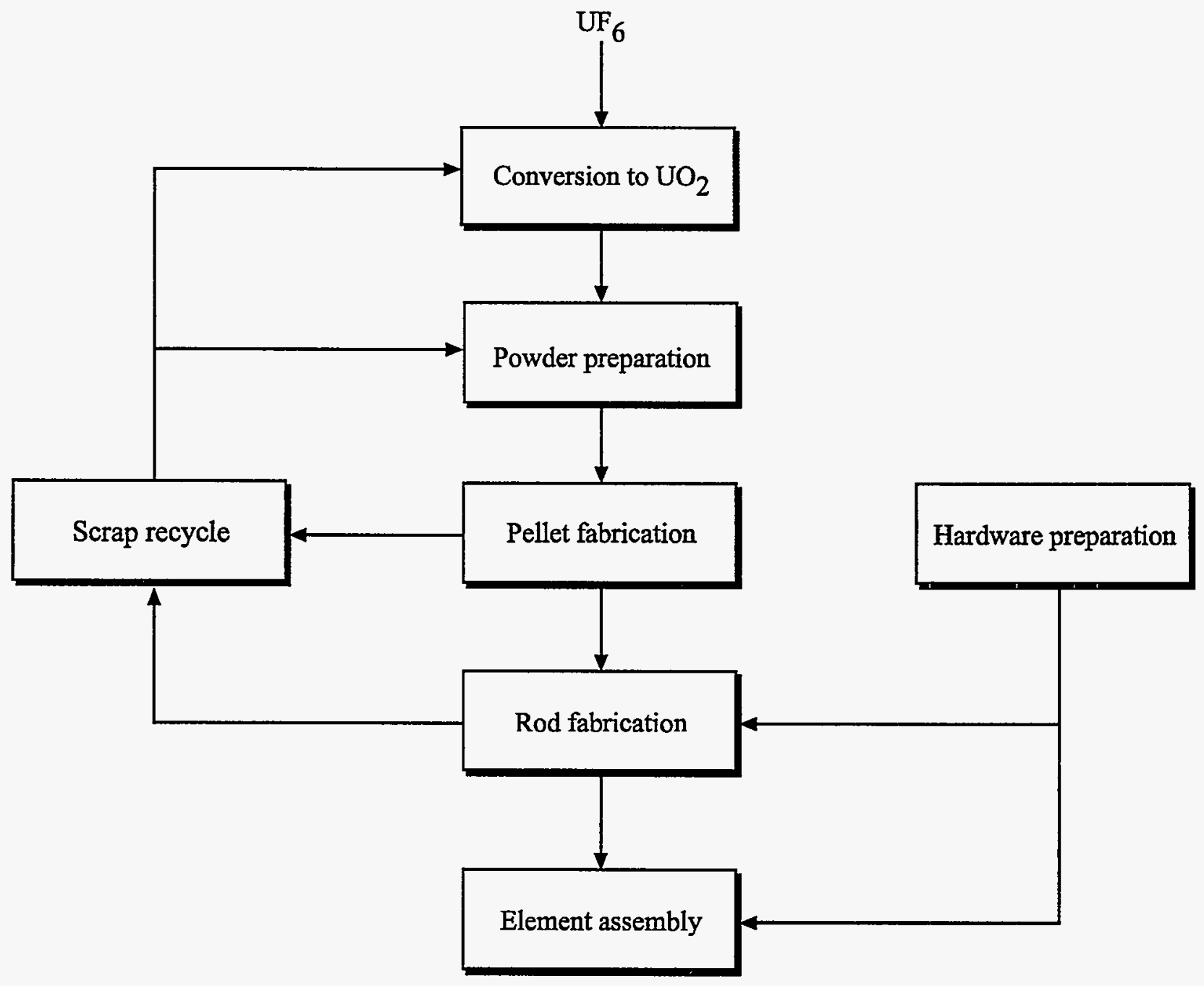

Figure A-2. Basic steps in light-water-reactor $\mathrm{UO}_{2}$ fuel fabrication 


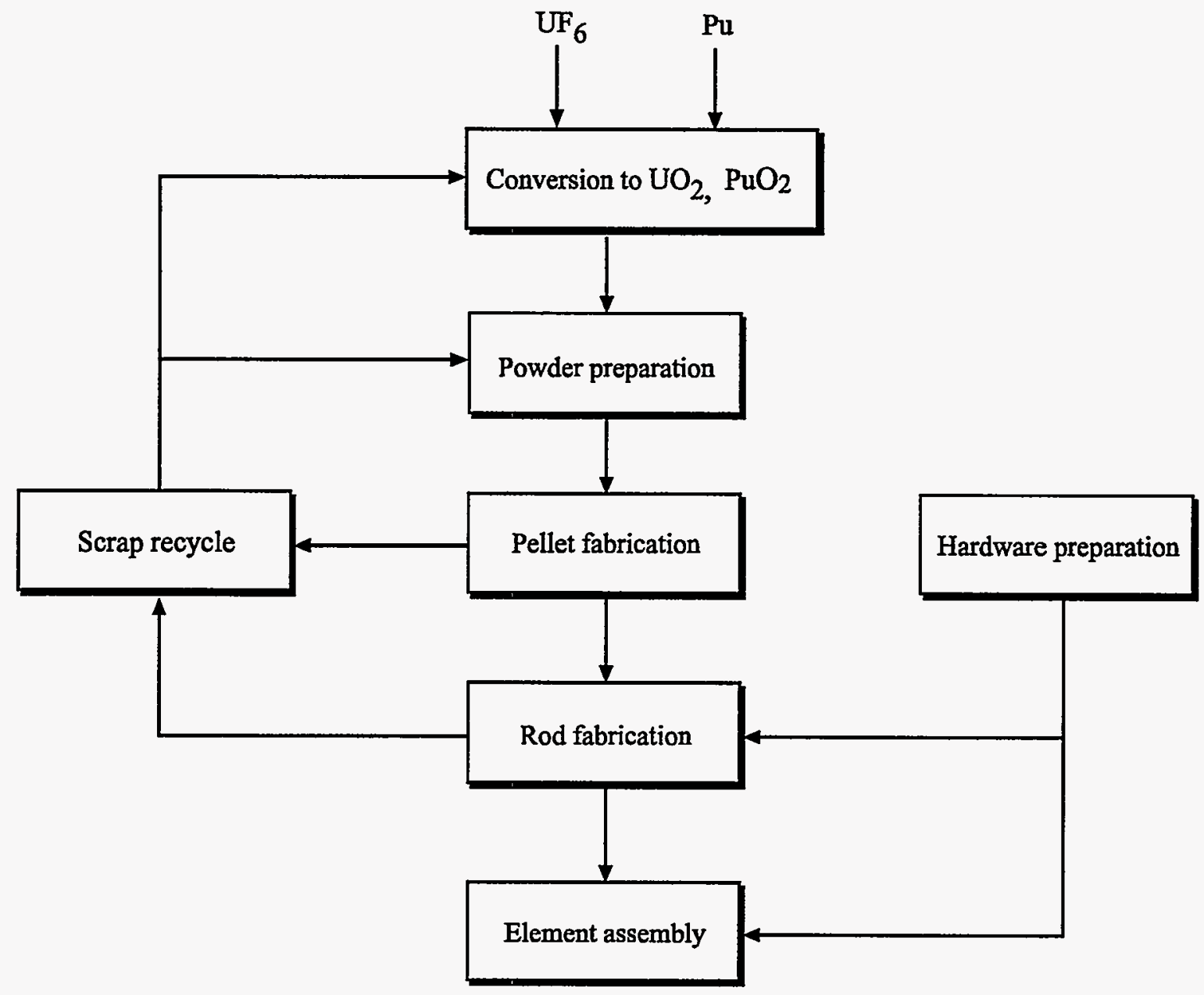

Figure A-3. Basic steps in light-water-reactor MOX fuel fabrication

$2880-2$ 


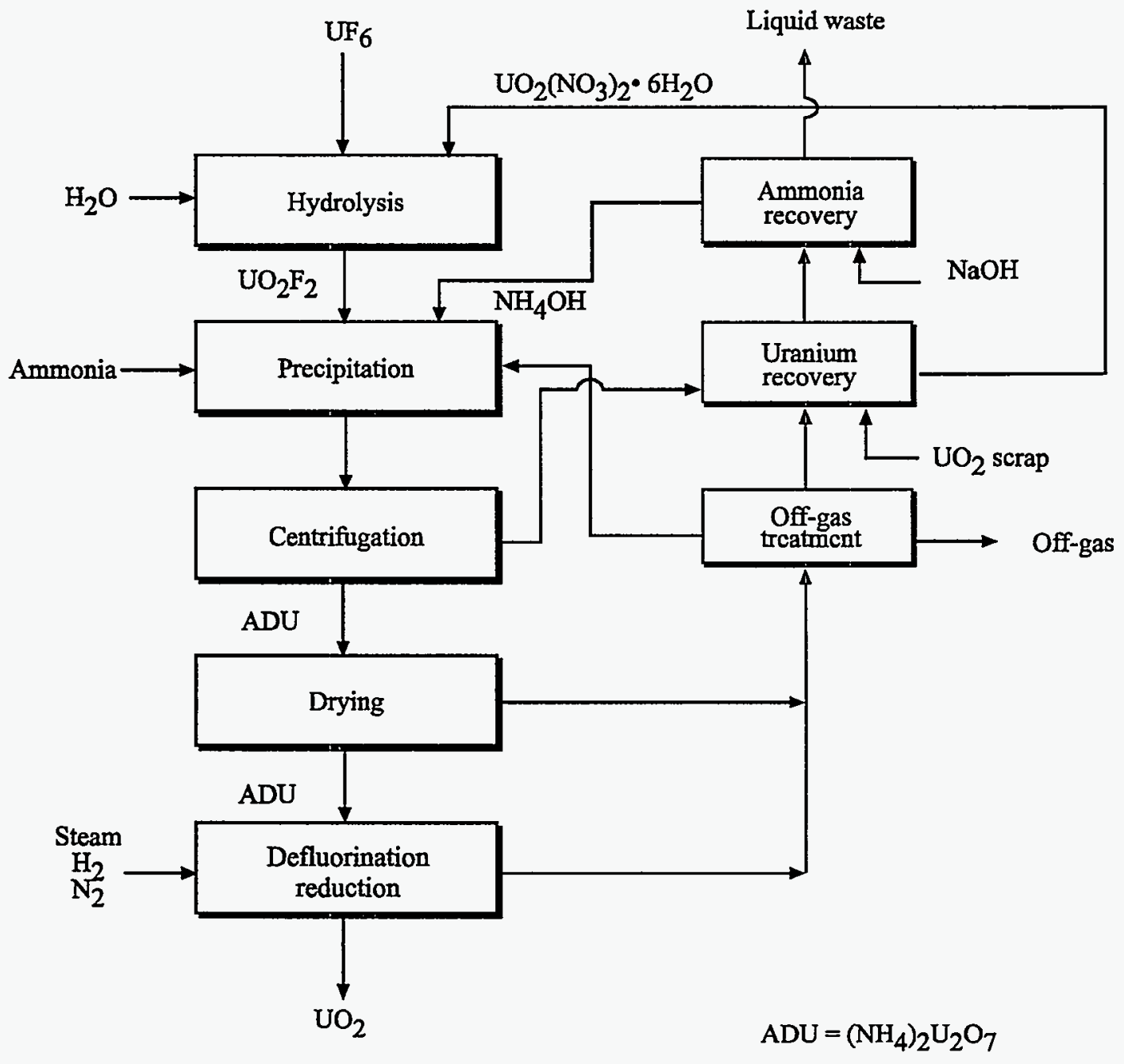

Figure A-4. Schematic $\mathrm{UO}_{2}$ fuel fabrication plant processing diagram for a wet ammonium diuranate (ADU) conversion process 
When needed for processing, individual $\mathrm{UF}_{6}$ cylinders are weighed and then transferred to a processing building where the valve seal is removed and the cylinder is connected to a delivery system. The $\mathrm{UF}_{6}$ solid is vaporized in a heated chamber, and the gas is valved to the delivery system. The ADU is transferred as a slurry to a drier, typically a centrifuge, to separate liquid from solids. The separated solids are further dried to produce ADU crystals. The dry ADU is fed to a calcination-defluorination-reduction furnace in which ADU decomposes to $\mathrm{U}_{3} \mathrm{O}_{8}$ which is reduced to $\mathrm{UO}_{2}$ in the nitrogen-hydrogen steam atmosphere of the furnace.

$$
\begin{gathered}
\text { Calcination: } 9\left(\mathrm{NH}_{4}\right)_{2}\left(\mathrm{U}_{2} \mathrm{O}_{7}\right) \rightarrow 2 \mathrm{~N}_{2}+14 \mathrm{NH}_{3}+6 \mathrm{U}_{3} \mathrm{O}_{8}+15 \mathrm{H}_{2} \mathrm{O} \\
\text { Reduction: } \mathrm{U}_{3} \mathrm{O}_{8}+2 \mathrm{H}_{2}-3 \mathrm{UO}_{2}+2 \mathrm{H}_{2} \mathrm{O}
\end{gathered}
$$

Waste streams from the wet $\mathrm{ADU}$ conversion process include ammonium fluoride, ammonium nitrate, excess $\mathrm{NH}_{4} \mathrm{OH}$, and off-gas scrubber solutions. Off-gases from the reduction furnaces and the calciners are typically treated by scrubbers and driers. Gaseous effluents are passed through high efficiency particulate air filters before being discharged to the atmosphere. Uranium is recovered from the centrifuges and the off-gas treatment system and is then reprocessed. $\mathrm{NH}_{3}$ from the uranium recovery process is reprocessed as $\mathrm{NH}_{4} \mathrm{OH}$.

\section{Dry Conversion}

In the dry conversion process, vaporized $\mathrm{UF}_{6}$ is reacted directly with a hydrogen-nitrogen-steam mixture. The $\mathrm{UF}_{6}$ is hydrolyzed, defluorinated, and reduced to form uranium oxide powder. In an initial reaction step, $\mathrm{UF}_{6}$ is hydrolyzed to $\mathrm{UO}_{2} \mathrm{~F}_{2}$. In a second reaction step, $\mathrm{UO}_{2} \mathrm{~F}_{2}$ is defluorinated and reduced to $\mathrm{UO}_{2}$.

The dry conversion process, which is illustrated in Figure A-5, is governed by the following reactions:

$$
\begin{gathered}
\mathrm{UF}_{6(\mathrm{~g})}+2 \mathrm{H}_{2} \mathrm{O}_{(\mathrm{g})} \rightarrow \mathrm{UO}_{2} \mathrm{~F}_{2(\mathrm{~s})}+4 \mathrm{HF}_{(\mathrm{g})} \\
\mathrm{UO}_{2} \mathrm{~F}_{2(\mathrm{~s})}+\mathrm{H}_{2(\mathrm{~g})}-\mathrm{UO}_{2(\mathrm{~s})}+2 \mathrm{HF}_{(\mathrm{g})}
\end{gathered}
$$

Enriched $\mathrm{UF}_{6}$ can be processed by several dry conversion methods, including the Integrated Dry Route, Direct Conversion, and the General Electric Dry Conversion Process, to obtain $\mathrm{UO}_{2}$ powder. Although these dry conversion processes vary considerably with respect to details and design, they all react $\mathrm{UF}_{6}$, water vapor, hydrogen from dissociated (cracked) ammonia, and oxygen from air in reaction vessels to form uranium oxide powder. The precipitate is $\mathrm{UO}_{2}$ in the Integrated Dry Route and the Direct Conversion processes, and the precipitate is $\mathrm{UO}_{2} \mathrm{~F}_{2}$ in the General Electric Dry Conversion process.

The uranium powder is recovered using porous metal filters. In the Direct Conversion and General Electric Dry Conversion processes, the powder is converted to $\mathrm{UO}_{2}$ by calcination which removes the fluorine. In all three dry conversion methods, $\mathrm{U}_{3} \mathrm{O}_{8}$ is added to the $\mathrm{UO}_{2}$ powder prior to milling, compaction, and granulation.

Waste streams from the dry conversion processes include HF, nitrogen, steam, and off-gas scrubber solutions. Gas streams passing from the reaction vessels are filtered several times to remove solids. After condensation of the HF, the gas is recycled as much as possible for use as a processing material. Residual gas is passed over calcium carbonate $\left(\mathrm{CaCO}_{3}\right)$ to remove $\mathrm{HF}$ completely. Off gases are typically treated by scrubbers and driers. Gaseous effluents are passed through high efficiency particulate air filters before 


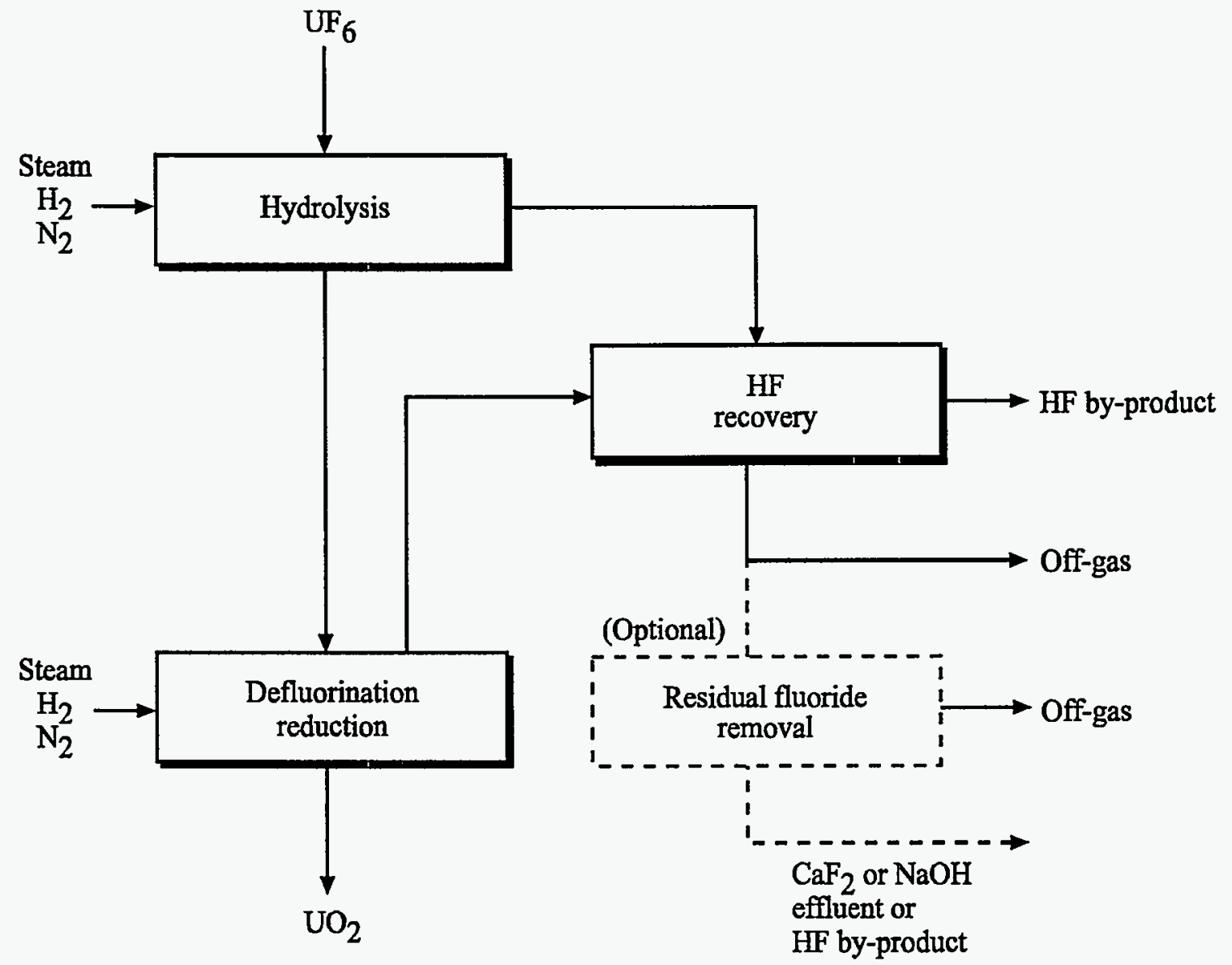

Figure A-5. Schematic $\mathrm{UO}_{2}$ fuel fabrication plant processing diagram for a dry conversion process 
being discharged to the atmosphere. Fluorine can be reused in the form of pure hydrofluoric acid, and the small quantities of $\mathrm{CaF}_{2}$ in the $\mathrm{CaCO}_{3}$ can be disposed of without further treatment. Uranium in the effluent streams is recovered by the centrifuges and the off-gas treatment system ( $\mathrm{VCH}$ Verlagsgesellschaft $\mathrm{mbH} 1996)$.

\section{Chemical Conversion and Preparation of MOX Powder}

Production of pellets for $\mathrm{MOX}$ fuel involves preparation of $\mathrm{UO}_{2}$ and $\mathrm{PuO}_{2}$ powders and blending of these powders into a homogeneous mixture. $\mathrm{UO}_{2}$ powder is prepared in either the wet or dry conversion processes described in the preceding paragraphs while $\mathrm{PuO}_{2}$ powder is prepared in the process represented in Figure A-6 (Buckner and Parks 1992 and USNRC 1976). The diagram shows metallic Pu as the primary feed stream but plutonium nitrate $\left[\mathrm{Pu}\left(\mathrm{NO}_{3}\right)_{4}\right]$ solution or $\mathrm{PuO}_{2}$ powder could enter the process at intermediate steps.

In the initial step in the $\mathrm{PuO}_{2}$ powder preparation process, metallic $\mathrm{Pu}$ is dissolved in nitric acid forming a solution containing $\mathrm{Pu}\left(\mathrm{NO}_{3}\right)_{4}$ and minor amounts of decay daughters and metallic impurities. The $\mathrm{Pu}$ then is separated from the impurities in a solvent extraction step in which $\mathrm{Pu}$ is transferred to an extractant phase comprising tributlyphosphate in an organic diluent. The decay daughters and metallic impurities remain in the aqueous phase and are treated as radioactive waste. The Pu is stripped from the organic phase using a nitric acid solution and recovered on an ion-exchange column. The concentrated $\mathrm{Pu}$ solution eluted from the ion-exchange column is then mixed with an oxalic acid $\left(\mathrm{H}_{2} \mathrm{C}_{2} \mathrm{O}_{4}\right)$ solution and the $\mathrm{Pu}$ is precipitated as plutonium oxalate $\left[\mathrm{Pu}\left(\mathrm{C}_{2} \mathrm{O}_{4}\right)_{2}\right]$. The precipitate is separated from the aqueous solution using filtration and the filtrate is transferred to the liquid waste treatment system. The moist Pu cake is dried and transferred to a calciner where the $\mathrm{Pu}\left(\mathrm{C}_{2} \mathrm{O}_{2}\right)_{2}$ is converted to $\mathrm{PuO}_{2}$. The resulting $\mathrm{PuO}_{2}$ powder is milled, screened, and blended with $\mathrm{UO}_{2}$ powder to prepare $\mathrm{MOX}$ material suitable for pellet fabrication.

\section{Pellet Fabrication}

In a $\mathrm{UO}_{2}$ fuel fabrication plant, $\mathrm{UO}_{2}$ powder is processed through a series of steps to enhance its sintering and pressing characteristics. To prepare the pellets, $\mathrm{UO}_{2}$ powder is transferred typically in drums or pails and offloaded into a blender. The material is then formed into pellets using mechanical rotary presses, sintered in molybdenum boats, and finished by centerless grinding to produce $\mathrm{UO}_{2}$ fuel pellets. Gadolinia $\left(\mathrm{Gd}_{2} \mathrm{O}_{3}\right)$, a non-radioactive nuclear poison (thermal neutron absorber), is typically blended with the $\mathrm{UO}_{2}$ powder to control the fuel burn-rate. As needed, recovered $\mathrm{U}_{3} \mathrm{O}_{8}$ powder is transferred to the pellet area where it is blended with the $\mathrm{UO}_{2}$ powder, gadolinium oxide powder, and binding agents, such as polyvinyl alcohols or zinc stearate. Following the blending step, the powder is transported to a feed hopper. The blended powder is then milled, compacted, granulated, and lubricated. The blended powder is then pressed into pellets. The pellets measure about $1.0 \mathrm{~cm}(0.4 \mathrm{in})$ in height by $1.25 \mathrm{~cm}(0.5 \mathrm{in})$ in diameter and weigh approximately 10 grams $(0.02 \mathrm{lb})$. Gadolinium scrap is recovered by solvent extraction.

The solvent mixture is comprised of four parts n-decane and one part tri-butyl phosphate (TBP). $\mathrm{N}$-decane, an aliphatic hydrocarbon, is a minor skin irritant in low concentrations and a narcotic in high concentrations. $\mathrm{N}$-decane should be stored and used in well-ventilated areas and kept away from sources of ignition and flammable materials. TBP is a hazardous chemical. If ignited, TBP will decompose into toxic, gaseous oxides of phosphorus oxide. TBP should be stored in sealed containers and be kept away from heat and flame. Protective clothing and safety goggles should be worn when splashing is expected. 


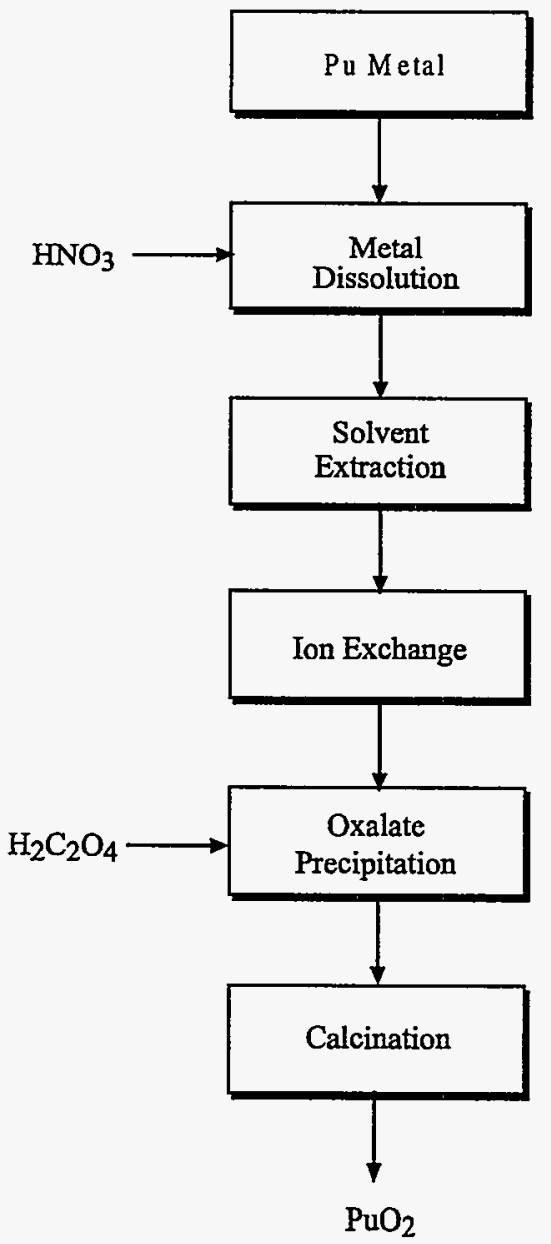

Figure A-6. Schematic MOX fuel fabrication plant process design for $\mathrm{PuO}_{2}$ powder preparation 
Following pelletizing, the pellets are sintered in high temperature furnaces. These operations are followed by grinding, pellet inspection, and storage. The grinders size the pellets to final diameter. The pellets are then washed to remove grinding dust, dried, and inspected for dimensions and flaws. Acceptable pellets are typically loaded onto trays, stacked, and weighed for storage.

A MOX fuel fabrication plant uses a sequence of pellet production steps similar to that of the $\mathrm{UO}_{2}$ fuel fabrication plant. Greater dependence on remote operations to manage the radiological hazards of Pu dust is distinguishing feature. Also, sintering of MOX pellets requires a reducing atmosphere [e.g., heliumhydrogen $\left.\left(\mathrm{He}-\mathrm{H}_{2}\right)\right]$ to achieve desired stoichiometry.

\section{Rod Fabrication}

In a $\mathrm{UO}_{2}$ fuel fabrication plant, the $\mathrm{UO}_{2}$ pellets are loaded into rods. Which are evacuated, injected with a helium atmosphere, and then welded. The cladding is typically an alloy of zirconium, chosen for its low neutron absorption cross-section and structural properties. After a check for contamination, the rods undergo a leak-check inspection.

Following loading, the final weld is made to the rod ends. Rods are removed from trays and individually $\mathrm{x}$-rayed. Following $\mathrm{x}$-raying, the fuel rods are transferred in trays to storage. The rods are removed from these trays and transferred for final rod inspection. The rods are subjected to a high-pressure, high temperature steam cycle, with both temperature and pressure being automatically controlled and monitored. Following final rod inspection, the rods are loaded in metal storage trays and moved to storage. During packaging, fuel assemblies are secured in inner shipping containers or strongboxes in vertical position. They are then lowered into a horizontal position inside the outer shipping container. Sealed, loaded, outer containers are then moved to the shipping and storage area to await delivery to a nuclear power plant. The typical light water reactor fuel rod is $4.0 \mathrm{~m}(13 \mathrm{ft})$ long.

The rod fabrication operations in a MOX fuel fabrication plant; rod loading, out-out-gassing, inert gas backfilling, and welding; are similar to those performed at $\mathrm{UO}_{2}$ fuel fabrication plant.

\section{Element Assembly}

In a $\mathrm{UO}_{2}$ fuel fabrication plant, fresh fuel consists of cylindrical pellets of slightly enriched ( 3 to 5 percent U-235) $\mathrm{UO}_{2}$ that are about $1 \mathrm{~cm}(0.4 \mathrm{in}$.) in diameter and about $1.25 \mathrm{~cm}(0.5 \mathrm{in}$.) Long. A zircaloy tube of wall thickness $0.6 \mathrm{~mm}(0.025 \mathrm{in}$.) is filled with pellets to an "active length" of $3.7 \mathrm{~m}(12 \mathrm{ft})$ and sealed to form a fuel rod (or pin). The metal tube serves to provide support for column of pellets, to provide cladding that retains radioactive fission products, and to protect the fuel from interaction with the coolant. About 50 to 290 fuel rods are grouped in a rectangular bundle called a fuel element about $20 \mathrm{~cm}(8 \mathrm{in}$.) On a side (Murray 1988). The bundles are the typical operational units for fuel handling and refueling. After a bundle is assembled, it is inspected, cleaned by washing (if warranted), and dried. A protective plastic sleeve is placed around each completed bundle, and then the bundle is moved to either hanging storage or to the packaging station.

A MOX fuel would be comprised of approximately 30 percent $\mathrm{PuO}_{2}$ and 70 percent $\mathrm{UO}_{2}$ with rods and assemblies of similar structure to those used with $\mathrm{UO}_{2}$ fuel (Buckner and Parks 1992). Thus element assembly operations are similar to those of the $\mathrm{UO}_{2}$ fuel fabrication plant described above. 


\section{Scrap Recovery}

Uranium, as compounds in various physical forms that do not meet quality standards or that have been mixed with foreign material, is reprocessed through the scrap recovery process. The process takes differing forms depending on the type and degree of contamination. Representative methods include:

\section{Method 1, Clean Scrap}

Grinding of fuel pellets and other process operations produce $\mathrm{UO}_{2}$ or $\mathrm{MOX}$ scrap material that does not require chemical purification and can be readily recycled to the fabrication process. Typical operations for this type of scrap include size reduction, air oxidation, $\mathrm{N}_{2}-\mathrm{H}_{2}$ reduction, and milling for final sizing. After these process steps, the material is suitable for recycling to the powder blending step of the fuel fabrication process.

\section{Method 2, Contaminated Scrap}

Material contaminated with corrosion products or other process chemicals requires chemical purification prior to recycling to the fuel fabrication process. The initial step for $\mathrm{UO}_{2}$ or $\mathrm{MOX}$ material is dissolution in $\mathrm{HNO}_{3}$ to produce nitrate solutions. A solvent extraction process is then used to transfer $\mathrm{UO}_{2}\left(\mathrm{NO}_{3}\right)_{2}$ or $\mathrm{UO}_{2}\left(\mathrm{NO}_{3}\right)_{2}$ and $\mathrm{Pu}\left(\mathrm{NO}_{3}\right)_{4}$ from the aqueous phase to an organic solvent phase. In the case of MOX fuel material, $\mathrm{Pu}$ is reduced to the +3 oxidation state and re-extracted to an aqueous acid phase while the $U$ is retained in the organic phase. The $\mathrm{Pu}$ is then oxidized, purified in further extraction steps, and returned to the $\mathrm{PuO}_{2}$ powder preparation process as $\mathrm{Pu}\left(\mathrm{NO}_{3}\right)_{4}$. The $\mathrm{U}$ may be stripped from the organic phase, purified in further extraction steps, and recovered as $\mathrm{UO}_{2}\left(\mathrm{NO}_{3}\right)_{2}$. The nitrate form is calcined to an oxide, reduced, and returned to the powder preparation process as $\mathrm{UO}_{2}$. The aqueous raffinate phases from the extraction processes are treated in the liquid waste treatment system.

\section{A.5.2.2 Hazardous Material Inventory}

\section{Chemical Inventory}

The primary chemicals associated with the light water reactor fuel fabrication process include:

- $\mathrm{NH}_{3}$ : converted to $\mathrm{NH}_{4} \mathrm{OH}$ and used in the wet conversion process to precipitate ADU from $\mathrm{UO}_{2} \mathrm{~F}_{2}$; used in calciner operations; also cracked to $\mathrm{H}_{2}$ and $\mathrm{N}_{2}$ before contacting $\mathrm{UF}_{6}$ in the dry conversion process

- $\mathrm{HNO}_{3}$ : used in the scrap recovery wet process

- $\mathrm{HF}$ : by-product of the $\mathrm{UF}_{6}$ conversion process

- $\mathrm{H}_{2} \mathrm{O}_{2}$ : used to adjust $\mathrm{pH}$ in wet recovery process

- $\mathrm{UF}_{6}$ : used as the feed-stock for producing $\mathrm{UO}_{2}$

- $\mathrm{F}_{2}$ : by-product of the defluorination process

Typical inventories of each of these chemicals are provided in Table A-8. 
Table A-8. Typical Chemical Inventories at Light-Water-Reactor $\mathrm{UO}_{2}$ Fuel Fabrication Facilities

\begin{tabular}{lccl}
\hline Chemical (symbol) & $\begin{array}{c}\text { Site inventory } \\
(\mathbf{k g})\end{array}$ & $\begin{array}{c}\text { Container size } \\
(\mathbf{k g})\end{array}$ & \multicolumn{1}{c}{ Storage conditions } \\
\hline Ammonia $\left(\mathrm{NH}_{3}\right)$ & 74000 & 50000 & Pressurized storage tanks \\
Nitric acid $\left(\mathrm{HNO}_{3}\right)$ & 36000 & 38000 & Aboveground storage tanks \\
Hydrogen fluoride $(\mathrm{HF})$ & 100000 & 77000 & Drums \\
Hydrogen peroxide $\left(\mathrm{H}_{2} \mathrm{O}_{2}\right)$ & 5000 & 5000 & Tanks \\
Uranium hexafluoride $\left(\mathrm{UF}_{6}\right)$ & 500000 & 12000 & Model 48-X, -Y, -G cylinders \\
& & 2200 & Model 30B cylinders \\
Fluorine $\left(\mathrm{F}_{2}\right)$ & minimal & minimal & Tanks \\
\hline
\end{tabular}

Source: General Electric Company (1983), Battelle Pacific Northwest Laboratories (1993), and Westinghouse

Electric Corporation (1995)

\section{Radiological Inventory}

The materials that produce the basis for the radiological hazards associated with the typical light water reactor $\mathrm{UO}_{2}$ fuel fabrication process and their typical possession limits (the amount of material allowed on site) are listed in Table A-9. Pu possession limits at first generation fuel fabrication facilities handling MOX materials ranged from 10 to $2000 \mathrm{~kg}$ (22 to $4400 \mathrm{lb}$ ) (USNRC 1976).

In fuel manufacturing, uranium and plutonium and their compounds may be important contributors to accidental release source term calculations for consequence analysis. As solids they are non-volatile, and they do not become airborne by heating without applying some mechanical force. ${ }^{2}$

\section{A.5.2.3 Process Hazards}

The main chemical process hazards at light water reactor fuel fabrication facilities involve $\mathrm{UF}_{6}, \mathrm{HF}, \mathrm{NH}_{3}$, $\mathrm{F}_{2}$, and $\mathrm{H}_{2}$.

\section{$\mathrm{UF}_{6}$ Releases}

A release of $\mathrm{UF}_{6}$ poses two chemical toxicity risks. Soluble uranium produced by the reaction of $\mathrm{UF}_{6}$ and water vapor can cause kidney damage, and the HF produced by the same reaction can cause skin, eye, and lung injury. The latter can impair the ability of an operator to take corrective measures.

A catastrophic rupture of a $U_{6}$ cylinder could release a significant portion of its contents in a very short period of time. This could occur for several reasons. The $\mathrm{UF}_{6}$ cylinder could fall from a crane, e.g., while being lowered or delivered to a steam chest or heating system, and rupture catastrophically upon impact on

$\mathrm{UF}_{6}$ solid, which can sublime, is an exception. 
Table A-9. Typical Radioactive Material Possession Limits

\begin{tabular}{|c|c|c|}
\hline Special Nuclear Material & Possession limit & Form \\
\hline \multirow[t]{4}{*}{ Uranium-235 } & $20000 \mathrm{~kg} /(43 \mathrm{Ci})$ & $\begin{array}{l}\text { In uranium compounds in any form } \\
\text { enriched to a maximum of } 5 \mathrm{wt} \\
\text { percent }\end{array}$ \\
\hline & $200 \mathrm{~kg} /(0.4 \mathrm{Ci})$ & $\begin{array}{l}\text { In uranium compounds enriched from } \\
5.00 \text { wt percent to a maximum of } \\
9.99 \text { wt percent }\end{array}$ \\
\hline & $9.5 \mathrm{~kg} /(0.02 \mathrm{Ci})$ & $\begin{array}{l}\text { In uranium compounds enriched from } \\
10.00 \text { wt percent to a maximum of } \\
19.99 \text { wt percent }\end{array}$ \\
\hline & $0.1 \mathrm{~kg} /(0.2 \mathrm{mCi})$ & $\begin{array}{l}\text { Any enrichment or form for analytical } \\
\text { purposes }\end{array}$ \\
\hline \multirow[t]{2}{*}{ Plutonium $(\mathrm{Pu})$} & $<0.5 \mathrm{~kg} /(27 \mathrm{Ci})$ & $\begin{array}{l}\text { As } \mathrm{PuO}_{2} \text { or } \mathrm{PuO}_{2}-\mathrm{UO}_{2} \text { as stored } \\
\text { waste }\end{array}$ \\
\hline & $0.001 \mathrm{~kg} /(1.5 \mathrm{mCi})$ & In sealed sources and standards \\
\hline
\end{tabular}

Source: General Electric Company (1983), Battelle Pacific Northwest Laboratories (1993), and Westinghouse Electric Corporation (1995)

a hard surface. A UF 6 cylinder could also rupture when overfilled and heated; this caused the accident in 1986 at the Sequoyah Fuels Corporation in Gore, Oklahoma (USNRC 1986a and 1986b).

$\mathrm{UF}_{6}$ exists as a solid in cylinders at ambient temperatures. If such a cylinder were to rupture catastrophically, solid $\mathrm{UF}_{6}$ would be exposed to the environment. In the presence of water, the $\mathrm{UF}_{6}$ will be gradually coated with a thin layer of $\mathrm{UO}_{2} \mathrm{~F}_{2}$ formed by the reaction of $\mathrm{UF}_{6}$ and airborne moisture. This will mitigate the consequences of the release of solid $\mathrm{UF}_{6}$. However, if the air is dry, $\mathrm{UF}_{6}$ will not be coated by a layer of $\mathrm{UO}_{2} \mathrm{~F}_{2}$, and sublimation of solid $\mathrm{UF}_{6}$ to vapor will occur. The rate of sublimation is controlled by a variety of factors. Important amongst these are the total exposed surface area of solid $\mathrm{UF}_{6}$, the ambient temperature, and the wind speed following the release.

If the solid $\mathrm{UF}_{6}$ comes in contact with water, then the exothermic hydrolysis reaction will yield gaseous $\mathrm{HF}$. For the reaction to go to completion, 1 unit mass of $\mathrm{UF}_{6}$ requires 0.1 unit mass of water and the reaction will yield 0.22 unit mass of $\mathrm{HF}$. The reaction is given by

$$
\mathrm{UF}_{6}+2 \mathrm{H}_{2} \mathrm{O} \rightarrow \mathrm{UO}_{2} \mathrm{~F}_{2}+4 \mathrm{HF}+\text { heat }\left(117147 \mathrm{~J} / \mathrm{mole} \text { at } 25^{\circ} \mathrm{C}\right)
$$

This reaction is very fast. Therefore, it can be assumed to occur instantaneously. $\mathrm{UF}_{6}$ can also be released when it is under pressure in a cylinder where it can exist as a solid, liquid, or gas. If the cylinder integrity is compromised and it depressurizes, then the liquid phase $\mathrm{UF}_{6}$ will change state to solid and vapor. The rate of depressurization will determine the rate of phase change. $A_{U^{\prime}}$ phase diagram (USDOE 1991) is provided in Figure A-7. Methods for calculating the mass of liquid $\mathrm{UF}_{6}$ that will flash to vapor are given in Appendix B. 


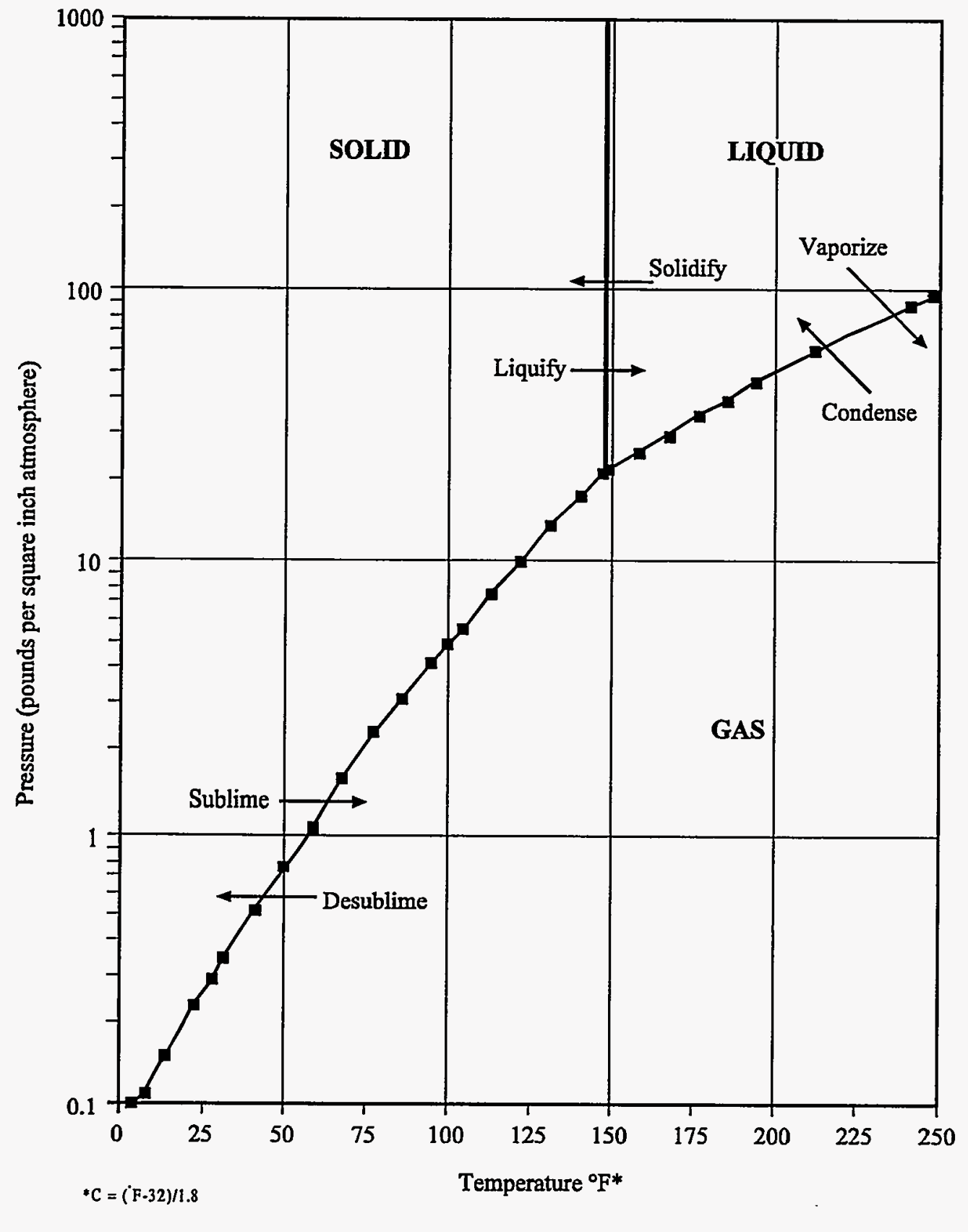

Figure A-7. $\mathrm{UF}_{6}$ phase diagram [source: USDOE (1991)] 
If the rupture is large and catastrophic, then all the liquid phase $\mathrm{UF}_{6}$ will change phase very quickly (vaporization). Conversely, if the rate of depressurization is low, then the rate of phase change will also be low. For simplicity, two bounding cases are considered:

1. when the rate of depressurization is very faxt (e.g., catastrophic rupture)

2. when the rate of depressurization is negligible

If the rate of depressurization is fast, then all of the inventory of $\mathrm{UF}_{6}$ can be assumed to be released to the environment instantaneously. The release and flashing process can be vigorous enough to render all the solid $\mathrm{UF}_{6}$ particulates airborne in the puff. The method for calculating the source term for this scenario is described in Section B.5 of Appendix B.

However, slower rates of depressurization can lead to smaller continuous releases of $\mathrm{UF}_{6} . \mathrm{A}$ break in the delivery system of the $U_{6}$ from the vaporizer to the hydrolyzer can lead to a continuous release of $U_{6} F_{6}$ vapor. A break in the pigtail of the delivery system can cause the same type of release. The method for calculating the rate of release of vapors through pipes is given in Sections B.3 and B.4 of Appendix B.

A distinction must be made between the situation in which the release occurs in the vapor phase of the $\mathrm{UF}_{6}$ above the liquid level in the cylinder and the situation in which the release occurs below the liquid level in the cylinder. Section B.3 of Appendix B gives a detailed description of the methods for modeling both of these situations. If a break occurs below the liquid level, then liquid $\mathrm{UF}_{6}$ will emanate from the breach. Upon depressurization to atmospheric pressure, the liquid will immediately flash to solid and vapor.

\section{HF Releases}

$\mathrm{HF}$ is a gas at room temperature and pressure, but it can form a solution with water. HF often forms a white fog upon coming into contact with air following a release. In the presence of cold air, HF can condense. HF also undergoes oligomerization; it exists in the monomer, dimer, and hexamer forms (Clough et al. 1987). For mixtures of HF and moist air, the phenomena of oligomerization, condensation, and formation of aqueous solutions must be modeled. Due to these effects, the plumes of HF are often denser than air.

$\mathrm{HF}$ produced as a byproduct of the process reaction between $\mathrm{UF}_{6}$ and $\mathrm{H}_{2} \mathrm{O}$ is recovered and stored. The storage of aqueous HF can lead to large accumulations of the chemical. Therefore, the primary hazards that arise from HF are from the recovery and storage systems. It must be noted that even though the relatively low molecular weight of HF may suggest that a cloud of HF will be buoyant in air (air has a molecular weight of 29), the actual situation is otherwise.

Oligomerization increases the effective molecular weight of HF. This effect and the fact that the depressurization and de-oligomerization induce cooling often makes HF clouds denser than air.

A failure of the HF recovery system may lead to the atmospheric release of $\mathrm{HF}$ for a certain duration of time before preventive measures can be applied. The emission rate is dependent upon the rate of conversion of $\mathrm{UF}_{6}$ to $\mathrm{UO}_{2} \mathrm{~F}_{2}$ or $\mathrm{UO}_{2}$.

A failure of the storage system can cause several types of releases. A catastrophic rupture of a storage tank (a typical size is $77000 \mathrm{~kg}(169000 \mathrm{lb})$ ) can release the entire inventory of HF in a relatively short period of time. 
Depending upon the storage temperature, the vapor pressure of $\mathrm{HF}$ can be above or below the ambient atmospheric pressure. For instance, at $298 \mathrm{~K}\left(76^{\circ} \mathrm{F}\right)$ the vapor pressure of pure $\mathrm{HF}$ is $121600 \mathrm{~Pa}$ (17.6 psia), and at $278 \mathrm{~K}\left(76^{\circ} \mathrm{F}\right)$ the vapor pressure is $58350 \mathrm{~Pa}(8.5 \mathrm{psia})$. In comparison, the atmospheric pressure is $101325 \mathrm{~Pa}(14.7 \mathrm{psia})$. Therefore, at $298 \mathrm{~K}\left(76^{\circ} \mathrm{F}\right)$, a storage tank containing $\mathrm{HF}$ under its own vapor pressure will be at a pressure higher than atmospheric. A release occurring under such conditions will cause flashing of some of the HF liquid, if any, to vapor. Section 2.3 of this report gives details on how to calculate the mass fraction of HF that will flash. If the storage temperature is high enough, then the flashing phenomena may be so vigorous as to break up the liquid contents of the tank to small HF droplets and render them airborne. Such a release scenario may cause the instantaneous generation of a puff. A detailed description of the puff release scenario is given in Section B.5 of Appendix B.

If the storage temperature is close to or lower than the atmospheric boiling point temperature of HF, then upon release, the HF may spill to the ground and form an evaporating pool. A dike can limit the growth of the surface area of the pool. A large surface area of a pool is detrimental because it increases the rate of evaporation. Therefore, a dike can mitigate the effects of a spill. A detailed discussion of the methods for calculating the rate of evaporation of HF from a liquid pool is given in Section B.2 of Appendix B.

A storage tank of HF can also release its contents in the form of jets through holes or cracks in the walls of the tank. Depending upon the storage conditions and the location of the vessel breach, the jets can contain HF in either liquid, vapor, or both forms. Sections B.3 and B.4 of Appendix B contain further details on how to calculate the release rates of $\mathrm{HF}$ for such scenarios. Figure A-8 gives a pictorial representation of various ways in which $\mathrm{HF}$ and other fuel cycle chemicals might be released to the atmosphere.

\section{$\mathrm{NH}_{3}$ Releases}

$\mathrm{NH}_{3}$ is disassociated to produce hydrogen for the reduction of $\mathrm{UF}_{6}$ to $\mathrm{UO}_{2}$ in the dry $\mathrm{ADU}$ conversion process. Exposure to $\mathrm{NH}_{3}$ can cause death, skin, lung, and eye injury.

$\mathrm{NH}_{3}$ can be stored in tanks under pressure at ambient temperature or under refrigerated conditions. A storage tank can fail in several different modes (see Figure A-8). It can fail catastrophically, thereby releasing all of its inventory instantaneously. Pressurized $\mathrm{NH}_{3}$ may flash from liquid to vapor upon depressurization. Some or all of the liquid $\mathrm{NH}_{3}$ may be entrained in the cloud following the flashing process. Note that even though the molecular weight of $\mathrm{NH}_{3}$ is less than the molecular weight of air, it is not always possible to assume that following a release the $\mathrm{NH}_{3}$ cloud will be lighter than air. If a cloud is very cold and contains liquid droplets following depressurization, it will be dense following a release. A detailed discussion of methods used for calculating the fraction of $\mathrm{NH}_{3}$ that can flash is given in Section B.3 of Appendix B. Liquid $\mathrm{NH}_{3}$ can also spill on the ground following a large rupture in a refrigerated tank. Since the atmospheric boiling point of $\mathrm{NH}_{3}$ is $239.7 \mathrm{~K}\left(-29^{\circ} \mathrm{F}\right)$, it will boil. Details on the methods used to calculate the evaporation rate following the spillage of cryogenic liquid are given in Section B.2.3 of Appendix B.

If a storage tank begins to leak or develops a perforation, then either the vapor or liquid can be released. If the leak is above the liquid level in the tank, then the released jet may consist entirely of vapor. There is a possibility of the vapor condensing following depressurization. However, if the leak is below the liquid level in the tank, then the jet will consist of flashing liquid $\mathrm{NH}_{3}$. Further details on both of these scenarios are given in Sections B.3 and B.4 of Appendix B. Figure A-8 illustrates the various scenarios for the release of $\mathrm{NH}_{3}$. 


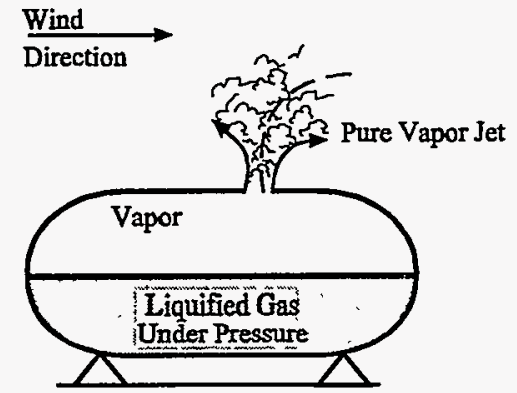

a. Small hole in vapor space of a pressurized vessel

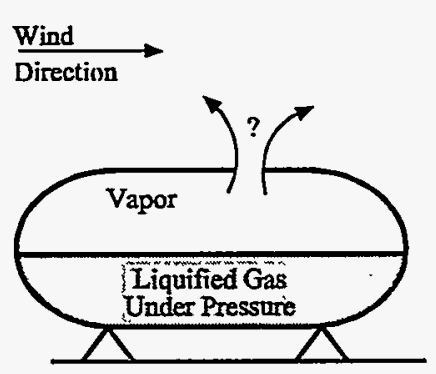

c. Intermediate hole in vapor space of a pressurized vessel

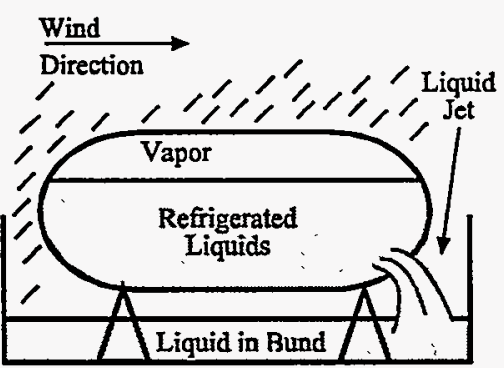

e. Spillage of refrigerated liquid into bund

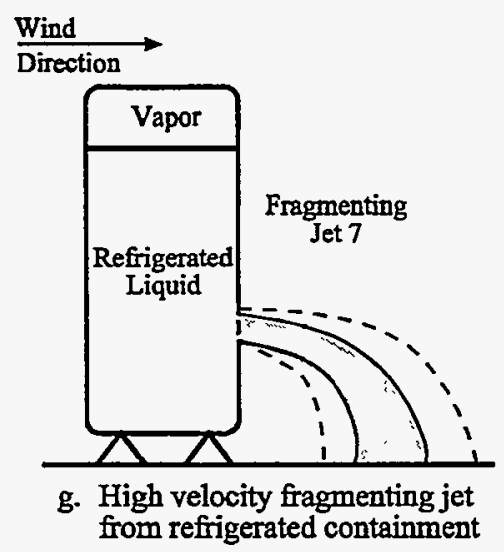

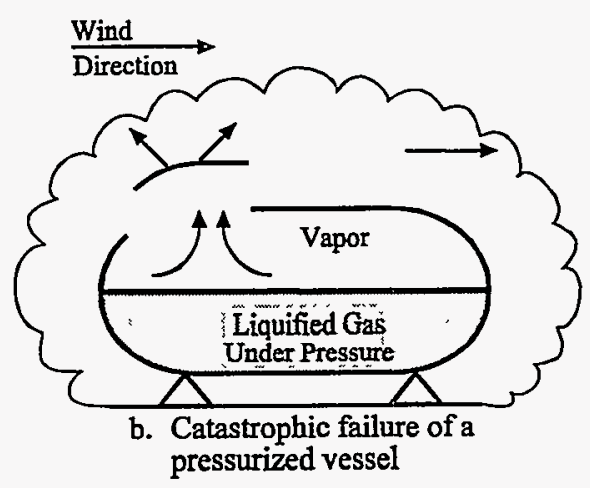
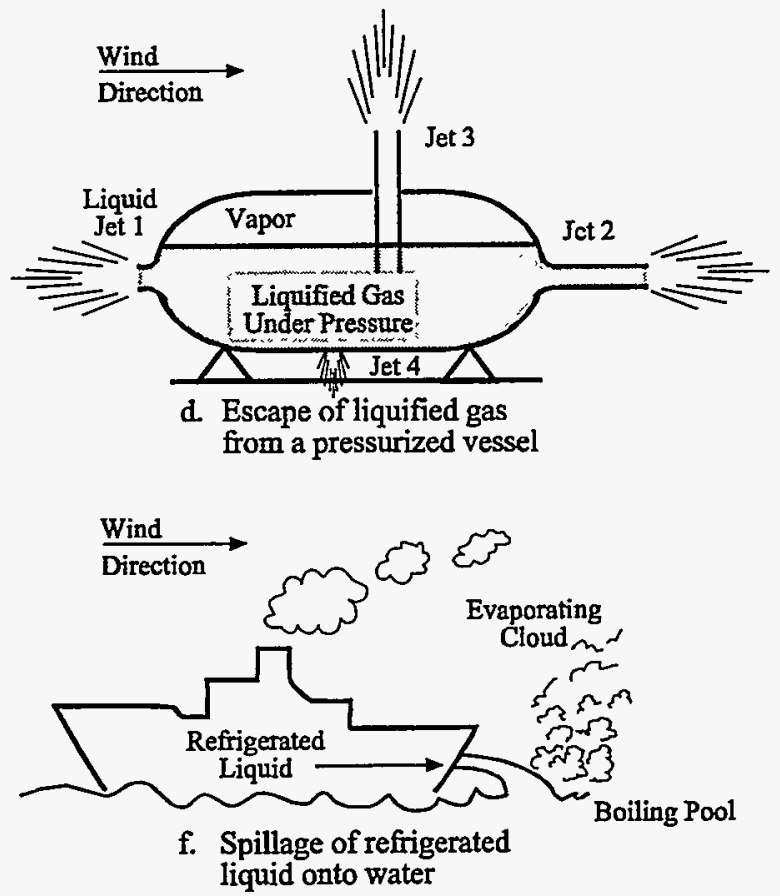

Figure A-8. Some conceivable release mechanisms for fuel cycle chemicals 


\section{Fluorine Releases}

Fluorine is produced as a byproduct of the defluorination process. It is a skin irritant and is corrosive to all living tissue. It can induce coughing, difficulty in breathing, and abnormal fluid formation in the nose, mouth, and throat. Its effects on the eyes are similar to those of HF. It can cause death, severe burning, and destruction of the tissues.

Fluorine is usually stored under pressure. A catastrophic rupture of such a tank will cause the fluorine to immediately flash to vapor with perhaps some liquid droplets. (Fluorine is likely to flash to vapor very vigorously and therefore the likelihood of an evaporating liquid pool of fluorine is low.) The released fluorine will be cold enough to cause the initial density of the cloud to be perhaps greater than the density of air. The methods for calculating the mass fraction of fluorine in the form of liquid droplets, if any, following a release and the initial density of the cloud are given in Section B.3 of Appendix B.

If storage tanks develop leaks, holes, or ruptures, then jets can release fluorine over a period of time. Depending upon the location and size of the hole, the jet can contain vapor, liquid, or both. Details on the methods for calculating release rates can be found in Sections B.3 and B.4 of Appendix B.

\section{Hydrogen Hazards}

Hydrogen gas is used in the $\mathrm{UF}_{6}$ conversion process to reduce $\mathrm{U}_{3} \mathrm{O}_{8}$ or uranium trioxide $\left(\mathrm{UO}_{3}\right)$ to $\mathrm{UO}_{2}$ and in the fuel fabrication process to convert $\mathrm{UO}_{2} \mathrm{~F}_{2}$ to $\mathrm{UO}_{2}$. To prevent the reverse flow of air in the hydrogen system which could cause fires, deflagrations, or explosions, an excess flow of hydrogen is maintained in the defluorination reduction unit. The excess hydrogen is then flared.

The pilot flame system is critical to ensure the safety of the process. If the pilot flame is inadvertently put out, then the situation can become hazardous due to the buildup of excess unburned hydrogen in the system. The resulting fire or explosion can cause worker injury and exposure to or releases of $\mathrm{HF}, \mathrm{UF}_{6}$, or other hazardous materials to the environment.

\section{Nuclear Criticalities}

Nuclear criticalities generate radioactive fission products which may be released into ventilated spaces. The spaces promote mixing of the short half-life radioactive materials with air which dilutes the fission product gases.

When evaluating potential criticality events, solutions of fissile material are of principal concern because they are moderated, have mobility, and can easily be formed into geometrically unfavorable shapes.

The inventory of fission products produced during a criticality event is a function of the fissile material (e.g., uranium, plutonium, thorium). The amount of fission products generally is a function of the total number of fissions that occurred during the criticality accident. The total number of fissions depends on the amount of fissile material involved, the configuration of the material, and how long the conditions necessary to maintain a critical configuration exist.

In the case of fissile materials, the energy produced by the criticality event is dissipated by heating the liquid resulting in evaporation of water which is a moderator. Eventually, loss of moderation due to the 
declining liquid, volume results in termination of the criticality. For solid systems, displacement of the solid or powder can alter the configuration and result in termination of the criticality.

Heating liquids can result in entrainment of droplets in a vapor flux above the heated liquid resulting in the airborne release of nonvolatile salts present in the solution. Thus, radioactive materials initially present in the fissile solution can be made airborne by the criticality as well as radioactive materials generated by the criticality.

\section{Fires and Explosions Involving Radioactive Materials}

The process of burning, as it pertains to uncontrolled fires, involves the oxidation of vapors. The vapors may come from the release of flammable gases or the release of vapors from liquids or solids. The consequences of the release of gases, vapors, solids, and heat from burning may have deleterious effects.

Non-nuclear explosive events fall into four classes that are based upon the types of reactions that generate energy (physical or chemical) and the rate at which energy is generated (fast or slow):

- Fast physical (e.g., molten metal dropped into water)

- Slow physical (e.g., pressurized releases)

- Fast chemical (e.g., detonations)

- Slow chemical (e.g., deflagrations).

\section{A.5.3 Uranium Enrichment Plants}

A uranium enrichment facility is a process plant designed to separate a feed stream containing the naturally occurring proportions of uranium isotopes into a product stream enriched in the U-235 isotope and a tails stream depleted in the U-235 isotope. The process is operated at the commercial scale using gaseous diffusion and gas centrifuge systems and at the demonstration stage using the AVLIS technique. Process description information and accident consequence analyses for gaseous diffusion plants are provided in response technical manuals prepared for the Portsmouth, $\mathrm{OH}$ and Paducah, KY facilities (Pacific Northwest National Laboratory, 1997). The following paragraphs describe the gas centrifuge and AVLIS processes and summarize the associated process hazards.

\section{A.5.3.1 Process Summary}

\section{Gas Centrifuge Enrichment}

The gas centrifuge enrichment process is entirely physical in nature, taking advantage of the tendency of materials of differing density to segregate in the force field produced by a centrifuge. The chemical form of the working material of the plant, $\mathrm{UF}_{6}$, does not require chemical transformations at any stage of the process. In the three primary steps of the process, $\mathrm{UF}_{6}$ is volatilized from a feed cylinder, passed through the separative centrifuges arranged in cascades, and condensed in product or tails cylinders. A block diagram of all steps in the process is presented in Figure A-9. The process comprises a linear sequence of steps and does not recycle material from later steps in the sequence to earlier steps. The description of plant design and operations presented in this appendix follows the flow of $\mathrm{UF}_{6}$ from its reception at the site through processing to the disposition of product and tails material. 


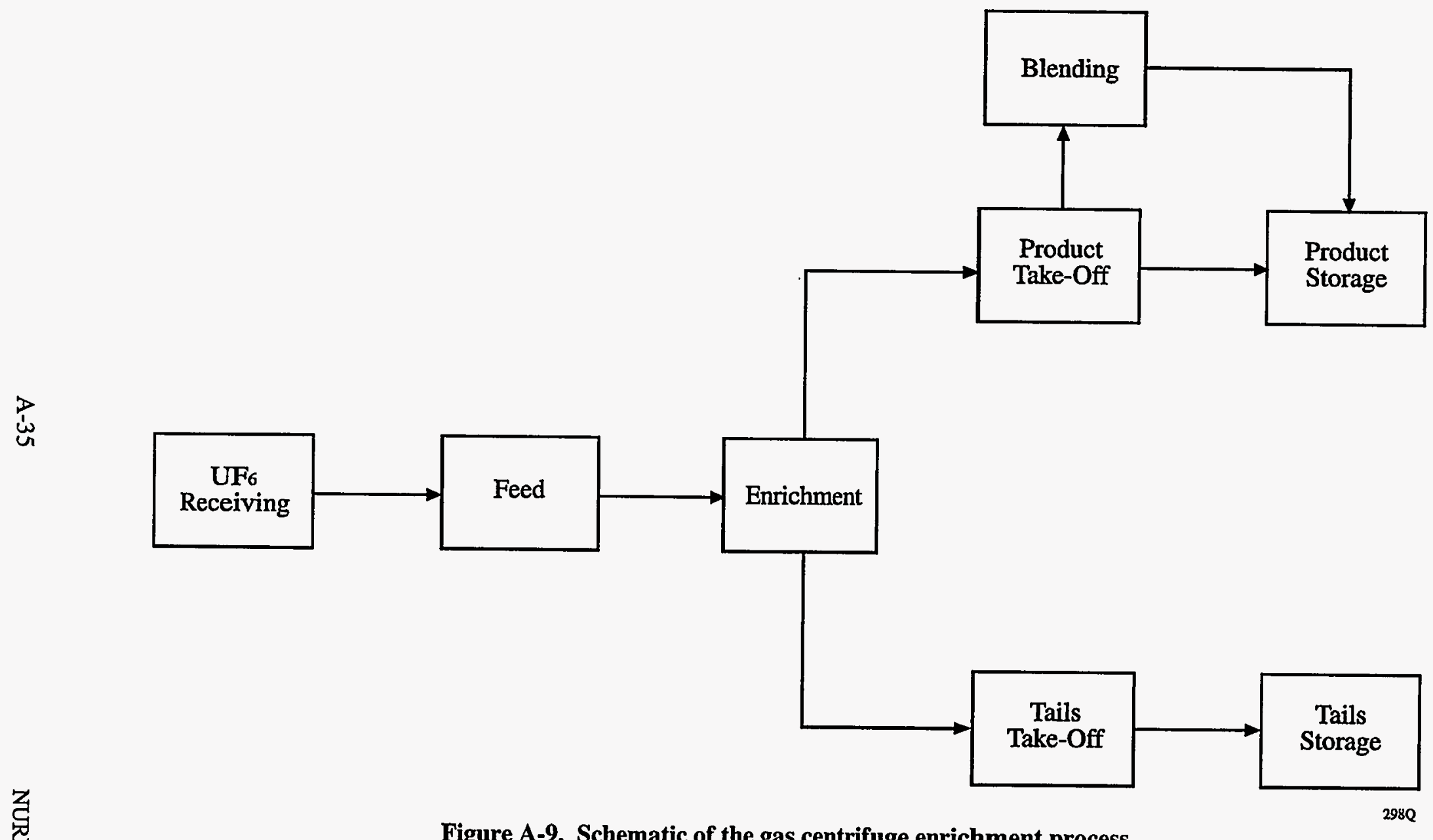

Figure A-9. Schematic of the gas centrifuge enrichment process 


\section{Feed Receiving and Storage}

Feed material in the form of solid $\mathrm{UF}_{6}$ in cylinders is transported to the facility on specially designed and fitted flat-bed trucks. Cylinders arriving onsite are inspected, weighed, and transferred to an outside storage area to await processing. Straddle carriers and modified forklifts transport cylinders from storage areas to and from the main processing building while an overhead bridge crane delivers feed cylinders to the process areas within the building.

\section{Feed Purification and Feed Operations}

The initial processing step is removal of light gas contaminants from the feed $\mathrm{UF}_{6}$. The primary pieces of equipment for this purpose are the feed autoclaves, feed purification desublimers and traps, feed purification cylinder station, and associated piping, valves, and controls. The autoclaves are rotated through purification, heat-up, feed, and cool-down cycles to maintain desired feed to the cascades.

The feed autoclave is a horizontally mounted, carbon-steel, cylindrically shaped vessel fitted with electrical resistance heaters. The autoclave air space communicates with the environment through two routes. The first piping line is a vent to the main process building air space which includes a normally closed shut-off valve. The second piping line connects the autoclave air space to the process off-gas vent system through a hand-operated valve which has a mechanical interlock to the autoclave door. The autoclave also has interior piping and associated valves which provide the flow path for $\mathrm{UF}_{6}$ being transferred to the desublimer or to the cascades. In addition, a cylinder is fitted with an open/close valve that is connected to the autoclave interior piping through a flexible pipe called a pigtail.

The autoclave exit line connecting the feed cylinder to the feed desublimer has two open/close valves that direct flow to the desublimer or to the cascade header. Desublimation at ambient temperature is possible at pressures used in the purification system. Valves are in hot boxes, and lines are trace heated to prevent desublimation. The feed purification desublimer comprises four stainless steel tubes sealed inside a stainless steel cabinet. Each pipe is wrapped in copper lines capable of carrying heat transfer fluids. The cabinet is filled with insulation and blanketed with nitrogen during operation to exclude moisture. The desublimer is connected to the process off-gas vent system through an exit line containing two valves, a pump, and two $\mathrm{UF}_{6} / \mathrm{HF}$ adsorption traps.

Feed purification operations begin with loading of a full feed cylinder into a feed autoclave. The cylinder valve is connected to the autoclave interior piping through a flexible pipe and purification is accomplished in two stages. In the first stage, termed cold purification, the unheated cylinder is vented repeatedly in a batch fashion to a chilled desublimer in order to remove light gases present in the cylinder vapor space. The $\mathrm{UF}_{6}$ transferred to the desublimer is solidified in the desublimer tubes at the desublimer operating temperature. Light gases, including air and $\mathrm{HF}$, and a quantity of $\mathrm{UF}_{6}$ determined by the vapor pressure of $\mathrm{UF}_{6}$ at the desublimer temperature are released in this operation. At the completion of cold venting, the autoclave door is closed, and heating of the cylinder is initiated. Heater controls are interlocked to door and valve positions and to autoclave air space temperature and pressure in order to avoid overheating of the cylinder. When the $\mathrm{UF}_{6}$ is fully liquefied, the cylinder is again vented to the desublimer in order to remove light gas contaminants which may have been trapped in the solid $\mathrm{UF}_{6}$. Generally only a single hot vent step is needed, and $1 \mathrm{~kg}$ ( $2.2 \mathrm{lbs}$.) of $\mathrm{UF}_{6}$ is transferred to the desublimer. At the completion of hot purification, the cylinder is ready for transfer of $U_{6}$ to the cascades. 
Uranium hexafluoride is transferred from a hot, purified cylinder to the cascade header at constant mass flow rate. When the flow can no longer be controlled at the desired rate, the cylinder is taken off-line and replaced by another feed autoclave. The cylinder heel is transferred to the purification cylinder, and the feed cylinder is cooled and removed from the feed autoclave.

\section{Enrichment}

The enrichment system separates a stream of gaseous $\mathrm{UF}_{6}$ produced in the feed system into a product stream enriched in U-235 and a tails stream depleted in U-235 using gas centrifuges grouped into cascades. Equipment comprising the enrichment section includes the centrifuges, control valves, instrumentation, and associated piping. The centrifuge is a thin-walled, vertical, cylindrically shaped rotor which spins around a central post within an outer casing. Each cascade has a closed-loop cooling water system to remove the heat generated by frictional losses and the electromagnetic motors. Cooling coils located at the top and bottom of the rotor remove heat and provide a temperature gradient that plays a role, along with centrifugal force, in producing the isotopic separation. Feed, product, and tails streams enter and leave the centrifuge through the central post. Each centrifuge has an exit safety valve that is closed by excess pressure within the centrifuge. Each cascade receives $\mathrm{UF}_{6}$ from an assay unit header through a control valve, resistor orifice, and controller that establish flow rate on the basis of monitored pressure level. Product flow is controlled in a similar manner.

Under normal conditions, the centrifuges operate continuously with minimal operator intervention. Centrifuge pressure, rotational frequency, and cooling conditions are continuously monitored by a central control system. The pressure within each centrifuge is subatmospheric, and each centrifuge contains ten grams $\left(0.02 \mathrm{lbs}\right.$.) of $\mathrm{UF}_{6}$. Ingress of light gas or process upsets can cause destabilization of the centrifuge rotor and a resulting failure, termed a "crash". In a centrifuge failure, rotational energy is converted to heat, the rotor disintegrates, and a quantity of gas is generated in the disintegration process and subsequent reaction with $\mathrm{UF}_{6}$. A pressure pulse occurring during the crash closes isolation valves and separates the failed centrifuge from the balance of the cascade. Solid reaction products accumulate in the bottom of the failed centrifuge, and over a period of weeks, the reaction gases leak into the cascade header and are removed through the process off-gas vent system. The failed centrifuge remains in place but no longer contributes to the separation capacity of the cascade.

\section{Product and Tails Take-Off}

The primary function of the product and tails take-off systems is to compress streams of $\mathrm{UF}_{6}$ from cascade pressure to an elevated but sub-atmospheric pressure to desublime $U_{6}$ in product or tails cylinders. $A$ secondary function of the product and tails take-off systems is to provide for rapid removal, or dumping, of the inventory of a cascade to product or tails cylinders.

Enriched and depleted $\mathrm{UF}_{6}$ are compressed to desublimation pressure in two stages of vacuum pumps. Desublimation in valves and piping is prevented by use of hot boxes and line tracing. The product stream is desublimed into $2280 \mathrm{~kg}(5020 \mathrm{lb})$ capacity cylinders (Type 30B) cooled by chilled air. The tails stream is desublimed into $12500 \mathrm{~kg}$ ( $27560 \mathrm{lb}$ ) capacity cylinders (Type $48 \mathrm{Y}$ ) cooled by chilled water. Product and tails take-off stations are equiped with load cells and are connected to desublimers for venting of light gas contaminants. When the load cells indicate that a cylinder is full, inlet and cylinder valves are closed, the lines are evacuated, and the cylinder is disconnected from the take-off station. 
Extraordinary conditions may require the rapid removal in the inventory of a cascade. In these circumstances, the inventory may be removed through the tails, or product take-off systems, or through a dedicated contingency dump system. In the case of removal through either the tails take-off system or the product take-off system, pressure to the low-pressure vacuum pumps is increased, mass flow to the cylinder stations is increased, and the $\mathrm{UF}_{6}$ inventory is desublimed into product or tails cylinders. If the product and tails removal function are unavailable, the plant inventory may be removed in a contingency dump system. The system comprises sodium fluoride beds to adsorb $\mathrm{UF}_{6}$ and surge vessels to provide flow control. Light gases passing through the dump system are released through the process off-gas vent system to the atmosphere.

\section{Product Sampling and Blending}

The function of the product sampling system is to certify that product meets customer specifications. Sampling of product cylinders is accomplished in electrically heated autoclaves used to liquefy and homogenize $\mathrm{UF}_{6}$ in the product cylinder. The autoclave air space is connected to the main process building air space and to the process off-gas vent system through valved piping while the sample manifold is connected to the cylinder valve inside the autoclave. The front support of the autoclave is hinged, and the rear support is mounted on a hydraulic lift, which can tilt the autoclave, cylinder, and sampling manifold allowing transfer of liquid $\mathrm{UF}_{6}$ from the product cylinder to the sample cylinder. Cooling of the autoclave is provided by a closed-circuit, non-contact cooling water system.

The function of the product blending system is to provide the ability to produce a range of compositions of enriched product with a minimum complexity of separation system configuration. Major pieces of equipment involved in a blending operation include two donor autoclaves, one blended product cylinder station, one product blending desublimer, and associated valves and piping. Each donor autoclave is a horizontal, cylindrical, carbon steel vessel. The two autoclaves are connected by common piping to the blending receiver cylinder station and to the blending system desublimer. The station is cooled by a closed-circuit air system and fitted with load cells to monitor cylinder contents. The desublimer is a single stainless-steel tube wrapped in copper, hot and cold, refrigerant tubes inside an insulated cabinet. The desublimer tube exit line is connected by two valves, a vacuum pump, and absorber traps to the process off-gas vent system.

A transporter loads full product cylinders and an empty receiver cylinder into the donor autoclaves and receiver cylinder station, respectively. The cylinders are connected to the process lines, and all lines exposed to air are evacuated. Before heating, the pressures of the donor cylinders are measured, and the cylinders are vented to the desublimer if necessary. The donor cylinders are heated, the $\mathrm{UF}_{6}$ liquified, and specified amounts of $\mathrm{UF}_{6}$ are transferred from each donor cylinder to the receiver cylinder until the receiver cylinder is full or the donor cylinders are empty. At the completion of operations, isolation valves are closed, connector lines evacuated and the receiver cylinder removed from the station.

\section{Product and Tails Storage}

Product and tails cylinders containing $\mathrm{UF}_{6}$ in the solid state at ambient temperature and subatmospheric pressure are stored in dedicated outside areas. Cylinders are stored on concrete saddles on a pad sloped 2 percent from the horizontal to drain rainwater. Cylinders are not stacked for storage and adequate clearance is provided for mobile carriers. 


\section{Atomic Vapor Laser Isotope Separation Process Design}

The AVLIS enrichment process is based on the selective excitation and ionization of U-235 atoms using precisely tuned laser light. Because the working material of the separation step is elemental uranium, feed preparation and product transformation operations would be required in a commercial plant.

\section{Feed Preparation}

Source material for the AVLIS process would likely be yellowcake powder which would be converted to the uranium metal form using chemical and metallurgical reduction. The first steps in the process; sizing, calcination, and chemical reduction to $\mathrm{UO}_{2}$; would be those used in the production of $\mathrm{UF}_{6}$. The source material would be sized using hammermills and grinders and dried and calcined in a rotating furnace. The sized material would be reduced to $\mathrm{UO}_{2}$ in a fluidized bed reactor using $\mathrm{H}_{2}$ gas as reductant. The $\mathrm{H}_{2}$ gas would be produced by cracking of $\mathrm{NH}_{3}$ over a catalyst. The $\mathrm{UO}_{2}$ powder would be placed in a crucible with elemental calcium and heated in a furnace. Metallic uranium produced in this manner is the feed to the enrichment process step.

\section{Enrichment}

Separation of the uranium isotopes is affected in a vacuum chamber containing an electron beam gun, a crucible containing feed uranium metal, and charged collection plates. The chamber has provision for illumination of the vapor space by multiple laser beams from an external source. Uranium metal placed in the crucible is heated to approximately $3000 \mathrm{~K}\left(4940^{\circ} \mathrm{F}\right)$, melted, and vaporized by the focused electron beam. Uranium atoms flowing upward from the metal surface pass through the beams of laser light where the U-235 is selectively excited and ionized. An external system uses copper lasers to energize dye lasers to produce the monochromatic light needed for the process. The copper lasers require a high-voltage, pulsed power system while the dye lasers require circulating organic liquid solutions. The ionized U-235 is deposited on a product collector plate while the non-ionized U-238 and U-234 condense on a second plate. Enriched metallic uranium produced in the process would be converted to an oxide form for use in commercial fuel fabrication.

\section{Product Preparation}

Product preparation involves size reduction and oxidation. The size reduction may be accomplished using shearing, crushing, rolling, or machining. Size reduced material is transferred to a furnace where it is oxidized in air. The resulting powder is stored for shipment to the fuel fabrication plant.

\section{A.5.3.2 Hazardous Material Inventory}

Hazardous materials present in gas centrifuge enrichment facilities include $\mathrm{UF}_{6}$ present in both the solid and liquid state, halogenated organic refrigerants, and fuel oil stored for heating purposes. The total site inventory of $\mathrm{UF}_{6}$ may be as large as 80 million $\mathrm{kg}$ ( 176 million $\mathrm{lb}$ ) while the main process building inventory may be on the order of $150000 \mathrm{~kg}(330000 \mathrm{lb})$. Of the $\mathrm{UF}_{6}$ present in the process building, $40000 \mathrm{~kg}(88000 \mathrm{lb})$ may be in the liquid state at a given time. The $\mathrm{UF}_{6}$ constitutes both a radiological and toxic chemical risk with the chemical effects generally controlling. Chemical toxicity of $U_{6}$ is discussed in Section A.2.2. As much as $4000 \mathrm{~kg}(8800 \mathrm{lb})$ of halogenated organic coolants may be present during a the main process building. The compounds are generally not strongly toxic but may constitute a risk to 
workers present in catastrophic failure event. Fuel oil stored in outside tanks constitutes a potential fire hazard but risks are generally small and managed by standard industrial practice.

Hazardous material inventory at an AVLIS enrichment facility will vary with the nature of the feed material and the design capacity of the facility. If the feed material is yellowcake, the primary process chemicals would include $\mathrm{NH}_{3}$ and $\mathrm{H}_{2}$ derived from the $\mathrm{NH}_{3}$. Uranium present as metal and oxide solids constitutes the primary radiological hazard associated with the facility. Short chain organic alcohols, such as ethyl or propyl alcohol, would be used as solvent for the dyes used in the laser light sources. Because the process is not in commercial operation, quantitative estimates of hazardous material inventory are not available.

\section{A.5.3.3 Process Hazards}

Process chemical hazards at a gas centrifuge enrichment plant are those which could result in release of $\mathrm{UF}_{6}$ to the workplace airspace or the surrounding atmosphere. Because the total centrifuge inventory is small, the material at risk is present in cylinders in storage areas and the main process building. Of this material, $U_{6}$ in the liquid state in autoclaves represents the greatest risk due to the potential for high release from that physical state. Release could be caused by failure of piping connecting to the cylinder or by cylinder failure caused by overheating/overpressurization. Process chemical hazards at the AVLIS enrichment plant include the presence of $\mathrm{NH}_{3}$ and $\mathrm{H}_{2}$ used in the reduction process step. Release of the toxic $\mathrm{NH}_{3}$ could be caused by pipe or vent system leakage or catastrophic tank failure leading to potentially injurious intake for workers and nearby off-site residents. Release of $\mathrm{H}_{2}$ would most likely occur as pipeline leakage and could lead to explosion or fire.

Radiological hazards at both the gas centrifuge and AVLIS enrichment facilities include occurrence of a criticality event, inhalation of airborne uranium, or exposure to direct radiation produced by decay of uranium daughters. Equipment design, mass and moderation control, and administrative procedures contribute to reduction in risk of a criticality. Workplace continuous air monitors provide alarm against presence of airborne uranium while time and distance controls limit direct exposure to gamma radiation.

\section{A.5.4 Enriched Uranium Downblending}

Uranium highly enriched in U-235 may be available from U.S. weapons programs or from other sources. This material may be available in metallic, oxide solid, or nitrate solution forms. Two processes, involving

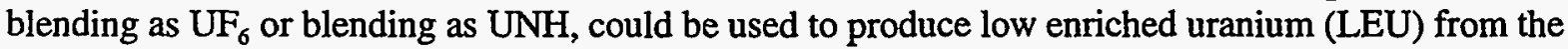
highly enriched material. Potential processes (USDOE 1995) are described in the following paragraphs.

\section{A.5.4.1 Process Summary}

\section{UF $_{6}$ Blending Process}

Blending of $\mathrm{HEU}$ source material as $\mathrm{UF}_{6}$ would require chemical and physical transformation of the feed metal, oxide solids, and UNH solutions as represented in Figure A-10. The steps may be grouped as feed preparation, $\mathrm{UF}_{6}$ conversion, and blending for descriptive purposes. 


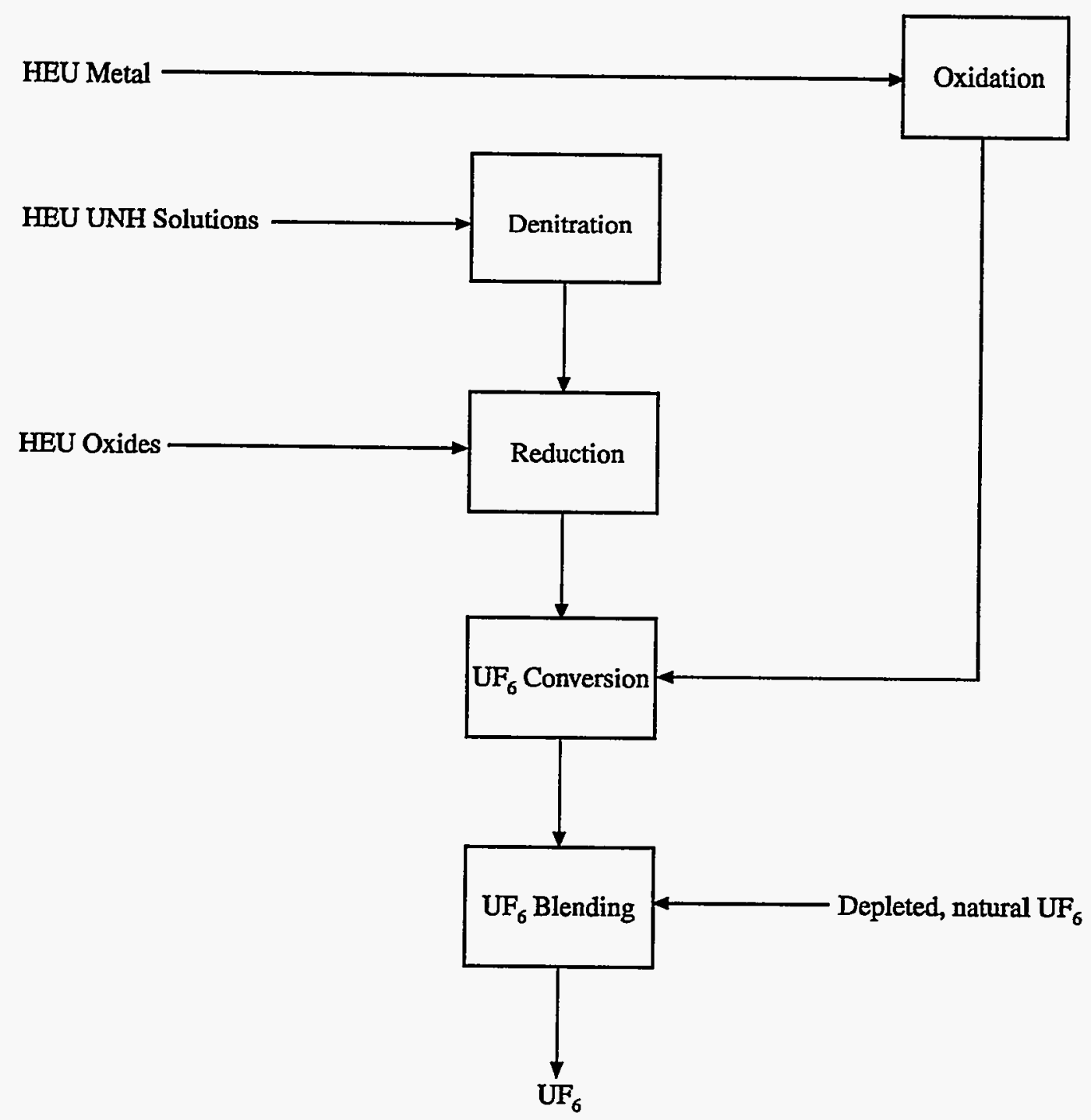

Figure A-10. Schematic of the $\mathrm{UF}_{6}$ downblending process 


\section{Feed Preparation}

The proposed processing scheme involves conversion of each of the feed forms to $\mathrm{UO}_{2}$ prior to transfer to the $\mathrm{UF}_{6}$ conversion step as represented in Figure A-10. For metallic uranium this requires size reduction using shearing, crushing, rolling, or machining followed by oxidation in air in a furnace. Solutions of UNH would be concentrated in an evaporator and boildown pots and denitrated in a furnace to produce uranium trioxide $\left(\mathrm{UO}_{3}\right)$. The $\mathrm{UO}_{3}$ and other feed oxides would then be reduced by $\mathrm{H}_{2}$ in a fluidized bed reactor.

\section{$U F_{6}$ Conversion}

Conversion of $\mathrm{UO}_{2}$ to $\mathrm{UF}_{6}$ would be accomplished using the hydrofluorination, fluorination, and purification process steps described in Section A.5.1. In summary, $\mathrm{UO}_{2}$ is converted to $\mathrm{UF}_{4}$ by reaction with gaseous $\mathrm{HF}, \mathrm{UF}_{4}$ is converted to $\mathrm{UF}_{6}$ by reaction with $\mathrm{F}_{2}$, and the resulting $\mathrm{UF}_{6}$ is purified by distillation. Supporting operations include catalytic cracking of $\mathrm{NH}_{3}$ to produce $\mathrm{H}_{2}$ and electrolysis of $\mathrm{HF}$ to produce $\mathrm{F}_{2}$. Details are provided in Section A.5.1.

\section{$U F_{6}$ Blending}

Enriched, natural, and depleted $\mathrm{UF}_{6}$ are stored as solids in cylinders at ambient temperature and subatmospheric pressure. Blending of enriched $\mathrm{UF}_{6}$ with natural or depleted $\mathrm{UF}_{6}$ is accomplished using a dual autoclave-product take-off station system. In this system, a cylinder containing enriched $\mathrm{UF}_{6}$ is loaded into one autoclave while a cylinder containing natural or depleted $\mathrm{UF}_{6}$ is loaded into the second autoclave. Both autoclaves are connected via piping to a product cylinder loaded into a take-off station. Material in the autoclaves is heated and liquefied to allow vaporization. Vaporized $\mathrm{UF}_{6}$ from each autoclave is delivered to the take-off cylinder at rates calculated to produce the desired product enrichment. The product cylinder is removed from the take-off station and transferred to a storage area for shipment to a fuel fabrication plant. Empty feed cylinders are cleaned and reused.

\section{UNH Blending Process}

Blending HEU and natural or depleted uranium in the UNH chemical form would require the processing steps represented in Figure A-11. The steps include conversion of the feed forms to UNH solutions, blending as solution, and product preparation.

\section{Chemical Conversion}

Uranium metal feed material would be reduced in size or crushed and converted to oxide by reaction with air in a furnace. This oxide and other feed oxide solids would then be dissolved in nitric acid solutions in heated digestion vessels. The solution of uranyl nitrate produced in the digestors may contain impurities which would be removed by solvent extraction. Uranium present in the acid solution would be extracted into an organic solvent and subsequently stripped into a dilute acid stream. The purified dilute acid stream would be concentrated to uranium assay required for blending. 


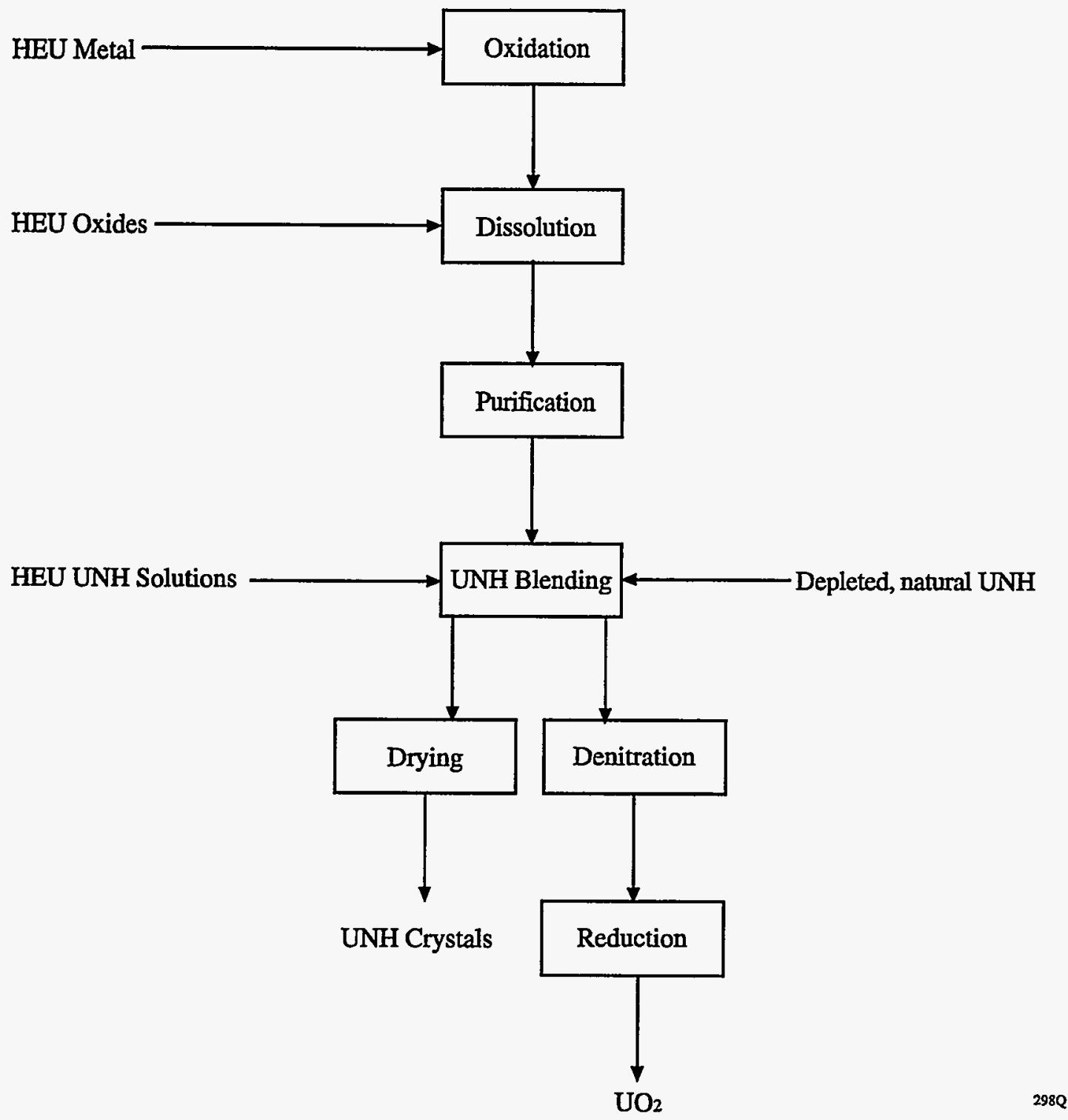

Figure A-11. Schematic of the UNH downblending process 


\section{Blending}

Production of UNH solution of specified assay is accomplished by mixing required volumes of high and low assay UNH solutions whose U-235 content is determined by sampling. Product solution is further processed to the desired chemical form.

\section{Product Preparation}

Product may be required in the form of $\mathrm{UNH}$ crystals or as $\mathrm{UO}_{2}$. Solutions are converted to crystal form by dewatering in evaporators and boildown pots. Dry product UNH crystals are then packaged for storage or shipment. If $\mathrm{UO}_{2}$ is the required product, the $\mathrm{UNH}$ solution is dewatered in evaporators and boildown pots and decomposed to $\mathrm{UO}_{3}$ in a furnace. The $\mathrm{UO}_{3}$ is reduced to $\mathrm{UO}_{2}$ by reaction with $\mathrm{H}_{2}$ in a fluidized bed. Product $\mathrm{UO}_{2}$ powder is packaged for shipment to a fuel fabrication facility.

\section{A.5.4.2 Hazardous Material Inventory}

Hazardous materials present at downblending facilities include uranium in the various chemical and physical forms and toxic and reactive chemicals used in the feed conversion and product preparation process operations. The uranium metals, oxides, and solutions are radiological hazards but are not readily dispersible. Uranium hexafluoride constitutes a radiological and hazardous chemical hazard as described in Section A.2.2. The primary process chemicals of concern include $\mathrm{NH}_{3}, \mathrm{H}_{2}, \mathrm{HF}$, and $\mathrm{F}_{2}$. Because the process is not in commercial operation, estimates of plant inventories are not available.

\section{A.5.4.3 Process Hazards}

Hazards present at downblending facilities include the radiological and hazardous chemical risks discussed above for enrichment facilities. Radiological hazards include release of energy and radionuclides in criticality accidents, inhalation of uranium, and direct exposure to gamma radiation from decay of uranium daughters. Hazardous chemical risks include toxic effects of inhalation of uranium, $\mathrm{HF}$, and $\mathrm{NH}_{3}$ and risk of fire and explosion due to use of $\mathrm{H}_{2}$. 


\section{A.6 References}

Allied Signal, Inc.,'License Renewal Application for SUB-526," 1990.

American Conference of Governmental Industrial Hygienists (ACGIH), "Threshold Limit Values for Chemical Substances and Physical Agents and Biological Exposure Indices," Cincinnati, Ohio, 1992.

American Industrial Hygiene Association (AIHA), "Emergency Response Planning Guidelines," AIHA Emergency Planning Guidelines Committee, Akron, Ohio, 1990.

American Institute of Chemical Engineers (AIChE), "Guidelines for Chemical Process Quantitative Risk Analysis," New York, New York, 1989.

American National Standards Institute, ANSI N.14-1984, "Uranium Hexafluoride: Packaging for Transport," New York.

Battelle Pacific Northwest Laboratories, Siemens Power Corporation - Emergency Assessment Resource Manual (EARM), Richland, Washington, 1993.

Brite, D.W., Nuclear Technology, V 18, pp 87-96, May 1973.

Buckner, M.R., and P.B. Parks, "Strategies for Denaturing the Weapon-Grade Plutonium Stockpile," WRSC-RP-92-1004, Westinghouse Savannah River Company, Aiken, South Carolina, 1992.

Chemical Manufacturers Association, “Material Safety Data Sheets,” Washington, D.C., 1994.

Clough, P.N., D.R. Grist, and C.J. Wheatley,"The Mixing of Anhydrous Hydrogen Fluoride with Moist Air," (John Woodward, ed.), International Conference on Vapor Cloud Modeling, (sponsored by the Center for Chemical Process Safety of the American Institute of Chemical Engineers, the Institution of Chemical Engineers, and the U.S. Environmental Protection Agency), Cambridge, Massachusetts 2-4 November 1987.

Daubert, T.E., and R.P. Danner, eds., Data Compilation, Tables of Properties of Pure Compounds, American Institute of Chemical Engineers, New York, New York, 1985.

General Electric Company, "Environmental Report,” NEDO-30183, 1983.

Maher, S.T., and G.D. Kaiser, "Torrance Refinery Safety Advisor Project: Evaluation of Modified HF Alkylation Catalyst," EQE International Report 59111.01, Submitted to the Superior Court of the State of California for the County of Los Angeles, 1995.

Murray, R.L., Nuclear Energy - An Introduction to the Concepts, Systems and Applications of Nuclear Processes, Third Edition, Pergamon Press, Elmsford, New York, 1988.

Occupational Safety and Health Administration (OSHA), "Process Safety Management of Highly Hazardous Chemicals; Explosives and Blasting Agents (29 CFR Part 1910)," Federal Register, Vol. 57, No. 36, pp. 6356-6417, February 24, 1992. 
Pacific Northwest National Laboratory, "RTM96 Supplement for the Portsmouth Gaseous Diffusion Plant," Richland, Washington, August 1997.

Ryan, R.M., U.S. Environmental Protection Agency, Region IV, memorandum to National Response Team, "OSC Report to the National Response Team Major Air Release of Hydrofluoric Acid Marathon Petroleum Company Texas City, Galveston County, Texas, October 30 to November 1, 1987," March 4, 1988.

Sax, N.I., and R.J. Lewis, Dangerous Properties of Industrial Materials, Seventh Edition, Van Nostrand Reinhold, New York, New York, 1989.

U.S. Department of Energy (USDOE), "Disposition of Surplus Highly Enriched Uranium Draft Environmental Impact Statement," DOE/EIS-0240-D, U.S. DOE, Washington, D.C., 1995.

U.S. Department of Energy (USDOE), "Uranium Hexafluoride: A Manual of Good Handling Practices," ORO-651, Rev. 6, Oak Ridge, Tennessee, 1991.

U.S. Department of Health and Human Services (DHHS), "NIOSH Pocket Guide To Chemical Hazards," DHHS (NIOSH) 90-117, U.S. Government Printing Office, Washington, D.C., 1990.

U.S. Environmental Protection Agency (USEPA), "Hydrogen Fluoride Study: Report to Congress, Section 112(n)(6) Clean Air Act as Amended," Final Report, EPA550-R-93-001, Washington, D.C., 1993.

U.S. Environmental Protection Agency (USEPA), "List of Regulated Substances and Thresholds for Accidental Release Prevention; Requirements for Petitions Under Section 112(r) of the Clean Air Act as amended (40 CFR Parts 9 and 68)," Federal Register, Vol. 59, No. 20, pp. 4478-4499, January 31, 1994.

U.S. Environmental Protection Agency (USEPA), Federal Emergency Management Agency (FEMA), and U.S. Department of Transportation (DOT), "Technical Guidance for Hazards Analysis," Appendix D, Washington, D.C., 1987.

U.S. Nuclear Regulatory Commission (USNRC), "Final Generic Environmental Statement on the Use of Recycle Plutonium in Mixed Oxide Fuel Light Water Cooled Reactors," NUREG-0002, Washington, D.C., 1976.

U.S. Nuclear Regulatory Commission (USNRC), "Assessment of the Public Health Impact from the Accidental Release of $\mathrm{UF}_{6}$ at the Sequoyah Fuels Corporation Facility at Gore, Oklahoma-Main Report," NUREG-1189, Vol. 1, Washington, D.C., 1986a.

U.S. Nuclear Regulatory Commission (USNRC), "Rupture of Model 48Y UF 6 Cylinder and Release of Uranium Hexafluoride: Sequoyah Fuels Facility at Gore, Oklahoma, January 4, 1986," NUREG-1179, Vol. 1, Washington, D.C., $1986 \mathrm{~b}$.

U.S. Nuclear Regulatory Commission (USNRC), "A Regulatory Analysis on Emergency Preparedness for Fuel Cycle and Other Radioactive Material Licensees - Final Report," NUREG-1140, Washington, D.C., 1988a. 
U.S. Nuclear Regulatory Commission (USNRC), "Nuclear Fuel Cycle Facility Accident Analysis Handbook," NUREG-1320, Washington, D.C., 1988 b.

U.S. Nuclear Regulatory Commission (USNRC), "Evaluation of Health Effects in Sequoyah Fuels Corporation Workers from Accidental Exposure to Uranium Hexafluoride," NUREG/CR-5566, Washington, D.C., 1990.

U.S. Nuclear Regulatory Commission (USNRC), "Chemical Toxicity of Uranium Hexafluoride Compared to Acute Effects of Radiation - Final Report," NUREG-1391, Washington, D.C., 1991.

VCH Verlagsgesellschaft mbH, Ullmann's Encyclopedia of Industrial Chemistry, Vol. A27, Fifth Edition, Weinheim, Germany 1996.

Westinghouse Electric Corporation,"Application for Renewal of License Number SNM-1107," Pittsburgh, Pennsylvania, 1995. 


\section{APPENDIX B}

SUMMARY OF METHODS FOR PREDICTING THE CHARACTERISTICS OF ACCIDENTAL RELEASES OF CHEMICALS 


\section{APPENDIX B TABLE OF CONTENTS}

\section{APPENDIX B: SUMMARY OF METHODS FOR PREDICTING THE CHARACTERISTICS OF ACCIDENTAL RELEASES OF CHEMICALS}

TABLE OF CONTENTS $\ldots \ldots \ldots \ldots \ldots \ldots \ldots \ldots \ldots \ldots \ldots \ldots \ldots \ldots \ldots \ldots \ldots \ldots \ldots$

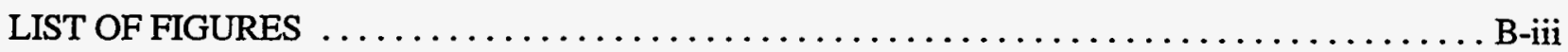

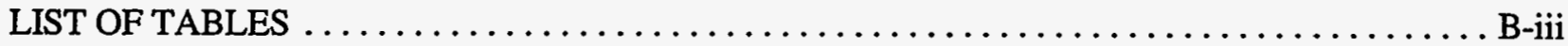

B.1 Identification of a Representative Range of Source Terms $\ldots \ldots \ldots \ldots \ldots \ldots \ldots \ldots$ B-7

B.1.1 Range of Possible Release Scenarios . . . . . . . . . . . . . . . . . B-7

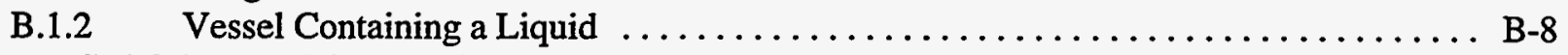

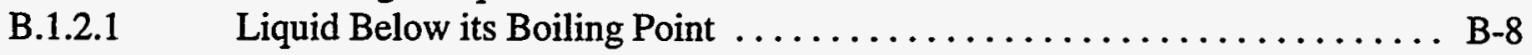

B.1.2.2 Refrigerated Liquid in a Vessel (Scenario 2, Figure B-1) ........... B-8

B.1.2.3 Gas Liquefied Under Pressure (Scenario 3, Figure B-1) ............ B-9

B.1.2.4 Releases from the Vapor Space of a Pressurized Vessel

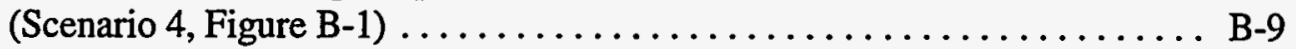

B.1.2.5 Spillage Onto Water (Scenario 5, Figure B-1) .............. B-10

B.1.3 Illustration of Use of Scenario Identification Flow Chart $\ldots \ldots \ldots \ldots \ldots \ldots \ldots$ B-10

B.1.3.1 Spillage of Hydrogen Fluoride from a Storage Vessel $\ldots \ldots \ldots \ldots \ldots \ldots$ B-10

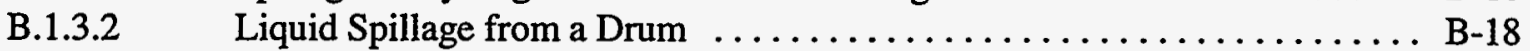

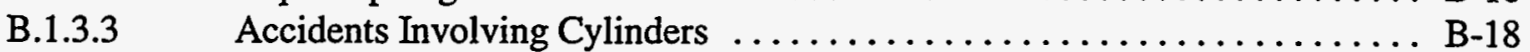

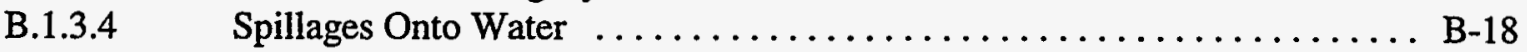

B.1.3.5 Spillage of Refrigerated Liquid ....................... B

B.1.3.6 Pressurized Releases - Flashing Jets . . . . . . . . . . . . . B-19

B.1.3.7 Vapor Releases Driven by High Pressure $\ldots \ldots \ldots \ldots \ldots \ldots \ldots \ldots \ldots \ldots \ldots \ldots$

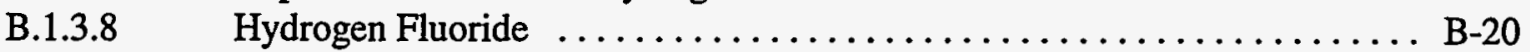

B.1.3.9 Uranium Hexafluoride $\ldots \ldots \ldots \ldots \ldots \ldots \ldots \ldots \ldots \ldots \ldots \ldots \ldots \ldots \ldots \ldots \ldots$

B.2 Spillages of Liquids Onto Surfaces $\ldots \ldots \ldots \ldots \ldots \ldots \ldots \ldots \ldots \ldots \ldots \ldots \ldots \ldots \ldots$

B.2.1 Spillage of Liquid with Above Ambient Boiling Point into a Diked Area

- Hydrogen Fluoride . . . . . . . . . . . . . . . . . . . . . . B-21

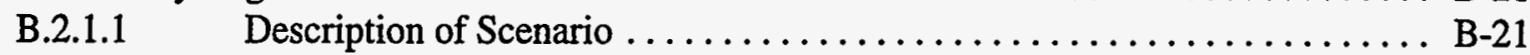

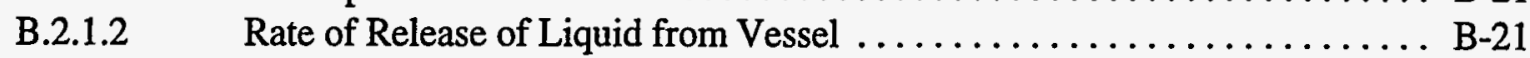

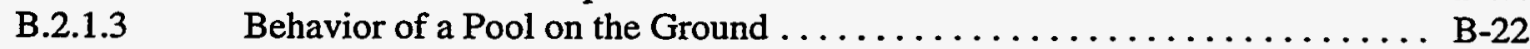

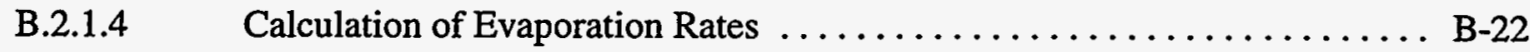

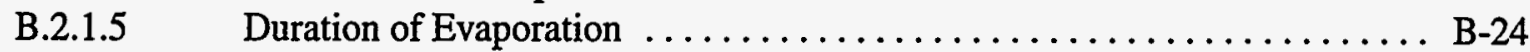

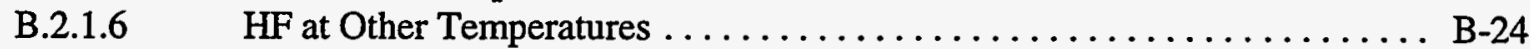

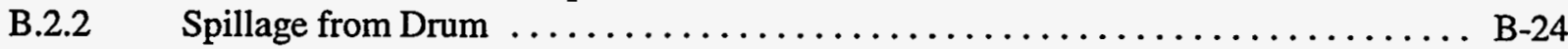

B.2.3 Spillage of Refrigerated Liquid into Diked Area $\ldots \ldots \ldots \ldots \ldots \ldots \ldots \ldots \ldots$ B-25

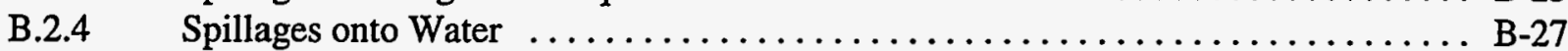

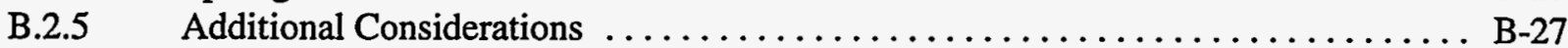

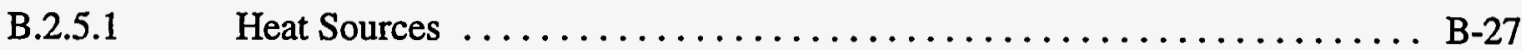

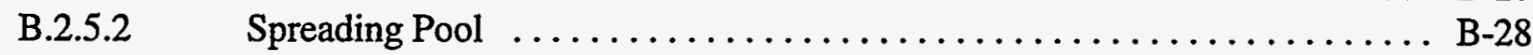




\section{APPENDIX B TABLE OF CONTENTS}

(Continued)

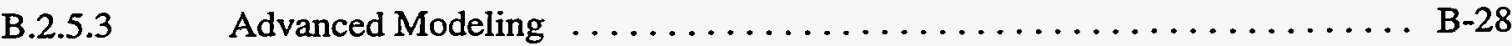

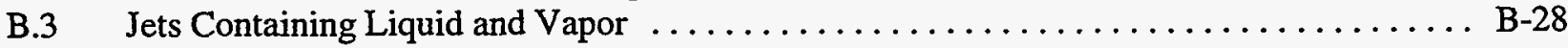

B.3.1 Theory of Emission Rate Formulas ......................... B-29

B.3.1.1 Gas That Partially Condenses on Depressurization $\ldots \ldots \ldots \ldots \ldots \ldots$ B-29

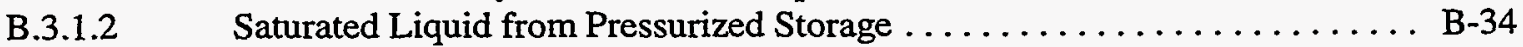

B.3.1.3 Subcooled Liquid in Pressurized Storage ................... B-36

B.3.2 Hydrogen Fluoride at Elevated Temperature and Pressure $\ldots \ldots \ldots \ldots \ldots \ldots \ldots$ B-37

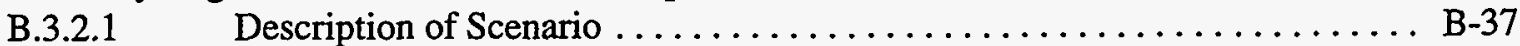

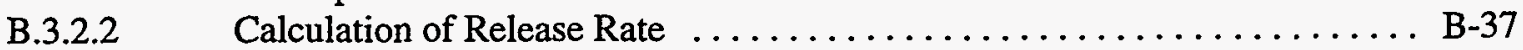

B.3.2.3 Other Characteristics of the Source Term ................. B-38

B.3.3 Release of Ammonia from a Large Tank . . . . . . . . . . . . . . . . B-39

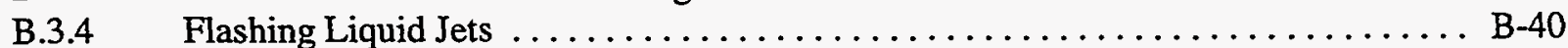

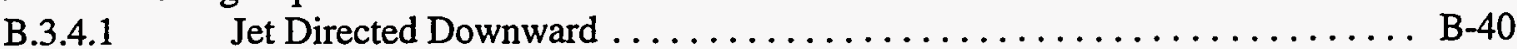

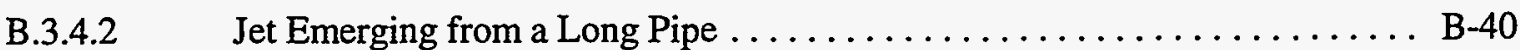

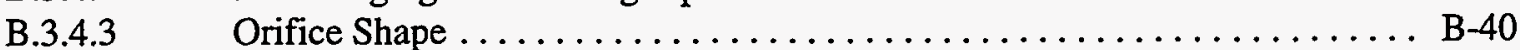

B.3.5 Jet Release of Liquid Uranium Hexafluoride From a Pressurized Cylinder . . . . . . B-40

B.3.5.1 Calculation of Release Rate of Uranium Hexafluoride . . . . . . . . B 41

B.3.5.2 Flashing and Sublimation of Uranium Hexafluoride $\ldots \ldots \ldots \ldots \ldots \ldots$ B-41

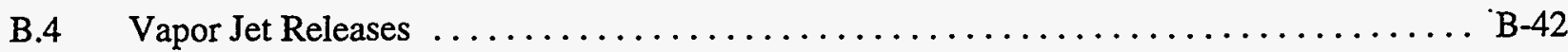

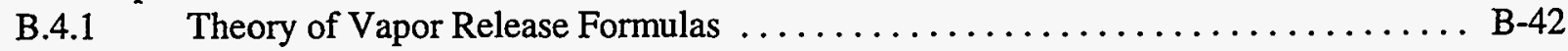

B.4.1.1 Estimate of Release Rate for a Gas Leak Directly from a Reservoir . . . . . . B-43

B.4.1.2 Discussion of Release Rates for a Gas Leak from a Pipeline Attached

to a Reservoir . . . . . . . . . . . . . . . . . . . . . . . B 49

B.4.2 Ammonia Vapor Release Scenario . ......................... B-49

B.4.3 Uranium Hexafluoride Vapor Releases From a Hole in a Cylinder Wall ........ B-51

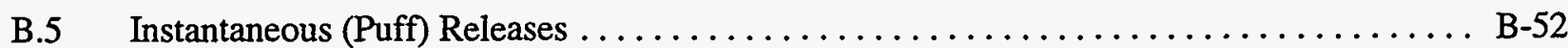

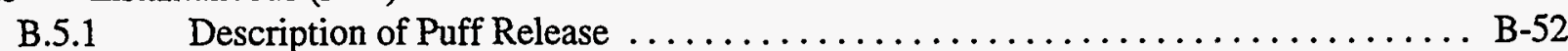

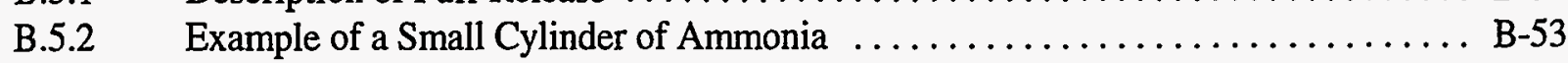

B.5.3 Example of a Large Cylinder of Uranium Hexafluoride $\ldots \ldots \ldots \ldots \ldots \ldots \ldots$ B-53

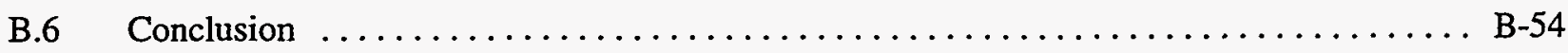

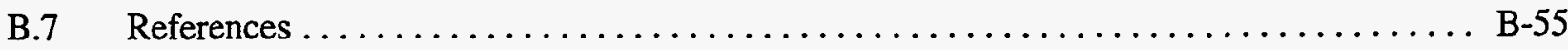




\section{APPENDIX B}

\section{LIST OF FIGURES}

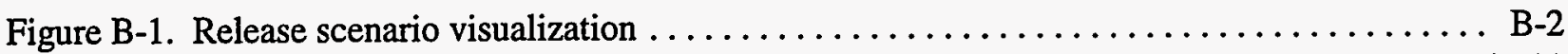

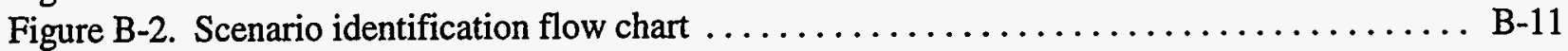

Figure B-3. Evaporation rate as a function of time and pool area $\ldots \ldots \ldots \ldots \ldots \ldots \ldots \ldots \ldots$ B-26

Figure B-4. Calculation flow chart for liquid droplet scenarios $\ldots \ldots \ldots \ldots \ldots \ldots \ldots \ldots \ldots$ B-30

\section{LIST OF TABLES}

Table B-1. Evaporation Rate as a Function of Time 


\section{APPENDIX B SUMMARY OF METHODS FOR PREDICTING THE CHARACTERISTICS OF ACCIDENTAL RELEASES OF CHEMICALS}

The objective of this Appendix is to provide guidance on developing source terms for atmospheric dispersion modeling for accidents involving the release of chemicals. In order to identify the physical processes that control the nature and rate of vapor cloud generation, a range of initial conditions is considered. The modes of failure of storage containers and the types of physical processes which occur during a release are reviewed. Procedures for estimating the release rate are presented for each of the identified release scenarios.

The following kinds of release scenarios are of interest (Christensen and Kaiser 1993; USNRC 1984):

- leaks, ruptures, and fires involving drums and cylinders

- evaporating pools formed by spills and tank failures

- flashing and evaporating liquefied gases released from pressurized storage.

The configuration of the system that contains the chemical and the geometry of a breach in the containment, coupled with the physical state of the material and the chemical and physical processes which occur in the release event, determine the nature of the appropriate release model. Section B.1 presents a classification of release events based upon these considerations. The section describes a set of basic release scenarios, summarized in Figure B-1, which may occur at fuel cycle facilities. The section also contains a flow chart that is intended to help the modeler accurately define the scenario of interest. The flow chart also directs the reader to specific sections of this report, where various release scenarios are discussed in detail, except in those cases where the details are beyond the scope of this report because complex physical phenomena, such as partial aerosolization, are involved. Discussions of the release of ammonia $\left(\mathrm{NH}_{3}\right)$ and hydrogen fluoride $(\mathrm{HF})$ are presented to introduce the range of phenomena that may be encountered.

Sections B. 2 through B.5 discuss in detail how several release scenarios should be modeled. The expectation is that, by following detailed discussions of the inputs, the reader will understand what is required to produce a credible source term for a particular scenario. The reader should note that Sections B.2 through B.5 are organized in groups for which the physical and chemical phenomena are similar:

- Section B.2 addresses vapors evaporating from liquids spilled onto surfaces (e.g., onto the ground or onto water)

- Section B.3 addresses flashing liquid jets that result in an initial airborne release containing both vapors and liquid droplets (aerosols)

- Section B.4 addresses vapor jet releases driven out of a vessel by high pressure

- Section B.5 addresses instantaneous (puff) releases.

As noted above, Section B.2 is concerned with the spillage of liquids onto surfaces from which evaporation subsequently occurs. Note that the spillage of uranium hexafluoride $\left(\mathrm{UF}_{6}\right)$ is not considered because $\mathrm{UF}_{6}$ does not exist as a liquid under ambient conditions. The first case is that of cool HF (i.e., HF at a temperature considerably below its atmospheric boiling point) spilling into a diked area. This scenario has been chosen because it serves as a good introduction to the topic of evaporating pools, which are the 


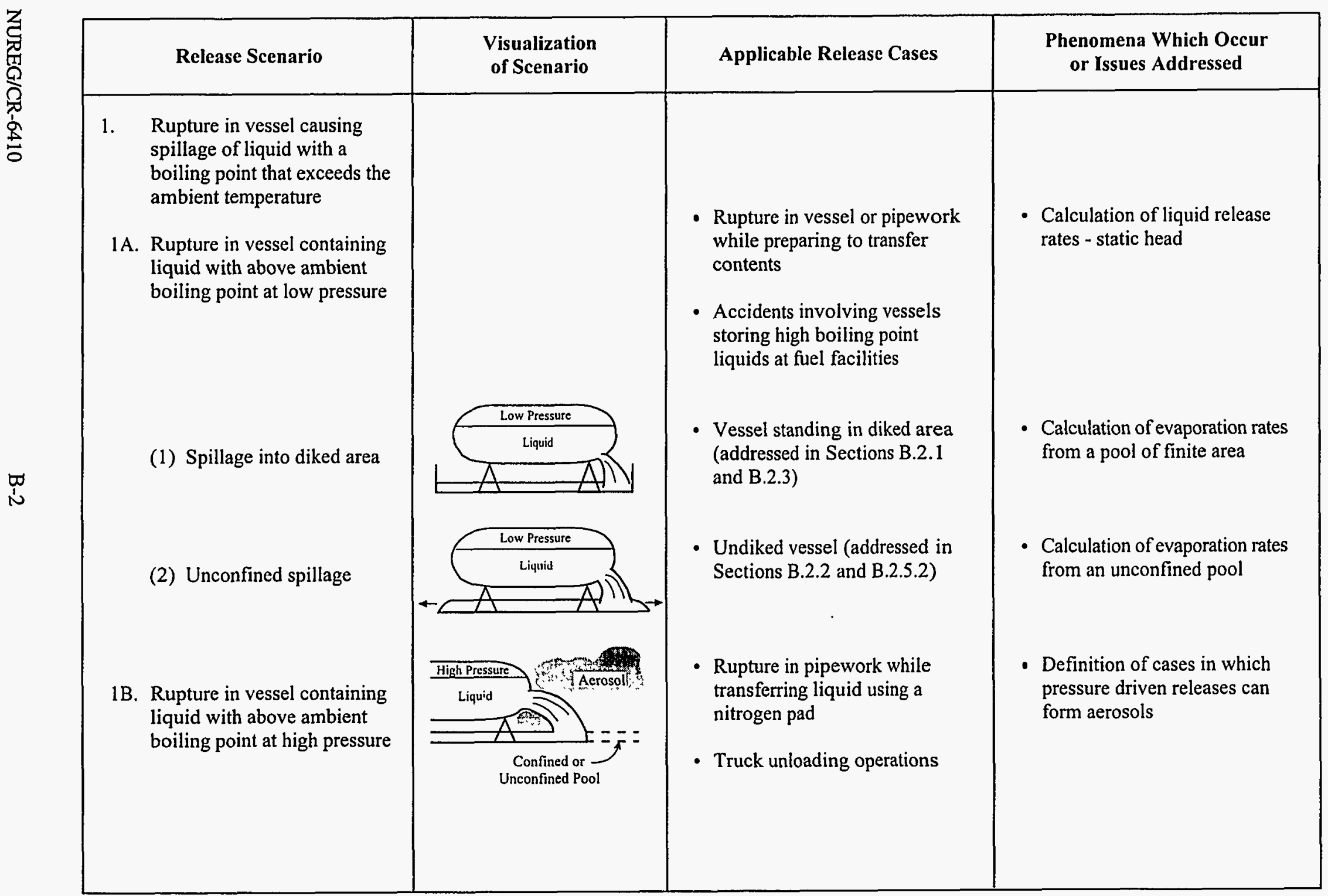

Figure B-1. Release scenario visualization, page 1 


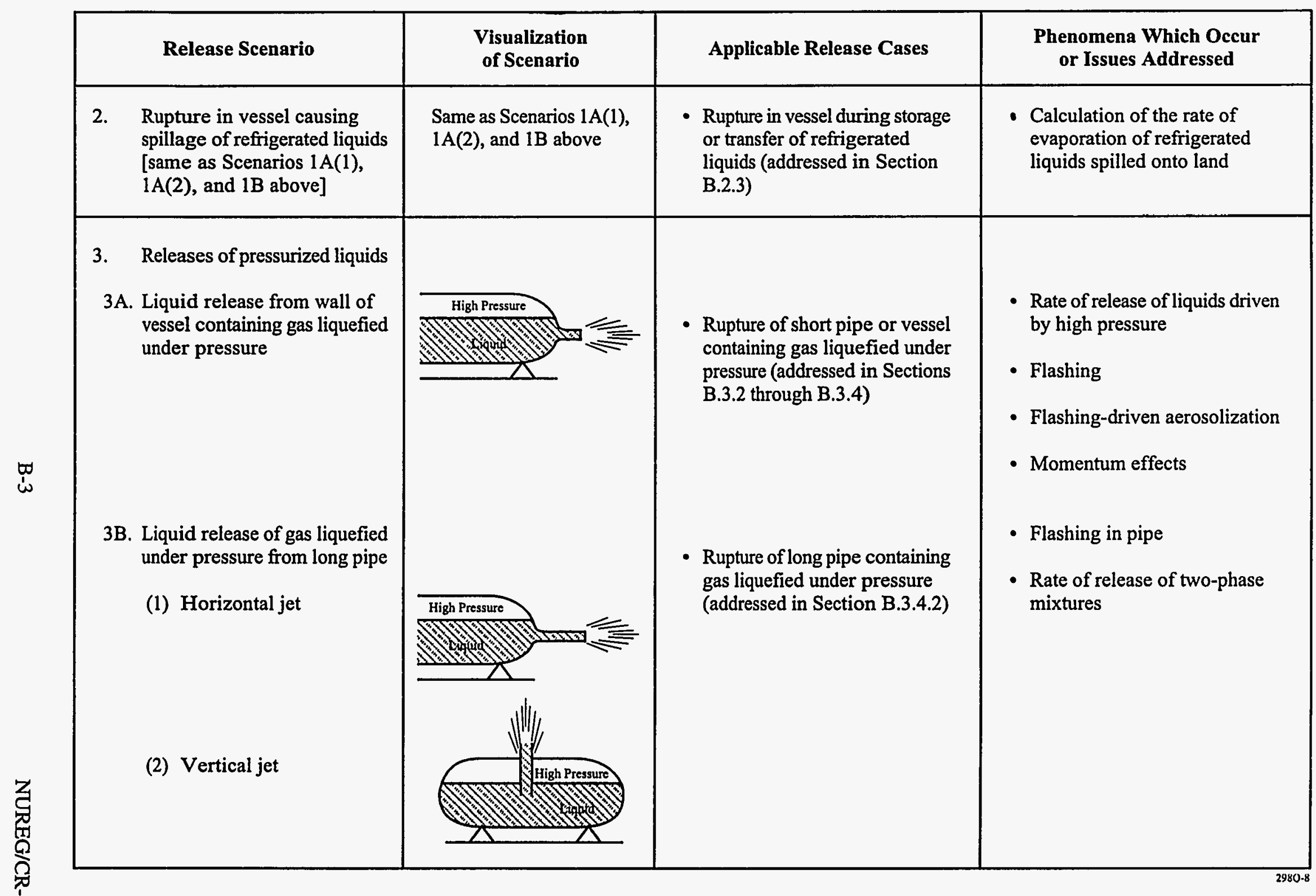

Figure B-1. Release scenario visualization,page 2 


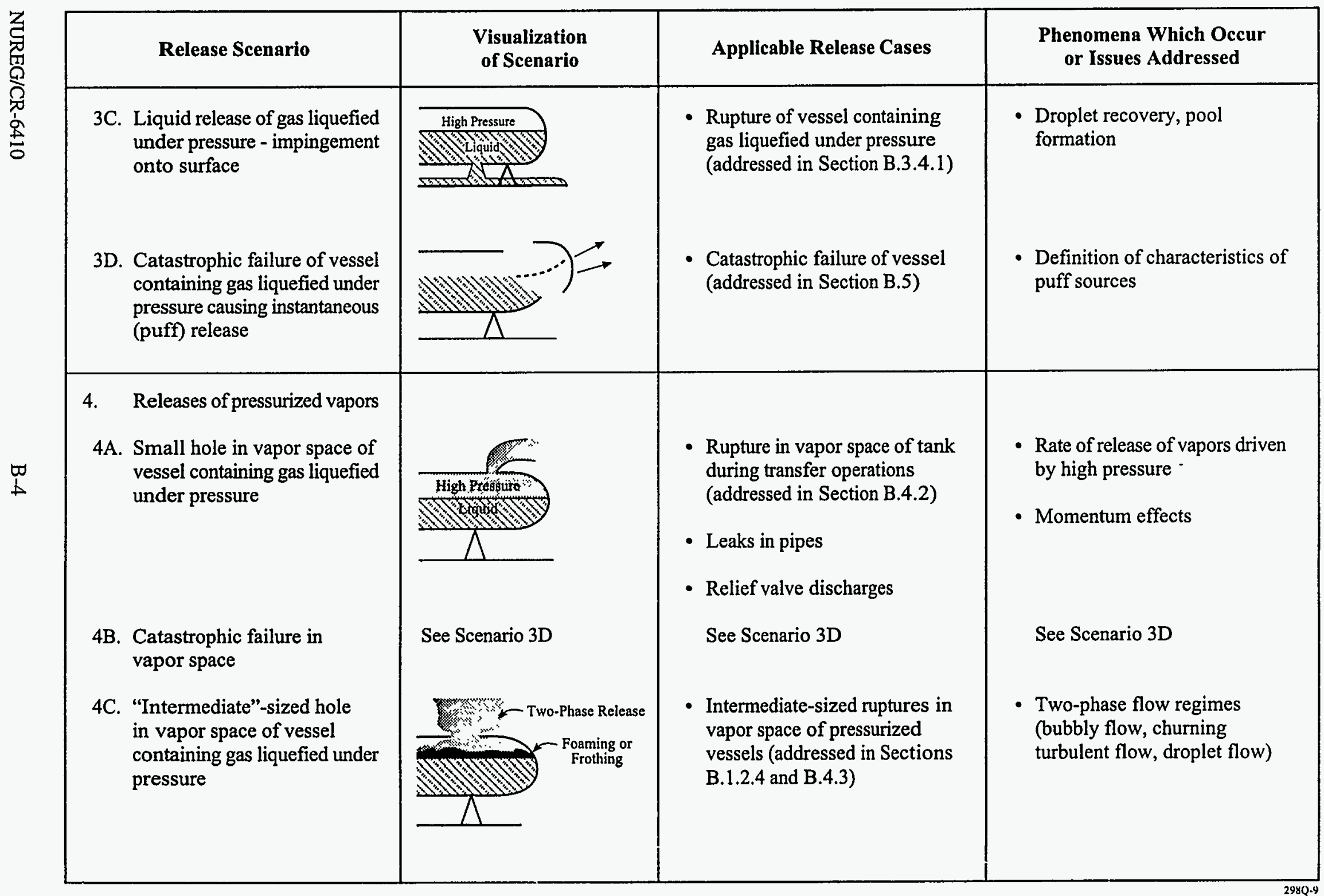

Figure B-1. Release scenario visualization, page 3 


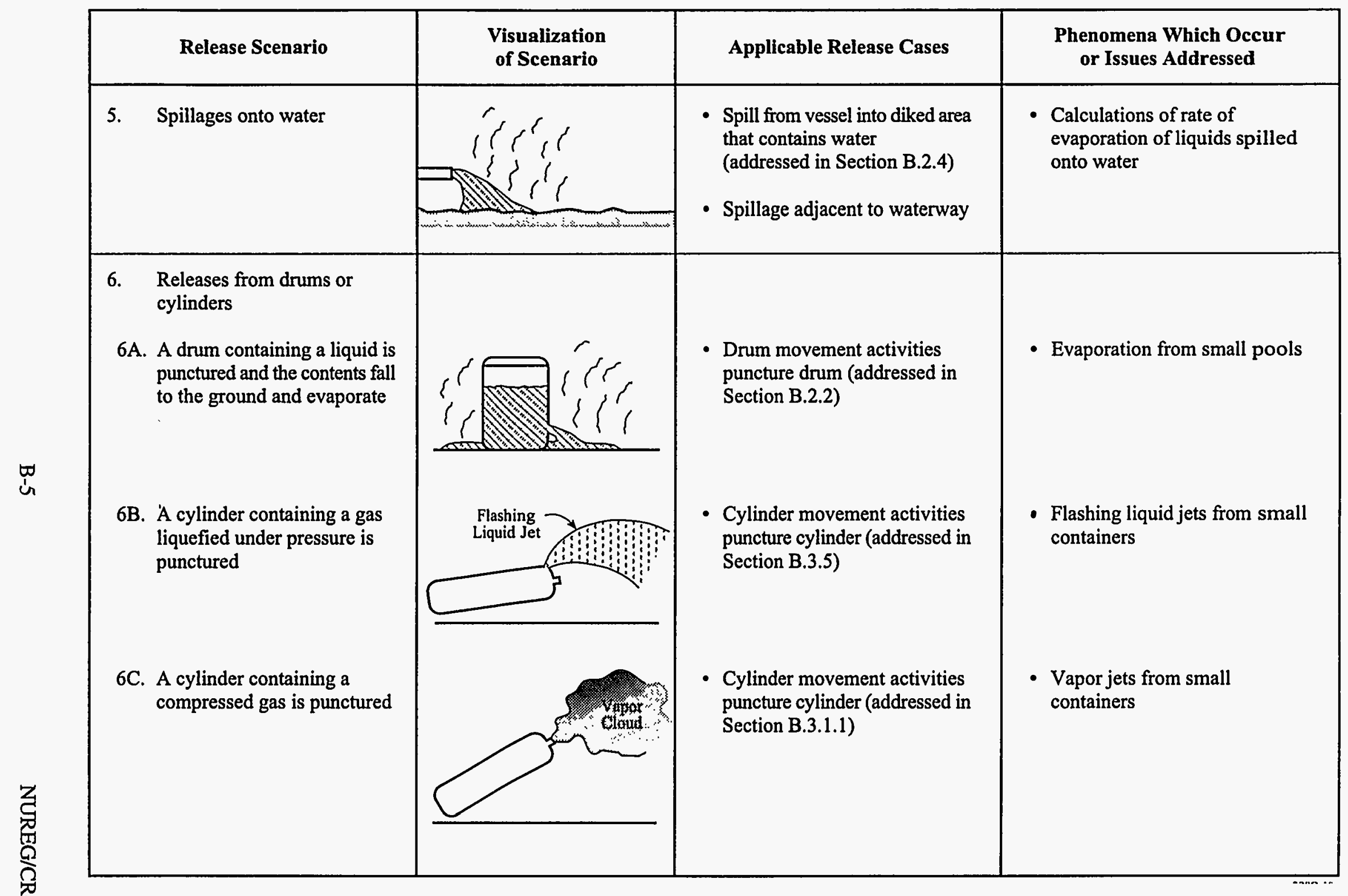

Figure B-1. Release scenario visualization, page 4 


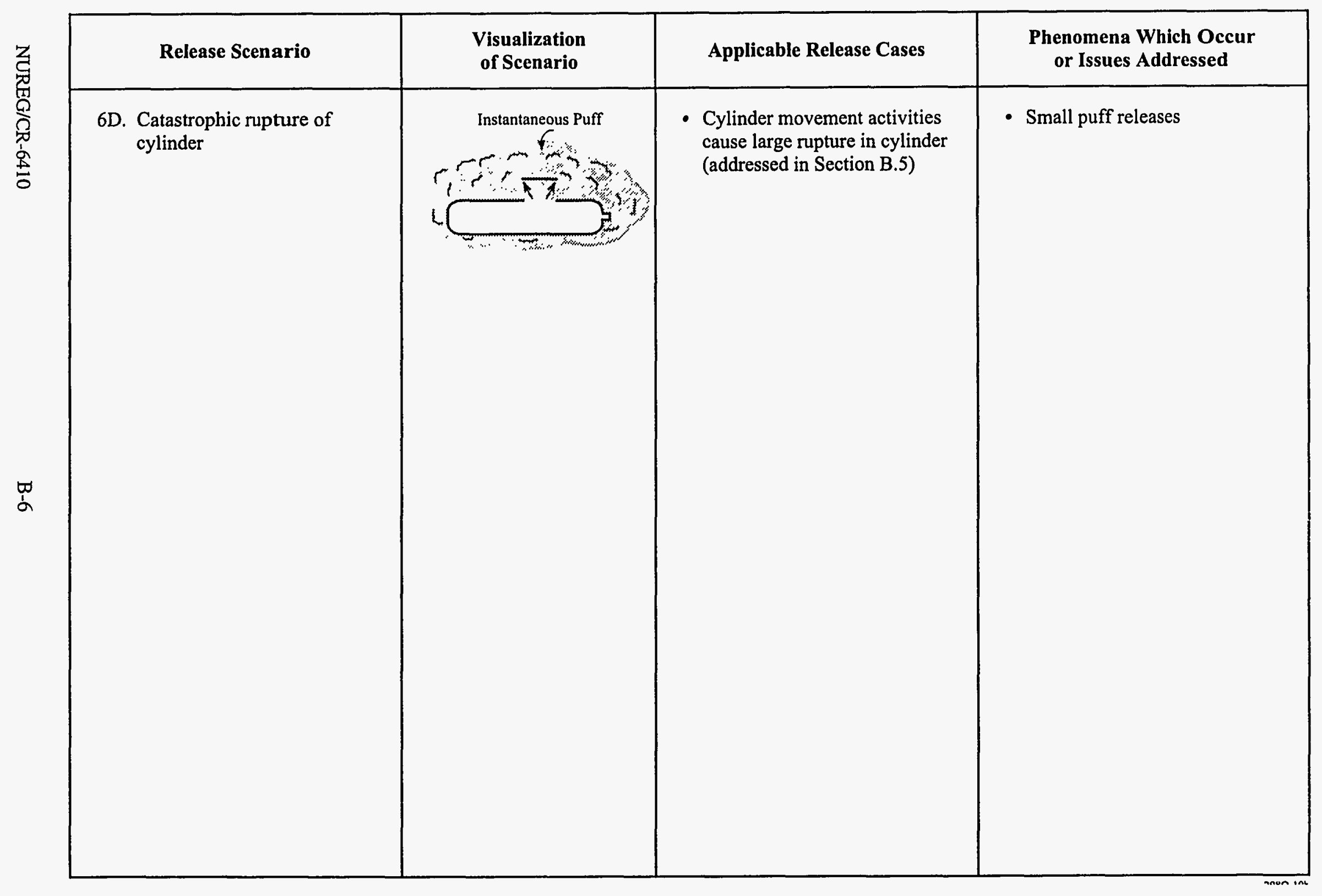

Figure B-1. Release scenario visualization, page 5 
likely mode of release for many high boiling point liquids at the fuel cycle facilities. A similar case considered is that of small-scale spillage from a drum. The principal difference from a large-scale spill is the relative smallness of the quantity released.

In Section B.2, the spillage of refrigerated $\mathrm{NH}_{3}$ into a diked area is also discussed as an introduction to the modeling of spillages of refrigerated liquids.

Section B. 2 continues with a brief discussion of spillages onto water. The discussion is not detailed but is included for completeness; the most important phenomena are summarized, and the reader is referred to appropriate references. Section B.2 concludes with discussions of some additional issues relating to evaporating pools. These include additional sources of heat, spreading pools, and advanced numerical modeling techniques.

Section B.3 is devoted to the subject of flashing liquid jets in which the initial source term consists of a mixture of vapor and liquid droplets that is released directly from a leaking vessel or pipework. The first example given is that of a release of HF from a $1.3 \mathrm{~cm}(1 / 2 \mathrm{in})$ diameter orifice in a vessel containing HF at elevated temperature and pressure. It is useful to begin with this scenario because, by carefully considering it, the reader will become familiar with many of the issues that must be addressed if such scenarios are to be modeled realistically.

The HF example is followed by consideration of a flashing liquid release from a large tank of $\mathrm{NH}_{3}$ at ambient temperature. Finally, the specific example of a tank containing $12,000 \mathrm{~kg}(27,000 \mathrm{lb})$ of $\mathrm{UF}_{6}$ is considered.

Section B.4 is devoted to a discussion of releases from the vapor space of a vessel from which the expected release will be pure vapor. Specific examples of $\mathrm{NH}_{3}$ and $\mathrm{UF}_{6}$ storage are chosen.

Section B.5 considers puff releases. The reader is shown how to model the catastrophic failure of vessels. The specific examples chosen are those of a $150 \mathrm{~kg}(330 \mathrm{lb})$ cylinder of $\mathrm{NH}_{3}$ and a $12,000 \mathrm{~kg}$ $(27,000 \mathrm{lb})$ cylinder of $\mathrm{UF}_{6}$.

\section{B.1 Identification of a Representative Range of Source Terms}

\section{B.1.1 Range of Possible Release Scenarios}

One of the first things a modeler learns is that there is no single source term and no single atmospheric dispersion model that will cover all of the different kinds of releases that might take place. The following examples are intended to serve as surrogates for many of the more likely accident scenarios that might be encountered at fuel cycle licensees' sites. The examples are organized in relation to the physical and chemical phenomena that need to be addressed.

It is convenient to begin with one simple case that can be used to illustrate many of the issues that confront a modeler. This is the case of a storage vessel or truck containing a liquid, together with some associated pipework. It is convenient to begin with a variety of possible leaks from the vessel because, in discussing the range of possible source terms, the reader will be introduced to many of the issues and phenomena that a modeler must consider where various liquids are stored and transferred. 
Figure B-1 contains a summary of the range of possible release scenarios that might arise for a vessel containing a liquid. The third column of Figure B-1 gives specific cases for which the release scenarios are applicable, along with the sections of this appendix for systems in which these cases are discussed. Those sections describe how to calculate the characteristics of the source terms.

\section{B.1.2 Vessel Containing a Liquid}

Consider the simple case of a vessel containing a liquid that must be transferred to another vessel and then shipped off site. The first question to address is whether the liquid is at or below its atmospheric boiling point, or whether it is a gas liquefied under pressure.

\section{B.1.2.1 Liquid Below its Boiling Point}

Suppose there is a liquid in a vessel with a boiling point that exceeds the ambient temperature. Two cases are considered: (a) the driving pressure is insufficient to cause aerosolization, and (b) the driving pressure causes aerosolization.

\section{Spillage with No Aerosolization (Scenario 1A, Figure B-1)}

In this case, the liquid spills onto the ground, where it may be confined in a dike or may spread over an unconfined area. The principal issue that must be addressed is the rate of evaporation. The rate of evaporation depends on factors such as wind speed, vapor pressure, area of the dike, temperature of the ground, and degree of insolation.

\section{Spillage with Aerosolization (Scenario 1B, Figure B-1)}

If the pressure in the vessel is high enough, a jet of liquid may emerge with a velocity high enough for hydrodynamic forces to cause aerosolization. Thus, there will be an initial airborne source term consisting of liquid droplets, followed by evaporation from the pool that remains behind. This scenario provides an introduction to circumstances in which aerosolization could be caused by the presence of a high driving pressure, such as might be present if, for example, nitrogen pressure is being used to effect the transfer from the vessel. This case also serves to introduce techniques for calculating the liquid release rate when driven by high pressures, in addition to the pressure arising from its own weight (the static head).

\section{B.1.2.2 Refrigerated Liquid in a Vessel (Scenario 2, Figure B-1)}

The next case to consider is that of a refrigerated liquid at atmospheric pressure with a boiling point that is lower than the ambient temperature, such as refrigerated chlorine $\left(\mathrm{Cl}_{2}\right)$ or $\mathrm{NH}_{3}$. The liquid may also be spilled with or without aerosolization into a dike or into an unconfined area. The principal difference between spillage of refrigerated liquid and the spillage of liquid with a boiling point above ambient temperature is that the rate of evaporation of the pool is driven by heat conducted from the surface on which the pool is lying in the former case, rather than by mass transfer into the stream of air flowing above the pool in the latter case. Thus, this scenario serves as an introduction to the modeling required to assess the consequences of spillages of refrigerated materials. 


\section{B.1.2.3 Gas Liquefied Under Pressure (Scenario 3, Figure B-1)}

Scenario 3 on Figure B-1 illustrates some of the potential ways in which liquid might be released from a vessel containing a gas liquefied under pressure. For example, Scenario $3 \mathrm{~A}$ shows the outcome of a puncture in the side of a vessel. The liquid will be driven out by a combination of the vapor pressure and the static head. In this case, the key phenomenon for this release is that of flashing, i.e., part of the liquid will immediately flash to vapor. Some of the remaining liquid will remain airborne as fine liquid droplets, and some will fall onto the ground, with the relative proportions being dependent on such factors as superheat. Thus, this scenario serves as an introduction to the key phenomena associated with flashing, liquid jets, including aerosolization, and the need to take into account momentum effects.

Scenario 3B applies when a rupture takes place in a long section of pipework. In this case, there will likely be some flashing in the pipe. This strongly influences the predicted rate of release. There will be further flashing and aerosolization once the release emerges into the atmosphere.

Scenario $3 \mathrm{C}$ applies when the emerging jet is directed at a surface. In this case, there is the potential for droplet recovery, leading to the formation of a pool on the ground, with only a fraction of the initiallyformed aerosol remaining airborne.

If there should be catastrophic failure of the vessel (Scenario 3D), there will be immediate bulk boiling and the formation of vapor and aerosol. The resultant expansion will be highly turbulent, causing an initial puff to form that will likely contain aerosol, vapor, and air. Thus, this source term is used to illustrate how to model puff releases.

\section{B.1.2.4 Releases from the Vapor Space of a Pressurized Vessel (Scenario 4, Figure B-1)}

One potential release scenario is that of an escape of gas from a small hole in the vapor space of a pressurized vessel (Scenario 4A, Figure B-1). In this context, the definition of a small hole is that $\mathrm{a} / \mathrm{A} \ll 1$, where $\mathrm{a}$ is the area of the hole and $\mathrm{A}$ is the area of the liquid surface. For most storage vessels, the shearing off of a valve in the vapor space leads to an orifice with $a / A<<1$. In this case, vapor will emerge from the orifice. The flow is likely to be choked (except for pressures of the order of only 100 to $200 \mathrm{kPa}$ [1 to 2 atmospheres]) - that is, the vapor emerges at the speed of sound. Thus, this case will enable the analyst to consider jet releases of vapor. This case also applies to releases from relief valves and to releases of lower velocity from stacks. In addition, the vapors in question may be buoyant or may be denser than air.

If there is a catastrophic failure in the vapor space of a vessel (Scenario $4 \mathrm{~B}$, Figure B-1), the consequences will be the same as for a catastrophic release in the liquid space (Scenario 3D, Figure B-1).

There is a category of intermediate failures, as illustrated in Scenario $4 \mathrm{C}$ on Figure B-1, in which it is not immediately clear whether the hole can be categorized as either small or large. Considerable relevant work has been done by the American Institute of Chemical Engineers' Design Institute for Emergency Relief Systems program (Fisher, et al. 1992). Any one of up to four flow regimes through the orifice is possible:

- pure vapor - already discussed for a small hole

- bubbly flow regime, in which the liquid phase is continuous with discrete bubbles 
- churning turbulent flow regime, in which the liquid phase is continuous with coalesced vapor regions of increasing size

- droplet flow regime, in which the vapor phase is continuous with discrete liquid droplets.

The transition between these various flow regimes occurs with increasing volumetric vapor flux and is influenced by fluid characteristics and by the presence of impurities. This case is not discussed because the details are beyond the scope of this report.

\section{B.1.2.5 Spillage Onto Water (Scenario 5, Figure B-1)}

For completeness, the case of spillage onto water is discussed in Section B.2.4, which gives brief guidance to the modeler on how to calculate rates of evaporation when the important driving forces are the rate of transfer of heat across the water/substance interface and the generation of heat if the substance is soluble in water.

\section{B.1.3 Illustration of Use of Scenario Identification Flow Chart}

Figure B-2 helps the modeler to identify and to select different accident scenarios by means of a scenario identification flow chart. The purpose of the flow chart is to enable the modeler to make decisions on various modeling assumptions and to choose from a range of possible release scenarios. Sections B.1.3.1 through B.1.3.9 describe how to use the flow chart.

\section{B.1.3.1 Spillage of Hydrogen Fluoride from a Storage Vessel}

Assume that there is a vessel containing $\mathrm{HF}$ at a temperature considerably below its boiling point. This corresponds to Scenario 1 on page 1 of Figure B-2, where a number of variations are displayed.

The boiling point of $\mathrm{HF}$ is approximately $293 \mathrm{~K}\left(67^{\circ} \mathrm{F}\right)$, which may be above the ambient temperature; the temperature on a cold day might be, for example, $273 \mathrm{~K}\left(32^{\circ} \mathrm{F}\right)$, or the HF might be deliberately refrigerated, so the temperature of the HF would be well below its boiling point. Therefore, the reader chooses the upper branch on page 2 of Figure B-2, where it must be determined whether the HF is under its own static head, i.e., the pressure is due to its own weight (Case A on Figure B-2), or under additional pressure from some other source (Case B on Figure B-2).

Generally, HF will be under its static head prior to being transferred from the vessel in which it is stored. It will also be under the static head in the vessel if it is being withdrawn by a pump. In this case, the reader is directed to go to page 3 of Figure B-2, where the choice is between spillage into a diked or undiked area. The reader is then directed to Sections B.2.1 or B.2.3 for spillage into a diked area or to Section B.2.5.2 for spillage into an undiked area. Section B.2.1 gives a detailed analysis of how to calculate the rate of evaporation of HF spilled into a diked area.

Returning to page 2 of Figure B-2, the HF may be under high pressure (Case B), for example, if a nitrogen pad is being used to transfer the liquid HF from the vessel. In this case, the reader proceeds to page 3 of Figure B-2 and on to Sections B.2.1, B.2.3, or B.2.5.2 of this report just as was illustrated for the case of "static head only". On page 3 of Figure B-2, Cases C and D differ from Cases A and B only by their effective pressure ranges. This means the liquid will be driven out of the vessel at a higher rate than it would be for the case of a static head only. At this point, an important assumption is made, namely that the 


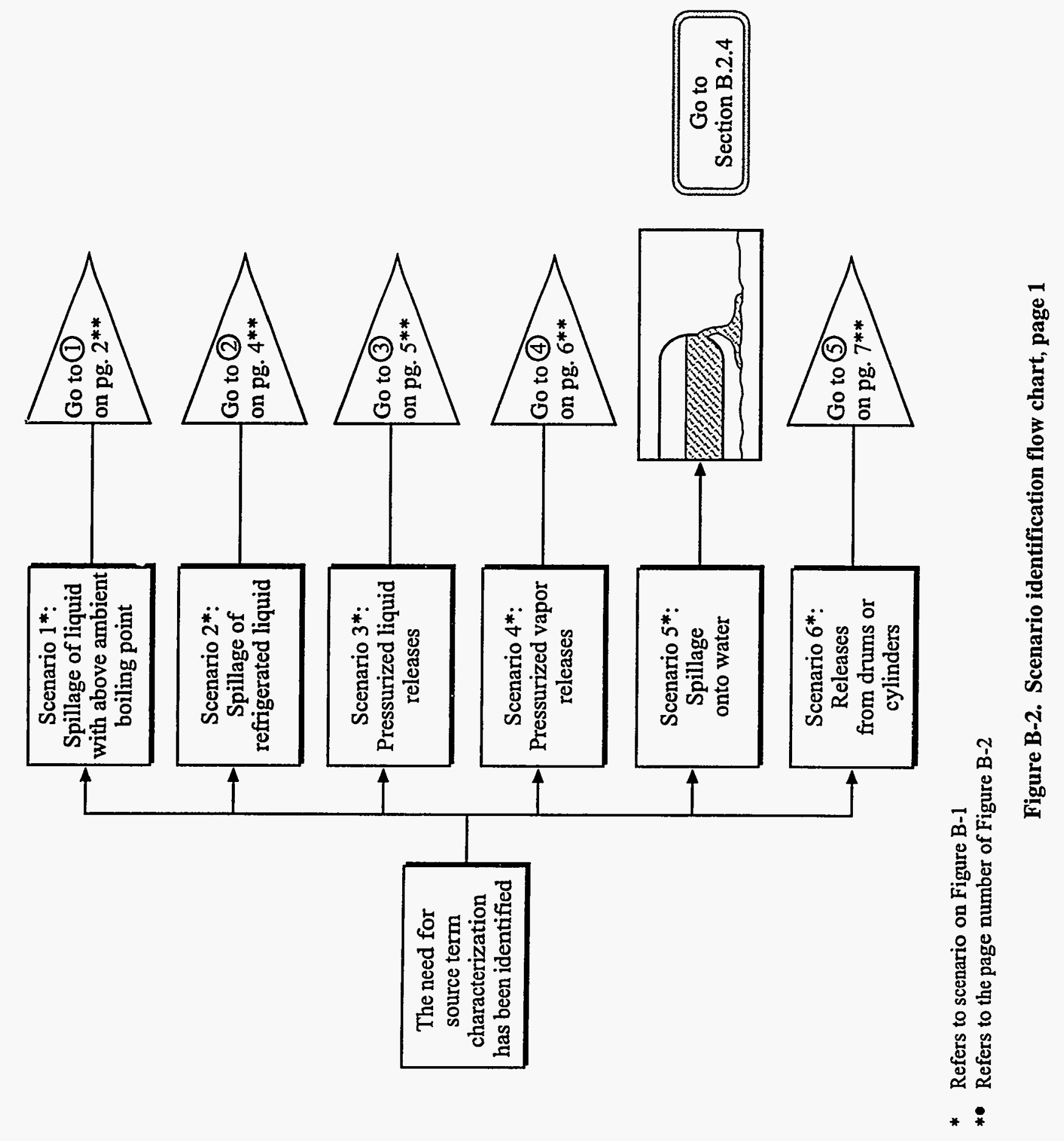




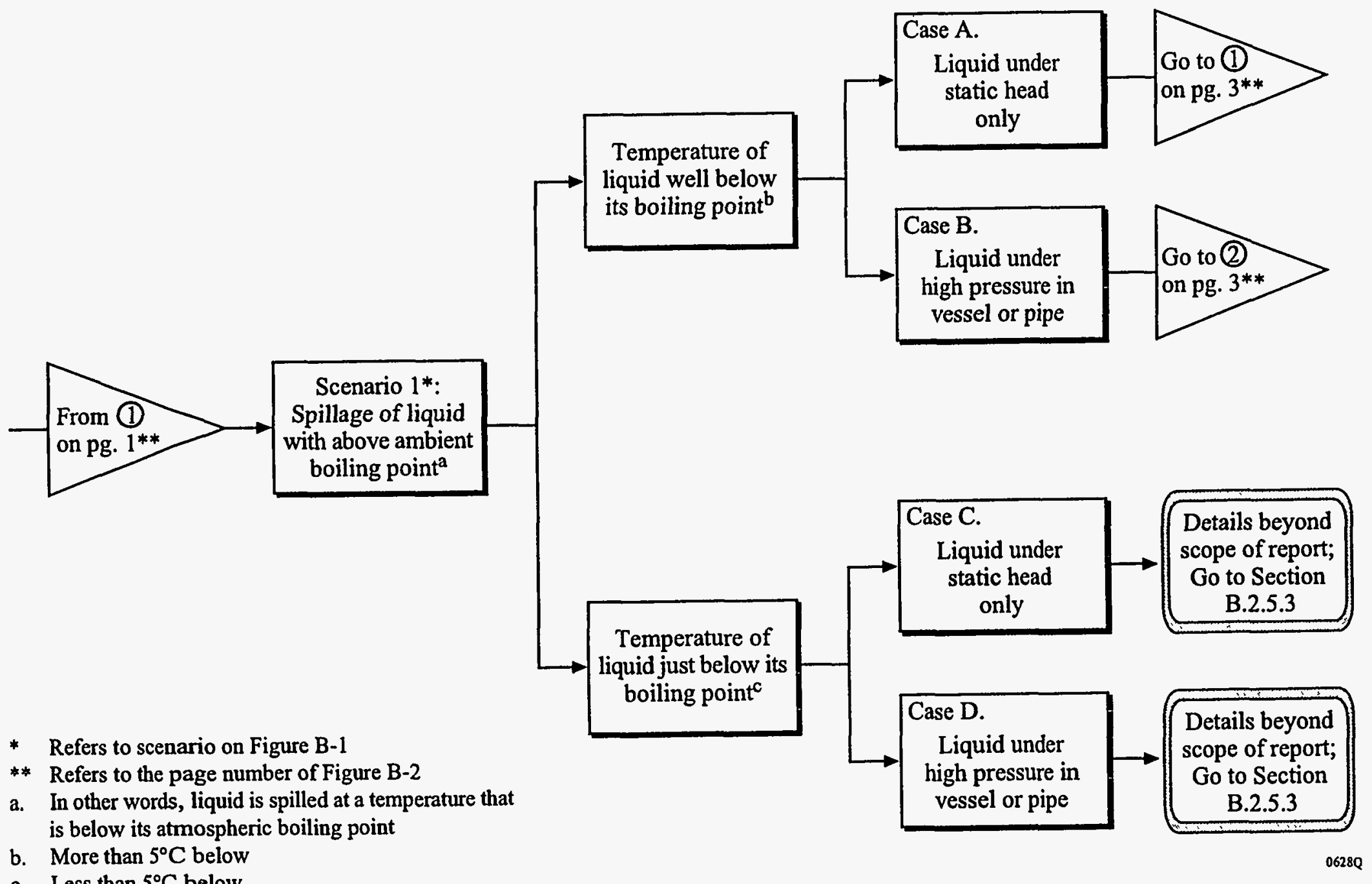

Figure B-2. Scenario identification flow chart, page 2 


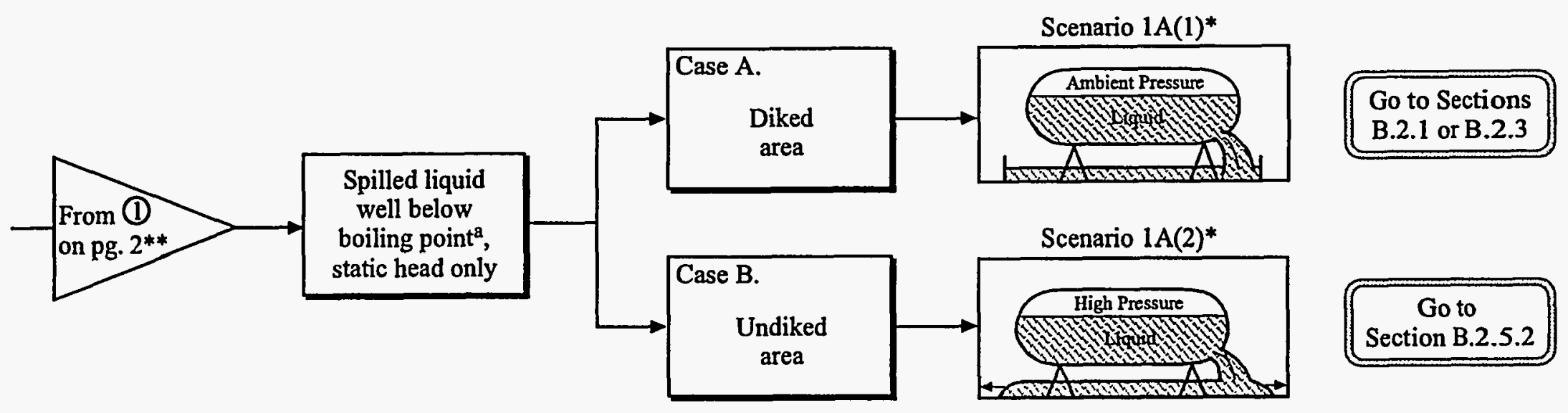

$\stackrel{\square}{\omega}$

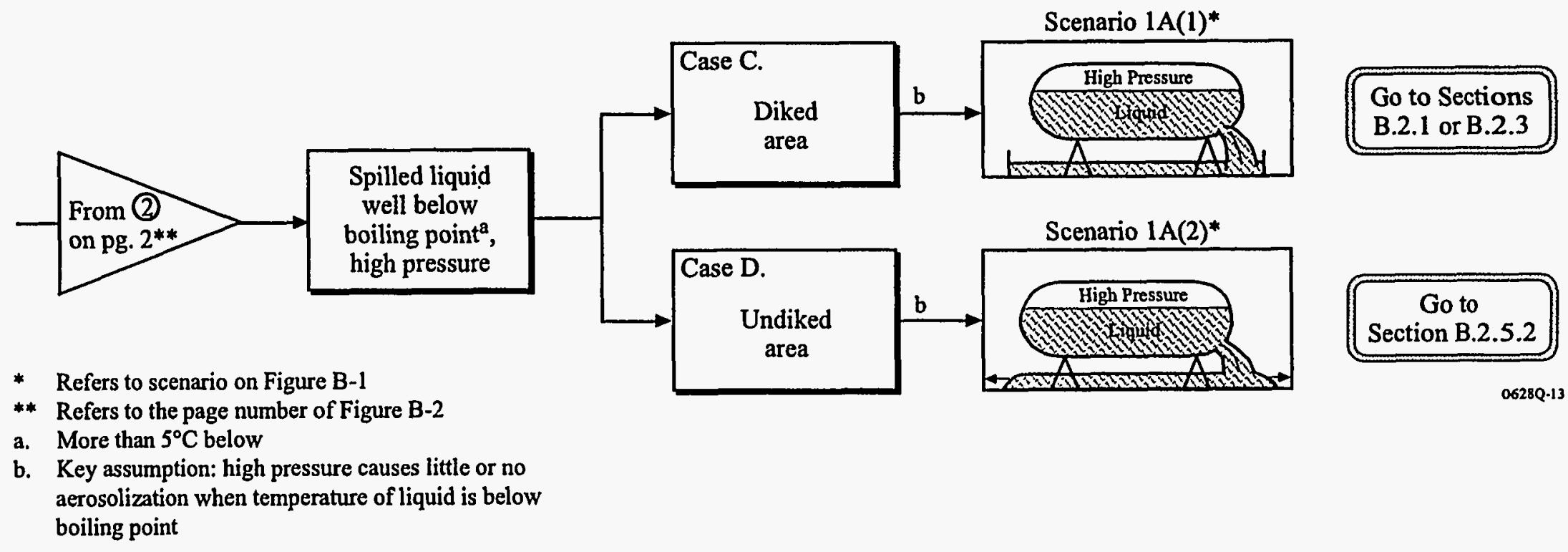

Figure B-2. Scenario identification flow chart, page 3 

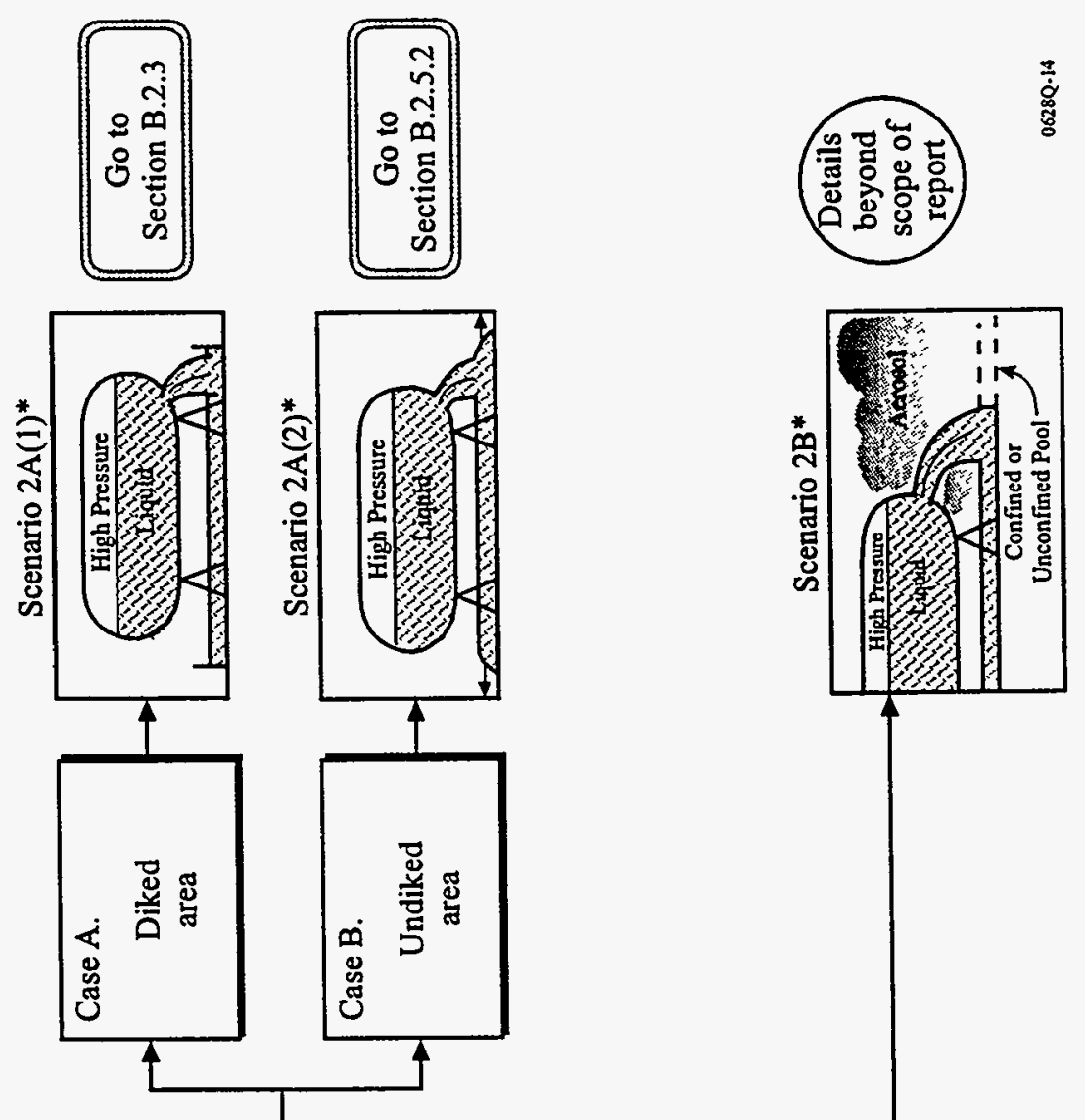

ช. 


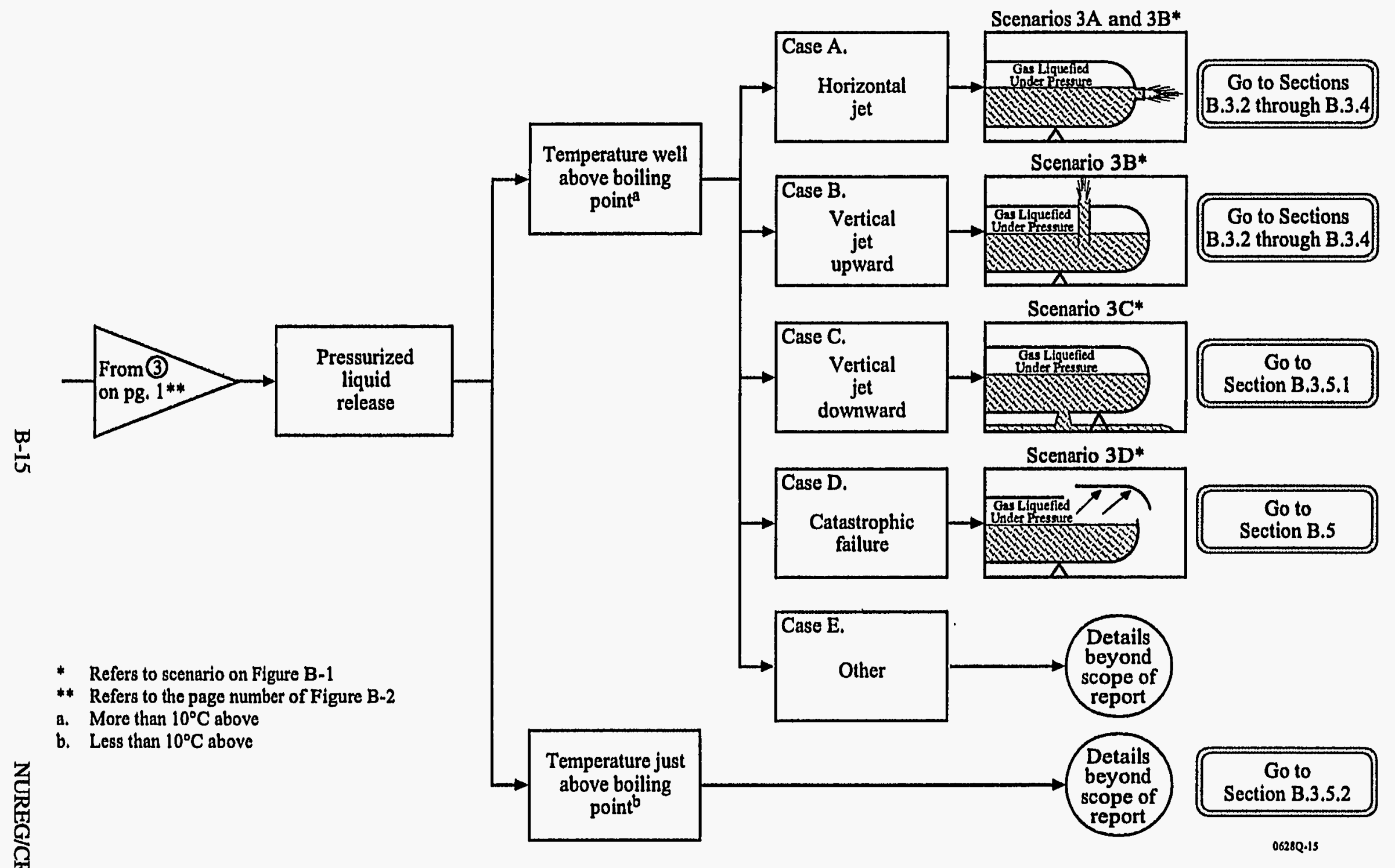

Figure B-2. Scenario identification flow chart, page 5 


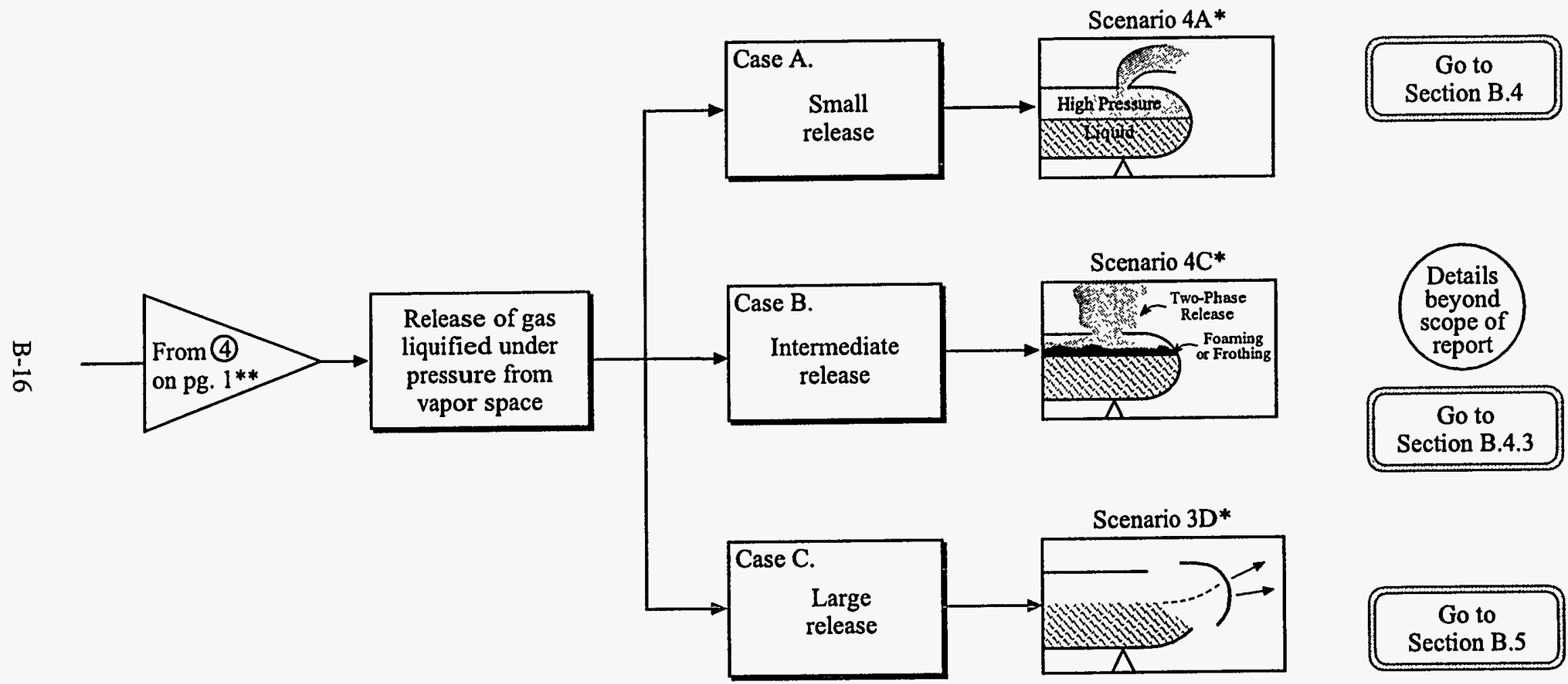

* Refers to scenario on Figure B-1

** Refers to the page number of Figure B-2 

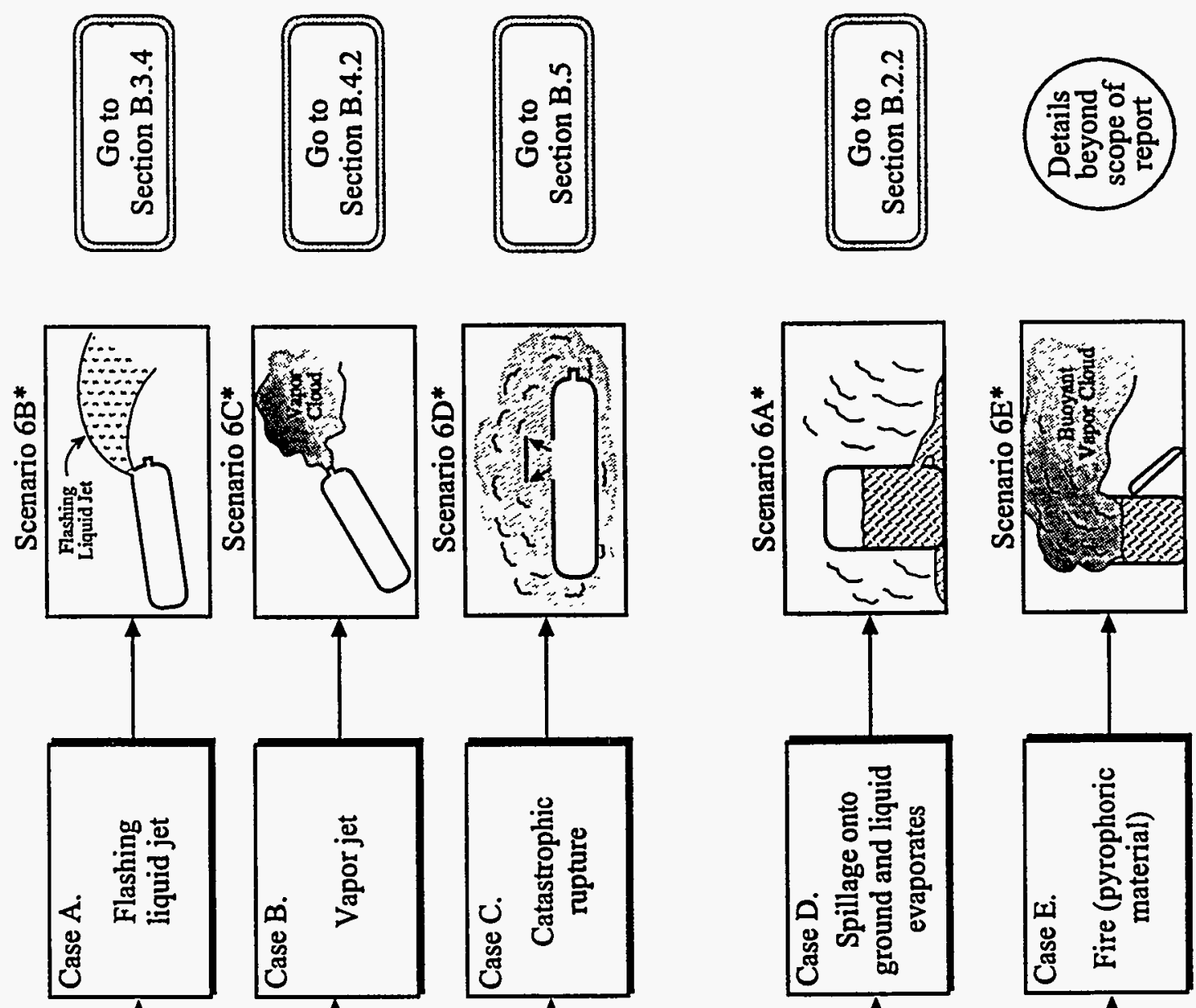


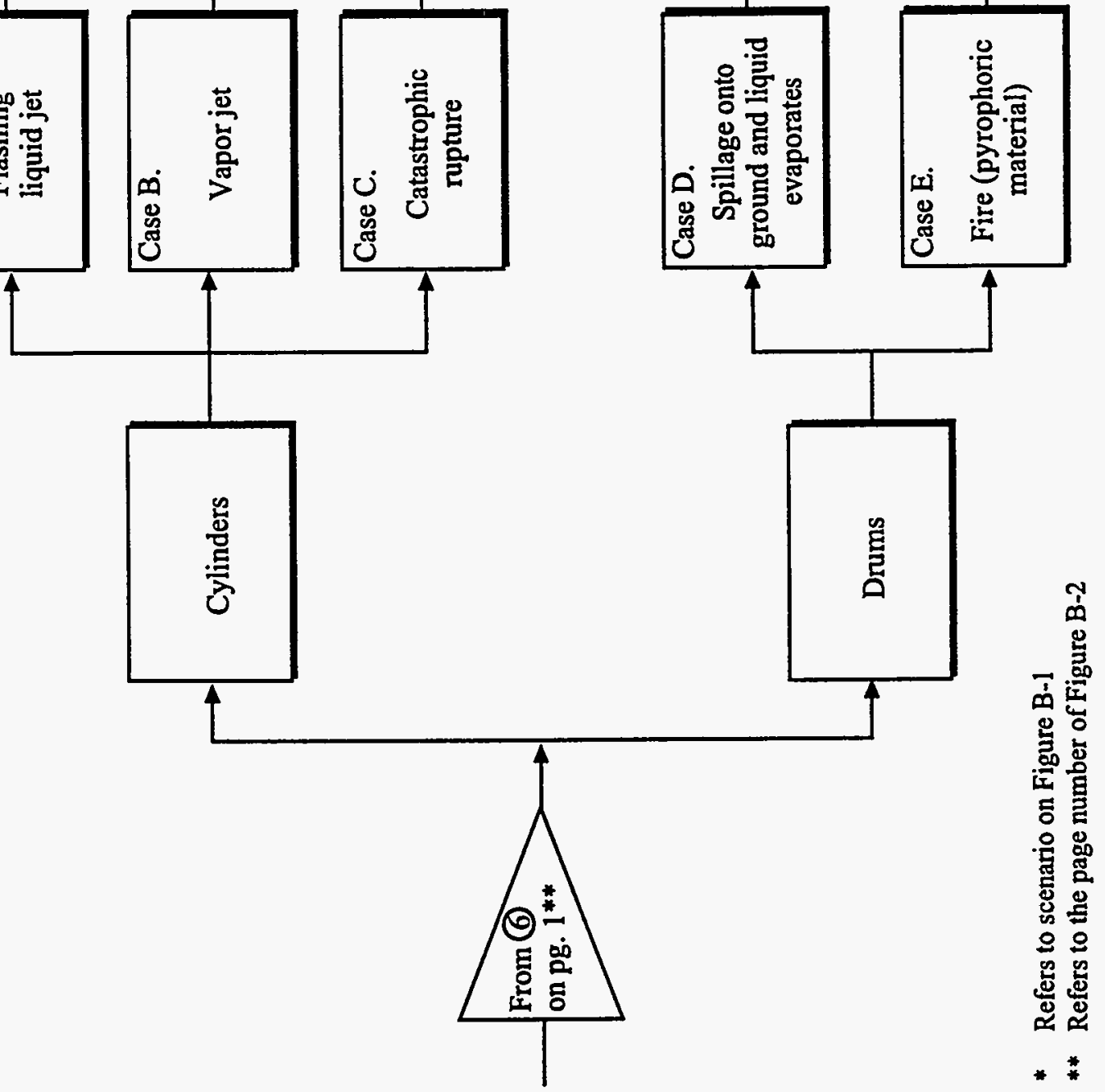

B-17 
temperature of the material is low enough to preclude the formation of small liquid droplets (aerosol) that arise as the outgoing jet shatters due to the action of hydrodynamic forces. That is, aerosolization is not expected. Therefore, once the pool has formed, there is no difference between the calculations for these cases (Cases C and D on page 3 of Figure B-2) and those for the "static head only" case, and the reader is directed to the same sections of the report (Sections B.2.1, B.2.3, and B.2.5.2).

The methods appropriate for a spill of $\mathrm{HF}$ are also appropriate for many other materials likely to be found at a fuel cycle facility.

\section{B.1.3.2 Liquid Spillage from a Drum}

Assume that there is a drum containing a liquid stored at a fuel facility. By definition, the liquid has a vapor pressure considerably below $100 \mathrm{kPa}$ (1 atmosphere) (i.e., a boiling point considerably above ambient temperature). It is not particularly important what the liquid is. The drum may leak because it has been dropped or punctured.

On page 1 of Figure B-2, the closest scenario is Scenario 6. The reader is directed to go to page 7 of Figure B-2, where the lower branch refers to drums. Case $D$ is the liquid spillage scenario, which is discussed in Section B.2.2. There the reader will find that the principal difference between the calculations used for the drum case and those used for a large spill of cool HF is that the total volume of the spill is much smaller.

\section{B.1.3.3 Accidents Involving Cylinders}

Cylinders are used to supply gases and large amounts of solids or liquids stored at a range of pressures. Acetylene used for welding is an example of a pressurized gas while $\mathrm{UF}_{6}$ used for fuel fabrication is an example of a solid.

On page 1 of Figure B-2, Scenario 6 identifies releases from drums or cylinders and directs the reader to page 7, where three alternative cylinder release cases are shown: (A) a flashing, liquid jet, (B) a vapor jet, and $(C)$ a catastrophic rupture.

Assume that a cylinder contains $\mathrm{NH}_{3}$, which is liquefied under pressure. Therefore, any of the three scenarios for cylinders (Cases A, B, or C) is possible depending on whether the rupture is located in the liquid or vapor space and how big the rupture is. For example, if the cylinder is upright, the concern might be that valving at the top could fail. In this case, there would be a vapor jet as discussed in Section B.4.2. If the concern is that the cylinder might be dropped, then either Case A (flashing liquid jet, Section B.3.4) or Case B (catastrophic rupture, Section B.5) would be appropriate.

\section{B.1.3.4 Spillages Onto Water}

Spillages onto water are not highly probable at fuel cycle facilities, but it is possible to envision circumstances in which spills may occur if operations are being carried out close to a body of water. Scenario 5 on page 1 of Figure B-2 directs the reader to Section B.2.4, where the issues involved in modeling spills onto water are briefly discussed. 


\section{B.1.3.5 Spillage of Refrigerated Liquid}

Assume that a leak occurs in a vessel or its associated pipework that contains $\mathrm{NH}_{3}$ refrigerated at ambient pressure. This corresponds to Scenario 2 on page 1 of Figure B-2. The reader is directed to page 4 of Figure B-2, where there are two options. Either the pressure in the vessel is solely due to the $\mathrm{NH}_{3}$ (its static head) or there is additional pressure from other sources (e.g., a nitrogen pad for transfer purposes).

For the case of the static head, the liquid may spill into a diked or undiked area. For the case of a diked area, Section B.2.3 shows the reader how to calculate the rate of evaporation. For the case of an undiked area, Section B.2.5.2 discusses the issues involved if the spill is unconfined.

\section{B.1.3.6 Pressurized Releases - Flashing Jets}

Consider the case of a vessel containing $\mathrm{NH}_{3}$ or liquid $\mathrm{UF}_{6}$ under pressure in which leakage occurs from the liquid space. This type of release is characterized by partial flashing to vapor and fragmentation of the liquid jet to form an aerosol. This case corresponds to Scenario 3 on page 1 of Figure B-2. The reader is directed to page 5 of Figure B-2, where it must be determined whether the temperature is just above its boiling point $\left(<10^{\circ} \mathrm{C}\left(18{ }^{\circ} \mathrm{F}\right)\right.$ above) or well above its boiling point $\left(>10^{\circ} \mathrm{C}\left(18^{\circ} \mathrm{F}\right)\right.$ above $)$. The issue here is whether complete aerosolization can be assumed. For $\mathrm{NH}_{3}$ the atmospheric boiling point is $239.7 \mathrm{~K}$

$\left(-29^{\circ} \mathrm{F}\right)$ and a typical ambient temperature may be in the range 273 to $303 \mathrm{~K}\left(32\right.$ to $\left.85^{\circ} \mathrm{F}\right)$. Therefore, for $\mathrm{NH}_{3}$, the upper branch on page 5 of Figure B-2 is appropriate, because the temperature is in the range 307 to $337 \mathrm{~K}\left(93\right.$ to $\left.147^{\circ} \mathrm{F}\right)$ above the boiling point and complete aerosolization is expected.

Five possible cases (Cases A through E) are considered including three different jets (horizontal, vertical upward, and vertical downward). For the horizontal and vertical jet cases, the reader is directed to Sections B.3.2 through B.3.4 and Section B.3.5.1. In addition, Section B.5 considers the case in which the rupture in the vessel is so large that there is catastrophic failure and the contents are essentially lost instantaneously (Scenarios 3D and 6D).

\section{B.1.3.7 Vapor Releases Driven by High Pressure}

For the case of a release from the vapor space of a vessel containing $\mathrm{NH}_{3}$ at ambient temperature and high pressure, Scenario 4 on page 1 of Figure B-2 directs the reader to page 6 of Figure B-2, where three types of releases are considered: small, intermediate, and large.

A "small" hole is one in which a/A $\ll<1$, where $a$ is the area of the hole and $\mathrm{A}$ is the area of the liquid surface. For a typical penetration into a vessel (e.g., 2.5 or $5.0 \mathrm{~cm}$ [1 or 2 in] in diameter), a/A is clearly very small and Case A on page 6 of Figure B-2 applies. The reader is directed to Section B.4, which discusses high pressure vapor releases.

If the release is "catastrophic" so that the contents of the vessel are lost almost instantaneously, the case is that of a large puff release. The reader is directed to Section B.5. For releases of "intermediate" size, complicated phenomena occur that are difficult to calculate, and the reader is referred to Section B.4.3. 


\section{B.1.3.8 Hydrogen Fluoride}

Some of the scenarios considered in this report involve the accidental release of $\mathrm{HF}$, which has a boiling point of about $293 \mathrm{~K}\left(67^{\circ} \mathrm{F}\right)$. The temperature of HF could be well below its boiling point, just below its boiling point, just above its boiling point, or well above its boiling point.

For example, $\mathrm{HF}$ storage vessels are sometimes refrigerated so that the temperature is about $10 \mathrm{~K}\left(18^{\circ} \mathrm{F}\right)$ below its boiling point. In this case, following through page 4 of Figure B-2 leads the reader to Section B.2.3 which considers a spillage of HF into a diked area (see Section B.1.3.1).

In some industrial applications, $\mathrm{HF}$ may be pressurized at a relatively high temperature (about $313 \mathrm{~K}$ $\left(100^{\circ} \mathrm{F}\right)$ ), and any accidental release may take the form of one of the jets shown on page 5 of Figure B-2. Specifically, Section B.3.2 considers the case of a horizontal flashing jet of HF.

For HF in storage that is directly affected by ambient conditions, its temperature can fluctuate above and below the boiling point during a single day. If the temperature is just above the boiling point, the reader will arrive at the lower branch on page 5 of Figure B-2. There is uncertainty about how much aerosolization there will be and how much liquid will remain behind as a pool on the ground.

If the temperature of the HF is slightly below its boiling point, the reader will arrive at the lower branch of the flow chart on page 2 of Figure B-2. Details in this area are beyond the scope of this report because (a) there is the potential for partial aerosolization, and (b) sources of heat that are neglected in some simpler treatments of evaporation (such as that described in Section B.2.1) cannot be neglected in this case. Section B.2.5.3 references additional information on this subject.

\section{B.1.3.9 Uranium Hexafluoride}

Some of the scenarios considered in this report involve accidental release of $\mathrm{UF}_{6}$, which has an atmospheric sublimation point of $329.8 \mathrm{~K}\left(133.6^{\circ} \mathrm{F}\right)$ and a triple point of $337.3 \mathrm{~K}\left(147^{\circ} \mathrm{F}\right)$ at $150 \mathrm{kPa}$ (22 pounds per square inch absolute). $\mathrm{UF}_{6}$ is often stored in cylinders as a solid at ambient temperature. To move $\mathrm{UF}_{6}$ from a cylinder, the cylinder is often heated to melt or vaporize the $\mathrm{UF}_{6}$.

Rupture of a $\mathrm{UF}_{6}$ cylinder or loss of confinement in a heated $\mathrm{UF}_{6}$ cylinder can lead to several different accidents. If the contents of the cylinder are under pressure and a hole develops below the liquid level, then a flashing liquid jet of $\mathrm{UF}_{6}$ is possible. This corresponds to Scenario 3 on Figure B-2 and is further described in Section B.3.5. If, on the other hand, the hole is in the vapor space, then Scenario 4 on Figure B-2 is appropriate. Section B.4.3 describes a method to calculate the flow rate of $\mathrm{UF}_{6}$ vapor from a hole in a cylinder.

If the cylinder containing liquid $\mathrm{UF}_{6}$ ruptures catastrophically, then it is possible to have a flashing instantaneous "puff" of UF 6 . Case D of Scenario 3 on Figure B-2 illustrates this scenario. Section B.5.3 describes an example of an instantaneous release of $\mathrm{UF}_{6}$. 


\section{B.2 Spillages of Liquids Onto Surfaces}

\section{B.2.1 Spillage of Liquid with Above Ambient Boiling Point into a Diked Area - Hydrogen Fluoride}

This scenario corresponds to release Scenario 1A in Figure B-1. This scenario has been chosen because it is an example of how to model spillages of liquids with high boiling points onto the ground with subsequent evaporation and formation of a vapor cloud. The spill is assumed to occur through a hole in the wall of the storage vessel. For the purposes of this report, a high boiling point is taken to be $10 \mathrm{~K}$ $\left(18^{\circ} \mathrm{F}\right)$ or more above the temperature of the atmosphere.

\section{B.2.1.1 Description of Scenario}

The following example is chosen to illustrate a case in which finding appropriate values of input parameters is difficult. The example involves anhydrous HF in a storage vessel that is cooled by a brine cooling loop that keeps the temperature of the HF at $278 \mathrm{~K}\left(40^{\circ} \mathrm{F}\right)$, about $15 \mathrm{~K}\left(27^{\circ} \mathrm{F}\right)$ below its boiling point. (Note that anhydrous HF contains no water; it differs from aqueous HF, which is a solution of HF in water.) In this hypothetical example, a pump withdraws $\mathrm{HF}$ from the vessel and transfers it to a reactor, where it is used for fluorination in a $\mathrm{UF}_{6}$ conversion facility.

The vessel and the associated pipework may leak for a number of reasons, e.g., gasket failure, corrosion, or puncture by an external agent such as a fork lift, truck, or vessel. The storage vessel is assumed to stand in a dike. The vessel contains HF liquid at atmospheric pressure and ambient temperature (i.e., for simplicity, the temperature of the air is assumed to be equal as that of the $\mathrm{HF}, 278 \mathrm{~K}\left(40^{\circ} \mathrm{F}\right)$. The liquid has a boiling point that is higher than the ambient temperature so that its vapor pressure is below $100 \mathrm{kPa}$ (1 atmosphere). It is assumed that the leak is large enough to fill the diked area quickly.

The driving force for the leak is assumed to be only a small static head that does not cause aerosolization. Thus, the source term arises from evaporation of the pool. In this example, it is assumed that the dike has an area of $400 \mathrm{~m}^{2}\left(4300 \mathrm{ft}^{2}\right)$. (This is not an unusual size for a diked area at a chemical facility.)

\section{B.2.1.2 Rate of Release of Liquid from Vessel}

The rate of release of liquid from an orifice is given by Bernoulli's formula (AIChE 1989) as:

$$
\mathrm{Q}=\operatorname{ca\rho }_{\ell}\left[2\left(\mathrm{p}-\mathrm{p}_{\mathrm{a}}\right) / \rho_{\ell}+2 \mathrm{gh}\right]^{1 / 2}
$$

where:

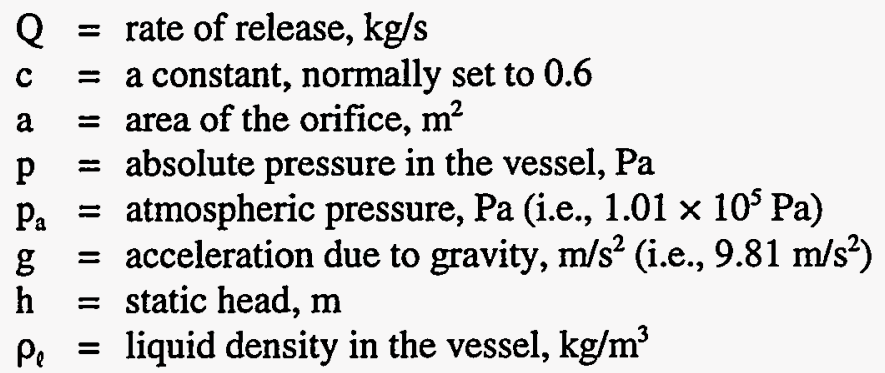


Equation B.1 is suitable for calculating the rate of pure liquid flow through a circular orifice. (There are variations on the formula for a non-circular orifice.)

As an example, suppose the static head is $h=3 \mathrm{~m}$. The density of liquid $\mathrm{HF}$ is $1002 \mathrm{~kg} / \mathrm{m}^{3}\left(62.4 \mathrm{lb} / \mathrm{ft}^{3}\right)$. (Note that a good reference for the standard properties of materials, such as density and specific heat, can be found in Data Compilation - Tables of Properties of Pure Compounds [Daubert and Danner 1985].) Since there is no additional source of pressure, $\mathrm{p}=\mathrm{Pa}_{\mathrm{a}}$. It is assumed that there is a leak through a hole with an effective diameter of $1.3 \mathrm{~cm}(1 / 2 \mathrm{in})$. Then $\mathrm{a}=\pi \mathrm{r}^{2}=\pi(0.65 \mathrm{~cm})^{2}=1.3 \mathrm{~cm}^{2}$ or $1.3 \times 10^{-4} \mathrm{~m}^{2}$. Using equation B.1, the initial rate of release is:

$$
Q=(0.6)\left(1.3 \times 10^{-4}\right)(1002)[(2)(0) /(1002)+(2)(9.81)(3)]^{3 / 5}=0.60 \mathrm{~kg} / \mathrm{s}
$$

Similarly, if the hole has a diameter of $5 \mathrm{~cm}(2 \mathrm{in})$, the area $\mathrm{a}$ is $2.0 \times 10^{-3} \mathrm{~m}^{2}$ and $\mathrm{Q}=9.2 \mathrm{~kg} / \mathrm{s}$.

\section{B.2.1.3 Behavior of a Pool on the Ground}

As the liquid spills from the vessel, it will spread across the ground. There are several possibilities, for example:

1. The spill is so rapid that the diked area is covered almost at once and the subsequent evaporation takes much longer than the spill from the vessel.

2. The pool spreads until the rate of evaporation just equals the rate of spillage. This can happen for a small rate of spillage within a diked area, or for any rate of spillage in an undiked area.

3. The contents of a vessel or drum spill very rapidly and the pool continues to spread after spillage has ceased.

For simplicity, the case of a rapid spill covering a diked area with a subsequent relatively long period of evaporation [case (1) above] is considered below in Sections B.2.1.4 and B.2.1.5.

\section{B.2.1.4 Calculation of Evaporation Rates}

There is considerable literature that addresses the evaporation rate of liquids from pools on the ground (AIChE 1989). For slowly evaporating pools, the following approximation is often used:

$$
Q_{0}=k_{g} A_{p} p_{v} M /\left(R T_{p}\right)
$$

where:

$\mathrm{Q}_{0}=$ rate of evaporation, $\mathrm{kg} / \mathrm{s}$

$\mathrm{k}_{\mathrm{g}}=$ mass transfer coefficient, $\mathrm{m} / \mathrm{s}$

$A_{p}=$ area of the pool, $\mathrm{m}^{2}$

$\mathrm{p}_{\mathrm{v}}=$ vapor pressure, $\mathrm{Pa}$

$\mathrm{M}=$ molecular weight, $\mathrm{kg} / \mathrm{kg}$-mol

$\mathrm{R}=$ gas constant, (i.e., $8314 \mathrm{~J} / \mathrm{kg}-\mathrm{mol} / \mathrm{K}$ )

$\mathrm{T}_{\mathrm{p}}=$ temperature of the pool, $\mathrm{K}$ 
The mass transfer coefficient $\mathrm{k}_{\mathrm{g}}$ is given by the formula:

$$
\mathrm{k}_{\mathrm{g}}=\mathrm{D}_{\mathrm{m}} \mathrm{N}_{\mathrm{sh}} / \mathrm{d}
$$

where:

$D_{m}=$ molecular diffusivity of the vapor in air, $\mathrm{m}^{2} / \mathrm{s}$

$\mathrm{d}=$ effective diameter of the pool, $\mathrm{m}$

$\mathrm{N}_{\mathrm{sh}}=$ Sherwood number

The Sherwood number is found by:

$$
\mathrm{N}_{\mathrm{sh}}=0.037\left(\mathrm{k}_{\mathrm{m}} / \mathrm{D}_{\mathrm{mm}}\right)^{1 / 3}\left[\left(\mathrm{ud} / \mathrm{k}_{\mathrm{m}}\right)^{0.8}-15200\right]
$$

where:

$$
\begin{aligned}
& k_{m}=\text { kinematic viscosity of air, } \mathrm{m}^{2} / \mathrm{s} \\
& \mathrm{u}=\text { windspeed at a height of } 10 \mathrm{~m}, \mathrm{~m} / \mathrm{s}
\end{aligned}
$$

(Note that this approach assumes that heat transfer is rapid relative to mass transfer and need not be considered when estimating the evaporation rate.) The rate of evaporation is limited by mass transfer across a stagnant film of air at the surface of the pool and the temperature of the pool remains constant. Refer to Section B.2.5.1 for discussion of heat transfer limited evaporation.

\section{Equation B.3 is applied as follows:}

- The temperature $T_{p}$ of the pool is $278 \mathrm{~K}$ (assumed to be either a typical ambient temperature during atmospheric stability category F conditions or the temperature of the refrigerated HF).

- The vapor pressure $p_{v}$ of the HF over the pool at $T_{p}=278 \mathrm{~K}$ is given by: $\mathrm{p}_{\mathrm{v}}=\exp \left(-3030 / \mathrm{T}_{\mathrm{P}}+21.9\right)$ from which $\mathrm{p}_{\mathrm{v}}=5.99 \times 10^{4} \mathrm{~Pa}$.

- The area $A_{p}$ of the pool is $400 \mathrm{~m}^{2}$ as stated above.

- Although the molecular weight $M$ of $H F$ is $20 \mathrm{~kg} / \mathrm{kg}$-mol, oligomerization may cause the effective molecular weight to be greater. The molecular weight $M$ of $H F$ at $278 \mathrm{~K}$ and atmospheric pressure is about $70 \mathrm{~kg} / \mathrm{kg}$-mol because of the oligomerization effect (that is, it exists as a mixture of $\mathrm{HF},[\mathrm{HF}]_{2}$ and $[\mathrm{HF}]_{6}$ ). However, wind tunnel experiments on the evaporation of HF from pools show that there is very little evidence of heavier-than-air vapor effects. It is possible, therefore, that $\mathrm{HF}$ evaporates from the pool as a monomer and does not immediately form $(\mathrm{HF})_{2}$ and $(\mathrm{HF})_{6}$. However, to be conservative in equation B.2, where the rate of evaporation of $H F$ is proportional to $\mathrm{M}$, the molecular weight is taken to be $70 \mathrm{~kg} / \mathrm{kg}-\mathrm{mol}$. (This assumption might require further consideration at a later date when more knowledge is gained about the relative evaporation rates of $\mathrm{HF}$ and its oligomers.)

- As stated above, the gas constant $R$ is $8314 \mathrm{~J} / \mathrm{kg}-\mathrm{mol} / \mathrm{K}$.

- The effective diameter of the pool $\mathrm{d}$ is $22.57 \mathrm{~m}\left[\mathrm{~d}=\left(4 \mathrm{~A}_{\mathrm{p}} / \pi\right)^{1 / 2}\right]$.

- The windspeed $\mathrm{u}$ at a height of $10 \mathrm{~m}$ is $1.5 \mathrm{~m} / \mathrm{s}$ because the conditions in this example are assumed to be atmospheric stability category $F$ with a low windspeed of $1.5 \mathrm{~m} / \mathrm{s}$. 
- The kinematic viscosity of air $\mathrm{k}_{\mathrm{m}}$ is given as $1.1 \times 10^{-5} \mathrm{~m}^{2} / \mathrm{s}$ in standard texts (see, for example, American Institute of Chemical Engineers [1987]).

- The molecular diffusivity $\mathrm{D}_{\mathrm{m}}$ of HF in air is $1.294 \times 10^{-5} \mathrm{~m}^{2} / \mathrm{s}$ (Clough, et al. 1987).

Using the conditions defined above, a sample calculation using equations B.5, B.4, and B.3 is as follows:

$$
\begin{aligned}
\mathrm{N}_{\text {sh }} & =0.037\left(1.1 \times 10^{-5} / 1.294 \times 10^{-5}\right)^{1 / 3}\left\{\left[(1.5)(22.57) / 1.1 \times 10^{-5}\right]^{0.8}-15200\right\} \\
\mathrm{N}_{\text {sh }} & =4,900 \\
\mathrm{k}_{\mathrm{g}} & =\left(1.294 \times 10^{-5}\right)(4,900) / 22.57=2.8 \times 10^{-3} \\
\mathrm{Q}_{\mathrm{o}} & =\left(2.8 \times 10^{-3}\right)(400)\left(5.99 \times 10^{4}\right)(70) /[(8314)(278)] \\
& =2.0 \mathrm{~kg} / \mathrm{s} \text { or } 260 \mathrm{lb} / \text { minute }
\end{aligned}
$$

From Section B.2.1.2, the rate of spillage from a $5 \mathrm{~cm}$ (2 in) diameter hole is predicted to be $9.2 \mathrm{~kg} / \mathrm{s}$ $(20.2 \mathrm{lb} / \mathrm{s})$ which exceeds the predicted rate of evaporation, $2.0 \mathrm{~kg} / \mathrm{s}(4.4 \mathrm{lb} / \mathrm{s})$. Thus, the assumption that the whole diked area is covered before evaporation has been completed is a reasonable one.

\section{B.2.1.5 Duration of Evaporation}

Suppose that there is $1000 \mathrm{~kg}(2200 \mathrm{lb})$ of $\mathrm{HF}$ spilled from the vessel. If the spill were to evaporate at a constant rate of $2.0 \mathrm{~kg} / \mathrm{s}(4.4 \mathrm{lb} / \mathrm{s})$, evaporation would be complete in about 8 minutes, assuming that no mitigating measures are available.

In general, the duration of release must be assessed on a case-by-case basis, taking into account the quantity released, rate of evaporation, availability of mitigating measures, and potential operator actions.

\section{B.2.1.6 HF at Other Temperatures}

Note that the specific example given above is for HF that is kept cooled to $278 \mathrm{~K}\left(40^{\circ} \mathrm{F}\right)$ and for which the atmospheric and ground temperatures are at $278 \mathrm{~K}\left(40^{\circ} \mathrm{F}\right)$. An alternative scenario would be the spillage of HF from a storage vessel during the winter. Note that, if it is a hot day, then if cooled HF is spilled on to the ground, the above treatment of the HF evaporation is not valid because there will be transfer of heat from the ground to the pool. See Section B.2.3 for further discussion of this situation. In addition, if $\mathrm{HF}$ at a temperature that exceeds its boiling point of $293 \mathrm{~K}\left(67^{\circ} \mathrm{F}\right)$ is spilled, some of it will flash to vapor and the evaporation model of equation B. 3 is not appropriate.

\section{B.2.2 Spillage from Drum}

In this case, it is assumed that a drum containing a liquid is punctured and the liquid spills on the ground. It is unlikely that there will be a dike to contain the spill. A simplified and likely conservative approach is to assume that the whole contents of the vessel spill at once and spread to a depth $\mathrm{h}$ of $1 \mathrm{~cm}$, or $0.01 \mathrm{~m}$ ( $0.4 \mathrm{in}$ ). If the volume released is $\mathrm{V}$, the area $A$ covered by the spill is $\mathrm{V} / \mathrm{h}=\mathrm{V} / 0.01 \mathrm{~m}^{2}$.

The rate of evaporation $Q_{0}$ can then be calculated using equations B.3 and B.4. If the density of the liquid is $\rho_{\ell}$ the duration of release is $t_{d}=\rho_{\ell} V / Q_{0}$. Once these quantities have been determined, input for the computer models can be generated in exactly the same way as is described in Section B.2.1. 


\section{B.2.3 Spillage of Refrigerated Liquid into Diked Area}

This example is for a refrigerated $\mathrm{NH}_{3}$ vessel standing within a diked area. There is a leak for one of the reasons already discussed in Section B.2.1.1 for HF (gasket failure, corrosion, or puncture). It is assumed that the leak is large enough to fill the diked area quickly. In this case, the rate of evaporation is limited by the rate at which heat can be transferred to the liquid from the surface on which the pool lies. The rate of mass transfer from the pool surface is assumed to be rapid relative to the rate of heat transfer to the pool. The rate of evaporation is given by AIChE's Center for Chemical Process Safety (1989) as:

$$
\mathrm{Q}_{0}=A_{P}\left[k_{s}\left(T_{g}-T_{p}\right)\right] /\left[\left(\pi \alpha_{s}\right)^{0.5} H_{L}\right]
$$

where:

$\mathrm{Q}_{\mathrm{o}}=$ rate of evaporation, $\mathrm{kg} / \mathrm{s}$

$\mathrm{A}_{\mathrm{p}}=$ area of pool, $\mathrm{m}^{2}$

$\mathrm{k}_{\mathrm{s}}=$ thermal conductivity of the material on which the pool lies, $\mathrm{W} / \mathrm{m} / \mathrm{K}$

$\mathrm{T}_{\mathrm{g}}=$ temperature of the ground, $\mathrm{K}$

$\mathrm{T}_{\mathrm{p}}=$ temperature of the liquid pool, $\mathrm{K}$

$\alpha_{s}=$ thermal diffusivity of the soil, $\mathrm{m}^{2} / \mathrm{s}$

$\mathrm{t}=$ time after spill, $\mathrm{s}$

$\mathrm{H}_{\mathrm{L}}=$ latent heat of vaporization of spilled material, $\mathrm{J} / \mathrm{kg}$

Thus, this example is one in which the rate of evaporation varies as a function of time; it is proportional to $\mathrm{t}^{-0.5}$.

Equations B.7 and B. 3 describe the extreme cases in which the rate of evaporation is determined solely by resistance to heat transfer or solely by resistance to mass transfer. For the mass transfer limited case (equation B.3), the driving force for mass transfer (vapor pressure) is low, and wind speed determines the thickness of the stagnant air film which limits the rate of mass transfer. For the heat transfer limited case (equation B.7), the vapor pressure is high, mass transfer rates are assumed to be high, and evaporation is driven by the rate at which heat is conducted into the pool from the surface beneath.

- The thermal conductivity $\mathrm{k}_{\mathrm{s}}$ of surfaces such as concrete and soil is generally on the order of 2 $\mathrm{W} / \mathrm{m} / \mathrm{K}$. For insulating concrete or sand, this value can be considerably smaller.

- The temperature of the ground $\mathrm{T}_{\mathrm{g}}$ is $278 \mathrm{~K}$ as in all of the examples in this report.

- The temperature of the liquid pool $\mathrm{T}_{\mathrm{p}}$ is assumed to be the saturation temperature at atmospheric pressure. For $\mathrm{NH}_{3}$ the boiling point is $239.7 \mathrm{~K}$. Therefore, $\mathrm{T}_{\mathrm{g}}-\mathrm{T}_{\mathrm{p}}=278-239.7=38.3 \mathrm{~K}$.

- The typical value of the thermal diffusivity $\alpha_{\mathrm{s}}$ of the underlying surface is $10^{-6} \mathrm{~m}^{2} / \mathrm{s}$.

- The latent heat of vaporization $\mathrm{H}_{\mathrm{L}}$ of $\mathrm{NH}_{3}$ is $1.37 \times 10^{6} \mathrm{~J} / \mathrm{kg}$.

Using the above values in equation B.7 and assuming a pool of unit area, $Q_{0}=(2)(38.3) /\left[\left(\pi 10^{-6} t\right)^{0.5}(1.37\right.$ $\left.\left.\times 10^{6}\right)\right]=0.031 t^{-0.5}$. After $t=300$ seconds, the predicted rate of evaporation $Q_{0}=0.031(300)^{-0.5}=1.8 \times$ $10^{-3} \mathrm{~kg} / \mathrm{s} / \mathrm{m}^{2}$. The rate of release as a function of time is described as shown in Figure B-3 and in Table B-1. 


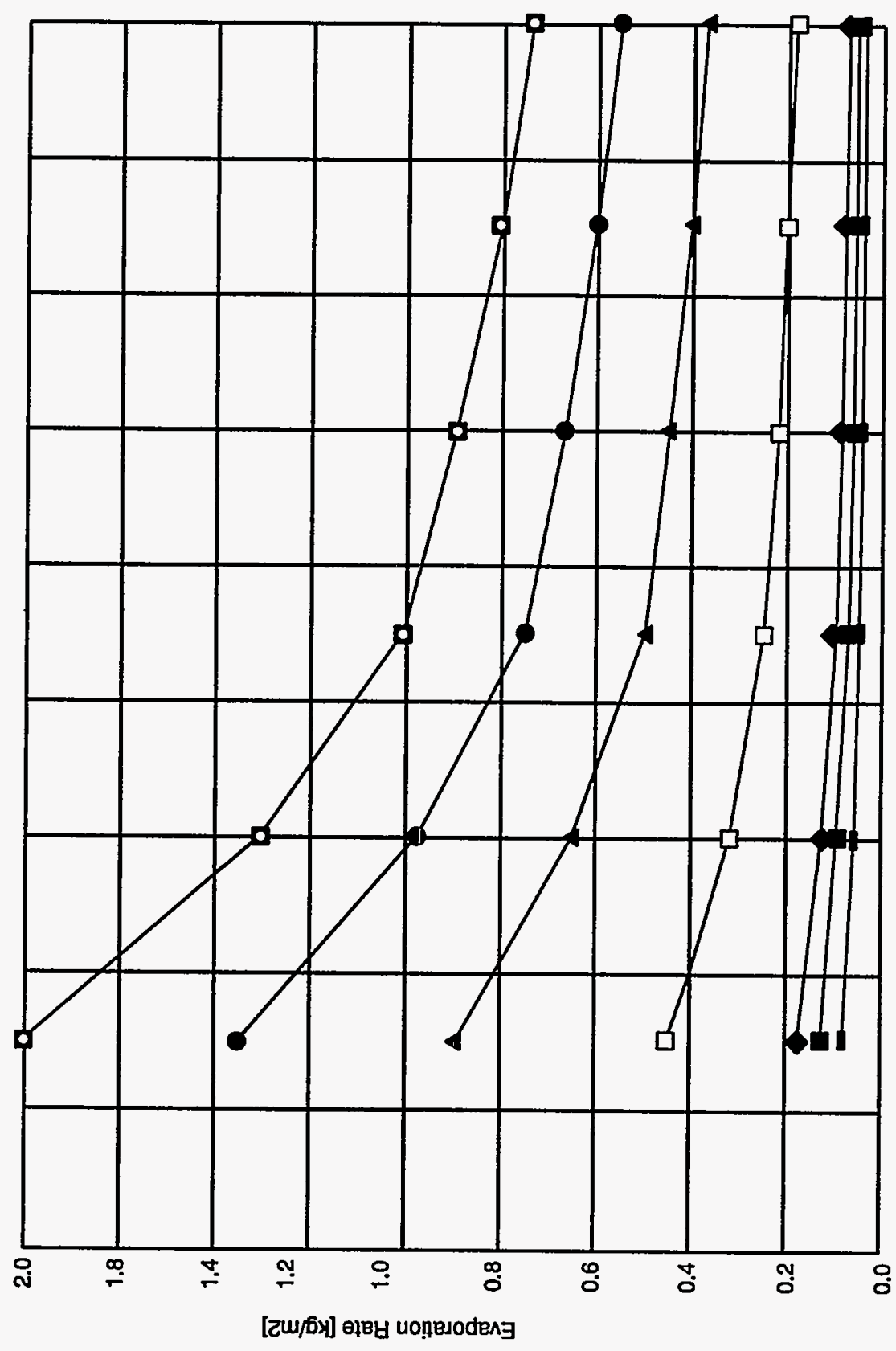

용 兽

웅

욤

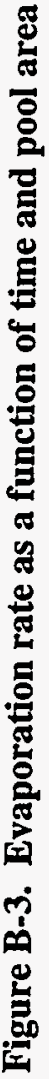

จั

옹

옹

$\delta_{\infty}^{\stackrel{\underline{\sigma}}{\mathbf{E}}}$

용

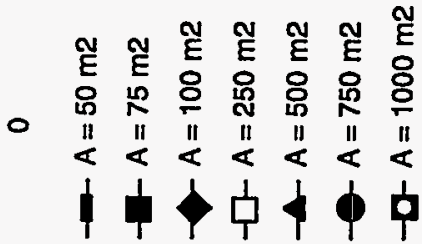


Table B-1. Evaporation Rate as a Function of Time

\begin{tabular}{cc}
\hline $\begin{array}{c}\text { Time } \\
\text { (seconds) }\end{array}$ & $\begin{array}{c}\text { Evaporation rate } \\
\text { per unit area } \\
\left(\mathrm{kg} / \mathrm{m}^{2} / \mathrm{s}\right)\end{array}$ \\
\hline 1 & 0.031 \\
300 & $1.8 \times 10^{-3}$ \\
600 & $1.3 \times 10^{-3}$ \\
900 & $1.0 \times 10^{-3}$ \\
1,200 & $8.9 \times 10^{-4}$ \\
1,500 & $8.0 \times 10^{-4}$ \\
1,800 & $7.3 \times 10^{-4}$ \\
\hline
\end{tabular}

\section{B.2.4 Spillages onto Water}

The models used for calculating the rates of evaporation of a chemical floating on water differ somewhat from the methods used for calculating releases onto land. The principal differences arise in the behavior of the chemical immediately after release and in the rate of evaporation. For example, a refrigerated liquid, such as liquefied natural gas, released onto water boils rapidly at almost a constant rate. Other materials may interact with the water (e.g., anhydrous $\mathrm{NH}_{3}, \mathrm{UF}_{6}$, and HF). In such cases, chemicalspecific models need to be developed.

Raj (1991 and 1981) has reviewed models for evaporation following spillages onto water. The specific example of $\mathrm{NH}_{3}$ is covered by Raj, et al. (1974).

\section{B.2.5 Additional Considerations}

There are additional items, several of which are discussed in this section, that should be considered and have not been addressed in the above discussion of specific source terms. These items generally cover areas where the details are beyond the scope of this report.

\section{B.2.5.1 Heat Sources}

Equation B.2 uses the assumptions that the rate of evaporation is slow and the temperature of the pool remains constant. These assumptions will certainly not always be correct and a comprehensive model should take account of the following sources of heat:

- the rate of convective heat transfer from the air to the pool in cases where the temperatures of the pool and the air differ; the heat transfer rate is proportional to the temperature difference

- the rate of radiative heat transfer from the air to the pool; this effect is proportional to the difference in the fourth power of the temperatures

- solar radiation 
- transfer of heat from the dike walls

- heat lost due to evaporation of the pool

- heat added as additional liquid enters the pool from the vessel.

A clear and concise discussion of these heat sources may be found in Cavanaugh, et al. (1992).

\section{B.2.5.2 Spreading Pool}

The examples given in Section B.2 above are all for a pool confined within a diked area. If there is no diked area, the pool will spread and the evaporation rate becomes a function of time. Refer to Raj (1991 and 1981) for further details on modeling a spreading pool in an unconfined area. An earlier, "classical" reference is by Shaw and Briscoe (1978).

\section{B.2.5.3 Advanced Modeling}

The modeling described in Section B.2 is considerably simplified. As noted in Sections B.2.5.1 and B.2.5.2, the modeling discussed in this report does not cover heat sources such as solar radiation or spreading pools. In general, the evaporation rate is a function of the wind speed, pool temperature, pool size, properties of the liquid under consideration, and thermal properties of the environment. The problem simplifies to two limits: (1) the "boiling refrigerated liquid" limit, where the evaporation rate is entirely controlled by the heat flux into the pool, and (2) the "evaporation" limit, where the pool is essentially at ambient temperature and mass transfer is controlled by the rate at which the air streaming over the pool can remove the vapor. In the first case, the evaporation rate is independent of the wind speed (see Section B.2.4). In the second case, the evaporation rate depends strongly on the wind speed (see Sections B.2.1 and B.2.3).

In general, and in particular for substances that boil close to ambient temperature, neither of these two limits is appropriate. In that case, there are a number of coupled linear differential equations that need to be solved and numerical modeling is required. The issues involved when neither limit is appropriate are discussed in Webber and Jones (1987).

\section{B.3 Jets Containing Liquid and Vapor}

Releases of jets containing liquid and vapor correspond to the release cases for Scenarios 3, 4, or 6 in Figure B-1. The releases are characterized by liquid jets flashing to vapor and liquid droplets or by vapor jets condensing on expansion from the pressure in the reservoir to atmospheric pressure (see Section B.4). The cases considered here differ from the pure vapor releases in Sections B.2 or B.4 in that the airborne release consists of both vapor and liquid droplets. In the case of $\mathrm{UF}_{6}$, there may be some solid particles also.

Experience has shown that the nature of a release depends in part on the size of the hole (small, intermediate, large) in the storage vessel (Kaiser 1989). A small hole is one in which the area of the hole is less than 1 percent of the free surface area of the liquid stored in the vessel. For small holes, the release rate is determined by a single phase flow constraint, and the flashing or condensation associated with the pressure reduction is considered to occur outside of the storage vessel. Failures involving large holes are considered to cause immediate release of the vessel contents in an adiabatic flash event (the vapor mass fraction can be predicted as described in Section B.3.1.2). 
There exists a category of intermediate failures, such as that illustrated in Scenario 4C in Figure B-1, in which the hole can be categorized as neither small nor large. Considerable relevant work has been done by the American Institute of Chemical Engineers' Design Institute for Emergency Relief Systems program (Fisher, et al. 1992).

Section B.3.1 contains a detailed theoretical discussion of various release formulas which closely follows the methods presented by the EPA (1992). Sections B.3.2 and B.3.3 contain specific examples, including consideration of flow through a $1.3-\mathrm{cm}(1 / 2-\mathrm{in})$-diameter orifice in a vessel containing HF at elevated temperature and pressure (see Section B.3.2). It is useful to begin with this example because the reader will become familiar with many of the issues that must be addressed if such scenarios are to be modeled realistically. The HF example is followed by a liquid release from a large tank containing $\mathrm{NH}_{3}$ at ambient temperature (see Section B.3.3). Lastly, Section B.3.5 contains an example of a liquid UF jet $_{\text {jet }}$ depressurizing and flashing to vapor and solid particulates.

\section{B.3.1 Theory of Emission Rate Formulas}

This section describes how to estimate the flow rate of momentum jets that contain a mixture of vapor and fine liquid droplets (two-phase leaks). Sections B.3.1.1 through B.3.1.3 show how to estimate the release rate for three scenarios:

1. a release of gas that partly condenses when depressurized

2. a saturated liquid from pressurized storage

3. a release of a subcooled liquid from pressurized storage

For these three scenarios, the following assumptions apply:

- any vapor phase obeys the perfect gas law ( $\mathrm{pV}=\mathrm{nRT})$

- the pressure and temperature of a reservoir remain essentially constant

- for two-phase flows, all released liquid is assumed to travel downwind with negligible rainout near the source

A flow chart that illustrates the calculation steps for the three scenarios [(1), (2), and (3)] identified above is given in Figure B-4.

\section{B.3.1.1 Gas That Partially Condenses on Depressurization}

This section contains a procedure for estimating a continuous release of gas that partially condenses during depressurization. The release may occur, for example, through a hole in the wall of the storage vessel or through a ruptured pipeline connected to the storage vessel. The screening procedures for determining whether condensation occurs are described in Section B.4.1.1. The required input information is as follows: 

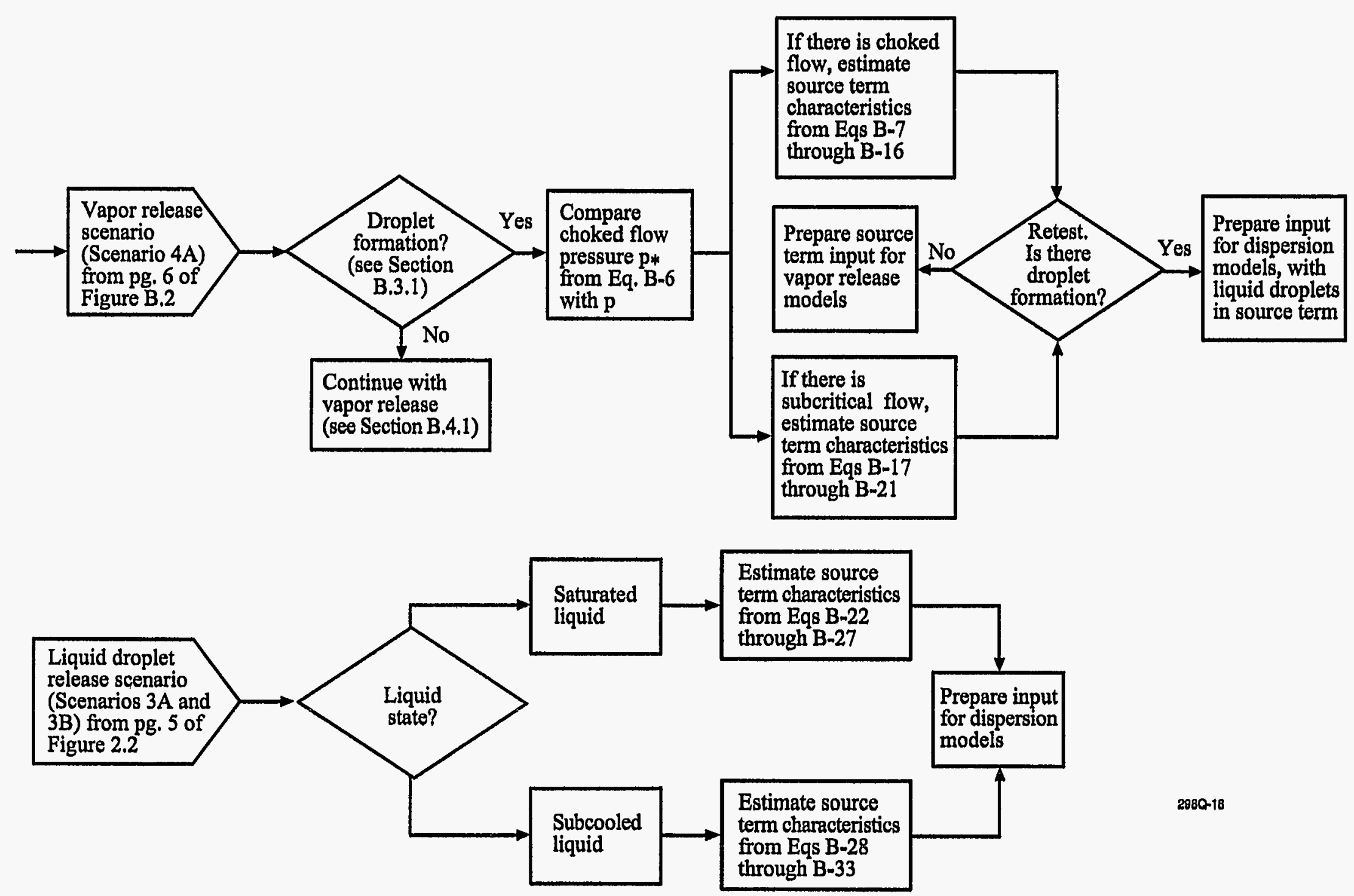

Figure B-4, Calculation flow chart for liquid droplet scenarios 


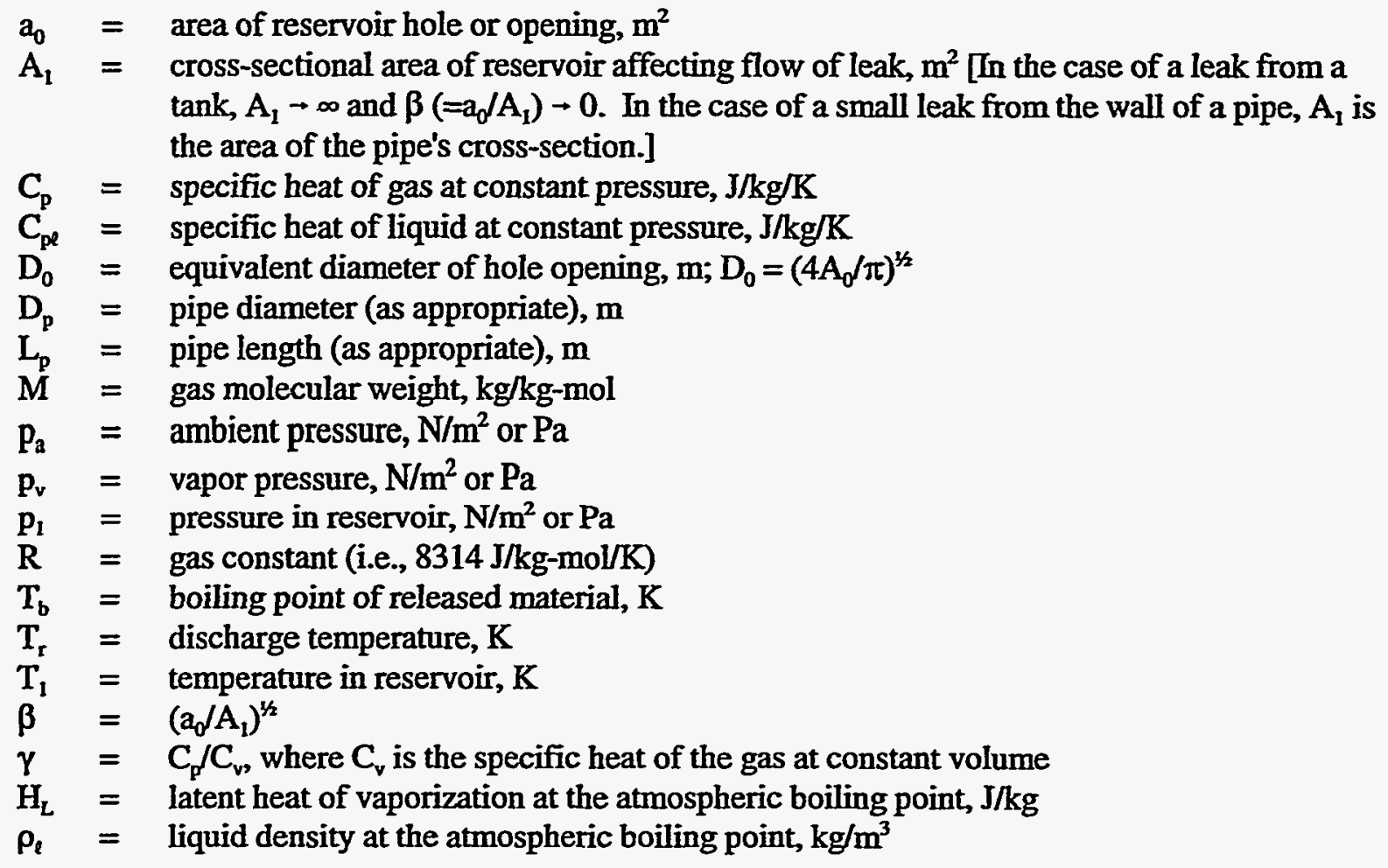

The calculations of emission characteristics should proceed as follows:

1. Calculate choked flow pressure p. from:

$$
\frac{p_{*}}{p_{1}}=\left(\frac{2}{\gamma+1}\right)^{\gamma /(\gamma-1)}
$$

where $\mathrm{p}_{*}$ is the choked flow pressure.

If $\mathrm{p}_{*}>\mathrm{p}_{\mathrm{a}}$, the flow is choked; go to step 2 below. If $\mathrm{p}_{*}<\mathrm{p}_{\mathrm{a}}$, the flow is subcritical; go to step 3 below.

2. Choked flow: For choked flow, estimate the discharge temperature $T_{r}$ the discharge density $\rho_{r}$ and the emission rate $Q$ using the following procedures.

a. For pure components, estimate the choked flow temperature T. (the temperature that corresponds to $\mathrm{p}$. when condensation has occurred) from the Clausius-Clapeyron equation:

$$
p_{*}=1.01 \times 10^{5} \exp \left[\frac{H_{L} M}{R}\left(\frac{1}{T_{b}}-\frac{1}{T_{*}}\right)\right]
$$

For multicomponent mixtures, the value of $T_{*}$ can be estimated using the methods of Sandler (1989) (not discussed further here). 
b. Estimate properties at choked flow conditions. Assuming isentropic conditions, estimate the vapor fraction $\mathrm{x}_{*}$ at choked flow conditions by:

$$
\mathrm{x}_{*}=1+\frac{\mathrm{T}_{*}}{\mathrm{MH}_{\mathrm{L}}}\left[\mathrm{MC} \mathrm{C}_{\mathrm{p}} \ln \left(\mathrm{T}_{1} / \mathrm{T}_{*}\right)-\mathrm{R} \ln \left(\mathrm{p}_{1} / \mathrm{p}_{*}\right)\right]
$$

Using $X_{*}$ from equation B.10, estimate the change in enthalpy $\left(\mathrm{H}_{1}-\mathrm{H}_{*}\right)$ and the density $\rho_{*}$ as:

$$
\begin{aligned}
& \left(\mathrm{H}_{1}-\mathrm{H}_{*}\right)=\mathrm{C}_{\mathrm{p}}\left(\mathrm{T}_{1}-\mathrm{T}_{*}\right)+\mathrm{H}_{\mathrm{L}}\left(1-\mathrm{x}_{*}\right) \\
& \rho_{*}=\left[\mathrm{x}_{*}\left(\frac{R T_{*}}{\mathrm{p}_{*} \mathrm{M}}\right)+\left(\frac{1-\mathrm{x}_{*}}{\rho_{\ell}}\right)\right]^{-1}
\end{aligned}
$$

c. Estimate emission rate. The formula for the emission rate $Q$ through a ruptured pipeline is based on work by the EPA (1992):

$$
Q=a_{0} \rho_{*}\left[2(0.85)\left(\frac{\mathrm{H}_{1}-\mathrm{H}_{*}}{1+4 \mathrm{fL}_{\mathrm{p}} / \mathrm{D}_{\mathrm{p}}}\right)\right]^{1 / 2}
$$

where the factor of 0.85 is included to account for irreversibilities in the flow based on work by Lewitt (1953), and the term $4 \mathrm{fL}_{\mathrm{p}} / \mathrm{D}_{\mathrm{p}}$ accounts for the pressure drop between the reservoir and the hole opening. The term $f$ is known as the Fanning friction factor. Plots of $f$ as a function of Reynold's numbers are available in the literature, for example, in Figure 5-26 of Perry and Chilton's Chemical Engineers' Handbook (Perry and Chilton 1973). For high Reynold's numbers $\left(>10^{5}\right)$ and typical industrial pipework, a typical value of $\mathrm{f}$ is 0.0045 . This corresponds to commercial steel pipe having a diameter of approximately $6 \mathrm{~cm}$ ( $2.4 \mathrm{in})$ and a surface roughness of $0.0045 \mathrm{~cm}(0.0018 \mathrm{in})$. The Reynold's number is high in the present case because the discharge is very turbulent. Use $f=0.0045$.

d. Estimate discharge temperature and density. Estimate the discharge temperature $T_{r}$ after depressurization. If a condensed phase is present, $\mathrm{T}_{\mathrm{r}}$ will be given from:

$$
\mathrm{p}_{\mathrm{a}}=1.01 \times 10^{5} \exp \left[\frac{\mathrm{H}_{\mathrm{L}} \mathrm{M}}{\mathrm{R}}\left(\frac{1}{\mathrm{~T}_{\mathrm{b}}}-\frac{1}{\mathrm{~T}_{\mathrm{r}}}\right)\right]
$$

Using this estimate of $T_{r}$, the released vapor fraction $x_{r}$ is given by:

$$
\mathrm{x}_{\mathrm{r}}=\mathrm{x}_{*}+\mathrm{C}_{\mathrm{p} \ell}\left(\mathrm{T}_{*}-\mathrm{T}_{\mathrm{r}}\right) / \mathrm{H}_{\mathrm{L}}
$$

If $1 \geq x_{r} \geq 0$, the above estimate of $T_{r}$ is valid and the density of the discharged material is given by: 


$$
\rho_{r}=\left[x_{r}\left(\frac{R T_{r}}{p_{a} M}\right)+\left(\frac{1-x_{r}}{\rho_{\ell}}\right)\right]^{-1}
$$

If $\mathrm{x}_{\mathrm{r}}<0$ or if $\mathrm{x}_{\mathrm{r}}>1$, the condensed contaminant phase that was present at the choked conditions $\mathrm{p} *$ and $\mathrm{T}$. is no longer present and the release now consists of a pure vapor, without any condensed phase, in which case the discharge temperature and density are estimated as:

$$
\begin{gathered}
T_{r}=T_{*}-H_{L}\left(1-x_{*}\right) / C_{p \ell} \\
\rho_{r}=\frac{p_{a} M}{R T_{r}}
\end{gathered}
$$

and $\mathrm{x}_{\mathrm{r}}=1$.

3. Subcritical (non-choked) flow: For subcritical flow, estimate the gas/liquid discharge temperature $T_{r}$, the discharge density $\rho_{r}$, and the emission rate $Q$ as follows:

a. Estimate $\mathrm{T}_{\mathrm{r}}$. For pure components, estimate $\mathrm{T}_{\mathrm{r}}$ from the Clausius-Clapeyron equation:

$$
\mathrm{p}_{\mathrm{a}}=1.01 \times 10^{5} \exp \left[\frac{\mathrm{H}_{\mathrm{L}} \mathrm{M}}{\mathrm{R}}\left(\frac{1}{\mathrm{~T}_{\mathrm{b}}}-\frac{1}{\mathrm{~T}_{\mathrm{r}}}\right)\right]
$$

For multicomponent mixtures, $T_{r}$ can be determined by the methods of Sandler (1989) (not discussed here).

b. Estimate properties at discharge conditions. Assuming isentropic behavior, the vapor fraction $\mathrm{x}_{\mathrm{r}}$ at flow discharge conditions is:

$$
x_{r}=1+\frac{T_{r}}{M H_{L}}\left[M C_{p} \ln \left(T_{1} / T_{r}\right)-R \ln \left(p / p_{a}\right)\right]
$$

Using $x_{r}$ from equation B.20, the change in enthalpy $\left(H_{1}-H_{r}\right)$ and the density $\rho_{r}$ can be estimated from the following two equations:

$$
\begin{gathered}
\left(\mathrm{H}_{1}-\mathrm{H}_{\mathrm{r}}\right)=\mathrm{C}_{\mathrm{p}}\left(\mathrm{T}_{1}-\mathrm{T}_{\mathrm{r}}\right)+\mathrm{H}_{\mathrm{L}}\left(1-\mathrm{x}_{\mathrm{r}}\right) \\
\rho_{\mathrm{r}}=\left[\mathrm{x}_{\mathrm{r}}\left(\frac{\mathrm{RT} \mathrm{p}_{\mathrm{r}} \mathrm{M}}{\mathrm{p}_{\mathrm{a}}}+\left(\frac{1-\mathrm{x}_{\mathrm{r}}}{\rho_{\ell}}\right)\right]^{-1}\right.
\end{gathered}
$$

c. Estimate emission rate. Based on work presented by EPA (1992) for flow through a ruptured pipeline, the emission rate is given by: 


$$
Q=a_{0} \rho_{r}\left[2(0.85)\left(\frac{H_{1}-H_{r}}{1+4 \mathrm{fL}_{p} / D_{p}}\right)\right]^{1 / 2}
$$

where the factor of 0.85 is included to account for irreversibilities in the flow (see work by Lewitt [1953]), and the term $4 \mathrm{fL}_{\mathrm{p}} / \mathrm{D}_{\mathrm{p}}$ is included to account for the pressure drop between the reservoir and the point of discharge. As explained in step (2)(c) above, use $f=0.0045$.

The emission rate for flow through small holes is determined by single phase flow conditions (refer to the discussion of subcritical flow in Section B.4.1.1).

4. Example: EPA (1992) gives an example of the use of steps (1) through (3) above to model a saturated chlorine vapor leak driven by a pressure of $2.586 \times 10^{6} \mathrm{~Pa}(375 \mathrm{psia})$ through an orifice of diameter $10.16 \mathrm{~cm}(4.0 \mathrm{in})$.

One of the examples from EPA (1992) is reproduced in Section B.4.1.1.

\section{B.3.1.2 Saturated Liquid from Pressurized Storage}

This section describes procedures for estimating a continuous release through a ruptured pipeline of a pressurized liquid stored under saturated conditions. The required input information is as follows:

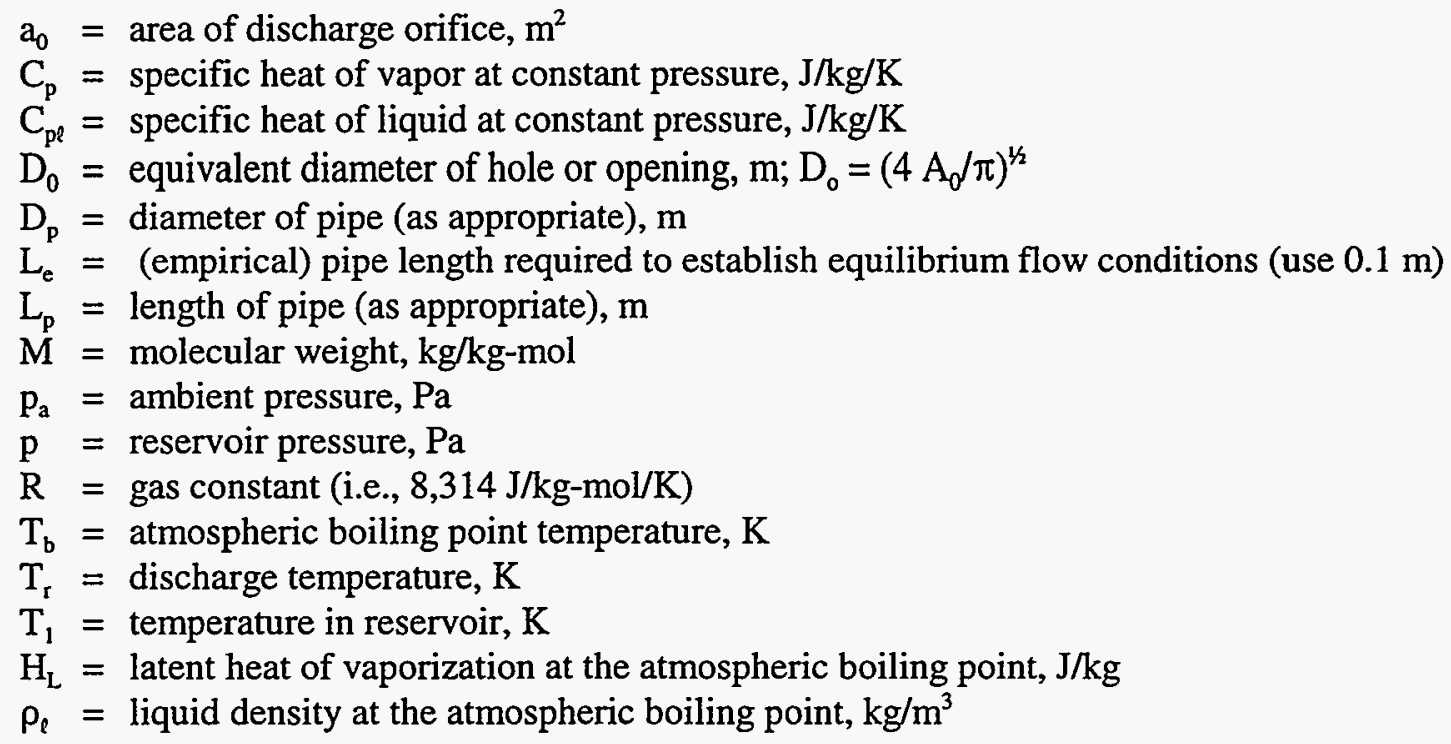

The procedures for estimating emission characteristics are as follows:

1. Estimate discharge temperature. The discharge temperature $\mathrm{T}_{\mathrm{r}}$ can be estimated from the ClausiusClapeyron equation: 


$$
\mathrm{p}_{\mathrm{a}}=1.01 \times 10^{5} \exp \left[\frac{\mathrm{H}_{\mathrm{L}} \mathrm{M}}{\mathrm{R}}\left(\frac{1}{\mathrm{~T}_{\mathrm{b}}}-\frac{1}{\mathrm{~T}_{\mathrm{r}}}\right)\right]
$$

Note that for a pressure of 1 atmosphere, or $1.01 \times 10^{5} \mathrm{~Pa}, \mathrm{~T}_{\mathrm{r}}=\mathrm{T}_{\mathrm{b}}$. For multicomponent mixtures, the discharge temperature can be calculated using the methods of Sandler (1989) (not discussed here).

2. Calculate vapor mass fraction after depressurization. The vapor mass fraction after depressurization is given by:

$$
\mathrm{x}_{\mathrm{r}}=\mathrm{C}_{\mathrm{pl}}\left(\mathrm{T}_{1}-\mathrm{T}_{\mathrm{r}}\right) / \mathrm{H}_{\mathrm{L}}
$$

If $1 \geq x_{r} \geq 0$, equation B.25 is valid and the reader should proceed to step (3) below. If $x_{T}>1$ or if $x_{\mathrm{r}}<0$, the solution is non-physical. The details for this case are beyond the scope of this report.

3. Calculate release rate. The release rate $(\mathrm{Q}$ in $\mathrm{kg} / \mathrm{s})$ can be calculated from the formulas of Fauske and Epstein (1987). If $L_{p} / L_{e} \leq 1$ (where $L_{e}=0.1 \mathrm{~m}$ ),

$$
\mathrm{Q}=\mathrm{a}_{0}\left(\frac{\mathrm{H}_{\mathrm{L}} \mathrm{Mp}}{\mathrm{RT}_{1}^{2}}\right)\left(\frac{\mathrm{T}_{1}}{\mathrm{NC}_{\mathrm{p \ell}}}\right)^{1 / 2}
$$

where:

$$
N=\frac{R\left(H_{L} M p\right)^{2}}{2\left(p-p_{a}\right) \rho_{\ell} c^{2}\left(R T_{1}\right)^{3} C_{p \ell}}+L_{p} / L_{e}
$$

Here, $\mathrm{c}$ is the discharge coefficient, which has a value of 0.6 .

If $\mathrm{L}_{\mathrm{p}} / \mathrm{L}_{\mathrm{c}}>1$,

$$
\mathrm{Q}=\mathrm{a}_{0} \mathrm{~F}\left(\frac{\mathrm{H}_{\mathrm{L}} \mathrm{Mp}}{\mathrm{RT}_{1}^{2}}\right)\left(\frac{\mathrm{T}_{1}}{\mathrm{C}_{\mathrm{pl}}}\right)^{1 / 2}
$$

where $F$ represents the effect of friction in the pipe. $F^{2}=1 /\left(1+4 f L_{p} / D_{p}\right)$, and use $f=0.0045$. (Refer to step (2)(c) in Section B.3.1.1 for the rationale for choosing this value of f.)

4. Calculate discharge density. The density after depressurization is:

$$
\rho_{r}=\left[x_{r}\left(\frac{R T_{r}}{p_{a} M}\right)+\left(\frac{1-x_{r}}{\rho_{\ell}}\right)\right]^{-1}
$$

5. Example. EPA (1992) gives an example of a saturated liquid chlorine leak from a reservoir at pressure $2.586 \times 10^{6}$ (375 Psia) $\mathrm{Pa}$ through an orifice of diameter $10.16 \mathrm{~cm}(4.0 \mathrm{in})$. 


\section{B.3.1.3 Subcooled Liquid in Pressurized Storage}

This scenario is similar to that described in Section B.3.1.2 except that the liquid is subcooled, i.e., the storage pressure is greater than the saturated vapor pressure at the temperature of storage. The pressure and temperature in the reservoir are assumed not to change over the duration of release. The required input information is as follows:

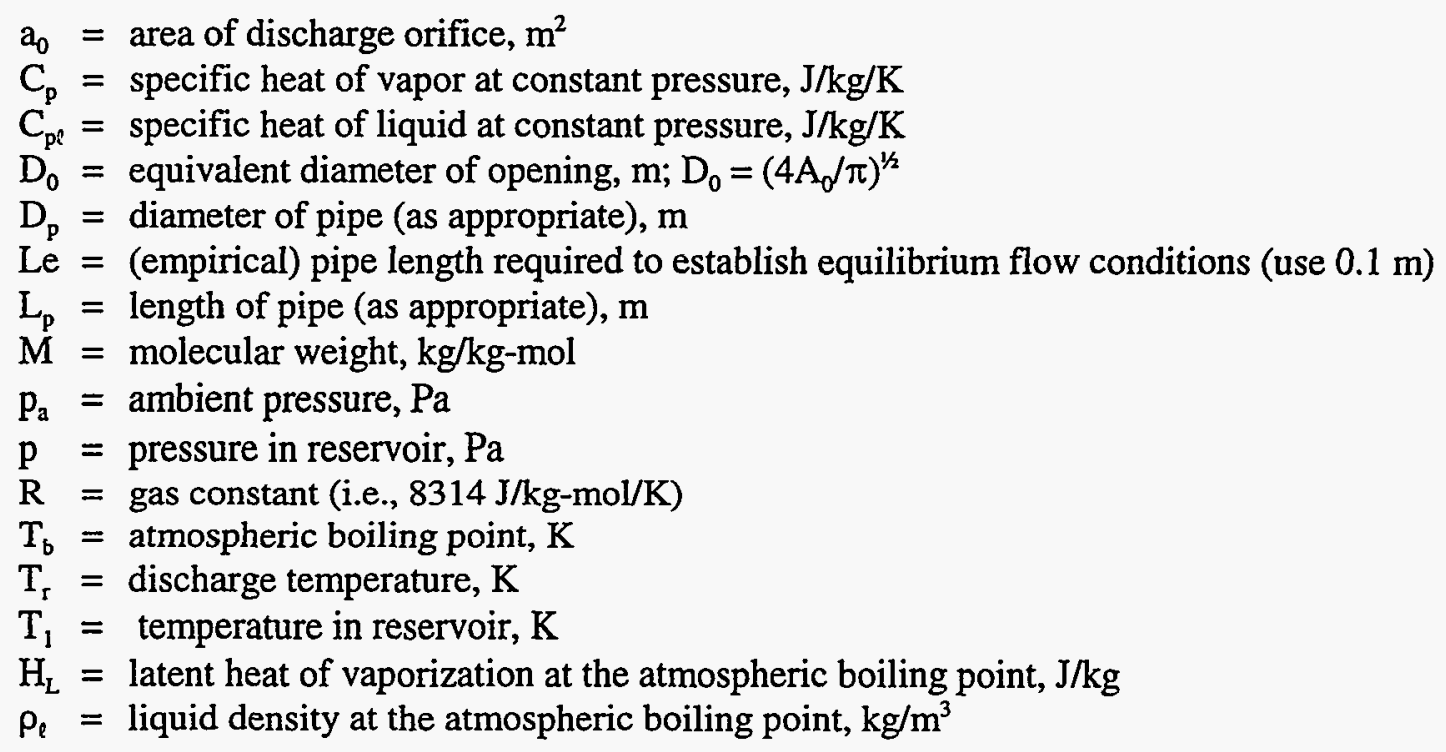

The procedures for estimating emissions characteristics are as follows:

1. Estimate the discharge temperature $T_{r}$ from the Clausius-Clapeyron equation:

$$
\mathrm{p}_{\mathrm{a}}=1.01 \times 10^{5} \exp \left[\frac{\mathrm{H}_{\mathrm{L}} \mathrm{M}}{\mathrm{R}}\left(\frac{1}{\mathrm{~T}_{\mathrm{b}}}-\frac{1}{\mathrm{~T}_{\mathrm{r}}}\right)\right]
$$

Note that for $\mathrm{p}_{\mathrm{a}}=1$ atmosphere $=10.1 \times 10^{5} \mathrm{~Pa}, \mathrm{~T}_{\mathrm{r}}=\mathrm{T}_{\mathrm{b}}$. For multicomponent mixtures, the discharge temperature can be calculated using the methods of Sandler (1989) (not discussed here).

2. Calculate vapor mass fraction after depressurization by:

$$
\mathrm{x}_{\mathrm{r}}=\mathrm{C}_{\mathrm{p} \ell}\left(\mathrm{T}_{1}-\mathrm{T}_{\mathrm{r}}\right) / \mathrm{H}_{\mathrm{L}}
$$

If $1 \geq x_{r} \geq 0$, then equation B.31 is valid, and the reader should proceed to step (3). If $x_{r}>1$ or if $x_{r}<$ 0 , the solution is non-physical. The details for this case are beyond the scope of this report. 
3. Calculate emission rate $Q$ using the work of Fauske and Epstein (1987):

$$
Q=A_{o}\left[2 c^{2}\left(p-p_{1 V}\right) \rho_{\ell}+\frac{F^{2}}{C_{p \ell} T_{1}}\left(\frac{H_{L} M p}{R T_{1}}\right)^{2}\right]^{1 / 2}
$$

where $C_{p l}$ is the specific heat of the liquid at constant pressure and:

$$
\mathrm{p}_{1 \mathrm{~V}}=1.01 \times 10^{5} \exp \left[\frac{\mathrm{H}_{\mathrm{L}} \mathrm{M}}{\mathrm{R}}\left(\frac{1}{\mathrm{~T}_{\mathrm{b}}}-\frac{1}{\mathrm{~T}_{1}}\right)\right]
$$

and where $c=0.6$ is the discharge coefficient. The letter $F$ represents the effect of pipe friction and is calculated by:

$$
F^{2}=1 /\left(1+4 f L_{p} / D_{p}\right)
$$

Here, use $f=0.0015$. This value of $f$ for this particular case is consistent with the values of $F$ given by Fauske and Epstein (1987) and corresponds to release through smooth pipe having negligible surface roughness.

4. Estimate discharge density $\rho_{r}$ by

$$
\rho_{r}=\left[x_{r}\left(\frac{R T_{r}}{p_{a} M}\right)+\left(\frac{1-x_{r}}{\rho_{\ell}}\right)\right]^{-1}
$$

5. Example: EPA (1992) gives an example of a discharge of subcooled liquid chlorine through an orifice of diameter $10.16 \mathrm{~cm}$ from a reservoir in which the pressure is $2.586 \times 10^{6} \mathrm{~Pa}$ (375 psia) and the temperature is $298.15 \mathrm{~K}\left(77^{\circ} \mathrm{F}\right)$.

\section{B.3.2 Hydrogen Fluoride at Elevated Temperature and Pressure}

The scenario of $\mathrm{HF}$ at elevated temperature and pressure is included to illustrate some of the issues that need to be addressed when the thermodynamics is complex. This scenario corresponds to Scenario $3 \mathrm{~A}$ on Figure B-1.

\section{B.3.2.1 Description of Scenario}

It is assumed that there is a vessel containing $\mathrm{HF}$ at an elevated temperature of $313 \mathrm{~K}\left(104^{\circ} \mathrm{F}\right)$ and a pressure of $1.4 \times 10^{6} \mathrm{~Pa}$ (200 psia). Possible causes of leaks are the same as discussed in Section B.2.1 (gasket failure, corrosion, or puncture). For the present case, it is assumed that there is a leak of effective diameter $1.3 \mathrm{~cm}(1 / 2 \mathrm{in})$.

\section{B.3.2.2 Calculation of Release Rate}

The rate of release of liquid from an orifice is given by Bernoulli's formula (AIChE 1989):

$$
\mathrm{Q}=\operatorname{cap}_{\ell}\left[2\left(\mathrm{p}-\mathrm{p}_{\mathrm{a}}\right) / \rho_{\ell}+2 \mathrm{gh}\right]^{1 / 2}
$$


where:

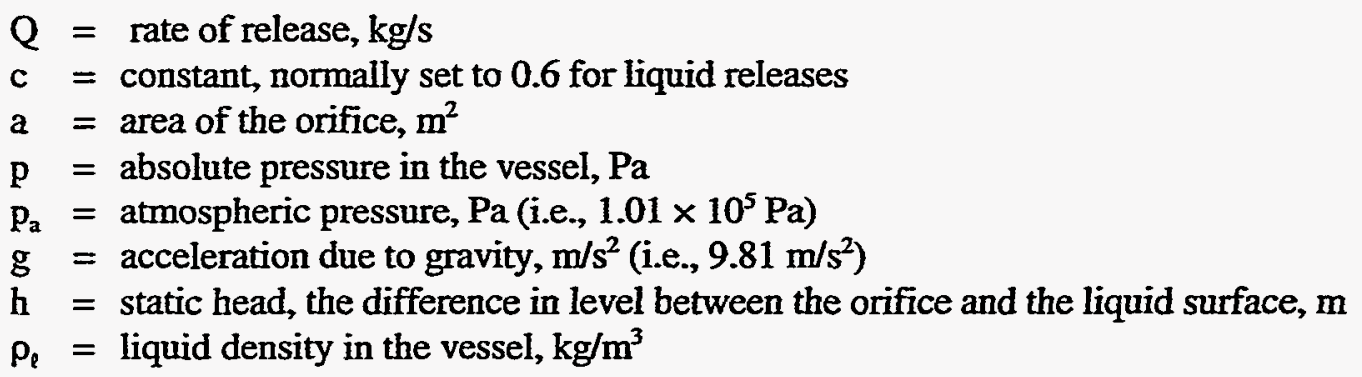

The above formula (which is the same as equation B.1) is suitable for calculating the rate of pure liquid flow through a circular orifice. It is also the same as equation $B .26$ for $L_{p} / L_{c}=0$. There are variations on the formula for a non-circular orifice and for cases where there is flashing in the pipe upstream of the orifice. See Section B.3.1.2 for further discussion of releases through ruptured pipelines. Values to be assigned to the variables in equation B.36 are as follows:

- For the case of a $1.3 \mathrm{~cm}\left(1 / 2\right.$ in)-diameter orifice, the area $\mathrm{a}=\pi \mathrm{r}^{2}=\pi(0.65 \mathrm{~cm})^{2}=1.3 \mathrm{~cm}^{2}=$ $1.3 \times 10^{-4} \mathrm{~m}^{2}$.

- The density of liquid HF $\rho_{e}$ is approximately $1,000 \mathrm{~kg} / \mathrm{m}^{3}$.

- The operating pressure in the vessel $\mathrm{p}$ is $1.4 \times 10^{6} \mathrm{~Pa}$ (200 pounds per square inch gage). This is well above the saturated vapor pressure of $\mathrm{HF}$ at an operating temperature of $40^{\circ} \mathrm{C}\left(104^{\circ} \mathrm{F}\right)$. For other applications to liquids such as $\mathrm{NH}_{3}$ or chlorine stored under their own vapor pressure, the pressure in the vessel can be obtained from standard curves of vapor pressure versus temperature (e.g., see Daubert and Danner [1985]).

- The static head $h$ is generally of the order of a few meters (assume $5 \mathrm{~m}$ ). For the present scenario, this makes a very small contribution to the total rate of release.

Using the values defined above in equation $B .36$ gives a rate of release of $Q=0.6\left(1.3 \times 10^{-4}\right)(1,000) \times$ $\left[2\left(1.4 \times 10^{6}-1.01 \times 10^{5}\right) / 1,000+2(9.81)(5)\right]^{1 / 2}=4.1 \mathrm{~kg} / \mathrm{s}$ (or 65 gallons per minute). This rate will persist for some time before there is a significant decrease of pressure in the vessel.

\section{B.3.2.3 Other Characteristics of the Source Term}

Other characteristics of the source term include velocity and direction of the release, flashing and vaporization of the liquid, and duration of the release. These characteristics are discussed below.

\section{Velocity and Orientation}

The velocity of release is given by $Q /\left(\rho_{\ell} a\right)=4.1 /\left[(1,000)\left(1.3 \times 10^{-4}\right)\right]=32 \mathrm{~m} / \mathrm{s}$. For the present example, it is assumed that the release is horizontal in the direction of the wind (this is the most conservative assumption).

\section{Flashing and Vaporization}

Upon being released, the liquid will immediately flash, and part of it will vaporize. The fraction of liquid that flashes to vapor is given by the formula (AIChE 1989): 


$$
F_{v}=C_{p l}\left(T_{1}-T_{b}\right) / H_{L}
$$

where:

$F_{v}=$ fraction of the liquid that is vaporized

$C_{p \ell}=$ heat capacity of the liquid averaged over the temperature range $T_{1}$ to $T_{b}, J / k g / K$

$\mathrm{T}_{1}=$ initial temperature of the liquid, $\mathrm{K}$

$T_{b}=$ atmospheric boiling point of the liquid, $K$

$\mathrm{H}_{\mathrm{L}}=$ latent heat of vaporization of the liquid, $\mathrm{J} / \mathrm{kg}$

For the present example, the initial temperature of the liquid is $313 \mathrm{~K}\left(104^{\circ} \mathrm{F}\right)$. The atmospheric boiling point of $\mathrm{HF}$ is $292.7 \mathrm{~K}\left(67^{\circ} \mathrm{F}\right)$. The heat of vaporization is $208 \mathrm{~kJ} / \mathrm{kg}(86 \mathrm{Btu} / \mathrm{lb})$. The heat capacity of the liquid is approximately $2,500 \mathrm{~J} / \mathrm{kg} / \mathrm{K}\left(0.6 \mathrm{Btu} / \mathrm{lb} /{ }^{\circ} \mathrm{F}\right)$. Substituting these values into equation $\mathrm{B} .37$ gives $F_{v}=0.2$ or 20 percent.

The balance of the HF ( 80 percent) remains a liquid at the boiling point of HF. From large scale HF experiments, it is clear that this liquid does not fall to the ground but remains airboine as a fine aerosol. Thus, the initial release consists of 80 percent liquid droplets and 20 percent vapor at the atmospheric boiling point of HF.

\section{Duration of Release}

Generically, the duration of the release is hard to predict because it depends on site-specific mitigating equipment and procedures. For example, there may be valves that can be closed manually in order to isolate the leak. In such a case, the operators would first have to put on cumbersome protective clothing. It therefore might be 10 to 20 minutes before the release could be stopped.

\section{B.3.3 Release of Ammonia from a Large Tank}

Two examples of the types of releases that can take place from a $76000 \mathrm{l}\left(20000\right.$ gallon) tank of $\mathrm{NH}_{3}$ include (1) a shearing off of the pipework, leaving an unobstructed flow to the atmosphere, and (2) a leak in the vessel itself, perhaps caused by impact by an external agent. For the present example, it is assumed that there is a $5 \mathrm{~cm}$ ( $2 \mathrm{in}$ ) diameter hole in the vessel through which liquid emerges under a $5 \mathrm{~m}$ static head at a conservatively assumed constant rate until the vessel is empty. (A diameter of $5 \mathrm{~cm}$ [ $2 \mathrm{in}$ ] is a typical size for pipework connected to the liquid space of large $\mathrm{NH}_{3}$ tanks.) The liquid density of $\mathrm{NH}_{3}$ is $630.9 \mathrm{~kg} / \mathrm{m}^{3}\left(39 \mathrm{lb} / \mathrm{ft}^{3}\right)$.

Using equation B.36, the release rate calculated for $\mathrm{NH}_{3}$ at $278 \mathrm{~K}\left(40^{\circ} \mathrm{F}\right)$ is $-28 \mathrm{~kg} / \mathrm{s}(62 \mathrm{ib} / \mathrm{s})$. Using equation B.37, the flash fraction is 0.14 and the liquid aerosol fraction is 0.86 . It is assumed that all of the liquid aerosol fraction remains airborne as fine droplets. The resulting aerosol/vapor mixture is at the atmospheric boiling point of $\mathrm{NH}_{3}, 239.7 \mathrm{~K}\left(-29^{\circ} \mathrm{F}\right)$. For a volume of $76000 \ell$ ( 20000 gallons) or approximately $\mathrm{V} \times p=76 \times 630.9 \sim 48,000 \mathrm{~kg}$ in the vessel, the duration of release is (48000 $\mathrm{kg}) /(28 \mathrm{~kg} / \mathrm{s}) \sim 1720$ seconds or $\sim 29$ minutes. 


\section{B.3.4 Flashing Liquid Jets}

This section discusses two items that require further study: (1) a flashing liquid jet that is directed downward, and (2) a flashing jet from a long pipe. The shape of the orifice will also influence the rate of release.

\section{B.3.4.1 Jet Directed Downward}

The case of a flashing liquid jet directed downward corresponds to Scenario $3 \mathrm{C}$ on Figure B-1. When a jet containing an aerosol is directed downward, a significant fraction of the initially airborne aerosol is recovered. Experiments with $\mathrm{NH}_{3}$ show that the fraction recovered can be as high as 75 percent (Resplandy 1969). Thus, the source term will be a mixture of an initial airborne cloud with some remaining aerosol together with a cloud from an evaporating pool. The details for this case are beyond the scope of this report.

\section{B.3.4.2 Jet Emerging from a Long Pipe}

The case of a flashing liquid jet emerging from a long pipe corresponds to Scenario 3B on Figure B-1. If the pipe from which the liquid jet emerges is long, there will be some flashing before the material is released to the atmosphere. In this case, there will be a two-phase flow at the outlet, with liquid and vapor in thermal equilibrium. The flow may still be choked at the outlet, causing further flashing to occur in the atmosphere. Two-phase flow has a smaller discharge rate than pure liquid flow. Therefore, the cases described above in Sections B.3.2 and B.3.3 may represent conservative, high flow rates.

In addition to liquid flow and equilibrium flow, there is a continuum of cases where there is two-phase flow at the outlet but the flow is not in thermal equilibrium. Such cases have intermediate flow rates.

A discussion of rate of release is presented in Wheatley (1987), whose article contains a useful source of references. Another useful reference is Fauske and Epstein (1987); see Section B.3.1.2 and equations B.26 through B.35 for further discussion of calculation of discharge flow rates.

\section{B.3.4.3 Orifice Shape}

The shape of the orifice will influence the predicted rate of release. The examples described above are appropriate for a circular orifice. If the orifice has a different shape, for example, if the orifice is a long and narrow rectangle, the constant $\mathrm{c}$ in equation $\mathrm{B} .36$ will be considerably reduced.

\section{B.3.5 Jet Release of Liquid Uranium Hexafluoride From a Pressurized Cylinder}

$\mathrm{UF}_{6}$ is technologically important for the separation of fissile isotope uranium-235 from natural uranium by gas diffusion or centrifugation. The property that makes $U F_{6}$ technologically important is its very high volatility; it is the most volatile uranium compound known. $\mathrm{UF}_{6}$ is a solid at room temperature and it has a vapor pressure of $112 \mathrm{~mm}$ mercury or $15 \mathrm{kPa}(0.15$ atmosphere $)$ at $298 \mathrm{~K}\left(76^{\circ} \mathrm{F}\right)$. Its sublimation point is $329.4 \mathrm{~K}\left(133^{\circ} \mathrm{F}\right)$ and $100 \mathrm{kPa}$ ( 1 atmosphere), and its triple point (i.e., where the solid, liquid, and vapor phases coexist) is $337.02 \mathrm{~K}\left(147^{\circ} \mathrm{F}\right)$ and $1137.5 \mathrm{~mm}$ mercury or $150 \mathrm{kPa}(1.5$ atmosphere). The triple point conditions are quite close to normal atmospheric conditions. 
Solid $\mathrm{UF}_{6}$ is supplied and stored in cylindrical containers. The 1986 accident resulting in one fatality at the Sequoyah Fuel Plant in Gore, Oklahoma, happened when one of these containers was overfilled and heated (NUREG-1189 [USNRC 1986]). Accidental releases of $\mathrm{UF}_{6}$ from such containers could involve either accidental heating by a fire or deliberate heating to transfer the $\mathrm{UF}_{6}$ in either liquid or vapor form.

\section{B.3.5.1 Calculation of Release Rate of Uranium Hexafluoride}

Assume that a $\mathrm{UF}_{6}$ cylinder is being heated for delivery to the hydrolysis unit of a fuel fabrication facility. If the $\mathrm{UF}_{6}$ 's temperature and pressure are equal to or above its triple point, then the $\mathrm{UF}_{6}$ will exist as a liquid. If the integrity of the cylinder is compromised due to a small hole, liquid $\mathrm{UF}_{6}$ may begin to exit the cylinder. A hole may be formed from corrosion-induced valve failure, gasket failure, puncture from a fork-lift, etc.

As an example, assume that the $\mathrm{UF}_{6}$ inside the cylinder is at its triple point and the size of the small hole is $5 \mathrm{~cm}$ ( $2 \mathrm{in}$ ) in diameter. The location of the hole is assumed to be $1 \mathrm{~m}$ below the liquid level of $\mathrm{UF}_{6}$. Equation B.1, the equation for the estimation of the release rate of liquid from a vessel can be used. The density of liquid $\mathrm{UF}_{6}$ is $3674 \mathrm{~kg} / \mathrm{m}^{3}\left(229 \mathrm{lb} / \mathrm{ft}^{3}\right)$ at its triple point temperature $\left(337 \mathrm{~K}\left(147^{\circ} \mathrm{F}\right)\right)$. Using these assumptions, the following values can be used in equation B.1:

$$
\begin{aligned}
& c=0.6 \\
& A=\pi r^{2}=\pi\left(\frac{5 \mathrm{~cm}}{2}\right)^{2}=20 \mathrm{~cm}^{2}=2.0 \times 10^{-3} \mathrm{~m}^{2} \\
& \rho_{l}=3,674 \mathrm{~kg} / \mathrm{m}^{3} \\
& \mathrm{p}-\mathrm{p}_{\mathrm{a}}=1.5 \times 10^{5}-1.0 \times 10^{5}=5.0 \times 10^{4} \mathrm{~Pa} \\
& \mathrm{~h}=1 \mathrm{~m}
\end{aligned}
$$

Using equation B.1, the release rate $Q=(0.6)\left(2 \times 10^{-3}\right)(3674)\left[2\left(5 \times 10^{4}\right) / 3674+(2)(9.81)\right]^{3 / 2}=30 \mathrm{~kg} / \mathrm{s}$ of liquid $\mathrm{UF}_{6}$. The exit velocity is equal to $\mathrm{Q} /\left(\mathrm{p}_{\mathrm{e}} \mathrm{A}\right)=4.1 \mathrm{~m} / \mathrm{s}$

\section{B.3.5.2 Flashing and Sublimation of Uranium Hexafluoride}

As soon as liquid $\mathrm{UF}_{6}$ exits the cylinder and depressurizes, it no longer exists as a liquid. Rather it undergoes a simultaneous phase change to vapor and solid. Although it is possible that solid particles of $\mathrm{UF}_{6}$ may actually plug the hole in the cylinder, this phenomenon is ignored in the following discussion.

If liquid $\mathrm{UF}_{6}$ under pressure in the cylinder is at an initial storage temperature $T_{i}$ such that $T_{i}>T_{v}$, where $\mathrm{T}_{\mathrm{t}}$ is the triple point temperature, then from the heat balance, the mass fraction of $\mathrm{UF}_{6}$ that flashes from liquid to vapor is:

$$
f=\frac{m_{l}^{i}\left[\lambda_{f}+C_{p s}\left(T_{t}-T_{s}\right)+C_{p \ell}\left(T_{i}-T_{l}\right)\right]+m_{v}^{i}\left[\lambda_{s}+C_{p s}\left(T_{t}-T_{s}\right)+C_{p v}\left(T_{i}-T_{l}\right)\right]}{\left(m_{\ell}^{i}+m_{v}^{i}\right)\left[\lambda_{s}+C_{p s}\left(T_{t}-T_{s}\right)+C_{p v}\left(T_{s}-T_{l}\right)\right.}
$$

where:

$\mathrm{f}=$ mass fraction of liquid $\mathrm{UF}_{6}$ that is initially flashed to vapor

$\mathrm{C}_{\mathrm{p} \ell}=$ specific heat at constant pressure for liquid $\mathrm{UF}_{6}$ (i.e., $563.3 \mathrm{~J} / \mathrm{kg}-\mathrm{K}$ ) 
$\mathrm{C}_{\mathrm{ps}}=$ specific heat at constant pressure for solid $\mathrm{UF}_{6}$ (i.e., $518.14 \mathrm{~J} / \mathrm{kg}-\mathrm{K}$ )

$\mathrm{C}_{\mathrm{pv}}=$ specific heat at constant pressure for $\mathrm{UF}_{6}$ vapor (i.e., $369.35 \mathrm{~J} / \mathrm{kg}-\mathrm{K}$ )

$\mathrm{T}_{\mathrm{i}}=$ initial storage temperature of $\mathrm{UF}_{6}$, i.e., $337 \mathrm{~K}$

$\mathrm{T}_{\mathrm{t}}=$ triple point temperature of $\mathrm{UF}_{6}$, i.e., $337 \mathrm{~K}$

$\mathrm{T}_{\mathrm{s}}=$ sublimation temperature (i.e., $329.4 \mathrm{~K}$ )

$\mathrm{H}_{\mathrm{L}}=$ latent heat of vaporization of liquid $\mathrm{UF}_{6}$ (i.e., $2.442 \times 10^{6} \mathrm{~J} / \mathrm{kg}$ )

$\lambda_{\mathrm{f}}=$ heat of fusion for the solid-liquid transition (i.e., $5.458 \times 10^{4} \mathrm{~J} / \mathrm{kg}$ )

$\lambda_{\mathrm{s}}=$ heat of sublimation (i.e., $1.369 \times 10^{5} \mathrm{~J} / \mathrm{kg}$ )

$\mathrm{m}_{\mathrm{i}}^{\mathrm{i}}=$ initial mass of liquid $\mathrm{UF}_{6}$ (i.e., $14000 \mathrm{~kg}$ )

$\mathrm{m}_{\mathrm{v}}=$ initial mass of $\mathrm{UF}_{6}$ vapor $(0 \mathrm{~kg}$ : in reality, there maybe some vapor, but it is ignored here)

Equation B.38 has been derived from first principles specifically for this report.

For the present example, the initial storage temperature of $\mathrm{UF}_{6}$ is equal to its triple point temperature, i.e., $T_{i}=T_{t}=337 \mathrm{~K}\left(133^{\circ} \mathrm{F}\right)$. Therefore, with the initial inventory entirely in the liquid phase, equation B.38 predicts that the mass fraction of $\mathrm{UF}_{6}$ that flashes to vapor is:

$$
\begin{aligned}
f & =\frac{5.458 \times 10^{4}+(518.14)(337 .-329.4)}{1.369+10^{5}+(518.14)(337-329.4)+(369.35)(329.4-337 .)} \\
& =0.42
\end{aligned}
$$

This means that 42 percent by mass of the liquid $\mathrm{UF}_{6}$ flashes to vapor and the remaining 58 percent by mass of $\mathrm{UF}_{6}$ changes phase to solid. The temperature of the jet is equal to the sublimation temperature of $\mathrm{UF}_{6}\left(329.4 \mathrm{~K}\left(133^{\circ} \mathrm{F}\right)\right)$.

The density of the mixture of the solid and vapor $\mathrm{UF}_{6}$ can be found using equation $\mathrm{B} .12$, where $\mathrm{x}_{*}=0.42$ and the $U F_{6}$ solid density $\rho_{s}=5,053.8 \mathrm{~kg} / \mathrm{m}^{3}$. Using equation $B .12$, the density at the exit, $\rho_{*}$, is:

$$
\begin{aligned}
\rho_{*} & =\left[(0.42) \frac{(8,314)(329.4)}{(101,325)(352)}+\frac{(1-0.42)}{5,053.8}\right]^{-1} \\
& =31 \mathrm{~kg} / \mathrm{m}^{3}
\end{aligned}
$$

\section{B.4 Vapor Jet Releases}

The purpose of this section is to describe how to estimate vapor jet release rates for conditions under which condensation does not affect release rate. Section B.4.1 contains a detailed theoretical discussion of various release formulas. Section B.4.2 contains a specific example of $\mathrm{NH}_{3}$ released from a small hole in the vapor space of a vessel that contains $\mathrm{NH}_{3}$ liquefied under pressure. The reader who is not interested in theoretical details can move directly on to the example in Section B.4.2. Section B.4.3 includes an example of $\mathrm{UF}_{6}$ vapor releases from a cylinder.

\section{B.4.1 Theory of Vapor Release Formulas}

This section describes how to model the atmospheric dispersion of pure vapors that are driven through an orifice by internal pressure. Initially, the issues involved in calculating the release rates and other 
characteristics of the source term are discussed. Sections B.4.1.1 and B.4.1.2 demonstrate how to estimate the rate of release of a gas for two scenarios: (1) a release of gas from an orifice directly in the wall of a reservoir, and (2) a release from a pipe attached to a reservoir.

For all of the releases considered in Section B.4.1 it is assumed that: (a) the released material is a vapor under the stated conditions, and (b) the pressure and temperature of the gas in the reservoir are essentially constant. Note that the discussions in Sections B.4.1.1 and B.4.1.2 draw heavily on the work performed by EPA (1992), i.e., EPA's "Workbook of Screening Techniques for Assessing the Impacts of Toxic Air Pollutants (Revised)" and the accompanying TSCREEN model (USEPA, 1988).

\section{B.4.1.1 Estimate of Release Rate for a Gas Leak Directly from a Reservoir}

This section discusses a release of gas through a hole or opening in the wall of a reservoir in which the pressure and temperature remain constant. It is assumed that the released material is an ideal gas at the reservoir conditions both during and after the depressurization process. These assumptions are clearly simplifications. The assumption that the release rate is constant is conservative because: (a) for a vessel containing vapor only, the pressure in the vessel declines as the release proceeds, causing a corresponding reduction in the rate of release, and (b) for a vessel containing both vapor and liquid, the escaping vapor is replaced as the liquid boils. This boiling in turn causes the liquid to cool (autorefrigeration) and leads to a corresponding reduction of pressure in the vapor space.

The ideal gas law states that $\mathrm{pV}=\mathrm{nRT}$, where $\mathrm{V}$ is the volume of the gas at temperature $\mathrm{T}$ and pressure $\mathrm{p}, \mathrm{n}$ is the number of moles of the gas, and $\mathrm{R}$ is the gas constant. For $\mathbf{n}=1 \mathrm{~mole}, \mathrm{pV}=\mathrm{RT}$. For a nonideal gas, the actual behavior of the gas is expressed by a standard text book equation of the form $\mathrm{pV}=$ $\mathrm{RT}\left(1+\mathrm{B} / \mathrm{V}+\mathrm{C} / \mathrm{V}^{2}+\cdots\right)$, where the quantities $\mathrm{B}$ and $\mathrm{C}$ are known as virial coefficients. Values for the second virial coefficient $\mathrm{B}$ can be found for many substances in Data Compilation - Tables of Properties of Pure Components, which has been published by the American Institute of Chemical Engineers (Daubert and Danner 1985). If $\mathrm{B} / \mathrm{V}$ is large compared to unity, the ideal gas law breaks down. In general, for most commonly encountered vapors, the ideal gas law is a reasonable approximation.

If a reservoir contains both vapor and liquid, it is assumed that the hole is in the vapor space of the tank. Possible scenarios include a gas leak from a tank, a small gas leak from the wall of a large pipe, or a gas discharge from a pressure relief valve mounted on a tank.

The following procedures demonstrate how to calculate the release rate and the density and temperature of the gas after depressurization. The input required for the calculation is as follows:

$a_{0}=$ area of reservoir hole or opening, $\mathrm{m}^{2}$

$A_{1}=$ cross-sectional area of reservoir affecting flow conditions, $m^{2}$. (For a leak from a tank, $A_{1} \rightarrow \infty$ [and $\beta=0$, see below]. For a leak from a pipe, $A_{1}$ is the cross sectional area of the pipe.)

$C_{p}=$ specific heat of the released gas at constant pressure, $\mathrm{J} / \mathrm{kg} / \mathrm{K}$

$D_{0}=$ equivalent diameter of reservoir hole or opening, $m ; D_{0}=\left(4 a_{0} / \pi\right)^{1 / 2}$

$\mathrm{H}_{\mathrm{L}}=$ heat of vaporization at the boiling point $\mathrm{T}_{\mathrm{b}}, \mathrm{J} / \mathrm{kg}$

$\mathrm{M}=$ molecular weight of the released gas, $\mathrm{kg} / \mathrm{kg}-\mathrm{mol}$

$\mathrm{p}_{\mathrm{a}}=$ ambient pressure, $\mathrm{Pa}$

$\mathrm{p}_{\mathrm{v}}=$ vapor pressure as a function of temperature, $\mathrm{Pa}$

$\mathrm{p}_{1}=$ reservoir pressure, $\mathrm{Pa}$

$\mathrm{R}=$ gas constant (i.e., $8314 \mathrm{~J} / \mathrm{kg}-\mathrm{mol} / \mathrm{K}$ ) 
$\mathrm{T}_{\mathrm{b}}=$ boiling point at atmospheric pressure, $\mathrm{K}$

$\mathrm{T}_{c}=$ critical temperature, $\mathrm{K}$

$\mathrm{T}_{\mathrm{r}}=$ discharge temperature, $\mathrm{K}$

$\mathrm{T}_{1}=$ reservoir temperature, $\mathrm{K}$

$\beta=\left(a_{0} / A_{1}\right)^{1 / 2}$

$\gamma=C_{p} / C_{v}$ where $C_{v}=C_{p}-R$ (for ideal gases) is the specific heat at constant volume, $J / k g / K$

$\rho_{1}=$ density of gas inside reservoir, $\mathrm{kg} / \mathrm{m}^{3}$

The calculational procedure is shown in the following steps:

1. Estimate choked flow pressure. Determine whether the flow is choked or not by first estimating the choked flow pressure $p_{*}$ from:

$$
\mathrm{p}_{*}=\mathrm{p}_{1}\left(\frac{2}{\gamma+1}\right)^{\gamma(\gamma-1)}
$$

If $\mathrm{p}_{*} \geq \mathrm{p}_{\mathrm{a}}$, then the flow is choked; go to step (2) below. If $\mathrm{p}_{*}<\mathrm{p}_{\mathrm{a}}$, then the flow is subcritical; go to step (3) below.

2. Choked flow: For choked flow, estimate (a) the gas temperature $\mathrm{T}_{* *}$ when the gas pressure is $\mathrm{p}_{*}$, (b) the emission rate $Q$, and (c) the discharge temperature $T_{r}$ as discussed in steps (2)(a), (2)(b), and (2)(c), respectively, below.

a. Estimate $\mathrm{T}_{* *}$ from the equation:

$$
\mathrm{T}_{* *}=2 \mathrm{~T}_{1} /(\gamma+1)
$$

First, it is necessary to determine whether condensation will occur by comparing $\mathrm{T}_{* *}$ with the (pseudo) critical temperature $\mathrm{T}_{\mathrm{c}}$. If $\mathrm{T}_{* *}>\mathrm{T}_{\mathrm{c}}$, there is no condensation and the discharge temperature can be estimated as shown in step (2)(c) below. If $\mathrm{T}_{* *} \leq \mathrm{T}_{\mathrm{c}}$, first calculate the vapor pressure of the gas at temperature $\mathrm{T}_{* *}$ using the Clausius-Clapeyron equation:

$$
\mathrm{p}_{\mathrm{v}}=\left(1.01 \times 10^{5}\right) \exp \left[\frac{\mathrm{H}_{\mathrm{L}} \mathrm{M}}{\mathrm{R}}\left(\frac{1}{\mathrm{~T}_{\mathrm{b}}}-\frac{1}{\mathrm{~T}_{* *}}\right)\right]
$$

If $\mathrm{p}_{\mathrm{v}}\left(\mathrm{T}_{* *}\right)>\mathrm{p}_{*}$, then condensation does not occur during depressurization and the release rate $\mathrm{Q}$ can be estimated as described in step (2)(b) below. If $p_{v}\left(T_{* *}\right) \leq p_{*}$, then the release is considered two-phase flow at the critical pressure, and the appropriate procedures are given in Section B.3.1. Note that, for some releases, even if there is liquid present at choked conditions, there may not be liquid when the final expansion to atmospheric pressure takes place (see Section B.3.1).

For multicomponent mixtures, the mixture dewpoint temperature at $\mathrm{p}_{*}$ should be calculated. This can be done using methods described by Sandler (1989) (not further discussed here). If $\mathrm{T}_{* *}$ is less than the dewpoint temperature, then condensation occurs and the reader should use the procedures in Section B.3.1. 
b. For evaporation in which condensation does not occur, estimate the release rate $Q$ as:

$$
\mathrm{Q}=\mathrm{c}_{0} \mathrm{a}_{0}\left[\mathrm{p}_{1} \rho_{1} \gamma(2 /(\gamma+1))^{(\gamma+1)(\gamma-1)}\right]^{1 / 2}
$$

Taking into account the ideal gas law which gives $\rho_{1}=\mathrm{pM} / \mathrm{RT}$, equation B.44 can be rewritten in a form in which it is frequently found in textbooks (AIChE 1987 and 1989):

$$
\mathrm{Q}=c_{0} \mathrm{a}_{0} \mathrm{p}_{1}\left[\left(\gamma \mathrm{M} / \mathrm{RT} \mathrm{T}_{1}\right)(2 /(\gamma+1))^{(\gamma+1)(\gamma-1)}\right]^{1 / 2}
$$

In equation $\mathrm{B} .45, \mathrm{c}_{0}$ is a discharge coefficient for the orifice and can conservatively be set equal to one. This is appropriate for a vapor release. Note that previously a value of 0.6 has been used when the discharge is liquid or two phase.

c. Estimate the discharge temperature. EPA (1992) recommends the following formula for conditions under which condensation does not occur:

$$
\mathrm{T}_{\mathrm{r}}=\mathrm{T}_{1}[1-(0.85)(\gamma-1) /(\gamma+1)]
$$

based on the assumptions that the expansion from reservoir to choked conditions occurs adiabatically and reversibly, and the expansion from choked conditions to atmospheric pressure will occur adiabatically and irreversibly. Based on work by Lewitt (1953) the irreversible, adiabatic expansion is 85 percent efficient. After estimating $T_{r}$ by equation B.46, proceed to step (4) below.

\section{Subcritical flow:}

a. Estimate the emission rate Q. Perry's Chemical Engineer's Handbook (Perry, et al. 1984) gives the rate of discharge for subcritical flow as:

where:

$$
Q=K Y a_{0}\left[2 \rho_{1}\left(p_{1}-p_{a}\right)\right]^{1 / 2}
$$

$\mathrm{K}=c /\left(1-\beta^{4}\right)^{1 / 2}$

$c=$ coefficient of discharge, dimensionless

$\beta=$ ratio of throat diameter to pipe diameter, dimensionless

(Note that for $\beta=0, \mathrm{~K}=\mathrm{c}$.)

$$
\mathrm{Y}=1-\left[\left(\mathrm{p}_{1}-\mathrm{p}_{2}\right) /\left(\mathrm{p}_{1} \gamma\right)\right]\left(0.41+0.35 \beta^{4}\right)
$$

For $\beta=0$,

$$
\mathrm{Y}=1-0.41\left[\left(\mathrm{p}_{1}-\mathrm{p}_{2}\right) /\left(\mathrm{p}_{1} \gamma\right)\right]
$$

A frequently encountered alternative formula for Q (AIChE 1987 and 1989) is:

$$
\mathrm{Q}=\mathrm{ca}_{0}\left\{2 \mathrm{p}_{1} \mathrm{p} \gamma /(\gamma-1)\left[\left(\mathrm{p}_{\mathrm{a}} / \mathrm{p}\right)^{2 / \gamma}-\left(\mathrm{p}_{\mathrm{a}} / \mathrm{p}\right)^{(\gamma+1) / \gamma}\right]\right\}^{1 / 2}
$$


Spot hand calculations show that equation B.47 is somewhat conservative with respect to equation B.50.

b. Estimate discharge temperature $\mathrm{T}_{\mathrm{r}}$ The discharge temperature is given by:

$$
\mathrm{T}_{\mathrm{r}}=2 \mathrm{~T}_{1} /\left[1+\left(1+4 \mathrm{ET}_{1}\right)^{1 / 2}\right]
$$

where:

$$
\mathrm{E}=\left[1 /\left(2 \mathrm{C}_{\mathrm{p}}\right)\right]\left[\mathrm{QR} /\left(\mathrm{pMa}_{0}\right)\right]^{2}
$$

This formula is presented by the EPA (1992).

The estimate for $T_{r}$ must be checked to see if there will be condensation. If $T_{r}>T_{c}$, the (pseudo) critical temperature, equation $B .51$ is valid. If $T_{r} \leq T_{c}$, equation $B .51$ is not valid, and the following procedure for single component parameters should be used. First, calculate the vapor pressure $p_{v}$ at temperature $T_{r}$ using the Clausius-Clapeyron equation (equation B.43). If $p_{v}\left(T_{r}\right) \leq$ $\mathrm{p}_{\mathrm{a}}$, then condensation occurs during the process of depressurization and the release should be treated as two-phase flow (see Section B.3.1). For multicomponent contaminants, estimate the dewpoint of the mixture at pressure $\mathrm{p}_{\mathrm{a}}$ using the methods of Sandler (1989) (not discussed here). If $\mathrm{T}_{\mathrm{r}}$ is less than the dewpoint, there will be condensation, and the reader should proceed to Section B.3.1.

4. Calculate discharge density. $\rho_{\mathrm{r}}$ can be calculated from the discharge temperature using the ideal gas law:

$$
\rho_{\mathrm{r}}=\mathrm{p}_{\mathbf{a}} \mathrm{M} /\left(\mathrm{RT}_{\mathrm{r}}\right)
$$

5. Examples: EPA (1992) illustrates the procedures in steps (1) through (4) above using the following examples:

- Air leak with the following conditions: reservoir pressure of $1.01 \times 10^{6} \mathrm{~Pa}$ (147 psia), hole of diameter $5.25 \mathrm{~cm}(2.0 \mathrm{in})$, choked flow

- Air leak with the following conditions: reservoir pressure of $1.82 \times 10^{5} \mathrm{~Pa}$ ( $26 \mathrm{psia}$ ), hole of diameter $5.25 \mathrm{~cm}$ ( $2.0 \mathrm{in})$, subcritical flow

- Chlorine gas leak with the following conditions: reservoir pressure of $6.89 \times 10^{5} \mathrm{~Pa}$ (100 psia), temperature of $320 \mathrm{~K}\left(117^{\circ} \mathrm{F}\right)$, hole of diameter $2.8 \mathrm{~cm}(1.1 \mathrm{in})$, choked flow.

The following example is reproduced from EPA, (1992):

\section{Example: Chlorine Gas Leak - Choked}

For this example, chlorine gas stored at $6.89 \times 10^{5} \mathrm{~Pa}(100 \mathrm{psia})$ and $320 \mathrm{~K}\left(116^{\circ} \mathrm{F}\right)$ is released through a $2.8 \mathrm{~cm}(1.1 \mathrm{in})$ hole. This example demonstrates the procedure when the flow is choked.

The following information will be required:

$a_{0}=$ area of reservoir hole or opening $\left(\pi D_{0}^{2} / 4=0.0006158 \mathrm{~m}^{2}\right)$ 


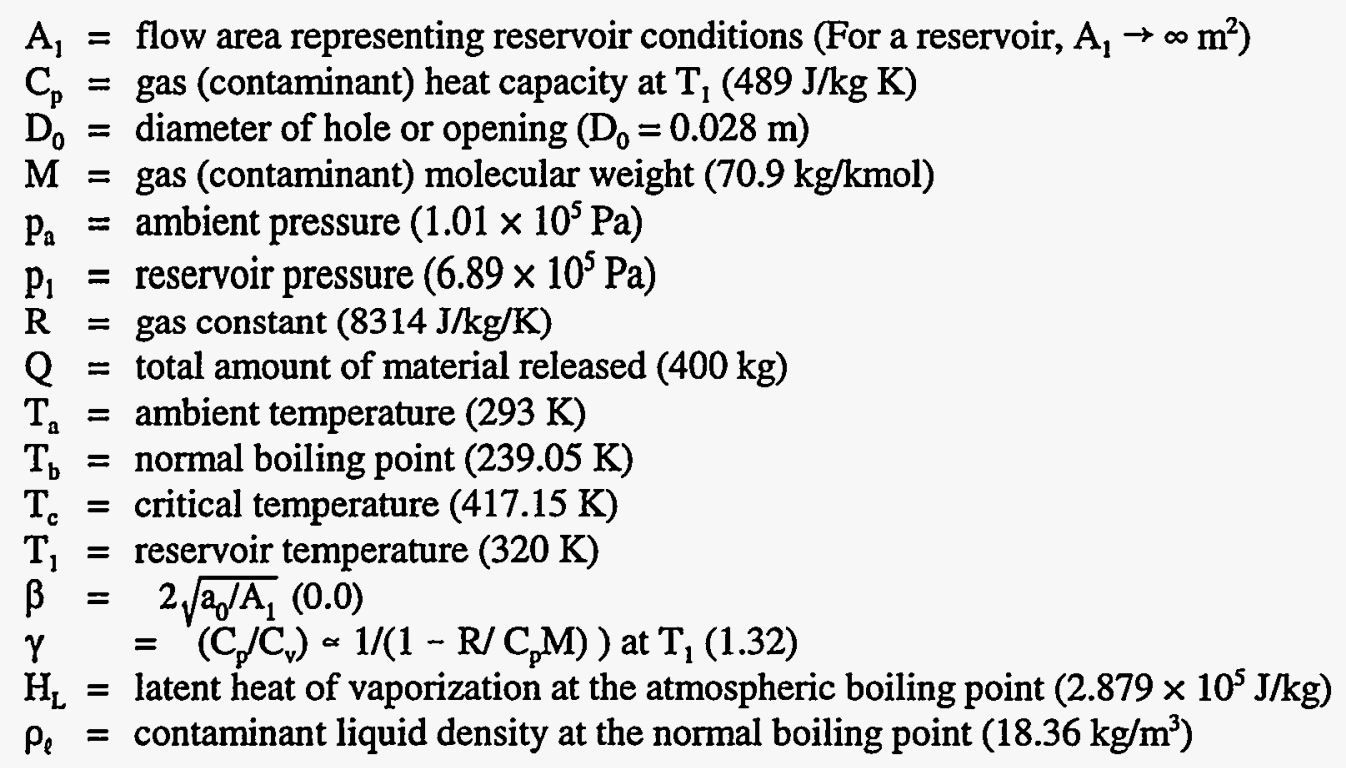

With this information, the procedure discussed above determines the release rate, the discharge temperature, and the discharge density.

1. Choked Pressure. Estimate the choked pressure p* to determine if the flow is choked. From equation B.39:

$$
\mathrm{p}_{*}=\left(\frac{2}{1.32+1}\right)^{1.32 /(1.32-1)}\left(6.89 \times 10^{5}\right)=3.74 \times 10^{5} \mathrm{~Pa}
$$

Since $\mathrm{p}_{\text {. }}>\mathrm{p}_{\mathrm{a}}$, the flow is choked; go to step (2).

2. Choked Flow. For choked flow, estimate the gas temperature $\mathrm{T}_{* *}$ when the pressure is $\mathrm{p}_{*}$, the emission rate $Q$, and the discharge temperature $T_{2}$.

a. Estimate $\mathrm{T}_{* *}$ Estimate $\mathrm{T}_{* *}$ using equation $\mathrm{B} .42$ with $\gamma=1.32$ and $\mathrm{T}_{1}=320 \mathrm{~K}$ :

$$
T_{* *}=\left(\frac{2}{1.32+1}\right)(320)=276 \mathrm{~K}
$$

The Clausius-Clapeyron equation can be conveniently used to estimate the vapor pressure at $T$.* as follows:

$$
\begin{aligned}
\mathbf{p}_{v} & =\left(1.01 \times 10^{5}\right)\left[\frac{2.879 \times 10^{5} \cdot(70.9)}{1.987}\left(\frac{1}{239.05}-\frac{1}{276}\right)\right] \\
& =5.81 \times 10^{8}>p_{*}
\end{aligned}
$$

Since $p_{v}\left(T_{*}\right)>p_{*}$, no condensation occurs. 
b. Estimate Emission Rate. Estimate the emission rate Q using equation B. 44 with $\mathrm{c}_{0}=0.75$ :

$$
\begin{aligned}
Q & =c_{0}(0.0006158)\left[6.89 \times 10^{5}(18.36)(1.32)\left(\frac{2}{1.32+1}\right)^{(1.32+1) /(1.32-1)}\right]^{3 / 2} \\
& =1.10 \mathrm{~kg} / \mathrm{s}
\end{aligned}
$$

c. Estimate Discharge Temperature. Estimate the emission discharge (after depressurization) temperature $\mathrm{T}_{\mathrm{r}}$ with equation B.46:

$$
\begin{aligned}
& \mathrm{T}_{\mathrm{r}}=320\left[1-0.85\left(\frac{1.32-1}{1.32+1}\right)\right] \\
& \mathrm{T}_{\mathrm{r}}=283 \mathrm{~K}
\end{aligned}
$$

3. Discharge Density. Estimate the discharge density $\rho_{\mathrm{r}}$ from the discharge temperature $\mathrm{T}_{\mathrm{r}}$ using the ideal gas law equation B.53:

$$
\rho_{\mathrm{r}}=\left(1.01 \times 10^{5}\right)(70.9) /(8314)(283)=3.04 \mathrm{~kg} / \mathrm{m}^{3}
$$

(For these choked flow conditions, correct application of a dispersion model may require that the diameter of the hole or opening be modified to $D_{0}\left(\mathrm{p}_{*} / \mathrm{p}_{\mathrm{a}}\right)^{3 / 2}=0.028\left(3.74 \times 10^{5} / 101325\right)^{3 / 2}=0.054 \mathrm{~m}$.

4. Perform Buoyancy Check.

a. Calculate density of air using the ideal gas law as follows:

$$
\begin{aligned}
& \rho_{\text {air }}=\frac{(101325)(28.9)}{(8314)(293)} \\
& \rho_{\text {air }}=1.20 \mathrm{~kg} / \mathrm{m}^{3}
\end{aligned}
$$

b. $\rho_{\mathrm{r}} / \rho_{\text {air }}>1.02$. Therefore, buoyancy is negative (i.e., vapor is heavier than air).

5. Release Duration. Calculate the duration of release $t_{d}$ as follows:

$$
\begin{aligned}
t_{d}(\min ) & =\frac{400 \mathrm{~kg}}{(1.10 \mathrm{~kg} / \mathrm{s})(60 \mathrm{~s} / \mathrm{min})} \\
t_{d} & =6.06 \mathrm{~min}
\end{aligned}
$$

Additional details can be found in EPA (1992). Also, Section B.4.2 contains an example of an $\mathrm{NH}_{3}$ gas leak from a reservoir at a pressure of $4.3 \times 10^{5} \mathrm{~Pa}(62 \mathrm{psia})$, with choked flow through a $5 \mathrm{~cm}(2$ in) diameter hole. 


\section{B.4.1.2 Discussion of Release Rates for a Gas Leak from a Pipeline Attached to a Reservoir}

The release rate of gas through the end of a pipe requires a determination of whether or not the flow through the pipe is choked. If the flow is choked then the speed of the gas at the exit approaches the speed of sound. However, to estimate the rate of discharge, a system of up to eight simultaneous quadratic and higher-order equations would need to be solved (USEPA, 1988 and 1992). Numerical solution techniques are usually employed for such a complicated system of equations.

\section{B.4.2 Ammonia Vapor Release Scenario}

The example of an $\mathrm{NH}_{3}$ vapor release is relevant to the case of a gas liquefied under pressure. It is assumed that there is a hole in the vapor space which could be caused for any of several reasons, e.g., impact from an external agent, failure at a corroded area, valve failure, or gasket failure. This example corresponds to Scenario 4A on Figure B-1.

It is assumed that there is a $76000 \ell\left(20000\right.$ gallon) tank containing $\mathrm{NH}_{3}$ at $278 \mathrm{~K}\left(40{ }^{\circ} \mathrm{F}\right)$. There is a leak from the vapor space following the rupture of a pipe. It is assumed that the orifice is $5 \mathrm{~cm}(2 \mathrm{in})$ in diameter because this is a typical size for pipework from a large tank. $\mathrm{NH}_{3}$ vapor jets vertically upward out of the orifice.

The modeler must first compare $\mathrm{p}_{\alpha} / \mathrm{p}$ with $[2 /(\gamma+1)]^{\gamma /(\gamma-1)}$, where $\mathrm{p}_{\mathrm{a}}$ is the ambient pressure, $1.01 \times 10^{5} \mathrm{~Pa}, \mathrm{p}$ is the absolute pressure in the vessel $(\mathrm{Pa})$, and $\gamma=\mathrm{C}_{\mathrm{p}} / \mathrm{C}_{\mathrm{v}}$ is the ratio of specific heats, which is 1.31 for $\mathrm{NH}_{3}$. For $\mathrm{NH}_{3}$ at $278 \mathrm{~K}$, the vapor pressure is $5.124 \times 10^{5} \mathrm{~Pa}$ (from standard vapor pressure equations) so that $\mathrm{p}_{\mathrm{a}} / \mathrm{p}=\left(1.01 \times 10^{5} \mathrm{~Pa}\right) /\left(5.124 \times 10^{5} \mathrm{~Pa}\right)=0.20 .[2 /(\gamma+1)]^{\gamma /(\gamma-1)}=[2 /(1.3+1)]^{1.31 /(1.31-1)}=0.54$, so that $\mathrm{p}_{\mathrm{a}} / \mathrm{p}$ $<[2 /(\gamma+1)]^{\gamma /(\gamma-1)}$, and the flow is choked. The choked flow pressure, $\mathrm{p}_{*}=(0.54)\left(5.124 \times 10^{5}\right)=2.77 \times 10^{5}$ $\mathrm{Pa}$.

The quantity T.. in equation B.42 is equal to $(2)(278) /(1.31+1)=240 \mathrm{~K}$. This is well below the critical temperature $\mathrm{T}_{\mathrm{c}}$ of $\mathrm{NH}_{3}, 405.6 \mathrm{~K}$, so that $\mathrm{T}_{* *}<\mathrm{T}_{\mathrm{c}}$. From equation B.43, the vapor pressure $\mathrm{p}_{\mathrm{v}}$ corresponding to temperature $T_{* *}$ is $\left(1.01 \times 10^{5}\right) \exp \left[\left(1.355 \times 10^{6}\right)(17.03) / 8,314(1 / 239.72-1 / 240)\right]=$ $1.05 \times 10^{5} \mathrm{~Pa}<\mathrm{p}_{*}$. Therefore, there is condensation, and the reader should proceed to equation $\mathrm{B} .9$, from which the temperature $T$. corresponding to the choked flow pressure $\mathrm{p}$ * can be calculated from:

$$
2.77 \times 10^{5}=1.01 \times 10^{5} \exp \left[\frac{\left(1.355 \times 10^{6}\right)(17.03)}{8,314}\left(\frac{1}{239.72}-\frac{1}{\mathrm{~T}_{*}}\right)\right]
$$

This gives, $T_{*}=262.5 \mathrm{~K} . \mathrm{T}_{*}$ and $\mathrm{p}_{*}$ are the temperature and pressure at which the material actually emerges from the orifice. The properties of the gas at these conditions are as follows: (a) the vapor fraction $\mathrm{X}_{*}$ is 0.964:

$$
\begin{aligned}
x_{*} & =1+\frac{262.5}{(17.03)\left(1.355 \times 10^{6}\right)}\left[(17.03)(2066) \ln \left(\frac{278}{262.5}\right)-8314 \ln \left(\frac{5.124}{2.77}\right)\right] \\
& =0.964
\end{aligned}
$$

(b) the density $\rho_{*}$ is $2.241 \mathrm{~kg} / \mathrm{m}^{3}$ : 


$$
\begin{aligned}
P_{*} & =\left[0.964\left(\frac{(8,314)(262.5)}{\left(2.77 \times 10^{5}\right)(17.03)}\right)+\frac{(1-0.964)}{681.6}\right]^{-1} \\
& =2.241 \mathrm{~kg} / \mathrm{m}^{3}
\end{aligned}
$$

and (c) the predicted rate of release $Q$ is $1.4 \mathrm{~kg} / \mathrm{s:}$

$$
\begin{aligned}
\mathrm{H}_{1}-\mathrm{H}_{\star} & =(2066)(278-262.5)+\left(1.355 \times 10^{6}\right)(1-0.964) \\
& =80803 \mathrm{~J}
\end{aligned}
$$

Assuming pipe length $=1 \mathrm{~m}$,

$$
Q=\pi\left(2.5 \times 10^{-2}\right)^{2}(2.241)\left[\frac{2(0.85)(80803)}{1+(4)(0.0045)(1)} \frac{1}{5 \times 10^{-2}}\right]^{1 / 2}=1.40 \mathrm{~kg} / \mathrm{s}
$$

From equation B.14, the discharge temperature $T_{r}$ equals the atmospheric boiling point, $239.7 \mathrm{~K}$ :

$$
\begin{aligned}
101325 & =101325 \ln \left[\frac{\mathrm{H}_{\mathrm{L}} \mathrm{M}}{\mathrm{R}}\left(\frac{1}{239.7}-\frac{1}{\mathrm{~T}_{\mathrm{r}}}\right)\right] \\
\mathrm{T}_{\mathrm{r}} & =239.7 \mathrm{~K}
\end{aligned}
$$

released vapor fraction $x_{\mathrm{r}}$ is 1.04 :

and the corresponding

$$
\begin{aligned}
x_{r} & =0.964+\frac{(4632)(262.5-239.7)}{1.355 \times 10^{6}} \\
& =1.04
\end{aligned}
$$

Since $x_{\tau}>1$, the condensed phase that was present at choked conditions is no longer present, and the release consists of pure vapor.

The corresponding temperature $\mathrm{T}_{\mathrm{r}}$ is $274.2 \mathrm{~K}$ :

$$
\begin{aligned}
\mathrm{T}_{\mathrm{r}} & =262.5-\frac{\left(1.355 \times 10^{6}\right)(1-1.04)}{4,632} \\
& =274.2 \mathrm{~K} \\
\rho_{r} & =\frac{(101325)(17.03)}{(8314)(274.2)} \quad \text { and the discharge density } \rho_{\mathrm{r}} \text { is: } \\
& =0.76 \mathrm{~kg} / \mathrm{m}^{3}
\end{aligned}
$$


In practice, the release rate would begin to decline immediately because, as vapor escapes, the pressure in the vessel declines. This causes more vapor to evaporate, cooling the liquid in the vessel, thus reducing the pressure.

\section{B.4.3 Uranium Hexafluoride Vapor Releases From a Hole in a Cylinder Wall}

If a pressurized cylinder containing $\mathrm{UF}_{6}$ is punctured above the solid or liquid levels, then $\mathrm{UF}_{6}$ vapor may be released. Equation B.71 gives the temperature-dependent pressure, $P_{v}\left(\mathrm{~N} / \mathrm{m}^{2}\right)$ of saturated $\mathrm{UF}_{6}$ vapors in equilibrium with the condensed phase (Rodean 1989):

$$
\log _{10} P_{v}=6.44923+\left(7.5337 \times 10^{-3}\right) \mathrm{T}-\frac{942.76}{\mathrm{~T}-89.784}
$$

For $\mathrm{UF}_{6}$, the value of $\gamma$ is 1.07 . Assume that $\mathrm{UF}_{6}$ is at equilibrium at its triple point $(\mathrm{T}=337.1 \mathrm{~K}$ $\left(147^{\circ} \mathrm{F}\right)$ ) and a leak occurs through a $5 \mathrm{~cm}(2 \mathrm{in})$ diameter hole. From equation B.71, the storage pressure is:

$$
\begin{aligned}
& \log _{10} P_{v}=6.44923+7.5337 \times 10^{-3}(337.1)-\frac{942.76}{(337.1-89.78)} \\
& \log _{10} P_{v}=5.17 \\
& P_{v}=1.5 \times 10^{5} \mathrm{~Pa}
\end{aligned}
$$

The initial vapor density is:

$$
\rho_{1}=\frac{(150271)(352)}{(8314)(337.1)}=18.87 \mathrm{~kg} / \mathrm{m}^{3}
$$

Using $\gamma=1.07$, the choked flow pressure $\mathrm{p}_{*}$ from equation $\mathrm{B} .41$ is $88,818 \mathrm{~Pa}$. Since $\mathrm{p}_{*}<\mathrm{p}_{\mathrm{a}}$, the flow is subcritical. From equation B.47, the rate of release can be conservatively estimated by setting $c=1$ and $\beta=0$,

where:

$$
Y=1-(0.41) \frac{(150271-101325)}{150271 \times 1.07}=0.875
$$

Then:

$$
\begin{aligned}
\mathrm{Q} & =(1)(0.875) \pi\left(2.5 \times 10^{-2}\right)^{2}[(2)(18.87)(150271-101325)]^{1 / 2} \\
& =2.3 \mathrm{~kg} / \mathrm{s}
\end{aligned}
$$


The discharge temperature is given by:

$$
\mathrm{T}_{\mathrm{r}}=\frac{(2)(337)}{1+[1+(4 \mathrm{E})(337.1)]^{1 / 2}}
$$

Where:

$$
\begin{aligned}
E & =(0.5 / 369.4)\left[\frac{(2.3)(8314)}{(150271)(352) \pi\left(2.5 \times 10^{-2}\right)^{2}}\right]^{2} \\
& =4.59 \times 10^{-5}
\end{aligned}
$$

Thus,

$$
\begin{aligned}
& \mathrm{T}_{\mathrm{r}}=\frac{(2)(337.1)}{1+\left[1+(4)\left(4.59 \times 10^{-5}\right)(337.1)\right]^{1 / 2}} \\
& \mathrm{~T}_{\mathrm{r}}=332 \mathrm{~K}
\end{aligned}
$$

Note: $T_{r}>$ sublimation point and, therefore, the discharge is pure vapor.

The discharge density $\rho$ :

$$
\rho=\frac{(101325)(352)}{(8314)(332)}=12.9 \mathrm{~kg} / \mathrm{m}^{3}
$$

Therefore, the velocity of the gas as it exits is:

$$
\begin{aligned}
& v=\frac{Q}{\pi r^{2} \rho} \\
& v=\frac{2.3}{\pi\left(2.5 \times 10^{-2}\right)^{2}(12.97)} \\
& v=90.8 \mathrm{~m} / \mathrm{s}
\end{aligned}
$$

\section{B.5 Instantaneous (Puff) Releases}

\section{B.5.1 Description of Puff Release}

A puff release corresponds to the catastrophic failure of a vessel containing $\mathrm{NH}_{3}$ under pressure. The sequence of events for a puff release is that first a major rupture of a vessel or cylinder occurs, releasing 
the whole contents almost at once. Some percentage of the $\mathrm{NH}_{3}$ flashes to vapor and the remainder is fragmented, remaining airborne as fine liquid droplets. This initial flashing process is highly turbulent and much air is entrained almost immediately. Experiments and observations of the outcome of actual accidents (Kaiser and Walker 1978; Kaiser 1979) suggest that the initial mass of air entrained can equal about ten times the initial mass of gas released. This mixture can be taken to be the starting point for subsequent atmospheric dispersion model calculations.

As an example, the rupture of a cylinder is considered in Sections B.5.2 and B.5.3. The spontaneous rupture of such a vessel is very unlikely; it generally corresponds to a worst-case scenario.

\section{B.5.2 Example of a Small Cylinder of Ammonia}

Assume that a pressurized cylinder containing $150 \mathrm{~kg}(330 \mathrm{lb})$ of liquid $\mathrm{NH}_{3}$ at ambient temperature $\left(278 \mathrm{~K} \cdot\left(40^{\circ} \mathrm{F}\right)\right)$ catastrophically ruptures. The vapor pressure of $\mathrm{NH}_{3}$ in the cylinder is $5.124 \times 10^{5} \mathrm{~Pa}$ (74 psia), which is more than five times the atmospheric pressure. The ruptured cylinder rapidly depressurizes, and liquid $\mathrm{NH}_{3}$ is fragmented and rendered airborne. In past accidents involving large releases of liquid $\mathrm{NH}_{3}$, it was observed that no $\mathrm{NH}_{3}$ was left on the ground and that the entire inventory of liquid $\mathrm{NH}_{3}$ was fragmented (Kaiser 1979). In Section B.3.3 it was shown that the flash mass fraction of $\mathrm{NH}_{3}$ is 0.14 and the mass fraction of liquid $\mathrm{NH}_{3}$ is 0.86 . The temperature of the puff is equal to the boiling point of $\mathrm{NH}_{3}\left(239.7 \mathrm{~K}\left(-29^{\circ} \mathrm{F}\right)\right)$.

Of the initial $150 \mathrm{~kg}$ (330 lb) of liquid $\mathrm{NH}_{3},(0.14)(150 \mathrm{~kg})=21 \mathrm{~kg}(46 \mathrm{lb})$ immediately flashes to vapor and $(0.86)(150 \mathrm{~kg})=129 \mathrm{~kg}(284 \mathrm{lb})$ remains liquid. Since the flashing process is quite vigorous, it has been observed that about ten times, by mass, of air is generally mixed in the puff almost instantaneously, as noted above. However, due to the mixing with relatively warm air (at $278 \mathrm{~K}$ ), all the liquid droplets evaporate. The puff, consisting of about $1500 \mathrm{~kg}\left(3300 \mathrm{lb}\right.$ ) of air and $150 \mathrm{~kg}(330 \mathrm{lb})$ of $\mathrm{NH}_{3}$, establishes thermodynamic equilibrium at $240 \mathrm{~K}\left(-29^{\circ} \mathrm{F}\right)$, a slightly higher temperature than the boiling point of $\mathrm{NH}_{3}$. The density of the puff is:

$$
\rho=\frac{(1500+150)(101325)}{\left(\frac{1500}{29}+\frac{150}{17.03}\right)(8314)(240)}=1.384 \mathrm{~kg} / \mathrm{m}^{3}
$$

where the molecular weight of air is 29 . The density of the surrounding air at $278 \mathrm{~K}\left(40^{\circ} \mathrm{F}\right)$ is $1.3 \mathrm{~kg} / \mathrm{m}^{3}$ $\left(0.08 \mathrm{lb} / \mathrm{ft}^{3}\right)$. Thus, the puff is initially denser than air.

\section{B.5.3 Example of a Large Cylinder of Uranium Hexafluoride}

Consider the catastrophic rupture of a $12000 \mathrm{~kg}(27000 \mathrm{lb})$ cylinder of $\mathrm{UF}_{6}$. This type of accident can take place if the cylinder is overfilled and subsequently heated. For example, the large release of $U_{6}$ in Gore, Oklahoma (NUREG-1189 [USNRC 1986]), occurred for this reason.

Assume that the cylinder is at a temperature and pressure that are slightly higher than the corresponding triple point values for $\mathrm{UF}_{6}\left(337 \mathrm{~K}\left(147^{\circ} \mathrm{F}\right)\right.$ and $150 \mathrm{kPa}$ [1.5 atmospheres]) when the rupture occurs. Under these conditions, the $\mathrm{UF}_{6}$ inside the cylinder will be liquid. 
Following the rupture, depressurization will cause vigorous flashing of the liquid to vapor and solid. In Section B.3.5.2, it was shown that if the initial conditions of the $\mathrm{UF}_{6}$ in the cylinder are close to its triple point, then 42 percent by mass of the liquid $\mathrm{UF}_{6}$ flashes to vapor and the remaining 58 percent by mass of $\mathrm{UF}_{6}$ changes phase to solid. Thus, $(0.42)(12000 \mathrm{~kg})=5000 \mathrm{~kg}$ (or $11000 \mathrm{lb}$ ) of $\mathrm{UF}_{6}$ will flash to vapor and $(0.58)(12000 \mathrm{~kg})=7000 \mathrm{~kg}$ (or $15000 \mathrm{lb}$ ) of $\mathrm{UF}_{6}$ will change phase to solid. The temperature of the cloud will be equal to the sublimation temperature of $\mathrm{UF}_{6}$ (i.e., $329 \mathrm{~K}\left(133^{\circ} \mathrm{F}\right)$ ) if no air is mixed in.

However, as noted in Section B.5.2, it has been observed that approximately ten times by mass of air is initially mixed in a puff if there is vigorous flashing following the release. Moisture carried by the air will react with $\mathrm{UF}_{6}$, and a complex thermodynamic equilibrium will be established. The calculations necessary to establish the equilibrium conditions are too complicated to be attempted by hand.

Atmospheric dispersion models developed for NRC can calculate the initial conditions of the puff (SAIC 1993).

\section{B.6 Conclusion}

Information on estimating chemical source terms from fuel cycle facilities that are used in atmospheric dispersion models has been provided in this Appendix. Analytical methods and examples have been provided to aid in estimating source terms for a variety of release scenarios. A wide range of release scenarios that may be of interest has been addressed, including leaks and ruptures of cylinders, evaporating pools formed by spills or tank failures, and flashing and evaporating liquefied gases released from pressurized storage. 


\section{B.7 References}

American Institute of Chemical Engineers (AIChE), Workbook of Test Cases for Vapor Cloud Source Term Dispersion Models, New York, New York, 1987.

American Institute of Chemical Engineers (AIChE), Guidelines for Chemical Process Quantitative Risk Analysis, New York, New York, 1989.

Cavanaugh, T.J., II, J.H. Siegell, and K.W. Steinberg, "Simulation of Vapor Emissions from Liquid Spills," $85^{\text {th }}$ Annual Meeting \& Exhibition of the Air and Waste Management Association, Kansas City, Missouri, 1992.

Christensen, D., and G.D. Kaiser, "Contingency Analysis Modeling for Superfund Sites and Other Sources," prepared for U.S. Environmental Protection Agency, EPA-454/R-93-001, Research Triangle Park, North Carolina, 1993.

Clough, P.N., D.R. Grist, and C.J. Wheatley, "Thermodynamics of Mixing and Final State of a Mixture Formed by the Dilution of Anhydrous Hydrogen Fluoride with Moist Air," SRD/HSE/SRDR 396C.1, United Kingdom Atomic Energy Authority Safety and Reliability Directorate, Warrington, United Kingdom, 1987.

Daubert, T.E., and R.P. Danner, eds., Data Compilation, Tables of Properties of Pure Compounds, American Institute of Chemical Engineers, New York, New York, 1985.

Fauske, H.K., and M. Epstein, "Source Term Considerations in Connection with Chemical Accidents and Vapor Cloud Modeling," (John Woodward, ed.), International Conference on Vapor Cloud Modeling, (sponsored by the Center for Chemical Process Safety of the American Institute of Chemical Engineers, the Institution of Chemical Engineers, and the U.S. Environmental Protection Agency), Cambridge, Massachusetts, 2-4 November 1987.

Fisher, H.G., et al., "Emergency Relief System Design Using DIERS Technology," ISBN 0-8169-0568-1, American Institute of Chemical Engineers, New York, New York, 1992.

Kaiser, G.D., and Walker, B.A., "Releases of Anhydrous Ammonia from Pressurized Containers - The Importance of Denser-Than-Air Mixtures." Atmospheric Environment, Vol. 12, pp. 2289-2300, 1978.

Kaiser, G.D., "Examples of the Successful Application of a Simple Model for the Atmospheric Dispersion of Dense, Cold Vapors to the Accidental Release of Anhydrous Ammonia from Pressurized Containers," United Kingdom Atomic Energy Authority Safety and Reliability Directorate Report, SRD R150, Warrington, United Kingdom, 1979.

Kaiser, G.D., "A Review of Models for Predicting the Dispersion of Ammonia in the Atmosphere," Plant/Operations Progress, Vol. 8, No. 1:58-64, 1989.

Lewitt, E.H., Thermodynamics Applied to Heat Engines, Fifth Edition, Sir Isaac Pitman and Sons, London, United Kingdom, 1953. 
Perry, R.H., and C.H. Chilton, Chemical Engineer's Handbook, Fifth Edition, ISBN 0-07-049478-9, McGraw-Hill Book Company, New York, New York, 1973.

Perry, R.H., D.W. Green, and J.O. Maloney, Perry's Chemical Engineer's Handbook, Sixth Edition, McGraw-Hill Book Company, New York, New York, 1984.

Raj, P.K., J. Hagopian, and A.S. Kalelkar, "Prediction of the Hazards of Anhydrous Ammonia Spillage onto Water," CG-D-74-74, prepared for the use by U.S. Coast Guard by Arthur D. Little, Inc., Cambridge, Massachusetts, 1974.

Raj, P.K., "Models for Refrigerated Liquid Spill Behavior on Land and Water," Journal for Hazardous Materials, 5:111-130, 1981.

Raj, P.K., "Chemical Release/Spill Source Models - A Review," International Conference and Workshop on Modeling and Mitigating the Consequences of Accidental Releases of Hazardous Materials, American Institute of Chemical Engineers, New Orleans, Louisiana, 1991.

Resplandy, A., "Étude Experimentale des Propriétés de l'Ammoniac," Chim. Ind. - Gen. Chim., 102: 691, 1969.

Rodean, H.C., "Toward More Realistic Material Models for Release and Dispersion of Heavy Gases," UCRL-53902, Lawrence Livermore National Laboratory, Livermore, California, 1989.

Sandler, S.I., Chemical and Engineering Thermodynamics, Second Edition, John Wiley and Sons, New York, New York, 1989.

Science Applications International Corporation (SAIC), "SAIC's Computer Programs for Modeling the Atmospheric Dispersion of Hazardous Vapors - Model Description and User's Guide," draft prepared for U.S. Nuclear Regulatory Commission, 1993.

Shaw, P., and F. Briscoe, "Evaporation from Spills of Hazardous Liquids on Land and Water," United Kingdom Atomic Energy Authority Safety and Reliability Directorate Report SRD R120, Warrington, United Kingdom, 1978.

U.S. Environmental Protection Agency (USEPA), "User's Guide to TSCREEN, a Model for Screening Toxic Air Pollutant Concentrations," EPA 450/4-89-013 (NTIS PB 91-141820), Research Triangle Park, North Carolina, 1988.

U.S. Environmental Protection Agency (USEPA), "Workbook of Screening Techniques for Assessing Impacts of Toxic Air Pollutants" (revised), EPA-454/R-92-024 (NTIS PB93-21036), Research Triangle Park, North Carolina, 1992.

U.S. Nuclear Regulatory Commission (USNRC), "Scenarios and Analytical Methods for UF 6 Releases at NRC-Licensed Fuel Cycle Facilities,” NUREG/CR-3139, Washington, D.C., 1984.

U.S. Nuclear Regulatory Commission (USNRC), "Assessment of the Public Health Impact from the Accidental Release of $\mathrm{UF}_{6}$ at the Sequoyah Fuels Corporation Facility at Gore, Oklahoma-Main Report," NUREG-1189, Vol. 1, Washington, D.C., 1986. 
Webber, D.M., and S.J. Jones, “A Model of Spreading, Vaporizing Pools," (John Woodward, ed.), International Conference on Vapor Cloud Modeling, (sponsored by the Center for Chemical Process Safety of the American Institute of Chemical Engineers, the Institution of Chemical Engineers, and the U.S. Environmental Protection Agency), Cambridge, Massachusetts, 1987.

Wheatley, C.J., "Discharge of Liquid Ammonia to Moist Atmospheres - Survey of Experimental Data and Model for Estimating Initial Conditions in Dispersion Calculations," United Kingdom Atomic Energy Authority Safety and Reliability Directorate Report SRD/HSE/R410, Warrington, United Kingdom, 1987. 


\section{APPENDIX C}

COMPARISON OF NRC, OSHA; AND EPA PROGRAMS THAT ADDRESS CHEMICAL SAFETY 


\section{APPENDIX C TABLE OF CONTENTS}

\section{APPENDIX C: COMPARISON OF NRC, OSHA, AND EPA PROGRAMS THAT ADDRESS CHEMICAL SAFETY}

TABLE OF CONTENTS $\ldots \ldots \ldots \ldots \ldots \ldots \ldots \ldots \ldots \ldots \ldots \ldots \ldots \ldots \ldots \ldots \ldots \ldots \ldots \ldots$

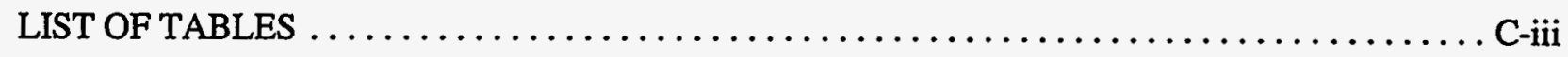

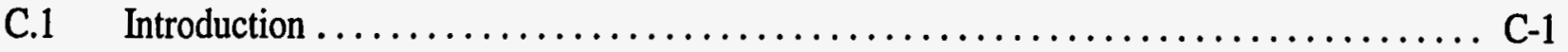

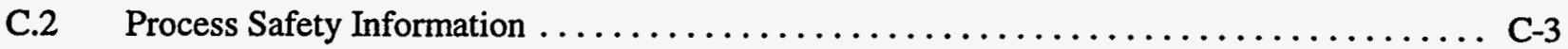

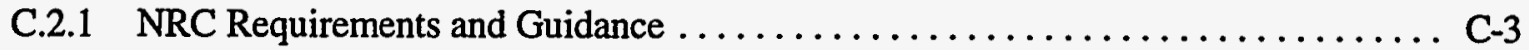

C.2.2 OSHA's Process Safety Management Standard $\ldots \ldots \ldots \ldots \ldots \ldots \ldots \ldots \ldots$ C-3

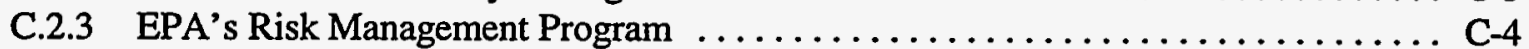

C.2.4 Comparison of NRC, OSHA, and EPA Requirements $\ldots \ldots \ldots \ldots \ldots \ldots \ldots$ C-4

C.3 Hazard Identification and Assessment $\ldots \ldots \ldots \ldots \ldots \ldots \ldots \ldots \ldots \ldots \ldots \ldots \ldots \ldots$

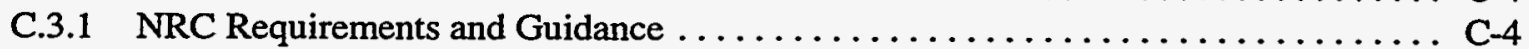

C.3.2 OSHA's Process Safety Management Standard . . . . . . . . . . . . . . . C-7

C.3.2.1 Initial Process Hazards Analysis $\ldots \ldots \ldots \ldots \ldots \ldots \ldots \ldots \ldots \ldots \ldots$ C-7

C.3.2.2 Methodology $\ldots \ldots \ldots \ldots \ldots \ldots \ldots \ldots \ldots \ldots \ldots \ldots \ldots \ldots \ldots \ldots$ C-7

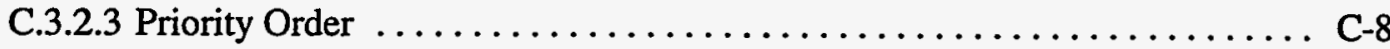

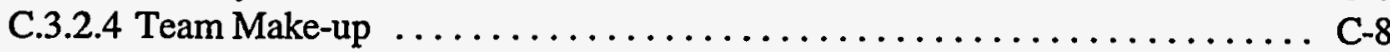

C.3.3 EPA's Risk Management Program $\ldots \ldots \ldots \ldots \ldots \ldots \ldots \ldots \ldots \ldots \ldots \ldots \ldots \ldots \ldots \ldots$

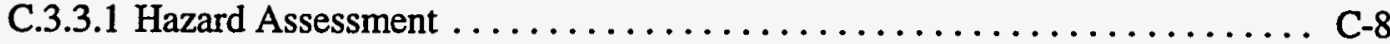

C.3.3.2 Process Hazards Analysis $\ldots \ldots \ldots \ldots \ldots \ldots \ldots \ldots \ldots \ldots \ldots \ldots \ldots$ C-8

C.3.4 Comparison of NRC, OSHA, and EPA Requirements $\ldots \ldots \ldots \ldots \ldots \ldots \ldots$ C-11

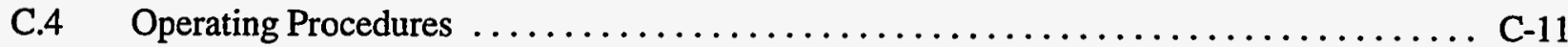

C.4.1 NRC Requirements and Guidance .......................

C.4.2 OSHA's Process Safety Management Standard $\ldots \ldots \ldots \ldots \ldots \ldots \ldots \ldots \ldots . \ldots . \ldots \ldots$

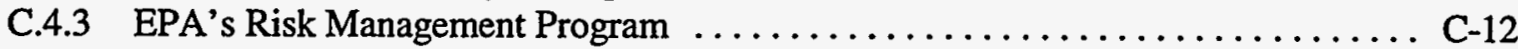

C.4.4 Comparison of NRC, OSHA, and EPA Requirements $\ldots \ldots \ldots \ldots \ldots \ldots \ldots$ C-12

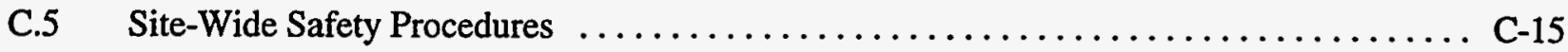

C.5.1 NRC Requirements and Guidance .........................

C.5.2 OSHA's Process Safety Management Standard $\ldots \ldots \ldots \ldots \ldots \ldots \ldots \ldots$ C-15

C.5.3 EPA's Risk Management Program ........................... C-16

C.5.4 Comparison of NRC, OSHA, and EPA Requirements $\ldots \ldots \ldots \ldots \ldots \ldots \ldots$ C-16

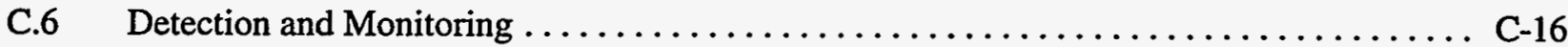

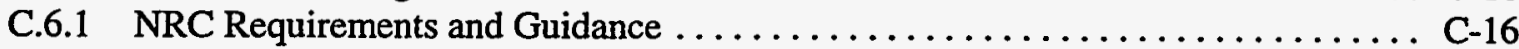

C.6.2 OSHA's Process Safety Management Standard .................... C-16 


\section{APPENDIX C TABLE OF CONTENTS (Continued)}

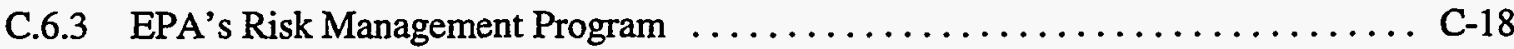

C.6.4 Comparison of NRC, OSHA, and EPA Requirements $\ldots \ldots \ldots \ldots \ldots \ldots \ldots$ C-18

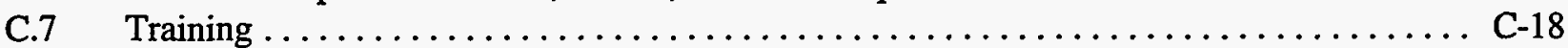

C.7.1 NRC Requirements and Guidance $\ldots \ldots \ldots \ldots \ldots \ldots \ldots \ldots \ldots \ldots \ldots \ldots \ldots \ldots \ldots$

C.7.1.1 NRC Requirements . .......................... C-18

C.7.1.2 Regulatory Guidance and Branch Technical Position ........... C-18

C.7.2 OSHA's Process Safety Management Standard .................. C-20

C.7.3 EPA's Risk Management Program . ......................... C-21

C.7.4 Comparison of NRC, OSHA, and EPA Requirements $\ldots \ldots \ldots \ldots \ldots \ldots \ldots$ C-21

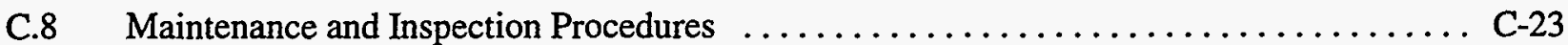

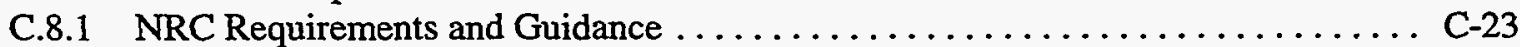

C.8.2 OSHA's Process Safety Management Standard ................... C-23

C.8.3 EPA's Risk Management Standard ........................ C-23

C.8.4 Comparison of NRC, OSHA, and EPA Requirements $\ldots \ldots \ldots \ldots \ldots \ldots \ldots$ C-23

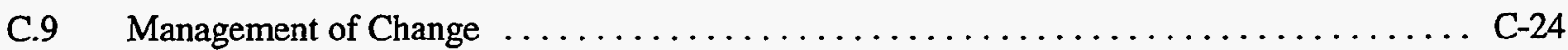

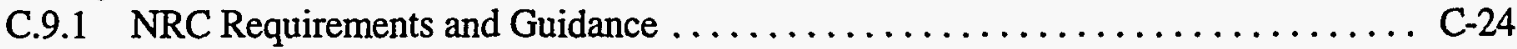

C.9.2 OSHA's Process Safety Management Standard ................. C-24

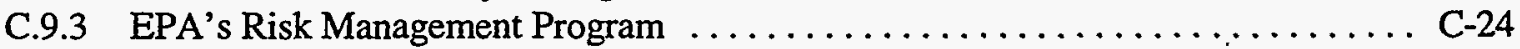

C.9.4 Comparison of NRC, OSHA, and EPA Requirements $\ldots \ldots \ldots \ldots \ldots \ldots \ldots$ C-26

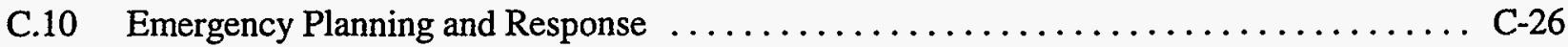

C.10.1 NRC Requirements and Guidance .......................... C-26

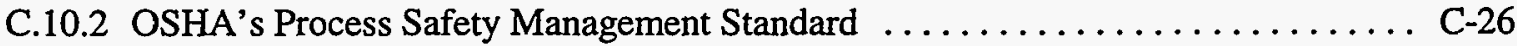

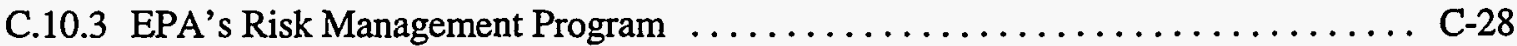

C.10.4 Comparison of NRC, OSHA, and EPA Requirements $\ldots \ldots \ldots \ldots \ldots \ldots \ldots$ C-28

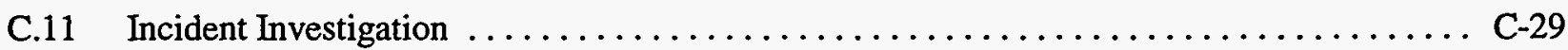

C.11.1 NRC Requirements and Guidance ......................... C-29

C.11.2 OSHA's Process Safety Management Standard ................... C-29

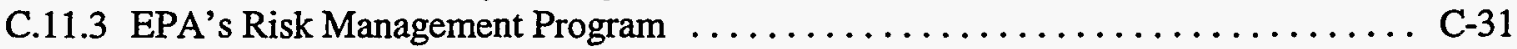

C.11.4 Comparison of NRC, OSHA, and EPA Requirements $\ldots \ldots \ldots \ldots \ldots \ldots \ldots$ C-31

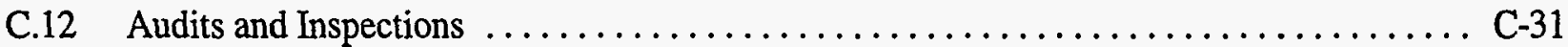

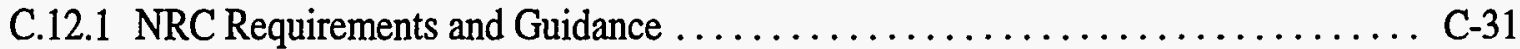

C.12.2 OSHA's Process Safety Management Standard $\ldots \ldots \ldots \ldots \ldots \ldots \ldots \ldots$ C-31

C.12.3 EPA's Risk Management Program . . . . . . . . . . . . . . . . C-31

C.12.4 Comparison of NRC, OSHA, and EPA Requirements $\ldots \ldots \ldots \ldots \ldots \ldots \ldots$ C-33

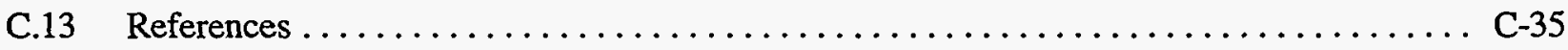




\section{APPENDIX C LIST OF TABLES}

Table C-1. Comparison of Process Safety Information Required by NRC, OSHA, and EPA . . . . C-5

Table C-2. Comparison of Hazard Identification and Assessment Required by

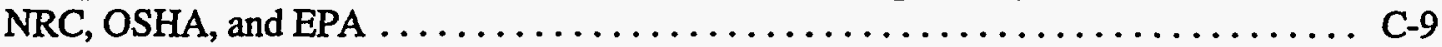

Table C-3. Comparison of Operating Procedures Required by NRC, OSHA, and EPA ....... C-13

Table C-4. Comparison of Site-Wide Safety Procedures Required by NRC, OSHA, and EPA ... C-17

Table C-5. Comparison of Detection and Monitoring Required by NRC, OSHA, and EPA . . . . . C-19

Table C-6. Comparison of Training Required by NRC, OSHA, and EPA . . . . . . . . . . . C-22

Table C-7. Comparison of Maintenance and Inspection Procedures Required by

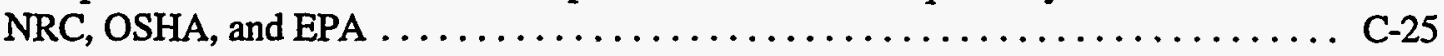

Table C-8. Comparison of Management of Change Required by NRC, OSHA, and EPA . . . . C C-27

Table C-9. Comparison of Emergency Planning Required by NRC, OSHA, and EPA ........ C-30

Table C-10. Comparison of Incident Investigation Required by NRC, OSHA, and EPA ....... C-32

Table C-11. Comparison of Audits and Inspections Required by NRC, OSHA, and EPA ...... C-34 


\section{APPENDIX C COMPARISON OF NRC, OSHA, AND EPA PROGRAMS THAT ADDRESS CHEMICAL SAFETY}

\section{C.1 Introduction}

Several serious chemical incidents, such as the 1974 explosion in Flixborough, England, the 1976 release of dioxin in Seveso, Italy, and the 1984 release of methyl isocyanate in Bhopal, India, have heightened public awareness of the potential dangers posed by hazardous chemicals. In 1986, Congress passed the Emergency Planning and Community Right to Know Act of 1986, also known as Title III of the Superfund Amendments and Reauthorization Act (SARA) of 1986, which requires state and local emergency planning agencies to develop chemical emergency response plans for the community based on information provided by the facility. Congress recognized the importance of an accident prevention program by requiring that the Environmental Protection Agency (EPA) conduct a review of emergency systems to monitor, detect, and prevent chemical accidents. In addition, the Clean Air Act Amendments of 1990, signed into law on November 15, 1990, amended Clean Air Act Section 112 by adding a new Section (r), which addresses the prevention of accidental releases of extremely hazardous substances and the minimization of the consequences of releases by focusing preventive measures on those chemicals that pose the greatest risk. As a result of the Clean Air Act Amendment the Occupational Safety and Health Administration (OSHA) promulgated its Process Safety Management (PSM) standard ${ }^{1}$, and EPA has promulgated its Risk Management Program (RMP) ${ }^{2}$. The Nuclear Regulation Commission (NRC) also has programs which address chemical safety. ${ }^{3}$

Nuclear fuel cycle licensees possess certain hazardous chemicals that are regulated by various bodies, such as NRC, OSHA, and EPA. These regulatory authorities have varying levels of interest in the safe operation of NRC-licensed fuel cycle facilities. OSHA is primarily interested in the health and safety of workers at these facilities, whereas EPA's main focus is on the protection of public health and the environment. There is a 1988 Memorandum of Understanding (53 FR 43950-43952) that provides general guidelines for interface activities between OSHA and NRC (USNRC 1988). Four kinds of hazards associated with NRC-licensed nuclear facilities are recognized:

1. radiation risk produced by radioactive material

2. chemical risk produced by radioactive material

3. plant conditions that may affect the safety of radioactive material, and

4. plant conditions that might result in risk to workers but do not affect the safety of licensed radioactive material.

Generally, NRC covers the first three hazards and OSHA covers the fourth. NRC's responsibilities include protecting public health and safety, protecting the environment, protecting and safeguarding OSHA's Process Safety Management standard is found in 29 CFR 1910.119 (OSHA 1992).

2 This refers to EPA's risk management program (40 CFR 68) promulgated on June 20, 1996 (USEPA 1996).

3 These refer to the various regulations and guidance documents prepared by NRC for NRC-licensed facilities (e.g., 10 CFR Parts 30, 40, and 70; Reg. Guides 3.52, 3.67, etc.). 
materials and plants in the interest of national security, and assuring conformity with antitrust laws for certain types of facilities, e.g., nuclear reactors.

10 CFR 70.22, "Contents of applications," and 10 CFR 70.23, "Requirements for the approval of applications," provide application information requirements and NRC approval requirements related to equipment, facilities, and procedures that will be used to protect health and minimize danger to life or property. Similar provisions are contained in 10 CFR Part 30 (see 10 CFR 30.32 and 30.33), 10 CFR Part 40 (see 10 CFR 40.31 through 40.34) and 10 CFR Part 72 (see 10 CFR 72.22, 72.24, 72.26, 72.28, $72.40,72.42$, and 72.44). However, these requirements are general. NRC continues to develop supplementary guidance for the applicants in the form of Regulatory Guides, Standard Format and Content Guides, and Branch Technical Positions.

In the past, NRC has focused on radiological hazards at fuel cycle facilities and left the regulation of chemical hazards to EPA and OSHA. The January 1986 incident at Sequoyah Fuels Corporation, which involved a rupture of a 13 metric ton (14 ton) cylinder of $\mathrm{UF}_{6}$, and resulted in one fatality, highlighted two facts: (1) that chemical and radiological hazards can compound one another, and (2) that radioactive materials can have high chemical toxicity, which led NRC to reconsider its responsibilities and regulatory activities in the area of chemical safety.

A study of the various NRC regulations and guidelines and the EPA and OSHA regulations highlights the different philosophies adopted by these agencies. NRC regulations tend to focus on commitments on the part of the licensee and descriptions of the control systems in place to prepare, review, revise, approve, and implement various programs. In addition, NRC's regulations and guidelines focus on radiological safety since the Commission has the responsibility for licensing and regulating nuclear facilities and materials. OSHA's regulations are performance based. It is the responsibility of the owner or operator to develop an effective PSM program that is appropriate for the level of hazards present at the facility. There is no requirement to provide any information to OSHA, and OSHA does not have a schedule of regular audits. Similarly, EPA's regulations are performance based. However, there is a requirement to submit a written Risk Management Plan to a central point to be designated by EPA. The first submittals are required by June 20,1999. The Risk Management Plan is intended to serve as a means of communicating risks to Federal, State, and local agencies and to the public.

A further difference between OSHA's PSM standards and EPA's RMP is that the latter recognizes three levels, which it calls Program 1, Program 2, and Program 3. A covered process is eligible for Program 1 requirements if it meets all of the following requirements:

1. For the five years prior to the submission of the Risk Management Plan, the process has not had an accidental release of a regulated substance where exposure to the substance, its reaction products, overpressure generated by an explosion involving the substance, or radiant heat generated by a fire involving the substance led to any of the following offsite consequences: (a) death, (b) injury, or (c) response or restoration activities following an exposure of an environmental receptor.

2. The distance to a toxic or flammable endpoint for a worst-case release assessment is less than the distance to any public receptor.

3. Emergency response procedures have been coordinated between the facility and local emergency planning and response organizations.

The prevention program requirements and reporting requirements for Program 1 are minimal. 
A facility is assigned to Program 3 if it is in Standard Industrial Code (SIC) classes 2611, 2812, 2819, $2821,2865,2873,2879$, or 2911 or if it is already subject to OSHA's PSM standard. Any facility that is not in Program 1 or Program 3 automatically falls into Program 2. The principal difference between Program 3 and Program 2 lies in the prevention program. The prevention program for Program 3 is essentially identical to OSHA's PSM standard, while the prevention program for Program 2 is limited to safety information, hazard review, operating procedures, training, maintenance, compliance audits, and incident investigation (see 40 CFR 68.48, 68.50, 68.52, 68.54, 68.56, 68.58, and 68.60).

Finally, EPA specifically requires a management system to oversee the implementation of the Risk Management Plan [40 CFR 68.15]. OSHA does not explicitly ask for such a system, although a management system is implicit in the OSHA requirements.

NRC is cognizant of the fact that chemical process safety has not been sufficiently addressed in the past at most nuclear fuel cycle facilities. The current attention given to chemical safety is an attempt to provide an adequate level of NRC oversight. Eleven elements have been identified in the areas of:

1. hazard identification and assessment,

2. prevention and mitigation of identified hazards, and

3. examination of the elements in 1 and 2 (both on a regular basis and after incidents).

An element-by-element comparison is provided in Sections C. 2 through C.12, which provide comparisons of the following eleven elements: process safety information, hazard identification and assessment, operating procedures, site-wide safety procedures, detection and monitoring, training, maintenance and inspection procedures, management of change, emergency planning and response, incident investigation, and audits and inspections. In most cases, detailed information for each element is required by OSHA and EPA. The same information is usually implied as being necessary by NRC regulations and guidance.

\section{C.2 Process Safety Information}

\section{C.2.1 NRC Requirements and Guidance}

NRC requires the applicants for specific licenses for source materials to submit information relating to the design, manufacture, prototype testing, quality control procedures, labeling or marking, proposed uses, and potential hazards of the industrial product or device in question. This information is used to provide reasonable assurance that possession, use, or transfer of depleted uranium in the product or device is not likely to cause any individual to receive an unacceptable dose of radiation [10 CFR 40.34(2)].

NRC also requires licensees to prepare a description of equipment and facilities that will be used by the applicant to protect health and minimize danger to life or property. Requirements for procedures containing elements to protect health and minimize danger to life and property have also been proposed [10 CFR 70.22(a)(7) and (a)(8)].

\section{C.2.2 OSHA's Process Safety Management Standard}

OSHA requires employers to compile process safety information before conducting a Process Hazards Analysis (PHA) [29 CFR 1910.119(d)]. The process safety information must contain information on the 
hazards of chemicals used or produced in the process, process technology, and process equipment. Material Safety Data Sheets, as mandated by OSHA's 29 CFR 1910.1200(g) may be used for information on the physical and chemical hazards of chemicals to the extent that they contain the required information. Information on process technology includes process chemistry, maximum inventory levels, process parameters, and consequences of deviations from parameters. Information on process equipment includes materials of construction, piping and instrumentation diagrams, design specifications and standards, safety equipment design, and electrical classification. Material and energy balances are required for processes built after May 24, 1992. The employer must document that equipment complies with recognized and generally-accepted good engineering practices. If the original technical information no longer exists, such information may be developed in conjunction with the initial PHA.

In addition, employers must determine and document that equipment designed and constructed in accordance with any codes, standards, or practices that are no longer in general use are maintained, inspected, tested, and operated in a safe manner [29 CFR 1910.119(d)].

\section{C.2.3 EPA's Risk Management Program}

EPA's Program 3 requirements for process safety information [40 CFR 68.65] are the same as the requirements in the OSHA standard [29 CFR 1910.119(d)].

EPA's Program 2 requirements [40 CFR 68.48] are limited to: (1) Material Safety Data Sheets that meet the requirements of 29 CFR $1910.1200(\mathrm{~g})$; (2) maximum intended inventory of equipment in which the regulated substances are stored or processed; (3) safe upper and lower temperatures, pressures, flows, and compositions; (4) equipment specifications; and (5) codes and standards used to design, build, and operate the process. The owner or operator must also ensure that the process is designed in compliance with recognized and generally-accepted good engineering practices. Overall, the Program 2 information requirements are fewer than those for Program 3.

\section{C.2.4 Comparison of NRC, OSHA, and EPA Requirements}

The EPA and OSHA programs contain more detailed requirements than do the NRC regulations and require more details on several aspects of process safety information. EPA's Program 3 process safety information [40 CFR 68.65] is identical to OSHA's process safety information system. EPA's Program 2 requires the collection of less information. Table C-1 presents a comparison of NRC, OSHA and EPA requirements for process safety information.

\section{C.3 Hazard Identification and Assessment}

\section{C.3.1 NRC Requirements and Guidance}

As part of the requirements for developing emergency plans, NRC requires licensees to identify each type of radioactive material accident for which protective actions may be needed [10 CFR

70.22(i)(3)(ii)]. 


\section{Table C-1. Comparison of Process Safety Information Required by NRC, OSHA, and EPA}

\begin{tabular}{|c|c|c|c|c|c|}
\hline \multirow[b]{2}{*}{ Process Safety Information } & \multirow[b]{2}{*}{ NRC Guidance } & \multirow{2}{*}{$\begin{array}{c}\text { OSHA's Process } \\
\text { Safety Management } \\
\text { Program }\end{array}$} & \multicolumn{3}{|c|}{ EPA's Risk Management Program² } \\
\hline & & & Program 3 & Program 2 & Program 1 \\
\hline $\begin{array}{l}\text { Compile written process safety information before the } \\
\text { PIHA }\end{array}$ & Not specific about order & Required & Required & Not required & Not required \\
\hline $\begin{array}{l}\text { Process safety information pertaining to hazards of the } \\
\text { regulated substance: } \\
\text { - toxicity } \\
\text { - permissible exposure limits } \\
\text { - physical data } \\
\text { - reactivity data } \\
\text { - corrosivity data } \\
\text { - thermal and chemical stability data } \\
\text { - hazards of inadvertent mixing of chemicals }\end{array}$ & Implied by 10 CFR 70 & Required & Required & $\begin{array}{l}\text { Material Safety } \\
\text { Data Sheets }\end{array}$ & Not required \\
\hline $\begin{array}{l}\text { Process safety information pertaining to the technology } \\
\text { of the process: } \\
\text { - block flow diagram } \\
\text { - process chemistry } \\
\text { - maximum intended inventory } \\
\text { - limits on process operation parameters } \\
\text { - consequences of deviation }\end{array}$ & $\begin{array}{l}\text { Implied by proposed } \\
\text { guidance }\end{array}$ & Required & Required & $\begin{array}{l}\text { Maximum intended } \\
\text { inventory; safe } \\
\text { limits on process } \\
\text { operation } \\
\text { parameters }\end{array}$ & Not required \\
\hline $\begin{array}{l}\text { Process safety information pertaining to the process } \\
\text { equipment: } \\
\text { - materials of construction } \\
\text { - process and instrumentation diagrams } \\
\text { - electrical classification } \\
\text { - relief system design and design basis } \\
\text { - ventilation system design } \\
\text { - design codes and practices }\end{array}$ & $\begin{array}{l}\text { Implied by proposed } \\
\text { guidance }\end{array}$ & Required & Required & $\begin{array}{c}\text { Equipment } \\
\text { specifications; } \\
\text { design codes and } \\
\text { practices }\end{array}$ & Not required \\
\hline Develop unavailable process safety information. if any & Not specifically required & Required & Required & $\begin{array}{l}\text { Not specifically } \\
\text { required }\end{array}$ & Not required \\
\hline
\end{tabular}


Table C-1. Comparison of Process Safety Information Required by NRC, OSHA, and EPA (Continued)

\begin{tabular}{lccccc}
\hline & NRC Guidance & $\begin{array}{c}\text { OSHA's Process } \\
\text { Safety Management } \\
\text { Program }\end{array}$ & \multicolumn{2}{c}{ EPA's Risk Management Program $^{2}$} \\
Process Safety Information & Program 3 & Program 2 & Program 1 \\
\hline $\begin{array}{l}\text { Documentation that equipment is in compliance with } \\
\text { good engineering practices }\end{array}$ & Not specifically required & Required & Required & Required & Not required \\
$\begin{array}{l}\text { Documentation that safe design, maintenance. } \\
\text { inspection, testing, and operation of existing equipment } \\
\text { is in compliance with old codes }\end{array}$ & Not specifically required & Required & Required & $\begin{array}{c}\text { Not specifically } \\
\text { required }\end{array}$ & Not required \\
\hline
\end{tabular}

1. Codified in 29 CFR 1910.11\%

2. Codified in 40 CFR Part 68. 
Furthermore, NRC requires a description of the methods and equipment to assess releases of radioactive materials [10 CFR 70.22(i)(3)(vi)].

NRC asks for a process description and safety analyses that contain process steps and flowsheets, safety analysis, and safety features of each step [Reg. Guide 3.55, p.23 (USNRC 1985)].

In addition, NRC has provided guidance on Integrated Safety Analysis (ISA) (USNRC 1995). ISA is a "systematic examination of a facility's processes, equipment, structures and personnel activities to ensure that all relevant hazards that could result in unacceptable consequences have been adequately evaluated and appropriate protective measures have been identified." NRC's ISA guidance discusses techniques that are largely based upon other guidance on hazard evaluation techniques that has been provided by the Center for Chemical Process Safety (CCPS) on the American Institute of Chemical Engineers (AIChE 1992). There is further discussion of ISA in Chapter 2 of this Accident Analysis Handbook.

\section{C.3.2 OSHA's Process Safety Management Standard}

\section{C.3.2.1 Initial Process Hazards Analysis}

OSHA requires employers to perform an initial PHA [29 CFR 1910.119(e)]. OSHA has established a completion schedule that all covered facilities are required to meet. The PHA must be appropriate to the complexity of the process and must identify, evaluate, and control the hazards involved in the process. The PHA must address the hazards of the process, accident history, engineering and administrative controls (such as detection methodology), consequences of the failure of the control, facility siting, human factors, and qualitative evaluation of safety and health effects of the accident.

\section{C.3.2.2 Methodology}

The PHA must be appropriate to the complexity of the process and be based on one or more of the following methodologies:

- What-If

- Checklist

- Hazard and Operability Study

- Failure Mode and Effect Analysis

- Fault Tree Analysis

- Any other appropriate and equivalent methodology.

In non-mandatory Appendix D to 29 CFR 1910.119, OSHA suggests that Center for Chemical Process Safety references be used to guide the selection of the PHA methodology. Moreover, in the preamble to OSHA's PSM standard [under Process Hazard Analysis, paragraph (e)], OSHA allows employers to mesh the PHA results with the requirements in EPA's RMP rule (40 CFR Part 68, Subpart B, Hazard Assessment). 


\section{C.3.2.3 Priority Order}

A priority order for conducting initial PHAs must be determined and documented. The PHA takes into account such factors as extent of the process hazards, number of potentially affected employees, age of process, and operating history of the process.

\section{C.3.2.4 Team Make-up}

The PHA must be performed by a team of experts in engineering and process operation. The team must have at least one member who is experienced in the particular process and a team leader who is knowledgeable in the PHA method. The employer must establish a system for prompt response to the team's findings and must update the PHA at least once every five years. The PHA and updates, along with the documented resolution of recommendations, must be retained for the life of the process [ 29 CFR 1910.119(e)].

\section{C.3.3 EPA's Risk Management Program}

EPA's management program requires a hazard assessment and a PHA.

\section{C.3.3.1 Hazard Assessment}

EPA's hazard assessment has no counterpart in the OSHA regulations and includes evaluation of a range of releases, including a worst-case accidental release scenario, as well as the more likely "alternative" release scenarios, analysis of potential offsite consequences, and a five-year accident history. When examining the potential worst-case release scenarios, facilities are allowed to assume that passive mitigation systems, such as containment dikes, function properly, as long as they are expected to survive an event. Active mitigation systems, such as excess flow valves, fail-safe systems, scrubbers, flares, deluge systems, and water curtains must be assumed to fail. Facilities are required to analyze offsite consequences of identified worst-case release scenarios under worst-case weather conditions.

Alternative scenarios must be examined under average weather conditions and can take into account successful operation of active mitigation systems. EPA requires the five-year accident history to document releases that caused deaths, injuries, or significant property damage onsite or known offsite deaths, injuries, evacuations, sheltering in place, property damage, or environmental damage.

The accident history includes: (1) date, time, and approximate duration of release; (2) chemical(s) released; (3) estimated quantity released (in pounds); (4) type of release event and its source; (5) weather conditions, if known; (6) onsite impacts; (7) known offsite impacts; (8) initiating event and contributing factors, if known; (9) whether offsite responders were notified, if known; and (10) operational or process changes that resulted from investigation of the release.

\section{C.3.3.2 Process Hazards Analysis}

The EPA's Program 3 requirements for a PHA [40 CFR 68.67] are identical to the requirements of the OSHA standard. The Program 2 requirements are called a "Hazard Review" [40 CFR 68.50] and require a "review of hazards" to identify the following: (1) the hazards associated with the process and regulated substances, (2) opportunities for equipment malfunctions or human errors that could cause an accidental release, (3) the safeguards needed to control the hazards or prevent equipment malfunctions or human 
Table C-2. Comparison of Hazard Identification and Assessment Required by NRC, OSHA, and EPA

\begin{tabular}{|c|c|c|c|c|c|}
\hline \multirow[b]{2}{*}{ Process Safety Information } & \multirow[b]{2}{*}{ NRC Guidance } & \multirow{2}{*}{$\begin{array}{l}\text { OSHA's Process Safety } \\
\text { Management Program } \\
\end{array}$} & \multicolumn{3}{|c|}{ EPA's Risk Management Program 2} \\
\hline & & & Program 3 & Program 2 & Program 1 \\
\hline $\begin{array}{l}\text { Offsite consequence analysis for worst-case } \\
\text { and alternative accidental release scenarios }\end{array}$ & $\begin{array}{l}\text { Methods of assessment implied by } \\
10 \text { CFR } 70\end{array}$ & Not required & Required & Required & $\begin{array}{l}\text { Required only for } \\
\text { worst-case scenario }\end{array}$ \\
\hline Five-year accident history & Not specifically required & Required & Required & Required & Required \\
\hline Onsite consequence analysis & Not specifically required & Required & Required & $\begin{array}{l}\text { Not specifically } \\
\text { required }\end{array}$ & Not required \\
\hline $\begin{array}{l}\text { Recognized hazard assessment methodology } \\
\text { used }\end{array}$ & Not specifically required & Required & Required & $\begin{array}{c}\text { Checklist is the only } \\
\text { method specifically } \\
\text { mentioned }\end{array}$ & Not required \\
\hline $\begin{array}{l}\text { Thorough assessment of: } \\
\text { - process hazards } \\
\text { - previous incidents } \\
\text { - engineering and administrative controls } \\
\text { - consequences of failure of engineering and } \\
\text { administrative controls } \\
\text { - human factors } \\
\text { - facility siting }\end{array}$ & $\begin{array}{l}\text { Process description and safety } \\
\text { analysis implied [Reg. Guide } 3.52 \text {, } \\
\text { p.29]; also, hazards analysis } \\
\text { implied }\end{array}$ & Required & Required & $\begin{array}{l}\text { Process hazards; } \\
\text { equipment } \\
\text { malfunction; human } \\
\text { errors; safeguards }\end{array}$ & Not required \\
\hline $\begin{array}{l}\text { Balanced make-up of hazard assessment } \\
\text { team }\end{array}$ & Not specifically required & Required & Required & $\begin{array}{l}\text { Not specifically } \\
\text { required }\end{array}$ & Not required \\
\hline $\begin{array}{l}\text { Documentation and resolution of } \\
\text { recommendations }\end{array}$ & $\begin{array}{l}\text { Summary of principal approaches } \\
\text { used to preclude or mitigate } \\
\text { accidents should be described }\end{array}$ & Required & Required & Required & Not required \\
\hline
\end{tabular}




\begin{tabular}{|c|c|c|c|c|c|}
\hline \multirow[b]{2}{*}{ Process Safety Information } & \multirow[b]{2}{*}{ NRC Guidance } & \multirow{2}{*}{$\begin{array}{l}\text { OSHA's Process Safety } \\
\text { Management Program }^{1}\end{array}$} & \multicolumn{3}{|c|}{ EPA's Risk Management Program ${ }^{2}$} \\
\hline & & & Program 3 & Program 2 & Program 1 \\
\hline Implementation schedule & Not specifically required & $\begin{array}{l}\text { Five years from May 24, } \\
1992\end{array}$ & $\begin{array}{l}\text { Three years from } \\
\text { date of } \\
\text { promulgation } \\
\text { (June 20, 1996) }\end{array}$ & June 20,1996 & June 20, 1996 \\
\hline $\begin{array}{l}\text { Schedule for updating and revalidating the } \\
\text { PHA }\end{array}$ & Not specifically required & At least every five years & $\begin{array}{l}\text { At least every } \\
\text { five years }\end{array}$ & $\begin{array}{l}\text { At least every five } \\
\text { years }\end{array}$ & Not required \\
\hline Retention time for the PHA & Not specifically required & $\begin{array}{l}\text { Throughout the life of the } \\
\text { process }\end{array}$ & $\begin{array}{l}\text { Throughout the } \\
\text { life of the } \\
\text { process }\end{array}$ & $\begin{array}{l}\text { Throughout the life of } \\
\text { the process }\end{array}$ & Not required \\
\hline $\begin{array}{l}\text { Atmospheric dispersion models and } \\
\text { calculation methods for consequence } \\
\text { analysis of releases, using both average and } \\
\text { worst-case weather conditions }\end{array}$ & Implied by $10 \mathrm{CFR} 70$ & Not required & Required & Required & $\begin{array}{l}\text { Required (worst- } \\
\text { case only) }\end{array}$ \\
\hline
\end{tabular}


error, and (4) any steps needed to detect or monitor releases. EPA states that the owner or operator may use checklists developed by persons or organizations knowledgeable about the process and equipment as a guide to conducting the Hazard Review, but does not otherwise recommend a selection of possible methods.

\section{C.3.4 Comparison of NRC, OSHA, and EPA Requirements}

Table C-2 presents a comparison of NRC, OSHA, and EPA requirements for the identification and assessment of hazards. To summarize, some differences between EPA and OSHA standards are as follows:

- EPA's hazard assessment includes offsite consequence analysis and a five-year accident history, while OSHA's standard requires a qualitative onsite consequence analysis and identification of any previous incidents related to accidental release scenarios.

- EPA requires the use of air dispersion models under specific meteorological conditions to estimate the distances releases might travel before falling below toxic or overpressure endpoints.

- The qualitative evaluation of safety and health impacts for EPA focuses on impacts on public health and the environment rather than on employees.

- EPA's hazard assessment requires a five-year release history.

- EPA's Program 3 PHA requirements are essentially identical to those required by OSHA.

\section{C.4 Operating Procedures}

\section{C.4.1 NRC Requirements and Guidance}

NRC requires licensees to include adequate information about proposed procedures (e.g., procedures for avoiding accidental criticality, procedures for personnel monitoring and waste disposal, and postcriticality accident emergency procedures) in their applications. These procedures must be used to protect health and minimize danger to life and property [10 CFR 70.22(a)(8), 10 CFR 70.23(a)(4)].

NRC requires licensees to state a commitment to conduct activities involving licensed materials in accordance with approved written procedures. The control system that ensures that written procedures are prepared, reviewed, revised, approved, and implemented must be described. The method by which procedures are made available for use by plant personnel must also be described [Reg. Guide $3.55 \mathrm{pp} .3$ and 17 and Reg. Guide 3.52 pp.3 and 20] (USNRC 1986). NRC recommends that licensees develop written administrative and general plant procedures, including procedures for evaluating changes to procedures, equipment, tests, and processes [implied by or addressed by $10 \mathrm{CFR} 40.31(\mathrm{j})(1)(\mathrm{i}),(\mathrm{j})(3)(\mathrm{vi})$, and (j)(3)(xii); 10 CFR 76.35(a)(4); and 10 CFR 76.91(f)]. Such procedures must be reviewed, approved, and documented in a manner approved by management (54 FR 11592 [USNRC 1989]):

\section{C.4.2 OSHA's Process Safety Management Standard}

OSHA requires employers to "develop operating procedures that provide clear instructions for safe completion of processes consistent with the process safety information" [29 CFR 1910.119(f)(1)]. These procedures must address at least the following: 
- $\quad$ steps for each operating phase

- initial startup

- normal operations

- temporary operations

- emergency shutdown procedures, including shutdown responsibility

- emergency operations

- normal shutdown

- startup following turnaround or emergency shutdown

- operating limits

- consequences of deviations

- corrective actions

- safety and health considerations

- properties of, and hazards presented by, process chemicals

- precautions to prevent exposure

- control measures following exposure or contact

- quality control and hazardous chemical inventory control

- any special or unique hazards

- safety systems and their functions.

In addition, OSHA requires employers to have "operating procedures readily accessible to employees who work in or maintain processes." The operating procedures must be reviewed and updated as often as necessary to reflect any changes [29 CFR 1910.119(f)].

\section{C.4.3 EPA's Risk Management Program}

EPA's Program 3 standard procedures requirement [40 CFR 68.28] is identical to OSHA's operating procedures [29 CFR 1910.119(f)] except for the introductory paragraph and editorial changes. EPA's Program 2 requirements are for procedures that cover the steps in each operating phase (see steps in Section C.4.2), consequences of deviation, corrective actions, and equipment inspections.

\section{C.4.4 Comparison of NRC, OSHA, and EPA Requirements}

The EPA and OSHA programs contain more detailed requirements than do NRC regulations and require more details on several aspects of developing and implementing written operating procedures. A comparison of NRC with OSHA and EPA regulations also illustrates the contrasts between their regulatory philosophies. EPA and OSHA regulations tend to address what should be in standard operating procedures. NRC, however, often requires that an effective oversight or control system be maintained for the preparation, review, and approval of written procedures. NRC emphasizes the methods used to develop written operating procedures, while OSHA and EPA emphasize compliance with various aspects of standard operating procedures rather than the control system employed to develop them. Table C-3 provides a comparison of operating procedures required by NRC, OSHA, and EPA. 
Table C-3. Comparison of Operating Procedures Required by NRC, OSHA, and EPA

\begin{tabular}{|c|c|c|c|c|c|}
\hline \multirow[b]{2}{*}{ Process Safety Information } & \multirow[b]{2}{*}{ NRC Guidance } & \multirow{2}{*}{$\begin{array}{c}\text { OSHA's Process } \\
\text { Safety Management } \\
\text { Program }^{1} \\
\end{array}$} & \multicolumn{3}{|c|}{ EPA's Risk Management Program² } \\
\hline & & & Program 3 & Program 2 & Program 1 \\
\hline \multicolumn{6}{|l|}{ Operating phase: } \\
\hline - Initial startup & Not specifically required & Required & Required & Required & Not required \\
\hline - Normal operations & Implied & Required & Required & Required & Not Required \\
\hline - Temporary operations & Not specifically required & Required & Required & Required & Not Required \\
\hline - Emergency shutdown & $\begin{array}{l}\text { Training to respond to an } \\
\text { emergency required for } \\
\text { postulated probable accident } \\
\text { scenarios }\end{array}$ & Required & Required & Required & Not Required \\
\hline - Emergency operations & $\begin{array}{l}\text { Required [10 CFR } \\
40.31(j)(3)(x i) \text { and also } \\
10 \text { CFR 70] }\end{array}$ & Required & Required & Required & Not Required \\
\hline - Normal shutdown & Not specifically required & Required & Required & Required & Not Required \\
\hline $\begin{array}{l}\text { - Startup after turnaround or emergency } \\
\text { shutdown }\end{array}$ & Not specifically required & Required & Required & Required & Not Required \\
\hline \multicolumn{6}{|l|}{ Operating Limits: } \\
\hline - Consequences of deviations & Implied & Required & Required & Required & Not Required \\
\hline $\begin{array}{l}\text { - Corrective actions and steps to prevent } \\
\text { deviations }\end{array}$ & Implied & Required & Required & Required & Not Required \\
\hline \multicolumn{6}{|l|}{ Safety and Health: } \\
\hline - Chemical properties and hazards & Not specifically required & Required & Required & $\begin{array}{l}\text { Not specifically } \\
\text { required }\end{array}$ & Not required \\
\hline - Measures to prevent exposure & Required & Required & Required & $\begin{array}{l}\text { Not specifically } \\
\text { required }\end{array}$ & Not required \\
\hline - Control measures following exposure & Required & Required & Required & $\begin{array}{l}\text { Not specifically } \\
\text { required }\end{array}$ & Not required \\
\hline $\begin{array}{l}\text { - Raw material quality control and } \\
\text { chemical inventory levels control }\end{array}$ & Implied & Required & Required & $\begin{array}{c}\text { Not specifically } \\
\text { required }\end{array}$ & Not required \\
\hline
\end{tabular}




\begin{tabular}{|c|c|c|c|c|c|}
\hline \multirow[b]{2}{*}{ Process Safety Information } & \multirow[b]{2}{*}{ NRC Guidance } & \multirow{2}{*}{$\begin{array}{c}\text { OSHA's Process } \\
\text { Safety Management } \\
\text { Program } \\
\end{array}$} & \multicolumn{3}{|c|}{ EPA's Risk Management Program² } \\
\hline & & & Program 3 & Program 2 & Program 1 \\
\hline - Special or unique hazards & Required & Required & Required & $\begin{array}{l}\text { Not specifically } \\
\text { required }\end{array}$ & Not required \\
\hline Safety systems and their functions & Required & Required & Required & Not required & Not required \\
\hline $\begin{array}{l}\text { Standard operating procedure development } \\
\text { method and system }\end{array}$ & $\begin{array}{l}\text { Recommended } \\
\text { (Reg. Guides } 3.52,3.55 \text { ) }\end{array}$ & Required & Required & Not required & Not required \\
\hline $\begin{array}{l}\text { Standard operating procedure approval } \\
\text { system and currency }\end{array}$ & $\begin{array}{l}\text { Recommended } \\
\text { (Reg. Guides 3.52, 3.55) }\end{array}$ & Required & Required & Not required & Not required \\
\hline Updating Procedures & Required & Required & Required & Required & Not required \\
\hline $\begin{array}{l}\text { 1. Codified in } 29 \text { CFR } 1910.119 . \\
\text { 2. Codified in } 40 \text { CFR Part } 68 .\end{array}$ & & & & & \\
\hline
\end{tabular}




\section{C.5 Site-Wide Safety Procedures}

Site-wide safety procedures are defined in this section as:

- safe work practices, such as control of access into the facility, lockout/tagout procedures, procedures for opening process equipment/piping, etc.

- hot work practices involving electric or gas welding, cutting, brazing, or similar flame or sparkproducing operations

- contractor management programs, including training, safety records, contractor responsibilities, etc.

\section{C.5.1 NRC Requirements and Guidance}

NRC requires licensees to include adequate information about proposed procedures in their license applications to protect health and minimize danger to life and property [10 CFR 70.22(a)(8) and 10 CFR 70.23(a)(4)].

NRC requires a commitment to conduct activities involving licensed materials in accordance with approved written procedures. The control system that ensures that written procedures are prepared, reviewed, revised, approved, and implemented must be described.

NRC also requires each application for a license that would authorize the transport or delivery to a carrier for transport of special nuclear material to include [10 CFR 70.22(g)]:

1. a description of the plan for physical protection of special nuclear material

2. a licensee safeguards contingency plan or response procedures, as appropriate, for dealing with threats, thefts, and radiological sabotage relating to the special nuclear material in transit.

\section{C.5.2 OSHA's Process Safety Management Standard}

As part of site-wide safe operating procedures, OSHA requires employers to develop and implement safe work practices to provide for the control of hazards during operations such as lockout/tagout; confined space entry; opening process equipment or piping; and control over entrance into the facility by maintenance, contractor, and other support personnel [29 CFR 1910.119(f)(4)].

OSHA also requires employers to issue hot work permits for hot work operations conducted on or near a covered process [29 CFR 1910.119(k)]. The permit must document that fire prevention and protection requirements in accordance with 29 CFR 1910.252(a) have been implemented before beginning hot work operations. The permit is retained until the hot work operation has been completed.

Under the section on contractors [29 CFR 1910.119(h)], OSHA requires employers to have a contractor management program in place, which outlines the employer's responsibilities, as well as the contract employer's duties. Employer responsibilities include evaluation of the contractor's safety performance and programs, informing contractors of known potential hazards related to the contractor's work, explaining applicable provisions of the emergency plan to contractors, developing and implementing safe 
work practices consistent with 29 CFR 1910.119(f)(4), maintaining a contractor illness/injury log, and reviewing contractor safety performance regularly. Contractor responsibilities include training each contract employee to safely perform his/her job, instructing each contract employee on any known potential hazards associated with his/her particular job, as well as applicable provisions of the emergency plan, documenting that each employee has received and understood the training provided, assuring that each contract employee follows safe work practices, and advising the employer of any special hazards presented by the contract employer's work or of any hazards found by the contract employer's work.

\section{C.5.3 EPA's Risk Management Program}

EPA's Program 3 requirements on site-wide safe operating procedures are similar to OSHA's requirements. Facilities are required to develop and implement safe work practices to provide for the control of hazards during operations such as lockout/tagout, confined space entry, opening process equipment/piping, and control over entrance into the facility by employees and contract employees [ 40 CFR 68.69(d)]. EPA also requires hot work permits [40 CFR 68.85]. EPA's Program 3 contractor requirements are also the same as OSHA's. Neither safe work permits nor contractor safety are explicitly mentioned in the context of EPA's Program 2.

\section{C.5.4 Comparison of NRC, OSHA, and EPA Requirements}

NRC does not regulate in the areas of contractors and hot work permits, each of which is covered by a separate section of the OSHA and EPA standards. A comparison of site-wide safety procedures required by NRC, OSHA, and EPA is given in Table C-4.

\section{C.6 Detection and Monitoring}

\section{C.6.1 NRC Requirements and Guidance}

NRC recommends that means be provided to detect and to alert the licensee's operating staff to any abnormal operating condition or any other danger to safe operations (e.g., a severe weather warning) [Regulatory Guide 3.67, p. 4 (USNRC 1992)]. For each type of accident identified in the licensee's emergency plan, it is recommended that the means of detecting the accident, the means of detecting any release of radioactive or other hazardous material, the means of alerting the operating staff, and the anticipated response of the operating staff be described. The licensee should indicate at what stage of the accident it would be detected.

Furthermore, NRC recommends that the licensees should determine that proper procedures are in place and proper facilities and equipment are available for measuring the extent of mitigating the consequences of, and otherwise dealing with, any potential accidental release of hazardous chemicals (54 FR 11595 [USNRC 1989]). These procedures, facilities, and equipment should be described in the licensee's emergency plan.

\section{C.6.2 OSHA's Process Safety Management Standard}

OSHA requires the employer to perform a PHA appropriate to the complexity of the plant to identify, evaluate, and control hazards involved in the process [29 CFR 1910.119(e)]. According to part (3) of paragraph (e) in the OSHA standard, the PHA must address: 
Table C-4. Comparison of Site-Wide Safety Procedures Required by NRC, OSHA, and EPA

\begin{tabular}{|c|c|c|c|c|c|}
\hline \multirow{2}{*}{$\begin{array}{l}\text { Site-Wide Safety } \\
\text { Procedures }\end{array}$} & \multirow{2}{*}{$\begin{array}{c}\text { NRC Regulations and } \\
\text { Guidance }\end{array}$} & \multirow{2}{*}{$\begin{array}{c}\text { OSHA's Process } \\
\text { Safety Management } \\
\text { Program } \\
\end{array}$} & \multicolumn{3}{|c|}{ EPA's Risk Manage Program² } \\
\hline & & & Program 3 & Program 2 & Program 1 \\
\hline Hot work procedures & Not specifically required & Required & Required & $\begin{array}{l}\text { Not explicitly } \\
\text { required }\end{array}$ & Not required \\
\hline Confined space entry permits & Not specifically required & Required & Required & $\begin{array}{l}\text { Not explicitly } \\
\text { required }\end{array}$ & Not required \\
\hline Lockout/tagout procedures & Not specifically required & Required & Required & $\begin{array}{l}\text { Not explicitly } \\
\text { required }\end{array}$ & Not required \\
\hline Opening process equipment/piping & Not specifically required & Required & Required & $\begin{array}{l}\text { Not explicitly } \\
\text { required }\end{array}$ & Not required \\
\hline Contractor program management & Not specifically required & Required & Required & $\begin{array}{l}\text { Not explicitly } \\
\text { required }\end{array}$ & Not required \\
\hline $\begin{array}{l}\text { Contractor safety training and } \\
\text { documentation }\end{array}$ & Not specifically required & Required & Required & $\begin{array}{l}\text { Not explicitly } \\
\text { required }\end{array}$ & Not required \\
\hline $\begin{array}{l}\text { Contractor safety performance } \\
\text { review }\end{array}$ & Not specifically required & Required & Required & $\begin{array}{l}\text { Not explicitly } \\
\text { required }\end{array}$ & Not required \\
\hline Contractor safety logs & Not specifically required & Required & Required & $\begin{array}{l}\text { Not explicitly } \\
\text { required }\end{array}$ & Not required \\
\hline
\end{tabular}

1. Codified in 29 CFR 1910.119

2. Codified in 40 CFR Part 68. 
"(iii) engineering and administrative controls applicable to hazards in the process and their interrelations, such as appropriate application of detection methodologies to provide early warning of releases. (Acceptable detection methods might include process monitoring and control instrumentation with alarm and detection hardware such as hydrocarbon sensors);

(iv) consequences of failure of engineering and administrative controls."

\section{C.6.3 EPA's Risk Management Program}

The EPA Program 3 requirement for areas addressed by the PHA [40 CFR 68.67] is identical to the OSHA requirement.

\section{C.6.4 Comparison of NRC, OSHA, and EPA Requirements}

Detection and monitoring does not exist as a separate paragraph or section in the EPA or OSHA standards. However, the notion is addressed as part of the PHA. EPA and OSHA place emphasis on safety systems, mitigation systems, and emergency alarms. Similar to OSHA, NRC does not address detection and monitoring separately but does address pertinent issues as discussed in Section C.6.1. Table C-5 gives a comparison of NRC, OSHA, and EPA requirements for detection and monitoring.

\section{C.7 Training}

\section{C.7.1 NRC Requirements and Guidance}

\section{C.7.1.1 NRC Requirements}

NRC regulations that are presented in 10 CFR Parts 40 and 70 identify training as a topic that must be addressed in the license application and considered by the staff in evaluating the applicant's qualifications, and training frequency performance objectives as topics to be addressed in an emergency plan:

- $\quad 10$ CFR 70.22(a)(6) calls for an applicant to discuss the qualifications, based on training and experience, to engage in the proposed activities. Training is mentioned as a basis for qualification, but no additional requirements are identified.

- 10 CFR 40.32(b) and 10 CFR 70.23(a)(2) state that an application for a specific license will be approved if the applicant is qualified by reason of training and experience to use the source material in such a manner as to protect health and minimize danger to life or property.

- 10 CFR 40.31(j)(3)(x) and 10 CFR 70.22(i)(3)(x) call for an emergency plan to describe the frequency, performance objectives, and plans for training workers on how to respond to an emergency.

\section{C.7.1.2 Regulatory Guidance and Branch Technical Position}

NRC regulatory guidance provides information on training topics, but quantitative standards are not specifically stated or implied. Regulatory Guide 3.55 (USNRC 1985) (for conversion facilities) calls for a description of the training program and the system for maintaining records of training and retraining operators and other personnel in safety (see Section 2.5 of the Regulatory Guide). The program should include training in radiological safety for personnel with access to restricted areas, training in criticality 
Table C-5. Comparison of Detection and Monitoring Required by NRC, OSHA, and EPA

\begin{tabular}{|c|c|c|c|c|c|}
\hline \multirow[b]{2}{*}{ Detection and Monitoring } & \multirow{2}{*}{$\begin{array}{c}\text { NRC Regulations and } \\
\text { Guidance } \\
\end{array}$} & \multirow{2}{*}{$\begin{array}{c}\text { OSHA's Process } \\
\text { Safety } \\
\text { Management } \\
\text { Program } \\
\end{array}$} & \multicolumn{3}{|c|}{ EPA's Risk Management Program ${ }^{1}$} \\
\hline & & & Program 3 & Program 2 & Program 1 \\
\hline $\begin{array}{l}\text { Site diagram showing location of chemical } \\
\text { leak detection devices }\end{array}$ & Not specifically required & Not required & Not required & Not required & Not required \\
\hline \multicolumn{6}{|l|}{ Detection and monitoring for: } \\
\hline - toxic releases & Implied & Required & Required & Implied & Not required \\
\hline - explosivity & Implied & Required & Required & Implied & Not required \\
\hline - fire, smoke, excessive heat & Required & Required & Required & Implied & Not required \\
\hline $\begin{array}{l}\text { Frequency of field monitoring as opposed to } \\
\text { distributed control system monitoring }\end{array}$ & Not specifically required & Not required & Not required & Not required & Not required \\
\hline $\begin{array}{l}\text { Logic in deciding which monitors sound } \\
\text { alarms versus which activate automatic active } \\
\text { mitigation systems }\end{array}$ & Not specifically required & Not required & Not required & Not required & Not required \\
\hline $\begin{array}{l}\text { Program to determine plant's detection and } \\
\text { monitoring needs }\end{array}$ & $\begin{array}{l}\text { Required } \\
\text { (54 FR 11592) }\end{array}$ & Required & Required & Implied & Not required \\
\hline
\end{tabular}

1. Codified in 29 CFR 1910.119.

2. Codified in 40 CFR Part 68. 
safety control, fire protection, as-low-as-reasonably-achievable practices, instrumentation and control, control of contamination, decontamination procedures, and emergency procedures. Regulatory Guide 3.55 also calls for specialized training "commensurate with the extent of the employee's contact with hazardous materials" (Section 10.6 of the Regulatory Guide).

Regulatory Guide 3.52 (USNRC 1986) (for fuel fabrication facilities) calls for a commitment to a training program in several areas, including "special skills" (Section 2.5 of the Regulatory Guide). Neither identifies specific standards in these areas.

NRC has addressed the issue of training in 54 FR 11592 (USNRC 1989). Based on this Branch Technical Position, "licensees should establish and implement training programs to provide employees with the skills and knowledge to perform their jobs safely."

Management controls must provide for the evaluation of the effectiveness of training programs against predetermined objectives and criteria.

\section{C.7.2 OSHA's Process Safety Management Standard}

OSHA requires employers to train employees involved in operating a process, employees involved in a newly-assigned process [29 CFR 1910.119(g)(1)(i)], maintenance employees [29 CFR 1910.119(j)(3)], contractor employees [29 CFR 1910.119(h)(3)(i)], and to provide initial training to new employees [29 CFR 1910.119(g)(1)].

Initial operator training should emphasize specific safety and health hazards, emergency operations, and safe work practices as they apply to the employee's specific job tasks. Employers must retrain employees every three years, or more often if necessary, based on consultation with employees [29 CFR $1910.119(\mathrm{~g})(2)]$. OSHA also requires employers to "maintain a record containing the identity of the employee, the date of training, and the means used to verify that the employee has understood the training" [29 CFR 1910.119(g)(3)].

The initial and refresher training must be provided to assure that each employee involved in operating a process understands and adheres to the overview of the process and the current operating procedures of the process as specified in 29 CFR 1910.119(f), 29 CFR 1910.119(g)(1)(i), and 29 CFR 1910.119(g)(2).

In addition to operator training, the OSHA PSM standard (29 CFR 1910.119) contains many other training and informational requirements as follows:

- Communication of PHA findings and planned corrective actions to those whose safety might be affected [29 CFR 1910.119(e)(5)].

- Training concerning confined spaces, which is included by reference. A procedure for confined space should be used for a high-hazard site [see 29 CFR 1910.146(g)].

- Training in lockout-tagout procedures, which is included by reference. A procedure for lockouttagout should be used for a high-hazard site [see 29 CFR 1910(c)(7)].

- References in the PSM standard to the Hazard Communication standard call attention to the applicability of the latter to high hazard sites. Training requirements for this are given in 29 CFR 1910.1200(h). 
- Training for emergency spill response for high-hazard chemical sites [referenced in 29 CFR 1910.119(n) and detailed in 29 CFR 1910.120].

- Contractor employees are to be trained in an overview of the site hazards, their job duties, actions to take in an emergency, and other details [29 CFR 1910.110(H)(3)(i),(ii), and (iii)].

- Maintenance employees are to be trained in their job duties and in an overview of the process and its hazards [29 CFR 1910.119(h)(3)].

- When there is a change in equipment, operating procedures, technology of the process, or in processing materials, operators and others whose safety might be affected must be trained in the change prior to startup [29 CFR 1910.119(1)(3)], and there must be a verification that the training has been completed prior to startup [29 CFR 1910.119 (i)(2)(iv)].

- When there is an incident that did cause or might have caused a catastrophic release, the incident is to be investigated and a report prepared. The report must be reviewed with all persons who might be affected by the findings [29 CFR $1910.110(\mathrm{M})(6)$ ].

- There should be an emergency action plan [29 CFR 1910.119(n)] and associated training [29 CFR 1910.38(a)(5)]. In addition, employees must be trained in the emergency alarm systems [29 CFR 1910.165(b)(4)].

\section{C.7.3 EPA’s Risk Management Program}

EPA's Program 3 requires employers to provide initial training, to train employees operating a newlyassigned process, and to train maintenance employees. The owner or operator must also ensure that contractors train their employees. Refresher training must be provided, in consultation with the employees, at least every three years, and more often if necessary, to each employee. EPA also requires that the owner or operator must ascertain that each employee involved in operating a process has received and understood the training and must prepare a record that contains the identity of the employee, the date of training, and the means used to verify that the employee has understood the training. Furthermore, EPA requires that the owner or operator evaluate the effectiveness of the training program. A schedule for reviewing and revising the program must be maintained at the stationary source. Thus, the EPA's Program 3 training requirements are essentially identical to those of OSHA.

EPA's Program 2 states that the owner must ensure that each process operator has been trained or tested competent in the appropriate operating procedures. Refresher training should be applied at least every three years. EPA's Program 1 has no training requirements.

\section{C.7.4 Comparison of NRC, OSHA, and EPA Requirements}

EPA's Program 3 training section [40 CFR 68.30] is identical to OSHA's training section [29 CFR 1910.119(g)]. NRC does not require a minimum training schedule for either radiological or chemical hazards. NRC does not explicitly require that contractors and maintenance personnel undergo training. However, NRC recommends that specialized training be commensurate with the extent of the employee's contact with hazards. NRC regulations leave the content and frequency of the training program to the discretion of the licensee. Unlike EPA and OSHA, NRC does not require, but does recommend, maintaining training records and evaluating training program effectiveness. Table C- 6 provides a comparison of training required by NRC, OSHA, and EPA. 


\begin{tabular}{|c|c|c|c|c|c|}
\hline \multirow[b]{2}{*}{ Training } & \multirow{2}{*}{$\begin{array}{c}\text { NRC Regulations and } \\
\text { Guidance }\end{array}$} & \multirow{2}{*}{$\begin{array}{c}\text { OSHA's Process } \\
\text { Safety } \\
\text { Management } \\
\text { Program } \\
\end{array}$} & \multicolumn{3}{|c|}{ EPA's Risk Management Program² } \\
\hline & & & Program 3 & Program 2 & Program 1 \\
\hline $\begin{array}{l}\text { Initial training: } \\
\text { - operating procedures } \\
\text { - overview of process } \\
\text { - safety and health hazards } \\
\text { - safe work practices }\end{array}$ & $\begin{array}{l}\text { Recommended } \\
\text { [Reg. Guide 3.55] }\end{array}$ & Required & Required & Required & Not required \\
\hline Refresher training frequency & Not specifically required & $\begin{array}{l}\text { At least every three } \\
\text { years (consult with } \\
\text { employees) }\end{array}$ & $\begin{array}{l}\text { At least every three } \\
\text { years (consult with } \\
\text { employees) }\end{array}$ & $\begin{array}{l}\text { At least every three } \\
\text { years (consult with } \\
\text { employees) }\end{array}$ & Not required \\
\hline $\begin{array}{l}\text { Training documentation: } \\
\text { - that employee has received and } \\
\text { understood training } \\
\text { detailed employee training and } \\
\text { testing record }\end{array}$ & $\begin{array}{l}\text { Not specified, but licensees } \\
\text { must state frequency. } \\
\text { [10 CFR } 40.31(j)(3)(x), 10 \\
\text { CFR 70, and Reg. Guide } \\
\text { 3.55] }\end{array}$ & Required & Required & $\begin{array}{l}\text { Not specifically } \\
\text { required }\end{array}$ & Not required \\
\hline $\begin{array}{l}\text { Contractor and maintenance } \\
\text { employee training }\end{array}$ & Not specifically required & Required & Required & Not required & Not required \\
\hline Emergency response training & $\begin{array}{l}\text { Required [10 CFR } \\
40.31(\mathrm{j})(3)(\mathrm{x}) \text {, and } 40.32(\mathrm{~b})]\end{array}$ & Required & Required & Required & Implied \\
\hline $\begin{array}{l}\text { Evaluate training effectiveness and } \\
\text { review and revise program }\end{array}$ & $\begin{array}{l}\text { Required } \\
\text { [Reg. Guide 3.52] }\end{array}$ & Not required & Implied & Implied & Not required \\
\hline
\end{tabular}

1. Codified in 29 CFR 1910.119.

2. Codified in 40 CFR Part 68. 


\section{C.8 Maintenance and Inspection Procedures}

\section{C.8.1 NRC Requirements and Guidance}

NRC requires that a license application should contain, in addition to other information, a description of the testing and operation of the structures, systems, and components of the plant [10 CFR 70.22(f)]. Safety systems should be tested and documented on a scheduled frequency. NRC recommends that licensees conduct surveillance, tests, and inspections of items and activities important to safety in accordance with written procedures that identify the requirements and acceptable limits (54 FR 11592 [USNRC 1989]).

\section{C.8.2 OSHA's Process Safety Management Standard}

OSHA requires employers to establish and implement written procedures to maintain the on-going integrity of the following process equipment:

- pressure vessels and storage tanks

- piping systems

- relief and vent systems and devices

- emergency shutdown systems

- controls

- pumps.

The results of tests and inspections performed as preventive maintenance are to be used to decide whether preventive maintenance is being performed frequently enough, or if the method is satisfactory [29 CFR 1910.119(j)(4)(iii)]. If deficiencies are found in equipment, they are to be corrected before further use. If corrections cannot be made promptly, other actions may be necessary (e.g., reducing pressure) to restore safety during continued operation [29 CFR 1910.119(j)(5)].

Employees have to be trained for process maintenance activities and in process hazards and overview. Inspections and tests should be performed and documented on process equipment that are consistent with applicable manufacturer's recommendations [29 CFR 1910.119(j)] and conform with good engineering practices. Each inspection and test should be documented.

The employer should ensure that installation of new equipment is according to design specifications and manufacturer's instructions. In addition, maintenance materials, spare parts, and equipment should be suitable for the process application that will be used.

\section{C.8.3 EPA's Risk Management Standard}

EPA's Program 3 requirements are the same as OSHA's. EPA's Program 2 requires procedures to be prepared and implemented to maintain the on-going integrity of the process equipment. Maintenance employees and contractors' employees must be trained in the procedures. There must be inspection and testing procedures in accordance with good practice.

\section{C.8.4 Comparison of NRC, OSHA, and EPA Requirements}

The EPA and OSHA programs contain more detailed requirements than do NRC regulations and require more details on several aspects of maintenance and inspection. EPA's Program 3 maintenance require- 
ments [40 CFR 68.73] use the same language as OSHA's mechanical integrity paragraph [29 CFR 1910.119(j)]. Table C-7 gives a comparison of maintenance and inspection procedures required by NRC, OSHA, and EPA.

\section{C.9 Management of Change}

\section{C.9.1 NRC Requirements and Guidance}

NRC requires licensees to "develop written administrative and general plant procedures including procedures for evaluating changes to procedures, equipment, tests, and processes. Such procedures should be reviewed, approved, and documented in a manner approved by management" [Regulatory Guide 3.52 (USNRC 1986)]. Regarding changes in procedures, facilities, and equipment, NRC requires fuel cycle facilities to "describe the responsibility for initiating changes in procedures, facilities, and equipment. The licensees should describe the procedures and controls that will ensure that an analysis and independent safety review of any proposed activity is performed and documented prior to the start of the new activity or change in an existing activity involving licensed material." The administrative procedure should include a consideration of analysis, review, approval, verification, and records.

The Branch Technical Position in 54 FR 11590-11598 (USNRC 1989) provides guidance on management controls and quality assurance for fuel cycle facilities. This Branch Technical Position describes a management controls and quality assurance program that licensees should use to improve operational safety. Establishing procedures for systematic review of proposed changes to procedures, equipment, tests, and processes by a plant safety committee is suggested.

\section{C.9.2 OSHA's Process Safety Management Standard}

OSHA requires employers to "establish and implement written procedures to manage changes to process, chemicals, technology, equipment (except replacement-in-kind), and procedures and changes to facilities that affect a covered process" [29 CFR 1910.119(1)(1)]. OSHA further requires that the procedures must assure that the technical basis for the proposed change, impact on safety and health, modifications to operating procedures, necessary time period for phasing in the change, and authorization requirements for the proposed change be considered [29 CFR 1910.119(1)(2)].

OSHA's management-of-change requirements include a follow-up review to ensure that management-ofchange requirements have been carried out before modified equipment is started up [29 CFR 1910.119(i)].

Employees involved in operating a process and contractor and maintenance personnel whose job tasks will be affected by a change must be informed of, and trained in, the change prior to start-up of the process [29 CFR 1910.119(1)(3)]. If a change results in a change in the process safety information, operating procedures, or practices, such information, procedures, or practices must be updated accordingly [29 CFR 1910.119(1)(4,5)].

\section{C.9.3 EPA's Risk Management Program}

EPA's Program 3 requirements [ 40 CFR Part 68.75] are identical to OSHA's requirements. There is no explicit "management of change" requirement in Program 2, although a management of change program is implicit in the requirement that the facility operate safely. 
Table C-7. Comparison of Maintenance and Inspection Procedures Required by NRC, OSHA, and EPA

\begin{tabular}{|c|c|c|c|c|c|}
\hline \multirow[b]{2}{*}{ Training } & \multirow{2}{*}{$\begin{array}{c}\text { NRC Regulations and } \\
\text { Guidance } \\
\end{array}$} & \multirow{2}{*}{$\begin{array}{c}\text { OSHA's Process } \\
\text { Safety Management } \\
\text { Program } \\
\end{array}$} & \multicolumn{3}{|c|}{ EPA's Risk Management Program ${ }^{2}$} \\
\hline & & & Program 3 & Program 2 & Program 1 \\
\hline $\begin{array}{l}\text { Develop a list of critical equipment } \\
\text { and controls }\end{array}$ & Required & Required & Required & $\begin{array}{l}\text { Not explicitly } \\
\text { required }\end{array}$ & Not required \\
\hline $\begin{array}{l}\text { Written procedures for maintenance } \\
\text { of process equipment }\end{array}$ & $\begin{array}{l}\text { Recommended } \\
\text { [54 FR 11592] }\end{array}$ & Required & Required & Required & Not required \\
\hline $\begin{array}{l}\text { Training for process maintenance } \\
\text { activities }\end{array}$ & $\begin{array}{l}\text { Training for process } \\
\text { malfunctions implied [Reg. } \\
\text { Guide 3.55] Training for } \\
\text { modifications required }\end{array}$ & Required & Required & Required & Not required \\
\hline $\begin{array}{l}\text { Appropriate schedule for inspection, } \\
\text { testing, and preventive maintenance } \\
\text { for critical equipment }\end{array}$ & $\begin{array}{l}\text { Implied } \\
\text { [Reg. Guide 3.52] }\end{array}$ & Required & Required & Implied & Not required \\
\hline $\begin{array}{l}\text { Correction of equipment } \\
\text { deficiencies in a safe and timely } \\
\text { manner }\end{array}$ & Not specifically required & Required & Required & Implied & Not required \\
\hline $\begin{array}{l}\text { Quality assurance for maintenance } \\
\text { material, spare parts, and equipment }\end{array}$ & Not specifically required & Required & Required & Implied & Not required \\
\hline $\begin{array}{l}\text { Ensure equipment installation is } \\
\text { consistent with design specifications }\end{array}$ & Not specifically required & Required & Required & Implied & Not required \\
\hline $\begin{array}{l}\text { Ensure inspection frequencies are } \\
\text { consistent with good engineering } \\
\text { practices }\end{array}$ & Not specifically required & Required & Required & Implied & Not required \\
\hline $\begin{array}{l}\text { Maintain detailed, accurate records } \\
\text { for inspections and tests }\end{array}$ & Not specifically required & Required & Required & Implied & Not required \\
\hline
\end{tabular}

1. Codified in 29 CFR 1910.119.

2. Codified in 40 CFR Part 68. 


\section{C.9.4 Comparison of NRC, OSHA, and EPA Requirements}

NRC regulations emphasize a management system that will ensure that management of change issues are properly addressed. NRC regulations are less prescriptive than OSHA's or EPA's, although the intent of all three is the same. EPA's Program 3 management of change requirements [40 CFR 68.75] are identical to OSHA's [29 CFR 1910.119(1)]. Table C-8 gives a comparison of NRC, OSHA, and EPA requirements for management of change.

\section{C.10 Emergency Planning and Response}

\section{C.10.1 NRC Requirements and Guidance}

NRC requires licensees to submit an emergency response plan as a requirement for approval of an application and issuance of specific licenses. The emergency plan must contain a facility description, types and classification of accidents, means of detection of accidents, mitigation of consequences, assessment of release, responsibilities of the licensee personnel, notification and coordination, and information to be communicated (e.g., radioactive releases, facility status, recommended protective action). The emergency response plan must also contain the description of emergency response training, safe shutdown, hazardous chemicals, and exercises for communication checks [10 CFR 40.31(j)(3) and 10 CFR 70.22(i)(3)].

NRC has provided additional guidance for the standard format and content of emergency response plans. Based on this guidance, the emergency response plan document must include a description of the licensed activity, facility, and site; area near the site; description of postulated accidents; and description of detection of accidents. The plan must also provide information about the classification system, notification, and coordination for "Alert" and "Site Area Emergency" incidents. In addition, the licensee must describe the normal facility organization, onsite emergency response organization, local offsite assistance to facility, and coordination with participating government agencies.

In order to identify specific emergency response measures, the licensee must describe the means used to assess actions, activate the emergency response organization, and mitigate the consequences for each class of emergency. Protective actions, exposure control in radiological emergencies, medical transportation, and treatment must also be described. Onsite equipment and facilities, such as communication and emergency monitoring equipment, command centers, and medical facilities must be discussed.

To demonstrate emergency preparedness capability, the licensee must provide a written emergency plan/procedure, describe the content of training, describe drills and exercises, prepare a critique of each drill and exercise, discuss the program for auditing the emergency response procedures, and describe the plan for maintenance of emergency equipment. Changes to the emergency plan must be communicated to the offsite response agencies. The responsibility for reporting and recording incidents and recording preparedness assurance must be discussed. Recovery and plant restoration and compliance with community right-to-know must be described [Reg. Guides 3.42 and 3.67 (USNRC 1979 and 1992)].

\section{C.10.2 OSHA's Process Safety Management Standard}

OSHA requires employers to establish and implement an emergency action plan for the entire plant in accordance with the provisions of 29 CFR 1910.38(a). The emergency action plan provides emergency 
Table C-8. Comparison of Management of Change Required by NRC, OSHA, and EPA

\begin{tabular}{|c|c|c|c|c|c|}
\hline \multirow[b]{2}{*}{ Training } & \multirow{2}{*}{$\begin{array}{l}\text { NRC Regulations and } \\
\text { Guidance } \\
\end{array}$} & \multirow{2}{*}{$\begin{array}{c}\text { OSHA's Process } \\
\text { Safety Management } \\
\text { Program } \\
\end{array}$} & \multicolumn{3}{|c|}{ EPA's Risk Management Program² } \\
\hline & & & Program 3 & Program 2 & Program 1 \\
\hline $\begin{array}{l}\text { Establish and implement written } \\
\text { procedures }\end{array}$ & $\begin{array}{l}\text { Implied } \\
\text { [Reg. Guide 3.52] }\end{array}$ & Required & Required & Not required & Not required \\
\hline $\begin{array}{l}\text { Description of technical basis for } \\
\text { change }\end{array}$ & $\begin{array}{l}\text { Implied } \\
\text { [Reg. Guide 3.52] }\end{array}$ & Required & Required & Not required & Not required \\
\hline $\begin{array}{l}\text { Impact of change on safety and } \\
\text { health }\end{array}$ & $\begin{array}{l}\text { Implied } \\
\text { [Reg. Guide 3.52/3.55] }\end{array}$ & Required & Required & Not required & Not required \\
\hline $\begin{array}{l}\text { Impact of change on likelihood of a } \\
\text { significant accidental release }\end{array}$ & $\begin{array}{l}\text { Implied } \\
\text { [Reg. Guide 3.52] }\end{array}$ & Not required & Not Required & Not required & Not required \\
\hline $\begin{array}{l}\text { Modifications to operating } \\
\text { procedures }\end{array}$ & $\begin{array}{l}\text { Covered by requiring an } \\
\text { analysis and independent } \\
\text { safety review }\end{array}$ & Required & Required & Not required & Not required \\
\hline $\begin{array}{l}\text { Designate what constitutes a process } \\
\text { change and what is replacement-in- } \\
\text { kind }\end{array}$ & Not specifically required & $\begin{array}{c}\text { Required } \\
\text { [29 CFR 1910.119(i)(1)] }\end{array}$ & Required & Not required & Not required \\
\hline $\begin{array}{l}\text { Consider necessary time period to } \\
\text { complete the change }\end{array}$ & $\begin{array}{l}\text { Implied } \\
\text { [Reg. Guide 3.52, } \\
\text { Sec. 11.6] }\end{array}$ & Required & Required & Not required & Not required \\
\hline $\begin{array}{l}\text { Consider authorization requirements } \\
\text { for the proposed change }\end{array}$ & $\begin{array}{l}\text { Implied } \\
\text { [Reg. Guide 3.52, } \\
\text { Sec. 11.6] }\end{array}$ & Required & Required & Not required & Not required \\
\hline $\begin{array}{l}\text { Inform and train employees, } \\
\text { maintenance personnel, and contract } \\
\text { personnel }\end{array}$ & Not specifically required & Required & Required & Not required & Not required \\
\hline $\begin{array}{l}\text { Update operating procedures, } \\
\text { practices, and process safety } \\
\text { information }\end{array}$ & $\begin{array}{l}\text { Covered by requiring an } \\
\text { analysis, independent safety } \\
\text { review, and documentation } \\
\text { before start-up and new } \\
\text { activity }\end{array}$ & Required. & Required & Not required & Not required \\
\hline $\begin{array}{l}\text { 1. Codified in } 29 \text { CFR } 1910.119 \\
\text { 2. Codified in } 40 \text { CFR Part } 68 .\end{array}$ & & & & & \\
\hline
\end{tabular}


responders with the necessary training and equipment. An emergency alarm system is also required (by reference to 29 CFR 1910.165), having distinctive alarms for different emergencies. Training of employees in how to respond to each alarm is required. Emergency action plans must include procedures for handling small releases. Employers covered under this standard may also be subject to the hazardous waste and emergency response provisions contained in 29 CFR 1910.120(a), (n), (p), and (q).

As a minimum, OSHA requires employers to have an emergency action plan that will facilitate the prompt evacuation of employees when an unwanted release of highly hazardous chemicals occurs [29 CFR 1910.119(n)]. The emergency action plan will be activated by a clearly understood alarm system. If the employer wants specific employees in the release area to control or stop the minor emergency or incidental release, these actions must be planned in advance, and procedures must be developed and implemented.

When a serious release of a highly hazardous chemical occurs, the employer, through preplanning, will have determined in advance what actions employees are to take. If the employer wishes to use plant personnel to render aid to those in the immediate release area or use employees to mitigate the incident, these actions are covered by 29 CFR 1910.120, the Hazardous Waste Operations and Emergency Response standard. The safety and health protection required for emergency responders are the responsibility of their employers and of a competent on-scene incident commander.

Drills, training exercises, or simulations with local community emergency response planners and responder organizations are recommended to achieve better preparedness. Establishing and fully equipping an emergency control center to enhance coordination and communication during emergencies for on-plant operations is recommended.

\section{C.10.3 EPA's Risk Management Program}

Owners or operators of both Program 2 and Program 3 processes must develop and implement an emergency response program for the purposes of protecting public health and the environment, including: (1) an emergency response plan containing procedures for informing the public and local emergency response agencies about accidental releases, documentation of proper first-aid and emergency medical treatment necessary to treat accidental human exposures, and procedures and measures for emergency response after an accidental release of a regulated substance; (2) procedures for the use of emergency response equipment and for its inspection, testing, and maintenance; (3) training for all employees in relevant procedures; and (4) procedures to review and update, as appropriate, the emergency response plan to reflect changes at the stationary source and ensure that employees are informed of changes. In addition, EPA indicates that a written plan that complies with other Federal contingency plan regulations or is consistent with the approach in the National Response Team's "Integrated Contingency Plan Guidance" ("One Plan") will be satisfactory provided that the emergency response plan is coordinated with the community emergency response plan developed under 42 U.S.C. 11003. Upon request of the local emergency planning committee or emergency response officials, the owner or operator must promptly provide to the local emergency response officials information necessary for developing and implementing the community emergency response plan.

\section{C.10.4 Comparison of NRC, OSHA, and EPA Requirements}

EPA's proposed emergency response provisions are somewhat different from those in the OSHA standard. Under the OSHA standard, facilities must comply with one of two existing OSHA standards. Facilities that are currently in compliance with OSHA's Hazardous Waste Operations and Emergency 
Response Standard [29 CFR 1910.120] are likely to be in substantial compliance with EPA's proposed rule. OSHA's emergency action plan regulation [29 CFR 1910.38(a)] basically requires an evacuation plan. The Clean Air Act requires EPA's emergency response program to include "specific actions to be taken in response to an accidental release of a regulated substance so as to protect human health and the environment" [Clean Air Act Section 112(r)(7)(B)(ii)]. Therefore, facilities that currently have only an emergency action plan required under 29 CFR 1910.138(a) would, under EPA's proposed rule, need to develop a more extensive emergency response plan that details how the facility would respond to a release to limit offsite consequences. In addition, EPA requires coordination with the community emergency response plan developed under 42 U.S.C. 11003, something that is not required by OSHA. Table C-9 gives a comparison of emergency planning required by NRC, OSHA, and EPA.

\section{C.11 Incident Investigation}

\section{C.11.1 NRC Requirements and Guidance}

$\mathrm{NRC}$ requires that the license application contain a description of the procedures for complying with the requirements for reportable incidents. The management positions responsible for investigating, recording, reporting, and following up on actions of reportable incidents should also be identified [Reg. Guide 3.52, p. 4 (USNRC 1986), Reg. Guide 3.55, p. 4 (USNRC 1985)]. Regulatory Guide 10.1, "Compilation of Reporting Requirements for Persons Subject to NRC Regulations", (USNRC 1981) provides a listing of NRC reporting requirements.

$\mathrm{NRC}$ also requires a description of the system for maintaining records, including unusual operational incidents and events associated with radioactivity releases. The retention times for records should be described [Reg. Guide 3.52 and 3.55 (USNRC 1986 and 1985)].

\section{C.11.2 OSHA's Process Safety Management Standard}

OSHA requires that employers investigate each incident which resulted in, or could reasonably have resulted in, a catastrophic release in the workplace. Incident investigation must be initiated as soon as possible, but no later than 48 hours following the incident. A knowledgeable, experienced team must be established to thoroughly investigate and analyze the incident [29 CFR 1910.119 (m)]. The investigation will result in a report, which includes at a minimum:

- date of incident

- date investigation began

- description of incident

- factors contributing to incident

- recommendations resulting from investigation.

A system to promptly address and resolve incident report findings and recommendations must be established. Results and corrective actions must be documented. Relevant portions of the report must be communicated with all affected personnel, including contract employees. Incident investigation reports shall be retained for five years. 


\begin{tabular}{|c|c|c|c|c|c|}
\hline \multirow[b]{2}{*}{ Training } & \multirow{2}{*}{$\begin{array}{c}\text { NRC Regulations and } \\
\text { Guidance } \\
\end{array}$} & \multirow{2}{*}{$\begin{array}{c}\text { OSHA's Process } \\
\text { Safety Management } \\
\text { Program }^{1} \\
\end{array}$} & \multicolumn{3}{|c|}{ EPA's Risk Management Program² } \\
\hline & & & Program 3 & Program 2 & Program 1 \\
\hline Evacuation routes for employees & Required & Required & Required & Required & Not required \\
\hline $\begin{array}{l}\text { Procedures for employees } \\
\text { responding to release }\end{array}$ & Required & Required & Required & Required & Not required \\
\hline $\begin{array}{l}\text { Description of all response and } \\
\text { mitigation technologies available at } \\
\text { facility }\end{array}$ & Required & Not required & Required & Required & Not required \\
\hline $\begin{array}{l}\text { Procedures for informing the public } \\
\text { and emergency response agencies } \\
\text { about releases }\end{array}$ & Required & Not required & Required & Required & Not required \\
\hline $\begin{array}{l}\text { Written procedures for using } \\
\text { emergency equipment and for its } \\
\text { inspection, testing, and maintenance }\end{array}$ & Not specified & Not required & Required & Required & Not required \\
\hline $\begin{array}{l}\text { Document proper first-aid and } \\
\text { emergency medical treatment for } \\
\text { accidental exposure }\end{array}$ & Required & Not required & Required & Required & Not required \\
\hline $\begin{array}{l}\text { Documented training of all } \\
\text { employees in relevant emergency } \\
\text { response procedures }\end{array}$ & Required & Not required & Required & Required & Not required \\
\hline $\begin{array}{l}\text { Conduct drills and exercises to test } \\
\text { emergency response plan and } \\
\text { evaluate its effectiveness }\end{array}$ & Required & Not required & Not required & Not Required & Not required \\
\hline Document each drill and exercise & Not specifically required & Not required & Not required & Not Required & Not required \\
\hline $\begin{array}{l}\text { Revise emergency response plan } \\
\text { based on findings of drill and } \\
\text { exercises }\end{array}$ & Implied & Not required & Not required & Not Required & Not required \\
\hline $\begin{array}{l}\text { Coordinate emergency response } \\
\text { plan with local emergency planning } \\
\text { committee or emergency response } \\
\text { officials }\end{array}$ & Required & Not required & Required & Required & Required \\
\hline
\end{tabular}

1. Codified in 29 CFR 1910.119

2. Codified in 40 CFR Part 68. 


\section{C.11.3 EPA's Risk Management Program}

EPA's Program 3 and Program 2 includes accident investigation requirements [ $40 \mathrm{CFR}$ 68.81], which are identical to OSHA's incident investigation paragraph [29 CFR 1910.119 (m)].

\section{C.11.4 Comparison of NRC, OSHA, and EPA Requirements}

$\mathrm{NRC}$ requires the identification of the management positions responsible for investigations and reporting, while EPA and OSHA require the establishment of a management system to address incident report findings and recommendations. EPA and OSHA require the investigation report to conform to a specific format, while NRC has flexible requirements. EPA and OSHA require that incident investigation reports be retained for at least five years, whereas NRC leaves the decision regarding duration of retention to the licensees. Table $\mathrm{C}-10$ gives a comparison of incident investigation requirements by NRC, OSHA, and EPA.

\section{C.12 Audits and Inspections}

\section{C.12.1 NRC Requirements and Guidance}

NRC recommends that licensees state their requirements for internal audits and inspections [Reg. Guide 3.52, p. 4 (USNRC 1986)]. Audits and inspections must be conducted at specified frequencies to determine that plant operations are conducted in compliance with regulatory requirements, license conditions, and written procedures. Audits and inspections must apply to radiation protection, nuclear criticality safety control, hazardous chemical safety, fire protection, chemical systems, safety devices, and environmental protection and must be performed according to a written plan. Qualified personnel without direct responsibility for the function and area being audited must be used for audits. Inspections should be performed routinely by qualified staff personnel that are not responsible for production activities. The staff positions and committees responsible for audits and inspection should be specified. The level of management to which results are reported and the system to ensure that corrective action is taken should also be described [Reg. Guide 3.55 pp. 4 and 17 (USNRC 1985) and Reg. Guide 3.52 pp. 4 and 20 (USNRC 1986)].

\section{C.12.2 OSHA's Process Safety Management Standard}

OSHA requires employers to certify that they have evaluated compliance with all of the provisions of the PSM standard. Audits and inspections are required at least every three years to verify that the procedures and practices developed under the standard are adequate and are being followed. The compliance audit must be conducted by at least one person knowledgeable in the process. The findings of the audits must be documented in a report. The employer must promptly determine and document an appropriate response to each of the findings of the compliance audit and document that deficiencies have been corrected. Employers must retain the two most recent compliance audit reports [29 CFR 1910.119 (o)].

\section{C.12.3 EPA's Risk Management Program}

EPA's Program 3 and Program 2 safety audit requirements [40 CFR 68.79 and 40 CFR 68.58] are identical to OSHA's compliance audit requirement [29 CFR 1910.119 (o)]. 
Table C-10. Comparison of Incident Investigation Required by NRC, OSHA, and EPA

\begin{tabular}{|c|c|c|c|c|c|}
\hline \multirow[b]{2}{*}{ Training } & \multirow{2}{*}{$\begin{array}{c}\text { NRC Regulations and } \\
\text { Guidance }\end{array}$} & \multirow{2}{*}{$\begin{array}{c}\text { OSHA's Process } \\
\text { Safety Management } \\
\text { Program } \\
\end{array}$} & \multicolumn{3}{|c|}{ EPA's Risk Management Program² } \\
\hline & & & Program 3 & Program 2 & Program 1 \\
\hline $\begin{array}{l}\text { Establish and implement written } \\
\text { procedures for investigating } \\
\text { incidents and near-misses }\end{array}$ & $\begin{array}{l}\text { Procedures should be } \\
\text { described but need not } \\
\text { necessarily be written } \\
\text { [Reg. Guide 3.52] }\end{array}$ & $\begin{array}{l}\text { Specifies incidents should } \\
\text { be investigated }\end{array}$ & $\begin{array}{l}\text { Specifies } \\
\text { incidents should } \\
\text { be investigated }\end{array}$ & $\begin{array}{l}\text { Specific incidents } \\
\text { should be } \\
\text { investigated }\end{array}$ & Not required \\
\hline $\begin{array}{l}\text { Initiate investigation as soon as } \\
\text { possible, but no later than } 48 \text { hours } \\
\text { after incident }\end{array}$ & Not specifically required & Required & Required & Required & Not required \\
\hline $\begin{array}{l}\text { Establish an investigation team with } \\
\text { at least one process expert and } \\
\text { personnel involved in incident }\end{array}$ & $\begin{array}{l}\text { Not specifically required. } \\
\text { Identify responsible } \\
\text { management positions for } \\
\text { investigation, recording, } \\
\text { reporting, and follow-up action } \\
\text { [Reg. Guide 3.52] }\end{array}$ & Required & Required & $\begin{array}{l}\text { Not specifically } \\
\text { required }\end{array}$ & Not required \\
\hline $\begin{array}{l}\text { Prepare detailed report of } \\
\text { investigation, including: } \\
\text { - date of incident } \\
\text { - date investigation began } \\
\text { - description of incident } \\
\text { - contributing factors } \\
\text { - recommendations }\end{array}$ & $\begin{array}{l}\text { Maintain records of unusual } \\
\text { operational incidents } \\
\text { [Reg. Guide 3.52] }\end{array}$ & Required & Required & Required & Not required \\
\hline $\begin{array}{l}\text { Promptly address and resolve report } \\
\text { findings and recommendations }\end{array}$ & $\begin{array}{l}\text { Describe system to ensure that } \\
\text { corrective action is taken [Reg. } \\
\text { Guide } 3.52 \text { ] }\end{array}$ & Required & Required & Required & Not required \\
\hline $\begin{array}{l}\text { Document resolutions and } \\
\text { corrective action }\end{array}$ & Not specified & Required & Required & Required & Not required \\
\hline $\begin{array}{l}\text { Review relevant report findings } \\
\text { with affected personnel }\end{array}$ & Not specified & Required & Required & Required & Not required \\
\hline Report retention time & Up to licensee to decide & Five years & Five years & Five years & Not required \\
\hline
\end{tabular}

1. Codified in 29 CFR 1910.119

2. Codified in 40 CFR Part 68. 


\section{C.12.4 Comparison of NRC, OSHA, and EPA Requirements}

EPA and OSHA have specified that the PSM system and program should be audited at least every three years. NRC, however, does not specify the frequency with which the hazardous chemical safety program should be audited. While EPA and OSHA require that two most recent audit reports be retained, NRC does not require the retention of previous audit reports. Table $\mathrm{C}$ - 11 gives a comparison of audits and inspections required by NRC, OSHA, and EPA. 


\begin{tabular}{|c|c|c|c|c|c|}
\hline \multirow[b]{2}{*}{ Training } & \multirow{2}{*}{$\begin{array}{c}\text { NRC Regulations and } \\
\text { Guidance }\end{array}$} & \multirow{2}{*}{$\begin{array}{c}\text { OSHA's Process } \\
\text { Safety Management } \\
\text { Program } \\
\end{array}$} & \multicolumn{3}{|c|}{ EPA's Risk Management Program² } \\
\hline & & & Program 3 & Program 2 & Program 1 \\
\hline $\begin{array}{l}\text { Periodic examination of } \\
\text { management systems and programs }\end{array}$ & $\begin{array}{l}\text { Expected } \\
\text { [Reg. Guide 3.55] }\end{array}$ & Required & Required & Required & Not required \\
\hline $\begin{array}{l}\text { Evaluate compliance every three } \\
\text { years }\end{array}$ & Not specifically required. & Required & Required & Required & Not required \\
\hline At least one expert & $\begin{array}{l}\text { Independent and unbiased } \\
\text { qualified personnel }\end{array}$ & Required & Required & Required & Not required \\
\hline $\begin{array}{l}\text { Report on audit with findings and } \\
\text { recommendations }\end{array}$ & Indicate level of management & Required & Required & Required & Not required \\
\hline $\begin{array}{l}\text { Document response to audit } \\
\text { findings }\end{array}$ & $\begin{array}{l}\text { Specify management system } \\
\text { responsible for audits and } \\
\text { inspections }\end{array}$ & Required & Required & Required & Not required \\
\hline Address deficiencies found by audit & $\begin{array}{l}\text { Identify management system } \\
\text { for following up on } \\
\text { deficiencies }\end{array}$ & Required & Required & Required & Not required \\
\hline Retain two most recent audit reports & Not specifically required. & Required & Required & Required & Not required \\
\hline
\end{tabular}

1. Codified in 29 CFR 1910.119.

2. Codified in 40 CFR Part 68. 


\section{C.13 References}

Center for Chemical Process Safety of the American Institute of Chemical Engineers (AIChE), Guidelines for Hazard Evaluation Procedures, Second Edition with Worked Examples, New York, New York, 1992.

Occupational Safety and Health Administration (OSHA), "Process Safety Management of Highly Hazardous Chemicals; Explosives and Blasting Agents (29 CFR Part 1910)," Federal Register, Vol. 57, No. 36, pp. 6356-6417, February 24, 1992.

U.S. Environmental Protection Agency (USEPA), "Accidental Release Prevention Requirements: Risk Management Program Under the Clean Air Act, Section 112(r)(7); List of Regulated Substances and Thresholds for Accidental Release Prevention, Stay of Effectiveness; and Accidental Release Prevention Requirements: Risk Management Programs Under Section 112(r)(7) of the Clean Air Act as Amended, Guidelines; Final Rules and Notice (40 CFR Part 68)," Federal Register, Vol. 61, No. 120, pp. 3166731730, June 20, 1996.

U.S. Nuclear Regulatory Commission (USNRC), "Emergency Planning for Fuel Cycle Facilities and Plants Licensed Under 10 CFR Parts 50 and 70," Revision 1 to Regulatory Guide 3.42, Washington, D.C., 1979.

U.S. Nuclear Regulatory Commission (USNRC), "Compilation of Reporting Requirements for Persons Subject to NRC Regulations," Revision 4 to Regulatory Guide 10.1, Washington, D.C., 1981.

U.S. Nuclear Regulatory Commission (USNRC), "Standard Format and Content for the Health and Safety Sections of License Renewal Applications for Uranium Hexafluoride Production," Regulatory Guide 3.55, Washington, D.C., 1985.

U.S. Nuclear Regulatory Commission (USNRC), "Standard Format and Content for the Health and Safety Sections of License Renewal Applications for Uranium Processing and Fuel Fabrication," Revision 1 to Regulatory Guide 3.52, Washington, D.C., 1986.

U.S. Nuclear Regulatory Commission and the Occupational Safety and Health Administration (USNRC and OSHA), "Memorandum of Understanding Between the Nuclear Regulatory Commission and the Occupational Safety and Health Administration; Worker Protection at NRC-licensed Facilities," Federal Register, Vol. 53, No. 210, pp. 43950-43952, October 31, 1988.

U.S. Nuclear Regulatory Commission (USNRC), "Guidance on Management Controls/Quality Assurance, Requirements for Operation, Chemical Safety, and Fire Protection for Fuel Cycle Facilities (10 CFR Parts 70.22 and 70.23)," Federal Register, Vol. 54, No. 53, pp. 11590-11598, March 21, 1989.

U.S. Nuclear Regulatory Commission (USNRC), "Standard Format and Content for Emergency Plans for Fuel Cycle and Materials Facilities," Regulatory Guide 3.67, Washington, D.C., 1992.

U.S. Nuclear Regulatory Commission (USNRC), "Integrated Safety Analysis Guidance Document," NUREG-1513 (Draft), Washington, D.C., 1995. 
APPENDIX D

SAMPLE PROBLEMS 


\section{APPENDIX D \\ TABLE OF CONTENTS}

\section{APPENDIX D: SAMPLE PROBLEMS}

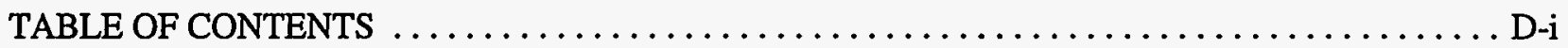

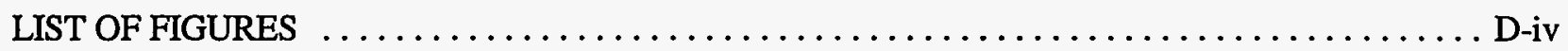

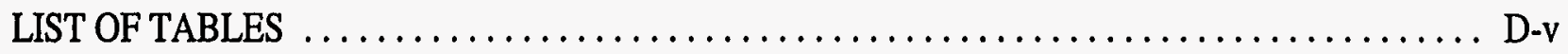

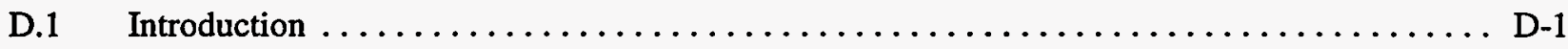

D.2 Sample Problem 1: Free-Fall Spill of Powder $\ldots \ldots \ldots \ldots \ldots \ldots \ldots \ldots \ldots \ldots \ldots \ldots \ldots \ldots \ldots \ldots \ldots$

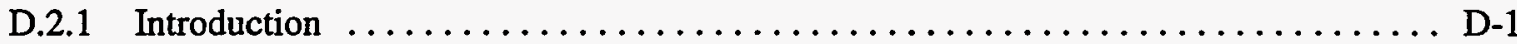

D.2.2 Example 1 - Free-Fall Spill of Powder Within Experimental Data Limits ....... D-4

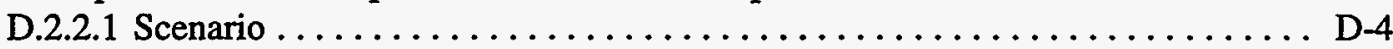

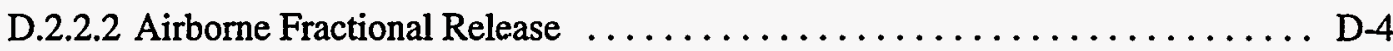

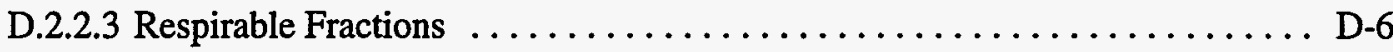

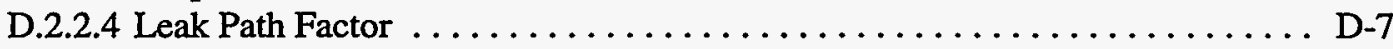

D.2.2.5 Building Source Term ...................... D 12

D.2.3 Example 2 - Free-Fall Spill of Powder Over a Fall Distance Greater than the

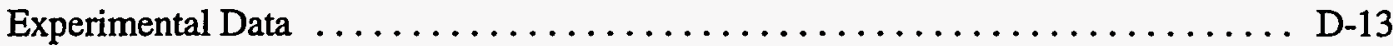

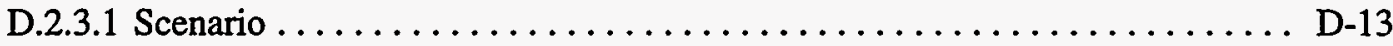

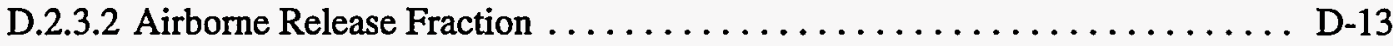

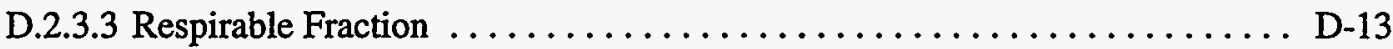

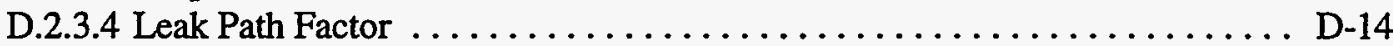

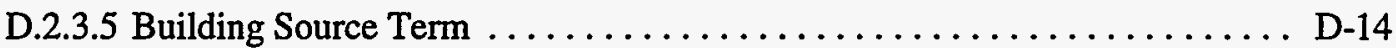

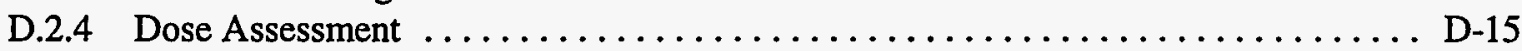

D.2.4.1 Choice of Dispersion Model . . . . . . . . . . . . . . . D 15

D.2.4.2 Example Problem Parameters for Atmospheric Dispersion .......... D-16

D.2.4.3 Example Atmospheric Dispersion Problems ................ D-17

D.3 Sample Problem 2: Explosion with Radioactive Release $\ldots \ldots \ldots \ldots \ldots \ldots \ldots \ldots \ldots \ldots$ D-21

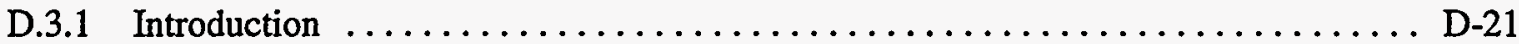

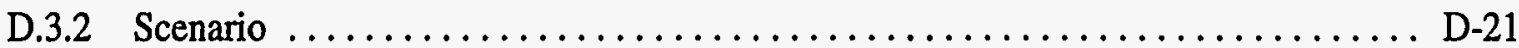

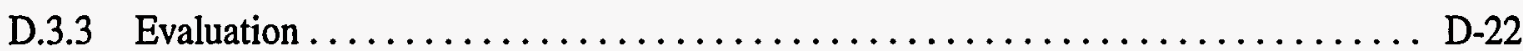

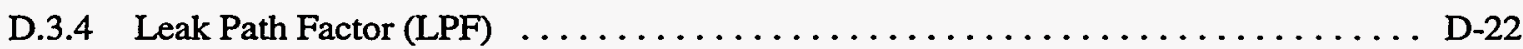

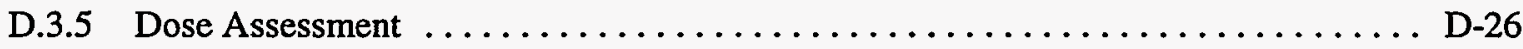

D.3.5.1 Choice of Dispersion Model . . . . . . . . . . . . . . . . D-26

D.3.5.2 Example Problem Parameters for Atmospheric Dispersion ........... D-27

D.3.5.3 Example Atmospheric Dispersion Problems ................. D-28

D.4 Sample Problem 3: Fire with Radioactive Release $\ldots \ldots \ldots \ldots \ldots \ldots \ldots \ldots \ldots \ldots \ldots \ldots$ D-30

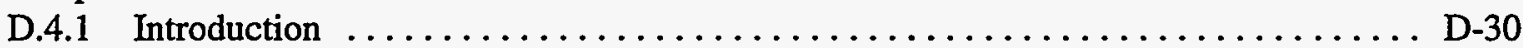

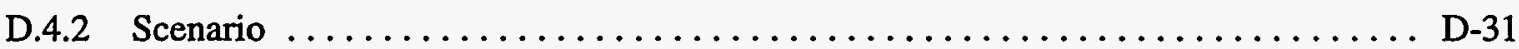




\section{APPENDIX D TABLE OF CONTENTS (Continued)}

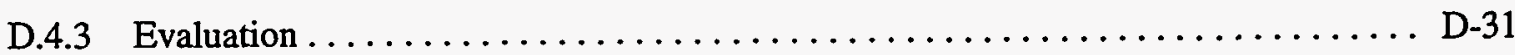

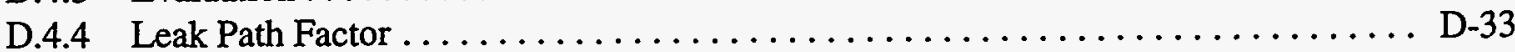

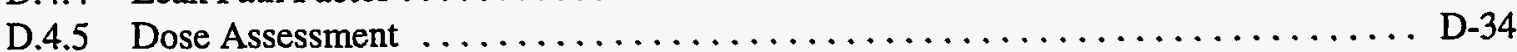

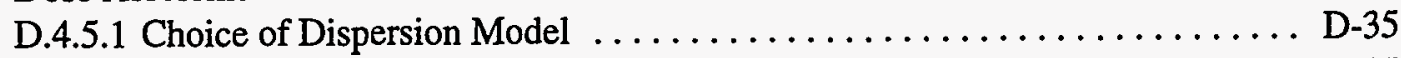

D.4.5.2 Example Problem Parameters for Atmospheric Dispersion .......... D-35

D.4.5.3 Example Atmospheric Dispersion Problems ............... D -36

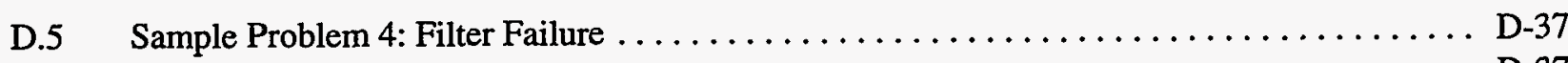

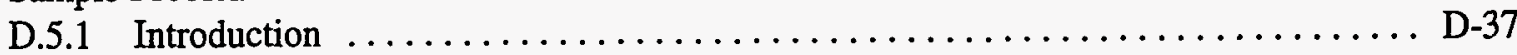

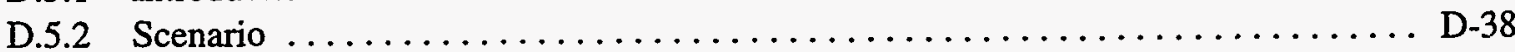

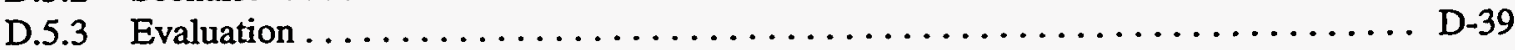

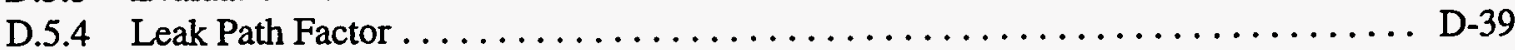

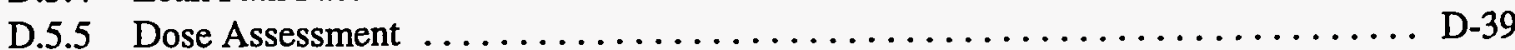

D.5.5.1 Choice of Dispersion Model ...................... D-39

D.5.5.2 Example Problem Parameters for Atmospheric Dispersion ......... D 40

D.5.5.3 Example Atmospheric Dispersion Problems .............. D 40

D.6 Sample Problem 5: Hydrogen Fluoride Release from a Tankcar ............. D-42

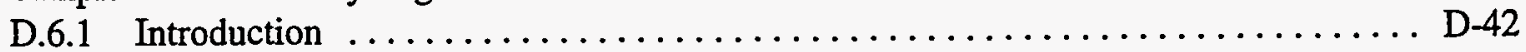

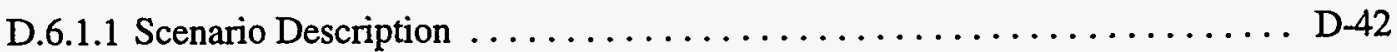

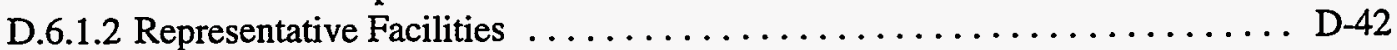

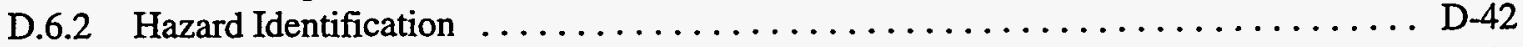

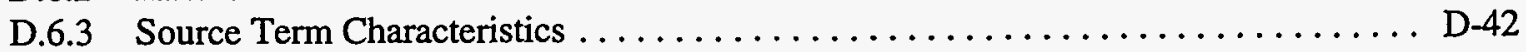

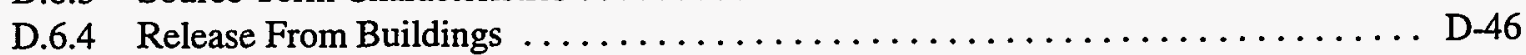

D.6.5 Atmospheric Dispersion and Consequence Modeling ................ D-49

D.6.5.1 Choice of Dispersion Models . . . . . . . . . . . . . . . D 49

D.6.5.2 Health Effect Model . . . . . . . . . . . . . . . . . . . D -50

D.6.5.3 Prediction of Distances to Toxic Endpoints ................ D-51

D.6.5.4 Uncertainties in the Dispersion Analyses ................ D -53

D.7 Sample Problem 6: Uranium Hexafluoride Liquid $\left(>70^{\circ} \mathrm{C}\right)$ Cylinder Rupture $\ldots \ldots \ldots$ D-53

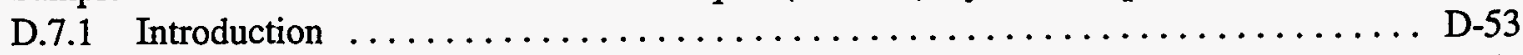

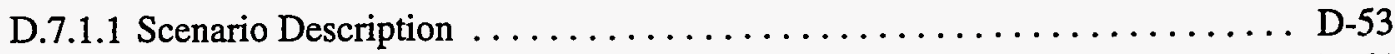

D.7.1.2 Facilities Where Possible . . . . . . . . . . . . . . . . . .

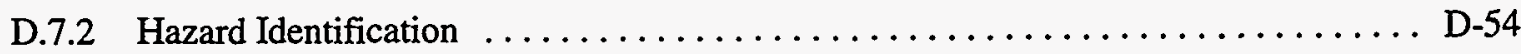

D.7.3 Determination of Source Term Characteristics $\ldots \ldots \ldots \ldots \ldots \ldots \ldots \ldots \ldots$ D-54

D.7.3.1 Scenario 1 - Catastrophic Cylinder Rupture Resulting In

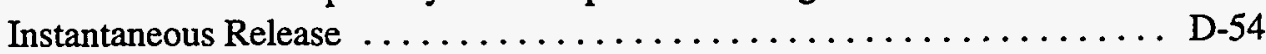

D.7.3.2 Scenario 2A - Small Hole ( $5 \mathrm{~cm}$ ( 2 in) Diameter) Below Liquid Level Resulting in a Continuous Flashing Jet Release . . . . D-59

D.7.3.3 Scenario 2B - Small Hole (5 cm (2 in) Diameter) Above

Liquid Level Resulting in a Continuous Vapor Release .......... D-63

D.7.3.4 Summary of Source Terms $\ldots \ldots \ldots \ldots \ldots \ldots \ldots \ldots \ldots \ldots \ldots \ldots \ldots$ 


\section{APPENDIX D \\ TABLE OF CONTENTS \\ (Continued)}

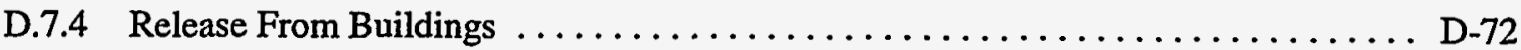

D.7.5 Atmospheric Dispersion And Consequence Modeling $\ldots \ldots \ldots \ldots \ldots \ldots \ldots$ D-72

D.7.5.1 Choice of Dispersion Models ..................... D-72

D.7.5.2 Choice of Appropriate Health Effects Models .............. D-74

D.7.5.3 Prediction of Affected Distances ...................... D-75

D.7.5.4 Discussion of Results ....................... D -75

D.8 Sample Problem 7: Liquid Spill in Vitrification Plant $\ldots \ldots \ldots \ldots \ldots \ldots \ldots \ldots \ldots$ D-78

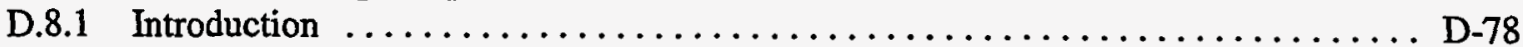

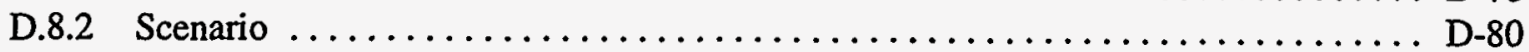

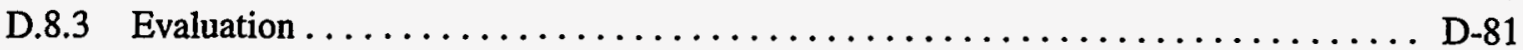

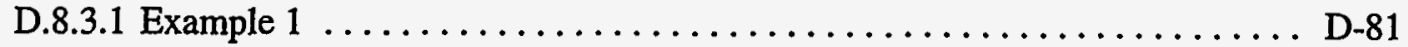

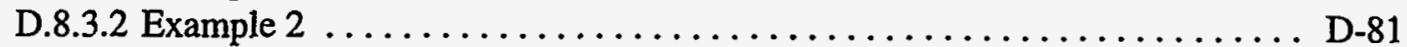

D.8.4 Leak Path Factor . . . . . . . . . . . . . . . . . . . . . . . . D

D.8.5 Dose Assessment ................................ D

D.8.5.1 Example Problem Assumptions for Atmospheric Dispersion . . . . . . . . D-82

D.8.5.2 Choice of a Dispersion Model ...................... D-83

D.8.5.3 Evaluation Results ......................... D-86

D.9 Sample Problem 8: Criticality Incident $\ldots \ldots \ldots \ldots \ldots \ldots \ldots \ldots \ldots \ldots \ldots \ldots \ldots \ldots$

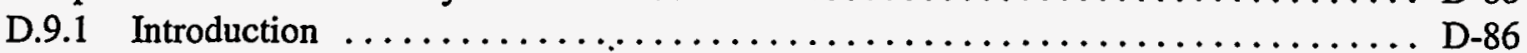

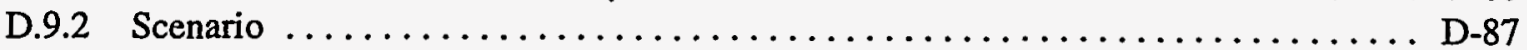

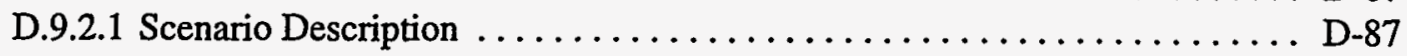

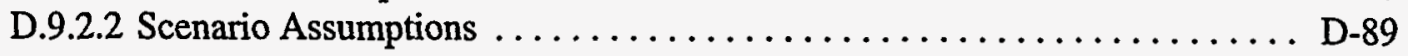

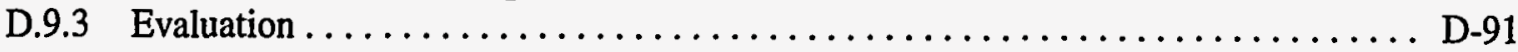

D.9.3.1 Prompt Radiation Estimates ...................... D-92

D.9.3.2 Dose Due to Aerosol Estimates ..................... D-93

D.9.3.3 Dose From the Release of Noble Gases and Iodine ............ D-94

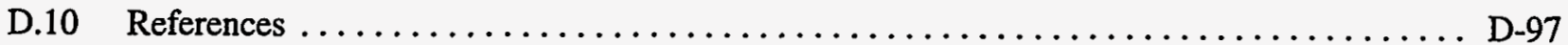




\section{APPENDIX D LIST OF FIGURES}

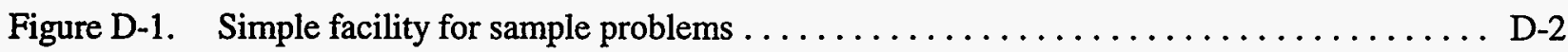

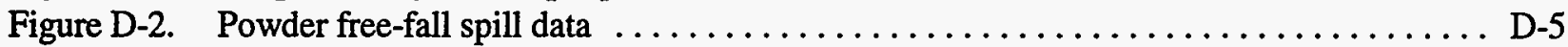

Figure D-3. Leak path factor (LPF) versus respirable fraction $(\mathrm{RF})$ for enclosures $\ldots \ldots \ldots \ldots \ldots$ D-10

Figure D-4. Leak path factor (LPF) versus respirable fraction (RF) for ducts $\ldots \ldots \ldots \ldots \ldots \ldots$ D-11

Figure D-5. HF pool evaporation rate as a function of pool temperature and pool area-windspeed

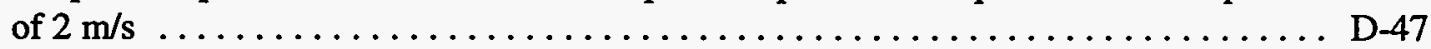

Figure D-6. HF pool evaporation rate as a function of pool temperature and pool

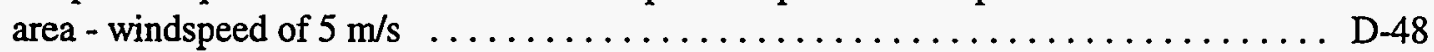

Figure D-7. HF pool evaporation - distance to ERPG-2 $(20 \mathrm{ppm}) \ldots \ldots \ldots \ldots \ldots \ldots \ldots \ldots$ D-52

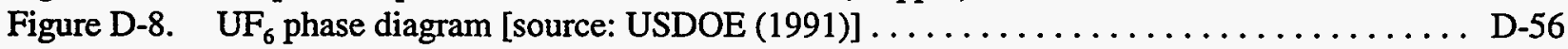

Figure D-9. Dependence of flash percentage, $f$, on storage temperature, $T_{i} \ldots \ldots \ldots \ldots \ldots \ldots$ D-58

Figure D-10. Model $48 \mathrm{Y}$ normally filled $\mathrm{UF}_{6}$ cylinder $\ldots \ldots \ldots \ldots \ldots \ldots \ldots \ldots \ldots \ldots \ldots \ldots \ldots$ 


\section{APPENDIX D LIST OF TABLES}

Table D-1. LPFs versus RF Values for Enclosures $\ldots \ldots \ldots \ldots \ldots \ldots \ldots \ldots \ldots \ldots \ldots \ldots \ldots$

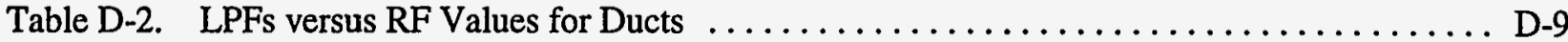

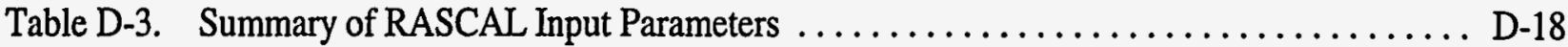

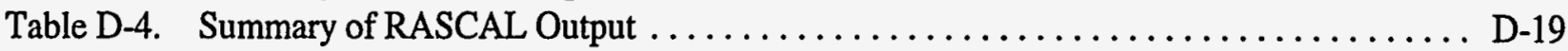

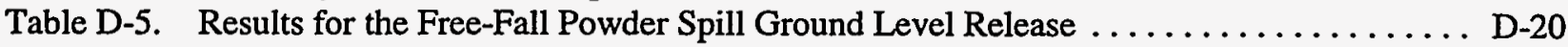

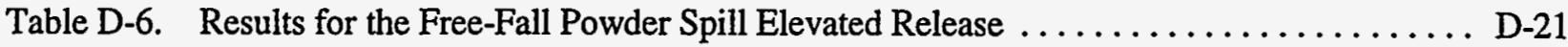

Table D-7. LPFs for Series Room and Duct $(\mathrm{Q} / \mathrm{A}(\mathrm{room})=0.1 \mathrm{~m} / \mathrm{s}) \ldots \ldots \ldots \ldots \ldots \ldots \ldots \ldots \ldots$

Table D-8. LPFs for Series Room and Duct $(\mathrm{Q} / \mathrm{A}(\mathrm{room})=0.01 \mathrm{~m} / \mathrm{s}) \ldots \ldots \ldots \ldots \ldots \ldots \ldots \ldots$

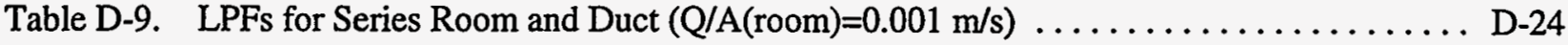

Table D-10. LPFs for Series Room and Duct $(\mathrm{Q} / \mathrm{A}(\mathrm{room})=0.0001 \mathrm{~m} / \mathrm{s}) \ldots \ldots \ldots \ldots \ldots \ldots \ldots$. . . . . . .

Table D-11. LPFs for Series Room and Duct $(\mathrm{Q} / \mathrm{A}(\mathrm{room})=0.00001 \mathrm{~m} / \mathrm{s}) \ldots \ldots \ldots \ldots \ldots \ldots \ldots$. . . . . . . .

Table D-12. LPFs for Series Room and Duct $\left(\mathrm{Q} / \mathrm{A}(\mathrm{room})=10^{-6} \mathrm{~m} / \mathrm{s}\right) \ldots \ldots \ldots \ldots \ldots \ldots \ldots \ldots$. . . . . . . . . .

Table D-13. HOTSPOT Example Input Summary and Output $\ldots \ldots \ldots \ldots \ldots \ldots \ldots \ldots$ D-29

Table D-14. Results for the Explosion Ground Level Release . . . . . . . . . . . . . . . . . . D-29

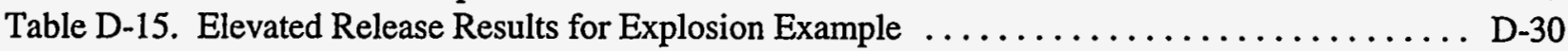

Table D-16. Summary of Fire Event Combined Room/Duct LPFs $\ldots \ldots \ldots \ldots \ldots \ldots \ldots \ldots$ D-34

Table D-17. Results for the Fire Example Ground Level Release (No Building Wake) ......... D-37

Table D-18. Consequences from an Elevated Release ........................ D-37

Table D-19. Results for the Filter Failure Example Ground Level Release $\ldots \ldots \ldots \ldots \ldots \ldots$ D-41

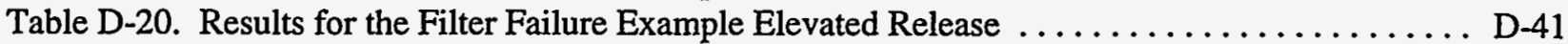

Table D-21. Dependence of Flash Fraction, $f$, on Initial Storage Temperature $\ldots \ldots \ldots \ldots \ldots \ldots$ D-57

Table D-22. Source Term Characteristics Following Puff Release of $\mathrm{UF}_{6}$ (Scenario 1) ........ D-60

Table D-23. Source Term Characteristics of a Liquid Jet through a $5 \mathrm{~cm}(2 \mathrm{in})$ Hole in a

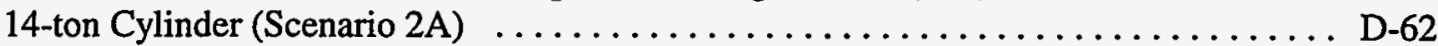

Table D-24. Source Term Characteristics of a $U_{6}$ Vapor Jet through a $5 \mathrm{~cm}(2 \mathrm{in})$ Diameter

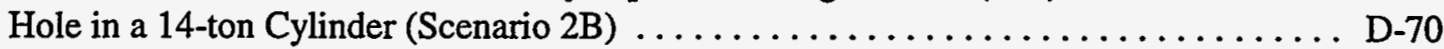

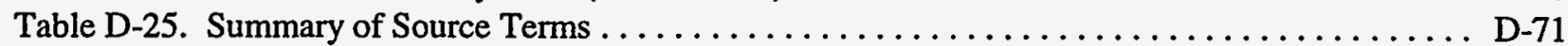

Table D-26. Affected Distances (meters) - Rural Terrain $\ldots \ldots \ldots \ldots \ldots \ldots \ldots \ldots \ldots \ldots \ldots$ D-76

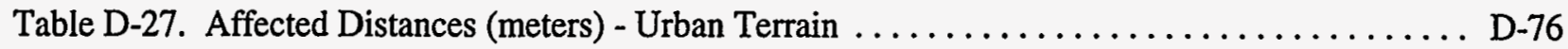

Table D-28. Median and Bounding ARF/RF Values for Aqueous Solutions, Slurries, and Viscous Solutions for Spills with Arch $_{2}<1.6 \mathrm{E} 8 \ldots \ldots \ldots \ldots \ldots \ldots \ldots \ldots \ldots \ldots \ldots \ldots \ldots$

Table D-29. Hanford Waste Vitrification Plant Reference Feed Maximum Radionuclide Composition ............................... D 84

Table D-30. West Valley Vitrification Plant Key Radionuclides for a Concentrated Feed Make-Up Tank (CFMT) Spill . . . . . . . . . . . . . . . . . . . . D 85

Table D-31. Results for the Vitrification Plant Elevated $(60 \mathrm{~m}) 1 \mathrm{~cm}^{3}$ Release ............. D-86

Table D-32. Subcritical Limits for Uniform Aqueous Solutions of Low-Enriched Uranium . . . . . . D 88

Table D-33. Prompt Radiation Dose from $10^{18}$ Fissions, From a Moderated Criticality Accident .... D-92

Table D-34. Results for the Release of Uranium Particulate from a UNH Solution Criticality . . . . . D-93

Table D-35. Downwind Concentration of Uranium $\ldots \ldots \ldots \ldots \ldots \ldots \ldots \ldots \ldots \ldots \ldots \ldots \ldots$

Table D-36. RASCAL Output for the Release of Noble Gases and Iodine Particulates

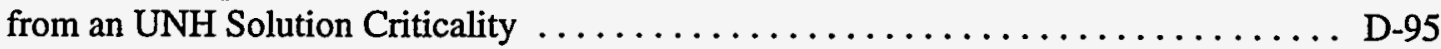




\title{
APPENDIX D \\ SAMPLE PROBLEMS
}

\section{D.1 Introduction}

The present work contains eight sample problems:

\author{
Section D.2 - Free-Fall Spill of Powder \\ Section D.3 - Explosion with Radioactive Release \\ Section D.4 - Fire with Radioactive Release \\ Section D.5 - Filter Failure \\ Section D.6 - HF Release from a Tankcar \\ Section D.7 - UF 6 Cylinder Rupture \\ Section D.8 - Liquid Spill in Vitrification Plant \\ Section D.9 - Criticality Incident
}

So far as is possible, the sections on the sample problems cover the same spectrum of issues. There is material that describes the scenario that is being analyzed, together with how it would have been identified. There is a description of how the characteristics of the source term are estimated, including such quantities as the total amount released, the rate of release, the duration of release, the density, the momentum flux, etc. Where relevant, there is also discussion about the transport of gases and aerosols through buildings. For this purpose, a "standard building" has been defined (see Figure D-1). This building consists of a ventilation inlet into a room having an attached smaller room (e.g., a glove box), exhaust ducting to a manifold, and, finally, a stack. This is a simple configuration that nevertheless illustrates many of the phenomena that control transport and deposition in buildings. There is further discussion of atmospheric dispersion models--the reasons for their choice and how they are used. There is a concluding Subsection that contains references.

Finally, each of the Subsections contains material that discusses uncertainties. This is a matter of significant importance. In some instances, uncertainty is addressed by taking conservative values of input parameters (i.e., parameters that will lead to higher, rather than lower, estimates of calculated dose or airborne concentration). In other cases, sensitivity studies are performed. In general, however, the question of uncertainty is addressed qualitatively. See Appendix G for further discussions on uncertainty.

\section{D.2 Sample Problem 1: Free-Fall Spill of Powder}

\section{D.2.1 Introduction}

Powders are a collection of small solid particles, usually of many different sizes and shapes, held together by weak cohesion forces. Powders of radioactive material are handled and processed in a variety of non-reactor, non-medical nuclear facilities. Powder particles, both individual and smaller aggregates, can be separated and become airborne through events ranging from spills to explosions. One of the simplest and least energetic stresses that can be imposed upon powders is the free-fall spill. This initiating event results in the powder falling as a coherent body that acts as a single entity, referred to as a slug, through the air or gas. As the slug of powder falls, its forward face is impacted by the air and is continuously made more dispersed; particles at the sides of the "slug" are subject to shear stress that can entrain the material; and the region of lesser pressure induced on the rear face by the flow around the "slug" can also induce particle 


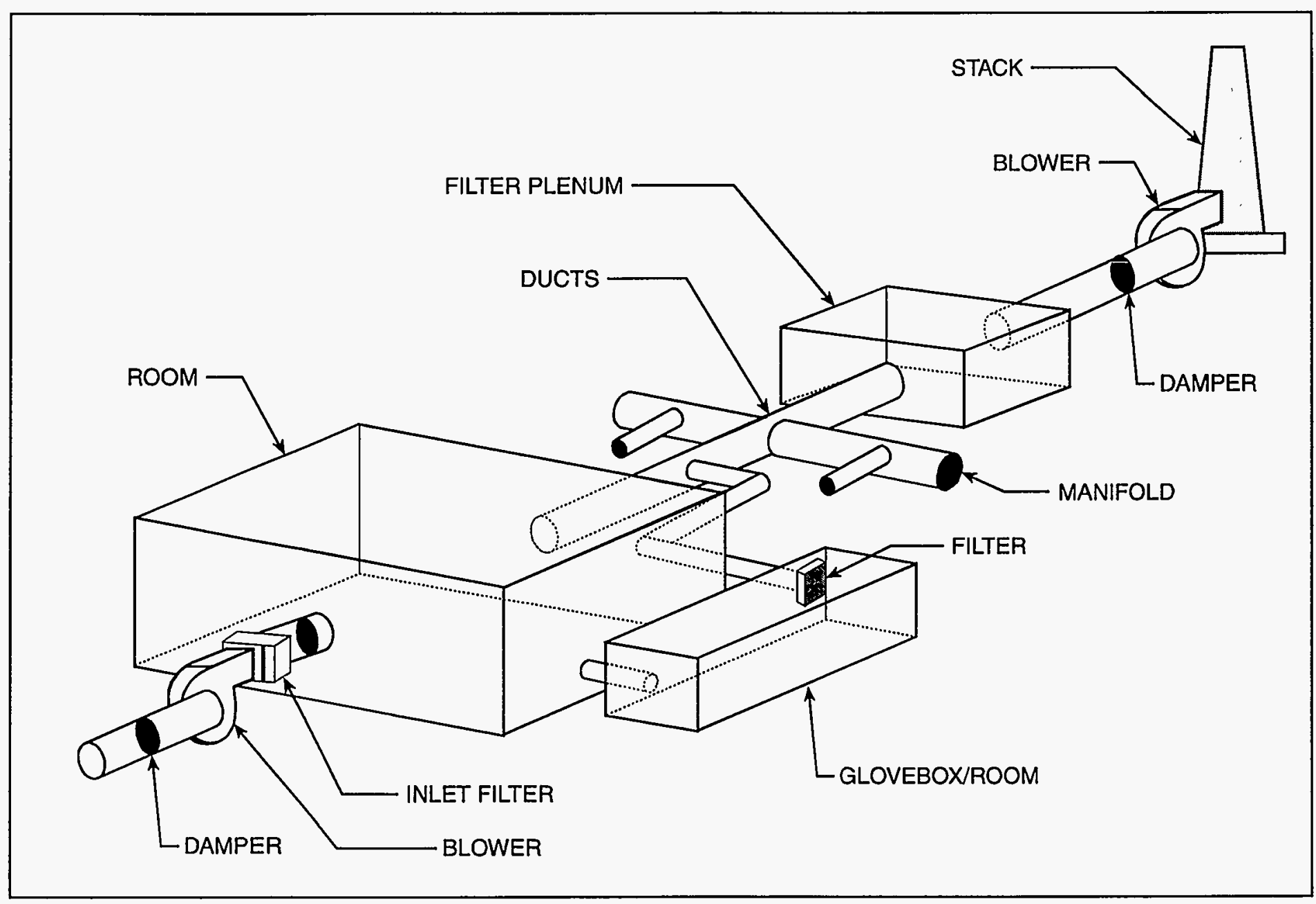

Figure D-1. Simple facility for sample problems 
entrainment. For short fall distances, the dominant cause of dispersion appears to be impact upon a hard, unyielding surface. As the fall distances increase, the mechanisms that result in greater dispersion of the mass tend to increase in importance, and correlation of the experimentally measured values for Airborne Fractional Release (ARF) and Respirable Fraction (RF) should be viewed with caution. The underlying assumption in this sample problem is that the powder is released as a slug and not a highly-dispersed mass.

The scenario postulated is the elevated release of uranium dioxide $\left(\mathrm{UO}_{2}\right)$ powder used in a dry process fuel fabrication plant producing commercial light-water-reactor (LWR) fuel, resulting in the free-fall spill with impact of the powder on a hard, unyielding surface. Such powders are transported and handled in a container or under confinement. The powder could be released from the confinement by various mechanisms that result in release via openings in the confinement. During the conveyance or transfer of the powder in a fuel cycle facility, spills could occur. Typical spills could result in a free-fall distance of 1 to 3 meters ( 3 to $10 \mathrm{ft}$ ) from a process enclosure into a room or directly into the exhaust duct system, or $10 \mathrm{~m}$ (30 ft) from an overhead conveyor into a fairly large room. The exact location and configuration of the release varies with the specific facility. The mass of powder spilled may range from $<5 \mathrm{~kg}(11 \mathrm{lb})$ to $>1000 \mathrm{~kg}(2200 \mathrm{lb})$. For the purposes of these illustrative examples, the potential airborne release, transport within the facility to the facilityatmosphere interface, and the atmospheric transport to the receptor will be illustrated. Two levels of analysis will be covered: Example 1 is a simple event that allows the use of either the experimentally measured "bounding" airborne release values or the empirical correlation to the experimental data; Example 2 postulates an event that exceeds the fall distance parameter for the experimentally measured data and requires an extrapolation of the empirical correlation.

The amount of $\mathrm{UO}_{2}$ escaping the facility is calculated by use of the five factor formula:

$$
\text { Building Source Term }=[\mathrm{MAR}][\mathrm{DR}][\mathrm{ARF}][\mathrm{RF}][\mathrm{LPF}]
$$

where:

MAR = Material-at-Risk, the amount of material that could potentially be affected by the event.

$\mathrm{DR}=$ Damage Ratio, the fraction of the MAR that is actually impacted for the specific event under consideration.

$\mathrm{ARF}=$ Airborne Release Fraction, the fraction of the [MAR][DR] that is made airborne as a consequence of the type and level of stress imposed by the event.

$\mathrm{RF}=$ Respirable Fraction, the fraction of the [MAR][RF][ARF] that is composed of particulate material (solid and/or liquid) that can be transported to and taken into the deep lung of the receptor. The RF is typically assumed to be composed of particles 10 micrometer AED (Aerodynamic Equivalent Diameter, the diameter of a sphere of material with a density of 1 $\mathrm{g} / \mathrm{cm}^{3}$ with the same terminal velocity as the particle), or less.

$\mathrm{LPF}=$ Leak Path Factor, the amount of the [MAR][DR][ARF][RF] that can be transported from the point of origin to some other location. In the examples illustrated here, the LPF is that associated with transport of the RF through the building-atmosphere interface. Other LPFs may be used for other purposes, such as from the point of origin in an enclosure to the operating areas around the enclosure. 


\section{D.2.2 Example 1 - Free-Fall Spill of Powder Within Experimental Data Limits D.2.2.1 Scenario}

The scenario postulated for this example is the free-fall spill of $5 \mathrm{~kg}(11 \mathrm{lb})$ of uranium dioxide $\left(\mathrm{UO}_{2}\right)$ powder held in a container $2 \mathrm{~m}(6.6 \mathrm{ft})$ from a process enclosure onto the floor of the operating area. The starting point for this calculation is that:

- The MAR is $5 \mathrm{~kg}(11 \mathrm{lb})$

- The DR is 1.0 (the entire MAR is lost in this event).

Values necessary for estimating the amount of material released from the facility-atmosphere interface are:

- The ARF

- The RF

- The LPF

- The height at which the material is released to the atmosphere.

\section{D.2.2.2 Airborne Fractional Release}

The ARFs and RFs for the free-fall spill of 100 to $1000 \mathrm{~g}(0.22$ to $2.2 \mathrm{lb})$ slugs of DUO (depleted uranium dioxide) and $\mathrm{TiO}_{2}$ (titanium oxide) powder for fall distances of 1 to $3 \mathrm{~m}$ ( 3 to $10 \mathrm{ft}$ ) have been experimentally measured (Sutter et al. 1981). The maximum values measured for a $3 \mathrm{~m}$ (10 ft) fall distance are an ARF of $2 \mathrm{E}-3$ and an RF of 0.3 . These values could be applied as bounding values for the free-fall of a powder slug for distances less than the maximum value.

Alternatively, a more precise value for the ARF could be derived using the empirical correlation to the experimental values shown in Figure D-2 within the range of experimental parameters of fall distance and powder characteristics. The basis for the correlation shown is reported in Ballinger et al. (1988) and is a function of the quantity (DN):

$$
\mathrm{DN}=\left[\mathrm{M}^{0.125}\right]\left[\mathrm{H}^{2.37}\right] /\left[\mathrm{BD}_{\mathrm{p}}{ }^{1.02}\right]
$$

where:

$$
\begin{aligned}
& \mathrm{M}=\text { mass of powder spilled, } \mathrm{kg} \\
& \mathrm{H}=\text { fall distance, } \mathrm{m} \\
& \mathrm{BD}_{\mathrm{p}}=\text { bulk density of powder, } \mathrm{kg} / \mathrm{m}^{3}
\end{aligned}
$$

As shown, $\mathrm{DN}$ is a strong function of the fall distance and is a limited function of the total energy of impact and the degree of powder dispersion (how much void space exists between individual particles). To illustrate, the bulk density of $\mathrm{UO}_{2}$ powder is typically about $3000 \mathrm{~kg} / \mathrm{m}^{3}\left(187 \mathrm{lb} / \mathrm{ft}^{3}\right)$, whereas the fundamental particle density of $\mathrm{UO}_{2}$ is $10960 \mathrm{~kg} / \mathrm{m}^{3}\left(683 \mathrm{lb} / \mathrm{ft}^{3}\right)$.

Through modeling and data regression analysis of the data, two lines are shown in Figure D-2-Best Fit ARF vs. DN and an Upper Bound ARF vs. DN. For the median ARF value, the ARF is:

$$
\mathrm{ARF}_{\mathrm{BF}}=0.1064[\mathrm{DN}]
$$




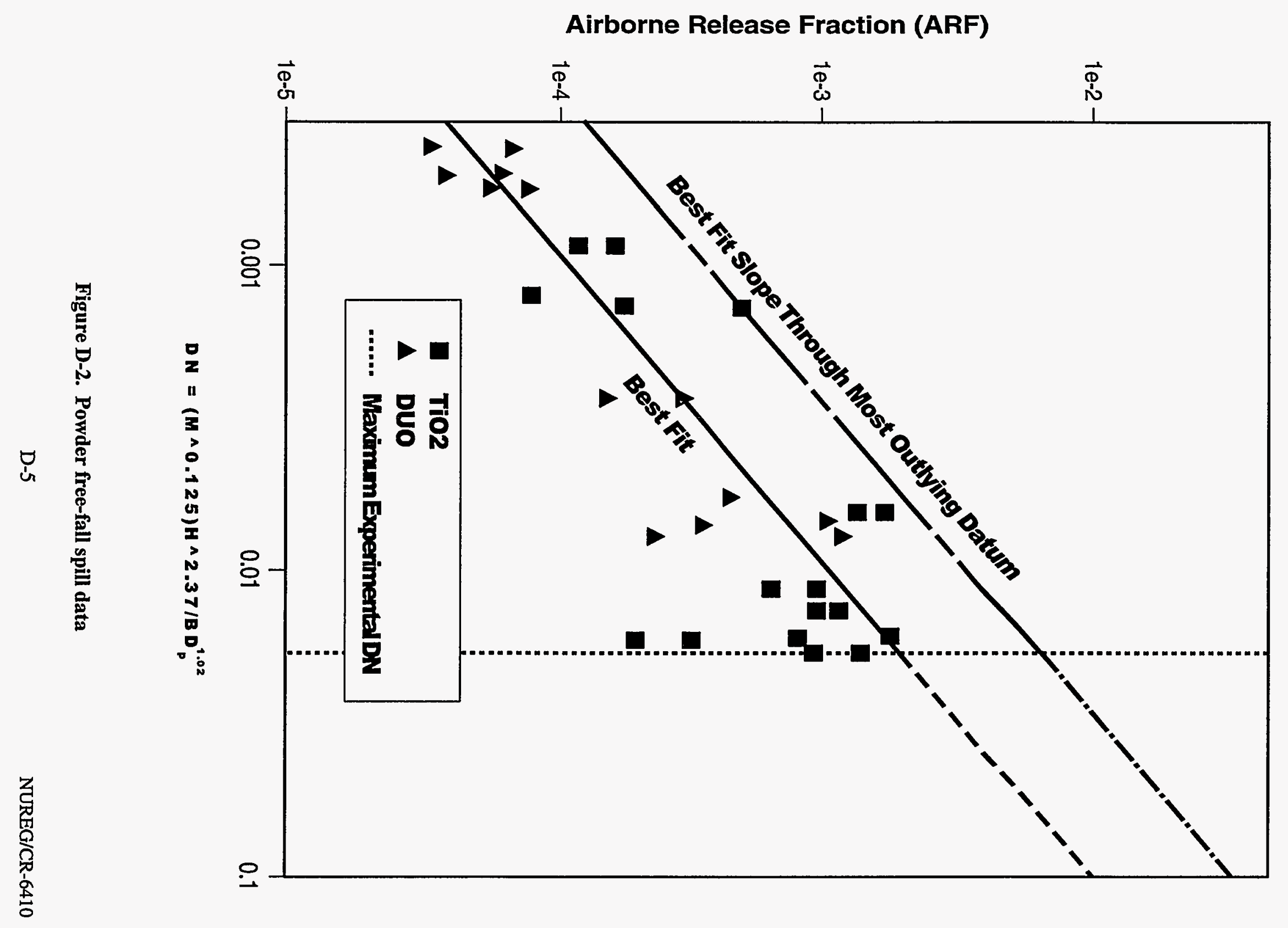


For the Upper Bound value, ARF is:

$$
\mathrm{ARF}_{\mathrm{UB}}=0.3573[\mathrm{DN}]
$$

These equations are intended for use at $298 \mathrm{~K}\left(76^{\circ} \mathrm{F}\right)$ and $101.1 \mathrm{kPa}(14.67 \mathrm{psia})$. Significant variations exceeding $10 \mathrm{~K}\left(18^{\circ} \mathrm{F}\right)$ and $10 \mathrm{kPa}(7 \mathrm{psia})$ would require correction.

For the event postulated, a $2 \mathrm{~m}(6.6 \mathrm{ft})$ fall of $5 \mathrm{~kg}(11 \mathrm{lb})$ of $\mathrm{UO}_{2}$, the $\mathrm{DN}$ is:

$$
\begin{aligned}
\mathrm{DN} & =\left[5^{0.125}\right]\left[2^{2.237}\right] /\left[3000^{1.02}\right] \\
& =0.0018
\end{aligned}
$$

and the Best Fit ARF is:

$$
\begin{aligned}
\mathrm{ARF}_{\mathrm{BF}} & =0.1064[0.0018] \\
& =2 \mathrm{E}-4
\end{aligned}
$$

The Upper Bound ARF is:

$$
\begin{aligned}
\mathrm{ARF}_{\mathrm{UB}} & =0.3573[0.0018] \\
& =6 \mathrm{E}-4
\end{aligned}
$$

For the purpose of these analyses, the bounding value for the experimental data set, $2 \mathrm{E}-3$, is selected. The $A R F$ selected is a factor of 3.3 greater than $A R F_{U B}$ and a factor of 10 greater than the $A R F_{B F}$, with a resultant dose that is larger by the same amounts. This factor of 10 represents the range of uncertainty arising from the characterization of the source term. See Section 3.3.4 for further information on spill of powders.

\section{D.2.2.3 Respirable Fractions}

For the bounding values measured experimentally, the corresponding measured value, $R F=0.3$, can be applied.

As noted above, there are several options available for estimates of the ARF. If the best fit ARF is selected, the median RF for ARFs in this release range may be applied. Inspection of the experimental data for DUO indicates the Best Fit ARF calculated, above, 2E-4, corresponds to the third-highest of thirteen DUO ARF values measured and is, therefore, a median value for this experimental set. The RF measured at this level is 0.25 , and rounding the value results in an RF of 0.3 that is the same RF value for the "bounding" measured value for a 3-m (10-ft) fall distance.

A more conservative approach would be to assume that all of the particles in the respirable size range of the source powder are made airborne. If the particle size distribution of the spilled powder is available, the RF can be limited to the mass of the particles in the 10 micrometers $\left(4.0 \times 10^{-4}\right.$ in) AED and less range (the mass of the powder in the $[A R F][R F]$ will not exceed the mass of respirable particles present in the source powder because the forces generated in free-fall spills are generally not sufficient to fragment the particles further). As an example, if the RF in the source powder is 0.001 and the estimated ARF is 5E-3 (0.005), the RF assumed for the event would be 0.2 (i.e., 0.001/0.005). 
In the absence of any data, the most conservative approach is to assume that all the particles made airborne are in the respirable size range $(R F=1.0)$. However, since the maximum experimentally measured $A R F$ was selected for the purposes of these analyses, the RF associated with that value, 0.3 , is selected.

\section{D.2.2.4 Leak Path Factor}

A schematic diagram of the reference facility is shown in Figure D-1. The facility configuration consists of a ventilation flow into a room having an attached smaller room (e.g., a glove box room), exhaust ducting to a manifold, and a stack. The event is postulated to occur in a room that is $7-\mathrm{m}(23-\mathrm{ft})$ wide by $10-\mathrm{m}$ (33-ft) long by 3-m (10-ft) high. Ventilation flow remains normal during this event at 10 air changes per hour (ach), and the room temperature is maintained at $298 \mathrm{~K}\left(76^{\circ} \mathrm{F}\right)$. Air pressure in the room is $101.1 \mathrm{kPa}$ (14.67 psia). The exhaust outlet ducting from the smaller room has dimensions of $0.6 \mathrm{~m}(2 \mathrm{ft})$ by $0.6 \mathrm{~m} \mathrm{(2}$ $\mathrm{ft})$, traveling $15 \mathrm{~m}(50 \mathrm{ft}$ ) before entering a manifold that merges the flow with exhaust from other areas with a volumetric flow 10 times greater than the exhaust flow from the smaller room. The exhaust from the manifold travels an additional $21 \mathrm{~m}(70 \mathrm{ft})$ before entering a filter plenum and travels an additional $30 \mathrm{~m}$ $(\sim 100 \mathrm{ft})$ to a $60 \mathrm{~m}(200 \mathrm{ft})$ high stack. The flow beyond the first duct is ignored in this calculation. The additional duct length would further reduce the mass of particles released to the atmosphere, as would the filter particle collection efficiency.

The fraction of the airborne particles in the respirable size range ([MAR][DR][ARF][RF]) that is carried by the ventilation-exhaust flow to the facility-atmosphere interface is modeled as a function of the flowrate and the area of upward-facing surfaces. Under the assumptions of the model, the particles are assumed to be lognormally distributed with a Geometric Standard Deviation (GSD) of 2 (a value often found in nuclear industry powders [Pinkston 1993]).

For steady-state flow, the transport through rooms and ducts is calculated using the LPF \#1 code (Pinkston 1993). The room is assumed to be as a single, well-mixed volume, and airborne particles in the respirable size range are extracted with time and injected into the exhaust system. The exhaust ducting transport is modeled as plug flow. The particles are assumed perfectly mixed in a vertical direction for each cell. Gravitational settling is the only depletion mechanism included and is integrated over the entire period required to transport all of the material through the system. Since gravitational settling is the only depletion mechanism considered in the model, estimates tend to overstate the amount of particles that remain airborne. Individual models for each specific configuration are necessary to consider all mechanisms that may be operative in a postulated event.

Thus, the results of the LPF \#1 code are a function of the initial RF and the parameter Q/A ("escape velocity"), where $Q=$ volumetric flowrate, $\mathrm{m}^{3} / \mathrm{s}, \mathrm{A}=$ the upward facing area, $\mathrm{m}^{2}$, and the gravitational settling is integrated over the period required to release all the material.

Table D-1 ("LPFs versus RF Values for Enclosures") and Table D-2 ("LPFs versus RF Values for Ducts") show the variation in LPF as a function of initial RF (left column) and Q/A (remaining columns). Figures D3 and D-4 graphically display the contents of Tables D-1 and D-2. Note that the values of Q/A range from $10^{-2}$ to $10^{-9} \mathrm{~m} / \mathrm{s}\left(3.3 \times 10^{-2}\right.$ to $\left.3.3 \times 10^{-9} \mathrm{ft} / \mathrm{s}\right)$, spanning 7 orders of magnitude, and RFs range from 1.0 to 0.0005 , spanning greater than three orders of magnitude for this parameter. These values are the range of these parameters that have been noted in the literature. The range is extreme and the rate of change is nonlinear, making interpolation difficult. If the parameters in a problem are near the values given in the table, an approximation of the LPF could be derived. This illustrates a general difficulty associated with trying 
Table D-1. LPFs versus RF Values for Enclosures

\begin{tabular}{|c|c|c|c|c|c|}
\hline $\mathbf{R F} \downarrow \mathbf{Q} / \mathbf{A ~ m} / \mathbf{s} \rightarrow$ & $\therefore 10-9$ & $10^{-7}$ & $\therefore 10^{-5}$ & $10^{-3}$ & $10^{-2}$ \\
\hline 0.000494 & $5.1 \mathrm{E}-07^{*}$ & 5.1E-05 & 0.0050 & 0.32 & 0.82 \\
\hline 0.009753 & $6.1 \mathrm{E}-07$ & $6.1 \mathrm{E}-05$ & 0.0060 & 0.35 & 0.84 \\
\hline 0.03168 & $7.1 \mathrm{E}-07$ & $7.1 \mathrm{E}-05$ & 0.0070 & 0.38 & 0.85 \\
\hline 0.08418 & 8.2E-07 & $8.2 \mathrm{E}-05$ & 0.0080 & 0.40 & 0.86 \\
\hline 0.1543 & $9.0 \mathrm{E}-07$ & $9.0 \mathrm{E}-05$ & 0.0088 & 0.41 & 0.86 \\
\hline 0.1845 & $9.6 \mathrm{E}-07$ & $9.6 \mathrm{E}-05$ & 0.0092 & 0.42 & 0.86 \\
\hline 0.2181 & 9.8E-07 & $9.8 \mathrm{E}-05$ & 0.0096 & 0.43 & 0.87 \\
\hline 0.255 & $1.0 \mathrm{E}-06$ & $1.0 \mathrm{E}-04$ & 0.0098 & 0.43 & 0.87 \\
\hline 0.28 & 1.1E-06 & 0.00011 & 0.010 & 0.44 & 0.87 \\
\hline 0.2949 & 1.1E-06 & 0.00011 & 0.011 & 0.45 & 0.88 \\
\hline 0.3375 & $1.2 \mathrm{E}-06$ & 0.00012 & 0.012 & 0.46 & 0.88 \\
\hline 0.3823 & 1.3E-06 & 0.00013 & 0.013 & 0.47 & 0.88 \\
\hline 0.4287 & $1.4 \mathrm{E}-06$ & 0.00014 & 0.014 & 0.49 & 0.89 \\
\hline 0.4761 & $1.6 \mathrm{E}-06$ & 0.00016 & 0.015 & 0.50 & 0.89 \\
\hline 0.5713 & $1.9 \mathrm{E}-06$ & 0.00019 & 0.017 & 0.51 & 0.90 \\
\hline 0.6177 & 2.0E-06 & 0.00020 & 0.019 & 0.53 & 0.90 \\
\hline 0.7051 & 2.3E-06 & 0.00023 & 0.021 & 0.55 & 0.91 \\
\hline 0.7819 & 2.8E-06 & 0.00028 & 0.026 & 0.58 & 0.91 \\
\hline 0.8457 & 3.7E-06 & 0.00037 & 0.033 & 0.62 & 0.93 \\
\hline 0.9158 & 5.3E-06 & 0.00053 & 0.045 & 0.67 & 0.94 \\
\hline 0.9588 & $8.6 \mathrm{E}-06$ & 0.00086 & 0.068 & 0.74 & 0.96 \\
\hline 0.9902 & 1.7E-05 & 0.0017 & 0.12 & 0.83 & 0.97 \\
\hline 0.9995 & 5.7E-05 & 0.0056 & 0.27 & 0.94 & 0.99 \\
\hline 1.000 & 0.00017 & 0.016 & 0.49 & 0.98 & 1.0 \\
\hline
\end{tabular}

* 5.1E-07 $=5.1 \times 10^{-7}$ etc. 
Table D-2. LPFs versus RF Values for Ducts

\begin{tabular}{|c|c|c|c|c|c|c|}
\hline $\mathbf{R F} \downarrow \mathbf{Q} / \mathbf{A ~ m} / \mathrm{s} \rightarrow$ & $10^{-9}$ & $10^{-6}$ & $10^{-5}$ & $10^{-4}$ & $10^{-3}$ & $10^{-2}$ \\
\hline 0.000494 & $-\cdots$ & $2.8 \mathrm{E}-20$ & $1.0 \mathrm{E}-07$ & 0.00040 & 0.12 & 0.80 \\
\hline 0.009753 & -.-- & $6.6 \mathrm{E}-10$ & $5.0 \mathrm{E}-07$ & 0.00068 & 0.17 & 0.82 \\
\hline 0.03168 & $1.1 \mathrm{E}-31$ & $2.9 \mathrm{E}-08$ & $2.5 \mathrm{E}-06$ & 0.0015 & 0.21 & 0.84 \\
\hline 0.08418 & $2.2 \mathrm{E}-21$ & $1.2 \mathrm{E}-07$ & 5.7E-06 & 0.0030 & 0.24 & 0.85 \\
\hline 0.1543 & $2.5 \mathrm{E}-17$ & $1.9 \mathrm{E}-07$ & $9.5 \mathrm{E}-06$ & 0.0045 & 0.25 & 0.85 \\
\hline 0.1845 & $7.5 \mathrm{E}-16$ & $2.1 \mathrm{E}-07$ & $1.2 \mathrm{E}-05$ & 0.0055 & 0.26 & 0.85 \\
\hline 0.2181 & $3.4 \mathrm{E}-15$ & $2.2 \mathrm{E}-07$ & $1.4 \mathrm{E}-05$ & 0.0064 & 0.27 & 0.86 \\
\hline 0.255 & $1.5 \mathrm{E}-14$ & $2.3 \mathrm{E}-07$ & $2.0 \mathrm{E}-05$ & 0.0077 & 0.28 & 0.86 \\
\hline 0.2949 & $1.7 \mathrm{E}-13$ & $2.5 \mathrm{E}-07$ & $2.9 \mathrm{E}-05$ & 0.0090 & 0.29 & 0.86 \\
\hline 0.3375 & $1.0 \mathrm{E}-12$ & 2.7E-07 & $4.2 \mathrm{E}-05$ & 0.011 & 0.32 & 0.87 \\
\hline 0.3823 & $3.6 \mathrm{E}-12$ & $2.8 \mathrm{E}-07$ & $5.7 \mathrm{E}-05$ & 0.014 & 0.33 & 0.88 \\
\hline 0.4287 & $1.2 \mathrm{E}-11$ & $2.9 \mathrm{E}-07$ & $8.2 \mathrm{E}-05$ & 0.017 & 0.35 & 0.88 \\
\hline 0.4761 & $3.9 \mathrm{E}-11$ & $3.1 \mathrm{E}-07$ & 0.00012 & 0.021 & 0.37 & 0.88 \\
\hline 0.5713 & $2.0 \mathrm{E}-10$ & $3.5 \mathrm{E}-07$ & 0.00022 & 0.028 & 0.39 & 0.88 \\
\hline 0.6177 & $3.2 \mathrm{E}-10$ & $3.8 \mathrm{E}-07$ & 0.00028 & 0.033 & 0.41 & 0.90 \\
\hline 0.7051 & $8.8 \mathrm{E}-10$ & 5.1E-07 & 0.00047 & 0.042 & 0.43 & 0.90 \\
\hline 0.7819 & $2.3 \mathrm{E}-09$ & $8.5 \mathrm{E}-07$ & 0.00084 & 0.056 & 0.47 & 0.91 \\
\hline 0.8457 & $5.6 \mathrm{E}-09$ & $2.0 \mathrm{E}-06$ & 0.0017 & 0.081 & 0.53 & 0.92 \\
\hline 0.9158 & $1.3 \mathrm{E}-08$ & $6.1 \mathrm{E}-06$ & 0.0037 & 0.12 & 0.60 & 0.94 \\
\hline 0.9588 & 3.3E-08 & $2.8 \mathrm{E}-05$ & 0.0096 & 0.20 & 0.69 & 0.95 \\
\hline 0.9902 & $2.5 \mathrm{E}-07$ & 0.0002 & 0.031 & 0.34 & 0.81 & 0.97 \\
\hline 0.9995 & $9.3 \mathrm{E}-07$ & 0.0033 & 0.14 & 0.62 & 0.93 & 0.99 \\
\hline 1.000 & 3.3E-05 & 0.027 & 0.38 & 0.84 & 0.98 & 1.0 \\
\hline
\end{tabular}




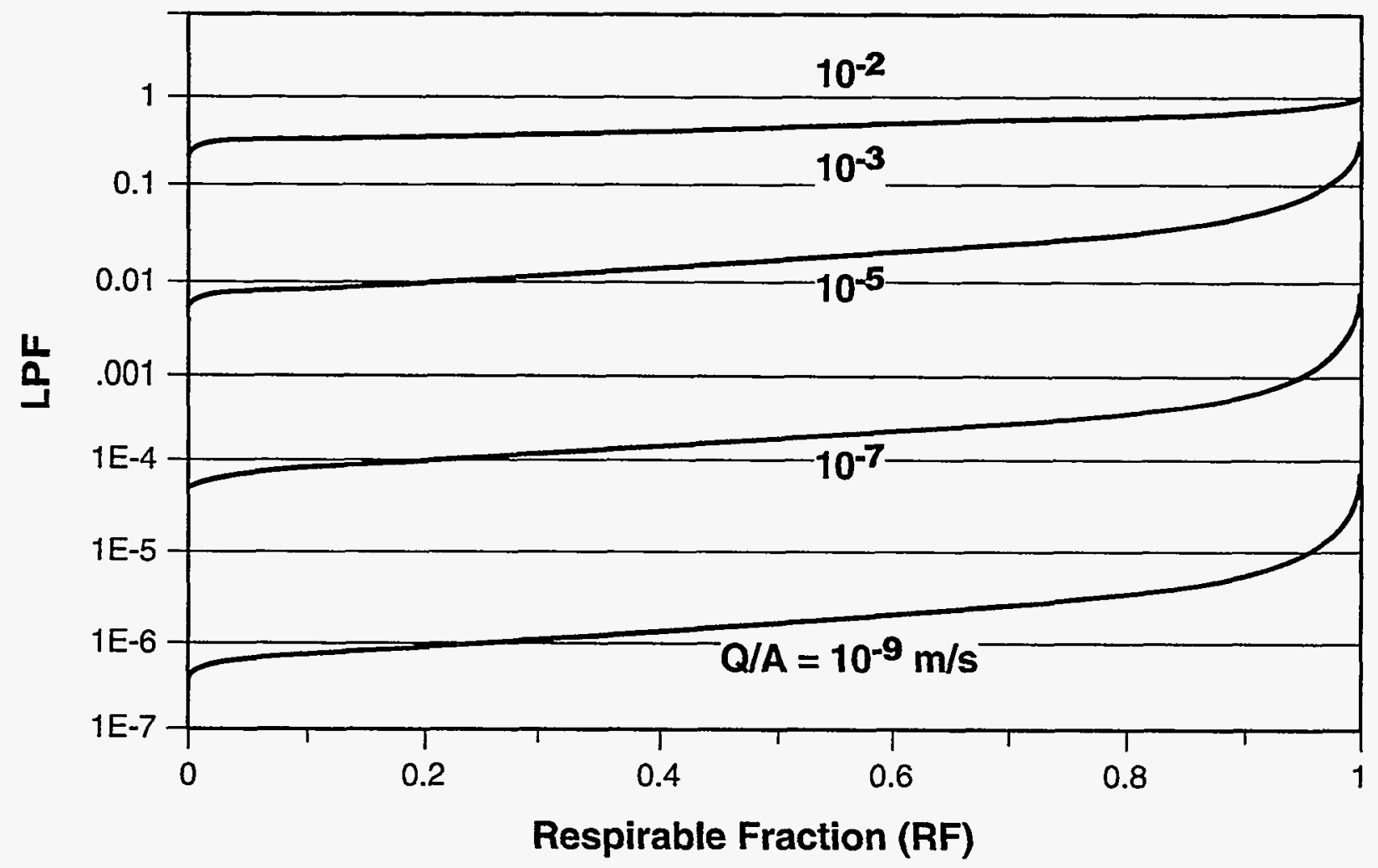

Figure D-3. Leakpath factor (LPF) versus respirable fraction (RF) for enclosures 


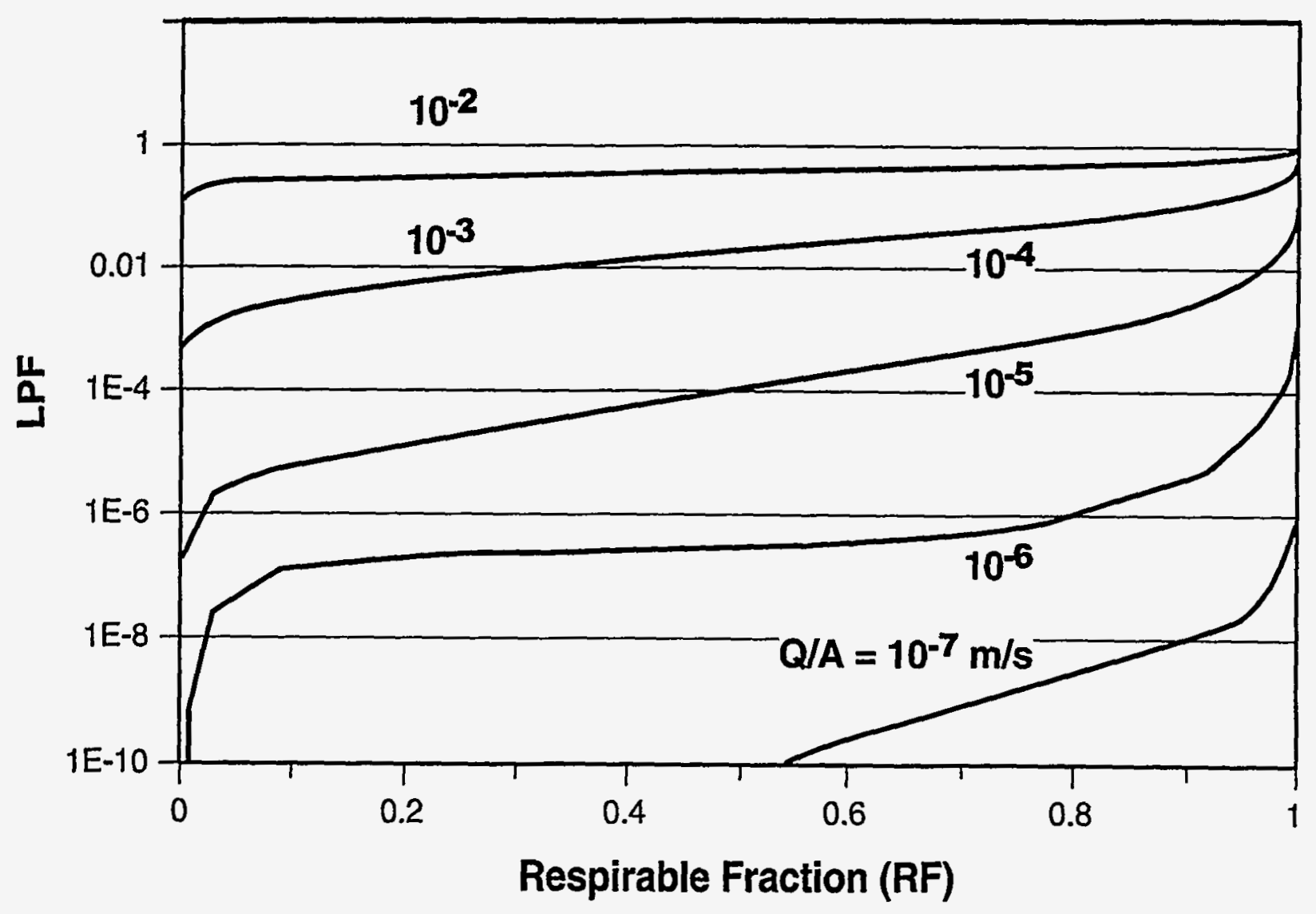

Figure D-4. Leakpath factor (LPF) versus respirable fraction (RF) for ducts 
to produce tables and nomographs that can fit every conceivable calculation. However, the LPF \#1 code is easy to use, and a copy of a recent version LPF \#1B, has been provided as part of this handbook.

Room/Enclosure. The room size is $7 \mathrm{~m}(23 \mathrm{ft})$ by $10 \mathrm{~m}(33 \mathrm{ft})$ by $3 \mathrm{~m}(10 \mathrm{ft})$ with a volume of $210 \mathrm{~m}^{3}(7400$ $\left.\mathrm{ft}^{3}\right)$. Ventilation flow is 10 ach or $10\left[210 \mathrm{~m}^{3}\right]=2100 \mathrm{~m}^{3} / \mathrm{hr}\left(74170 \mathrm{ft}^{3} / \mathrm{hr}\right)$ or $0.583 \mathrm{~m}^{3} / \mathrm{s}\left(20.6 \mathrm{ft}^{3} / \mathrm{s}\right)$. The upward facing surface is $7 \mathrm{~m}(23 \mathrm{ft})$ by $10 \mathrm{~m}(33 \mathrm{ft})=70 \mathrm{~m}^{2}\left(754 \mathrm{ft}^{2}\right)$. The $\mathrm{Q} / \mathrm{A}$ is:

$$
\begin{aligned}
\mathrm{Q} / \mathrm{A} & =0.583 \mathrm{~m}^{3} \mathrm{~s}^{-1} / 70 \mathrm{~m}^{2} \\
& =0.00833 \mathrm{~m} / \mathrm{s}
\end{aligned}
$$

The initial RF is 0.3 . The LPF from Table D- 1 is between 0.88 and 0.45 . Calculations using the LPF \#1 code yield a value of 0.85 .

Duct. The initial section of the single exhaust duct from the room is $0.6 \mathrm{~m}(2 \mathrm{ft})$ by $0.6 \mathrm{~m}(2 \mathrm{ft})$ by $15 \mathrm{~m}(50$ $\mathrm{ft})$. The volume flow rate from the room that enters the duct is $0.583 \mathrm{~m}^{3} / \mathrm{s}\left(20.6 \mathrm{ft}^{3} / \mathrm{s}\right)$. The upward facing surface area, $\mathrm{A}$, is $0.6 \mathrm{~m}(2 \mathrm{ft})$ by $15 \mathrm{~m}(50 \mathrm{ft})=9 \mathrm{~m}^{2}\left(100 \mathrm{ft}^{2}\right)$. The Q/A is:

$$
\begin{aligned}
\mathrm{Q} / \mathrm{A} & =0.583 \mathrm{~m}^{3} \mathrm{~s}^{-1} / 9 \mathrm{~m}^{2} \\
& =0.0648 \mathrm{~m} / \mathrm{s}
\end{aligned}
$$

The initial RF is 0.3 . The LPF from Table D-2 has a value greater than 0.86 . The LPF calculated using the LPF \#1 code has a value of 0.98 . See Chapter 4 for further discussion of LPFs.

\section{D.2.2.5 Building Source Term}

To summarize the assumptions and data from the previous Subsection, the following are the parameters that are used to calculate the Building Source Term (BST):

$\begin{array}{lll}\mathrm{MAR} & = & 5 \mathrm{~kg}(11 \mathrm{lb}) \mathrm{UO}_{2} \text { powder } \\ \mathrm{DR} & =1.0 \text { (all the powder released is involved in the postulated spill) } \\ \mathrm{ARF} & = & 2 \mathrm{E}-3 \text { (the maximum experimentally measured value for fall distance less than } 3 \mathrm{~m} \text { ) } \\ \mathrm{RF} & = & 0.3 \text { (the value associated with the maximum experimentally measured } \mathrm{ARF} \text { ) } \\ \mathrm{LPF} & =0.85 \text { for the Respirable Fraction during transport to the duct } \\ & =0.98 \text { for the transport of } \mathrm{RF} \text { through the duct to the manifold } \\ & =\quad \text { overall } \mathrm{LPF}[0.85][0.98]=0.83 \text { (multiplication permissible if } \mathrm{LPFs} \text { are near } 1 \text { ) }\end{array}$

Therefore, the Building Source Term is:

$$
\begin{aligned}
\mathrm{BST} & =[\mathrm{MAR}][\mathrm{DR}][\mathrm{ARF}][\mathrm{RF}][\mathrm{LPF}] \\
& =[5 \mathrm{~kg}][1.0][2 \mathrm{E}-3][0.3][0.83] \\
& =0.0025 \mathrm{~kg}\left(2.5 \mathrm{~g} \mathrm{UO}_{2}\right)
\end{aligned}
$$

Alternative values based on the other ARFs derived for a $2 \mathrm{~m}$ fall distance are:

$$
\begin{aligned}
\mathrm{BST}_{\mathrm{BF}} & =[5 \mathrm{~kg}][1.0][2 \mathrm{E}-4][0.3][.83] \\
& =0.00025 \mathrm{~kg}\left(0.25 \mathrm{~g} \mathrm{UO}_{2}\right) \\
\mathrm{BST}_{\mathrm{UB}} & =[5 \mathrm{~kg}][1.0][6 \mathrm{E}-4][0.3][0.83] \\
& =0.00075 \mathrm{~kg}\left(0.75 \mathrm{~g} \mathrm{UO}_{2}\right)
\end{aligned}
$$


As can be seen, there is a range of a factor of 10 in the magnitude of the source term.

\section{D.2.3 Example 2 - Free-Fall Spill of Powder Over a Fall Distance Greater than the Experimental Data}

\section{D.2.3.1 Scenario}

In this scenario, the same amount of $\mathrm{UO}_{2}$ powder, $5 \mathrm{~kg}(11 \mathrm{lb})$, is spilled from a height of $10 \mathrm{~m}$ (33 ft) into a room $30 \mathrm{~m}(98 \mathrm{ft})$ wide by $40 \mathrm{~m}(131 \mathrm{ft})$ long by $10 \mathrm{~m}$ (38 ft) high. The spill from this height reflects the use of conveyor systems in some $U$ fabrication facilities. Although the amount of powder for this event may be much greater than assumed here, the same mass is used in this example to allow direct comparison of results with Example 1 above.

\section{D.2.3.2 Airborne Release Fraction}

The ARF for this event has a DN of:

$$
\begin{aligned}
\mathrm{DN} & =\left[5^{0.125}\right]\left[10^{2.37}\right] /\left[3000^{1.02}\right] \\
& =0.0814
\end{aligned}
$$

that exceeds the DN (0.018) for the experimental data base. Using the correlation for the extrapolated "Best Fit" line in Figure D-3 (equation D.2), the calculated "Best-Fit" ARF is:

$$
\begin{aligned}
\mathrm{ARF}_{\mathrm{BF}} & =0.1064[\mathrm{DN}] \\
& =0.00866(9 \mathrm{E}-3)
\end{aligned}
$$

Using the more conservative correlation to the extrapolated "Upper Bound" line in Figure D-3 (equation D.3), the calculated "Upper Bound" ARF is:

$$
\begin{aligned}
\mathrm{ARF}_{\mathrm{UB}} & =0.3573[\mathrm{DN}] \\
& =0.0242(2 \mathrm{E}-2)
\end{aligned}
$$

For the purposes of these analyses, the more conservative value, $2 \mathrm{E}-2$, is selected. This value is a factor of 2.2 greater than the $A R F_{B F}$ and would result in a calculated dose 2.2 times greater than the dose resulting from use of the less conservative ARF.

\section{D.2.3.3 Respirable Fraction}

Estimating the RF for this high spill height cannot be based on the data base because $\mathrm{DN}$ is approximately 4.5 times larger than the maximum experimental DN (0.018). The options available are to:

- Assume the same RF (0.3) as measured for the Upper Bound ARF;

- Assume the maximum RF based on the mass of particles in this size range measured in the source powder (in this case, no size distribution is available); or

- Assume the most conservative value for RF, 1.0 (the RF of the ball-milled DUO used in the experiments was greater than 0.5 ; the AMAD of the powder was measured to be approximately 3 micrometers (1.0x10-4 in) AED, therefore, an RF of 1.0 would be possible for an ARF 5E-1). 
In the absence of other data, the most conservative value, 1.0, is selected for the purposes of these analyses. To estimate the effect of this conservatism, the dose would be a factor of 3 less if an RF of 0.3 were selected.

\section{D.2.3.4 Leak Path Factor}

The event occurs in a room $30 \mathrm{~m}(98 \mathrm{ft})$ wide by $40 \mathrm{~m}(131 \mathrm{ft})$ long by $12 \mathrm{~m}(39 \mathrm{ft})$ high. The four room

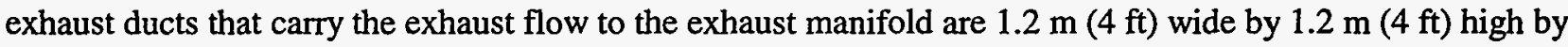
$15 \mathrm{~m}$ (50 ft) long. The ventilation flow is steady and normal during and following the event at $2.5 \mathrm{ach}$ at a temperature of $298 \mathrm{~K}\left(76^{\circ} \mathrm{F}\right)$. Air pressure in the room is $101.1 \mathrm{kPa}(14.7 \mathrm{psia})$. The volumetric flow, $\mathrm{Q}$, from the room is 2.5 [volume of the room], $10 \mathrm{~m}^{3} / \mathrm{s}\left(2.5[30 \mathrm{~m}][40 \mathrm{~m}][12 \mathrm{~m}]=36000 \mathrm{~m}^{3} / \mathrm{h}\right)\left(21000 \mathrm{ft}^{3} / \mathrm{min}\right)$. The upward facing surface area, $A$, is $([30 \mathrm{~m}][40 \mathrm{~m}]=) 1200 \mathrm{~m}^{2}\left(13000 \mathrm{ft}^{2}\right)$. The escape velocity, $\mathrm{Q} / \mathrm{A}$, is:

$$
\begin{aligned}
\mathrm{Q} / \mathrm{A} & =10 \mathrm{~m}^{3} \mathrm{~s}^{-1} / 1200 \mathrm{~m}^{2} \\
& =0.00833 \mathrm{~m} / \mathrm{s}(0.019 \mathrm{mph})
\end{aligned}
$$

the same as the escape velocity value calculated for Example 1. As for Example 1, the LPF \#1 code considers the room as a single, well-mixed volume with exponential dilution of the airborne particles with time (as each fraction of airborne material is extracted from the room volume, the remainder becomes wellmixed so that the airborne concentration decreases exponentially with time). Table D-1, "LPFs versus RF

Values for Enclosures", shows that, for the initial RF considered, 1.0, and a Q/A between $10^{-3}$ and $10^{-2} \mathrm{~m} / \mathrm{s}$ $\left(3.3 \times 10^{-3}\right.$ and $\left.3.3 \times 10^{-2} \mathrm{ft} / \mathrm{s}\right)$, the LPF is between 0.98 and 1.0. An LPF of 0.99 is calculated by the LPF \#1 code for these conditions.

All four exhaust ducts are assumed to have identical flows. The volumetric flowrate in each duct then is 10 $\mathrm{m}^{3} / \mathrm{s}\left(353 \mathrm{ft}^{3} / \mathrm{s}\right)$ divided by 4 or $2.5 \mathrm{~m}^{3} / \mathrm{s}\left(88.3 \mathrm{ft}^{3} / \mathrm{s}\right)$. The upward facing surface area, A, of each duct is ([1.2 $\mathrm{m}][15 \mathrm{~m}] \Rightarrow 18 \mathrm{~m}^{2}$. Therefore, $\mathrm{Q} / \mathrm{A}$ is:

$$
\begin{aligned}
\mathrm{Q} / \mathrm{A} & =2.5 \mathrm{~m}^{3} \mathrm{~s}^{-1} / 18 \mathrm{~m}^{2} \\
& =0.139 \mathrm{~m} / \mathrm{s}
\end{aligned}
$$

Table D-2, "LPFs versus RF Value for Ducts," shows that, for all practical purposes, the LPF value for these conditions (RF 1.0, Q/A $0.139 \mathrm{~m} / \mathrm{s}(0.44 \mathrm{ft} / \mathrm{s})$ ) is greater than 0.9977 . This compares with an overall LPF of 0.83 in Example No. 1. The principal reason for the difference is that the RF is 1.0 (unity) in Example No. 2 and 0.3 in Example No. 1. Therefore, the powder in Example No. 1 contains a greater fraction of particles with AED's exceeding $10 \mu \mathrm{m}\left(4.0 \times 10^{-4} \mathrm{in}\right)$ and gravitational settling is more important than in Example No. 2.

\section{D.2.3.5 Building Source Term}

To summarize the assumptions and data from the previous Subsection, the following parameters are used to calculated the Building Source Term (BST) for Example No. 2:

MAR $=5 \mathrm{~kg}(11 \mathrm{lb}) \mathrm{UO}_{2}$ powder

$\mathrm{DR}=1.0$ (all the powder is involved in the spill)

$\mathrm{ARF}_{\mathrm{B}}=2 \mathrm{E}-2$ (a calculated value based on the $\mathrm{DN}$, a ARF $\mathrm{m}_{\mathrm{m}}$ was also calculated)

$R F=1.0$ (a conservative value; an alternative $R F$ is 0.3 ) 


$$
\begin{aligned}
\mathrm{LPF} & =0.99 \text { (transport of } \mathrm{RF} \text { through room) } \\
& =1.0 \text { (transport of } \mathrm{RF} \text { through ducts) } \\
& =0.99 \text { (overall LPF, }([0.99][1.0])
\end{aligned}
$$

Therefore, the Building Source Term is:

$$
\begin{aligned}
\mathrm{BST}_{\mathrm{UB}} & =[\mathrm{MAR}][\mathrm{DF}][\mathrm{ARF}][\mathrm{RF}][\mathrm{LPF}] \\
& =[5 \mathrm{~kg} \mathrm{UO}][1.0][2 \mathrm{E}-2][1.0][0.99] \\
& =0.1188 \mathrm{~kg} \mathrm{UO} \mathrm{O}_{2}(120 \mathrm{~g})
\end{aligned}
$$

\section{D.2.4 Dose Assessment}

See Chapter 5 for further information on this topic.

\section{D.2.4.1 Choice of Dispersion Model}

For the free-fall sample problem, the dispersion model should be able to model the following:

- Elevated and ground level releases

- Neutrally buoyant plumes

- Building wake effects

- Estimate doses resulting from exposure to enriched uranium

- Plume depletion due to radioactive decay and deposition (dry)

The model chosen to calculate consequences for the free-fall spill sample problems is the Radiological Assessment System for Consequence Analysis (RASCAL) developed by the U.S. Nuclear Regulatory Commission (USNRC 1993). The international version of the model was chosen since its nuclide library contains the appropriate nuclides.

RASCAL contains two atmospheric transport and diffusion models. One is a straight-line Gaussian plume model, and the other is a Lagrangian-trajectory Gaussian puff model. Users select the appropriate model based on meteorological conditions and distance from the source. The plume model should be used for all distances when meteorological conditions are constant and windspeed is $0.45 \mathrm{~m} / \mathrm{s}(1 \mathrm{mph})$ or greater. The plume model results become unrealistic as the average windspeed approaches zero because windspeed is in the denominator of the dispersion equation. Diffusion takes place even when the wind appears calm. Therefore, RASCAL includes a puff model for these situations. The acute and chronic cumulative inhalation dose equivalent at each location are computed by multiplying the time-integrated air concentration, by dose factors, and a breathing rate. The cumulative ground-shine dose at each location is computed by multiplying the cumulative surface concentration by dose factors and a correction factor for scattering from surface roughness. The cloud-shine model is used in both the straight-line and puff model calculations. Near the source, the cloud shine is calculated using a finite-plume approximation. After the plume grows to sufficient size, the code shifts to a semi-infinite model for cloud shine. 


\section{D.2.4.2 Example Problem Parameters for Atmospheric Dispersion}

\section{Site and Facility:}

Sample problems have been performed for a generic facility and site. Therefore, no specific terrain or meteorological conditions will be considered, i.e., the terrain is flat and rural.

The generic building has dimensions of $61 \mathrm{~m}$ by $61 \mathrm{~m}$ by $9.14 \mathrm{~m}$ ( $200 \mathrm{ft}$ by $200 \mathrm{ft}$ by $30 \mathrm{ft}$ ), and the building's ventilation system sustains approximately 5 air changes per hour. The stack is $60 \mathrm{~m}(200 \mathrm{ft})$ high with a diameter of $2 \mathrm{~m}(6.6 \mathrm{ft})$. This results in an air flow of $47.2 \mathrm{~m}^{3} / \mathrm{s}\left(10^{5} \mathrm{cfm}\right)$ with an exit velocity of approximately $15 \mathrm{~m} / \mathrm{s}(49.2 \mathrm{ft} / \mathrm{s})$.

In an operational facility with an intact ventilation system, it would be expected that one to several HEPA filters would be in place between the point of release and the environment. However, for purposes of this example, no filtration will be considered. To estimate the effect that filtration would have on the consequences, the calculational results can be reduced in direct proportion to the filter efficiency.

\section{Release Path:}

For purposes of illustration, one ground level and one stack (elevated) release are examined. To illustrate the effect of a building wake on a ground level release, calculations are performed with and without the effect enabled.

For the elevated release case, the actual plume height may not be the physical release height (the stack height). Plume rise can occur because of the velocity of the stack emission, and the difference in temperature between the effluent and the surrounding air. This effective increase in height leads to lower concentrations at ground level. If there is insufficient data available to calculate the effective release height, it is recommended that the actual physical release height be used. This will almost always yield a conservative estimate.

Since the RASCAL model does not have a subroutine that calculates effective plume height, a release height equal to the stack height $(60 \mathrm{~m}(200 \mathrm{ft}))$ has been used for the elevated release examples.

\section{Meteorological Conditions:}

Meteorological conditions are assumed to be constant for the duration of the release (this are the case in all of the sample problems unless stated otherwise). In order to illustrate the effect of meteorological conditions on the calculated consequences, one representative severe and average meteorological condition are used for each release pathway. For the ground level release case, the severe meteorological case consists of a windspeed of $2 \mathrm{~m} / \mathrm{s}(6.6 \mathrm{ft} / \mathrm{s})$ and an atmospheric stability class of $\mathrm{F}$, and the average case is represented by $5 \mathrm{~m} / \mathrm{s}(16.4 \mathrm{ft} / \mathrm{s})$ and $D$ stability. For the elevated release, the severe meteorological condition is represented by $2 \mathrm{~m} / \mathrm{s}(6.6$ $\mathrm{ft} / \mathrm{s}$ ) and A stability and the average conditions by $5 \mathrm{~m} / \mathrm{s}$ and $\mathrm{D}$ stability.

\section{Source Term:}

The first portion of this example problem determined the environmental source term for two free-fall spill cases. For purposes of illustrating atmospheric dispersion and consequence modeling, the higher of the 
estimated Upper Bound source terms for Example \#2 (Section D.2.3.5) is used for both the ground and elevated release examples.

The material released is enriched uranium in the form of $\mathrm{UO}_{2}$ powder. The total quantity released to the environment, as determined in Section D.2.3.5, is $0.12 \mathrm{~kg}(0.26 \mathrm{lb})$. Weapons grade uranium is enriched in the nuclide U-235. A typical breakdown of the nuclides in a batch of enriched Uranium is as follows:

- U-235 93.15 percent

- U-234 1.00 percent

- U-236 0.50 percent

- U-238 5.35 percent

The RASCAL model requires a source term input in the form of a release rate (e.g., activity per unit time). The free-fall example is a term release rather than a continuous release. A fixed amount of powder is dispersed into the room atmosphere when the container falls and opens. If the ventilation system is assumed to be intact and operating following the event, it acts to replace the room air volume with external air and transports the suspended material through the duct work to a point of exhaust. Once sufficient air has been exchanged in the room, the suspended material is removed and the release effectively terminated (with the exception of material that has been deposited in the room and ventilation system which can be resuspended, causing a slight residual release). For the purpose of this example, resuspension from material deposited on internal surfaces of the building is not considered.

To simplify the analysis, it is assumed that the suspended material rapidly mixes with the room air and that it is completely removed in approximately 2.5 air volume changes. Since the ventilation system performs 5 air changes per hour, the release duration will be set at 30 minutes.

To calculate the rate of release of each nuclide, the percentage of each will be multiplied by the total quantity released, then by its specific activity (e.g., radioactivity per unit mass) and the result divided by the release duration. Specific activities were obtained from the Health Physics and Radiological Health Handbook, Revised Edition (Shleien 1992).

- $\quad \mathrm{U}-235=(93.15$ percent $)(120 \mathrm{gm})(2.16 \mathrm{E}-6 \mathrm{Ci} / \mathrm{gm})(1 / 1800 \mathrm{sec})=1.34 \mathrm{E}-7 \mathrm{Ci} / \mathrm{s}$

- $\mathrm{U}-234=(1.00$ percent $)(120 \mathrm{gm})(6.24 \mathrm{E}-3 \mathrm{Ci} / \mathrm{gm})(1 / 1800 \mathrm{sec})=4.16 \mathrm{E}-6 \mathrm{Ci} / \mathrm{s}$

- $\mathrm{U}-236=(0.50$ percent $)(120 \mathrm{gm})(6.49 \mathrm{E}-5 \mathrm{Ci} / \mathrm{gm})(1 / 1800 \mathrm{sec})=2.16 \mathrm{E}-8 \mathrm{Ci} / \mathrm{s}$

- $\mathrm{U}-238=(5.35$ percent $)(120 \mathrm{gm})(6.35 \mathrm{E}-7 \mathrm{Ci} / \mathrm{gm})(1 / 1800 \mathrm{sec})=2.27 \mathrm{E}-9 \mathrm{Ci} / \mathrm{s}$

\section{D.2.4.3 Example Atmospheric Dispersion Problems}

Examples are provided for a ground level release, with and without wake effects, and for an elevated release. Each case presented is performed using two sets of meteorological conditions, one representative of severe meteorology (e.g., higher consequences) and one representative of average meteorological conditions.

Consequences are calculated at six arbitrary distances. The range is from $100 \mathrm{~m}(0.06 \mathrm{mi})$ to $16000 \mathrm{~m}(10 \mathrm{mi})$ and represents the approximate limits within which the Gaussian dispersion model yields meaningful results. This range also encompasses the primary population at risk (e.g., workers and general population) from any accidental release of hazardous material. The international version of the RASCAL model (USNRC 1993) has been used to perform all calculations for these examples. 
Dispersion Example 1: The first example consists of a release from a building roof top vent (assumed to be swept down to ground level). One set of calculations is performed with the building wake model turned on and one with it off.

The following table (Table D-3) is an example of the input summary provided by the RASCAL model. These represent all of the parameters that are user definable and represent the inputs for the ground level release with no building wake and worst-case meteorology.

Table D-3. Summary of RASCAL Input Parameters

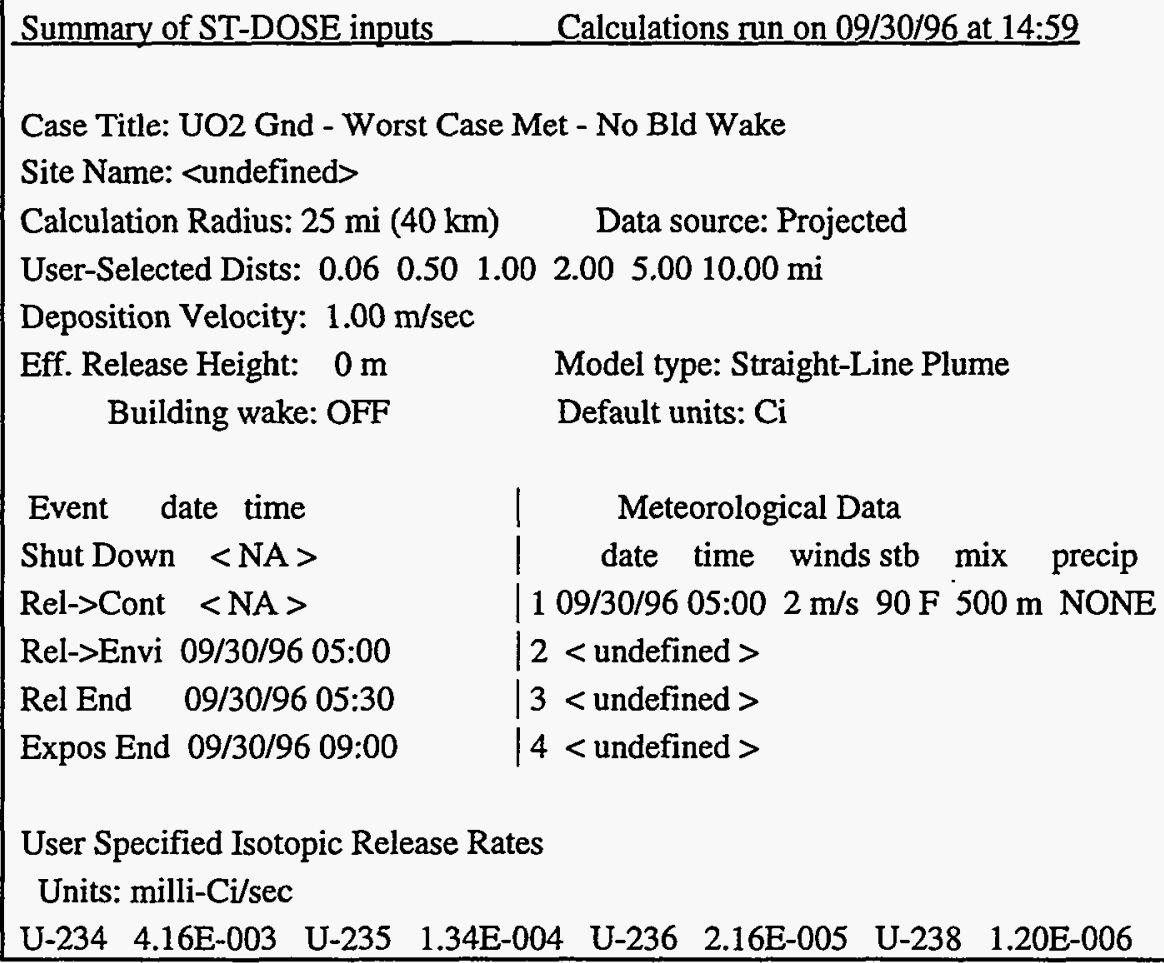

The model provides output in terms of dose in rems and concentration in curies per square meter. Doses are provided for several body organs (e.g., thyroid, lung, and bone), and whole body doses based on exposure pathway (e.g., cloud/ground shine and inhalation). Tissue and whole body doses for the ground-level release, worst-case meteorology example are presented in Table D-4.

For many applications, the Total Effective Dose Equivalent (TEDE) is the result of interest. The TEDE is determined by summing whole body dose from all external and internal pathways. Uranium is primarily an alpha emitter, therefore, contributions to dose from cloud and ground shine are zero. Dose from alpha emitting nuclides is a result of material that is deposited inside the body via inhalation or ingestion. In these examples, the dose resulting from acute exposures is of interest. Therefore, the ingestion pathway is not considered. From Table D-4 results, it is evident that the TEDE is almost entirely due to the Committed Effective Dose Equivalent (CEDE) from inhalation. The results also indicate that the organ receiving the greatest dose is the lung. 
Table D-4. Summary of RASCAL Output

\begin{tabular}{|l|l|l|l|l|l|l|}
\hline \multicolumn{7}{|c|}{ Maximum EARLY Doses (rem) from Plume Model } \\
\hline $\begin{array}{l}\text { Distance from Site, } \mathrm{km} \\
\text { (mi) }\end{array}$ & $0.1(0.1)$ & $0.8(0.5)$ & $1.6(1.0)$ & $3.2(2.0)$ & $8.0(5.0)$ & $16.0(10.0)$ \\
\hline Total EDE & $3.6 \mathrm{E}-01$ & $7.6 \mathrm{E}-02$ & $3.5 \mathrm{E}-02$ & $1.5 \mathrm{E}-02$ & $5.0 \mathrm{E}-03$ & $2.1 \mathrm{E}-03$ \\
\hline Thyroid & $0.0 \mathrm{E}+00$ & $0.0 \mathrm{E}+00$ & $0.0 \mathrm{E}+00$ & $0.0 \mathrm{E}+00$ & $0.0 \mathrm{E}+00$ & $0.0 \mathrm{E}+00$ \\
\hline Acute Lung & $2.9 \mathrm{E}-02$ & $6.2 \mathrm{E}-03$ & $2.9 \mathrm{E}-03$ & $1.3 \mathrm{E}-03$ & $0.0 \mathrm{E}+00$ & $0.0 \mathrm{E}+00$ \\
\hline Acute Bone Total & $0.0 \mathrm{E}+00$ & $0.0 \mathrm{E}+00$ & $0.0 \mathrm{E}+00$ & $0.0 \mathrm{E}+00$ & $0.0 \mathrm{E}+00$ & $0.0 \mathrm{E}+00$ \\
\hline Bone Surface & $1.1 \mathrm{E}-02$ & $2.4 \mathrm{E}-03$ & $1.1 \mathrm{E}-03$ & $0.0 \mathrm{E}+00$ & $0.0 \mathrm{E}+00$ & $0.0 \mathrm{E}+00$ \\
\hline Acute Bone Inhalation & $0.0 \mathrm{E}+00$ & $0.0 \mathrm{E}+00$ & $0.0 \mathrm{E}+00$ & $0.0 \mathrm{E}+00$ & $0.0 \mathrm{E}+00$ & $0.0 \mathrm{E}+00$ \\
\hline Cloud Shine & $0.0 \mathrm{E}+00$ & $0.0 \mathrm{E}+00$ & $0.0 \mathrm{E}+00$ & $0.0 \mathrm{E}+00$ & $0.0 \mathrm{E}+00$ & $0.0 \mathrm{E}+00$ \\
\hline Ground Shine & $0.0 \mathrm{E}+00$ & $0.0 \mathrm{E}+00$ & $0.0 \mathrm{E}+00$ & $0.0 \mathrm{E}+00$ & $0.0 \mathrm{E}+00$ & $0.0 \mathrm{E}+00$ \\
\hline CEDE Inhalation & $3.6 \mathrm{E}-01$ & $7.6 \mathrm{E}-02$ & $3.5 \mathrm{E}-02$ & $1.5 \mathrm{E}-02$ & $5.0 \mathrm{E}-03$ & $2.1 \mathrm{E}-03$ \\
\hline Ground Concentration & $0.0 \mathrm{E}+00$ & $0.0 \mathrm{E}+00$ & $0.0 \mathrm{E}+00$ & $0.0 \mathrm{E}+00$ & $0.0 \mathrm{E}+00$ & $0.0 \mathrm{E}+00$ \\
\hline
\end{tabular}

NOTES for International Version:

1. All values below $1.0 \mathrm{E}-03$ have been set to zero.

$2 *$ marks values exceeding EARLY GILs.

3. Thyroid dose includes Iodine only.

4. Total $\mathrm{EDE}=\mathrm{CEDE}$ Inhalation + Cloud Shine + Ground Shine.

5. Acute Bone Total $=$ Acute Bone Inh.+ Cloud Shine + Ground Shine.

6. EARLY IAEA Generic Intervention Level $(\mathrm{GLL})=5.0 \mathrm{E}+00 \mathrm{rem}$ in a week, normally evacuate.

The RASCAL model was developed for emergency response and one of its purposes is to identify when thresholds have been exceeded that require that protective actions be implemented. Therefore, the model calculates dose occurred during the initial or early phase of emergency response. The term "EARLY" in the output title shown in Table D-4 refers to the "early phase" of emergency response as defined by the EPA in, "Manual of Protective Actions Guides and Protective Actions for Nuclear Incidents" (USEPA 1991). During the early phase doses accrue from airborne and deposited materials. The EPA suggests that the early phase be considered to last for up to four days following the release.

Table D-5 is a summary of the TEDE at each downwind location for four ground level release cases-with and without building wakes, in severe and average weather conditions. The severe, no wake case is the one already presented in Table D-4. Note that the RASCAL code sets all values less than 1E-5 Sv (1E-3 rem) to zero. However, by using an associated utility, it is possible to obtain values less than the $1 \mathrm{E}-5 \mathrm{~Sv}$ (1E-3 rem) limit. For purposes of this example, values less than $1 \mathrm{E}-5 \mathrm{~Sv}(1 \mathrm{E}-3)$ rem have been included. 
Table D-5. Results for the Free-Fall Powder Spill Ground Level Release

\begin{tabular}{|c|c|c|c|c|}
\hline \multicolumn{5}{|c|}{ Total Effective Dose Equivalent (rem) } \\
\hline \multirow{2}{*}{ Distance (km) } & \multicolumn{2}{|c|}{ Severe Meteorology } & \multicolumn{2}{|c|}{ Aiverage Meteorology } \\
\hline & Wake & No Wake & Wake & No Wake \\
\hline 0.10 & 8.7E-02 & $3.6 \mathrm{E}-01$ & $6.9 \mathrm{E}-02$ & $9.2 \mathrm{E}-02$ \\
\hline 0.80 & 5.3E-03 & $7.6 \mathrm{E}-02$ & $5.4 \mathrm{E}-03$ & $9.5 \mathrm{E}-03$ \\
\hline 1.6 & 3.6E-03 & $3.5 \mathrm{E}-02$ & 2.6E-03 & 3.7E-03 \\
\hline 3.2 & 2.9E-03 & $1.5 \mathrm{E}-02$ & $1.1 \mathrm{E}-03$ & $1.4 \mathrm{E}-03$ \\
\hline 8.0 & 1.9E-03 & $5.0 \mathrm{E}-03$ & 3.4E-04 & 3.6E-04 \\
\hline 16.0 & 1.1E-03 & $2.1 \mathrm{E}-03$ & $1.3 \mathrm{E}-04$ & $1.3 \mathrm{E}-04$ \\
\hline
\end{tabular}

From the results, it can be seen that the effect of the building wake is to increase dispersion (i.e., lower dose) near the release point; however, the farther the plume travels downwind, the smaller the effect. Severe meteorological conditions tend to minimize dispersion, resulting in higher concentrations of materials (e.g., doses) farther downwind.

Dispersion Example 2: The second example is for a release from the facility stack. As discussed in Section D.2.4.2, the release height is at least 2.5 times higher than the surrounding structures, and the ratio of stack exit velocity to windspeed is greater than 1.5. Therefore, no building wake or stack downwash effects need be considered. The source term remains the same as used in Example No. 1. Severe meteorological conditions are assumed to be $2 \mathrm{~m} / \mathrm{s}(4.5 \mathrm{mph})$ and A stability class and average are $5 \mathrm{~m} / \mathrm{s}(11 \mathrm{mph})$ and D stability.

Table D-6 is a summary of the TEDE at each downwind location for the two elevated release cases described above.

The effect of severe meteorology is to bring the elevated plume down to ground level relatively close to the release point. This results in higher doses at the shorter distances. For the severe conditions, the plume

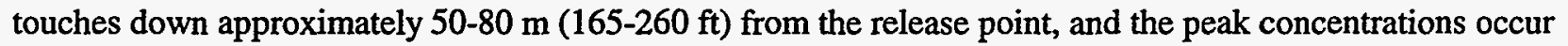
between $100-300 \mathrm{~m}$ (330-1000 ft). For average meteorology, plume touchdown occurs between $200-300 \mathrm{~m}$ (650-1000 ft), and the maximum concentrations between $900-1000 \mathrm{~m}(2900-3300 \mathrm{ft})$. For an elevated release, the highest doses at each distance downwind from the release point are dependent on the atmospheric stability class. For example, quoting from the RASCAL output from which Table D-6 was derived, A stability results in the highest doses between $100-300 \mathrm{~m}(0.06-0.19 \mathrm{mi})$, B stability $300-500 \mathrm{~m}(0.19-0.31$ $\mathrm{mi})$, C stability $500-1000 \mathrm{~m}$ (0.31-0.62 mi), D stability $2000-8000 \mathrm{~m}$ (1.25-5.0 mi), and E stability 10000$20000 \mathrm{~m}(6.25-12.5 \mathrm{mi})$. 
Table D-6. Results for the Free-Fall Powder Spill Elevated Release

\begin{tabular}{|c|c|c|}
\hline \multicolumn{2}{|c|}{ Total Effective Dose Equivalent (rem) } \\
\hline Distance $(\mathbf{k m})$ & Severe Meteorology & Average Meteorology \\
\hline 0.10 & $3.3 \mathrm{E}-04$ & $2.5 \mathrm{E}-06$ \\
\hline 0.80 & $8.8 \mathrm{E}-04$ & $1.4 \mathrm{E}-03$ \\
\hline 1.6 & $3.9 \mathrm{E}-04$ & $1.2 \mathrm{E}-03$ \\
\hline 3.2 & $2.1 \mathrm{E}-04$ & $6.6 \mathrm{E}-04$ \\
\hline 8.0 & $9.2 \mathrm{E}-05$ & $2.3 \mathrm{E}-04$ \\
\hline 16.0 & $4.9 \mathrm{E}-05$ & $9.1 \mathrm{E}-05$ \\
\hline
\end{tabular}

\section{D.3 Sample Problem 2: Explosion with Radioactive Release}

\section{D.3.1 Introduction}

Flammable/combustible gases can be used in some facilities for processing (e.g., to provide a reducing atmosphere during sintering of compacted $\mathrm{UO}_{2}$ pellets) and for space heating. When flammable gas is used in a process, appropriate flammable gas detectors are placed in strategic locations to warn of release and accumulation of explosive quantities. The explosive limits for gases cover a range of concentrations in air, from fuel-lean to fuel-rich mixtures. The flame velocity and energies generated vary with gas, concentration, and confinement.

\section{D.3.2 Scenario}

The scenario used to illustrate the airborne release and transport of the suspended material from an explosion is the deflagration of a limited volume of flammable gas in a large room*. This deflagration does not result in

Explosion is a general term and is defined:

"In general, an explosion is said to have occurred in the atmosphere if energy is released over a sufficiently small time in a sufficiently small volume so as to generate a pressure wave of finite amplitude traveling away from the source. This energy may have originally been stored in the system in a variety of forms; these include nuclear, chemical, electrical, or pressure energy, for example. However, the release of energy is not considered to be explosive unless it is rapid enough and concentrated enough to produce a pressure wave that one can hear. Even though many explosions damage their surroundings, it is not necessary that external damage be produced by an explosion. All that is necessary is that the explosion is capable of being heard." (Baker et al., 1983)

For explosions from a chemical energy source, the explosion may be categorized by the flame speed. Detonations are those chemical reactions (combustion/oxidation) with a flame speed that equals or exceeds the local speed of sound (typically, branch-chain reactions in the solid or condensed phase). The product, generated in microseconds to milliseconds, cannot be dissipated by the normal mass and heat transport mechanisms and generates a shock (no mass involved) and a pressure wave. Deflagrations are chemical reactions (typically in the gas phase) that have flame speeds that are less than the local speed of sound, but burm rapidly. The products, generated in milliseconds to seconds, produce a pressure impulse with a positive, followed by a negative, phase. Under special circumstances of ignition and/or configuration, a reaction may undergo a Deflagration to Detonation Transition (DDT). 
serious overpressures within the volume that would result in loss of the structure or exhaust flow. It is postulated that $0.3 \mathrm{~m}^{3}\left(10 \mathrm{ft}^{3}\right)$ of hydrogen gas escapes into the operating room $30.5 \mathrm{~m}(100 \mathrm{ft})$ wide by 91.4 $\mathrm{m}$ ( $300 \mathrm{ft}$ ) long by $6.1 \mathrm{~m}(20 \mathrm{ft})$ high, with a total volume of $16,992 \mathrm{~m}^{3}\left(600,000 \mathrm{ft}^{3}\right)$. The gas is assumed to rise in the volume and mix with air. Some undefined ignition source, for example, an electrical connection such as lighting, is assumed to ignite the mixture in the upper portion of the volume. Ambient air accelerated to high velocity by the rapid burning is assumed to impact and entrain powder from a homogenous substrate (metal bench or equipment).

\section{D.3.3 Evaluation}

The highest measured $A R F$ and $R F$ values for the suspension of powder due to aerodynamic entrainment are $\mathrm{ARF}=7.6 \mathrm{E}-2$ and $\mathrm{RF}=0.14$ (Mishima and Schwendiman 1973) for uranium dioxide powder with a AMAD (Activity Median Aerodynamic Diameter) of 3.4 micrometers $\left(1.3 \times 10^{-4}\right.$ in) at a windspeed of $\sim 35 \mathrm{kph}(\sim 20$ $\mathrm{mph}$ ) for 24 hours. There are limited data for this situation, and an ARF of $1 \mathrm{E}-1$ and RF of 0.2 are selected for conservatism.

It is assumed that $5 \mathrm{~kg}(11 \mathrm{lb})$ of $\mathrm{UO}_{2}$ powder $(0.88$ mass fraction uranium) are impacted; therefore, the postulated airborne release is $[5000 \mathrm{~g}$ powder $][1 \mathrm{E}-1]=500 \mathrm{~g}(1.1 \mathrm{lb})$ uranium dioxide. The powder in the respirable size range is $[5000 \mathrm{~g}][1 \mathrm{E}-1][0.2]=100 \mathrm{~g}(0.22 \mathrm{lb})$ uranium dioxide powder.

Other values for the ARF and RF would be applied to loose surface contamination--powder in sealed, sheetmetal, cans; powders in other configurations; and other physical forms (e.g., liquids, bulk metal, etc.). These will be discussed in the updated Handbook.

\section{D.3.4 Leak Path Factor (LPF)}

In this example, the explosion occurs in a room large enough to maintain normal ventilation flow. The explosion gases and aerosol particles made airborne are immediately well-mixed with the room air. The mixing with post explosion ventilation air continues at a steady normal flow.

The LPF for this problem builds on some concepts introduced in the free-fall spill Sample Problem 1. In that sample problem for LPF calculations, the airborne particles created in the spill were dumped into the primary spill room, followed by the primary exhaust duct leading to the stack. One LPF was calculated for the room and one for the duct, each independently. An estimate of the overall LPF was calculated by multiplying the two independent LPFs. In reality, even in this simple system, the room and duct are not independent but are attached in series and a combined LPF should be calculated. A method to accomplish this makes use of a different set of tables calculated by the LPF\#1 code (Pinkston 1993). This set of six tables (Tables D-7 through D-12) consists of LPFs for 36 combinations of flow/settling areas (Q/As) for the room and duct with $\mathrm{RF}$ as a parameter (nine values). Thus, with these six tables, an LPF can be 
Table D-7. LPFs for Series Room and Duct $(Q / A(r o o m)=0.1 \mathrm{~m} / \mathrm{s})$

\begin{tabular}{|l|l|l|l|l|l|l|}
\hline RF duct $\mathbf{Q} / \mathbf{A} \mathbf{~ m} / \mathrm{s} \rightarrow$ & 0.1 & 0.01 & 0.001 & 0.0001 & 0.00001 & 0.000001 \\
\hline 0.9996 & 0.1 & 0.991 & 0.93 & 0.63 & 0.15 & $3.4 \mathrm{E}-03$ \\
\hline 0.9900 & 0.1 & 0.97 & 0.80 & 0.34 & 0.032 & $2.1 \mathrm{E}-04$ \\
\hline 0.9082 & 0.99 & 0.93 & 0.59 & 0.12 & $3.4 \mathrm{E}-03$ & $5.4 \mathrm{E}-06$ \\
\hline 0.7102 & 0.98 & 0.89 & 0.43 & 0.042 & $4.8 \mathrm{E}-04$ & $5.4 \mathrm{E}-07$ \\
\hline 0.5000 & 0.97 & 0.87 & 0.35 & 0.020 & $1.2 \mathrm{E}-04$ & $3.2 \mathrm{E}-07$ \\
\hline 0.2898 & 0.97 & 0.85 & 0.30 & $9.3 \mathrm{E}-03$ & $2.8 \mathrm{E}-05$ & $2.8 \mathrm{E}-07$ \\
\hline 0.09185 & 0.97 & 0.83 & 0.23 & $3.1 \mathrm{E}-03$ & $6.1 \mathrm{E}-06$ & $1.5 \mathrm{E}-07$ \\
\hline $9.995 \mathrm{E}-03$ & 0.96 & 0.79 & 0.15 & $5.3 \mathrm{E}-04$ & $6.1 \mathrm{E}-06$ & $3.4 \mathrm{E}-10$ \\
\hline $4.447 \mathrm{E}-04$ & 0.96 & 0.78 & 0.13 & $5.3 \mathrm{E}-04$ & $6.1 \mathrm{E}-06$ & $2.2 \mathrm{E}-20$ \\
\hline
\end{tabular}

Table D-8. LPFs for Series Room and Duct $(\mathrm{Q} / \mathrm{A}(\mathrm{room})=0.01 \mathrm{~m} / \mathrm{s})$

\begin{tabular}{|l|l|l|l|l|l|l|}
\hline RF duct। Q/A m/s - & 0.1 & 0.01 & 0.001 & 0.0001 & 0.00001 & 0.000001 \\
\hline 0.9996 & 0.99 & 0.98 & 0.93 & 0.63 & 0.15 & $3.4 \mathrm{E}-03$ \\
\hline 0.9900 & 0.97 & 0.95 & 0.79 & 0.34 & 0.032 & $2.0 \mathrm{E}-04$ \\
\hline 0.9082 & 0.93 & 0.88 & 0.57 & 0.11 & $3.4 \mathrm{E}-03$ & $5.4 \mathrm{E}-06$ \\
\hline 0.7102 & 0.90 & 0.82 & 0.41 & 0.042 & $4.8 \mathrm{E}-04$ & $5.4 \mathrm{E}-07$ \\
\hline 0.5000 & 0.88 & 0.79 & 0.33 & 0.020 & $1.1 \mathrm{E}-04$ & $3.2 \mathrm{E}-07$ \\
\hline 0.2898 & 0.86 & 0.76 & 0.27 & $9.2 \mathrm{E}-03$ & $2.8 \mathrm{E}-05$ & $2.8 \mathrm{E}-07$ \\
\hline 0.09185 & 0.84 & 0.73 & 0.21 & $3.0 \mathrm{E}-03$ & $6.1 \mathrm{E}-06$ & $1.5 \mathrm{E}-07$ \\
\hline $9.995 \mathrm{E}-03$ & 0.80 & 0.67 & 0.13 & $5.1 \mathrm{E}-04$ & $6.1 \mathrm{E}-06$ & $3.4 \mathrm{E}-10$ \\
\hline $4.447 \mathrm{E}-04$ & 0.80 & 0.66 & 0.11 & $5.1 \mathrm{E}-04$ & $6.1 \mathrm{E}-06$ & $2.2 \mathrm{E}-20$ \\
\hline
\end{tabular}


Table D-9. LPFs for Series Room and Duct $(\mathrm{Q} / \mathrm{A}(\mathrm{room})=0.001 \mathrm{~m} / \mathrm{s})$

\begin{tabular}{|l|l|l|l|l|l|l|}
\hline RF duct $\mathbf{Q} / \mathrm{A} \mathrm{m} / \mathbf{s} \rightarrow$ & 0.1 & 0.01 & 0.001 & 0.0001 & 0.00001 & 0.000001 \\
\hline 0.9996 & 0.94 & 0.93 & 0.88 & 0.61 & 0.14 & $3.4 \mathrm{E}-03$ \\
\hline 0.9900 & 0.83 & 0.82 & 0.71 & 0.32 & 0.031 & $2.1 \mathrm{E}-04$ \\
\hline 0.9082 & 0.66 & 0.63 & 0.45 & 0.11 & $3.3 \mathrm{E}-03$ & $5.4 \mathrm{E}-06$ \\
\hline 0.7102 & 0.54 & 0.51 & 0.29 & 0.037 & $4.7 \mathrm{E}-04$ & $5.4 \mathrm{E}-07$ \\
\hline 0.5000 & 0.49 & 0.44 & 0.22 & 0.017 & $1.1 \mathrm{E}-04$ & $3.2 \mathrm{E}-07$ \\
\hline 0.2898 & 0.44 & 0.40 & 0.17 & $7.9 \mathrm{E}-03$ & $2.7 \mathrm{E}-05$ & $2.8 \mathrm{E}-07$ \\
\hline 0.09185 & 0.40 & 0.35 & 0.12 & $2.5 \mathrm{E}-03$ & $6.0 \mathrm{E}-06$ & $1.5 \mathrm{E}-07$ \\
\hline $9.995 \mathrm{E}-03$ & 0.33 & 0.28 & 0.06 & $4.2 \mathrm{E}-04$ & $6.0 \mathrm{E}-06$ & $3.3 \mathrm{E}-10$ \\
\hline $4.447 \mathrm{E}-04$ & 0.31 & 0.26 & 0.05 & $4.2 \mathrm{E}-04$ & $6.0 \mathrm{E}-06$ & $2.1 \mathrm{E}-20$ \\
\hline
\end{tabular}

Table D-10. LPFs for Series Room and Duct $(Q / A(r o o m)=0.0001 ~ m / s)$

\begin{tabular}{|l|l|l|l|l|l|l|}
\hline RF duct $/ \mathbf{Q} / \mathrm{A} \mathrm{m} / \mathrm{s}-$ & 0.1 & 0.01 & 0.001 & 0.0001 & 0.00001 & 0.000001 \\
\hline 0.9996 & 0.69 & 0.69 & 0.66 & 0.50 & 0.13 & $3.3 \mathrm{E}-03$ \\
\hline 0.9900 & 0.46 & 0.45 & 0.41 & 0.23 & 0.028 & $2.0 \mathrm{E}-04$ \\
\hline 0.9082 & 0.24 & 0.24 & 0.19 & 0.063 & $2.8 \mathrm{E}-03$ & $5.2 \mathrm{E}-06$ \\
\hline 0.7102 & 0.15 & 0.14 & 0.097 & 0.020 & $3.9 \mathrm{E}-04$ & $5.3 \mathrm{E}-07$ \\
\hline 0.5000 & 0.11 & 0.11 & 0.062 & $8.5 \mathrm{E}-03$ & $9.1 \mathrm{E}-05$ & $3.2 \mathrm{E}-07$ \\
\hline 0.2898 & 0.090 & 0.082 & 0.042 & $3.6 \mathrm{E}-03$ & $2.2 \mathrm{E}-05$ & $2.7 \mathrm{E}-07$ \\
\hline 0.09185 & 0.071 & 0.063 & 0.025 & $1.1 \mathrm{E}-03$ & $5.3 \mathrm{E}-06$ & $1.4 \mathrm{E}-07$ \\
\hline $9.995 \mathrm{E}-03$ & 0.050 & 0.043 & 0.011 & $1.7 \mathrm{E}-04$ & $5.3 \mathrm{E}-06$ & $3.0 \mathrm{E}-10$ \\
\hline $4.447 \mathrm{E}-04$ & 0.047 & 0.039 & $8.8 \mathrm{E}-03$ & $1.7 \mathrm{E}-04$ & $5.3 \mathrm{E}-06$ & $1.6 \mathrm{E}-20$ \\
\hline
\end{tabular}


Table D-11. LPFs for Series Room and Duct $(\mathrm{Q} / \mathrm{A}(\mathrm{room})=0.00001 \mathrm{~m} / \mathrm{s})$

\begin{tabular}{|l|l|l|l|l|l|l|}
\hline RF duct $\mathbf{Q} / \mathrm{A} \mathrm{m} / \mathrm{s} \rightarrow$ & 0.1 & 0.01 & 0.001 & 0.0001 & 0.00001 & 0.000001 \\
\hline 0.9996 & 0.27 & 0.27 & 0.27 & 0.22 & 0.080 & $2.8 \mathrm{E}-03$ \\
\hline 0.9900 & 0.12 & 0.12 & 0.11 & 0.076 & 0.015 & $1.6 \mathrm{E}-04$ \\
\hline 0.9082 & 0.043 & 0.042 & 0.036 & 0.016 & $1.3 \mathrm{E}-03$ & $4.1 \mathrm{E}-06$ \\
\hline 0.7102 & 0.021 & 0.020 & 0.015 & $4.2 \mathrm{E}-03$ & $1.6 \mathrm{E}-04$ & $4.6 \mathrm{E}-07$ \\
\hline 0.5000 & 0.014 & 0.014 & $8.7 \mathrm{E}-03$ & $1.6 \mathrm{E}-03$ & $3.5 \mathrm{E}-05$ & $2.9 \mathrm{E}-07$ \\
\hline 0.2898 & 0.011 & 0.01 & $5.4 \mathrm{E}-03$ & $6.4 \mathrm{E}-04$ & $8.3 \mathrm{E}-06$ & $2.4 \mathrm{E}-07$ \\
\hline 0.09185 & $7.9 \mathrm{E}-03$ & $7.1 \mathrm{E}-03$ & $3.0 \mathrm{E}-03$ & $1.7 \mathrm{E}-04$ & $3.0 \mathrm{E}-06$ & $1.1 \mathrm{E}-07$ \\
\hline $9.995 \mathrm{E}-03$ & $5.4 \mathrm{E}-03$ & $4.6 \mathrm{E}-03$ & $1.3 \mathrm{E}-03$ & $3.6 \mathrm{E}-05$ & $3.0 \mathrm{E}-06$ & $1.6 \mathrm{E}-10$ \\
\hline $4.447 \mathrm{E}-04$ & $5.1 \mathrm{E}-03$ & $4.3 \mathrm{E}-03$ & $1.1 \mathrm{E}-03$ & $3.6 \mathrm{E}-05$ & $3.0 \mathrm{E}-06$ & $4.6 \mathrm{E}-20$ \\
\hline
\end{tabular}

Table D-12. LPFs for Series Room and Duct $\left(\mathrm{Q} / \mathrm{A}(\mathrm{room})=10^{-6} \mathrm{~m} / \mathrm{s}\right)$

\begin{tabular}{|l|l|l|l|l|l|l|}
\hline RF duct $!$ Q/A m/s $\rightarrow$ & 0.1 & 0.01 & 0.001 & 0.0001 & 0.00001 & 0.000001 \\
\hline 0.9996 & 0.050 & 0.050 & 0.049 & 0.043 & 0.020 & $1.1 \mathrm{E}-03$ \\
\hline 0.9900 & 0.017 & 0.017 & 0.016 & 0.011 & $2.9 \mathrm{E}-03$ & $5.8 \mathrm{E}-05$ \\
\hline 0.9082 & $4.9 \mathrm{E}-03$ & $4.9 \mathrm{E}-03$ & $4.2 \mathrm{E}-03$ & $2.0 \mathrm{E}-03$ & $2.1 \mathrm{E}-04$ & $1.4 \mathrm{E}-06$ \\
\hline 0.7102 & $2.3 \mathrm{E}-03$ & $2.2 \mathrm{E}-03$ & $1.6 \mathrm{E}-03$ & $5.0 \mathrm{E}-04$ & $2.5 \mathrm{E}-05$ & $2.4 \mathrm{E}-07$ \\
\hline 0.5000 & $1.5 \mathrm{E}-03$ & $1.4 \mathrm{E}-03$ & $9.2 \mathrm{E}-04$ & $1.9 \mathrm{E}-04$ & $5.5 \mathrm{E}-06$ & $1.5 \mathrm{E}-07$ \\
\hline 0.2898 & $1.1 \mathrm{E}-03$ & $1.0 \mathrm{E}-03$ & $5.6 \mathrm{E}-04$ & $7.2 \mathrm{E}-05$ & $1.5 \mathrm{E}-06$ & $1.1 \mathrm{E}-07$ \\
\hline 0.09185 & $8.1 \mathrm{E}-04$ & $7.2 \mathrm{E}-04$ & $3.1 \mathrm{E}-04$ & $1.9 \mathrm{E}-05$ & $8.0 \mathrm{E}-07$ & $3.4 \mathrm{E}-08$ \\
\hline $9.995 \mathrm{E}-03$ & $5.5 \mathrm{E}-04$ & $4.7 \mathrm{E}-04$ & $1.3 \mathrm{E}-04$ & $4.8 \mathrm{E}-06$ & $8.0 \mathrm{E}-07$ & $2.7 \mathrm{E}-11$ \\
\hline $4.447 \mathrm{E}-04$ & $5.1 \mathrm{E}-04$ & $4.3 \mathrm{E}-04$ & $1.1 \mathrm{E}-04$ & $4.8 \mathrm{E}-06$ & $5.0 \mathrm{E}-07$ & $5.6 \mathrm{E}-22$ \\
\hline
\end{tabular}


estimated by interpolation over a wide range of Q/As $(0.1$ to $1 \mathrm{E}-06 \mathrm{~m} / \mathrm{s}(0.3$ to $3 \mathrm{E}-6 \mathrm{ft} / \mathrm{s}))$ for both the primary room and primary duct. Sometimes three-dimensional interpolation will be required and may be difficult, but the example that follows and the Fire Sample Problem (see Section D.4) illustrates this technique.

As already noted, a version of the LPF \#1 code is provided as part of this handbook and eliminates the need for cumbersome interpolation.

The exhaust system consists of ten ducts leading from the room to a downstream plenum. They carry the room ventilation exhaust of $6 \mathrm{ach}$, which is $28.3 \mathrm{~m}^{3} / \mathrm{s}(60000 \mathrm{cfm})$. The average horizontal distance along each duct to the plenum is $90 \mathrm{~m}$ ( $300 \mathrm{ft})$. Each duct is $0.6 \mathrm{~m}$ by $0.6 \mathrm{~m}$ ( $2 \mathrm{ft}$ by $2 \mathrm{ft})$. Rigorous calculations would require that each duct be handled separately, because each would have a unique pathway and flow rate to the plenum. But, for the sake of simplicity, average values are used here.

The LPF calculation requires the calculation of $\mathrm{Q} / \mathrm{A}(\mathrm{room})$ and $\mathrm{Q} / \mathrm{A}$ (duct). The settling area (upward facing) for the room is $30.5 \mathrm{~m}(100 \mathrm{ft})$ by $91.4 \mathrm{~m}$ (300 ft) or $2788 \mathrm{~m}^{2}\left(30000 \mathrm{ft}^{2}\right)$, with an exhaust flow rate out of $28.3 \mathrm{~m}^{3} / \mathrm{s}\left(1000 \mathrm{ft}^{3} / \mathrm{s}\right), \mathrm{Q} / \mathrm{A}(\mathrm{room})=1.02 \mathrm{E}-02 \mathrm{~m} / \mathrm{s}(3.06 \mathrm{E}-2 \mathrm{ft} / \mathrm{s})$. The total upward facing area for the ducts is $10 \mathrm{~m}(30 \mathrm{ft})$ by $0.6 \mathrm{~m}(2 \mathrm{ft})$ by $90 \mathrm{~m}(100 \mathrm{ft})=540 \mathrm{~m}^{2}\left(6000 \mathrm{ft}^{2}\right)$ and $\mathrm{Q} / \mathrm{A}($ duct $)=28.3 / 540=5.24 \mathrm{E}-$ $02 \mathrm{~m} / \mathrm{s}(0.17 \mathrm{ft} / \mathrm{s})$. Table $D-8[\mathrm{Q} / \mathrm{A}(\mathrm{room})=0.01 \mathrm{~m} / \mathrm{s}(0.03 \mathrm{ft} / \mathrm{s})]$ will suffice for this problem. Since $\mathrm{RF}=$ 0.16 , interpolated table values of 0.85 [first $L P F$ column for $Q / A(d u c t)=0.1 \mathrm{~m} / \mathrm{s}(0.3 \mathrm{ft} / \mathrm{s})$ ] and 0.75 [second LPF column for $\mathrm{Q} / \mathrm{A}(\mathrm{duct})=0.01 \mathrm{~m} / \mathrm{s}(0.03 \mathrm{ft} / \mathrm{s})$ ] provide for the final interpolation. For the sake of simplicity, the arithmetic average LPF is 0.8 . The LPF \#1 code gives 0.84 for this situation.

\section{D.3.5 Dose Assessment}

The explosion being modeled in this example does not result in serious overpressures which cause damage to the structure or ventilation system. Therefore, the possible release points to the environment are either a roof top vent (ground level) or the facility stack (elevated). As with the previous examples, no consideration is

given to leak path filtration. For this example, the considerations for atmospheric transport and dispersion are the same as discussed in the free-fall powder spill discussed in Section D.2.4.

\section{D.3.5.1 Choice of Dispersion Model}

As with the free-fall sample problem discussed in Section 2.4.1, the dispersion model should have the ability to model the following:

- Elevated and ground level releases

- Neutrally buoyant plumes

- Building wake effects

- Estimate doses resulting from exposure to enriched uranium

- Plume depletion due to radioactive decay and deposition (dry) 
The RASCAL model developed by the U.S. Nuclear Regulatory Commission (USNRC 1993) would also be a good choice for this example. However, to illustrate the use of a different model, the HOTSPOT model (Homann 1994) has been used to determine consequences resulting from the release in this example.

The HOTSPOT codes were created as a portable calculation tool for evaluating accidents involving radioactive materials. They provide a fast first order approximation of the radiation effects associated with the atmospheric release of radioactive materials. They also provide a quick and easy method for performing numerous calculations during hazards analyses.

The HOTSPOT codes contain four general programs to calculate consequences from an airborne puff or continuous release, explosive release, fuel fire, or an area contamination event. Variations of the general models are designed to deal with the release of plutonium, uranium, or tritium resulting from an accident involving a nuclear weapon. Other models are designed to estimate inhalation dose from workplace exposure, calibrate radiation survey instruments, or screen plutonium uptake in the lung.

For purposes of this example, the General Plume model has been be used. Atmospheric transport and dispersion in HOTSPOT are based on the Gaussian plume model (see Chapter 5 of this handbook). HOTSPOT models do not have the option of including building wake effects or estimating effective release height (effective release height can be entered manually). With the exception of calculations involving noble gases, dose values are due solely to the inhalation of released material during plume passage. For noble gases (e.g., $\mathrm{Kr}$-85), the submersion dose is determined. The General Plume model provides the following output values: deposition, integrated air concentration, 50-year committed dose to the target organ (unweighted), and committed effective dose equivalent (CEDE) to the whole body. The TEDE is not calculated because, for acute exposures (i.e., less than 24 hours) incurred during accidental releases, the CEDE is usually much larger . than the submersion and ground shine components (see Table D-4, summary of RASCAL output for the freefall spill example). Consequences can be calculated at predetermined or user-specified distances. For this example, the same distances as in the free-fall spill example problem has been used.

\section{D.3.5.2 Example Problem Parameters for Atmospheric Dispersion}

Site and Facility:

The same generic site and facility described for Sample Problem 1, Free-Fall Spill of Powder, has been assumed for this problem (see Section D.2.4.2).

Release Path:

Since either pathway is a possibility for the scenario being examined in this example, calculations are performed for a ground level and an elevated (facility stack) release. The HOTSPOT models do not have subroutines to calculate the effects for building wake or effective release height. The effect of building wake was demonstrated in the free-fall spill example (see Section D.2.4.3). In this example, the effect of release height has been examined by manually inputting three different release heights $(60,90$, and $120 \mathrm{~m}(200,300$ and $400 \mathrm{ft})$ ).

Meteorological Conditions: 
The same meteorological conditions as those described in the free-fall spill sample problem have been assumed for this example (see Section D.2.4.2).

\section{Source Term:}

In the explosion scenario, it has been assumed that the material released is rapidly dispersed and mixed with the room air. The material at risk (MAR) is $5.0 \mathrm{~kg}(11 \mathrm{lb})$ of $\mathrm{UO}_{2}$ powder. In the previous discussion, the following source term factors have been determined: $\mathrm{ARF}=1 \mathrm{E}-1, \mathrm{RF}=0.2$, and $\mathrm{LPF}=0.8$. Therefore, the material available for release to the atmosphere is equal to:

$$
\begin{aligned}
\text { MAR x ARF x RF x LPF } & =(5.0 \mathrm{~kg})(1 \mathrm{E}-1)(0.2)(0.8) \\
& =8 \mathrm{E}-2 \mathrm{~kg}
\end{aligned}
$$

The uranium dioxide powder is assumed to be enriched and consists of 0.88 by mass uranium. Therefore, the mass of uranium released to the atmosphere is $(0.88)(80 \mathrm{gm})=70.4 \mathrm{gm}(0.16 \mathrm{lb})$. The HOTSPOT model asks for source term in total curies released. The model assumes that the receptor is exposed throughout the duration of plume passage. The dose received by the receptor depends only on the total amount of radioactive material that passes by. Therefore, the duration of release does not need to be specified. A typical percentage of nuclides for a batch of enriched $\mathrm{UO}_{2}$ is: 93.15 percent $U-235,1.00$ percent $U-234,0.50$ percent $U-236$, and 5.35 percent $\mathrm{U}-238$. Total curies of each release are:

- $\quad \mathrm{U}-235=(93.15$ percent $)(70.4 \mathrm{gm})(2.16 \mathrm{E}-6 \mathrm{Ci} / \mathrm{gm})=1.42 \mathrm{E}-4 \mathrm{Ci}$

- $\mathrm{U}-234=(1.00$ percent $)(70.4 \mathrm{gm})(6.24 \mathrm{E}-3 \mathrm{Ci} / \mathrm{gm})=4.39 \mathrm{E}-3 \mathrm{Ci}$

- $\mathrm{U}-236=(0.50$ percent $)(70.4 \mathrm{gm})(6.49 \mathrm{E}-5 \mathrm{Ci} / \mathrm{gm})=2.28 \mathrm{E}-5 \mathrm{Ci}$

- $\mathrm{U}-238=(5.35$ percent $)(70.4 \mathrm{gm})(3.35 \mathrm{E}-7 \mathrm{Ci} / \mathrm{gm})=1.26 \mathrm{E}-6 \mathrm{Ci}$

\section{D.3.5.3 Example Atmospheric Dispersion Problems}

Examples are provided for a ground level release and an elevated release at several different effective release heights. As noted previously, each case presented is performed using two sets of meteorological conditions, one representative of severe meteorology (e.g., higher consequences) and one representative of average meteorological conditions. Consequences are calculated at six arbitrary distances. The range is from $100 \mathrm{~m}$ to $16000 \mathrm{~m}$ ( 0.06 to $10 \mathrm{mi})$ and represents the approximate limits within which the Gaussian dispersion model yields meaningful results. This range also encompasses the primary population at risk (e.g., workers and general population) from any accidental release of hazardous material.

Example 1: The first example consists of a release from a building roof top vent (swept down to ground level). Tables D-13, D-14, and D-15 are examples of the input summary and output provided by HOTSPOT. Input shown is for the ground level release with severe meteorology. The output is for the $0.10 \mathrm{~km}$ distance; output for all other distances is in the same format.

Example 2: In this example, consequences from an elevated release have been calculated for severe and average meteorology at three different release heights. Table D-15 summarizes the results. 
Table D-13. HOTSPOT Example Input Summary and Output

HOTSPOT 8.0 GENERAL PLUME 10-03-1996 16:18

USER MIXTURE : D:LHOTSPOTUNC1.MIX EFFECTIVE RELEASE HEIGHT : $\quad 0.00 \mathrm{~m}$

WIND SPEED $(\mathrm{h}=2 \mathrm{~m}): 2.0 \mathrm{~m} / \mathrm{s}$

STABILITY CLASS $\quad$ :F RECEPTOR HEIGHT $\quad: 0.0 \mathrm{~m}$

INVERSION LAYER HEIGHT : NONE

SAMPLE TIME $\quad: 10.000 \mathrm{~min}$

MAXIMUM DOSE DISTANCE $:<0.10 \mathrm{~km}$ MAXIMUM CEDE $:>2.8 \mathrm{rem}$

$\mathrm{D}=0.100 \mathrm{~km}$

$\mathrm{DEP}=6.4 \mathrm{E}-01 \mathrm{uCi} / \mathrm{m}^{\wedge} 2$

$\mathrm{CHI}=6.4 \mathrm{E}-05(\mathrm{Ci}-\mathrm{s}) / \mathrm{m}^{\wedge} 3$

50-YR DOSE COMMITMENT:

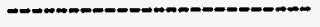

LUNG 2.3E+01 rem

EFFECTIVE DOSE

EQUIVALENT $2.8 \mathrm{E}+00 \mathrm{rem}$

Table D-14. Results for the Explosion Ground Level Release

\begin{tabular}{|c|c|c|}
\hline & Committed Effective Dose Equivalent (rem) \\
\hline Distance $(\mathbf{k m})$ & Severe Meteorology & Average Meteorology \\
\hline 0.10 & $2.8 \mathrm{E}+00$ & $2.6 \mathrm{E}-01$ \\
\hline 0.80 & $3.1 \mathrm{E}-02$ & $5.5 \mathrm{E}-03$ \\
\hline 1.6 & $7.6 \mathrm{E}-03$ & $1.7 \mathrm{E}-03$ \\
\hline 3.2 & $2.0 \mathrm{E}-03$ & $5.8 \mathrm{E}-04$ \\
\hline 8.0 & $3.7 \mathrm{E}-04$ & $1.5 \mathrm{E}-04$ \\
\hline 16.0 & $8.0 \mathrm{E}-05$ & $5.7 \mathrm{E}-05$ \\
\hline
\end{tabular}


Table D-15. Elevated Release Results for Explosion Example

\begin{tabular}{|c|c|c|c|c|c|c|}
\hline \multicolumn{7}{|c|}{ Committed Effective Dose Equivalent (rem) } \\
\hline \multirow{2}{*}{ Distance (km) } & \multicolumn{3}{|c|}{ Severe Meteorology } & \multicolumn{3}{|c|}{ Average Meteorology } \\
\hline & $60 \mathrm{~m}$ & $90 \mathrm{~m}$ & $120 \mathrm{~m}$ & $60 \mathrm{~m}$ & $90 \mathrm{~m}$ & $120 \mathrm{~m}$ \\
\hline 0.10 & 6.3E-04 & 2.2E-06 & 8.2E-10 & $1.6 \mathrm{E}-22$ & $1.6 \mathrm{E}-22$ & $1.6 \mathrm{E}-22$ \\
\hline 0.80 & 8.3E-04 & 7.4E-04 & $6.5 \mathrm{E}-04$ & 6.7E-04 & 7.4E-05 & $3.5 \mathrm{E}-06$ \\
\hline 1.6 & 2.2E-04 & 2.1E-04 & 2.1E-04 & 6.1E-04 & 2.5E-04 & 7.7E-05 \\
\hline 3.2 & $6.0 \mathrm{E}-05$ & 5.8E-05 & 5.7E-05 & 3.1E-04 & 2.1E-04 & $1.2 \mathrm{E}-04$ \\
\hline 8.0 & $1.1 \mathrm{E}-05$ & 1.1E-05 & $1.1 \mathrm{E}-05$ & 9.7E-05 & $8.2 \mathrm{E}-05$ & $6.7 \mathrm{E}-05$ \\
\hline 16.0 & 3.3E-06 & $3.2 \mathrm{E}-06$ & $3.2 \mathrm{E}-06$ & $3.9 \mathrm{E}-05$ & 3.6E-05 & 3.3E-05 \\
\hline
\end{tabular}

Table D-15 shows that the effect of increasing elevation is to increase the distance to the point where the plume touches the ground, which results in a lower dose near the release point. Once the plume has fully touched the ground, there is little effect on doses for the remaining distances.

\section{D.4 Sample Problem 3: Fire with Radioactive Release}

\section{D.4.1 Introduction}

Limited quantities of solid combustible materials are found in non-reactor, non-medical nuclear facilities. The locations of the combustible materials within the operating areas of a facility are generally scattered and not amendable to propagation that could result in a general facility fire. Furthermore, only a limited portion of the combustible materials within the operating area are contaminated with radioactive materials.

The combustion of a solid, combustible material is a heterogeneous process--heat applied to the solid material generates a combustible vapor (pyrolyzate) that rises and mixes with air drawn from around the edges of the flame. Eventually, the vapor-air mixture attains a dilution that is flammable and is ignited and burns. Heat generated by the flames radiates back to the surface of the solid material that continues the pyrolyzation process to generate more vapors. The height of the flames above the surface is a function of the vapor generation and mixing required to achieve a burnable mixture. Heat radiated by the flames may also ignite other materials at some distance, depending upon the characteristics of the material, the flame size, and separation distance. Materials contaminating the combustible solids may be suspended by destruction of the solid substrate upon which the contamination lies. The physical forms of the contaminant under these conditions (e.g., vapor, solid particles) and the magnitude of the velocity of the vapor generated at the locale combine to carry the particles to the convective flow beyond the flames. 


\section{D.4.2 Scenario}

It is postulated that contaminated combustible materials are accumulated within the operating area at several locations within a facility handling and processing enriched uranium. The contaminated wastes are from various processes where uranium solutions and oxide powders could be lost as minor leaks. The contaminant could be air-dried residue from uranium nitrate solutions or uranium oxide powders. The waste is accumulated at five locations within an operating room $30.5 \mathrm{~m}$ (100 ft) wide by $91.4 \mathrm{~m}(300 \mathrm{ft})$ long by 6.1 $\mathrm{m}(20 \mathrm{ft})$ high, that has a total volume of $17,000 \mathrm{~m}^{3}\left(600,000 \mathrm{ft}^{3}\right)$. It is postulated that the fire propagates slowly by igniting other non-contaminated combustibles (e.g., rags, paper, plastic) in the area, resulting in the sequential ignition and burning of the contaminated combustibles held in metal cans.

The combustible loading is assumed to be:

- combustibles contaminated with air-dried residues (two locations) $20 \mathrm{~g}(0.04 \mathrm{lb}) \mathrm{U}$ as UNH, $10 \mathrm{~g}$ $(0.02 \mathrm{lb})$ in each location

- combustibles contaminated with powder (three locations) $30 \mathrm{~g}(0.07 \mathrm{lb}) \mathrm{UO}_{2}, 10 \mathrm{~g}(0.02 \mathrm{lb})$ in each location

\section{D.4.3 Evaluation}

Sample problems are presented to illustrate the evaluation of the airborne release by using hand calculations to derive the ARFs and RFs and computer model generated LPFs.

The combustibles at the five separate locations are assumed to burn sequentially. The contaminated combustibles are assumed to be composed of a loose accumulation of cellulosic materials, plastic, and rubber gloves held in a sheet metal can with the contents exposed to the ambient environment.

Airborne release fractions have been measured during the burning of combustibles contaminated with $\mathrm{UO}_{2}$

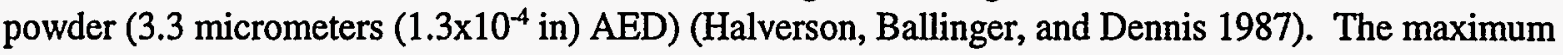
fraction made airborne in these limited experiments (only a single datum is available for some combinations) varied by combustible material and contaminant:

\begin{tabular}{|l|l|l|}
\hline \multicolumn{1}{|c|}{ Material } & \multicolumn{1}{|c|}{ Contaminant } & ARF \\
\hline Polychloroprene (elastomer, rubber) & $\mathrm{UO}_{2}$ & 0.0103 \\
\hline Polychloroprene & Air-dried UNH & 0.0042 \\
& $\mathrm{UNH}$ & 0.0347 \\
\hline Polystyrene (plastic, IX resin) & $\mathrm{UNH}^{\prime}$ & 0.0078 \\
\hline Polymethyl methacrylate & $\mathrm{UO}_{2}$ & 0.045 \\
\hline Polymethyl methacrylate & $\mathrm{UNH}$ & 0.020 \\
\hline
\end{tabular}




\begin{tabular}{|c|c|c|}
\hline Material $\because \because:$ & Contaminant & ARF \\
\hline Polychloroprene (elastomer, rubber) & $\begin{array}{l}\mathrm{UO}_{2} \\
\text { Air-dried UNH }\end{array}$ & $\begin{array}{l}0.0103 \\
0.006\end{array}$ \\
\hline Cellulose & $\begin{array}{l}\mathrm{UO}_{2} \\
\text { UNH } \\
\text { Air-dried UNH }\end{array}$ & $\begin{array}{l}0.003 \\
0.0001 \\
0.0003\end{array}$ \\
\hline
\end{tabular}

Respirable fractions were measured in a few experiments:

\begin{tabular}{|c|c|c|}
\hline Material and Contaminant & ARF & $\mathbf{R F}$ \\
\hline Polychloroprene+ $\mathrm{UO}_{2}$ & 0.0037 & 0.16 \\
\hline Polystyrene+UNH & 0.0078 & 0.9 \\
\hline Polymethylmethacrylate+UNH & 0.019 & 0.84 \\
\hline Polymethylmethacrylate+Air-dried UNH & 0.006 & 0.63 \\
\hline Polymethylmethacrylate $+\mathrm{UO}_{2}$ & 0.036 & 0.84 \\
\hline Polymethylmethacrylate $+\mathrm{UO}_{2}$ & 0.0152 & 0.95 \\
\hline Cellulose $+\mathrm{UO}_{2}$ & 0.017 & 0.97 \\
\hline Cellulose $+\mathrm{UO}_{2}$ & 0.000475 & 0.4 \\
\hline Cellulose $+\mathrm{UO}_{2}$ & 0.0009 & 0.47 \\
\hline
\end{tabular}

For best application, the fraction of each type of combustible-contaminant form should be multiplied by the appropriate ARF/RF. In most cases, none of the fraction of combustible materials, the type and level of contamination, or the physical configuration (i.e., packaged or unpackaged with what materials) are defined. Therefore, a bounding value can be obtained by applying the largest ARF/RF for each type of contaminant in this case where the materials are segregated:

- $\mathrm{UO}_{2}$ powder with undefined combustible material, 3 piles of $10 \mathrm{~g}(0.02 \mathrm{lb}) \mathrm{UO}_{2}$ each. The maximum $\mathrm{ARF} / \mathrm{RF} \mathrm{UO} \mathrm{U}_{2}$ with combustible materials is for $\mathrm{PMMA}$, for which $\mathrm{ARF}=0.045 / \mathrm{RF}=0.95$, therefore:

Airborne Release $=\left[30 \mathrm{~g} \mathrm{UO}_{2}\right]\left[0.88 \mathrm{~g} \mathrm{U} / \mathrm{g} \mathrm{UO}_{2}\right][0.045][0.95]=1.13 \mathrm{~g} \mathrm{U}$

- UNH liquid or air-dried UNH + combustible material, 2 piles of $10 \mathrm{~g}(0.02 \mathrm{lb}) \mathrm{U}$. A plausible combination of $\mathrm{ARF}$ and $\mathrm{RF}$ for these forms is $\mathrm{ARF}=0.0347$ and $\mathrm{RF}=0.16$, where this $\mathrm{ARF} / \mathrm{RF}$ combination can occur when the combustible material is polychloroprene. Therefore: 
Airborne Release $=[20 \mathrm{~g} \mathrm{U}$ as UNH $][0.0347][0.16]$

$$
=0.11 \mathrm{~g} \mathrm{U}
$$

- Total U released to the operating area volume is:

$$
1.13 \mathrm{~g} \mathrm{U}+0.11 \mathrm{~g} \mathrm{U}=1.2 \mathrm{~g} \mathrm{U} \text {. }
$$

Note the assumption that the RF depends on the underlying combustible material.

\section{D.4.4 Leak Path Factor}

Calculating the LPF during a fire can be complicated. The complications arise from the dynamic nature of the fire and its combustion products. Even if the fire is confined to a single room and the room integrity survives, the fire itself is usually not a constant source of smoke and energy, and the smoke eventually fills the entire room. This smoke might slow or put out the fire. If the normal ventilation system remains operational, the smoke might be caught on a downstream filter, thus slowing the ventilation rate. The unsteady process of a burn of combustibles and the above factors have led to some assumptions to make the problem tractable.

The assumptions are:

- The combustibles are restricted in size and do not overpower the ventilation system, which provides a steady burning rate throughout the fire.

- The ventilation system remains intact but can suffer filter plugging. This problem with the LPF is illustrated with two ventilation flow rates, normal, and $0.1 \mathrm{x}$ normal.

- The smoke produced will mix well in the fire room.

\section{LPF Calculations}

One-fourth of the LPF calculations here are exactly the same as for the explosion problem (3.0), where the same room size, initial flow rate, and $R F$ are used. That part is repeated below.

The exhaust system consists of ten ducts leading from the room to a downstream plenum. They carry the room ventilation exhaust of $6 \mathrm{ach}$, which is $28.3 \mathrm{~m}^{3} / \mathrm{s}(60000 \mathrm{cfm})$. The average horizontal distance along each duct to the plenum is $90 \mathrm{~m}(\sim 300 \mathrm{ft})$. Each duct is $0.6 \mathrm{~m}$ by $0.6 \mathrm{~m}(2 \mathrm{ft}$ by $2 \mathrm{ft})$. Rigorous calculations would require that each duct be handled separately, since each would have a unique pathway and flow rate to the plenum. However, for the sake of simplicity, average values are used here.

The results of the LPF calculation have been presented in Tables D-7 through D-12 for a set of values of Q/A (room) and Q/A (duct). Methods for calculation of LPFs are discussed in Chapter 4 of this Handbook. The settling area (upward facing) for the room is $30.5 \mathrm{~m}$ (100 ft) by $91.4 \mathrm{~m}(300 \mathrm{ft})$, or $2788 \mathrm{~m}^{2}\left(30000 \mathrm{ft}^{2}\right)$. With an exhaust flow rate out of $28.3 \mathrm{~m}^{3} / \mathrm{s}(92.9 \mathrm{ft} / \mathrm{s}), \mathrm{Q} / \mathrm{A}(\mathrm{room})=1.02 \mathrm{E}-02 \mathrm{~m} / \mathrm{s}(0.03 \mathrm{ft} / \mathrm{s})$. The total upward-facing area for the ducts is 10 times $0.6 \mathrm{~m}$ by $90 \mathrm{~m}(2$ by $295 \mathrm{ft})=540 \mathrm{~m}^{2}\left(5180 \mathrm{ft}^{2}\right)$ and Q/A (duct) $=28.3 / 540=5.24 \mathrm{E}-02 \mathrm{~m} / \mathrm{s}(0.17 \mathrm{ft} / \mathrm{s})$. LPFs are determined by interpolation of Table D-8 data, and scenario 
conditions are summarized in Table D-16. Since $\mathrm{RF}=0.16$ for the $\mathrm{UNH}$, interpolated values of 0.85 (first LPF column for $\mathrm{Q} / \mathrm{A}$ (duct) $=0.1$ ) and 0.75 (second

Table D-16. Summary of Fire Event Combined Room/Duct LPFs

\begin{tabular}{|l|l|l|}
\hline Flow & RF $=0.16(\mathrm{UNH})$ & $\mathrm{RF}=0.95\left(\mathrm{UO}_{2}\right)$ \\
\hline Normal & LPF $=0.80$ & LPF $=0.94$ \\
\hline Normal/10 & LPF $=0.26$ & LPF $=0.65$ \\
\hline
\end{tabular}

LPF column for $\mathrm{Q} / \mathrm{A}$ (duct) $=0.01$ ) provide for the final interpolation. For the sake of simplicity, the arithmetic average LPF of 0.8 is used.

For $\mathrm{UO}_{2}$, another $\mathrm{RF}=0.95$ was chosen (see Section D.6.3). This choice requires another set of interpolations in Table D-8. Since $R F=0.95$, interpolated values of 0.95 (first $L P F$ column for $Q / A$ (duct) = $0.1 \mathrm{~m} / \mathrm{s}$ ) and 0.92 (second LPF column for $\mathrm{Q} / \mathrm{A}$ (duct) $=0.01$ ) provide for the final interpolation. Since 0.95 and 0.92 are very close numbers, an LPF of 0.94 was selected.

The calculations have been repeated for slower ( 0.1 normal) flow. Here, $\mathrm{Q} / \mathrm{A}$ (room) $=1.02 \mathrm{E}-03 \mathrm{~m} / \mathrm{s}(3.3 \mathrm{E}-3$ $\mathrm{ft} / \mathrm{s})$ and $\mathrm{Q} / \mathrm{A}(\mathrm{duct})=5.24 \mathrm{E}-03 \mathrm{~m} / \mathrm{s}(1.7 \mathrm{E}-3 \mathrm{ft} / \mathrm{s})$. Using Table $\mathrm{D}-9$, for $\mathrm{RF}=0.16$, the interpolated values are 0.37 and 0.14 , giving a final $L P F=0.26$. For $R F=0.95$, the interpolated values are 0.73 and 0.58 , giving a final $L P F=0.65$.

The above table shows the effects of particle size and flow rate. The LPF goes up as flow rate increases and settling residence time decreases. The effect of RF shows that the LPF goes down as the respirable tail of a log-normal distribution decreases (i.e., with a low RF, most particles in the distribution have a relatively high mass and settle out quickly).

To apply the values in Table D-16, each of the two parts of the $1.2 \mathrm{~g} \mathrm{U}$ made airborne has its own LPF, since each part has a different RF. For example, the atmospheric source term for normal flow would be $0.94(1.13)$ $+0.80(0.11)=1.15 \mathrm{~g}(0.0025 \mathrm{lb}) \mathrm{U}$.

For a more sophisticated analysis, the transient fire with filter plugging can be done using the FIRAC/FIRIN code system (Gregory, et al. 1983). See Chapter 3 for further discussion of this code.

\section{D.4.5 Dose Assessment}

The fire being modeled in this example is assumed not to result in serious damage to the structure or ventilation system. Therefore, the possible release points to the environment are either a roof top vent (ground level) or the facility stack (elevated). As with the previous examples, no consideration is given to leak path filtration. For this example, the considerations for atmospheric transport and dispersion are the same as discussed in the free-fall powder spill (see Section D.2.6.2). 


\section{D.4.5.1 Choice of Dispersion Model}

As with the free-fall sample problem discussed in Section D.2.4.1, the dispersion model should have the ability to model the following:

- Elevated and ground level releases

- Neutrally buoyant plumes

- Building wake effects

- Estimate doses resulting from exposure to enriched Uranium

- Plume depletion due to radioactive decay and deposition (dry)

The RASCAL model developed by the U.S. Nuclear Regulatory Commission (USNRC 1993) is used for this example.

\section{D.4.5.2 Example Problem Parameters for Atmospheric Dispersion}

\section{Site and Facility:}

The same generic site and facility described in Sample Problem 1 has been assumed for this problem (see Section D.2.4.2).

\section{Release Path:}

Since either pathway is a possibility for the scenario being examined in this example, calculations are performed for a ground level and an elevated (facility stack) release. Since the building wake and effective release height effects have been demonstrated previously, and are not considered in this example.

\section{Meteorological Conditions:}

The same meteorological conditions assumed in Sample Problem \#1 (free-fall spill) have been assumed for this example.

\section{Source Term:}

It is assumed that the material released is rapidly dispersed and mixed with the room air. As discussed in Section D.4.3, the material released is in two physical forms-- $\mathrm{UO}_{2}$ and $\mathrm{UNH}$ liquid or dried. It is assumed that the duration of the release is 30 minutes $(1,800$ seconds) and that the air flow through the ducts is normal. As in previous problems, no credit is taken for the effect of in-line filtration. The RASCAL model requires that the source term be entered in terms of a release rate or curies per unit time. A typical percentage of nuclides for a batch of enriched $\mathrm{UO}_{2}$ is: 93.15 percent $U-235,1.00$ percent $U-234,0.50$ percent $U-236$, and 5.35 percent $U-238$. To determine the release rate by nuclide, the total quantity released to the operating volume for each physical form is multiplied by the LPF given in Table D-16 for the normal flow multiplied 
by the percentage of each nuclide, multiplied by the specific activity for each nuclide, and divided by the release duration in seconds. The total release rate of each nuclide is:

$\underline{\mathrm{UO}}_{2} \underline{\text { Powder }}$

- $\quad \mathrm{U}-235=(93.15$ percent $)(0.94)(1.13 \mathrm{gm})(2.16 \mathrm{E}-6 \mathrm{Ci} / \mathrm{gm})(1 / 1800 \mathrm{sec})=1.19 \mathrm{E}-09 \mathrm{Ci} / \mathrm{sec}$

- $\mathrm{U}-234=(1.00 \mathrm{percent})(0.94)(1.13 \mathrm{gm})(6.24 \mathrm{E}-3 \mathrm{Ci} / \mathrm{gm})(1 / 1800 \mathrm{sec})=3.86 \mathrm{E}-08 \mathrm{Ci} / \mathrm{sec}$

- $\mathrm{U}-236=(0.50$ percent $)(0.94)(1.13 \mathrm{gm})(6.49 \mathrm{E}-5 \mathrm{Ci} / \mathrm{gm})(1 / 1800 \mathrm{sec})=1.92 \mathrm{E}-10 \mathrm{Ci} / \mathrm{sec}$

- $\mathrm{U}-238=(5.35 \mathrm{percent})(0.94)(1.13 \mathrm{gm})(3.35 \mathrm{E}-7 \mathrm{Ci} / \mathrm{gm})(1 / 1800 \mathrm{sec})=1.06 \mathrm{E}-11 \mathrm{Ci} / \mathrm{sec}$

$\underline{\text { UNH }}$

- $\quad \mathrm{U}-235=(93.15$ percent $)(0.80)(.11 \mathrm{gm})(2.16 \mathrm{E}-6 \mathrm{Ci} / \mathrm{gm})(1 / 1800 \mathrm{sec})=9.84 \mathrm{E}-11 \mathrm{Ci} / \mathrm{sec}$

- $\mathrm{U}-234=(1.00$ percent $)(0.80)(.11 \mathrm{gm})(6.24 \mathrm{E}-3 \mathrm{Ci} / \mathrm{gm})(1 / 1800 \mathrm{sec})=3.05 \mathrm{E}-09 \mathrm{Ci} / \mathrm{sec}$

- $\mathrm{U}-236=(0.50$ percent $)(0.80)(.11 \mathrm{gm})(6.49 \mathrm{E}-5 \mathrm{Ci} / \mathrm{gm})(1 / 1800 \mathrm{sec})=1.58 \mathrm{E}-11 \mathrm{Ci} / \mathrm{sec}$

- $\mathrm{U}-238=(5.35$ percent $)(0.80)(.11 \mathrm{gm})(3.35 \mathrm{E}-7 \mathrm{Ci} / \mathrm{gm})(1 / 1800 \mathrm{sec})=8.76 \mathrm{E}-13 \mathrm{Ci} / \mathrm{sec}$

Total Release Rate by Nuclide

- $\mathrm{U}-235=1.29 \mathrm{E}-09 \mathrm{Ci} / \mathrm{sec}$

- $\mathrm{U}-234=4.17 \mathrm{E}-08 \mathrm{Ci} / \mathrm{sec}$

- $\mathrm{U}-236=2.08-10 \mathrm{Ci} / \mathrm{sec}$

- $\mathrm{U}-238=1.15 \mathrm{E}-11 \mathrm{Ci} / \mathrm{sec}$

\section{D.4.5.3 Example Atmospheric Dispersion Problems}

Results are presented for a ground level release (Table D-17) and an elevated release (Table D-18). Each case presented has been performed using two sets of meteorological conditions--one representative of severe meteorology (e.g., higher consequences) and one representative of average meteorological conditions. Consequences are calculated at six arbitrary distances. The range is from $100 \mathrm{~m}$ to $16000 \mathrm{~m}(0.06$ to $10 \mathrm{mi})$ and represents the approximate limits within which the Gaussian dispersion model yields meaningful results. This range also encompasses the primary population at risk (e.g., workers and general population) from any accidental release of hazardous material.

Example 1: The first example consists of a release from a building roof top vent (assumed to be swept down to ground level). An example of the input summary and output provided by RASCAL has been provided in Section D.2.4.3. Potential accident impacts are summarized in Table D-17.

Example 2: In this example, consequences from an elevated release have been calculated for severe and average meteorology. Table D-18 summarizes the results. 
Table D-17. Results for the Fire Example Ground Level Release (No Building Wake)

\begin{tabular}{|c|c|c|}
\hline \multicolumn{3}{|c|}{ Total Effective Dose Equivalent (rem) } \\
\hline Distance $(\mathbf{k m})$ & Severe Meteorology & Average Meteorology \\
\hline 0.10 & $3.6 \mathrm{E}-03$ & $9.2 \mathrm{E}-04$ \\
\hline 0.80 & $7.6 \mathrm{E}-04$ & $9.5 \mathrm{E}-05$ \\
\hline 1.6 & $3.5 \mathrm{E}-04$ & $3.7 \mathrm{E}-05$ \\
\hline 3.2 & $1.5 \mathrm{E}-04$ & $1.4 \mathrm{E}-05$ \\
\hline 8.0 & $5.0 \mathrm{E}-05$ & $3.6 \mathrm{E}-06$ \\
\hline 16.0 & $2.1 \mathrm{E}-06$ & $1.3 \mathrm{E}-06$ \\
\hline
\end{tabular}

Table D-18. Consequences from an Elevated Release

\begin{tabular}{|c|c|c|}
\hline \multicolumn{3}{|c|}{ Total Effective Dose Equivalent (rem) } \\
\hline Distance (km) & Severe Meteorology & Average Meteorology \\
\hline 0.10 & $3.3 \mathrm{E}-06$ & $2.5 \mathrm{E}-08$ \\
\hline 0.80 & $8.8 \mathrm{E}-06$ & $1.4 \mathrm{E}-05$ \\
\hline 1.6 & $3.9 \mathrm{E}-06$ & $1.2 \mathrm{E}-05$ \\
\hline 3.2 & $2.1 \mathrm{E}-06$ & $6.9 \mathrm{E}-06$ \\
\hline 8.0 & $9.2 \mathrm{E}-07$ & $2.3 \mathrm{E}-06$ \\
\hline 16.0 & $4.9 \mathrm{E}-07$ & $9.1 \mathrm{E}-07$ \\
\hline
\end{tabular}

\section{D.5 Sample Problem 4: Filter Failure}

\section{D.5.1 Introduction}

High Efficiency Particulate Air (HEPA) filters are used in many nuclear facilities as the final barrier between particulate materials airborne in the facility and the ambient environment around the facility. HEPA filters are used within the facility to remove particulate materials made airborne by processes known to have a significant potential for such events. HEPA filters are also used to protect the exhaust system by filtration of exhaust from devices such as glove boxes and hoods where particulate generating activities occur. 
A HEPA filter is essentially a shallow frame of metal or pressed fiber that contains a filtration medium. The medium most commonly found in U.S. facilities is a fine, glass fiber mat but other materials such as cellulose, mineral, and metal fibers are also used. Particles in air passing through the medium are collected by three mechanisms--impaction, interception, and diffusion. Impaction collects larger particles $>1$ micrometer $\left.\left(4 \times 10^{-5} \mathrm{in}\right) \mathrm{AED}\right)$ by the inertial force generated by the mass of the particle and the velocity of air and the inability of the particle to follow the streamlines as it encounters the fine fiber. Smaller particles have less inertia and can partially follow the flow changes. If the particle (micrometer to submicrometer AED) approaches the fiber within the largest dimension of the particle, the particle can be collected on the surface of the fiber. Submicrometer AED particles penetrate in to the fiber mat and, because of the tortuous path via the cells created by the matted fiber, diffuse to the surface of the fibers. For a given combination of fiber diameter and face velocity, there is a most penetrating particle. For the $0.6 \mathrm{~m}(2 \mathrm{ft})$ by $0.6 \mathrm{~m}(2 \mathrm{ft}) \mathrm{HEPA}$ filter used in the U.S. with a volumetric flow of $0.49 \mathrm{~m}^{3} / \mathrm{s}(1000 \mathrm{cfm})$ at a differential pressure of $248 \mathrm{~Pa}(1-$ inch WG (Water Gauge)), the most penetrating particle is in the range of $0.1-$ to $0.2-\mu \mathrm{m}\left(4 \times 10^{-6}\right.$ to $\left.8 \times 10^{-6} \mathrm{in}\right)$ AED. Particles with larger and smaller diameters are collected more efficiently. Filters are designed and tested at the factory to maintain a collection efficiency of 99.97 percent or greater for $0.3 \mu \mathrm{m}\left(1.2 \times 10^{-5}\right.$ in) AED test particles (typically dioctyl phthalate, DOP, or dioctyl sebacate, DOS). Depending upon the size and characteristic of the materials deposited, HEPA filters can accumulate several kilograms of particulate materials before exhibiting a differential pressure greater than the $1500 \mathrm{~Pa}$ (6-inches WG) (a typical value where the cost to generate the differential pressure begins to exceed the cost of replacement) required to maintain the $0.47 \mathrm{~m}^{3} / \mathrm{s}$ (1000 cfm flow).

Much of the loss of efficiency can be attributed to minute leaks in the sealant joining the filter mat to the frame or pathways through the gasket sealing the filter to the frame. Such paths must be minute in order to maintain the required collection efficiency ( 99.97 percent).

Various conditions can fail HEPA filters--temperature, pressure, or blinding (inadvertent blocking). HEPA filters must withstand flame impingement and momentary high temperatures. Filters with mineral sealant have retained collected materials at a temperature as high as $623 \mathrm{~K}\left(660^{\circ} \mathrm{F}\right)$. There is no experimental data for the retention of accumulated materials by glass fiber upon melting, but, based on the behavior of glass, it is postulated that the fibers soften and become "sticky" in the melting process and would retain all accumulated material in the melted glass (similar to vitrification of HLW). New glass fiber filter mat withstands up to $20000 \mathrm{~Pa}$ (80-inches WG) before failure but, upon loss of binder (binderless glass fiber contains up to 5 percent organic binder), failure can occur at 2500 pa (10-inches WG) or less. Experimental data indicate that pleated glass fiber mats used in HEPA filter are perforated at few locations along a few of the back pleats when challenged by shock waves (Gregory et al. 1983).

There is more discussion about HEPA filters in Appendix F.

\section{D.5.2 Scenario}

It is postulated that a filter at the end of its productive cycle is subjected to high temperatures that result in filter failure and that the filter accumulation is a maximum of $2 \mathrm{~kg}(4.4 \mathrm{lb})$ of $\mathrm{UO}_{2}$ particles. 


\section{D.5.3 Evaluation}

Experimental measurements reported in Ammerich et al. (1989) show the release of accumulated materials during the passage of heated air prior to failure. The efficiency of the filters was tested prior to heating using $1.8 \mu \mathrm{m}\left(7.1 \times 10^{-5} \mathrm{in}\right)$ AED particles and ranged from 99.997 percent to $\gg 99.99$ percent. No release was detected up to temperatures of $423 \mathrm{~K}\left(300^{\circ} \mathrm{F}\right)$. Release increased with temperature with the initial measured rate of release decreasing exponentially to the rate measured at 60 minutes. For a 1-hour passage of heated air up to $523 \mathrm{~K}\left(480^{\circ} \mathrm{F}\right)$, the release is bounded by an ARF of 1E-5. Since no Respirable Fraction was measured, a conservative value of 1.0 is assumed.

For the scenario, above, the release is estimated to be:

$$
\begin{aligned}
\text { Airborne Release } & =\left[2000 \mathrm{~g} \mathrm{UO}_{2}\right]\left[0.88 \mathrm{~g} \mathrm{U} / \mathrm{g} \mathrm{UO}_{2} \times[1 \mathrm{E}-5][1.0]\right. \\
& =0.0176 \mathrm{~g} \mathrm{U}^{-}
\end{aligned}
$$

\section{D.5.4 Leak Path Factor}

The high $\mathrm{RF}=1$ above indicates that these reentrained particles in a large duct flow system upstream (with a large $\mathrm{Q} / \mathrm{A}$ (duct)) of the stack will have little opportunity to settle out in the final ductwork. Therefore, no number exercise has been performed here to show that the LPF 1.

\section{D.5.5 Dose Assessment}

The failure mode being modeled in this example does not result in damage to the structure or ventilation system (other than the filters). Therefore, the possible release points to the environment are either a roof top vent (ground level) or the facility stack (elevated). The filter damage is assumed to eliminate all filtration in the leak path. For this example, the considerations for atmospheric transport and dispersion are the same as discussed in the free-fall powder spill (see Section D.2.4.2).

\section{D.5.5.1 Choice of Dispersion Model}

As with the free-fall sample problem discussed in Section D.2.4.1, the dispersion model should have the ability to model the following:

- Elevated and ground level releases

- Neutrally buoyant plumes

- Building wake effects

- Estimated doses resulting from exposure to enriched Uranium

- Plume depletion due to radioactive decay and deposition (dry)

The HOTSPOT model (Homann 1994) has been used to determine consequences resulting from the release in this example (see Section D.3.5.1). 


\section{D.5.5.2 Example Problem Parameters for Atmospheric Dispersion}

Site and Facility:

The same generic site and facility as is described in Sample Problem 1 has been assumed for this problem (see Section D.2.4.2).

\section{Release Path:}

Since either pathway is a possibility for the scenario being examined in this example, calculations have been performed for a ground level and an elevated (facility stack) release. Since the building wake and effective release height effects have been demonstrated previously, they have not been considered in this example.

\section{Meteorological Conditions:}

The same meteorological conditions as are assumed in Sample Problem 1 (Free-Fall Spill) have been assumed for this example, see Section 2.4.2.

\section{Source Term:}

In the previous discussion, the airborne release of enriched $U$ due to the filter failure is determined to be approximately $0.0176 \mathrm{~g}\left(3.9 \times 10^{-5} \mathrm{lb}\right)$. The HOTSPOT model asks for source term in terms of total quantity (Ci) released. A typical percentage of nuclides for a batch of enriched $\mathrm{UO}_{2}$ is: 93.15 percent $\mathrm{U}-235,1.00$ percent $U-234,0.50$ percent $U-236$, and 5.35 percent $U-238$. Total curies of each released are:

- $\mathrm{U}-235=(93.15$ percent $)(0.0176)(2.16 \mathrm{E}-6 \mathrm{Ci} / \mathrm{gm})=3.54 \mathrm{E}-8 \mathrm{Ci}$

- $\mathrm{U}-234=(1.00$ percent $)(0.0176)(6.24 \mathrm{E}-3 \mathrm{Ci} / \mathrm{gm})=1.11 \mathrm{E}-6 \mathrm{Ci}$

- $\mathrm{U}-236=(0.50$ percent $)(0.0176)(6.49 \mathrm{E}-5 \mathrm{Ci} / \mathrm{gm})=5.78 \mathrm{E}-9 \mathrm{Ci}$

- $\mathrm{U}-238=(5.35$ percent $)(0.0176)(3.35 \mathrm{E}-7 \mathrm{Ci} / \mathrm{gm})=3.19 \mathrm{E}-10 \mathrm{Ci}$

\section{D.5.5.3 Example Atmospheric Dispersion Problems}

Results have been prepared for a ground level release and an elevated release. Each case has been performed using two sets of meteorological conditions, one case representative of severe meteorology (e.g., higher consequences) and one representative of average meteorological conditions. Consequences were calculated at six arbitrary distances. The range is from $100 \mathrm{~m}$ to $16000 \mathrm{~m}(0.06$ to $10 \mathrm{mi})$ and represents the approximate limits within which the Gaussian dispersion model yields meaningful results. This range also encompasses the primary population at risk (e.g., workers and general population) from any accidental release of hazardous material.

Example 1: The first example consists of a release from a building roof top vent swept down to ground level. An example of the input summary and output provided by HOTSPOT has already been provided in Section D.3.5.3. Results for the ground level release are presented in Table D-19. 
Table D-19. Results for the Filter Failure Example Ground Level Release

\begin{tabular}{|c|c|c|}
\hline \multicolumn{3}{|c|}{ Committed Effective Dose Equivalent (rem) } \\
\hline Distance $(\mathbf{k m})$ & Severe Meteorology & Average Meteorology \\
\hline 0.10 & $7.1 \mathrm{E}-04$ & $6.7 \mathrm{E}-05$ \\
\hline 0.80 & $7.9 \mathrm{E}-06$ & $1.4 \mathrm{E}-06$ \\
\hline 1.6 & $1.9 \mathrm{E}-06$ & $4.3 \mathrm{E}-07$ \\
\hline 3.2 & $5.1 \mathrm{E}-07$ & $1.5 \mathrm{E}-07$ \\
\hline 8.0 & $9.5 \mathrm{E}-08$ & $3.8 \mathrm{E}-08$ \\
\hline 16.0 & $2.0 \mathrm{E}-08$ & $1.5 \mathrm{E}-08$ \\
\hline
\end{tabular}

Example 2: In this example, consequences from an elevated release have been calculated for severe and average meteorology. Table D-20 summarizes the results.

Table D-20. Results for the Filter Failure Example Elevated Release

\begin{tabular}{|c|c|c|}
\hline \multicolumn{2}{|c|}{ Committed Effective Dose Equivalent (rem) } \\
\hline Distance (km) & Severe Meteorology & Average Meteorology \\
\hline 0.10 & $1.6 \mathrm{E}-07$ & $1.6 \mathrm{E}-22$ \\
\hline 0.80 & $2.1 \mathrm{E}-07$ & $1.7 \mathrm{E}-07$ \\
\hline 1.6 & $5.7 \mathrm{E}-98$ & $1.6 \mathrm{E}-07$ \\
\hline 3.2 & $1.5 \mathrm{E}-08$ & $7.7 \mathrm{E}-08$ \\
\hline 8.0 & $2.8 \mathrm{E}-09$ & $2.4 \mathrm{E}-08$ \\
\hline 16.0 & $8.2 \mathrm{E}-10$ & $9.9 \mathrm{E}-09$ \\
\hline
\end{tabular}




\section{D.6 Sample Problem 5: Hydrogen Fluoride Release from a Tankcar}

\section{D.6.1 Introduction}

See Appendix B for detailed discussions on releases of hazardous chemicals.

\section{D.6.1.1 Scenario Description}

It is assumed that hydrogen fluoride (HF) is normally supplied to the facility by tankcar. The unloading process utilizes nitrogen to pressure HF out of the tankcar into an Acid Storage Vessel. The transfer lines connecting the tankcar and the storage vessel are "HF-service" flexible hoses.

Potential accident scenarios arising from the HF tankcar unloading process include:

a. HF vapor release due to a break in the nitrogen padding gas hose.

b. HF liquid release due to a break in the HF liquid transfer hose.

This section addresses accident scenario (b). A vapor release scenario similar to (a) has been developed in another sample problem (Section D.7, see $\mathrm{UF}_{6}$ liquid [>343 K $\left(157^{\circ} \mathrm{F}\right)$ ] cylinder rupture problem, Sample Problem No. 6, Alternative No. 2b).

\section{D.6.1.2 Representative Facilities}

The above scenarios could occur in $\mathrm{UF}_{6}$ conversion facilities or in NRC-licensed ore processing facilities.

\section{D.6.2 Hazard Identification}

The scenarios described above would likely have been identified from a formal hazard analysis such as HAZOP or a "What-if?" analysis.

\section{D.6.3 Source Term Characteristics}

This scenario consists of an HF liquid release due to a break in the liquid transfer hose.

It is assumed that the liquid transfer hose is ruptured. There are no automatic or remote shut-off valves on the unloading system, and it is assumed that any operator who may be on the unloading rack at the time will be incapacitated." The release will continue until an operator can suit-up, climb to the top of the tankcar, and manually close the isolation valve on the tankcar. It is assumed that this will take about 20 minutes.

\footnotetext{
** Note that the best commercial practice for HF tank truck unloading includes remotely operated shut-off valves on each side of the hose and operators/drivers who wear protective clothing and remain near the truck while it is being unloaded. Therefore, the above assumptions are conservative.
} 
The driving pressure from the tankcar is assumed to be $5.3 \times 10^{6} \mathrm{~Pa}(75$ psia) (i.e., the nitrogen padding pressure), and the hose break has a $2.5 \mathrm{~cm}$ (1 in) orifice. If the accident occurs during a cold day upon which the ambient temperature is at or below the boiling point of $\mathrm{HF}\left(293 \mathrm{~K}, 20^{\circ} \mathrm{C}\right.$, or $\left.68^{\circ} \mathrm{F}\right)$, the release will fall to the ground and evaporate from a pool. This sample problem is confined to the case in which the temperature of the HF and the ambient temperature is less than its boiling point.

There are several possibilities that lead to different ways in which HF will be released.

1. If the HF is very warm, at temperatures $10 \mathrm{~K}$ or more in excess of its atmospheric boiling point of $293 \mathrm{~K}\left(67^{\circ} \mathrm{F}\right)$, and it is released from the liquid space of the vessel or truck, it takes on the characteristics of a flashing liquid jet, with aerosol formation. An example of a flashing liquid jet calculation is given in Sample Problem 6, Section D.7, which is for liquid $\mathrm{UF}_{6}$ releases. The models used there are similar to those that would be used for liquid HF releases at elevated temperatures.

2. If the HF is cool, at temperatures $10 \mathrm{~K}\left(18^{\circ} \mathrm{F}\right)$ or more less than its atmospheric boiling point, it will fall to the ground and form an evaporating pool. This is the case considered here, in order to give an example of an evaporating pool calculation.

3. For intermediate temperatures, the modeling becomes more complex. At temperatures slightly above the boiling point, the difficult question to answer is what percentage of the HF will remain airborne as fine liquid droplets and what percentage will fall to the ground and form an evaporating pool. If the temperature is just below the boiling point, the simple evaporation models described below are not applicable. Attention needs to be paid to all sources and sinks of heat, such as the latent heat of boiling and differences in temperature between the pool and the ground.

In the pool evaporation model, the source term for the vapor dispersion modeling is the rate of evaporation of HF vapor from the pool. There are two cases that govern the driving forces for the evaporative process: (1) if there is a large temperature difference between the pool temperature $(T)$ and the ground $\left(T_{g}\right)$, then the driving force will depend upon the temperature gradient $\left(T_{g}-T\right) ;(2)$ if the spill temperature is below the boiling point of the chemical, then the driving force will be the normal evaporation through the diffusion of the chemical vapor above the liquid pool into the air.

In this sample problem, it is initially assumed that the temperature of the HF spill is at $280 \mathrm{~K}\left(44^{\circ} \mathrm{F}\right)$, which is below its boiling point, and, therefore, case (2) will be most appropriate for modeling the HF pool evaporation process.

As described in the literature (US EPA 1993), the rate of evaporation from a liquid chemical pool can be estimated using the following equation:

$$
\mathrm{Q}=\mathrm{k}_{\mathrm{g}} \mathrm{A}_{\mathrm{p}}\left(\mathrm{P}_{\mathrm{vp}} \mathrm{M}\right) /\left(\mathrm{RT}_{\mathrm{p}}\right)
$$

where:

$$
\begin{aligned}
& \mathrm{Q}=\text { rate of evaporation }(\mathrm{kg} / \mathrm{s}) \\
& \mathrm{k}_{\mathrm{g}}=\text { mass transfer coefficient }(\mathrm{m} / \mathrm{s})
\end{aligned}
$$




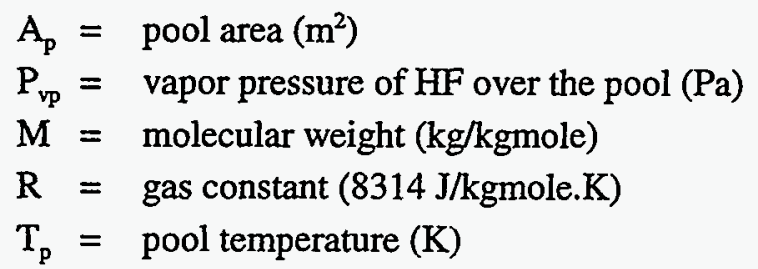

The mass transfer coefficient $\left(\mathrm{k}_{\mathrm{g}}\right)$ can be calculated using the following equation:

where:

$$
\mathrm{k}_{\mathrm{g}}=\mathrm{D}_{\mathrm{m}} \mathrm{N}_{\mathrm{sh}} / \mathrm{d}_{\mathrm{p}}
$$

$D_{m}=$ diffusivity coefficient of the chemical vapor in air $\left(\mathrm{m}^{2} / \mathrm{s}\right)$

$\mathrm{N}_{\mathrm{sh}}=$ Sherwood number (dimensionless)

$\mathrm{d}_{\mathrm{p}} \quad=$ effective pool diameter $(\mathrm{m})$

The Sherwood number $\left(\mathrm{N}_{\mathrm{sh}}\right)$ can be estimated as follows:

$$
\left.\mathrm{N}_{\mathrm{sh}}=0.037\left(\mathrm{~K}_{\mathrm{m}} / \mathrm{D}_{\mathrm{m}}\right)^{1 / 3}\left[\left(\mathrm{ud}_{\mathrm{p}} / \mathrm{K}_{\mathrm{m}}\right)^{0.8}-15,200\right)\right]
$$

where:

$\mathrm{K}_{\mathrm{m}}=$ kinematic viscosity of air $\left(1.1 \times 10^{-5} \mathrm{~m}^{2} / \mathrm{s}\right)$

$\mathrm{u}=$ windspeed at height of $10 \mathrm{~m}(\mathrm{~m} / \mathrm{s})$

Assuming that the liquid pool is a circle, then the effective pool diameter $\left(d_{p}\right)$ can be expressed as follows:

$$
\mathrm{d}_{\mathrm{p}}=\left(4 \mathrm{~A}_{\mathrm{p}} / \pi\right)^{1 / 2}=1.13 \mathrm{~A}_{\mathrm{p}}^{1 / 2}
$$

The formula for estimating the diffusivity coefficient $\left(D_{m}\right)$ is given by Bird, Stewart and Lightfoot $(1960)$ and can be written as follows:

where:

$$
D_{m}=4.6 \times 10^{-8}(a / P)\left[T /\left(T_{c A} T_{c B}\right)^{1 / 2}\right]^{b}\left(P_{c A} P_{c B}\right)^{1 / 3}\left(T_{c A} T_{c B}\right)^{5 / 12}\left(1 / M_{A}+1 / M_{B}\right)^{1 / 2}
$$

$$
\begin{aligned}
& \mathrm{a}=27.81 \\
& \mathrm{~b}=1.823 \\
& \mathrm{P}_{\mathrm{cA}}=\text { critical pressure of component } \mathrm{A}\left(6.48 \times 10^{6} \mathrm{~Pa}\right) \\
& \mathrm{T}_{\mathrm{CA}}=\text { critical temperature of component } \mathrm{A}(461 \mathrm{~K}) \\
& \mathrm{M}_{\mathrm{A}}=\text { molecular weight of component } \mathrm{A}(20 \mathrm{~kg} / \mathrm{kgmole}) \\
& \mathrm{P}_{\mathrm{cB}}=\text { critical pressure of component } \mathrm{B}\left(3.69 \times 10^{6} \mathrm{~Pa}\right) \\
& \mathrm{T}_{\mathrm{CB}}=\text { critical temperature of component } \mathrm{B}(132 \mathrm{~K})
\end{aligned}
$$




$$
\begin{aligned}
& \mathrm{M}_{\mathrm{B}}=\text { molecular weight of component } \mathrm{B}(29.0 \mathrm{~kg} / \mathrm{kgmole}) \\
& \mathrm{P}=\text { atmospheric pressure, } 1.01 \times 10^{5} \mathrm{~Pa} \\
& \mathrm{~T}=\text { ambient temperature }(\mathrm{K})
\end{aligned}
$$

and components $\mathrm{A}$ and $\mathrm{B}$ are $\mathrm{HF}$ and air, respectively.

Assuming the ambient temperature is $280 \mathrm{~K}\left(45^{\circ} \mathrm{F}\right)$, the diffusivity coefficient $\left(\mathrm{D}_{\mathrm{m}}\right)$ of $\mathrm{HF}$ in air can then be estimated using equation D.34 to have a value of $1.32 \times 10^{-5} \mathrm{~m}^{2} / \mathrm{s}$.

From equations D.31 and D.33, the product $k_{g} A_{p}$ can be written as follows:

$$
\begin{aligned}
\mathrm{k}_{\mathrm{g}} \mathrm{A}_{\mathrm{p}} & =\left(\mathrm{D}_{\mathrm{m}} \mathrm{N}_{\mathrm{sh}} / \mathrm{d}_{\mathrm{p}}\right) \mathrm{A}_{\mathrm{p}}=\left[\mathrm{D}_{\mathrm{m}} \mathrm{N}_{\mathrm{sh}} /\left(1.13 \mathrm{~A}_{\mathrm{p}}^{1 / 2}\right)\right] \mathrm{Ap} \\
& =(1 / 1.13) \mathrm{D}_{\mathrm{m}} \mathrm{N}_{\mathrm{sh}} \mathrm{A}_{\mathrm{p}}^{1 / 2}
\end{aligned}
$$

For atmospheric stability class $F$, the windspeed at $10 \mathrm{~m}$ height $(u)$ is assumed to be $2 \mathrm{~m} / \mathrm{s}$. Based on the given value of $1.1 \times 10^{-5} \mathrm{~m}^{2} / \mathrm{s}$ for $\mathrm{K}_{\mathrm{m}}$ and equations D.33 and D.34, equation D.35 can be rewritten as follows:

$$
\begin{aligned}
& \mathrm{k}_{\mathrm{g}} \mathrm{A}_{\mathrm{p}}=(1 / 1.13) \mathrm{D}_{\mathrm{m}} 0.037\left(1.1 \times 10^{-5} / \mathrm{D}_{\mathrm{m}}\right)^{1 / 3}
\end{aligned}
$$

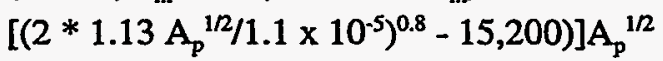

$$
\begin{aligned}
& =\left(7.28 \times 10^{-4}\right) * D_{m}^{2 / 3} *\left[\left(1.78 \times 10^{4} A_{p}^{0.4}-15,200\right)\right]^{*} A_{p}^{1 / 2}
\end{aligned}
$$

By replacing the value of $1.32 \times 10^{-5} \mathrm{~m}^{2} / \mathrm{s}$ for $D_{m}$, equation $D .22$ can be expressed as follows:

$$
\begin{aligned}
\mathrm{k}_{\mathrm{g}} \mathrm{A}_{\mathrm{p}} & =\left(7.28 \times 10^{-4}\right)\left(1.32 \times 10^{-5}\right)^{2 / 3}\left[\left(1.78 \times 10^{4} \mathrm{~A}_{\mathrm{p}}^{0.4}-15,200\right)\right] \mathrm{A}_{\mathrm{p}}{ }^{1 / 2} \\
& =\left(4.07 \times 10^{-7}\right)\left[\left(1.78 \times 10^{4} \mathrm{~A}_{\mathrm{p}}^{0.4}-15,200\right)\right] \mathrm{A}_{\mathrm{p}}^{1 / 2} \\
& =7.24 \times 10^{-3} \mathrm{~A}_{\mathrm{p}}^{0.9}-6.18 \times 10^{-3} \mathrm{~A}_{\mathrm{p}}{ }^{0.5}\left(\mathrm{~m}^{3} / \mathrm{s}\right)
\end{aligned}
$$

Equation D.30 can be rewritten as a function of the pool area $\left(A_{p}\right)$, pool temperature $\left(T_{p}\right)$, and the vapor pressure of the chemical over the pool $\left(\mathrm{P}_{\mathrm{vp}}\right)$ as follows:

$$
\mathrm{Q} / \mathrm{k}_{\mathrm{g}} \mathrm{A}_{\mathrm{p}}=\mathrm{P}_{\mathrm{vp}} \mathrm{M} / \mathrm{RT}_{\mathrm{p}}
$$

The vapor pressure of HF over a pool of pure HF can be obtained from the following equation (CRC 1974):

$$
\log _{10} P_{v p}=(-0.2185 * 6018.2 / T)+7.37
$$

At a pool temperature of $280 \mathrm{~K}\left(45^{\circ} \mathrm{F}\right)$, the vapor pressure of $\mathrm{HF}$ over the pool can be calculated using equation D.38. 


$$
\begin{aligned}
\log _{10} P_{v p} & =(-0.2185 * 6018.2 / 280)+7.37=2.673 \\
& \text { or } \\
P_{v p} & =472 \text { Torrs }=6.21 \times 10^{4} \mathrm{~Pa}
\end{aligned}
$$

Replacing the calculated vapor pressure of $\mathrm{HF}$ and the pool temperature in equation D.37, the product $\mathrm{Q} / \mathrm{k}_{\mathrm{g}} \mathrm{A}_{\mathrm{p}}$ can be estimated as:

$$
\begin{aligned}
\mathrm{Q} / \mathrm{k}_{\mathrm{g}} \mathrm{A}_{\mathrm{p}} & =\left(6.21 \times 10^{4}\right)(20.01) /(8314 \times 280) \\
& =0.534 \mathrm{~kg} / \mathrm{m}^{3}
\end{aligned}
$$

Finally, the evaporation rate from the pool can be expressed as a function of the pool area $\left(A_{p}\right)$ as follows:

$$
\begin{aligned}
Q & =0.534 k_{g} A_{p}=0.534\left[7.24 \times 10^{-3} A_{p}^{0.9}-6.18 \times 10^{-3} A_{p}^{0.5}\right] \\
& =3.87 \times 10^{-3} A_{p}^{0.9}-3.30 \times 10^{-3} A_{p}^{0.5}(\mathrm{~kg} / \mathrm{s})
\end{aligned}
$$

For this sample problem, if the effective pool area is assumed to be $500 \mathrm{~m}^{2}\left(5380 \mathrm{ft}^{2}\right)$, the evaporation rate or the source term can be estimated using equation D.26.

$$
\mathrm{Q}=3.87 \times 10^{-3}(500)^{0.9}-3.30 \times 10^{-3}(500)^{0.5}=0.97 \mathrm{~kg} / \mathrm{s}
$$

This evaluation of the evaporation rate $(Q)$ as a function of the pool area $\left(A_{p}\right)$, pool temperature $\left(T_{p}\right)$, and windspeed $(\mathrm{u})$ is simplified by incorporating it into nomographs which are illustrated in Figures D-5 and D-6. It should be noted that, in both Figures D-5 and D-6, the model is reaching its limit of validity in the temperature range of $290-295 \mathrm{~K}\left(62-71^{\circ} \mathrm{F}\right)$ for the reasons described in Section D.6.3(3).

The use of the nomographs is outlined below:

1. Select the appropriate figure (D-5 or D-6) for the windspeed condition under evaluation. Figure D-5 is given for a windspeed of $2 \mathrm{~m} / \mathrm{s}(4.5 \mathrm{mph})$; Figure D-6 is for a windspeed of $5 \mathrm{~m} / \mathrm{s}$ (11 mph).

2. Select a pool temperature in Kelvin and enter it on the $\mathrm{x}$-axis of the appropriate figure.

3. Step vertically to the curve representing the pool area $\left(A_{p}\right)$.

4. From the point of intersection on the curve, step horizontally to the $y$-axis to determine the evaporation rate $(Q)$. This value of $Q$ can then be used as the input to the atmospheric dispersion and consequence modeling (Section D.6.5).

\section{D.6.4 Release From Buildings}

(Not applicable for this sample problem.) 


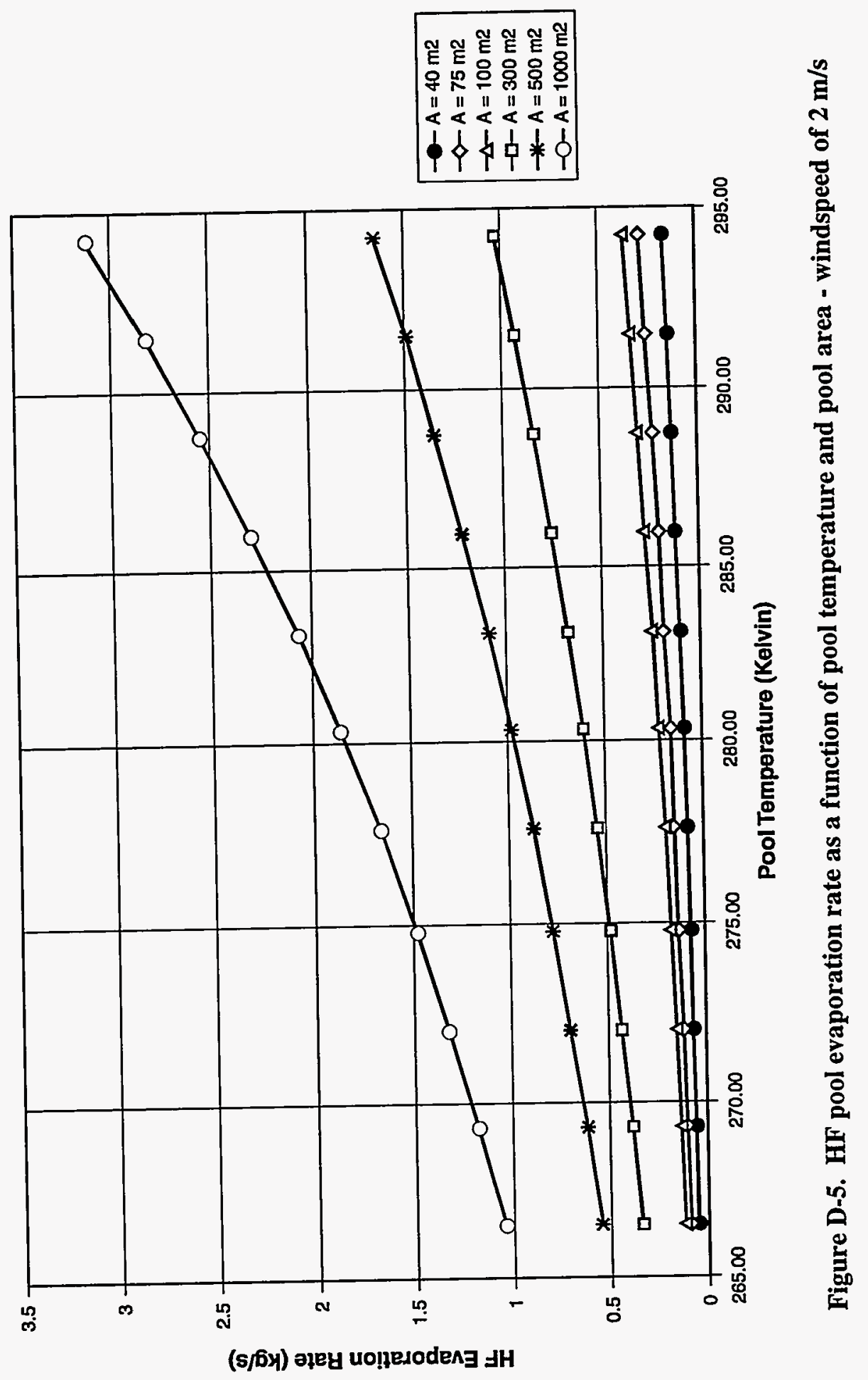




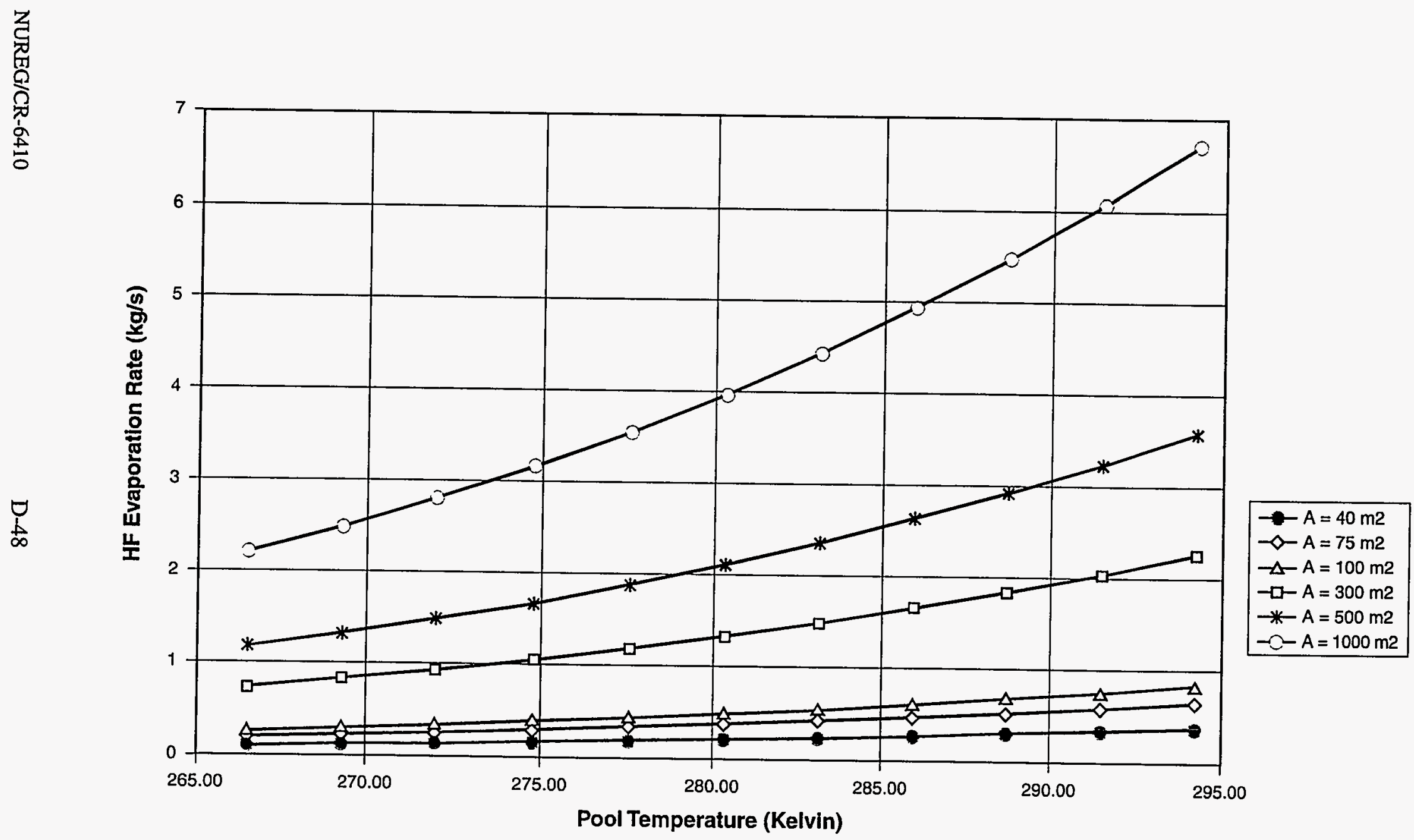

Figure D-6. HF pool evaporation rate as a function of pool temperature and pool area - windspeed of $5 \mathrm{~m} / \mathrm{s}$ 


\section{D.6.5 Atmospheric Dispersion and Consequence Modeling}

\section{D.6.5.1 Choice of Dispersion Models}

A complete dispersion model should have the following characteristics:

- Capable of handling heavier-than-air and neutrally buoyant behavior

- Accounting for the unique chemical behavior of anhydrous hydrogen fluoride, such as oligomerization (pure $\mathrm{HF}$ vapor, has an effective molecular weight of about 70 because it consists of a mixture of $\mathrm{HF},(\mathrm{HF})_{2}$ and $\left.(\mathrm{HF})_{6}\right)$

- Capable of handling aerosols

- Capable of handling both instantaneous "puffs" and continuous releases

- Capable of modeling "jet" releases, and

- Capable of adjusting to various heath effects models, such as time-dependent, time-independent, etc.

However, for the present case, a considerable simplification is possible. Experiments with HF evaporating from a cool pool, such as that considered here, show no evidence of the heavier-than-air effects that would be expected from oligomerized $\mathrm{HF}^{* * *}$. In addition, no aerosol is formed from an evaporating pool. Therefore, it is possible to use a relatively simple model, such as ALOHA (National Safety Council 1989).

The ALOHA code is most useful for estimating plume extent and concentration downwind from the release source for short-duration chemical accidents. It uses a Gaussian dispersion model to describe the movement and spreading of a gas that is neutrally buoyant. For heavier-than-air vapor releases, it uses calculations that are similar to those used in the DEGADIS model (USEPA 1993).

There are a number of limitations to the model, and these are summarized below:

- ALOHA is not intended for use with accidents involving radioactive chemicals.

- It is not intended for use in permitting of stack gas or chronic, low-level ("fugitive") emissions.

- The ALOHA-DEGADIS heavy gas module is more conservative than the DEGADIS model.

- ALOHA does not consider the effects of thermal energy from fire scenarios or the by-products resulting from chemical reactions.

- $\quad$ ALOHA does not include the processes needed to model particulates.

- ALOHA does not consider the topography of the ground under the spill or in the area affected by the plume.

- ALOHA does not work at very low windspeeds $(<1 \mathrm{~m} / \mathrm{s})$, since the wind direction may become inconsistent at these conditions.

- During very stable atmospheric conditions (usually during late at night or the early morning), the ALOHA model will give results with high levels of uncertainties due to shifting wind directions

*** W. Hague, Allied Signal, Private Communication (1990). 
and virtually no mixing of the plume into the surrounding "clean" air. Thus, these processes may lead to high concentrations of the gas remaining near the source for a long time.

Examples of the use of more complex vapor dispersion models are given in Sample Problem \#6, Section D.7.

\section{Weather Conditions}

Two weather conditions were used: (a) atmospheric stability class $\mathrm{D}, 300 \mathrm{~K}\left(80^{\circ} \mathrm{F}\right)$, and a windspeed of $5 \mathrm{~m} / \mathrm{s}(11 \mathrm{mph})$; and (b) atmospheric stability class F, $285 \mathrm{~K}\left(53^{\circ} \mathrm{F}\right)$, and a windspeed of $2 \mathrm{~m} / \mathrm{s}(4.5 \mathrm{mph})$. The $\mathrm{D}$ atmospheric stability category and $5 \mathrm{~m} / \mathrm{s}(11 \mathrm{mph})$ windspeed conditions provide average consequences for releases that take place and remain at ground level. For this reason, this weather condition is often used to approximate expected outcomes. The D stability class is a neutral weather condition applicable to a heavy overcast day or night associated with moderate to brisk windspeeds.

The $\mathrm{F}$ atmospheric stability and $2 \mathrm{~m} / \mathrm{s}(4.5 \mathrm{mph})$ windspeed conditions provide conservative or worst-case consequences for releases that take place and remain at ground level. There are exceptions to this rule, especially when the plume rise is an important issue; however, plume rise is not pertinent to the current case. The F stability class is a stable weather condition applicable to cloudy nights with surface windspeeds less than $2 \mathrm{~m} / \mathrm{s}(4.5 \mathrm{mph})$.

\section{Terrain}

The terrain affects the rate of entrainment of air in the cloud. An urban terrain model, characterized by distributed heat sources, buildings, and associated turbulence, dilutes the cloud more rapidly than a rural model does. In this sample problem, it is assumed that the release occurs in a rural terrain setting.

\section{D.6.5.2 Health Effect Model}

The dispersion analyses result in contours delineating the so-called Level of Concern (LOC). A definition of LOCs is given in Appendix D of the EPA's "Technical Guidance for Hazards Analysis," which was published in December, 1987 (USEPA 1987).

"Levels of Concern (LOCs)--are defined as the concentrations of an Extremely Hazardous Substance (EHS) in air above which there may be serious irreversible health effects or death as a result of a single exposure for a relatively short period of time."

There is sufficient information on HF in the literature to justify using Emergency Response Planning Guidelines (ERPGs) as LOCs. The ERPGs are published by the American Industrial Hygiene Association (AIHA) Emergency Response Planning Guideline Committee in April 1988 (AIHA 1988). For HF, the ERPGs are as follows: 
- $\quad$ ERPG-3: $50 \mathrm{ppm}$ - the maximum airborne concentration below which it is believed that nearly all individuals could be exposed for up to one hour without experiencing or developing life-threatening health effects.

- ERPG-2: $20 \mathrm{ppm}$ - the maximum airborne concentration below which it is believed that nearly all individuals could be exposed for up to one hour without experiencing or developing irreversible or other symptoms which could impair an individual's ability to take protective action.

- ERPG-1: 5 ppm - the maximum airborne concentration below which it is believed that nearly all individuals could be exposed for up to one hour without experiencing other than mild, transient adverse health effects or without perceiving a clearly defined objectionable odor.

These ERPGs have been estimated according to a protocol for community exposure guidelines that was developed by a consortium of 25 chemical firms and was based upon the National Research Council/National Response Center guidelines, known as Emergency Exposure Guideline Levels (EEGLs) and Short-Term Public Exposure Guideline Levels (SPEGLs). The American Industrial Hygiene Association is providing technical review. These ERPGs represent the latest thinking by experts in the field and should, therefore, be regarded as authoritative.

The ERPG-2 level has been taken to be the LOC. Note that, in its recent Risk Management Program Regulation (40 CFR Part 68), the EPA now use the term "Toxic Endpoint" rather than LOC. In addition, when they are available, EPA uses the ERPG-2s as toxic endpoints.

\section{D.6.5.3 Prediction of Distances to Toxic Endpoints}

To facilitate the prediction of the affected distances (i.e., the maximum distance to which concentrations exceed the toxic endpoint), a nomograph was developed and illustrated (see Figure D-7). This figure provides two plotted curves, one for atmospheric stability class $D$ with a windspeed of $5 \mathrm{~m} / \mathrm{s}(11 \mathrm{mph})$ and the other for stability class $\mathrm{F}$ and a windspeed of $2 \mathrm{~m} / \mathrm{s}(4.5 \mathrm{mph})$.

The data on the affected distances have been estimated using ALOHA 5.05 vapor dispersion code.

To determine the maximum extent of the ERPG-2 downwind of the release source, the following steps are required:

1. Use Figure D-7, "HF Pool Evaporation - Distance to ERPG-2 (20 ppm)".

2. Enter the estimated HF release rate (determined from Section 6.3 above) on the "x-axis" of Figure D7.

3. Step vertically to the appropriate plotted curve (i.e., Stability class $D$ or F).

4. From the point of intersection on the plotted curve, step horizontally to the "y-axis" to determine the distance downwind of the release source at which the airborne concentration is predicted to fall below the ERPG-2 could occur. As shown in Figure D-7, the distance is in meters (m). 

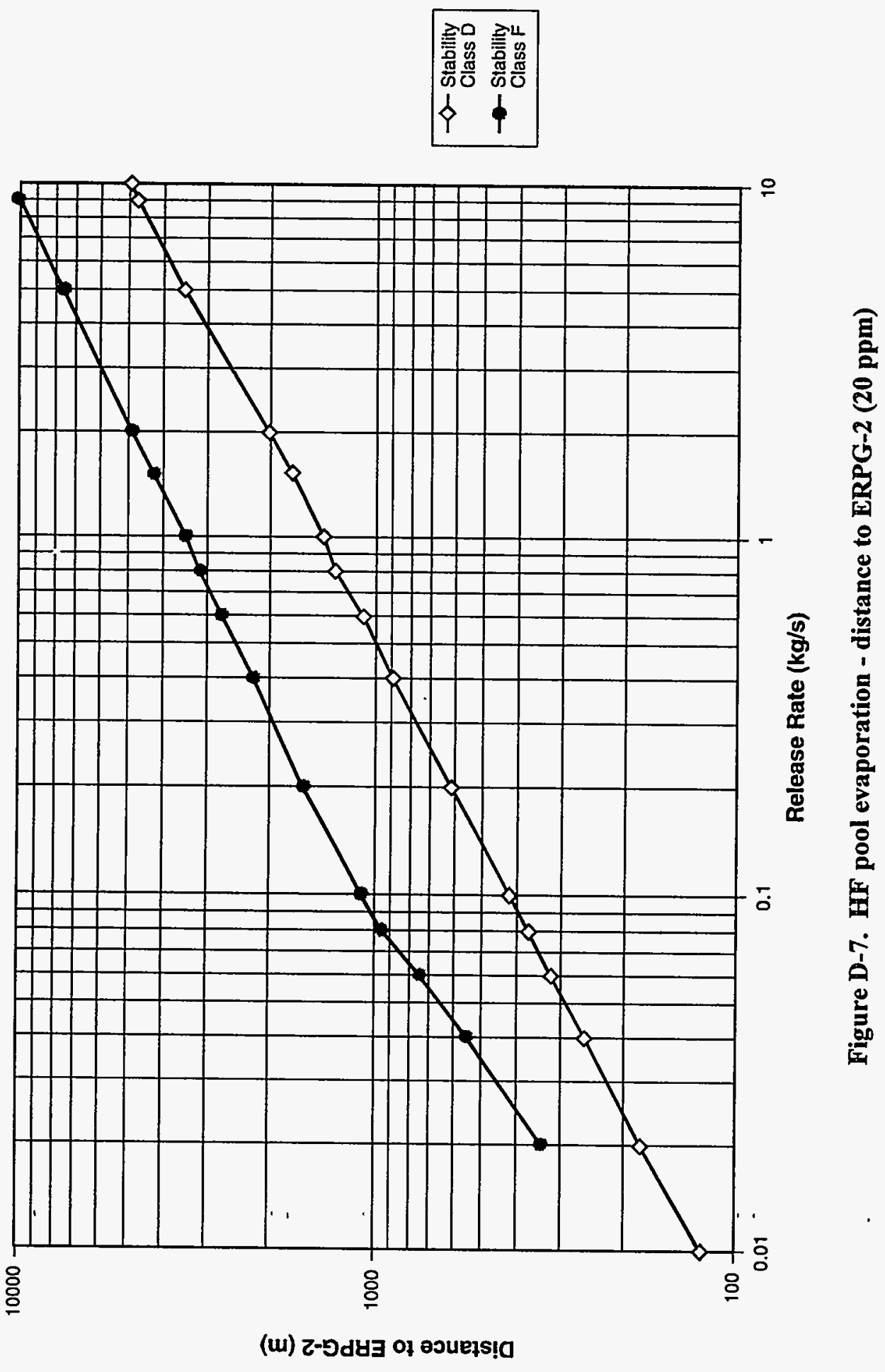
Using the results derived in Section D.6.3, an evaporation rate of $0.97 \mathrm{~kg} / \mathrm{s}(2.1 \mathrm{lb} / \mathrm{s})$ of $\mathrm{HF}$ from the spill could lead to exceeding an ERPG-2 concentration out to a distance of $3600 \mathrm{~m}$ ( $2.2 \mathrm{mi})$ downwind from the pool in atmospheric stability class $\mathrm{F}(2 \mathrm{~m} / \mathrm{s}(11 \mathrm{mph}))$ and 1400 meters $(0.87 \mathrm{mi})$ in stability class $\mathrm{D}(5 \mathrm{~m} / \mathrm{s}$ (11 mph)).

\section{D.6.5.4 Uncertainties in the Dispersion Analyses}

The results obtained from Figure D-7 are subject to uncertainties, some of which are summarized below:

- On the day of an accident, it will undoubtedly be very difficult to establish exactly the rate or magnitude of release.

- The weather conditions and windspeed may well be different from those used in this chapter.

- The dispersion modeling has not taken into account the reduction in the predicted concentrations due to the dilution caused by the structures on the site or the potential for mitigating the release. There are no accurate methods for predicting the extent of this dilution, but predicted concentrations at any point near the source could well be too high by factors of 2 to 5 or more.

- The dispersion modeling does not take account of the deposition of highly reactive HF vapors onto surfaces, such as equipment and ground, water, and vegetation. This means that the model overestimates airborne concentrations at longer distances.

- Overall, as a rule of thumb, uncertainties in predicted distances to the LOC can be as large as a factor of two each way.

In view of these uncertainties, the results should not be presented as absolute numbers but should be quoted with an accompanying caveat to the effect that uncertainties exist.

\section{D.7 Sample Problem 6: Uranium Hexafluoride Liquid $\left(>70^{\circ} \mathrm{C}\right)$ Cylinder Rupture}

\section{D.7.1 Introduction}

\section{D.7.1.1 Scenario Description}

This scenario is possible under the following conditions:

\section{Scenario 1:}

An overfilled Model $48 Y \mathrm{UF}_{6}$ cylinder, containing $14000 \mathrm{~kg}$ (30800 lb) of $\mathrm{UF}_{6}$, in a fuel enrichment facility is heated. The operator does not realize that the cylinder has been overfilled. Thermal expansion of $\mathrm{UF}_{6}$ causes cylinder rupture. In this scenario, all of the $\mathrm{UF}_{6}$ is released instantaneously and forms a puff. 


\section{Scenario 2:}

A Model $48 Y$ cylinder containing $12,600 \mathrm{~kg}(27,700 \mathrm{lb})$ of liquid $\mathrm{UF}_{6}$ is accidentally dropped from a height during transportation/moving operations. The fall causes a small hole developing in the cylinder wall. For this scenario, a continuous jet release through a $5 \mathrm{~cm}(2 \mathrm{in})$ diameter hole is assumed. The hole size is a typical one resulting from a cylinder drop. Depending upon the location of the rupture, the contents of the cylinder may either be released:

(A) as a continuous liquid jet if the hole is below the liquid level, or

(B) as a continuous vapor jet if the hole is above the liquid level.

The above scenarios have been chosen to highlight the impact of source term and dispersion model assumptions on source term estimates and on the predictions of affected distances downwind. Furthermore, the choice of these release scenarios and assumptions regarding dispersion modeling discussed below (terrain, weather conditions, health effects models) has been made to bound the range of results and to illustrate the magnitude of uncertainty in the predictions.

\section{D.7.1.2 Facilities Where Possible}

This scenario is possible in fuel conversion, enrichment, blending and fabrication facilities.

\section{D.7.2 Hazard Identification}

This hazard is a well-known concern that has been discussed in many previous studies (e.g., NUREG/CR4360 [USNRC 1985]). An adequate hazard identification procedure would be a checklist based on previous experience or a What-If? team session or a formal hazards identification exercise such as a Hazards and Operability Analysis (HAZOP).

\section{D.7.3 Determination of Source Term Characteristics}

\section{D.7.3.1 Scenario 1 - Catastrophic Cylinder Rupture Resulting In Instantaneous Release}

\section{Parameters}

Mass of $\mathrm{UF}_{6}$ in cylinder $=14000 \mathrm{~kg}(30800 \mathrm{lb})$

- For ease of analysis, the contents of the cylinder are assumed to rupture at a slightly higher temperature and pressure than at the triple point of $\mathrm{UF}_{6}\left(151 \mathrm{kPa}\right.$ or 22 psia and $337.1 \mathrm{~K}$ or $\left.147^{\circ} \mathrm{F}\right)$. The temperature of the cylinder is assumed to be $343 \mathrm{~K}\left(158^{\circ} \mathrm{F}\right)$. This is an arbitrary assumption for purely illustrative purposes. The exact temperature at which the cylinder would rupture depends on how much it is overfilled in the first place. Analytical models that describe the thermal response of $\mathrm{UF}_{6}$ containers engulfed in a fire are detailed in (Clayton, et al. 1991). 
- When the cylinder ruptures, the contents initially come to equilibrium at the sublimation point of $\mathrm{UF}_{6}$ at atmospheric pressure. Some of the $\mathrm{UF}_{6}$ immediately flashes to vapor and some forms solid particles. (See Figure D-8: UF $_{6}$ Phase Diagram.)

- All of the $\mathrm{UF}_{6}$ solid particles remain airborne (Note - this assumption is conservative because deposition of solid $\mathrm{UF}_{6}$ particles near the source is a possibility. However, estimation of the amount that may deposit is uncertain and depends on various factors such as cylinder damage characteristics, particle size distribution and flow direction of ejected material and the presence or absence of obstacles). Large-scale experiments called "Desert Tortoise" with flashing liquid ammonia at the Nevada Test Site have shown that all of the liquid droplets are entrained in the cloud (Goldwire et al. 1985).

- The flashing phenomenon results in the almost instantaneous mixing with ten times by mass of air at an ambient temperature of $285 \mathrm{~K}\left(53^{\circ} \mathrm{F}\right)$ and 50 percent ambient relative humidity (RH) initially at the source (air density $=1.236 \mathrm{~kg} / \mathrm{m}^{3}\left(0.077 \mathrm{lb} / \mathrm{ft}^{3}\right)$ ). Mixing with ten times by mass of air is a reasonable assumption based upon eye-witness accounts of accidents involving instantaneous release and experiments (Kaiser and Walker 1978; Kaiser 1979). Note that predictions of the distance the cloud travels to (discussed in Section D.7.5.4.4) are not very sensitive to variations in the initial air mass mixing ratios.

The ambient conditions of $285 \mathrm{~K}\left(53^{\circ} \mathrm{F}\right)$ and 50 percent $\mathrm{RH}$ are chosen to reflect typical conditions. As part of a sensitivity analysis, calculations were repeated for 90 percent relative humidity and $300 \mathrm{~K}\left(80^{\circ} \mathrm{F}\right)$ ambient temperature (for both 50 percent and 90 percent relative humidity conditions) in Section D.7.5 Atmospheric Dispersion and Consequence Modeling. For illustrative purposes only, the 50 percent relative humidity values and $285 \mathrm{~K}\left(53^{\circ} \mathrm{F}\right)$ ambient temperature values are chosen for the worked example below. A similar treatment has been adopted for Scenarios $2 \mathrm{~A}$ and $2 \mathrm{~B}$.

\section{Source Term}

The mass fraction of $\mathrm{UF}_{6}$ that flashes to vapor is given by:

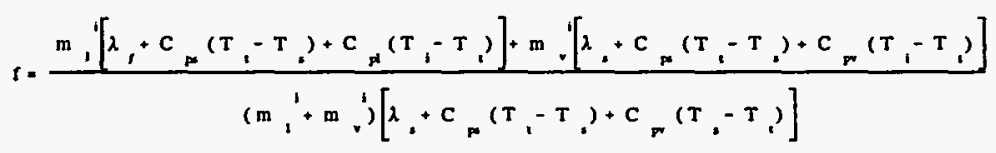

where:

$$
\begin{aligned}
& \mathrm{f}=\text { mass fraction of } \mathrm{UF}_{6} \text { that flashes to vapor after cooling to sublimation point } \\
& \mathrm{T}_{\mathrm{i}}=\text { storage temperature, } 343 \mathrm{~K} \\
& \mathrm{~T}_{\mathrm{s}}=\text { sublimation temperature of } \mathrm{UF}_{6}, 329.4 \mathrm{~K} \\
& \mathrm{~T}_{\mathrm{t}}=\text { triple point temperature, } 337 \mathrm{~K} \\
& \lambda_{\mathrm{s}}=\text { heat of sublimation of } \mathrm{UF}_{6}, 1.369 \times 10^{5} \mathrm{~J} / \mathrm{kg} \\
& \lambda_{\mathrm{f}}=\text { heat of fusion for the solid-liquid } \mathrm{UF}_{6} \text { transition, } 5.458 \times 10^{4} \mathrm{~J} / \mathrm{kg} \\
& \mathrm{C}_{\mathrm{pv}}=\text { specific heat at constant pressure for } \mathrm{UF}_{6} \text { vapor, } 369.35 \mathrm{~J} / \mathrm{kg}-\mathrm{K} \\
& \mathrm{C}_{\mathrm{ps}}=\text { specific heat at constant pressure for solid } \mathrm{UF}_{6}, 518.14 \mathrm{~J} / \mathrm{kg}-\mathrm{K}
\end{aligned}
$$




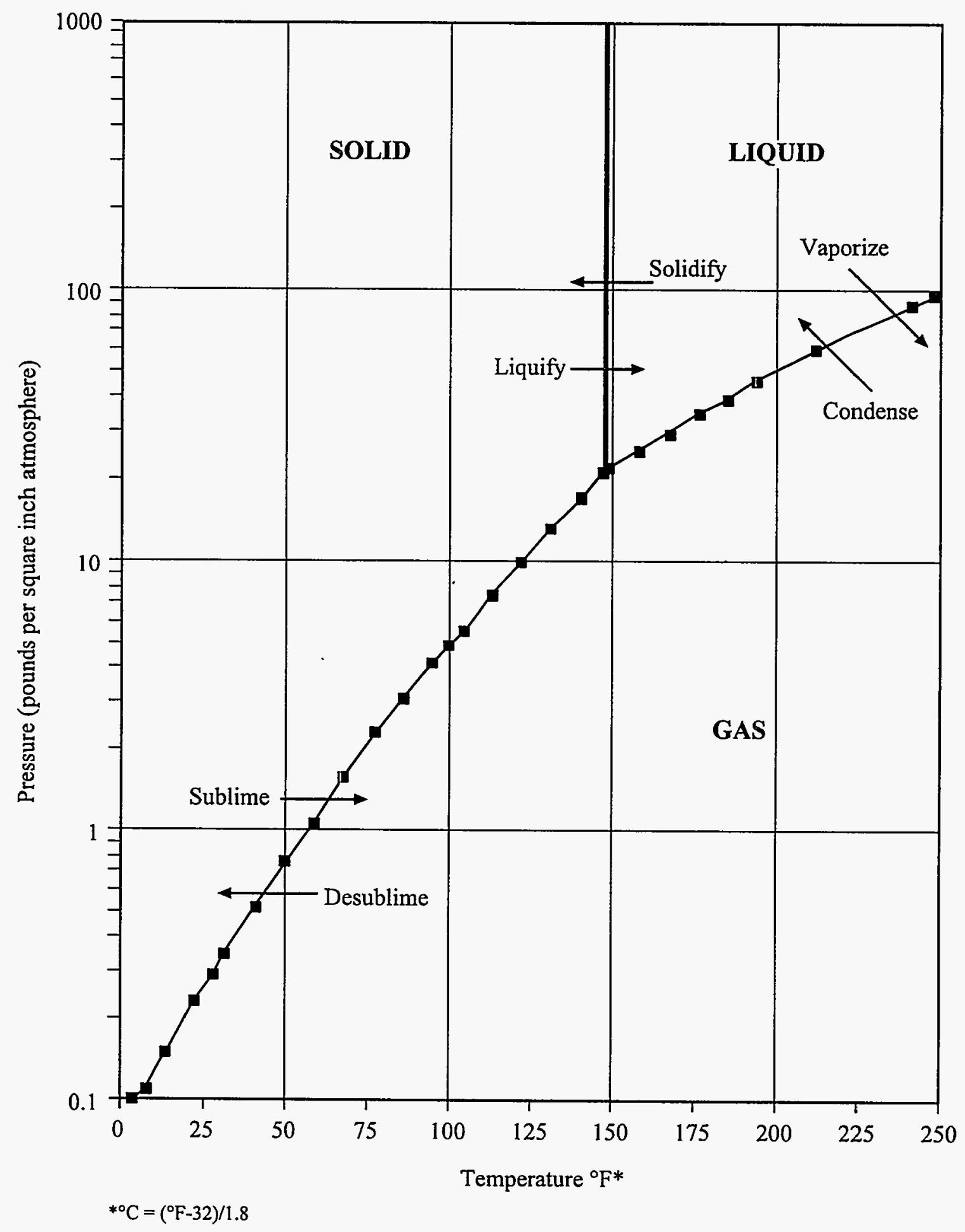

298Q-22

Figure D-8. UF $_{6}$ phase diagram [source: USDOE (1991)] 
$\mathrm{C}_{\mathrm{pl}}=$ specific heat at constant pressure for liquid $\mathrm{UF}_{6}, 563.3 \mathrm{~J} / \mathrm{kg}-\mathrm{K}$

$\mathrm{m}_{1}^{\mathrm{i}}=$ initial mass of liquid $\mathrm{UF}_{6}, 14,000 \mathrm{~kg}$

$\mathrm{m}_{\mathrm{v}}^{\mathrm{i}}=$ initial mass of vapor $\mathrm{UF}_{6}, 0 \mathrm{~kg}$ (In reality there may be some vapor; it is ignored here.)

Equation D.27 represents a simple energy balance. The various sources of heat released are:

- Sensible heat of cooling of liquid from initial temperature to triple point;

- Latent heat of fusion for conversion of liquid to solid at the triple point; and

- Sensible heat of cooling of solid and vapor from the triple point to the sublimation point.

These sources of heat are counterbalanced by the heat required to vaporize the $U_{F}$ fraction $f$. Figure $D-9$ shows the dependence of the flash fraction of $U_{6}(f)$ on storage temperature $\left(T_{i}\right)$. Table D-21 shows the data represented by Figure D-9 in a tabular format. For temperatures between values displayed here, linear interpolation of the flash fraction is acceptable.

Table D-21. Dependence of Flash Fraction, f, on Initial Storage Temperature

\begin{tabular}{l|l|l|l|l|l|l|l|l|l|l|l|l|l|l}
$\begin{array}{l}\text { Storage } \\
\text { Temperature } \\
\mathbf{T}_{\mathbf{g}}(\mathbf{K})\end{array}$ & 340 & 350 & 360 & 370 & 380 & 390 & 400 & 410 & 420 & 430 & 440 & 450 & 460 & 470 \\
\hline $\begin{array}{l}\text { Flash } \\
\text { Fraction, f }\end{array}$ & 0.44 & 0.48 & 0.52 & 0.56 & 0.60 & 0.64 & 0.68 & 0.72 & 0.76 & 0.80 & 0.84 & 0.89 & 0.93 & 0.97
\end{tabular}

From equation D.44, the value of $f$ obtained is 0.45 . Thus, of the original $14000 \mathrm{~kg}$ ( $30800 \mathrm{lb}$ ) of $\mathrm{UF}_{6}, 45$ percent by mass $(6300 \mathrm{~kg}(13900 \mathrm{lb}))$ of $\mathrm{UF}_{6}$ initially flashes to vapor, and 55 percent by mass $(7700 \mathrm{~kg}$ (16900 lb)) desublimes to solid.

The temperature of the $\mathrm{UF}_{6}$ immediately following the flash, but before mixing with air, is equal to the sublimation temperature of $\mathrm{UF}_{6}$ at atmospheric pressure $329.4 \mathrm{~K}\left(133^{\circ} \mathrm{F}\right)$. Assuming that the solid $\mathrm{UF}_{6}$ particles are rendered airborne, the density of pure $\mathrm{UF}_{6}$ (solid and vapor), $\rho^{\prime}$, is given by the formula:

$$
\rho^{\prime}=\frac{14.000}{\frac{6.300}{P_{\text {UF }}^{v}} \cdot \frac{7.700}{\rho_{\text {LF }}^{s}}}
$$

where:

$$
\begin{aligned}
& P_{\mathrm{vF}}^{v}=\text { density of } \mathrm{UF}_{6} \text { vapor at } 329.4 \mathrm{~K}, 12.98 \mathrm{~kg} / \mathrm{m}^{3} \text {, and } \\
& \rho_{\mathrm{vF}} .=\text { density of } \mathrm{UF}_{6} \text { solid at } 329.4 \mathrm{~K}, 5053.8 \mathrm{~kg} / \mathrm{m}^{3}
\end{aligned}
$$




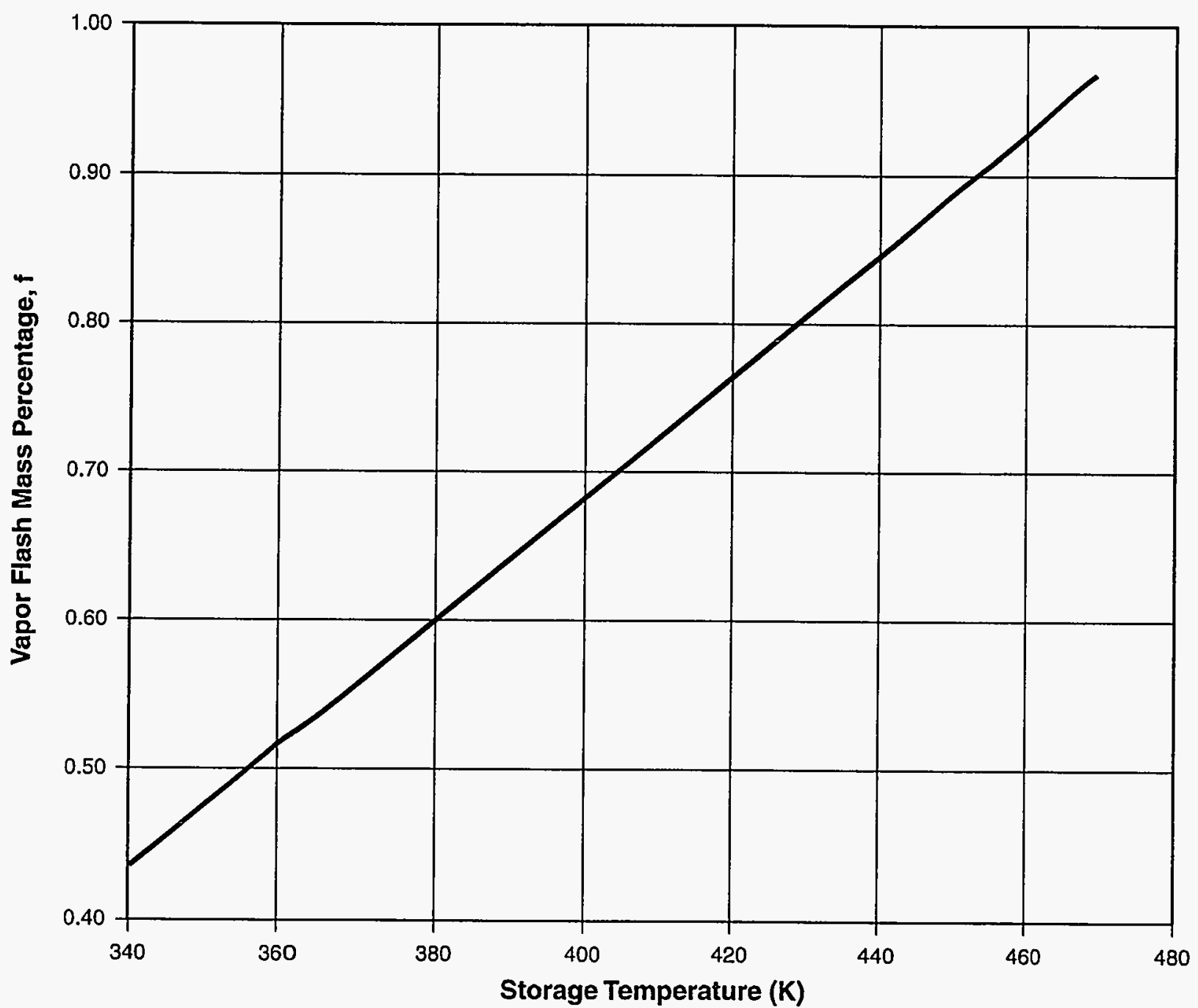

Figure D-9. Dependence of flash percentage, $f$, on storage temperature, $T_{i}$ 
Substituting the vapor and solid densities into equation D.45, the resultant initial cloud density is $28.75 \mathrm{~kg} / \mathrm{m}^{3}$ $\left(1.8 \mathrm{lb} / \mathrm{ft}^{3}\right)$. For scenarios in which no initial mixing of air at the source is postulated, this density can be used for atmospheric dispersion modeling. However, in the current scenario, it is assumed that ten times by mass $(140000 \mathrm{~kg}(308000 \mathrm{lb}))$ air at 50 percent $\mathrm{RH}$ and $285 \mathrm{~K}\left(53^{\circ} \mathrm{F}\right)$ is mixed at the source.

$\mathrm{UF}_{6}$ reacts with airborne moisture according to the following equation:

$$
\mathrm{UF}_{6}+2 \mathrm{H}_{2} \mathrm{O} \rightarrow \mathrm{UO}_{2} \mathrm{~F}_{2}+4 \mathrm{HF}+117,147 \mathrm{~J} / \mathrm{kg}-\mathrm{mol}_{-} \mathrm{UF}_{6}
$$

The thermodynamics of this reaction are complicated by the following phenomena (Clough, et al. 1987; Rodean 1989):

- Heat is released by the exothermic reaction of $\mathrm{UF}_{6}$ with water

- Hydrogen fluoride (HF) oligomerizes to $(\mathrm{HF})_{2}$ and $(\mathrm{HF})_{6}$ accompanied with release of heat

- $\mathrm{UF}_{6}$, water, and HF may change phase from condensate to vapor

- $\mathrm{HF}$ and water form a non-ideal solution accompanied by release of heat

On behalf of and funded by NRC, SAIC has developed computer programs NRCRUNCH, NRCDENZ and NRCPLUME to evaluate the thermodynamic properties of mixtures of $\mathrm{UF}_{6}$ and moist air, and HF and moist air (Kaiser and Chhibber 1994). The $\mathrm{UF}_{6}$ thermodynamics algorithm incorporated in these models yields results similar to those of Rodean (Rodean 1989). Another atmospheric dispersion model capable of modeling $\mathrm{UF}_{6}$ releases is HGSYSTEM (Hanna, Chang and Zhang 1996). Using the NRC-sponsored computer programs, the equilibrium thermodynamic properties of the UF $\mathrm{UF}_{6}$ /air cloud were calculated, and are shown in Table D-22.

The source term characteristics in Table D-22 form the input to a puff model of atmospheric dispersion. The resulting mixture density is greater than the density of the ambient air. Given the assumption of catastrophic failure of the vessel, one of the biggest sources of uncertainty is whether all of the puff remains airborne. The 55 percent of the $\mathrm{UF}_{6}$ that desublimes may drop out, particularly if there are many obstacles in the vicinity of the source, thus reducing the amount of $\mathrm{UF}_{6}$ that remains airborne by about a factor of two. However, since there are no models that will effectively predict how much $\mathrm{UF}_{6}$ solid will drop out, the analyst is forced to make the conservative choice that all of the $\mathrm{UF}_{6}$ remains airborne.

\section{D.7.3.2 Scenario 2A - Small Hole ( $5 \mathrm{~cm}$ ( 2 in) Diameter) Below Liquid Level Resulting in a Continuous Flashing Jet Release}

\section{Parameters}

- Cylinder dimensions conform to those of a Model $48 \mathrm{Y}$ container. Wall thickness is $1.6 \mathrm{~cm}(5 / 8 \mathrm{in})$ steel. Cylinder body is $3 \mathrm{~m}$ (117 in) long and inside diameter is $1.23 \mathrm{~m}$ (48 in) (internal volume = $\left.3.47 \mathrm{~m}^{3}\left(123 \mathrm{ft}^{3}\right)\right)$. 
Table D-22. Source Term Characteristics Following

\begin{tabular}{l|l}
\multicolumn{2}{c}{ Puff Release of UF $_{6}$ (Scenario 1) } \\
\hline Total Mass of UF & $14000 \mathrm{~kg}$ \\
Density & $1.314 \mathrm{~kg} / \mathrm{m}^{3}$ \\
Temperature & $291.5 \mathrm{~K}\left(18.5^{\circ} \mathrm{C}\right)$ \\
$\begin{array}{l}\text { Total Volume } \\
\text { (including air) }\end{array}$ & $117200 \mathrm{~m}^{3}$ \\
$\begin{array}{l}\text { Total Mass } \\
\text { (including air) }\end{array}$ & $154000 \mathrm{~kg}$ \\
Horizontal & \\
Momentum & $280000 \mathrm{~kg}-\mathrm{m} / \mathrm{s}$ \\
\hline
\end{tabular}

- Cylinder temperature is $366 \mathrm{~K}\left(200^{\circ} \mathrm{F}\right)$. (Note: the initial conditions are chosen to be different than for $\mathrm{UF}_{6}$ Scenario No. 1 because, for these conditions, the liquid and vapor volumes inside a normally filled Model $48 Y$ cylinder containing $12560 \mathrm{~kg}(27560 \mathrm{lb})$ of $\mathrm{UF}_{6}$ are available from published data (USDOE 1991). In a cylinder containing $12560 \mathrm{~kg} \mathrm{UF}_{6}$ at $366 \mathrm{~K}\left(93^{\circ} \mathrm{C}\right.$ or $\left.200^{\circ} \mathrm{F}\right)$ the liquid occupies approximately 90 percent of the cylinder volume and the vapor occupies 10 percent of the cylinder volume (Figure 3.17, NUREG-1179 [USNRC 1986]).

- A $5 \mathrm{~cm}$ ( 2 in) diameter hole develops at the lowest point of cylinder assuming the cylinder lies with its length axis horizontal.

- The flow through the bottom of the cylinder is single-phase.

- The flash phenomenon results in mixing with ten times by mass of air at $285 \mathrm{~K}\left(12{ }^{\circ} \mathrm{C}\right.$ or $\left.53.6^{\circ} \mathrm{F}\right)$ and 50 percent relative humidity initially at the source (air density $=1.236 \mathrm{~kg} / \mathrm{m}^{3}\left(0.077 \mathrm{lb} / \mathrm{ft}^{3}\right)$ )

A computer program, CYLIND, useful for analyzing multi-phase, transient releases of $\mathrm{UF}_{6}$ from ruptured cylinders, is described in (NUREG-CR/4360 [USNRC 1985]). However, in this sample problem, the source term is developed using simple, hand calculations.

\section{Rate of Release}

The rate of liquid release through a hole is given by Bernoulli's formula:

$$
\mathrm{Q}=\mathrm{cA}_{\mathrm{o}} \rho_{1}\left[2\left(\mathrm{p}-\mathrm{p}_{\mathrm{a}}\right) / \rho_{1}+2 \mathrm{gh}\right]^{0.5}
$$

where:

Assuming a wind speed of $2 \mathrm{~m} / \mathrm{s}$. Since the $\mathrm{UF}_{6}$ has no initial momentum, the air imparts a momentum $(280,000 \mathrm{~kg}-\mathrm{m} / \mathrm{s})$ equal to mass of air $(140,000 \mathrm{~kg})$ times wind speed $(2 \mathrm{~m} / \mathrm{s})$. 
$\mathrm{Q}=$ rate of release $(\mathrm{kg} / \mathrm{s})$

$\mathrm{c}=$ constant, normally set to 0.6 for liquid releases

$A_{0}=$ area of the orifice, $2.03 \times 10^{-3} \mathrm{~m}^{2}$

$\rho_{1}=$ liquid density in the vessel at $366 \mathrm{~K}, 3,670 \mathrm{~kg} / \mathrm{m}^{3}$

$\mathrm{p}=$ absolute pressure in vessel $344 \mathrm{kPa}$ (50 psia at $366 \mathrm{~K}$, Figure D-8)

$\mathrm{p}_{\mathrm{a}}=$ atmospheric pressure, $101 \mathrm{kPa}$

$\mathrm{g}=$ acceleration due to gravity, $9.81 \mathrm{~m} / \mathrm{s}^{2}$

$\mathrm{h}=$ static head, (assuming 90 percent volume is liquid, 10 percent volume is vapor and the cylinder is lying horizontally) is calculated by performing a volume balance (see Figure D10). $h$ is calculated as follows:

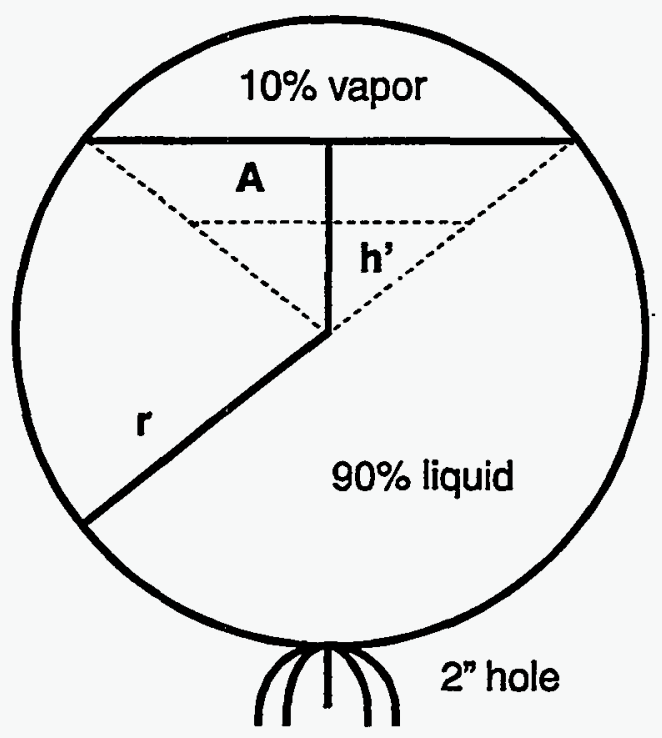

Figure D-10. Model $48 Y$ normally filled $\mathrm{UF}_{6}$ cylinder

$h=r+h^{\prime}$

where $h^{\prime}$ is the height of liquid level above the cylinder centerline (m) but, $r=24$ in (given) $=0.61 \mathrm{~m}$

Furthermore, the volume of the vapor segment is $V_{v}=0.5 r^{2}(\operatorname{rad} A-\sin A) \times L$, where $A=$ radian measure of angle subtended at the center, and $L=$ cylinder length $(117$ in or $2.97 \mathrm{~m})$.

We know that $V_{v}=10$ percent of cylinder volume (given) $=0.347 \mathrm{~m}^{3}$

Thus, $0.347=0.5 r^{2}(\operatorname{rad} A-\sin A) \times L=0.5 \times(0.61)^{2} \times(\operatorname{rad} A-\sin A) \times 2.97$ 


$$
0.628=\operatorname{rad} \mathrm{A}-\sin \mathrm{A}
$$

Thus, $\mathrm{A}=93.2^{\circ}$ (by trial and error)

$$
\begin{aligned}
& h^{\prime}=r \cos (A / 2)=0.61 \times \cos 46.6=0.42 m \\
& \text { and } h=0.61+0.42=1.03 m
\end{aligned}
$$

It is worth noting that the effect of the first term within brackets in equation D.29 is much larger than that of the second term. The first term represents the flow due to the pressure difference alone whereas the second term represents flow due to static head. [ $\left.2\left(\mathrm{p}-\mathrm{p}_{\mathrm{a}}\right) / \rho_{1}\right]$ is equal to $132.2 \mathrm{~N}-\mathrm{m} / \mathrm{kg}$, and $2 \mathrm{gh}$ is equal to $20.2 \mathrm{~N}$ $\mathrm{m} / \mathrm{kg}$. Therefore, if the analyst makes the simplifying assumption that $\mathrm{h}=2 \mathrm{r} \sim 1.2 \mathrm{~m}$, (or neglects $\mathrm{h}$ completely) the accuracy of the calculation will not be significantly affected.

Using the above constants in equation D.47, the flow rate is $55.2 \mathrm{~kg} / \mathrm{s}(121.4 \mathrm{lb} / \mathrm{s})$. Thus, the entire contents of the cylinder will escape in about 228 seconds ( -3.5 minutes). This assumption is conservative because the cylinder pressure and temperature will reduce with time. This will reduce the flow rate. However, not much $\mathrm{UF}_{6}$ will solidify inside the cylinder. This is because, as liquid $\mathrm{UF}_{6}$ leaves the vessel, it does not directly cool the remaining liquid. This is in contrast to the case of an orifice in the vapor space, when vapor leaving the vessel is replenished by evaporation from the liquid, thus leading to cooling of the liquid and eventual solidification.

The velocity of the jet coming out from the bottom of the cylinder is $Q /\left(A_{o} \rho_{1}\right)=55.2 /\left(2.03 \times 10^{-3} \times 3670\right)=7.4$ $\mathrm{m} / \mathrm{s}(24.3 \mathrm{ft} / \mathrm{s})$. The initial momentum of the jet is equal to $55.2 \mathrm{~kg} / \mathrm{sx} 7.4 \mathrm{~m} / \mathrm{s}=409 \mathrm{~kg}-\mathrm{m} / \mathrm{s}^{2}\left(2950 \mathrm{lb}-\mathrm{ft} / \mathrm{s}^{2}\right)$. Since the jet is directed downwards in this configuration, any solid particles might well stay on the ground. It is conservative to assume that they all remain airborne. Since the jet impinges vertically on the ground, it has no horizontal momentum. However, ambient air imparts a horizontal momentum upon mixing after the flash. This net horizontal momentum gain is equal to the momentum flux of air initially mixed in the jet.

Using equation $\mathrm{D} .44$, the fraction of $\mathrm{UF}_{6}$ that will flash to vapor is determined to be 54 percent at the sublimation temperature of $\mathrm{UF}_{6}$ at atmospheric pressure. The final properties of the jet after mixing with ten times by mass air are given in Table D-23.

Table D-23. Source Term Characteristics of a Liquid Jet through a $5 \mathrm{~cm}(2 \mathrm{in})$ Hole in a 14-ton Cylinder (Scenario 2A)

\begin{tabular}{l|l}
\hline Flow Rate & $\begin{array}{l}\mathrm{UF}_{6}-55.2 \mathrm{~kg} / \mathrm{s} \\
\text { Air }-552 \mathrm{~kg} / \mathrm{s}\end{array}$ \\
\hline Density & $1.313 \mathrm{~kg} / \mathrm{m}^{3}$ \\
\hline Temperature & $291.6 \mathrm{~K}\left(18.6^{\circ} \mathrm{C}\right)$ \\
\hline Volume Flux & $463 \mathrm{~m}^{3} / \mathrm{s}$ \\
\hline $\begin{array}{l}\text { Horizontal } \\
\text { Momentum Flux }\end{array}$ & $\begin{array}{l}1104 \mathrm{~kg}-\mathrm{m} / \mathrm{s}^{2} \text { (assuming } 2 \mathrm{~m} / \mathrm{s} \\
\text { wind speed) }\end{array}$ \\
\hline
\end{tabular}


A spot comparison with a sample problem solved using the computer code CYLIND (NUREG/CR-4360), developed for predicting release rates from $\mathrm{UF}_{6}$ cylinders, revealed that the method outlined here predicts a larger source term than does CYLIND. CYLIND predicted a flow rate of $2.87 \mathrm{~kg} / \mathrm{s}(6.3 \mathrm{lb} / \mathrm{s})$ through a $2.2 \mathrm{~cm}(0.875 \mathrm{in})$ diameter hole. For a $5 \mathrm{~cm}(2 \mathrm{in})$ hole, such as in Scenario \#2A, the flow predicted by CYLIND is $15 \mathrm{~kg} / \mathrm{s}$ (33 lb/s)--approximately 3.7 times smaller than the prediction of $55.2 \mathrm{~kg} / \mathrm{s}(121.4 \mathrm{lb} / \mathrm{s})$ in Table D-23.

The difference in the flow rates can be explained on the basis of the following:

- Bernoulli's formula assumes non-flashing, single phase, liquid release. All flashing occurs outside the orifice. CYLIND assumes multiphase releases and pipe friction losses. Multiphase flow reduces the mass flow rate because the vapor phase is much less dense than the liquid phase and reduces the predicted flow rate. Since it is known that Bernoulli's formula is accurate for pure liquid releases, it is probable that the lower CYLIND results are due to an assumption that there is a two-phase flow through the orifice.

- Scenario 2A assumes no pipe friction losses because flow comes out directly from an orifice. A discharge coefficient is used. CYLIND assumes pipe friction losses through a pipe leading to the valve of a Model $48 \mathrm{Y}$ cylinder.

Thus, given the different conceptual models used in Scenario 2A and in CYLIND, differences in the source term are to be expected.

\section{D.7.3.3 Scenario 2B - Small Hole $5 \mathrm{~cm}$ (2 in) Diameter) Above Liquid Level Resulting in a Continuous Vapor Release}

\section{Parameters}

- Cylinder dimensions conform to those of a Model $48 Y$ container. Wall thickness is $1.6 \mathrm{~cm}\left(5 / 8^{\prime \prime}\right)$ steel. Cylinder body is $3 \mathrm{~m}$ (117 in) long and inside diameter is $1.23 \mathrm{~m}$ (48 in) (internal volume = $\left.3.47 \mathrm{~m}^{3}\left(123 \mathrm{ft}^{3}\right)\right)$.

- Cylinder contents are at $352.4 \mathrm{~K}\left(174^{\circ} \mathrm{F}\right)$. The vapor pressure is $240 \mathrm{kPa}$ ( $35 \mathrm{psia}$ ) from Figure D$8-U_{6}$ phase diagram. The cylinder contains $12600 \mathrm{~kg}(27700 \mathrm{lb})$ of $\mathrm{UF}_{6}$. These values of mass, temperature, and pressure are actual operating conditions.

- A $5 \mathrm{~cm}$ ( 2 in) diameter hole develops at the highest point of cylinder, thus leading to a vertical vapor jet. The escaping gas is rapidly made up by evaporation of liquid $\mathrm{UF}_{6}$. The evaporation cools the cylinder contents, first to the triple point, and then to the sublimation point of $\mathrm{UF}_{6}$. At the sublimation point, the vapor pressure equals atmospheric pressure and the source is terminated.

- Unlike Scenarios 1 and 2A, no flashing occurs outside the cylinder in Scenario No. 2B. Thus there is no need to estimate the amount of air mixed initially at the source as a result of flashing $\mathrm{UF}_{6}$. There is an air entrainment model built into the atmospheric dispersion model NRCPLUME used in Scenario $2 \mathrm{~B}$ to calculate the amount of air that mixes with the jet downstream of the source. The flashing puff assumption used in Scenario 1 and the flashing liquid jet assumption used in Scenario 2A necessitated estimates of the amount of air entrained by the flash phenomenon at the source.

- The emission rates are estimated based upon the methods described in (USEPA 1993). 
- The vapor phase obeys the perfect gas law (PV $=\mathrm{nRT}$ )

- For two-phase flows, all released solid is assumed to travel downwind with negligible deposition near the source.

The contents of cylinder are at $\mathrm{UF}_{6}$ vapor-liquid equilibrium. $\mathrm{UF}_{6}$ vapor partly desublimes to solid when depressurized.

The choked flow pressure, $\mathrm{p}_{*}$, is calculated by (USEPA 1993):

$$
\frac{p^{p}}{p_{1}} \cdot\left(\frac{2}{\gamma+1}\right)^{r(r-1)}
$$

where:

$$
\begin{aligned}
& \mathrm{p}_{1}=\text { the cylinder pressure, } 240 \mathrm{kPa} \\
& \gamma=\text { the ratio of specific heats }\left(\mathrm{C}_{\mathrm{p}} / \mathrm{C}_{\mathrm{v}}\right)
\end{aligned}
$$

For $\mathrm{UF}_{6}, \mathrm{C}_{\mathrm{p}}$ is $369.35 \mathrm{~J} / \mathrm{kg}-\mathrm{K}$. R is the Universal Gas Constant, $23.61 \mathrm{~J} / \mathrm{kg}-\mathrm{K} . \mathrm{C}_{\mathrm{v}}=\mathrm{C}_{\mathrm{p}}-\mathrm{R}=369.35-23.61$ $=345.73$. Thus, $\gamma=369.35 / 345.73=1.07$.

$$
\begin{aligned}
& p=2.4 \times 10^{s}\left(\frac{2}{1.07+1}\right) 1.07(1.07-11 \\
& =2.4 \times 10^{5}(0.59)=142 \times \mathrm{P} 2
\end{aligned}
$$

Since $p_{*}>p_{a}$ (atmospheric pressure, $101 \mathrm{kPa}$ ), the flow is choked.

The pseudo-critical temperature, T.* can be estimated from the equation (USEPA 1993):

$$
\text { т.. }{ }^{2} \mathrm{~T}_{1} /(\gamma+1)
$$

where $T_{1}$ is the storage temperature, $352.4 \mathrm{~K}$.

Thus,

$$
\begin{gathered}
\text { T .. }=2 \times 352.4 / 2.07 \\
=340 \quad .52 \mathrm{~K}
\end{gathered}
$$

The next step is to estimate the vapor pressure $\mathrm{P}_{\mathrm{V}}$ at $\mathrm{T}_{* *}$ by using the Clausius Clapeyron equation (USEPA 1993): 


$$
P_{V}-1.51 \times 10, \exp \left[\frac{H_{L} M}{R}\left(\frac{1}{T,}-\frac{1}{T \ldots}\right)\right]
$$

where:

$\mathrm{H}_{\mathrm{L}}=$ latent heat of vaporization of liquid $\mathrm{UF}_{6}, 8.375 \times 10^{4} \mathrm{~J} / \mathrm{kg}$ (from liquid to vapor)

$\mathrm{M}=$ molecular weight of $\mathrm{UF}_{6}, 352 \mathrm{~kg} / \mathrm{kg}-\mathrm{mol}$

$\mathrm{R}=$ Universal Gas Constant, 8,314 J/kg-mol/K

$\mathrm{Tt}=$ triple point temperature of $\mathrm{UF}_{6}, 337.1 \mathrm{~K}$

$$
\begin{aligned}
P_{V} & =1.51 \times 10^{3} \exp \left[\frac{8.375 \times 10^{4} \times 352}{8314}\left(\frac{1}{337.1} \cdot \frac{1}{340.5}\right)\right] \\
& =168 \mathrm{kP2}
\end{aligned}
$$

Since, $P_{v}\left(T_{* *}\right)>p_{*}$, condensation does not occur during depressurization, and the release rate $Q$ can be estimated using the equation below (USEPA 1993).

$$
Q=c_{0} \cdot\left[p_{1} p_{1} r\left(\frac{2}{r+1}\right)^{\frac{r-1}{r-1}}\right]^{0 . s}
$$

where:

$c_{0}=$ discharge coefficient, normally set to one for vapor releases

$A_{0}=$ discharge area, $2.028 \times 10^{-3} \mathrm{~m}^{2}$ for a $5.12 \mathrm{~cm}$ ( 2 in) diameter hole

$\mathrm{p}_{1}=$ storage pressure, $240 \mathrm{kPa}$ (35 psia)

$\rho_{1}=$ storage density, calculated from Ideal Gas

Law:

$$
\begin{aligned}
\rho_{\mathrm{i}} & =\mathrm{p}_{1} \mathrm{M} /\left(\mathrm{RT}_{1}\right) \\
& =2.4 \times 10^{5} \times 352 /(8314 \times 352.4) \\
& =28.79 \mathrm{~kg} / \mathrm{m}^{3}
\end{aligned}
$$

and the other constants are as defined before. 
Substituting the appropriate values in equation D.55:

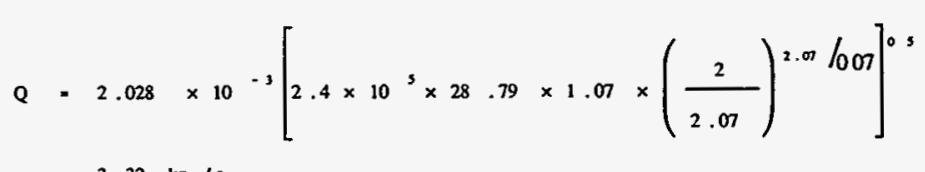

The discharge temperature $\left(\mathrm{T}_{\mathrm{r}}\right.$ ) for conditions under which condensation does not occur is given by (USEPA 1992):

$$
\begin{aligned}
\operatorname{Tr} & =\operatorname{T} 1[1-0.85(\gamma-1) /(\gamma+1) \\
& =352.4 \times[1-0.85 \times 0.07 / 2.07] \\
& =342.3 \mathrm{~K}
\end{aligned}
$$

The discharge density $\left(\rho_{\mathrm{r}}\right)$ is given by the Ideal Gas Law:

$$
\begin{aligned}
\rho_{\mathrm{r}} & =\mathrm{p}_{\mathrm{a}} \mathrm{M} /\left(\mathrm{RT}_{\mathrm{r}}\right) \\
& =1.01 \times 10^{5} \times 352 /(8314 \times 342.3) \\
& =12.49 \mathrm{~kg} / \mathrm{m}^{3}
\end{aligned}
$$

To estimate the duration of release, perform an energy balance by equating the heat absorbed by evaporating liquid $\mathrm{UF}_{6}$ with the heat released in cooling the tank contents from $352.4 \mathrm{~K}$ to the triple point, $\mathrm{T}_{1}$, of $\mathrm{UF}_{6}$ ( 337 $\mathrm{K})$ :

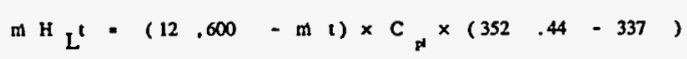

where:

$$
\begin{aligned}
& \mathrm{m}^{\mathrm{m}}=\text { the mass flow rate, } 3.32 \mathrm{~kg} / \mathrm{s} \\
& \mathrm{H}_{\mathrm{L}}=\text { the latent heat of vaporization of liquid } \mathrm{UF}_{6}, 8.375 \times 10^{4} \mathrm{~J} / \mathrm{kg} \\
& \mathrm{t}=\text { the duration of release, seconds } \\
& \mathrm{C}_{\mathrm{pl}}=\text { the specific heat of liquid } \mathrm{UF}_{6}, 563.3 \mathrm{~J} / \mathrm{kg} / \mathrm{K}
\end{aligned}
$$

Solving for $t$, leads to a release duration of approximately 357 seconds. Thus, in about six minutes the tank cools down to the triple point of $\mathrm{UF}_{6}$. A total of $3.32 \times 357 \approx 1185 \mathrm{~kg}(2600 \mathrm{lb})$ is released, and about 11415 $\mathrm{kg}(25100 \mathrm{lb})$ of $\mathrm{UF}_{6}$ remain. This initial, short-lived release is relatively important from the point of view of atmospheric dispersion modeling.

After the tank contents have cooled down to the triple point, with a temperature equal to $337.1 \mathrm{~K}$ and a pressure equal to $150 \mathrm{kPa}$ (22 psia), a new release rate can be calculated. At the triple point, all three phases coexist. Further cooling occurs as material continues to be released, and the liquid phase changes to solid and vapor. The release will continue to occur until the tank cools down to the sublimation point of $\mathrm{UF}_{6}$. At the sublimation point, the vapor pressure of $\mathrm{UF}_{6}$ equals the atmospheric pressure and the source term becomes zero. 
To calculate the conditions at the triple point transition, perform an energy balance on the contents inside the cylinder by assuming the solid phase to be the reference state:

$$
\mathrm{H}_{v} \mathrm{~m}_{1-\mathrm{v}}+\mathrm{H}_{s} \mathrm{~m}_{1-\mathrm{s}}=\mathrm{H}_{1} \mathrm{~m}_{1}
$$

where:

$$
\begin{aligned}
& \mathrm{H}_{\mathrm{s}}=\text { enthalpy of the solid phase }=\mathrm{C}_{\mathrm{ps}}\left(\mathrm{T}-\mathrm{T}_{\mathrm{t}}\right) \text { where } \mathrm{C}_{\mathrm{ps}} \text { is the specific heat of the solid, } 518.14 \\
& \mathrm{~J} / \mathrm{kg} / \mathrm{K} \text { and } \mathrm{T} \text { is the initial temperature } \\
& \mathrm{m}_{\mathrm{l-s}}=\text { the mass that changes phase from liquid to solid } \\
& \mathrm{H}_{\mathrm{v}}=\text { enthalpy of the vapor phase }=\lambda_{\mathrm{s}}+\mathrm{C}_{\mathrm{pv}}\left(\mathrm{T}-\mathrm{T}_{\mathrm{v}}\right) \text { where } \lambda_{\mathrm{s}} \text { is the heat of sublimation, } \\
& 1.369 \times 10^{5} \mathrm{~J} / \mathrm{kg} \\
& \mathrm{C}_{\mathrm{pv}}=\text { the specific heat of the vapor, } 369.4 \mathrm{~J} / \mathrm{kg} / \mathrm{K} \\
& \mathrm{m}_{1 \rightarrow \mathrm{v}}=\text { the mass that changes phase from liquid to vapor } \\
& \mathrm{H}_{1}=\text { enthalpy of the liquid phase }=\lambda_{\mathrm{f}}+\mathrm{C}_{\mathrm{pl}}\left(\mathrm{T}-\mathrm{T}_{\mathrm{V}}\right) \text { where } \lambda_{\mathrm{f}} \text { is the heat of fusion of solid } \mathrm{UF}_{6} \text {, } \\
& 54580 \mathrm{~J} / \mathrm{kg} \\
& \mathrm{C}_{\mathrm{pl}}=\text { the specific heat of liquid of } \mathrm{UF}_{6}, 563.3 \mathrm{~J} / \mathrm{kg} / \mathrm{K}
\end{aligned}
$$

The initial temperature, $T=T_{1}$ because the mass that undergoes a phase change at the triple point is being estimated. Solving, equation D.59, leads to the final mass ratio $(\epsilon)$ of the vapor and liquid phase at the triple point:

$$
\begin{aligned}
\epsilon & =\mathrm{m}_{\mathrm{v}} / \mathrm{m}_{1}=\lambda_{\mathrm{f}} / \lambda_{\mathrm{s}} \\
& =54,580 / 136,900=0.40
\end{aligned}
$$

Thus, 40 percent (by mass) of liquid $\mathrm{UF}_{6}$ at the triple point changes phase to vapor, and the remaining 60 percent (by mass) to solid. The quantity that remains to be calculated now is the duration of the phase transition at the triple point conditions. Vapor will continue to escape through the hole. It is assumed that the solid remains inside the cylinder.

The mass release rate at the triple point is calculated as follows. First, calculate the critical pressure:

$$
\begin{aligned}
& \text { P. } 1.5 \times 10^{5}\left(\frac{2}{\gamma+1}\right)^{\gamma(\gamma-1)} \\
& =1.5 \times 10^{5}\left(\frac{2}{1.07+1}\right)^{1.00(1.07-11} \\
& =89 \mathrm{kPa}
\end{aligned}
$$

where the vapor pressure is $151 \mathrm{kPa}$ at the triple point. Since $\mathrm{p}_{*}<\mathrm{p}_{\mathrm{a}}$ (atmospheric pressure, $101 \mathrm{kPa}$ ), the flow is subcritical. The release rate can be conservatively estimated from (USEPA 1993): 


$$
\mathrm{Q}=\operatorname{KYA_{0}}\left[2 \rho_{\mathrm{t}}\left(\mathrm{p}_{\mathrm{t}}-\mathrm{p}_{\mathrm{a}}\right)\right]^{0.5}
$$

Here, $\rho_{t}=$ the vapor density at the triple point, and

where:

$$
\mathrm{K}=\mathrm{c}_{\mathrm{o}} /\left(1-\beta^{4}\right)^{0.5}
$$

$c_{0}=$ coefficient of discharge, dimensionless (normally set to one for vapor releases)

$\beta=$ ratio of throat diameter to pipe diameter, dimensionless (normally set to zero for releases from a reservoir)

Note that by setting $c_{o}=1$ and $\beta=0, K=1$.

$$
\mathrm{Y}=1-\left[\left(\mathrm{p}_{\mathrm{t}}-\mathrm{p}_{\mathrm{a}}\right) / \mathrm{p}_{\mathrm{t}} \gamma\right]\left(0.41+0.35 \beta^{4}\right)
$$

so that, for $\beta=0$ :

$$
\begin{aligned}
\mathrm{Y} & =1-0.41\left[\left(\mathrm{p}_{1}-\mathrm{p}_{\mathrm{a}}\right) / \mathrm{p}_{1} \gamma\right] \\
& =1-0.41\left[\left(1.5 \times 10^{5}-1.01 \times 10^{5}\right) /\left(1.5 \times 10^{5} \times 1.07\right)\right] \\
& =0.875
\end{aligned}
$$

The vapor density inside the cylinder at the triple point, $\rho_{v}$ is:

where:

$$
\rho_{\mathrm{t}}=\mathrm{P}_{\mathrm{t}} \mathrm{M} / \mathrm{RT} \mathrm{T}_{\mathrm{t}}
$$

$$
\begin{aligned}
M & =\text { the molecular weight of } \mathrm{UF}_{6} \\
\rho_{\mathrm{t}} & =\left(1.5 \times 10^{5} \times 352\right) /(8314 \times 337.1) \\
& =18.84 \mathrm{~kg} / \mathrm{m}^{3}
\end{aligned}
$$

From equation D.44, the flow rate through the hole is:

$$
\begin{aligned}
Q & =0.875 \pi \times\left(2.54 \times 10^{-2}\right)^{2} \times\left[2 \times 18.84 \times\left(1.5 \times 10^{5}-1.01 \times 10^{5}\right)\right]^{0.5} \\
& =2.41 \mathrm{~kg} / \mathrm{s}
\end{aligned}
$$

The discharge temperature, $T_{r}$, is calculated by:

where:

$$
\mathrm{T}_{\mathrm{r}}=2 \mathrm{~T}_{\mathrm{r}} /\left[1+\left(1+4 \mathrm{ET}_{\mathrm{V}}\right)^{0.5}\right]
$$

$$
\mathrm{E}=1 /\left(2 \mathrm{C}_{\mathrm{p}}\right) \times\left[(\mathrm{QR}) /\left(\mathrm{p}_{\mathrm{p}} \mathrm{MA} \mathrm{A}_{\mathrm{o}}\right)\right]^{2}
$$




$$
\begin{aligned}
& =1 /(2 \times 369.4) \times\left[(2.41 \times 8314) /\left(1.5 \times 10^{5} \times 352 \times \pi \times\left(2.54 \times 10^{-2}\right)^{2}\right)\right]^{2} \\
& =4.73 \times 10^{-5}
\end{aligned}
$$

Thus, from equation D.68

$$
\begin{aligned}
& \mathrm{T}_{\mathrm{r}}=(2 \times 337.1) /\left[1+\left(1+4 \times 4.73 \times 10^{-5} \times 337.1\right)^{0.5}\right] \\
& \mathrm{T}_{\mathrm{r}}=331.9 \mathrm{~K}
\end{aligned}
$$

Since the temperature of release is greater than the sublimation temperature $(329.6 \mathrm{~K})$, the discharge is pure vapor.

The discharge density is:

$$
\begin{aligned}
\rho & =\mathrm{PM} / \mathrm{RT} \\
\rho & =\left(1.01 \times 10^{5} \times 352\right) /(8314 \times 331.9) \\
& =12.92 \mathrm{~kg} / \mathrm{m}^{3}
\end{aligned}
$$

The exit velocity, $v$, is:

$$
\begin{aligned}
\mathrm{v} & =\mathrm{Q} /\left(\pi \rho \mathrm{A}_{\mathrm{o}}\right) \\
& =2.41 /\left(\pi \times 12.92 \times\left(2.54 \times 10^{-2}\right)^{2}\right) \\
& =92 \mathrm{~m} / \mathrm{s}
\end{aligned}
$$

To estimate the duration of release at the triple point, assume that the vapor release is made up entirely of the $\mathrm{UF}_{6}$ liquid that changes phase to vapor. From equation $\mathrm{D} .60,40$ percent of the liquid $\mathrm{UF}_{6}$ changes phase to vapor. Thus, since the initial mass of liquid when the triple point was first reached was $11415 \mathrm{~kg}(25100 \mathrm{lb})$, the amount that vaporizes is $0.4 \times 11415=4566 \mathrm{~kg}(10000 \mathrm{lb})$. At a release rate of $2.41 \mathrm{~kg} / \mathrm{s}(318 \mathrm{lb} / \mathrm{min})$ the time, $t$, taken by the liquid $\mathrm{UF}_{6}$ to change phase completely is $\mathrm{t}=4566 / 2.41=1895$ seconds $(\sim 32$ minutes).

This duration is much longer than the six minutes needed to cool the tank from the initial storage temperature to the triple point, and the quantity of $\mathrm{UF}_{6}$ released $(4566 \mathrm{~kg}(10000 \mathrm{lb}))$ is also larger than the one obtained previously (1185 $\mathrm{kg}(2600 \mathrm{lb}))$.

This result is within a factor of two of the result from the computer code CYLIND (NUREG/CR-4360). CYLIND predicts a flow rate of $1.17 \mathrm{~kg} / \mathrm{s}(2.57 \mathrm{lb} / \mathrm{s})$ for 2340 seconds from a $2.2 \mathrm{~cm}$ ( $0.875 \mathrm{in})$ diameter hole. Through a $2.5 \mathrm{~cm}(1 \mathrm{in})$ diameter hole, the mass flow rate will equal $2.57 \mathrm{x}(1 / 0.875)^{2}=3.36 \mathrm{lb} . / \mathrm{s}(1.52$ $\mathrm{kg} / \mathrm{s})$. The durations of release are almost equal.

At the end of $357 \mathrm{~s}+1895 \mathrm{~s}=2252$ seconds, there will be no liquid $\mathrm{UF}_{6}$ left. The solid that remains $(0.6 \times 11415=6849 \mathrm{~kg})$ will cool down to the sublimation point. For simplicity, it is assumed that the pressure inside the cylinder remains constant, though in practice, it will reduce to atmospheric pressure as the sublimation point is approached. To estimate the duration of release, perform a heat balance by equating the heat absorbed in subliming solid $\mathrm{UF}_{6}$ with the heat released in cooling the tank contents from the triple point 
to the sublimation point of $\mathrm{UF}_{6}-\mathrm{-}^{-329} \mathrm{~K}\left(133^{\circ} \mathrm{F}\right)$ (ignoring the temperature change of the vapor for simplicity):

$$
\mathrm{m} \quad \lambda_{\mathrm{t}} \mathrm{t}=(6,849-\mathrm{m} \mathrm{t}) \times \mathrm{c}_{\mathrm{p}} \times(337-1-329)
$$

where:

$$
\begin{aligned}
& \mathrm{m}=\text { the mass flow rate, } 2.41 \mathrm{~kg} / \mathrm{s} \\
& \lambda_{\mathrm{s}}=\text { the heat of sublimation of solid } \mathrm{UF}_{6}, 136,900 \mathrm{~J} / \mathrm{kg} \\
& \mathrm{t}=\text { the duration of release, seconds } \\
& \mathrm{C}_{\mathrm{ps}}=\text { the specific heat of solid } \mathrm{UF}_{6}, 518.14 \mathrm{~J} / \mathrm{kg} / \mathrm{K}
\end{aligned}
$$

Solving for $\mathrm{t}$ leads to a release duration of 85 seconds ( $\sim 1.5$ minutes). After an additional $2.41 \mathrm{x} 85 \mathrm{~s}=204$ $\mathrm{kg}(449 \mathrm{lb})$ of $\mathrm{UF}_{6}$ have leaked, the source term will essentially become zero because the pressure inside the tank will become atmospheric. The amount of solid $\mathrm{UF}_{6}$ left inside the cylinder is $12600-(1185+4566+$ $204)=6645 \mathrm{~kg}(14620 \mathrm{lb})$. Thus, the entire source term can be approximated by using the characteristics calculated for cooling the $\mathrm{UF}_{6}$ cylinder from the triple point to the sublimation point, i.e., a release rate of $2.41 \mathrm{~kg} / \mathrm{s}$. The total duration is approximately $357 \mathrm{~s}+1,895 \mathrm{~s}+85 \mathrm{~s}=2336$ seconds $(\sim 39$ minutes). The source term for this scenario is summarized in Table D-24:

Table D-24. Source Term Characteristics of a $\mathrm{UF}_{6}$ Vapor Jet through a $5 \mathrm{~cm}$ ( 2 in) Diameter Hole in

\begin{tabular}{l|l} 
a 14-ton Cylinder (Scenario 2B) \\
\hline Flow Rate & $2.41 \mathrm{~kg} / \mathrm{s}$ \\
\hline Density & $12.92 \mathrm{~kg} / \mathrm{m}^{3}$ \\
\hline Temperature & $\begin{array}{l}331.9 \mathrm{~K} \\
\left(58.9^{\circ} \mathrm{C}\right)\end{array}$ \\
\hline Volume Flux & $0.19 \mathrm{~m}^{3} / \mathrm{s}$ \\
\hline Velocity & $92 \mathrm{~m} / \mathrm{s}$ \\
\hline Duration & $39 \mathrm{minutes}$ \\
\hline
\end{tabular}

\section{D.7.3.4 Summary of Source Terms}

Three scenarios were chosen to highlight the impact of model assumptions regarding source term estimation on the type and amount of release. Table D-25 summarizes the source terms and illustrates the range of source term magnitudes that can result from different modes of release.

Note that in Scenario 1, the release is instantaneous. Therefore, the mass, volume and momentum are expressed in $\mathrm{kg} / \mathrm{m}^{3}, \mathrm{~m}^{3}$, and $\mathrm{kg}-\mathrm{m} / \mathrm{s}$, respectively. In Scenarios $2 \mathrm{~A}$ and $2 \mathrm{~B}$, the releases are continuous. Thus, the release rate of mass, volume and momentum are expressed in $\mathrm{kg} / \mathrm{s}, \mathrm{m}^{3} / \mathrm{s}$, and $\mathrm{kg}-\mathrm{m} / \mathrm{s}^{2}$, respectively. 
The release rate in Scenario 2A is higher than in Scenario 2B because, in the former case, the release consists of a flashing liquid, which is much denser than the vapor $-3500 \mathrm{~kg} / \mathrm{m}^{3}\left(218 \mathrm{lb} / \mathrm{ft}^{3}\right)$ for liquid $\mathrm{UF}_{6}$ versus $12.92 \mathrm{~kg} / \mathrm{m}^{3}\left(0.8 \mathrm{lb} / \mathrm{ft}^{3}\right)$ for the vapor, respectively. The higher liquid density more than compensates for the fact that the vapor release velocity $(92 \mathrm{~m} / \mathrm{s}(300 \mathrm{ft} / \mathrm{s}))$ is higher than the liquid release velocity $(8 \mathrm{~m} / \mathrm{s}(17.9$ $\mathrm{mph})$ ).

The results shown in Table D-25 have relatively small sources of uncertainty. The phenomena of jet (liquid and vapor) flow are well understood. For a set of given initial conditions, the source term can be estimated with a high degree of confidence $(< \pm 10$ percent). Uncertainty arises when the initial conditions are not fully known, or when the leak size is unknown. Uncertainty caused by a lack of knowledge of conditions inside a tank can only be calculated on a case-by-case basis. For example, the release rate depends linearly on the leak size--doubling the leak area doubles the release rate.

Table D-25. Summary of Source Terms

\begin{tabular}{|c|c|c|c|}
\hline & Scenario 1 & Scenario 2A & Scenario 2B \\
\hline Type of Release & $\begin{array}{l}\text { Instantaneous, Flashing } \\
\text { Liquid Puff }\end{array}$ & $\begin{array}{l}\text { Continuous, Flashing } \\
\text { Liquid, Low Velocity, } \\
\text { Ground Level Release }\end{array}$ & $\begin{array}{l}\text { Continuous, Vapor, } \\
\text { High Velocity, Vertical, } \\
\text { Elevated Release }\end{array}$ \\
\hline $\begin{array}{l}\text { Mass UFd } \\
\text { Mass Flux (for Scenario 2A } \\
\text { and 2B) }\end{array}$ & $14,000 \mathrm{~kg}$ & $57 \mathrm{~kg} / \mathrm{s}$ & $2.41 \mathrm{~kg} / \mathrm{s}$ \\
\hline $\begin{array}{l}\text { Mass of Air/ } \\
\text { Mass Flux (for Scenario 2A } \\
\text { and 2B) }\end{array}$ & $140,000 \mathrm{~kg}$ & $570 \mathrm{~kg} / \mathrm{s}$ & 0 (initially at source) \\
\hline Density & $1.314 \mathrm{~kg} / \mathrm{m}^{3}$ & $1.313 \mathrm{~kg} / \mathrm{m}^{3}$ & $12.92 \mathrm{~kg} / \mathrm{m}^{3}$ \\
\hline Temperature & $291.5 \mathrm{~K}\left(18.5^{\circ} \mathrm{C}\right)$ & $291.6 \mathrm{~K}\left(18.6^{\circ} \mathrm{C}\right)$ & $331.9 \mathrm{~K}\left(58.9^{\circ} \mathrm{C}\right)$ \\
\hline $\begin{array}{l}\text { Volume/ } \\
\text { Volume Flux (for Scenario } \\
\text { 2A and 2B) }\end{array}$ & $117,200 \mathrm{~m}^{3}$ & $535 \mathrm{~m}^{3} / \mathrm{s}$ & $0.19 \mathrm{~m}^{3} / \mathrm{s}$ \\
\hline $\begin{array}{l}\text { Momentum } \cdots \text { / / } \\
\text { Momentum Flux (for } \\
\text { Scenario 2A and 2B) }\end{array}$ & $\begin{array}{l}280,000 \mathrm{~kg}-\mathrm{m} / \mathrm{s} \\
\text { (horizontal) }\end{array}$ & $\begin{array}{l}1140 \mathrm{~kg}-\mathrm{m} / \mathrm{s}^{2} \\
\text { (horizontal) }\end{array}$ & $\begin{array}{l}221.8 \mathrm{~kg}-\mathrm{m} / \mathrm{s}^{2} \\
\text { (vertical) }\end{array}$ \\
\hline Release Height & ground level & ground level & $1.2 \mathrm{~m}$ (4 feet) \\
\hline Duration & Instantaneous & 3.5 minutes & 39 minutes \\
\hline
\end{tabular}

Assuming a wind speed of $2 \mathrm{~m} / \mathrm{s}$. Since the $\mathrm{UF}_{6}$ has no initial momentum, the air imparts a momentum $(280,000 \mathrm{~kg}-\mathrm{m} / \mathrm{s})$ equal to mass of air $(140,000 \mathrm{~kg})$ times wind speed $(2 \mathrm{~m} / \mathrm{s}$ in Scenario \#1 and $\$ 2 \mathrm{~A})$. In Scenario \#2B the momentum of air at the source is not needed. 
In this sample problem, the initial aerosolization has been estimated by using the flash characteristics of $\mathrm{UF}_{6}$ and is about 50 percent. It has been assumed that this aerosolized material remains airborne with the vapor fraction as fine solid particles. If the particles were to fall out, the source term magnitude would be reduced by a factor of two. Other initial conditions, in which the flash fraction is smaller than 50 percent and the aerosol fraction is larger than 50 percent, lead to larger uncertainties. Aerosolization can affect the source density.

\section{D.7.4 Release From Buildings}

For the purpose of this sample problem, release from buildings was not considered. To estimate the source term from a building, the flow paths caused by outside wind pressures at building openings need to be described. Releases from buildings are dependent upon building geometry, particle size distribution and its influence on gravity settling and diffusive deposition, convection within the building-natural or forced, and external atmospheric conditions. These are generally complex calculations.

\section{D.7.5 Atmospheric Dispersion And Consequence Modeling}

\section{D.7.5.1 Choice of Dispersion Models}

The dispersion models should have the ability to model the following:

- Dense and neutrally buoyant plumes

- Instantaneous "puffs" and continuous releases

- Jets

- $\mathrm{UF}_{6} / \mathrm{HF}$ thermodynamics

- Various health effects models such as time-dependent, time-independent, etc.

- Validated against existing experimental data sets.

As has previously been mentioned, NRC sponsored and funded a suite of atmospheric dispersion models that are specifically tailored to take into account $\mathrm{UF}_{6} / \mathrm{HF}$ thermodynamics (Kaiser and Chhibber 1993). They include modules known as NRCDENZ, NRCPLUME, and NRCRUNCH. They possess the desired characteristics. NRCDENZ is a puff model and was used to simulate Scenario 1. NRCRUNCH can model ground level ambient releases of dense and neutrally buoyant vapors. NRCRUNCH was used to model Scenario 2A. NRCPLUME is a jet model and can be used to model a jet release such as that in Scenario $2 \mathrm{~B}$. However, because the plume is so heavy, it rapidly turns over and falls to the ground. At this point, NRCRUNCH takes over the modeling.

The assumptions, other than source term characteristics described in Section D.7.1, that have the greatest impact on prediction of affected distances are described below: 


\section{Weather Conditions}

Two weather conditions were used, (1) D atmospheric stability, $300 \mathrm{~K}\left(80^{\circ} \mathrm{F}\right)$ and a wind speed of $5 \mathrm{~m} / \mathrm{s}(11$ $\mathrm{mph})$, and (2) $\mathrm{F}$ atmospheric stability, $285 \mathrm{~K}\left(53^{\circ} \mathrm{F}\right)$ and a wind speed of $2 \mathrm{~m} / \mathrm{s}(4.5 \mathrm{mph})$. The reason for selecting two weather conditions was to better represent the range of possible outcomes by means of bounding the estimates between a best estimate case and a conservative case. The sensitivity of dispersion modeling results to assumptions about weather conditions is so high, that one weather condition cannot appropriately approximate the range of possible outcomes.

D atmospheric stability and $5 \mathrm{~m} / \mathrm{s}(11 \mathrm{mph})$ wind speed conditions provide average consequences for releases that take place and remain at ground level. For this reason $D$ stability and $5 \mathrm{~m} / \mathrm{s}(11 \mathrm{mph})$ wind speed are often used to approximate expected outcomes. D Pasquill stability is a neutral weather condition applicable to a heavy, overcast day or night, typically associated with surface wind speeds in the range of 4 to $6 \mathrm{~m} / \mathrm{s}$ (9 to $13 \mathrm{mph}$ ).

$\mathrm{F}$ atmospheric stability and $2 \mathrm{~m} / \mathrm{s}(4.5 \mathrm{mph})$ wind speed conditions provide conservative case consequences for releases that take place and remain at ground level. There are exceptions to this rule, especially when plume rise is an important issue. F Pasquill stability is a stable weather condition applicable to cloudy nights with surface wind speeds less than $2 \mathrm{~m} / \mathrm{s}$ ( $4.5 \mathrm{mph}$ ).

Although the sensitivity of affected distance to ambient relative humidity is not as great as to the choice of atmospheric stability and wind speed, a sensitivity analysis was performed to illustrate the affect of varying relative humidity. Two values were chosen, 50 percent and 90 percent.

It should be becoming apparent that the selection of values for input parameters is not an independent process. The values of relative humidity, wind speed, and ambient temperature are not independent of the atmospheric stability class, for example.

\section{Inversion Lids}

An inversion lid is defined as the atmospheric layer above which the atmosphere is stable and prevents vertical mixing. If a plume is unable to penetrate the inversion lid, then vertical diffusion is prevented and the material is trapped below the inversion lid. Therefore, inversion lids play a significant role in terminating plume rise and affect ground level concentrations. The constraint on plume rise and mixing in the vertical direction by the action of ambient atmospheric turbulence results in higher ground-level concentrations than what would have been expected had there been no such constraint.

The following formula is used to calculate inversion lid heights in each weather category (Ermak 1990):

$$
\ell=130 \cdot 2^{7-s}
$$

where $\ell$ is the inversion lid height $(m), s$ is the atmospheric stability category (for $A, s=1$, for $B, s=2, \ldots$, for $\mathrm{F}, \mathrm{s}=6)$. Thus, for atmospheric stability category $\mathrm{D}, \ell=130 \cdot 2^{7-4}=1040 \mathrm{~m}(3400 \mathrm{ft})$, and likewise for category, $F, \ell=260 \mathrm{~m}(850 \mathrm{ft})$. 


\section{Terrain}

Two terrain models were used--(1) Briggs' urban and (2) rural (EPA 1987). The terrain affects the rate of entrainment of air in the cloud. An urban terrain model, characterized by distributed heat sources, buildings and associated turbulence, dilutes the cloud more rapidly than a rural terrain model does. Thus the affected distances are larger when using the rural terrain assumption.

\section{Building Wake}

To illustrate the effect of building wakes a simple building wake model was used. Building wakes tend to dilute the source term by mixing in a large amount of air at the source. This has the beneficial effect of lowering concentrations close to the source. However, a building wake also tends to entrain the released material into it (Hall et al. 1995). This has the undesirable effect of suppressing the rise of certain buoyant plumes that would ordinarily have risen in the absence of a wake. The result is an increase in the ground level concentrations. The overall effect of building wakes can be predicted only after carefully considering these two effects on a case-by-case basis for each type of release. See Section 5.4 for further information on this topic.

\section{D.7.5.2 Choice of Appropriate Health Effects Models}

Three different health effects models were used--two for exposure to soluble uranium and one for exposure to hydrogen fluoride.

\section{Exposure to Soluble Uranium}

Health Effects Model 1-The health effects level specified in NUREG-1391 to cause permanent renal damage to a $70-\mathrm{kg}$ (154-lb) individual by inhalation is $40 \mathrm{mg}(0.0014 \mathrm{oz})$ soluble uranium. The breathing rate of the exposed individual was assumed to be $2.6 \times 10^{-4} \mathrm{~m}^{3} / \mathrm{s}\left(33 \mathrm{ft}^{3} / \mathrm{hr}\right)$, consistent with people in an active state (USNRC 1988). The intake level necessary to cause renal damage is independent of exposure duration.

Health Effects Model 2-The American Industrial Hygiene Association has recently published Emergency Response Planning Guideline (ERPG) values for $\mathrm{UF}_{6}$. The ERPG-2 value is the maximum airborne concentration below which it is believed nearly all individuals could be exposed for up to one hour without experiencing or developing irreversible or other serious health effects that could impair an individual's ability to take protective action. The ERPG-2 value for $\mathrm{UF}_{6}$ is $15 \mathrm{mg} / \mathrm{m}^{3}$. This corresponds to $9.5 \mathrm{mg}\left(3.3 \times 10^{-4} \mathrm{oz}\right)$ of soluble uranium intake in one hour. Haber's law can be used to extrapolate to different exposure times:

$$
\mathrm{C} \times \mathrm{t}_{\mathrm{e}}=\text { constant }
$$

where $\mathrm{C}$ is the concentration in $\mathrm{mg} / \mathrm{m}^{3}$ and $\mathrm{t}_{\mathrm{c}}$ is exposure time in minutes. The Haber's law constant for the $\mathrm{UF}_{6}$ ERPG-2 is $900 \mathrm{mg}$-minutes $/ \mathrm{m}^{3}$. 


\section{Exposure to Hydrogen Fluoride}

Moderate exposure to $\mathrm{HF}$ in air can cause smarting of the skin, respiratory irritation, irritation of the conjunctiva, and pronounced taste. Massive exposure to $\mathrm{HF}$ in air can cause progressive destruction of the bronchial mucous membrane and swelling of lung tissue, which can be fatal.

Health Effects Model 3-The criterion specified in NUREG/CR-1391 for HF toxicity is:

$$
C=2.5 \times 10^{-5}\left(30 / t_{e}\right)^{0.5}
$$

where $C$ is the concentration $\left(\mathrm{kg} / \mathrm{m}^{3}\right)$ of HF that an individual can be exposed to for a duration of $\mathrm{t}_{\mathrm{e}}$ minutes that would not cause "any escape-impairing symptoms or any irreversible health effects" (NUREG-1391 [USNRC 1991]). This level corresponds to a toxic load of $25 \mathrm{mg} / \mathrm{m}^{3}\left(1.5 \times 10^{-6} \mathrm{lb} / \mathrm{ft}^{3}\right)$ of $\mathrm{HF}$ for thirty minutes.

Noting that when 352 mass-units of $\mathrm{UF}_{6}$ react completely with water, 80 mass-units of HF are produced, the exposure criterion can be rewritten in terms of an equivalent concentration of $\mathrm{UF}_{6}$ that will produce the same effect:

$$
\mathrm{C}_{\mathrm{HF}}=2.5 \times 10^{-5} \times(352 / 80)\left(30 / \mathrm{t}_{\mathrm{e}}\right)^{0.5} \sim 1.1 \times 10^{-4}\left(30 / \mathrm{t}_{\mathrm{e}}\right)^{0.5}
$$

The above equation states that an individual could be exposed for thirty minutes to HF produced by the complete reaction of a $\mathrm{UF}_{6}$ concentration of $1.125 \times 10^{-4} \mathrm{~kg} / \mathrm{m}^{3}\left(7.0 \times 10^{-6} \mathrm{lb} / \mathrm{ft}^{3}\right)$ without causing any escapeimpairing symptoms or any irreversible health effects. This alternate form of expressing the exposure criterion in terms of $\mathrm{UF}_{6}$ concentration is meaningful because, at such low concentrations $\mathrm{UF}_{6}$ will completely react to form HF.

\section{Exposure Duration}

Exposure duration was assumed to be equal to the actual release duration for continuous releases in Scenarios $2 \mathrm{~A}$ and $2 \mathrm{~B}$. For the instantaneous release (Scenario \#1), the exposure duration was assumed to be equal to the duration of cloud passage, which varies with wind speed and distance downwind.

\section{D.7.5.3 Prediction of Affected Distances}

Tables D-26 and D-27 give predictions of the affected distance prediction for soluble uranium and HF for each alternative.

\section{D.7.5.4 Discussion of Results}

Tables D-26 and D-27 confirm that the choice of terrain, source term type, health effects model and weather stability category have the greatest effect on predictions of distances. 
Table D-26. Affected Distances (meters) - Rural Terrain

\begin{tabular}{|c|c|c|c|c|c|c|c|c|}
\hline $\begin{array}{l}\text { Weather } \\
\text { Condition }\end{array}$ & \multicolumn{4}{|c|}{$\begin{array}{l}\text { F Atmospheric Stability } \\
285 \mathrm{~K}, 2 \mathrm{~m} / \mathrm{s} \text { wind speed }\end{array}$} & \multicolumn{4}{|c|}{$\begin{array}{l}\text { D Atmospheric Stability } \\
300 \mathrm{~K}, 5 \mathrm{~m} / \mathrm{s} \text { wind speed }\end{array}$} \\
\hline Scenario & \multicolumn{2}{|c|}{$50 \%$ Relative Humidity } & \multicolumn{2}{|c|}{ 90\% Relative Humidity } & \multicolumn{2}{|c|}{$50 \%$ Relative Humidity } & \multicolumn{2}{|c|}{$90 \%$ Relative Humidity } \\
\hline & w/o Wake & w/ Wake & w/o Wake & w/ Wake & w/o Wake & w/ Wake & w/o Wake & w/ Wake \\
\hline & \multicolumn{8}{|c|}{ Uranium Toxicity - NUREG/CR-1391 (40 mg Intake) } \\
\hline 1 & 5700 & & 5300 & & 1100 & & 950 & \\
\hline $2 \mathrm{~A}$ & 6100 & 4100 & 6090 & 4100 & 1075 & 760 & 1000 & 760 \\
\hline \multirow[t]{2}{*}{ 2B } & 1700 & 1740 & not exceeded & 1740 & 350 & 380 & 350 & 380 \\
\hline & \multicolumn{8}{|c|}{ Uranium Toxicity - ERPG-2 } \\
\hline 1 & $>46500$ & & $>44600^{*}$ & & 3900 & & 3800 & \\
\hline $2 A$ & $>125000^{*}$ & 66000 & $>125000^{\circ}$ & 66000 & 4650 & 3500 & 4580 & 3500 \\
\hline \multirow[t]{2}{*}{ 2B } & 4750 & 4800 & 3600 & 4800 & 800 & 850 & 800 & 850 \\
\hline & \multicolumn{8}{|c|}{ HF Toxicity - NUREG/CR-1391, $\left(25 \mathrm{mg} / \mathrm{m}^{3}\right.$ for Half-Hour) } \\
\hline 1 & 3700 & & 3400 & & 2300 & & 2200 & \\
\hline $2 A$ & 19500 & 12000 & 19500 & 12000 & 2100 & 1500 & 2000 & 1500 \\
\hline 2B & 1700 & 1700 & not exceeded & 1700 & 350 & 375 & 350 & 375 \\
\hline
\end{tabular}

* beyond range of validity of model

Table D-27. Affected Distances (meters) - Urban Terrain

\begin{tabular}{|c|c|c|c|c|c|c|c|c|}
\hline $\begin{array}{l}\text { Weather } \\
\text { Condition }\end{array}$ & \multicolumn{4}{|c|}{$\begin{array}{l}\text { F Atmospheric Stability } \\
285 \mathrm{~K}, 2 \mathrm{~m} / \mathrm{s} \text { wind speed }\end{array}$} & \multicolumn{4}{|c|}{$\begin{array}{l}\text { D Atmospheric Stability } \\
300 \mathrm{~K}, 5 \mathrm{~m} / \mathrm{s} \text { wind speed }\end{array}$} \\
\hline Scenario & \multicolumn{2}{|c|}{$50 \%$ Relative Humidity } & \multicolumn{2}{|c|}{$90 \%$ Relative Humidity } & \multicolumn{2}{|c|}{$50 \%$ Relative Humidity } & \multicolumn{2}{|c|}{$90 \%$ Relative Humidity } \\
\hline & w/o Wake & w/ Wake & w/o Wake & w/ Wake & w/o Wake & w/ Wake & w/o Wake & w/ Wake \\
\hline & \multicolumn{8}{|c|}{ Uranium Toxicity - NUREG/CR-1391 (40 mg Intake) } \\
\hline 1 & 700 & & 625 & & 500 & & $\overline{400}$ & \\
\hline $2 \mathbf{A}$ & 970 & 800 & 1000 & 800 & 475 & 340 & 400 & 340 \\
\hline \multirow[t]{2}{*}{ 2B } & 390 & 440 & 330 & 440 & 150 & 200 & 150 & 200 \\
\hline & \multicolumn{8}{|c|}{ Uranium Toxicity - ERPG-2 } \\
\hline 1 & 1500 & & 1400 & & 1330 & & 1220 & \\
\hline $2 \mathrm{~A}$ & 4350 & 3300 & 4370 & 3300 & 1460 & 1100 & 1390 & 1100 \\
\hline \multirow[t]{2}{*}{ 2B } & 830 & 900 & 840 & 900 & 310 & 370 & 310 & 370 \\
\hline & \multicolumn{8}{|c|}{ HF Toxicity - NUREG/CR-1391, $\left(25 \mathrm{mg} / \mathrm{m}^{3}\right.$ for Half-Hour) } \\
\hline 1 & 850 & & 750 & & 970 & & 850 & \\
\hline $\mathbf{2 A}$ & 1850 & 1500 & 1870 & 1500 & 775 & 575 & 700 & 575 \\
\hline $2 B$ & 380 & 430 & 320 & 430 & 150 & 200 & 150 & 200 \\
\hline
\end{tabular}




\section{Effect of Terrain}

The effect of terrain is demonstrated by the fact that the predicted distances for urban terrain in Table D-27 are consistently much smaller than the corresponding distances for rural terrain in Table D-26. This is because there is considerably more turbulence in urban areas than in rural areas. Greater turbulence causes increased dilution of the plume in urban areas and results in predictions of significantly smaller affected distances.

\section{Effect of Source Term}

The effect of type of source term on the results is also very significant. The vapor release scenario (Scenario 2B) gives the smallest predictions of distances affected overall. This is because (a) the vapor release scenarios have the lowest mass release rate, and (b) the jet is oriented vertically upward.

As noted earlier, two weather conditions were considered-(a) F stability, $285 \mathrm{~K}\left(53^{\circ} \mathrm{F}\right), 2 \mathrm{~m} / \mathrm{s}(4.5 \mathrm{mph})$ wind speed to represent "worst-case" conditions, and (b) D stability, $300 \mathrm{~K}\left(80^{\circ} \mathrm{F}\right), 5 \mathrm{~m} / \mathrm{s}(11 \mathrm{mph})$ wind speed to represent "average" conditions. Note that for Scenario 1, the models used could not model the instantaneous release of $\mathrm{UF}_{6}$ within a building wake. Thus, for Scenario 1, the table entries for the "w/wake" case have been left blank.

\section{Effect of Weather Condition}

Atmospheric turbulence plays a very significant role in diluting a release. Thus, stable atmospheric conditions tend to produce larger predictions of affected distances than neutral or unstable conditions. In Tables D-26 and D-27, the predictions of affected distances in Stability Category F are consistently larger than the same in Stability Category D. These differences are particularly sharp in the rural terrain scenarios (Table D-26). In the urban terrain scenarios (Table D-27), these differences become smaller due to turbulence produced by distributed heat sources in both stable and neutral weather conditions. In stability $F$, the height of the inversion lid is relatively small (see discussion on inversion lids in Section D.7.5.1.1). Thus, the material is trapped below the lid and, in combination with the rural terrain assumption, this can lead to predictions of large affected distances.

The effect of varying ambient relative humidity is only slight on affected distances. Thus, in comparison to assumptions regarding source term type, atmospheric stability and health effects model, the sensitivity of the predicted distances to relative humidity is small.

\section{Effect of Health Effects Model}

The affected distances vary greatly for each health effects model used. As described in Section D.7.5.2, three different health effects models were used: 


\section{Renal Injury Due to Uranium (NUREG/CR-1391)}

The $40 \mathrm{mg}$ (1.3 oz)-soluble uranium threshold for permanent renal injury (NUREG-1391) does not vary with exposure duration. This means that a short-duration/high concentration cloud will have the same effect as a long-duration/low concentration cloud if the intake remains the same.

\section{UF $_{6}$ ERPG-2}

It was assumed that this level of concern depends upon the exposure duration as described by Haber's Law. If the duration of exposure is long, then the level of concern is reduced, and if the duration of exposure is short, then the level of concern is increased. Furthermore, for a one-hour exposure, the ERPG-2 value of UF 6 is $15 \mathrm{mg} / \mathrm{m}^{3}\left(3.8 \times 10^{-5} \mathrm{lb} / \mathrm{ft}^{3}\right)$ and is equivalent to approximately $9.5 \mathrm{mg}\left(8.5 \times 10^{-4} \mathrm{lb}\right)-\mathrm{U}$--one-fourth of the NUREG-1391 level. Thus, the affected distances are much higher than corresponding figures for the NUREG-1391 level of concern.

\section{HF (NUREG-1391)}

The distances predicted by Scenario 2B are shorter than in Scenarios 1 and 2A because the longer release duration in Scenario $2 B$ results in a smaller rate of release.

\section{Effect of Building Wake}

In comparison to the effect of weather conditions, terrain and health effects model, the presence of a building wake has little effect. That said, in Scenario $2 \mathrm{~A}$ (continuous ground-level release of flashing $\mathrm{UF}_{6}$ liquid), the presence of building wake has a beneficial effect. This is because the source is diluted by the turbulence in a wake. However, in Scenario $2 \mathrm{~B}$--continuous elevated vertically upward release of $\mathrm{UF}_{6}$ vapor, the presence of a building wake has a deleterious effect in some cases. This is because the rise of the vertically upward directed plume that would ordinarily have risen clear off the ground near the source in the absence of a wake is suppressed. The result is an increase in the ground level concentrations.

\section{D.8 Sample Problem 7: Liquid Spill in Vitrification Plant}

See Sections 3.3.4.3 and 3.3.4.3 for more information on liquid spills.

\section{D.8.1 Introduction}

Liquid spills can pose human health and environmental problems if the liquid released is toxic, radioactive, or otherwise hazardous. Liquid releases result from spills that occur during transfer, leaks in pipes or containers, and ruptures caused by external forces such as catastrophic impacts or internal overpressurization from uncontrolled reactions.

A liquid spill of hazardous or radioactive material creates airborne, as well as liquid, transport pathways as a result of evaporation and aerosolization from the liquid surface. The transport of aerosolized particles in air 
is considered in other sample problems (free-fall spill, explosion, fire, and filter failure). This sample problem focuses on the initial aerosol as liquid and its transport pathways.

The two methods discussed below for determining ARF/RF are based on liquid spill data. The first method (for Archimedes numbers $<1.6 \mathrm{E} 8$, the largest experimental value) uses a table of bounding values. The second method (for Archimedes numbers $>1.6 \mathrm{E} 8$ ) uses a correlation for $\mathrm{ARF}$ based on the data and an $\mathrm{RF}=$ 1. The Archimedes number for spills in air, $\mathrm{Arch}_{\mathrm{a}}$, is defined by:

$$
\begin{aligned}
& \text { Archimedes number, Arch }=\rho_{\mathrm{a}}{ }^{2} \mathrm{H}^{3} \mathrm{~g} / \mu^{2} \\
& \text { Fraction of spill airborne, ARF }=\mathrm{m}_{\mathrm{p}} / \mathrm{m}_{\mathrm{s}} \\
& \text { Geometric standard deviation }=\sigma_{\mathrm{g}}
\end{aligned}
$$

where:

$$
\begin{aligned}
& \rho_{\mathrm{a}}=\text { air density }\left(\mathrm{kg} / \mathrm{m}^{3}\right) \\
& \mathrm{H}=\text { spill height }(\mathrm{m}) \\
& \mathrm{g}=\text { the acceleration due to gravity }\left(9.81 \mathrm{~m} / \mathrm{s}^{2}\right) \\
& \mu=\text { liquid viscosity (poise) } \\
& \mathrm{m}_{\mathrm{p}}=\text { the mass of droplets airborne }(\mathrm{kg}) \\
& \mathrm{m}_{\mathrm{s}}=\text { the mass of the spill }(\mathrm{kg})
\end{aligned}
$$

The correlation of original data with the Archimedes number (dimensionless) is as follows:

$$
\mathrm{ARF}=8.12 \times 10^{-10} \mathrm{Arch}_{\mathrm{a}}^{0.55}
$$

Equation D.80 and variations are found in the report by Ballinger (1988). Equation D.80 is the best fit of the variations and is valid for $\mathrm{Arch}_{\mathrm{a}}>1.6 \mathrm{E} 8$. The correlations for the fraction airborne were obtained using the original data of Sutter et al. (1981) and Ballinger and Hodgson (1986). The data were taken from 1- to 3-m (3-to 10-ft) spills of uranyl nitrate hexahydrate solution (density $>1600 \mathrm{~kg} / \mathrm{m}^{3}\left(100 \mathrm{lb} / \mathrm{ft}^{3}\right)$, viscosity $2.1 \mathrm{E}-3$ Pa-s (2.1 cp)), sucrose solution (various densities and viscosities), slurries (various densities and viscosities), and aqueous solutions of surfactant.

For liquid spills with fall distances of over $3 \mathrm{~m}(10 \mathrm{ft})$, data for aqueous solutions, slurries, and viscous solutions indicate that the empirical correlations for $\mathrm{ARF}$, and drop size distribution parameter presented in equation D.80 are adequate, provided that $A R F \times R F$ value exceeds the bounding $3 \mathrm{~m}(10 \mathrm{ft})$ values.

Historical data on spills of aqueous solutions, slurries, and viscous solutions with a free-fall distance of $3 \mathrm{~m}$ provides the guidelines for airborne release fraction estimates shown in Table D-28, in which the experimental value of $\mathrm{Arch}_{\mathrm{a}}<1.6 \mathrm{E} 8$. The values shown in Table D-28 are for two types of aqueous solutions: general aqueous solutions with a density of $1.0 \mathrm{~g} / \mathrm{cm}^{3}\left(62.4 \mathrm{lb} / \mathrm{ft}^{3}\right)$ and concentrated heavy metal nitrate solutions, such as uranium nitrate hexahydrate (UNH) or plutonium nitrate, with densities of greater 
Table D-28. Median and Bounding ARF/RF Values for Aqueous Solutions, Slurries, and Viscous Solutions for Spills with Arch $_{\mathrm{a}}<1.6 \mathrm{E8}$

\begin{tabular}{|l|l|l|}
\hline \multicolumn{1}{|c|}{ Liquid Type } & \multicolumn{1}{c|}{ Median } & \multicolumn{1}{c|}{ Bounding } \\
\hline Aqueous Solution & ARF 4E-5/RF 0.7 & ARF 2E-4/RF 0.5 \\
\hline Concentrated Heavy Metal Solution & ARF 1E-6/RF 0.3 & ARF 2E-5/RF 1.0 \\
\hline Slurry & ARF 2E-5/RF 0.7 & ARF 5E-5/RF 0.8 \\
\hline Viscous Solution & ARF 3E-6/RF 0.8 & ARF 7E-6/RF 0.8 \\
\hline
\end{tabular}

Source:USDOE (1994)

than $1.2 \mathrm{~g} / \mathrm{cm}^{3}\left(74.9 \mathrm{lb} / \mathrm{ft}^{3}\right)$. The highest release fraction is for the general aqueous solutions. The representative slurry contains 40 percent solids. The viscosity of the viscous solution is greater than 3 centipoise.

\section{D.8.2 Scenario}

To demonstrate the calculation of release fractions, LPFs, and doses from a liquid spill, the liquid spill scenario has been based on safety analyses from a facility that is intended to combine nuclear waste with glass in a vitrification process. At the vitrification plant, a slurry composed principally of insoluble inorganic salts is fed through underground piping to the process cells housed in the vitrification building. The salts are mixed with glass frit in the slurry mix evaporator and fed to the glass melter via the melter feed tank. In the melter, the frit/waste salt mixture is heated to over $1273 \mathrm{~K}\left(1830^{\circ} \mathrm{F}\right)$ to form a molten glass. The glass is poured into canisters which are cooled, sealed, and stored.

In this generic vitrification facility, the potential for liquid spills is found in the following situations:

- Overflow in process cells

- Overflow in pump pits and auxiliary pits

- Leaks in process cells (excluding salt processing cell)

- Leaks in salt processing cell

- Leaks in pump pits

- Transfer line leaks

- Canister rupture

- Release of contaminated steam condensate

- Release of contaminated cooling tower water

For illustrative purposes, a process cell line leak of 1 liter $(0.26 \mathrm{gal})$ of salt slurry has been chosen. The line is assumed to run from near the base of a slurry feed tank to the top of the melter. The slurry has a fall path of $2 \mathrm{~m}(6.6 \mathrm{ft})$ in Example 1 and $5 \mathrm{~m}(16.4 \mathrm{ft})$ in Example 2. 


\section{D.8.3 Evaluation}

\section{D.8.3.1 Example 1}

As noted above, a prócess cell line leak of 1 liter $(0.26 \mathrm{gal})$ of salt slurry (density $\left.1.25 \mathrm{~g} / \mathrm{cm}^{3}\left(78 \mathrm{lb} / \mathrm{ft}^{3}\right)\right)$ that has a potential fall path of $2 \mathrm{~m}(6.6 \mathrm{ft})$ has been chosen for this example. This slurry is a non-Newtonian fluid that was measured to have a viscosity of $0.003 \mathrm{~Pa}-\mathrm{s}(3 \mathrm{cp})$ at the conditions of the process cell. The process cell is $20 \mathrm{~m}$ by $10 \mathrm{~m}$ by $7 \mathrm{~m}$ ( $66 \mathrm{ft}$ by $33 \mathrm{ft}$ by $23 \mathrm{ft}$ ) high with 5 air changes per hour ventilation flow. The cell has four exhaust ducts, each $0.6 \mathrm{~m}$ by $0.6 \mathrm{~m}$ ( $2 \mathrm{ft}$ by $2 \mathrm{ft}$ ) and averaging $60 \mathrm{~m}$ ( $197 \mathrm{ft}$ ) long, before entering the exhaust plenum.

The calculation for $\operatorname{Arch}_{\mathfrak{a}}$ is as follows:

$$
\operatorname{Arch}_{\mathrm{a}}=\left[(1.185)^{2} /(0.003)^{2}\right] 2^{3}(9.8)=1.22 \mathrm{E} 7 \text { for a spill in air at } 298 \mathrm{~K}\left(76^{\circ} \mathrm{F}\right)
$$

Since this $\operatorname{Arch}_{\mathrm{a}}$ is less than 1.6E8, then the values in Table D-28 apply.

Assume the bounding values for a slurry yields an ARF of 5E-5 and an RF of 0.8 . Thus, $0.8(1250 \mathrm{~g})(5 \mathrm{E}-5)$ $=0.05 \mathrm{~g}\left(1.1 \times 10^{-4} \mathrm{lb}\right)$ of respirable aerosol particles are produced.

\section{D.8.3.2 Example 2}

This example differs from Example 1 only in the fall height, which is $5 \mathrm{~m}(16.4 \mathrm{ft})$ instead of $2 \mathrm{~m}(6.6 \mathrm{ft})$. The new $\mathrm{Arch}_{\mathrm{a}}$ is now 1.91E8 instead of 1.22E7. The new $\mathrm{Arch}_{\mathrm{a}}$ is larger than the cutoff value of 1.6E8, so equation D.46 is used to estimate the ARF. The predicted ARF is $2.91 \mathrm{E}-5$, which should be considered as equivalent to the median $A R F=2 E-5$. The ratio of bounding/median ARFs for slurries is $5 / 2$, or 2.5 , so the apparent bounding ARF for this example is $2.5(2.91 \mathrm{E}-5)=7.27 \mathrm{E}-5$. The bounding RF to be used is 1.0. The corresponding amount of respirable airborne particulate is $1.0(1250)(7.27 \mathrm{E}-5)=0.09 \mathrm{~g}$ $\left(2.0 \times 10^{-4} \mathrm{lb}\right)$.

\section{D.8.4 Leak Path Factor}

The LPF here can be estimated in the same manner as for the Explosion Sample Problem found in Section 3.0. The volumetric flow rate through the cell (room) is ( 20 by 10 by 7$) 5 / 3,600=1.944 \mathrm{~m}^{3} / \mathrm{s}$. The room floor area is $20 \times 10=200 \mathrm{~m}^{2}$ and the duct floor area is $4 \times 0.6 \times 60=144 \mathrm{~m}^{2}$. The parameters Q/A (room) and $Q / A$ (duct) are $1.944 / 200$ and $1.944 / 144$ or 0.01 and $0.014 \mathrm{~m} / \mathrm{s}$, respectively.

The LPF is obtained by interpolation of Table $D-8[Q / A(r o o m)=0.01 \mathrm{~m} / \mathrm{s}]$ values. For an $R F=0.8$ and $\mathrm{Q} / \mathrm{A}($ duct $)=0.01$, the $\mathrm{LPF}=0.85$. For $\mathrm{Q} / \mathrm{A}($ duct $)=0.1 \mathrm{~m} / \mathrm{s}$, the $\mathrm{LPF}=0.91$, approximately. Since $\mathrm{Q} / \mathrm{A}(\mathrm{duct})=0.014$ is much closer to 0.01 than 0.1 , the final interpolated LPF should be $\approx 0.86$. The final source terms are $0.86(0.05)$ and $0.86(0.09)$ grams of slurry, or $0.043 \mathrm{~g}$ and $0.077 \mathrm{~g}$, respectively, for Example 1 and Example 2. 


\section{D.8.5 Dose Assessment}

\section{D.8.5.1 Example Problem Assumptions for Atmospheric Dispersion}

\section{Site and Facility:}

The sample problem is being performed for a generic facility and site. Therefore, no specific terrain or meteorological conditions has been considered. The terrain is assumed to be flat and rural.

As in previous problems, the generic building is assumed to have dimensions of $61 \mathrm{~m}$ by $61 \mathrm{~m}$ by $9.14 \mathrm{~m}$ ( $200 \mathrm{ft}$ by $200 \mathrm{ft}$ by $30 \mathrm{ft}$ ), and the ventilation system sustains approximately 5 air changes per hour. The stack is $60 \mathrm{~m}$ high with a $2 \mathrm{~m}$ diameter. This results in an air flow of $47.2 \mathrm{~m}^{3} / \mathrm{s}(1 \mathrm{E} 5 \mathrm{cfm}$ ), with an exit velocity of approximately $15 \mathrm{~m} / \mathrm{s}(49 \mathrm{ft} / \mathrm{s})$.

\section{Release Path:}

The process cell in which the example event occurs and the associated ventilation parameters are described in Sections D.8.3.1 (Example Problem 1) and D.8.4 (Leak Path Factor). The release point to the atmosphere is assumed to be the facility stack. The effective height or release is equal to the physical height of the stack.

In an operational facility with an intact ventilation system, it would be expected that one to several HEPA filters would be in place between the point of release and the environment. However, for purposes of this example, no filtration is considered.

It is assumed that the material released is uniformly distributed in the volume from the point of origin to the exhaust dust and that the material is completely removed in 2.5 air changes (e.g., 30 minutes).

\section{Meteorological Conditions:}

Meteorological conditions are assumed to be constant for the duration of the release. In order to illustrate the effect of meteorological conditions on the calculated consequences, one representative severe and average meteorological condition are used. For the elevated release, the severe meteorological condition are represented by a windspeed of $2 \mathrm{~m} / \mathrm{s}(4.5 \mathrm{mph})$ and stability Class $A$ and the average conditions by a windspeed of $5 \mathrm{~m} / \mathrm{s}(11 \mathrm{mph})$ and stability Class D. Note that, here, "severe" means the meteorological condition that, for elevated releases, maximizes the near field ground-level concentration.

Since the height of release is equal to the actual stack height $(60 \mathrm{~m}(200 \mathrm{ft}))$, the release is considered elevated, and no building wake correction is included.

\section{Source Term:}

In this problem, the material available for release is generated by the spill of a liquid solution from the height of a few meters. The spill creates a liquid aerosol containing primarily insoluble inorganic salts. Since the 
majority of the radionuclides in the solution are contained in the insoluble salts, very little additional airborne radioactive material is released due to evaporation from the liquid surface. A few nuclides in volatile form (e.g., ${ }^{3} \mathrm{H}$ ) would be expected to create a slight continuing release. For purposes of this example problem, the contribution from these nuclides has not been considered.

As the aerosolized liquid droplets are transported through the atmosphere, the liquid begins to evaporate, leaving behind solid particulates. These particulates will be smaller and lighter then the original droplets, thus having an effect on the dry deposition velocity. Experimental results indicate that for a natural aerosol composed of particles with a diameter range of $1-10 \mu \mathrm{m}\left(4 \times 10^{-5}-4 \times 10^{-4}\right.$ in $)$ and a windspeed of $6 \mathrm{~m} / \mathrm{s}$ (13 mph), the deposition velocity is approximately $0.8 \mathrm{~cm} / \mathrm{s}(.32 \mathrm{in} / \mathrm{s})$ (Randerson 1984).

The radionuclide composition of the liquid solution is dependent on the type of material being processed by the vitrification plant. Currently, there are two vitrification plants in existence, one at the Savannah River Site and one at West Valley, and there are plans to build a third at the Hanford Site. The West Valley plant processes spent commercial nuclear fuel, and the Savannah River plant (and later the Hanford plant) process defense nuclear wastes. Table D-29, taken from the Hanford Waste Vitrification Plant preliminary safety analysis report, lists the radionuclide composition for the maximum reference process feed (Herborn 1994). Table D-30, taken from the West Valley safety analysis report (SAR), lists those radionuclides that are key contributors to dose from a spill associated with the concentrated feed make-up tank (WVNS 1994).

For the purposes of this example, the key radionuclides from the West Valley SAR have been used. The result can then be ratioed to determine the consequences for each of the release quantities.

The density of the solution is assumed to be $1.25 \mathrm{~g} / \mathrm{cm}^{3}\left(78 \mathrm{lb} / \mathrm{ft}^{3}\right)$. Therefore, the release for Example 1 is $0.034 \mathrm{~cm}^{3}\left(1.2 \times 10^{-6} \mathrm{ft}^{3}\right)$ and for Example 2, it is $0.062 \mathrm{~cm}^{3}\left(2.2 \times 10^{-6} \mathrm{ft}^{3}\right)$. Multiplying the results for a $1 \mathrm{~cm}^{3}$ release by 0.034 and 0.062 produces the consequences for Example 1 and Example 2 releases, respectively.

\section{D.8.5.2 Choice of a Dispersion Model}

For this liquid spill problem, the dispersion model should have the ability to model the following:

- Elevated releases

- Neutrally buoyant plumes

- Estimate doses resulting from exposure radionuclides in vitrification process

- Plume depletion due to dry deposition

Many models have the features necessary to address the dispersion and transport. The difficulty is in finding a model that has all of the necessary isotopes in its internal library. The international version of the RASCAL model (USNRC 1993) has all of the isotopes listed in Table D-30 except C-14. The HOTSPOT model (Homann 1994) also contains all of the isotopes listed. 
Table D-29. Hanford Waste Vitrification Plant Reference Feed Maximum Radionuclide Composition ${ }^{\mathrm{a}}$

\begin{tabular}{|c|c|c|c|c|c|}
\hline Isotope & Ci/gal & Isotope & $\mathrm{Ci} / \mathrm{gal}$ & Isotope & Ci/gal \\
\hline${ }^{3} \mathrm{H}$ & $3.63 \mathrm{E}-05^{\mathrm{b}}$ & ${ }^{113} \mathrm{Sn}$ & 7.12 E-06 & ${ }^{147} \mathrm{Pm}$ & $1.12 \mathrm{E}+01$ \\
\hline${ }^{14} \mathrm{C}$ & $2.54 \mathrm{E}-06$ & ${ }^{115 \mathrm{~m}} \mathrm{Cd}$ & $2.48 \mathrm{E}-09$ & ${ }^{148 m} \mathrm{Pm}$ & 3.73 E-09 \\
\hline${ }^{55} \mathrm{Fe}$ & 3.97 E-02 & ${ }^{119 m} \mathrm{Sn}$ & 1.53 E-03 & ${ }^{151} \mathrm{Sm}$ & $2.36 \mathrm{E}-01$ \\
\hline${ }^{59} \mathrm{Ni}$ & 3.84 E-05 & ${ }^{121 \mathrm{~m}} \mathrm{Sn}$ & 2.99 E-05 & ${ }^{152} \mathrm{Eu}$ & 7.74 E-04 \\
\hline${ }^{60} \mathrm{Co}$ & $1.21 \mathrm{E}-03$ & ${ }^{123} \mathrm{Sn}$ & 8.17 E-04 & ${ }^{153} \mathrm{Gd}$ & $3.26 \mathrm{E}-06$ \\
\hline${ }^{63} \mathrm{Ni}$ & 4.44 E-03 & ${ }^{126} \mathrm{Sn}$ & $1.30 \mathrm{E}-04$ & ${ }^{154} \mathrm{Eu}$ & 9.48 E-02 \\
\hline${ }^{79} \mathrm{Se}$ & 1.10 E-06 & ${ }^{12 A} \mathrm{Sb}$ & $9.87 \mathrm{E}-09$ & ${ }^{155} \mathrm{Eu}$ & 1.16 E-01 \\
\hline${ }^{89} \mathrm{Sr}$ & 1.84 E-05 & ${ }^{126} \mathrm{Sb}$ & $1.83 \mathrm{E}-05$ & ${ }^{160} \mathrm{~Tb}$ & 3.12 E-08 \\
\hline${ }^{90} \mathrm{Sr}$ & $1.18 \mathrm{E}+01$ & ${ }^{126 \mathrm{~m}} \mathrm{Sb}$ & $1.30 \mathrm{E}-04$ & ${ }^{234} \mathrm{U}$ & 1.36 E-06 \\
\hline${ }^{90} \mathrm{Y}$ & $1.18 \mathrm{E}+01$ & ${ }^{129} \mathrm{Sb}$ & $4.97 \mathrm{E}-01$ & ${ }^{235} \mathrm{U}$ & $5.56 \mathrm{E}-08$ \\
\hline${ }^{91} \mathrm{Y}$ & $2.05 \mathrm{E}-04$ & ${ }^{129 \mathrm{~m}} \mathrm{Te}$ & $1.21 \mathrm{E}-01$ & ${ }^{236} \mathrm{U}$ & 1.34 E-07 \\
\hline${ }^{93 \mathrm{~m}} \mathrm{Nb}$ & $1.63 \mathrm{E}-04$ & ${ }^{127} \mathrm{Te}$ & 8.34 E-04 & ${ }^{238} \mathrm{U}$ & 1.05 E-06 \\
\hline${ }^{93} \mathrm{Zr}$ & $3.65 \mathrm{E}-04$ & ${ }^{127 \mathrm{~m}} \mathrm{Te}$ & 8.47 E-04 & ${ }^{237} \mathrm{~Np}$ & 5.63 E-05 \\
\hline${ }^{95} \mathrm{Zr}$ & 7.80 E-04 & ${ }^{129} \mathrm{Te}$ & $1.06 \mathrm{E}-10$ & ${ }^{238} \mathrm{Pu}$ & 2.17 E-04 \\
\hline${ }^{95} \mathrm{Nb}$ & 1.50 E-03 & ${ }^{129 \mathrm{~m}} \mathrm{Te}$ & $1.63 \mathrm{E}-10$ & ${ }^{239} \mathrm{Pu}$ & 3.97 E-04 \\
\hline${ }^{99} \mathrm{Tc}$ & $2.54 \mathrm{E}-03$ & ${ }^{129} \mathrm{I}$ & $4.60 \mathrm{E}-09$ & ${ }^{240} \mathrm{Pu}$ & 1.53 E-04 \\
\hline${ }^{103} \mathrm{Ru}$ & 8.42 E-08 & ${ }^{134} \mathrm{Cs}$ & 3.40 E-01 & ${ }^{241} \mathrm{Pu}$ & $7.28 \mathrm{E}-03$ \\
\hline${ }^{103 \mathrm{~m}} \mathrm{Ru}$ & 7.59 E-08 & ${ }^{135} \mathrm{Cs}$ & 7.08 E-05 & ${ }^{242} \mathrm{Pu}$ & 3.70 E-08 \\
\hline${ }^{106} \mathrm{Ru}$ & $1.41 \mathrm{E}+00$ & ${ }^{137} \mathrm{Cs}$ & $1.44 \mathrm{E}+01$ & ${ }^{241} \mathrm{Am}$ & $1.63 \mathrm{E}-01$ \\
\hline${ }^{106} \mathrm{Rh}$ & $1.41 \mathrm{E}+00$ & ${ }^{137 \mathrm{~m}} \mathrm{Ba}$ & $1.36 \mathrm{E}+01$ & ${ }^{242} \mathrm{Am}$ & 1.17 E-04 \\
\hline${ }^{107} \mathrm{Pd}$ & 1.15 E-05 & ${ }^{141} \mathrm{Ce}$ & 3.19 E-09 & ${ }^{243} \mathrm{Am}$ & 1.91 E-05 \\
\hline${ }^{110 m} \mathrm{Ag}$ & $4.50 \mathrm{E}-04$ & ${ }^{144} \mathrm{Ce}$ & 8.42 E-00 & ${ }^{242} \mathrm{Cm}$ & $1.41 \mathrm{E}-04$ \\
\hline
\end{tabular}


Table D-29. Hanford Waste Vitrification Plant Reference Feed Maximum Radionuclide Composition² (Continued)

\begin{tabular}{|c|c|c|c|c|c|}
\hline Isotope & Ci/gal & Isotope & Ci/gal & Isotope & Ci/gal \\
\hline${ }^{113 \mathrm{~m}} \mathrm{Cd}$ & $4.11 \mathrm{E}-03$ & ${ }^{144} \mathrm{Pr}$ & $8.42 \mathrm{E}-00$ & ${ }^{244} \mathrm{Cm}$ & $3.53 \mathrm{E}-03$ \\
\hline${ }^{113 \mathrm{~m}} \mathrm{In}$ & $7.12 \mathrm{E}-06$ & ${ }^{144 \mathrm{~m}} \mathrm{Pr}$ & $1.01 \mathrm{E}-01$ &. & \\
\hline \multicolumn{7}{|c|}{ Total Activity (Ci/gal) ${ }^{\mathrm{c}} 8.42 \mathrm{E}+01$} \\
\hline \multicolumn{7}{|c|}{ Decay heat (W/gal) ${ }^{\mathrm{d}} 2.40 \mathrm{E}-01$} \\
\hline
\end{tabular}

a Radionuclide composition values given in this table are based on a "nominal" overall waste loading of 0.26 lb. non-volatile oxides per gallon.

b $3.63 \mathrm{E}-05=3.6 \times 10^{-5}$ etc.

c To convert $\mathrm{Ci} / \mathrm{gal}$ to $\mathrm{Bq} / \mathrm{L}$, multiply by $9.78 \times 10^{9}$.

d To convert W/gal to W/L, divide by 3.79 .

Table D-30. West Valley Vitrification Plant Key Radionuclides for a Concentrated Feed Make-Up Tank (CFMT) Spill

\begin{tabular}{|c|c|}
\hline Key Dose Isotopes & Ci/L \\
\hline H-3 & $5.02 \mathrm{E}-06$ \\
\hline C-14 & $1.64 \mathrm{E}-05$ \\
\hline Sr-90 & $1.95 \mathrm{E} 01$ \\
\hline Ru-106 & $4.11 \mathrm{E}-05$ \\
\hline $\mathrm{I}-129$ & $5.28 \mathrm{E}-07$ \\
\hline Cs-137 & $2.10 \mathrm{E} 01$ \\
\hline Pu-238 & $2.43 \mathrm{E}-02$ \\
\hline Pu-239 & $4.75 \mathrm{E}-03$ \\
\hline Pu-240 & $3.47 \mathrm{E}-03$ \\
\hline Pu-241 & $2.36 \mathrm{E}-01$ \\
\hline Am-241 & $1.56 \mathrm{E}-01$ \\
\hline Cm-244 & $2.23 \mathrm{E}-02$ \\
\hline TOTAL & $4.11 \mathrm{E}+01$ \\
\hline
\end{tabular}




\section{D.8.5.3 Evaluation Results}

Results for an elevated release of $1 \mathrm{~cm}^{3}\left(3.5 \times 10^{-5} \mathrm{ft}^{3}\right)$ of feed solution from a generic vitrification plant are presented in Table D-31. The consequences have been calculated using two sets of meteorological conditions. One is representative of severe meteorology (e.g., higher consequences close to the release point), and one is representative of average meteorological conditions. Consequences were calculated at six arbitrary distances. The range is from $100 \mathrm{~m}$ to $16000 \mathrm{~m}(0.06$ to $10 \mathrm{mi})$ and represents the approximate limits within which the Gaussian dispersion model yields meaningful results. This range also encompasses the primary population at risk (e.g., workers and general population) from any accidental release of hazardous material.

\section{D.9 Sample Problem 8: Criticality Incident}

\section{D.9.1 Introduction}

Under certain accident conditions, fissile and fissionable radionuclides may undergo a self-sustaining nuclear reaction (chain reaction) called an inadvertent nuclear criticality or nuclear excursion. For a discussion of the conditions leading to a nuclear criticality and the methods for estimating the resulting initial release of radioactive material see Section 3.4 of this Handbook.

Table D-31. Results for the Vitrification Plant Elevated $(60 \mathrm{~m}) 1 \mathrm{~cm}^{3}$ Release

\begin{tabular}{|c|c|c|}
\hline & Total Effective Dose Equivalent $(\mathbf{r e m})$ \\
\hline Distance $\mathbf{( k m )}$ & Severe Meteorology & Average Meteorology \\
\hline 0.10 & $1.4 \mathrm{E}-04$ & $6.4 \mathrm{E}-22$ \\
\hline 0.80 & $1.8 \mathrm{E}-04$ & $1.5 \mathrm{E}-04$ \\
\hline 1.6 & $4.9 \mathrm{E}-05$ & $1.3 \mathrm{E}-04$ \\
\hline 3.2 & $1.3 \mathrm{E}-05$ & $6.7 \mathrm{E}-05$ \\
\hline 8.0 & $2.4 \mathrm{E}-06$ & $2.1 \mathrm{E}-05$ \\
\hline 16.0 & $7.2 \mathrm{E}-07$ & $8.8 \mathrm{E}-06$ \\
\hline
\end{tabular}

The hazard evaluation and scenario development procedure described in Chapter 2 is used to evaluate potential accidents involving nuclear criticality safety (NCS). The procedure incorporates the integrated safety analysis principles and is applied to all plant processes involving fissile or fissionable material. An additional consideration for NCS evaluations that is not normally an element of analysis of other types of accidents involving radioactive material is demonstration of adherence to the double contingency principle for all process operations. This demonstration involves logical analysis of each accident pathway to ensure that two or more unlikely, concurrent, and independent changes in process conditions are required before criticality could occur and experimental or analytical verification that criticality cannot occur if the double contingency principle is followed. 
A large amount of data related to critical masses, concentrations, and volumes and to the limiting conditions under which a criticality event could occur is available in the literature (Thomas 1978, Carter 1982). For example, Table D-32 (ANSI 1983) presents a summarization of single-parameter limits for uranium systems which could be relevant to analysis of systems represented in this sample problem. This data is useful in identifying conditions under which a criticality event could occur given relatively stringent constraints. Demonstration of subcritical conditions for complex systems with multiple controls is generally accomplished using computer codes such as KENO V.A (Petrie 1984) or MCNP 4A (Briesmeister 1993). KENO is a multigroup Monte Carlo criticality program used primarily to calculate effective neutron multiplication factor (k-effective) for systems with variable materials and geometry. MCNP is a continuous energy spectra Monte Carlo photon and neutron transport and shielding code which may be used to calculate k-effective for NCS analysis. The reliability of the codes is supported by experimental and benchmarking programs conducted internationally. Status reports of the experimental programs in the U.S., Japan, and Europe are available along with descriptions of specific experimental results (NEA 1991 and LANL 1995). Tabulation of results of specific criticality experiments and benchmarking of NCS codes against these results are also available (NEA 1995). The experiments and codes described above can be used to demonstrate that a criticality event can or can not occur but do not provide detailed information on the history of the event or on the amount of energy or radioactive material released in the event.

Because potential criticality events are of a complex nature strongly dependent on the system characteristics, this sample problem is of a generic nature intended to evaluate the adequacy of the NCS protection system for protection of public health and safety.

\section{D.9.2 Scenario}

\section{D.9.2.1 Scenario Description}

The facility assumed for the sample problem is a uranium fuel fabrication plant. In this type of facility, an inadvertent criticality might be initiated in the following situations:

- Inadvertent transfer or leakage of a solution of fissile material from a geometrically safe containing vessel into an area or vessel with an unsafe geometrical configuration

- Introduction of excess fissile material solution to a vessel or solution

- Overconcentration of a solution

- Failure to maintain sufficient neutron-absorbing materials in a vessel

- Precipitation of fissile solids from a solution and their retention in a vessel

- Introduction of neutron moderators or reflectors (e.g., by addition of water to a highly under moderated system)

- Deformation of or failure to maintain safe storage arrays

- Similar actions that can lead to increases in the reactivity of fissile systems

For the purposes of this sample problem it is assumed that human error has caused the introduction of a uranium nitrate hexahydrate (UNH) solution into a vessel of unsafe geometry causing an inadvertent nuclear criticality. The vessel is vented directly to a ventilated room atmosphere. The ventilation system exhausts to the facility stack. 
Table D-32. Subcritical Limits for Uniform Aqueous Solutions of Low-Enriched Uranium

\begin{tabular}{|c|c|c|c|}
\hline \multirow{2}{*}{\begin{tabular}{l} 
Parameter \\
\hdashline \\
\hdashline
\end{tabular}} & \multirow{2}{*}{ 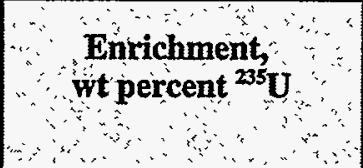 } & \multicolumn{2}{|c|}{ Subcritical Limit } \\
\hline & & $\mathrm{UO}_{2} \mathrm{~F}_{2}$ & $\mathrm{UO}_{2}\left(\mathrm{NO}_{3}\right)_{2}$ \\
\hline \multirow[t]{5}{*}{ Mass, $\mathrm{kg}^{235} \mathrm{U}$} & 10.0 & 1.07 & 1.47 \\
\hline & 5.0 & 1.64 & 3.30 \\
\hline & 4.0 & 1.98 & 6.50 \\
\hline & 3.0 & 2.75 & - \\
\hline & 2.0 & 8.00 & - \\
\hline \multirow[t]{5}{*}{ Cylinder diameter, $\mathrm{cm}$} & 10.0 & 20.1 & 25.2 \\
\hline & 5.0 & 26.6 & 42.7 \\
\hline & 4.0 & 30.2 & 58.6 \\
\hline & 3.0 & 27.4 & - \\
\hline & 2.0 & 63.0 & - \\
\hline \multirow[t]{5}{*}{ Slab thickness, cm } & 10.0 & 8.3 & 11.9 \\
\hline & 5.0 & 12.6 & 23.4 \\
\hline & 4.0 & 15.1 & 33.7 \\
\hline & 3.0 & 20.0 & - \\
\hline & 2.0 & 36.5 & - \\
\hline \multirow[t]{5}{*}{ Volume, $\ell$} & 10.0 & 14.8 & 26.7 \\
\hline & 5.0 & 30.6 & 111.0 \\
\hline & 4.0 & 42.7 & 273.0 \\
\hline & 30 & 77.0 & - \\
\hline & 2.0 & 340.0 & - \\
\hline \multirow[t]{2}{*}{ Concentration, g U/l } & 10.0 & 123.0 & 128.0 \\
\hline & 5.0 & 261.0 & 283.0 \\
\hline
\end{tabular}


Table D-32. Subcritical Limits for Uniform Aqueous Solutions of Low-Enriched Uranium (Continued)

\begin{tabular}{|c|c|c|c|}
\hline Parameter & $\begin{array}{c}\text { Enrichment, } \\
\text { wt percent }{ }^{235} \mathbf{U}\end{array}$ & \multicolumn{2}{|c|}{ Subcritical Limit } \\
\cline { 3 - 4 } & 4.0 & 335.0 & 375.0 \\
\hline $\mathrm{UO}_{2} \mathrm{~F}_{2}$ & $\mathrm{UO}_{2}\left(\mathrm{NO}_{3}\right)_{2}$ \\
\hline 3.0 & 470.0 & - \\
2.88 & - & 594.9 \\
2.0 & 770.0 & - \\
$1 / 45$ & $1190.0^{(2)}$ & - \\
\hline
\end{tabular}

\section{D.9.2.2 Scenario Assumptions}

Site and Facility:

The sample problem is being performed for a generic facility and site. Therefore, no specific terrain or meteorological conditions are considered. The terrain is assumed to be flat and rural.

The generic building is assumed to have dimensions of $61 \mathrm{~m}$ by $61 \mathrm{~m}$ by $9.14 \mathrm{~m}$ ( $200 \mathrm{ft}$ by $200 \mathrm{ft}$ by $30 \mathrm{ft}$ ), and the ventilation system sustains approximately 5 air changes per hour. The stack is $60 \mathrm{~m}(200 \mathrm{ft})$ high with a $2 \mathrm{~m}(6.6 \mathrm{ft})$ diameter. The resulting air flow is $47.2 \mathrm{~m}^{3} / \mathrm{s}(1 \mathrm{E} 5 \mathrm{cfm})$ with an exit velocity of approximately $15 \mathrm{~m} / \mathrm{s}(49.2 \mathrm{ft} / \mathrm{s})$.

In an operational facility with an intact ventilation system, it would be expected that one to several HEPA filters would be in place between the point of release and the environment. However, for the purposes of this example no filtration is considered. Note: In any event, filter systems are assumed to have no effect on the noble gases or volatiles released during a criticality event.

The energy released during the event is assumed to be insufficient to damage the containment vessel, piping, or facility structure.

\section{Criticality Event:}

The criticality occurs in a vented vessel of unfavorable geometry containing a solution of $400 \mathrm{~g} / \mathrm{l}\left(2.5 \times 10^{-5}\right.$ $\mathrm{lb} / \mathrm{ft}^{3}$ ) of uranium enriched in U-235. The criticality produces an initial burst of $1 \mathrm{E}+18$ fissions in 0.5 seconds followed by 47 bursts of $1.9 \mathrm{E}+17$ fissions for a total of $1 \mathrm{E}+19$ fissions in eight hours. The criticality is assumed to be terminated by the evaporation of $100 \ell(26.4 \mathrm{gal})$ of the initial total of $400 \ell(105.7 \mathrm{gal})$. 


\section{Release Path:}

The point of generation of the released material is assumed to be in the center of the room. Other assumptions regarding the event are that the room air exchange rate is approximately 6 per hour, the materials released to the ventilated space are expelled as the next criticality burst occurs, and the release to the ventilation system is continuous. It is further assumed that the materials released are uniformly distributed in the volume from the point of origin to the exhaust outlet. The release point to the atmosphere is the facility stack. The effective release height is assumed to equal to the physical height of the stack.

For this example, no filtration, deposition, or plate-out is considered within the facility ventilation system. Therefore, the LPF is set to 1 . Determination of a LPF for a specific facility can be performed using methods provided in previous example problems.

Source Term:

All of the noble gas fission products, 25 percent of the iodine radionuclides resulting from the criticality, and the aerosol generated from the evaporation of solution are assumed to be released directly to the ventilated room atmosphere. The aerosol is assumed to comprise 0.05 percent of the salt content of the solution that is evaporated $(100 \ell(26.4 \mathrm{gal}))$. It is also assumed that all airborne particulate material generated is of a

- respirable size and remains suspended in the flow.

Table 3-14 presents the radioactivity of important nuclides generated in a criticality accident involving a solution of fissile material in a fuel fabrication plant. The quantities shown in the table are based on cumulative yields, which determines the total production of each nuclide by fission and by ingrowth from the decay of fission-produced parents and does not account for subsequent decay. Therefore, these values should be considered very conservative. Data in the table do not include the iodine reduction factor mentioned above.

Thus, for example, Table 3-14 shows that ther are $\sim 45000 \mathrm{Ci}$ of $\mathrm{Kr}^{89}$ produced in the criticality event considered here. All of this will be released to the external atmosphere. Table 3-14 shows that $7.3 \mathrm{Ci}$ of $\mathrm{I}^{131}$ is produced, of which 25 percent $\sim 1.8 \mathrm{Ci}$ will be released. Similarly, $0.01 \mathrm{Ci}$ of ${ }^{137} \mathrm{Cs}$ is produced, of which 0.05 percent of the evaporated solution (100l), so that the total amount of ${ }^{137} \mathrm{Cs}$ released will be $0.01 \times 0.05 \mathrm{x}$ $(100 / 400)=0.0013 \mathrm{Ci}$.

Determination of the material released as an aerosol is complex because production of radionuclides in the solution depends on fission yield, neutron absorption by other fission-produced nuclides, and ingrowth as a result of decay of parent nuclides produced by fission. Losses occur by neutron absorption, radioactive decay, and evaporation of the solution. Since the accident is taking place in a fuel fabrication plant, the uranium solution is assumed to be composed of non-irradiated uranium fuel. Fission products will start to be produced during the initial fission pulse and during each successive pulse. Aerosol will be generated at a rate determined by the thermal oscillations created by the pulses. In order to produce a realistic source term for the aerosol generated the time behavior of the important nuclides needs to be determined using a computer code such as ORIGEN2 (Hermann 1984), which utilizes the composition and power history of the system to calculate the fission product inventory and accounts for the production and removal process noted above. However, based on past experience with similar calculations, the contribution to dose from the nuclides in the 
aerosol is relatively minor when compared to that of the noble gases and iodines produced. Therefore, for the purposes of this sample problem only the uranium component of the aerosol is considered.

Over the eight-hour history of the reaction, $100 \ell(26.4 \mathrm{gal})$ of the $400 \mathrm{~g} / 1\left(2.5 \times 10^{-5} \mathrm{lb} / \mathrm{ft}^{3}\right)(<5$ percent enrichment) solution are evaporated. As noted above, the aerosol is assumed to comprise 0.05 percent of the salt content of the solution that is evaporated.

Mass of uranium aerosolized:

$$
(100 \mathrm{l})(400 \mathrm{~g} / \mathrm{l})(0.0005)=20 \mathrm{~g} \text { of uranium }
$$

A typical uranium isotopic abundance for commercial feed enrichment is:

- $\mathrm{U}-238$

97.01 percent $x(20 \mathrm{~g})=19.40 \mathrm{~g}$

- U-235

2.96 percent $\times(20 \mathrm{~g})=0.592 \mathrm{~g}$

- U-234

$$
0.03 \text { percent } x(20 \mathrm{~g})=0.006 \mathrm{~g}
$$

The activity of uranium released is:

- $\quad \mathrm{U}-238$

$(19.40 \mathrm{~g})(3.35 \mathrm{E}-07 \mathrm{Ci} / \mathrm{g})=6.50 \mathrm{E}-06 \mathrm{Ci}$

- U-235

$(0.592 \mathrm{~g})(2.16 \mathrm{E}-06 \mathrm{Ci} / \mathrm{g})=1.28 \mathrm{E}-06 \mathrm{Ci}$

- U-234

$(0.006 \mathrm{~g})(6.24 \mathrm{E}-03 \mathrm{Ci} / \mathrm{g})=3.74 \mathrm{E}-05 \mathrm{Ci}$

\section{Meteorological Conditions:}

Meteorological conditions have been assumed to be constant for the duration of the release. In order to illustrate the effect of meteorological conditions on the calculated consequences, one representative severe and average meteorological condition is used. Here, "severe" is interpreted as meaning the meteorological condition that, for an elevated release, causes the highest concentrations in the near field. For the elevated release, the severe meteorological condition is represented by $2 \mathrm{~m} / \mathrm{s}(4.5 \mathrm{mph})$ and A stability and the average conditions by $5 \mathrm{~m} / \mathrm{s}(11 \mathrm{mph})$ and D stability.

Since the release height is equal to the actual stack height $(60 \mathrm{~m})$, the release is considered elevated and no building wake correction is included.

\section{D.9.3 Evaluation}

The principal product of nuclear criticality is radiation, which arises from three sources. The first is prompt radiation as gamma photons and neutrons resulting from the fission process. The second source is radiation (primarily gamma photons and beta particles) from the radioactive decay of fission products produced by the reaction. And the third source is radiation from the radioactive decay of materials surrounding the reaction that have been activated by neutrons. 
The prompt radiation has potentially the most serious consequences for personnel in the near vicinity (i.e., tens of meters) of the event. Radiation doses capable of causing immediate health effects up to and including death are possible. During the first pulse of an accident, there are no actions that an individual can take to limit dose. The prompt dose is solely a function of pulse size, distance, and intervening shielding.

Radiation from the fission products that remain in the solution are not usually considered significant, because it is a small source compared to the prompt radiation, it decays away rapidly following termination of the reaction, and the fission products in the vicinity of the event are manageable with suitable radiation control practices. In the environs, the effects of transport of certain fission products, mainly the noble gases (krypton and xenon) and a fraction of the iodine produced, must be estimated.

Radiation from neutron activation of materials around the accident site is almost never considered significant. The reason is that irradiation of materials is inefficient compared to that which occurs within a light-water power reactor, where materials are in close contact with the reaction and fission yields are several orders of magnitude greater then from an inadvertent criticality. The irradiated materials are expected to be immobile and any radiation from this source is manageable with appropriate radiation control practices.

\section{D.9.3.1 Prompt Radiation Estimates}

In a moderated criticality accident, the prompt radiation will be predominantly gamma photons. Moderated systems are characterized by a relatively low neutron leakage fraction with a relatively soft neutron leakage spectrum. They typically do not contain dense or massive materials that would reduce gamma photon emission.

The prompt photons generation rate for this accident is presented in Table 3-15. Doses resulting from release of these photons are calculated using the MICROSHIELD computer code (Grove Engineering 1992).

Estimated doses are presented in Table D-33 for six distances, with and without shielding. It is assumed that, following the initial pulse, facility warning devices will cause personnel to evacuate the immediate area prior to the initiation of the second pulse. As stated above in the assumptions, the initial burst yield is 1E18. The corresponding doses at specific distances from the source are given in Table

D-33.

Table D-33. Prompt Radiation Dose from $10^{18}$ Fissions, From a Moderated Criticality Accident

\begin{tabular}{|c|c|c|}
\hline $\begin{array}{c}\text { Distance } \\
(\mathbf{m})\end{array}$ & $\begin{array}{c}\text { Gamma Dose (rem) } \\
\text { No Shielding }\end{array}$ & $\begin{array}{c}\text { Gamma Dose (rem) } \\
\mathbf{1 2} \text { in Concrete Shielding }\end{array}$ \\
\hline 1 & $1.89 \mathrm{E}+04^{*}$ & $5.68 \mathrm{E}+03$ \\
\hline 10 & $1.76 \mathrm{E}+02$ & $3.52 \mathrm{E}+01$ \\
\hline 50 & $6.24 \mathrm{E}+00$ & $1.13 \mathrm{E}+00$ \\
\hline 100 & $1.30 \mathrm{E}+00$ & $2.22 \mathrm{E}-01$ \\
\hline 500 & $8.51 \mathrm{E}-03$ & $1.48 \mathrm{E}-03$ \\
\hline 1000 & $2.40 \mathrm{E}-04$ & $4.81 \mathrm{E}-05$ \\
\hline
\end{tabular}

$* 1.89 \mathrm{E}+04=1.89 \times 10^{4}$ etc. 


\section{D.9.3.2 Dose Due to Aerosol Estimates}

Separate transport and dispersion calculations has been performed for the aerosol component and the noble gases and iodine component of the airborne release in order to more clearly see the contribution to consequences from each.

The RASCAL atmospheric transport and dispersion model, described in the free-fall spill sample problem (Section 2.0), was chosen to model this release. The release is modeled as an elevated release for worst case and average meteorological conditions. The deposition velocity is set at $1 \mathrm{~cm} / \mathrm{s}(0.03 \mathrm{ft} / \mathrm{s})$ and the exposure is calculated for the entire 8-hour release duration. Table D-34 is a summary of the RASCAL results.

Table D-34. Results for the Release of Uranium Particulate from a UNH Solution Criticality

\begin{tabular}{|c|c|c|}
\hline & \multicolumn{2}{|c|}{ Total Effective Dose Equivalent (rem) } \\
\hline Distance $(\mathbf{k m})$ & Severe Meteorology & $1.2 \mathrm{E}-07$ \\
\hline 0.10 & $2.2 \mathrm{E}-05^{*}$ & $7.7 \mathrm{E}-06$ \\
\hline 0.80 & $5.0 \mathrm{E}-06$ & $7.1 \mathrm{E}-06$ \\
\hline 1.6 & $2.2 \mathrm{E}-06$ & $4.0 \mathrm{E}-06$ \\
\hline 3.2 & $1.2 \mathrm{E}-06$ & $1.3 \mathrm{E}-06$ \\
\hline 8.0 & $5.3 \mathrm{E}-07$ & $5.2 \mathrm{E}-07$ \\
\hline 16.0 & $2.8 \mathrm{E}-07$ & \\
\hline
\end{tabular}

$* 2.2 \mathrm{E}-05=2.2 \times 10^{-5}$ etc.

The dependence of the magnitude of the doses for severe and average meteorological conditions on distance from the source reflects an aspect of elevated source dispersion which is relevant to characterization of the meteorological condition as severe or average. For an elevated release and given atmospheric stability class, ground level contaminant concentrations are very low near the source, increase rapidly to a maximum fairly close to the source, and decrease at greater distances from the source. In Stability Class A conditions, which are highly turbulent, turbulent mixing rapidly brings the cloud down to the ground near the point of release, leading to the largest predicted ground level concentration of any weather condition. However, beyond this maximum, the high degree of atmospheric turbulence causes a rapid fall off in ground level concentrations.

In Stability Class D, the conditions are less turbulent than in Stability Class A, so the cloud travels further downwind before the lower edge touches the ground. The balance between plume velocity and turbulent mixing leads to a smaller maximum concentration than in Stability class A. However, once the maximum ground level concentration has been reached, the rate of dilution as the plume travels further downwind is less than in Stability Class A. This behavior accounts for the crossover in dose magnitudes shown in the results presented in Table D-35. 
From Table D-34 and the resultant doses, it can be seen that the aerosolized uranium is a very small contributor to dose. However, uranium is also a toxic material if taken into the body in sufficient quantity. To determine if uranium concentration poses a health hazard, downwind concentrations have been estimated using the Emergency Prediction Information (EPI) code (Anderson 1988) and the results compared to health protection limits (see also the $\mathrm{UF}_{6}$ release sample problem, Section D.7).

Table D-35. Downwind Concentration of Uranium

\begin{tabular}{|c|c|c|}
\hline \multicolumn{2}{|c|}{ Uranium Concentration $\left(\mathrm{mg} / \mathrm{m}^{3}\right)$} \\
\hline Distance $(\mathbf{k m})$ & Severe Meteorology & Average Meteorology \\
\hline 0.10 & $2.2 \mathrm{E}-06$ & $\sim 0^{*}$ \\
\hline 0.80 & $2.9 \mathrm{E}-06$ & $2.4 \mathrm{E}-06$ \\
\hline 1.6 & $7.9 \mathrm{E}-07$ & $2.2 \mathrm{E}-06$ \\
\hline 3.2 & $2.1 \mathrm{E}-07$ & $1.1 \mathrm{E}-06$ \\
\hline 8.0 & $3.9 \mathrm{E}-08$ & $3.4 \mathrm{E}-07$ \\
\hline 16.0 & $1.1 \mathrm{E}-08$ & $1.4 \mathrm{E}-07$ \\
\hline
\end{tabular}

* The plume is still elevated at this distance downwind and the lower edge has not touched the ground. See discussion in Sec D.9.3.2.

The EPI code was developed to provide emergency response personnel and emergency planners with a software tool to help evaluate the atmospheric release of toxic substances. It is designed to provide a rapid first order estimation of consequences. The library contains over 600 toxic substances. Atmospheric transport and dispersion calculations are based on the Gaussian Plume model. Results of downwind concentration estimates for severe and average meteorological conditions are presented in Table D-35. As discussed in the UF release sample problem, Section 7, NUREG-1391 lists a health effect limit of $40 \mathrm{mg}\left(1.4 \times 10^{-3} \mathrm{oz}\right)$ of soluble uranium to cause renal damage to an individual. The American Industrial Hygiene Association has published an Emergency Response Planning Guide (ERPG) value for $\mathrm{UF}_{6}$ of $15 \mathrm{mg} / \mathrm{m}^{3}\left(9.4 \times 10^{-7} \mathrm{lb} / \mathrm{ft}^{3}\right)$, which corresponds to $9.5 \mathrm{mg}\left(3.4 \times 10^{-4} \mathrm{oz}\right)$ of soluble uranium. The NIOSH Pocket Guide to Chemical Hazards lists the OSHA workplace exposure limit (TWA) for soluble uranium as $0.05 \mathrm{mg} / \mathrm{m}^{3}\left(3.1 \times 10^{-9} \mathrm{lb} / \mathrm{ft}^{3}\right)$ (NIOSH 1990). At a breathing rate of $2.6 \mathrm{E}-04 \mathrm{~m}^{3} / \mathrm{s}\left(0.009 \mathrm{ft}^{3} / \mathrm{s}\right)\left(33 \mathrm{ft}^{3} / \mathrm{hr}\right)$ and an exposure of 8 hours, even the highest concentration shown above will not exceed the OSHA workplace limit.

\section{D.9.3.3 Dose From the Release of Noble Gases and Iodine}

The remaining radionuclides released are noble gases and radioactive iodine particulates. Table 3-14 was used to identify the source term. As it was for aerosol, above, the release is modeled as an elevated release for worstcase and average meteorological conditions. The deposition velocity is set at $0.3 \mathrm{~cm} / \mathrm{s}$, and the exposure is calculated for the entire 8-hour release duration. Table D-36 is a summary of the RASCAL output. 
Table D-36. RASCAL Output for the Release of Noble Gases and Iodine Particulates from an UNH Solution Criticality

\begin{tabular}{|c|c|c|c|c|c|c|}
\hline \multicolumn{7}{|c|}{ Severe Meteorology } \\
\hline & \multicolumn{6}{|c|}{ Maximum EARLY doses, rem } \\
\hline Distance, km (mi) & $01 .(0.1)$ & $0.8(0.5)$ & $1.6(1.0)$ & $3.2(2.0)$ & $8(5)$ & $16(10)$ \\
\hline Total EDE & $1.9 \mathrm{E}-02 *$ & $6.2 \mathrm{E}-03$ & $3.6 \mathrm{E}-03$ & 2.3E-03 & $1.0 \mathrm{E}-03$ & 0.00 \\
\hline Thyroid & $5.2 \mathrm{E}-03$ & $1.4 \mathrm{E}-02$ & $6.0 \mathrm{E}-03$ & $3.2 \mathrm{E}-03$ & $1.4 \mathrm{E}-03$ & $0.0 \mathrm{E}+00$ \\
\hline Acute Lung & 0.00 & $0.0 \mathrm{E}+00$ & $0.0 \mathrm{E}+00$ & $0.0 \mathrm{E}+00$ & $0.0 \mathrm{E}+00$ & $0.0 \mathrm{E}+00$ \\
\hline Acute Bone Total & $1.9 \mathrm{E}-02$ & $5.6 \mathrm{E}-03$ & $3.3 \mathrm{E}-03$ & $2.1 \mathrm{E}-03$ & $0.0 \mathrm{E}+00$ & $0.0 \mathrm{E}+00$ \\
\hline Bone Surface & 0.00 & $0.0 \mathrm{E}+00$ & $0.0 \mathrm{E}+00$ & $0.0 \mathrm{E}+00$ & $0.0 \mathrm{E}+00$ & $0.0 \mathrm{E}+00$ \\
\hline $\begin{array}{l}\text { Acute Bone } \\
\text { Inhalation }\end{array}$ & 0.00 & $0.0 \mathrm{E}+00$ & $0.0 \mathrm{E}+00$ & $0.0 \mathrm{E}+00$ & $0.0 \mathrm{E}+00$ & $0.0 \mathrm{E}+00$ \\
\hline Cloud Shine & $1.9 \mathrm{E}-02$ & 4.3E-03 & $2.7 \mathrm{E}-03$ & $1.8 \mathrm{E}-03$ & $0.0 \mathrm{E}+00$ & $0.0 \mathrm{E}+00$ \\
\hline Ground Shine & 0.00 & $1.2 \mathrm{E}-03$ & $0.0 \mathrm{E}+00$ & $0.0 \mathrm{E}+00$ & $0.0 \mathrm{E}+00$ & $0.0 \mathrm{E}+00$ \\
\hline CEDE Inhalation & 0.00 & $0.0 \mathrm{E}+00$ & $0.0 \mathrm{E}+00$ & $0.0 \mathrm{E}+00$ & $0.0 \mathrm{E}+00$ & $0.0 \mathrm{E}+00$ \\
\hline $\begin{array}{l}\text { Ground } \\
\text { Concentration }\end{array}$ & 0.00 & $0.0 \mathrm{E}+00$ & $0.0 \mathrm{E}+00$ & $0.0 \mathrm{E}+00$ & $0.0 \mathrm{E}+00$ & $0.0 \mathrm{E}+00$ \\
\hline \multicolumn{7}{|c|}{ Average Meteorology } \\
\hline Total EDE & $6.6 \mathrm{E}-03$ & $1.1 \mathrm{E}-02$ & $7.6 \mathrm{E}-03$ & $4.6 \mathrm{E}-03$ & $1.9 \mathrm{E}-03$ & $0.0 \mathrm{E}+00$ \\
\hline Thyroid & 0.00 & $2.1 \mathrm{E}-02$ & $1.9 \mathrm{E}-02$ & $1.1 \mathrm{E}-02$ & $3.6 \mathrm{E}-03$ & $1.4 \mathrm{E}-03$ \\
\hline Acute Lung & 0.00 & $1.5 \mathrm{E}-03$ & $1.4 \mathrm{E}-03$ & $0.0 \mathrm{E}+00$ & $0.0 \mathrm{E}+00$ & $0.0 \mathrm{E}+00$ \\
\hline Acute Bone Total & $6.6 \mathrm{E}-03$ & $9.7 \mathrm{E}-03$ & $6.8 \mathrm{E}-03$ & 4.1E-03 & $1.8 \mathrm{E}-03$ & $0.0 \mathrm{E}+00$ \\
\hline Bone Surface & 0.00 & $0.0 \mathrm{E}+00$ & $0.0 E+00$ & $0.0 \mathrm{E}+00$ & $0.0 \mathrm{E}+00$ & $0.0 \mathrm{E}+00$ \\
\hline $\begin{array}{l}\text { Acute Bone } \\
\text { Inhalation }\end{array}$ & 0.00 & $0.0 \mathrm{E}+00$ & $0.0 \mathrm{E}+00$ & $0.0 \mathrm{E}+00$ & $0.0 \mathrm{E}+00$ & $0.0 \mathrm{E}+00$ \\
\hline Cloud Shine & $6.6 \mathrm{E}-03$ & 7.7E-03 & $5.0 \mathrm{E}-03$ & $3.1 \mathrm{E}-03$ & $1.4 \mathrm{E}-03$ & $0.0 \mathrm{E}+00$ \\
\hline
\end{tabular}


Table D-36. RASCAL Output for the Release of Noble Gases and Iodine Particulates from an UNH Solution Criticality (Continued)

\begin{tabular}{|l|l|l|l|l|l|l|}
\hline & \multicolumn{5}{c|}{ Average Meteorology } \\
\hline & \multicolumn{5}{|c|}{ Maximum EARLY doses, rem } \\
\hline Ground Shine & 0.00 & $1.9 \mathrm{E}-03$ & $1.7 \mathrm{E}-03$ & $0.0 \mathrm{E}+00$ & $0.0 \mathrm{E}+00$ & $0.0 \mathrm{E}+00$ \\
\hline CEDE Inhalation & 0.00 & $0.0 \mathrm{E}+00$ & $0.0 \mathrm{E}+00$ & $0.0 \mathrm{E}+00$ & $0.0 \mathrm{E}+00$ & $0.0 \mathrm{E}+00$ \\
\hline $\begin{array}{l}\text { Ground } \\
\text { Concentration }\end{array}$ & 0.00 & $0.0 \mathrm{E}+00$ & $0.0 \mathrm{E}+00$ & $0.0 \mathrm{E}+00$ & $0.0 \mathrm{E}+00$ & $0.0 \mathrm{E}+00$ \\
\hline
\end{tabular}

NOTES for International Version:

* $1.9 \mathrm{E}-02=1.9 \times 10^{-2} \mathrm{etc}$.

1. All values below $1.0 \mathrm{E}-03$ have been set to zero.

2. * marks values exceeding EARLY GILs.

3. Thyroid does includes Iodine only.

4. Total EDE $=$ CEDE Inhalation + Cloud Shine + Ground Shine

5. Acute Bone Total $=$ Acute Bone Inhalation + Cloud Shine + Ground Shine

6. EARLY IAEA Generic Intervention Level (GIL) $=5.0 \mathrm{E}+00 \mathrm{rem}$ in a week, normally evacuate

The RASCAL results presented in Table D-36 show that even for a full eight-hour exposure, the maximum doses (TEDE and thyroid) do not exceed the 0.01 and $0.05 \mathrm{~Sv}$ (1 and 5) rem protective action guides specified by the EPA (EPA 1991). 


\section{D.10 References}

American Industrial Hygiene Association (AIHA) "Emergency Response Planning Guideline - Hydrogen Fluoride", Akron, Ohio, 1988.

American Industrial Hygiene Association (AIHA). "Emergency Response Planning Guidelines", AIHA Emergency Planning Guidelines Committee, Akron, Ohio, 1990..

American National Standards Institute (ANSI), "American National Standard for Nuclear Criticality Safety in Operations with Fissionable Materials Outside Reactors", ANSI/ANS-8.1-1983, American Nuclear Society, LaGrange Park, IL, October 7,1983

Ammerich, M., A. Briand, J.C. LaBorde, Ph. Mulcey and J. Savornin, "Contamination Releases From HEPA Filters Under High Temperature Conditions," Proceeding of the 20th Air Cleaning Conference (M.W. First, Ed), NUREG/CP-0098 (CONF-880822), Harvard Air Cleaning Laboratory, Boston, Massachusetts, 1989.

Anderson, Kevin, “Emergency Prediction Information Code - User's Manual," Homann Associates, Inc., Fremont, California, 1988.

Baker, W.E., P.A. Cox, P.S. Westine, J.J. Kulesz, and R.A. Shrehlow, Explosion Hazard and Evaluation, Elsevier Scientific Publishing Company, New York, New York, 1983.

Ballinger, M.Y., and W.H. Hodgson, "Aerosols Generated by Spills of Viscous Solutions and Slurries," NUREG/CR-4658, U.S. Nuclear Regulatory Commission, Washington, D.C., 1986.

Bird, R.B., W.E. Stewart and E.N. Lightfoot, Transport Phenomena. John Wiley \& Sons, Inc., New York, New York, 1960.

Briesmeister, J.F., Ed., "MCNP - A General Monte Carlo N-Particle Transport Code, Version 4A", LA-12652-M, Los Alamos National Laboratory, Los Alamos, NM, November 1993

Burchsted, C.A. and A.B. Fuller, "Design, Construction, and Testing of High-Efficiency Air Filtration Systems for Nuclear Application,” ORNL-NSIC-65, Oak Ridge National Laboratory, Oak Ridge, Tennessee, 1970.

Burchsted, C.A., J.E. Kahn, and A.B. Fuller, "Nuclear Air Cleaning Handbook," ERDA 76-21, U.S. Energy Research and Development Administration (currently the U.S. Department of Energy), Oak Ridge National Laboratory, Oak Ridge, Tennessee, 1976.

Carter, R.D., G.R. Kiel, and K.R. Ridgway, "Criticality Handbook, Vol I, II, and III", ARH-600, Atlantic Richfield Hanford Co, Richland, WA, June 1982 
Clayton, D.G., T.J. Hayes, E. Livesey, J. Lomas, and M. Price, "Modelling of the Thermal Behaviour of 48 Inch Cylinders", Proceedings of the Second International Conference Uranium Hexafluoride Handling, CONF9110117, October 29-31, 1991, Oak Ridge, Tennessee.

Clough, P.N., D.R. Grist, and C.J. Wheatley, "The Mixing of Anhydrous Hydrogen Fluoride with Moist Air," Proceedings of the International Conference on Vapor Cloud Modeling, November 2-4, 1987, Cambridge, Massachusetts.

CRC Press, Handbook of Chemistry and Physics. Robert C. Weast. Chemical Rubber Company, 54th Edition, Cleveland, Ohio, 1974.

CRC Press, Handbook of Chemistry and Physics. R.C. Weast (ed.), Chemical Rubber Company, Cleveland, Ohio, 1994.

Ermak, D.L., "User's Manual for SLAB: An Atmospheric Dispersion Model for Denser-than-Air Releases," UCRL-MA-105607, Lawrence Livermore National Laboratory, Livermore, California, 1990.

First, M.W., "A Brief History of the Air Cleaning Conferences," Proceedings of the 23rd DOE/NRC Nuclear Air Cleaning Conference (M.W. First, Ed), NUREG/CP-0141 (CONF-940738), Harvard Air Cleaning Laboratory, Boston, Massachusetts, 1995.

Goldwire, H.C., Jr., et al., “Desert Tortoise Series Data Report 1983, Pressurized Ammonia Spills," Report UCLD-20562, Lawrence Livermore National Laboratory, Livermore, California, 1985.

Grove Engineering Inc., “Microshield, Version 3.0,” Rockville, Maryland, 1992.

Hague, W.J., Private Communication, Allied Signal, Morristown, New Jersey, 1990.

Hall, D.J, V. Kukadia, S. Walker, and G.W. Marsland, "Plume Dispersion From Chemical Warehouse Fires," Building Research Establishment Client Report CR 56/95, Building Research Establishment, Watford, United Kingdom,1995.

Halverson, M.A., M.Y. Ballinger, and G.W. Dennis, "Combustion Aerosols Formed During Burning of Radioactively Contaminated Materials - Experimental Results," NUREG/CR-4736 (PNL-5999), Pacific Northwest Laboratory, Richland, Washington, 1987.

Hanna, S.R., J.C. Chang, and J.X. Zhang, "Technical Documentation of HGSYSTEM/UF6 Model," Report No. K/SUB/93-XJ947, Oak Ridge K-25 Site, Oak Ridge, Tennessee, 1996.

Herborn, D.I., "Hanford Waste Vitrification Plant Preliminary Safety Analysis Report," WHC-SD-HWV-PSAR001, Rev. 1, Westinghouse Hanford Co., Richland, Washington, 1994. 
Hesketh, H.E., Fine Particles in Gaseous Media, Ann Arbor Science Publishers Inc, Ann Arbor, Michigan, 1977.

Homann, S.G., "HOTSPOT - Health Physics Codes for the PC", UCRL-MA-106315, Lawrence Livermore National Laboratory, University of California, Livermore, California, 1994.

Kaiser, G.D., and B.C. Walker, "Releases of Anhydrous Ammonia From Pressurized Containers - The Importance of Denser-Than-Air Mixtures," Atmospheric Environment, 12, pp. 2289-2300, 1978.

Kaiser, G.D., "Examples of the Successful Application of a Simple Model for the Atmospheric Dispersion of Dense, Cold Vapors to the Accidental Release of Anhydrous Ammonia from Pressurized Containers," Safety and Reliability Directorate, UKAEA, SRD R 150, Warrington, United Kingdom, 1979.

Kaiser, G.D. and S. Chhibber, "SAIC's Computer Programs for Modeling the Atmospheric Dispersion of Hazardous Vapors - Model Description and User's Guide”, prepared for USNRC, Washington, D.C., 1993.

Los Alamos National Laboratory (LANL), "Proceedings of the Fifth International Conference on Nuclear Criticality Safety", Los Alamos National Laboratory, Los Alamos, NM, September 1995

Mishima, J., and L.G. Schwendiman, "Fractional Airborne Release of Uranium (Representing Plutonium) During the Burning of Contaminated Waste," BNWL-1732, Pacific Northwest Laboratory, Richland, Washington, 1973.

National Safety Council (NSC), ALOHA Computer Code, Version 5.05, Washington, D.C., 1989.

National Institute of Safety and Health (NIOSH), "NIOSH Pocket Guide to Chemical Hazards," DHHS (NIOSH) Publication No. 90-117, U.S. Department of Health and Human Services, Washington, D.C., 1990.

Nuclear Energy Agency (NEA), "Proceedings of the International Conference on Nuclear Criticality Safety 1991", AEA Technology, Oxford, England, September 1991

Nuclear Energy Agency (NEA), "International Handbook of Evaluated Criticality Safety Benchmark Experiments, Volumes I through VII", NEA/NSC/DOC(95)03, Organization for Economic Cooperation and Development, Paris France, 1995

O.W. Hermann and R.M. Westfall, "Origen-S Scale System Model to Calculate Fuel Depletion, Actinide Transmutation, Fission Product Buildup and Decay, and Associated Radiation Source Terms," NUREG/CR0200, Martin Marietta Energy Systems, Inc., Oak Ridge National Laboratory, Oak Ridge, Tennessee, 1984.

Petrie, L.M. and N.F. Landers, "KENO V.a, An Improved Monte Carlo Criticality Program with Supergrpouing", NUREG/CR-200, Oak Ridge National Laboratory, Oak Ridge TN, December 1984 
Pinkston, D., "U.S. Department of Energy Defense Programs Safety Survey Report, Volume 1: Main Report," DOE/DP/70056-KJ (SAIC 93/1181), Science Applications International Corporation for the U.S. Department of Energy, Germantown, Maryland, 1993.

Randerson, Darryl, ed., Atmospheric Science and Power Production, DOE/TIC-27601, Technical Information Center, Office of Scientific and Technical Information, U.S. Department of Energy, Washington, D.C., 1984.

Rodean, H. C., "Toward More Realistic Material Models for Release and Dispersion of Heavy Gases," UCRL53902, Lawrence Livermore National Laboratory, Livermore, California, 1989.

Shleien, B. (Ed.), The Health Physics and Radiological Health Handbook, Revised Edition, Scinta, Inc., Silver Spring, Maryland, 1992.

Sutter, S.L., J.W. Johnston, and J. Mishima, "Aerosols Generated by Free Fall Spills of Powders and Solutions in Static Air" NUREG/CR-2139. U.S. Nuclear Regulatory Commission, Washington, D.C., 1981.

Thomas, J.T. Ed, "Nuclear Safety Guide, TID-7016, Revision 2", NUREG/CR-0095, U.S. Nuclear Regulatory Commission, Washington, DC, June 1978

U.S. Department of Energy (USDOE), "Uranium Hexafluoride - A Manual of Good Handling Practices," ORO651 (Rev. 6), DE9101581, 1991.

U.S. Department of Energy (DOE), "DOE Handbook - Airborne Release Fractions/Rates and Respirable Fractions for Nonreactor Nuclear Facilities," DOE-HDBK-3010-94, Washington, D.C., 1994.

U.S. Environmental Protection Agency (USEPA), Federal Emergency Management Agency and U.S. Department of Transportation, Technical Guidance for Hazards Analysis, Washington, D.C., 1987.

U.S. Environmental Protection Agency (USEPA), "Technical Guidance for Hazards Analysis", Washington, D.C., 1987.

U.S. Environmental Protection Agency (USEPA), "Manual of Protective Action Guides and Protective Actions for Nuclear Incidents," EPA 400-R-92-001, Washington, D.C., 1991.

U.S. Environmental Protection Agency (USEPA), "Workbook of Screening Techniques for Assessing Impacts of Toxic Air Pollutants (revised)”, EPA-454/R-92-024 (NTIS PB93-21036), 1992.

U.S. Environmental Protection Agency (USEPA), "Contingency Analysis Modeling for Superfund Sites and Other Industrial Sources”, EPA-454/R-93-001, Research Triangle Park, North Carolina, 1993.

U.S. Nuclear Regulatory Commission (USNRC), "Calculational Methods for Analysis of Postulated UF 6 Releases," NUREG/CR-4360, 1985. 
U.S. Nuclear Regulatory Commission (USNRC), "Rupture of Model 48Y UF 6 Cylinder and Release of Uranium Hexafluoride," NUREG-1179, Washington, D.C., February, 1986.

U.S. Nuclear Regulatory Commission (USNRC), "Regulatory Analysis on Emergency Preparedness for Fuel Cycle and Other Radioactive Material Licensees," NUREG-1140, Washinton, D.C., 1988.

U.S. Nuclear Regulatory Commission (USNRC), "Chemical Toxicity of Uranium Hexafluoride Compared to Acute Effects of Radiation", NUREG-1391, Washington, D.C., 1991.

U.S. Nuclear Regulatory Commission (USNRC), "RASCAL Version 2.0 User's Guide", NUREG/CR-5247, Vol. 1, Rev. 1, Washington, D.C., 1993.

West Valley Nuclear Services (WVNS), "Safety Analysis Report for Vitrification Operations and High-Level Waste Interim Storage,” WVNS-SAR-003, West Valley Nuclear Services Company, Inc., 1994. 
APPENDIX E

RESULTS OF BENCH-MARKING THE LPF \#1B CODE WITH THE MELCOR CODE 


\title{
APPENDIX E
}

\section{TABLE OF CONTENTS}

\begin{abstract}
APPENDIX E: RESULTS OF BENCH-MARKING THE LPF\#1B CODE WITH THE MELCOR CODE
TABLE OF CONTENTS $\ldots \ldots \ldots \ldots \ldots \ldots \ldots \ldots \ldots \ldots \ldots \ldots \ldots \ldots \ldots \ldots \ldots \ldots \ldots \ldots \ldots \ldots$

LIST OF TABLES $\ldots \ldots \ldots \ldots \ldots \ldots \ldots \ldots \ldots \ldots \ldots \ldots \ldots \ldots \ldots \ldots \ldots \ldots \ldots \ldots \ldots \ldots$

ATTACHMENT 1

BENCH-MARK DATA GENERATED BY MELCOR FOR LPF\#1 AND LPF\#1B

ATTACHMENT 2

RESULTS OF LPF\#1B BENCH-MARKING
\end{abstract}

\section{LIST OF TABLES}

Table E-1 Steady State Leakpath Factors for Flow through a Compartment . . . . . . . E-2

Table E-2 Steady State Leakpath Factors for Flow through a Duct .............. E-2

Table E-3 Steady State Leakpath Factors for Flow through a Compartment

Connected to a Duct . . . . . . . . . . . . . 


\section{APPENDIX E \\ RESULTS OF BENCH-MARKING THE LPF\#1B CODE WITH THE MELCOR CODE}

LPF (leakpath factor) results for 20 runs of both the MELCOR code and the LPF\#1B code were compared over a wide range of controlling variables. Both codes perform in-facility particle transport calculations. For simple LPF calculations LPF\#1B is easier to use. The objective of the comparison was to demonstrate that the LPF\#1B code can be used with confidence for LPF calculations in conjunction with this handbook. MELCOR is widely accepted and has validation credentials (see Attachment 1 to this Appendix).

The controlling variables are flow rate, particle settling area, and particle size, which are represented by Q/A ratios, RFs (respirable fractions of the initial airborne aerosol), and $\sigma_{g}$, the geometric standard deviation. $Q / A$ ratios are the compartment or duct volumetric flow rates of air $(Q)$ per unit settling area for deposition (A).

The LPF\#1B code provides LPFs for steady flows only over infinite time. MELCOR can do comparable calculations. Whereas LPF\#1B depletes airborne particles by gravitational settling only, MELCOR has other deposition mechanisms (particle diffusion, turbulent diffusion, etc.) and performs agglomeration calculations. Test case conditions were selected to minimize the contribution of agglomeration to particle settling. Since all LPFs were only calculated for RF's (respirable fractions) of typical fuel cycle powders, the gravitational settling mechanism appeared to dominate in the MELCOR calculations.

The 20 runs were completed for a compartment, duct, and a compartment and duct in series. Attachments 1 and 2 to this Appendix contain the MELCOR results and explanations of the MELCOR runs. The MELCOR results and the LPF\#1B results are compared in Tables E-1, E-2, and E-3.

In Table E-1, for the single compartment, agreement is good over the full range of variables (Q/A from 0.1 to $1 \mathrm{E}-06 \mathrm{~m} / \mathrm{s}(0.3$ to $3 \mathrm{E}-6 \mathrm{ft} / \mathrm{s})$, RFs at $0.9996,0.5$, and $4.45 \mathrm{E}-04)$, and $\sigma_{\mathrm{g}}=2$. The LPF\#1B results here, if different from the MELCOR results, are always higher than the MELCOR results. This implies that LPF\#1B will be more conservative than MELCOR for a single compartment. The reason for the differences is that MELCOR has additional depletion mechanisms operating, which are magnified in the very slow flow cases with the smallest particles.

In Table E-2, for the single duct, agreement is good down through $\mathrm{Q} / \mathrm{A}=1 . \mathrm{E}-03 \mathrm{~m} / \mathrm{s}(3 . \mathrm{E}-3 \mathrm{ft} / \mathrm{s})$. Since MELCOR does not run ducts explicitly, it replaces a duct with a series of small well-mixed compartments (here, 10). Here also, a second row of LPF\#1B calculations was run to copy the MELCOR 10 compartment approach. Agreement in absolute numbers for $Q / A=1 . E-06 \mathrm{~m} / \mathrm{s}(3 . \mathrm{E}-6 \mathrm{ft} / \mathrm{s})$ was not good. At this very low ratio of flow to deposition area, the general agreement is that the LPF is very small. Here, one cannot assume that LPF\#1B is more conservative than MELCOR.

Only two runs were made with a compartment in series with a duct (Table E-3). The agreement is very good. Again, with very small Q/A values, one would expect the LPF's to be very small.

The basic conclusion is that LPF\#1B can be used with confidence for estimates of LPFs within the constraints of the code. These are: the initial distribution is log normal, steady flows exist until no more aerosol is in the facility, no significant agglomeration occurs, and gravity settling is the dominant 
depletion mechanism. The exception to this conclusion is when the LPF is very small, in which case inaccuracies in the MELCOR or LPF\#1B results are immaterial to the conclusion that consequences will be very small.

Table E-1. Steady State Leakpath Factors for Flow through a Compartment

\begin{tabular}{|c|c|c|c|c|}
\hline \multirow{3}{*}{$\begin{array}{l}\text { Respirable } \\
\text { Fraction/(AMM } \\
\text { D } \\
\text { in micrometers) }\end{array}$} & \multirow{3}{*}{ Code } & \multicolumn{3}{|c|}{$\begin{array}{l}\text { Leak Path Factors at Three Volumetric Flow Rate per } \\
\text { Unit Deposition Surface Area (Q/A) Values }\end{array}$} \\
\hline & & Q/A 1.0E-1 & Q/A 1.0E-3 m/s & Q/A 1.0E-6 m/s \\
\hline & & \multicolumn{3}{|c|}{ Leakpath Factors } \\
\hline $\begin{array}{l}0.9996 \\
(0.99)\end{array}$ & $\begin{array}{l}\text { MELCOR } \\
\text { LPF\#1B }\end{array}$ & $\begin{array}{l}9.99 \mathrm{E}-1 \\
9.99 \mathrm{E}-1\end{array}$ & $\begin{array}{l}9.26 \mathrm{E}-1 \\
9.37 \mathrm{E}-1\end{array}$ & $\begin{array}{c}2.81 \mathrm{E}-2 \\
5.0 \mathrm{E}-2\end{array}$ \\
\hline $\begin{array}{l}0.50 \\
(10)\end{array}$ & $\begin{array}{l}\text { MELCOR } \\
\text { LPF\#1B }\end{array}$ & $\begin{array}{l}9.86 \mathrm{E}-1 \\
9.87 \mathrm{E}-1\end{array}$ & $\begin{array}{l}4.78 \mathrm{E}-1 \\
4.90 \mathrm{E}-1\end{array}$ & $\begin{array}{c}1.33 \mathrm{E}-3 \\
1.5 \mathrm{E}-3\end{array}$ \\
\hline $\begin{array}{l}4.45 E-4 \\
(101)\end{array}$ & $\begin{array}{l}\text { MELCOR } \\
\text { LPF\#1B }\end{array}$ & $\begin{array}{l}9.78 \mathrm{E}-1 \\
9.78 \mathrm{E}-1\end{array}$ & $\begin{array}{l}3.21 \mathrm{E}-1 \\
3.22 \mathrm{E}-1\end{array}$ & $\begin{array}{l}4.98 \mathrm{E}-4 \\
5.23 \mathrm{E}-4\end{array}$ \\
\hline
\end{tabular}

Table E-2. Steady State Leakpath Factors for Flow through a Duct

\begin{tabular}{|c|c|c|c|c|}
\hline \multirow{3}{*}{$\begin{array}{l}\text { Respirable } \\
\text { Fraction/(AMMD } \\
\text { in micrometers) }\end{array}$} & \multirow{3}{*}{ Code } & \multicolumn{3}{|c|}{$\begin{array}{l}\text { Leak Path Factors at Three Volumetric Flow Rate per } \\
\text { Unit Deposition Surface Area }(\mathrm{Q} / \mathrm{A}) \text { Values }\end{array}$} \\
\hline & & Q/A 1.0E-1 m/s & Q/A 1.0E-3 m/s & Q/A 1.0E-6 m/s \\
\hline & & \multicolumn{3}{|c|}{ Leakpath Factors } \\
\hline $\begin{array}{l}0.9996 \\
(0.99)\end{array}$ & $\begin{array}{l}\text { MELCOR } \\
\text { LPF\#1B } \\
\text { LPF\#1B }^{2}\end{array}$ & $\begin{array}{c}9.98 \mathrm{E}-1 \\
9.99 \mathrm{E}-1 \\
9.996 \mathrm{E}-1\end{array}$ & $\begin{array}{l}9.21 \mathrm{E}-1 \\
9.31 \mathrm{E}-1 \\
9.32 \mathrm{E}-1\end{array}$ & $\begin{array}{l}9.81 \mathrm{E}-6 \\
3.41 \mathrm{E}-3 \\
4.90 \mathrm{E}-5\end{array}$ \\
\hline $\begin{array}{l}0.50 \\
(10)\end{array}$ & $\begin{array}{l}\text { MELCOR } \\
\text { LPF\#1B } \\
\text { LPF\#1B }^{2}\end{array}$ & $\begin{array}{l}9.87 E-1 \\
9.87 E-1 \\
9.87 E-1\end{array}$ & $\begin{array}{l}3.56 \mathrm{E}-1 \\
3.56 \mathrm{E}-1 \\
3.74 \mathrm{E}-1\end{array}$ & $\begin{array}{c}5.81 \mathrm{E}-11 \\
2.97 \mathrm{E}-7 \\
3.81 \mathrm{E}-7\end{array}$ \\
\hline $\begin{array}{l}4.45 E-4 \\
(101)\end{array}$ & $\begin{array}{l}\text { MELCOR } \\
\text { LPF\#1B } \\
\text { LPF\#1B }{ }^{2}\end{array}$ & $\begin{array}{l}9.77 \mathrm{E}-1 \\
9.78 \mathrm{E}-1 \\
9.78 \mathrm{E}-1\end{array}$ & $\begin{array}{l}1.51 \mathrm{E}-1 \\
1.31 \mathrm{E}-1 \\
1.55 \mathrm{E}-1\end{array}$ & $\begin{array}{l}8.38 \mathrm{E}-15 \\
7.40 \mathrm{E}-20 \\
1.57 \mathrm{E}-10\end{array}$ \\
\hline
\end{tabular}

${ }^{1}$ LPF\#1B run as one duct.

${ }^{2}$ LPF\#1B run as 10 small compartments replacing one duct. 
Table E-3. Steady State Leakpath Factors for Flow through a Compartment Connected to a Duct

\begin{tabular}{|l|l|c|c|}
\hline $\begin{array}{l}\text { Respirable } \\
\text { Fraction } \\
\text { (AMMD in } \\
\text { micrometers) }\end{array}$ & \multirow{4}{*}{ Code } & \multicolumn{2}{|c|}{$\begin{array}{r}\text { Leakpath Factors at Three Volumetric Flow Rate per } \\
\text { Unit Deposition Surface Area (Q/A) Values }\end{array}$} \\
\cline { 3 - 4 } & & Q/A 1.0E-1 m/s & Q/A 1.0E-3 m/s \\
\cline { 2 - 4 } & $\vdots$ & \multicolumn{2}{|c|}{ Leakpath Factors } \\
\hline 0.500 & MELCOR & $9.74 \mathrm{E}-1$ & $2.11 \mathrm{E}-1$ \\
$(10)$ & LPF\#1B & $2.17 \mathrm{E}-1$ \\
& LPF\#1B & $9.74 \mathrm{E}-1$ & $2.24 \mathrm{E}-1$ \\
\hline
\end{tabular}

${ }^{1} \mathrm{LPF} \# 1 \mathrm{~B}$ run as one duct and one compartment.

${ }^{2}$ LPF\#1B run as 10 small compartments replacing one duct plus one larger compartment. 


\title{
ATTACHMENT 1
}

TO

\author{
APPENDIX E
}

\section{BENCH-MARK DATA GENERATED BY MELCOR FOR LPF\#1 AND LPF\#1B}

\author{
Prepared by \\ Susan E. Bayley \\ Science Applications International Corporation \\ Abingdon, MD \\ February 1997
}




\section{BENCH-MARK DATA GENERATED BY MELCOR FOR LPF\#1 AND LPF\#1B}

The inter-compartment ventilation transport computer code MELCOR was used to generate bench mark data for the leak path factor codes LPF\#1 and LPF\#1B. A description of the code itself can be found in SNL (1991a \&b) while assessment of the code is documented in Kmetyk (1993a \&b). The MELCOR code was initially developed for integrated severe accident analysis of nuclear reactor facilities, but has been applied to nonreactor facilities as well. The MELCOR code is modular in nature, permitting the development of a detailed representation of facility rooms and the ducts connecting them. As a transient transport code, MELCOR can track aerosol concentrations on a room-by-room basis under changing facility conditions including pressure transients, fan failures, isolation damper closures, and wall breaches. In addition, MELCOR can model HVAC system components such as fans, dampers, and filters.

The MELCOR code solves a series of equations, including the conservation equations for mass, momentum, and energy, to predict facility response under postulated accident scenarios. MELCOR is a control volume code. This means that uniform mixing is assumed in each control volume (or compartment). MELCOR models variations in thermodynamic properties between control volumes and aerosol deposition within control volumes. Only the mass and energy equations are solved within control volumes. Bulk fluid motion is handled by the flow path input, which is typically used to represent ducts. Only the momentum equation is solved for flow paths. As such, flow path input governs bulk fluid motion between control volumes, but changes in thermodynamic properties or aerosol settling are not modeled in a flow path.

In modeling complex facility configurations, the assumption that all deposition occurs in the rooms (represented by control volumes) is generally sufficient. For these calculations, though, this is not the case. To accomplish specific modeling of deposition in a duct, the duct is discretized into a series of ten small control volumes connected by flow paths. Deposition occurs in each of the ten control volumes (the sum of which is the estimated amount deposited in the duct as a whole) and bulk flow is handled by the flow path input.

MELCOR calculations were defined to provide bench marking data in three areas:

- Aerosol transport through a compartment;

- Aerosol transport through a duct (modeled as a series of compartments);

- Aerosol transport through a compartment and a duct in series.

For flow through a compartment, nine calculations were run for aerosol mass median diameters (AMMD) of $0.99,10$, and 101 microns $(0.00004,0.0004$, and $0.004 \mathrm{in})$ and for volumetric flow rate per unit deposition surface areas $(\mathrm{Q} / \mathrm{A})$ of $1.0 \times 10^{-1}, 1.0 \times 10^{-3}$, and $1.0 \times 10^{-6}$ meters per second $(4.0,0.04$, and $0.00004 \mathrm{in} / \mathrm{s}$ ). The same matrix of runs was conducted for flow though a duct. For flow through a compartment and a duct in series, two representative calculations were selected: an ammd of $10 \mu \mathrm{m}$ (0.0004 in) and Q/A values of $1.0 \times 10^{-1}$ and $1.0 \times 10^{-3} \mathrm{~m} / \mathrm{s}(4.0$ and $0.04 \mathrm{in} / \mathrm{s})$.

A leak path factor was calculated for each calculation by dividing the amount of aerosol leaving a specified volume by the amount of aerosol entering the volume. In these calculations, either the compartment, the duct, or the compartment-duct system are the volumes of interest. These LPFs provide an estimate for the amount of aerosol released to the environment for a given aerosol distribution, flow 
rate, and facility configuration.

Flow through a compartment was modeled by specifying four control volumes: one acts as an air source, one is used as the aerosol source volume, one is the compartment being modeled, and one acts as an air sink. These volumes are connected in series by flow paths. The velocity in the flow path between the air source and the aerosol source volume is specified such that the desired Q/A ratio is achieved.

For flow through a duct, the same configuration is used except that the single compartment control volume is replaced by a series of ten smaller control volumes connected by flow paths representing the duct. Finally, for the compartment and duct in series, the compartment control volume and the appropriate flow path connections are added upstream of the duct.

The deposition surface in a control volume is specified through heat structures input. Each control volume is required to have an aerosol deposition surface. This surface area is minimized in the aerosol source volume and the volume change out rate is maximized so that aerosol deposition in the aerosol source volume is kept to a minimum. The output was checked to verify that any aerosol mass deposited in the aerosol source volume was sufficiently small that it did not affect the LPF calculations.

For each ammd, a lognormal distribution with a geometric standard deviation of 2 was specified. Only the respirable fraction (that portion of the distribution with diameters less than 10 microns) was input into MELCOR. The aerosol source was represented by a low vapor pressure aerosol group in MELCOR to ensure that the aerosol was not converted to a vapor. To avoid agglomeration, the aerosol source rate was specified such that the concentration in the control volumes did not exceed $10^{-20} \mathrm{~kg} / \mathrm{m}^{3}\left(6 \times 10^{-22}\right.$ $\left.\mathrm{lb} / \mathrm{ft}^{3}\right)$. This concentration is well below the calculated concentration for negligible agglomeration of $10^{-8}$ $\mathrm{kg} / \mathrm{m}^{3}\left(6 \times 10^{-10} \mathrm{lb} / \mathrm{ft}^{3}\right)$. In this manner, the original aerosol size distribution was maintained.

The results for each of the three configurations are presented in tables 1,2 , and 3 in attachment 2 . As expected, the larger the aerosol size and the slower the flow rate, the more aerosol mass retained (that is, the smaller the LPF). In addition, for the same $\mathrm{Q} / \mathrm{A}$ ratio and aerosol distribution, more aerosol is retained by a duct than a compartment alone whereas the duct-compartment configuration retained the most aerosol.

\section{ATTACHMENT 1: REFERENCES}

SNL (Sandia National Laboratories), "MELCOR 1.8.2 Computer Code Manual Volume 1: Primer and Package Users' Guides," Thermal/Hydraulic Analysis Division, Albuquerque, New Mexico, 1991a.

SNL (Sandia National Laboratories), "MELCOR 1.8.2 Computer Code Manual Volume 2: Reference Manuals and Programmers' Guides," Thermal/Hydraulic Analysis Division, Albuquerque, New Mexico, $1991 b$.

Kmetyk, L.N., "MELCOR Assessment: Gedanken Problems," SAND92-0762, 1993a.

Kmetyk, L.N., "MELCOR 1.8.1 Assessment: Marviken-V Aerosol Transport Test ATT-2b/ATT-4," SAND92-2243, 1993b. 


\section{ATTACHMENT 2}

TO

APPENDIX E

\section{RESULTS OF LPF\#1B BENCH-MARKING}

Prepared by

Susan E. Bayley

Science Applications International Corporation

Abingdon, $\mathbf{M D}$

February 1997 
Table 1. Steady State Leak Path Factors for Flow Through a Compartment

\begin{tabular}{lccc}
\hline \hline $\begin{array}{l}\text { Respirable Fraction } \\
\text { (ammd in microns) }\end{array}$ & $\begin{array}{c}\text { Volumetric Flow Rate per Unit Deposition Surface Area }(\mathrm{Q} / \mathrm{A})(\mathrm{m} / \mathrm{s}) \\
1.0 \times 10^{-1}\end{array}$ & $1.0 \times 10^{-3}$ & $1.0 \times 10^{-6}$ \\
\hline $\begin{array}{l}0.9996 \\
(0.99 \text { microns) }\end{array}$ & $9.99 \times 10^{-1}$ & $9.26 \times 10^{-1}$ & $2.81 \times 10^{-2}$ \\
0.5000 & $9.86 \times 10^{-1}$ & & $1.33 \times 10^{-3}$ \\
$(10$ microns) & & $4.78 \times 10^{-1}$ & \\
$4.447 \times 10^{-4}$ & $9.78 \times 10^{-1}$ & $3.21 \times 10^{-1}$ & $4.98 \times 10^{-4}$ \\
$(101$ microns) & & & \\
\hline \hline
\end{tabular}

Table 2. Steady State Leak Path Factors for Flow through a Duct

\begin{tabular}{lccc}
\hline \hline $\begin{array}{l}\text { Respirable Fraction } \\
\text { (ammd in microns) }\end{array}$ & $\begin{array}{c}\text { Volumetric Flow Rate per Unit Deposition Surface Area }(\mathrm{Q} / \mathrm{A})(\mathrm{m} / \mathrm{s}) \\
1.0 \times 10^{-1}\end{array}$ & $1.0 \times 10^{-3}$ & $1.0 \times 10^{-6}$ \\
\hline $\begin{array}{l}0.9996 \\
(0.99 \text { microns) }\end{array}$ & $9.98 \times 10^{-1}$ & $9.21 \times 10^{-1}$ & $9.81 \times 10^{-6}$ \\
0.5000 & $9.87 \times 10^{-1}$ & $3.56 \times 10^{-1}$ & $5.81 \times 10^{-11}$ \\
$(10$ microns) & & &. \\
$4.447 \times 10^{-4}$ & $9.77 \times 10^{-1}$ & $1.51 \times 10^{-1}$ & $8.38 \times 10^{-15}$ \\
$(101$ microns $)$ & & \\
\hline \hline
\end{tabular}

Table 3. Steady State Leak Path Factors for Flow through a Compartment Connected to a Duct

\begin{tabular}{lcc}
\hline \hline $\begin{array}{l}\text { Respirable Fraction } \\
\text { (ammd in microns) }\end{array}$ & Volumetric Flow Rate per Unit Deposition Surface Area (Q/A) (m/s) \\
\hline $\begin{array}{l}0.5000 \\
(10 \text { microns })\end{array}$ & $1.0 \times 10^{-1}$ & $1.0 \times 10^{-3}$ \\
\hline \hline
\end{tabular}




\section{APPENDIX F}

\section{FILTRATION}




\section{APPENDIX F \\ TABLE OF CONTENTS}

APPENDIX F: FILTRATION

TABLE OF CONTENTS $\ldots \ldots \ldots \ldots \ldots \ldots \ldots \ldots \ldots \ldots \ldots \ldots \ldots \ldots \ldots \ldots \ldots \ldots \ldots \ldots \ldots \ldots \ldots \ldots$

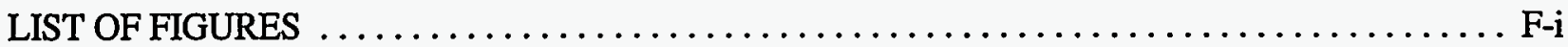

LIST OF TABLES $\ldots \ldots \ldots \ldots \ldots \ldots \ldots \ldots \ldots \ldots \ldots \ldots \ldots \ldots \ldots \ldots \ldots \ldots \ldots \ldots \ldots \ldots \ldots \ldots$

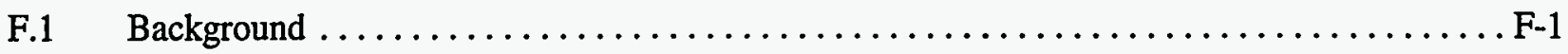

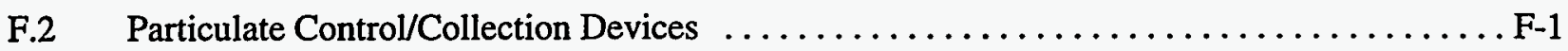

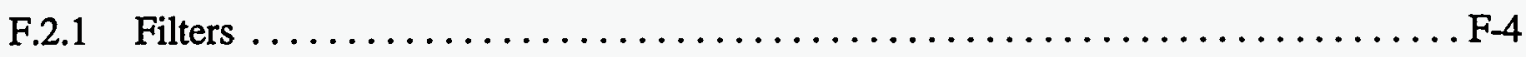

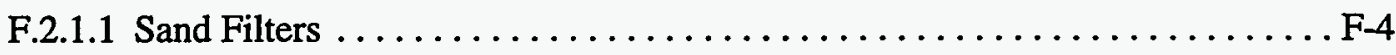

F.2.1.2 Deep Bed Glass Fiber (DBGF) Filters $\ldots \ldots \ldots \ldots \ldots \ldots \ldots \ldots \ldots \ldots$ F-4

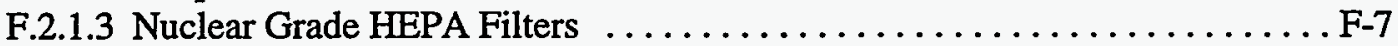

F.2.2 Efficiency of U.S. Standard Nuclear Grade 2-ft x 2-ft Deep Pleated HEPA Filter with Glass Fiber Medium Under Accident Conditions . . . . . . . . . . . F-7

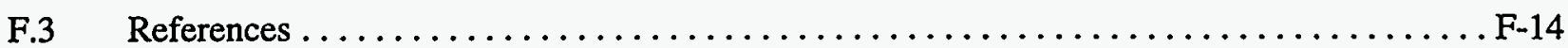

\section{LIST OF FIGURES}

Figure F-1 Particle Collection Efficiencies for Various Dust Collectors (Moore, et. al. 1984) . ..... F-3

Figure F-2 Isometric of Sand Filter (Moore, et al. 1984) . . . . . . . . . . . . . . . F

Figure F-3 Sand Filter Collection Efficiency as a Function of Superficial Face Velocity

(Moore, et al. 1984) ................................ 6

Figure F-4 Construction of Standard Deep-Pleated HEPA Filters (Moore, et al. 1984) . . . . . . . . . F-9

Figure F-5 Penetration of Di Octyl Sebacate Aerosol Through Standard Nuclear Grade

HEPA Filter (Bergman, et al. 1995a) . . . . . . . . . . . . . . . . . F-10

Figure F-6 Maximum HEPA Filter Penetration of 0.3 Micrometer DOP Particles as a

Function of Velocity (Bergman, et al. 1995a) ................... F-13

\section{LIST OF TABLES}

Table F-1 Comparison of Some Important Dust Collector Characteristics (Moore, et al. 1984) ... . . F-2

Table F-2 Particle Collection Efficiency for DBGF Filters, DOP Test (Moore, et al. 1984) . . .... F-4

Table F-3 Effect of Environment and Filter Parameters on the Penetration of HEPA Filters

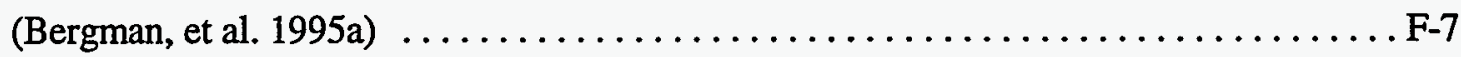

Table F-4 Range of Experimental Values for Effect of Parameters on HEPA Filters

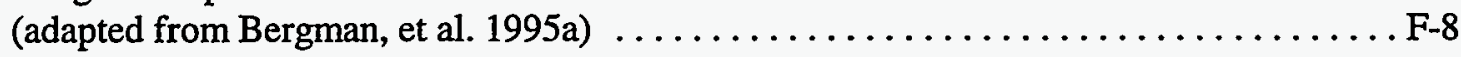

Table F-5 Limited Threshold Values of Differential Pressure Required to Structurally Damage the Standard HEPA Filter (adapted from Bergman, et al. 1995a) . . . . . . . . . . F-11

Table F-6 Range of Experimental Values for Structurally Damaged Standard HEPA Filters

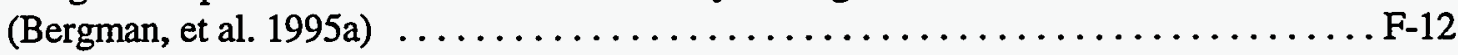




\section{APPENDIX F FILTRATION}

\section{F.1 Background}

In general, the nuclear industry utilizes the same types of control devices as are used by the commercial sector to control airborne particulate materials in the process and in emissions in gaseous exhausts from the facility. These devices range from mechanical devices (such as a cyclone, a centrifugal inertial device) to various devices that result in contact between the particle-bearing stream and water or aqueous solutions (e.g., scrubbers, submerged packed beds, submerged demisters, venturi scrubbers, and spray chambers), electromechanical devices (electrostatic precipitators), to many forms of filtration (e.g., packed beds, bag-type filters, cartridge filters, fibrous filters with various fibers such as cellulose, asbestos, other ceramic materials, metal fibers, glass fibers and powdered or sintered metal filters).

There have been 24 biannual air cleaning conferences, beginning in 1951 (First 1995). The majority of tests on High Efficiency Particulate Air (HEPA) filters reported in these conferences are for operational characteristics to improve filter performance, and little testing has been performed to determine behavior under accident conditions. The Department of Energy (DOE) has also sponsored testing of filter collection efficiencies at various locations, but much of the effort has been discontinued due to the very high reliability of the HEPA filters. DOE has also sponsored a Nuclear Air Cleaning Handbook (Burchsted, Kahn, and Fuller 1970) and a first revision (Burchsted, Kahn, and Fuller 1976). At the time of writing, a second revision is being prepared under the leadership of Dr. Mel First, Harvard Air Cleaning Laboratory. DOE has also attempted to prepare a HEPA filter standard (Dr. Werner Bergman, Lawrence Livermore National Laboratory) but could not achieve consensus. The technical aspects are covered in Bergman, et al. (1995a).

Many of the devices used are covered in Moore (1984). Due to the need for very efficient removal of particulate materials with very small diameters (particles less than $10 \mu \mathrm{m}(0.0004$ in) Aerodynamic Equivalent Diameter), filtration is the dominant technique employed. For the purpose of determining the leak path factor (LPF) for volumes that exhaust through such a device under accident conditions, the important characteristics are the normal particle collection efficiency (for accidents that do not have an effect upon the control device) and the particle removal efficiency during severe accident conditions. The discussion here is focused upon these areas.

\section{F.2 Particulate Control/Collection Devices}

The particulate control/collection devices found in DOE nuclear fuel cycle facilities are described and discussed in Moore, et al. (1984) and are representative of those found in most non-reactor, non-medical nuclear facilities. Table F-1 tabulates some of the relevant characteristics of each class of device, and Figure F-1 shows the efficiencies as a function of particle size for each device. The class of particle control/collection devices that are predominantly used to minimize emission of airborne particulate materials from these facilities, namely filters, is covered in greater depth in subsequent portions of this Appendix. 


\begin{tabular}{|c|c|c|c|c|c|c|c|c|}
\hline & . & & & & Sensitivity $\mathbf{t}$ & fm Change & & \\
\hline Type & $\begin{array}{l}\text { Higher Efficiency } \\
\text { Range on Particles } \\
\text { Greater than Mean } \\
\text { Size in Microns }\end{array}$ & $\begin{array}{c}\text { Pressure } \\
\text { Loss } \\
\text { (Inches } \\
\text { of Water) }\end{array}$ & $\begin{array}{l}\mathrm{H}_{2} \mathrm{O} \text { Rate (gal } \\
\text { per } 1,000 \mathrm{cfm})\end{array}$ & Space & Pressure & Efficiency & $\begin{array}{l}\text { Humid Air } \\
\text { Influence }\end{array}$ & $\begin{array}{c}\text { Max. Temp. }{ }^{\circ} \mathbf{F}, \\
\text { Standard } \\
\text { Construction } \\
(\text { Note 4) } \\
\end{array}$ \\
\hline Electrostatic & 0.25 & 0.5 & -- & Large & Negligible & Yes & $\begin{array}{l}\text { Improves } \\
\text { Efficiency }\end{array}$ & 500 \\
\hline $\begin{array}{l}\text { Fabric: } \\
\text { Conventional }\end{array}$ & 0.25 & $3-6$ & -- & Large & As cfm & Negligible & $\begin{array}{l}\text { May make } \\
\text { reconditioning } \\
\text { difficult }\end{array}$ & $\begin{array}{c}180 \\
\text { (Note 1) }\end{array}$ \\
\hline Reverse Jet & 0.25 & $3-8$ & - & Moderate & As $\mathrm{cfm}$ & Negligible & & 180 \\
\hline $\begin{array}{l}\text { Glass, Reverse Flow } \\
\text { Wet: }\end{array}$ & 0.25 & $3-8$ & - & Large & As cfm & Negligible & & 550 \\
\hline $\begin{array}{l}\text { Packed Tower } \\
\text { Wet Centrifugal } \\
\text { Wet Dynamic } \\
\text { Orifice Types }\end{array}$ & $\begin{array}{l}1-5 \\
1-5 \\
1-2 \\
1-5\end{array}$ & $\begin{array}{l}1.5-3.5 \\
2.5-6 \\
\text { (Note 2) } \\
2.5-6\end{array}$ & $\begin{array}{l}5-10 \\
3-5 \\
0.5 \text { to } 1 \\
10-40\end{array}$ & $\begin{array}{l}\text { Large } \\
\text { Moderate } \\
\text { Small } \\
\text { Small }\end{array}$ & $\begin{array}{c}\text { As cfm } \\
\text { As (cfm })^{2} \\
\text { (Note } 2) \\
\text { As cfm or less }\end{array}$ & $\begin{array}{c}\text { Yes } \\
\text { Yes } \\
\text { No } \\
\text { Varies with } \\
\text { design }\end{array}$ & $\begin{array}{l}\text { None } \\
\text { None } \\
\text { None } \\
\text { None }\end{array}$ & $\begin{array}{l}\text { Unlimited } \\
\text { Unlimited } \\
\text { Unlimited } \\
\text { Unlimited }\end{array}$ \\
\hline $\begin{array}{l}\text { Higher Efficiency: } \\
\text { Fog Tower } \\
\text { Venturi } \\
\text { Dry Centrifugal: }\end{array}$ & $\begin{array}{l}0.5-5 \\
0.5-2\end{array}$ & $\begin{array}{c}2-4 \\
10-100\end{array}$ & $\begin{array}{l}5-10 \\
5-15\end{array}$ & $\begin{array}{l}\text { Moderate } \\
\text { Moderate }\end{array}$ & $\begin{array}{l}\text { As }(\mathrm{cfm})^{2} \\
\text { As }(\mathrm{cfm})^{2}\end{array}$ & $\begin{array}{l}\text { Slightly } \\
\text { Yes }\end{array}$ & None & $\begin{array}{l}\text { (Note 3) } \\
\text { Unlimited }\end{array}$ \\
\hline $\begin{array}{l}\text { Low Pressure } \\
\text { Cyclone }\end{array}$ & $20-40$ & $0.75-1.5$ & -- & Large & As $(\mathrm{cfm})^{2}$ & Yes & $\begin{array}{l}\text { May cause } \\
\text { condensation } \\
\text { and plugging }\end{array}$ & 750 \\
\hline $\begin{array}{l}\text { High Efficiency } \\
\text { Centrifugal }\end{array}$ & $10-30$ & $3-6$ & -. & Moderate & As $(\mathrm{cfm})^{2}$ & Yes & $\begin{array}{l}\text { May cause } \\
\text { condensation } \\
\text { and plugging }\end{array}$ & 750 \\
\hline Dry Dynamic & $10-20$ & (Note 2) & -- & Small & (Note 2) & No & $\begin{array}{l}\text { May cause } \\
\text { condensation } \\
\text { and plugging }\end{array}$ & 750 \\
\hline
\end{tabular}

Note 1: $180^{\circ} \mathrm{F}$ based on cotton fabric. Synthetic fabric may be used to $275^{\circ} \mathrm{F}$.

Note 2: A function of the mechanical efficiency of these combined exhausters and dust collectors.

Note 3: Precooling of high-temperature gases will be necessary to prevent rapid evaporation of fine droplets.

Note 4: See NFPA requirements for fire hazards; i.e., zirconium, magnesium, aluminum, wood working, etc. 


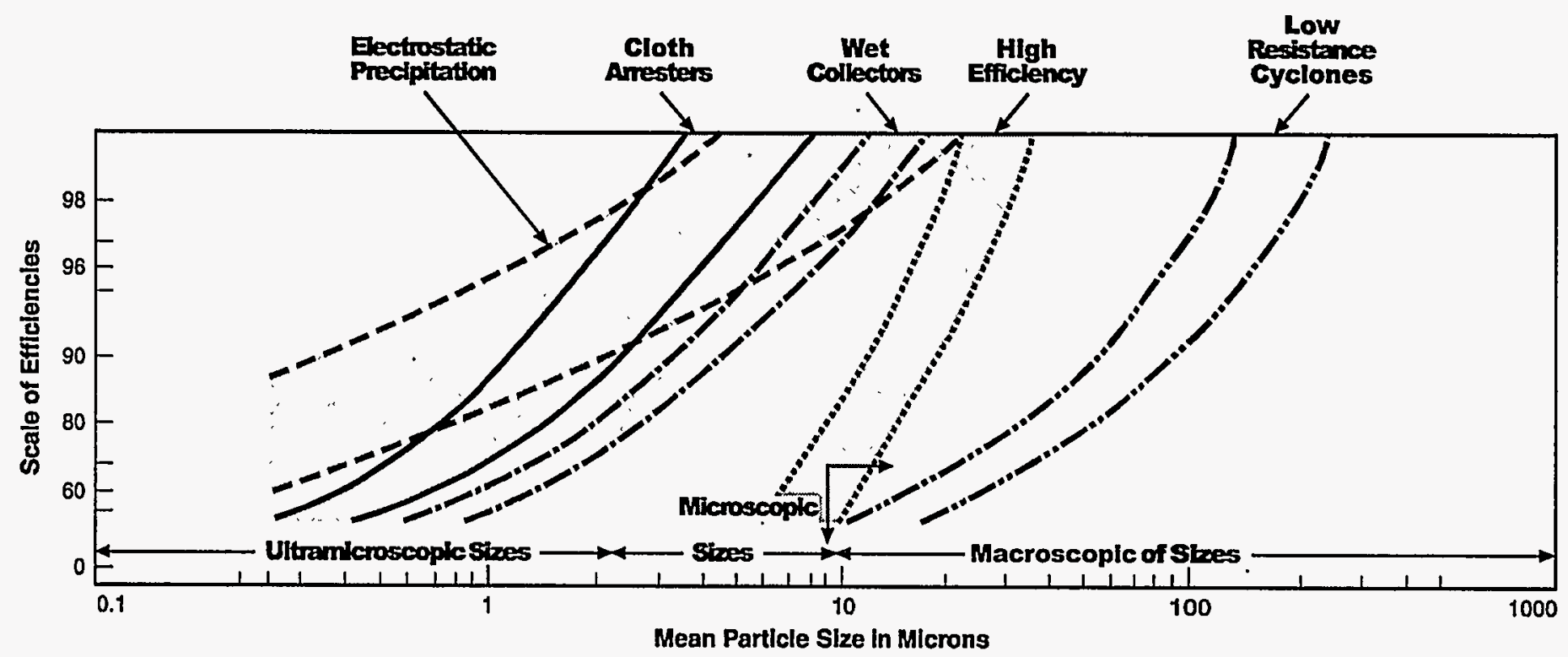

Figure F-1. Particle collection efficiencies for various dust collectors (Moore, et al. 1984) 


\section{F.2.1 Filters}

Three types of filtration devices are predominantly used to control emissions of airborne particulate materials from nuclear fuel cycle facilities: sand filters (deep, packed beds of large, graded particles); deep bed fibrous (glass) filters, and the standard U.S. deep pleated, glass fiber medium, HEPA filters.

\section{F.2.1.1 Sand Filters}

Sand filters have been used in DOE nuclear facilities for more than four decades. The device, properly designed and built, has large absorption capacity, low maintenance requirements, high heat capacity, fire resistance, and the ability to withstand shock loadings and large changes in air stream pressure without loss of function. Vibration or seismic events may lead to loss of flow capacity but probably increases efficiency (Moore, et al. 1984). A typical system is shown in Figure F-2, and the efficiency as a function of velocity is shown in Figure F-3. Kovach (1995) reports a particle collection efficiency of 99.95 percent, and that maximum penetration of sand beds (beds of several average particle sizes) occurred for the particles of dioctyl phthalate (DOP) with diameters in the range of 0.25 to $0.5 \mu \mathrm{m}\left(1 \times 10^{-5}\right.$ to $2 \times 10^{-5}$ in). The pressure drop across the system is $\sim 1120 \mathrm{~Pa}$ [4.8 in water column (wc)]. There are no data available to determine the effect of accident conditions on particle collection efficiency.

\section{F.2.1.2 Deep Bed Glass Fiber (DBGF) Filters}

Packed beds $2 \mathrm{~m}-3 \mathrm{~m}(6 \mathrm{ft}-10 \mathrm{ft})$ deep containing glass fiber particles with diameters from one to several hundred $\mu \mathrm{m}$ in the same general configuration shown for the sand filter, above, are also used as final filtration devices prior to exhausting gaseous effluents from nuclear fuel cycle facilities. DBGF filters have more predictable physical characteristics and a larger airflow rate per unit volume at lower pressure differential, resulting in lower operating costs. They also have potentially lower disposal costs than do sand filters. However, DBGF filters may have lower particle collection efficiencies, less resistance to fire and corrosion, little heat capacity and self-healing characteristics, and lower resistance to shock and high pressure transient than sand filters. Particle collection efficiency as a function of flow is shown in Table F-2 (Moore, et al. 1986). Kovach (1995) reports a particle collection efficiency of 99.99 percent (size of test particles not given). Airflow rates were $60000 \mathrm{~m}^{3} / \mathrm{hr}\left(2.1 \times 10^{6} \mathrm{ft}^{3} / \mathrm{hr}\right)$ for a $2.772 \mathrm{~m}(9 \mathrm{ft}$ ) deep bed of fiber graded from 1 to $200 \mu \mathrm{m}\left(4.0 \times 10^{-5}\right.$ to $\left.8.0 \times 10^{-3} \mathrm{in}\right)$ diameter. Superficial velocity is 12.4 $\mathrm{cm} / \mathrm{s}(5.0 \mathrm{in} / \mathrm{s})$ at a pressure differential of $1245 \mathrm{~Pa}(5 \mathrm{in} \mathrm{wc})$.

Table F-2. Particle Collection Efficiency for DBGF Filters, DOP Test (Moore, et al. 1984)

\begin{tabular}{ccc}
$\begin{array}{c}\text { Flow } \\
\left(\mathbf{m}^{3} / \mathbf{m i n}\right)\end{array}$ & $\begin{array}{c}\text { Total } \\
\Delta \mathbf{P} \\
(\mathbf{P a})\end{array}$ & $\begin{array}{c}\text { Efficiency } \\
\text { Percent } \\
\text { Total }\end{array}$ \\
\hline 0.76 & 340 & 99.95 \\
1.42 & 750 & 99.94 \\
3.68 & 1,250 & 99.92 \\
\hline
\end{tabular}




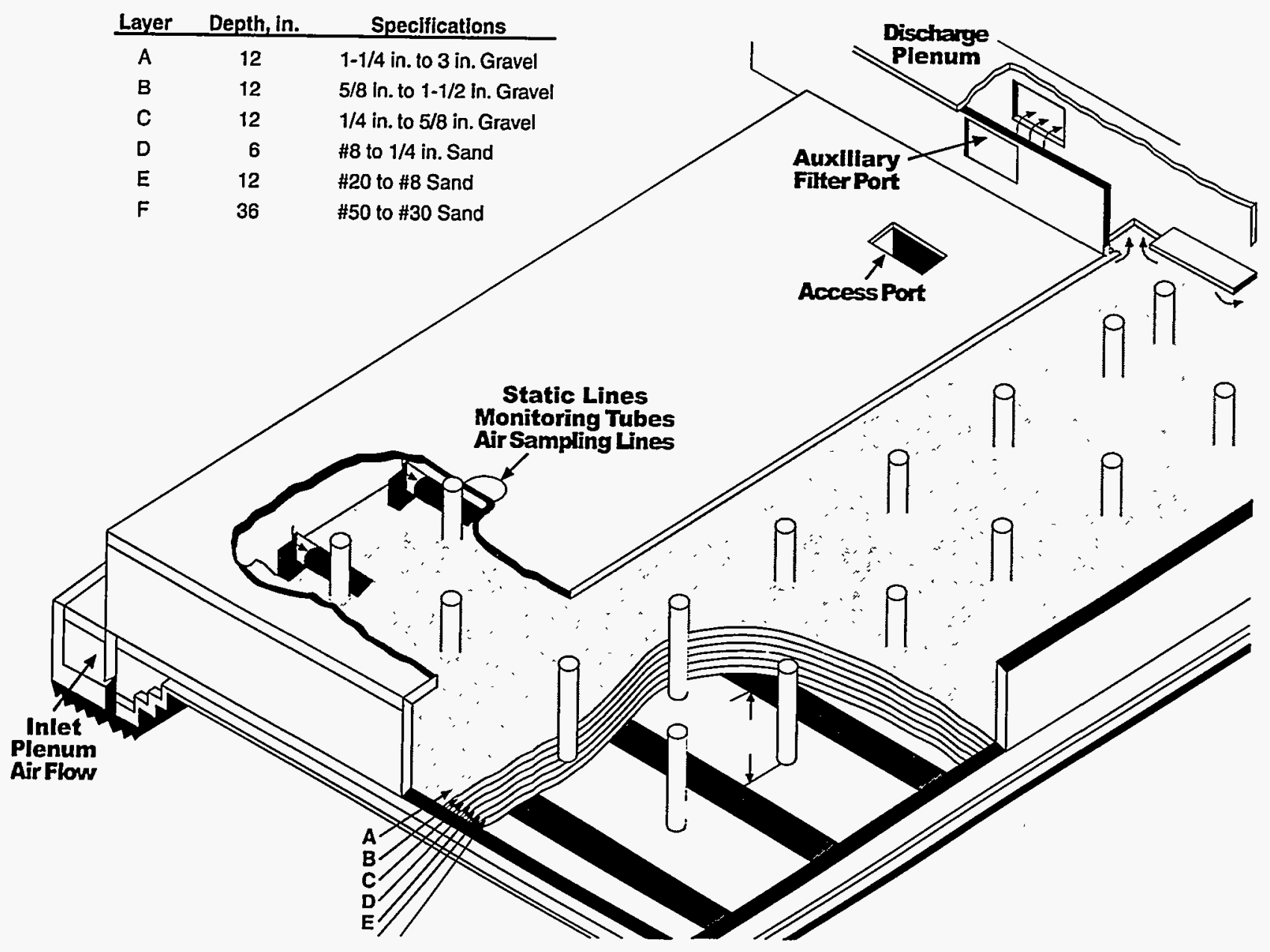

Figure F-2. Isometric of sand filter (Moore, et al. 1984) 


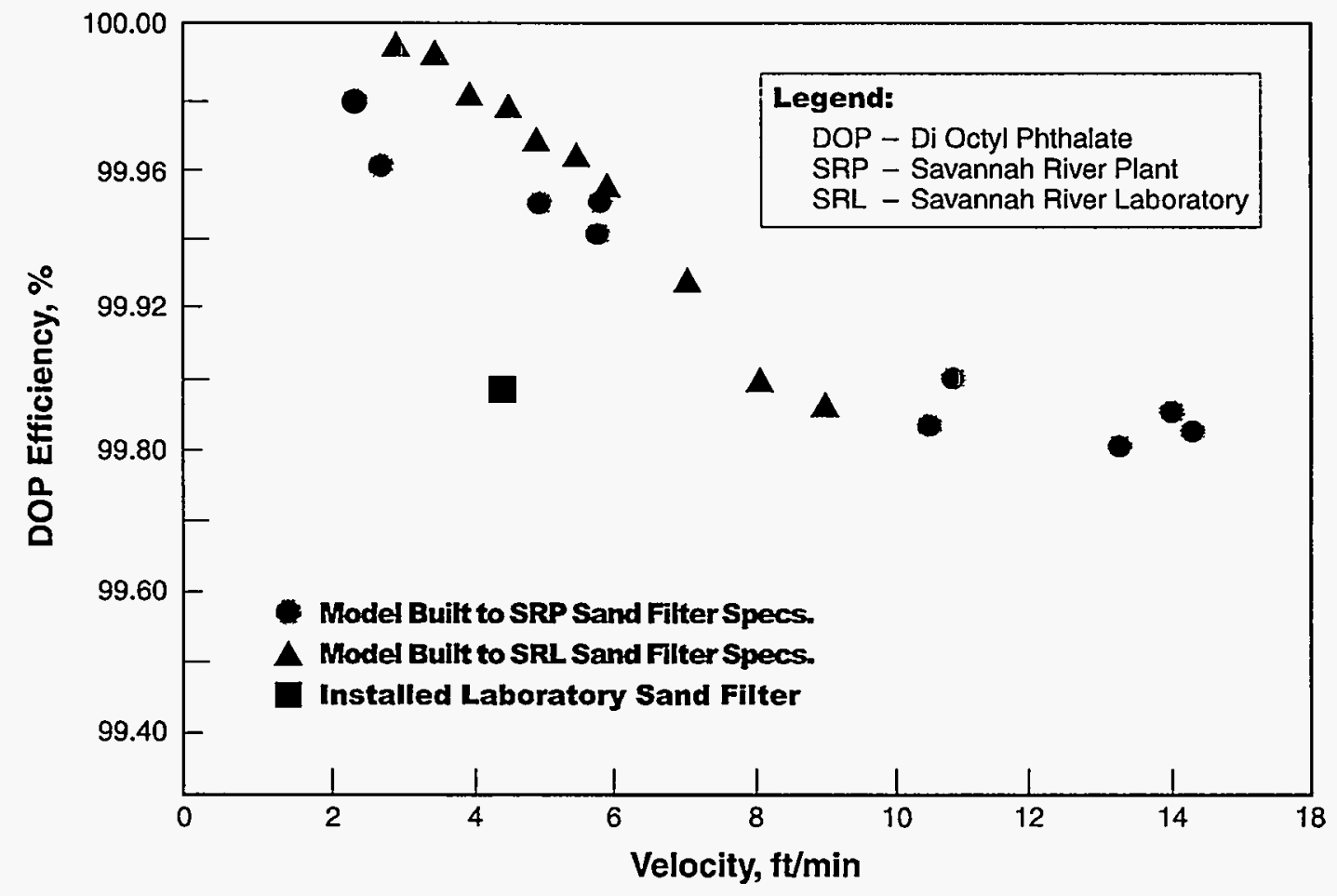

Figure F-3. Sand filter collection efficiency as a function of superficial face velocity (Moore, et al. 1984) 


\section{F.2.1.3 Nuclear Grade HEPA Filters}

The fibrous medium is a $0.38-\mathrm{mm}(0.01 \mathrm{in})$ thick, non-woven mat of 1 to $4 \mu \mathrm{m}\left(4.0 \times 10^{-5}\right.$ to $2.0 \times 10^{-4}$ in) diameter glass fibers (Kovach 1995). The construction of both steel- and wood-frame HEPA filters is shown in Figure F-4. HEPA filters must demonstrate a particle collection efficiency of $>99.97$ percent for $0.3-\mu \mathrm{m}$ diameter particles and have a particle collection efficiency of $>99.95$ percent for similar sized particles in-situ (installed in the system). For accidents in which conditions at the HEPA filter are unchanged from normal operating conditions, use of the in-situ tested efficiency is recommended for analysis (Elder, et al. 1986). If a series of HEPA filters is protected by pre-filters, sprinklers, and demisters, efficiencies of 99.9 percent for the first filter and 99.8 percent for all subsequent filters is recommended for accident analysis (Elder, et al. 1986). If conditions are severe or the filters are unprotected, efficiencies as low as 99 to 95 percent are recommended (USNRC 1978).

\section{F.2.2 Efficiency of U.S. Standard Nuclear Grade 2-ft x 2-ft Deep Pleated HEPA Filter with Glass Fiber Medium Under Accident Conditions}

Bergman, et al. (1995a) reviewed the available experimental data for failure threshold and particle capture efficiency values for this grade of HEPA filters, and the information in this Subsection is extracted from this source. Figure F-5 shows the penetration efficiency as a function of diameter for dioctylsebacate aerosols.

The loss of particle capture efficiency (increase in penetration) for various environmental effects that may be present during an accident has been estimated based upon a review of the experimental data on filter efficiency. The results are presented in Table F-3. The values presented are limiting values, and the range of values (uncertainty) is shown in Table F-4. The efficiency for these filters under normal operating conditions (i.e., in-situ efficiency of $>99.95$ percent for $0.3 \mu \mathrm{m}\left(1.2 \times 10^{-5} \mathrm{in}\right)$ DOP at a flow of $28.32 \mathrm{~m}^{3} / \mathrm{min}$ [1000 $\mathrm{cfm}])$, based upon the difference in efficiency between $0.3 \mu \mathrm{m}\left(1.2 \times 10^{-5} \mathrm{in}\right)$ particles and the efficiency for the most penetrating particle $\left(0.15 \mu \mathrm{m}\left(2.0 \times 10^{-6}\right.\right.$ in $\left.)\right)$ shown in Figure F-5 is 99.9 percent. The loss of efficiency shown in Table F-3 is subtracted from this value to arrive at the loss under accident conditions.

Table F-3. Effect of Environment and Filter Parameters on the Penetration of HEPA Filters (Bergman, et al. 1995a)

\begin{tabular}{lc}
\hline \multicolumn{1}{c}{ Parameter } & Filter Penetration* \\
\hline Baseline & 0.1 percent \\
HF Corrosion & 0.1 percent \\
1,500 ppm-hr. & \\
Temperature & \\
Less than $200^{\circ} \mathrm{C}\left(392^{\circ} \mathrm{F}\right)$ & 0.0 percent \\
$200-300^{\circ} \mathrm{C}\left(392-572^{\circ} \mathrm{F}\right)$ & 0.1 percent \\
$300-350^{\circ} \mathrm{C}\left(572-662^{\circ} \mathrm{F}\right)$ & 0.4 percent \\
$350-500^{\circ} \mathrm{C}\left(662-932^{\circ} \mathrm{F}\right)$ & 3.0 percent \\
\hline
\end{tabular}




\section{Table F-3. Effect of Environment and Filter Parameters on the Penetration}

of HEPA Filters (Bergman, et al. 1995a) (Continued)

\begin{tabular}{lc}
\hline \multicolumn{1}{c}{ Parameter } & Filter Penetration* \\
\hline Particle Deposits & \\
Solids & $\sim 0.05$ percent \\
Liquids** & $1.3 \mathrm{P}_{\mathrm{i}} \Delta \mathrm{P} / \Delta \mathrm{P}_{\mathrm{i}}$ percent \\
Air Flow & $3.65 \times 10^{-4}(\mathrm{flow} / 400)^{2.58}$ \\
& percent \\
\hline
\end{tabular}

* These values represent the most conservative values taken from an analysis of experimental studies reviewed and summarized in Table 3 of Bergman et al. (1995a). Filter penetration (in percent) is equal to 100 minus filter efficiency (in percent).

** $P_{i}$ is the initial pressure on the upstream face of the filter. $\Delta P_{i}$ is the initial pressure drop after the particles have been deposited.

Table F-4. Range of Experimental Values for Effect of Parameters on HEPA Filters (adapted from Bergman, et al. 1995a)

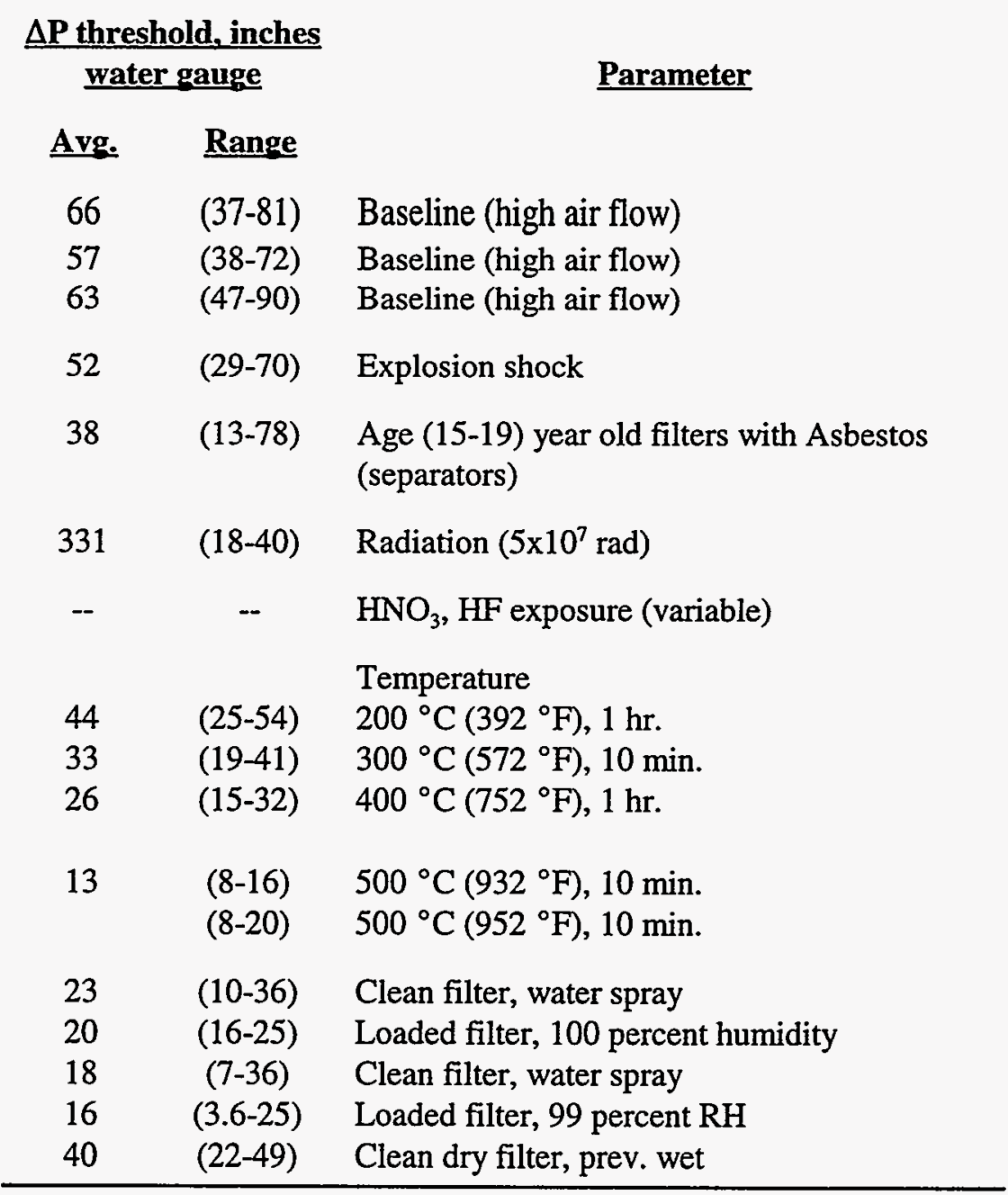




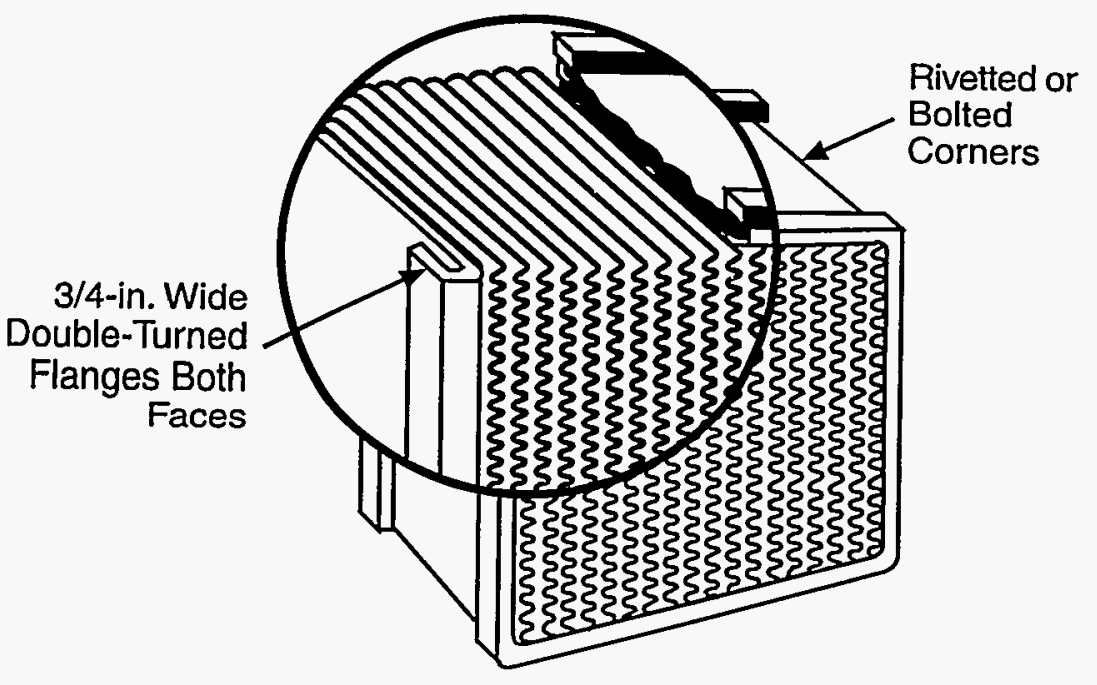

Steel-Cased HEPA

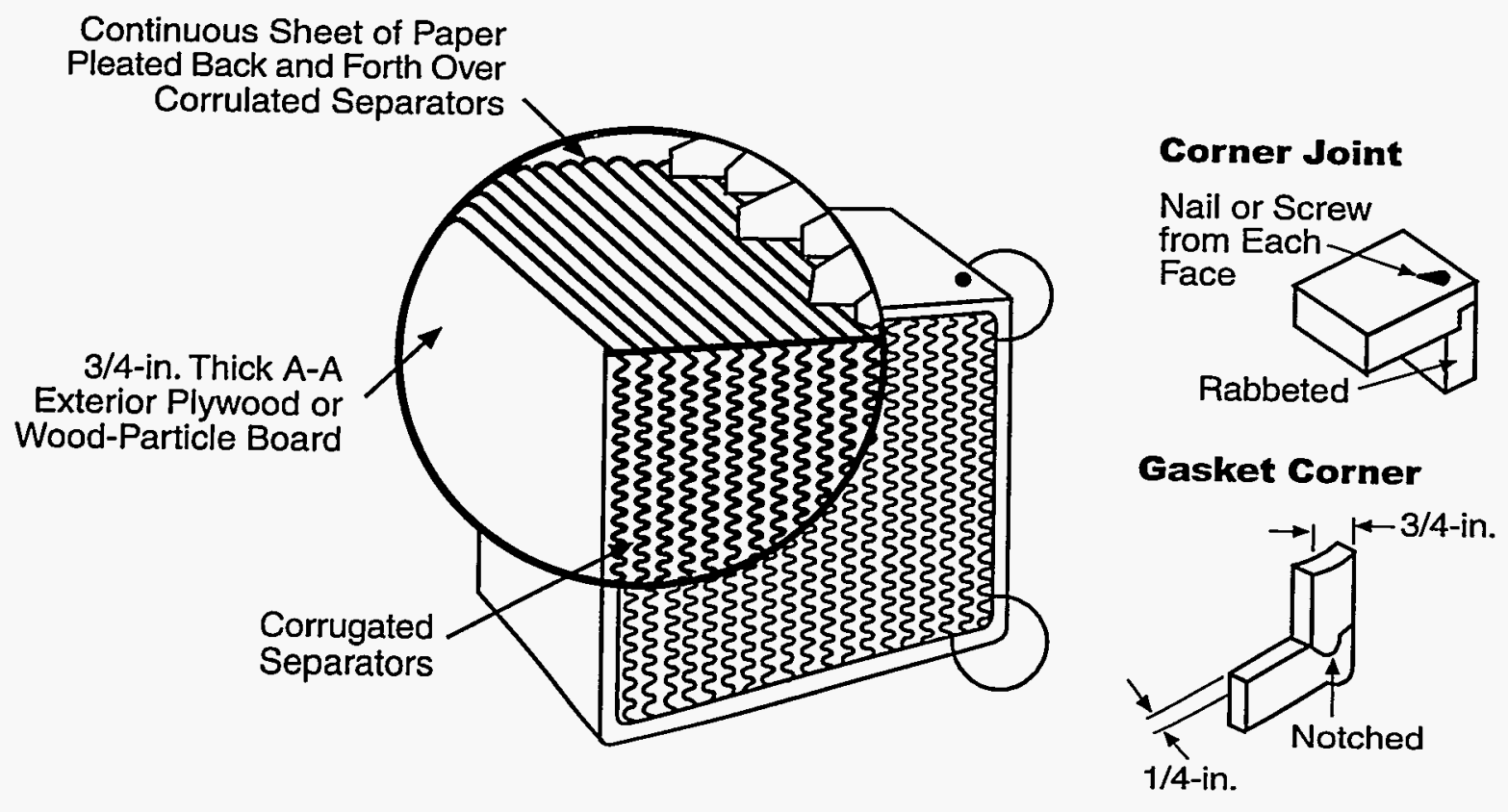

Wood-Cased HEPA

Figure F-4. Construction of standard deep-pleated HEPA filters (Moore, et al. 1984) 


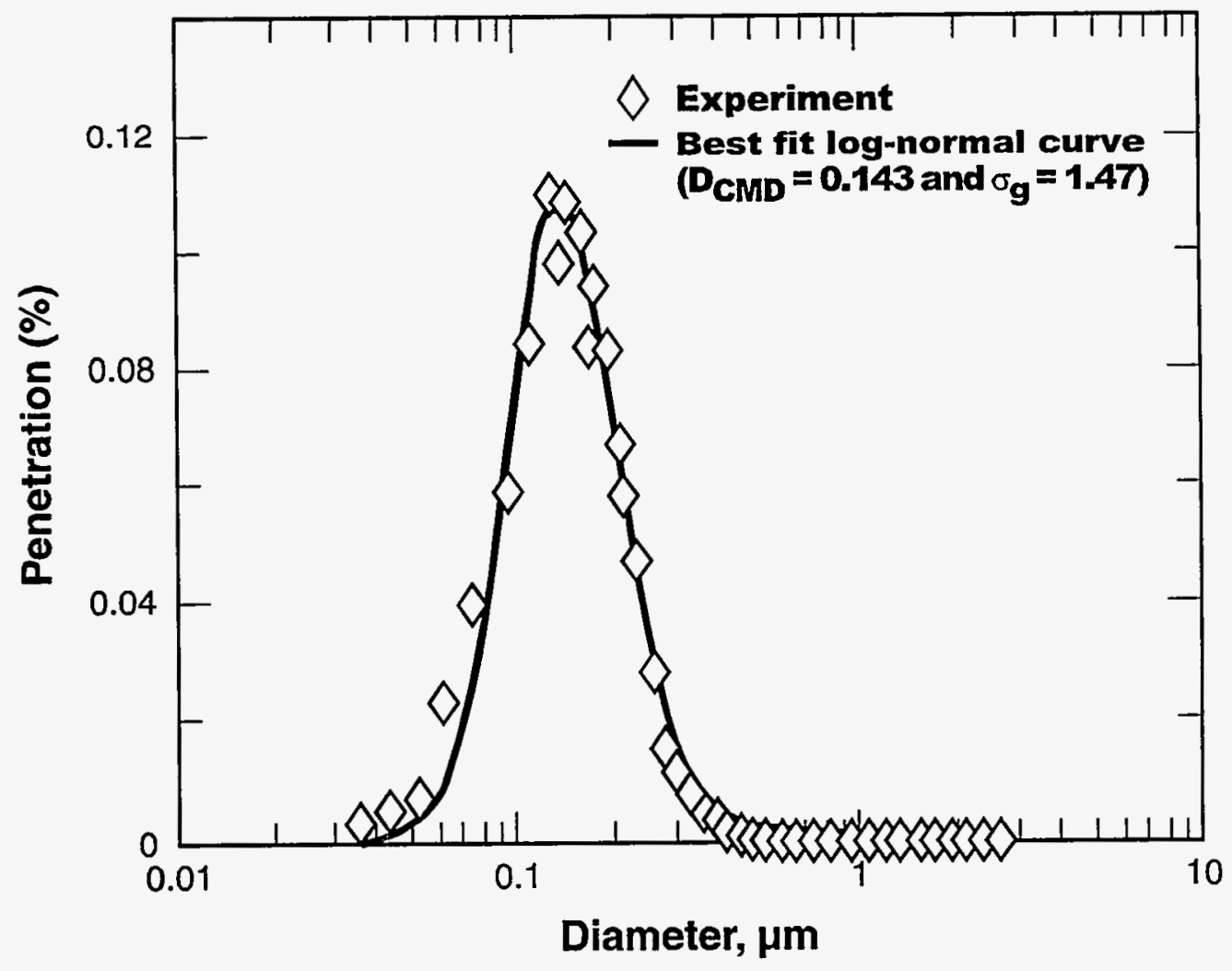

Figure F-5. Penetration of di octyl sebacate aerosol through standard nuclear grade HEPA filter (Bergman, et al. 1995a) 
Use of these values depends upon the survival of the device under accident conditions. The failure threshold limiting value for this class of HEPA filter is shown in Table F-5, and the range of values (uncertainty) is shown in Table F-6. The limiting values are a function of the pressure imposed on the filter. The pressure is in turn a function of the flow of the airborne effluents through the filter under accident conditions. The limiting assumption is that the filter efficiency drops to zero upon failure but data is cited that indicates filter efficiency can remain at 94 percent to 99 percent for partial failure (separation of medium from frame, tears in the medium). Particle collection efficiency for HEPA filters is also a function of velocity through the filter (see Figure F-6).

Other aspects of HEPA filter performance have been investigated. As an example, Gilbert et al. (1995) describe an attempt to determine the shelf life for HEPA filters. One finding appears to be that loss of structural strength of the glass fiber medium involves loss/deterioration of the binder used to hold together the individual fibers in the mat. Use of other materials as the medium are also explored: metal fibers in Bergman, et al. (1995b) and Grewal et al. (1993); stainless steel-quartz fibers in Bergman and Sawyer (1989); self contained HEPA filters in Arnedt (1995); permanently magnetized fibers in Watson (1995); using papers of graded density in Dyment and Hamblin (1995); and high-capacity HEPA filters in Allan (1989).

Table F-5. Limited Threshold Values of Differential Pressure Required to Structurally Damage the Standard HEPA Filter (adapted from Bergman, et al. 1995a)

\section{Parameter}

Baseline (new filter, normal conditions) Age (15 years or older)

Radiation (6x10 $\mathrm{Rad})$

Chemical $\left(\mathrm{HNO}_{3}, \mathrm{HF}\right)$

Temperature

Less than $200^{\circ} \mathrm{C}\left(392^{\circ} \mathrm{F}\right)$

200-300 ${ }^{\circ} \mathrm{C}\left(192-572^{\circ} \mathrm{F}\right)$

10 minutes

1 hour

10 hours

$300-400^{\circ} \mathrm{C}\left(572-752^{\circ} \mathrm{F}\right)$

$400-500^{\circ} \mathrm{C}\left(752-932{ }^{\circ} \mathrm{F}\right)$
$\Delta$ P Threshold* inches w.g.

37

13

18

0-37

37

33

30

22

15

10

10

22

29

Air Pulse from Explosion

These values represent the most conservative values (except for moisture) taken from an analysis of experimental studies reviewed in this report. 
Table F-6. Range of Experimental Values for Structurally Damaged Standard HEPA Filters (Bergman, et al. 1995a)

\section{Parameter}

Baseline

HF Corrosion

$1,500 \mathrm{ppm}-\mathrm{hr}$.

Temperature

Increase from

$25-200{ }^{\circ} \mathrm{C}$

$200{ }^{\circ} \mathrm{C}$

$240{ }^{\circ} \mathrm{C}$ for 6 hours

$300^{\circ} \mathrm{C}$

$350^{\circ} \mathrm{C}$

$500^{\circ} \mathrm{C}$

$500{ }^{\circ} \mathrm{C}$ for $10-45 \mathrm{~min}$.

$538^{\circ} \mathrm{C}$

Moisture

Up to 100 percent $\mathrm{RH}$

Water spray loaded to 8 in.

\section{Filter Clogging}

Solid particle loading

$\mathrm{NaCl}$ deposits to 1.9 in.

Liquid DOP loaded to 4 in.

Oil aerosols

\section{Air Flow}

Increasing velocity from 0.5 $\mathrm{cm} / \mathrm{s}$ to $20 \mathrm{~cm} / \mathrm{s}$

Increasing air flow by 10 times

Air Pulse

1 psi pulse

Shock tests on filters preloaded with $.46 \mu \mathrm{m}$ latex

\section{Effect on Filter Penetration}

0.1 percent

0.1 percent increase

Decreases penetration

from 0.01 to 0.001 percent

0.03-0.01 percent

0.01 percent

0.12-0.01 percent

0.4-0.03 percent

0.9-0.2 percent

0.9-0.1 percent

1.2-0.5 percent

Negligible effect

Increase by 10 times

Decreases penetration

Decreases penetration from 0.003 to 0.000001 percent

Penetration increases by factor of 10

Penetration increase is 1.3P $\Delta \mathrm{P} / \Delta \mathrm{P}_{\mathrm{i}}$ increase

Penetration increases from 0.00003 percent to 0.5 percent

Penetration of $0.1 \mu \mathrm{m}$ particles increases by 100 times

Penetration of $0.46 \mu \mathrm{m}$ latex particles is 0.1 percent

Penetration is 0.9 percent

Negligible effect 


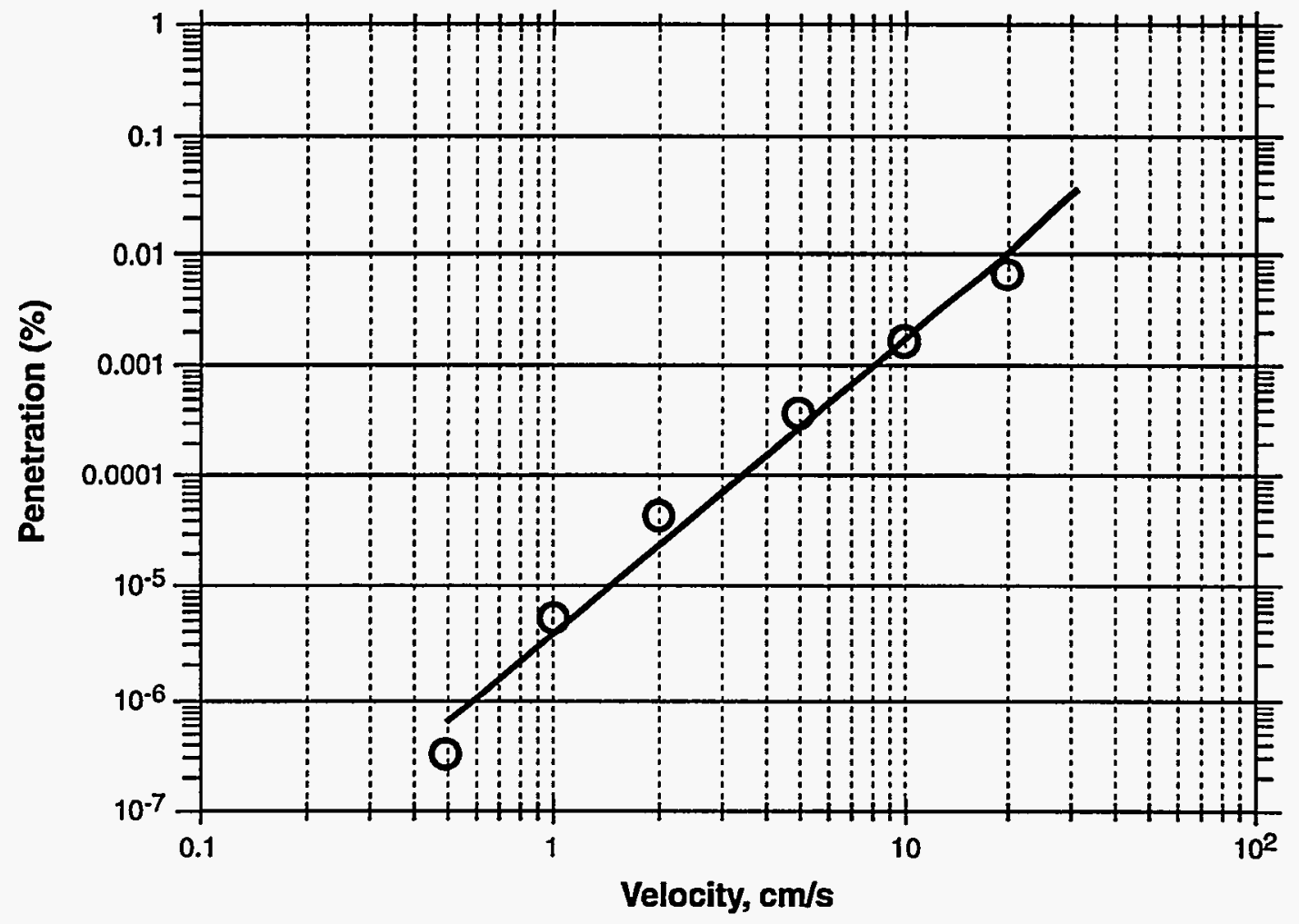

Figure F-6. Maximum HEPA filter penetration of 0.3 micrometer DOP particles as a function of velocity (Bergman, et al. 1995a) 


\section{F.3 References}

Allan, T.T., "Introduction of a New Generation of High Capacity HEPA Filters and a Comparison of Their Performance to HEPA Filters Available on the Market," Proceedings of the 21st DOENRC Air Cleaning Conference (M.W. First, Ed.), CONF 900813, Harvard Air Cleaning Laboratory, Boston, Massachusetts, 1989.

Arnedt, T.R., "Evaluation of Self-Contained HEPA Filter," Proceedings of the 23rd NRC/DOE Nuclear Air Cleaning Conference (M.W. First, Ed), NUREG/CP-0141 (CONF-940738), Harvard Air Cleaning Laboratory, Boston, Massachusetts, 1995.

Bergman, W. and S.R. Swayer, "Development of a High-Efficiency, High-Performance Air Filter Medium," Proceeding of the 20th DOE Nuclear Air Cleaning Conference (M.W. First, Ed), CONF-880822, Harvard Air Cleaning Laboratory, Boston, Massachusetts, 1989.

Bergman, W., M.W. First, W.L. Anderson, H. Gilbert, and J.W. Jacox, "Criteria for Calculation the Efficiency of Deep-Pleated HEPA Filters with Aluminum Separators During and After Design Basis Accidents," Proceedings of the 23rd DOE/NRC Nuclear Air Cleaning Conference (M.W. First, Ed), NUREG/CP-0141 (CONF-940738), Harvard Air Cleaning Laboratory, Boston, Massachusetts, 1995a.

Bergman, W., G. Larsen, W.P. Wilson, R. Lopez, G. Vilha, J. Conners, J. Carr, K. Williams, A. Bierman, K. Wilson, P. Moore, C. Gellner, D. Rapchun, K. Simons, J. Rurley, L. Frye, and D. Moore, "Development and Evaluation of Cleanable High Efficiency Steel Filter," Proceedings of the 23rd NRC/DOE Nuclear Air Cleaning Conference (M.W. First, Ed), NUREG/CP-0141 (CONF-940738), Harvard Air Cleaning Laboratory, Boston, Massachusetts, $1995 \mathrm{~b}$.

Burchsted, C.A., J.E. Kahn, and A.B Fuller, "Design, Construction, and Testing of High-Efficiency Air Filtration Systems for Nuclear Application," ORNL-NSIC-65, Oak Ridge National Laboratory, Oak Ridge, Tennessee, 1970.

Burchsted, C.A., J.E. Kahn, and A.B. Fuller, Nuclear Air Cleaning Handbook, ERDA 76-21, U.S. Energy Research and Development Administration (currently the U.S. Department of Energy), Oak Ridge National Laboratory, Oak Ridge, Tennessee, 1976.

Dyment, J. and C. Hamblin, "The Development of a HEPA Filter with Improved Dust Holding Characteristics," Proceedings of the 23rd DOE/NRC Nuclear Air Cleaning Conference (M.W. First, Ed), Harvard Air Cleaning Laboratory, Boston, Massachusetts, 1995.

Elder, J.C., J.M. Graf, J.M. Dewart, T.E. Buhl, W.J. Wenzel, L.J. Walker, and A.K, Stoker, "A Guide to Radiological Accident Considerations for Siting and Design of DOE Nonreactor Nuclear Facilities," LA10294-MS, Los Alamos National Laboratory, Los Alamos, New Mexico, 1986.

First, M.W., "A Brief History of the Air Cleaning Conferences," Proceedings of the 23rd DOE/NRC Nuclear Air Cleaning Conference (M.W. First, Ed), NUREG/CP-0141 (CONF-940738), Harvard Air Cleaning Laboratory, Boston, Massachusetts, 1995. 
Gilbert, H., J.K. Frehold, F. Ranier, W. Bergman, and D. Beeson, "Preliminary Studies to Determine the Shelf Life of HEPA Filters," UCRL-1 15891, Lawrence Livermore National Laboratory, Livermore, California, 1995.

Grewal, G., Z. Milatovic, F.L Landon, and W.R Harty, "Application of High Efficiency Metal Fiber Filters in Ventilation Systems of Non-Reactor Nuclear Facilities," Proceeding of the 22nd NRCDDOE Nuclear Air Cleaning Conference (M.W. First, Ed), CONF-920823, Harvard Air Cleaning Laboratory, Boston, Massachusetts, 1993.

Kovach, J.L., "Review of Containment Vent Filter Technology," Proceedings of the 23rd DOE/NRC Nuclear Air Cleaning Conference (M.W. First, Ed), NUREG/CP-0141 (CONF-940738), Harvard Air Cleaning Laboratory, Boston, Massachusetts, 1995.

Moore, E.B. (ed), R. Aaberg, G.H. Bryan, L.L. Berger, C.A. Counts, D.A. Dingee, H.T. Fullam, C.M. Heeb, J.D. Ludwick, E.D. McClanahan, J. Mishima, L.G. Morgan, A.M. Screiber, and R.I. Smith, "Control Technology for Radioactive Emissions to the Atmosphere at U.S. Department of Energy Facilities," PNL4621, Pacific Northwest Laboratory, Richland, Washington, 1984.

U.S. Nuclear Regulatory Commission (USNRC), "Design, Testing, and Maintenance Criteria for PostAccident Engineered-Safety-Feature Atmospheric Cleanup System Air Filtration and Adsorption Units of Light-Water-Cooled Nuclear Power Plants," Regulatory Guide 1.52, Washington, DC, 1978.

Watson, J.P.H., "A Novel Permanently Magnetized High Gradient Filter using Assisted Capture for Fine Particles," Proceedings of the 23rd DOE/NRC Nuclear Air Cleaning Conference (M.W. First, Ed), NUREG/CP-0141 (CONF-940738), Harvard Air Cleaning Laboratory, Boston, Massachusetts, 1995. 


\section{APPENDIX G}

UNCERTAINTY 


\section{APPENDIX G}

\section{TABLE OF CONTENTS}

\section{APPENDIX G: UNCERTAINTY}

TABLE OF CONTENTS $\ldots \ldots \ldots \ldots \ldots \ldots \ldots \ldots \ldots \ldots \ldots \ldots \ldots \ldots \ldots \ldots \ldots \ldots \ldots \ldots \ldots \ldots$

LIST OF FIGURES $\ldots \ldots \ldots \ldots \ldots \ldots \ldots \ldots \ldots \ldots \ldots \ldots \ldots \ldots \ldots \ldots \ldots \ldots \ldots \ldots \ldots \ldots$

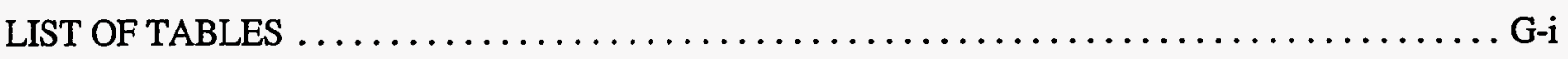

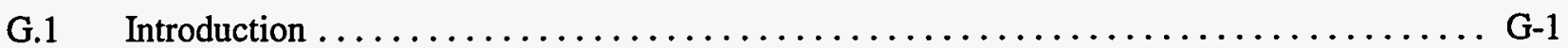

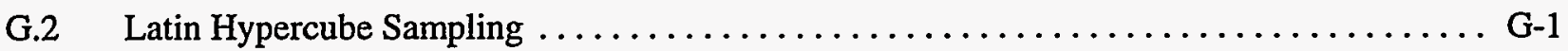

G.3 Sample Problem - Latin Hybercube Sampling $\ldots \ldots \ldots \ldots \ldots \ldots \ldots \ldots \ldots \ldots \ldots$ G-8

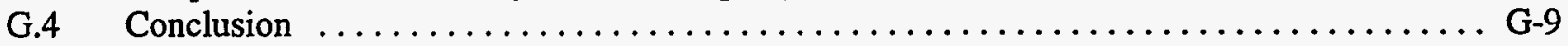

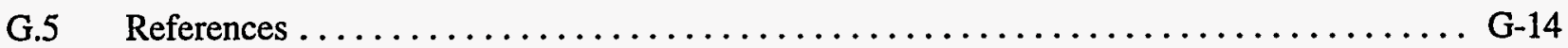

\section{LIST OF FIGURES}

Figure G-1. Intervals used with a LHS of Size $n=5$ in terms of the density function and cumulative distribution function for a normal random variable $\ldots \ldots \ldots \ldots \ldots, \mathrm{G}-4$

Figure G-2. Intervals used with a LHS of Size $n=5$ in terms of the density function and Cumulative distribution function for a uniform random variable $\ldots \ldots \ldots \ldots \ldots$ G-4

Figure G-3. A two-dimensional representation of one possible LHS of size 5 utilizing $X_{1}$ and $X_{2} \ldots$ G-6

Figure G-4. Interval endpoints used with a LHS of Size 5 (top) and specific values of $X$ Selected through the inverse of the distribution function (bottom) $\ldots \ldots \ldots \ldots \ldots$ G-7

Figure G-5. Distribution functions for time to 90 percent and 99 percent deposition for the first component ( $1 \sim$ time to 90 percent deposition, $2 \sim$ time to 99 percent

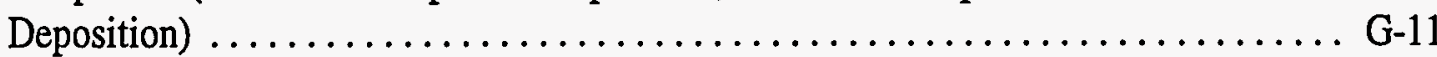

Figure G-6. Distribution function for total integrated concentration $\left(\mathrm{kg} \mathrm{sec} / \mathrm{m}^{3}\right)$ of first

Component . .............................. 12

Figure G-7. Distribution Function for total integrated concentration $\left(\mathrm{kg} \mathrm{sec} / \mathrm{m}^{3}\right)$ of second

Component

\section{LIST OF TABLES}

Table G-1. One Possible Selection of Values for an LHS of Size 5 from a Normal Distribution

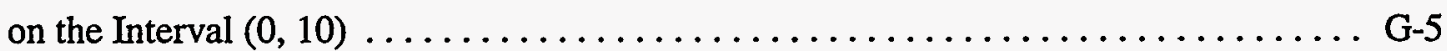

Table G-2. Variables Used in MAEROS Analysis ....................... G-10 


\section{APPENDIX G UNCERTAINTY}

\section{G.1 Introduction}

The results of the source term and dispersion calculations that are described in this "Nuclear Fuel Cycle Facility Accident Analysis Handbook," Revision 1 (hereafter the Handbook) are subject to considerable uncertainty. The Handbook does not definitively answer the question: how large are these uncertainties? Uncertainties are, in fact, addressed in an ad hoc manner in the context of various examples and are approached in one of two ways. When the experimental data upon which the calculations are based is very sparse--in some cases, there may only be one relevant experimental data point--an upper bound is taken. In other examples, sensitivity studies are performed to give the reader some idea of how much the results might vary if input parameters are varied over plausible ranges.

In no case does the Handbook attempt to estimate statistical parameters such as the mean, the median, the 95th, or the 5th percentiles. The reasons for this omission are as follows. First, such uncertainty analyses are very time consuming and expensive. For example, Nair, et al. (1997), have conducted an exhaustive study of models for the release and atmospheric dispersion of uranium hexafluoride $\left(\mathrm{UF}_{6}\right)$ and concluded that a comprehensive uncertainty analysis would be a major undertaking. Second, even in an arena in which there have been detailed studies of uncertainty, namely nuclear reactor Probabilistic Risk Assessments (PRAs), there has been no study that integrates uncertainties across all of the elements of such a risk assessment (such as estimating frequencies of core melt and containment failure, accident phenomenology, source term characteristics and atmospheric dispersion, and consequence analysis), thus illustrating the inherent difficulty of the undertaking (USNRC 1989).

The purpose of this Appendix is to illustrate how uncertainty analyses might be performed, assuming that the resources to do so are made available. The illustration is based on the method of Latin Hypercube Sampling (LHS), which is described in Section G.2. In Section G.3, the method is then applied to an example that is somewhat relevant to fuel cycle licensees' facilities. This is the behavior of aerosols suspended in the containment building of a nuclear power plant during a core melt accident. This behavior has some similarities to the treatment of building source terms in Chapter 4 and to some of the sample problems in Appendix D.

\section{G.2 Latin Hypercube Sampling}

The following discussion of Latin hypercube sampling (LHS) draws heavily upon NUREG/CR-3624 (Iman and Shortencarier 1984).

The outcome of a source term calculation is the estimation of a release rate that is a function of a number of input variables, such as the size of an orifice, the length of pipe between a vessel and an orifice, the pressure, the temperature, the static head, the number of bends in the pipework, etc. The outcome of an atmospheric dispersion and consequence analysis is a quantity such as the estimated airborne concentration at a given distance downwind. This concentration is a function of input variables such as the release rate, the windspeed and atmospheric stability category, the height of release, the momentum and orientation of release, the initial liquid droplet content, etc. In general, such calculations lead to a variable of interest, $Y$, that is a function of a number of other variables, $X_{1}, X_{2},----, X_{K}$. This function 
can be complicated and highly non-linear, e.g., as expressed in a computer model such as MACCS, MELCOR, or HGSYSTEM.

In general, the X's are themselves uncertain. For example, the size of a hole resulting from a random failure due to corrosion is uncertain. The temperature of a vessel in the open will vary during the day. The value of the dry deposition velocity in an atmospheric dispersion model is not accurately known. The question to be answered is: how does $Y$ vary when the $X$ 's vary over their plausible ranges? The answer to this question should also take into account that some of the $\mathrm{X}$ values may be correlated. $\mathrm{A}$ simple example of correlation is that the pressure in a vessel may increase as the temperature increases. Similarly, for a release of a flashing liquid jet, the amount of airborne liquid droplets will increase as the temperature increases. A more precise expression of the question is: how does $Y$ vary when the $X$ 's vary according to some assumed joint probability distribution? Related questions are: what is the expected value of $Y$ ? What is the 99th percentile of $Y$ ?, etc.

A conventional approach to these questions is to use a Monte Carlo analysis. By sampling repeatedly from the joint probability density function of the $X$ 's and evaluating the value of $Y$ for each sample, the distribution of $Y$, its mean, median, and percentiles can be estimated. An alternative approach, which can yield more precise estimates, is to use a constrained sampling scheme. One such scheme, developed by McKay, et al. (1979), is Latin Hypercube sampling (LHS).

LHS selects $\mathrm{n}$ different values from each of the $\mathrm{k}$ variables $\mathrm{X}_{1}, \mathrm{X}_{2},-\cdots, \mathrm{X}_{\mathrm{K}}$, as follows. The range of each variable is divided into $\mathrm{n}$ non-overlapping intervals on the basis of equal probability. One value selected from each interval is selected at random with respect to the probability density in that interval. The $\mathrm{n}$ values thus obtained for $\mathrm{X}_{1}$ are paired in a random manner (equally likely combinations) with the $\mathrm{n}$ values of $X_{2}$. These $n$ pairs are combined in a random manner with the $n$ values of $X_{3}$ to form $n$ triplets, and so on until k-tuplets are formed. This is the LHS. It is convenient to think of the sample as forming an $\mathrm{n} \times \mathrm{k}$ matrix of input, where the ith row contains specific values of each of the $\mathrm{k}$ input variables to be used for the ith run of the computer model, $X_{K}$.

The LHS technique has been applied to many different computer models since 1975 . The results of an application of LHS to a large computer model can be found in Steck, Iman, and Dahlgren (1976). A more detailed description of LHS with application to sensitivity analysis techniques can be found in Iman, Helton, and Campbell (1981a, 1981b). A tutorial on LHS may be found in Iman and Conover (1982b).

To help clarify how intervals are determined in the LHS, consider a simple example where it is desired to generate an LHS of size $n=5$, with two input variables. Let us assume that the first random variable $X_{1}$ has a normal distribution concentrated on the range from $A$ to $B$. The normal distribution, in fact, extends over an infinite range of the variable $X_{1}$ and must be truncated at $A$ and $B$ to facilitate calculation. A typical way of doing this is to make the following assumption:

$$
\mathrm{P}\left(\mathrm{X}_{1} \leq \mathrm{A}\right)=.001 \text { and } \mathrm{P}\left(\mathrm{X}_{1} \geq \mathrm{B}\right)=.001 \text {, }
$$

where $P(E)$ denotes the probability of event $E$. That is, $A$ is defined as the .001 quantile, and $B$ is defined as the .999 quantile of the distribution of $\mathrm{X}_{1}$. Thus, $\mathrm{P}\left(\mathrm{A} \leq \mathrm{X}_{1} \leq \mathrm{B}\right)=.998$, so the distribution is truncated slightly in a typical LHS computer program. That is, the sampling procedure excludes values outside the interval $[A, B]$. 
For a normal distribution with mean $\mu$ and standard deviation $\sigma$, the value of the standardized normal variate $Z=(X-\mu) / \sigma$ is established by selection of the value of the cumulative probability below the given value of $Z$. Thus,

$$
\operatorname{Pr}(\mathrm{Z} \leq-3.09)=0.001 \text { and } \operatorname{Pr}(\mathrm{Z} \geq 3.09)=0.001
$$

With the values of the interval and points $A$ and $B$ determined by knowledge of the system under consideration, the mean and standard deviation are calculated as:

$$
\mu=(\mathrm{A}+\mathrm{B}) / \mathrm{Z} \text { and } \sigma=(\mathrm{B}-\mathrm{A}) / 6.18
$$

The intervals for $n=5$ are illustrated in Figure G-1 in terms of both the density function $f(x)$ and the more easily used cumulative distribution function (cdf, $\mathrm{F}(\mathrm{x})$ ). For all practical purposes, the five intervals correspond to 20 percent probability.

In this example, it is assumed that the second random variable, $\mathrm{X}_{2}$ has a uniform distribution on the interval from $G$ to $H$. The corresponding intervals used in the LHS for $X_{2}$ are given in Figure $G-2$ in terms of both the density function and the cdf.

The next step in obtaining the LHS is to pick specific values of $X_{1}$ and $X_{2}$ in each of their five respective intervals. This selection should be done in a random manner with respect to the density in each interval; that is, the selection should reflect the variation of the density function across the interval. For example, in the $(A, C)$ interval for $X_{1}$, values close to $C$ will have a higher probability of selection than will those values close to $A$. Next, the selected values of $X_{1}$ and $X_{2}$ are paired to form the required five input vectors. In the original concept of LHS, as outline in McKay, Conover, and Beckman (1979), the pairing was done by associating a random permutation of the first $n$ integers with each input variable. For purposes of illustration, in the present example, consider two random permutations of the integers $(1,2$, $3,4,5$ ) as follows:

Permutation Set No. 1: $(3,1,5,2,4)$

Permutation Set No. 2: $(2,4,1,3,5)$

By using the respective position within these permutation sets as interval numbers for $X_{1}\left(\right.$ Set 1 ) and $X_{2}$

\begin{tabular}{|c|c|c|}
\hline Computer Run & $\begin{array}{c}\text { Interval } \\
\text { No. }\end{array}$ & $\begin{array}{c}\text { Interval } \\
\text { No. }\end{array}$ \\
\hline No. & $\frac{\text { Used for }}{\underline{x}_{1}}$ & $\frac{\text { Used for }}{\underline{X}_{2}}$ \\
\hline 1 & 3 & 2 \\
\hline 2 & 1 & 4 \\
\hline 3 & 5 & 1 \\
\hline 4 & 2 & 3 \\
\hline 5 & 4 & 5 \\
\hline
\end{tabular}
(Set 2), the following pairing of intervals would be formed: 

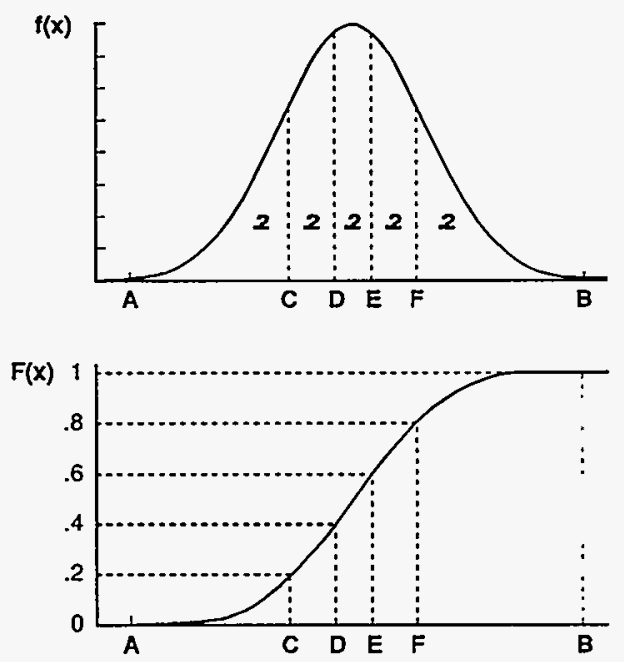

Figure G-1. Intervals used with a lhs of size $n=5$ in terms of the density function and cumulative distribution function for a normal random variable
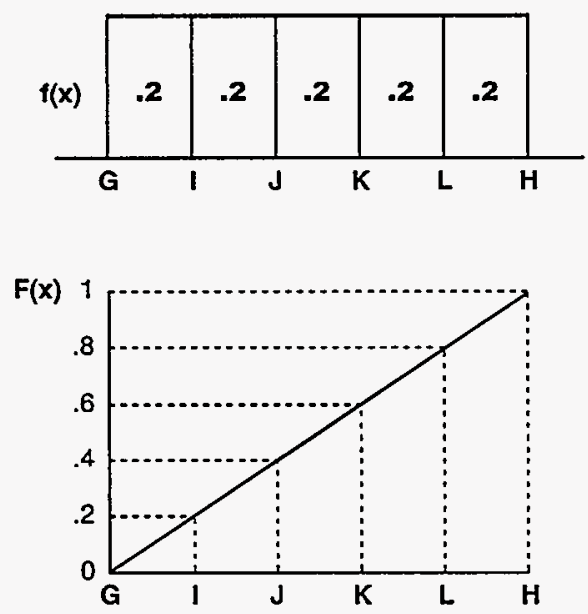

Figure G-2. Intervals used with a lhs of size $n=5$ in terms of the density function and cumulative distribution function for a uniform random variable 
Thus, on computer run number 1 , the input vector is formed by selecting the specific value of $\mathrm{X}_{1}$ from interval number 3 (D to $E$ ) and pairing this value with the specific value of $X_{2}$ selected from interval number 2 ( $\mathrm{i}$ to J), etc. Once the specific values of each variable are obtained to form the five input vectors, a two-dimensional representation of the LHS can be made, such as given in Figure G-3.

To illustrate how the specific values of variables are obtained in an LHS, consider the following example. Suppose it is desired to obtain an LHS of size $n=5$ from a normal distribution on the range from 0.0 to 10.0. Recall that these two limits are taken to represent the lower and upper .001 quantities, respectively. Therefore, the random variable has a mean of 5 and a standard deviation of 1.618 (variance of 2.618), as indicated in Figure G-4. These points, together with the density characteristics of the normal distribution, allow for the definition of the equal probability interval endpoints. These endpoints are shown in Figure G-4 in terms of a density function. The next step is to randomly select an observation within each of the intervals. This selection is not done uniformly within the intervals shown in Figure G-4, rather, it is done relative to the distribution being sampled (in this case, the normal distribution). This means that the sampling is done uniformly on the vertical axis of the cdf, rather than uniformly on the horizontal axis of the density function.

Therefore, to get the specific values, $n=5$ randomly selected uniform $(0,1)$ numbers $\left(U_{m}, m=1,2,3,4\right.$, 5) are obtained to serve as probability levels. These probabilities are then scaled by:

$$
P_{m}=U_{m}(.2)+(m-1)(.2) \quad m=1,2,3,4,5
$$

This ensures that exactly one probability, $\mathrm{P}_{\mathrm{m}}$, will fall within each of the five intervals $(0, .2),(.2, .4),(.4$, $.6),(.6, .8)$, and $(.8,1)$. The values $P_{m}$ are used with the inverse normal distribution function to produce the specific values to be used in the LHS. Note that exactly one observation is taken from each interval of the density function shown in Figure G-4 (top). The entire process is shown in Table G-1, while the specific values selected and their associated probability levels are shown on the cumulative distribution plot of Figure G-4 (bottom).

The above illustration shows how one input variable having a normal distribution is sampled with LHS. This procedure is repeated for each input variable, each time working with the corresponding cumulative distribution function. If a random sample is desired, it is not necessary to divide the vertical axis into $\mathrm{n}$ intervals of equal width. Rather, $\mathrm{n}$ random numbers between 0 and 1 are obtained, and each is mapped through the inverse distribution function to obtain the specific values. The final set in the sampling process involves pairing the selected values.

Table G-1. One Possible Selection of Values for an LHS of Size 5 from a Normal Distribution on the Interval $(0,10)$

\begin{tabular}{|c|c|c|c|c|}
\hline $\begin{array}{l}\text { Interval } \\
\text { Number m }\end{array}$ & $\begin{array}{c}\text { Uniform }(0,1) \\
\text { Random No. } \\
U_{\mathrm{m}}\end{array}$ & $\begin{array}{l}\text { Scaled Probabilities } \\
\text { with the Interval } \\
P_{\mathrm{m}}+\mathrm{U}_{\mathrm{m}}(.2)+ \\
(\mathrm{m}-1)(.2)\end{array}$ & $\begin{array}{c}\text { Corresponding } \\
\text { Standard Normal Value } \\
\text { (z-score) rom the } \\
\text { Inverse distribution }\end{array}$ & $\begin{array}{c}\text { Corresponding } \\
\mathrm{N}(5,2.618) \\
\text { Observation } \\
\text { within the Intervals }\end{array}$ \\
\hline 1 & .12718 & .016 & -2.144 & 1.529 \\
\hline 2 & .57689 & .33 & -0.462 & 4.252 \\
\hline 3 & .03652 & .505 & 0.013 & 5.021 \\
\hline 4 & .29372 & .787 & 0.796 & 6.288 \\
\hline 5 & .39332 & .924 & 1.433 & 7.31 \\
\hline
\end{tabular}




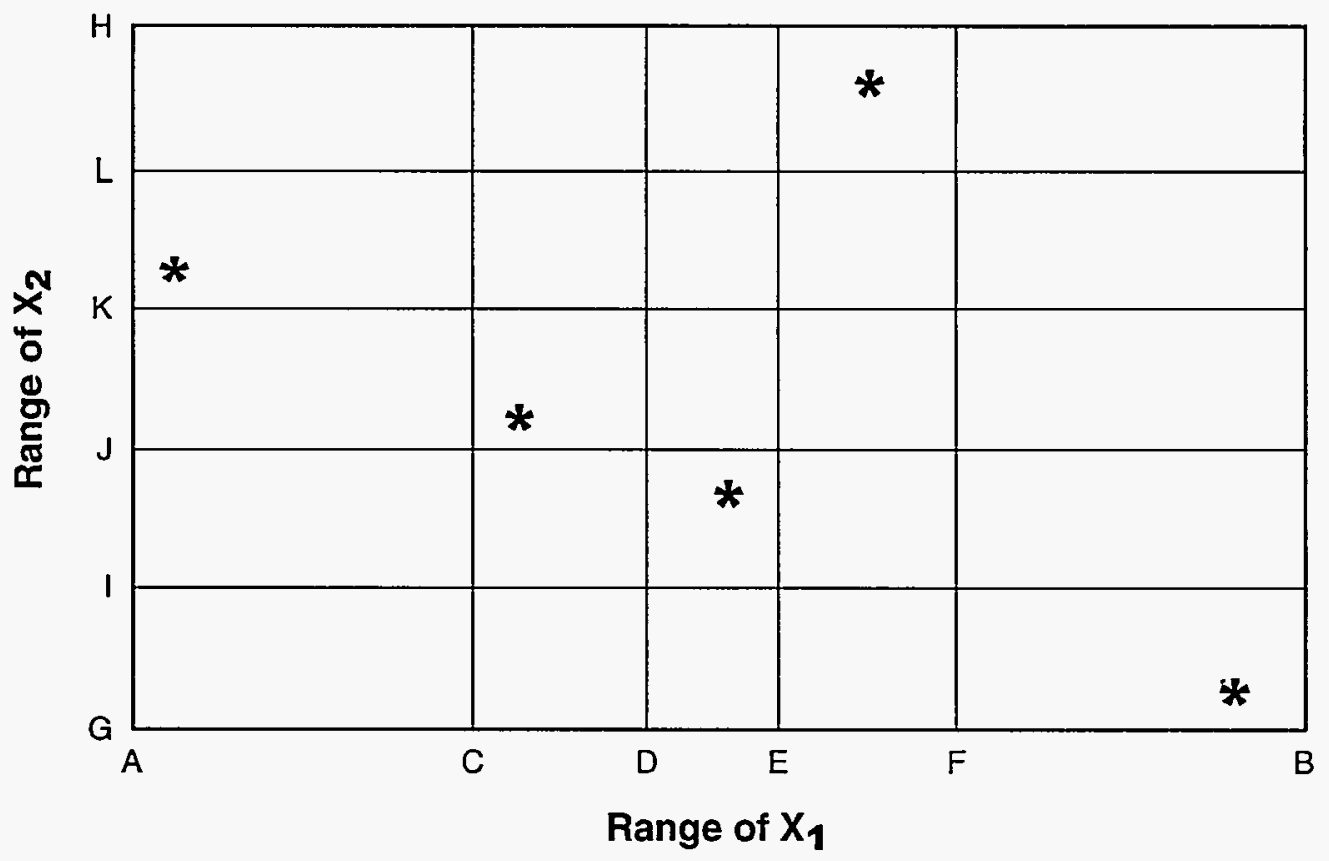

Figure G-3. A two-dimensional representation of one possible LHS of size 5 utilizing $X_{1}$ and $X_{2}$ 

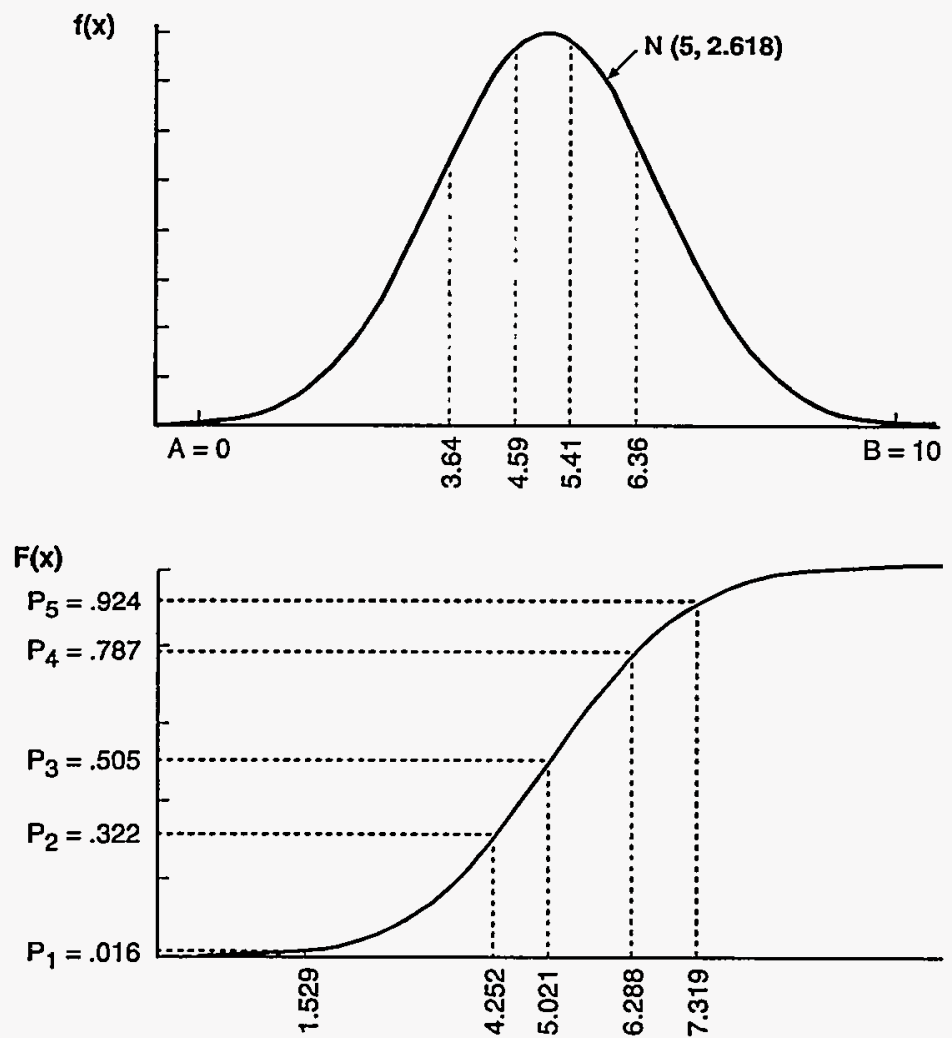

Figure G-4. Interval endpoints used with a lhs of size 5 (top) and specific values of $x$ selected through the inverse of the distribution function (bottom) 


\section{G.3 Sample Problem - Latin Hypercube Sampling}

The problem analyzed here involves the behavior of aerosols suspended in the containment building of a nuclear power plant during a hypothetical severe core-melt accident. The aerosol model implemented in the MAEROS computer program (Gelbard 1982) was chosen. MAEROS was subsequently incorporated into the MELCOR computer program.

The scope of the problem is limited to the time after vessel failure, when the in-vessel aerosols have been released and the core-concrete interactions are providing an ex-vessel aerosol source into containment. Two aerosol components are considered: in-vessel aerosols and ex-vessel aerosols. The first component is assumed to be suspended at the start of the problem, and the second component is introduced as a source. The distributions of particle size for both the initial aerosol suspended in the containment and the aerosol source are assumed to be lognormal with respect to particle diameter. This assumption is consistent with lognormal particle size distributions observed in experiments (Whitby 1975).

A large, dry containment building is assumed. The geometric specifications are similar to those for the Zion nuclear power plant. Containment atmospheric conditions are similar to those predicted by computer analysis (Lipinski, et al. 1985) for a transient accident with loss of AC power (i.e., a TMLB accident). In particular, based on calculations for TMLB accidents using the CONTAIN computer code (Bergeron, et al. 1985), a super-heated containment atmosphere is assumed. The problem is not designed to simulate a TMLB accident in the Zion power plant, but rather to represent conditions that are possible during that type of accident.

Table G-2 lists the independent variables considered in this investigation. In addition, the containment volume and the particle slip coefficient are taken to be $7.68 \mathrm{E} 4 \mathrm{~m}^{3}\left(2.7 \mathrm{E} 6 \mathrm{ft}^{3}\right)$ and 1.37 , respectively. Each variable in Table G-2 is assigned a range of possible input values based on conditions expected in a TMLB accident. In most cases, defining the range of possible input values is hindered by a lack of analytical methods for defining the quantity and a lack of direct measurements of the quantity. The ranges given in Table G-2 reflect information gathered from CONTAIN computer calculations, simple scoping calculations, and published experimental and analytical data.

Several sets of experiments provide perspective with respect to the nature of aerosols likely to be found in nuclear reactor containments. Two of the most useful sets are the experiments conducted at Oak Ridge National Laboratory with sodium oxide and uranium oxide aerosols (Adams and Tobias 1983) and the ABCOVE tests (Hilliard, et al 1983). Other relevant experiments programs are presented in Kress and Tobias (1980), Adams, et al. (1980, 1981, 1982), Fermandjian, et al. (1980), and Gieseke, et al. (1984). Values for the mass median diameter of the size distribution, the standard deviation of the size distribution, the aerosol shape factors, and the particle material density are based on the observations reported in such experiments.

Ranges for the initial aerosol mass loading and the aerosol source rate and timing are derived from calculations of in-vessel and ex-vessel aerosol production reported in a recent study on the reevaluation of the radiological source term (Gieseke, et al. 1984). The input value ranges given in Table G-2 for containment atmosphere parameters (i.e., temperature, pressure, molecular weight of atmospheric gas, ratio of thermal conductivity of atmospheric gas to that of suspended particles, and containment temperature gradients) are bounded by time-dependent variation for these parameters calculated for TMLB accidents by the CONTAIN code. The diffusion boundary layer thickness values are based on the 
work of van de Vate and ten Brink (1980). However, boundary layer thicknesses as low as 1.E-5 m (0.004 in) have been used (Lipinski et al. 1985).

Scoping calculations for the turbulent energy dissipation rate similar to those given in Appendix $E$ of Lipinski et al. (1985) are the basis for the range chosen for turbulent energy dissipation in this study. Values given in Lipinski's Appendix E bound those given here. Similarly, scoping estimates of the area available for settling in the reactor containment define the ranges chosen for the area to volume ratios in Table G-2. The input ranges for the constant associated with the thermal accommodation coefficient and the probability sticking factor are strictly postulated.

For most of the parameters in Table G-2, little is known about the distribution of values within the specified ranges. As a result, most of the parameters are given uniform or loguniform distributions. Loguniform distributions are generally used when the input range spans several orders of magnitude. The types of distributions listed by Iman and Shortencarier (1984) include normal, lognormal, uniform, loguniform, triangular, and beta. The distribution function and its range are sometimes obtained by using the expert witness or Delphi method.

The following dependent variables are considered in this investigation: total suspended mass of each component as a function of time $(\mathrm{kg})$, time to 90 percent and 99 percent deposition of the first component (s), and time-integrated concentration of each component $\left(\mathrm{kg} \mathrm{s} / \mathrm{m}^{3}\right)$. The total suspended mass of each component is related to the amount of radioactivity that can potentially reach the public. The suspended mass of a component at any given time can be released directly to the environment if the containment fails catastrophically. Since aerosols produced in-vessel generally contain the more volatile and more radiotoxic materials, the time for deposition of the first component affects the radiotoxicity of the materials suspended in the containment. The time-integrated concentration of a component provides information about the overall importance of a parameter in the accident sequence independent of time and about the amount of material that might be released through a leak path.

The analysis was performed for an LHS of size 50 generated from the 21 variables listed in Table G-2. Figures G-5 through G-7 provide summaries of the predictions associated with the resultant sample.

As can be seen, the predicted time to 90 percent deposition varies between about 100 s and 800 s, while that for 99 percent deposition varies between about 200s and 1200s. Finally, Figures G-6 and G-7 contain the distribution functions for the integrated concentrations from $t=0 \mathrm{~s}$ to $t=72000 \mathrm{~s}$ for the first and second components.

\section{G.4 Conclusion}

A common technique for analyzing uncertainties in computer models has been described. In principle, such techniques could be applied to accident analyses of fuel cycle facilities. 
Table G-2. Variables Used in MAEROS Analysis

\begin{tabular}{|c|c|c|c|c|}
\hline Variable & Definition & Range & Distribution & Restrictions \\
\hline GSD1 & $\begin{array}{l}\text { Geometric standard deviation for diameter of first } \\
\text { component (unitless) }\end{array}$ & 1.3 to 4 & Uniform & \\
\hline MMD1 & Mass median diameter for first component (m) & $\begin{array}{l}0.2 \mathrm{E}-6 \text { to } \\
5.0 \mathrm{E}-6\end{array}$ & Loguniform & $\begin{array}{l}.5 \text { rank correlation } \\
\text { with RM1 }\end{array}$ \\
\hline RM1 & Total released mass for first component $(\mathrm{kg})$ & 100. to 1000 . & Loguniform & $\begin{array}{l}.5 \text { rank correlation } \\
\text { with MMD1 }\end{array}$ \\
\hline GSD2 & $\begin{array}{l}\text { Geometric standard deviation for diameter of } \\
\text { second component (unitless) }\end{array}$ & $1.3-4$ & Uniform & \\
\hline MMD2 & $\begin{array}{l}\text { Mass median diameter for second component } \\
(\mathrm{m})\end{array}$ & $\begin{array}{l}.05 \mathrm{E}-6 \text { to } \\
5.0 \mathrm{E}-6\end{array}$ & Loguniform & $\begin{array}{l}.5 \text { rank correlation } \\
\text { with SR2 }\end{array}$ \\
\hline SR2 & $\begin{array}{l}\text { Total mass source rate for second component } \\
(\mathrm{kg})\end{array}$ & .1 to 1 . & Loguniform & $\begin{array}{l}.5 \text { rank correlation } \\
\text { with MMD2 }\end{array}$ \\
\hline $\mathrm{RD} 2$ & Release duration for second component (s) & $\begin{array}{l}7.2 \mathrm{E} 3 \text { to } \\
1.8 \mathrm{E} 4\end{array}$ & Uniform & \\
\hline $\mathrm{T}$ & Temperature (K) & 375. to 600 . & Uniform & $\mathrm{T}<.001 \mathrm{P}$ \\
\hline $\mathbf{P}$ & Pressure $(\mathrm{Pa})$ & $\begin{array}{l}3.75 \mathrm{E} 5 \text { to } \\
8.85\end{array}$ & $\begin{array}{l}\text { Triangular with } \\
\text { apex at } 5.8 \mathrm{E}-5\end{array}$ & $\mathrm{P}>1000 . \mathrm{T}$ \\
\hline $\mathrm{RCV}$ & $\begin{array}{l}\text { Ratio of ceiling area to volume }\left(\mathrm{m}^{-1}\right) ; \mathrm{RCV} \text { also } \\
\text { assumed to be ratio of floor area to volume }\end{array}$ & $\begin{array}{l}0.025 \text { to } \\
0.075\end{array}$ & Uniform & \\
\hline RWV & Ratio of wall area to volume $\left(\mathrm{m}^{-1}\right)$ & 0.08 to .24 & Uniform & \\
\hline$\chi$ & Dynamic shape factor (unitless) & 1. to 3 . & Uniform & $\chi \leq \gamma$ \\
\hline$\delta$ & Diffusion boundary layer thickness (m) & 5.E-5 to $8 . \mathrm{E}-3$ & Loguniform & \\
\hline$\rho$ & Particle material density $\left(\mathrm{kg} / \mathrm{m}^{3}\right)$ & 2.E3 to $8 . \mathrm{E} 3$ & Normal & \\
\hline $\mathrm{C}_{\mathrm{T}}$ & $\begin{array}{l}\text { Constant associated with thermal } \\
\text { accommodation coefficient (unitless) }\end{array}$ & 1. to 3 . & Uniform & \\
\hline$\gamma$ & Agglomeration shape factor (unitless) & 1. to 3 . & Uniform & $\gamma \geq \chi$ \\
\hline ST & Probability sticking factor (unitless) & 0.5 to 1. & Uniform & \\
\hline$\Delta \mathrm{T}$ & Temperature gradient $(\mathrm{K} / \mathrm{m})$ & 0. to $5 . \mathrm{E}-4$ & Uniform & \\
\hline$\kappa$ & $\begin{array}{l}\text { Radio of thermal conductivity of gas to that of } \\
\text { particle (unitless) }\end{array}$ & 0.05 to 1 & $\begin{array}{l}\text { Triangular with } \\
\text { apex at } .5\end{array}$ & \\
\hline$\epsilon$ & Turbulence dissipation rate $\left(\mathrm{m}^{2} / \mathrm{sec}^{3}\right)$ & 0.001 to 0.03 & Uniform & \\
\hline MW & Molecular weight of gas (kg/kg-mole) & 20. to 40 . & Uniform & \\
\hline
\end{tabular}




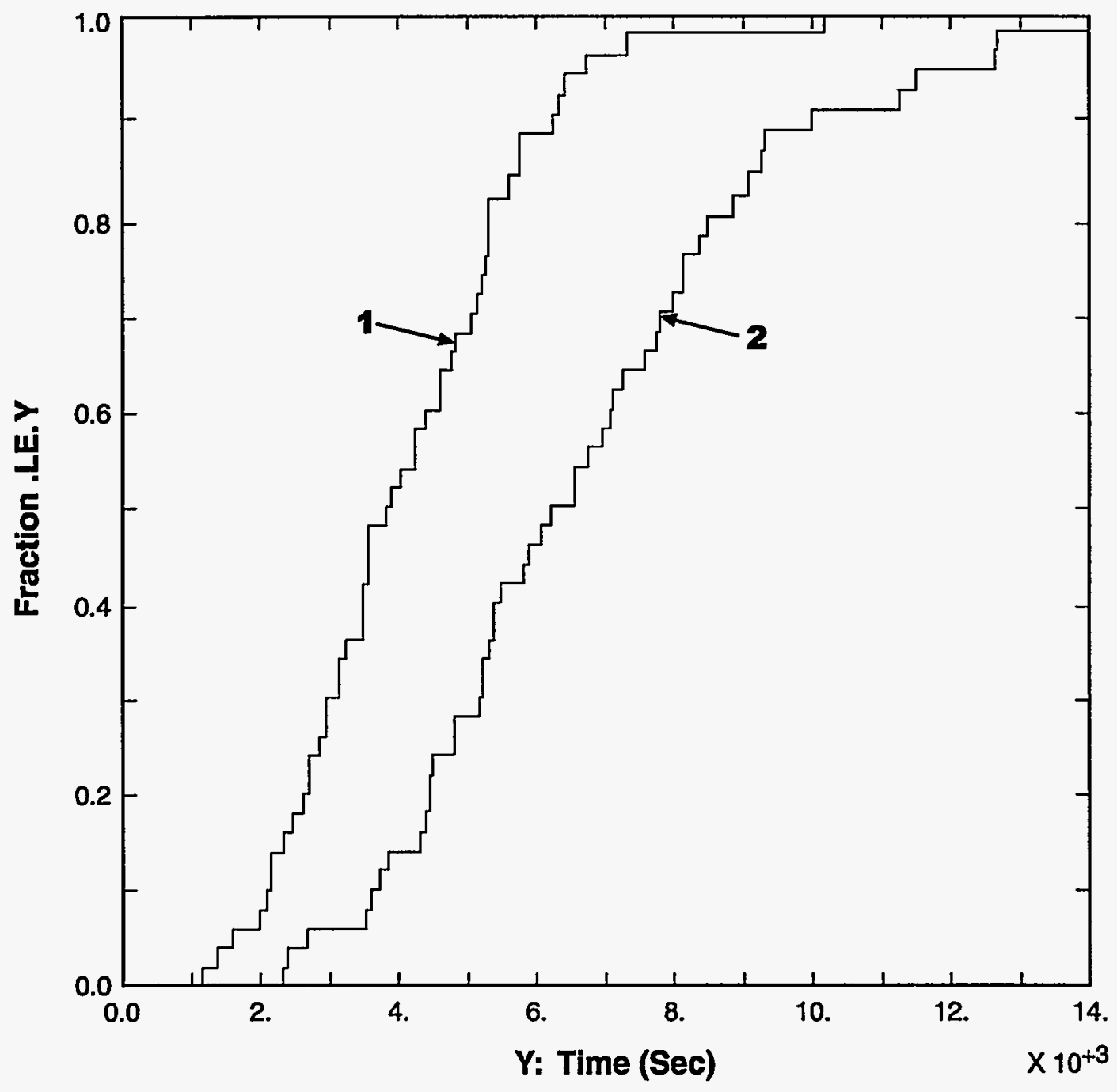

Figure G-5. Distribution functions for time to 90 percent and 99 percent deposition for the first component ( $1 \sim$ time to 90 percent deposition, $2 \sim$ time to 99 percent deposition) 


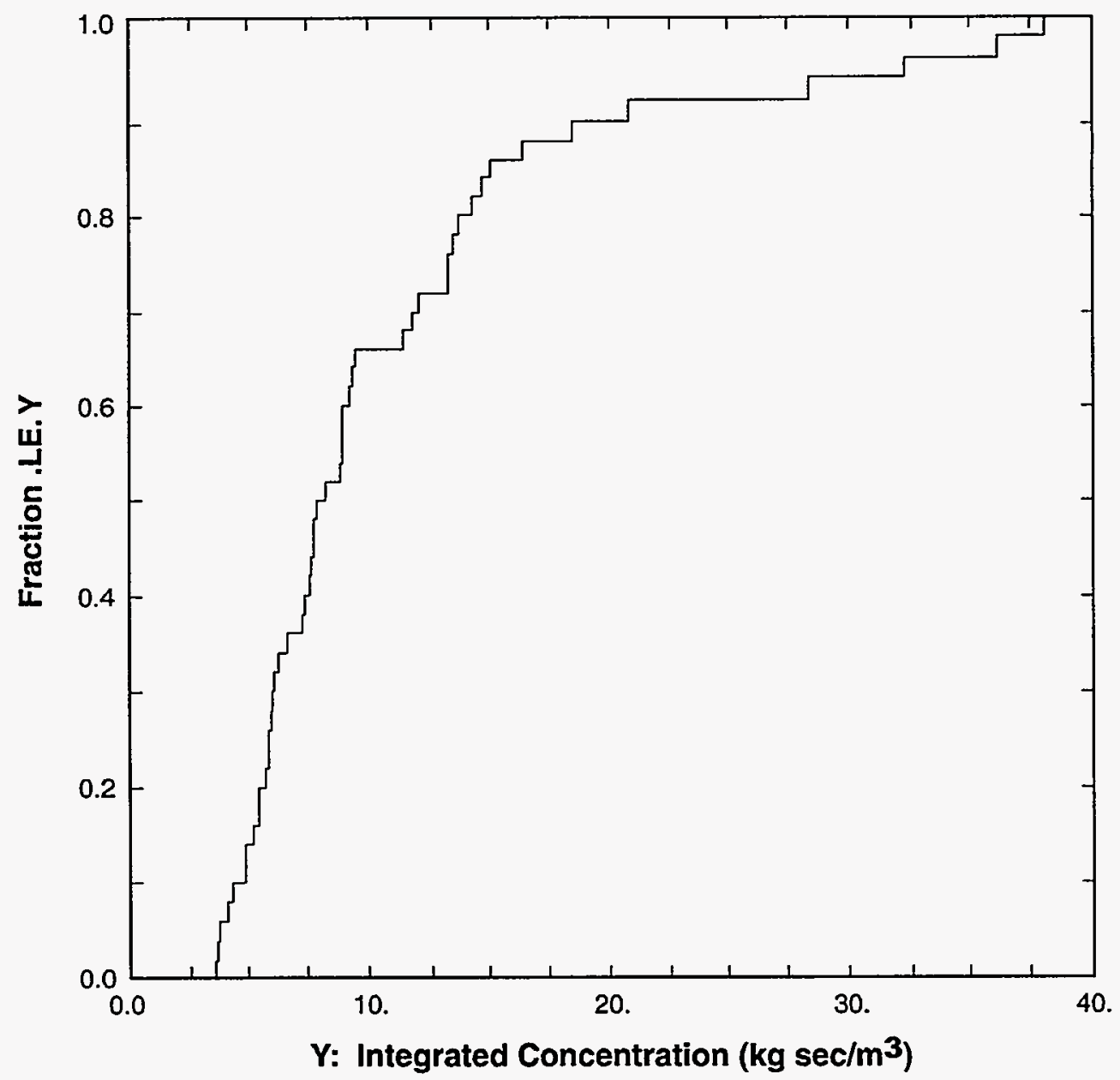

Figure G-6. Distribution function for total integrated concentration (kg $\mathrm{sec} / \mathrm{m}^{3}$ ) of first component 


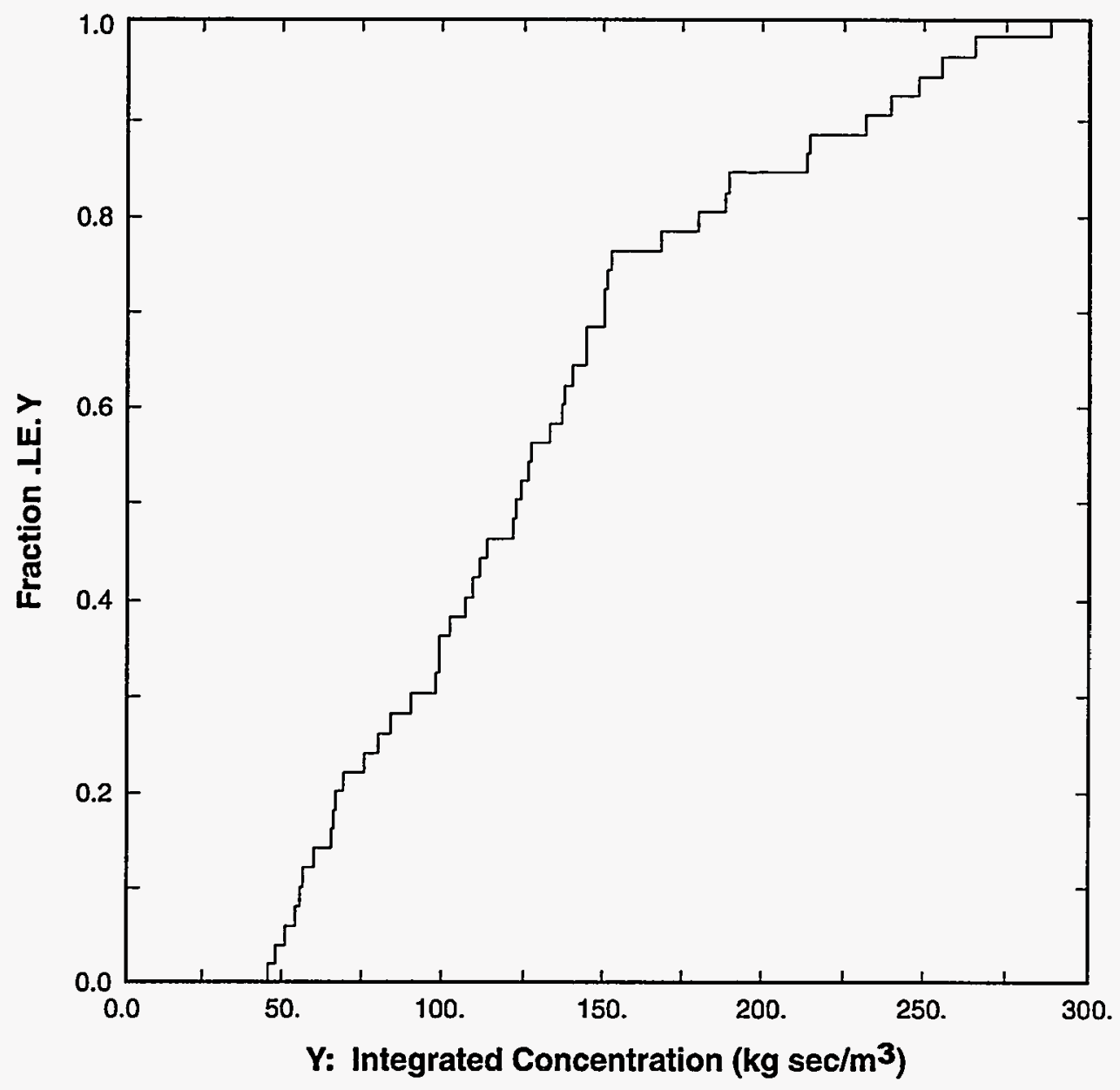

Figure G-7. Distribution function for total integrated concentration (kg $\mathrm{sec} / \mathrm{m}^{3}$ ) of second component 


\section{G.5 References}

Adams, R.E., J.T. Han, T.S. Kress, and M. Silberburg, "Behavior of Sodium Oxide, Uranium Oxide and Mixed Sodium Oxide - Uranium Oxide Aerosols in a Large Vessel," in Proceedings of the CSNI Specialists Meetings on Nuclear Aerosols in Reactor Safety, NUREG/CR-1724, ORNL/NUREG/TM404, CSNI-45, Oak Ridge National Laboratory, Oak Ridge, Tennessee, pp. 499-518, 1980.

Adams, R.E., T.S. Kress, and M.L Tobias., "Sodium Oxide and Uranium Oxide Aerosol Experiments: NSPP Tests 106-108 and Tests 204-207, Data Record Report," NUREG/CR-1767, ORNL/NUREG/TM408, Oak Ridge National Laboratory, Oak Ridge, Tennessee, 1981.

Adams, R.E., T.S. Kress, and M.L. Tobias, "Uranium Oxide and Sodium Oxide Aerosol Experiments: NSPP Mixed-Oxide Tests 303-307, Data Record Report," NUREG/CR-2697, ORNL/TM-835, Oak Ridge National Laboratory, Oak Ridge, Tennessee, 1982.

Adams, R.E., and M.S. Tobias, "Aerosol Release and Transport Program Quarterly Progress Report for July - September 1982," NUREG/CR-2809, Vol. 3, ORNL/TM-8397/V3, Oak Ridge National Laboratory, Oak Ridge, Tennessee, 1983.

Fermandjian, J., J.C. Malet, C. Casselman, G. Duverger de Cuy, D. Boulard, and G. Madelaine, "Interpretation of the Behavior of Aerosols Generated by a Sodium Pool Fire," in Proceedings of the CSNI Specialists Meetings on Nuclear Aerosols in Reactor Safety, NUREG/CR-1724, ORNL/NUREG/TM-404, CSNI-45, Oak Ridge National Laboratory, Oak Ridge, Tennessee, pp. 482-498, 1980.

Gelbard, F., "MAEROS User Manual,” NUREG/CR-1391, SAND80-0822, Sandia National Laboratories, Albuquerque, New Mexico, 1982.

Gieseke, J.A., P. Cybulskis, R.S. Denning, M.R. Kuhlman, and K.W. Lee, "Radionuclide Release Under Specific LWR Accident Conditions," Vols. j-VII, BMI-2104, Battelle Columbus Laboratories, Columbus, Ohio, 1984.

Hilliard, R.K., J.D. McCormack, and A.K. Postma, "Results and Code Predictions for ABCOVE Aerosol Code Validation - Test AB5," HEDL-TME 83-16, UC-79T, Ti, Tp, Hanford Engineering Development Laboratory, Richland, Washington, 1983.

Iman, R.L. and W.J. Conover, "Sensitivity Analysis Techniques Self-Teaching Curriculum," Nuclear Regulatory Commission Report, NUREG/CR-2350, Technical Report SAND81-1978, Sandia National Laboratories, Albuquerque, New Mexico, 1982.

Iman, R.L., J.M. Davenport, and D.K. Zeigler, "Latin Hypercube Sampling (Program User's Guide)," Technical Report SAND79-1473, Sandia National Laboratories, Albuquerque, New Mexico, 1980.

Iman, R.L., J.C. Helton, and J.E. Campbell, "An Approach to Sensitivity Analysis of Computer Models, Part 1. Introduction, Input Variable Selection and Preliminary Variable Assessment," Journal of Quality Technology, 13(3), 174-183, 1981a. 
Iman, R.J., J.C. Helton, and J.E. Campbell, "An Approach to Sensitivity Analysis of Computer Models, Part 2. Ranking of Input Variables, Response Surface Validation, Distribution Effect and Technique Synopsis," Journal of Quality Technology, 13(4), 232-240, 1981 b.

Iman, R.L. and M.J. Shortencarier, "A FORTRAN 77 Program and User's Guide for the Generation of Latin Hypercube and Random Samples for Use with Computer Models," NUREG/CR-3624 (SAND832365), prepared for the U.S. Nuclear Regulatory Commission, Washington, D.C., 1984.

Kress, T.S., and M.S. Tobias, "LMFBR Aerosol Release and Transport Program Quarterly Progress Report for January-March 1980," NUREG/CR-1790, ORNL/NUREG/TN-416, Oak Ridge National Laboratory, Oak Ridge, Tennessee, 1980.

Lipinski, R.J., D.R. Bradley, J.E. Brockmann, J.M. Griesmeyer, C.D. Leigh, K.K. Murata, D.A. Powers, J.B. Rivard, A.R. Taig, J. Tills, and D.C. Williams, "Uncertainty in Radionuclide Release Under Specific LWR Conditions," Vols. i and II, SAND84-0410, Sandia National Laboratories, Albuquerque, New Mexico, 1985.

McKay, M.D., W.J. Conover, and R.J. Beckman, "A Comparison of Three Methods for Selecting Values of Input Variables in the Analysis of Output from a Computer Code," Technometrics, 21, 239 - 245, 1979.

Nair, S.K., D.B. Chambers, S.H. Park, Z.R. Radonjic, P.T. Coutts, C.J. Lewis, J.S. Hammonds, and F.O. Hoffman, "Review of Models for Determining Consequences of UF $_{6}$ Release," NUREG/CR-6481, Vol. 2, U.S. Nuclear Regulatory Commission, Washington, D.C., 1997.

Steck, G.P., R.L. Iman, and D.A. Dahlgren, "Probabilistic Analysis of LOCA, Annual Report for FY1976," Technical Report SAND76-0535 (NUREG 766513), Sandia National Laboratories, Albuquerque, NM, 1976.

van de Vate, J.F., and H.M. ten Brink, "The Boundary Layer for Diffusive Aerosol Deposition onto Walls," in Proceedings of the CSNI Specialists Meeting on Nuclear Aerosols in Reactor Safety, NUREG/CR-1724, ORNL/NUREG/TM-404, CSNI-45, Oak Ridge National Laboratory, Oak Ridge, Tennessee, pp. 162-170, 1980.

Whitby, K.T., "Modeling of Atmospheric Aerosol Size Distributions," Particle Technology Laboratory Report No. 253, Dept. of Mechanical Engineering, University of Minnesota, Minneapolis, Minnesota, 1975.

U.S. Nuclear Regulatory Commission (USNRC), "Severe Accident Risks: An Assessment for Five U.S. Nuclear Power Plants," NUREG-1150, Washington, D.C., 1989. 
NRC FORM 336

(2-89)

NRCM 1102

3201,3202
U.S. NUCLEAR REGULATORY COMMISSION

BIBLIOGRAPHIC DATA SHEET

(Seo instuctions on the reverse)

2. TITLE AND SUBTITLE

Nuclear Fuel Cycle Facility Accident Analysis Handbook

5. AUTHOR(S)

8. PERFORMING ORGANIZATION
provide name and malling eddress.)

Science Applications International Corporation

11252 Roger Bacon Drive

Reston, VA 20190

9. SPONSORING ORGANIZATION - NAME AND ADDRESS (IFNRC, type "Same as above", if contrector, provide NRC Division, Ofice or Region, U.S. Nuclear Regulatory Commission, and malling address.)

Division of Fuel Cycle Safety and Safeguards

Office of Nuclear Material Safety and Safeguards

U.S. Nuclear Regulatory Commission

Washington, DC 20555-0001

10. SUPPLEMENTARY NOTES

11. ABSTRACT (200 words o less)

The purpose of this Handbook is to provide guidance on how to calculate the characteristics of releases of radioactive materials and/or hazardous chemicals from nonreactor nuclear facilities. In addition, the Handbook provides guidance on how to calculate the consequences of those releases. There are four major chapters: Hazard Evaluation and Scenario Development; Source Term Determination; Transport Within Containment/Confinement; and Atmospheric Dispersion and Consequence Modeling. These chapters are supported by Appendices, including: a summary of chemical and nuclear information that contains descriptions of various fuel cycle facilities; details on how to calculate the characteristics of source terms for releases of hazardous chemicals; a comparison on NRC, EPA, and OSHA programs that address chemical safety; a summary of the performance of HEPA and other filters; and a discussion of uncertainties. Several sample problems are presented: a free-fall spill of powder; an explosion with radioactive releases; a fire with radioactive releases; filter failure; hydrogen fluoride release from a tankcar; a uranium hexafluoride cylinder rupture; a liquid spill in à vitrification plant; and a criticality incident. Finally, this Handbook includes a computer model, LPF\#1b, that is intended for use in calculating leakpath factors.

spill

nuclear fuel cycle

nuclear criticality

accident analysis

leakpath factors

unlimited

14. SECURTY CLASSIFICATON (This Pege)

unclassified

(This Roport)

unclassified

15. NUMBER OF PAGES

16. PRICE 